Slavistische Beiträge $\cdot$ Band 412

(eBook - Digi20-Retro)

\title{
Malgorzata Świderska
}

\section{Studien zur \\ literaturwissenschaftlichen \\ Imagologie}

Das literarische Werk F. M. Dostoevskijs aus imagologischer Sicht mit besonderer Berücksichtigung der Darstellung Polens

Verlag Otto Sagner München · Berlin · Washington D.C.

Digitalisiert im Rahmen der Kooperation mit dem DFG-Projekt „Digi20“

der Bayerischen Staatsbibliothek, München. OCR-Bearbeitung und Erstellung des eBooks durch den Verlag Otto Sagner:

http://verlag.kubon-sagner.de

( $)$ bei Verlag Otto Sagner. Eine Verwertung oder Weitergabe der Texte und Abbildungen, insbesondere durch Vervielfältigung, ist ohne vorherige schriftliche Genehmigung des Verlages unzulässig.

«Verlag Otto Sagner» ist ein Imprint der Kubon \& Sagner GmbH. 


\title{
SLAVISTISCHE BEITRÄGE
}

\author{
Herausgegeben von \\ Peter Rehder
}

Beirat:

Tilman Berger - Walter Breu - Johanna Renate Döring-Smirnov Walter Koschmal · Ulrich Schweier · Miloš Sedmidubský · Klaus Steinke

BAND 412 


\section{Małgorzata Świderska}

\section{Studien zur}

\section{literaturwissenschaftlichen Imagologie}

Das literarische Werk F.M. Dostoevskijs aus imagologischer Sicht mit besonderer Berücksichtigung der Darstellung Polens

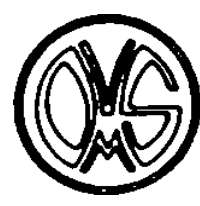

Verlag OtTo SAgner

MÜNCHEN 2001 


\title{
SLAVISTISCHE BEITRÄGE
}

\author{
Herausgegeben von \\ Peter Rehder
}

\author{
Beirat: \\ Tilman Berger - Walter Breu - Johanna Renate Döring-Smirnov \\ Walter Koschmal · Ulrich Schweier · Miloš Sedmidubský $\cdot$ Klaus Steinke
}

BAND 412 


\section{Małgorzata Swiderska \\ Studien zur \\ literaturwissenschaftlichen Imagologie}

Das literarische Werk F.M. Dostoevskijs aus imagologischer Sicht mit besonderer Berücksichtigung der Darstellung Polens

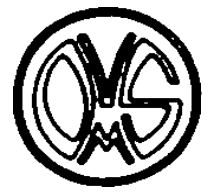

Verlag OtTo SAgner

MÜNCHEN 2001 


\section{8}

Gedruckt mit freundlicher Unterstützung der

Alexander von Humboldt Stiftung

und der

Vereinigung der Freunde der Universität Tübingen e.V.

(Universitätsbund)

ISBN 3-87690-816-7

(C) Verlag Otto Sagner, München 200I

Abteilung der Firma Kubon \& Sagner

D-80328 München

Gedruckt auf alterungsbeständigem Papier

PO2 


\section{VORWORT}

Die vorliegende Arbeit ist wăhrend meines Studiums der Slavistik in Tübingen entstanden und wurde am 22. November 2000 von der Neuphilologischen Fakultät der Eberhard-Karls-Universităt Tübingen als Dissertation angenommen.

Frau Susanne Kiderlen, der diese Studie gewidmet ist, sowie meiner Mutter möchte ich besonders herzlich für ihre vielfaltige Hilfe und für ihr Mit-Leiden beim Schreiben dieser Arbeit danken.

Herm Prof. Dr. Rolf-Dieter Kluge, meinem Doktorvater am Slavischen Seminar der Universität Tübingen, danke ich sehr herzlich für seine freundliche und verständnisvolle Betreuung, für die Anregungen beim Abfassen und Überarbeiten dieser Studie sowie für die unermüdliche Geduld bei ihrer Lektüre.

Ganz herzlich möchte ich auch den Gutachtem, Frau Prof. Dr. Maria MoogGrünewald und den Herren Proff. Dr. Dr. Ludolf Müller und Dr. Dietrich Wörn für ihre wichtigen Anregungen danken, die beim Erstellen der Druckfassung bcsonders wertvoll waren.

Schließlich danke ich besonders Herm Michael Raffel für die unermüdliche und freundliche Hilfe beim Korrekturlesen aller Fassungen dieser Studie. Für alle Fehler und Unstimmigkeiten. die sich in der vorliegenden Druckfassung noch finden mögen, übernehme ich selbstverständlich die Verantwonung

Nicht zuletzt möchte ich allen meinen Bekannten danken. die mir geholfen haben. diese Studie fertig zu schreiben.

Herrn Prof. Dr. Peter Rehder bin ich für die Aufnahme meiner Dissertation in die renommierte Reihe Slavistische Beiträge sehr dankbar.

Der Alexander von Humboldt-Stiftung und der Vereinigung der Freunde det Universität Tübingen e.V. (Universitătsbund) danke ich herzlich für die Gewährung eines großzügigen Druckkostenzuschusses. der mir die Drucklegung der Arbeit ermöglicht hat. 


\section{ZUR ZITIERWEISE}

Alle Texte Dostoevskijs werden im Original nach der russischen Ausgabe in 30 Bănden zitiert: FEDOR MICHAJLOVIĆ DOSTOEVSKU: Polnoe sobranie sočinenij v tridcati tomach [Sämtliche Werke in dreißig Bänden]. Leningrad 1972-1990. Im folgenden werden in Klammern Band-sowie Seitenzahl angeführt.

lhre Übersetzung sowie die Übersetzungen weiterer russischer sowie polnischer Zitate ins Deutsche werden mit dem Namen des jeweiligen Übersetzers bzw. der jeweiligen Übersetzerin angegeben.

Russische Titel erscheinen in Kapitelüberschriften im Original. Im Text und in den Fußnoten werden sie transliteriert und bei der ersten Nennung mit einer deutschen Übersetzung in Klammern versehen. Polnische Titel werden ebenfalls bei der ersten Nennung mit einer Übersetzung ins Deutsche in Klammern angeführt.

Wo aus Gründen der Eindeutigkeit fremdsprachige Bezeichnungen oder Begriffe in der Originalsprache verwendet werden, wird bei der ersten Nennung die deutsche Öbersetzung in Klammern angegeben. Soweit nicht anders angegeben. stammen die Übersetzungen von mir.

Russische Namen werden im Text und in den Fußnoten in der wissenschaftlichen Transliteration angeführ. Von diesem Prinzip wird abgewichen, wenn andere Namensformen eingebürgert sind oder aus Publikationen zitiert wird. in denen eine andere Schreibweise erscheint.

Im Literaturverzeichnis werden russische (kyrillische) Titel und Namen in wissenschaftlicher Transliteration angeführt und nach dem lateinischen Alphabet eingeordnet. 


\section{INHALT}

VORWORT.

ZUR ZTTIERWEISE

EINLEITUNG

\section{ERSTER TEIL}

\section{Zu TheORIE UND METHODE: DIE PROBlematIK DER LITERATURWISSENSCHAFTLICHEN IMAGOLOGIE}

I. ERGEBNISSE DER LITERATURWISSENSCHAFTLICHEN IMAGOLOGIE UND VERWANDTER ANSÄTZE BEI DER ERFORSCHUNG KULTURELLER UND LITERARISCHER FREMDHEIT.

I. Exkurs zur Stereotypenforschung.

2. Exkurs: Paul Ricœurs hermeneutische Phänomenologie

II. IMAgologische ANSÄtze Und Untersuchungen als Desiderat DER SLAVISTISCHEN LITERATURWISSENSCHAFT LIND DER DOSTOEVSKU-FORSCHUNG.

III. "IMAGEM" UND "IMAGOTHËME" - DIE KONZEPTION DER IMAGOLOGISCHEN TEXTINTERPRETATION

\section{ZWEITER TEIL}

POLEN IN DEN LITERARISCHEN WERKEN F. M. DOSTOEVSKIIIS. TEXTINTERPRETATIONEN

VORBEMERKUNG

I. EINZELINTERPRETATIONEN

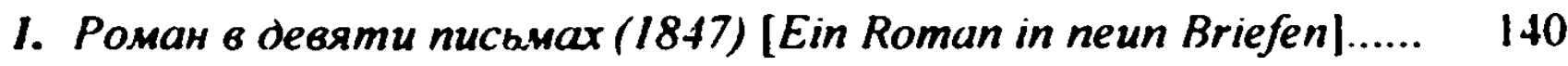


2. Ha европейские соб́ытия в 1854 zоду (1854) [Auf europäische Ereignisse von 1854]

3. Дядюшкин сон (Из мордасовских летописей) (1859) [Onkelchens Traum (A us den Chroniken der Stadt Mordasov)]....... 148

4. Записки из Мертвого дома (1860-1862) [Aufeeichnungen aus einem Totenhaus]

5. Униженные и оскоро̆ленные. Роман в четырех частях $c$ эпилогом (186I) [Die Erniedrigten und Beleidigten].................... 204

6. Зимние заметки о летних впечатлениях (1863) [Winterauffeichnungen über Sommereindrücke] .......................... 226

7. Игрок. Роман (Из записок молодого человека) (1866) [Der Spieler (Aus den Aufeeichnungen eines jungen Menschen)]

8. Преступление и наказание. Роман в щести частях с эпилогом (1866) [V'erbrechen und Strafe]

9. Иоиот. Роман в четырех частах (1869) [Der Idiot] 284

10. Вечный му.ж. Рассказ (1870) [Der ewige Gatte. Erzählung]. 310

11. Бесы. Роман в трех частях (187i-1872) [Böse Geister]

12. Подросток. Роман [в трех частяx] (1875) [Der Jüngling].

13. Братья Карамазовы Роман в четырех частях с эпипогом (1879-1880) [Die Brüder Karamazov]

II. ZUSAMMENFASSUNG DER EINZ.EIINTERPRETATIONEN 


\section{Farbenzwerg-Russe}

Schwarz-weiß /.../: Fell schneeweiß mit schwarzer Maske, die nur die Nase bedecken darf, schwarzen Ohren und schwarzen „Stiefelchen“. Im Winter erscheint die Zeichnung am reinsten (Kălteschwărzung); Jungen reinweiß, Färbung erst nach der 8 . Woche. Krallen dunkelbraun. Augen wie bei Albinos rot leuchtend.

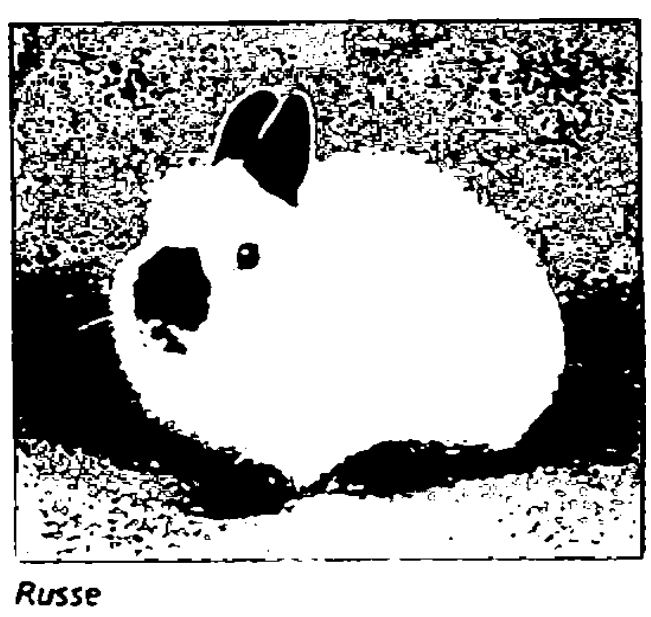

\section{Das Hermelinkaninchen}

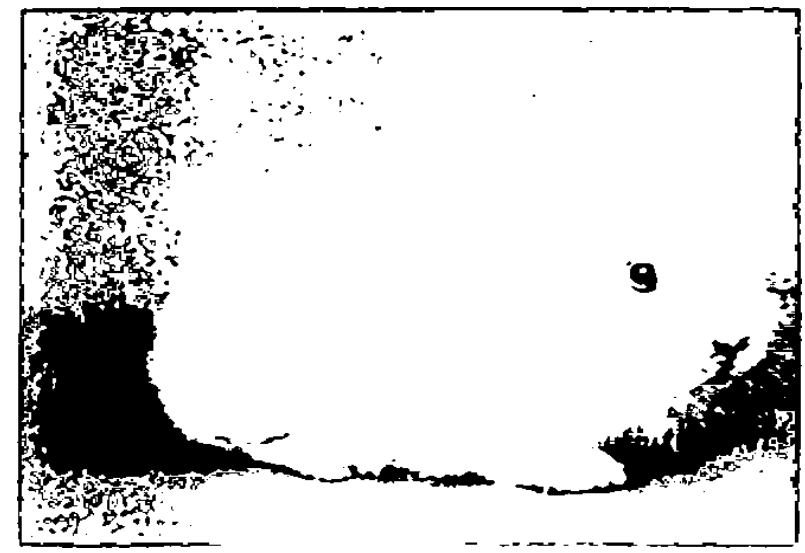

Hermelin mit blauen Augen.
Das Hermelinkaninchen mit den roten Augen /.../ ist das Zwergkaninchen, das wir am lăngsten kennen und das folglich von allen Arten am meisten durchgezüchtet ist. Unter dieser Rasse finden sich die Spitzentiere mit den kürzesten Ohren und den ausgeprägtesten „Bullenköpfen“. /.../ Man nannte sie Hermeline, weil sie aus den reinweißen polnischen Kaninchen entstanden, die man züchtete, um Ersatz fur die begehrten, aber raren Hermelinfelle zu schaffen. Die Zucht der Hermeline mit den blauen Augen gelang erstmals 1918. [fett und kursiv die Verf.]

(MONIKA WEGLER: Zwergkaninchen richtig pflegen und verstehen. München: Grafe und Unzer 1994, 4. unverănderte Auflage, S. 46f. und S. 12) 


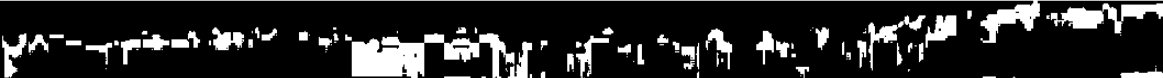

$\Rightarrow \rightarrow$

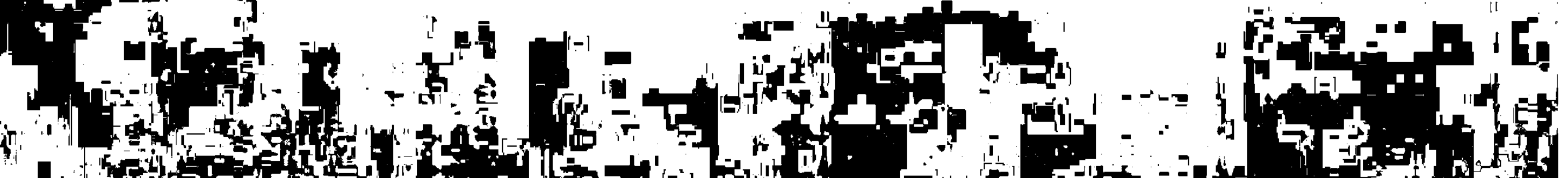

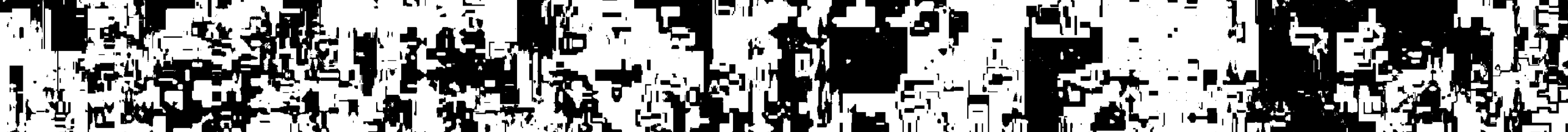

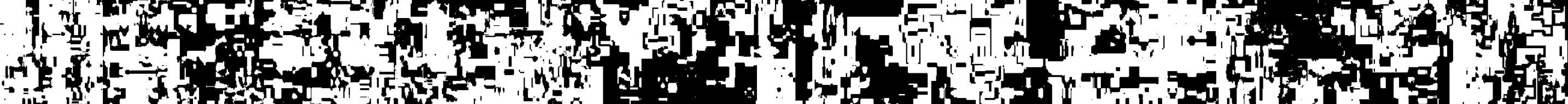

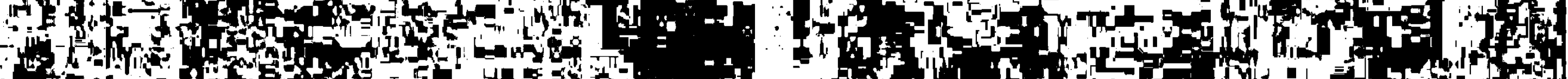

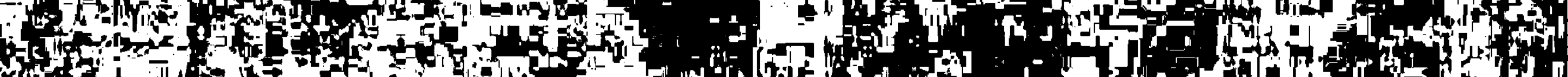

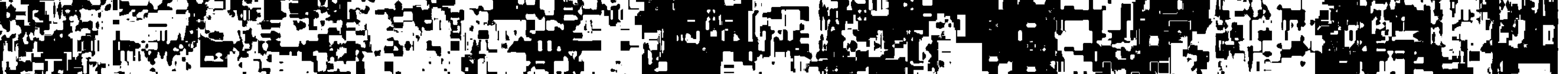

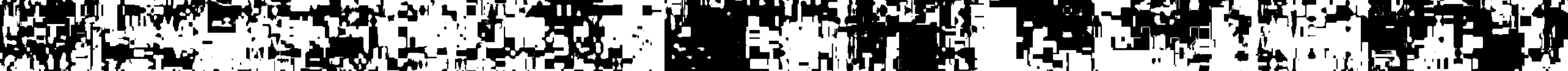

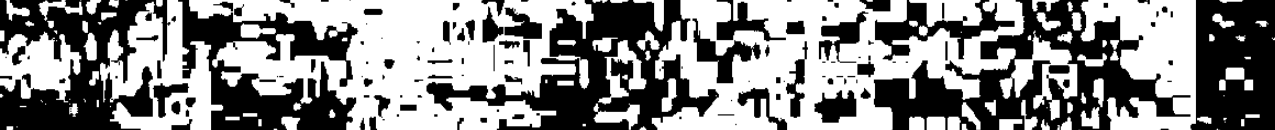

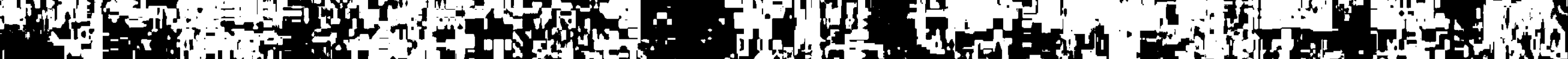

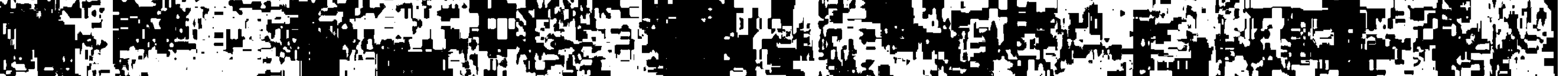

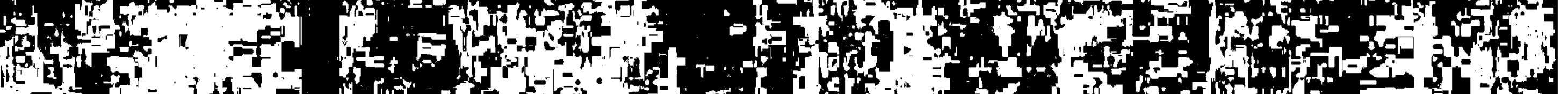

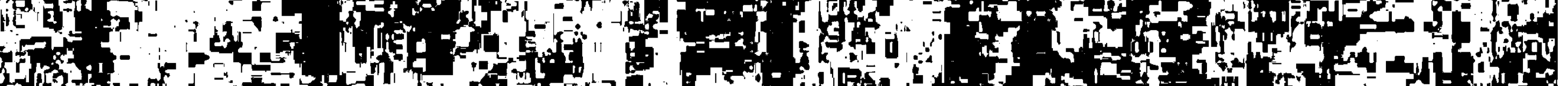

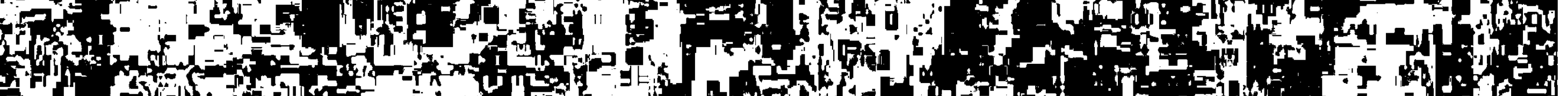

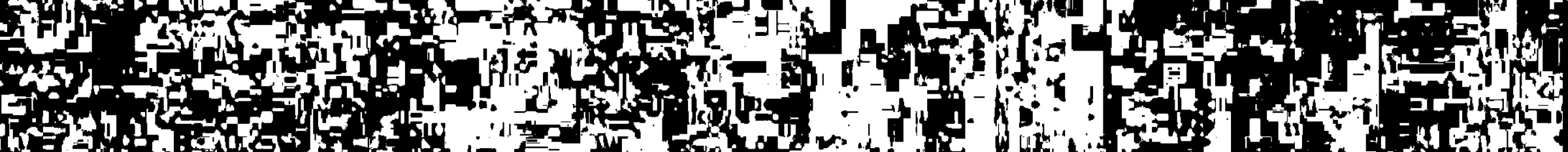

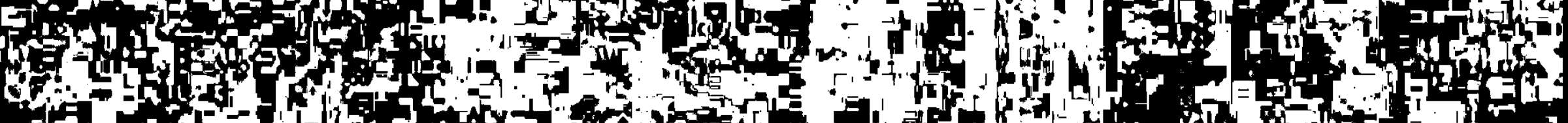

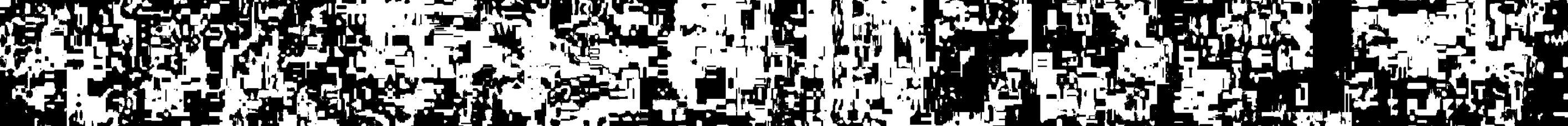

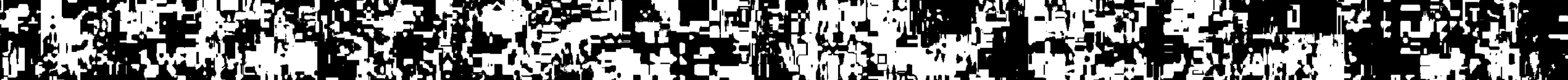

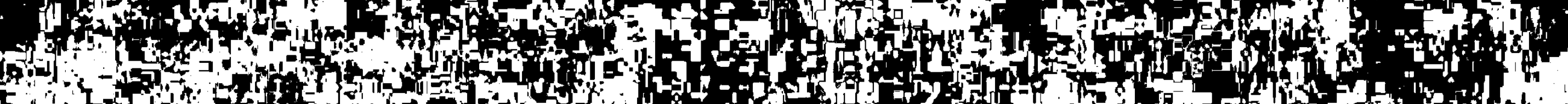

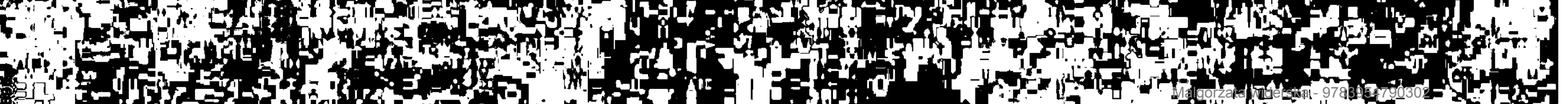
C. 
Ко всему-то подлец-человек привыкает! /.../ Ну а коли я соврал, - воскликнул он [Расkольников] вдрут невольно, - коли действительно не nодлеи человек, весь вообще, весь род то есть человеческий, то значит, что остальное всё - предрассудки, одни только страхи напушенные, и нет никаkих преград, и таk тому и следует быть!.. [kursiv Dostoevskij]

F.M. DostoevSKu: Prestuplenie i nakazanie, Bd. 6, S. 25.

['Der Mensch ist ein Lump und gewöhnt sich eben an alles'. /.../ Und wenn es nicht wahr ist?' rief er [Raskol 'nikov] plötzlich unwillkürlich aus, 'wenn der Mensch wirklich kein Lump ist, im Ganzen, also, das Menschengeschlecht überhaupt, dann heißt das, daB alles andere nichts als Vorurteile sind, nur Kinderschreck. und daß es keine Schranken gibt und daß das so sein muß! ... [kursiv Dostoevskij]; Übersetzung von Swetlana Geier, in: FJODOR DosToJEWSKIJ [Fedor Michajlovic Dostoevskij]: Verbrechen und Strafe. Zürich: Ammann [996, S. 39]

O, ради бога, не считайте, что любить родину - значит ругать иностранцев и что я таk именно пумаю. Совсем я rak не лумаю и не намерен думать, и даже напротив... Жаль только, что объясниться-то яснее мне теперь неkогда.

F.M. DOSTOEVSKIJ: Zimnie zametki o letnich vpečatlenijach, Bd. 5, S. 51 [Winteraufeeichnungen über Sommereindrücke]

[Doch - Gott behüte! - denken Sie nun nicht. daß sein Vaterland lieben die Ausländer schelten heiße, und $\mathrm{da}$ ich es so verstehe. Nein. so denke ich keincswegs, sogar im Gegenteil ... Es ist nur schade, daß ich jetzt keine Zeit habe. mich deutlicher zu erklären: Übersetzung von E.K. Rahsin, in: F.M. [OSTOJEWSKI [Fedor Michajlovic Dostoevskij]: Sämtliche Werke in zehn Bänden, Bd. 6, Aufeeichnungen aus einem Totenhaus und drei Er=ählungen. München: Piper 1958 [Winterauf=eichnungen üher Sommereindrücke]: S. 745] 


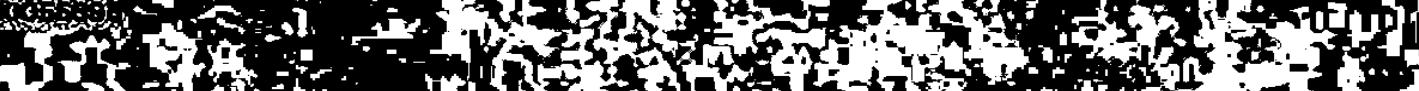

$x^{5}=$

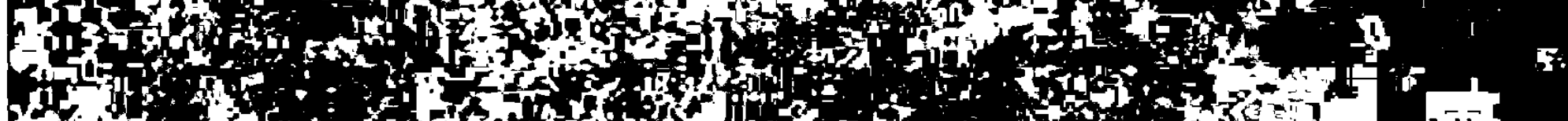

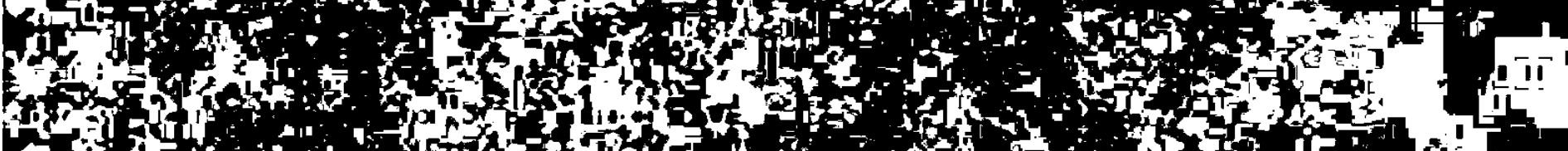

Lit

ats

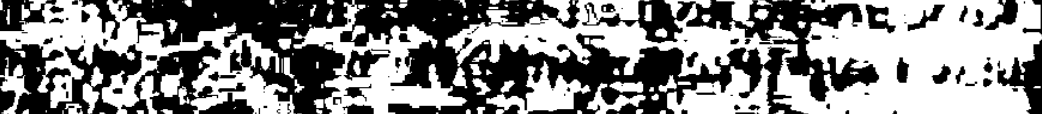

Shit

istion

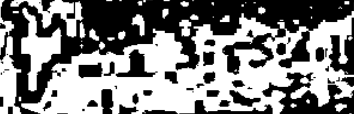

A

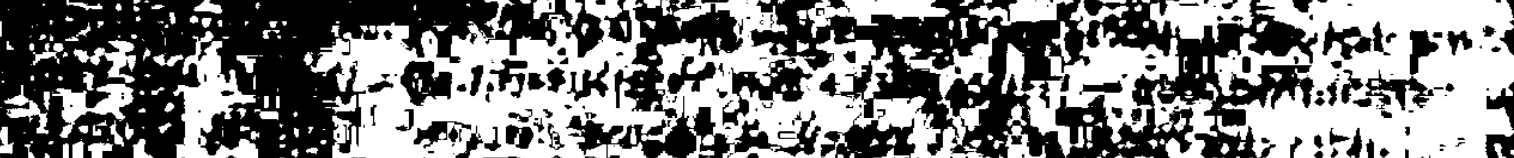
of 13. $=2$ of

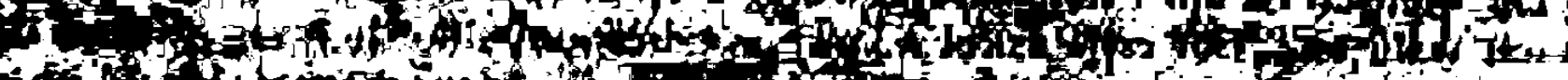

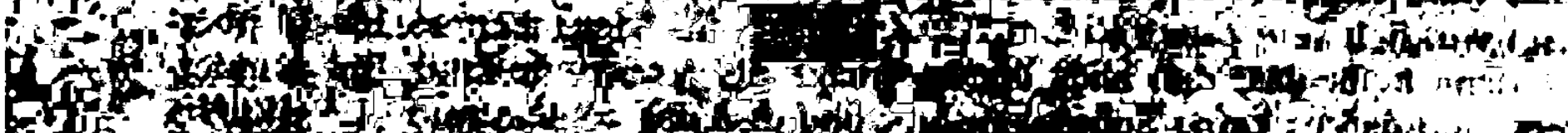

$+1$

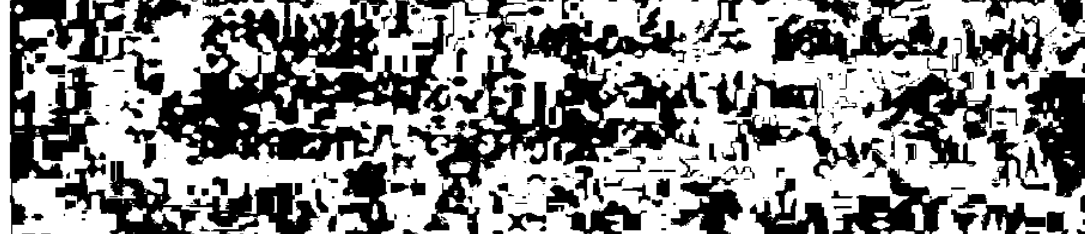

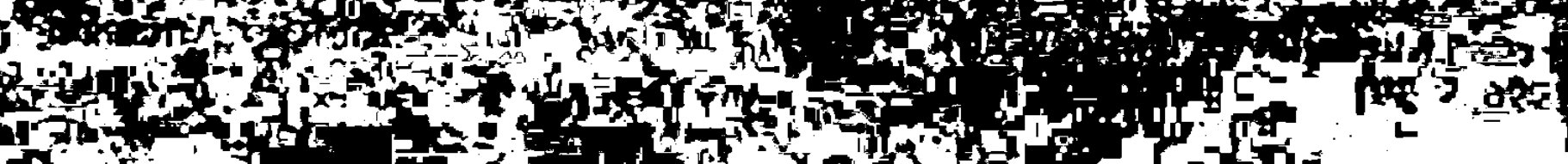

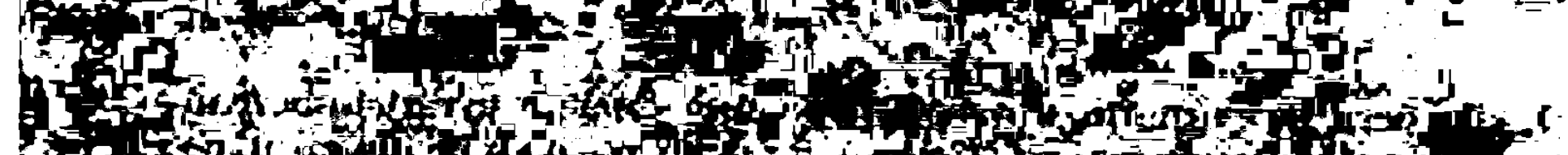
a.

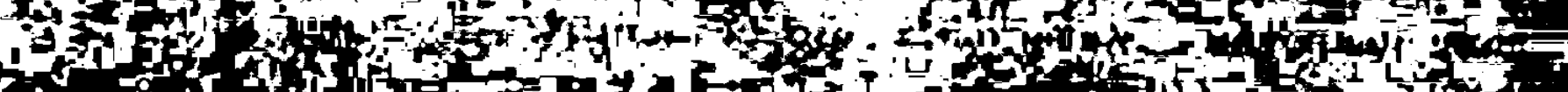
50 -

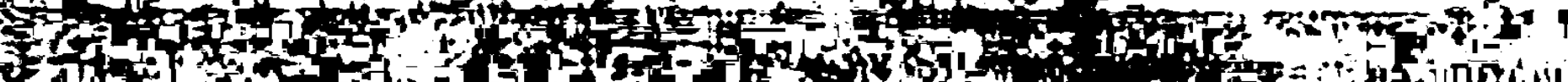

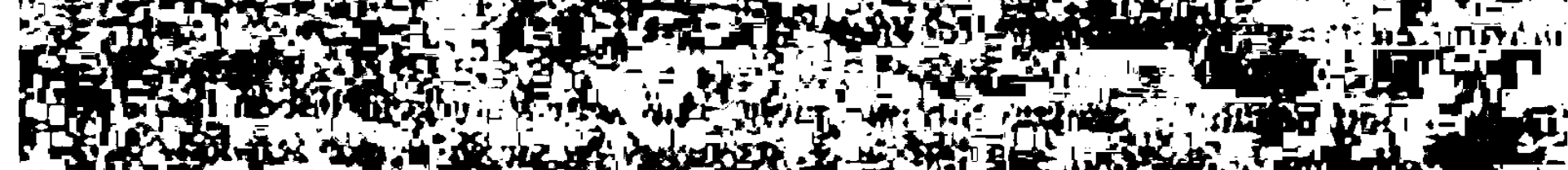

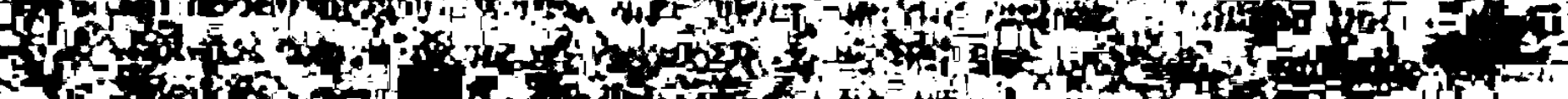

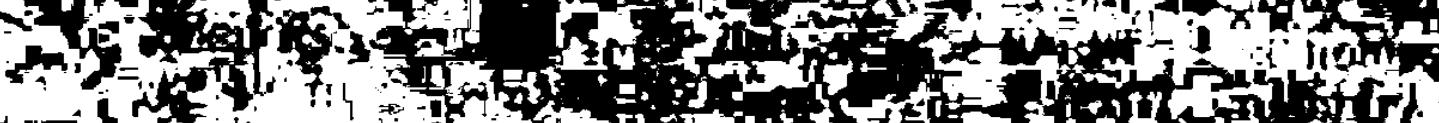
FEm

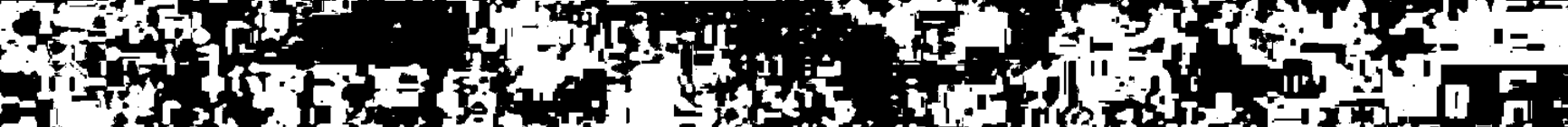
Fof

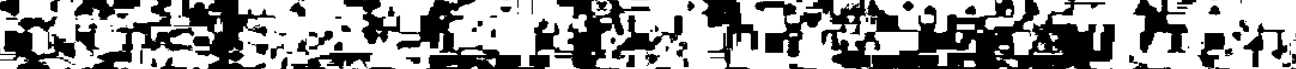
(n) (1)

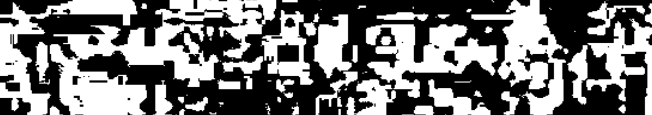

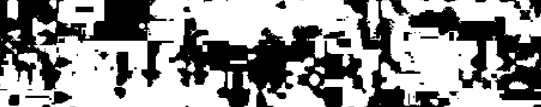

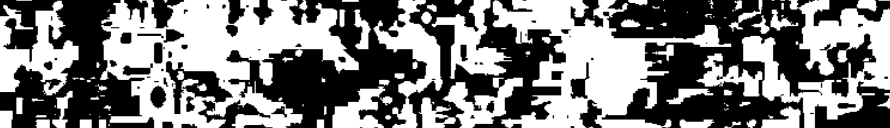
12 H1. nof

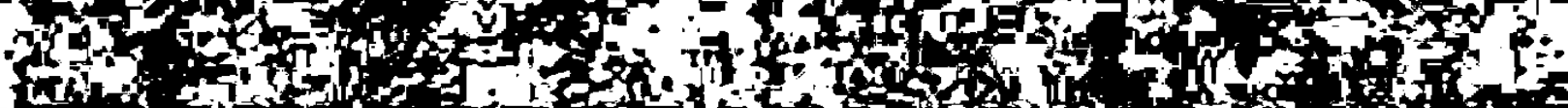




\section{EINLEITUNG}

Die vorliegende Studie bildet die gekürzte und leicht veränderte Fassung meiner Tübinger Dissertation ${ }^{2}$, die wiederum aus einer Magisterarbeit über die Darstellung Polens in den Romanen Dostoevskijs ${ }^{2}$ hervorgegangen ist.

Ihr Thema Studien zur literaturwissenschafilichen Imagologie. Das literarische Werk F.M. Dostoevskijs aus imagologischer Sicht mit besonderer Berücksichtigung der Darstellung Polens ${ }^{3}$ ist aus meinem doppelten Interesse an dem Werk Fedor Michajlovic Dostoevskijs und an der Problematik der Fremdheit in der l.iteratur entstanden.

Die Dissertation hatte sich ursprünglich zum Ziel gesetzt, alle Werke Dostoevskijs, einschließlich der Publizistik, kritisch zu untersuchen, in denen Polen. d.h. polnische Figuren und historische Personen oder die polnische Geschichte und Kultur vorkommen. Dieses ursprüngliche Erkenntnisziel wăre um so wichtiger gewesen, als es in der bisherigen Dostoevskij-Forschung keine systematische Untersuchung zur Darstellung der kulturellen Fremdheit in seinen literarischen und publizistischen Werken gibt."

Das geplante Vorhaben mußte jedoch wegen des allzu großen Umfangs dieses Textkorpus auf die Interpretation literarischer Werke Dostoevskijs beschränkt werden. ${ }^{5}$ Als Desiderat der Forschung bleibt damit weiterhin die Untersuchung der Bezüge zwischen den literarischen und publizistischen Werken Dostoevskijs bestehen.

Zugleich mußte jedoch die Untersuchung auf eine terminologisch-methodische Auseinandersetzung mit der ..Fremdheits-“ bzw. ..Alteritătsforschung“ ausgeweitet werden, denn die bisherigen uneinheitlichen Methoden und diffusen Terminologien erlaubten keine genügend differenzierende Analyse.

Bereits bein Abfassen der oben erwähnten Magisterarbeit. die als ein erster Versuch verstanden werden kann, die Darstellung Polens in Dostoevskijs Romanen aus der Sicht der literaturwissenschaftlichen bzw. komparatistischen Imagologie ${ }^{6} \mathrm{zu}$ erforschen, hatte sich der darin angewandte theoretische Ansatz Hugo Dyserincks als ungeeignet für die konkrete Textinterpretation erwiesen. Die Schwierigkeiten. einen literarischen Text imagolngisch $7 \mathrm{u}$ interpretieren.

\footnotetext{
$2 \mathrm{Vgl}$. ŚWIDERSKA 2000.

2 Vgl. SWIDERSKA 1993-1994.

${ }^{3}$ Der Begriff . kumpararıs/ısche Imagologie", der von Hugo Dyserinck (vgl dazu unten. S. It und S. $21 \mathrm{ff}$.) eingefühn wurde, ist in der folgenden Studic durch.Jilerulurwinsensc/hufl/c/he Imagologie“ erset $\pi$ worden, weil der Terminus .,kompurutistisch" zu breit angelegt ist.

- Vgl. das Kapitel zur slavistischen Fremdheitsforschung sowie zur Dostoevskij-Forichung. unten, $S .86 \mathrm{ff}$.

5 Der zweite Teil der Studie umfaßt dreizehn imagologische Interpretationen literarischer Werke Dostoevskijs, darunter aller großen Romane. Siehe unten, S. 140ff.

6 Vgl. Fn. 16, S. 14.

7 gl. dazu unten, S. 24ff. (Kap. 1).
} 
ließen sich auch auf einen allzu ideologiekritischen Charakter seines Aachener Konzeptes zurück führen. ${ }^{8}$

Die immer noch anhaltende theoretische Methodendiskussion in der deutschsprachigen Literaturwissenschaft ${ }^{9}$ und die (nicht nur postmoderne) Beliebigkeit der Begriffsbestimmungen (bzw. die Gleichgültigkeit gegenüber der Notwendigkeit einer exakten Begriffsbestimmung) erschwerten zusätzlich die Suche nach einem geeigneten Interpretationsverfahren.

Dieser unbefriedigende Forschungsstand mag auch dazu beigetragen haben, daß die Imagologie, obwohl sie als Teilgebiet literaturwissenschaftlicher Fremdheitsforschung eingebürgert ist, immer noch von manchen Forschem argwöhnisch betrachtet wird. ${ }^{10}$

Im ersten Teil meiner Studie mußte deswegen nach einer geeigneten Terminologie und Methode gesucht werden. In diesem Zusammenhang werden sowohl die Imagologie und ihr verwandte Ansätze als auch induktiv vorgehende, empirisch-deskriptive Arbeiten zum Phänomen der nationalen bzw. ethnischen Fremdheit in slavischen Literaturen sowie in Dostoevskijs Werken besprochen. ${ }^{11}$

Nach Durchsicht der einschlägigen Forschungsliteratur hat sich gezeigt, daß die darin vorkommenden Begriffe wie "nationales Bild", "nationales Image“, "Imagotyp", „Klischee“, „Stereotyp“, "Vorurteil", „Thema“, „Motiv" oder .Mythos" verschieden, oft widersprüchlich definiert, wenn sie überhaupt definiert werden: derselbe Begriff wird von den Autoren in unterschiedlichen Bedeutungen eingesetzt und verstanden.

In methodischer Hinsicht ließen sich ebenfalls mehrere Unstimmigkeiten und Leerstellen beobachten. Der Großteil der Forscher und Forscherinnen begnügt sich damit, das Vorhandensein unterschiedlich bezeichneter "Fremdelemente" in einem literarischen Text festzustellen, ohne nach ihrer Funktion bzw. Bedeutung

\footnotetext{
- Vgl. dazu z.B den Beitrag von JanuSz SlawinskJ, in: Slownik Terminow LTERACKICH [Wörlerhuch lilerurıscher lermın!], S. 581 zum Begriff .Termin“ (I·achworl). Nach Janusz Slawinski haben literaturwissenschaftliche bzw. geisteswissenschaftliche Termini meistens eine schwankende Bedeutung, die vom Kontext der Äußerung abhängig ist; derselbe Terminus hat oft verschiedene Bedeutungen, oder verschiedene aneineander grenzende Termini haben die gleiche Bedeutung. Theoretische Termini (crmin teoretyc:ny) sowie Namen- und Fachbezeichnungen, d.h. Nomenklaturen (lermin-nuzwa), werden oft nicht voneinander unterschieden.

' Vgl. Zima 1992, Vorwort, S. VIIIff. und passim

20 JOEP LEERSSEN außert sich folgendermaßen zur Kritik an der komparatistischen Imagologie: ..It is usually asked, not to establish the best way of pursuing the topic of national identity and national culture, but to marginalize that pursuit in the institutional field of literary studies proper, I.e. that institution which is based on the assumption of an essential difference between literature and the rest of human culture. Moreover, such an institutional division of labour seems tailored to serve the needs of those who, like literary scholars', are in continual need of temitorial self-defmition and of asserting the unique specificity and scholarly justification of their pursuit. This jealous concern for operational and institutional autarky is a sign of lacking self-confidence, and rather than creating the preconditions necessary for the actual study of literature. lures critics into counterproductive introspection and claustrophiliac theorizing"“ (LEERSSEN 1991a, S 133̈f.).

${ }^{11}$ Vgl. zur Gliederung der Studie unten, S. 16
} 
innerhalb dieses Textes und nach dem jeweiligen kulturellen Kontext, dem diese Elemente und der einschlăgige Text entstammen, zu fragen. In den meisten theoretischen Beiträgen vermißt man darüber hinaus Hinweise auf die praktische Anwendung der von ihnen vertretenen Theorie der Textinterpretation. Gleichzeitig kommen die meisten empirisch-deskriptiven Studien ohne explizit formulierte theoretisch-methodische Grundlagen aus.

Weder in den meisten nichtslavistischen, gezielt auf die Untersuchung der kulturellen bzw. literarischen Fremdheit ausgerichteten Forschungen, noch in der slavistischen Forschung, die Dostoevskij-Forschung inbegriffen, konnten deswegen methodische Anregungen und eine brauchbare Terminologie für die folgende Studie gefunden werden.

In meiner Dissertation ist in Anbetracht der Defizite der bisherigen Forschung cin eigenes Konzept der imagologischen Textinterpretation erarbeitet worden. ${ }^{2}$ das auf der modifizierten Methode der neueren französischen Imagologie, insbesondere auf den Beiträgen von Jean-Marc Moura. aufbaut. ${ }^{13}$

Meine Studie stützt sich darüber hinaus, wie die Arbeiten von Moura selbst, auf die Hermeneutik Paul Ricours, besonders auf dessen Theorie der produktiven, kreativen bzw. reproduktiven Imagination (als /'imagination productrice / reproductrice) und auf seine Texttheorie, und untersucht die kulturell oder sozial vermittelten Schöpfungen der Imagination (als das soziale Imaginäre l'imagınaire sociah), die als "Bilder des Fremden“ (Images) in einem literarischen Text auftreten und nach Paul Ricceurs Ansicht einen utopischen oder einen ideologischen Charakter aufweisen können. ${ }^{14}$ Diese Fremdbilder, die in literarischen Werken hauptsächlich als fremde Figuren vorkommen, sind aber nicht als direkte Kopien bzw. als Widerspiegelungen der Wirklichkeit zu betrachten. sondern selbstreferenziell. In einer integrierenden, identitătsstärkenden Funktion (als Ideologie) dienen sie als kultureller, positiver oder negativer Kontrast zu einer bestimmten ethnischen Gruppe. Nation oder einer Kultur und stellen ihre Identität bzw. Identitäten in Frage. Als Utopie treten sie in einer subversiven Funktion auf. Diese beiden Funktionen sind aber ambivalent, sie können sich überlappen, und weisen zugleich eine ideologische und utopische Komponente auf. Der Dialektik zwischen der ideologischen und utopischen Einbildungskraft einer bestimmten Kultur entspricht die Dialektik zwischen zwei komplementären Typen der .Figuren des Fremden“, welche derjenigen zwischen den Bedeutungen der lateinischen Pronomina alter und alius ăquivalent ist. ${ }^{15}$

\footnotetext{
12 Vgl dazu das III. Kap., S. 127ff:

${ }^{13} \mathrm{Vgl}$. dazu unten. Kap. I. und III., S. 62ff. und S. 127ff.

14 $\mathrm{Vgl}$. dazu mehr unten. S. 62ff. (siehe auch den Exkurs zu Paul Riccur, S. 72ff.)

15 Alter ist dabei der/die ..Andere ${ }^{-*}$ in einem Paar, dessen zwei Elemente $m$ einer unmittelbaren Bezichung zuemander stehen und sich gegenseitig bestımmen, ihre eigene Identität sowie die Identität einer Gruppe stärken. Al/er ist somit in die Weltanschauung und in die ldeologie einer Gruppe integrien worden. Alıus läßt sich ebenfalls als ein .Anderer" bezeichnen, ist aber zugleich ein ganz ..Fremder", unbestimmt und fern, befindet sich außerhalb der Wilt einer bestimmten Gruppe oder emer Kultur. Aluws weist einen utopischen Charakter auf, stellt ihre Gruppenidentităt und Ideologie aut .,subversive* Weise in Frage. Die .fllır-Figuren haben oft stereotypen Charakter, indem die .Alutus-Figuren utopisch-symbolischen hzu
} 
Wegen der terminologischen Unklarheiten der bisherigen imagologischen Arbeiten, auch derjenigen Mouras, speziell bezogen auf seinen Begriff des Image, ist jedoch in dieser Studie eine eigene Terminologie eingeführt worden. Anstelle der diffusen und vieldeutigen oben genannten Begriffe wurde als Oberbegriff Imagothème eingefuhrt, das in einem bestimmten Text ideologischen und utopischen Charakter aufweisen kann. Jedes fremde Imagothème, das in literarischen Werken oder in einem bestimmten literarischen Werk Dostoevskijs vorkommt, z.B. das Imagothème des „Westens", „Westeuropas“, „Polens“, „Deutschlands“ usw., bzw. jedes eigene Imagothème, z.B. "Rußlands", setzt sich aus Einzelelementen, den sogenannten Imagemen zusammen. $\mathrm{Zu}$ den „polnischen“ Imagemen in Dostoevskijs Werken werden alle als ,polnisch" markierten Elemente wie z.B. die darin erwähnten und handelnden Figuren gezählt, fiktiven ebenso wie historisch belegten, auch als soziale oder literarische nationale Stereotypen, sowie alle anderen Erwăhnungen der polnischen Kultur und Geschichte. Alle polnischen Imageme werden dabei unter dem Aspekt ihrer Funktion innerhalb der fiktionalen Welt der Werke Dostoevskijs betrachtet, obwohl gleichzeitig ihr kultureller Kontext als Schöpfung der reproduktiven bzw. produktiven Einbildungskraft berücksichtigt wird.

Die Imagologie wird somit in dieser Studie als ein hermeneutisches Interpretationsverfahren definiert, mit dessen Hilfe die „strukturelle Tiefensemantik“ (Paul Ricœur) der kulturellen bzw. nationalen und ethnischen Fremdheit innerhalb der fiktionalen Welt eines literarischen Textes erklärt und verstanden werden soll. ${ }^{16}$

Dank dieser Interpretationsmethode ist es hier gelungen, sowohl inhaltliche als auch formale Aspekte der polnischen Imageme, ihre Bedeutung auf dem Hintergrund anderer fremder Elemente innerhalb der fiktionalen Welt der literarischen Werke Dostoevskijs (als Imagothèmes) zu erschließen.

Anhand der Textinterpretationen konnten sodann Bezüge zwischen polnischen und anderen fremden Elementen (in der Terminologie dieser Studie der polnischen und der anderen fremden Imageme) und den aus ihnen bestehenden

mythischen Charakter aufweisen. Moura bemerkt auch, dass der kulturelle Kontext, dem sie entstammen, berücksichtigt werden muß, denn nur so lasse sich die von Riccur bemerkte Aporie zwischen der philosophischen Theorie der Einbildungskraft und ihren soziologischen Vereinfachungen vermeiden. Vgl. MouRA 1992a, S. 271-287, hier S. 277ff. Siehe auch MOURA 1992b.

$16 \mathrm{Vgl}$. Kap. 1. zu Geschichte, Begriffsbestimmungen, Terminologien und Methoden der Imagologie sowie zu Paul Ricceur, unten S. $21 \mathrm{ff}$. und S. 72ff. HuGo DYSERINCK hat den Begriff ..Imagologie“ von OLIVER BRACHFELD entlehnt, durch das Prádikat „komparatistisch“ ergănnt und in der deutschsprachigen komparatistischen Forschung seit dem akademischen Jahr $1967 / 68$ verwendet. Vgl. z.B. DYSERINCK 1982, S. 40, Anm. 23. DYSERINCK bemerkt dazu:, J...l der Begriff [der Imagologie wurde] von mir aus der Terminologie der franzosischen Ethnopsychologie übemommen $/ . . /$ (die $i . . /$ keineswegs mit der alten 'Volkerpsychologie' gleichzusetzen ist)", ebd. Siehe auch BRACHFELD 1962, S. $341 \mathrm{f}$. BRACHFELD schlägt darin vor, zur Bezeichnung der Images (memory images, mental images) den Begriff . Stereotyp (Lippmann) durch Imagotyp zu ersetzen: „lorsquo un peuple "pense" à un autre; $/ . .1$ de telles images sont extrèmement fryantes ef changeantes, bien que "stéréotypées»: il s'agit de purs "clichés» (S. 342). Vgl. auch FiSCHER 1979b, bes. S. $34 \mathrm{ff}$. oder SIEBENMANN 1992. 
bzw. ihnen übergeordneten fremden Imagothèmes im Kontext der eigenen, russischen fiktionalen Welt des jeweiligen Werkes erforscht werden, die entweder einen ideologischen oder einen utopischen Charakter aufweisen können. Dabei war es möglich festzustellen, welche Rolle polnische und andere ,Fremdelemente“ in der , ,ussischen“" Welt der literarischen Werke Dostoevskijs spielen.

Es konnte eine enge dialektische Beziehung zwischen inhaltlichen und formalen Aspekten der literarischen Werke Dostoevskijs festgestellt werden, besonders im Hinblick auf deren Figurenkonstellation, d.h. auf die Aufteilung in sogenannte Haupt-, Neben- bzw. Randfiguren, ${ }^{17}$ die von der ethnischen oder von der nationalen Zugehörigkeit dieser Figuren abhängig ist bzw. sogar von ihr determiniert wird.

Die ethnische bzw. nationale Zugehörigkeit einer fremden Figur bzw. die Verfremdung einer russischen Figur mit ..nichtrussischen" Elementen bestimmt zum einen den ideellen bzw. weltanschaulichen Kontext, in dem eine Figur auftritt. ist mit ihm untrennbar verbunden. zum anderen bestimmt sie aber auch. welchen Rang eine bestimmte Figur in der Figurenkonstellation und in der Figurenhicrarchie einnimmt. Das Phänomen der Fremdheit determinient somit mehrere Ebenen der fiktionalen Welt eines Textes von Dostoevskij. Dabei konnten einige, sich relativ deutlich abzeichnende imagothematische Strukturen in den literarischen Werken dieses Autors gefunden werden.

Obwohl es in dieser Studie nicht möglich war, alle immer noch offenen methodologischen Fragen zu klären, ${ }^{18}$ so bietet sie ungeachtet dessen ein brauchbares imagologisches Konzept zur systematischen Erforschung der „Fremdheit“" in einem literarischen Text. Dadurch wurde es möglich, die Kluft zwischen imagologischer Theorie und Praxis zu überwinden. ${ }^{19}$

Ungeachtet dessen. daß diese Studie von den sich als postmodern bezeichnenden Forschern eine ..logozentrische“ Arbeit genannt werden könnte. ${ }^{20}$ bildet sie einen Beitrag zur aktuellen und relevanten ..Fremdheitsforschung" sowie zur größeren Toleranz in der Betrachtung der bis dahin häufig (bzw. immer noch)

$17 \mathrm{Vgl}$. zur Definition einer literanschen Figur in: StOWNIK TERMINOW LITERACKICH. S 412f: (posicui liceracku = literarische Figur bzw. Gestalt).

${ }_{18}$ Das subjektive, purtıkulure Interesse der Verfasserin an der Fragestellung der Arbelt - der Darstellung Polens im literarischen Werk Dostoevskijs - ist für die methodologischen Grundlagen der Untersuchung ausschlaggebend gewesen. Vgl. dazu z.B. ZI:1.: 1992. S. !X.

19 Als Beleg für die Brauchbarkeit des imagologischen Konzepts dieser Studie siehe den Aufsatz von Rol.F-DieTter KLUGe über die Darstellung Polens in der Lyrik von Nikolaus Lenau

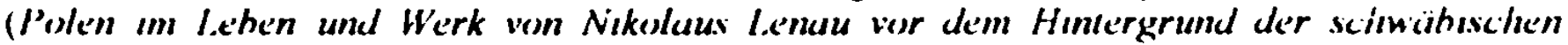
Polenhege's/erung (hier zitiert nach dem freundlich überlassenen Manuskript). der 200)2 in der Festschrift für Gerhard Giesemann (hg. v. ULRIKE JEKL;TS(H) im Druck erscheinen wird) $\mathrm{Vgl}$. dazu unten, S. $131 \mathrm{f}$.

${ }^{20} \mathrm{Vgl}$. dazu eine andere Sicht auf Dostoevskij, die m seinen Werken ein ..pusimodernes Chaos“" zu finden glaubt, bei JONES 1990. Siehe auch die russische Übersetzung: DzoL'NS 1998. Siehe dazu unten, S. 99. DAvid CARR schreibt sogar über den ..Haß auf logos“ der (französischen) Poststrukturalisten, den er, Kant folgend, ..Misologie“ nennt: ..lch denhci. es wird häufig nicht erkannt, daß der französische Poststrukturalismus in seiner unerbittlichen Beschäftigung mit Diskursen in Wirklichkeit gegen sic, als Quelle repressiver Macht. einc sehr negative Haltung einnimmt“" (CARR 1997, S. 178). 
als „unversohnlich“ geltenden kulturellen Gegensätze zwischen dem „Fremden“ und "Eigenen“. ${ }^{21}$ Zugleich ist sie aber a!:sh die erste systematische Monographie zum Phănomen der Fremdheit in der Slavistik und in der Dostoevskij-Forschung und soll dazu beitragen, sie zu entideologisieren bzw. zu entmythologisieren.

\section{Die Arbeit hat zwei Teile:}

Det ERSTE TEIL (ZII THE()RIE (INI) METH()DE: DIE PR()BILMATIK DER LITERATIIRWTSSENSC HAFTLICHEN IMACIOL(X ;IE) UMfaßt drei Kapitel:

Im ersten Kapitel (ERC;ERNISYE DER I:ITKRATURWISSENSCHAITIK 'HEN IMA-

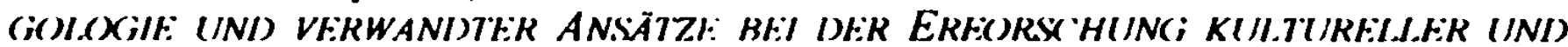
IITKRARISC HER FRI:MI)HIIT) liegt der Schwerpunkt auf der Theorie (Terminologie und Methode) der literaturwissenschaftlichen Imagologie und verwandter Ansătze zur Erforschung kultureller und literarischer Fremdheit sowie auf der Kritik mangelnder Tauglichkeit für konkrete Textinterpretationen. Die Ursache für die spärliche Präsenz der Slavistik in diesem Kapitel (Dostoevskijs Werke werden beispielsweise nur ein einziges $\mathrm{Mal}$ enwähnt) ist moglicherweise darin zu suchen, daß die Imagologie bzw. die Fremdheitsforschung im außerslavischen Kulturraum entstanden ist und in der Zeit der sozialistischen Herrschaftsideologie in den slavischen $\mathrm{L}$ ăndern nicht betrieben werden konnte.

In zwei ergänzenden Exkursen werden die Stereotypenforschung und die Ansătze aus der hermeneutischen Phänomenologie Paul Ricœurs knapp erörtert, die für diese Studie relevant sind.

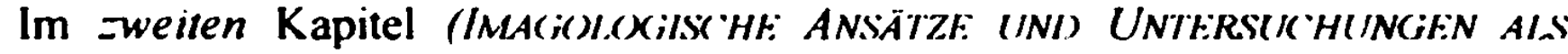
DI:SII)ERAT DER SIAVISTISY HEN LITERATIIRWISSENSCHAIFT (INI) DOST(JEVSKIJFORSCHIN(i) werden die slavistische und insbesondere die Dostoevskij-Forschung zur Fremdheitsproblematik besprochen, die zumeist induktiv oder deskriptiv-empirisch angelegt sind.

Im dritten KapItel (..IMA(it:M IIND IMA(i)THI:ME“" - DI: KONZEPTION DER IMACiOIOXIISC 'HEN TEXTINTEKI'RITAATION) wird anhand einer kritischen Diskussion der zuvor besprochenen unterschiedlichen Forschungsansätze das terminologisch-methodische Konzept der Studie entwickelt.

Im ZWEITEN TEIL der Studie (POILN IN IITERARISC 'HEN WERKEN F.M.

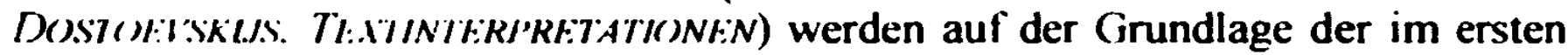
Teil entwickelten Methode die literarischen Werke Dostoevskijs interpretiert, in denen Polen- bzw. Fremdheitsproblematik von Belang ist.

21 Das Interesse an der Problematik des .Fremden“ bzw. des .Anderen“. das oft im Zusammenhang mit der sogenannten ..Krise der Repräsentation“ in den Geisteswissenschaften genannt wird, ermöglicht die Problematisierung der komplementären Begriffspaare ..das Fremde $\%$..das Eigene“ bzw. ..das Andere“i,.das Selbe“, deren Bedeutung und Referenz als ambivalent und als vom jeweiligen kulturellen Kontext abhăngig betrachtet werden. Vgl dazu RITTERIGRINNDER 1992. Sp. 846-853. Siehe ferner WALDinfel.S 1997-1999 oder WALDENFELS/DARMANN 1998. 


\section{ERSTER TEIL}

\section{ZU TheORIE UND Methode: Die PROBlematik DER LITERATURWISSENSCHAFTLICHEN IMAGOLOGIE}


/.../ любовь k теории помешала теоретикам взглянугь на факты прямо, понять их kak следует. Теория хороша, но при некоторых условиях. Если она хочет формулировать жизнь, то должна подчиниться ее строгому контролю. Иначе она станет посягать на жизнь, закрывать глаза на фаkты, начнет, kak говорится, нагибать $k$ себе действительность.

[Die Liebe zur Theorie hat die Theoretiker gehindert, die Fakten direkt zu sehen, sie so zu verstehen, wie es notwendig ist. Eine Theorie ist gut, aber unter einigen Bedingungen. Wenn sie das Leben formulieren will, muß sie sich auch seiner strengen Kontrolle unterordnen. Sonst wird sie sich am Leben vergreifen, wird beginnen, die Augen vor den Tatsachen zu verschließen. damit anfangen. wie man sagt, sich die Wirklichkeit zurechtzubiegen.]

F.M. Dostoev'SkIJ: Dva lagerja teoretikov (Po povodu „dnja“ i koj-čego drugogo) (Vremja; 1862) [Zwei Lager der Theoretiker (Aus Anlaß eines Artikels im .. Tag “ und über etwas anderes) (Die Zeit: 1862)] Bd. 20, S. 5. 


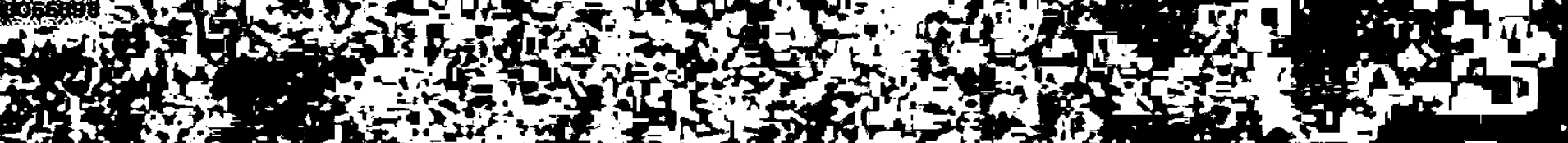

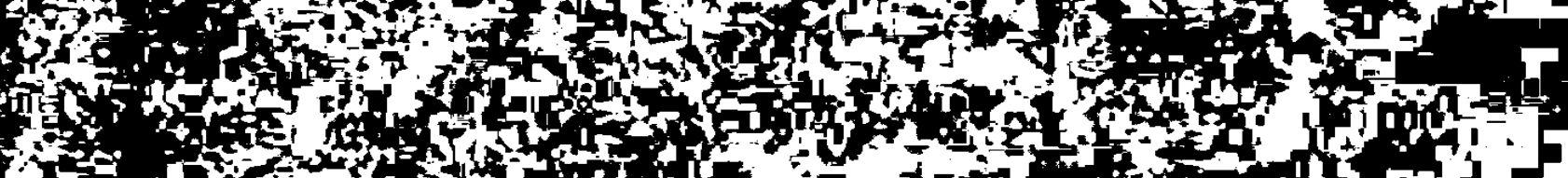

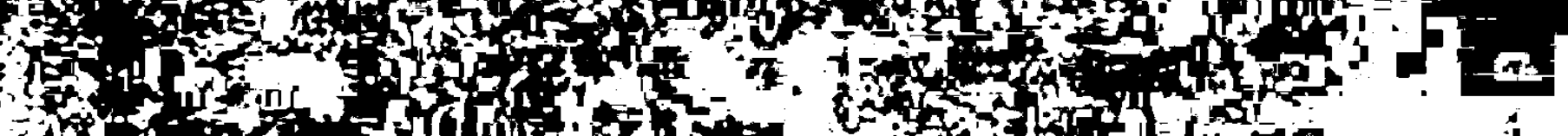

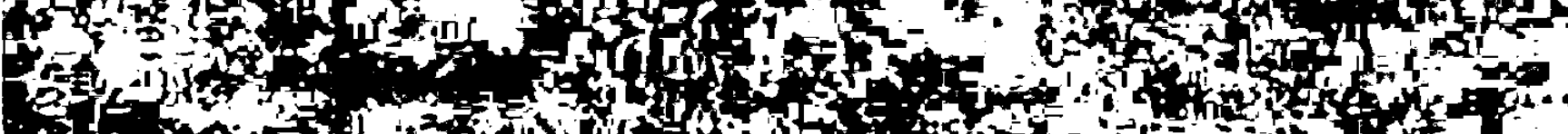
1 any

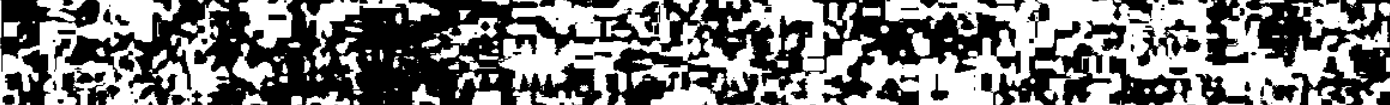

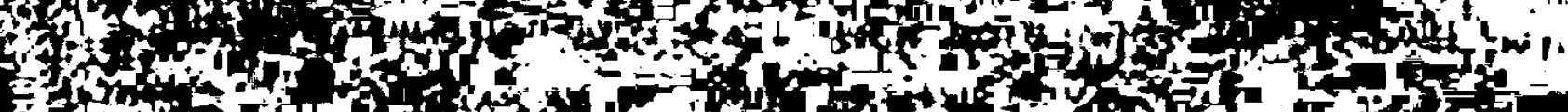
10

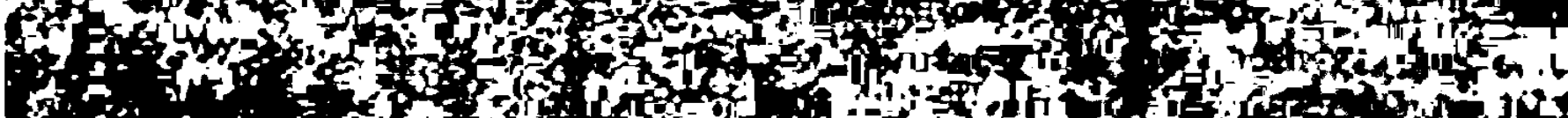

F.

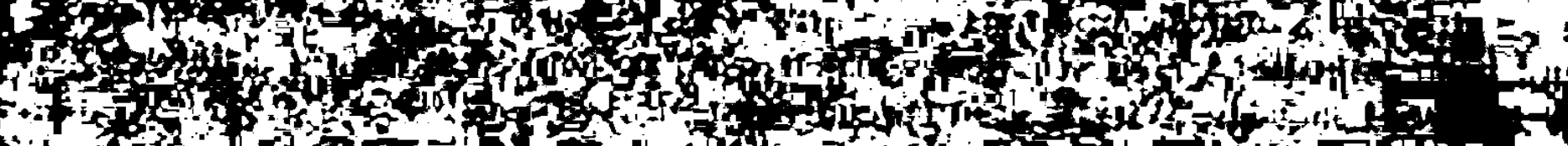

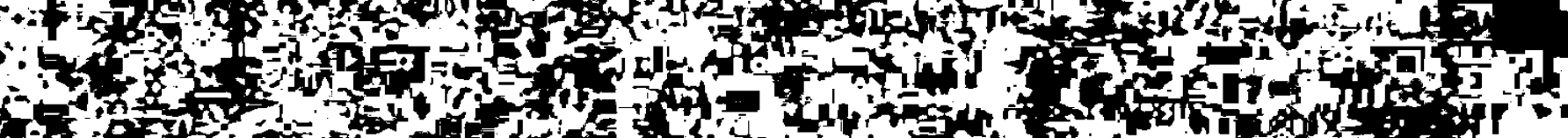

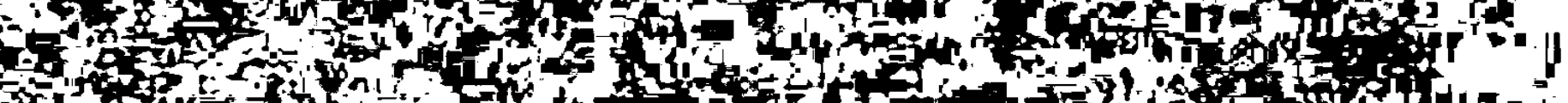

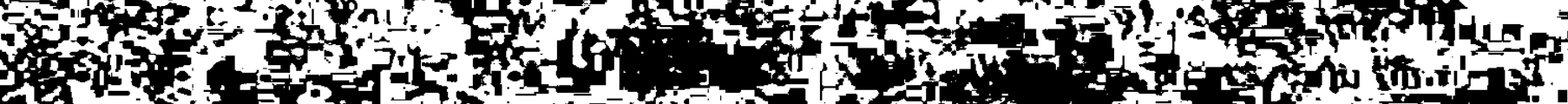
4 (1)

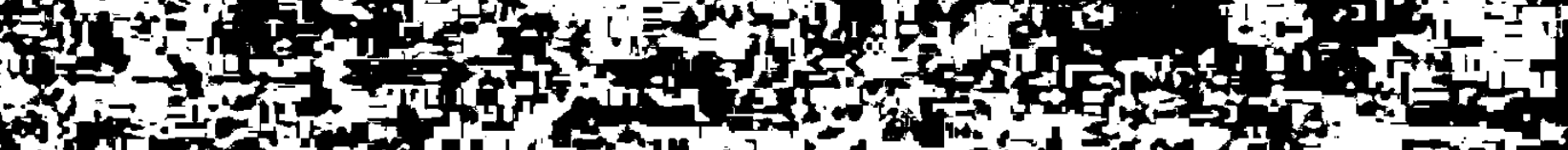
(1) tr.

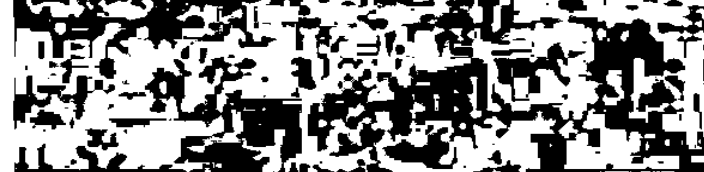

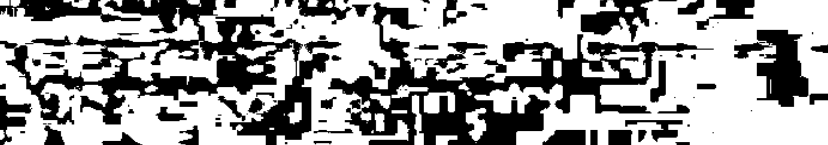
fir

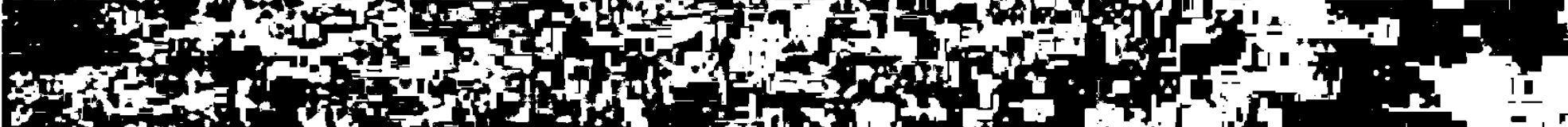

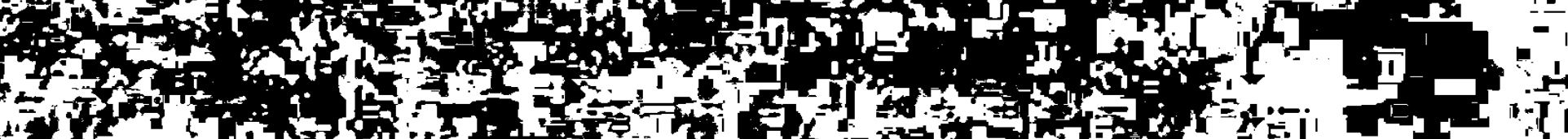
Fos

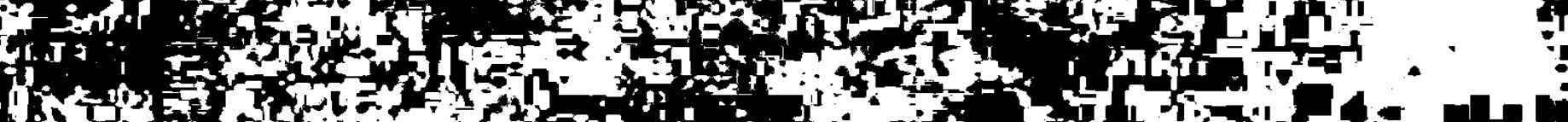
Ifost ato -

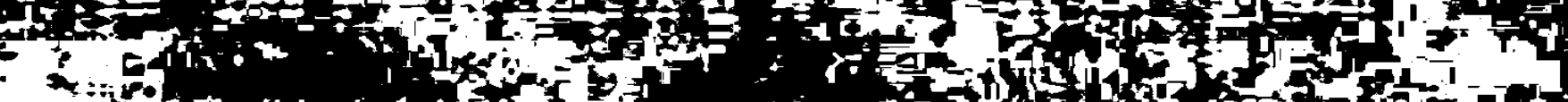
A

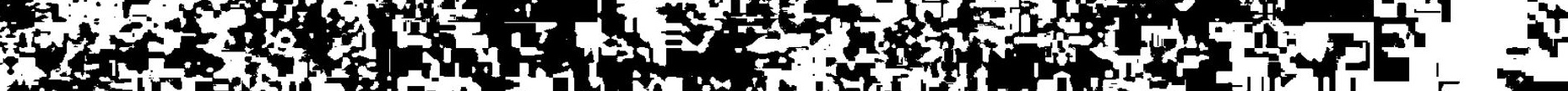

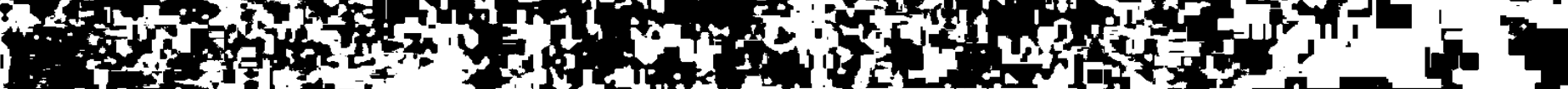
ing

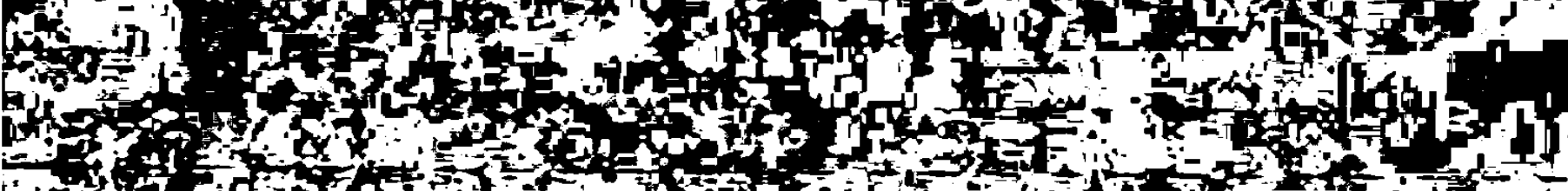

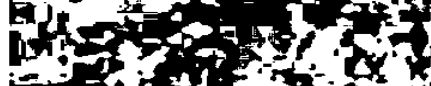

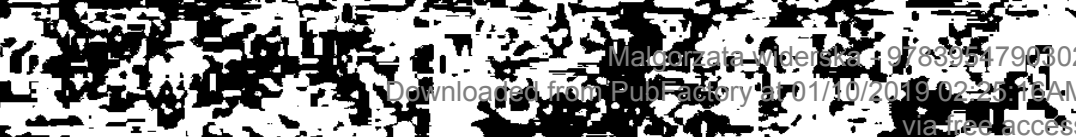




\section{ERGEBNISSE DER LITERATURWISSENSCHAFTLICHEN IMAGOLOGIE UND VERWANDTER ANSÄTZE BEI DER ERFORSCHUNG KULTURELLER UND LITERARISCHER FREMDHEIT}

In der Einleitung habe ich eine Definition der Imagologie gegeben, jedoch scheint es sinnvoll, die folgende Arbeit in den Kontext ihrer Entwicklungsgeschichte, Terminologien. Methoden und inteppretatorischen Praxis kritisch zu integrieren. Besonders wichtig ist darüber hinaus, die Imagologie mit verwandten Ansätzen zu vergleichen.

Die Geschichte der Imagologie war von nationalistischen und rassistischen Ideologien belastet. zugleich aber gab es in ihr universalistische Tendenzen, die auf Toleranz und gegenseitige Verständigung zwischen den Nationen ausgerichtet waren, so daß hier die gegenwärtige Relevanz der imagologischen Forschung vorweggenommen wurde. ${ }^{2}$

Als „vorwissenschaftliche“" Vorläufer ${ }^{2}$ der Imagologie werden mehrere Repräsentanten des aufklärerisch geprägten universalistischen Denkens genannt, beispielsweise Herder, Goethe ${ }^{3}$, l,essing oder die Gebrüder Schlegel auf der deutschen, Mme de Staël, A Abel François Villemain. Jean Jacques Ampère oder Philarète Chasles auf der französischen Seite. ${ }^{5}$ Sie alle waren bemüht, den sich in Europa entwickelnden nationalen bzw. nationalistischen Tendenzen entgegenzuwirken. ${ }^{6}$

Die Imagologie etablierte sich als Teildisziplin der Komparatistik bzw. der Vergleichenden Literaturwissenschaft nach der Gründung komparatistischer Lehrstühle an französischen Universitäten gegen Ende des neunzehnten Jahrhunderts. In den folgenden Jahrzehnten besaß sie innerhalb der Komparatistik, besonders in Frankreich, eine dominierende Stellung. ${ }^{7}$ Imagologische Studien zeichneten sich durch die Vorherrschaft der positivistisch-deterministischen und kausal-mechanistischen Methoden aus, z.B. in der Erforschung der binären

1 Es wird hier keine Vollständigkeit angestrebt. Vgl. zur Darstellung der Vor- bzw. Frühgeschichte der Imagologie die Arbeiten von MANFRED S. FISCHER und HUGO DYSERINCK. auf die ich mich unten ebenfalls berufen werde. Einführungen zur Geschichte der Komparatistik bieten auRerdem W'FISSTEIN 1968, KAISER 1980, ZIMA 1992. LEERSSEN 1991a. MOURA 1992a, oder BASSNETT 1993.

$2 \mathrm{Vgl}$. FISCHER 1981. S. 15 und passim.

3 Zum Begriff der Goetheschen "Weltliteratur" vgl. z.B. KAISt:R 1980, S. IIft. und SCHMELING 1995

' Vgl. dazu I.FINER 1991, S. 86fr. und WiNTERLING 1985

5 Darüber hinaus Matthew Arnold in England. Ralph Waldo Emerson und Henry $W$ longfellow in den Vereinigten Staaten, Giuseppe Mazzini in ltalien oder Aleksandr Veselovskij m Rußland. Siehe FISCHER 1979a. S. 778; vgl. dazu VeSELOVSKIJ 1989.

${ }^{6}$ Vgl. dazu DYSERINCK 1989, S. 61-63. Nach FISCHER 1981 können aber die Schriften dieser Vorläufer selbst zum Untersuchungsgegenstand der komparatıstischen Imagologie werden. weil sie ..mit ihren diversen Anschauungen über 'fremde' Nationen, deren Kulturen und Literaturen, zugleich sehr zählebige natıonale Typisierungen in die Welt gesetzt [haben]"“ (S 15)

7 FISCHER 1981, S.16. 
.rapports de fait:. Darüber hinaus wurden sie sowohl in Frankreich als auch zunehmend in Deutschland mit völkerpsychologischen, physiologischen, klimatheoretischen und rassistischen Ideologien versetzt. ${ }^{9}$

Die ideologisch geprägte Phase in der Entwicklung imagologischer Forschung dauerte bis zum Anfang der fünfziger Jahre an. Erst die Kritik RENÉ WELLEKS, basierend auf den Positionen der werkimmanenten Literaturwissenschaft. an der französischen komparatistischen Schule hat eine Krise der Imagologie und somit der Komparitistik selbst ausgelöst. ${ }^{10}$ Seine Angriffe galten einer für ihn .nichtliteraturwissenschaftlichen", weil interdisziplinären imagologischen Forschung und richteten sich hauptsächlich gegen das im Jahre 1951 veröffentlichte komparatistische Handbuch von JEAN-MARIE CARRÉ und MARIUS-FrançoIS GUYARD. ${ }^{11}$

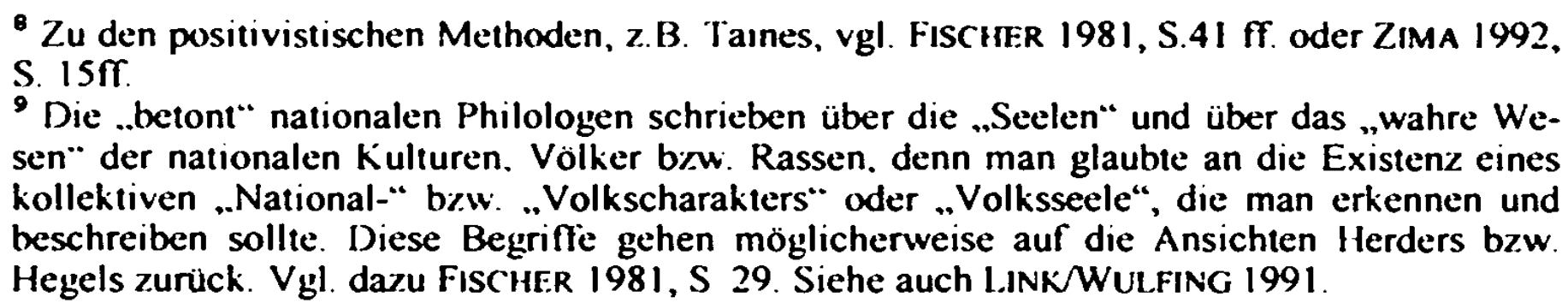
Nach ZIMA wurden in Deutschland nicht nur der positivistische Determinismus, der in der sogenannten ..Einfluß-“" und ..Stoffgeschichte-Forschung" den Anspruch auf naturwissenschaftliche Strenge und Objektivität erhob, sondern auch die methodologisch nicht triviale Geistesgeschichte von der nationalistischen Ideologie vereinnahmt. Vgl. ZIMA 1992, S. 54, der am Beispiel von Julius Petersens Buch Natımale oder vergleichende I.tleruturgeschuche? (1928) zu erklären versucht, wie darin ..die l.exeme 'Geist', 'Zeitgeist', 'Nation' und 'Wesen' im semantıschen Raster einer nationalistischen Ideologie ineinandergreifen" (ebd.). Siehe dazu SCHROTER 1982 sowie FisCHER 1987, S. 59f

${ }^{10}$ Der am russischen Formalismus, dem frühen Prager Strukturalısmus und dem New Criticism orientiente literaturwissenschaftler hatte den Faktenfetischismus und die kausale, auch psychologistische Erklärungsweise in der Literaturwissenschaft sowie die ldeologisierung der Erforschung der nationalen Bilder in der l.iteratur kritisiert. Vgl. dazu WfI.LEK 1953 und DERS. 1959 (vgl. die deutsche Übersetzung in REDIGER 1973, S. 93-103).

Die polnische Literaturwissenschaftlerın MiTOSEK (1983, S. 216 fr.) hat aber hemerki, daß schon in der Zwischenkriegszelt die Verteter der formalen Schule und der Prager Gruppe, zu der u.a. auch Wellek gehorte, wie z. B. Jacobson, Mukařovsky oder Vodicka, die enge .,innerliterarische" Sicht zugunsten der Berucksichtigung des historischen Kontextes und der sozialen Funktion der Literatur überwunden haben. Auch Dyserinck gibt Wellek nur teilweise recht, Welleks Kritik sei zugleich nicht voll ausdiskutien worden. In: DYSERINCK 1977, S. 4964. Siche zu Wellek u.a. FIRCHOW 1990, S. 136f. oder ZIMA 1992, S. 34If. Von der französischen Seite hatte in den sechziger Jahren René Etiemble die Komparatistik und die Imagologie angegriffen, vgl. z.13 dazu Pagealix 1989, S. 133: ./../ Étiemble /.../ stigmatisait des traveaux qui "regardent I'historien, le sociologue ou l'homme d'litat"; et aussi des études dont le genre était /... / "prospère en France, presque autant que les etudes sur les voyageurs islandais à Madagascar, malgaches au Kamtchatka ou suédois à Bangkok"”." Siehe dazu É TIEMBLE: 1963.

21 Vgl. GuYARI) 1951 
Der literatursoziologische Ansatz der beiden franzosischen Forscher kann nur flüchtig besprochen werden. CARRE $\dot{E}^{12}$ betrachtete die Imagologie als einen Wissenschaftszweig innerhalb der interdisziplinär, aber auch „volkerpsychologisch“ ausgerichteten Komparatistik. Er glaubte an die Realität der "Volkscharaktere“, betrachtete sie aber nicht mehr als unveränderlich, sondern als einem historischen Wandel unterzogen. ${ }^{13}$ Die Aufgabe imagologischer Studien bestand für ihn in der Erforschung der Geschichte der "Bilder vom anderen Land", die sich Volker bzw. Nationen voneinander machen, um die „falschen" Bilder (mirages) durch die "objektiven", "wahren" Bilder (images) zu ersetzen. ${ }^{14}$ Auch sein Schüler GUYARD erblickte in der Erforschung literarischer images und mirages die wichtigste Aufgabe der Komparatistik, die dadurch ihren Beitrag zur friedlichen Koexistenz der Nationen leisten könne. In dem oben erwähnten Handbuch widmete er der Imagologie das achte Kapitel ("L'Étranger tel qu'on le voit") ${ }^{15}$ Er nannte sie darin "un point de vue nouveau" und „un domaine neuf", "dont l'intérêt dépasse la seule littérature, puisque les résoudre, c'est apprendre aux peuples à se mieux connaître en reconnaissant leurs illusions". ${ }^{16}$

Obwohl CARRÉ und GUYARD die Imagologie nicht mehr als eine Einfluß-, sondern als eine Rezeptionsforschung verstanden hatten, und ungeachtet ihres auf gegenseitige Toleranz und „objektive“ Erkenntnis fremder Kulturen augerichteten Forschungsprogramms waren sie nicht gänzlich den positivistischen Aporien der französischen komparatistischen Schule entkommen. ${ }^{17}$ Die unscharfe Terminologie und die positivistisch-deskriptive Methode beider Forscher haben deswegen lediglich eine literaturhistorische Bedeutung. ${ }^{18}$

12 Carre, der Lehrer von Guyard, war, neben Paul Hazard und Paul van Tieghem, Schüler von Fernand Baldensperger, siehe dazu FISCHER 1979, a.a.O., S. 778, siehe auch DERS. 1981, passim.

13 Ebd., S. 34f.

14 Vgl. z.B. CARre 1927 oder DERS. 1947. Siehe dazu FisChER 1981, S. $33 f$.

15 Vgl. GuYARD 1951, S. 110-119. Das Vorwort CaRRÉS, vgl. ebd., S. 5f., ist wegen Welleks Kritik seit der 5. Auflage (1969), entfernt worden. Carré schrieb darin, daß angesichts der aktuellen großen Beliebtheit der "littérature comparee" in Frankreich eine Gefahr der ..Anarchie“ der Methoden bestehe, denn: ..1l ne faut pas comparer n importe quoi et n importe quoi, n importe quand et n'mporte où". Die littérature comparèe ist in der Auffasung von Carré "I'étude des relations spirituelles internationales, des rapports de fuit qui ont existe entre Byron et Pouchkine, Goethe et Carlyle /.../, entre les avres, les inspirations $\ldots /^{*}$. Wichtig dabei seien aber ,transformations que chaque nation, chaque auteur fait subir à ses emprunts“, denn ..qui dit influence dit souvent interprétation, réaction, résistance. combat. 'Rien de plus original, écrit Valèry, rien de plus soi que de se nourir des autres. Mais il faut les digérer. Le lion est fait de mouton assimile. "“ Carrè nennt in seinem Vorwort die Einflußstudien „difficiles à mener, souvant décevantes“ und weist auf die anderen Forschungsbereiche hin, u.a. auf . .l'interprétation réciproque des peuples, des voyages et des mirages. Comment nous voyonsnous entre nous, Anglais et Français, Français et Allemands, etc." (ebd.). RIESZ 1979 verneidigt jedoch Carre gegen den Vorwurf des Positivismus (S. 9).

${ }^{16}$ GuYARD 1951, S. 110 und S. $118 f$.

17 Vgl. z.B. die Tabellen im Handbuch GuYarDS (1951, S. 124-126), die nach der positivistischen Methode auf die noch zu füllenden Leerstellen in der komparatistisch-imagologischen Forschung hinweisen.

18 Sie unterscheiden beispielsweise mehrere Bezeichnungen des .Forschungsgegenstandes“, die nicht näher definiert werden. - In den Arbeiten CaRRÉS treten neben dem Begriffpaar 
Die Kontroverse zwischen Wellek und den französischen Forschem verursachte die Spaltung der Komparatistik in die ,amerikanische“ und „französische" Schule. ${ }^{19}$ Die Imagologie wurde für ein Jahrzehnt „in einen kaum noch beachteten Hintergrund gedrängt ${ }^{20}$, obwohl in Frankreich weiterhin deskriptivsoziologische imagologische Studien betrieben wurden. ${ }^{21}$

In den sechziger Jahren kam es aber zur methodischen Emeuerung, indem der interdisziplinäre Ansatz der französischen Schule weiterentwickelt wurde. ${ }^{22}$

HUGO DYSERINCK hat als erster Forscher in der Geschichte der Imagologie positive Ansătze gefunden, die ihre methodischen und weltanschaulichen Belastungen überwinden halfen. Sein grundlegender Verdienst besteht darin. daß er die Imagologie fü die Literaturwissenschaft wieder relevant gemacht hat.

Der theoretische Ansatz Dyserincks und seiner Aachener Schule, der wegen seiner besonderen Bedeutung zuerst erörtert werden soll, ist in Anlehnung an die Ansichten der französischen komparatistischen Schule und in der Auseinandersetzung mit René Wellek entstanden. Dyserinck gelang es dabei nachzuweisen, daß die images nicht nur einen rezeptionsästhetischen bzw. soziopsychologischen, sondern auch einen textimmanenten, d.h. in Terminologie Welleks einen "literaturwissenschaftlichen" Sinn aufweisen können. Seine Arbeiten haben aber auch zum ersten Mal eine entideologisierte imagologische Forschung ermöglicht, für die „Volkscharaktere“ lediglich als fiktive, ideologische Konstruktionen sowohl in literarischen als auch in literaturwissenschaftlichen Texten zu betrachten sind. ${ }^{23}$

image bzw. mirage (Bıld bzw. Trughıld. Zerrbild) auch noch der Begriff préjugé (Vorurteil) auf. In seiner Monographie l.es ecrivaıns françaıs et le mirage allemand $1800-19+0$ schreibt er über ..une image traditionelle de l'Allemagne, celle qu avait fixée Mme de Staël dans son grand livre en 1813" bzw. auf der anderen Seite über ..le mırage fatal" von Deutschland, das sich die franzósischen Schriftsteller neben dem idealisierten ..image“ von Mme de Staël geschaffen haben. Obwohl .I'Allemagne bouge, I Allemagne vit, I'Allemagne se développe /.../, nous vivons sur ceite image, parce que nous y tenons. Nous cultivons, nous entretenons le prejjugè qui nous est cher. Préjugé politique, littèraire, philosophique, hıstorique, philologique. musical" (CARRE 1947, S. VIIIff.). Siehe auch zum Begriff des ,décalage" (die zeitliche .Verschicbung“" der Bedeutung) von miragess bzw. zu ihrer Langlebigkeit (ebd. S. IX.). Vgl. auch DERS. 1920.

Für GUYARD ist das imuge, „que chaque homme, et même chaque pays se font des autres peuples,“ .,une image sımplifiéc, où subsistent seuls des traits, parfois essentiels à l'original, à d autres moments accidentels. Il n y a pas I Allemagne, mais I Allemagne de Michelet, celle des philosophes, celle des Français". Je größer die Gruppe, die ein solches ımage bildet. desto größer die Gefahr der Abstraktion: ., l image est caricaturale, schematıque et frappante“. Es sej notwendig zu erforschen, wie solche ..grands mythes nationaux" sowohl im individuellen als auch im kollektıven BewuBtsein entstehen. Er nennt folglich die images nicht nur mythes, sondem auch les Illusions (GUYARD 1951, S. 110-119, hier S. 110f und S. 119).

19 Vgl. 2.B. ZIMA 1992, S. 32ff.

20 DYSERINCK 1966, S. 108.

21 FISCHER 1987, S. 60.

22 Siehe DYSERINCK 1980a zu II. R. JauB' Kritik an der Imagologie

${ }^{23}$ Seiner Ansicht nach gab es Anzeıchen der Herausbildung eines Rezeptionsmodells in der Erforschung wechselscitiger Beurteilung der Nationen und Völker von einem neutralen oder ..supranationalen“ Standpunkt aus bei den Komparatisten aus Frankreich und aus der Schweiz, z.B. bei Fernand Baldensperger, Paul Hazard. Paul Van Tieghem, I ouis Paul Betz, 
In seinen Beitrăgen aus den sechziger und siebziger Jahren bezeichnet Dyserinck die Imagologie immer noch als Erforschung des sogenannten „Bildes vom fremden Land" im Rahmen des Problems ,l'étranger tel q'on le voit" (nach Carré und Guyard). ${ }^{24}$ Die Imagologie bildet für ihn aber das wichtigste Teilgebiet der Vergleichenden Literaturwissenschaft, ${ }^{25}$ denn beide hătten sich schon immer mit dem „Phănomen der Fremderfahrung“ befasst. Er hebt deswegen besonders den rezeptionsästhetischen und interdisziplinären Aspekt der ImageForschung hervor.

Dyserinck hat jedoch keine wesentlichen Korrekturen der Terminologie Carrés und Guyards eingeführt. Er schreibt von nationalem Bild bzw. Image und fügt weitere ebenfalls nicht năher definierte Bezeichnungen wie Stereotypen, Vorstellungen, les illusions (Guyard) oder Vorurleile hinzu, von denen sich die Literaturwissenschaft und -kritik befreien sollte. In den siebziger Jahren bezeichnete er die Images auch als die Schilderung von Fremden oder von Fremdem in einem literarischen Werk. In späteren Beiträgen wird diese Terminologie um ein oppositionelles bzw. komplementäres Paar erweitert, das sich aus Eigen- und Fremdbild (bzw. Auto- und Heteroimage) zusammensetzt. ${ }^{26}$

Dyserinck befaßt sich darüber hinaus ausführlich mit dem „ontologischen Status" der Images. Dabei hălt er sich an die Ansichten des französischen Sozialpsychologen Lipianskys, der seinerseits Michel Foucaults Begriff der formation discursive in die Diskussion eingeführt hat. Dyserinck nennt aber die Bilder zugleich Elemente der World 3 (Popper), ${ }^{27}$..Produkte des menschlichen

Fritz Emst oder Albert Bèguin bis hm zu Jean-Marie Carre. Vgl. DYSeRINCK 1988b. S. 41, DERS. 1992a, S. 31 ff. oder DERS. 1989. S. 64 f.

24 DYSERINCK 1980a, S. 135-140. Dyserinck wirft Jauß vor, daß jener die rezeptionsästhetischen Ansătze der frühen Komparatistik nicht genügend gewürdigt habe. Zur Alterität siehe Z.B. SYNDRAM 1991 und KONSTANTINOVIC 1988; außerdem TURK 1990. S. 10fr., und DERS. 1993, S. 58f.

${ }^{25}$ So z.B. DYSERINCK 1966, ebd., S. 108ff. und passim. Vgl. dazu GuYaRd 1951, S. I10f und $\mathrm{S} .119$.

${ }^{26} \mathrm{Vgl}$. Z.B. DYSERINCK 1988a, S. 13ff. Siche auch DERS. 1988b, S. 26f, DERS. 1977, S. 128 und 132f., sowie DERS. 1966, S. 118 Dyserinck schrieb in diesem Aufsatz vom Bild isaw. image oder mirage eines Landes, das sich z. B. in einem Werk von Bernanos auf Flandern. das Land und seine Bewohner beziehe (S. 112f.).

${ }^{27}$ Ebd. Vgl. dazu L.IPIANSKY 1979a, siehe auch DERS. 1979b; vgl auch: LIPIANSKY I.ADMiral. 1989; Folcault 1969 und POPPER 1972. Vgl die deutsche Übersetzung: Popper 1973, S. 123ff: siehe auch DERS. 1979, S.263ff. In (hjekırve Eirkenninıs (POPPER 1973) unterscheidet er drei Welten oder Universen (in dem Kapitel ..Erkenntnistheoric ohne erkennendes Subjekt“): „erstens die Welt der physikalischen Gegenstände oder physikalischen Zustănde; zweitens die Welt der Bewußtseinszustannde oder der geistugen Zustănde oder vielleicht der Verhaltensdispositionen zum Handeln: und drittens die Welt der ohjeksrven (iedunkenunhalte. insbesondere der wissenschaftlichen und dichterischen Gedanken und der Kunstwerke". Die drifle Welt hătte also viel mit Platons Theorie der Formen und Ideen gemeinsam und daher auch mit Hegels objektivem Geist: Popper schreibt aber, daß seine Theorie sich in einigen entscheidenden Punkten von der Platons und Hegels unterscheide und mehr mit Bolzanos Theorie des Reichs der Säze an sich und Wahrheiten an sich, bzu. mit der Welt von Freges objektiven Gedankeninhalten zu tun habe. Zu der dritten Welt gehören: theorr:/ssc/h' Systeme. kritische Aryumente. der Siland einer Diskussion oder der Silund itmer kritisihe'n Auscinunderselzungy, oder auch der Inhalt von Zels.schrifien. Büchern und Bihlioshe'ke'n. Sie 
Geistes", die in Texten festgehalten sind, eine besondere Wirkung auf Menschen haben, und zu unbeabsichtigten Konsequenzen führen können. Die nationalen Bilder und die imagotypen Systeme lassen sich als "real vorhandene Objekte" betrachten, als „ein äußerst kompliziertes Netz. von gegenseitigen Vorstellungen der 'Völker' (br.w. Nationen, Iănder, Sprachgemeinschaften, Stämme usw.) untereinander", die den Gegenstand eines spezialisierten Forschungszweiges bilden und deren Bedeutung nicht nur bzw. nicht mehr in literaturästhetischen Kategorien gemessen werden kann. Dem literaturwissenschaftlichen Teilgebiet der Images-Forschung bleibe es vorbehalten, den ,jene Images hervorbringenden literarischen Sektor" zu untersuchen, obwohl sie auch autonom und interdisziplinär erforscht werden könnten. Die Aufgabe des Image-Forschers bestehe darin, den ideologischen Charakter jener Images zu entmystifizieren, denn sie seien „vorübergehend im historischen Raum verwirklichte Denkmodelle."

Bereits in dem programmatischen Aufsatz aus dem Jahre 1966 formulierte Dyserinck die wichtigsten methodischen Postulate und nannte drei ,genuin literaturwissenschaftliche Aspekte“ der Images, die ihre Erforschung unentbehrlich machten:

1. ihr Vorhandensein in gewissen literarischen Werken:

2. die Rolle, die sie bei der Verbreitung von Übersetzungen oder auch Originalwerken außerhalb des jeweiligen national-literarischen Entstehungsbereiches spielen und

3. ihre vorwiegend störende Anwesenheit in der Literaturwissenschaft und kritik selbst. $^{29}$

Die Images sollten zum einen in solchen literarischen Werken untersucht werden, in denen sie eine wichtige textimmanente Fuktion haben, so daß diese Werke ohne die Erforschung der Fremdbilder nicht verstanden werden könnten, als auch in ihrer außerliterarischen Bedeutung, die den werkimmanenten Sinn überschreitet. $\mathrm{Zu}$ den außerliterarischen Forschungsbereichen der komparatistischen Imagologie gehören nach Dyserinck:

I. die Rezeption von literarischen Werken außerhalb ihres nationalen Entstehungsbereichs;

können nicht alle in die zweite Welt der Bewußtseinszustände verwiesen werden (S. 123f.). Popper fühn zwei Gedankenexperimente an: 1. alle Maschinen und Werkzeuge sowic unser subjektives Wissen werden zerstört, es bleiben aber die Bıhlıotheken und die lä̈hıkkeıt. aus Büchern zu lernen. d.h. es wird möglich, die Zivilisation wieder erstehen zu lassen; 2 . Wenn auch die Bibliotheken zerstört werden, könnte die Zivilisatıon jahrtausendelang nicht wieder erstehen (S. 125). LEERSSEN 1991 a bemerkt zu Recht zu Dyserinck: „The shift from essence to perceptions is a primarily ontological matter for Popperians like Dyserinck, who would classify images and stereotypes as objects of a world-3 '“ (S. 128).

28 Als Beispiel eines imagologischen Forschungsgebietes fühn er die Geschichte der Nationalıtătenproblernatik im Europa des 19. Jahrhunderts an, in der die Literatur eine führende Rolle als Produzenten nationaler Images gespielt habe (DYSERINCK 1982, S. 37fr.). Dyserinck betont darüber hinaus die Macht der „Ianglebigen Images“ über den Menschen. Die Relevanz solcher Bilder beweise z.B. das Deutschlandbild von Mme de Staël, das sich zwei Jahrhunderte hindurch ..durch Auswechslung der Bewertungsakzente mit derselben Polaritătsstruktur" zur Bildung jeweils entgegengesetzter Theorien uminterpretieren ließ (DERS. 1988b, S. 26ff.).

${ }^{29}$ DYSERINCK 1966, S. 119. 
2. das Vorhandensein von Images in der Literaturwissenschaft und -kritik selbst sowie

3. die Wirkung der in der Welt der Literatur entstandenen Bilder auf das gesellschaftliche und politische Geschehen.

Man soll also die Herkunft, Struktur und Funktion der Images innerhalb des literarischen Textes und ihre Wirkung (Rezeption) untersuchen. Für Hugo Dyserinck ist dabei der Literaturbegriff für die Untersuchung der Images irrelevant. $^{30}$

Dyserinck unterstreicht immer wieder unermüdlich die außerliterarische, politische Dimension der „Bildforschung“"31 und distanziert sich von einer überholt positivistisch-thematologischen und völkerpsychologischen Beschăftigung mit dem „Bild vom andern Land“, 32 indem er den ideologischen Charakter der Images und der Volks- und Nationenbegriffe hervorhebt. In der Entideologisierung der negativen Images erblickt Dyserinck „eine in sich durchaus vollendete Forschungstätigkeit". Die Imagologie wird als literaturvissenschaftliche Disziplin nicht mehr in Frage gestellt. ${ }^{33}$

Das theoretische Konzept Dyserincks ist dagegen nur in wenigen Interpretationen verwirklicht worden, da es primär zur Durchsetzung und Anerkennung der Imagologie dienen sollte.

In einem frühen Aufsatz ${ }^{34}$ versuchte er, die Genese des belgischen Flandernbildes in den Werken französisch schreibender flämischer Autoren zu

${ }^{30} \mathrm{Vgl}$. FISCHER 1987, S. 56 und DYSERINCK 1977, S. 127ff. sowie DERS. 1988b, S. $31: . / \ldots /$ die Diskussion um die Definition dessen, was 'Literatur' eigentlich ist, [ist] für die komparatistische Imagologie lediglich von zweitrangiger Bedeutung und letzten Endes irrelevant. Wir wissen, daB es im Rahmen dieser wie immer auch verstandenen Literatur und den sich mit ihr beschäftigenden kritischen und wissenschaftlichen Publikationen nationenbezogene Images gegeben hat und immer noch gibt."

31 DYSERINCK 1977, S. 138; vgl. auch KONSTANTINOvic 1992b, S. 279f. Die Imagologie soll grenzüberschreitend verschiedene Formen eines .,nationalen Selbstverstándnisses“ von einem sogenannten ,.supranationalen Standort“ aus untersuchen, der besonders für das von nationalen und ethnischen Konflikten heimgesuchte Europa relevant ist: imagologische Studien sollen daher in die .Europaforschung" eingebunden werden: DERS. 1989, S 68f. Dabei wird ..Europaforschung” nicht als eurozentrische .Festung Europa“, sondern als ein ..Laboratorium Europa" verstanden. Vgl. DERS. 1992b, S. 49f. und DERS. 1997.

${ }^{32} \mathrm{Vgl}$. aber zu der erneuerten, nicht mehr positivistischen komparatistischen Thematologie CHARDIN 1989 sowie z.B.: BRACHFELD 1962 b7w. L.IPIANSKY 1979, oder DERS. L.ADMIRAL. 1989. Den oben genannten Forschem geht es um die sozialpsychologisch ausagcrichtete imagologische Forschung, die nichts mehr mit der ...Volkerpsychologie“ als lehre von den "Sezlen der Volker“ zu tun hat, sondern solche Hypostasen als nationale Stereotypen bzur Mythen mit dem Ziel untersucht, die interkulturelle Zusammenarbeit und Erziehung zu erleichtern.

${ }^{33}$ DYSERINCK 1988b, S.25ff. und S. 39ff. Vgl. auch ebd., S. 19f., bes S. 20. Anm. 1. zu Welleks veränderter Stellungnahme. Dyserinck wehn sich aber zugleich gegen die Kritik Gérard Raulets, in der von der Imagologie angestrebten Aufoosung der Auto- und Heteroimages nur eine literaturwissenschaftlıche, postmoderne déconsiructıon zu sehen (DYSERINCK 1992a, S. 55; vgl. auch ebd., Anm. 18 u. 19 zu RaUlet 1988). Vgl. auch Raulets Buch (jehemmte Zukunfi. Zur gegenwärtıgen Ḱrise der Fimunzupatıon (RAULET 1986), in dem er die ..postmoderme Krise der Vernunft“ aus den Positionen der Kritischen Theoric darstellt. 34 DYSERINCK 1964. 
erklären. ${ }^{35}$ Dabei gelang es ihm, die von diesen Schriftstellern angestrebte Schaffung eines fiktiven Flandernbildes (mirage flamand) überzeugend nachzuzeichnen: Um eine national-literarische Eigenstăndigkeit gegenüber Frankreich zu bewahren, hatten sie die „Flamen" als ein .mystisch" veranlagtes, aber "lebensfroh-sinnliches" und kreatives Volk dargestellt. Dieses Bild war als Antwort auf die französische und deutsche Literaturkritik aufzufassen, die sich mit dem Problem der Sonderstellung jener belgischen Autoren innerhalb der französischen Literatur befaßte. ${ }^{36}$ In diesem Aufsatz wird der ideologische, fiktive Charakter eines literarischen „Völkerbildes“ exemplarisch vorgeführ, obgleich Dyserinck sich auf keine ausführlichen Interpretationen der darin erwähnten Texte eingelassen hat.

Auch der zweite, bereits erwähnte „programmatische“ Aufsatz von 1966 enthălt keine ausführlichen Textinterpretationen, obwohl Dyserinck am Beispiel des Journal d'un Curé de Campagne zu zeigen versucht, auf welche Weise sich Georges Bernanos auf das im ersten Aufsatz besprochene dualistische Flandembild der flämischen Symbolisten bezog. ${ }^{37}$ Dyserinck hebt die werkimmanente, strukturelle Funktion der "flämischen images und mirages" in diesem Werk hervor, die für sein Verständnis wesentlich ist, geht aber einseitig deskriptiv vor. Anschließend weist er anhand der Studie Jean-Marie Carrés zum französischen Deutschlandbild auf die störende Anwesenheit der images und mirages in der Literaturwissenschaft hin. ${ }^{38}$

Obwohl Dyserinck in diesen Beiträgen nicht nur politisch-ideologische, sondern auch textimmanente Funktionen mehrerer literarischer images nachgewiesen hatte, konzentrierte er sich mehr auf den genetisch-deskriptiven und rezepti-

${ }^{35} \mathrm{Zu}$ denen Verhaeren, Maeterlinck, Rodenbach, Van Lerberghe, Eekhoud oder Elskamp gehören, ebd., S. 468.

${ }^{36}$ Es wurde dabei auf die international bekannte und geschätzte flämische Kunsttradition zuruckgegriffen, v.a. auf die flämısche Malerei, um auch in der Literatur eine nationale écolc flumunde zu grunden. Dyserinck nennt in diesem Zusammenhang z.B. Iwan Gilkin und E. Verhaeren. der vor den Z.eitgenussen als Vertreter einer ganzen gleichgesinnten Dichtergruppe aufgetreten war und die ..sensualistische“ Richtung bei den Teniers. Jordaens, Breughel. Brouwer oder Rubens, die ..mystische“ dagegen bei Van Eyck und Memling zu finden glaubte (ebd., S. 475. und S 469fr).

$37 \mathrm{Vgl}$. Dyserinck 1966, S. I 10f: Bernanos habe in der Gestalt des Cure de Torcy das sensualistisch-mystische Flandernbild der belgischen und französischen Literatur des 19. und 20. Jahrhunderts als Muster benutzt, indem er sich ...in großzügiger Weise über die eigentliche Realität" hınwegsetzte. Der Cure de Torcy sei ausdrücklich als Flame charakterisiert, habe dank seiner flämischen Herkunft den Hang zu lebensbejahung und Lebensmut. Auch seıne Toleranz gegenüber dem sowjetischen Kommunismus bzw. Sozialismus sowie dem Protestantısmus verdankt er seinem flämischen Charakter, der die Revolte ..im Blut“" habe. Die Russen seien für ihn die Flamen des extremen Nordens (S. 110fr.).

${ }^{38}$ DYSERINCK 1966, S. 117. Siehe auch seinen Aufsatz Die Quellen der Négriude-Theorice als (iegensiand kompuratis/tscher Imagologie (DYSERINCK 1980b), in dem er sich mit der .Négritude" Léopold Sédar Senghors befaßt, die als ein afrikanisches Autoumage aus mehreren europäischen Helerommuges geschaffen wurde und eine wichtige Rolle bei der Identitätsund Selbstbewußtseinsbildung im Prozeß der kulturellen Entkolonialisierung der afrikanischen Volker gespielt hatte. 
onsästhetischen Aspekt solcher Bilder, also auf ihre außerliterarische Bedeutung.

Der theoretische Ansatz Dyserincks wurde von seinen Schülern bzw. Mitarbeitem, Manfred S. Fischer und KarL UlRICH SYNDRAM, übernommen und weiterentwickelt. Ihre Ansichten unterscheiden sich nur geringfügig voneinander.

FisCHER stellt aber im Unterschied zu Dyserinck in den Mittelpunkt seiner theoretischen Überlegungen weniger die politische Dimension der imagologischen Forschung als die imagologische Textinterpretation selbst. Er definiert die Imagologie als „die literaturwissenschaftliche Beschăftigung mit nationenbezogenen Images, insofern diesen für das Verständnis literarischer Texte und Prozesse eine Bedeutung zukommen kann". Obwohl er die Imagologie als eine Teildisziplin der Komparatistik betrachtet (beide betrachten die Literatur als einen fait social), sollte man sie aber nicht als identisch ansehen. ${ }^{39}$

Fischer unterscheidet, ähnlich wie sein Lehrer, folgende imagologische Forschungsbereiche: 1. textimmanente Untersuchung nationenbezogener Auto- und Hetero-Images in der Literatur und in allen Bereichen der Literaturwissenschaft und Literaturkritik; 2. Erklärung von Genese und Wirkung der Images sowohl im literarischen als auch im außerliterarischen Bereich, und 3. Berücksichtigung ihrer ,modifikationsauslösenden Funktionen“, d.h. ihrer ideologischen Funktion. im Rahmen des internationalen Literaturaustausches und -verständnisses. ${ }^{\circ} \mathrm{Er}$ distanziert sich ebenfalls von klimatheoretischen, kausalmechanistischen sowie biologistischen literaturwissenschaftlichen Modellen. ${ }^{41}$

Obwohl Fischer sich eingehender als Dyserinck mit dem Begriff des Bildes bzw. Image befaßt und sich um seine definitorische Bestimmung bemüht, trăgt seine Definition kaum zur Klarheit und Eindeutigkeit der imagologischen Terminologie bei. Er definien den Begriff Image als „eine mit Historizităt und Varianz belegte, strukturierte Gesamtheit von Einzel- und Kollektivaussagen, als ein äußerst komplexes Zusammenwirken von 'Vorstellungen' über Andersnationales“, die sich ,in ihrer Aussage auf alle Bereiche des als andersnational Beschriebenen" beziehen können und in einem historischen Prozeß der Literarisierung und Sozialisierung entstehen. ${ }^{12}$ Fischer nennt die ,.gesamtstrukturierte Aussage des Images“ bzw. dessen „einzelne Elemente“ imagotyp ${ }^{43}$ und unterscheidet zwischen dem sozialpsychologischen Begriff des Stereotvps und dem literaturwissenschaftlichen des Image. "Der Begriff des Stereotyps bleibt für ihn "immer auf die Aussage in ihrem Wortbild bzw. -laut beschränkt", indem die

39 FiSCHER 1987, S. 55f.

10 Ebd., S. 57.

1 Nicht nur alle literarischen, sondern auch literaturwissenschaftlichen Texte mußten auf das Vorkommen der zu ideologischen Zwecken eingesetzten Images überpruft werden, obwohl sie sich manchmal ..mit der Autorität der nach Gadamer (1972) rehabilitierten Vor-Urteile tamen würden“ (ebd.). Vgl. auch zur ..Rehabilitierung“ der Vorurteile O’Sı 'Ll.IVAN 1989, S 14-16.

12 FISCHER 1987, S. 57.

${ }^{43}$ FISCHER 1981, S. 20fr. Fischer bezieht sich wie Dyserinck auf Brachfelds Terminologie. siehe dazu oben, S. 14 sowie BRACHFELD1962.

${ }^{44}$ FISCHER 1987, S. 58. 
imagotypen Aussagen mehrdeutig und von dem kommunikativen Kontext der historischen Situation abhängig seien. Fischers Unterscheidung würde aber bedeuten, daß er entweder das Vorkommen nationaler Stereotypen in literarischen Texten aus dem Forschungsbereich der Imagologie ausschließen möchte oder die literarischen nationalen Stereotypen für ihn gleichbedeutend mit kontextabhängigen Imagotypen bzw. Images wăren. ${ }^{45}$

In einer 1977 veröffentlichten Studie zu Le Roi des Aulnes von Michel Tournier $^{16}$ untersucht Fischer die unterschiedliche Rezeption dieses Romans in Frankreich und in Deutschland. Zusammenfassend wird festgestellt, da $B$ nicht nur die sprachliche Verschiedenheit der Textvorlagen (französischer Originaltext vs. deutsche Übersetzung von Hellmut Waller) dafür verantwortlich waren, ${ }^{47}$ sondern daß das im Roi des Aulnes enthaitene Deutschlandbild eine besonders wichtige Rolle gespielt hatte. Dieses Bild enthalte sowohl Merkmale des romantisch-mythischen Deutschlandbildes von Mme de Stael wie auch des Bildes der Deux Allemagnes, das nach 1870/71 in Frankreich das idealistischromantische Deutschlandbild ablöste. ${ }^{\star \theta}$ Im Mittelpunkt seiner Studie steht somit nicht der Roman Tourniers selbst bzw. kaum seine imagologische Interpretation. sondern die außerliterarische, wirkungsåsthetische Funktion des darin vorkommenden Deutschlandsbildes. Die Struktur und Funktion dieses Bildes innerhalb des literarischen Textes selbst wurde unberücksichtigt gelassen.

Der zweite Vertreter der Dyserinckschen Schule, KARL ULRICH SYNDRAM, ${ }^{49}$ bezeichnet sowohl Imagologie als auch Komparatistik als kritische Kultur- und

45 Die Imagess zeichneten sich durch die partielle Konstanz und Universalität aus, enstünden aus einer punktuellen Beobachtung des Besonderen, erhöben jedoch Ansprüche auf allgemeine Bedeutung, seien abstrakt und könnten somit als typisierende Unteile zur Charakterisierung des Besonderen dienen. Der Satz ..Alle Schotten sind geizig” oder abgewandelt "Alle Schotten sind sparsam" zeige z.B. nur in einem situativen Kontext einen bestimmten Sinn, nicht aber in zweien. Ihre Semantik ist variabel. Siehe auch DERS. 1981, S. 20ff. sowie zu der Kritik an Fischer: BLAICHER 1992, S. 6f. Vgl. aber auch unten zur kognitiv-sozialpsychologischen Stereotypenforschung, die diese nicht mehr als invariabel und fest bezeichnet, S. 43ff.

${ }^{46}$ FISCHER 1977.

17 Ebd., S. 84fr. So sah z.B. Jean Amery in dem Roman Tourniers „die fehlende Moral einer Nurästhetisierung des Nationalsozıalısmus". d.h. eine Ästhetisierung und Mythisierung der Barbareı des Dritten Reiches, die sich in gefăhrlicher Năhe zum Kitsch befand, wohingegen auf französischer Seite Daniel Bougnoux sich der werkimmanenten Strukturanalyse des Romans zuwandte, sich also nicht ausschließlich mit seinem ideologischen bzw. ideengeschichtlichen Kontext auseinandersetzte. Die deutschen Rezensenten sahen v.a. das Deutschlandbild des Dritten Reiches bzw. seine Verarbeitung durch einen Franzosen als Thema des Romans, wogegen die französischen Kritiker die Darstellung Nazideutschlands nur als ein Beispiel für das eigentliche Hauptthema des Romans verstanden, das allgemeinere psychologische und philosophische Überlegungen zum Leben. Wesen und Handeln des Menschen thematisiere (ebd., S. 22ff. und S. 116ff.).

4 Ebd., S. 126fr Die Anwesenheit der phantastischen und romantischen Tradition in dem Roman Tourniers war in der Auffassung Fischers für die abweichende Rezeption in Deutschland und Frankreich ausschlaggebend, wobei die deutschen Kritiker sich weit weniger fasziniert und befremdeter als die französischen zeigten (ebd. S. 129).

19 SYNDRAM $1992 \mathrm{~b}$. 
Fremderfahrungswissenschaften. ${ }^{50}$ Eine vorurteilsfreie Betrachtung des Anderen bzw. Fremden soll die Ausgangsperspektive bilden, aus der sich Literatur als ein vielschichtiges Medium kultureller Verständigung und Welterfahrung für vergleichende Untersuchungen erschließen lasse, ohne den Mythos nationaler Wesenheiten fortzuschreiben. ${ }^{\text {s1 }}$

Syndrams Terminologie ist wie diejenige Dyserincks und Fischers nicht einheitlich, denn er schreibt von Images, imagotypen Strukturen / Elementen bzw. von anschaulich typisierenden Darstellungen des , anderen Landes " und anderer Nationen, legt aber zugleich größeres Gewicht auf die Rolle der literarischasthetischen Einbildungskraft bei deren Genese. Die images haben einen ästhetischen und historisch-politischen Charakter, sind Ausdruck dialektischer Beziehung zwischen Identităts- und Alteritătskategorien. Syndram zählt zu den images neben den Darstellungen geographischer Räume (als Regionen oder politische Gebilde), ihrer Bewohner und der dortigen Lebensart (Sitten und Gebrăuche) „die Schilderungen der Lănder aus dem Reich der Phantasie“, wozu beispielsweise die "Imagerie" eines Orients der Geschichten von Tausendundeiner Nacht gehört. Solche literarischen Darstellungen überdauerten den historischen Wandel der Gesellschaften, ${ }^{52}$ wiesen jedoch Bezüge zu realen geographischen Răumen und sozialen Formationen und zu geschichtlichen Erfahrungen auf, seien in bestimmte Strukturen der Darstellung und der Rezeption eingebunden. ${ }^{53}$ Als "imagotype Strukturen oder ästhetische Konfigurationen“ verfügten sie zugleich über ein besonderes Vermögen der Veranschaulichung und ahnelten den „Mythen“. Im assoziativen Raum von sprachlich-literarischer Symbolik und Metaphorik wird aus Worten wie "Nation" oder "Volk“ ein Gegenstand sinnlicher Erfahrung (mit narrativer Struktur) kreiert, der jenseits logischer Gesetzmäßigkeit zu existieren vermag. Es gibt keine "richtigen“ und keine „falschen" Images, sie übersteigen immer die Möglichkeiten individueller Erfahrung. ${ }^{54}$ In diesem Zusammenhang läßt sich nicht von ihrem Wahrheitsgehalt sprechen. Durch sie kann in Textgestalt vorstellbar werden, was in der Welt konkreter Erfahrungen nicht $\mathrm{zu}$ verifizieren ist. ${ }^{55}$

so Syndram definiert Komparatistik als ..sprachgrenzüberschreitend-vergleichende Textwissenschaft". Ihr hermeneutisches Interesse richte sich auf die Beziehungen, Gemeinsamkeiten und Unterschiede zwischen verschiedenen literarischen Systemen. Die Imagologie als Teilgebiet der Komparatistik kann man in diesem Kontext ihren Kembereich nennen, der sich mit den .,imagotypen Strukturen“" befaßt. Er würdigt dabei die Rolle Dyserincks bei der Konstituierung der Imagologie. (SYNDRAM 1992b, S. 84ff.) Vgl. auch DERS. 1990.

31 Auch bei Syndram ist von dem ..supranationalen Blick brw. Standort" der komparatistischen Forschung die Rede, obwohl zugleich „,aus komparatistischer Sicht“ die Sprachgrenzen die beständigsten und konkretesten sind (SYNDRAM 1992b, S. 86ff.)

52 Als Beispiele nennt er die Darstellungen der Schweiz von Haller, Schiller und Frisch, Schottlands von Bums und Scott, Irlands von Yeats. Synge und Joyce, der Provence von Mistral, Daudet und Pagnol. Das "Deutschlandbild“ von Tacitus soll sich in seiner Struktur wic in den charakterisierenden Elementen noch bei Mme de Stael, Jean Giraudoux und Michel Tournier wiederfinden (ebd., S. 89ff.).

53 Ebd.

54 Ebd., S. 92.

$55 \mathrm{Vgl}$. auch SYNDRAM 1991, in dem er schreibt: „The imagologist's working ground is that of discourse: s/he studies statements and texts, and keeps aloof from making, or entering into an 
Syndram hebt aber als erster in dieser Studie besprochener Theoretiker die hermeneutische Dimension einer imagologischen Textinterpretation hervor, die zugleich die ästhetische und soziale Referenz von Texten in ihrer historisch bedingten Darstellung und Rezeption berücksichtigen würde. Eine solche Interpretation soll „Verständigung förder" und „sich selbst aller Wertungen (im Sinne von zutreffend-unzutreffend bzw. wahr-unwahr) enthalten“.56 Syndram begnügt sich aber mit der Formulierung einiger deduktiv-theoretischer Postulate, ohne sie in die Praxis umgesetzt zu haben.

Der theoretische Ansat der Aachener Schule DYSERINCKS läßt sich insgesamt positiv bewerten. Störend wirken dagegen seine terminologischen Defizite. Solche Begriffe wie nationales oder nationenbezogenes Image bzw. Bild. Stereotyp oder V'orstellung. imagotype imagotypische Elemente / Strukturen bzw. Imagotup. die von französischen Ethnopsychologen und Komparatisten übernommen wurden, werden nicht definiert bzw. sind die vorhandenen Definitionen (M.S. Fischer) verschwornmen oder im interdisziplinären Kontext überholt. Relevant für eine Textinterpretation ist dagegen die Beobachtung, daß das Fremdbild (Heteroimage) einer bestimmten ethnischen oder nationalen Gruppe immer zusammen mit dem komplementären Eigenbild (Autoimage) einer das Fremdbild produzierenden Gruppe vorkommt. Wichtig ist auch der Hinweis auf eine mögliche Äquivalenz zwischen Images, Stereotypen und Mythen, obwohl kein Versuch unternommen wird, diese Begriffe miteinander zu vergleichen bzw. voneinander abzugrenzen.

In methodischer Hinsicht erscheint sowohl die Hervorhebung der historischsozialen Herkunft der images als literarisch-ideologische Konstrukte besonders wichtig als auch das Postulat. die images sowohl in ihrer Struktur, in ihrer Funktion innerhalb des literarischen Textes als auch in ihrer Herkunft und Wirkung (Rezeption) zu untersuchen. Diese Voraussetzungen bleiben aber weitgehend unerftillt. weil sie kaum in konkreten Textinterpretationen verwirklicht worden sind. Die wenigen auf die Praxis ausgerichteten Arbeiten der Aachener Schule gehen deduktiv vor, sind aber zugleich einseitig deskriptiv-empirisch bzw. sozial-politisch auf die Ideologiekritik ausgerichtet. ${ }^{57}$

Die Defizite des Dyserinckschen imagologischen Konzepts verringern jedoch nicht grundsätzlich seine Relevanz für die methodische Emeuerung und Entideologisierung der Imagologie. In der "Gründerphase“, in der es entstanden war, mußte das (jewicht auf die Schaffung einer Theoric sowie auf ihre Begründung und Verbreitung und nicht auf die interpretatorische Praxis gelegt werden.

argument with, real world truth claims - for these (e.g., chmatological od biological determinism) are usually essentialist reifications" (S. 184), und weiter: "Neither in their literary embeddeness nor in their extraliterary reference can such images be considered true or false. They reflect social attitudes, and their relation to empincal reality is far from straighforward" (S. 185f.).

56 SYNDRAM 1992b, S. 92

57 Auch zwei Studien von STFins 1972 und von SCHMidT 1992, die sich an das Dyserincksche Konzept halten, sind ebenfalls deskriputv. Vgl. auch ähnliche Arbeiten: SADJi 1985, JURT 1978-79, TIETZ 1980 oder SORGE 1995. 
Seit den sechziger Jahren haben sich außer Dyserinck mehrere deutschsprachige Forscher mit der imagologischen Problematik beschaftigt. Ihre theoretischen Ansätze unterscheiden sich aber nicht wesentlich von dem der Aachener Schule. Neben GuSTav SIEBENMANN ${ }^{58}$, dessen Ansichten im folgenden zusammengefaßt werden, sind dabei PETER BOERNER ${ }^{59}$ bzw. ZORAN KONSTANTINOVIC ${ }^{60}$ zu nennen.

SIEBENMANN hat als Oberbegriff die Bezeichnung Imagotype [sic!] bzw. Auto- und Hetero-Imagotype von der Aachener Schule übernommen, die als mentales Bild in sich "Stereotype, Mentalităten, Vorurteile, Einstellungen, Images und Attitüden" enthalte. Die Frage nach der Referenz der Imagotypen ist fur ihn ebenfalls irrelevant, denn die "unzutreffenden“ Bilder fügten sich zusammen mit den "objektiv unzutreffenden" zur Konstellation einer Referenzebene und wirkten dort als Stützen der „Wahrhaftigkeit“. Wichtig erscheint dabei seine Beobachtung, daß kulturelle Identităt einer nationalen bzw. ethnischen Gruppe sich aus imagotypen Systemen bzw. Bildkomplexen zusammensetze. Siebenmann bezeichnet diese Systeme aber nicht als "ideologische“ oder „soziopolitische Mythen" (Barthes), sondern als "Makro-Imagotypen", die aus „Rastern" bzw. "Bäumen" von Imagotypen entstehen. Als Beispiele von Makrobildern Lateinamerikas innerhalb der europäischen Auto- und Heterostereotypen nennt er „die kulturelle Überlegenheit der Europăer; die Herrschaftsmission der Weißen; die Überlegenheit des Christentums und die entsprechende Legitimation des Missionsgedankens; die besondere Fähigkeit, die Arbeitswelt und auch andere Bereiche der Gesellschaft organisatorisch zu durchdringen; die Förderung beruflicher Fähigkeiten in allen drei Sektoren der Volkswirtschaft auf ein hohes Niveau“" ${ }^{61}$ Sie zeichnen sich durch „Mutationsfahigkeit" und die Labilităt der Wertungen aus. Einem und demselben Einzelzug können einmal positive, dann negative Konnotationen verliehen werden. Das unterscheide die Imagotype von den „unveränderbaren Stereotypen“, zu den letzteren zählt er außer den expliziten auch implizite Stereotypen, die in syntagmatischem Kontext verborgen seien. Es wird aber dabei nicht klar, wodurch sich die Stereotypen von den Ima-

50 Vgl. SIFBENMANN 1992 oder DERS. 1988.

59 BOERNER hält sich an den Begriff des Bildes vom anderen land, das sich aus vielen Einzelbcobachtungen, Meinungen und subjektiven Bewertungen, d.h. aus leıtmotıven zusammensetze, sei „ein verwickeltes Konglomerar“. Für Bocmer besteht ..Verwandschaft“ zwischen den Bildern und Stereotypen, Klischees oder Vorurteilen, die er jedoch nicht einzeln definiert. Auch hier haben wir es mit einer unpräzisen Terminologie zu tun (BOERNER 1975a, S. $315 f f$.). Vgl. auch DERS. $1975 b$.

${ }^{60}$ KONSTANTINOVIC $1992 \mathrm{~b}$ setzt sich wie Dyserinck für eine Beschränkung der Komparatistik und der Imagologic auf die Untersuchung der literarisch vermittelten Fremderfahrung ein. Eine Moglichkeit der komparatistischen Erforschung des Problems der Alterität und deren Konkretisation erblickt er in Anlehnung an Jauß und Ingarden im ..Text" (als ..Intertext" begriffen, d.h. mit allen ..Verbindungen mit Texten in anderen Literaturen ${ }^{*}$ ), im ...Archetext“" (d.h. in dem ,Entstehungsprozeß eines Textes im Autor /.../ bis zum Augenblick, wo ein Text schriftlich fixiert wird“), und im ..Kontext“ (d.h. in den Aktualisierungen des Textes), auch .in einer anderssprachigen Mitte“, die unterschiedlich rezipient werden, ...im Vergleich zu den offensichtlichen Intentionen seines Autors“. Auch hier wird nicht klar, wie diese methodischen Postulate in der Praxis verwirklicht werden sollen (ebd., S. 275ff.).

${ }^{62}$ SIFBENMANN 1988, S. 70 
gotypen unterscheiden und wie beide definiert werden sollten. Auch diese Terminologie eignet sich somit kaum dazu, um in dieser Studie eingesetzt zu werden. $^{62}$

Gelegentlich haben sich außer den oben genannten Forschern andere deutschsprachige Komparatisten wie Gerhard R. KAISER, ${ }^{63}$ PETER V. ZIMA, ${ }^{64}$ ThOMAS BLEICHER $^{65}$ und JÁNOS RIESZ ${ }^{66}$ zur Theorie der Imagologie geảußert. Von den englischsprachigen Forschern kann an dieser Stelle PETER FIRCHOW gennant werden. ${ }^{63}$

Keinem der bisher besprochenen Forscher ist es jedoch gelungen, die terminologisch-methodischen Defizite der Aachener Schule zu beheben. Das Phänomen der literarischen bzw. kulturellen Fremdheit wird immer noch in deduktiv erarbeiteten und diffusen Begriffen beschrieben, die kaum in konkreten Textinterpretationen angewandt werden. Die wenigen Interpretationen setzen sich darüber hinaus mit der Problematik der historisch und sozial bedingten Genese und Wirkung der Fremdbilder um ihrer Entideologisierung willen auseinander.

Am relevantesten erscheint lediglich die theoretische Beobachtung Siebenmanns, daß die "Fremdbilder" nicht einzeln. sondern in strukturierten Systemen ideologischen Charakters auftreten können.

Trotz der terminologisch-methodischen Schwăchen aller angeführten imagologischen Ansătze konnten sie sich jedoch von den überholten. positivistischen Methoden der französischen Schule der fünfziger Jahre befreien. Die Imagologie gilt daher zurecht als einer der wichtigsten Forschungsbereiche der Komparati-

62 SiebenMani 1992, S. Iff. Sowie DeRs. 1988, S. 59 und S. 69f.

${ }^{63}$ Fur KAISER 1980 ist es wichtig, "die spezifische Funktion der Literatur in der Geschichte herauszuarbeiten“. Es gehe darum, ...3sthetische Gehalte und Funktionen mit Hilfe von Sozialgeschichte zu verstehen“ (S. 58-68, bes. S. 66f.).

84 ZIMA 1992, S. 9-12, setzt sich für eine interdisziplinäre soziokritische und textsoziologische Komparatistik ein, die sich ihrer kulturellen und sprachlichen Bedingtheit bewußt sei und sich offen für den Dialog mit anderen Wissenschaften. v.a. mit den Sozialwissenschaften, zeige. In seiner an die frühe Kritische Theorie Adomos und Horkheimers anknüpfenden Methode hätte die Imagologie nicht nur zu erforschen. wie fremde Kulturen in einer bestimmten l.iteratur dargestellt werden, sondern auch, wie die Literatur im Rahmen bestimmter Institutıonen (Schule, Hochschule) auf das Kollektıvbewußtscin einwirkt (S. 10)

$65 \mathrm{Vgl}$. Bleicher 1980. Vgl. unten, S. 57f., zu den in der Folge veranderten methodologischen und terminologischen Ansichten Bleichers (vgl. DERS. 1993).

${ }^{66} \mathrm{Vgl}$. RiESz 1979, S. 7-18, bes. S. 13. Bei Riesz ist von .,Stereotypen“, bzw. von ..pattern of stereotyps“, die Rede. Vgl. auch DERS. 1980b oder RUDICER 1971, der die ..Bildforschung“" v.a. unter dem Aspekt der Faszination durch das Exotische sieht, z B. in Gestalt des ,Feminınen". Dabeı habe man aber oft mı eıner An von săkularısienter Mythologie zu tun, die vom Vor-Uneil bestimmt sei (S. 12ff.).

67 FirChOW 1990 definien die Imagologie als ..the study of national/ethnic/racial cultural images or stereotypes as they appear in literary contexts. Imagology explicitly includes the study of literary images of other groups (hetero-images) as well as images of one 's own group (auto-images)", schreibt aber nicht, was er unter imuges bzw. Sereorypen verstehen will. Er tritt dabei fur einen erwelterten Begriff der I.ıteratur und Literaturvissenschaft ein: "The quest for pure 'literariness' has passed the way of the quest for other absolutes; and methodology (wether structuralist, psychoanalytic, imagological or other) is no longer thought of as inexorably tied to a single discipline, like the study of literature. Literary study is today largely defined by its subject matter, not by its approach" (S. 135 und S. 137). 
stik, als eine interdisziplinăre Erforschung von literarischen Aspekten der Fremdheits- und Identitätserfahrungen der Kulturen.

Die erneuerte literaturwissenschaftliche imagologische Forschung setzt sich aber zugleich zu einseitig mit der Ideologiekritik bzw. mit der Entideologisierung der Forschungsmethoden auseinander, obwohl dies aus ihrer schwierigen Geschichte heraus verstandlich sein mag. Die Schaffung eines theoretischen imagologischen Konzeptes, das frei vom Verdacht einer (falschen) Ideologie sein soll, hat sich negativ auf seine Anwendung in konkreten Textinterpretationen ausgewirkt, so daß eine Kluft zwischen der imagologischen Theorie und Praxis weiterhin bestehen bleibt. Besonders störend wirkt dabei in den wenigen vorhandenen imagologischen Textinterpretationen die verworrene Terminologie, die mit einer allzu deskriptiven methodischen Vorgehensweise einhergeht.

Neben den oben erörterten Theoretikern gibt es auch weitere, hauptsăchlich auf die Praxis ausgerichtete, induktive Arbeiten zu nationalen bzw. ethnischen Fremdbildern, die ohne ein explizit formuliertes theoretisches Konzept auskommen. Dazu gehören beispielsweise die deskriptiv-empirischen, sowohl thematisch als auch methodisch ăhnlichen Untersuchungen von GÜNTHER BLAICHER $^{68}$ und WOLFGANG LEINER ${ }^{69}$.

BlAICHER konzentrien sich auf die Aspekte der Rezeption des literarischen Bildes eines $I$.andes durch das intendierte Publikum, d.h. in seiner Funktion für die literarische Kommunikation ${ }^{70}$, während LEINER die diachronische Entwicklung des französischen Deutschlandbildes bzw. der französischen Deutschlandbilder nachgezeichnet hat. ${ }^{71}$

Beide Monographien enthalten außerst umfangreiches diachronisch geordnetes Material zur Geschichte, Genese und Rezeption der englischen bzw. französischen literarischen Deutschlandbildern, ohne jedoch nach ihrer Struktur und Bedeutung bzw. Funktion in einzelnen literarischen Texten zu fragen. Es handelt sich somit um historische Beschreibungen nationaler Bilder ,an sich“. Für eine

${ }^{60}$ BLAiCHER 1992. Vgl. auch: ZaCh 1987 und ZACHARASIEWICZ 1977

69 L.EINER 1991. Vgl. auch ăhnliche Studien von ŽMEGAC 1996 oder von HETMIANN 1996

${ }^{70}$ BLAICHER 1992, S. Iff. Obwohl Blaicher die bisherigen Definitionen des nurumulen Bildes als unzulanglich knitisiert, tragen seine eigenen Formulierungen ebenfalls wenig zur terminologischen Klărung des Forschungsstandes bei Er unterscheidet konsitante Ixominumien, z.B gewisse ..Standestypen“" die den stereorypen bzw. klische'c/hifle'n ..überzeitlichen Charakter" aufweisen (..Furor Teutonicus“, ..Cloudy Metaphysicians“, ..Hunnen“, „Der deutsche Professor", .Der deutsche Student“", S. 7).

71 LEINER 1991, S. 18ff. Seine Terminologie ist ebenfalls nicht eindeutig. Das Bild bedeutet für ihn ..die Summe aller individuellen, subjektiven und oft sehr widersprüchlichen Deutschlandbilder, die, zu einem bunten Mosaik gefügt. nur im Idealfall die Vielfalt der französischen Deutschlandvisionen widerspiegeln“. In der Folge schreibt er von sich wiederholenden franzosischen Klıschees, ohsessionellen Konsfanten bezüglıch Deutschlands (..Erfinder des Krieges“. .Incertitudes allemandes,“ „Widersprüchlichkeit. Unberechenbarkeit.” ..La lenteur et Iinertie du peuple allemand“" (Mme de Staël), „Germanorum vivere bibere est”, S. 206ff., S. 210-235). Leiner nennt sie aber auch mit Max Weber Sicressypen, eine Art von Idealvirste'lunge'n (ebd., S. 3f.). Vgl. dazu WEBER 1968, S. 190f. Siehe auch die Kritik an Leiner in SYNDRAM 1991: "It should be pointed out that similar works, even nowadays, are often vitiated by a striking ignorance of the state of research in image studies" (S. 185, Anm. 13). 
slavistische Studie können sie daher nur mit Einschränkung thematisch relevant sein. $^{72}$

Für die folgende slavistische Studie ist dagegen der Aufsatz von Rolf-DiETER KLUGE Deutsche und Polen: eine neuralgische Nachbarschafi im Spiegel der Literatur ${ }^{73}$ von Bedeutung, in dem der Verfasser in einer äußerst konzentrierten Weise einen Überblick über die Geschichte und Wandlungen der wechselseitigen nationalen Bilder der beiden Nachbarn bis in die neunziger Jahre des zwanzigsten Jahrhunderts gibt.

Obwohl dieser Aufsatz wie die zwei oben angeführten Arbeiten induktiv und historisch-deskriptiv ist, unterscheidet er sich von ihnen durch eine klare Terminologie. Kluge bemüht sich um die definitorische Bestimmung bzw. Abgrenzung solcher tradierten Begriffe wie nationales Bild, Vorurteil bzw. Stereotyp. Als nationales Bild in der Literatur einer Nation (in seinem Fall: in den deutschen und polnischen Literaturen) bezeichnet er ,die fiktionale Gesamtvorstellung einer Gruppe - hier einer Nation in ihrer historisch-kulturellen, sozialen und mentalen Eigenart, sei es als Individual-oder Kollektivgestalt, isoliert typisiert oder im raum-zeitlichen Kontext". Das Bild entsteht aus dem historisch vermittelten "manifesten Vorwissen vom anderen". Es erscheint deswegen hăufig als V'orurteil, als ,nicht hinlänglich abgesicherte Verallgemeinerung von großer Stabilităt, ein verfestigtes vorgefaßtes negatives Urteil“". Die Stereotypen können sich aus diesen abstrakten, diffusen, aber elastischen Vorurteilen niederschlagen, es sind vereinfachte Konstruktionen von als allgemeingültig gefaßten Eigenarten, hochemotionalisiert, die dennoch als kategorische Aussagen funktionieren und als im Kommunikationsproze $B$ erhärteter, irreversibler, prägnanter Topos erscheinen. Die Stereotypen können aber auch zum Schlagwort, zum Klischee verkürzt werden. wenn das Stereotyp auf eine isolierte Eigenschaft reduziert wird. Vorurteile, Stereotypen und Klischees funktionieren vor dem Hintergrund der öffentlichen Meinung, sie können zeitweise aus dem

72 Beispielsweise die Frgebnisse der Studie Blalchers, in denen er drei ambivalente, historisch und politisch bedingte englische Bilder Deutschlands unterscheidet: 1 . das positive Bild der ( 'ousins (iermun, das vom englischen politischen Liberalismus geprägt wird; 2. das negative .Gegenbild“", das besonders durch den Ersten Weltkrieg bedingt war, und 3. das auf derm Hintergrund des englischen Empirismus und Utilitarismus geschaffene Bild der deutschen idealistischen Philosophie und Literatur .,als metaphysische Spekulation und Traumtänzerei“. Das Bild Deutschlands als das Land idealistischer Trâumer, das sich von der Romantik bis in die dreißiger Jahre des 20. Jahrhundert hielt ( $\mathrm{vgl}$. das Kapitel über das Rheinerlebnis in der englischen Reiseliteratur, z.B. bei Edward Bulwer-Lytton in The P'llgrım.s of the Rhıne (1834), BLAICHER 1992, S. $110 \mathrm{ff}$. und S. 259), wurde besonders nach 1871 durch das Bild eines wirtschaftlich und militärisch erstarkenden Staates ersetż (ebd.). LEINER zeigt ebenfalls den vergleichbaren, politisch durch den Krieg von 1870-71 bedingten Wandel des französischen Deutschlandbildes (LEINER 1991, S. 124ff.), so daß sich das positive Bild Deutschlands zu einem Trauma veränderte und die Entstehung des „franzosischen Mythos“ des ,zweierlei Deutschland" verursachte (S. 146f. und S. I54ff.). Es wäre zu untersuchen, ob es auch bei Dostoevskij àhnliche antinomische Fremdheitsstrukturen, darunter über Deutschland, gibt

${ }^{73}$ KLUGE 2000. 
kollektiven Gedachtnis abtauchen, bleiben aber potentiell vorhanden, um bei gelegentlicher Provokation wieder vehement aufzutauchen. ${ }^{74}$

An zahlreichen, „besonders neuralgischen Beispielen" wird gezeigt, wie sich die nationalen Bilder beider Lánder in der Literatur und Publizistik sowie auf dem Hintergnund der schwierigen deutsch-polnischen Geschichte niedergeschlagen haben. Hervorgehoben wird die besonders wichtige Rolle historischer Personlichkeiten (beispielsweise Luthers) und geschichtlicher Ereignisse (Reformation in Polen; die Auseinandersetzungen mit dem Deutschen Orden; die Teilungen Polens bzw. der Novemberaufstand gegen Rußland von 1830/31), die, in literarischen und publizistischen Texten fixier, zur Entstehung und Festigung gegenseitiger Bilder bzw. Vorurteile, Stereotypen, Schlagworte oder Klischees beigetragen haben, wobei es sich sowohl um positive als auch um überwiegend negative Bilder handelt. ${ }^{75}$

In allen bisher erörterten Forschungen kommt nicht nur der Begriff Image bzw. Bild einer nationalen oder ethnischen Gruppe vor, sondern auch weitere interdisziplinär gebrauchten Begriffe wie Stereotyp, Klischee bzw. Mythos. Um einen Überblick über ihre Anwendung zu schaffen, werden sie im folgenden an ausgewăhlten Forschungsbeitrăgen erơrtert.

Mit der Problematik der nationalen Bilder und Stereotypen befaßt sich JENS STÜBEN, der in dem zweiten in dieser Arbeit besprochenen slavistischen Beitrag versucht, Verwendungsweisen und Funktionen der deutschen Polen-Bilder in der Literatur zu bestimmen, die in Imagotypen und die ihnen untergeordneten Stereotypen aufgeteilt werden. ${ }^{76}$

Unter Imagologie versteht Stüben literaturwissenschaftliche Forschung, die untersucht, welche körperlichen, seelischen und geistigen Eigenschaften in literarischen Werken bestimmten sozialen, religiösen, ethnischen oder anders definierten Gruppen oder deren Mitgliedern zugeschrieben werden. Diese Zuschreibung kann explizit sein. wenn der Erzăhler oder eine Figur über eine Person oder Gruppe urteilt, oder implizit. aus dem Charakter der Figur oder mehrerer

${ }^{74}$ Beıspiele für. Stereorypen von Polen und Deutschen, die Kluge angeführt hat: Der typische Pole ist freihettsliebend, höflich und küßt den Damen die Hand. der typische Deutsche ein sentimentaler romantischer Idealist: für .ichlugworle: .polnische Wirtschaft”, deutscher .Drang nach Osten“. ebd.. S. 439f. Vgl. auch H. ORLOwSKI 1996

${ }^{\text {is }} \mathrm{Zu}$ den wenigen positiven deutschen Stereotypen von Polen gehort z B. der „edle Pole“" eine literarische Figur, die im Zusammenhang mit der ..Polenbegeisterung" nach der Niederschlagung des Novemberaufstandes in Werken der Schwabischen Romantik (bei Wilhelm Ilauff, Gustav Schwab oder Nikolaus Lenau) vorkommt: zu den negativen der ..polnische, anarchisch gesinnte Adlige" bzw. die „schone, aber egoistische und machtgierige Polin" aus dem nachgelassenen Ieme'irıus-Fragment von F. Schiller (KLUGe 2000, S. 445ff.). Zu den negativen polnischen Stereotypen von Deutschen zahlt die Gestalt Martin Luthers, die in der 7eit der Gegenreformation „verteufelt“ wurde. bzw. die des deutschen dámonischen Kreuzritters, der den beiden allegorischen. gegen die russische Zarenautokratie gerichteten dramatischen Dichtungen von Mickiewicz, Konrad Wallenrod und (iruitrna, entstammt und in der Folge in ein Stereotyp des dämonischen Deutschen uminterpretiert wurde (S. 450). Siehe auch KLUGE 1969.

${ }^{76}$ STIÜEN 1995, S. 42. 
Figuren, aus ihrem Verhalten, ihren Gedanken usw. ablesbar. Für die imagologische Forschung sind besonders Charakterzüge der Figur bzw. der Figuren interessant, die vorgeblich allen Personen ihrer sozialen Gruppe oder Nationalităt zugesprochen werden. ${ }^{77}$

Anstelle des Begriffs des nationalen Bildes oder des Stereotyps führt Stüben als Oberbegriff den von deutschen Imagologen übernommenen Terminus Imagotyp ein, der für ihn mehr als nur ethnische (nationale) Stereotypen um$\mathrm{faßt}^{38}$ Das nationale Imagotyp, das sich aus verschiedenen Elementen zusammensetzt (u.a. aus nationalen Stereotypen) und figural sein kann, begreift er ebenfalls nicht als direkte Abbildung des Wirklichen, weil es mit den Mitteln der Sprache geschaffen werde. Imagotypen, die in einem Text in ihren Verwendungsweisen und Funktionen zu analysieren sind, gehen meistens auf generalisierende Urteile, z.B. auf (negative oder positive) Stereotypen, zurück, haben eine ideologische oder eine ulopische Funktion und sind historischem Wandel unterzogen. Weil aber nicht jedes Imagotyp ein Stereotyp ist, geht die Imagologie über Stereotypenforschung hinaus.

Stereotypen definiert Stüben synonym mit Klischees als „oft wiederholte, festgefügte Bilder, die Träger und Auslöser einer vorgeprägten, von vielen geteilten Vorstellung sind, welche sich von der Wirklichkeit entfernt hat, wobei vorausgesetzt wird, daß ihre Inhalte unveränderbar und überzeitlich gültig seien." "99

In der Literatur treten sie auf, „wenn dieselben sprachlich konkretisierten Bilder und generalisierenden Urteile eine Reihe von Malen wiederkehren und auf realiter unterschiedliche Phänomene bezogen werden oder wenn ein Autor oder mehrere Autoren aufgrund eingeschliffener Vorstellungen fiktiven Personen einer Gruppe immer dieselben Wesenszüge zuschreiben." Ein Werk kann aber auch Gegenbilder zu den tradierten Bildern. utopische Elemente oder auch positive Stereotypen enthalten. Literarische Bilder von Völkem und Nationen entstehen in bestimmten historischen Situationen und können z.T. eine gewisse Berechtigung haben, sie werden aber zu Stereotypen, wenn sie sich den Veränderungen der historischen Situation nicht anpassen. ${ }^{80}$

Stüben versucht anhand einer diachronen Übersicht über die deutschen literarischen fiktionalen und nichtfiktionalen Polenbilder am Ende des 18. Jahrhunderts, in der Mitte des 19. Jahrhunderts und nach $1945 \mathrm{zu}$ zeigen, daß sich solche Bilder entsprechend den deutsch-polnischen politischen Beziehungen ändern können. Dabei sei es nicht zu bestreiten, daß es zwischen ethnischen Gruppen historisch bedingte Mentalitătsunterschiede gibt. Man müsse diese für eine fremde Ethnie typische Denk- und Verhaltensweisen wahmehmen, um kulturelle Eigenarten besser verstehen und respektieren zu helfen. Entscheidend ist, ob in einem literarischen Werk eine stereotype Unveränderbarkeit der fremden Wesenseigenschaften suggeriert wird, um ideologisierte Feindbilder zu schaffen. Es muß daher ergänzend anhand der nichfiktionalen Werke eines

\footnotetext{
77 Ebd.

78 Ebd.

${ }^{79}$ Ebd., S. $48 f$.

${ }^{\circ}$ Ebd.
} 
Autors überprüft werden, ob es seine Intention war, Ideologeme und negative Stererotypen zu festigen bzw. ob diese innerhalb der fiktiven Welt widerlegt werden.

Der Aufsatz Stübens zeichnet sich wie derjenige von Rolf-Dieter Kluge durch eine klare Terminologie und methodisch relevante Bemerkungen aus, beispielsweise zum ideologisch-utopischen und historisch wandelbaren, über die einfachen Stereotypen hinausgehenden Charakter der nationalen Bilder bzw. der Imagotypen. Man vermißt aber ihre Anwendung in ausführlicberen Textinterpretationen mehrerer, hier lediglich erwăhnter Werke. ${ }^{82}$

Im folgenden werden Beiträge ${ }^{83}$ von EMER O'SULLIVAN ${ }^{84}$ und von ZOFIA MrrosEK $^{85}$ diskutiert, die sich mit den methodologischen Fragen der nationalen bzw. ethnischen Stereotypen in der Literatur befassen.

$\mathrm{O}^{\prime}$ SUlLIVAN ${ }^{86}$ hat in zwei komplementären Monographien am Beispiel des Englandbildes in der deutschsprachigen und des Deutschlandbildes in der britischen Kinder- und Jugendliteratur die textimmanente Funktion nationaler Stereotypen untersucht. ${ }^{\theta /}$ Im theoretischen Teil ihrer ersten Studie hat sie

-1 Ebd., S. 50ff. Als Beispiel eines solchen negativen, auf zeitbedingte Vorurteile zuruckgehenden Polenbildes wird das Polenbild in Gustav Freytags Roman Soll und Haben (1855) angefüht (S. 58). Stüben erwähnt jedoch nicht Freytags Romanzyklus Die Ahnen (1772-1880), in denen Polen anders als in Soll und Haben (1855) dargestellt wird, auch nicht das positive Polenbild von Clara Viebig, z.B. in Das schlafende Heer (1904). Ein „Nationalcharakter" lăßt sich nach Stüben als die Gesamtheit von zu einer bestimmten Zeit hăufig anzutreffenden Wesens- und Verhaltensmerkmalen der Angehörigen eines Volkes verstehen, obwohl die Völkeranthropologie keine verallgemeinernden Aussagen zu treffen vermag. Bereits Heinrich Heine außerte seine Abneigung gegen „eine Charakterschilderung der polnischen Edelleute“ und gegen ..allgemeine Charakteristiken" und Volkerbilder (S. 55ff.) Vgl. Heine 1973 (leber Polen, S. 62). Siehe auch den Aufsatz von LeERSSEN 199lb, in dem anhand der literarischen Heldentypen in den realistischen Romanen des 19. Jahrhunderts das Problem der Wahrscheinlichkeit und der Konventionalităt der Figuren erortert wird. Auch Haupthelden, z.B. in Balzacs Romanen, werden als Typen mit Hilfe der literarischen Konventionen dargestellt. Nationale Stereotypen als Teil der narrativen Konventionen ermöglichen es, v.a. Nebenfiguren zu schaffen, die an den Lesern bekannte Muster appellieren.

-2 So wird u.a. die Erzählung Der Tód in V'enedig von Thomas Mann erwähnt, in der die polnischen Stereotypen positiv eingesetzt wurden. denn der polnische Knabe Tadzio ubt auf den deutschen Ästheten einen fremdartigen Reiz aus. Dabei wird jedoch nicht auf die Struktur und die textimmanente Funktion dieses Stereotyps eingegangen, ebd., S. 67. Stuben zitier dabei Marian Szyrocki, der Tadzio als ..glückliche Vereinigung der Idealbilder vom 'edlen Polen' und der 'schonen Polin' bezeichnet hat, in: SzYrockı 1975, S. 6

-3 Auch MOURA 1992b analysiert die ideologische Funkion der strukturalen und themuttschen Sicreorypen (nach Pageaux) in den franzosischen Spionageromanen uber die Dritte Welt (S. 153-166). Siehe dazu unten, S.68f.

84 O'Sullivan 1989 und difs. 1990 . Vgl. auch Winkgens 1987, Gilman: 1985, BASSEWTtz 1990, ZTTZEWITZ 1991 Oder HAHN 1995.

${ }^{85}$ MrTOSEK 1974.

${ }^{86}$ O'Sullivan 1989 und DIES. 1990.

'7 O'Sullivan fragt, ob ein Autor ..bewußt" die Stereotypen einsetzt oder ob er ihnen verhaftet, in ihrer Macht bleibt bzw. sie absichtlich ausspart, obwohl diese Frage methodisch nicht richtig formuliert ist (O'Sullivan 1989, S. 25f.). Die Fragestellung, ob ein Autor .,bewußt" die Stereotypen einsetzt, hăngt von dem Konzept des Autors eines literarischen Werkes ab. 
sozialpsychologische, philosophische und literaturwissenschaftliche Definitionen solcher Begriffe wie Stereotyp, Vorurteil, Klischee, Motiv, Image bzw. Bild zusammengestellt, aber zugleich kritisch bemerkt, daß diese Begriffe außerst diffus bzw. Synonym gebraucht werden. ${ }^{88}$

Für O'Sullivan selbst sind die Begriffe nationales Stereotyp und Vorurteil auf sozialpsychologische Bereiche auszudehnen, aber nur das Stereotyp bezieht sich auch auf literarische Texte. Das Klischee bezeichnet sie dagegen als „a wom out expression“ (u.a. nach Shaw) ${ }^{89}$, d.h. als eine rein sprachliche Erscheinung. Die Verfasserin bemüht sich um eine definitorische Abgrenzung zwischen dem literarischen nationalen Stereotyp und dem Image bzw. Bild und hält fest, daß die in den imagologischen Studien vorkommenden Definitionen eines ,literarischen Bildes vom fremden Land" mehr umfassen als der Begriff eines Stereotyps (falls beide überhaupt definiert werden). Das Bild eines bestimmten Autors von einem Land kann seine individuelle Schöpfung sein, aber sich auch aus den bereits vorhandenen nationalen Stereotypen zusammensetzen. ${ }^{90}$ Die nationalen Stereotypen sind dagegen historisch bedingt, ihre Anwendung und Rezeption hängen von dem Stand der politischen Beziehungen zwischen den jeweiligen Lăndern $a b$. In literarischen Texten können sie beispielsweise zur Konstruktion eines sogenannten "flachen" Charakters dienen, der sich nur aus typischen Eigenschaften zusammensetzen würde. Es gibt aber auf der Skala der Verwendungsmöglichkeiten der nationalen Stereotypen auch ihre „Nicht-Verwendungsfunktion". ${ }^{91} \mathrm{Zu}$ fragen wäre allerdings, ob das Bild eines bestimmten Autors zum Stereotyp werden könnte.

O'Sullivan gelingt es, wie den meisten bisher erörterten Forschern, kaum, eindeutige Einzeldefinitionen der von ihr gebrauchten Begriffe anzugeben. Die ausschließliche Beschäftigung mit nationalen Stereotypen wirkt sich in methodischer Hinsicht negativ als eine Einschränkung aus, zumal die Verfasserin zuvor selbst bemerkt hat, daß ein nationales Bild in der Literatur mehr als Stereotypen umfassen kann. Daher sind nicht nur ihre theoretischen Ausführungen, sondern auch die Interpretationen der Kinder- und Jugendliteratur nicht einleuchtend. ${ }^{92}$

Nach Janusz Slawiniski und Aleksandra Okopien-Slawinska wird z.B. das melasprachliche' Bewußlsein des Autors bzw. des Subjekts der kreattven Tätıgke'tlen [podmiot czynnosict In'irczych], das sich in der Poetik eines literarischen Werkes außert, als die besondere Rolle eines Schrifstellers verstanden. Das metasprachliche BewuBtsein eines literarischen Werkes ist aber mit dem Bewußtsein des realen Schriftstellers nicht identisch. Ein Schriftsteller kann jedoch in der Rolle des Autors von den überliefenten literarischen Konventionen abhängig sein (SlOWNIK TERMINOW I.ITERACKICH, S. 392f.); siehe auch HARRIS 1992, S. 15-20 (zU Author).

${ }^{80}$ O'SUllivan 1989 , S. 22

99 l:bd., S. 23. Vgl. Shaw 1972.

${ }^{\circ}$ O'SULLIVAN 1989, S. 42. O'Sullivan bezieht sich auf FisCHER 1981, S. 57

92 O'SULLIVAN 1989, S. 35ff. Sie bemerkt außerdem wie die meisten oben besprochenen Forscher, dal3 der Nationalcharakter nicht angeboren sei, es gebe jedoch variable nationale Charakteristika, die auf die natürliche Umgebung und auf historisch-wirtschaftliche Bedingungen zurückzuführen seien (S. 30ff.). Vgl. auch ALLPORT 1971 und PEABODY 1985.

\$2 So schreibt sie von den Bestandteilen des deutschen .Englandbildes" (..Landschaft und Wetter”, „Schlösser und Häuser”, ..Essen und "Trinken“, ..Der Engländer" - von außen betrachtet” und die „Annäherung an sein Innenleben“" sowie „sprachliche und andere Merkwür- 
O'Sullivan befaßt sich aber auch mit der Rezeption nationaler Stereotypen durch die jungen Leser, so daß ihre ursprungliche Fragestellung erheblich erweitert und dadurch uneinheitlich wird. ${ }^{93}$

MrTOSEK $^{94}$ untersucht dagegen die Genese und Funktion der nationalen Stereotypen in polnischen literarischen und ,paraliterarischen“ Textsorten (Romanen, in der Publizistik, in politischen Flugblattern und in ethnischen Sprichwortern). ${ }^{95}$ Sie beklagt ebenfalls die uneinheitlichen Definitionen des sozialwissenschaftlichen Begriffs Stereotyp, den sie selbst nicht als literarische bzw. ästhetische Kategorie, sondern als eine pragmatische Sinneinheit versteht. Stereotypen entstammen der gesellschaftlichen, historisch und ideologisch bedingten Realităt und werden entweder als "Werkzeuge der Textpropaganda“ oder als "Objekte der künstlerischen Demaskierung“ eingesetzt. Ihre Genese und Rezeption müßten daher gleichermaßen berücksichtigt werden. ${ }^{96}$ In ihrer Studie wird demzufolge zwischen dem soziologischen Begriff des ethnischen bzw. nationalen Stereotyps unterschieden, der sich auf die Äußerung der menschlichen Haltungen (postawy) gegenüber der eigenen bzw. fremden Nation bezieht und der Problematik der „Konventionalităt"“ bzw. der „Banalităt" der Kulturobjekte, u.a. der sprachlichen Kunstwerke, in denen z.B. stereotype bzw. klischeehafte Landschaftsschilderungen vorkommen. ${ }^{97}$ Die Interpretationsmethode wurde den

digkeiten “), zu denen doch nicht nur nationale Stereotypen gehoren (O'SULLIVAN 1989 S. 124-161). In der zweiten Studie (O'Sullivan 1990, S. 310) hat sie wie Blaicher zwei "Deutschlandbilder", das positive, „feminine“ (Deutschland als das Land der Mărchen, einfacher, hoflicher, frommer und sentimentaler Leute, ebd.) und das negative, "maskuline“ (Deutschland als ,the country of militaristic, arrogant, bullying, brutal people who bow to authority of any kind and abide mechanically by any law", ebd.), so daß es sich um zwei mythische Strukturen handelt. Interessant dabei ist, daB sich diese Strukturen mit denen in den Texten für Erwachsene deckt, was mit der Abhängigkeit der Kinderliteratur von deren Vorbild erklăt werden konnte.

93 Ebd., S. 212 ff. Die Arbeit von Emer O'Sullivan wird dem Spezifikum der Kinder- und Jugendliteratur nicht gerecht, denn die in dieser Literatur vorkommenden Stereotypen konnen von den Lesern im frühen Lebensalter unkritisch internalisiert werden und lassen sich spater nur schwer neutralisieren. Die Autoren der Kinder- und Jugendbücher müßten daher die eingeschrănkte Rezeptionsfahigkeit der kindlichen bzw. jugendlichen l.eser berücksichtigen, der sich mit dem Inhalt des Gelesenen identifiziert. Vgl. dazu KLUGE 1984.

94 MrTOSEK 1974.

95 Dic Fragestellung der Arbeit wird als Beschreibung der Spannungen zwischen der sozialen Strukturierung der Wirklichkeit und dem literarischen Bewußtsein auf der Ebene der ,versteinerten Rezeptionsmuster der Welt" bezeichnet, ebd., S. 5ff.

96 Mitosek vergleicht verschiedene Definitionen des Stereotyps miteinander, sowohl im Sinne von (iemeinplat = [tdea potox:na] als auch in den Sozialwissenschaften, der Philusophie (Erkenntnistheorie) bzw. Kommunikationstheorie, und geht auf die Ansichten von Walter Lippmann und Adam Schaff ein. Sie übemimmt Schaffs Unterscheidung zwischen den Begriffen .,Stereotyp“ und „Begriff”, der den „Begriff“ als eine gedanklich-logische und das "Stereotyp" als eine gedanklich-pragmatische Kategorie auffaßt, die nicht nur kognitive. sondem auch wertende Funktion hat (ebd., S. I3ff. und S. 34). Vgl. dazu SCHAFF 1967, S. $116 f$.

${ }^{27}$ Sereorypen konnen nicht nur verbale Form haben, sie ăußern sich in verschiedenem Zeichenmaterial. Manchmal werden sie daher mit den sprachlichen, stilistisch geprägten Klıschees (polnisch: szlampa, bzw. russisch: štamp) identifiziert, obwohl die letuten eher von 
theoretisch-terminologischen Grundlagen entsprechend zur Erforschung typologischer Beziehungen zwischen der literarischen Praxis und den nationalen Stereotypen eingesetzt. ${ }^{98}$ Der theoretische Ansatz hat somit die Kriterien der Auswahl des untersuchten literarischen Materials beeinflußt. In der Zusammenfassung wurden drei Aspekte der wechselseitigen Wirkung zwischen den Stereotypen und der Literatur genannt: 1. das Vorkommen der nationalen Stereotypen in literarischen Werken kann in der Rezeption zu ihrer Stabilisierung führen; 2. literarische Symbole dringen in das Gebiet des gesellschaftlichen Bewußtseins ein und werden zu Stereotypen [kreacja stereotypów], 3. Stereotypen können in einem literarischen Werk als solche "demaskiert", destruiert werden. ${ }^{99}$

Die Studie von Mitosek läßt sich, ungeachtet vieler Vorzüge, zu denen die Bemühung um terminologisch-methodische Klarheit gehört, als terminologisch zu einseitig auf das nationale Stereotyp und methodisch zu sozialkritisch ausgerichtet bewerten. Am interessantesten erscheinen die Kapitel über die textimmanente Funktion von Stereotypen, obwohl die Beschränkung auf die Erforschung nationaler Stereotypen als ein methodischer Mangel betrachtet werden kann, der sich negativ auf die Textinterpretationen ausgewirkt hat. ${ }^{100}$

der Konventionalität der Darstellung zeugen, z.B. in den Landschaftsschilderungen in einem literarischen Werk (MrTOSEK 1974, S. 40ff.). Dieses Problem wird eingehend im zweiten Kapitel über das Verhältnis zwischen dem Sprichwortklischee und dem in ihm artikulierten Stereotyp untersucht (ebd., S. 43-6I).

${ }^{90}$ Ebd., S. 174. Vgl. auch $\angle 4$ den Kulturtexten: Lotman/PIATIGORSKy 1969 bzw. zur literarischen Evolution: TYNJANOV 1969, S. 432.

99 So werden einerseits am Beispiel polnischer ethnischer Sprichwörter über die Deutschen sowie oberschlesischer Flugblätter aus der Zeit nach dem ersten Weltkrieg die Beziehungen zwischen Stereotypen und historischer Tradition erörtent, u.a. die Entstehung des negativen Stereotyps des "feindlichen Deutschen" aus dem literarischen Symbol des Kreuzritters in der polnischen romantischen Literatur gezeigt (MrroseK 1974, S. 43ff. und S. 62-95, bes. 65ff.); andererseits ihre immanente Funktion in literarischen Texten: die ästhetische "Zähmung" [oswajunie] und Stabilisienung der Stereotypen in dem polnischen Trivialroman aus der Zwischinkriegszeit l'tęc minut do pólnıxy [Fünf Minuten vor Mitlernacht] (1928) von Antoni Ferdynand Ossendowski sowie das avantgardistisch-modernistische In-Frage-Stellen jeglicher Stereotypen, thre Destruktion und das sprachlich-parodistische Spiel mit ihnen im Roman von Stanislaw Ignacy Witkiewicz Jechne wyjście [Der einzige Ausweg] (1931-33) (S. 119-144 und S. 145-172). Vgl. zum polnischen Stereotyp des Kreuzritters: KLUGE 1969.

${ }^{100}$ Die Methode von MrTOSEK hat neulich OLSCHOWSKY 1999 angewedet. Er kritisiert den Ansatz der Aachener Schule aufgrund ihrer "wenig köhärenten Systematik“, die "die Funktionen des Stereotyps unzulässig auf das Vonurteil" reduziere. In seinem Aufsatz W' lassen

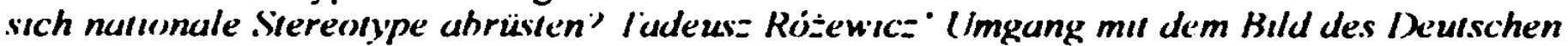
berücksichtigt er aber nur einen Aspekt der Anwendung des nationalen Stereotyps, indem er zu zeigen versucht, wie Różewicz die polnischen nationalen. Sereorypen über Deutschland zu seinem Ieutschlandbıld bzw. Imagoryp umfunkionient hat. Analysiert wird dabei hauptsăchlich die wirkungsästhetische Dimension der Texte von Różewicz: diese lasse sich als eine ambivalente Lenkung des (polnischen) lesers verstehen, die weder in der Affirmation noch in der Destruktion der negativen polnischen Stereotypen über die Deutschen erfolge (S. 254). 


\section{EXKURS ZUR STEREOTYPENFORSCHUNG}

In den meisten oben angeführten Forschungsbeiträgen wurde der Begriff des nationalen Stereotyps bzw. Vorurteils oft synonym oder komplementăr zu dem des Bildes, Images oder Imagotyps eingesetzt. Um terminologische Klarheit in dieser verworrenen Terminologie zu schaffen, müßten an dieser Stelle verschiedene Definitionen der Begriffe Stereotvp oder Vorurteil erörtert werden. Ein ausführlicher Bericht über die Stereotypen- und Vorurteilsforschung würde jedoch die Fachkompetenzen der Philologin überschreiten und sich in der "wilden Interdisziplinarităt" (Moura) verlieren. In dem folgenden, kurzen Exkurs sollen aber einige ausgewählte Definitionsbeispiele der Begriffe Stereotyp oder Vorurteil aus der Sozialpsychologic, Sprachwissenschaft und Literaturwissenschaft ergänzend angeführt werden.

Aus der sozialpsychologischen Forschung werden drei Beispiele angeführt, die als reprăsentativ für den neueren Forschungsstand bezeichnet werden können.

Wolfgang Stroebe und Chester A. INSKO ${ }^{101}$ definieren Stereotyp ,as a set of beliefs about the personal attributes of a group of people." Diese allgemeine Definition drückt die Zurückhaltung der Verfasser gegenüber der Auffassung aus, daß Stereotypen als starr [rigid] oder exakt [accurate] zu betrachten seien. Damit wird auch Skepsis gegenüber der Lippmannschen (1922) Metapher von den „pictures in our heads" geăußert; diese habe bewirkt, daß in der Lippmann folgenden Forschung Stereotypen als fehlerhatte, starre und dauerhafte Vereinfachungen verstanden worden seien, obwohl Lippmann selbst ambivalent in der Beurteilung der Stereotypen gewesen sei. ${ }^{102}$

Die Autoren unterscheiden im folgenden zwvischen dem Begriff des Stereotups und Vorurteils: „The distinction between stereotype and prejudice parallels the distinction commonly made between beliefs or opinions and attitudes. Stereotypes are beliefs or opinions about the attributes of a social group or its members, whereas prejudice is usually conceptualized as a negative intergroup attitude." wobei .. an attitude" als ... a tendency to evaluate an entity (attitude object) with some degree of favor or disfavor" definiert wird. Unter lorurteil verstehen Stroebe und Insko demzufolge ..an attitude toward members of some outgroup and in which the evaluative tendencies are predominantly negative." Vorurteil hat ein „cognitive component (e.g., a stereotyp about the members of the outgroup), an affective component (e.g., dislike) and a conative component

101 STROEBEIINSKO 1989.

102 Ebd. S. 4f. Die ..Starrheit” des Stereotyps ist auf die ursprüngliche Bedeutung dieses Wortes zurückzuführen, das 1798 im Sinne von ..to describe a printing process involving the use of fixed casts of the pages of type"* benutzt worden ist und zuerst von Lippmann 1922 aut kognitıve Vorstellungen sozialer Gruppen voneinander übertragen worden ist. Siehe auch dic Übersicht über die diachrone Entwicklung des Stereotyps-Konzepts sowie über Methoden und Theorien in der sozialpsychologischen Stereotypenforschung (S. 4-8). Vgl. dazu z.B. NOELLF-NEUMANN 1990, L.IPPMANN 1922, DERS. 1964 
(e.g., discriminatory behavior toward the members of the outgroup)." Es gibt nicht nur negative, sondern auch positive Vorurteile. Vorurteil und Stereotyp stehen in enger kausalen Beziehung zueinander. Die Ausrichtung dieser Kausalităt [the direction of causality] wird aber je nach Forscher unterschiedlich gesehen, z.B.: „While information-processing approaches postulate that a person's attitude towards a social group results from his salient beliefs about that group $/ . . . /$, consistency theories make the additional assumption, that attitude change can lead to changes in a person's beliefs about a given group $/ \ldots /^{.103}$

Als Anhänger der kognitiven Stereotypen- und Vorurteilstheorie verstehen die Autoren unter Stereotypisieren [stereotyping] und Vorurteil soziale Konstrukte, die als Ergebnis kognitiver Prozesse die Beziehungen zwischen den Gruppen [intergroup relations] und ihr Verhalten zueinander wie „confrontations, violence, wars, cooperation, alliance, negotiation. or coordination $/ \ldots /$ by perceptions. beliefs and attitudes" vermitteln [mediate]. ${ }^{104}$

JOHN E. FARLEY'105 unterscheidet ebenfalls zwischen den Begriffen des Stereotyps und Vorurteils:

/.../ Prejudice means just what it suggests: attitudes and beliefs involving a tendency to prejudge people, usually negatively and usually on a basis of a single personal characteristic (such as race, sex, religion, hair length, etc.), without any objective basis for making such a judgement. This prejudgment takes the form of overcategorization - the tendency to think of or react to everyone in some category (for example, black. Chinese, female, gay) in a more or less fixed way, based on the category. ${ }^{106}$

Vorurteil weist auch für Farley kognitive, affektive und konative ${ }^{107}$ Komponenten auf, die jeweils drei, auch voneinander getrennt auftretende, Vorurteilstypen bilden können. ${ }^{108}$ Es gibt aber mehrere Typen von Vorurteilen. Stereotyp bzw. Stereotypisteren ist der Typ des kognitiven V'orurteils.

Das Stereotvp definiert Farley nach Allport (1954) als ,.an exaggerated belief associated with a category (a group of people, such as racial, ethnic. or religious group).“109 Stereonpen können auch für Farley negatn und posttiv sein. Meistens werden einer einzigen Eigenschaft positive Konnotationen für die ingroup, aber negative für die out-group zugeschrieben. Stereotvpenmustern können sich ändern, so z.B. werden durch die neuere Forschung drastische Ände-

\footnotetext{
103 Stroebe/INSKO 1989, S. 8 f.

104 Ebd., Preface, S V

105 FARLEY 1995 Farley interessien sich für..the princıples and processes that shape the patterns of relations between racıal, ethnic, and other groups in society“, v.a. am Beispiel der USA. ebd. S. IX.

${ }^{106}$ Ebd., S. 13.

107 |konativ: strebend, antriebhaft. Vgl. Konation, die -. en (lat.engl.): zielgerichtete Aktivität. Antrieb, Streben. Wollen.]

208 Ebd., S 14.

109 Ebd.
} 
rungen der Stereotypen uber "Chinese", "Jews", "Negroes" und "Turks" in den USA festgestellt. 220

Penelope J. Oakes, S. Alexander Haslam, John C. Turner ${ }^{111}$ bemühen sich, die Theorie der kognitiven Stereotypenforschung um die Frage nach den Beziehungen zwischen dem Stereotypisieren und der sozialen Wirklichkeit zu erweitern. Die von ihnen entwickelte self-categorization-theory versucht, das Paradoxon zu lösen, daß Stereotypisierungsprozesse, die in der kognitiven Forschung seit den siebziger Jahren als normal, rational und pragmatisch positiv bezeichnet werden, Stereotypen hervorbringen können, die in der traditionellen Stereotypenforschung als negativ, starr und falsch, als "unimaginative images" angesehen wurden. ${ }^{22}$ Die Autoren antworten auf diese Frage und definieren Stereotypen als:

/.../ social categorical judgements, perceptions of people in terms of their group memberships. They represent categorizations at the level of social identity, in which people are defined in terms of the characteristics of the group as a whole in the context of intra- and intergroup relations. They are fluid, variable and context-dependent. A stereotype of the same people may vary in categorical level, kind, content, and prototypical meaning as a function of the relationship between self and others, the frame of reference, the dimensions of comparison, and the background knowledge, expectations, needs, values and goals of the perceiver. ${ }^{113}$

Wichtig ist dabei, daß Stereotypen nicht mehr als „rigid or fixed /.../ mental representations. stored in memory“ verstanden werden. sondern als Ergebnis .,of dynamic process of social judgement and meaningful inference. ${ }^{\cdots 14}$ Die Forschung soll außerdem den Mythos von der Starrheit der Stereotypen überwinden. Stereotypen und Stereotvpisierungsprozesse sollen nicht mehr als irrationale, ungültige [invalid], kognitive Vorurteile, Vereinfachungen [oversimplification] bzw. als eine kognitive Entstellung des Selbst angesehen werden: „/.../ social categorical perception is a basic. normal and adaptive process of

120 Ebd. S. 15 .

111 OAKHS / HASLAM / TURNER 1994, siehe darin z.B.: S. 1-11: Intrexduction: The Six:1al 1'sychology' of Stereofyping; S. 12-33: liarly' Approaches to Stereotypes ans P'rejudice; S. 186213: Politic:s. Prejudice and Myth in the Sudy of Stereotypes. Vgl. auch den z.T. verwandten theoretischen Ansatz in: LEYENS / YZERBIT / SCHADRON 1994. Siehe ferner HASTEDT 1998.

112 OAKES / HASLAM i TURNER 1994, S. XIf., If: .. Why do we so often characterize people in terms of their memberships rather than in terms of their qualities as differentiated individuals? Is this done to deny individuality, or to facilitate prejudice $! . .$. i In what sense, if any, are these characterizations deficient? Are stereotypes wrong because /...' they are the manifestation of defective psychological processes? $/ . . /$ In the past almost all researchers have assumed at the outset that stereotyping is deficient. /.../ We shall provide an alternative theoretical perpective and argue that this assumptions is unwarranted," ebd., S.2, und weiter: .. This is the central puzle that we wish to address: how can a veridical cognitive process $1 . . /$ produce psychologically valid images, some of which, nevertheless, society is entıled to reject as false ${ }^{\text {r. }}$ (S 187).

113 Ebd., S. 211.

114 Ebd., S. $211 \mathrm{ff}$ 
group life. It defines people in terms of their group relationships and underlies group formation and collective behaviour."

Soziale Gruppen und kollektive Beziehungen sind ebenso objektiv existent wie individuelle Persönlichkeiten und individuelle Unterschiede. Menschen können gleichzeitig als Individuen bzw. als Gruppen handeln, sie kategorisieren und unterscheiden andere Menschen auf unterschiedlichen Identitätsebenen, entweder als Individuen oder als Gruppen. Stereotypische Akzentuierungsprozesse [stereotypic accentuation] reflektieren eine rationale und selektive Perzeption, in der Menschen kontextbezogen auf der Ebene der sozialen und nicht auf der Ebene der individuellen Identităt gesehen werden. ${ }^{115}$

In Stereotypen werden also kontextbezogene Attribute einer Gruppe repräsentiert, was nicht bedeutet. daß sie eine "wirkliche“ individuelle Charakteristik der einzelnen Gruppenmitglieder enthalten, weil eine Gruppe sich nicht auf ein Individuum reduzieren läßt. Es ist aber keine Entstellung der Wirklichkeit, Menschen im Hinblick auf ihre soziale Gruppenidentität zu sehen. Sowohl individuelle Unterschiede als auch soziale Ähnlichkeiten sind real. ${ }^{116}$ Stereotypen müssen im sozialen Kontext betrachtet werden. Jede individuelle kognitive Aktivităt wird immer durch den sozialen Kontext vermittelt [mediated], in dem sie stattfindet. ${ }^{117}$ Die soziale Wirklichkeit ist jedoch nicht homogen, sie enthält unterschiedliche Werte und Wertsysteme, ist für jeden Beobachter anders. Der Inhalt der Stereotypen drückt diese untereinander differierenden Werte und Wertsysteme der sozialen Gruppen aus. Er ändert sich mit den Änderungen der Werte, der Wertsysteme und der politischen Gruppenbeziehungen, der psychologische Entstehungsprozess der Stereotypen verläuft jedoch immer gleich. ${ }^{118}$

Stereotypen sind soziale Normen, enthalten politische Analysen und dienen als politische Waffen. Politische und soziale Konflikte sind kein psychologisches Problem, kein Produkt des Mißverstăndnisses: „When we propound some stereotypes and reject others, it is not that we are sane and our opponents crazy; we are psychologically equal, but different social beings with different social purposes and perspectives./.../ Social and political conflict over stereotypes is not evidence of underlying psychological deficit, but of the political dimension of stereotype validity. "119 Meinungsunterschiede und Konflikte zwischen Individuen und Gruppen über Richtigkeit einiger Stereotypen sind Teil sozialer, politischer und historischer Prozesse, in denen Gesellschaften sich bemühen, Stereotypen zu schaffen, die aus der Perspektive der ganzen Gemeinschaft gültig sind. In bestimmten Zeitpunkten kann z.B. ein Stereotyp als falsch

115 Ebd., S. 212f.
116 Fbd., S. 188ff.
117 Ebd., S. 212f.

118 ..No judgement of society (or nature) is possible but from a human perspective stamped by values and ideologies. Reality is apprehended not merely through our ideas, cognitive schemata etc., but also trough our values /.../ Psychologically, it is reasonable for political conservatives to construct a stereotype stamped with their own political values as it is for their opponents to do likewise. /.../ The difference is in the political values applied and therefore the outcome of judgment. Veridicality is not in opposition to values, therefore, but is relative to the specific values applied" (ebd., S. 203).

119 Ebd., S. 206f. und S. 212 
[wrong] beurteilt und dann verworfen [rejected] werden. Auf jeden Fall sind es aber soziale Prozesse, die Stereotypen entstellen. die eine besondere Gruppe über eine andere formt. ${ }^{120}$

Aus sprachwissenschafilicher Sicht ist det Aufsatz von GERD HENTSCHEL ${ }^{121}$ erwăhnenswert, weil er die sprachliche Form und Bedeutung von Stereotypen und ihre Abgrenzungen zum Begriff des Protoryps analysiert. der in der psycholinguistischen Prototypensemantik entwickelt worden ist. Hentschel bemerkt. daß sowohl der Begriff des Stereotyps als auch des Prototyps in der Literatur synonym mit anderen Begriffen verwendet wird: z.B. mit Vorurteil. Schlagwort bzw. Slogan. Klischee, aber auch mit Begriff, Kategorie oder Konzept.

Die Termini Stereotyp und Prototyp können jedoch auch auf dem Hintergrund der allgemeinen objektsprachlichen Begriffsbildung erörtert werden. Als Beispiel eines Prototyps führt Hentschel die Bezeichnung für eine deutsche Frau aus polnischer Sicht an - den Phraseologismus "fest baba“ (oder „baba fest "); als Beispiel eines Stereotyps wird das polnische Stereotvp „Rosjanka jest ladna. a Niemka brzydka" ["Die Russin ist hübsch, die Deutsche ist håßlich"] angeführt, wobei bemerkt wird, daß Ausnahmen zugelassen werden. ${ }^{122}$ Das Konzept des Prototyps wird in der radikalen neueren kognitiven Sprachwissenschaft an der Wittgensteinschen Kategorienkonzeption („Familienăhnlichkeit“) orientient bzw. als Kompromiß zwischen der klassischen Aristotelischen Kategorienlehre und der Wittgensteinschen „Familienähnlichkeit" aufgefaßt. ${ }^{123}$

${ }^{120}$ Ebd., S. 212. Vgl. auch den Aufsatz von JOHN D. DelaMater über Altıudes und Sereotyp (in: BORGOTTABORGOTTA 1992, S. 117- 124 und S. 117f.); den Aufsatz von MARYLEe C. TAYlor und ThOMAS F. PETtigrew über P'rejulice (ebd., Bd. 3, S. 1536-154I); den Aufsatz von John HaRding über Siereorypes (in: SILLS 1968, S. 259-261); HILLMANN 1994 (S. $842 f$. über Siereotyp; S. 914f. über Virurtell); Koschitk 1993 (S. 1630-1632 über Stereotyp); BENZ 1996; BARRES 1978; SILBERMANN 1994 und SIX 1987.

121 HeNTSCHEL 1995. Vgl. auch z.B. QuASTiOff 1973. Siehe ferner den Beitrag zur Stereotypenforschung aus systemtheoretischer bzw. konstruktivistischer Sicht: TUSCHAU 1998.

122 HENTSCHEL 1995, S. 14ff.

$123 \mathrm{Vgl}$. ebd. S. $21 \mathrm{ff}$ : Der späte „Wittgenstein hatte am Beıspıel des Wortes 'Spiel' gezeigt. daß sich eine derartige Kategorie aus Unterkategorien $A, B, C, D, \ldots . K, L, \ldots$ zusammensetzen kann, für welche gilt: Jede dieser Unterkategorien steht in gewissen Ähnlichkeitsrelationen zu einigen (mindestens einer) anderen und nicht notwendigerweise, sondern nur moglicherweise zu allen anderen. Das heißt $A$ kann Ähnlichkeit mit $B$ haben, $B$ mit $C$ sowie $C$ mit $D$, usw. Aber, und das ist der springende Punkt, eine Unterkategorie $\mathrm{K}$ muß absolut keine Ähnlichkeit mit einer Unterkategorie A aufweisen." Der klassischen, antiken und strukturalistischen Kategorienlehre liegt dagegen der Gedanke zugrunde, daß alle potentiellen Unterkategorien ciner übergeordneten Kategorie durch (mindestens) einen gemeinsamen Nenner verbunden smd (ebd., S. 22). Der KompromiBcharakter der prototypischen Kategorisierung zwischen der klassischen und der Wittgensteinschen liegt darin, daß einerseits am Gedanken des kleinslen gemeinsamen Nenners festgehalten wird, aber dieser (in der Form mindestens einer gemeınsamen Eigenschaft) nicht für alle Unterkategorien untereinander gegeben zu sein braucht, vielmehr muß jede nichtprototypische Unterkategorie mindestens eine gemeinsame Eigenschaft mit der prototypischen aufweisen, d.h., es muß jeweils ein gemeinsamer Nenner für alle Nicht-Prototypen in der Kategorie mit dem Prototyp vorliegen. Andererseits kann es auch einzelne nicht-prototypische Unterkategorien geben, die nichts miteinander gemein haben, was die Affinität zur Familienăhnlichkeit ausmacht (S. 24). 
Der Prototyp einer solchen Kategorie ist diejenige Kategorie, welche die meisten der überhaupt in der Kategorie auftretenden Merkmale umfaßt: 1. Prototypen im Sinne von guten Beispielen bestehen aus einem Komplex von Merkmalen, jedoch ist keines davon unbedingt notwendig, noch ist der Komplex ausreichend für die Abgrenzung der gesamten Kategorie; 2. die Merkmale können skalar sein; 3. die Kategorien und Unterkategorien haben nicht unbedingt scharfe Grenzen; 4. die Mitglieder einer Kategorie haben unterschiedlichen Status im Sinne von besseren oder schlechteren Beispielen für die jeweilige Kategorie. ${ }^{124}$

Es ist also möglich, daß einzelne nicht-prototypische Unterkategorien nichts miteinander gemein haben. Auch Stereotypen erlauben Ausnahmen, deshalb stehen sie den prototypischen Kategorisierungen nah. ${ }^{125}$ Auch was den sprachlichen Status der Stereotypen angeht, ăhneln sie den Prototypen. Die Diskussion, ob Stereotyp als Satz oder Wort in der Sprache vorliegt. ist gegenstandslos. Prototypische Eigenschaften - z.B.: [kann fliegen] - „Vogel", [lebt in Eis und Schnee] - „Eskimo“, [ist hăßlich] - „Die Deutsche“, gehören als implizite Prädikation zum Merkmalkomplex der jeweiligen Kategorien. Stereotypen können sogar bis zur Ebene des Lexems "eingefaltet" werden. ${ }^{126} \mathrm{Zu}$ den weiteren Affinităten zwischen Stereotypen und Prototypen gehört ihr Konflikt mit der Wirklichkeit, v.a. wegen der Möglichkeit von Ausnahmen. Der Wahrheitsgehalt von Stereotypen ist irrelevant für ihren Status, sie können z.B. Ängste erwecken, als Mittel zur Abgrenzung benutzt werden usw. Stereotype Vorstellungen sind mögliche Wirklichkeiten, die man nicht falsifizieren kann. ${ }^{127}$

Unter Berücksichtigung des konnotativen, emotional wertenden Aspekts lassen sich nach Hentschel beide Begriffe des Stereotyps und des Prototyps in ihren Gemeinsamkeiten folgendermaßen beschreiben:

Stereotype Eigenschaften können als Subtyp der prototypischen Eigenschaften verstanden werden. Stereotype Eigenschaften sind ähnlich wie die Eigenschaften der Prototypen weder notwendig noch ausreichend zur Abgrenzung der Kategorie. Daher das gemeinsame Moment der Möglichkeit der Ausnahmen. Prototypische und stereotype Eigenschaften können skalar sein, und die Mitglieder der Kategorie können unterschiedlichen Status haben. Innerhalb der letztgenannten können wir sie definitorisch eingrenzen, als mögliche, aber kaum falsifizierbare typische Eigenschaften einer lexikalischen Kategorie Q: (1) Diese Eigenschaften sind auf einer emotionalen Positiv-Negativ-Skala einer Kulturgemeinschaft markiert (das heißt nicht neutral) oder markierbar (das heißt möglicherweise nicht neutral). Das heißt. eine stereotype Eigenschaft muß nicht konsequent wertend sein, sondern nur potentiell: Zum Prototypen der Kategorie 'Italiener' im Deutschen

${ }^{124}$ Ebd., S. 23f. In der aristotelischen Kategorielehre muß dagegen ein gemeinsamer Nenner, ein gemeinsames Merkmal usw. in allen Unterkategorien einer übergeordneten Kategorie vorhanden sein (S. 22).

125 Fbd., S. 24

126 Ebd., S. 25f., nach GRTYBEK 1990, S. 316.

127 HENTSCHEL 1995, S.27f. 
gehören sicher [ißt Spaghetti/ißt Pizza]. Diese sind in der jüngeren Generation vollig wertneutral, konnen aber (von eingefleischten 'Kartoffelessern') abgrenzend negativ verwendet werden und sind zum Teil sogar metonymisch lexikalisiert worden: 'Spaghettifresser'. Der Übergang von nicht wertenden prototypischen zu stereotypen Eigenschaften ist also fließend. (2) Die Kategorie $\mathbf{Q}$ kann in sprachlichen Äußerungen verwendet werden, ohne daß die in (1) beschriebenen Eigenschaften aktualisiert werden. Ist dagegen eine Verwendung von $\mathbf{Q}$ immer mit einer kommunikativen Aktualisierung dieser emotionalen bzw. auf einer kulturspezifischen Werteskala fixierten oder möglicherweise zu fixierenden Eigenschaft verbunden, so stellt sich die Frage nach der 'Stereotyphaftigkeit' nicht. Sprechen wir also von Stereotypen, so beziehen wir uns auf die Verwendung bzw. die Moglichkeit der Verwendung einer prototypisch strukturierten Kategorie bei kommunikativer Aktualisierung der so definierten stereotypen Eigenschaften. ${ }^{228}$

Ergänzend kann noch eine exemplarisch ausgewăhlte literaturwissenschafiliche Definition des Stereotyps angefüht werden.

Im SLOWNIK TERMINOW LITERACKICH ${ }^{129}$ wird Stereotyp im allgemeinen als eine vereinfachte Vorstellung oder Formulierung, die betont axiologische. wertende Tendenz aufweist $[, / . . /$ uproszczone wyobrażenie lub sformułowanie o wyrazistym ukierunkowaniu aksjologicznym"], definiert. In der Literatur sowie in anderen Künsten ist es eine Darstellung, die an die allgemeingültigen, tief in dem sozialen Bewußtsein einer gegebenen Gruppe verankerten Meinungen und Vorstellungen appelliert. Diese Meinungen und Vorstellungen werden kritiklos für unumstößliche Wahrheiten gehalten. In einem literarischen Werk können Stereotypen I. in seiner Fabelstruktur auftreten, z.B. happy end in den populären Romanen, ${ }^{130}$ 2. in dem Figurenaufbau, der den allgemeinen Vorstellungen darüber enspricht, wie der Typ des Romanhelden sein sollte, 3. auf der stilistischen Ebene als u.a. stabile Formulienungen bzw. Formeln. Literarische Werke. die sich auf stereotypisierte Sprachmittel beschränken, erheben minimale ästhetische und epistemologische Ansprüche und sind extrem konform gegenüber dem in der gegebenen Gesellschaft vorherrschenden Weltbild. Andererseits treten gewisse stereotype Elemente in jedem literarischen Werk. auf allen seinen Ebenen auf, die den Erwartungshorizont und somit die Rezeption des Werkes bestimmen. ${ }^{131}$

Zusammenfassend läßt sich $\mathrm{zu}$ allen oben besprochenen sozialpsychologischen, sprachwissenschaftlichen und literaturwissenschaftlichen Beiträgen zur Stereotypenforschung festhalten. daß die in ihnen behandelten terminologischen Fragen, trotz. der Bemühung um definitorische Festlegung, immer noch ungelöst

120 Ebd., S. 36f.

129 SLOWNIK TERMINOW LTTERACKICH, S. 522

130 Wobei es sich hier eher um ein konventionelles, kompositorisches Verfahren als um ein Stereotyp handeln würde

131 Ebd. 
bleiben und zu erheblichen terminologischen Verwirnungen und Unklarheiten führen können.

1. Denn, wenn in den sozialpsychologischen, kognitiv ausgerichteten Beitrăgen das Stereotyp

- als eine Unterkategorie von Vorurteil sowie als Ergebnis der dynamischen kognitiven (und lediglich aus synchroner Sicht beobachteten) sozialen Prozesse verstanden und definiert wird und folglich nicht mehr als „starr" und „unverănderbar" angesehen, so wird es gegen die ursprüngliche semantische Bedeutung des Wortes definiert.

- Darüber hinaus, wenn die Ansicht verworfen wird, daß das „Stereotyp“ ein "feststehender, erstarter, unveränderlicher Typus“ ist, wird ignoriert, daß es ein sprachlich (u.a. in literarischen Texten) fixiertes und daher, diachronisch betrachtet, ein sozial irrelevantes, unveränderliches Ergebnis der sozialen Stereotypisierungsprozesse ist, wie z.B. „der dumme Michel“ (= Deutscher) oder „der charmante Pole", ,furor teutonicus" oder "die polnische Wirtschaft", das nichts mit den variablen und flexiblen Eigenschaften des Glaubens zu tun hat.

Daher wăre es aủßerst angebracht, wenn die Sozialpsychologie eine neue Terminologie eingeführt hătte, wo doch ihr Erkenntnisgewinn darin besteht, daß sie die „Stereotypen“ als ein unvermeidliches Produkt der durch die jeweilige Ideologie beinflußbaren sozialen Prozesse betrachtet.

2. Der sprachwissenschaftliche Beitrag, der auf der Grundlage allgemeiner objektsprachlicher Begriffsbildung das Stereotyp als einen Subtyp des Prototyps auffaßt, kann nur dadurch für eine literaturwissenschaftliche Beschäftigung mit literarischen Stereotypen hilfreich werden. indem er auf ihre sprachliche Form sowohl als Satz als auch als einzelnes Wort bzw. sogar als Lexem hinweist. Relevant ist auch der Hinweis auf die Möglichkeit von Ausnahmen innerhalb einer bestimmten stereotypen Kategorie.

3. SchlieBlich ist die literaturwissenschafiliche Definition des Stereotyps insofern methodisch wichtig, weil sie die formale und semantische Vielfalt stereotyper Elemente in einem literarischen Werk betont. Sie können (zugleich) auf mehreren Textebenen auftreten.

Anhand der Zusammenstellung der oben angeführten Beiträge låßt sich festhalten, daß der Reichtum stereotyper Elemente in cinem literarischen Text, darunter solcher, die sich auf das Phänomen kultureller Fremdheit beziehen, in allen seinen semantischen und strukturellen Aspekten nur innerhalb der fiktionalen Welt dieses Textes und in ihrer Gesamtheit verstanden und interpretiert werden könnte.

Als ein Beispiel für die ausschließliche Beschältigung mit literarischen $K / i$ schees wird im folgenden die Dissertation von RüDIGER KunOw ${ }^{132}$ erwähnt. Kunow hat darin die Funktion des Klischees bei der „Sinnkonstitution des Textes“ am Beispiel postmoderner englischsprachiger Literatur erörtert. ${ }^{133} \mathrm{Da}$ -

132 KUNOW 1981.

133 Mit dem Kltsche'e wird seit der Übernahme dieses Terminus in die Literaturkritik gegen Ende des 19. Jahrhunderts aus der Druckersprache, in der es einen vorgefertigten Druckstock für Abbildungen bezeichnet, die pejorativ besetzte Eigenschaft des Vorgefertigten und belie- 
bei hat er aber bei dem Versuch, den Begriff des Klischees von den uneinheitlich, alternativ bzw. synonym gebrauchten sozialwissenschaftlichen Begriffen des Stereotyps und von den negativ besetzten literaturwissenschaftlichen Termini wie Phrase, Mode-, Schlagwort, Leerformel oder Gemeinplat abzugrenzen, bemerkt, daß sie in außerst unterschiedlichen Kontexten gebraucht werden. ${ }^{134}$

Für Kunow umfaßt das Klischee als Oberbegriff die Komponenten von Phrase, Leerformel oder Gemeinplat,. Mode- oder Schlagwort, ${ }^{135}$ denn sie zeichnen sich durch das gemeinsame stilistische Merkmal der Wiederholung bzw. Wiederholbarkeit aus. Der repetitive Charakter des Klischees wird aber dabei absolut verstanden, indem bei dem Begriff Phrase bzw. Leerformel die semantische Leere, bei Gemeinplat dessen universale Verfügbarkeit sowie bei Mode- $b=w$. Schlagwort der zeitbedingte Charakter ausschlaggebend wird. ${ }^{136}$ In der Arbeit Kunows wird jedoch anstelle des meistens negativ besetzten Begriffs des Klischees der Oberbegriff der Verfestigung gebraucht, weil er besonders geeignet sei, „verfestigte klischeehafte Elemente“ auf verschiedenen Strukturebenen des literarischen Kunstwerkes zu analysieren, obwohl der Verfasser doch darauf verzichtet hat, eine synthetisierende Definition dieser Begriffe zu formulieren. ${ }^{137}$

Um die Formelhaftigkeit des Klischees im literarischen Text möglichst umfassend $\mathrm{zu}$ erforschen, wird sie sowohl im sprachlich-kognitiven Kontext (Klischee und Stil), als auch im außersprachlichen, sozialen Bezug zur dargestellten Wirklichkeit (Klischee und Mimesis) untersucht. ${ }^{138}$

big Wiederholbaren, der ..Reproduzierbarkeit“, somit auch des Unechten, Abgegriffenen und Vereinfachenden assoziiert (ebd., S. 2).

${ }^{134}$ Bei der Analyse der Leerformeln oder des Schablonencharakters der Alltagssprache werde das Problem des Klıschees bzw. seiner Funktion in groberen sprachlichen oder soziologischen Zusammenhången gebraucht (ebd., S. 22f.); die englischsprachige Forschung verstehe das Klischee als einen stilistisch abgegriffenen Ausdruck, eine durch häufigen Gebrauch abgenutzte Aussage (Wort, Wortgruppe oder Satz) (S. 6-14), während die deutschsprachige sich für seinen kognitiven Aspekt, für seine sprachliche und gedankliche Inorıginalität, interessiere (S. 14-22). Stereoryp wird dagegen sprachnormativ (Partridge, Gowers), sprachăsthetisch (Gowers, Orwell), semantisch-soziologisch (Zijderveld, Coulmas) oder kognitiv-konzeptuell (McLuhan'Watson) verstanden (S. 22 und zum Begriff des sozialen. Stereotyps und Klischeces. S. 74-84). Siehe auch ZUDERVELD 1979, und DERS. 1987. Vgl. auch VANDERMEY 1993.

${ }^{135}$ KUNOW 1981, S.4.

${ }^{136}$ Ebd., S. 3f.

137 Ebd., S. 24.

${ }^{238}$ Ebd., S. 4f. und S. 26. Die kommunikative Funktion des Klischees in einem fiktionalen Text als ..Reduktion der außeren Weltkomplexitat" sei mit der Funktion der Sinnsteuerung in der Systemtheorie Luhmanns zu vergleichen. Das Klıschee als „kognitive Strategie“ sel aber nicht mit den gesellschaflichen Systemen identisch, sondern ihnen homolog. Die ..Verankerung" dieser Systeme im Text qua Klischee werde in sozialen, sprachlichen und ästhetischen Kontexten gezeigt. Die Relation zwischen dem fiktionalen Text. als einem Wirklichkeitsmodell (Iser), und den .,textexternen Kontextstrukturen“, gesellschafilichen Normen. Ideologien (auch als Klıschees), werde als die Text-Kontext-Relation zwischen Modellen eines jeweiligen Wirklichkeitsverstándnisses aufgefaßt (S. 65ff.). Vgl. LuHMANN 1977 und LuHMANN : HABERMAS 1976. 
Für die vorliegende Studie ist besonders das Kapitel über die textimmanente Funktion des Klischees am Beispiel der Typisierung sozialer Gruppen (als Mittel zur Charakteristik der Figuren durch klischeehafte Ausdrucksweise) thematisch interessant, obwohl darin nationale Klischees bzw. Stereotypen nicht berücksichtigt werden. ${ }^{139}$

Kunow stellt in der Zusammenfassung fest, daß das Klischee in den untersuchten fiktionalen Texten der Postmoderne unter dem Aspekt seiner Negation auftritt, obwohl diese Negation nie vollständig sei, was als eine Bestătigung der Ergebnisse der Studie von Mitosek über die ..Destruktion“ der Stereotypen in einem parodistischen, die Postmoderne vorwegnehmeden Roman von St.l. Witkiewicz betrachtet werden kann. ${ }^{140}$

Trotz theoretischer Vorzüge und der Bemühungen um die terminologische Begriffsbestimmung des Klischees kann auch die Terminologie und Methode der Arbeit Kunows nicht als methodische Grundlage der vorliegenden Studie herangezogen werden. Der Oberbegriff der klischeehaften V'erfestigung ist zu umfassend und unscharf. Trotz der Berücksichtigung des außerliterarischen Kontexts eignet er sich nicht zur literaturwissenschaftlichen Interpretation des Phănomens der Fremdheit, denn er wird auf den sprachlich-stilistischen Bereich beschränkt, ohne auf seine kultursemantischen Aspekte einzugehen. ${ }^{141}$

Mythos läßt sich schließlich als der letzte Hauptbegriff bezeichnen, der parallel oder synonym zu solchen wie Bild (Image), Stereotyp oder Klischee in den bisher erwähnten Forschungen vorkommt. ${ }^{112}$

Als ein Beispiel aus der äußerst umfangreichen Mythosforschung wird hier die komparatistische Arbeit von ERAZM KUŻMA ${ }^{143}$ ausgewählt. Seine Studie ist

\footnotetext{
139 KUNOW 1981, S. 128-130.

140 Dadurch wird eine neue Sinnstiftung des Textes durch die Negierung des Klischees und ein kritischer Zugang zu den ..sozialen Sinnsystemen" möglich, z.B. in den Romanen Becketts. Kunow nennt es ein Verfahren des ,.kreuzweisen Durchstreichens“, das ursprünglich von Husserl und Heidegger herrühre und von Dernda übernommen worden sei, denn das Durchgestrichene bleibe noch lesbar, werde destruien, mache aber dennoch den Blick auf die Idee des Zeichens selbst frei (ebd. S. 184-187). Vgl. DERRIDA 1974, S. 31. Siehe auch PETERSEN 1994 zur ..Demaskierung“ der Klischees in der..Zwölfton-Operette“ The Finglısh (iat von Hans Werner Henze.

${ }^{241}$ Ähnlich wird das Klischee (poln. klıs=a, eng. stereotyped expression, cliché, franz. cliché. russ. klise, sitump) in SLOWNIK TERMINOW LITERACKICH als eine in der gegebenen Sprache allgemein gebrauchliche Äußerung (ein Idiom), die zur stereotypen Beschreibung einer Situation, eines Zustands oder einer Sache dient, z.B. im Polnischen: gloxlny juk wilk [hungrıg wie em Wolf ]. zlojic wizvte [eınen Besuch abstutten], definiert. In der poetischen Sprache treten Kleschees als Ausdruck des konventionalisierten Stils auf (S. 245). Die Verfasserin des Beitrags. TERES.A KOSTKIEWICZOWA, bezieht sich auf RIFfATERRF 1971. Vgl. auch BERTRAM : SPEARS 1993 und NUITEN / GEELEN 1989.

$142 \mathrm{Vgl}$. 2.B. STIBEN 1995. S. 52: .Fthnische Imagotype in der Literatur beruhen auch auf dichterischer Phantasie - man denke an das idealisierte Slawenbild Herders - oder greifen säkulare Mythen auf, die eine lange Tradition haben." Diese durchaus richtige Bemerkung Stübens ist jedoch im Hinblick auf Herders Auffassung von den ,slawischen Stämmen und Völkern“ nicht ganz zutreffend, denn dıeser begründet immerhin seine Ansichten, wenngleich seine Argumentation aus heutiger Sicht nicht ausreichend und überzeugend sein mag.
} 
aber nicht nur wegen ihrer semiotisch orientierten Methode ${ }^{144}$ interessant, sondern auch, weil der Verfasser den historiosophischen Mythos des Orients und des Westens in det polnischen, französisch-bzw. deutschsprachigen sowie in der russischen Literatur erörtert hat, unter Anderem in Dostoevskijs Werken. ${ }^{145}$

Im ersten Teil der Studie werden voluntaristische Geschichtskonzepte untersucht, die zur Entstehung und Verbreitung dieses "Doppeimythos" geführt haben, im zweiten Teil seine Pragmatik, Struktur und Funktion, an Beispielen aus literarischen Werken, in denen die Opposition zwischen „Orient und Westen“ artikuliert worden ist. ${ }^{146}$

Kuźma unterscheidet dabei drei „terminologische Mikrosysteme“ (mikrosystem terminologiczmy nach Sławiński) ${ }^{147}$ zur Eingrenzung des Mythosbegriffs: 1. Mythos als Strukturgesetz (Lévi-Strauss), 2. als Substanz (N. Frye oder C.G. Jung) und, 3. als Form sozialer Kommunikation ( $R$. Barthes ${ }^{148}$ bzw. B. Malinowski ${ }^{149}$ ), wobei er sich auf den dritten, funktional-pragmatischen Begriff konzentriert. $^{150}$

143 KUŻMA 1980. Vgl. auch. JOHNSTON 1990; JEISMANN 1992; GIESEN 1991; LINK/WÜLFING 1991 und KOOPMANN 1979. Siehe auch WINKLER 1995 und LUCHSINGER 1996.

1 14 KuŻMA 1980, S. Sff. Kużma richtet sich v.a. nach der semiotischen Methode der Untersuchung der ráumlichen Zeichensprache in der Auffassung Lotmans und nach der Pragmatik der Zeichenkommunikation nach Ch. Morris, ebd. S. 8 und 26ff. Vgl. LOTMAN 1972 und DERS. 1971.

${ }^{245}$ KUŻMA 1980, S. 9; dabei werden nicht nur fiktionale literarische Texte, sondern auch sogenannte Paraliteratur und Publizistik berücksichtigt.

${ }^{148}$ Ebd., S. 5.

147 Ebd., S. 11.

140 Ebd., S. 17f. Kużma kritisiert allerdings die Ansicht von Barthes, daß die avangardistische Literatur gegen den modernen Mythos ankămpfen soll. Die moderne, avantgardistische Poesie zerstơn nach Kużma lediglich den profanen Mythos, um an seiner Stelle den sakralen zu schaffen, ebd., S. 18f. Vgl. dazu BARTHES 1957: „Voici un autre langage qui résiste autant qu'il peut au mythe: notre langage poetique. La poésie contemporaine est un système sémiologique régressif" (S. 241f.) bzw. HüBNER 1985: S. 349-365 (Das Mythische in der Politik heute); S. 357- 362 (Kritik an R. Barthes).

149 Für Kużma liegt der Unterschied zwischen den archaischen und den zeitgenossichen Mythen darin, daB die letzteren rational seien und zu bestimmten Zwecken geschaffen und eingesetzt uüden (ebd., S. 17 und S. 21). Vgl. dazu MAL.NOWSKI 1958 und DERS. 1990.

${ }^{250}$ KUŻMA 1980, S. 11 ff. Die Aufteilung in eine formale (als Struktur), inhaltliche (als Substanz) und pragmatische (als Kommunikation) Auffassung des Mythos ist idealtypisch zu verstehen. Nach Kużma gibt es zwischen diesen drei ..Mikrosystemen“ Übergänge und Überschneidungen. Andererseits werden solche Begriffe wie Bild, Mtetapher, Symbol und Mtythos synonym verwendet (S. 12). Kużma nennt auch den Orientmythos einen soziopolitischen oder ideologischen Mythos, obwohl er auch zugibt, daB man diesen in inhaltlichen Kategorien untersuchen könnte, z.B. nach C.G. Jung als kosmogonischen und eschatologischen Mythos (S. 19ff.). Es sei ebenfalls moglich, diesen Mythos als eine Struktur aufzufassen. Die moglichen "orientalischen“ bzw. "westlichen“ mythischen Denkstrukturen ließen sich auch als fiktionale Konstrukte beschreiben, so z.B. die Opposition zwischen dem .dionysischen und appollinischen Element" in der Literatur, das europaisient in den Romanen von W. Berent oder orientalisiert in den Romanen von F.M. Dostoevskij auftrete. Zu den anderen Oppositionen gehören solche wie Asien vs. Europa. gelbe Rasse vs. weiße Rasse, Byzanz vs. Rom. Protestantismus vs. Katholizismus (S. 22ff.). 
Der funktional-pragmatische Begriff des Mythos impliziert Unterschiede in seiner formalen und inhaltlichen Auffassung bei der literarischen Untersuchung: die klassische Mythologie verlient ihre dominierende Rolle, zugleich werden die Bezüge zur fiktionalen Literatur geschwăcht, indem Ideologie und Propaganda an Bedeutung gewinnen. ${ }^{151}$

Im Hauptteil der Studie wird untersucht, wie die romantisch-nationalen Mythen in Polen, Deutschland, Frankreich oder Rußland entstanden sind und wie sie sich vom 19. Jahrhundert bis hin zur zweiten Hälfte des 20. Jahrhunderts gewandelt haben. Im Kontext dieser Studie sind besonders die Kapitel über den Mythos des Westens und des Orients in RuBland ${ }^{152}$ in seinen drei Varianten interessant. RuBland symbolisierte dabei: I. den Orient selbst als das Land der Antipoden zum "faulen Westens"; 2. Asien, wobei das Zentrum des mythischen Raumes hinter dem Ural lag: 3. Europa als ein „Bollwerk der westlichen Kultur" gegen die "gelbe Gefahr". ${ }^{153}$

Kużma erörtert im folgenden am Beispiel Danilevskijs die .,slavophile russische Ideologie", die sich zuerst auf die im Westen bekannte Losung ex Oriente lux berufen habe. ${ }^{154}$ Auch Dostoevskij habe diese Ideen von der Überlegenheit der slavisch-byzantinischen über der dekadenten westlichen Kultur in seine Publizistik aufgenommen. ${ }^{155}$ Rußland und Moskau, im Gegensatz zum westlichen Petersburg, symbolisierten fur Dostoevskij die mythische Mitte bzw. das geistige Zentrum der Welt. Rußland war aber dabei keine Inkamation des „Geistes von Asien“, wie es später in Deutschland interpretiert worden war. ${ }^{156}$

151 Ebd., S. 17. Kużma nennt zwei Arbeiten, die ebenfalls den Mythos in der pragmatischen ideologischen Funktion untersuchen: GOLLWTTZER 1962 und ZiEJKA 1977. Vgl. auch BOBROWNICKA 1992 und DIES. 1995; KABBANI 1986 oder MAGNUSZEWSKI 1990.

152 In diesem Land habe man sich entscheiden müssen, ob man zum „Westen,“ zu .Europa“, oder zum „Orient,“ zu "Asien“ gehört. Zum „Westen“ konnten dabei zugleich das katholische und antagonistische Polen. Frankreich und das verbündete protestantische Deutschland bzw. Preußen gehören: der „Orient“ bedeutete zugleich die ,gelbe Gefahr” und eine Hoffnung auf Vereinigung asiatischer Volker unter Leitung Rußlands gegen die westliche Welt (KUŻMA 1980, S. 157ff.).

153 Ebd., S. 158. Obwohl diese Ausführungen sehr undifferenziert sind, denn die Einheit .Rußland-Asien“ galt doch nur für die Eurasier-Bewegung.

is4 Danilevskij habe im protestantischen Deutschland, d.h. in Preußen, den natürlichen Verbündeten Rußlands im Kampf gegen den lateinischen und katholischen Westen erblickt, die polnısche katholisch-adlige Kultur hatte sich für ihn dagegen dem Westen und Rom verkauft. Vgl. DANILEVSKIJ 1991. KUŻMA scheint aber die sich voneinander unterscheidenden Ideologien der Slavophilen und Panslavisten identifizient zu haben. Vgl. z B. DIELS 1963 bzw den Exkurs über die russischen Slavophilen und Westler in: KLUGE 1992, S. 50-59.

155 Kuzma 1980, S. 158f: Dostoevskij hat in der Auffassung Kużmas die Abneigung Danilevskijs gegenüber romanischen und katholischen europäischen ländern, darunter gegenüber Polen, geteilt. In dem ..Tagebuch des Schriftstellers“”, besonders zwischen 1877-78, gab es starke germanophile Tendenzen, verbunden mit dem russischen Großmachtdenken, die erstaunlich an die Ansichten von Th. Mann aus den ..Betrachtungen eines Unpolitischen" gemahnen. Der russische Chauvinismus Dostoevskijs wurde in der späteren Puškin-Rede gemildert: Rußland soll in seiner "Allmenschlichkeit" die patriarchale Familie aller Völker anführen und ihnen als moralische Stütze dienen.

156 Ebd., S. 160ff. Kużma bespricht auch die Wandlungen des russischen Mythos von der .gelben Gefahr" aus Asien vom Ende des 19. bis in die 30er Jahre des 20. Jahrhunderts. In der 
Trotz der überzeugend eingesetzten semiotisch-strukturalen Methode ist der interpretatorische Teil der Arbeit zu deskriptiv, wăhrend seine deduktiv und verallgemeinernd formulierten Schlußfolgerungen kaum durch die ausführlichen Textinterpretationen erhărtet werden, so daß sie einer historiosophischen Spekulation ahneln. Dies wird besonders an den Interpretationen der Werke Dostoevskijs sichtbar, die nicht ausreichend durch einschlagige Texte belegt werden.

Eine terminologische Klarheit im Hinblick auf eine Begriffsbestimmung bzw. Abgrenzung des Mythosbegriffs von anderen synonym gebrauchten Begriffen bringt auch der theoretische Aufsatz von KuŹMA ${ }^{157}$ nicht, denn diese Bezeichnung wird sowohl in der wissenschaftlichen als auch in der Alltags- und Literatursprache verwendet. Daher sei eine historische Beschreibung leichter als eine allgemein verbindliche Definition. Der Mythos wăre demnach das, was in einer bestimmten Zeit dafür gehalten worden ist. Die Vieldeutigkeit dieses Begriffs laßt sich dadurch erklären, daß mit ihm verschiedene Erzăhlformen in Verbindung gebracht werden: 1. Volkserzahlformen über die Vergangenheit: (Volks)märchen [klechda, baśn'], Sage [podanie], Legende [legenda] oder Volksepos [epos ludowy]; 2. literarische Formen über die Zukunft: Offenbarung, Prophezeiung, Utopie; 3. Bezeichnungen fur sich wiederholende Themen und Bilder: Stereotyp. Topos oder Archetyp; 4. Bezeichnungen für das kollektive, soziale Bewußtsein und für psychotechnische Manipulationen des sozialen Bewußtseins: Religion, Idee, Ideologie, Propaganda oder Werbung. ${ }^{158}$

Wegen der interdisziplinär außerst verwickeiten Lage der Mythosforschung ist es an dieser Stelle nicht möglich, andere Definitionen dieses Begriff in einem knappen Exkurs miteinander zu vergleichen. ${ }^{159}$

Anhand dieser kurzen Übersicht zu den Forschungen von Kużma ist darüber hinaus deutlich geworden, daß auch der Begriff des Mythos nicht als Oberbegriff zur literaturwissenschaftlichen Erforschung des Phănomens der kulturellen Fremdheit geeignet ist.

Zusammenfassend läßt sich zu allen oben besprochenen Begriffsbestimmungen wie Bild, Image, Imagotyp, Stereotyp, Vorurteil, Klischee oder Mythos festhalten, daß sie synonym oder komplementär gebraucht sowie unreflektiert aus verschiedenen Wissenschaftsgebieten in die literaturwissenschaftliche Forschung übernommen werden. Keiner von ihnen könnte deswegen ohne Vorbe-

messianistischen Variante war Rußland Beschützer des Orients gegen die westliche Expansion, in der zweiten, ..panmongolischen" Variante seit VI. Solov 'ev bildete Asien eine Gefahr nicht nur für Rußland. sondern für die ganze Welt. Er referiert darüber hinaus den ..eurasianischen" Mythos bei N. Berdjaev und die widersprüchliche Suche nach neuen russischen Mythen bei den russischen Dichter des Symbolismus (V. Brjussov, A. Blok bzu: A. Belyj). ihre weitere Entwicklung bei den Akmeisten. Futuristen und später bei Lenin und Lunacarskij.

157 KuŻma 1992. vgl. auch Segal 1996a-c, Geyer 1996, Graevenitz 1987 oder Jamme 1991

158 KuŻMA 1992, S. 636 und S. 638.

159 $\mathrm{Vgl}$ auch die psychokritische Methode der Analyse des literarischen persionlichen Mythos: MAURON 1962. Siehe auch GüNTHER 1993; DERS. 1994 oder ÉTEMBI.F. 1954-1961 
halte, als terminologische Grundlage in der vorliegenden Studie eingeführ werden.

Neben der Fremdbild-, Stereotypen- oder Mythosforschung gibt es aber auch weitere der Imagologie verwandte Ansätze. Dazu gehơren die Alteritäts-, Mentalitätsforschung und die interkulturelle Germanistik bzw. Xenologie, die, ohne bestimmte Terminologien und Methoden entwickelt zu haben, sich mit dem weit verstandenen Phänomen der kulturellen "Fremdheit" ("Alterităt") beschäftigen. ${ }^{160}$

RAYMOND CORBEY und JOEP LEERSSEN definieren die Alterität (Otherness) als ,a fundamental category of experience and reflection $/ . . /$, as an important perspective in the study of human thought, intercourse and culture". ${ }^{161}$ Alterität kann aus dem anthropologischen, philosophischen, psychologischen, sozialen, feministischen sowie nicht zuletzt literaturwissenschaftlichen Blickwinkel betrachtet werden, wobei nicht ihre neutral kognitiven, sondern ideologischen und ethischen Aspekte untersucht werden, denn ..human dignity is distributed unequally between an elite and its Others. "162

LEERSSENS ${ }^{163}$ theoretische Ausführungen zu den .,image studies" können als eine Reflexion über die Imagologie betrachtet werden, die ein postmodernes "Vokabular" benutzt. Er definiert die Imagologie (image studies) als "the study of national and ethnic stereotype and of the literary representation of intercultural confrontation“. ${ }^{164}$ Der "imagologische Metadiskurs" betrachte die images als intellektuelle Produkte bzw. textuelle Konstrukte über das Fremde und Eigene. Die Aufgabe der Imagologie sieht Leerssen in dem Versuch, die den literarischen Typologien der verschiedenen nationalen Figuren zugrundeliegenden Strukturen der nationalen ,imageries" zu verstehen und ihren konventionellen, nicht empirisch referentiellen Charakter zu zeigen. ${ }^{165}$ Sein Beitrag gehört somit

160 Vgl. den oben besprochenen Aufsatz von LeERSSEN 1991a. Vgl. ferner auch den Sammelband: W'EmanN 1997; siehe darin z.B. die Einführung in die Problematik der Alterităt von ROBERT WEIMANN: Einleitıng: Repräsentatıon und Alteritüt diessetts jensetts der Moderne (S. 7-43).

162 CORBEyíLEersSEN 1991, S. IXff. und S. VI- XVIII (Siudying Alterily: Backgrounds and Perspectives).

${ }_{262}$ Die philosophische Reflexion über das Fremde bzw. Andere entstammt dem nachhegelianischen bzw. nachnietzscheanischem Denken (Foucault, Kojève, Bataille, Sartre. Girard, Lyotard. Derrida oder Lèvinas), das sich gegen die of gewaltsame Vereinnahmung des Fremden (Anderen) durch das erkennende Subjekt in der dialektischen Vermittlung und Aufhebung richtet, um die elgene Identität zu stărken (ebd. S. VIllff.). Siehe auch das Literaturverzeichnis und z.B. DerRIDA 1967a-b, RICGEl:R 1989b, KRISTEVA 1990, TODOROV 1982, DERS. 1989, GREVERUS 1995

163 LEERSSEN $1991 \mathrm{a}$

164 Ebd. S. 126ff. Leerssen bemerkt zwei Tendenzen in der Entwicklung der imagologischen Theorie: $1 . . \ldots$ the shift from a traditional notion of existence towards one of perception" und $2 . . . . /$ the differentiation of what traditionally counted as a single unit called identity' into a binary polarity between identity and alterity".

${ }_{165}$ Ebd., S. $128 \mathrm{ff}$. Leerssen betont auch, daß die imagologische Forschung radikal die Möglichkeit der Lektüre einschlägiger literarischer Texte als referentıell bzw. nichtfiktiv ausschließt und somit dem "l n'y a pas de hors-lexle (Derrida) folgt (ebd., S. 130). 
zu den theoretischen und deskriptiv-typologischen Ansätzen, deren Terminologien jedoch zu vereinfacht erscheinen. Darüber hinaus geht er nicht darauf ein, wie sich das Fremde und das Eigene (auch als nationales oder ethnisches Stereotyp) in einem konkreten literarischen Text artikulieren und wie es in der Pra$x$ is interpretient werden sollte. ${ }^{166}$

Die Imagologie wird aber auch als ein Mittel der „interkulturellen Mediation“ zwischen Komparatistik und interkultureller Germanistik bzw. Xenologie ${ }^{167}$ bei der Entwicklung einer interdisziplinären Fremdheitsforschung verstanden. THOMAS BLEICHER nennt diese Forschung eine der vielfaltigen Formen der interkulturellen Vermittlung zwischen den je „eigenen“ und "fremden“ Literaturen, zu deren Bereichen „Übersetzungsanalyse, Imagologie, internationaler Vergleich von Gattungen, Themen und die Untersuchung von übergreifenden Literaturkomplexen und ihren Interferenzen /.../gehören. Sie sollen in einen frucht-

${ }^{166}$ Methodische Defizite weisen auch dekonstruktivistische bzw. feministische Aufsätze von SCHROVER 1991 und SPORK 1993 auf. SCHROVER versucht in der Interpretation von Michel Tourniers Romans Vendredı ou les lımbes du Pacıfique zu beweisen, daß trotz der Kritik an der westlichen Zivilisation die Opposition zwischen der westlichen Identät Robinsons und der Alterität Vendredis nicht überwunden wird (S. 210). SPORKs Ausführungen sind dagegen in polemisch-publizistischer Absicht ideologisiert worden. So werde beispielsweise in Grillparzers Stück Dıe Jüdın von Toledo (1824-1855; verơff. posthum 1872) Rahel durch ihren Körper definiert, sie ist verkörperte Unvernunf und Sinnlichkeit, ..eine Leerstelle im christlichen Symbolischen" (S. 221). Diese Figur hat aber eine symbolische Funktion und stellt dem starren Prinzip von Ordnung und Gesetz emotionale Menschlichkeit entgegen, wozu auch Sinnlichkeit gehorrt. Die Verfasserin hat zugunsten ihrer ideologisierten Sichtweise nur solche Autoren wie Grillparzer, Karl Emil Franzos und Leo Perutz ausgewăhlt, ohne Gegenbeispiele zur Kenntnis nehmen zu wollen, wie z.B. Thomas Manns Novelle Wölsungenhlut (entst. 1905; ersch. 1921), die nur im jüdischen ..Milieu" spielt (vgl. das jüdische Geschwisterpaar Siegmund und Sieglınde) und der Roman Lin Kumpf um Rom (1876) von Felix Dahn, in dem die Jüdin Miriam positiv gezeichnet wird. Aus den slavischen Literaturen wären die Erzahlung von Anton P. Cechov Times $[/ \mathrm{m}$. Sump $(1886)$ bzw. die alttestamentarischen Gestalten wie Esther und Judith bei MARKo MARULic (1450-1524) aus seinem Drama ./udtua [.Judith] (um 1501: gedr. in Venedig 1521) zu nennen. Siehe auch: SPORK 1996. Vgl. dazu GRILlPAR7.ER 1987 bzw. Marulic 1970. Siehe ferner: Karpf 1995, SAID 1995, DERS. 1993. BHIABHA 1991

${ }^{267} \mathrm{Vgl}$. zur Interkulturellen Germanistik und Xenologie, ihrer Terminologie und Methoden WIERLACHER 1985 (MIt fremden Augen oder: liremdhett als fierment Öherlegungen zur Begründung einer interkulturellen Hermeneuilk deutscher I.tlerulur. S. 3-28), DERS. 1987. DERS./KRUSCHF 1990, DERS. 1993. Wierlacher geht es um die ..Grundlegung einer aus der Hermeneutik weiterzuentwickelnden Fremdheitsforschung ('Xenologie') /.../. Es wird nicht an ein eigenes Fach dieses Namens gedacht. sondern an eine Schnittfläche veschiedener Disziplinen. Fernziel ist, auf dem Weg über die interdisziplinäre Vertiefung unseres allgemeinen Fremdheitswissens vor allem die Handlungskompetenzen der Menschen in jenen Arbeitsbereichen zu verbessern, die tagtaglich mit Fremdheitsproblemen konfrontien sind" ( $S$. 10ff.). $\mathrm{Vgl}$. auch seine Definition des ..Fremden”....Das 'Fremde' ist .... grundsätzlich als das aufgefaßte Andere, als Interpretament der Andersheit und Differenz zu definieren“". die Begriffe des Eigenen, Anderen und Fremden werden im übergeordneten Konzept der kulturellen Alterität zueinander in Beziehung gesetzt, weil das Fremde und das Fremdverstehen ..zureichend kaum nach dem Modell von ego und alter ego, also unter Zugrundelegung nur einer Systemreferenz. erklăr werden kann“"(WIERLACHER 1993, S. 62ff.). Siehe auch TURK 1990. 
baren Zusammenhang mit den komponenten 'Xenologie' und 'Kulturkomparatistik' der Interkulturellen Germanistik gebracht werden konnen. “168 Die Kategorie der Fremdheit verbindet somit Komparatistik und Interkulturelle Germanistik, der Unterschied zwischen den beiden Disziplinen erblickt Bleicher darin, daß Fremdheit in der Komparatistik "theoretisch ein nahezu absolutes Phănomen" sei, in der interkulturellen Germanistik erhalte sie dagegen methodologisch eine kulturrelative Funktion zur deutschsprachigen Kultur. ${ }^{169}$

Der deduktive theoretische Ansatz Bleichers kann die terminologischen und methodischen Fragen genauso wenig wie die Alteritătsforschung lösen, denn er erschopft sich in der Formulierung von einigen allgemein formulierten theoretischen Postulaten. Die interkulturelle Germanistik bzw. die Xenologie beschränken sich darüber hinaus auf die Erforschung der Fremdheit in deutscher bzw. in deutschsprachigen Literaturen und Kulturen, so daß sie sich weder im Hinblick auf die theoretischen Grundlagen ${ }^{270}$ noch auf die Praxis dazu eignen, übernommen zu werden.

Auch die interdisziplinäre Umwandlung bzw. Ausweitung der Komparatistik und der Imagologie zu einer Mentalitätsforschung schlechthin ${ }^{271}$ eignet sich nicht dazu, um in der folgenden Studie eingesetzt zu werden. Ihre Terminologie und Methode als Teildisziplin einer umfassenden Mentalitätsgeschichte ${ }^{172}$ bzw. Kulturtheorie berücksichtigt kaum die Spezifik literarischer Texte. ${ }^{173}$ Es ist aber

160 BLEICHER 1993: „Andere Lander, neuartige Ereignisse, fremde Menschen: dies deutet schon an, zu welchen Zielen Komparatistik aufbrechen will, kennzeichnet aber auch, an welchem Ort dieses Wagnis des Aufbruchs beginnen muß - im eigenen Land, im vertrauten Erfahrungsbereich, mit bekannten Menschen, also im Umfeld einer allmáhlich gewonnenen Selbstverstăndlichkeit, die das Gefühl von (angstfreier) Sicherheit vermittelt“" (S. 333). Vgl. auch ebd., S. 336 und S. $353 f$.

169 Ebd., S. 348. Vgl. zur Kritik an diesem Ansatz: KonStANTINOVIC 1991, DERS: 1992a und bei SYNDRAM 1991: „Cognizance of imagological theory and piactice might also benefit those 'intercultural germanists' who, from a narrowly German basis, are now shedding their light on the topic of cross-cultural confrontation and experiences of foreigness" (S. 185), oder bei WERTHEIMER 1993, bes. S. 81f., Anm. 1.

170 Es sollten erforscht werden: 1. die Bilder von Deutschland und den Deutschen in den fremdsprachigen Literaturen; 2. die Bilder vom Ausland und den Ausländern in der deutschsprachigen Literatur und 3. die vergleichbaren Beziehungen zwischen den jeweiligen Fremdund Selbstbildern, sowie das .,Problemfeld Imagologie“ getrennt von dem der ,inhaltlichen Textkomponenten" wie "Themen", .Stoffe", "Motive“, "Symbole" und "Mythen". Dabei wird bemerkt, daß die methodoiogischen Probleme der Imagologie noch immer ungelost bleiben, da solche Fragen wie: „Warum ist dieser Stoff so typisch deutsch und jener so ganz undeutsch?" oder "Ist dieser Mythos nun national, europaisch oder gar universal?" noch immer zu beantworten seien. Bleicher geht jedoch auf diese Begriffsbestimmungen nicht năher ein (BLEICHER 1993, S. 339 und S. 351f.).

171 Vgl. Z.B. DUTU: 1980

172 Vgl. Z.B. DinzelbaCher 1993, VeSter 1996 odet KORTUM 1996.

$173 \mathrm{Vgl}$. z.B. Dinzelbachers Definition der Mentalitätsgeschichte, die sich ,,auf die bewußten und besonders unbewußten Leitlinien, nach denen Menschen in epochentypischer Weise Vorstellungen entwickeln, nach denen sie empfinden, nach denen sie handeln" richte. „Historische Mentalitat", die sich als ,historische Kategorie“ besser beschreiben als definieren lasse. 
denkbar, daß die Ergebnisse einer literaturwissenschaftlich-imagologischen Studie als Grundlage eines diachronisch-deskriptiven mentalitätsgeschichtlichen Beitrags benutzt werden kőnnten.

In den letzten zwei Jahrzehnten läßt sich aber zugleich, hauptsächlich in Frankreich, eine vielversprechende weitere Entwicklung imagologischer Theorie beobachten. Zum SchluB dieses Kapitels werden daher zwei Ansătze aus der neueren franzosischen imagologischen Schule besprochen. Als besonders relevant und inspirierend hat sich dabei sowohl fur die theoretischen Voraussetzungen als auch fur die interpretatorische Praxis dieser Studie das Konzept von JEAN-MARC MOURA ${ }^{174}$ erwiesen. Zuvor wird jedoch wegen seiner klaren terminologischen und textnahen methodischen Grundlagen der Ansatz von Mouras Lehrer DANIEL-HENRI PAgEAUX erörtert. ${ }^{175}$

Die Terminologie von Pageaux enthält neben bereits bekannten Begriffen wie Image, Stereotyp und Mythos zusäzlich den Oberbegriff des imaginaire culturelle (des kulturellen Imaginären), das sich aus allen oben genannten Elementen zusammensetzen kann: „L'imaginaire que nous étudions est le théâtre, le lieu où s'expriment, de manière imagée (assumons le jeu de mots), c'est-à-dire à l'aide d'images, de reprêsentations, les façons (la littérature, entre autre) dont une société se voit, se défínit, se rêve." 276

Die Bestandteile des imaginaire culturelle werden dabei als Elemente kultureller Diskurse über das Fremde bzw. Andere und das Eigene betrachtet.

Pageaux definiert „arbeitshypothetisch" das literarische Bild (Image) als ein Ensemble der „Ideen über das Fremde bzw. das Andere“ (l'étranger / l'autre),

sei das .Ensemble der Weisen und Inhalte des Denkens und Empfindens, das für ein bestimmtes Kollektiv in einer bestimmten Zeit prägend ist. Mentalităt manifestiert sich in Handlungen" (DINZELBACHER 1993, S. IX). Vgl. auch ebd., S. XXI (DERS.: Zu Theorie und Pruxis der Mentalitätsgeschichte), sowie den Aufsatz von DAGMAR STUTZINGER, HARRY KÜHNEL und ALBRECHT CLASSEN über Das liremde und litgene in der europaischen Antike, im Mittelalter und in der Neuzeit (ebd. S. 400- 450).

176 Vgl. MOURA 1992a und DERS. 1992b.

${ }^{175}$ Die Arbeiten von MOURA sind als Erweiterung und Weiterentwicklung des Konzeptes von Pageaux zu bezeichnen. Vgl. PAGeaux 1982, Ders. 1984, Ders. 1986, Ders. 1988, Ders. 1992, sowie DERS. 1971. Auch für CHEVREL, einen Schüler von Marius-François Guyard (vgl. CHEVREL 1989), ist die Komparatistik als eine umfassende Kulturwissenschaft zu verstehen, wobei die Erforschung der literarischen Texte nur ein Teilgebiet der weitraumigen Betrachtung der verschiedenen kulturellen Phănomene in ihrem Zusammenhang bildet (S. 25f.). Die Ansichten von PICHOIS und ROUSSEAUS 1967 unterscheiden sich dagegen kaum von den oben besprochenen, z.B. von Dyserinck. Siehe auch: BRUNEL/PiChois/RousSEAU, 1983, S. 64-67

176 PAGEAUX 1989, S. 135f. Dieser Begriff hebt die wichtige Funktion der Vorstellungskraft (Imaginatıon) bei der Schaffung von kulturell vermittelten Images, Stereotypen und Mythen hervor. Vgl. dagegen die teilweise berechtigte Kritık an Pageaux bei FisciuER 1987, S. 68ff. Nach Fischer mochte Pageaux so komplex wie moglich vorgehen, um das kulturelle ımage an sich, seinen Diskurs, seine Mechanismen, Voraussetzungen usw. zu erforschen. die Literatur aber bleibe dabei nur als Teilstrukur eines großeren Systems der Kultur zurück. Sie diene als Veranschaulichungsmaterial zur Konstruktion der immer abstrakteren und komplexeren Strukturen. Dabei liege die Gefahr der Moglichkeit willkürlicher Schlußfolgerungen nahe (ebd., S. 69). 
als „un mot passe-partout, un objet flou“, das im Prozeß der Literarisierung und Sozialisienung aus einer ,prise de conscience, d'un Je par rapport à l'Autre, d'un Ici par rapport à un Ailleurs" ensteht. Er betont ebenfalls wie die bisher besprocbenen Forscher den Doppelcharakter eines Image, in dem die Opposition zwischen Identităt und Alterităt als "Sprache über den Anderen“ (,langage sur l'Autre") (Emile Benveniste) zum Ausdruck kommt. Images verweisen auf eine konstruierte, sekundäre "Wirklichkeit“, die sie bedeuten und bezeichnen. Sie sind somit nicht eine "falsche oder richtige Widerspiegelung der Wirklichkeit", d.h. keine icône im Sinne von Peirce, sondem im ideologischen Modell der betrachtenden Kultur verwurzelt. Ein Image weist als ein interkulturelles Zeichen die Funktion einer „Idee“ (Symbols) oder eines Stereotyps auf. ${ }^{177}$

Pageaux widmet viel Aufmerksamkeit dem Begriff des Stereotyps, das er für die elementare Form des Image hält. ${ }^{178}$ Obwohl er wie die meisten bereits besprochenen Forscher die nationalen oder ethnischen Stereotypen als Ideologie betrachtet, erblickt er in ihnen, im Unterschied zur kognitiven soziopsychologischen Stereotypenforschung, emblematisch erstarte Diskurselemente einer bestimmten Kultur. Stereotyp ist als ein Träger einer Definition des Fremden oder Anderen, Ausdruck des kollektiven Wissens in jedem historischen Moment gültig, es stellt eine konstante Hierarchie und Dichotomie der Kulturen dar, eine Verbindung zwischen moralischen oder sozialen Normen. ${ }^{179}$

Pageaux unterscheidet drei konstitutive Elemente des Image: das Wort (le mot), die hierarchische Beziehung (la relation hiérarchisée) und das Szenarium (le scénario). In jedem dieser Elemente năhert sich das Image seiner Struktur nach dem Mythos, weil es einen symbolischen Diskurs darstellt. ${ }^{180}$

\footnotetext{
177 PAGEALX 1989, S. 135ff.

170 Ebd., S. I 39 ff.
}

179 Die morphopoetische Făhigkeit einer Kultur, Images zu pruduzieren, wird zu einer einzigen Botschaft reduziert: Die minimale Information wird in einem Stereoryp für die maximale Kommunikation benutzt. Es etablient und unterstützt den möglichst breiten öffentlichen Konsensus, indem es das Attribut zum Rang des Wesentlichen erhebt, es ist nicht polysemisch, dafür aber polykontextuell, immer zum Gebrauch bereit. In einem Text treten Sterentypen in der Funktion des Epithetons, des Attributs auf, das zum Wesen erklărt wird (z. B. die Nase der Juden, das Lächeln und die weißen Zähne der Neger) [Auch die „Nase der Polen“ gehört zu solchen . Stereotypen (Anm. d. Verf.)]. Das physische Attribut vermischt sich dabei mit der normativen Ordnung. Die Zeit des Stereoryps ist ebenfalls erstam, nur auf die Gegenwart bezogen. Dadurch lasse sich die Standardisierung und die Vermehrung (prolifération) der Stereotypen in jeder kulturellen seriellen Produktion erklăren, z.B. in der Trivialliteratur des XIX. Jahrhundert oder in den Feuilletons (ebd. S. 139ff.).

100 Von den Worten (auch als Slereotypen) über ihre hierarchischen Relationen bzw. Sequenzen (récıls) gelangt man zu den narrativen SEenuric'n (scénurios), die auch als Mythe'n zu bezeichnen sind. Als Beispiel eines Szenurıums werden französische literarische Spanien-Beschreibungen genannt, die aus stereorypen Elementen wie ..elendes Wirtshaus, schlechte Küche, Banditen auf den Wegen" bestehen. Aus solchen Elementen kann ein Mythos des spanischen Raumes in der französischen Kultur entstehen. Es gibt aber auch mythische spanische Figuren wie die femme fatule (vgl. ( armen von P. Mérimé) oder der ,edle Irre, Don Quichotte als Kämpfer gegen die Windmühlen“. Für Pageaux gibt es keinen Mythos ohne Sequenz. der erzählten Geschichte, die aus drei Elementen besteht: aus der Geschichte, dem $W^{\prime}$ issen und der Autorität einer Gruppe; sie konstituieren die ethnische Geschichte der Gruppe, die den Mythos erzảhlt. Das Image lāßt sich manchmal ebenfalls als eine kollektive 
Methodisch gesehen sollen die Images als ein Teil des kulturellen Imaginären nach den komplementären Methoden der strukturalen Anthropologie, der Semiologie und der Nouvelle Histoire untersucht werden, ohne jedoch ihren literarischen Charakter zu ignorieren: ${ }^{181}$

1. Auf der Ebene des Wortes werden anhand der Wortfelder einer Epoche oder einer Kultur affektive bzw. begriffliche verbale Konstellationen ermittelt, die sowohl dem Publikum als auch dem Schriftsteller gelăufig sind. Die Imagologie ist in diesem Stadium eine Hilfswissenschaft der Ideengeschichte. Die entsprechende Methode wăre die strukturale Ana!yse (Michel Foucault); 2. danach werden narrative Sequenzen in Texten, die hierarchischen, syntagmatischen Relationen in der Lexik (Claude Lévi-Strauss) erforscht, und 3. wird anhand der semiologischen Analyse der Images (Roland Barthes) und der Methode der Nouvelle Histoire (u.a. Michelle Vovelle und Georges Duby) nicht nur ihre textuelle, sondern auch soziale und kulturelle Bedeutung, der breite kulturelle Kontext im historischen Prozeß, untersucht. ${ }^{182}$ Die interdisziplinăre Erweiterung der methodischen Fragestellung ist notwendig, um sich von der zu reduktionistischen Analyse der Texte zu befreien, weil die Images in engen Beziehungen zum historischen, sozialen und kulturellen Kontext stehen.

Der theoretische Ansatz von Pageaux ist sowohl in seiner Terminologie als auch in der Methode grundsätzlich einleuchtend und zeichnet sich durch seine Textnăhe aus. Zu seinen Măngeln gehoren aber: 1. die Übernahme diffuser Begriffe wie Bild (Image), Stereotyp und Mythos, deren Relationen zueinander sowie zum imaginaire culturelle nicht genügend differenziert dargestellt werden; 2. in der vorgeschlagenen strukturell-semiologischen bzw. deskriptivhistorischen Methode der Interpretation wird zu wenig Aufmerksamkeit dem semantisch-funktionalen Aspekt der drei hierarchischen Ebenen des Imaginären in literarischen Texten geschenkt. Der historische bzw. der kulturell-semantische Kontext wird darüber hinaus im letzten methodischen Schritt untersucht, als ob die Images nur um ihrer selbst willen beschrieben werden sollen. Die theoretischen Ausführungen von Pageaux bleiben darüber hinaus abstrakte Postulate,

oder individuelle Träumereı über den Fremden bzw. Anderen bezeichen. Sie wird zur Autodefinition, zur Rechtfertigung der mirages und der fantusmes einer Gesellschafi oder einer Gruppe. Für Pageaux gibt es insgesamt einige Grundtypen der Haltungen gegenüber einer fremden Kultur: 1) die Manien: Russomanie, Anglomanie - die fremde Kultur wird als der eigenen überlegen angesehen; die ..brutale Akkulturaltion der fremden Kultur'; 2) die I'hobie: die fremde Kultur ist unterlegen, z.B. die Germanophobie in Frankreich (un mirage latın vs. barbarie germanique); der „symbolische Tod der fremden Kultur“; 3) die Philie: die fremde Kultur wird als gleich positiv verstanden; der ..einzige Fall gegenseitiger Anerkennung. des echten Austausches der Kulturen"; 4) V'ereinigung (unificurion): Panlatinismus, Pangermanismus, Panslavismus, auch als Kosmopolitismus oder Intermationalismus anzutreffen; sie bedeutet eine Vielfalt von Beziehungen, aber nur zwischen den kulturellen ..Schwestemgruppen", in einem geordneten Ensemble. Dabei gibt es komplementäre Paare: Panlatinismus vs. Pangermanismus, Pangermanismus vs. Slavophobie, oder Antisemitısmus (ebd. S. 150ff.).

101 Ebd., S. $135 f$.

102 Ebd., S. 148-151. 
solange sie, wie in den meisten bereits dargestellten Forschungen, nicht in konkreten Interpretationen verwirklicht worden sind.

JEAN-MARC MOURA bewertet aber die Terminologie und Methode seines Lehrers als prázis und innovatorisch. Dessen theoretischer Ansatz erfülle die Postulate der imagologischen Forschung, weil er die Ausarbeitung des ImageKonzeptes auf drei Ebenen vorgeschlagen habe: 1. als Image an sich, 2. seine Beziehung zum imaginaire social und 3 . in der Methode seiner Textanalyse. In methodischer Hinsicht habe Pageaux das Image wie die bisherigen imagologischen Studien in seinen drei thematischen Aspekten untersucht: 1. als Image des Ausländers (Fremden / Anderen), 2. als Produkt einer Nation (einer Kultur oder Gesellschafi) und 3. als Image, das von einem bestimmten Autor geschaffen worden ist. Der erste und dritte Aspekt bergen jedoch in sich Gefahren, daß man das Image entweder für ein Abbild der Wirklichkeit oder für eine literarische Hypostase hält, die keinen Zusammenhang mit sozialem Kontext hat. Moura sieht darüber hinaus eine weitere methodische Gefahr in einer ,interdisciplinarité sauvage et nationalisme voire psychologie des peuples non avoués“. ${ }^{183}$

Um diesen möglichen methodischen Mängeln vorzubeugen, schlägt er daher eine Methode vor, die den Ansätzen aus der Hermeneutik PAUL. RICCEURS, besonders dessen Reflexion über das Image und die Phantasie (imagination), verpflichtet ist. $^{184}$

Ricœurs Theorie der reproduktiven und produktiven Imagination (l'imagination reproductrice et productrice), seine Begriffsbestimmungen des image und des imaginaire social sind Mouras philosophische Grundlagen, die bei der imagologischen Interpretation angewendet werden soliten. Das sozial bzw. kulturell vermittelte literarische Image des Fremden wird dabei nicht als Widerspiegelung oder als entstellte Übertragung des Wirklichen in den Kategorien der traditionellen Erkenntnistheorie aufgefaßt. Zugleich muß es aber interdisziplinär untersucht werden, um Beziehungen zwischen der Literatur und dem Bereich des sozialen Imaginären erforschen zu können, das nach Ricours Unterscheidung in literarischen Texten in scinen beiden Ausdrucksformen als Ideologie bzw. Utopie vorkommt. ${ }^{185}$

$103 \mathrm{Vgl}$. MOURA 1992a. S. 271ff: Diese Gefahren entstehen, weil die Imuges des Fremden (Anderen bzw. des Ausländers) zu den ältesten Faktoren zählen, die kulturelle und nationale Grenzen einer Gesellschaft markieren, und weil nur ein Teil der Imugess aus dem Komplex des ımagınuıre' soc'ıal dem literarischen Bereich angehört. Der interdisziplinäre Ansatz stellt somit die Imagologie vor dic Aufgabe, die Beziehungen zwischen der Literatur und dem Bereich des Imaginären sowie ihren eigenen Platz innerhalb der .. Iittcrature générale et comparce“ bzw. der literaturwissenschaft und der Sozialwissenschaften zu bestimmen. Der sozial bzw. kulturell vermittelte Charakter der Images hat in der Vergangenheit oft zu ihrer einseitigen soziologischen bzw. positivistischen Deutung in der franzosischen Komparatistik geführt, die dem Spruch de Bonalds: ..la littérature est l'expression de la societé" (A fercure de lirunce. 1802) folgte. Als ein Beispiel einer zeitgemäßen imagologischen Methode nennt Moura die Begegnung zwischen Semiologie und Rezeptionsästhetik (ebd.).

${ }^{204}$ Ebd. S. $276 f$.

285 Besonders wichtig ist die Betonung des nicht-anulogen Charakters des Imuge: „[/muge] est pertinente par référance à une idée ou un système de valeur préexistant à la représentation", außerdem läßt ein /muge' sich nicht mit dem . . .../ vocabulaire tiré de l'optique (perception, regard, prisme, vision)" beschreiben, es ist keine Widerspiegelung oder keine entstellte 
Die Image-Interpretation soll deswegen in zwei Phasen erfolgen: zuerst soll der kulturelle Kontext, dem das Image entstammt, und danach sein Vorkommen in literarischen Texten untersucht werden. Dabei sollen beide Aspekte des Image betrachtet werden, sowohl der reproduktive, stereotype als auch der kreative, denn es kann zum einen als Wiedergabe des kollektiven Stereotyps betrachtet werden, zum anderen als eine neue Schðpfung, Innovation der produktiven Einbildungskraft in den Texten eines bestimmten Autors, und sich von den sozialen bzw. kollektiven Images distanzieren. Eine imagologische Interpretation setzt also die Miteinbeziehung des imaginaire social voraus, die auf mehreren Ebenen erfolgen kann: Images in der offentlichen Meinung, im intellektuellen Leben einer Gesellschaft oder als symbolische Darstellungen. ${ }^{186}$

Die Beziehungen zwischen einem literarischen Werk (einem Schriftsteller) und den kollektiven Images sind jedoch komplizierter als die zwischen den Images und der offentlichen Meinung bzw. dem intellektuellen Leben. Ein Autor kann z.B. einen Mythos über das Fremde der öffentlichen Meinung aufzwingen, er kann aber auch einen schon vorhandenen Mythos aufgreifen bzw. sich ganz und gar von den kollektiven Images distanzieren und eine eigene, individuelle $V$ ision der fremden Welt vorschlagen. ${ }^{187}$

Ausgehend von Ricceurs Theorie des imaginaire social wird im folgenden die Typologie der literarischen Images des Fremden entworfen. die sich durch die Spannung zwischen Ideologie und Utopie auszeichnen und entweder eine ideologisch-integrative oder utopisch-subversive Funktion aufweisen kann. ${ }^{188} \mathrm{Nach}$

Übertragung des Wirklichen. Imuges können nicht als Repräsentation [représentation] des dem einschlăgigen Text prăexistenten Fremden (Anderen bzw. Ausländers) aufgefaßt werden oder als eine Doppelung oder ein Reflex der fremden Wirklichkeit [un double de la réalité étrangère] in den Kategorien der traditionellen Erkenntnistheorie. Die Images sollten als selbstreferentielle literarische Schopfungen untersucht weden, zB. im Unterschied zur Ethnopsychologie, die die fremde Realită zu reproduzieren. wiederzugeben versucht. Sie sind keine direkte Erfassung der fremden Realität durch einen Schriftsteller oder einen Rezipienten, sondern werden vermittelt durch die Gruppe oder die Gesellschaft, denen sie angehören. Moura hebt die Originalităt des von Cadot untersuchten Rußlandbildes de Custines hervur, das einen scharfen Kontrast zu den in dieser Zeit üblichen Rußlandsdarstellungen bildet (S. 275f. und S. 279). Vgl. CADOt 1967. Siehe auch den Exkurs zu PAUL RICCEUR, unten, S. 72fr.

${ }^{186}$ Ebd., S.280f; vgl. dort auch die von Moura angegebenen Beispiele der imagologischen Forschungen zu den oben erwahnten Bereichen

${ }^{297}$ Ebd., S. 281. Als Beispiele für die drei oben erwăhnten Möglichkeiten nennt Moura erstens den „russischen Mythos“ (le mythe de Pierre le (irand. la légende de ("atherine oder le mirage russe), der von den französischen Philosophen des XVIII. Jahrhunderts geschaffen wurde (vgl. LORTHOLARY 1951); zweitens die Übernahme des Imuge Mythos von Afrika als geheimnisvollem und fruchtbarem Erdteil und seine Umfunktionierung in den Mythos des faszinierenden, freien und ursprünglichen Kontinents, der von den schwarzen amerikanıschen Schriftstellem aufgegriffen worden ist; die dritte Moglichkeit stellt Asien von Marguerite Duras dar

${ }^{218}$ Nach RICOEUR 1969 und DERS. 1986a. Siehe dort die von Ricoeur eingefürten Defmitionen der Ideologie und der Utopie, die Moura übernimmt, Indem er die Ideologie als eine für eine bestimmte Gruppe unumgangliche Notwendigkeit versteht, sich von sich selbst ein Bild zu machen, $d . h$., sich im theatralischen Sinne zu reprasentieren, darzustellen. um eigene identităt zu starken; die Utopie dagegen als eine Funktion der sozialen Subversion (MOliRA 1992a, 
Moura entspricht diese Unterscheidung der dialektischen Opposition und Spannung in der Bedeutung der lateinischen Pronomina alter vs. alius. ${ }^{189}$

Dank der Untersuchung der ideologischen bzw. utopischen Images (auch als alterlalius) in ihrer Beziehung zum imaginaire social und in ihrer textimmanenten Funktionalităt wird es möglich, die literarische produktive Phantasie (l'imagination productrice im Sinne von Sartre) in ihrer Beziehung zu der reproduktiven Phantasie (l'imagination reproductrice im Sinne von Hume) zu untersuchen; dadurch kann die Imagologie sowohl den Aporien der philosophischen Theorien über die Einbildungskraft als auch den soziologischen Vereinfachungen entgehen, die Images entweder für die Wirklichkeit zu halten oder sie als Mittel der Wirklichkeitskritik zu benutzen. ${ }^{190}$

MOURA hat darüber hinaus an einer anderen Stelle die Beziehungen zwischen der Imagologie (imagologie littéraire) und der Mythosforschung (l'étude des mythes littéraires) ${ }^{191}$ erörtert, denn die literarischen Images können zur mythischen literarischen Projektion werden. ${ }^{192}$ Forschungsinteressen der Imagologie

S. 28Iff.). Als Beispiel des ideologıschen Image nennt Moura die französische Spaniendarstellung des XVIII. Jahrhunderts. Spanien war für Frankreich eine Art des „, negativen Ideals“, die Opposition zur .,aufgeklärten Nation“, und trug zur Stärkung der französischen nationalen Identităt bei, die sich „par les Lumières“ definiert hatte. Hermann Hesses „Asien“ in der Morgenlandfahri (1931) und in Sicldharla (1922) ist dagegen ein Beispiel der utopischen Vision, eines subversiven Images einer alternativen und idealisierten, der europåischen Kultur entgegengesetzten Alterität (ebd., S. 282f;; dort. S. 284f., auch weitere Beispiele für ideologische und utopische Images).

189. .Au fond, la distinction entre image idéologique et image de l'étranger est celle des pronoms latins 'alter' e! 'alius', masquée par la méta-catégorie d'altérité et par le mot français autre'. Alter est l'autre d'un couple, pris dans une dimension étroitement relative ou se définit une identité et donc son contraire. Alıus est l'autre indéfini, l'autre de l'identité $i \ldots /$ mis a distance de toute association facile, l'autre utopique. Alter est integre dans une conception du monde dont le centre est le groupe; Alıus est éloignè, excentrique, et atteint au prix d'une errance hors de ce groupe. Alter est un reflet de la culture du groupe; Alius un refus radical." Moura bemerkt, daß die Images von Alter nicht immer die Überlegenheit der "beirachteriden“" gegenüber der ..betrachteten" Gruppe bedeuten, dasselbe gilt für die Images von Alıus, die nicht immer ein Zeichen der Inferiorität sind (ehd., S. 285). Zwei Konzepte des Exotismus vom Ende des 19. und Beginn des 20. Jahrhunderts können als Beispiele für die romantische Ideologie der französischen Träume über den Orient, der Poetik des Alter (Pierre Lotis (Orıent) bzw. als Ästhetik des Diversen. des Alıus (Victor Segalens Ozeunten) dienen. Moura stellt abschließend fest: . J.../ toute image est mirage, au sens où elle redécrit la réalité ètrangère à la societé, et, à l'instar de toute fiction, la recrée à un plus haut niveau de réalisme" (ebd. S. 286f.)

190 Ebd., S. 278f. Moura unterscheidet in der Perzeption des Imuge (nach Ricoeur 1986a, S. 214fr.): .du còté de l'objet, l'axe de la présence et de l'absence; du côté du sujet, l'axe de la conscience fascinèe et de la conscience critique“. Die erste Möglichkeit faßt Riccur als die geschwachte Spur der Anwesenheit des Anderen auf (Hume), oder als seine Abwesenheit (Sartre). Die zweite wird verstanden als die kritisch bewußte Fähigkeit bzw. Unfăhigkeit des Subjekts. den Unterschied zwischen Imaginaire und réel wahrzunehmen (S. 277). Siehe dazu auch unten. S. $81 \mathrm{ff}$.

${ }^{191}$ MOURA 1994. Vgl dazu BRUNEL. 1981

192 Auch als .Gottesersatz" besonders in der modernen Literatur. Moura beruft sich dabei auf Georg Lukäs, der den modernen Roman als "Epopöe einer Welt ohne Gott" bezeichnet hat. Vgl. LUKÁcs 1962, S. 87: ..Der Roman ist die Epopöe der gottverlassenen Welt". Diese For- 
und der Mythosforschung begegneten sich somit in der Untersuchung der mythisierten Fremdheit/Alterităt in der Literatur, obwohl der Ort, an dem sie sich begegnen, noch nicht genügend untersucht worden sei. ${ }^{193}$

Moura erörtert anschließend komplementäre Begriffe der literarischen étrangeté und altérité, denn der Unterschied zwischen ihnen ist grundlegend bei der Ermittlung und Erforschung literarischer Mythen bzw. mythischer Figuren uber das Andere/Fremde.

Als étrangeté wird dabei ,toute représentation où l'autre est posé comme un double, renvoyé par un miroir à peine déformant" verstanden, die sich in stereotypen Darstellungen åußert. ${ }^{194}$ Dagegen gibt es zwei Arten von altérité: 1. „irréductible, du simple donné, relevant de l'indicible, de l'in-nommable, de l'immonde. /.../ immédiateté qui ne peut être saisie par la littérature, ni par aucun discours"; 2. „posée et reconnue comme telle par un discours [ou une représentation] qui, pour sa part, aurait renoncé, au contact de cette différence à sa propension à tout ramener à la fixité des schèmes““. Solche altérité untersagt "toute identité plate de soi à soi“, sie kommt in der Literatur zum Ausdruck und ist offen für Interpretationen. ${ }^{195}$

Literarische Darstellungen des Fremden / Anderen können sich daher ăußern:

mulierung bezieht sich jedoch moglicherweise auf die epische Darstellung der Privatisierung der Lebensbestimmung im sozioskonomischen Kontext.

${ }^{193} . J . . /$ le réseau des symboles par lesquels les imaginaires culturels se conçoivent, se rejoignent ou se distimguent, et la mythocritique n'a guère été abordée," (MOURA 1994, S. 130). Moura hält sich an die Definition des Mythos von BRUNEL 1994a, S. 7-15: Der Mythos habe drei Funktionen: 1. Je mythe raconte. Le mythe est un recit". 2. , explique, il explique les causes, il est étiologique $/ . . . \Gamma^{\prime}$. 3. „Le mythe révèle l'être, il révèle le dieu". Brunel unterscheidet einerseits zwischen dem elhno-religiösen und liferarischen Mythos, sowie andererseits zwischen dem literarischen Mythos und dem literarischen Thema. In der Literatur gibt es sowohl literarisierte ethno-religiöse Mythen als auch mythisierte literarische Themen. Literarische Themen können entweder den religiösen $A$ ty then entstammen oder zu literarischen Mythen werden, wie z.B. die literarischen Figuren von Antigone einerseits, von Faust oder Napoleon andererseits. Für Brunel ist der Begriff des Themus dem des Konzupts [un concept] nah. Ein literarischer Mythos kann dagegen ein Themu illustrieren, so z.B. die mythische Figur der Antigone ..représente la révolte contre la loi de la polis quand cette loi ignore les liens du sang et les exigences du sacré;" es gibt aber für Brunel auch genuine literarische Mythen, die er nach André Dabezies (Visages de liaust uu $X X^{2}$ siècle) als "une illustration symbolique et fascinante d'une situation humaine exemplaire pour telle ou telle collectivite" definiert (ebd. S. 10ff.). Brunel beruft sich u.a. auf EliAdE 1963, DURAND 1978 und JOLles 1958. Siehe auch zum Begriff des literarischen Themas und zum Unterschied zwischen literarischem Stoff, Motiv und Thema: BELLER 1992 (vgl. ebd., S. 33f. zu den deutschen und amerikanischen Forschungen sowie S. 34-36 zu den französischen Mythos- und Themenforschungen, u.a. zu Pierre Brunel (S. 37f.)).

${ }^{194}$ Molira 1994. .Il s'agit donc d'un reflet, d' un jeu réglè de renvoss, dependant entièrement du sujet (et de la culture) qui met l'étranger en scene. Le stéréotype, figeant un peuple ou toute autre collectivité en quelques traits grossiers, est le cas-limite de cette réduction deutrui à une dimension étroitement relative" (S. 130f.).

${ }^{195}$ Ebd., Moura zitient Labarrière (vgl. LaBARRIERE 1982, S. 10). An einem anderen Ort delimert er .Alterităt" nach Ricoeur (RiCOEUR 1990a) als ein Phänomen. das: ..ne se resume en effet nullement à l'étrangeté d'autrui. Elle $s$ 'atteste dans toutes les expériences de passivité qui affectent une identité (MOURA 1992b, S. 8). 
1. Als étrangeté im „Bild des Anderen“ bzw. des "Auslănders" (l'image de l'étranger), in dem das imaginaire social einer Kultur zum Ausdruck gebracht wird. In der imagologischen Untersuchung solcher Bilder begegnen sich Ideengeschichte und Literaturgeschichte an den Grenzen zwischen sozio-politischen Mythen und der Erzählung. ${ }^{196}$

2. Als altérité, als die ,identité inachevée, fondée sur le respect d'un temps et d'un espace hors de soi et reconnus en tant que tels", wobei der Exotismus von Victor Segalen exemplarisch für eine solche Haltung der altérité gegenüber genannt werden könne.

3. Die Unerforschheit der altérité bringt die Fiktion an die Grenze zur Fabel und zum Mythos; mythische archaische Figuren werden auf die Fremdbilder projizient. $^{198}$

Im folgenden wird anhand dieser Unterscheidung versucht, Gemeinsamkeiten und Unterschiede zwischen der Imagologie und der Mythosforschung năher zu betrachten.

Obwohl sich in allen drei Fällen die philosophische Aporie äußere: „/.../ comment, enveloppé dans ce qui constitue mon identité, puis-je parler de ce qui lui est radicalement extérieur?"', so daß sie von der Imagologie untersucht werden können, ${ }^{199}$ handle sich im ersten und zweiten Fall der Darstellung des Fremden/Anderen um genuin imagologische Forschungen. Erst im dritten Fall der Darstellung einer inscrutabilité de l'altérité überschnitten sich Forschungsbereiche der Imagologie und Mythosforschung.

Solche literarische Fremdbilder können als ein „ensemble symbolique unique“ unabhängig von der Ideengeschichte oder den zeitgenössischen Darstellungen des Fremden, der étrangeté littéraire, interpretient werden, z.B. nach der archetypologischen Methode von Gilbert Durand, denn: ..Au-delà de la construction de contre-modèles destinés à convoquer une vérité absente de la réalité sociale /.../ on touche là aux frontières de la fable et du mythe“. Die Darstellung dieser altérité unscrutable tritt auf der Ebene der Erzählung als ..débordement du genre romanesque par d’autres genres littéraires, /.../

196 MOLRA 1994 Am Beispiel zweier französischer Romane über die drıtte Welt: lésert (1980) von Jean-Maric Le Clézio und l.e cump des. Suınts (1973) von Jean Raspail illustriert Moura zwei gegensatzliche Haltungen der dritten Welt gegenüber, in denen Projektionen des .. imaginuire du déar" bzw. des .. imagimaire de leffros" als Opposition zur westlichen Welt auf die Fremdbilder übertragen werden. Solche Fremdbilder, die dem imuginaire sex.tal der westlichen bzw. französischen Kultur enstammen, lassen sich als eine Form des Mitthux bezeichnen: ..l.es images de l étranger appartiennet au réseau des répresentatins fondamentales d une societé: tout groupe constitue son identité par un partage et un rejet" (S. 134-137).

197 Ebd, S. $132 \mathrm{f}$ Moura bemerkt, daß in Segalens ..esthétique du divers" .l impenetrabilite de IAutre" eine Quelle der Freude und Bereicherung darstelle; seine Schriften sind ..une ecriture heureuse de l' inscrutable. Une opposition au mode de penser dominant de l'époque. et surtout au positis isme ethnologique confrontant d une manière rigide Occident et mondes primitifs. /.../ En ce sens, la litterature de l'alterité est celle du plaisir de sa distance. Elle procède du rententissement (G. Bachelard) en la consience de la découverte d'un écart irreductible. Selon la belle expression de Segalen lui-méme. elle est Désir-Imaginant plutôt qu image de l'Autre"

100 Ebd., S 131.

$199 \mathrm{Ebd}$ 
débordement de la dimension historico-sociale du roman vers une autre temporalité, /.../ débordement /.../ de l'avre singulière." In dieser dreifachen Überschreitung der Grenzen der Romangattung kommt es nach Moura zur Annaherung an den literarischen Mvthos. ${ }^{200}$ Literarische Mythen lassen sich mit den archaischen (anciens) vergleichen und sind als ideologisch zu bezeichnen, wobei sie nicht nur auf Stereotypen reduziert werden können. ${ }^{201}$

Die Aufgabe der Imagologie an der Grenze zur Mythoskritik liege darüber hinaus nicht nur in der Untersuchung der synchronen, sondern auch der diachronen Dimension der Fremdbilder. Die Erweiterung der Imagologie um die mythokritische Methode konne somit in der zeitlichen Dimension die Annahme von der „structure réiterative des grandes figures européennes de l'étranger" erhärten. "La persistance des mythes de l'autre primitif ou barbare au long de l'histoire littéraire de l'Furope mérite d'être examinè “. ${ }^{202}$

Dieses theoretische Konzept hat Moura in einer Studie zum Bild der Dritten Welt in den französischen Romanen der fünfziger bis zu den achtziger Jahren angewandt. ${ }^{203}$

In ihrem ersten Teil werden aber zunächst franzosische theoretische Schriften analysiert, die sich mit der Problematik der Entkolonialisierung der Dritten Welt bzw. mit der Position des "Westens" dieser Welt gegenüber auseinandersetzen, ${ }^{204}$ die im zweiten Teil als die ideengeschichtliche Grundlage der literarischen Images der Dritten Welt betrachtet werden. Diese Schriften lassen sich in liberale oder radikale aufteilen, je nachdem, welche Position sie gegenüber der Opposition zwischen den entwickelten vs. unterentwickelten Landern einnehmen, ob sie sich für oder gegen den „Westen.“ für oder gegen die Dritte Welt einsetzen. ${ }^{205}$ Diesen beiden Tendenzen entsprechen darüber hinaus weniger intellektuell ausgerichtete symbolische Darstellungen der Dritten Welt. In der

\footnotetext{
${ }^{200}$ Ehd., S 131 und 137ff. Vgl. oben S. 65, zu Bruncls Definition des Mythos.

${ }^{201}$ Ebd., S. 140

202 Ebd., S. 141
}

$203 \mathrm{Vgl}$. MOURA 1992b. Die Studie Mouras läßt sich im Kontext der Abrechnung mit der kolonialen Vergangenheit Frankreichs verstehen, denn in der Zeit nach dem Ende der franzosischen Kolonialherrschaft lasse sich eine intensive Konfrontation französischer Intellektueller und Schriftsteller mit der Alterităt der Dritten Welt beobachten, die zur Stärkung der durch historisch-politische Ereignisse erschüttenen kulturellen Identităt Frankreichs diente ( $S$. 148ff.)

204 Dazu gehören ..les doctrines $1 . . . /$ sur le tiers monde, $/ . .$. les grandes tendances de l'imaginaire social", so daß „le champ des sciences humaines, paradigmatique pour le second plan de l'étude, celui des doctrines vulgarisées, enfin celui de discours plus distants des recherches savantes, aux tendances archéologique ou eschatologiques" untersucht werden soll (ebd., S. 11; S. 17-141).

${ }^{205}$ Vgl. ebd., das Kapitel über „Le champ scientifique“ (..La theorisation liberale“ und „La théorisation radicale"), S. 29ff: Die konservativ-liberale Tendenz laßt sich als ..l'affirmation de l' excellence du primat de l'Occident libéral (ou capitaliste) sur l'ordre international et la justification consecutive de l'ordre qui assure se primat" auffassen (S. 79). Die revolutionärradikale Tendenz wird als ..le procés de l'Occident mené grâce à l'érocation d'un espace. le tiers monde, à la fois victime et régénérateur potentiel dun ordre international injuste" bezeichnet (S. 105). 
liberalen Tendenz wird sie als eine apokalyptische Bedrohung dargestellt: Das Gefühl der Überlegenheit vermischt sich mit dem der Angst vor der Barbarei. In der radikalen wird die Dritte Welt zum Ort des ursprünglichen mythischen Glücks und symbolisiert das verlorene Paradies. In diesen Schriften überwiegt das Gefühl der Schuld oder des Begehrens nach dem Ursprungsland. Die Dritte Welt wird somit entweder zum Ort des Mythos der Barbarei oder des Goldenen Zeitalters stilisiert. ${ }^{206}$

Der zweite Teil der Arbeit untersucht, auf welche Weise diese ideengeschichtlichen Oppositionen des imaginaire social als lexikalische, thematische und symbolische Strukturen im imaginaire littéraire fiktionalisiert werden. Untersucht werden aber vorwiegend Romane der sogenannten paralittérature, obwohl auch anspruchsvollere Werke ergänzend angefuhrt werden. Dabei wird gezeigt, daß das soziale Imagınäre entweder als ideologische ,mirages collectifs sur l'étranger" vorkommen oder in den herausragenden literarischen Werken überwunden werden kann. Nach Moura lassen sich dabei vier thematische Inspirationsquellen nennen: 1. Exotismus oder 2. Verurteilung des Westens sowie 3. Kult des ursprünglichen Glücks oder 4. Angst vor der Barbarei: ${ }^{207}$

1. Die Romane des Exotismus schöpfen ihre Inspiration aus der liberalen Ideologie und erzählen Spionage- oder Abenteuergeschichten.

Ein Spionageroman wird mit Hilfe strukturaler und thematischer Stereotypen konstruiert, wobei Moura diese Unterscheidung von Pageaux übernommen hat: Auf der strukturalen Ebene wird ein Agent des Westens, ein "Übermensch“, intelligent, oft aristokratischer Herkunft. dem Chaos der Dritten Welt gegenübergestellt; auf der thematischen wird der exotische Rahmen, die Arbeit des Agenten und die meist exotische Frau dargestellt. Es handelt sich um einen vereinfachten maximalen Realismus und Exotismus, der mit nationalen Stereotypen operiert. dabei werden die Figuren der Dritten Welt als unterlegen, Opfer oder

206 Ebd., S. 109: „A l'écan des deux idéologies précédentes se construisent ainsi deux complexes. brassant images e: schèmas rationnels, qui mettent en scène sur un ton souvent hyperbolique, un univers originel ou apocalyptique. Dans un cas, un tiers monde idyllique est opposé à l'Occident selon différentes approches critiques. anti-productivisme, écologisme ou anti-ethnocentrisme; dans l'autre, un univers barbare menace une civilisation occidentale vulnérable, selon des perspectives cartiènstes, néo-malthusiennes ou d intégrité culturelle. $i . .$. Le tiers monde, alpha d une archéologie ou oméga d une eschatologie, devient la figure centrale d'un récit dont la coherence est moins rationelle que symbolique". Vgl. auch ebd., $\mathrm{S}$. 297ff. sowie zum Begriff der ..Dritten Welt“ und des „Westens“, S. 17ff. und S. $271 \mathrm{ff}$.

207 Ebd., S. 145-263. Somit wird die historische und ideologische Bedingtheit der fiktionalen Literatur erforscht und die Darstellung des Raumes, .la représentation de l' espace (tant topologique que social)" sowie literarischer Figuren. .le système des personnages (au plan, cardinal, des relations entre personnages occidentaux et personnages du tiers monde)" analysiert. Die meisten Romane über die Dritte Welt sind überholten Poetiken verpflichtet, bevorzugen eine vereinfachte ideologische Darstellungsweise. Die Auseinandersetzung mit der Problematik der Dritten Welt und der Entkolonialisierung wird kaum mit den Mitteln innovativer Poetik versucht (S. 147 und S. 150f.). Es geht dabel um die Beziehung zwischen wissenschaftlichen und ideologischen sowie fiktionalen Texten, die als ein Problem der Intertextualität aufgefaßt wird. Als methodisches Prinzip gilt weiterhin eine ..pluralitè d approches critiques“, eine semiotisch-hermeneutische Methode, die es vermeidet, sich an die ..cèlèbres théories du reflet" zu halten (S. 12f.). 
Henker, geschildert. Die exotische Frau ist die Verkorperung der Unterwerfung, dient dem westlichen Agenten als erotisches Lustobjekt, ist sein einziger Trost im Kampf gegen die feindliche Umwelt bzw. die feindliche Organisation. In solchen Romanen werden Angehorige des Westens gegenüber der unterentwickelten Welt ausschließlich als ihr überlegen dargestellt. Sie setzen sich für den westlichen Nationalismus ein, der liberale ideologische Wurzeln hat. Der überlegene Westen wird somit in stereotyper Weise von der Dritten Welt bedroht, ein ,paladin de l'Occident et un espace de l'anarchie“ werden in manichåischer, dualistischer Weise einander gegenübergestellt. ${ }^{208}$

Im Abenteuerroman erscheint die Dritte Welt als Schauplatz der Abenteuer des westlichen Protagonisten, sie wird auf die Schilderungen der schönen Landschaft oder der chaotischen Gesellschaft reduziert und ebenfalls oft mit Hilfe von Stereotypen geschildert. Individualismus und Verehrung des Energischen zeichnen den westlichen Abenteurer aus, der den Gefahren der exotischen "fremden Fremde" ausgesetzt wird. Betont wird oft die Dekadenz des Westens. ${ }^{209}$

2. Die Romane, in denen der Westen verurteilt wird, sind dagegen den radikalen intellektuellen Ideen verpflichtet. Dazu gehoren u.a. die Romane der Ideologie des tiers-mondisme, die eine revolutionäre Apokalypse beschworen, und die Romane des Diskurses, die die Schuld des Westens gegenüber der Dritten Welt thematisieren, seine Verantwortung für die Unterentwicklung und den Wunsch nach Erlosung von der Schuld, nach ihrer Wiedergutmachung betonen. Der Protagonist dieser Romane ist ebenfalls fast immer ein Vertreter des Westens, der in den unterentwickelten Ländern die Schuld des westlichen Imperialismus gegenüber der Dritten Welt entdeckt und innerlich zum Kämpfer für ihre Rechte heranreift. Das Schema solcher Romane erinnert somit an einen Bildungsroman. Exotismus wird vermieden, das Streben nach Authentizităt wird betont, obwohl sie oft ebenfalls in vereinfachter Weise mit Stereotypen erzielt wird. In der strengen Gegenüberstellung des Westens und der Dritten Welt wird diese dabei hăufig mythisiert, zum Ort des Goldenen Zeitalters stilisiert. ${ }^{210}$

3. In den Romanen, die das ursprüngliche Glück [bonheur primitif] bzw. die Sehnsucht danach thematisieren, werden die Wüste und der Dschungel, der Urwald. zu utopischen idyllischen Orten. in denen sich der Mythos vom Ursprung der Welt inkarniert, die somit als Kontrast zum Westen dienen. ${ }^{211}$

200 Ebd., S. 153ff. Die Unterscheidung von strukturalen und thematschen Stereotypen erinnert zum einen an die terminologischen Ausführungen von Zofia Mitosek (vgl. MrTOSEK 1974, S. 40ff.) über die narrativen Klischees bzw. Stereotypen, zu denen auch konventionelle Schilderungen von Landschaften oder Menschen gehören, zum anderen aber auch an die Definition des literarischen Stereotyps in StowNIK TERMINOW LTERACKICH( S. 522). Siehe dazu oben, S. 49.

209 MOURA 1992b, S. 166ff. und S. $218 \mathrm{ff}$.

210 Ebd., S. $181 \mathrm{ff}$. und bes. $215 \mathrm{ff}$. Das Schema dieser Romane erinnert aber auch an dasjenige des Sozrealismus.

2:1 Untersucht werden Romane uber die „Wüste“ le marıage herhère und lalla Zahra von Sımone Jacquemard sowie Déserı von Jean-Marie Le Clézio. Als Beispiel eines Romans über den Dschungel wird $L$ 'adıeu au rol von Pıerre Schoendoerffer angeführt (ebd., S. $221 \mathrm{ff}$.). Diese Romane enthalten außer der allegorischen Dimension, der Darstellung der ganzheitli- 
4. Schließlich werden Romane angefuhrt, in denen die Barbarei der Dritten Welt die westliche Zivilisation bedroht und in apokalyptischen Visionen der Untergang des Westens evoziert wird. ${ }^{212}$

Im folgenden wird versucht, dieses in die literarische Fiktion umgesetzte imaginaire intellectue $P^{13}$ in der Terminologie Riccurs als die Opposition zwischen Ideologie und Utopie zu beschreiben. Demzufolge sind die liberal beeinflußten Darstellungen der Dritten Welt, auch als Verkorperung der Barbarei, Ideologien, weil sie die Überlegenheit des Westens, seine zivilisatorische Dominanz, die vorherrschende soziale und politische Ordnung und Macht aufrechterhalten mochten. Die radikalen Darstellungen sowie die Darstellung des ursprünglichen Glücks sind dagegen Utopien, weil sie subversive Absichten haben und die bestehende Ordnung in Frage stellen wollen. ${ }^{214}$

In den Romanen, die die liberale Ideologie oder radikale Utopie fiktionalisieren, werden stereotype Darstellungen der Dritten Welt bevorzugt. Die ideologische Darstellungen der Barbarei setzt aber nicht nur Stereotypen ein, sondern kann sich auch dem Mythos bzw. Symbol nähem. ${ }^{215}$ Die liberale Ideologie und die radikale Utopie setzen sich mit dem Problem der westlichen Identităt gegenüber der Alterităt der Dritten Welt auseinander, die ideologische Darstellung der Barbarei und besonders die utopische des ursprünglichen Glücks überschreiten die Grenze des Mythos. ${ }^{216}$

Die Opposition zwischen den ideologischen und utopischen Schilderungen der Dritten Welt ăußert sich aber auch in der Typologie der Fremdenfiguren, die entweder als Alter oder als Alius vorkommen. ${ }^{217}$ Sowohl in den ideologischliberalen als auch in den utopischen-radikalen Darstellungen werden die frem-

chen ursprünglichen, obwohl bedrohten Gesellschaft der Dritten Welt, die sich von den radikalen Ideologien herleiten lasse, auch die symbolische Dimension: "les figures de l'euphorie primitive. les figures du désir occidental, la destruction du monde primitif" (S. 239ff.). Die Wüste und der Urwald, der ..wilde Raum,“ werden dem Leben in den zivilisierten westlichen Stadten gegenübergestellt. Die Stadt wird zur negativen Metapher des dekadenten Westens, zum Ort der Entfremdung und Einsamkeit Der ursprüngliche, ,wilde“ Raum der Wüste wird zur Metapher der Freiheit. Dabei wird die Wüste als Ort des Lichts, der Offenbarung und Prüfung dargestellt, der Unwald dagegen als On der Dunkelheit, ein dunkles Labyrinth, bedrohlieh und faszinierend, der jedoch auch befreiende Energien freisetzt. DURAND (vgl. DERS. 1978) folgend, interpretiert Moura sowohl die Wüste als auch den Urwald als ein System der Symbole: der Symbolik des Lichts, der Reinigung und der Auferstehung (symboles diurnes, dicairelıques und ascentıonnels) wird die der Animalităt, der Finsternis und des Untergangs (symboles thérumorphes, nyctomorphes und catamorphes) gegenübergestellt. ..Récit des origines, le Bonheur primitif explore les confins de la fable et du mythe. Sa forme tragique souligne que l'experience inaugurale du temps ne peut être racontee sans que soit simultanement mise en scène sa destruction“" (Moura 1992b, S. 229ff. und 242f.)

${ }_{212}$ Dazu gehör u.a. der Roman von Jean Raspail le cump des saints (ebd. S. 245ז und $\mathrm{S}$ 260ff.).

${ }_{213}$ Molira definien limaginare social als "l ensemble des représentations collectives propres à une société; in seiner Studie beschäfigt er sich mit seinen Bestandteilen: mit dem imaginaire intellectuel und littéraire, ebd., S. 267f.

214 Ebd., S. 274ff.

215 Ebd., S. 277ff.

226 Ebd.

${ }^{217}$ Ebd., S. 280ff. 
den Figuren meistens zum Alter, zur "difference opèratoire dans la sphère d'intérêt du groupe, et son altérité est ignorée“. ${ }^{218}$ Die ideologisch-liberalen Darstellungen der Fremdheit, auch als Barbarei. konstituieren die Identität der eigenen Gruppe, ihre Autorităt gegenüber der fremden Gruppe. Sie stellen die Fremden als die Anderen, reduzierend und stereotyp, dar, obwohl sie sich des Symbols oder des Mythos bedienen. ${ }^{219}$ Die utopischen Darstellungen, in der radikalen Variante oder als Darstellungen des ursprünglichen Glücks, zeichnen sich durch einen Dualismus der Darstellung aus: das Fremde wird entweder als ganz anders, subversiv oder auch als idealisient dargestellt. ${ }^{220}$ Der Fremde als Alius läßt sich dagegen nur in den utopischen Darstellungen des bonheur primitif finden. ${ }^{221}$

Zum Schluß werden ergänzend poetologisch innovative Darstellungen des Fremden als Alius erörtert, die sich als persönliche Mythen bezeichnen lassen. Diese Darstellungen überschreiten die Grenzen des imaginaire social. Dazu gehören „Asien“ von Marguerite Duras oder die "Dritte Welt" in der Jalousie von A. Robbe-Grillet. ${ }^{222}$ Ihre Werke spiegeln die metaphysische Krise des Subjekts und des Erzăhlens wider, indem die Welt richt mehr darstellbar ist, sich nicht abbilden läßt. Über diese Krise schreibt R. Barthes: „Ne pouvant plus maîtriser la réalité historique, elle [la littérature] est passée d'un système de représentation à un système de jeux symboliques“. 223

Moura hat sein theoretisches Konzept überzeugend in den Textinterpretationen umgesetzt und dadurch seine Textnăhe und Brauchbarkeit nachgewiesen, so daß seine Forschungen eine geschlossene Einheit bilden. Sie kőnnen deswegen, im Unterschied zu allen zuvor erörterten Ansătzen, als eine theoretisch-interpretatorische Grundlage angewendet werden.

Seine Terminologie, die er von Pageux übernommen hat, ist jedoch nicht genug differenzierend und bedarf einer Präzisierung, denn Moura bemüht sich nicht um Unterscheidungen bzw. Abgrenzungen zwischen solchen Begriffen wie "Image" und "Stereotyp", auch als ..thematisches" bzw. ,strukturelles" Stereotyp. Diese Begriffe werden darüber hinaus von ihm überhaupt nicht explizit definiert. Der Begriff des "Mythos", den er von Brunel übernommen hat, beschränkt sich auf seinen Inhalt bzw. seine Semantik. so daß er zu eng ist. ${ }^{224}$

${ }^{210}$ Ebd., S. $282 \mathrm{f}$.

219 Eldd., S. 280 f.

220 Eldd., S. 281

221 Moura bezieht sich auf TODOROv 1982, S. 254, der von der Fixolopie. von der bedingungslosen Affimation des Fremden. spricht. Auch bei Victor Segalen gibt es die beglückende und faszinierte Affimmation der Alterität (MOLRA 1992b, S. 285). Moura befaßt sich auch mit der psychoanalytischen Dimension der Darstellungen des Fremden nach MANNONI 1984 (S. 287ff.).

222 Ebd., S. 289ff. Moura fuhrt I.'Fimpire des signes von R. Barthes an. in dem Barthes eine persönliche ..mythologie heureuse ${ }^{*}$ kreiere, ein Zeichensystem, das sich auf sich selbst beziche, ebd., S. $292 f$.

223 Fbd., S. 300, zitiert nach BARTHES 1981, S. 193.

22. Vgl. dazu oben, S. 52ff. zu den Begriffsbestimmung von KlizMA 1980, der neben dem formalen und inhaltlichen besonders den funktional-pragmatischen Aspekt des Mṭıhus als 
um weitere Aspekte "mythischer" Strukturen in der literarischen Darstellung der Fremdheit zu berücksichtigen.

Besonders relevant ist aber die Interpretationsmethode Mouras in der Anwendung der Ansătze aus Paul Riccurs Hermeneutik. Dank der Unterscheidung zwischen dem ideologischen und utopischen Charakter des sozialen Imaginären, das in der Literatur als kulturell vermittelte Schöpfung der produktiven bzw. reproduktiven Einbildungskraft vorkommt, wird es möglich, die textimmanente Funktion und Semantik der Fremdbilder zu bestimmen. Moura ist es darüber hinaus gelungen, eine einleuchtende Typologie literarischer Figuren der Fremden oder Anderen als Alius vs. Alter vorzuschlagen, die ihrem ideologischen oder utopischen Charakter entspricht.

Lediglich die Fragestellung seiner Studie, die das Bild der Dritten Welt anhand der Trivialliteratur untersucht, kann teilweise als ein Mangel betrachtet werden. Die darin untersuchten Romane sind wegen ihres narrativen Schematismus und des konventionellen Charakters relativ einfach strukturiert und deswegen auch einfach zu interpretieren. Mouras Ansatz müßte daher in der Interpretation poetologisch anspruchsvollerer Texte eingesetzt werden, um seine Brauchbarkeit auch in diesem Fall bestätigen zu können oder ihn ggf. zu modifizieren. $^{225}$

\section{EXKURS: PAUL RICEUURS HERMENEUTISCHE PHÄNOMENOLOGIE}

Um die oben besprochenen Ausführungen von Jean-Marc Moura besser verstehen und sie für die Methode der vorliegenden Arbeit fruchtbar machen zu können, müßte an dieser Stelle ergänzend die hermeneutische Phänomenologie PAUL RICAEURS dargestellt werden. Eine ausführliche Darstellung würde aber die fachliche Kompetenz der Verfasserin überschreiten. Im folgenden Exkurs können daher lediglich die wichtigsten Ansătze der Ricourschen Hermeneutik im Kontext seines vielfältigen und zugleich, trotz. einer klaren sprachlichen Darbietungsweise, thematisch und strukturell dichten philosophischen Systems,

soziale Kommunikation (Barthes) hervorgehoben hat. Dieser Aspekt scheint aber gerade bei der Erforschung der literarischen Fremdheit relevant zu sein.

$225 \mathrm{Vgl}$. auch den Aufsatz von KI.OEPFER 1994, der sich ebenfalls auf Ricœurs Unterscheidung zwischen ideologischer und utopischer Weltsicht stützt. Image sei dabei ein Perzeptionsschema, eme sinngebende (icistult, besitze sowohl semantische als auch syntaktische Energien, pragmatische, appellative bzw. emotive Funktion. Es impliziere eine linstellung. Seinen textinternen pragmatisch-axiologischen brw. ethischen Aspekt nennt Kloepfer sympraxis, den er neben dem semantisch referentiellen (mimésis) und dem syntaktischen (discours) unterscheidet. Als Beispiel der Sympraxıs eines Image des Schwarzen fürt Kloepfer das Mitleid, das ein religiöser Text (im Leser) erwecken soll, oder Stimulation der Sinnlichkeit, die ein Image einer jungen schwarzen und gut gebauten Frau in einem exolischen Trivialroman bezweckt, auf (S. 528). Diese theoretischen Ausführungen sind aber zu einseitig deskriptiv und abstrakt deduktiv und eignen sich deswegen nicht als Grundlage einer Interpretation, um so mehr, als sie das Problem der Rezeption unmitttelbar betreffen. 
sowie einige für unsere Fragestellung besonders relevante Begriffe erörter werden.

Paul Ricœur gilt als der beste Kenner und, neben Lévinas, Sartre und Merleau-Ponty, als einer der fruchtbarsten Vertreter der Phänomenologie in Frankreich. ${ }^{226}$ Das umfangreiche Werk des 1913 in Valence in einer protestantischen Familie geborenen Philosophen ${ }^{27}$ ist noch nicht abgeschlossen und wird kontinuierlich durch neue Beiträge ergänzt und vervollkommnet. Alle Texte Ricœurs sind darüber hinaus in konkreten Diskussionszusammenhängen, im Dialog mit mehreren, nicht nur philosophischen Ansätzen entstanden und beziehen sich jeweils auf die vorhergehenden Werke, so daß ihre Interpretation schwierig ist und nach einer "Synopsis“ verlangt. ${ }^{228}$ Ungeachtet der schwierigen und besonders in Deutschland verzogerten Rezeption Ricœurs, gibt es bereits mehrere übergreifende synthetische Arbeiten und Einführungen in seine Philosophie. die neben dem hier relevanten Band $D u$ texte à l'action als Grundlage dieses „Exkurses“ dienen werden. ${ }^{229}$

Das Gesamtwerk Ricours, das sich über fünfzig Jahre erstreckt, zeichnet sich durch eine langsame, aber konsequente Entwicklung und Bereicherung des ursprünglichen phänomenologisch-reflexiven und zugleich personalistisch-existentialistischen Ausgangspunktes aus. Es setzte mit einer „Phănomenologie des Wollens" an und führt bis hin zu einer hermeneutisch-ontologischen ..Poetik des Wollens", die auch eine "Poetik des ethischen Handelns" genannt werden kann: ${ }^{230}$ Die Selbstfindung oder Selbsterkenntnis des Subjekts (und einer

$226 \mathrm{Vgl}$. WALDENFELS 1983, S 266.

227 Siethe zur Biographie Ricceurs beispielsweise ThOMASSET 1996, S. 49-52, oder WALDENFELS 1983, S. 267-271.

229 Bis vor kurzem wurde darüber hinaus, hauptsächlich in trankreıcn, die christliche Grundlage der Philosophie Ricueurs als ..Theologie“ kritisien. Auch CARR 1997 schreibt beispielsweise vom ..religiös, fundamental christlichen“ Charakter dieser Philosophie (S. 178): Ricœur selbst hat seine christliche Weltanschauung nie geleugnet (vgl. dazu THOMASSET 1996, S. 57). ZBINDEN 1997 findet in allen Schriften Ricours das Schema ..Krise-Rettung“ Dieses Konzept, das auf Husserls Krisebegriff zurückgeht, werde von Ricour übergreifend die existenzielle ..Krise des Sinns“ der modernen Kultur genannt. Sie soll in der allgemeinen ..Aporetik der Zeitlichkeit" ihre Ursache haben, sowie in dem ..Mimesis-Zirkel" eine (poetische) Lösung finden (S. 180 und S. 182). Die utopische und grundlegend ethische Dimension der Philosophie Ricoeurs wird deswegen auch von Theologen erörtert. Vgl. z.B. PRAMMfFR 1988, THOMASSET 1996 oder lifTREMA 1996.

$22{ }^{\circ}$ Es handelt sich um die Arbeiten von ThOMASSET 1996, WALDENFELS 1983, POLTI 1997. CARR 1997 sowie ZBINDEN 1997. Eine vollständige Bibliographie der Arbeiten von und über Ricour bis zum Ende der neuziger Jahre bietet VANSINA 2000. Siche ferner RICaEIR 1980a SOwie ZB. MEYER 1991, MONGIN 1994. MATTERN 1996, REAGAN 1979 oder WOOD 1991 Siehe ferner die Einführung in die Hermeneutik Riccurs von RoSNER 1989. Siehe ferner AYLESWORIH 1991 und LAWI.OR 1991

230 ThOMASSET 1996, S. 53, nennt das ,.menschliche Handeln“" (/ uctuon /mumus'me) die thematische Konstante des Ricceurschen Gesamtwerkes und zitiert eine Äußerung Ricosurs aus dem Jahre 1991: ..Ma démarche peut ètre mieux caractérisè dans l'ordre thematique parce qu en constitue la ligne directrice le préocupation de l'agir humaine. Je me suis d abord intéressé à la structuration de l'agir sur le plan du volontaire et de l'involontaire, puis au désir dans ses structures insconscientes, puis au rapport entre le narratif et le temporel (RICGE:R 1992. S. 18). 
Gemeinschaft), die durch Zeichen, Symbole und Texte vermittelt ist, erfolgt nicht in reflexiver Selbstsetzung, sondern auf dem "langen Weg" der unaufhörlichen Interpretation. ${ }^{231}$

WALDENFELS hat im Einklang mit der Selbstaussage Ricœurs folgende Entwicklungssphasen dieser Philosophie bis zum Anfang der achtziger Jahre unterschieden: ${ }^{232}$

die erste eidetische Phänomenologie des Wollens, die sich schrittweise zu einer Ontologie der konkreten Existenz, einer Ontologie der V'ersöhnung, ausweitet (Le Volontaire et I'Involontaire, 1950):

eine anthropologische Phase, die „von abstrakten Grundstrukturen des menschlichen Daseins ausgeht und bei einer konkreten Symbolik des Bösen endet" (Finitude et Culpabilité, 1960);

eine Hermeneutik der Symbole, ,die an die Sprache des Begehrens anknüpft und der reflexiven Wiederaneignung der Existenz eine Enteignung des unmittelbaren BewuBtseins voranstellt" (De l'interprétation. Essai sur Freud, 1965, Le Conflit des interprétations, 1969);

- eine umfassende Hermeneutik des Textes, in der „sich Zugehörigkeit und kritische Distanz" begegnen. sowie „die Ansprechbarkeit durch die Sprache“ dominiert (La Mélaphore vive, 1975). ${ }^{233}$

Die Hermeneutik des Textes weitet sich in der Folge zu einer umfassenden und allgemeinen Theorie der Erzählung aus (Temps et Récit, 3. Bände, 19831985), die die Aporien der menschlichen Zeiterfahrung sowie ihre Überwindung im kreativen Erzählen innerhalb des Zirkels der dreifachen Mimesis thematisiert. Diese Erzahltheorie wird anschließend zu einer Theorie des (sozialen) Handelns erweitert und durch mehrere Beiträge zur grundlegenden Rolle der Vorstellungskraft in ihren zwei komplementär-antinomischen Formen als Ideologie und L'topie ergänzt (Du texte ḋ l'action, 1986).

Als eine Art Zusammenfassung aller bisherigen Themen der Ricœurschen Philosophie gilt das 1990 erschienene umfangreiche Werk über die Hermeneutik des Selbst (Soi-mème comme un autre, 1990), dessen einzelne Kapitel ihre ver-

231 Ricelir hat in dem Vorwor zu Jervolino (1984, S. 7) das Hauptthema seiner Philosophie als ..le destin de l'idèe de subjectivité, soumise au feu croisé de Nietzsche et de Heidegger, d une part, de la sémiologie. de la psychanalyse et de la critique des idéologies, d'autre part" bezeichnet. Seine Methode beruhe dagegen in .le röle médiateur éxercé par l interpretation, princıpalement celle des textes, à l égard de la réflexion sur soi", es handle sich um die Erarbeitung einer Hermeneutik der menschlichen Praxis im Horizont ciner Poetik der Freihent (ebd, zitient nach THOMASSET 1996, S. 54)

232 W ALDENFFI.S 1983, S. 270f. Siche auch ebd., S. 266: „Gegenüber dem direkten Rückgriff auf das Ursprungliche und dem vorschnellen Ausgriff nach dem Ganzen bekennt er sich mehr und mehr zu indirekten Weisen der Aneignung, die durch das vermittelte Feld von Zeichen, Symbolen und Sprache hindurchgehen. Hegels Rede von dem Umweg als dem Weg der Wahrheit gewinnt cinen neuen Sinn. wir nähern uns den Sachen selbst auf limicegen der l)eutung"."

233 Ebud. 
schiedenen Aspekte, den ethischen, semantischen und narrativen behandeln und das Konzept der „narrativen Identităt" weiterentwickelt haben. ${ }^{234}$

Im AnschluB sollen hier die für die methodische Grundlage der vorlicgenden Arbeit relevanten Begriffe der hermeuneutischen Phase der Phänomenologie Ricours - „Sprache als discours", „der Text“ und „die Welt des Textes“, „die Dialektik des hermeneutischen Prozesses der Textinterpretation zwischen Erklären und Verstehen" und „die Mimesis“, „die produktive und reproduktive Vorstellungskraft“, „das Image“ sowie „das soziale Imaginäre als Utopie oder Ideologie“ - lediglich kurz erörtert werden. ${ }^{235}$ Eine knappe Darstellung dieser

$234 \mathrm{Vgl}$. dazu THOMASSET 1996, S. 59f. sowie S. 143-153. Thomasset nennt diese letzte Entwicklungsetappe der Philosophie Ricceurs „L'herméneutique du soi et l'ontologie de l'agir“, der drei frühere Phasen vorangehen sollen: 1. „Du Cogito réflexive à la découverte de Therméneutique“ (die Auseinandersetzung mit der reflexiven Philosophie von Descartes, Kant, und Husserl, die bis zur Erkenntis der Unmóglichkeit einer Selbstsetzung des reinen Subjekts führt, das durch das „Unwillentliche“ seiner endlichen Existenz ..innerlich gebrochen", "verletzt" wird; diese "Fehlbarkeit des Menschen“ wird in der Folge am Beispiel der Symbolik des Bosen erortert und verursacht die hermeneutische methodische Wende und die Auseinandersetzung mit der Ontologie Heideggers), 2. "Le conflit des interprétations" (die Auseinandersetzung mit der Freudschen Psychoanalyse und mit dem Strukturalismus, die die Erarbeitung eines Konzeptes der Interpretation ermöglicht, das sich vom Konzept Diltheys unterscheidet und eine Dialektik zwischen Frklären und Verstehen fordert). 3. "La créativité du langage: innovation sémantique et réfiguration narrative" (die Auseinandersetzung mit der Phănomenologie Husserls und mit der nachheideggerschen Hermeneutik Gadamers einerseits sowie mit der angelsăchsischen analytischen Sprachtheorien und mit der Poetik von Aristoteles andererseits führt zur Beschäftigung mit der Kreativität der Sprache, mit der Rolle der produktiven Vorstellungskraft, die in der erzählerischen Produktivităt eine poetische Neugestaltung der Welt ermöglicht) (ebd., S. 54-60).

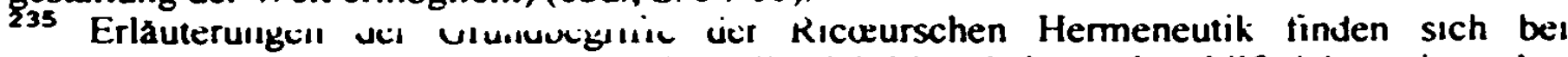
WALDENFELS 1983 und THOMASSET 1996, die sich hier als besonders hilfreich erwiesen haben. Siehe ferner PRAMMER 1988 oder HETrEMA 1996. Riccur hat darüber hinaus alle oben genannten Begriffe in dem bereits von Moura erórterten Essayband I u Iexic $\dot{a} I^{\prime}$ action (1986a) mehrmals zusammenfassend erläutert, in dem er seine Texttheoric zu einer Handlungstheorie ausgeweitet hat: De 1 hermineutlque des textes à 1 \%erméneutique de l'acrion (S. 137-277): darin bes. die beiden Kapitel: l.e modéle du fexte: l'actıon consicérée comme un texte (S. 183-211) und $l^{\circ}$ imagination dans le discours et dans l'action (S. 213-236), und den Abschnitt des letzteren Kapitels über l. 'imagınaıre social (S. 228-236); Idéologıe, utopice et politique: darin bes. das Kapitel l. idéologie 'l l'utopie: deux expressions de l'imugınure social (S. 379-392). Siehe femer PaUl RicceUR 1986b. Vgl. dazu unten, S. 80ff.

Vgl. auch bei WAI.DENFELS 1983, S. 293-300 zum Symbolbegriff RIC CEURS, dessen Erörtirung die vorhermeneutische Phase seiner Philosophie abgeschlossen hat. Die Auseınandersetzung mit der Betrachtung des „Bosen“ als ,.Schuld”, die an das „.Sprechereignis des religiósen Schuldbekenntnisses" gebunden ist, das sich zuerst in primären Symbolen äußert, sodann in der sekundären Sprache der Mythen nacherzăhlt sowie in der tertiären Spehulation reflexiv. ausgelegt wird, hat die neue, hermeneutische Methode erforderlich gemacht. Ricueur unterscheidet dabei eine kosmische (als Hierophanie), eine oneirische (als Traüme) und eine poetische Dimension (als Bild bzw. Metapher) des Symbols. Das Symbol wird dabei in Anlehnung an die romantische Auffassung als ein doppeldeutiges Zeichen verstanden, bei dem der ubertragene Sinn nur vermittels des wörtlichen Sinns faßbar ist: das Symbol gibt seınen Sinn. anders als die Allegorie, nicht durch Über-setzung (tra-duction) preis, sondern in einem untergründigen „Durch-scheinen“ (trans-parence). Der philosophische Diskurs wird datxei möglich, denn ..das Symbol gibt zu denken.“ Es gıhl zunächst einen anfánglichen Bezug zur 
Terminologie erfordert eine besondere interpretatorische Anstrengung, denn sie bildet ein zusammenhängendes Koordinatensystem und läßt sich nicht außerhalb des Kontextes der Text- und Handlungstheorie Ricœurs verstehen. Da alle gröBeren Arbeiten Ricœurs sich zugleich aus mehreren ursprünglich getrennt veröffentlichten Beiträgen zusammensetzen, werden alle Begriffe in jedem dieser Beiträge mehrmals definiert, ergänzt und mit neuen Inhalten angereichert.

Ricœur hat seine Auffassung von der "Sprache als discours", vom „Text" und von der "Interpretation“ als dialektischen ProzeB, als eine dialektische Vermittlung zwischen „Erklären“ und „Verstehen“ im Zusammenhang mit dem Projekt einer Erneuerung der hermeneutischen Tradition herausgebildet. Dieses dialektische Modell der "Interpretation" unterscheidet sich somit sowohl von dem Diltheys (und Schleiermachers) als auch von dem der strukturalen Linguistik oder der Psychoanalyse, knüpft an die analytischen Sprachtheorien und an die Ontologie Heideggers an und läßt sich als eine synthetisch-dialektische Lösung dieses "Konfliktes der Interpretationen" betrachten. ${ }^{236}$ Riccur möchte dadurch die grundlegende hermeneutische Frage beantworten, wie ein in Form von Texten fixierter Diskurs mit Hilfe von geisteswissenschaftlich erklärenden Methoden interpretient und zugleich zum Selbstverständnis des Interpreten beitragen kann. Dabei wird das strukturalistische Modell des ,absoluten Textes“, ungeachtet der Autonomie der Schrift, der Entfremdung eines Textes von der Intention des Autors, abgelehnt und seine referentielle und heuristische

sakralen Wirklichkeit, den das Nachdenken unmittelbar nicht zu finden vermag, und gibt $=u$ denken, da es von Anfang an (ausgelegte) Sprache ist. In der darauffolgenden Freud-Studie (De l'interprétatıon. Essaı sur Freud, 1965) wird unter Symbol ein sprachlicher Ausdruck mit doppeltem Sinn verstanden. Es bleibt zunächst offen, ob der erste Sinn den zweiten enthüllt oder verschleier; der Symbolbegriff wird somit zum einen nicht auf alle Sprachzeichen ausgeweitet (Cassirer) und zum anderen nicht auf Analogien eingeengt (ebd., S. 301ff.). Auch hier wird im Streit der Hermeneutiken die Doppelbewegung der Interpretation unterstrichen: „das Symbol sucht Zuflucht bei der Reflexion und diese beim Symbol“ (ebd., S. 302). In den Schlußfo!gerungen der Studie wird dagegen festgestellt, daß dieselben Symbole sowohl resressiv und progressiv, archaisch und prophetisch seien, indem sie Verklerdung und linthüllung in sich vereinen, die Ziele unserer Triebe verbergen und den Prozeß des Selbstbewußtseins offenbar machen. Dabei werden insgesamt sinnschöpferische Möglichkeiten des Symbols von den ,hoheren“ (Poesie) bis hin zu ..niederen“ (soziale Stereotypisierung) mitreflektient (ebd., S. 313). Siehe ferner auch ThOMASSET 1996, S. 54f. und S. 104-108. Vgl. auch RICEUR 1971b [franz: Irimtude et ('ulpabılité. II. Ia Sivmbolıque du Mal. Paris 1960. (= Philosophie de l'Esprit)], hes. S. 9-32 (Einleitung) und S. 395-406 (Das Symbol gibt zu denken). Vgl. auch den einzıgen Beitrag Ricœurs zu Dostoevskij: RicaUR 1996, der leider vor der Herstellung der Druckfassung dieser Studie der Verfasserin nicht zugänglich war

236 RiCeEUR 1969. Vgl. THOMASSET 1996, S. 117ff. Siehe auch die Definition Ricceurs 1986a, S. 75: „l'herméneutique est la théorie des opérations de la compréhension dans leur rapport avec l"interprétation des textes". Siehe ferner zur Auseinandersetzung Ricaurs mit dem Strukturalismus bei WELSEN 1991, S. 500f: ...bwohl sich R[iccur] der Auffassung vom transzendentalen Charakter der Beziehungen zwischen den Zeichen anschließt, weist er die These der Suisuffizienz zurück. Er unterscheidet zwischen der Semiologie, die das Zeichen als Element des Systems, und der Semantik, die den Satz als Element des Diskurses untersucht. Aufgrund des Vorrangs der Semantik vor der Semiologie gelinge es dem Bewußtsein, sich durch das Medium der Sprache hindurch intentional auf Wirklichkeit zu beziehen und auf diese Weise die strukturalistische Herausforderung abzuwehren.“ 
Dimension hervorgehoben. ${ }^{237}$ Die "Sprache“ (le langage) spricht nicht nur "über sich selbst", sondern „über etwas", über „eine symbolische Welt", die im Text dargestellt wird und uns eine neue existentielle Moglichkeit für ein neues "In-der-Welt-Sein" (d'être dans le monde) eroffnen kann. ${ }^{238}$

Ricœurs Texttheorie läßt sich in vier Kategorien beschreiben: 1. Die Sprache ist für Ricœur, der sich an den Vorarbeiten von Benveniste, Austin und Searle orientiert, als ein "Diskurs“ (discours) zu verstehen, ihre "Struktur" (langue) unterscheidet sich von dem des „.Sprechereignisses“ (I'événement de la parole), wobei der "Satz" (phrase) eine semantische Crundeinheit bildet. Der Diskurs hat darüber hinaus eine "Sinndimension“ (sens, signification), die sich als eine Überschreitung, als eine Objektivierung des Sprechereignisses, des „Sagens“ (le dire) im „Gesagten“ (le dit) außert. ${ }^{239} 2$. Der Diskurs objektivien sich aber in der Schrift als "Werk" (l'cevre) und bildet eine abgeschlossene Satzfolge, eine dem Satz ubergeordnete Komposition (composition); somit wird er in Form einer literarischen Gattung (genre littéraire) kodifiziert. Obwohl sich das Werk durch eine einmalige individuelle stilistische Konfiguration (un style) auszeichnet, entfernt es sich aber von der Intention des Autors, ist Ergebnis einer ordnenden, schöpferischen „Arbeit an der Sprache“ (un travail), die eine besondere Anstrengung der Interpretation erfordert. Als eine sprachliche Einheit kann es deswegen auch mit strukturalen Methoden erklärt werden. Dadurch wird eine neue Texthermeneutik ermöglicht, denn "l'explication est désormais le chemin obligé de la compréhension“, „expliquer plus, c"est comprendre mieux“. Es gibt kein Verstehen ohne Erklären: beides ergănzt sich gegenseitig in einer Interpretation. ${ }^{240}$

3. Mit der komplementären Problematik der Objektivation und der Depsychologisierung des Diskurses in einem "Werk" sowie mit seiner Internretation hängt die Problematik der sogenannten „Welt des Textes" (,.le monde du texte“; vgl. auch "die Sache des Textes“ nach Gadamer) und seiner "Referenz" (.,Bedeutung“) zusammen, die Ricœur, Frege folgend, von seinem „Sinn“ unterscheidet. Anders als in mündlichem Diskurs läßt nicht sich von einem unmittelbaren Bezug des Textes auf eine die Gesprächspartner umgebende Wirklichkeit sprechen. Für Ricœur wird aber diese ,primăre Referenz" eines Textes nicht aufgehoben. Er spricht von einer sekundären Referenz des Textes, die fiktionale Werke haben sollen. Sie beziehe sich nicht mehr auf die Wirklichkeitsebene der ..manipulierbaren Objekte“, sondern auf die ..Lebenswelt" (Husserl) bzw. auf das „In-der-Welt-Sein“ (Heidegger). Die Fiktion bietet dank der Fähigkeit der Vorstellungskraft eine Mőglichkeit, die „Welt menschlicher Handlungen“ neu

237 THOMASSET 1996, S. 117 f. Vgl. WeLSEN 1991 zum Begriff des Textes. ..Das ausschlaggebende Merkmal des Textes sieht $R$. [Ricaur] in der durch die Fixierung bedingten Ablosung vom Ereignis des Sagens. Er fordert eine Synthese von strukturaler Erklarung und hermeneutischer Auslegung. wobei letztere die vom Text entfaltete Welt erschließt. Die dadurch erreichte Aneignung läuft freilich nicht auf eine Vereinnahmung des Textes hinaus. sondern befahigt den Interpreten. sich angesichts von dessen Andersheit besser zu verstehen" ( $S$. 50If.).

${ }^{230}$ Ebd.. S. 118. Siehe auch RICceUR 1986a. S. 145-150

${ }^{239}$ THOMASSET 1996, S. 124. Vgl. auch BENVENISTE 1966, AUSTIN 1962, SEARLE 1977

240 ThOMASSET 1996, S. 125, RicelsR 1986a. S. 22, S. 110 und passim 
zu beschreiben, sie erzahlend nachzuschaffen, eine neue, kreative Sicht der Welt. Dieser Entwurf einer ,neuen Welt" wird im Vorgang der Interpretation offengelegt und kann emeut in die Praxis eingebunden werden. ${ }^{212} 4$. Die letzte Kategorie des Textes betrifft die Problematik der Subjektivităt des Lesers und der besonderen "Aneignung eines Textes“. Ricœur unterscheidet dabei zwei komplementäre Möglichkeiten der Lektüre. Aufgrund der Suspendierung der primăren Referenz ist sowohl eine struktural orientierte, erklärende Lesart des Textes als einer autonomen sprachlichen Komposition als auch eine Aufhebung dieser Distanz und eine Wiedereingliederung in den lebendigen Diskurs und in die Handlung mőglich, was Ricœur die „wahre Bestimmung der Lektüre“ nennt: „Par appropriation, $\mathrm{j}$ 'entends ceci, que l'interprétation d'un texte s'achève dans l'interprétation de soi d'un sujet qui désormais se comprend mieux, se comprend autrement, ou même commence à se comprendre". Sich Verstehen bedeutet somit, sich angesichts des Textes zu verstehen (se comprendre devant le Texte), sich dem Text auszusetzen, "prendre le chemin de pénsée ouvert par le texte, se mettre en route vers l'orient de Texte“. ${ }^{242}$ Der hermeneutische Zirkel der Interpretation zwischen dem „objektiven Sinn“ des Textes und seinem „Vorverstädnis“ bei dem Leser wird jetzt durch die gegenseitige Korrelation zwischen Erklären und Verstehen konstituiert. ${ }^{243}$

Im Zusammenhang mit Ricœurs Texttheorie wurde bereits die Problematik der „sekundären Referenz“ sowie der komplementären Interpretation eines fiktionalen Textes erörtert, die zur Selbstfindung des Rezipienten ...angesichts der Welt eines Textes" beitragen kann. Eine besonders wichtige Rolle bei der poetischen Neugestaltung der Wirklichkeit wird dabei der produktiven Vorstellungskraft zugeschrieben. Kant folgend nennt Ricœur dieses schöferisch-spielerische Potential der Sprache eine Art des kreativen Schematismus, der nach bestimmten Regeln verfahrt und sowohl in literarischen Texten als auch in der Geschichtsschreibung als „erzählte Intrige“, als „Handlung“ (als erzähltes Modell der Wirklichkeit und als Anleitung zum (sozialen) Handeln) betrachtet werden kann. Ricœur geht dabei von der aristotelischen Kategorie der Mimesis als Mythos, d.h. von einer in zeitlicher Abfolge der Ereignisse nachgeschaffenen Handlung, von einer Intrige, aus:

„D'une manière ou d'une autre, tous les systèmes de symboles contribuent à configurer la réalité. l... les intrigues que nous inventons nous aident à configurer notre expérience temporelle confuse, informe, et $\dot{a}$ la limite muette. /.../ C'est dans la capacité de la fiction de configurer cette

${ }^{241}$ Riccur hat diese Problematik später in mehreren Schritten zur Theorıe der ..Metapher als semantischer Innovation", zur "dreitachen Mimesis" (nach Aristoleles) sowie zur "Erzählung“" (als Fiktion und als Geschichtsschreibung) und zur „Vorstellungskraft" ausführlich dargelegt, die ihm als Grundlage seiner späteren Handlungstheorie gedient haben. Diese Problematik wird deswegen unten im Zusammenhang mit dem komplementä-antinomischen Charakter der Vorstellungskraft erörtert. Siehe auch THOMASSET 1996, S. 126f., RiCGUR 1986a. Vgl. auch FREGE 1967.

242 RiCGEUR 1986a, S. 29 und S. 156

243 Ebd., S. 211. 
expérience temporelle quasi muette que réside la fonction référentielle de l'intrigue. Nous retrouvons ici le lien entre muthos et mimèsis dans la Poétique d'Aristote: 'C'est la fable, dit-il, qui est l'imitation de l'action' (Poétique, 1450a2). La fable imite l'action dans la mesure où en construit avec les seules ressources de la fiction les schèmes d'intelligibilité. Le monde de la fiction est un laboratoire des formes dans lequel nous essayons des configurations possibles de l'action pour en éprouver la consistance et la plausibilité. Cette expérimentation avec les paradigmes relève de ce que nous appelions plus haut l'imagination productrice. A ce stade, la référence est comme tenue en suspens /.../. Fiction, c'est fingere, est fingere, $c^{\prime}$ est faire. Le monde de la fiction, en cette phase de suspens, $n$ est que le monde du texte, une projection du texte comme monde. /.../ Le monde du texte, parce qu'il est monde, entre nécessairement en collision avec le monde réel, pour le 'refaire', soit qu'il le confirme, soit qu'il le dénie. /.../ Si le monde du texte était sans rapport assignable avec le monde réel, alors le langage ne serait pas 'dangereux', au sens où Hölderlin le disait, avant Nietzsche et Walter Benjamin". [ fett und kursiv Paul Ricour; kursiv die Verf.] $]^{244}$

Ricœurs Schlüsselbegriffe - die „(lebendige) Metapher“ und der „mimetische Vorgang" der kreativen Nachahmung der menschlichen Handlung als "Intrige“ oder "Fabelkomposition" (mise-en-intrigue) ${ }^{245}$, die er als "deux fenêtres ouvertes sur l'énigme de la créativité" bezeichnet und ausführlich in seinen beiden umfangreichen Studien erörtert hat ${ }^{266}-$ können somit auch in der Handlungstheorie angewendet werden. Sowohl die "Metapher" als auch die "Intrige“ weisen eine heuristische Dimension auf, sind als „semantische Innovationen“ zu bezeichnen. Indem die „Metapher" etwas „als etwas anderes“ sehen hilft, verfügt sie über eine besondere „metaphorische Referenz", drückt eine neue Wahrheit aus, denn „zu sehen wie..." (voire comme) ist zugleich „zu sein wie..." (être comme). ${ }^{247}$ Die Erzăhlung als .Intrige" ermöglicht dagegen die "Re-“ und „Konfiguration" der heterogenen Zeiterfahrung, die sich lediglich als erzăhlte Handlung poetisch synthetisieren läßt. ${ }^{248}$

$244 \mathrm{Vgl}$. ebd., S. $17 \mathrm{f}$

245 MEUTER 1995, S. 126 schlăgt eine andere deutsche Übersetzung des Begriffs musc-e'nintriguc als .Einfadeln einer Intrige“ (nach der Übersetzerin von Zufull und l'ermun/l in der (ieschuchte (Tübingen o.J. [1985], S. 12)) vor, die seinen dynamischen Aspekt besser hervorheben soll.

246 RiCCEUR 1986a, S. 21. Vgl. dazu RICEEUR 1975 und 1983-85.

247 Vgl dazu ThOMASSET 1996, S. 133fr. und RicceUR 1975 und 1986a. S. 34, sowie WeLSEN 1991: .R[iccur] untersucht die Metapher auf der Ebene des Wortes, des Satzes sowie des Diskurses, um festzustellen. daß ihr schopferisches Potential erst auf der letztgenannten volt zur Geltung kommt. Denn die Metapher erschöpft sich nicht in rein sprachlicher Innovation: sie stiftet vielmehr eine besondere. die wörtiche Referenz überlagemde metaphorische Referenz, kraft derer sie neue Aspekte der Wirklichkeit zu zeigen vermag. Deshalb fühn $R$ den von Heidegger inspirierten Begriff einer 'metaphorischen Wahrheit' ein"* (S. 501f)

$248 \mathrm{Vgl}$. ThOMASSET 1996, ebd. Siehe auch WELSEN 1991 zur Theorie der Zeit: ..Nach langwierigen Analysen zur Temporalität in Geschichtsschreibung, Literatur und Philosophie 
Die „Mimesis“, die Riccur, Aristoteles folgend (obwohl er dessen Begriff eigentumlich erweitert hat) als einen dynamischen Vorgang der kreativen Darstellung einer (fiktionalen) Handlung auffaßt, bildet einerseits einen „Bruch“ mit der präexistenten Wirklichkeit, andererseits aber partizipiert sie an der (ethischen) Wirklichkeit, die sie poetisch umgestalten will. Der mimetische ProzeB läßt sich somit als dreifachen Zirkel beschreiben: Die „Mimesis I." (le récit préfiguré), „Mimesis II.“ (la configuration narrative) und „die Mimesis III.“ (l'action réfigurée). Die „Mimesis I.“ bildet den Ausgangspunkt des mimetischen Vorgangs und bezeichnet seine „Verankerung“ in einer Welt des menschlichen Handelns, das bereits erzählerisch präfiguriert ist, und zugleich dessen Vorverstăndnis erforderlich macht; die „Mimesis II.“ konfiguriert die erzăhlte Zeit in einer Komposition, ist das Ergebnis der Arbeit der kreativen Vorstellungskraft, stellt eine fiktive Handlung dar; die „Mimesis III.“ ermöglicht als Folge der Rezeption eines fiktionalen Werkes, seine praktische Anwendung der gewonnenen Kenntnisse in der Wirklichkeit. ${ }^{249}$

Ricœur hat somit seine Texttheorie zur einer umfassenden Erzăhltheorie ausgeweitet, in der die Rolle der Zeitdimension in der Erzählung (récit) hervorgehoben wird. Der zeitliche Charakter des fiktionalen Textes, in dem eine sinnhafte Handlung (action) kreativ nacherzählt wird, ermöglicht es, den Text als ein epistemologisches Modell der menschlichen Handlung, und umgekehrt, die Handlung als die Referenzebene des Textes zu betrachten. ${ }^{250}$

In den ergånzenden Überlegungen zu den Theorien der Imagination und des Bildes (image), die von Aporien durchsetzt gewesen seien, unterscheidet Riccur vier traditionelle Möglichkeiten, die Begriffe „Imagination“ bzw. „Bild“ zu definieren:

(Augustinus, Kant, Husserl, Heidegger) registnen er [Ricœur] das Scheitern eıner Phänomenologie der Zeit, das sich aus der Diskrepanz zwischen erlebter und kosmologischer Zeit ergibt. Er entwickelt als Alternative einen narrativen Ansatz. In seinem Zentrum steht der Begriff der Intrige, die nicht allein die zeitlichen Verhältnisse innerhalb von Texten regelt, sondern darüber hinaus - wie schon die Metapher - zur Konstitution der Wirklichkeit beitrăgt “ (S. 502).

249 Vgl. dazu ThomasSet 1996, S. 137-143. Siehe ferner zur Kritik an diesem Konzept bei ZBINDEN 1997, S. 185ff., der auf die Unmöglichkeit hinweist, genaue Subjektbezüge in allen drei Mimesis-Phasen zu ermitteln, obwohl er zugleich bemerkt, daß Riccurs Konzept, anders als die strukturalistische und poststrukturalistische Mimesis-Auffassung, in der ...ebenswelt" wurzelt und in dem mimetischen Zirkel wieder in diese "Lebenswelt" eingebunden wird (S. 189). Siehe dazu auch RICEljR 1976; DERS. 1975; DERS. 1983. Vgl. auch zum Mime.sis-Begriff: TATARKIEWICZ 1976, S. 312-339; vgl. auch die englische Übersetzung: TATARKIEWICZ 1980. Vgl. ferner MitoSEK 1997, S. 152-169 (Koniec mimesis' [I)as linde der Mimesis?]) (Vergleich zwischen Ricœur und Derrida): Die Autorin weist darin auf die Ähnlichkeiten zwischen den beiden anscheinend so unterschiedlichen Philosophen hin.

$250 \mathrm{Vgl}$. dazu ThOMASSET 1996, S. I29ff: Ricœur bezieht sich dabei auf die angelsāchsische Handlungstheorie und auf die Ansichten des finnischen Philosophen G.H. von Wright. Das menschliche Handeln wird als „operer un changement dans le monde“ definiert (S. 131) und kann als ein Text betrachtet werden: "L'action peut ètre considérée comme un texte“ (S. 132). Vgl. auch RICEUR 1986a, S. 190-197. 
1. „/.../ l'èvocation arbitraire de choses absentes, mais existant ailleurs, sans que cette évocation implique la confusion de la chose absente avec les choses présentes ici et maintenant";

2. „Selon un usage voisin du précédent, le même terme désigne aussi les portraits, tableaux, dessins, diagrammes, etc., dotés d'une existence physique propre, mais dont la fonction est de 'tenir lieu' des choses qu'ils représentent";

3. $/ . . . /$ les fictions qui n'evoquent pas des choses absentes, mais des choses inexistantes. A leur tour, les fictions se déploient entre des termes aussi éloignés que les rêves, produits du sommeil, et les inventions dotées d'une existence purement littéraire, tels les drames et les romans";

4.,...$/$ des illusions, c'est-à-dire des représentations qui, pour un observatuer extérieur ou pour une réflexion ulterieure, s'adressent à des choses absentes ou inexistantes, mais qui, pour le sujet et dans l'instant où celui-ci est livré à elles, font croire à la réalité de leur objet“" ${ }^{251}$

Die bisherigen philosophischen Theorien der Imagination lassen sich entsprechend diesen unterschiedlichen Versuchen, das Bild zu definieren, in zwei oppositionelle Gruppen aufteilen: „/.../ selon deux axes d'opposition: du côté de l'objet, l'axe de la présence et de l’àbsence; du côté du sujet, l'axe de la conscience fascinée et de la conscience critique."

Seinen eigenen Begriff des „Bildes“ erörtert Ricœur dabei im Kontext der Theorie der Metapher und der Erzăhlung als Schöpfungen der Imagination:

"/.../ le schématisme est une règle pour produire des images. /.../ en bref, le travail de l'imagination est de schématiser l'attribution métaphorique. Comme le schème kantien, elle donne une image à une signification émergente. Avant d'être une perception évanouissante, l'image est une signification émergante. Le passage à l'aspect quasi sensoriel, le plus souvant quasi optique, de l'image est dès lors facile à comprendre. La phénomenologie de la lecture offre ici un guide sûr. $C^{\prime}$ est dans l'expérience de la lecture que nous surprenos le phénomene de retentissement, d'écho ou de réverbćration, par lequel le schème à son tour produit des images“ [kursiv die Verf.] ${ }^{253}$

In dem Essay L'imagination dans le discours et dans l'action hat er darüber hinaus die soziale Funktion der Vorstellungskraft als das ,soziale Imaginare“" (imaginaire social) abgehandelt, ${ }^{254}$ das in seiner kollektiven Ausprägung in

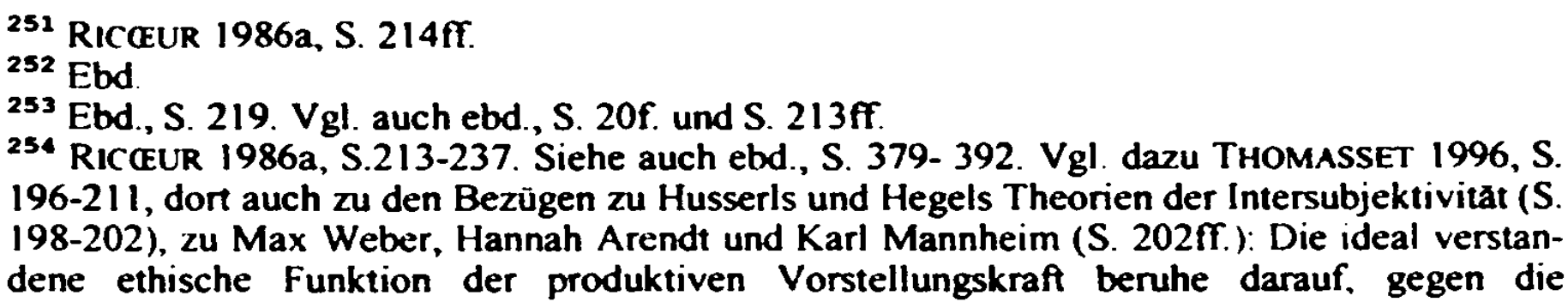


zwei komplementär-oppositionellen Grundformen als „Ideologie“ und „Utopie“ auftritt. Das soziale Handeln selbst wird erst dank dieser imaginativen "Praxis“ möglich. ${ }^{255}$ Sowohl die Ideologie als auch die Utopie weisen dabei nach Ricœur sowohl positive, ,gesunde“, als auch negative, pathologische Aspekte auf, die es zu kritisieren gilt:

La vérité de notre condition est que le lien analogique qui fait de tout homme mon semblable ne nous est accessible quà travers un certain nombre de pratiques imaginatives, telles que l'idéologie et l'utopie. Ces pratiques imaginatives ont pour caractéristiques générales de se définir comme mutuellement antagonistes et chacune à une pathologie spécifique qui rend presque méconnaissable sa fonction positive, c'est-à-dire sa contribution à la constitution du lien analogique entre moi et l'homme mon semblable. ${ }^{256}$

Die Ideologie bezeichnet Paul Ricœur, indem er den Gedanken Max Webers folgt, als:

/.../ la nécessité pour une groupe quelconque de se donner une image de lui-même, de se 'représenter', au sens théâtral du mot, de se mettre en jeu et en scène. /.../ Simplification, schèmatisation, stéréotypie et ritualisation procèdent de la distance qui ne cesse de se creuser entre la pratique réelle et les interprétations à travers lesquells le groupe prend conscience de son existence et de sa pratique. ${ }^{257}$

Die Pathologie der Ideologie, ihre Entstellung, die Marx einst das "falsche Bewußtsein" genannt hat, ist als das Ergebnis der Bemühungen einer Gruppe bzw. einer Gesellschaft anzusehen, sich als eine solche zu "legitimieren", als "Autorität" zu gelten, um dadurch ihre Integrität zu wahren, wobei die Legiti"mation und die Autorität mit allen Mitteln erzwungen werden kơnnen. ${ }^{258}$

Die Utopie, die im Unterschied zur Ideologie auch als literarische Gattung vorkommt, tritt dagegen in einer zur Ideologie oppositionellen bzw. komplementären Rolle auf, indem sie .la fonction de la subversion sociale“ erfüllt: deshalb wollen alle Utopien ,.,anders" leben, schlagen eine andere Lebensweise vor:

,$/ . . /$ les utopies, /.../ exposent la plus-value non déclarée de l'autorité et démasquent la prétention propre à tous les systèmes de légitimité. /.../ les utopies /.../ en viennent à offrir des manières 'autres' d'exercer le pouvoir, dans la famille, dans la vie économique, politique ou religieuse. ${ }^{259}$

„terrifiante entropie dans les relations humains“ (RICCEUR 1986a, S. 228) anzukämpfen und helfe uns, in jedem Menschen ein uns gleiches "Ich“" zu sehen (S. 206).

${ }^{255} \mathrm{Vgl}$. ebd. S. 220ff. bzw. S. 379ff.

256 Ebd. S. 228

257 Ebd. S. 230

258 Ebd. S. 230 f

259 Ebd. S. 232. 
Die Pathologie der Utopie besteht nach Ricœur in ihrer zur "Schizophrenie“ neigenden, „exzentrischen" Funktion: "Elle développe de manière caricaturale l'ambiguité d'un phénomèn qui oscille entre le fantasme et la créativité. 'Nulle part peut. ou non, réorienter vers 'ici et maintenant "“. ${ }^{260} \mathrm{Zu}$ dieser Pathologie kann somit auch der Versuch gehören, utopische Träume in Wirklichkeit umzuwandeln, und die Tendenz, die Wirklichkeit dem utopischen Traum unterzuordnen, bzw. die Fixierung auf bestimmte perfektionistische stereotype Lebensweisen und auf eine alternative Machtausübung. ${ }^{261}$

Ricœur erblickt jedoch in den beiden Ausdnıcksweisen der sozialen Imagination, die ineinander übergehen bzw. komplementär sein können (manchmal sei sogar kaum möglich zu entscheiden, ob es sich um eine Ideologie oder um eine Utopie handle), auch eine positive, ,gesunde“" Funktion, denn wer weiß:

si tel ou tel mode erratique d'existence n'est pas la prophétie de l'homme à venir? Qui sait même si un certain degrè de pathologie individuelle n'est pas la condition du changement social, dans la mesure où cette pathologic porte au jour la sclérose des institutions mortes? /... / Comme si, pour guérir la folie de l'utopie, il fallait en appeler à la fonction 'saine' de l'idéologie, et comme si la critique des idéologies ne pouvait être conduite que par une conscience susceptible de se regarder elle-même à partir de nulle part. C'est dans ce travail sur l'imaginaire social que se médiatisent les contradictions qu une simple phénoménologie de l'imagination individuelle doit laisser à l'état d'apories. [kursiv Paul Ricœur] ${ }^{262}$

Die Ideologie läßt sich als eine Form der reproduktiven, die Utopie als eine Form der produktiven Vorstellungskraft bezeichnen. Die erste bildet die Tradition, ist ein Ausdruck des historischen narrativen Gedächtnisses, die zweite verandert die Welt. stellt eine Innovation dar, drückt menschliche Hoffnungen aus. Beide ergänzen sich jedoch dialektisch und können nicht getrennt voneinander gedacht werden. Die Ideologie ist nötig, um eine narrative Identität zu bilden bzw. aufrechtzuerhalten, sie schützt vor den pathologischen Formen der Utopie. Die Utopie dient dagegen der Ideologiekritik, korrigiert die erstarten Formen der Ideologie. ${ }^{263}$

\footnotetext{
260 Ebd. S. 235.

$262 \mathrm{Fbd}$
}

262 Ebd. S. 235f. Siehe auch ebd S 379- 392 über die drei jeweils eınander entsprechenden, komplementären sinnkonstituierenden Funktionen der Ideologle (als Integration, als Legitimation der Macht und der Autoritat und als deren pathologische Entstellung) und der Utopie (als soziale Subversion, als das In-Frage-Stellen der Autorität und der Macht und als pathologischer schizophrener Perfektionismus, der versucht, utopische Vorstellungen zu venvirkl1chen, ihnen die Wirklichkeit mat allen Mitteln unterzuordnen). Vgl. dazu WEI.SEN 1991 ..Während sich Ideologie in ihrem positiven Gesichtspunkt (Integration) als unuberwindlich erweist. gilt es, den negativen Gesichtspunkt (Entstellung) durch Ideologiekritik zu entlarven / . Die Ideologiekritik muß sich mit einer unabschließbaren wechselseitigen Korrektur von Ideologie und Utopie bescheiden“" (S. 502).

${ }^{263} \mathrm{Vgl}$. THOMASSFT 1996, S. 2071r.: E.r hat eine tabellarısche Übersicht uber die drei jeueils komplementären Funktionen der Ideologie und Utopie zusammengestellt die pathologische 
ZUSAMMENFASSEND läßt sich zu den oben besprochenen Ansătzen allgemein festhalten, daß als ihre einzige gemeinsame Konstante die Notwendigkeit festgestellt werden kann, das (unterschiedlich bezeichnete) Phănomen der kulturellen Fremdheit in der Literatur zu untersuchen.

Nicht unerhebliche Unterschiede finden sich dagegen sowohl in der Terminologie als auch in der Methode der Beschreibung und Interpretationen dieses Phänomens.

Aus dem schwer beschreibbaren und ambivalenten Charakter der kulturell vermittelten und zugleich fiktionalen (selbstreferentiellen) Darstellungen oder Konstruktionen der literarischen Fremdheit ergeben sich Schwierigkeiten, eine einheitliche Terminologie zu schaffen. In den meisten einschlägigen Forschungen wird festgestellt, daß sich die "literarische Fremdheit" aus mehreren Elementen zusammensetze und eine komplizierte Struktur aufweise.

Als Oberbegriffe werden Bezeichnungen wie nationales Image, (Fremd)Bild, Imagotyp oder Mythos vorgeschlagen, die entweder unterschiedlich oder überhaupt nicht năher definiert werden. Alle diese Oberbegriffe trăten als oppositionelle Paare von Eigen- und Fremdbildern oder Images auf.

Darüber hinaus werden ebenfalls unterschiedlich bezeichnete Einzelelemente dieser Oberbegriffe benannt, zum Beispiel Stereotyp, Konstante, Motiv, Dominante bzw. Klischee, aber auch erneut Bild, Image oder Imagotyp.

Es erhebt sich somit die Frage, welche dieser Elemente der begrifflichen Meta-Ebene angehören bzw. wie sie hierarchisch geordnet werden sollen.

Methodisch gesehen wird in den meisten Forschungen die Notwendigkeit der literaturwissenschaftlichen, aber interdisziplinär orientierten Erforschung sowohl der Genese, der textimmanenten Struktur und Funktion der "Fremdheit" auf kulturell-sozialem Hintergrund als auch ihrer wirkungsästhetischen Dimension postuliert, wobei jedoch die meisten theoretisch-methodischen Vorschlăge nicht durch Textinterpretationen erhărtet werden und abstrakte Postulate bleiben.

Von allen erörterten theoretischen Ansătzen läßt sich somit im einzelnen festhalten, daß, abgesehen von dem imagologischen Konzept von Jean-Marc Moura, keiner davon als terminologisch-methodische Grundlage dieser Studie angewendet werden kann, denn,

der Ansatz von Hugo Dyserinck und seiner Aachener Schule sowie alle anderen ihm verwandten Ansätze, trotz ihrer großen Verdienste, die Imagologie als eine komparatistische Disziplin wieder relevant zu machen, sind nicht nur zu einseitig deskriptiv-empirisch auf die Ideologiekritik, sondern auch auf die rezeptionsästhetischen Aspekte der „Fremdbilder an sich“ ausgerichtet;

Funktion der Ideologie bildet "Dissimulation et distorsion de la réalité", die Hauptfunktion .. Iustification. Légitimation de l'autorité" und die positive ..Intégration er identification de la communauté. Renforcement du réel (tradition)". Die pathologische Funktion der Utopie ist .rêve fou, sans médiation ni compromis", die Hauptfunktion "Subversion et Variations imaginatives sur le pouvoir", die positive "Critique du present et proposition alternative. Mise en question du réel (innovation)" (S. 207). 
- darüber hinaus beschrănken sich die explizit „nichtimagologischen" Konzepte wie die Stereotypen-, Klischee- oder Mythosforschung jeweils auf einzelne Aspekte der literarisch vermittelten Fremdheit, ohne dieses Phänomen in seiner Komplexităt innerhalb einer fiktionalen Welt literarischer Texte zu analysieren;

außerdem zeichnen sich die meisten Ansătze nicht nur durch diffuse Terminologien und uneinheitliche Methoden aus, sondern auch durch ihren abstrakt-deduktiven Charakter, denn sie werden kaum in die Praxis umgesetzt;

lediglich der bereits positiv beurteilte Ansatz Mouras hebt sich durch eine vorwiegend einleuchtende Terminologie und textnahe hermeneutische Methode davon $a b$, die überzeugend in Textinterpretationen umgesetzt werden. Zugleich bedarf sein Konzept aber einiger präzisierender Ergänzungen, um für die Interpretationen der literarischen Werke Dostoevskijs fruchtbar gemacht zu werden. 


\section{IMAGOLOGISCHE ANSÄTZE UND UNTERSUCHUNGEN ALS DESIDERAT DER SLAVISTISCHEN LITERATURWISSENSCHAFT UND DER DOSTOEVSKIJ-FORSCHUNG}

Auffallig in der slavistischen und speziell in der Dostoevskij-Forschung zur Fremdheitsproblematik ist eine fast gänzliche Abwesenheit theoretischer, darunter explizit imagologischer Ansătze. Alle unten besprochenen Arbeiten sind somit als Beweis dafür zu betrachten, daß die moderne Imagologie noch keine theoretische Verarbeitung und Anwendung in der Slavistik und in der Dostoevskij-Forschung gefunden hat: ${ }^{264}$ Die meisten dieser lediglich thematisch relevanten Forschungen sind induktiv und deskriptiv-empirisch angelegt.

Zuerst werden einige ausgewählte Beitrăge zur Entstehung und zur Rezeption nationaler Stereotypen von und über Slaven referiert, vorwiegend solche, in denen Dostoevskijs Werke, auch im Kontext der hier relevanten polnisch-russischen Thematik, genannt werden. Sie sind hinsichtlich der Materialerfassung meistens zufriedenstellend, bieten einen literarhistorischen Überblick und tragen dazu bei, den historischen Kontext des imaginaire social hauptsächlich des slavischen Kulturraums zu beleuchten, dem nationale und ethnische Stereotypen in literarischen Werken Dostoevkijs entstammen.

INGE HANSLIK ${ }^{265}$ weist auf zwei jeweils ambivalenten Tendenzen bei der Stereotypenbildung über Rußland und Polen im Frankreich des 18. Jahrhunderts hin, die sich noch bis heute erhalten haben sollen. Anhand französischer Zeitschriften, Nachschlagewerke, Reiseberichte und politischer und historiographischer Texte wird untersucht, wie die beiden Nationen in der französischen Ôffentlichkeit beurteilt wurden, wobei die Herrschaft Peters des Großen eine deutliche Zăsur bei der Entstehung der französischen Rußlandbilder gebildet hatte. Hanslik unterscheidet seit dieser Zeit zwei komplementäre Haltungen in der Beurteilung Rußlands und Polens, die in der Weise strukturiert sind, daß das positive Fremdbild Polens mit dem negativen Rußlands, und umgekehrt, das positive Bild Rußlands mit dem negativen Polens verbunden war, und somit kein dominierendes nur positives oder nur negatives Bild von jeweils einem dieser Staaten die französische Öffentlichkeit beherrscht hat. Diese Doppel-Bilder leben, wie Hanslik bemerkt, bis heute in Frankreich fort. ${ }^{266}$

Die erste traditionelle I.inie der negativen Beurteilung Rußlands bzw. der Moskoviter, die diesem Staat die Bezeichnung ,europäisch“ verweigerte, ging auf die frühen Reiseberichte z.B. von Olearius oder Herberstein zurück, in denen

264 Dieser Mangel an theoretischen, auch imagologischen Forschungen in der Slavistik läßt sich dadurch erklären, daß die Imagologıe bzw. die Fremdheitsforschung im außerslavischen Raum entstanden ist und in der Zeit der sozialistischen Herrschaftsideologie in den slavischen ländern nicht betrieben werden konnte. Im Hinblick auf die Dostoevskij-Forschung. die doch in nichtslavischen Lándern ebenfalls intensiv betrieben wird, lăßt sich dagegen eine plausible Erklärung für ein ähnliches methodisches Defizit nicht so leicht finden.

265 HANSLIK 1985.

266 Ebd., S. 294ff. 
ein düsteres undifferenziertes Feindbild geschaffen wurde. ${ }^{267} \mathrm{Zu}$ den Anhängern dieses Bildes in Frankreich gehörte u.a. Rousseau.

Die zweite Tendenz, zu der hauptsăchlich Voltaire sowie Diderot und ihre Anhänger gerechnet werden können, zeichnete sich etwa seit dem Tod Peters des Großen ab und erblickte in dem , aufgeklärten" Despotismus, der unter dem Einfluß des Nützlichkeitsdenkens Peters des Großen und der Zarin Katharina II. entstanden war, das Ideal eines Staates. ${ }^{268}$

Die Einstellung zu Rußland bei den einzelnen franzorsischen Autoren hing jeweils von ihrer Beurteilung Polens ab, und umgekehrt wurde das Verhăltnis zu Polen an der Beurteilung Rußlands gemessen. Die Anhänger von Voltaire stellten die Anarchie der Adelsrepublik fest, die vom Papst und den Jesuiten zu ihrem selbst verschuldeten Untergang geführt wurde. Dic Freunde Polens, zu denen v.a. Rousseau gehörte, sprachen von einem Königreich malheureux, ohne jedoch die Schwăchen des polnischen politischen Systems zu übersehen. ${ }^{269}$

Es wäre lohnend nachzuprüfen, inwieweit die in dieser Arbeit dargestellten Tendenzen der französischen Aufklärung. Rußland dem Westen (auch einschließlich Polens) gegenüberzustellen und ambivalent, positiv oder negativ zu beurteilen, in den Werken Dostoevskij rezipiert bzw. diskutiert worden sind.

Der literatursoziologischen bzw. rezeptionsăsthetischen Methode der traditionellen franzosischen komparatistischen Schule verpflichtet sind dagegen die Beiträge von MICHEL CADOT ${ }^{270}$ zur Geschichte der französisch-russischen kulturellen Beziehungen und von ALBERT LORTHOLARY, ${ }^{271}$ der sich eingehend

\footnotetext{
267 Ebd., S. 294.

268 Ebd., S. $310 f$ t

269 Ebd., S. 302ft
}

${ }^{270}$ CADOT 1967. Dieser Schüler Cartés hat in seiner materialintensiven Studie die kulturellen und literarischen Beziehungen zwischen Frankreich und Rußland zwischen 1839 und 1856 (bis zum Krimkrieg) auf politischem und historischem Hintergrund untersucht. Der zeitliche Rahmen wurde auf die Zeit begrenzt, in der es zur Beruhigung der politischen Lage nach dem polnischen Aufstand im Jahre $1830 \mathrm{kam}$ und das franzósische Interesse für Rußland sich von neuem belebte. Dabei bemerkt er aber eine auffallende Unkenntnis dieses Landes, über die noch Herzen empört war (S. 9fr. und S. 13). Vgl. dazu SiGRIST 1990.

271 LORTHOL.ARY 1951 hat die Mythen Peters des Großen und der Zarin Katharina die Große bei Fontenelle, Voltaire, L'Abbé de Saint-Pierre und Montesquieu analysien, sowie anschlieBend direkte Kontakte der franzosischen ,aufgeklărten" Rußlandreisenden wie Bernardin de Saint-Pierre, lemercier de là Rivière. Rulhière, Chappe d'Auteroche und Diderot als „réalitès“ diesen Mythen gegenübergestellt Das 18 Jahrhundert habe sich aus den ..überlegenen belehrenden Positionen des Westens“" immer mehr für die .Fremde“, auch für Rußland intercssiert. Voltaire, Fontenelle und Diderot schufen sich dabei //hr Rußland, das für sie mit dem Peters des Großen und der Zarin Katharina identisch war, ohne sich für dieses I.and an sich. für dessen Sprache und Literatur zu interessieren, sondern nur für den russischen Staat und seine politische Rolle in Europa: es handelt sich somit zum einen um den .optimistischen“ Mythos Peter des Großen, des „russischen Marc Aurel, Prometheus und Herkules“, und zum anderen den der Zarin Katharina, der beiden aufgeklărten Despoten (S. 269f7. i. Ein Abschnitt ist auch der "crintsade vollatrienne contre la Pologne ef la lurquie" gewidmet (S. 109-134). Voltaire habe dieses politische Konzept im Hinblick auf seine französische ... Innenpolitik“" durchsetzen wollen und zu diesem Zweck das positive Bild des ,.aufgeklänen“" RuBlands henutzt das er als Vorbild für Frankreich kreierte und zugleich das Gegenbild, den muruge' Spa- 
mit der „positiven“ Variante des französischen aufgeklärten Diskurses über Rußland beschäftigt, nämlich mit den bereits bei Hanslick erwähnten .,Mythen“ der russischen aufgeklärten Herrscher, Peters des Großen und Katharinas II., wobei der „Polen-Diskurs“ eine negative Kontrastfolie dieser Mythen gebildet hatte.

Nach HANS ROTHE ${ }^{272}$ haben sich die westeuropäischen Fremdbilder über Slaven bzw. über die einzelnen slavischen Völker erst seit dem 15. Jahrhundert entwickelt. ${ }^{273}$ Bis zur Zeit von Leibniz sei das westeuropäische Bild der Russen bzw. ..Moskoviter" negativ und durch die Vermittlung Polens in den Westen gelangt, wobei das Polenbild zwiespältig war. ${ }^{274}$ Seit der Herrschaft Peters des Großen wurde Rußland zunehmend positiv, Polen negativ beurteilt. ${ }^{275}$ Die russischen Fremdbilder der westeuropäischen Nationen sind dagegen aus dem ..Bild vom Westen" überhaupt, im Kontext der Rezeption des westeuropäischen I iberalismus, entstanden. Insbesondere im 18. Jahrhundert kam es zur Herausbildung neuer russischer "Fremd- und Eigenbilder", die sich auf die Opposition zwischen Rußland und dem Westen festlegten. ${ }^{276}$ Dostoevskij stehe dabei in der Tradition des russischen Messianismus, des Topos vom antemurale Europae, der von Enea Silvio den Ungam zugeschrieben, dann von Polen (und Kroaten) übernommen wurde, und schließlich um die Mitte des 19. Jahrhunderts bis hin zur sowjetischen Ideologie den .russischen Gedanken“ beeinflußt hat. ${ }^{277}$ In diesem flüchtigen und zudem auf die nicht vollständige Beschreibung der „slavischen Bilder an sich" beschränkten Aufsatz wird aber die Beobachtung

mens schuf, das für ihn ein rückständiges, intolerantes und von dem katholischen Klerus versklavtes Land war. Vgl. dazu ĖTIEMBLE 1988-1989 oder KOMOROWSKI 1976.

272 ROTHE 1988.

${ }^{273}$ Ebd., S. 296-301.

274 Ebd., S. 299ff RonHE nennt aber Herbersteın und Olearıus nicht, die zum einen noch vor Leibniz lebten und zudem keine Polen waren.

275 Ebd., S. 301 f. Der von Herder geschaffene ..Mythos von den friedliebenden Slaven" sei dabei eine Umkehrung des negativen Slavenhildes der westeuropäischen Renaissance und in der Folge von den nach politischer Autonomie strebenden slavischen Völkern übernommen worden, obwohl nach Rothe auch das frühere Eigenbild der Slaven schon immer positiv gewesen sei und sie als freiheitsliebend zeichnete. Er erwähnt dabei den Alexander- $/$ /ythos oder das sogenannte P'rıvleggumm Sluvicum, auch den kroatischen Dominikaner Juraj Križanič (um 1612-1683) als Schöpfer des festen Bildes einer (ommunio. S/avicu (ebd.). An dieser Stelle müßten aber auch Pribojević. Orbim sowie Gundulić genannt werden Vgl. dazu DifLS 1983 (das Kapitel: .Z.usammengchörigkeitsgefühl Panslavismus“, S. 83-90, bes. S. 83).

276 Die uneinheitliche russische Kulturkritik am Westen lasse sich am Beispiel der positiven Deutschlandbilder Karamzins, Gončarovs oder der Symbolisten, der negativen Cechovs oder Dostoevskijs zeigen (S. 305-309). Das russische Polenbild, mit Ausnahme desjenigen von Pasternak, ist fur Rothe eindeutig negativ. Seine Genese liege zum einen in der Erinnerung an die polnische Großmachtpolitik im 16. und 17. Jahrhunder, zum anderen sei es im 20. Jahrhunder (Krieg von 1920) erneuert worden (S. 308ff.). Vgl. aber dazu KLuGE 1967 zum Verhaltnis Aleksandr Bloks zu Polen, das nicht nur negativ zu nennen ist (S. 16/f.) Siehe auch KLUGE 1964

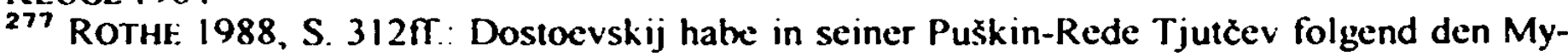
thos von der russischen Anpassungsfàhigkeit und Allmenschlichkeit kreiert, der von Blok und Solženicyn weiterentwickelt wurde. $V_{g l}$ dazu Kı.UGE 1967, ebd., S. 166ft., bes. S. 260-269 (zu Bloks Ansichten). 
Hansliks bestätigt, daß sich der dichotomische bzw. antinomische Charakter sowohl des west- als auch des osteuropäischen (russischen) imaginaire social im 18. Jahrhundert herauszubilden begann.

ALEKSANDER ROGALSKI ${ }^{278}$ behandelt ebenfalls literarisch-kulturelle Beziehungen zwischen Rußland und einigen westeuropäischen Ländern. In seiner umfangreichen Arbeit wird darüber hinaus die polnische Problematik, auch im Schaffen Dostoevskijs, knapp erörtert, wăhrend die Bedeutung Deutschlands, Frankreichs und Englands für die russische Kultur und Literatur sowie die Rezeption russischer Literatur und Kultur in diesen Ländern ausführlicher referiert werden. ${ }^{279}$

Das hier besonders relevante Kapitel über polnisch-russische Kontakte $W^{\prime}$ kregu sympatii $i$ awersji polsko-rosyjskich [Im Umkreis polnisch-russischer Sympathien und Abneigungen $]^{280}$ deutet auf ambivalente, emotionsgeladene politische und kulturelle Begegnungen zwischen diesen beiden Nachbarn, die immer zwischen $\mathrm{Haß}$ und Liebe bzw. Feindschaft und Freundschaft geschwankt haben. Rogalski beschäftigt sich mit den Freund- und Feindbildern bei polnischen und russischen Autoren bzw. Autorinnen wie Stanisław Staszic, Eliza Orzeszkowa, Boleslaw Prus, Joseph Conrad, Aleksandr Gercen, Fürst Petr Vjazemskij, und nicht zuletzt mit den antipolnischen Obsessionen Dostoevskijs. Der Ursprung der vorwiegend ambivalenten Beurteilung Polens bei den Russen liegt nach Rogalski in der "Zeit der Wirren“ und des Falschen Dmitrij. Im Laufe der polnisch-russischen Geschichte gab es seitdem noch weitere tiefe moralische Schulden auf beiden Seiten, die zu den Hindernissen und Mißverständnissen zwischen Polen und Russen wesentlich beigetragen hätten. ${ }^{281}$

Rogalski schreibt in diesem Zusammenhang über den $\mathrm{HaB}$ Dostoevskijs auf die Polen und führt dessen polnisches Feindbild auf die historisch bedingten russischen anti-polnischen Stereotypen zurück. Bei Dostoevskij habe aber die antipolnische Haltung das .durchschnittliche russische Maß" wegen der extremen Intensität übertroffen. ${ }^{282}$ Nach Rogalski läßt sich Dostoevskij grundsätzlich den slavophilen Kreisen zuordnen, in seinen literarischen Werken und in seiner Publizistik fänden sich auch zwei ideologische Konzepte wieder, wie die "fatale polnische Frage" gelöst werden sollte, die es damals in den breiten Kreisen der russischen gebildeten, aber nationalistischen Gesellschaft gegeben habe ${ }^{283}$ : 1 . Polen soll gewaltsam, durch die Vernichtung polnischer kultureller Autonomic, dem russischen Imperium ..einverleibt“" werden. Nach Rogalski war das die Ebene der tatsächlichen russischen Politik gegenüber Polen: 2. Das widerspen-

\footnotetext{
278 ROGALSKI 1960.

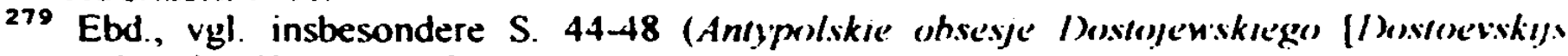
antipolnische (Obsessionen]).

200 Ebd., S. 24-50.

281 Ebd., S. 24tf.

202 Ebd., S. 47f. Er verneint die Hypothese von STEMPowski 1961 und stimmt dabei der Ansicht LEDNICKIS (LEDNICKI 1953) zu. Vgl. dazu unten, S. $114 \mathrm{fr}$.

${ }^{283}$ Ebd.
} 
stige Land und sein Volk sollen aus der Gemeinschaft der anderen, "echten“ slavischen Völkem ausgegliedert und seinem Schicksal überlassen werden. ${ }^{284}$

Für die besondere kulturelle Situation Polens gegenüber Rußland war nach Rogalski seine unterschiedliche historische Entwicklung, sein anderes politisches System, sein Katholizismus und der lateinische Charakter der polnischen adligen Kultur und Mentalităt im allgemeinen verantwortlich. Die westliche Prägung der polnischen Kultur habe negative Reaktionen bei den rusischen Autoren, d.h. bei beinahe allen Vertretern der russischen kulturschaffenden Intelligenz des 19. Jahrhunderts ausgelöst, so daß sich fast ausnahmslos von einer allgemeinen russischen "Idiosynkrasie“ gegenüber Polen sprechen lasse. $^{285}$

Aus den weiteren Untersuchungen zur Problematik der Darstellung Polens in der russischen bzw. Rußlands in der polnischen Kultur und Literatur, die den historisch-kulturellen Hintergrund des russisch-polnischen imaginaire social erörtern, wurden die Monographien von JAN ORtowSKI über die Darstellung Polens in der russischen Literaturgeschichte, ${ }^{286}$ von ANDRZEJ KĘPINSSK über RuBland- und Polenstereotypen in der polnischen und russischen Kultur und Literatur ${ }^{287}$ sowie der Aufsatz von STELLA GOLDGART über die Stereotypen von Polinnen und Polen in der russischen Literatur des neunzehnten Jahrhunderts ausgewählt. ${ }^{288}$

ORLOWSKI hat in seiner materialintensiven Monographie die Geschichte „antipolnischer Obsessionen", d.h. der vorwiegend antipolnischen Polenstereotypen und der sogenannten ,.polnischen Frage" in der russischen L.iteratur vom achuehnten Jahrhundert bis zum Jahre 1917 untersucht. ${ }^{289}$ Im einleitenden Kapitel analysiert er jedoch auch frühere Epochen der literarisch-kulturellen Be-

284 Ebd.

285 F.bd. S. 48. Vgl. auch die aus russischer Sicht geschricbenen Aufsátze von El.ıSTRATOV 1994, PAVLOVSKAJA und ZABROVSKJJ 1994. Aus den äußerst zahlreichen Forschungen über das deutsche Rußlandbild bzw. über das russische Deutschlandbild und zur gegenseitigen Rezeption der deutschen und russischen Kultur konnen hier lediglich einige Beiträge erwähnt werden: SrHul.Z 1969 (siche dazu auch unten, S 109), BRANCi 1995 oder KATAEV 1994 . Vgl. auch KaTAEV/KLLGE 1996 bzw. KI.l;GE 1996. Siche femer die von LEW KOPEl.EW gegründeten Reihen der Veroffentlichungen im Rahmen des Wuppertaler Projekts zur Erforschung der Geschichte deutsch-russischer Fremdbilder Vgl. KELLER 1985. DIES. 1987. DIES. 1992. SOwie HERRMANN 1988a-b und DIES. 1992. Diese Reihen werden fortgesetzt. Siehe auch die ausführliche Bibliographie in jedem Band.

286 ORLOWSKI 1992

287 KËPINSKI 1990.

288 GOLDGART 1986. Vgl. auch KULCZYCKA-SALONI 1991. Kulczycka-Saloni befaßt sich hauptsächlıch mit den Figuren der Deutschen in den polnischen Romanen von $B$. Prus oder $T$. Jeske-Choinski. Die Verfasserin stellt fest. daß es in den Romanen von B. Prus oder von WI. Si Rejmunt erstaunlich wenige russische Figuren gibt. obwohl die Handlung in den von Russen besetzten Gebieten spielt. Russen wurden sonst meistens als Uniformierte dargestellt (z.B. bei Eliza Orzeszkowa). Diese Eigentümlichkeit läßt sich teilweise durch Eingriffe der russischen Zensur erklären. ebd., S. 82f.

289 ORtowSkl 1992. Siehe dort auch die Bibliographie zur polnischen Problematik in der russischen L.iteratur- und Kulturgeschichte (S. 217-223). 
ziehungen beider Staaten, denn der Entstehungsprozeß russischer Polenstereotypen läßt sich bis in die Zeit der Kiever Rus ${ }^{\circ}$ zurückverfolgen. ${ }^{290}$

Orłowski stellt fest, daß schon in der Kiever und dann der Moskauer Rus negative Polenstereotypen, des Ljachs, ${ }^{291}$ d.h. der früheren Bezeichnung für Polen, sowie der schönen Polinn ${ }^{292}$ vorhanden waren. Ihre Genese fallt in die Zeit des Kriegszugs des polnischen Königs Bolesław Chrobry gegen Kiev, dann in die der Kriege zwischen dem polnischen Herrscher Stefan Batory und dem Moskauer Staat bzw. in die Zeit der Wirten (Smuta). Erst seit der dritten Teilung Polens 1795 enstand die sogenannte polnische Frage, die im 19. Jahrhundert, wăhrend und nach den beiden polnischen Aufständen von 1830 und 1863, bis hin zum Ende des ersten Weltkrieges die russische Öffentlichkeit beschăftigte. In der russischen Öffentlichkeit wurde das katholisch-adlige, ,abtrünnige“, rebellische Alte Polen für nicht mehr existent erklärt. Die polnische Nation und Kultur blieben aber lebendig, so daß die polnische Frage doch gelöst werden mußte. Im 19. Jahrhundert wurden deswegen auch die aus der früheren Zeit überlieferten Polenstereotypen endgültig ausgeprăgt, weiterentwickelt und variiert.

Orłowski bemerkt dabei, daß im Unterschied zu den negativen deutschen Polenstereotypen, die ideologisch-nationalistische Positionen der kulturellen und

290 Ebd. S. 15-32.

291 Vgl. daZu U.a. VASMER 1953-1955 (Bd. 2., S. 84); SL.OVAR' SOVREMENNOGO RUSSKOGO LTTERATURNOGO JAZYKA [Wörterbuch der literurıschen (iegenwartssprache] (Bd. 6, Spalte 461f.); PreOBRAŻenSKJ 1959, S. 499. Vgl. auch z.B. die Nestorchromk [ Povest' vremennych let]: „Es war noch ein anderer Starec, namens Matvej, der war hellseherisch. Als er einst in der Kirche an seinem Platze stand, seine Augen erhob und auf die Brüder schaute, die auf beiden Seiten singend dastanden, sah er einen Teufel $m$ Ljachengestalt [kursiv M.Ś.] mit einem Mantel bekleidet herumgehen, der trug in seinem Schoß eine Pflanze, die Klette heißt. Und wenn er an den Brüdem vorüberging, nahm er aus dem Schoß eine Klette und warf sie auf irgendeinen: wenn die Klette an einem der singenden Brüder festhing. so blieb der noch ein wenig stehen und ging geschwăchten Verstandes, nachdem er irgendeinen Fehler begangen hatte, aus der Kirche in seine Zelle und schlummerte dort ein und kehrte vor Ende des Singens nicht in die Kirche zurück," in: TrAUTMANN 1931, S. 137; siehe auch die neueste Überseuung von LUDOLF MülLER (zitiert nach dem Manuskript): ..Es war da auch ein anderer Starez, mit Namen Matfej; er war hellsichtig. Einmal nămlich stand er in der Kirche an seinem Platz und erhob seine Augen und schaute über die Brüder hin. die singend aut beiden Seiten standen, und er sah einen Dämon herumgehen in der (jestall eines ljachen [kursiv M.S. ], in einem Überkleid. und in seinem Rockschoß trug er Blüten [von der Blume,| die da heiBt 'Klette'. Und er ging umher neben den Brüdern und nahm aus dem Schoß eine Klette und warf sie auf einen." Vgl. auch seine Übersetzung derselben Stelle in MOLLER 1984, S. 68. in der allerdings von einem .Dämon in der Gestalt eines Polen“ die Rede ist. Siehe ferner

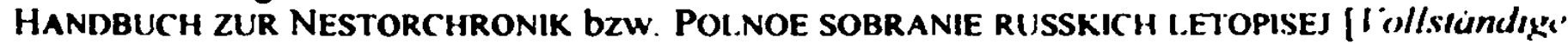
. Summlung russischer ('hroniken].

292 ORLOWSKI nennt als das Urbild des Stereotyps der .,schonen Polin“ in der russischen Literatur die Geschichte des asketisch veranlagten Moisi (Igrin aus dem Kievi-l'eciersky) Pulerık [Das Väterhuch des Kiever Höhlenklesters], in den sich eine Frau aus der l.jadski!) zemlı [= Land der Ljachen] unglücklich verliebt, ebd., S. 17f. Siehe: Kic'vi-l'ecierskı Pulcrik. In: PAMJATNIKI LTTERATURY DREVNEJ RUSI [Lilerururdenkmäler der Aliı'n Ru']. S. 543tf. Zu einem Sereotyp bzw. Mythos der russischen Literatur und Folkore ist Murynu Mniszchiwnu. die Frau des Imitrij Samozvanec, geworden (ORI.OWSki 1992. S. 23f.). 
zivilisatorischen Überlegenheit widerspiegelten, die russischen Polenstereotypen des 19. Jahrhunderts russische Komplexe der kulturellen Unterlegenheit und Schuld gegenüber Polen thematisiert haben. ${ }^{293}$ In der damaligen russischen Literatur und Publizistik gab es deshalb sowohl den negativen Typ des polnischen Intriganten, Verschwörers bzw. Rebellen als auch den positiven Typ des kämpferischen opferbereiten Märtyrers, der sich für die Sache der Befreiung von der Diktatur einsetzt (bei Herzen, Ogarev, Tolstoj und Korolenko). Nach 1863, als in Polen die Zeit der ,positivistischen" sozialen "Grundlagenarbeit" begann, wurde der romantische Rebell durch den fleißigen Arbeiter oder Kapitalisten ersetzt. $^{294}$ Bis dahin hatte die russische Literatur den negativen Typus des „adligen Prassers“, des polnischen Magnaten aus der Zeit der Sächsischen Dynastie, mit Vorliebe verwendet. Der Typ des aufständischen Kämpfers wurde dagegen zum politischen Verschwörer, zum .Konrad-Wallenrod-Typ“ umgewandelt, beispielsweise in den antinihilistischen Romanen. ${ }^{295}$ Es gab aber auch positive polnische Gestalten bei L. N. Tolstoj, A. Gerzen, Leskov, Korolenko, auch andere Autoren wie Vjazemskij, Puškin, Černyševskij, Blok oder Gor kij zeigten offen Interesse für die polnische Kultur und für die .,polnische Frage". 296

In der Zeit des ersten Weltkrieges wurde aber dieses frühere negative russische Polenbild aus politischen Gründen verworfen. Russische Dichter und Schriftsteller haben in den Jahren 1914-1917 Gedichte an die „polnischen Brüder" gerichtet, sie stellten Polen symbolisch auch als eine ,jüngere Schwester" Rußlands dar, als ein Land, das, durch den Krieg gequält, ihnen nahe steht und durch den ...älteren Bruder" bzw. durch die ,,liebende Mutter" Rußland geschützt werden sollte. ${ }^{297}$ Nach 1917 und 1945 wurde die Problematik der russisch-polnischen Literaturbezichungen und das Polenbild im Lichte der kommunistischen Ideologie einseitig, entweder zum Feindbild oder positiv zum Freundbild, uminterpretiert. Nach dem zweiten Weltkrieg zeigten die sowjetische und polnische Forschung ein verschönertes russisches Polenbild, auf dem es jedoch viele „weißen Flecken“ gab, die erst heutzutage getilgt werden können und dürfen. Orłowski stellt abschließend fest, daß das russische Polenbild jeweils von den politischen Bezichungen zwischen beiden Länder abhängig gewesen ist und von russischer Seite als ideologisches Mittel der russischen Politik gegenüber Polen eingesetzt wurde. ${ }^{298}$

293 OrLOwSki, S. 6f. Fr beruft sich dabel auf L.EDNICkl 1935, S. 9. Ortowski bemerkt zugleich, daß polnische literarische Russenstereotypen weniger negativ als russische Polenstereotypen waren (cbd.).

294 In dem polnischen Roman von B. Prus l.alka [//e /'upp'] ist jedoch der Hauptheld, Wokulski, ein Kapitalist mit der ..Seele eines Romantikers“"

295 Ebd., S. 9 ff

296 F.bd.

297 Ebd., S. 10f. Vgl. dazu Orlowski 1984; DERS. 1986; DERS. 1990 oder DERS. 1995.

298 OrlowSK1 1992, S. 12f. und $S$. 214-216. Wegen der ungeheuren Breite des Untcrsuchungsgegenstandes. der Darstellung Polens in der russischen Literatur und Kulturgeschichte im Laufe mehrerer Jahrhunderte, war es ihm leider nicht möglich, das Schaffen einzelner Autoren, z.B. auch Dostoevskijs, eingehender zu behandeln. „Dostoevskijs Reaktionen" auf die polnische l'ruge hat er aber in einem Aufsatz erörtert. vgl. dazu unten, S. I19ff. 
Auch KĘPINSKI hat sich mit negativen Stereotypen von und über Polen und Russen, hauptsächlich mit dem russischen Stereotyp des Ljach und dem polnischen des Moskal befaßt. In zwei Aufsätzen und in einer Monographhie hat er diese aufeinander bezogenenen Stereotypen in ihrer kulturgeschichtlichen Genese, Entwicklung und Funktion von den Anfängen der beiden Staaten bis zur ersten Hălfte des 19. Jahrhunderts mit einem Ausblick in das 20. Jahrhundert untersucht. ${ }^{299}$ Sie werden wie bei Orłowski nicht ausschließlich in literarischen Werken. sondern auch anhand anderer Quellen als ..Kulturtexte" (Lotman) beschrieben. Literarische und paraliterarische Texte, auch Sprichwörter, werden strukturell, geschichtsliterarisch und linguistisch analysiert. Kępinski geht es darum, das polnische Autostereotyp mit dem russischen zu vergleichen, da sich beide in Opposition zueinander und zu anderen Nachbarstereotypen geschichtlich herausgebildet hätten. ${ }^{300}$

In dem Kapitel über den Ursprung des negativen russischen Stereotyps des Polen als Ljach $^{301}$ versucht er, anhand von Quellen aus der Kiever Zeit sowie einiger späterer Dokumente zu bestimmen. wie es zur Herausbildung eines einheitlichen und dauerhaften Identitätsmodells der russischen Kultur gekommen ist. Das orthodoxe Christentum war der wichtigste Faktor bei der „Autoidentifikation und Differenzierung des nationalen Bewußtseins“ in der Zeit der Entstehung der Rus und dann des russischen Staates sowie der Herausbildung elementarer Begriffe der Nation und des Staates. ${ }^{302}$ Kępiński zeigt an Beispielen

299 KEPINSKI 1986 und DERS. 1990a-b.

300 Als das wichtigste Merkmal solcher stereotyper Vorstellungen wird die ..Anglcichung und Verdichtung ihrer Bedeutung" betrachtet. beispielsweise der Ausdrücke hurharziniskı $A$ foskal

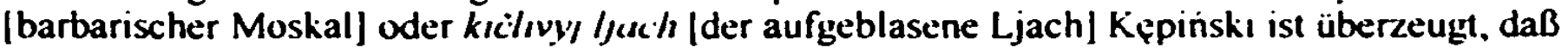
es universale anthropologische Gesetze gibt, die eine Haltung der Abneigung gegenüber Fremden verursachen und zu ihrer Verbalisierung führen. In den Stereotypen werden Ergebnisse der Ablagerungen kultureller Schichten, u.a. politischer Impulse, ..gespeichert". Rußland und Polen lassen sich gegenseitig in das schematische Vergleichsparadigma einschreiben, das auf der Opposition zwischen dem Eigenen und Fremden (.swojskosic vs. ohcesic) beruht, in der das Fremde oft mit dem Feindlichen (wrogesic) in eins gesetz wurde (ebd., S. 7-15). Er entwickelt somit eine eigene Theorie von der historisch-religiösen (sakralen) Herausbildung eines .,nationalen Stereotyps“, das als noch weit manifester und inflexibler angesehen werden muß als das der bisher behandelten, die lediglich im sprachlich-kulturellen und polıtischen Anderssein und in nationalen Konflikten gründen. Dieses theoretische Potential verdiente eine eigene Würdigung.

Auch der Religionsforscher PIf.RRF. PASCal hat sich über die widerspruchliche .. Beziehung zum Nächsten" in der russischen Volksfrómmigkeit geäußert. also über die der russischen Mentalităt nicht unbekannte Xenophobıe, die die Annahme erharten konne. Jall auch Dostoevskijs Werke dieser Tradition verpfichtet sein könnten. Er fügt jedoch sofort rechtiertigend hinzu, was die obige Feststellung relativiert und seinen ..Gilauben" an ein den Kusien angeblich angeborenes, in ,jeder russischen Seele" tief verankertes Gefuhl der menschlichen Gemeinschafi zeigt. Vgl. PASCAL 1966, S. 25; siehe auch zu dem Ideologem ..die russische Seele“" bei LAZARI 1995, S. 86 f

301 KEPINSKI 1990a, S. I $43 \mathrm{ff}$

302 Es war die Religion, die das überzeitliche Paradigna des Russie'ntums (roni\%skusic) entstehen ließ. Der orthodoxe Partikularismus bestimmte die grundsätzlichen Antınomıen des russischen Denkens Die religiöse Weltanschauung, die sich mit den mythıschen Strukturen der Wirklichkeitseinschätzung verbindet. umfaßt alle Elemente des ethnischen Bewußtseins und 
aus dem griechisch-byzantinisch-russischen Schriftum, wie die aus Byzanz übernommene Abneigung gegenüber dem Lateinertum (lacińskość), zu dem auch Polen gehörte, das Ethos des Andersseins, den Genotyp der russischen Kultur gebildet hatte, der auf einer konfessionellen und ethnischen Xenophobie aufgebaut wurde. ${ }^{303}$ Nach dem Fall von Byzanz und der Gründung des "Dritten Roms" ist dieses Ethos von dem Ausnahmecharakter, der Erwăhltheit der russischen Kultur weitergepflegt worden. ${ }^{304}$ Das Charisma der Heiligen Rus', verbunden mit dem Thron des Zaren, die erhabenen Ziele des Schutzes und der Verteidigung der „echten Religion“ werden mit dem partikularen nationalen Stigma und der Idee des auscrwählten Volkes verbunden. Das .lateinische“ Polen war dabei für Rußland kulturell eine Brücke, die Rußland mit dem Westen verband. zugleich aber auch ein Hindernis auf dem Wege zur Expansion in die Richtung des Baltischen Meeres und der Inflanten. ${ }^{305}$ Kępiński bespricht ebenfalls wie Orłowski die Zeit der Wirren (Smula). die nicht nur den $\mathrm{HaB}$ gegenüber Polen. sondern auch gegenüber den sogenannten ..Heiden" festigte. Obwohl es schon seit der zweiten Hälfte des 17. Jahrhunderts zum Zusammenbruch der polnischen Ostpolitik gekommen war, Rußland dagegen seine Expansion nach Westen begonnen hatte, sind die bereits in der kulturellen Tradition der beiden l.änder gefestigten Stereotypen des Ljachs und Moskals unverändert geblieben. Während die Polen ihre überlegene Haltung gegenüber der russischen Kultur behielten, berief sich Rußland gem auf die Vergangenheitsmuster, um seine Großmachtpolitik zu begründen. Sowohl in Polen als auch in Rußland wurden aus der Geschichte jeweils andere Schlußfolgerungen gezogen, die die traditionsreichen stereotypen Überzeugungen und kulturellen Mythen sanktionierte. ${ }^{306}$

sahralisien es, indem es zur Entstehung der Mythen über die Überlegenheit und den Ausnahmecharakter des eigenen Wertesystems führt, das in Form von Autostereotypen verfestigt und autbewahrt wird Schor in der Nes/orchromık wird die .,bessere“ Religion ausgewählt. Die Metapher von der ..Süße" der eigenen und der ..Bitterkeit" der anderen Religionen trägt dazu bei, daß nach deın Gesetz des Vergleichs jede fremnde Konfession das ..bittere“" l'rofanum sei (ebd., S. 144f.).

303 Ebd.. S. 147

304 Ebd. S 148

${ }^{305}$ E.bd., S. $148 f$ r.

306 Die sechzehnmonatige Belagerung des Sergiev-Troickij Klosters durch polnısche Soldaten. nach Pavel Florenskij ..das Herz der russischen Kultur“*, hat die heiligsten nationalen Gefühle verletzt. Der Kampf gegen die Polen wurde zum Relıgionskrieg erklärt: Man verteidigte

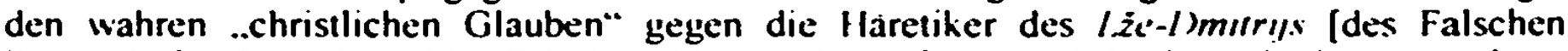
Dınitrij], des I.ze-( \%ris/ [des Falschen Christus bzw des Antichrists] (auch =lonravnu lutor (unsittlicher Luther]) genannt (ebd. S $161 \mathrm{f}$ und 148ff.). D.h., daß auch fur die Zeit der Wirren eıne religiös begründete Xenophobte Vorurteile und Stereotypen geprägt hatte, und daB man in Rußland polnische Klischees und Stereotypen übernommen (z.B. das negative polnische Stercotyp des Deutschen (=,Luther $\left.\left.{ }^{*}\right)\right)$ und sie dann als eine Bezeichnung für die Polen angewandi hatte, obwohl dieses negative Stereotyp im polnischen. katholisch geprägten Kontext entstanden war und im russischen funktionslos oder sogar positiv hätte sein müssen, wenn man dort dessen Inhalt gekannt häte, denn Lutheraner sind antirömisch. Dasselbe paradoxe Phänomen läßt sich übrigens auch bei Dostoevskij finden. Vyl. dazu z.B. KLUGE 2000). 
Im letzten Kapitel werden dagegen russische Auto- und Polenstereotypen in der ersten Hälfte des 19. Jahrhunderts erörtert. ${ }^{307}$ Obwohl die schwierige politische Lage die kulturellen Kontakte zwischen Russen und Polen kaum zu begünstigen schien. waren damals paradoxerweise diese Kontakte besonders intensiv, so daß sich ein positives Modell der Rezeption polnischer Kultur in Rußland herausgebildet habe, u.a. dank den Reisen russischer Schriftsteller und Dichter nach Polen. ${ }^{308}$ Zugleich blieb aber das frühere Stereotyp der ..Heiligen orthodoxen Rus"“ (als das Stereotyp des „Vaterlandes“) unverändert stabil. Militärische Siege Rußlands führten darüber hinaus zur Herausbildung eines imperialen Überlegenheitsbewußtseins in der russischen Mentalität. so daß .,Rußland“, das "Eigene", mit charismatischen Zügen ausgestattet wurde. Die russische Erde, das "eigene Sacrum", in dem sich der "russische Gott" verkörpert hat, wurde dem "fremden Profanum" gegenübergestellt. Auch die früheren Polenstereotypen, die jetzt zusätzlich mit der ..polnischen Frage“" zusammenhingen, wurden auf diesem Hintergrund wciterentwickelt. Polen wurde zum "slavischen Judas", war das Land des „falschen“ Glaubens, der Jesuiten und Priester, der hochmütigen adligen Verschwörer und auch der patriotischen schönen Frauen. Als Beispiel dieser Mentalität wird die Apologie des idealen orthodoxen RuBlands in Dostoevskijs Roman Besy angeführt. ${ }^{309}$

Als letzte Arbeit über die russischen Polenstereotypen wird der Aufsatz von STEI.LA GOL.DGaRT über eine von ihr vorgeschlagene Typologie der Figuren der Polen und Polinnen in der russischen L iteratur des 19. Jahrhunderts erörtert. ${ }^{320}$ Die polnischen Figuren gehören dabei zwei Kategorien an: sie treten als fiktrve oder historische Gestalten auf, d.h. als authentische Figuren aus der polnischen Geschichte bzw. persönliche Bekannte, Freunde und Verwandte des jeweiligen Schriftstellers. ${ }^{311}$

Der fiktive Pole, der in den russischen literarıschen Werken des vergangenen Jahrhunderts vorkommt. ist dabei nicht einheitlich und ausnahmslos negativ, da es damals mehrere Polentypen gegeben habe. ${ }^{312}$ Man soll aber zugleich beach-

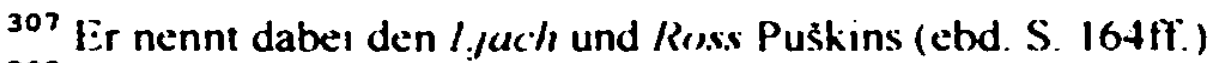

308 Ebd., S 167f.

309 Dies gilt auch für Puškın, Zagoskin, Lermontov oder Bestužev-Marlınskij, Gogol, sowie für die russischen Memoirenschreiber F. Glinka und P. Vjazemshij Sogar Gercen habe Polen mil dem .Papismus" und ..Jesultısmus" identitiziert und an unuberwindbare Unterschiede zwischen dem russischen und polnischen Nationalcharakter geglaube (ebd.. S. 174ff.) Kępinshi schreibı dabei über die Entstehung. nıcht nur bei den Slavophilen, eines russischen Mly'lex des Nerckens, der mit positiven Konnotationen versehen wurde, obwohl er heine Delinition des Begrifts $1 / 2 / h o x$ angibt (ebd. und passim, bes. S. 192ff. und 199ff. und $S$. $207 f$ ). Siche ferner WALICKI 1991: DERS 1975 und DERS. 1980.

310 GOLDGART 1986. Die Verfasserin geht aber nur deskriptiv vor, ohne auf die terminologischen Fragen zu ..literarische Figur". zu ..Typ“ oder gar zu ..Stereotyp” einzugehen.

311 Ebd., S.120t: Zu den beliebten hivirusche'n Gestalten gehören Mickiewic .. Mañna Mniszet und Kosciuszko. Kosciuszko und Mickiewicz werden als edle Mienschen und Genies verehrt. z.B. bei Gercen oder Puškin. Maryna Mniszek wird dagegen als dic polnısche L.ady. Macheth, die Verkörperung des Willens zur Macht und der Rücksichtslosigkeıt ım Sireben nach dem Ziel, dargestellt.

312 GOLIX Literatur, d.h mit den Ansichten russischer Schriftsteller, die politische, wirtschaftliche oder 
ten, daß die polnische Nationalităt vieler literarischer Figuren nicht immer direkt erkennbar ist. Es gibt zahlreiche mutmaßliche Polen, die einen ,polnisch klingenden Namen" haben, obwohl es zugleich oft schwierig ist, den Namen der einen oder der anderen Nation zuzuschreiben. weil es in beiden Sprachen ăhnliche Namensstrukturen gibt. ${ }^{313}$ Als Hinweis auf eine polnische Herkunft kann die römisch-katholische Konfession, die Erwähnung der Teilnahme an einem der polnischen Aufstände oder die Tatsache dienen, daß die Figur in Warszawa gewohnt hat. Hăufig werden einige polnische oder scheinbar polnische Idiome und einzelne Worte in den Text hineingeflochten, wie z.B. Matka Boska, kochany, pan, pani oder lajdak [= Die Mutter Gottes, lieber, Herr, Dame bzw. Herrin, oder Schufi] bzw. andere Ausrufe oder Schimpfworte. Zu den ..polnischen" Merkmalen in der russischen Literatur gehören auch die Kleidung sowie eine besondere Haltung [postawa], eine Adlemase oder ein Schnurrbart. ${ }^{31 \%}$

Fast alle Polen gehören darüber hinaus dem Adel an. Es sind entweder deklassierte Kleinadlige oder Hochadlige, falsche oder echte Aristokraten. ${ }^{315}$ Die dritte Kategorie bildeten Vertreter der polnischen Intelligenz, Beamte oder Industrielle, die ebenfalls oft nicht dem ,niederen Volk“ entstammten. Daraus ergibt sich die Regel, daß die in der russischen Literatur beschriebenen Polen typische Eigenschaften des polnischen Adels, seine Mentalităt aufweisen: den persőnlichen Stolz und das Ehrgefühl, manchmal ins Hypertrophische gesteigert; sie haben viel Ehrgeiz, sind vornehm, galant und ritterlich den Frauen gegenüber, sie weisen ein verhältnismäßig hohes Bildungsniveau bzw. Kultiviertheit auf, of sind sie aber voll Verachtung den Vertretern anderer Nationen oder dem einfachen Volk gegenüber. Der ausschlaggebende Charakterzug eines Polen ist die Bindung an die katholische Kirche, die sich im Kult der Mutter Gottes, in der Achtung vor dem Papst, manchmal im Mangel an religiöser Toleranz außert. Viele Schriftsteller betonen den negativen Einfluß der katholischen Geistlichkeit, v.a. der Jesuiten, auf die Herausbildung des polni-

sozıale Probleme der polnıschen Bevölkerung auf dem Giebiet des damaligen russischen Imperiums erörtert haben. Diese Frage ist natürlich mit der Problematik der ..Poienbilder" verbunden, aber nur teilweise, denn wie Goldgart schreibt, stellten viele russische Autoren Polen dar, ohne überhaupt auf die ..polnische Frage“ einzugehen. Manche Schriftsteller erörterten dagegen ausschließlich politische und geschichtliche Fragen, ohne polnische Figuren als Individuen darzustellen. Es gibt aber auch Schriftsteller, die beide Aspekte in ihrem Schaffen berücksichtigt haben, so zB. A. Gercen (ebd., S. $117 \mathrm{f}$ ). $\mathrm{Vgl}$. auch die frühe russische Arbeit von PYPIN 1881

${ }^{313}$ GOLDGART 1986, S. $117 \mathrm{ff}$

324 Wenn zusätzlich die vermeintliche polnische Figur Bewohner oder Bewohnerin der ukraınischen oder weißrussischen Gebiete ist, steigt die Wahrscheinlichkeit an, daß es sich um polnische Bewohner dieser Gebiete handelt. Als Beispiel wird die Heldin der Novelle

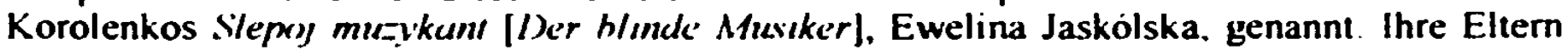
gehören dem Kleınadel in Wollnunien an, und sınd eifrige Katholiken. Ewelina ist also offenbar eine Polin, obwohl sie selbst nirgends darüber spricht. Auch der „slepoj muzykant” scheint ein Kind aus einer Mischehe zwischen einem Polen und einer Ukrainerin zu sein (ebd., hier S.119).

${ }^{325}$ Ebd. Diese soziale Herkunft dieser Figuren låßt sich dadurch erklăren, daß die meisten Russen Kontakte zu den adligen Polen hatten, die entweder in den weißrussischen oder ukrainischen Gebieten wohnten oder nach Sibirien verschickte Aufständische waren. 
schen Charakters. Die Jesuiten seien nach der russischen alten Tradition die Verkörperung der Scheinheiligkeit und Heuchelei. ${ }^{316} \mathrm{Zu}$ den Charakterzügen der literarischen Polen gehört auch der Patriotismus; einen negativ gezeichneten Typ des polnischen Patrioten bilden Intriganten, Rănkeschmiede, Verschwörer, Schwindler bzw. Spekulanten. Der Abenteurer-oder Betrüger-Typ zeichnet sich meistens durch vomehme Manieren aus. ${ }^{317}$ Nach dem Januaraufstand gegen Rußland von 1863 taucht noch ein weiterer Polentyp auf, nämlich der Nihilist, beispielsweise bei Leskov, obwohl es bei ihm auch den positiven Typ des "edlen, gerechten Mannes" gibt. Polen bekleideten aber auch hohe administrative Ämter, waren große Grundbesitzer, Fabrikanten oder Gutsverwalter bei reichen Aristokraten. Diesen Typ treffen wir im Stepnoj korol' lir [König Lear aus der Steppe] Turgenevs an; auch in dessen Roman Nakanune [Am Vorabend] ist der Beamte Kurnatowski Sohn eines solchen Verwalters. Gegen Ende des 19. Jahrhunderts schließt sich diesen Figuren eine weitere an: der "Kapitalist", zugleich ein neuer Typ unter den russischen Figuren. ${ }^{318}$

Goldgart unterscheidet dagegen nur zwei polnische Frauentypen: „polnische Mutter" (Matka-Polka) und ,junge Frau“ (Panna) bzw. .Dame der höheren Gesellschaft". Die ,junge Frau" ist ungewöhnlich schön, elegant, vornehm und gebildet, sehr oft stolz und unzugänglich den Feinden ihrer Heimat. Oft wird sie als kokett und zugleich als sanft und bescheiden beschrieben. ${ }^{319}$

Zusammenfassend stellt Goldgart fest, daß polnische Figuren in der russischen Literatur des 19. Jahrhunderts ein breites Panorama von beinahe idealen bis hin zu mörderischen und kriminellen Gestalten bilden. Das Verhältnis des jeweiligen russischen Autors zu Polen und zur polnischen Problematik sei das Ergebnis seiner ethischen und politisch-sozialen Anschauungen, seiner Lebenserfahrung und der Beziehung zur nationalen literarischen Tradition. ${ }^{320}$

316 Ebd., S. 119 fr.

327 Ebd., S. $121 \mathrm{ff}$ : Solche Typen treten bei Suchovo-Kobylin auf. Bei Vel tman ist es der falsche Graf pan خelyńskı. Siehe zu dieser Figur bei Dostoevskij unten, S. 386.

${ }^{318}$ Ebd. Alle diese Figuren sind intelligent, haben einen starken Charakter und persönlichen Charme, was sie noch gefährlicher macht. Der Pole als ein ..Ehrenmann" tritt dagegen in Knjagınja Lıgovskaja [ $/$ ̈ürsıın Lıgovskaja] von Lermontov auf. Stanisław Krasinski, ein verarmter Adliger, achtet nicht nur auf seine Ehre, er ist auch intelligent, schön und liebt seine Mutter. Er eröffnet die Reihe der sogenannten ..stolzen Bettler“" in der russsischen Literatur, die auch bei Dostoevskij anzutreffen sind.

319 Es handelt sich somit um positive oder negative Varianten des Stereotyps der „schönen Polin“. Als Beispiele solcher Frauen nennt Goldgart Marija in Puškins Poem Bachčsarajskıj fontan [Der Springhrunnen von Bachicusara]] oder die Polin in Taras Bul ha Gogol's bzw. Evelina in Korolenkos Slepoj Muzykamı. Bunins Galja Gan skaja gehört zu dem eher unberechenbaren und wilden Typ der polnischen Frau (ebd., S. 124.).

${ }^{320}$ Ebd. Ähnlich angelegt ist die Abhandlung KIPARSKYS 1964 über englische und amerikanische Figuren aus den letzten 250 Jahren der russischen und sowjetischen Literaturgeschichte. Zu diesen „typischen“, d.h. stereotypen Figuren gehören englische Männertypen und Frauentypen wie Iords and Tourısts, the Sallor, the Worker, Secret Agents, ('riminals and Detecivves sowie the (ioverness, Upper-class Lady, Middle-class and Workıng-class Woman; zu den amerikanischen u.a. the Neighbours in the Bering Sea. Businessimen and Millionaires, Preachers and Spiritualısts, the American Tourist and Newspuperman. Besonders die sowjetische Literatur gestaltete stereotype Figuren der „Klassenfeinde.“ die der anti-amerikanischen 
$\mathrm{Zu}$ den drei Beiträgen läßt sich zusammenfassend festhalten, daß sie trotz ihres ausschließlich induktiven bzw. empirisch-deskriptiven Charakters für die imagologischen Interpretationen literarischer Werke Dostoevskijs thematisch relevant sind. weil sie: 1. die grundlegende Rolle des katholischen (,lateinischen“) Polens bei der Herausbildung und Festigung russischer kultureller (bzw. national-religiöser) Identität hervorheben, das sowohl als politischer wie auch religiöser Feind der Kiever und Moskauer Rus 'bzw. dem späteren Rußland, dem modernen russischen Imperium, als negative Kontrast folie gegenübergestellt worden ist: 2 . die grundlegende Rolle der russischen Orthodoxie bei der Herausbildung einer dichotomischen Aufteilung des russischen imaginaire social in „das sakrale (= gute) Eigene“ und „das profane (= böse) Fremde“ betonen, wobei Polen immer das „böse Fremde" symbolisiert: 3. eine diachrone Übersicht über die Herausbildung und uber das reiche Repertoire gegenseitiger nationaler russisch-polnischer Stereotypen bieten, deren Herkunft sich bereits in die Zeit der Kiever und Moskauer Rus (Ljach vs. Moskal) zurückverfolgen läßt. und 4. zugleich auf den Reichtum stereotyper polnischer literarischer Figuren hinweisen, die zum Teil auf diese (alt)russischen Stereotypen der Polinnen und Polen zurückgehen und in der russsischen Literatur des neunzehnten Jahrhunderts differenziert und um weitere Varianten ergänzt wurden, beispielsweise um den polnischen politischen Verschwörer, den polnischen Jesuiten, den betrügerischen Kartenspieler oder um die schöne, verführerische und extrem patriotisch gesinnte Polin, die gleichzeitig fanatisch katholisch ist.

$\mathrm{Zu}$ untersuchen wäre dabei, welche dieser polnischen Stereotypen in den literarischen Werken Dostoevkijs vorkommen, sowie, welche Funktion sie innerhalb seiner fiktionaler Welt erfüllen, um so mehr, weil die oben referierten Forschungen lediglich diese Stereotypen ,.,an sich“ erörtert haben, ohne sie in literarischen Texten zu interpretieren.

Ausführlicher soll im folgenden die Dostoevskij-Forschung referiert werden, sowohl zum gesamten Fremdheitsphänomen als auch zu seinen einzelnen Aspekten, d.h. zur Darstellung einzelner fremder Nationen oder ethnischer Gruppen, obwohl es keine Beitrăge gibt, die die in den vorherigen Kapiteln erörterten Methoden anwenden. Abgesehen von kleineren Beiträgen gibt ebenfalls keine Studie, die Dostoevskijs (iesamtwerk bzw. sein literarisches oder publizistisches Werk im Hinblick auf ein bestimmtes nationales oder ethnisches Fremdhild oder Stereotụp interpretient hătte. Dic bisherige Dostocvskij-For-

brw ant1-westlichen Propaganda dienten, wotei die Zensur immer eine wichige Rolle bel der (jestaltung dieser Figuren gespielt hat (S. 11). Fs wird dabei bemerkt, daß im 19. Jahrhundert sowohl in den Werken der Slavophilen als auch der Westler ähnliche Ansichten über Fingland und Amerika und ähnliche angelsächsische Figuren bzw. soziale Typen anzutreffen sind, was von der Existenz ausgeprägter russischer Eingland- und Amerikastereotypen zeugen kann (S 186), obivohl Kiparsky keine konkreten Beispiele anführt. Anschließend fügt er eine tabellarische Übersicht über die Entwicklung russischer literarischer Fngländer- und Amerikanerstereotypen seit der Zeit vor !eeter dem Großen bis 1955 bei. So war z. B. der lyp des . Sullor. last durchgehend bis zum Zweiten Weltkrieg ...well-known". ..admired" oder ..reluctantly admired“" von 1941 bis 1945 ...ddmired as a gallant ally“, nach 1945 ..ignored“" bzw. ab 1955 .mentioned as a wartime ally" (S. 194f.). Vgl. auch (RoSS 1985. Siehe ferner Gi:RIGi 1995 
schung hat bereits hăufig den widersprüchlichen, dualistischen, ambivalenten oder auch paradoxen Charakter seiner Werke hervorgehoben und ihn sowohl auf der thematischen Ebene, in ihrer Weltanschauung bzw. Ideologie, als auch in ihrer Poetik ${ }^{321}$ untersucht. Die Forscher sind sich jedoch in der Antwort auf die Frage nicht einig, ob die von ihnen festgestellten Widersprüche, Aporien oder Antinomien darin aufgelöst. beispielsweise in einer hegelianisch-idealistischen bzw. religiösen Synthese aufgehoben werden, oder aber in einem modernen bzw. „postmodern" scheinenden ästhetischen und ethischen Relativismus ${ }^{322}$ nebeneinander bestehen bleiben.

Einige Dostoevskij-Forscherinnen und -Forscher betrachten die Werke Dostoevskijs im Hinblick auf inren fdeengehatt als eine relativ einheitliche Ganzheit, in dèr die đariñ thematisierten Konflikte überwunden werden, so daß ihr Interesse nicht primär den Darstellungen des national oder ethnisch Partikularen gilt, weil es für sie doch letztlich_eine untergeordnete Rolle im Hinblick auf den „ethischen Universalismus“ Dostoeyskijs spielt:

HALINA BRZOZA ${ }^{323}$ vertritt beispielsiveise die These von dem antinomischen Charakter der Poetik des "fantastischen Realismus“, setzt jedoch den Akzent auf den universalen Charakter der Weltanschauung der Werke Dostoevskijs, in denen die darin vorhandenen Widersprüche in einem ,inneren Welttheater" des

${ }^{321}$ Es wird hier nicht möglich sein, die Beiträge der Dostoevskij-Forschung zur Poetik seiner Werke erschöpfend zu erörtern. Angefangen mit der ..autorităren“" These Bachtins vom polyphonen bzw. dialogischen Charakter der Poetik Dostoevskijs (vgl. BACHTIN 1929), können hier exemplarisch genannt werden: ANDERSON 1986 und POŻNIAK 1992 (dieser schreibt über den antilhelischen. duchotomuschen (harakıer des Werks Dostoevskijs, vom Oszillieren zwischen realistischer Poetik und romantischer Fantastik bzw. Symbolismus, S. 11ff. und passim ); weiterhin INGOLD 1981

322 Siehe auch JONES 1990 (oben S. 15). Vg! dazu die Arbeitsdefinition des /'urcucuxons von Paul Geyer (in Geyer Hagenbuchi.e 1992, S. 11-24): ..Paradoxien sind Reibungsflàchen, die entstehen. wenn die zeitlose Logik des Entweder-Oder auf Gegenstandsberciche historischer BewuBtseinsphänomene, oder allgemeiner, auf dynamische Kontinua angewendet wird.

Sie sind Figuren des Widerstandes gegen die Machtergreifung der Logik des Entweder-Oder. Die Geschichte dieses Widerstandskampfes ist auch elne Geschichte des abendländischen Denkens.“ (S. 12) Seit der Romantik, in der Zeit der Moderne, sei ..alles paradox“. daher ..nichts mehr paradox" geworden, die Logik des Entweder-Oder, die Logik der Identität und Kausalität im Bereich (inter-) subjektiver Sinnschaffung werde definitiv abgewiesen. (S. 13) Geyer nennt drei Phasen der historischen Phănnmenologie des Paradoxen: 1. die m: thisch. vor-paradoxe Phase; 2 . die metaphysische, paradoxe Phase der ..Eschatologie der Eigentlichkeit" (Nietzsche), die an die Gegensätze der Werte wie Identıtät'Alterität. Einheit:Vielheit. Ursache/Wirkung. bewußt/unbewußt. FreiheitKnechtschaft. gut böse oder schön häßlich glaubt: 3 das modeme. nach-paradoxe Denken. Innerhalb der metaphysischen Phase ...lassen sich verschiedene Umdispositionen ausmachen. die als krisenhafte Epochenschwellen $r u$ analysieren sind" (S. 14ff.): Dostoevskij gestalte paradoxe Subjektivität aus der Perspektıc der ..Metaphysik der Eigentlichkeit“, weil .jenseits des Paradoxen /... die leere Transzendenz droht“. Darin ähnele er Kierkegaard und den Philosophen der Existenz. (S. 21): vgl dazı GERIGK 1992b. Nach Gerigk kennzeichnet Dostoevskijs Schaffen dic an paradoven Gestalten demonstrierte Einsicht, „daß logisches Folgern. wenn es nur sich selbst überlassen bleibt, in die Irre führt. /... Er pocht auf das lebendige l.eben, von dem sich das logische Folgern separiert" (cbd., S. 482).

${ }^{323}$ BRT.OZA 1995. 
menschlichen Bewußtseins überwunden würden. ${ }^{324}$ Auch RENÉ GIRARD ${ }^{325}$ erblickt die psychologische Überwindung des „romantischen Dualismus des gespaltenen menschlichen Bewußtseins“, der in den Doppelgängerfiguren bzw. in den Figuren der masochistischen „guten“ und den sadistischen "schlechten“ Helden Dostoevskijs zum Ausdruck kommt, im christlichen Glauben Dostoevskijs, in der Symbolik des seelischen „Todes“ und der "Auferstehung“ seiner Gestalten. ${ }^{326}$

Als einen universalen christlichen Humanisten bezeichnen Dostoevskij ANNA Kosciolek, ${ }^{327}$ die die Thematik des Dnevnik pisatelja [Tagebuch des Schriftstellers\} Dostoevskijs mit der Philosophie Gabriel Marcels verglichen hat, ohne jedoch den russischen Messianismus Dostoevskijs mitberücksichtigt zu haben. ${ }^{328}$ und V.A. KOTEL' NIKOV. ${ }^{329}$ der über die kenotische Selbsterniedrigung und Selbstentäußerung der Helden Dostoevskijs schreibt. Zuvor hatte VJACESLAV IVANOV ${ }^{330}$ in den Romanen Dostoevskijs das mystische "Sicheinssetzen“ des Subjekts mit dem Objekt in einem Willens- und Glaubensakt finden wollen, ,in welchem dasselbe fähig wird, das fremde ich nicht als Objekt. sondern als ein anderes Subjekt zu erfassen", es handele sich dabei um eine Art des „intuitiven Durchschauens“, um „geistiges Durchdringen“ und nicht um eine ,.peripherische Ausweitung der Grenzen des individuellen Bewußtseins /.../, sondern geradezu [um] eine Umkehrung seines gewöhnlichen Koordinatensystems /.../: im Erlebnis der wahren Liebe, die eben deshalb die einzige reale Erkenntnis ist, weil sie mit dem absoluten Glauben an die Realität des Geliebten zusammenfällt. und in der Selbstaufgabe oder Selbstentäußerung überhaupt, von der schon das Pathos der Liebe getragen wird". Das fremde Sein, das fremde .Du“ wird zu einer anderen Bezeichnung meines "Ich“- Es, ergo sum. ${ }^{331}$

Dostoevskij wird andererseits, beispielsweise von WACLAW LEDNICKI ${ }^{332}$ oder von ANDRZEJ DE LAZARI ${ }^{333}$, als ein nationalistischer bZW. chauvinistischer Ideologe präsentiert. wobei das allgemeine Problem der „Fremdheit“ auf die Aporie z.wischen christlichem Universalismus und russisch-orthodoxem Partikularismus bzw. der russischen Xenophobie zurückgeführt wird.

HORST-JÜRGEN GERIGK ${ }^{334}$ ist dagegen der Ansicht, daß sich in den Werken Dostoevskijs der „Dichter" mit dem .Ideologen" vereinige, wobei je nach der lextsorte der eine oder der andere die Oberhand gewinne, was er am Beispiel der Schilderungen von Juden und Polen in seinen Romanen und in der Publizistik nachzuweisen versucht hat. Gerigk verneint, daß es zwei Dostoevskijs gebe,

\footnotetext{
324 libd., S. 18ff:

325 GIRARD 1963.

326 libd., S. 57ff., 164-169.

327 Kosciotik 1994.

320 Was sic auch ausdrücklich betont (ebd., S. 7).

329 KOTEL NIKOV 1996. Vgl. auch DERS 1994 (S. 168-179).

330 IWANOW [IVANOV] 1932

331 libd., S. 211 .

332 L.EDNICKI 1953.

333 L.AZARI 19956.

334 GERIGK 1992a, S. 90-103: vgl. auch DERS. 1981. Vgl. auch die ähnliche Stellungnahme vON NEUHAUSER 1993, S. 9ff.
} 
die nebeneinander und unabhăngig voneinander bestünden: den universalen Dichter und den militanten patriotischen Publizisten, der gegen „Juden, Polen, Deutsche, Franzosen und Türken zu Felde zieht, weil sie in seinen Augen den falschen Glauben haben". 335

Schon seit der Veröffentlichung der Zapiski iz mertvogo doma [AufEeichnungen aus einem Totenhaus] zu Anfang der sechziger Jahre des neunzehnten Jahrhunderts werde deutlich, daß „der Ideologe Dostoevskij dem Dichter Dostoevskij in der Seele sizzt", daß der religiös inspirierte russische Nationalismus der zentrale moralische Punkt in dem Wertsystem Dostoevskijs sei. Nicht nur Dnevnik pisatelja, sondern alle fünf großen Romane Dostoevskijs seien als ideologische Werke konzipiert, dabei ließen sich in den großen Romanen ideologisch gefärbte publizistische Einschübe des ,räsonnierenden Feuilletonisten" Dostoevskij finden, in den primär ideologischen publizistischen Schriften literarische Erzählungen. Gerigk fragt sich nun, wie sich die Enttäuschung erklären lasse, die sich nach der Lektüre literarischer Werke Dostoevskijs einstellt, sobald man sich seiner Publizistik zuwendet. Die Antwort auf diese Frage lautet, daß sich die Einstellung des Lesers ändert, weil die Textsorte gewechselt hat: Man liest einen literarischen Text anders als einen nichtliterarischen. ${ }^{336}$

In Dostoevskijs Romanen „beherberge“ aber zugleich der Dichter den Ideologen, in der Publizistik der Ideologe den Dichter, ${ }^{337}$ weil er die Aufgabe des Schriftstellers in der politisch motivierten Sorge um die Zukunft Rußlands erblickt habe. ${ }^{338}$ Seine Ablehnung der Andersgläubigen ist eine Ablehnung der politischen Feinde Rußlands, die er in ihnen sieht, wobei seine Schilderungen dieser Fremden als moralisch böse (zumindest nicht gut), ästhetisch häßlich (zumindest nicht schön) und ökonomisch schädlich (zumindest nicht nützlich) der psychologischen Wirklichkeit entsprechen, in der ein politischer Feind zugleich menschlich abgewertet wird, wobei sich Gerigk auf den Begriff des politischen Feindes bei Carlo Schmitt beruft. ${ }^{339}$

Gerigk hat im folgenden an drei Beispielen zu zeigen versucht, welche Funktion die Ideologie bzw. die politisch-religiösen Vorurteile Dostoevskijs in seinen Romanen gespielt haben. Es handelt sich dabci: I. um die Szene aus dem Roman Podrostok [Der Jüngling], in der Versilov in einer Petersburger Kneipe zu Arkadij über die juristische Uberprüfung des Prozesses Christi in England spricht, 2. um die Selbstmordszene Svidrigajlovs im Roman Prestuplenie $i$ nakazanie [Verbrechen und Strafe], in der ein Jude auftritt, sowie 3. um das polnische Kapitel (die Mokroe-Szene) aus dem Roman Brat'ja Naramazovy [Die Brüder Karamazov].

335 Ebd., S. 90.

336 Ebd.

337 Ebd., S. 9 if.

${ }^{338}$ Den Begriff des Polılıschen übernimmt Gerigk von dem Staats- und Vülkerrechtler Carl Schmitt (1888-1985): d.h. die politische Unterscheidung zwischen Freund und Feind, wobet für diese Unterscheidung moralische, ästhetische oder wirtschaftliche Kriterien nicht ausschlaggebend sind (GERJGK 1992a. S. 92ff., hier S. 94). Vgl. dazu SCrumitT 1963.

${ }^{339}$ GERIGK 1992a, S. 96. 
In dem Roman Prestuplenie $i$ nakazanie ist der ,gleichgültige verschlafene Wachposten von säuerlichem Aussehen", der als Zeuge des Selbstmordes Svidrigajlovs eingeführt wird, ein Jude. Seine groteske Komik wird durch sein schlechtes Russisch betont. Dostoevskij brauchte hier einen Zeugen des Selbstmords Svidrigajlovs aus poetologischen Gründen, als notwendiges Element der Fabelkonstruktion, sein Judentum ist dagegen sekundär, es ist lediglich ideologisch motiviert, der Jude ist der politische Feind, weil er einen fremden Glauben hat. Der Leser, der diesen Roman als ein „dichterisches Kunstwerk" liest, muß überrascht sein, sobald er auf die für das poetologische Verstehen sekundäre politische Anspielung des Ideologen Dostoevskij stößt. ${ }^{340}$

Das gleiche Verfahren Dostoevskijs finden wir in der polnischen Szene in dem Roman Brat ja Karamazovy. ${ }^{341}$ Auch hier handelt es sich um die Darstellung der offentlichen politischen Feinde Rußlands, die zusätzlich durch ihr häßliches Aussehen, ihre „verwerfliche Gesinnung“ und okonomische Schädlichkeit (sie sind Betrüger und Falschspieler) sowie durch ihre sprachliche Unzulänglichkeit als solche charakterisiert werden. Poetologisch gesehen sind die beiden Polen als "Polen“ unmotiviert. denn Dostoevskij wollte in dieser Szene v.a. Dmitrijs Finanzlage beleuchten, seine Gradlinigkeit und Großzügigkeit hervorheben. Politisch gesehen sind die Polen als Vertreter des Katholizismus Feinde, wobei politische Feinde immer als ein fertiges Phänomen beschrieben werden, ohne daß etwas über die Genese dieser Feinbilder geäußert würde. ${ }^{362}$

Zusammenfassend wird feststellt, daß der Ideologe Dostoevskij als politisches Phänomen zum (jegenstand historischer Untersuchungen werden kann. der Dichter Dostoevskij aber ein Glücksfall für den Leser ist, der sich unbefangen von seiner fiktiven Welt faszinieren lassen darf. ${ }^{343}$ Dem Leser wird ,erlaubt", einen literarischen Text immanent als ein moralisch „unschuldiges" ästhetisches Objekt zu betrachten. indem historisch und sozial bedingte "Makel“ dieses Textes auf eine andere Rezeptionsebene verlegt werden. Über diese Schlußfolgerung Gerigks läßt sich diskutieren, denn wie soll eine solche säuberliche Trennung der Lesarten jeweils nach poetologischen und politischen Kriterien möglich sein'? ?44 $^{40}$

Skeptisch im Hinblick auf den ,universalen christlichen Humanismus“ Dostoevskijs äußert sich ebenfalls TEL.ESFOR POŻNiAk ${ }^{345}$ in einer Studie zum "Mythos des Ostens" in den literarischen und publizistichen Werken Dostoevskijs, wobei ihn sowohl die bereits oben referierte kulturtypologisch-

\footnotetext{
340 Ebd., S. $98 f$.

341 libd., S. 101 .

342 Ebd., S. 101 f. Im zweiten Teil werde ich aber eine andere Interpretation dieser Stellen vorschlagen $V$ gl dazu unten. S. 379ff, bes. S. 40717

343 Ebd., S. 102

344 Siche aber dazu unten, S. $431 \mathrm{fi}$.

345 Poz.Niak 1992. Besunders wertvoll ist die Betonung der .. Verwurzelung“ Dostoevskijs in der Kultur und Theologie der byzantinisch-orientalischen Tradition sowie die Hervorhebung der Ambivalenz bz.w. des antithetischen Dualismus nicht nur des Mythos des Ostens in seinen Werken, sondern auch seines gesamten Werks, das zwischen verschiedenen Poetiken und weltanschaulichen Systemen oszilliert, zB. zwischen der Poetik der Romantik und des Realismus. Vgl. z.B. ebd., S. Ilf. und passim.
} 
semiotische Studie von Erazm Kużma ${ }^{346}$ als auch Jurij M. Lotmans Kategorie des künstlerischen Raumes bzw. der räumlichen kulturellen Modelle inspiricrt haben. ${ }^{347}$

Seiner Ansicht nach läßt sich aber nicht von einem „Orientalismus“ im Schaffen Dostoevskijs bzw. lediglich von einzelnen orientalischen Motiven in seinen Werken sprechen. Zu Dostoevskijs Osten gehören Sibirien, Tataren, Islam, Türkei. Byzanz und die Bibel oder auch die Kultur Indiens, beispielsweise des Buddhismus. ${ }^{348}$ Poźniak erörtert in fünf selbständigen Essays die thematischen Aspekte dieses Mythos im Schaffen Dostoevskijs: 1. der asiatisch-koranische Mythos; $;^{349}$ 2. Sibirien als historiosophische Utopie; ${ }^{350} 3$. der byzantinischorientalische Mythos; ${ }^{351}$ 4. der biblische Orient am Beispiel der Symbole Babylon und Jerusalem; ${ }^{352}$ 5. die jüdische Problematik. ${ }^{353}$ Betont wird daruber hinaus die Wichtigkeit dieser Problematik, auch ihrer asiatischen Variante, denn Dostoevskijs Werk lasse sich in die Tradition der kulturellen slavisch-orientali-

\footnotetext{
${ }^{346}$ KUZma 1980. Siehe dazu oben. S. 52ff.

${ }^{347}$ Er zitiert LOTMAN 1974 sowie DERS. 1976. Vgl. auch POŻNIAK 1992, S. $6 f$.

348 Ebd., S. 9.
}

349 Ebd., S. 12-36: Schon im Frühwerk Dostoevskijs, das romantisch orientalische, asiatischislamische Motive enthălt, wird Asien antithetisch, einerseits als ein Symbol des elementaren Bösen und andererseits als das verlorene Paradies der kontemplativen Geistigkeit verstanden. v.a. innerhalb der Problematik der Freiheit und zugleich der fatalistischen Flucht vor der Freiheit. Nach der Rückkehr aus der Katorga und Sibirien läßt sich eine Veranderung des negativen Asienstereotyps bei Dostoevskij beobachten. Sibirien wird zum ,gelobten Land", auch der biblische, byzantinische Orient und seine kontemplative theologische Tradition sowie die altrussische Hagiographie erwecken sein Interesse; hinzu kommt das Interesse für die ambivalent beurteilte Gestalt des Epileptikers und Propheten Mohammed, für den Koran und für die ekstatisch-mystische Tradition des Islam, obwohl die negative Variante dieses Mythos doch immer wieder thematisiert wird. "Asien" sollte jedoch für Rußland, besonders in den spăteren publizistischen Schriften Dostoevskijs, das Gebiet der ..panslavisch-allmenschlichen" Mission werden.

${ }^{350}$ Ebd., S. 37-51: Auch ..Sibirien“ wird antithetisch thematisiert: einerseits als die „Holle“ der Katorga, des geschlossenen Raumes, und andererseits als das .Paradies“, als .Arkadien“ der Freiheit, der offenen, weiten Steppe und der unberührten Natur.

351 Ebd., S. 52-76: Pożniak findet sowohl in den literarischen als auch in den publizistischen Werken Dostoevskijs zwei Arten des ..Byzantinismus": den ..politisch-theokratischen" in seiner Vision des theokratischen russischen Staates und den .mystischen" in seiner Anthropologie und Christologic, den er von Kirchenlehrern und Theologen der Ostkirche übernommen habe; der ..mystisch-theologische Byzantinismus“ Dostoevskijs sei in einem langen ProzeB durch die Überwindung der theokratischen und politischen Einstellung entstanden. Das Universum Dostoevskijs sei nicht alttestamentarisch-antinomisch, sondern christlich und byzantinisch-antithetisch. In der byzantinischen apophatischen Theologie sind die Zeit und der Raum gottlich, statt der Opposition ..heilig“ - ..profan“, .rein“ - ..unrein“ gibt es dic Opposition ..heilig“ - .mehr heilig“. Die Opposition zwischen der Transzendenz und Immanenz wird im mystischen Prozeß der ..Entgottung" (odhis/wilenic) und ... Vergottung" (delfikacja) des Menschen überwunden, Gott vereinigt sich in Liebe mit dem Menschen Dustoevskij habe diese Theologie übernommen, in seiner Christologie und Anthropologie fortgesetzt; er habe z.B. in dem Roman Brut 'ja Kuramuzovy' in Starec Losima die Gestalt eines Hesychasten geschaffen.

${ }^{352}$ Ebd., S. 77-99.

${ }^{353}$ Ebd.. S. 100-137. 
schen bzw. russisch-orientalischen Beziehungen einreihen. Dostoevskij hebt aber zugleich immer die zentrale Bedeutung Rußlands in seiner ,proorientalischen bzw. proasiatischen Ideologie des russischen Bodens“ (počva) hervor, das er nie als einen Gegensatz zu Asien betrachtet. Der Osten tritt somit bei ihm gleichberechtigt in einem triadischen kulturellen Modell neben dem Westen und Rußland auf, wobei Rußland eine Vermittler-Rolle als das „mythische Zentrum der Welt" zu erfüllen hat, und darin unterscheidet er sich sowohl von den russischen Westlem als auch von den Slavophilen. ${ }^{354}$ Die slavisch-orthodoxasiatische weltanschauliche Synthese soll die horizontale Opposition zwischen dem Westen und Osten aufheben: Rußland erlöst die Welt, indem es auf diesem dreifachen Fundament eine allumfassende theokratische Liebesgemeinschaft der Menschen erbauen wird.

Nach Pożniak ist der Universalismus dieser positiven Utopie Dostoevskijs, seiner ,russischen Idee“, jedoch eingeschränkt. denn er ist durch den mystischen Byzantinismus, eine hesychastische Haltung und durch den sibirisch-russischen geographischen Raum bestimmt und hauptsăchlich nach Osten orientiert. Der "sündige“ Westen wird in den Erlösungsplan Dostoevskijs miteinbezogen, aber außer Reichweite der „erlösenden russischen Idee“ bleiben die „fremden Zeitgenossen Dostoevskijs“, Bewohner der westlichen Babylons: Atheisten, Sozialisten, Katholiken und die Juden. ${ }^{355}$

Pożniak stellt zusammenfassend fest, daß der "Mythos des Ostens" bei Dostoevskij immer in zwei ambivalenten Varianten bzw. als "Doppelmythos" auftritt: zum einen wird Asien als Bedrohung, als "gelbe Gefahr," so z.B. in den katastrophischen Träumen Raskol'nikovs, ${ }^{356}$ sowie zum anderen als der „messianische Orient", den Dostoevskij aus der judaistischen und romantischen Tradition übernommen hat. Die messianische Variante als sacrum bildet der biblische und by=antinische Mythos (u.a. als Jerusalem und Konstantinopel) im Gegensatz zum profanem Mythos der Bedrohung Rußlands durch den lateinischen Westen sowie durch die jüdische Idee des Diaspora-Judaismus, die von den in Europa und Rußland lebenden Juden verbreitet wird. ${ }^{357}$ Sowohl sakrale als auch profane Varianten konnten entweder positw oder negativ konnotiert werden: vorwiegend positiv war jeweils die asiatisch-koranische, sibirische und byzantinische Variante, negativ die biblische (Babylon) und judaistische, sowie die Darstellungen der jüdischen Gestalten. ${ }^{358}$

Interessant ist auch das Kapitel, ${ }^{359}$ in dem die jüdische Problematik sowohl in den literarischen als auch in den publizistischen Werken und in den Briefen Dostoevskijs in ihrer diachronen Entwicklung dargestellt wird. Zuerst wird die einschlägige Dostoevskij-Forschung erörtert, die in zwei l ager gespalten sei: Dostoevskij wird entweder als Antisemit und ein Mitverantworticher für die Entstehung des russischen Nationalismus oder als ein unschuldiges Opfer der

354 Ebd., S. 138

355 Ebd., S. $138 f$

$356 \mathrm{Vgl}$. aber dazu unten, S. 275.

357 Ebd.

358 Ebd., S. 10

359 Ebd., S. 100-137. 
russischen Xenophobien seiner Zeit betrachtet, die sich nicht mit dem russischen Nationalismus identifizieren lassen. ${ }^{360}$

Pożniak stellt fest, daß Dostoevskij einerseits den „biblischen Judaismus“ akzeptien hat, dem das ostliche Christentum entstammt und von ihm ,akkulturiert" worden ist, wăhrend er die Kultur der ,jüdischen Diasporagemeinschaft" ablehnte, weil er sie in der Form der, jüdischen Idee“ als ideologisch-politische Bedrohung für seinen bodenstăndigen russischen Messianismus betrachtete. Im Kampf gegen diese Idee setzte er negative Stereotypen von Juden ein. Sein Weltbild ist in die guten "Eigenen" und die feindlichen "Fremden" gespalten. ${ }^{361}$ Pożniak sieht somit den Antisemitismus Dostoevskijs kulturtypologisch im Kontext des europäischen, auch des russischen, Antisemitismus, in dem kollektive Ängste, Phobien und Schamgefühle als Stereotypen und Mythen gestaltet wurden. ${ }^{362}$

In frühen Werken Dostoevskijs läßt sich noch keine ausgeprägte antisemitische Haltung bemerken. ${ }^{363}$ Erst nach der Zeit in der Katorga und Sibirien, d.h. nach der Herausarbeitung der Ideologie des počvenničestvo [Bodenständigkeit], die sich auf die byzantinische theokratische Tradition stützt und die Rückkehr zum russischen Boden und zum theophoren Volk verkündet, lassen sich immer stärkere antisemitische Tendenzen in seinen Werken finden: Ein Grundpfeiler des počvenničestvo war die Xenophobie, nicht nur gegenüber Juden, sondern v.a. gegenüber den westlichen Volkern (Deutschen, Franzosen und Polen) bzw. gegenüber den Nicht-Russen aus den asiatischen Teilen des Imperiums, den sogenannten inorodcy [pejorativ: die Fremden]. Die nicht-biblischen Juden bedrohten fur Dostoevskij, zusammen mit den Westlem, Liberalen, Nihilisten, Papisten und Sozialisten die ,russische Idee“. ${ }^{364}$ In den 60er und 70er Jahren

${ }^{360}$ Ebd. S. 100-103:

Zu den Kritikem Dostoevskijs, die Pożniak zitiert, gehơren u.a.: DUBNOV 1920, GOREV 1922, Pletnev 1976, Grossman 1924, S. 165-181, KOHN 1948, Friedberg 1970, S. 10-19, GOLDSTEIN 1981; zu den „Verteidigem“ bzw. gemåßigten Kritikem: GRISIN 1971, S. 138156, SARASKINA 1989 oder INGOLD 1981. Pożniak bemerkt, daß den ..Verteidigern“ Dostoevskijs die Tatsache entgehe, daß sogar die schlechtesten Russen bei ihm zur Sphăre des sacrum und alle Nicht-Russen pauschal zur Sphăre des profanum gehören (ebd., S. 102).

${ }^{361}$ Ebd., S. 100.

362 Ebd., S. 103ff. Im 19. Jahrhundert lassen sich zwei kontrastive Judenbilder in der russischen Kultur und Literatur beobachten: ein positives Bild. das mit der Bibel vertunden ist. z B. in der Thematisierung der jüdischen ,Prophetengestalten“ bei den Romantikem oder bei den Realisten, und gleichzeitig. seit Puskin und Gogol', ein negattves, stercorypes Bild des entmenschlichten Juden, der mit der Zeit nicht nur zum christoprodavec [pejoraliv: ,Judas", eigentl. "Christus-Verrăter"], sondern (neben dem Polen) zum Nihilisten, politischen Verschwơrer und Mơrder wird (ebd., S. 107). Pożniak bezieht sich u.a. auf GiRARD 1972 und LOTMAN 1970, S. 98-101.

${ }^{363}$ Ebd., S. 107ff: Das Drama Dostoevskijs Zid Jankel [1)er Jule .lankel'] (1844) ist nicht erhalten geblieben. Pożniak führt sie möglicherweise auf die Beschäftigung mit Gogol' bzw. Shakespeare zurück.

${ }^{364}$ Ebd., S. 108. In der Zeitschrift Vremja gab es zugleich noch Polemiken gegen antisemitische Ansichten von 1. Aksakov, der die liberale Politik der russischen Regierung gegenüber Juden in der Zeitschrift Den ' [Der Tag] (vom Februar 1862) angegriffen hatte; nach Pożniak is dies aber nur für die frühe Phase des počvenničestvo (ebd., S. 123) feststellbar. 
steigerte sich diese katastrophische Sicht, die Angst Dostoevskijs vor der ,jüdischen" Bedrohung.

Pożniak zeigt die Entwicklung des „Mythos von der jüdischen Bedrohung“ anhand literarischer und publizistischer Werke Dostoevskijs, seit den Zapiski iz mertvogo doma bis hin zum Dnevnik pisatelja und dem Roman Brat'ja Karamazovy. ${ }^{365}$ Die Idiosynkrasie Dostoevskijs gegenüber Juden steigere sich bis zum physischen Ekel, den er in seinen Briefen aus Bad Ems äußerte. Das "Ikonen-Antlitz Rußlands“ (lik) wurde für ihn immer mehr „von der jüdischen "Maske mit einer verächtlichen Grimasse verdeckt" (ličina) ${ }^{366}$ Die stereotypen Darstellungen der ,lebendigen“ Juden seien, so Pożniak. nicht nur als Ausdruck der Suche nach einem Sündenbock zu betrachten, die sich durch den epileptischen und schizophrenen Charakter des Schriftstellers erklären lasse, sondern auch Ausdruck einer Tendenz: der Jude als der .Andere" hat sich vom alttestamentarischen Ideal des Abraham entfernt. wurde entweder zum Juden-Kapitalisten oder zum gemeinen Eidok [Jüdchen]. ${ }^{367}$

Folglich lassen sich drei Phasen der Beziehung Dostoevskijs zu Juden und zum Judaismus unterscheiden: 1. vor 1849 die utopisch-sozialistische Phase, in der diese Problematik sekundär ist und v.a. auf die Rezeption literarischer Werke Gogol's oder Balzacs zurückgeht: 2. die nachsibirische Phase, die sich als eine Variante der populistisch-ethnischen Judophobie bezeichnen läßt: 3 . die historiosophisch-politische Phase seit den 70-er Jahren (der russische Christus vs. der Antichrist Rothschild; Satov vs. Disraeli und Ljamšin), daneben tritt auch der moralisch begründete Antijudaismus (Kritik an den Moneymakers, Fedor Karamazov und Grušen ka sowie an der perversen Liza, die mit Ritualmorden assoziiert wird). Der historiosophisch-politische und religiöse Antijudaismus Dostoevskijs soll jedoch nach Pożniak nicht mit einem vulgären Antisemitismus identifizient werden, obwohl er sich mit jenem auch teilweise überschneidet, beispielsweise in der Banalität der persönlichen Reaktionen Dostoevskijs in Dnevnik pisatelja. Auf diesem Hintergrund sei das Schweigen Dostoevskijs zur .jüdischen Frage" in der Puskin-Rede verständlich, die als sein ideologischliterarisches Testament gilt. in dem die allmenschlıche Versöhnung auf der Grundlage des russischen bodenståndigen Universalismus verkündet wird. ${ }^{368}$

Die Arbeit Pożniaks zeichnet sich durch ähnliche Schwächen und Vorzüge wie die Monographie Kużmas aus. 7.um einen setzt sie eine unheinheitliche Terminologie ein und ist trotz des deduktiven theoretischen Ansatzes in der Praxis rein deskriptiv, ohne Textinterpretationen der erwähnten Werke Dostoevskijs zu bieten, die einige spekulativ anmutenden Formulierungen Pö̀niaks erhärten könnten. Störend wirkt auch die Identifizierung der physi-

${ }^{365}$ Ebd., S. 108ff. Pożniak fühn auch die Polemik Dostoevskijs gegen den liberalen jüdischen Schriftsteller A.G. Kovner in seinen Briefen und Publizistik an (S. 125-129).

366 Ebd., S. $134 f f$.

367 E.bd. S. 136

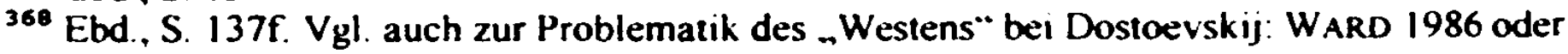
MULLER 1998 
schen Person Dostoevskijs mit dem Erzahler oder Autor seiner Werke ${ }^{369}$ sowie der unbefangene Umgang mit den angeführten Textstellen, die oft aus dem jeweiligen fiktionalen Kontext herausgenommen werden. Zugleich wird auch ihre Gattungszugehörigkeit nicht in Betracht gezogen.

Interessant ist dagegen die Einbeziehung der Werke Dostoevskijs in die russisch-orthodoxe bzw. russisch-byzantinische religiose sowie in die weit verstandene christlich-judaistische Tradition, die sich in dualistischer und symbolisch beladener Gegenüberstellung der russischen (eigenen) Kultur mit den fremden Kulturen (oder „das gute Heilige" vs. „das böse Profanum"), wobei die angeeigneten Fremdelemente nicht mehr als ein Teil des „böses Profanum“ fungieren. ${ }^{370}$ Er begründet diese oppositionelle Anthropologie Dostoevskijs mit dessen „universalistischem mystisch-theologischem Byzantinismus“, der den Menschen als ein überindividuelles Wesen betrachtet, in dem sich das individuelle Ich auflöst, nicht nur in der Kontemplation (hesychia), sondern auch in der "Gemeinschaft", mit dem „Du“ und „Wir" (sobornost') verschmilzt, und dem "doktrinăren theokratischen Byzantinismus", der seine Feinde aus dieser Gemeinschaft ausschließen will. Zu fragen wäre aber, inwieweit der ,mystisch-theologische Byzantinismus" tatsächlich universalistisch ist, und ob er sich nicht auf die eigene Gruppe beschränkt, denn Pożniak bemerkt auch. daß Dostoevkij die "fremden Feinde" seiner "russischen Idee" bekămpfe, sie als Stereotypen entmenschlicht habe. ${ }^{371}$

Obwohl Pożniak somit nicht ausfuhrlich auf die Struktur und Funktion der Darstellungen fremder und russischer Figuren Dostoevskijs eingeht, sondern ihren jeweils utopisch-sakralen oder ideologisch-profanen Charakter andeutet, wäre es in diesem Zusammenhang umso wichtiger, zu überprüfen, welche von ihnen sich als utopische Alius-oder als ideologische Alter-Figuren (Moura) bezeichnen ließen.

Mit der jüdischen Problematik bei Dostue'vonij 'ial sich ebenfalls GARY SAUL MORSON $^{37 \frac{1}{2}}$ in einem polemischen, gegen die bisherige einschlägige Dostoevskij-Forschung gerichteten Aufsatz auscinandergesetzt. Er vertritt nämlich die Ansicht, daß es nur einen Dostoevskij gegeben habe und verneint die These von den zwei nebeneinander existierenden Dostoevskijs: des „universalen Humanisten“ und des „fremdenfeindlichen Verteidigers der partikularen Interessen Rußlands". Fast die ganze bisherige Dostoevskij-Forschung, auf die sich Morson bezieht, war darum bemüht, entweder dessen Antisemitismus zu beweisen oder ihn von diesem Vorwurf, der aus heutiger Sicht besonders belastend erscheint, zu befreien. Man schuf zwei Dostoevskijs, den großen Künstler, ..the subtle, compassionate novelist" einerseits, und den häßlichen Chauvinisten, ..the neurotic chauvinist ideologue“" andererseits. ${ }^{373}$ Die Kontroverse entzündete sich

\footnotetext{
369 Siehe dazu oben. S. 54 f.

370 Die Studie Pożniaks bestätigt somit die Betrachtungen von Kepinski, vgl. dazu oben S 93ff.

${ }^{371}$ Ebd., S. 52 ff; 59-76; 136. Vgl. zur ostkirchlichen Theologie: ONASCH 1962. JtL.NY 1990, BULGAKOV 1996. Siehe auch ESAULOV 1994.

372 MORSON 1983

${ }^{373}$ Ebd., S. 309.
} 
u.a. an einer Passage aus dem Roman Brat ja Karamazovy. an der ausweichenden Antwort Alesas auf die Frage von Liza Chochlakova uber die Realităt der Ritualmorde, die die Juden an christlichen Kindern verübt haben sollen. ${ }^{374} \mathrm{Ei}$ nige Kritiker verziehen Dostoevskij diese Szene wegen ihrer ästhetischen Funktion im Roman. Nach Morson erlag Dostoevskij aber der vorherrschenden Meinung des antisemitischen Flügels der russischen Intelligencija seiner Zeit. Das führte ihn zur Unterstützung des russischen Chauvinismus und zur Identifikation Rußlands mit dem Groß-Rußland der russischen Orthodoxie. Die Theorie ,.der zwei Gesichter" Dostoevskijs bzw. die längst etablierte Tradition der Dostoevskij-Forschung, ihn zu apologisieren und ihm seine Abweichungen von dem Ruf eines Humanisten als Fehltritte zu verzeihen, sei deswegen falsch. ${ }^{375}$

FELIX PHILLIP INGOLD ${ }^{376}$ gehört dagegen zu den ,gemäßigten“ Kritikern Dostoevskijs, er betont wie Pożniak die Widersprüchlichkeit der Haltung Dostoevskijs gegenüber den Juden, seine .Faszination für den jüdischen Messianismus" und ,.seine uneingeschränkte Bewunderung für den religiösen Genius des Judentums", die „der Faszination des Liebenden" ähnelt, „der, um nicht sich selbst zu verlieren. den Gegenstand seiner Bewunderung pro forma von sich weist und doch immer wieder, ex negativo, auf ihn zurückkommt“. ${ }^{377}$ Andererseits störte Dostoevskij die Assimilations- und Integrationsfähigkeit der Juden. Sein Judenhaß war primär sozial begründet - der jüdische Messianismus war schließlich eine Konkurrenz für seinen russischen Utopismus. ${ }^{378}$ Diese paradoxe Ambivalenz. sei aber nicht dialektisch, sondern dialogisch bzw. „polyphon" (Bachtin) zu verstehen. Dostoevskij konnte zugleich zynisch und unschuldig sein, die nietzscheanisch zu nennende Paradoxalität seiner Redeweise lasse sich sowohl in seiner fiktionalen Prosa als auch in den publizistischen Schriften bemerken. ${ }^{379}$

Weder Morson noch Ingold (wie zuvor Pozniak) ist es wegen threr methodisch auf die Beschreibung der "Beziehung Dostoevskijs zum Judentum" ausgerichteten Forschungen gelungen, die Struktur und die Funktion jüdischer Figuren brw. von Elementen der jüdischen Tradition in den Texten Dostoevskijs überzcugend $z u$ interpretieren. Ihre Arbeiten sind somit lediglich aufgrund ihrer teilweise sehr ausführlichen Beobachtungen zum kulturellen Kontext, dem diese Figuren entstammen. relevant.

Aus den weiteren Untersuchungen, die sich mit der Darstellung ethnischer bzw. nationaler Fremdheit bei Dostoevkij befassen, können hier zwei Beiträge zur Darstellung der Deutschen und Deutschlands in den Werken Dostocvskijs erwähnt werden.

\footnotetext{
$374 \mathrm{Fbd}$ tıng. and evil alluring" (ebd., S. 31 if.)

376 |NGOL.D 1981

377 libd., S. 135

378 libd., S. 136

379 Ebd., S. $157 \mathrm{ff}$., hier S. 161
}

375 Morsun ist aber zugleich der Ansicht, daß ein Schriftsteller nicht unbedingt human. liberal und moralisch akzeptabel sein muß. In dieser Hinsicht hätten Plato und Tolstoj recht, als sie die Kunst der immoralität bezzichtiğt hätten, denn ...Sodom may be beautiful, fascism fascına- 
ROBERT KENNETH SCHUL $Z^{380}$ behandelt die Darstellung der deutschen Figuren nicht nur in literarischen und publizistischen Werken Dostoevskijs, sondern auch bei Goncarov, Turgenev, und L. Tolstoj. Schulz hat aber in der Tradition der Stoff-Forschung anhand biographischer Dokumente, Briefe, der Publizistik und literarischer Werke Dostoevskijs Stellen über Deutsche und Deutschland in chronologischer Ordnung zusammengestellt. ${ }^{381}$ Wegen der $^{3}$ positivistischen Methode kann seine Arbeit als eine Zitaten- bzw. Materialsammlung betrachtet werden, obwohl ihre einzelnen Ergebnisse inspirierend wirken kơnnen. Interessant ist beispielsweise die Beobachtung, daß man zwischen der positiven Einschätzung der deutschen Kultur bei Dostoevskij und dessen vorwiegend negativer Darstellung der Deutschen, d.h. sowohl der in Sachsen oder Preussen, als auch der in RuBland lebenden Deutschen, unterscheiden soll, auf die in den Textinterpretationen ausführlicher eingegangen werden müsse. ${ }^{382}$ Eine ahnliche Diskrepanz wird auch zwischen den negativen Schilderungen der deutschen Figuren in Dostoevskijs literarischen Werken gegenüber der positiven, weil "rationaleren und logischeren" Einschătzung Deutschlands in der Publizistik (Dnevnik pisatelja) festgestellt. Schulz bemerkt darüber hinaus, daß die Figuren deutscher Ärzte bei Dostoevskij eine positive Ausnahme bilden, was er auf die positiven Erfahrungen Dostoevskijs zuruckfüht, denn er ,received some sort of medical attention from a German physician whose treatment of the writer left a lifelong favorable impact upon [him]". Die deutschen Frauen werden dagegen immer negativ geschildert, was auf einen moglichen enttäuschenden Umgang mit ihnen in Reval zurückgehen kơnne. ${ }^{383}$ Insgesamt zeugen aber diese Schilderungen davon, da $B$ Deutsche im damaligen Rußland ein Teil des alltăglichen Lebens waren. ${ }^{384}$ Schulz bemüht sich aber in diesem Zusammenhang nicht darum. diese Figuren als literarische Stereotypen der Fremden zu analysieren, um ihre Bedeutung und Funktion in Dostoevskijs Werken theoretisch zu erklären.

LUDOLF MüLLER ${ }^{385}$ befaßt sich in seinen zwei Aufsătzen ebenfalls mit der Bedeutung Deutschlands und insbesondere der deutschen Kultur für Dostoevskij. Er sieht in ihm einen Anhănger der Philosophie Hegels bzw. der deutschen idealistischen Philosophie, deren Themen sich in seiner „kulturellen Typenlehre" wiederfmden lassen, in der vereinfachten, synthetischen Gegenüberstellung der Kulturen, die jeweils auf ein Prinzip zurückgeführt werden. so z.B. das „des schlechten materialistisch-atheistischen Westens und des byzantinisch-orthodox-russischen Ostens“. Er fügt aber hınzu, daß Dostoevskij mit

${ }^{380}$ SCHULZ 1969.

382 Ebd., S. 102-154.

382 Ebd., S. $152-154$ und passim.

${ }^{383}$ Ebd., S. 152f. Für Schulz hat Dostoevskij eine .typisch russische Mentalitat“", die sich als provinziell bezeichnen laßt und ihn von Turgenev unterschied: ..He lacked the patrician. sauve, cosmopolitan savoir faire of his nineteenth-century contemporary Turgenev. Since opposites supposedly attract. it is possible that some of those things which Dostoevskij attacked in the German character actually could have been qualities which our author had sought but was unable to attain" (S. 153f.).

304 Ebd, S. 153.

${ }^{305}$ MULLER 1996a und DERS. 1998. 
seiner Utopie von der allmenschlich-orthodoxen Liebesgemeinschaft und seiner Kritik ,an dem Westens in uns" zum Teil recht gehabt habe ${ }^{386}$ Müller bemerkt ebenfalls daß die Deutschen in Dostoevskijs Romanen negativ geschildert werden, ${ }^{387}$ darunter die deutschen Städte und ihre Bewohner, die Dostoevskij zu Beginn des deutsch-französischen Krieges 1870 aus eigener Erfahrung gekannt hat. $^{380}$ In seinem Dnevnik pisatelja beurteilte er dagegen positiv den Fleiß und die Arbeitsmoral der Deutschen, die er in Bad Ems beobachtet hatte und bewunderte deutsche Kulturlandschaften und Kulturdenkmäler. ${ }^{389}$ In der Publizistik Dostoevskijs spielt darüber hinaus die „deutsche protestantische Idee“, die in Bismarcks Politik ihren Ausdruck fand, als Gegengewicht im Kampf gegen den Katholizismus eine wichtige Rolle. In Preussen bzw. im Deutschen Reich erblickte Dostoevskij einen Verbündeten Rußlands und seiner ,orthodoxen slavischen Idee“. ${ }^{390}$ Besonders intensiv rezipierte er aber die deutsche I.iteratur und Philosophie, die bei der Herausbildung seiner Weltanschauung eine hervorragende Rolle gespielt hat. Dostoevskij kannte seit seiner Kindheit und Jugend Hübner $^{391}$ und Zschokke, D.F. Strauß und Ludwig Feuerbach, war mit den Werken Schillers und Goethes, E.T.A. Hoffmanns und mit den deutschen Philosophen wie Kant. Hegel, Schelling oder auch Carus bekannt. ${ }^{392}$ Während seine schriftstellerische Technik, abgesehen von E.T.A. Hoffmann, mehr Karamzin, (jogol' und Puškin oder Voltaire, Balzac und V. Hugo verdankte, ${ }^{393}$ sind dagegen Schillers Dramen Die Räuber und Don Carlos oder das Gedicht Resignation für den philosophischen Gehalt des Romans Brat 'ja Karamazovy grundlegend gewesen. $^{394}$ Nach Müller hat aber Dostoevskij die deutsche idealistische Philosophie nicht nur übernommen, sondern sie schöpferisch weiterentwickelt, worin er den Grund für seine Belicbtheit in Deutschland erblickt. ${ }^{395}$

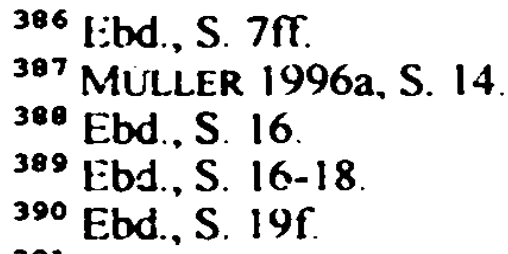

386 libd., S. 7ff.

${ }^{307}$ MULLER 1996a, S. 14

${ }^{380}$ Ebd., S. 16.

389 Ebd., S. 16-18.

390 Ebd., S. $19 f$.

$392 \mathrm{Vgl}$. zu Johannes Hübner (geb. 1668 in Türchau bei 7.ittau - gest. 1731 in Hamburg)

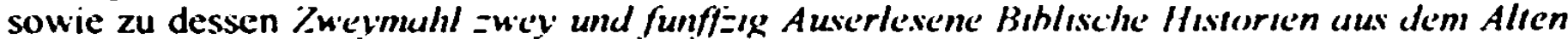
und Ne'ten Testumenic, der. Iugend zum Besien uhgefusise'... (erste Auflage leipzig 1714). die Dostoevskij nach den Erinnerungen seines Bruders Andrej in einer russischen Ubersetzung seit seiner Kindheit als Lesefibel bekannt waren und die er Zosima als eine ...kostbare Erinnerung" an dessen Kindheit aufbewahren laßt (vgl. Bd. 14: S. 264): ONASCH 1978. Siche auch REENTS 1984. In dem Moskauer Dostoevskij-Museum werden zwei Exemplare der russischen Übersetzung des Buchs von Hubner, vermutlich aus dem Besitz Dostoevskijs aufbewahri (die Ausgaben von 1815 und 1819 )

392 Fbd. S. 20t.

393 Ebd.

394 Fbd., S. $21 \mathrm{f}$

395 Ebd.. S. 22. Vyl. zu der deutschen Thematik bei Dostocvskij: LEDNICKI 1953 (liurope in

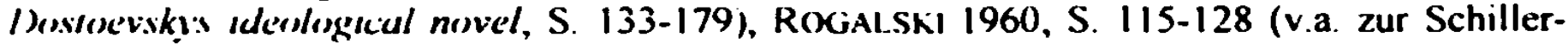
Rezeption). GERIGK 1992b bemerkt, daB die Gestalt des Deutschen Kraft aus dem Roman l'oxdrosiok ein Musterbeispiel für paradoxes Verhalten sei, denn Kraft begeht Selbstmord, weil er ..auf Grund phrenologischer Studien zu der Einsicht kommt, daß das russische Volk zweitrangig sei“. Diese Einsicht erweise sich in der Welt Dostoevskijs als .eein Störfall in logischer 
Zusammenfassend låßt sich zu den Dostoevskij-Forschungen über die jüdischorientalische und deutsche Problematik festhalten, daß sie ihre Ergebnisse wegen des Mangels an konkreten und ausfuhrlichen Interpretationen nicht hinreichend nachweisen konnten. Relevant bleibt aber die von allen hier angefürten Forschungen beobachtete Dichotomie in der Darstellung der Fremdheit bei Dostoevskij, die darauf beruht, daß fremde Figuren mit einigen wenigen Ausnahmen vorwiegend negativ geschilden werden, wahhrend Elemente fremder Kulturen positiv aufgenommen werden. Es wird auch angedeutet, daß diese Dichotomie in der „Weltanschaung Dostoevskijs“ ihre Ursache habe, die aus einer (nationalistischen) „Ideologie“ und einer (christlichen oder christlich-byzantinisch-russisch-orthodoxen) "Utopie“ sich zusammengesetzt oder dazwischen oszilliert habe. Es wird zugleich zwischen einer „ideologischen“ und einer „poetologischen" Ebene, insbesondere in literarischen Werken Dostoevskijs, unterschieden, die zwei Lesarten ermogliche, eine „ideologische“ und eine „ăsthetische".

Angesichts dieser nicht gänzlich befriedigenden Ergebnisse muß anhand von Einzelinterpretationen untersucht werden, welche Struktur, Funktion und Bedeutung diese Dichotomie in der Darstellungen der Fremdheit innerhalb der fiktionalen Welt einzelner Werke Dostoevskijs hat.

Im folgenden wird überprüft, ob auch Forschungen zur polnischen Problematik zu ăhnlichen SchluBfolgerungen wie die gerade erorterten geführt haben. Referiert werden dabei Arbeiten, auch essayistischen Charakters, aus sieben Jahrzehnten, die mit einer Ausnahme von polnischen Forscherinnen und Forscher verfaßt wurden und sich vorwiegend an polnische Leser richteten. Der früheste hier angeführte Aufsatz ist in den dreißiger, der letzte in den neunziger Jahren des zwanzigsten Jahrhunderts entstanden.

Der Essay von JERZY STEMPOWSKI über polnische Figuren in den Romanen Dostoevskijs ist im März 1931 wăhrend der Sitzung der Polnischen Gesellschaft für Osteuropa- und Nahostforschung in Kraków vorgetragen worden. ${ }^{396}$ Obwohl dieser Essay nur als ein Beispiel der Geschichte der polnischen Essayistik der 30-er Jahre erscheinen mag und nicht von einem Russisten oder DostoevskijForscher stammt. enthalt er doch einige Gedanken, die von der späteren polnischen Dostoevskij-Forschung bemerkt und gewürdigt wurden. Stempowski bemüht sich um die immanente Deutung der Funktion der polnischen Gestalten in einigen Romanen Dostoevskijs, v.a. in Prestuplenie i nakazanie. Es geht ihm nicht nur um ihre åsthetische Funktion. sondern um ihre Bedeutung für das „ethische Weltbild" Dostoevskijs. Stempowski war der Philosophie Nietzsches und Schopenhauers verpflichtet. Auch solche Dostoevskij-Deutungen wie z.B. diejenige von Lev Sestov, ${ }^{397}$ den Stempowski persőnlich gekannt hat, waren

Form, inspirient vom 'Teufel'" (S. 494). Siehe auch den Aufsatz von Falikova 1994 bzw. RAKUSNINGOLD 1981

396 HOSTOWIEC [STEMPOWSKI] 1961; vgl. STEMPOWSKI 1988 Siehe auch 7u Jern Stempowski (1894-1969): SLOWNIK WSPÓlCZESNYCH PISARZY POLSKICH, S. 213f. Vgl auch die deutsche Übersetzung: STEMPOWSKI 1995.

399 SESTOV 1903. 
dabei nicht ohne Bedeutung. Die Hauptthese Stempowskis lautet, daß Polen als Kontrastfiguren zu den tragischen rebellischen Helden Dostoevskijs wie z.B. Raskol'nikov, als deren mit Lüge und Betrug behaftete Gegensătze auftreten. ${ }^{398}$ Dostoevskij habe diese flachen, niedrigen Figuren als verlogene, unwahre, moralisch fragwürdige Konkurrenz gegenüber seinen Haupthelden kompromittieren wollen, denn diese Polen seien als die Kehrseite seines „wahren“ Messianismus zu begreifen, der die Erlösung der verdammten, gefallenen Menschen „aus dem Nichts", wie ein Phönix aus der Asche, verlangte. Raskol'nikov erreicht die unterste Stufe der Erniedrigung, indem er sich öffentlich zu seiner Schuld bekennt, ohne dabei Reue zu empfinden bzw. ein Bedürfnis nach Reue zu zeigen. ${ }^{399}$ Die Polen Dostoevskijs dagegen sind die „falschen Mărtyrer". Sie sind wie Marmeladov oder Raskol 'nikov Bewohner des podpol'e [,Untergrund" bzw. .Kellergeschoß"; vgl. Zapiski iz podpol"ja, Aufzeichnungen aus dem Untergrund (1864)], aber sie hoffen auf Erlösung. leben nicht wie jene düsteren Figuren in absoluter moralischer Hoffnungslosigkeit, während „oben ein gedeckter Tisch die Anderen zum Fest des Lebens" einlädt. ${ }^{400}$

Dostoevskijs Polen sind in der Auffassung Stempowskis fiktive, konstruierte Charaktere, denn Dostoevskij kannte Polen, das Land und seine Bewohner nicht, sondern lediglich die tragischen, einsamen und untröstlichen politischen Gefangenen aus der Katorga. Sic könnten in dieser Hinsicht als Projektionen, als reale "Folie" zur Schaffung der polnischen Gestalten in den Romanen Dostoevskijs gedient haben. ${ }^{101}$ An diesen politischen Gefangenen war der Glaube an die Auferstehung ihres Landes, wofür sie alles aufgeopfert hatten, abzulesen. Dadurch unterschieden sie sich so kraß von den nihilistischen Märtyrem Dostoevskijs. ${ }^{102}$

Ein anderer polnischer Dostoevskij-Forscher, ZBIGNiEW ŻAKIEWICZ ${ }^{103}$, nannte diese Interpretation Stempowskis eine intellektuelle Spekulation. Stempowski hatte tatsáchlich den kulturell-politischen Kontext. aus dem heraus die Romane Dostoevskijs entstanden sind, ignoriert. Er hat aber zum einen ihre textimmanente Kontrastfunktion, die sie gegenüber russischen zentralen Figuren zu erfullen haben bemerkt, und zum anderen ihren Symbolcharakter zu deuten versucht, obwohl er sie nicht als nationale Stereotypen bezeichnet hatte. Als eine Schwăche des Aufsatzes von Stempowski låßt sich aus heutiger Sicht auch die Identifizierung des Erzählers in den Romanen von Dostoevskij mit Dostoevskij selbst betrachten.

Als eine zeitgenössische Polemik mit Stempowski ist der Aufsatz. von Karol. WIKTOR ZAWODZIŃSKI (1931) angelegt. ${ }^{404}$ in dem er die Nichtberücksichtigung der sozialen Verwurzelung des Schaffens von Dostoevskij in dem Essay

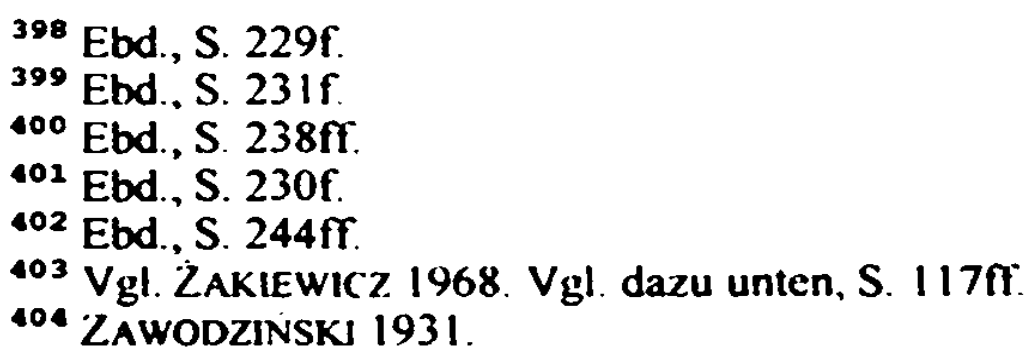


Stempowskis kritisiert hat. ${ }^{405}$ Das Hauptargument gegen die Hypothese Stempowskis, die besagt, die polnischen Figuren Dostoevskijs seien Kontrastfiguren zu den nihilistischen Märtyrem. lautet, daß alle polnischen Gestalten in den Romanen Dostoevskijs lediglich sekundär, in Episoden aufträten und als Schablonen bzw. Karikaturen geschildert seien. ${ }^{406}$ Schon diese Tatsache verweise darauf, daß sie kein wichtiges Symbol im künstlerischen und weltanschaulichen System Dostoevskijs sein könnten, wie es Stempowski behauptet hat. Man könnte jedoch mit Stempowski dagegen einwenden. daß sogenannte "flache Nebenfiguren" nicht unbedingt ästhetisch bzw. poetologisch unbedeutend sein müßten, was im zweiten Teil dieser Studie nachgewiesen wird. Zawodziński bemerkt darüber hinaus auch. daß die Polen in den Romanen Dostoevskijs kein persönliches Konstrukt, sondern lieux communs gewesen seien, Klischees, die der damaligen russischen Publizistik und Literatur sowie propagandistischen Schriften entnommen seien, die an die Massen des russischen Bürgertums gerichtet waren. ${ }^{107}$ Schon bei Gogol' oder Puskin gab es jenen polnischen ,schwarzen Charakter“, der Herrn Wroblewski in dem Roman Brat 'ja Karamazovy so ahnlich ist. Dieser gefährliche polnische Schurke habe sich noch in der sowjetischen antipolnischen Propaganda erhalten. ${ }^{408}$ Polen war zu Lebzeiten Dostoevskijs das Feindesland Rußlands schlechthin. Polen waren an dem offenen Kampf gegen den russischen Staat beteiligt, sowohl in Rußland als auch im Ausland, wăhrend die den Polen relativ positiv gesinnten Kreise der höheren Schichten der russischen Gesellschaft zahlenmäßig gering waren. Die nationalistische Mehrheit, zu der auch Dostoevskij gehörte, betrachtete Polen als einen Staatsfeind, den es zu besiegen galt. In der russischen Trivialliteratur jener Zeit gab es zahlreiche als Verschwörer gegen Rußland denunzierte Polen, die zusammen mit den Jesuiten gegen die Interessen RuBlands intrigierten. Das war außerdem das gelăufige Repertoire der chauvinistischen russischen Regierungspropaganda, die ihre antipolnische Politik rechtfertigen wollte. ${ }^{109}$

Zawodziński hat somit den stereotypen und ideologisch bedingten Charakter dieser Figuren als erster erkannt. Zugleich nennt er .,reale Ursachen“ für die Entstehung jener polnischen Figuren in der russischen Literatur, die dem sozialen Leben entstammen. Seiner Ansicht nach hätten Polen selbst zu dem Bild eines seine "Ehre“ schătzenden Adligen beigetragen, indem sie sich den Russen gegenüber oft distanzient verhielten. Sie hätten ferner alles durch das Prisma ihrer nationalen Sache gesehen, was manchen Russen engstimig erscheinen konnte. Es bildete sich ein Urteil über Polen, das Antipathie auf russischer Seite verursachen konnte. Russen stellten ihre östliche, „orthodoxe“ Mentalität dem katholischen "Europäismus“ Polens, der manchmal fragwürdig war, entgegen. ${ }^{410}$

\footnotetext{
${ }^{405}$ E:bd., S. 469-471

${ }^{106}$ Ebd., S. 469

${ }^{107}$ Ebd., S. 470

${ }^{108}$ Ebd.

109 Ebd.

${ }^{410}$ Ebd., S. 471
} 
Ähnlich verhielt es sich im Urteil der Russen mit den Franzosen, mit dem Unterschied, daß das Verhältnis $2 u$ Polen mit der Verachtung für den kleinlichen, besiegten Feind verbunden war, der ein Hindernis in der Verwirklichung der epochalen Mission Rußlands auf seinem Weg nach Westen bildete. ${ }^{41}$ Dostoevskij teilte dieses nationale Bewußtsein des russischen Imperialismus mit russischen Slavophilen.

Es gebe aber noch weitere Gründe für das negative Image Polens in Rußland. Nach Zawodzinski wirkten dort tatsáchlich viele polnische Falschspieler, denen der Spieler Dostoevskij begegnen mußte. Polen „exportierte“ nach dem Zusammenbruch des Aufstandes von 1863 auch andere z.wielichtige Gestalten in den „Osten“. Ein anderes Problem bildeten die Kontakte Dostoevskijs zu den Polen in der Katorga. in der verbrecherischen Umgebung der russischen kriminellen Bauern, zu denen jene Polen einen scharfen Kontrast bildeten. Diese Begegnung habe ihren Widerhall aber nicht nur in der Figur von Pan Wróblewski, sondern auch in den Zapiski iz mertvogo doma und in Prestuplenie i nakazanie gefunden. $^{112}$

WACLAW LEDNICKI versucht dagegen, die Ursachen des Hasses Dostoevskijs auf die Polen herauszufinden, ${ }^{113}$ indem er sich grundsătzlich auf die Erlebnisse Dostoevskijs in der Katorga und in Semipalatinsk bezieht, und stellt fest. daß dieser „pathologische $\mathrm{Haß}^{\circ}$ lediglich in den Zapiski iz mertvogo doma etwas gemildert werde, denn dort seien alle Polen relativ objektiv geschildert, obwohl auch in diesem Werk Dostoevskij ihre Würde ständig einer Probe unterzogen habe. ${ }^{14}$ In allen anderen Werken Dostoevskijs gebe es ein Polen-Stereotyp, das dem găngigen russischen literarischen Stereotyp seiner Zeit nachgebildet sei, jedoch mit besonders gesteigerter Abneigung dargestellt, mit ins "Gigantische“ reichenden negativen Eigenschaften ausgestattet. ${ }^{45}$ Außerdem gebe es in anderen Texten Dostoevskijs, außer in den Zapiski iz mertvogo doma, eingeflochtene kleine boshafte Allusionen, die dem durchschnittlichen russischen l.eser unkenntlich geblieben waren, in denen Dostoevskij aber heimlich seinen $\mathrm{Ha}$ entladen und seine Freude daran empfunden habc. ${ }^{46}$ Nur jene Polen aus den Zapiski sind mit Sympathie und Mitgefühl beschrieben worden. Diese Figuren. die individuell charakterisien werden, sind jedoch in ihrer ganzen Verbitterung und ihrem Mißtrauen gegenüber anderen Hăftlingen und in ihrer Isolation ge-

\footnotetext{
411 Fbd

412 Ebd., S. $471 \mathrm{f}$.

413 LEDNICKI 1953 (Dessicevsky and Poland: I. Dosioneviky and the Pole:s in Siheria, S. 262291; 2. Dostoevsky and Spasow'ic:=, S. 291-295; 3. Dostoevsky and Mickicwic:, S. 295-348). Siehe auch weitere Kapitel zu Dostoevskij: Lurope in Doxioc'vskys rdeological novel (S. 133-

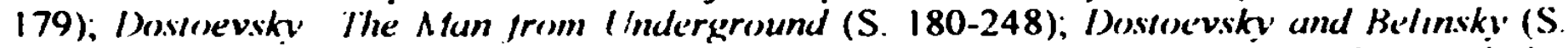
249-261). Die These vom ideologischen Charakter nicht nur der Publizistik, sondern auch der literarischen Werke Dostoevskijs wird noch weiter diskutiert (vgl. ebd., S. 133ff., bes. S. 140). Lednickis umfangreiche Studie kann hier nicht ausführlich referiert werden, auf die einzelnen Kapitel, beispielsweise zu Iostoevskijs Mickiewicz-Rezeption, wird jedoch im zweiten Teil Bezug genommen (vgl. dazu S. 329, S. 360ff. und S. 420ff.).

114 Ebd., S. 262ff. Lednicki bezieht sich auf den Aufsatz von Jerny Stempowski

125 Ebd., S. $262 f$.

416 Ebd.
} 
zeichnet worden. Sie sind nur mit einem alten altgläubigen Mann, mit einem Juden und mit Tscherkessen befreuntet.

Lednickis These im Zusammenhang mit dieser „überraschend positiven Schilderung" der Polen lautet, daß lediglich der Freund Dostoevskijs aus Semipalatinsk, Baron Vrangel', einen mildernden Einfluß auf Dostoevskij ausgeübt habe, denn Vrangel' selbst habe alle Polen in seinen Erinnerungen mit viel Sympathie beschrieben, außerdem habe er den jungen polnischen Gefangenen geholfen, die nach Sibirien verbannt worden waren.

Lednicki bemüht sich in seinem Buch um die Klärung dieser einzigen Ausnahme in Dostoevskijs Schaffen, dabei stützt er sich auch auf die Erinnerungen von Szymon Tokarzewski, ${ }^{18}$ der damals zusammen mit Dostoevskij als politischer Gefangener in der Omsker Katorga, wegen seiner Teilnahme an der polnischen Befreiungsbewegung zu Zwangsarbeit verurteilt, war. Lednicki schenkt den Erinnerungen von Tokarzewski volles Vertrauen, in denen dieser über die Konflikte zwischen Dostoevskij und den polnischen politischen Gefangenen berichtet. $^{19}$ Diese Auseinandersetzungen entzündeten sich meistens an den nationalistischen Ansichten beider Seiten, denn Dostoevskij vertrat dabei den großrussischen Nationalismus, der Polen die Autonomie für ihr Land absprach, während jene Polen von der Befreiung ihrer Heimat von der russischen Besatzung trảumten und auch dafür gekämpft hatten. Indem in der Schilderung Tokarzewskis Dostoevskij als ein Mensch gezeigt wird, der ständig auf seine adlige Herkunft pochte und sich den polnischen Adligen als ein Ebenbürtiger zeigen wollte, schreibt Dostoevskij in den Zapiski, daß er sich mit den unglücklichen russischen Bauern der Katorga eins gefühlt habe, die adligen Polen indessen hätten den einfachen russischen Menschen gegenüber nur Verachtung und $\mathrm{HaB}$ empfunden. ${ }^{120}$

Lednicki stellt fest. daß Dostoevskij in diesem .,halb-autobiographischen“ Werk ein Stereotyp von Polen geschaffen habe, das sich bis heute in Rußland und in der russischen Literatur erhalten habe. Indem alle Polen darin mit der "typical exclusivness" und ,national and social aloofness" ausgestattet werden. spricht der Erzähler ständig von seinem christlichen Mitgefühl und von der Demut, die er angesichts der russischen unglücklichen Bauern aus der Katorga emptindet. ${ }^{421}$ L.ednicki sieht darin Dostoevskijs ..unfaimess" und eine gewisse Doppelmoral gegenüber den Polen, wenn man seine wahre Geschichte und sein Benehmen in jener Zeit kennt. Er identifiziert allerdings den Erzăhler von Zapiski mit dem Autor und mit dessen persönlicher Lebensgeschichte.

In der Verlogenheit Dostoevskijs liege die Ursache für die Schaftung der poljaciski [schäbige Polackchen], der schäbigen Polentypen in seinen literarischen Werken, denn Dostoevskij habe sein Leben lang einen Schuldkomplex gegenber Polen und ihrem Land empfunden und unter eigener

417 VRANGEL' 1912. Vgl. auch DERS. 1992

${ }^{118}$ LEDNICKI 1953, S. 268ff. Vgl. dazu TOKARZFWSKI 1907-9, 1)ERS. 1918, DERS. 1922. Siche femer PODGÓRZEC 1984

¿19 LEDNICKI 1953, S. 268-278

420 Ebd., S. 277.

$421 \mathrm{Ebd}$. 
Unaufrichtigkeit gelitten. Was interessant erscheint und mit der Ansicht Gerigks übereinstimmt, ist die Feststellung Lednickis, daß die polnischen Episoden in den Romanen und Erzählungen Dostoevskijs vom àsthetischen Standpunkt aus völlig überflüssig („useless“) sind. ${ }^{22}$ Das polnische Problem, die schicksalhafte „polnische Frage“, sei dennoch für alle Russen sehr belastend. Dostoevskij selbst wollte sich für diesen Schuldkomplex in allen seinen folgenden Werken an den Polen rächen. indem er sie moralisch zu kompromittieren versuchte. Dostoevskij wollte dadurch beweisen, daß solche "niedrige Menschen, falsche Grafen und dumme, arrogante Kartenspieler", im Grunde kein Mitleid verdienten und nur dank den Russen überhaupt sich erneut „vermenschlichen“ könnten. ${ }^{423}$ Lednicki belegt anhand polnischer Szenen und Figuren in den Werken sowie mit Zitaten aus den nach 1863 geschriebenen Briefen Dostoevskijs die These über seinen Schuldkomplex gegenüber Polen. Er betont auch die hervorragenden Polnischkenntnisse Dostoevskijs, ${ }^{124}$ v.a. anhand polnischer Idiome aus den Notizen zu den Brat 'ja Karamazovy. Die vermeintliche polnische Abstammung der Familie Dostoevskijs von den z.T. polonisierten Dostoevskijs aus Weißrußland ist nach Lednicki nicht zu beweisen, Dostoevskij habe sie außerdem selbst nicht als etwas Positives angesehen. Die Haupthese Lednickis lautet:

The Poles in The Brothers Karamazov and in other novels represent Dostoevsky`s general idea about Poland; through these Poles he expresses his passionate faith that Poland is impossible in a true new world. In that sense Dostoevsky was the greatest enemy Poland ever had. ${ }^{425}$

Lednicki beschäftigt sich außerdem mit dem Verhăltnis Dostoevskijs zu dem seinerzeit in Rußland berühmten Rechtsanwalt polnischer Abstammung. Wlodzimier = Spasowicz, ${ }^{46}$ der in den Brat ja Karamazovy als Vorlage für den "fatalen" Verteidiger Mitjas, Fetjukovic, diente. ${ }^{427}$ Er behandelt auch die Rezeption der Werke Mickiewiczs in den Romanen sowie in den publizistischen Schriften Dostoevskijs und weist auf wichtige versteckte Allusionen, z.B. auf den dritten Teil des Poems Dzıach, [Die Ahnenfeier] sowie auf andere Werke des polnischen romantischen Dichters in den Romanen und in der Publizistik Dostocvskijs, hin. ${ }^{48}$ L.ednicki bemerkt außerdem, daß das häufig in den Werken Dostoevskijs vorkommendes Motiv des vergewaltigten jungen Mädchens auf die

${ }^{122}$ Ebd., S. $278 f$ f., hier S. 283.
$\$ 23$ Fbd., S. $284 f$.

24 Ebd., S. 284. LEDNICKI bemerkt: "Every phrase is not only correct, but even idiomatic. Dostoevsky faithfully adheres to the rules of Polish syntax and grammar, and $m$ all these phrases he makes only two or three mistakes“ (ebd.). Lednicki wußte wahrscheinlich nicht. daß Dostoevskij in seiner Jugend Polnisch gelernt hatte. Vgl. dazu KLMPAN/KONECNYJ 1981. Über das Niveau der Polnischkenntnisse Dostoevskijs ließe sich aber streiten.

${ }^{425}$ LEDNICKI 1953, S. 286

126 Ebd., S. 291-295. Vyl dazu KulCzYCKA-SAlONI 1972, DIES. 1975.

127 LEDNICKJ 1953

${ }^{128}$ F.bd. S. 295-347. Siehe dazu unten. S. 329, S. 360ff. und S. 420ff. 
junge Polin, Maryna O., zurückgehe, die ein ,Zögling“ der ersten Frau Dostoevskijs in Semipalatinsk war. ${ }^{429}$

Abschließend läßt sich festhalten, daß die kulturhistorisch glänzende, aber aus methodischer Sicht bereits „altmodische“ Studie Lednickis, interessante Annahmen enthalt, beispielsweise, daß Dostoevskij nach der Katorgazeit sein eigenes negatives Polenstereotyp geschaffen habe, das von der russischen Öffentlichkeit übernommen worden sei, oder daß dessen Werk wegen des ideologischen Charakters ethisch ambivalent sei. Diese Ansichten Lednickis werden von anderen polnischen Dostoevskij-Forschern geteilt, deren Beiträge im folgenden referiert werden.

ZBIGNIEW ZAKIEWICZ (1968) ${ }^{430}$ bezieht sich auf die Beiträge von Stempowski, Rogalski und Lednicki. ${ }^{431}$ Er erblickt wie jene Autoren die Quelle der Polonophobie Dostoevskijs in dem Schlüsselerlebnis der Katorga, das sich zum einen in den äußeren Schilderungen der Polen und zum anderen in den Ansichten Dostoevskijs zum Westen und Polen geăußert habe. ${ }^{432}$ Żakiewicz bemerkt zugleich, daß Dostoevskij während seiner Studienzeit in Petersburg Kontakte zu vielen Polen gehabt haben müsse. Diese Bekanntschaften hätten aber keine tieferen Spuren im Leben Dostoevskijs hinterlassen, erst in Omsk habe Dostoevskij intensive Kontakte zu Vertretern der polnischen Intelligenz, die z.T. adliger Abstammung waren, gehabt. Diese Polen seien aber selbst nicht frei von Vorurteilen gegenüber den Russen gewesen. ${ }^{433}$

Das Verhăltnis Dostoevskijs zu jenen Mitgefangenen wird jedoch anders als bei Lednicki interpretiert. Żakiewicz polemisiert gegen den Vorwurf Lednickis, daß Dostoevskij eine "Doppelmoral" habe, denn er schildere die Polen in den Zapiski objektiv, auch er selbst sei damals nicht weniger als die Polen in der Katorga isoliert gewesen. Der nationale Stolz der Polen und ihr $\mathrm{HaB}$ gegenüber den russischen einfachen Hăftlingen müßten Dostoevskij sehr gestört haben. ${ }^{44}$ Außerden seien die als konkrete Personen dargestellten Polen der gleichen gesellschaftlichen Schicht wie Dostoevskij zugehơrig. die übrige ..Masse“ der anderen nichtadligen Polen bleibe in diesem Werk anonym.

$\mathrm{Zu}$ Vrangel's Erinnerungen bemerkt Żakiewicz, daß jener auch die Absonderung der polnischen Kolonie in Semipalatinsk gegenüber Russen bemerkt hat. Vrangel schreibt zugleich auch über die nationale Solidarităt unter allen dort lebenden Polen. die Dostoevskij später oft verspottet hat. Żakiewicz erwähnt ebenfalls die Geschichte der unglücklichen Maryna $O$., die nacheinander ein Opfer von Verführung und Vergewaltigung geworden war und von ihrem polnischen Vater mit einem alten Fähnrich verheiratet wurde: deshalb rede einer der Polen in Prestuplenie i nakazanie Katerina Ivanovna als Pani Chorazina [Frau eines Fähnrichs] an. ${ }^{435}$

\footnotetext{
${ }^{129}$ Ebd., S. 150 ff.

430 ŻKIEWICZ 1968. Vgl. auch DERS. 1962.

¿31 ŻAKIEWICZ 1968, S. 75ff.

432 Ebd., S. 77.

${ }^{433}$ Edb., S. 78

434 Ebd., S. 80

${ }^{435}$ Ebd., S. 81 If., hier S. 85
} 
Die Zeit nach der Katorga und nach dem Aufenthalt in Semipalatinsk wird von Zakiewicz nur flüchtig gestreift. Er bemerkt, daß in der Publizistik Dostoevskijs die Auffassung vertreten wird, daß Polen völlig in Rußland integriert werden sollte. Erwähnt wird ebenfalls der Aufsatz Strachovs in Vremja (1863) und deren Schließung sowie die Kritik Dostoevskijs an Mickiewicz, besonders an dessen Konrad Wallenrod. ${ }^{46}$ Żakiewicz verneint die These Lednickis von dem Schuldkomplex Dostoevskijs gegenüber Polen. Diese Annahme ist für ihn nicht haltbar. Der falsche Graf in Djadjuškin son [Onkelchens Traum], der sich als ein Koch entpuppt, der wăhrend des Wiener Kongresses den polnischen Nationaltanz Krakowiak tanzt und sich dabei das Bein bricht, sei ein Symbol des "lateinischen" Polens und seines Adels, der in den Augen Dostoevskijs als ein "Lakai“ des Westens anzusehen ist. Der Glaube Dostoevskijs an die Mission RuBlands sei so tief und ehrlich gewesen, daß er die Polen an sich nicht habe mögen können, denn die "Wohltat", die ihnen Rußland habe erweisen wollen, hătten sie mit Verachtung und Unverstăndnis zurückgewiesen. ${ }^{437}$

Zakiewicz geht darüber hinaus auf polnische Szenen in den Romanen lgrok [Der Spieler], Prestuplenie i nakazanie und Bratja Karamazovy ein. In allen diesen Werken bemerkt er Spuren des sibirischen Erlebnisses und behauptet, daß Dostoevskij sich lebenslänglich für die Beleidigungen aus dieser Zeit gerăcht habe, die er damals seitens der Polen erlitten habe, außerdem habe die kulturelle Verschiedenheit, die Andersartigkeit der Polen und ihres Landes Dostoevskij besonders gestör, obwohl es eine slavische Nation war. ${ }^{438}$

Zakiewicz bezieht sich in seinem Aufsatz zu ausschließlich auf die vermeintlichen Erlebnisse Dostoevskijs, während er auf dessen Texte selbst kaum eingeht, so daß er die Entstehung negativer stereotyper polnischer Figuren lediglich auf die Biographie Dostoevskijs zurückführt, ohne sie als Teil des imaginaire social sowie ihre literarische Herkunft zu betrachten.

JANINA KULCZYCKA-SALONI hat sich dagegen in einem Essay (1972) mit der Rezeption Dostoevskijs in Polen beschăftigt und ergänzend die polnische Problematik in seinen Werken berührt. ${ }^{39}$ Die Verfasserın beschäftigt sich damit, weil die negativen Schilderungen der Polen Hindernisse bci der Verbreitung seiner Schriften in Polen darstellten und schuld an der relativ spăt einsetzenden Beschäftigung polnischer Autoren mit Dostoevskij waren.

Kulczycka-Saloni teilt die Ansichten von Rogalski und teilweise von Lednicki, daß Dostoevskij damalige russische literarische Polenstereotypen übernommen und ins "Apokalyptische" gesteigert habe. ${ }^{40}$ Dostoevskij sei durch den Katholizismus der polnischen Kultur im "slavophilen“ Teil seiner Seele zutiefst verletzt gewesen. Sie untersucht abschließend das Verhältnis

\footnotetext{
436 Ebd., S. 82.

437 Ebd., S. 84.

438 Ebd., S. 88.

439 Vgl. KulczycKa-Saloni 1972. Siehe auch den Aufsatz von Galster 1981, in dem er polnische Literatur über Dostoevskij sowie Übersetzungen seiner Werke und Briefe aus den 80er Jahren bespricht.

${ }^{410}$ Ebd., S. 39.
} 
Dostoevskijs zu Spasowicz ${ }^{\star 11}$ und die Bemühungen Spasowiczs, russische Literatur in Polen bekannt zu machen.

Der bereits oben erwahnte poinische Slavist JAN ORLOWSKI hat sich in einem Aufsatz aus dem Jahr 1982 zu "Dostoevskijs Reaktionen" auf poinische Fragen im russischen politisch-sozialen Leben seiner Zeit geăußert. ${ }^{112}$ Orłowski bezieht sich dabei sowohl auf literarische Werke Dostoevskijs als auch auf seine Briefe, publizistischen Arbeiten und Erinnerungen seiner Zeitgenossen. ${ }^{413} \mathrm{Er}$ betont in einer Übersicht über die früheren Forschungsbeitrage, zu denen nicht nur die bereits besprochenen Arbeiten von Stempow'ski, Lednicki oder Żakiewicz, sondern auch neuere Aufsătze, z.B. von Zofia Bobowicz-Potocka oder Ludwika Jazukiewicz-Osełkowska gehoren, ${ }^{114}$ daß die beiden letzteren aus ideologischpolitischen Gründen die Abneigung Dostoevskijs gegen Polen in ihr Gegenteil uminterpretiert hătten. Der Humanismus Dostoevskijs brauche keine Verteidiger, denn es sei kein „absoluter" Humanismus. Das Werk Dostoevskijs spreche für sich selbst, und die Tatsache, daß er Ausländer nicht mochte, bedeutete nicht, daß man ihn verurteilen müsse. ${ }^{415}$ Dostoevskijs Werk ist nicht in einem Vakuum entstanden, sondern ist als aktive Diskussion mit der russischen und westeuropåischen Öffentlichkeit seiner Zeit zu begreifen.

Die Beziehung Dostoevskijs zu Polen muß differenziert betrachtet werden. vor allgemeinen Urteilen wird gewarnt. Nur die Überprüfung des Gesamtwerks Dostoevskijs könne zu verbindlicheren Schlußfolgerungen in dieser Hinsicht beitragen. ${ }^{46}$ Der Charakter der Beurteilung Polens bei Dostoevskij war nicht von Anfang an festgelegt. Dostoevskij reagierte wăhrend seines ganzen Lebens auf die politische Wirklichkeit und auf alle Ereignisse, außerdem war das Schicksal Polens in seinen Augen keine außenpolitische bzw. moralische Angelegenheit, sondern ein, inner-russisches" Problem, darin unterschied er sich z.B. von Puskin oder Tolstoj.

Um etwas Entscheidendes über die Darstellung Polens bei Dostoevskij sagen zu konnen, müsse man unbedingt das allgemeine Thema des Auslandes und der Auslănder in seinem Schaffen unter Berücksichtigung seiner Briefe und anderer Dokumente erforschen. Im Leben Dostoevskijs gab es z.B. noch wăhrend der Studienzeit eine echte Freundschaft mit dem Polen Stanisław Stalewski. ${ }^{48}$

"41 Vgl dazu KulCZYCKA-SAlONi 1975. Siehe dazu auch unten im Zusammenha.is ilil ver Interpretation des Romans Brat 'ja Karamazovy, unten, S. 413, S. 416 und S. 420.

¿42 ORLOWSKI 1982. Siehe auch DERS. 1992 (zu Dostoevskij S 118-120. 149f. 156-158). Orlowski behauptet darin, daB mit Ausnahmen der autobiographischen Zuptskı $1=\Lambda$ 1errvogo domu, in denen authentische Polen beschrieben wurden, in allen anderen literarischen Werken Dostoevskijs nach 1863 lediglich epısodische polnische Gestalten auttreten, die als publizistische Anspielungen interpretiert werden sollen, ohne irgendeine Beziehung zur philosophischen Hauptproblematik dieser Werke aufzuweisen (S. 157).

143 ORLOWSKI 1982, S. 85-97.

4t4 Siehe z.B.: BOBOWICZ-POTOCKA 1975 und JAZUKIEWICZ-OSELKOWSKA 1981.

45 OrLOWSKI 1982, S. 85.

${ }^{146}$ Ebd., S. 85ff.

47 ORLOWSKI 1982. S. 87.

418 Ebd., S. 88. Orlowski zitien die Erinnerungen von RizenKampF 1973. Vgl. auch BAzYLOW 1984. 
Orłowski hebt ebentalls die objektive Darstellung der Polen in den Zapiski iz Mertvogo doma hervor. Die Zäsur bildete erst der Aufstand von 1863, denn bis dahin hatte das polnische nationale Problem im Bewußtsein Dostoevskijs eigentlich nicht existiert. Dostoevskij kannte nur einige Polen als Menschen, die für ihn einfach tragische Schicksale hatten. ${ }^{49}$ Den polnischen Aufstand interpretierte Dostoevskij dagegen als den Kampf des „Europăismus“, d.h. des Katholizismus und des Jesuitentums im Rahmen des westlichen bürgerlichen Systems gegen Rußland und den „Osten“ überhaupt. Diese Wende in der Einstellung Dostoevskijs gegenüber Polen ist eindeutig in den Werken zu beobachten, die nach 1863/64 entstanden sind. Die Haltung Dostoevskijs ist dabei mit der offiziellen durchaus konform. ${ }^{450}$ Die Aufsătze Dostoevskijs und seines Bruders in Vremja und Epocha [Die Epoche], auch anonym veröffentlicht, und viele Stellen aus den belletristischen Werken belegen es hinreichend. ${ }^{451}$ Der Untergang des polnischen Staates und seine Vereinigung mit Rußland war für Dostoevskij eine natürliche Folge der historischen Entwicklung. Der Aufsatz Strachovs (1863) wurde aber von der russischen Zensur mißverstanden, worauf die Schließung der Zeitschrift Vremja erfolgte. ${ }^{452}$

Dostoevskij glaubte, daß Rußland in seiner allmenschlichen Größe und in seinem Bewußtsein der Mission die kleineren slavischen Nationen geistig assimilieren werde. ${ }^{43}$ Dieses Ziel solle es jedoch nicht mit Gewalt durchsetzen, darin unterschied sich Dostoevskij z.B. von der chauvinistischen Gruppe um Katkov.

In den Schriften Dostoevskijs, besonders die nach 1863 veröffentlichten, findet sich ein hestimmtes Stereotyp des Polen. Der Pole ist als ein zu Propagandazwecken geschaffenes Klischee, als entindividualisiertes Bild eines poljacok [Polackchen] entstanden. Dostuevskij polemisierte auf diese Weise gegen die propolnischen Stimmen in der westlichen Presse. Alle diese Figuren tauchen plötzlich auf, ohne asthetische Begründung. ihre Falschheit und Flachheit entspricht der oberflächlichen aristokratisch-jesuitischen polnischen Kultur. Igrok bildet ein Beispiel solcher Polemik, die Pläne zu diesem Roman wurden 1863 konzipiert. ${ }^{454}$ Die polnischen Anspielungen haben darin eine ausgeprägt publizistische Funktion.

Nach Ansicht Orlowskis ist der scharfe polemische Ton dieses Romans in den späteren etwas gedämpft worden, denn auch die öffentliche Diskussion um Polen war nicht mehr so intensiv. Auch die Äußerungen im Dnevnik pisatelja lassen sich nach Orłowski kaum als Ausdruck einer Polonophobie Dostoevskijs ansehen, denn darin polemisiere er aus der Position seiner russischmessianistischen Weltanschauung, die sich in der kritischen Einstellung zu W'esteuropa insgesamt geäußert habe. Fir habe auch an die .polnische Verschwörung" bəw. an dic römisch-klerikale Intrige gegen Rußland geglaubt.

\footnotetext{
149 ORIOW'SKI 1982, S. 88.

450 F.bd., S. 89

451 Fibd.

452 Fbd., S. 91

453 Ebd. S. 9217 .

454 Fbd., S. 93.
} 
deren Absicht gewesen sei, mit Hilfe des Westens das Alte Polen zum Schaden Rußlands wiederherzustellen. ${ }^{455}$

Auch Orłowski ist wie vor ihm Stempowski der Ansicht, daß Dostoevskij das Land Polen nicht kannte, er schuf sich sein Polenstereotyp aus der ,russischen nationalen Idee", a priori. Dieses Stereotyp war also durch seine religiös-philosophischen und sozial-politischen Ansichten determiniert. ${ }^{456}$ Der Untergang Polens, der nach Dostoevskij v.a. den Jesuiten zuzuschreiben war, und die moralische Degeneration der Polen, so wie sie in seinen Werken gezeigt wird, hätte die soziale, ethische und religiöse Überlegenhei! des orthodoxen Rußlands über den bürgerlichen und katholischen Westen bewiesen: Das Polenstereotyp bei Dostoevskij sei als die Veranschaulichung seiner Hautpidee aufzufassen.

Hier trifft sich die Ansicht von Orlowski mit der von Stempowski, Żakiewicz oder von Lednicki zusammen, mit dem Unterschied zu Stempowski, daß Orfowski seine Argumente historisch begründet und die Thematik im politischideologischen Kontext sieht. Seine Betrachtung der polnischen Problematik wird unten im Zusammenhang mit einzelnen Textinterpretationen erörtert. Beachtenswert ist seine Feststellung, daß die polnische Problematik im Gesamtwerk Dostoevskijs untersucht, und, daß sie als Teil des umfassenderen Phănomens der Fremdheit betrachtet werden soll. Störend wirkt aber, wie in allen bereits besprochenen Forschungen, der direkte Bezug auf die Biographie Dostoevskijs. die die ästhetische Autonomie eines literarischen Textes ignoriert.

IZABELA F. KALINOWSKA (1994) befaßt sich dagegen mit den Schilderungen der Polen in dem Roman Brat 'ja Karamazovy. ${ }^{458}$ Indem sie die Ansichten von Stempowski und Lednicki hat methodisch "aktualisieren" wollen, konzentriert sie sich ausschließlich auf die immanente Textanalyse der polnischen Szenen in diesem Roman, so daß der ideologisch-historische Kontext unberücksichtigt bleibt. ${ }^{459}$ Die Autorin übernimmt die These Bachtins vom polyphonen Charakter der Prosa Dostoevskijs oder vom Dialog-Charakter seiner Werke, in denen „Hauptfiguren“ dem Erzähler bzw. dem fiktiven Autor gegenüber autonom sind. Die Nebenfiguren, zu denen beide Polen. Pan Musiałowicz und Pan Wróblewski, gehören, werden dagegen vom "Wort des Autors“ determiniert. bilden Teil seines "Monologs“. Die Polen bleiben deshalb zweidimensional, sic werden zu Karikaturen, ohne daß ihr inneres Leben gezeigt wird.

Die Fragestellung des Aufsatzes lautet: Worin unterscheiden sich diese Gestalten von anderen Figuren Dostoevskijs und warum verläßt der Autor die Ebene des Dialogs, sobald von Polen die Rede ist? ${ }^{460}$

Im folgenden wird die Szene in Mokroe genau analysien. in der Dmitrij als Rivale um die Liebe GruŠn kas mit ihrem früheren Verführer konfrontiert wird. Die beiden in dieser Szene eingeführten Polen wirken dabei kläglich. Die Ursache für diesen Eindrucks liege darin, daß sie immer von außen, aus der Perspek-

\footnotetext{
155 Ebd., S. 95.

456 Ebd., S. 97.

${ }^{457}$ Ebd.

450 Kal.INOWSKa 1994

459 Ebd., S. 59.

${ }^{460}$ Ebd., S. 60.
} 
tive anderer Figuren gezeigt werden. Der Leser hört ihre „inneren Stimmen“ nicht, sie sind "stumm", wir können sie nur anhand ihres Äußeren, ihres Verhaltens und ihrer Sprache beurteilen, ihr psychisches Leben wird nicht gezeigt. $^{461}$

Kalinowska stellt fest, daß dieses erzăhlerische Verfahren keine „Menschen“, sondern Typen bzw. Stereotypen schildert. Die zum Stereotyp reduzierten Polen, die "ohne eigenes BewuBtsein" sind, können keinen Dialog mit Russen führen, die Verständigung zwischen ihnen wird also von vornherein ausgeschlossen. Auch die „eigene“ Sprache dieser Figuren macht sie stumm, isoliert sie von den anderen. sie verfügen über ,keine Stimmen“, die gehör und erhört werden können, denn sie sprechen eine durch Polonismen entstellte russische Sprache. Dieses in poetologischer Absicht entstellte Russisch, wie der Erzähler den Lesern suggeriert, trennt sie, macht sie den Anderen gegenüber nicht nur fremd, sondern auch zu „Betrügem“. 462 Das Aussparen der psychologischen Motivation soll als Beweis ihrer intellektuellen und geistigen Armut dienen. ${ }^{63}$

Kalinowska untersucht im folgenden polnische Sätze im Roman Brat ja Karamazovy sowie in den Notizen Dostoevskijs zu diesem Roman. Sie findet darin mehrere Fehler, die davon zeugen sollen, daß Dostoevskij sie nach dem Gehor in Sibirien notiert habe, obwohl er die polnische Sprache gut gekannt und ihre Idiomatik mit viel Einfühlungsvermögen eingesetzt habe.

Auch in der Erzählung Müik Marej [Der Bauer Marej] (1876) wendet sich der Erzähler vom Polen M-ckij ab, obwohl er diesem Polen sozial näher steht als den russischen Kriminellen ...aus dem Volk“. Die Gefühle des Hasses den Häftingen gegenüber werden bei ihm aber innerlich in ihr Gegenteil umgewandelt, indem der Erzăhler sich bemüht, in allen diesen Häftlingen russische Bauem, die wie der einst von ihm geliebte Mužik Marej sind. zu sehen. ${ }^{465}$ Dasselbe Verfahren des Sich Abwendens gibt es in dem Roman Brat ja Karamazovy. Auch hier werden die negativen Gefühle auf die Fremden projiziert. dadurch entsteht die Kluft z.wischen den Russen und den „Anderen“, den Polen, wobei die Liste ihrer negativen Eigenschaften viel länger als in $M u=i k$ Marej ist. Diesen psychischen Mechanismus nennt Kalinowska den ..ProzeB der inneren Befreiung vom sogenanten opolaczenie [Polnisch-Werden] russischer Figuren. Dieses Stichwort, das von N.N. Strachov stammt, läßt sich hier anwenden, weil auch die russischen Figuren, die in der Szene in Mokroe auftreten. moralisch nicht makellos sind. Der Sinn dieser Szene liegt für Kalinowska darin. daß Dmitrij und Grusen 'ka innerlich stärker und zur geistigen psychischen Wiedergeburt fahig werden. Das Hautpthema sei die Überlegenheit der Russen. ihres Bewußtseins über die ..Anderen“, indem diesen ihre Stimmen weggenommen, sie als Stereotypen entmenschlicht und somit von der Moglichkeit des Dialogs mit Russen ausgeschlossen werden. ${ }^{466}$

\footnotetext{
${ }^{462}$ F.bd., S. $60 f$.

462 Ebd., S. 63.

463 Ebd.

464 Ebd., S. 64f. Siehe dazu unten, S. $426 f$

165 Ebu., S. 65f

${ }^{166}$ Ebd. S. $66 f$.
} 
Kalinowska hat in dem einzigen textnahen hier besprochenen Beitrag zur polnischen Problematik methodisch überzeugend das Erzählverfahren Dostoevskijs analysier, das nationale Stereotypen einsetzt. Die polnischen Figuren in dem Roman Brat ja Karamazovy. die sich in der Terminologie Mouras als Alter bezeichnen lassen, werden aber aus ihrem literarhistorischen Kontext herausgelöst betrachtet, so daß dieser wertvolle Aufsatz nur einen Aspekt der Fremdheitsproblematik in Dostoevskijs Romanen behandelt.

Die polnische Problematik hat auch auch Józef SMAGA in den Vorworten zu den polnischen Ausgaben der Romane Prestuplenie $i$ nakazanie und Brat $j a$ Karamazovy knapp berürt. ${ }^{467}$ Die Ursache des Hasses nicht nur auf Polen, sondern auch auf Juden, Deutsche oder Franzosen sei nach Smaga in der ,grenzenlosen und absoluten Liebe“ Dostoevskijs zu Rußland zu suchen, die anderen Nationen gegenüber lediglich Gleichgültigkeit bzw. Antipathie übriglasse. Besonders in der Publizistik Dostoevskijs wird diese Antipathie sichtbar, in der er, anders als in den literarischen Werken, keine induktive Methode zum Beweis seiner fremdenfeindlichen Argumente, sondem deduktiv-doktrinäre Willkür einsetzt, die sich auf Emotionen, Vorurteile und Stereotypen stützt. ${ }^{468}$

Polen war für Dostoevskij als ein Produkt der französischen Zivilisation und des Katholizismus abzulehnen, darüber hinaus konkurrierte es mit Rußland um die Führungsrolle in der slavischen Welt. ${ }^{469}$ Dostoevskij unterscheidet sich nach Smaga in seinen antipolnischen oder antisemitischen Ressentiments kaum von den Verfassern der sogenannten nihilistischen Trivialromane - V. Kljušnikov oder V. Krestovskij. ${ }^{70}$ Poljacki und ¿idki [die Jüdchen] wurden von Dostoevskij u.a. als Personifizierungen nationaler bzw. ethnischer Eigenschaften gestaltet. die Intensität seiner Antipathien den Fremden gegenüber war aber von der jeweiligen politischen Konjunktur abhängig. So wird in den Jahren 1874-79 dic negative Einstellung Dostoevskijs gegenüber Deutschland entsprechend dem milderen politischen Klima abgeschwächt: ähnliche Änderungen der politischen Lage zwischen Rußland und Polen gab jedoch es nicht, deshalb bleibt Polen in seiner Publizistik weiterhin als der "slavische Judas" und der "Verrăter Wallenrod" bestehen. ${ }^{41}$ Die Ansichten Smagas überschneiden sich somit mit denen von Orłowski, indem er ebenfalls den ausdrücklich ideologischen Charakter der Darstellung Polens bei Dostoevskij hervorgehoben hat. Er hat als erster die literarische Herkunft der stereotypen Polen in Dostoevskijs Werken betont.

Mit der Rezeption der Werke des polnischen Schriftstellers und Dichters Adam Mickiewic\% beschaftig sich dagegen die russische DustoevskıjForscherin A. V. ARCHIPOVA. ${ }^{82}$ Obwohl der Name Mickiewicz kein einziges

\footnotetext{
167 SMAGA 1987 (S. XCVIII-CI) und DERS 1995 (Vorwort. S. LXXXff.).

168 SMAGA 1987

469 Ebd., S. C.

470 Ebd., S. Cl.

171 SMAGA 1995, S. LXXXf.

172 ARCHIPONA 1994. Vgl. auch zu Dostoevskijs Mickiewicz-Rezeption bei l.ednicki, unten. S. 329, S. 360fr., S. 420fr. Siche ferner den Aufsatz der Verfasserin zu Michiewicz in
} 
Mal in den Werken Dostoevskijs genannt wird, lassen sich deutliche Spuren der Rezeption dieses Autors in ihnen finden. Die Diskussion Dostoevskijs mit Mickiewicz läßt sich dabei als ein Aspekt in der Auseinanderstzung mit der für Dostoevskij schmerzhaften ,polnischen Frage“ betrachten. ${ }^{43}$

Archipova betont die guten Kenntnisse der polnischen Sprache sowie der Werke Mickiewiczs, über die schon der junge Dostoevskij verfügte. ${ }^{41}$ Der Vergleich der Texte Dostoevskijs und Mickiewiczs erhärtet diese Annahme. Es lassen sich v.a. Ähnlichkeiten des „Petersburg-Bildes“ der beiden finden, v.a. des .Petersburg-Mythos“ ${ }^{45}$ Für Mickiewicz ist diese gespensterhafte zwielichtige Hauptstadt des russischen Imperiums, die dem Untergang geweiht ist, ein Symbol des Despotismus. So symbolisiere u.a. das Denkmal Peters des Großen die russische Geschichte. ${ }^{476}$

Diese Bilder finden sich bei mehreren russischen Autoren, auch als Polemik gegen Mickiewicz, seit Gogol, Puskin bis hin zu Achmatova wieder. ${ }^{47}$ Auch bei Dostoevskij ist das mythische Bild Petersburgs in der Skizze Peterburgskie snovidenija $v$ stichach $i$ proze [Petersburger Träume in Versen und in Prosa] (1861) oder im Roman Podrostok dem in den Werken Mickiewiczs, z.B. im Fragment Oleszkiewicz, so ähnlich, daß es keine zufällige Analogie sein kann. ${ }^{48}$

Die widersprüchliche Rezeption der Werke Mickiewiczs, auch im Hinblick auf die Polemik Puskkins gegen Mickiewicz, soll aber hauptsächlich als die Thematisierung der .,polnischen Frage“ bei Dostoevskij verstanden werden. ${ }^{49}$ Trotz der ablehnenden Haltung Dostoevskijs in Bezug auf die politisch-nationale Autonomie dieses $\mathrm{L}$ andes gegenüber Rußland finden sich in seinen Werken zahlreiche versteckte Mickiewicz-Zitate, die auf eine Anerkennung des polnischen Dichters schließen lassen. ${ }^{400}$ Die Gestalt des Konrad Wallenrod aus dem Poem Mickiewiczs (1828), die den damaligen russischen Lesern bekannt war,

Rußland und in der russischen Literatur des neunzehnten Jahrhunderts SWIDERSKA 1999b, auf den unten verwiesen wird. S. 314 und S. 316

173 ARChIPOVA 1994, S. 13. Der Name des polnischen Dichters durfte aber aus Zensurgründen nicht genannt werden, vgl. dazu unten, S. 314.

474 Ebd., S. 13f. Archipova schreibt über die Bekanntschaft der Brüder Dostoevskij mit dem Shepar Merkurov, bei dessen Frau, emer Ukramerin, beide Polnisch gelernt hatten: Mickieuiczs ..subversive“ Werke wurden auch von den l'etraševcy diskutiert. Unter den Bekannten von F.M Dostoevskij gab es einen Mickiewicz-Übersetzer: Nikolaj Petrovic Semonov, der Bruder von Petr Petrovic Semonov (Tjan-Šanskij). Auch die den beiden Dostoevskij-Brüdern bekannte französische Autorin George Sand hatte einen Aufsatz über Mickiewiczs Poem /) zuady 1839 veröffentlicht (ebd.)

${ }^{47}$ Ebd., S. 15ff. Auch L.FDNICkI hat das Petersburg-Bild Mickiewiczs und Dostoevskijs erörtert, in dem diese Stadt bei beiden als eine unheimliche, gespenstische Vision dargestellt wird (L.EDNICKI 1953, S. 295-348).

176 ARCHIPOVA 1994, S. $15 f$.

177 Ebd. S. 17

478 Das komplizierte Bild bzw. Konzept Petersburgs, das in allen Petersburger Romanen Dostoevskijs zu finden ist, sei Ergebnis der Verschmelzung persönlicher Eindrücke Dustoevskijs mit literarischen Assoziationen (ebd., S. 17ff., hier S. 20).

179 Ebd., S. 20f7.

${ }^{480}$ F.bd., S. 21. 
wird zweimal im Dnevnik pisatelja, 1877 und 1881, erwăhnt. In dem Feuilleton

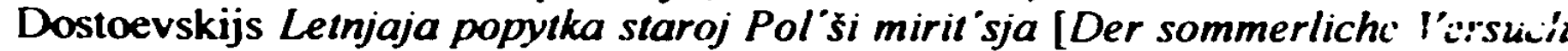
des Alten Polens, sich [mit den Russen] zu versöhnen] (1877) wird Konrad Wallenrod als Symbol des polnischen Verrăters aus dem Aufsatz N.I. Kostomarovs übernommen, in den Notizen zum Dnevnik pisatelja aus dem Jahre 1881 wird dagegen diese Gestalt in der Polemik gegen K.D. Kavelin, v.a. gegen seine Kritik der Puškin-Rede erwăhnt.

Archipova analysiert den Kontext, in dem Dostoevskij Konrad Wallenrod genannt hat. Für Dostoevskij waren ethische Werte absolut und mit christlicher Religion untrennbar verbunden, wogegen für Kavelin ethische Werte relativ, sozial und historisch bedingt waren. In diesem Zusammenhang wird Konrad Wallenrod als Beispiel einer ethisch falschen Haltung angefuhr, in der ein positiver Zweck, die Befreiung der Heimat, mit moralisch verwerflichen Mitteln. durch Betrug und Verrat, erreicht werden soll. ${ }^{481}$ Die Gestalt Konrad Wallenrods in dem Poem von Mickiewicz ist allerdings nicht so eindeutig moralisch schlecht, wie sie von Dostoevskij interpretiert wird. Für Archipova spiegeln sich in dieser Interpretation Wallenrods die Beziehungen zwischen Mickiewicz und Puškin wider ${ }^{\mathbf{1 8 2}}$. Dazu gehört die Idee des polnischen Messianismus, die als eine polnische Variante des Panslavismus mit dem russischen Messianismus Dostoevskijs konkurrierte. ${ }^{483}$ Es läßt sich sogar behaupten. daß das Konzept der "russischen Idee" Dostoevskijs eine seiner Wurzeln in Mickiewiczs polnischem Messsianismus gehabt hat. Nach Archipova wurde diese "russische Idee“ von der russischen orthodoxen Allmenschlichkeit, zusammen mit anderen nationalen Fragen, z.B. mit der jüdischen oder polnischen Frage, auf verschiedenen Ebenen unterschiedlich abgehandelt: Die politisch-publizistische Ebene unterscheidet sich daher von der philosophisch-ästhetischen, obwohl sie einander oft beinflußt haben. ${ }^{484}$

Auch Archipovas Aufsatz ist relevant, weil sie die Rezeption polnischer Kultur bei Dostoevskij an einem besonders markanten Beispiel erörtert, nämlich am Beispiel der Aufnahme der Werke des nationalen polnischen Dichters Mickiewicz: Sie bemerkt auch den ideologischen Charakter dieser intertextuellen Beziehung sowie die .mythopoetische" Funktion der Mickiewicz-Bezüge, geht aber auf die năhere Betrachtung einschlägiger Werke beider Autoren nicht ein, so daß ihre Schlußfolgerungen abstrakt bleiben.

481 Ebd., S. 22f.

482 Ebd., S. 24. Vgl. auch zu der Tragik der Gestalt Konrad Wallenrods in dem Poem Mickiewiczs bei KLUGE 1969. Kluge bemerkt, daß die allegorische Anspielung auf Rußland in diesem Poem von Mickiewicz in Polen schnell vergessen wurde und dem Fntstehen einer wahren Greuelliteratur gegen den Orden und gegen die Deutschen Vorschub geleistet hat (S. 44).

${ }^{43}$ Ebd., S. $24 f$.

${ }^{486}$ Ebd., S. 266 . 
ZUSAMMENFASSUNG: Anhand der Übersicht über die Forschungen zur polnischen Problematik bei Dostoevskij kann als ihr Ergebnis festgehalten werden, daß die Darstellung Polens eine ideologische Funktion sowohl in seinen literarischen als auch in publizistischen Werken hat und immer negativ konnotiert ist. Die meisten Beitrăge erörtern aber diese ideologisch besetzte Problematik entweder im biographischen Kontext, als Ausdruck eines Hasses des Schriftstellers auf Polen, der durch seine Erlebnisse in Sibirien verursacht worden sei, oder sie sehen sie als ein Ergebnis des „(groB)russischen“ und ,russischorthodoxen Nationalismus" Dostoevskijs, als eine Reaktion auf den polnischen Messianismus und zugleich als seine Antwort auf die "polnischen Frage“.

Die polnischen stereotypen Figuren werden dabei, abgesehen von dem Aufsatz von Kalinowska, nicht in ihrem fiktionalen textimmanenten Kontext erortert. Auch wird ihr kulturell-literarischer Hintergrund als nationale, literarisch überlieferte und historische bedingte Stereotypen nicht genügend mitberücksichtigt. Darüber hinaus geht nur Archipova auf die „mythopoetische“ Funktion der intertextuellen Bezüge zwischen den Werken von Mickiewicz und Dostoevskij ein.

Es fehlen auch Forschungen, die die polnische Problematik im Kontext anderer fremder Figuren und Kulturen und der eigenen, russischer K!ıltur und russischer Figuren in den Werken Dostoevskijs analysiert hătten. Es muß daher überprüt werden, welche Funktion sie, beispielsweise im Zusammenhang mit der positiven Darstellung deutscher Kultur und der negativen der meisten deutschen Figuren auf dem Hintergrund der Darstellung russischer Figuren zu erfüllen haben.

Insgesamt weist die einschlăgige slavistische und die Dostoevskij-Forschung zur Fremdheitsproblematik terminologisch-methodische Defizite und mehrere thematische Leerstellen auf. Sie ist dabei zu einseitig entweder auf die formalästhetische oder auf die inhaltlich-weltanschauliche Problematik ausgerichtet. Alle diese Arbeiten bieten darüber hinaus keine ausführlichen Textinterpretationen. so daß ihre Schlußfolgerungen infolgedessen weitgehend abstrakt bleiben. 


\section{III. „IMAGEM UND IMAGOTHĖME“ - DIE KONZEPTION DER IMAGOLOGISCHEN TEXTINTERPRETATION}

Als Ergebnis des ausführlichen Überblicks über die unterschiedlichen Ansăkze zur Erforschung kultureller Fremdheit, auch in den slavischen Literaturen und im Schaffen F.M. Dostoevskijs, konnte festgehalten werden, daß sie fast ausnahmslos erhebliche Detizite und mehrere Leerstellen sowohl in der Terminologie als auch bei der Methode der Textinterpretation aufweisen. Diese ungelösten terminologisch-methodischen Fragen sowie die Desiderate der (imagologischen) Fremdheitsforschung wurden bereits in den zusammenfassenden Bemerkungen zum ersten und zweiten Kapitel genannt, so daß hier nur an die wichtigsten nochmals erinnert werden soll. ${ }^{485}$

Die imagologischen und die ihnen verwandten Ansătze zeichnen sich erstens durch verworrene Terminologien und uneinheitliche Methoden der Textinterpretation aus; zweitens wurde - mit Ausnahme des imagologischen Konzeptes von Jean-Marc Moura - eine Kluft zwischen ihrer Theorie und der interpretatorischen Praxis festgestellt, und drittens sind die meisten der einschlägigen Forschungen einseitig auf die Ideologiekritik bzw. auf die rezeptionsästhetischen Aspekte der Fremdheitsproblematik ausgerichtet.

In der slavistischen und in der Dostoevskij-Forschung fehlen 1., abgesehen von einigen wenigen Aufsätzen, fast gänzlich imagologische Untersuchungen: 2. sind die meisten bereits vorhandenen Forschungen induktiv und empirisch-deskriptiv angelegt, und 3. gibt es noch keine systematische Untersuchung zum Phänomen der kulturellen Fremdheit in literarischen Werken Dostoevskijs. Ungelöst bleiben dabei Probleme eines möglichen Z.usammenhangs zwischen der formalen (poetologischen) und der inhaltlichen (u.a. ideell-weltanschaulichen) Ebene seiner Werke im Hinblick auf den hier relevanten Aspekt der Darstellung bzw. Konstruktion der Fremdheit. Es müßte ebenfalls untersucht werden, inwieweit fremde Figuren Dostoevskijs den stereotypen, kulturell vorgeprägten Mentalitätsmustern der russischen Kultur, dem imaginaire social, auch dessen literarischer Variante, entstammen.

Anschließend an diese Vorüberlegungen sollen Terminologie und Methode der vorliegenden Studic bestimmt werden. Es soll somit festgelegt werden, was unter Polen verstanden und wie es innerhalb der fiktionalen Welt Iostoevskijs interpretiert werden soll. In Anbetracht dessen, daB es keine Studic gibt. die das Phänomen der kulturellen Fremdheit im literarischen Werk eines einzigen, auch slavischen Schriftstellers erforscht hätte, und weiterhin, daß die meisten der bisherigen Forschungen mehrere theoretische Defizite aufweisen und zu wenig auf die interpretatorische Praxis ausgerichtet sind, muß vorerst nach einer I.ösung dieser offenen terminologisch-methodischen Probleme gesucht werden.

Im ersten Kapitel wurde innerhalb des vorwiegend unbefriedigenden imagologischen Forschungsstandes auf die Arbeiten von JEAN-MARC MOLRA hinge-

${ }^{485} \mathrm{Vgl}$. dazu oben $\mathrm{S} .84 \mathrm{f}$ und $\mathrm{S} .126$ 
wiesen, eines Vertreters der neueren französischen komparatistisch-imagologischen Schule, der sich methodisch auf die Ansătze aus der Hermeneutik PAUL RuCGURS stützt und darüber hinaus das eigene imagologische Konzept zur Untersuchung kultureller Fremdheit in Textinterpretationen überzeugend angewendet hat. ${ }^{186}$ Dieser textnahe und methodisch ergiebige Ansatz sowie die Hermeneutik PAUL RICœURS kommen daher arbeitshypothetisch als theoretischphilosophische Interpretationsgrundlagen dieser Studie in Frage. Es handelt sich dabei nicht um endgültige begriffliche und methodische Bestimmungen, denn sie sollen in den folgenden Textinterpretationen überprüft werden.

Um polnische Fremdelemente in ihren inhaltlichen und formalen Aspekten, in ihrer Bedeutung und Symbolik, in ihrer Struktur und Funktion in der vieldimensionalen Welt Dostoevskijs auf dem Hintergnund der Fremdheitsproblematik untersuchen zu können, sollen aber noch weitere Einzelheiten des Interpretationsvorgehens festgelegt werden. Der Ansatz Mouras muB auch zusătzlich, insbesondere terminologisch, modifizient bzw. ergänzt werden. ${ }^{487}$

Zuerst muß die Frage der Terminologie dieser Studie prăzise beantwortet werden. Oben wurden mehrere Moglichkeiten referiert, polnische und andere Fremdelemente, die in einem literarischen Werk auftreten, zu bezeichnen und zu definieren.

In Anbetracht dieser verworrenen terminologischen Forschungslage wird als Oberbegriff der Terminus Imagothème vorgeschlagen, der anstelle der vieldeutigen und unscharfen des Image oder des Bildes (Imagotyps) bzw. des Mythos eingeführt wird. Der Terminus Imagotyp wird außerdem von einigen Forschern zur Bezeichnung eines Bestandteils des Image oder Bildes benutzt, wenn sie den Begriff Image oder Bild als einen Oberbegriff verwenden, was zusátzlich zu einer terminologischen Verwirnung führen könnte.

Für das einzelne Element bzw. den einzelnen Bestandteil des fremden Imagothèmes wird aus diesem Grunde der Terminus Imagem vorgeschlagen, der analog zu solchen Bezeichnungen wie Mythem oder Ideologem gebildet wurde. Ein Imagem kann dabei u.a. als ein positives oder negatives nationales oder ethnisches Stereotyp vorkommen. ${ }^{488}$

${ }^{486} \mathrm{~V}$ gl. dazu oben, S. 67ff., sowie MOL:RA 1992a und 1992b.

497 Besonders, wenn man dabei den von der Forschung bemerkten philosophischen bzw. christlich-orthodoxen Personalismus der handlungsorientienten fiktionalen Welt der Romane Dostoevskijs hervorhebt. Vgl. das oben erwähnte Buch von BRzOZA 1995. Brzoza bezeichnet Dostoevskijs Werke als eine hermcneutischc Deutung der menschlichen Existenz, als eine philosophische Anthropologie ( $14 f$ ); vgl auch die hermeneutische Studie von HARRESS 1993, in der sie, Heideggers Philosophic folgend, die Figuren der literarischen Werke Dostoevskijs immanent in ihrer fiktionalen $W_{c} / l$ untersucht hat, ohne jedoch bzw. deshalb die Darstellungen des Fremden miteinbeziehen zu können oder zu wollen. Harress schreibt auch über den per.umalis/ısc/icen ( Karakier der Welt der Werke Dostoevskijs, der Welt der gleichherechliglen Bew'ußıseine, worin sie Bachtins These zustimmt. Damit aber werden die Wellhen'ohne' Dostoevskijs auf diejenıgen eingeschränkt, die mit einem ..Bewußtsein“" ausgestattet sind. Sie fügt jedoch hınzu, daß wichtiger als die Ideen der Figuren das Wesen des allgemeinen Weltzustandes sei, auf dessen Hintergrund diese Figuren ein Schicksal haben und handeln (ebd., S. 7r)

¿日8 Diese beiden neuen Termini /muge'm und /muguthème sind wegen der bislang problemat1schen imagologischen Terminologie eingeführt worden (siehe dazu das 1. Kap ). In der deut- 
$\mathrm{Zu}$ den polnischen Imagemen in den Werken Dostoevskijs werden in dieser Studie einerseits die als polnisch erkennbaren fiktiven und authentischen Figuren gerechnet, die in der Figurenkonstellation der Romane bzw. anderer literarischer Werke Dostoevskijs auftreten, andererseits gehören zu diesen Imagemen auch alle Enwähnungen Polens, seiner Kultur und Geschichte, u.a. die Außerungen zu der im Rußland des 19. Jahrhunderts politisch und ideologisch relevanten polnischen Frage. In den literarischen Texten Dostoevskijs gibt es dagegen keine Schilderungen des als polnisch erkennbaren Raumes, der polnischen Landschaft, die mitberücksichtigt werden könnten, die beispielsweise den (stereotypen bzw. in der Terminologie von ZOFIA MITOSEK konventionellklischeehaften) Schilderungen der "deutschen Rheinlandschaft" in der englischen oder auch in der russischen Literatur vergleichbar wären. ${ }^{489}$

Die in dieser Studie als Imageme bezeichneten polnischen Fremdelemente, die in der Welt eines literarischen Werks Dostoevskijs neben anderen fremden Imagemen, die aus anderen fremden, "nichtrussischen" Kulturen stammen, werden im folgenden auf Vorkommensweise und Funktion in den Texten Dostoevskijs untersucht und als ein Teil des darin vorkommenden bzw. nachgeschaffenen imaginaire (social) betrachtet.

Überprüft werden soll, ob diese polnischen Imageme ggf. ein komplexeres oder gar ein über einzelne Werke hinausgehendes übergreifendes Imagothème bilden und als Teile einer Ideologie und/oder einer Ulopie zu betrachten sind. ${ }^{400}$

Es wird auch untersucht, ob polnische Figuren in den literarischen Werken Dostoevskijs nach der Typologie Mouras den Charakter von alter oder alius haben, d.h., ob sie entweder eine bestimmte ideologische Rolle spielen und

schen Übersetzung würden sie, wie auch die beiden von Moura eingeführten und in dieser Studie übemommenen Termmi ulıer und ulıus an Eindeutigkeit verlieren, wären zu vieldeutig oder zu abgenutzt - so könnten beispielsweise Imugem nicht durch .I remalbila" und Imagothème durch "Bıldkomplex" sowie uller nicht durch .,denidie Andere " $"$ oder ulius durch

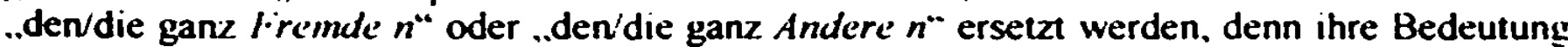
ist im Deutschen nicht präzise genug. Nur in dem Fall, daB es bereits solche prazısen Termini gegeben hătte, die als heuristisches Signal hătten gelten können, wäre es möglich, sie hier anzuwenden. Somit läßt sich die Vieldeutigkelt, die aus einer Fülle von Homonymen hervorgeht, vermeiden. Schließlich stammen auch fast alle wissenschaftlichen Begriffe aus dem Griechischen und Lateinischen. Dadurch haten sic, wenigstens im europäischen Kulturraum. eine internationale Verwendbarkeit. Sie wurden auch deswegen vorgeschlagen, weil das Deutsche für die Verfasserin eine Fremdsprache ist, so daß sic ursprünglich nicht nur an eine Anwendung im deutschsprachigen Raum gedacht hatte. Darüber hinaus bezeichnet der Terminus Image'm seine Funktion als Teil eines Imagothimes genauer als 7.B. ..ImagemThèmem", denn ein ..Themu" wird aus Imugemem gebildet Sowohl Imugr'm als auch Imitgorhème erwecken darüber hinaus Konnotationen mit dem ..Image“ und mit der ..Imagination“, mit der ..bildhaften Vorstellungskraft”, ohne dabei durch die Vieldeutigkeit dieser traditionsreichen Begriffe symbolisch belastet zu sein

489 Siehe dazu oben, S. 41 f. Vgl. auch MrroseK 1974.

490 Das /deologie- und l/hopieverständnis der Artxeit lehnt sich stark an die philosuphischen Termini Paul Ricours an, die bereits in der philosophischen Fachsprache eingebügern sind Diese Termini wurden bereist im ersten Kapitel im Kontext von dessen Henneneutik erklän. und in diesem Sinn werden sie auch in den folgenden Interpretationen der literarischen Werke Dostoevskijs eingesetrt. 
möglicherweise stereotyp ${ }^{491}$ dargestellt werden, wobei sie ein ideologisches Imagothème bilden würden, z.B. ein polnisches ideologisches Imagothème, oder ob sie möglicherwesie auch als Teil eines anderen fremden Imagothèmes, z.B. „Europas“ bzw. des „Westens“, sowie (möglicherweise gleichzeitig mit einem ideologischen) einen utopischen Charakter aufweisen und dabei symbolhafte, mythische oder sakrale Bedeutung (das Fremde als das Numinose) haben. ${ }^{492} \mathrm{Im}$ letzteren Fall der utopischen Funktion könnte es sich auch um ein innovatives, kreatives Imagem, ggf. als Teil eines Imagothèmes, handeln, d.h. um ein Konstrukt der schöpferischen Einbildungskraft, das für die literarischen Werke Dostoevskijs charakteristisch ist, und das darin beispielsweise als „Dostoevskijs Polen“ bzw. die „Polen“ vorkommt.

Polnische Imageme als Bestandteile eines möglichen polnischen und/oder eines anderen fremden Imagothèmes werden dabei im Kontext anderer fremder Imageme und der russischen Imageme interpretiert.

Auf der synchronen Ebene werden nebeneinander einzelne Werke Dostoevskijs und ihre Bezüge untersucht. Mitberücksichtigt werden darüber hinaus mögliche Bezüge zu anderen (russischen) Autoren. Auf der diachronen Ebene wird nach der Dynamik, nach den möglichen Veränderungen und Entwicklungen der Funktion und der Struktur der Imageme gesucht, die ggf. ein über einzelne literarische Werke hinausgehendes polnisches oder anderes fremdes Imagothème bildeten.

In der folgenden Studie wird also am Beispiel der polnischen Imageme bzw. des möglichen polnischen Imagothèmes als Teil der Darstellungen des Fremden in den Werken Dostoevskijs die oben erwähnte Aporie zwischen Universalismus und Partikularismus untersucht werden können, d.h. wie fremde Gestalten und Kulturen den Russen und der russischen Kultur gegenübergestellt werden.

\footnotetext{
${ }^{491} \mathrm{Vgl}$ zu den Definitionen des Stereotyps, oben, S. 43ff. Es wird hier die Auffassung vom Sicreotyp von OAKES / HASL.AM / TURNER 1994 übernommen, bzw. auch den Ansichten von HENTSCHEL 1995 über Sicereotypen und Prototypen zugestimmt.

$192 \mathrm{Vgl}$. auch Ricoeur 1980 (S. 73-118, bes. S. $116 \mathrm{f}$ : Toward a Hermene ufic of the ldea of Revelution) über die Rolle der Einbildungskraft bei der Darstellung und Aufnahme der sakralen Dimension, der Offenbarung als historischem Zeugnis, sowohl in den biblischen Texten als Poesie als auch in poetischen. literarischen Texten: ..... the imagination is that part of ourselves that responds to the text as a Poem, and that alone can encounter revelation no longer as an unacceptable pretension, but a nonviolent appeal". HARRESS 1993 schreibt ihrerseits über den ..Offenbarungscharakter" der späten Werke Dostoevskijs, in denen zeitgenössische Ereignisse als .Zeichen der Offenbarung" verstanden und künstlerisch umgesetzt werden könnten (S. 7). Über die ambivalente Haltung den Fremden gegenüber, die in der Geschichte des ganzen Christentums ihre tragischen Spuren hinterlassen habe, schreibt dagegen NicHOt.S 1995: ..God often comes to us in the guise of the stranger. In fact, for Christians. Jesus himself comes to the world as the ultimate stranger ... For Christian faith Jesus is the incarnation of the Wholy Other, so God appears on earth as both very familiar and very strange". Die widersprüchliche Beziehung zum fremden Menschen und dem ..mysterious, ambivalent and sometimes sacred character" des Fremden in mehreren, nicht nur christlichen Kulturen läBt sich nach Nichols als mysterium iremendum et fascinuns des Heiligen (Rudolf Otto) beschreiben Die Ambivalenz des Fremden lindet sich auch in der Bedeutung des lateinischen Wortes hos:ts wieder (ebd., S. Iff. , S 5 und S. 9). Siehe dazu OTro 1932 und DFRS. 1926.
} 
Es wird eine Antwort auf die Frage gesucht, wie eine fremde polnische Figur dargestellt bzw. konstruiert, wie sie gegenüber den anderen fremden und russischen Figuren gestaltet wird, ob sie z.B. auch als ein Subjekt der Handlung gegenuber anderen Subjekten, d.h. als eine „Hauptfigur", ${ }^{493}$ gezeigt wird oder gezeigt werden könnte. Es wird somit auch die Frage nach dem Menschenbild der Werke Dostoevskijs im Hinblick auf die Gestaltung des Fremden gestellt.

Mit dieser inhaltlichen weltanschaulichen Frage auf der thematischen Ebene ist aber auch zugleich untrennbar diejenige nach der formalen Funktion der polnischen und der anderen fremden Figuren bzw. der polnischen und fremden Imageme in der Figurenkonstellation und insgesamt nach ihrer Funktion innerhalb der fiktionalen Welt der literarischen Werke Dostoevskijs verbunden.

Es wird also in dieser Studie nach einem möglichen Zusammenhang zwischen den inhaltlichen und formalen Aspekten der literarischen Werke Dostoevskijs im Hinblick auf die Problematik der Fremdheit ${ }^{94}$ gefragt.

Zum Schluß dieses Kapitels, bevor das Konzept in den konkreten Interpretationen überprüft werden kann, wird der Aufsatz von ROLF-DIETER KLUGE über die Darstellung Polens in der Lyrik von Nikolaus Lenau kurz besprochen. Kluge hat als erster Forscher die in dieser Studie vorgeschlagene imagologische Terminologie und Interpretationsmethode überzeugend angewendet. somit kann sein Aufsatz als Nachweis für die Brauchbarkeit dieses Konzepts betrachtet werden. ${ }^{495}$ Kluge hat die "Polenlieder" Lenaus (Niembsch Edler von Strehlenau, 1802-1850) ${ }^{496}$ In der Schenke (1831), Der Maskenball (1832), Der Polenflüchtling (1833), Zwei Polen (1834) und Nächtliche Fahrt (1838) imagologisch interpretien und anhand dieser Untersuchung gezeigt, daß die darin vorkommenden Imageme ,als funktionale Bestandteile eines großen, übergreifend sinnstiftenden Themas, eines Imagothèmes erscheinen, das Lenaus Polenbild determiniert", auftreten. Es handelt sich dabei um das Imagothème der "(politischen und nationalen) Freiheit", die dem Angriff der Tyrannei und des Zwanges ausgeset $\pi$ ist und von „Polen“ als Opfer der politisch-militärischen Gewalt symbolisiert wird. ${ }^{497}$ Es setzt sich aus den drei folgenden polnischen Imagemen zusammen: 1. dem utopisch-răumlichen von „Polen als einem Land des Todes und der Winterkälte“; 2. der Figur eines „polnischen Mădchens, das mit den Attributen Polens geschmückt im 'historischen Weltreigen verschwin-

\footnotetext{
$193 \mathrm{Vgl}$. daru oben, S. 15.

494 Im Hinblick auf den komplementăren bzw. dichotomischen Charakter dieses Phänomens wird hier die Bezeichnung fremalhe"l im Sinne eines Oberbegriffes verstanden, der die von Moura eingeführte Unterscheidung zwischen étrange'té und altérıé umfaßt (siehc dazu oben. S. 65fr.). Diese zwei Begriffe könnten in deutscher Sprache auch als Alterıüı und .4lı'nucï wiedergegeben werden. Sie kommen in dieser Bedeutung bei TURK 1990 vor.

${ }^{495}$ Siehe dazu oben, S. I5 sowie KLUGE (voraussichtlich 2002). Kluge hat darüber hinaus die erste imagologische Interpretation von Lenaus Lyrik versucht, vgl. ebd., S. I4.

496 Diese Gedichte sind im Kontext der „schwäbischen Polenbegeisterung“ als Teil des damaligen politisch-literarischen Diskurses der deutschsprachigen Schriftsteller und Intellehtuellen nach dem von der russischen Teilungsmacht niedergeschlagenen polnischen Aufstand von 1830-1831 entstanden (vgl. ebd., S. I und S. 9fr. des unveröffentlichen Manuskripts) 497 Ebd., S. 14 f.
} 
det und stirbt" (wobei es sich um eine Anknüpfung an das Stereotyp von der „schönen Polin“ handelt), sowie 3. aus der ebenfalls stereotypen Figur des "Polenflüchtlings“, der „heimatlos im unendlichen Raum umherirrt“. Dieses dritte Imagem repräsentiert die existentielle Seinserfahrung des "Weltschmerzes", die bei Lenau die Entwurzelung des lyrischen Ich generiert. ${ }^{488}$

498 Ebd. Dieses Imagem ist somit cin Symbol der ,eigenen Fremdheit" und konnte als eine Alius-Figur bezeichnet werden. 


\section{ZWEITER TEIL}

\section{POLEN IN LITERARISCHEN WERKEN F.M. DOSTOEVSKIJS. TEXTINTERPRETATIONEN}




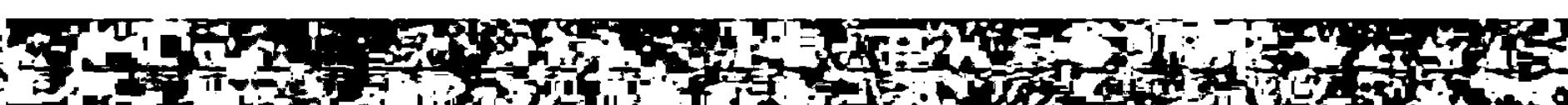
9lin

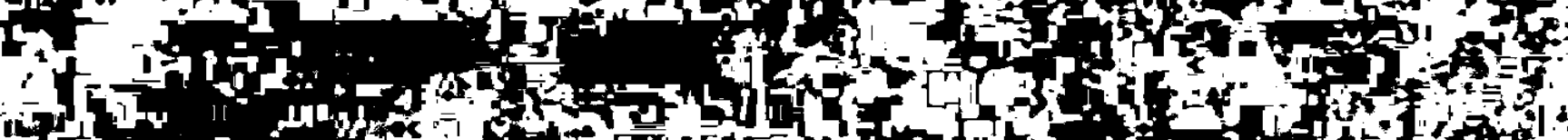

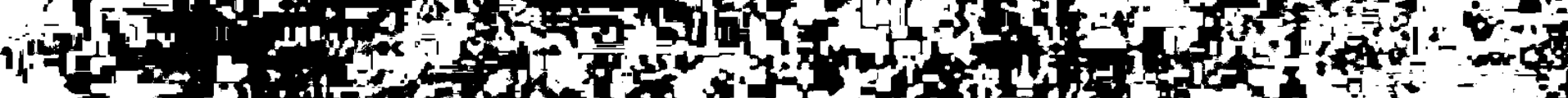
$\Rightarrow$ Th

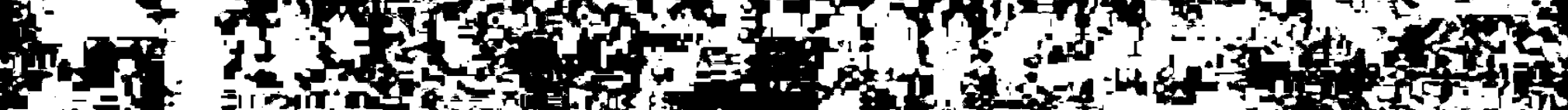
in

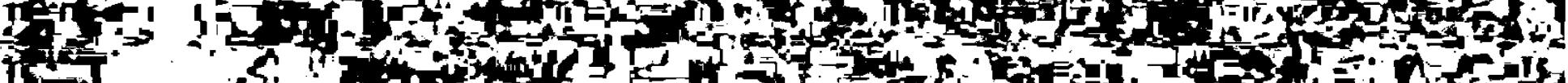

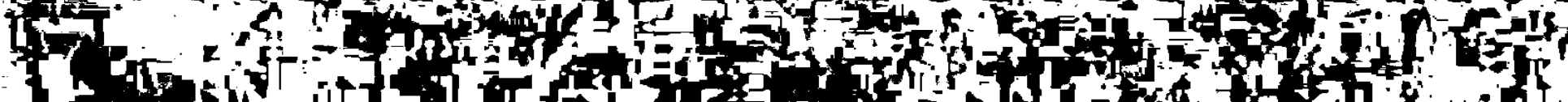
14 r. If $F$ Fin

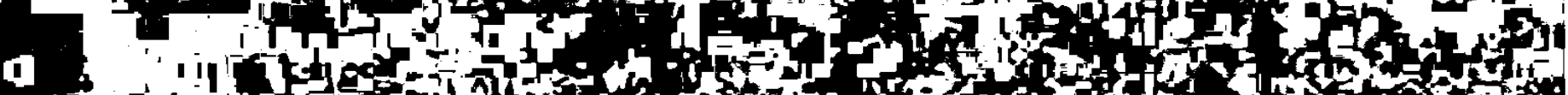
$\rightarrow-1$ - I t MF

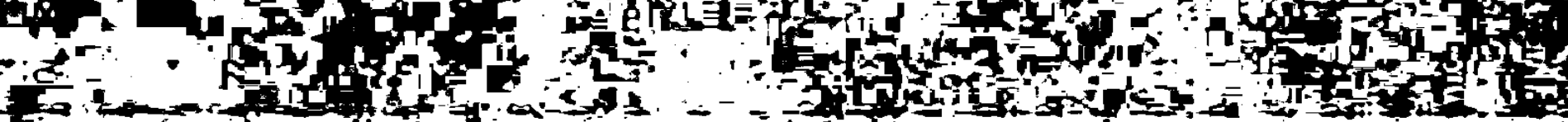

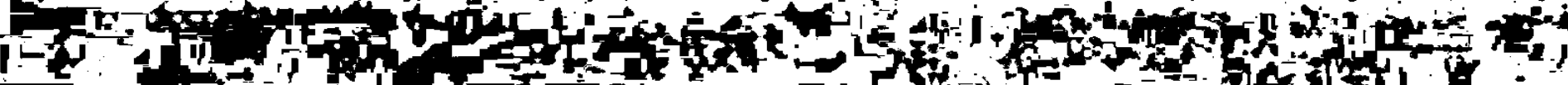

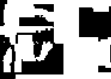

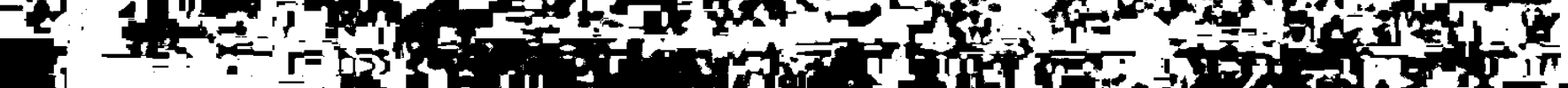
1
is

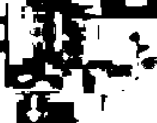

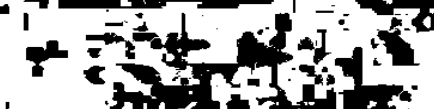

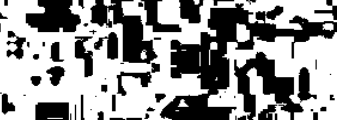

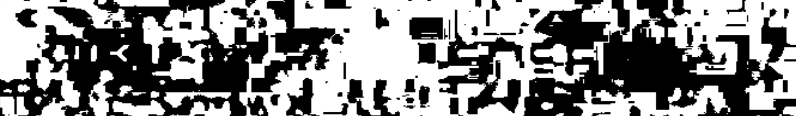 Ay

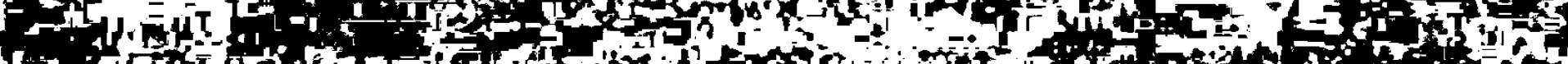

$\rightarrow 1$ to

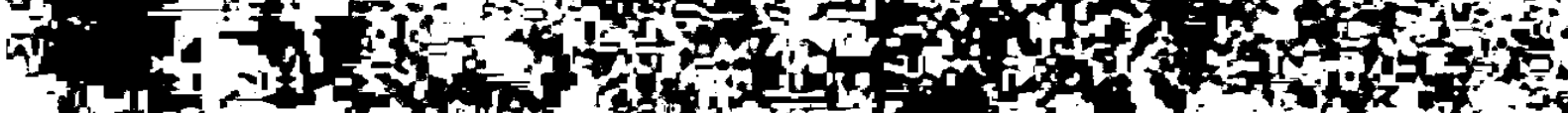
F.

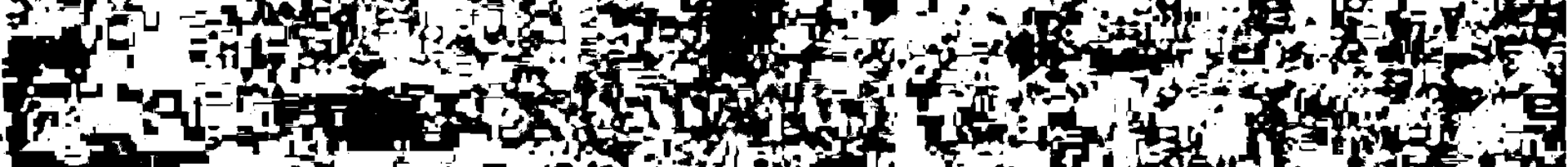

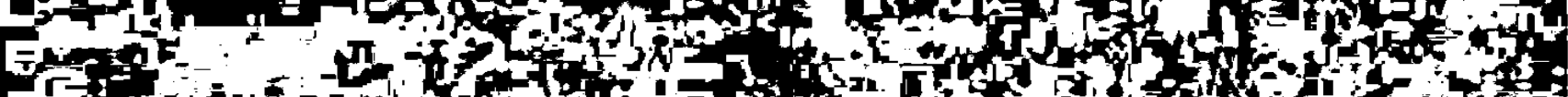

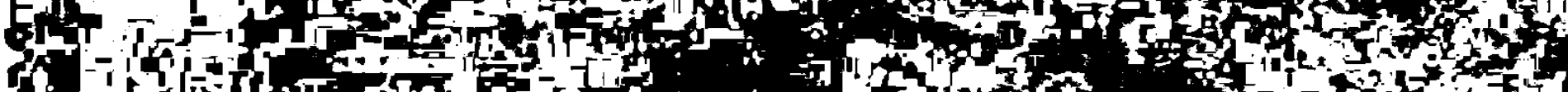

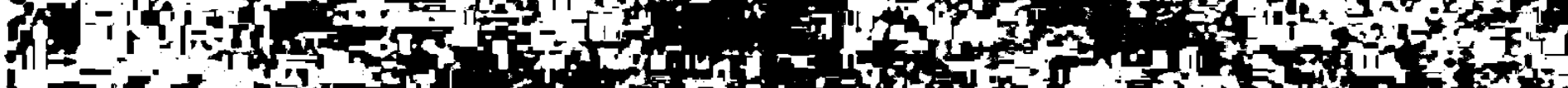

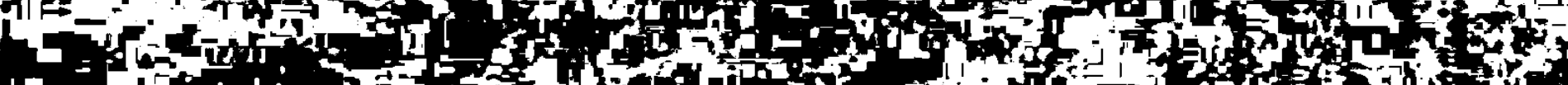

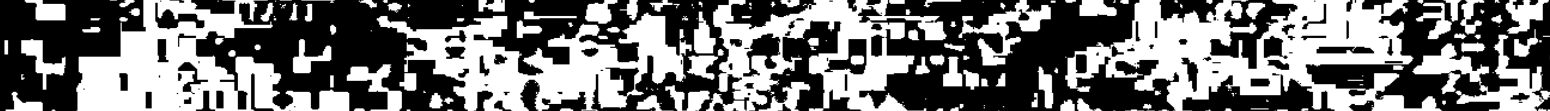

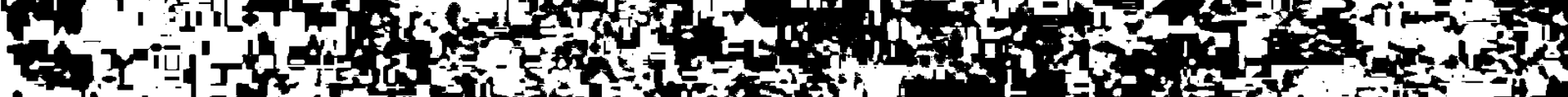
The 5.

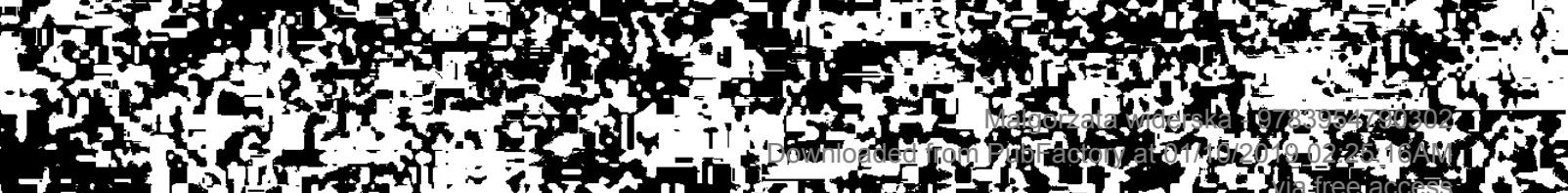


/.../ у меня на уме /.../ огромный роман, названіке ему «АтеІзм», /.../ но прежде чем приняться за который, мне нужно прочесть чуть не це.уюю биб.пютеку атенстов, kaто.тиков ІІ правос.лавных. /.../ Лıцо есть: русский человек нашего общества /.../ oдpуг, уже в .тетах mеряет веру в бога. /.../ Потеря веры в бога действует на него kо.тоссально. /.../ Он иныряет по новым поко.леніям, по ателстам, по с.лавянам и европейам, по руссkим изуверами пустынножлтте.ям, по свяшенникам; сильмо.

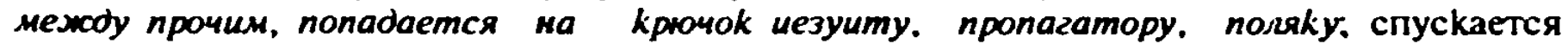
от него в г.тубину хтыстовщины - I под конец обретает и Христа и русскую земцю, pycckoro Xpilcta u pycckoro oora.

[i.../ ich plane $i \ldots /$ einen riesigen Roman mit dem Titel "Atheismus“, $i \ldots /$ aber bevor ich mich an die Arbeit mache, muB ich fast eine ganze Bibliothek atheistischer, katholischer und orthodoxer Autoren durchlesen. $i$.../ Die Hauptperson ist da: ein russischer Men.ch aus un.serer (iesellschafi /.../ plötzlich, schon bei Jahren, verliert er den (jlauben an (jolt. /.../ Der Verlust des Glaubens an Gott hat auf ihn eine kolossale Wirkung. i...i Er treibt sich herum bei den Vertretern der neuen Generation, Atheisten, Slawen und Europäern, bei den russischen Sektierern und Wüstenbewohnern; verfängt sıch ganz una gar in den Winkelzügen eınes .lesuiten. Propagundisten. eines Polen; versinkt danach in dem Abgrund der Flagellanten (der (hlysten), aber zum Schluß findet er sowohl Christus als auch die russische Erde, den russischen Christus und den russischen Gott.] [fett und kursiv Dostoevskij; kursiv die Verf.]

F.M. DOStoevskiJ: Pis 'mo $k$ A.N. Majkovu ot 11 (23) dekabrja 1868 . Florencija [Brief an A.N. Majkov vom 11. (23.) Dezember 1868. Floreñ]; Bd. 28,$2 ;$ S. 329.

/.../ идея моя состоя.ла в том, /.../ воспроизвести /.../ с русским взелядом ... вско русскую историю, отмечая в ней те точkı и пункты, в которых она /.../ выражатась вся, варуг, во всем свмем це.том./../ В горячей мыс.ли моей я думат даже, что не нало кончать бы.тины на ПІетре /.../. Я бы проне. до Бирона, до Екатерины и да.тее, - проше.1 цо освиобождении крестьян II до бояр, рассыпавшихся по Европе с пос.าедними кредиттыми руб.лишками, до /.../ семинарістов, проповедуюших атензм /.../. Поляки бы долмсны были занять много места. Затем кончнл бы фантастпчссkıми kартінами будушего: Россиі через два сто.летія, и рядом померкшей, ис-

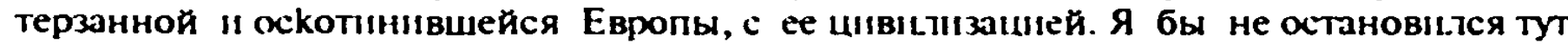
ки переd kakoü фамтазщей...

/.../ meine Idee bestand darin, /...i die gunze russusche (je.schuchte /... aus russusc/ker Sicht l.../ nuchzuerzühlen, indem in ihr genau alle Punkte hervorgehoben werden, in denen sie sich /.../ ganz ausgedrückt hat, plötzlich, in ihrer Ganzheit. .... In meiner glühenden Vorstcllungskratt dachte ich sugar, daß man diese Sage nicht mit Peter dem Großen beenden soll /.... Ich würde noch bis zu Biron, bis zu Ekaterina und noch weiter gehen, - bis zur Bauernbefreiung und bis zu den Bojaren, die sich in Europa mit ihren elenden letzten Rubelscheinen zerstreut haben, $i \ldots /$ bis zu den Seminaristen. die den Atheismus predigen /.... I Ie l'olen sollen clurin vel Plat = einnehnen. Hierauf würde ich mit den phantastischen Zukunftsbildern abschließen: Rußland in zwei Jahrhunderten, daneben das erloschene, gemarterte und viehisch verrohte Europa mit seiner ganzen Zivilisation. Ich würde dabei vor keiner Phantasie halt machen [fett und kursiv Dostoevskij: kursiv die Vert.]

F.M. IOSTOEvSkiJ: Pis mo k A.N. Majkovu ol 15 (27) maja 1869. Florencila [Brief an A.N. Majkov vom 15. (27.) Mai 1869. Florenz]); Bd. 29.1: S. $38 f f$. 


\section{VORBEMERKUNG}

Die im ersten Teil festgelegten methodischen Prämissen, die sich auf die philosophische Hermeneutik Paul Ricœurs stützen, sowie der dialogisch-personalistische Charakter der Poetik literarischer Werke Dostoevskijs, der sich in mimetischen (Aristotelischen) ästhetischen Kategorien beschreiben läßt, haben den interpretatorischen Erkenntnisweg des zweiten Teils meiner Studie maßgeblich geprägt.

Ausgehend von der Annahme Ricœurs, daß jeder literarische Text als eine Ganzheit, als ein „Werk“ bzw. als eine „Welt”, zu betrachten ist, deren Sinn und deren Wirklichkeitsbezug (die Referenz) ${ }^{1}$ sich in einem dialektisch verstandenen Interpretationsvorgang des Erklärens und Verstehens erschließen lassen, wird zuerst jedes literarische Werk Dostoevskijs ${ }^{2}$ einzeln im Hinblick auf die Darstellung Polens untersucht, um anschließend anhand dieser Einzelinterpretationen nach der "Tiefensemantik“ ( $=$ Sinn $)$ dieser Darstellung zu fragen. ${ }^{3}$

Das erste Kapitel umfaßt somit Einzelinterpretationen aller literarischen Texte Dostcevskijs, in denen polnische Imageme, u.a. fiktive und authentische polnische Figuren sowie andere Erwähnungen Polens, der polnischen Kultur und Geschichte, vorkommen. Die Gliederung dieses Kapitels wurde durch die (imago)thematische Fragestellung dieser Studie bestimmt: Es ist nicht nach dem Prinzip der Gattungszugehörigkeit, sondern nach dem der Chronologie geordnet worden." Dank dieser Anordnung wird es möglich, die zeitliche Entwicklung der Darstellung Polens verfolgen zu können.

${ }^{1}$ Paul Ricurur nennt den Sinn des Textes, Husserl folgend, auch das Noemu. Die Unterscheidung zwischen Sinn und Beckeutung (Referen:) eines Textes als discours hat er dagegen von Frege übernommen. Vgl. dazu z.B. Riccelir 1986a, S. 113: ..Son sens, c est l'objet idéal qu elle vise; ce sens est purement immanent au discours. Sa réfërence, c est sa valeur de vérité, sa prétension à atteindre la réalité". Der fiktionale, literarische Text zeichnet sici, aun. durch eine (poetische) Referenz ,zweiten Grades“ aus, enstanden aus der .,abolition“.der unmittelbaren Referenz des mündlichen Diskurses, „qui atteint le monde non plus seulement au niveau des objects manipulables, mais au niveau que Husserl designait par l'expression de l.ehenswelt et Heidegger par celle d'ètre au monde“ (ebd., S. 114). Vgl. dazu den Aufsatz von GOTTI.OB FREGE: liher Simn und Bedeutung (1892). Vgl auch FREGF 1967, S 143-162, sowie oben, S. 76ff., bes. S. 78 .

${ }^{2}$ Es wird jeweils das Datum der Erstveröftentlichung eines Werkes als maßgebend angeführ. die Texte Dostoevskijs werden nach den in der PSS veröffentlichten Fassungen ziticr, jeweils mit Band- und Seitenzahl.

${ }^{3}$ Vgl. Ricceur 1986a, S. 156: ..Ce que veut le texte. c est nous mettre dans son scns, c est-àdire - selon une autre acception du mot sens - dans la mème direction. Si donc l'intention est $l$ 'intention du texte. et si cette intention est la direction qu elle ouvre pour la pensée. il faut comprendre la scimantique profonde en un sens foncièrement dynamique: /.../ intcopréter. c est prendre le chemin de pensée ouvert par le texte, se mettre en route vers l imrichi du texte"

- Obwohl andererseits alle literarischen Werke Dostoevskijs einen eindeutig epischen (erzählenden) Charakter haben. Zu den unten behandelten Werken gehoren: ! Krmum I.

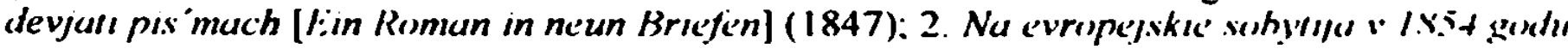


Im zweiten Kapitel werden die Ergebnisse der Einzelinterpretationen miteinander verglichen und zusammenfassend ausgewertet.

Die polnischen Imageme werden also zum einen, zusammen mit allen anderen fremden Imagemen, als ein Teil des kulturell vermittelten imaginaire social, im kulturell-literarischen und biographischen Kontext erörtert; ${ }^{5}$ zum anderen werden sie in jedem einzelnen literarischen Werk Dostoevskijs im Kontext anderer fremder Imageme innerhalb der fiktionalen Welt dieses Werks interpretiert. Besondere Aufmerksamkeit wird dabei auf die Figurenkonstellation des jeweiligen Werkes gerichtet, denn die fremden Imageme, zu denen auch polnische Imageme gehören, werden in der bereits erwähnten spezifischen Erzähltechnik Dostoevskijs direkt oder indirekt zur Charakteristik der russischen und fremden Figuren dieses Werkes cingesetzt. Dabei ist aber nicht beabsichtigt, alle fremden Imageme ausführlich zu besprechen. Nur die wichtigsten sollen exemplarisch zur Interpretation der polnischen Imageme herangezogen werden.

Auf diese Weise kann überprüft werden, welche strukturelle Semantik ${ }^{6}$ diese Imageme in den literarischen Werken Dostoevskijs haben, ob sie ein über die einzelnen Werke hinausgehendes Imagothème bilden und, ob dieses (polnische) Imagothème in jedem einzelnen literarischen Werk bzw. in allen literarischen

[Auf europü̈sche lireignisse von 1854] (1854); 3. Djadjuskin son. IE mordasovskıch lelopisej [Onkelchens Traum. Aus den ('hroniken der Stadt Mordasov] (1859); 4. Zapiski i= Merivogo doma [Aufzeichnungen aus einem Tolenhaus)] (1860-62); 5. (Inizennye , oskorblennve [Die lirniedriglen und Beleidigien] (1861); 6. Zimnie zumetkı o leinich vpeciallenijach [Winterauffeichnungen üher Siommereindrücke] (1863); 7. Igrok [Der Spieler] (1866); 8. Prestuplenie I nakazanie [Verhrechen und Sirafe] (1866); 9. Idoot [Der Idiot] (1868); 10. Veciny] muE. Rasskaz [Der en'ige (iatle. lirrählung] (1870), 11. Besy [Böse

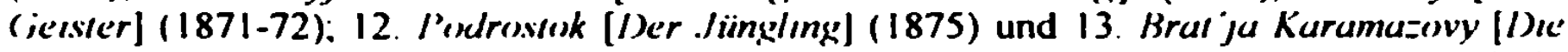
Brüder Kurumazov] (1880). Diese Aufzahlung zeigt. daß Polen in allen Romanen sowie in mehreren weiteren literarischen Texten Dostoevskijs Erwähnung findet Mit Ausnahme der Erzählung Romun v devjalı pis' mach (1847) treten in den literarischen Texten Dostoevskijs, die bis zur Verbannung nach Sibirien entstanden sind. keine polnischen Imageme auf, so gibt es auch in dem frühen und unvollendet gebliebenen Roman Netočka Nezunova (1849), der 1860 nach der Rückkehr Dostoevskijs aus Sibirien in einer umgearbeiteten Kurzfassung als Novelle bzw. Kurzroman [povest ] erschienen ist, keine polnischen Elemente (vgl. Bd. 2, S. 142fr. sowie den Kommentar der llerausgeber ebd. S. 4941\%. zu der Bezeichnung .prvess ${ }^{\prime *}$ siehe auch SLOWNIK TERMINOW LITERACKICH, in dem dieser russische literarische Fachausdruck als mikropowilesic (Mikro-h=w. Kur=roman) bzw. opowiesic (lirzählung, (icschichle) ms Polnische, als tale bzw. lemg short storn ins Finglische, als comte bzw. réctl ins Französische und als tirzühlung oder (ieschichle ins Deutsche übersetzh wird. ebd., S. 310 und 359).

5 Ergänzend werden die in der russischen Gesamtausgabe der Werke Dostoevskijs veröffentlichten Entwürfe und Notizen behandelt. Darüber hinaus werden Bezüge zu anderen literarischen Werken und Erinnerungen der Zeitgenossen an Dostoevskij und weitere, nicht nur literarische Werke Dostuevskijs mitberücksichtigt. Die äußerst umfangreiche Sekundărliteratur zum literarischen Werk Dostoevskijs wird exemplarisch mitberücksichtigt und vornehmlich auf die unmittelbar mit der Problematik dieser Studie zusammenhängenden Arbeiten beschränkt.

${ }^{6}$ Die Struktur eines literarischen Werkes wird hier als die dialektische Einheit der inhaltlichen und sprachlichen Elemente verstanden. 
Werken Dostoevskijs auch als Bestandteil eines anderen fremden Imagothèmes vorkommt. ${ }^{\text {? }}$

Der hermeneutische Zirkel der folgenden Interpretationen beginnt somit auf der thematischen (inhaltlichen) Ebene der Komposition der Texte Dostoevskijs, um, ausgehend von dem a priori angenommenen ideologischen und utopischen Charakter der fremden Imageme, nach ihren vertikalen und horizontalen (hierarchischen) Beziehungen innerhalb der dargestellten Welt dieser Texte (als Imagothèmes) zu fragen und zuletzt die Frage nach der Funktion der kulturellen (sozialen) Imagination bei der Schaffung der "Welt" literarischer Werke Dostoevskijs erneut zu erörtern, diesmal aber auf der Ebene des menschlichen lebensweltlichen Sinns, der die einzelnen Bedeutungsebenen übersteigt. ${ }^{8}$

7 So zum Beispiel in Gestalt eines Imagothemes des „Westens" bzw. "Westeuropas“, das demjenigen „Rußlands“ bzw. des .,byzantinisch-orthodoxen Ostens“ gegenübergestellt würde. Überprüft wird dabei auch, wie sich diese Imagothèmes in der Figurenkonstellation der literarischen Werke Dostoevskijs widerspiegeln, d.h., ob und inwieweit Figuren dieser Werke fremde bzw. russische Imagothèmes im Hinblick auf ihre kulturell-nationale Identităt, auf den Grad ihrer Bindung an die westlichen oder an die russischen kulturellen Traditionen reprăsentieren bzw. symbolisieren. Die in den folgenden Textinterpretationen vorgeschlagene vereinfachte Typologie der Figuren, die durch solche paradigmatischen Oppositionen wie (possilv vs ncgailv) ulopisch ideologisch, Alius Aller charakterisiert werden, soll lediglich dazu verhelfen, die Haupteigenschaften dieser Figuren im Hinblick auf ihre Verfremdung und Entfremdung von den russischen kulturellen Traditionen hervorzuheben, denn fast alle Figuren der literarischen Werke Dostoevskijs sind ..psychologisch“" und ..ideell“" viel differenzierter gestaltet.

Die Bezeichnungen ..Westen“ bzw. .(West-)Europa“ (= .Abendland". die .Alte Welt", .Okzident", die durch Antike und Christentum geformte kulturelle Einheit der europaischen Volker) auf der einen sowie ..byzantinisch-orthodoxer Osten“., das ..orthodoxe RuBland/Rus “" bzw. das seit den Reformen Peters des Großen „verwestlichte Rußland“ auf der anderen Seite, werden aber in ihrer ideologisch-utopischen Bedeutung verstanden, die diesen ursprünglich geographischen Bezeichnungen von den russischen Slavophilen und Westlem, darunter von den Zeitgenossen Dostoevskijs (und von Dostoevskij selbst), sowie auch von den späteren Forschern zugeschrieben worden sind, die sich mit der russischen Ideengeschichte befaßt haben.

Es handelt sich dabei um eine den literarischen Werken Dostoevskijs immanente, fiktive, autonome textuelle .Welt” (.,le quasi-monde“), die infolge der schriftlichen Fixierung des Diskurses kreiert wird. So läßt sich nach Ricœur beispielsweise von einer fiktiven, imaginăren .griechischen" oder ..byzantinischen" Welt sprechen, ..qu'il est présentı̣fié par l'écrit. au lieu mème où le monde était présenté par la parole, /.../ c'est un imaginaire littéraire“" (RIc)(ti:R 1986a. S. 141). In dem Sinne werden alle oben genannten Begriffe verstanden und eingeset $z$. Vgl. zu dieser Problematik und zu diesen Begriffen z.B.: LAZARI 1995a (S. 39f:: 7upud, (ocident - The West und S. 83ff: Ressija, Russiot). POZnIaK 1992, S 6ff., Walicki 1975 und WAI.ICKI 1980. Siehe auch die Veroffentlichungen der Zeitgenossen Dostoevskijs, z.B.. DANILEVSKU 1991 oder STRACHOV 1969.

8 In Vorgang der Interpretation wird der hermeneutische Zirkel vollendet, wiewohl nicht abgeschlossen: ..Le texte avait seulement une dimension sémiologique, il a maintenant, par sa signification, une dimension sémantique" (RicceUR 1986a, S. 153) - . la lecture est cet acte concret dans lequel s'achève la destinée du texte. C'est au coeur mème de la lecture que. indéfiniment, s'opposent et se concilient l'explication et l'interprétation" (ebd., S. 159). 


\title{
I. EINZELINTERPRETATIONEN
}

\author{
1. РОМАН В ДЕВЯТИ ПНСЬМАХ (1847) \\ [EIN RIMAN IN NH:IN BRIEFKN] ${ }^{9}$
}

Roman $v$ devjati pis 'mach ${ }^{10}$ gehört zu den frühen Werken Dostoevskijs, die unmittelbar nach dem erfolgreichen ersten Roman Bednye ljudi [Arme Leute] $(1846)^{11}$ entstanden sind. Die Briefform dieser Erzählung soll absichtlich von Dostoevskij gewăhlt worden sein, um in der gleichen Form wie im Roman Bednye ljudi andere stilistische Möglichkeiten zeigen zu können. ${ }^{12}$ Es handelt sich um den Briefwechsel zwischen zwei Petersburgern, Petr Ivanyc und Ivan Petrovic, die offenbar beide Falschspieler sind. ${ }^{13}$ Es ist das erste literarische Werk Dostoevskijs, in dem ein polnisches Imagem vorkommt, eine in kyrillischer Schrift korrekt wiedergegebene polnische Redewendung bzw. Höflichkeitsfloskel nadas do ног [= pln. padam do nóg; ergebenster Diener $]^{14}$ Sie

Die deutschen Übersetzungen der russischen Titel werden nach den in dieser Studie benutz-
ten deutschen Ausgaben angeführ.
10 Für diese Arbeit wurde die Übersetzung von Wilhelm Plackmeyer gewählt Vgl. Für diese Arbeit wurde die Übersetzung von Wilhelm Plackmeyer gewählt. Vgl.
DostojewSK 1986a, S. 349-364. Die Erzählung Roman v devjari pis'mach wurde 1847 im Joumal Sisvremennık [I/)er Zeılgenosse] veröffentlicht, vgl. Bd. 1, S. 230-239, siehe auch den Kommentar der Herausgeber, ebd., S. 499-501. Diese angeblich in einer Nacht im November 1845 entstandene Erzählung sollte ursprünglich in dem von Dostoevskij, Nekrasov und Grigorovic geplanten humoristischen Journal Zuhoskal [1)er W'itzbold] erscheinen. Zuhoskal konnte jedoch wegen des Verbots durch die Zensur nicht erscheinen, so daß der Roman $v$ divjuII pis much erst spater veröffentlicht wurde

${ }^{11} \mathrm{Vgl}$. Bd. 1, S. 13ff. und $462 \mathrm{fr}$.

12 Es handelt sich eigentlich um eine (Selbst)Parodie der „ernsthaften“ Gattung des Briefromans. Vgl. zur Form und Geschichte dieser Gattung: KLOOCKE 1985. Der doppeldeutige Titel der Erzählung spielt auf die traditionelle Thematik des ..Briefromans“ an und kann zugleich als ein .Roman" und als eine "Liebesgeschichte" verstanden werden. Siche zu den Vorbildern Dostoevskijs: Gogol’, Bestužev-Marlinskij oder Nekrasov: Bd. 1, S. 500f. Vgl dazu auch BELKNAP 1996.

${ }^{13}$ Dıese Namen, die einen Parallelismus .über Kreuz“" bilden, sowic andere - Cistoganov, Perepalkin oder Tolokonov erinnem an die komischen Namen der Figuren Gogol s, an Ivan Ivanovič und Ivan Nikoforovič bzw. an Kifa Mokievič und Mokij Kifovič, vgl. Bd. I, S. S00f. 14 Siehe zu dieser Wendung z.B bei IPPOt.DT o.J., S. 791: .Poln. Puclam des nigg $=z u d e n$ l.üß'n fallen brw. ich empfehle mich: meine Hechachtung: ergehenster l)iener". Diese Wendung drückt die polnische adlige Mentalität aus. Siche auch SkORUPKA 1967. S. 516: .Padać. upadać do nóg <zwrot, oznaczający powitanic lub pożegnanie>. Padam do nóg. Jaśnie Oświeconego Księcia /.../. Sienkiewicz" |Fallen, zu den Füßen fallen < Wendung, die Begrüßung oder $A$ bschied bedeutet $>$. Falle zu den Füßen, fußfällig. Euer Durchlaucht $/ . . /$. Sicnkiewicz|". Diese Wendung kommt darüber hinaus in einem Brief Dostoevskijs vom 26 April 1846 an den Bruder Michail vor, in dem er diesen im Namen von Belinskij bittet, in Revel eine .njanja“ |няня: Kinderfraul für dessen Frau zu finden ..а я перед тобой - падам - ло ног за это". [Ich werde einen Fußfall vor Dir dafür tun]. vgl. 
wird im ersten Brief von Petr Ivanyc an Ivan Petrovix in ironischem Kontext gebraucht:

Okоло половины прошедшего месяца вводите в мой дом одного знакомого вашего, именно Евгения Николаича, ассюрируете его дружесkой и для меня, разумеется, священнейшей рекомендацией вашей; я радуюсь случаю /.../ и вместе с тем kладу голову в петлю. /.../ нельзя ли каkим-нибудь образом, поделикатнее, в ckoбkax, на ушkо, втихомолочky, пошептать вашему молодому человеky, что есть в столице много домов, кроме нашего. Мочи нет, батюшka! Падам do ног, kak говорит приятель наш Симоневич. [kursiv die Verf.]

[Da führen Sie etwa Mitte vergangenen Monats in meinem Haus einen Ihrer Bekannten ein, nămlich Jewgeni Nikolaitsch, und legen Ihre freundschaftliche und für mich selbstredend heilige Fürsprache für ihn ein; ich freue mich /.../ und stecke damit den Kopf in die Schlinge. /.../ Könnten Sie Ihrem jungen Mann nicht irgendwie - taktvoll, beiläufig und stillheimlich - ins Ohr flüstem, daß es in der Hauptstadt noch viele Hăuser außer dem unseren gibt? Es ist unerträglich, mein Lieber! Padam do nóg, wie unser Freund Szymoniewicz zu sagen pflegt. $]^{15}$

Petr Ivanyc beklagt sich über einen gewissen Evgenij Nikolaič, der von Ivan Petroviz in sein Haus eingeführt worden ist und als unerwünschter Gast erscheint. Wie sich später herausstellen wird, ist Evgenij Nikolaix nicht nur der Freund des Hauses, sondem auch der Geliebte der Frau des Gastgebers geworden, und der fiktive Briefempfanger hat ihn absichtlich aus Rache an Petr Ivanyč, der ihm Geld schuldet, bei ihm eingeführ. Es handelt sich somit um das entscheidende Ereignis der selektiv, mit vielen Unbestimmtheitsstellen in allen Briefen erzăhlten Geschichte, die sich erst „retrospektiv“ als gegenseitiger Betrug und die Rache der handelnden Figuren rekonstruieren läßt.

Die polnische Redewendung ist hier ein Ausdruck eines gewissen Herm Simonevic, des ..gemeinsamen Freundes“ der beiden Briefpartner, und spielt ironisch-verfremdend auf die übertriebene "Unterwürfigkeit" von Petr lvanyz an. In diesem Kontext weicht der Gebrauch dieses Idioms von der ursprünglichen Bedeutung in der polnischen Sprache (als Grußformel) ab. Weil beide Briefpartner im folgenden sich selbst als Falschspieler und Betrüger entlarven. kann angenommen werden, daß Herr Simonevic nicht nur ein Pole, sondern darüber hinaus auch eine fragwürdige Spielerfigur ist.

Die ganze zitierte Stelle drückt in ähnlich verhüllend-ironischer Form die Empörung des Briefverfassers aus, der sich wegen der „Freundschaft" mit dem Briefpartner noch nicht so direkt wie in den nächsten Briefen äußern will. BELKNAP hat den ,altäglichen“ Charakter dieses und der folgenden Briefe be-

Bd. 28, 1, S 122, sowie in weiteren literarischen Werken Dostoevskijs vor. Vgl dazu unten. S. 226, S. 239f., S. 255, S. 357, S. 424.

15 Bd. 1, S. 231 [S. 350]. 
merkt, die so "lebensecht“, „realistisch" seien, daß sie den Lesern als authentischer Briefwechsel erscheinen könnten. ${ }^{16}$

Neben dem polnischen Idiom gibt es in diesem und in den anderen Briefen der beiden "Freunde" französische Fremdwörter: assjuriruete (von assjurirovat) [accюрupyeme/accюрuposamb; assurer; versichern] ${ }^{17}$ und pretekstiruete (von pretekstirovat') [npemekcmupyю/npemekcmuposamb; prétexter; zum Vorwand nehmen] ${ }^{18}$ und negliz̈irovat [неглuмироваmь; négliger; vernachlässigen]. ${ }^{19}$ Diese Lehnwörter charakterisieren den westlich gefärbten leichten und „eleganten" Konversationsstil beider Figuren, „Weltmänner" aus der Petersburger Gesellschaft.

Auch die Frau von Petr Ivanyč, Anna Michajlovna, nennt Evgenij Nikolaic in ihrem Brief Eugène. Der Stil dieses Briefs bildet einen Kontrast zum Brief der Frau des zweiten Briefpartners, Ivan Petrovičs, Tat'jana Petrovna, an denselben Evgenij Nikolaic. ${ }^{20}$ Aus diesem Brief geht hervor, daß Tat'jana Petrovna von Evgenij Nikolaic wegen ihrer Armut verlassen und an Ivan Petrovic "weitergegeben" worden ist. Dieser Brief enthält keine Fremdwörter, sondern russische umgangsprachliche bzw. volkssprachliche Ausdrücke „а мне доля лютая“ [.J.../ mir wird ein hartes Los zuteil", = Übers. v. W. Plackmeyer, S. 363] oder „прошайте... голубчик мой“ [,./.// leben Sie wohl, mein Liebster"; vgl. ebd. ; голубчuk = russ. Täubchen $[\text { Anm. die Verf.] }]^{21}$. Diese Figur erinnert an Varvara Alekseevna aus dem Roman Bednye ljudi. Ihr Name, Tat jana, bezieht sich intertextuell auf die nach Dostoevskijs Ansicht volksnahe Heldin des Evgenij Onegin. Der Name ihres ehemaligen Geliebten. Evgenij, weist einen parodistischen Bezug auf die Figur des Puškinschen Evgenij auf. Er erscheint der Heldin Puskkins als eine "Parodie" der literarischen Figuren aus den westlichen Romanen bzw. ihrer Autoren selbst. ${ }^{22}$

Tat janas Mann. Ivan Petrovič, spielt dagegen in einem seiner Briefe auf die Worte Julias aus Shakespeares Drama Romeo and Juliet an:

Известно вам, что воспитания и манеров хороших я не имею и пустозвонного шегольства я чуждаюсь, потому что по ropbkoму оныту познал наконец, сколь обманчива иногла бывает наружность и что под цветаяєи иногда таится жея. Но вы меня понимаци; не отвечати же мне таk, kak следует, потому, что вероломством души

\footnotetext{
${ }^{26} \mathrm{Vgl}$ Bel.KNAP 1996, S. 27.

27 Bd. 1, S. 231

18 Ehd., S. 232.

19 Ebd
}

20 Anna Michajlovna bescheinigt jeduch zynısch der früheren Geliebten von Evgenij Nikolaič, nachdem er ihr sämtlıche Briefe Tat janas geschenkt hatte, daß ihre Vorgängerin einen ..guten Stil“" habe. Vgl. ebd., S. 239 (..Bnpoyes, ectb c.7or“|..Ubrigens, Stil hat sie“; = Übers. v. W. Plackmeyer. S. 363 ().

21 libd., S. 2.39

22 Als ihre Lektüre wird der Roman Ion (Juijole erwähnt, was auf ihre Bildung sowie auf ihren Idealismus hindeuten mag. ebd, S. 238. Siehe auch die I'uskin-Recke Dostoevskijs, in der er gegen Finde seines 1 ebens Tat jana als eine einfache russische Frau schildert. $\mathrm{Vgl}$. Bd. 26, S. 136-149 sowie KLUGE 1987. 
своей положили заране изяенить своему честному слову и сунествовавшим межлу нами приятельскими отношениями. Совершенно же доказали вы это гнусным поведением вашим относительно меня в последнее время/.../ писаци вы под личиною дружбб /.../ [kursiv d. Verf.].

[Ihnen ist bekannt, daß ich weder Bildung noch gute Manieren besitze und hochtrabendes Geschwatz verabscheue; denn ich habe nach bitteren Erfahrungen letztlich eingesehen, wie sehr der Schein bisweilen trügt und daß sich unter lauter Blumen manchmal eine Schlange verbirgt. Doch Sie durchschauen mich; Sie antworten mir nicht, wie es sich geziemt hăte, weil Sie in threr treulosen Gesinnung von vornherein die Absicht hatten, Ihr Ehrenwort zu brechen und die zwischen uns bestehenden freundschaftlichen Beziehungen zu verraten. Neuester Beweis dafür war das schändliche Verhalten, das Sie in letzter Zeit mir gegenüber an den Tag gelegt haben I.../. Sie [schrieben] mir unter der Maske der Freunschaft /.../.] ${ }^{23}$

Ivan Petrovic, der sich selbst als ein „ungebildeter Mensch ohne gute Manieren" bezeichnet, widerspricht sich zugleich, indem er ein Zitat aus Shakespeare paraphrasiert, denn er verrät, wie seine Frau Tat jana, die Cervantes liest, eine gewisse Bildung bzw. Kenntnisse der westeuropáischen Literatur. Darüber hinaus erscheint seine an den Freund gerichtete pathetische Anklage, dem er Unehrlichkeit und Betrug vorwirft, im Kontext der ganzen Geschichte ebenfalls komisch und paradox, denn beide Freunde „spielen“ keineswegs mit .,offenen Karten".

Die in dieser Erzählung eingesetzten fremden Imageme, darunter die polnische Redewendung padam do nóg. dienen als ein Element des .Jargons“ der „verwestlichten" Petersburger zur Charakterisierung beider darin auftretenden negativen Figuren, die maskierte Lügner und Betrüger sind. Diese Wendung, die aus dem "fremden Wortschatz" eines polnischen Betrügers stammt, in der die (alt)polnische adlige Mentalität verspottet wird. wirkt im Brief eines Falschspielers in ihrem übertriebenen höflichen "Selbsterniedrigungspathos“ komısch. Die französischen Fremdwörter verleihen dagegen dem Stil der Erzählung den pseudomondänen, ornamentalen Charakter, denn die Briefe sind voll von Beschimpfungen. Die Anspielung auf Shakespeare ist in dieser Erzăhlung ebenfalls noch nicht eindeutig positiv konnotient wie in den spăteren Texten Dostoevskijs, in denen sie auf einen "utopischen Idealismus" der jeweiligen Figur hinweisen.

Der „verwestlichte“ Stil der Briefe zweier Falschspieler unterscheidet sich $\mathrm{kraß}$ von dem einfachen Stil des Briefs von Tat jana Petrovna. Es handelt sich also um die Opposition zwischen den negativ verwestlichten Russen und einer ebenfalls verwestlichten, aber positiv dargestellten Russin, die ihre, zumindest

\footnotetext{
${ }^{23}$ Bd. 1, S. 236 [S. 358f.].Vgl. auch ebd., S. 501 (die Anmerkung zu dem ShakespeareZitat: „... под цветам! иногда талтся зıнея"). Es ist eine Paraphrase der Worte Julias aus dem dritten Aufzug. die in der Übersetzung von M.N. Katkov aus dem Jahre $18+1$ ..3мея, змея, cokpытая в цветах" [Eine Schlange, Schlange, die in den Blumen versteckt ist] lauten. $\mathrm{Vgl}$. auch die englische Originalfassung: .O serpent heart, hid with a flow ring face!." (III. 2) (SHAKFSPFARE 1999, S. 238f.).
} 
„schriftlich“, im Stil ihres Briefs ausgedrückte russische kulturelle Identität nicht verloren hat und darüber hinaus als Opfer des negativ verwestlichten Russen (Evgenij) dargestellt wird. Das polnische Imagem ist dagegen ein Teil des verwestlichten (und als verlogen dargestellten) Petersburgs bzw. Rußlands schlechthin.

ZUSAMMENFASSUNG: In dieser parodistisch-satirischen Erzăhlung tritt das polnische Imagem (neben den französischen Imagemen) als Element der „fremden Rede" ausschließlich als Mittel zur immanenten Charakterisierung der negativen verwestlichten russischen Alius-Figuren auf, die einen Kontrast zu der positiv verwestlichten Figur Tat 'jana Petrovnas bilden.

Der lediglich einmal erwăhnte mutmaßliche Pole weist dabei Züge einer negativen Kontrast-Figur (als ein ideologisch gefărbter Alter) auf; die beiden russischen verwestlichten Briefpartner weisen dagegen in ihrer Negativităt utopischsubversive Eigenschaften auf, die sie durch die Aneignung der fremden, westlichen (franzosischen und polnischen) Kultur (Sprache) enworben haben, die ihre russische kulturelle Identität bedroht bzw. bereits zerstört hat.

Die durch ihren „volksnahen" Briefstil positiv charakterisierte „Heldin“ dieses Romans, Tat jana, wird dagegen durch die Elemente des ..positiven utopischen Idealismus" charakterisiert, der nicht nur durch den Bezug auf die gleichnamige Figur Puskins, sondern auch durch ihre Lektüre (Cervantes) angedeutet wird.

Vorläufig kann also festgehalten werden, daß, werkimmanent betrachtet, die in diesem "Briefroman" zur Charakterisierung der handelnden Figuren eingesetzten Imageme einerseits als Elemente des negativen utopischen Imagothèmes des verwestlichten, petrinischen Rußlands und andererseits des positiven utopischen Imagothèmes des verwestlichten Rußlands betrachtet werden können.

Die polnische Redewendung aus dem Munde eines polnischen Falschspielers (als einer negativen westlichen Alter-Figur) drückt einerseits eine ideologisch motivierte Kritik an der polnischen adligen, .,sarmatischen“ Mentalität aus und läßt sich andererseıts parallel dazu als ein Teil des negativen ideoiogischen Imagothèmes des venvestlichten Rußlands (in den durch diese Wendung immanent charakterisierten russischen negativen Alius-Figuren) bezeichnen. 


\section{2. НА ЕВРОПЕЙСКИЕ СОБЫТИЯ В 1854 ГОДУ (1854) \\ [AUF EUROPÄISCHE EREIGNISSE VON 1854]}

Die Ode Dostoevskijs Na evropejskie sobytija v 1854 godu ist 1854 in Semipalatinsk geschrieben und zum ersten Mal postum, im Jahre 1883, veröffentlicht worden $^{24}$. Dostoevskij hatte dieses Gedicht sowie zwei weitere: Na pervoe ijulja 1855 goda [Auf den ersten Juli 1855] $(1855)^{25}$ und Na koronaciju $i$ zaključenie mira [Auf die Krönung (des Zaren) und auf den Friedensschluß] $(1856)^{26} \mathrm{mit}$ der Absicht verfaßt, das über ihn verhängte Veröffentlichungsverbot rückgängig zu machen und sich als treuer russischer Untertan des Zaren zu zeigen und zu rehabilitieren. $^{27}$ Die Gedicht-Trilogie Dostoevskijs ist sowohl der feierlichen Form als auch dem patriotischen Inhalt nach eine Nachahmung ähnlicher Gedichte aus der Zeit des Krimkriegs, die in der damaligen Presse erschienen waren. ${ }^{28}$ Das erste Gedicht, die Ode Na evropejskie sobytija v 1854 godu, thematisiert den Ausbruch des russisch-türkischen Kriegs (Krimkriegs 1854-56), an dem die beiden Westmächte Frankreich und England auf der Seite der Türkei gegen Rußland beteiligt waren. Darüber hinaus enthält es mehrere Anspielungen auf die russische Geschichte, darunter auf den polnischen Aufstand von 18301831, wobei als Vorbild Puskins Gedicht Klevetnikam Rossii [An die Verleumder Rußlands] (1831) gedient haben soll. ${ }^{29}$

Das kollektive (chorische) lyrische Subjekt (,wir") wendet sich in der ersten Strophe an die Franzosen, ein "kluges Volk“, das sich lächerlich gemacht hat, indem es sich auf den Krieg gegen Rußland eingelassen hat:

\footnotetext{
„/.../ Kто виноват, kто первый начинает?

/.../ Народ вы умный /.../,

/.../ Смешно/.../ pycckoro пyraть!“

[Wer ist schuld, wer fangt als erster an?

/.../ Ihr seid ein kluges Volk /.../,

/.../ Es ist lächerlich /.../, den Russen einschüchtern zu wollen!]. ${ }^{30}$
}

\footnotetext{
$24 \mathrm{Vgl}$. Bd. 2, S. $403-406$ und den Kommentar, ebd., S. 519ff.

25 Ebd., S. 407f. und der Kommentar, ebd

26 Ebd., S. 409f. und der Kommentar ebd., S. 519 ff.

27 Ebd., S. 520-523.

28 Vgl. ebd. S. 521, wo z.B. die Gedichte von F. Glinka: (Jra [Hurra! / (1854). N. Arbuzov: Vragam Roxu [An die Feınde Rußlands] (1854) oder von N. Levasov: Ivjalaja bran' [Ier hellige Krieg] genannt werden.

29 Ebd., S. 523, siehe auch don zur Kritik der Petersburger Literaturkreise an der regierungstreuen, konformen Haltung Dostoevskijs, u.a. von I. I. Panaev. Vgl. auch PUSkiN 1949b. Bd. 3, S. 222f. (Klevelnikam Rossil). Siche auch KUSAKOV 1990, S. 70-89 (.4. S. Puskın i pol 'skoc vosssanie 1830-1831 godov [A.S. Puskin und der polnische Aufstand von /831)-1831]) bzw.

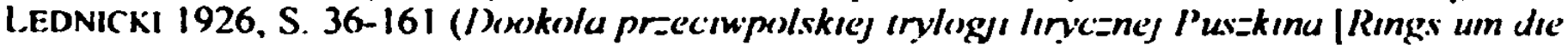
unipolnische (yrische Trilogie Puskins]).

${ }^{30}$ Bd. 2, S. 403
} 
In der zweiten Strophe wird die Zeit des „Tatarenjochs“ angesprochen, aus dem die Rus' siegreich hervogegangen ist. Seitdem ist sie so máchtig und groß wie ein "богатырь“ [ein sagenhafter Riese] geworden. In der dritten Strophe wird schließlich der polnische Aufstand von 1830-1831 als ein "hauslicher Streit" innerhalb des russischen Reiches, als Bürgerkrieg zwischen blutsverwandten Volkem bezeichnet, nach dem „die heilige Rus“" trotz der vielen Wunden lebensfahig geblieben war:

\section{Страдала Русь в боях междоусобных, \\ По kапле кровью чуть не изошла,}

Томясь в борьбе своих единокровных;

Но живуча святая Русь была! ${ }^{31}$

[Die Rus hatte in den inneren Fehden gelitten,

Sie war beinahe im Kampf gegen ihre Blutsvewandten,

Tropfen für Tropfen verblutet,

Aber die heilige Rus ' war immer lebensfahig gewesen!]

Das lyrische Subjekt wendet sich in den folgenden Strophen an die westlichen Nationen, um ihnen anhand von Beispielen aus der russischen Geschichte die Aussichtslosigkeit des Versuchs zu beweisen, die heilige, glaubensfeste orthodoxe Rus' besiegen zu wollen:

\section{„/.../ Спасемся мы в годину наваждений, \\ Cпасут нас крест, святыня, вера, трон! \\ Мы верою из мертвых воскресали, \\ И верою живет славянский рол".}

[Wir werden uns selbst in der Zeit der schweren Versuchungen retten.

Kreuz, Heiligtum, Glaube und Thron werden uns erretten,

Wir waren immer dank dem Glauben von den Toten zum Leben auferstanden

Und das Geschlecht der Slaven lebt nur dank dem Glauben allein. $j^{32}$

Bogust.AW MUCHA sieht in diesem Gedicht sowie in den zwei anderen Gedichten der "Trilogie" den Ausdruck einer neuen Ideologie Dostoevskijs, die sich in der sibirischen Katorga in einem komplizierten weltanschaulichen Pro$z e B$ hcrausgebildet habc. ${ }^{33}$ Die crste Ode $\mathrm{Na}$ evropejskıe sobytija $v 1854$ godu sei eine ideologische Polemik mit der westeuropäischen antirussischen Diplomatic uvährend des Krimkriegs. MUCHA hat ebenfalls die ideelle Nähe dieses Gedichts zur antipolnischen Trilogie Puškins bemerkt. v.a. zum Gedicht Klevetnikam Rossii. Die thematische Struktur der Ode erinnert an Puškins Gedicht. Beide Gedichte haben drei gemeinsame Motive: Die Sorge um das Schicksal Rußlands, die Polemik gegen die europäische offentliche Meinung und den (jlauben an den Sieg der russischen Armee. Das politische Bündnis

${ }^{31}$ Ebd.

32 libd.

33 Vgl. MuCha 1977, S. 93. 
zwischen Frankreich, England und der Türkei wird von Dostoevskij in religiosen Kategorien aufgefaßt: als ein Verrat der westlichen Lander am Christentum. ${ }^{34}$ Nach Mucha ist in diesem Gedicht Dostoevskijs zum ersten Mal das utopische Programm der allmenschlichen Mission Rußlands und seines orthodoxen Volkes explizit formuliert worden. ${ }^{35}$ Die Ansichten Dostoevskijs treffen sich darin mit denjenigen anderer Slavophilen, z.B. F.I. Tjutcevs. ${ }^{36}$

ZUSAMMENFASSUNG: In der Ode Na evropejskie sobytija $v 1854$ godu ist zum ersten $\mathrm{Mal}$ in den Werken Dostoevskijs explizit die positive Utopie des "orthodox-russischen Christentums" dem negativen des "falschen", „westlichen Christentums" gegenübergestellt und in den Dienst der (groß)russischen nationalen bzw. nationalistischen Ideologie gestellt worden. ${ }^{37}$ Aus textimmanenter Perspektive erscheint diese Ideologie als ein ,historiosophisch" begründetes „Heilsgeschehen“. Die darin erwähnten feindlichen Fremden aus dem Westen (,Ihr": Franzosen und Englander in der Funktion als Alter) werden den Russen ("Wir ${ }^{\text {" }}$ ) und der "heiligen Rus"“ (personifiziert als ein sagenhafter Riese bzw. als ein christophorisches Volk, als ein Alius) gegenübergestellt. Dem traditionellen mythopoetischen Charakter der literarischen Gattung der Ode enstprechend, erfüllen die fremden Imageme eine Kontrastfuntion, um die Ideologie und die Identităt der eigenen Nation zu stärken. ${ }^{38}$ Somit lăßt sich von der in diesem frühen episch-lyrischen Werk zum ersten Mal ausgedrückten paradigmatischen Opposition zwischen dem negativen ideologischen Imagothème des Westens und dem positiven utopischen Imagothème des orthodoxen Rußlands (als die heilige Rus') sprechen.

\footnotetext{
34 Ebd., S. 95.

35 Ebd., S. 96.

36 Ebd., S. 97. MuchA nennt als Beispiel einer solchen Ideologie das Gedicht Tjutcevs Russkaja geografija [Die russische (jeographie] (1848-49) (vgl. TruTCEV 1987, S. 152). Was die zwei anderen Oden Dostoevskijs betriff, so seien sie den Oden Lomonosovs, Derzavins oder Zukovskijs nachgebildet worden. MUCHA stellt außerdem das niedrige künstlerische Niveau der Gedichte Dostoevskijs fest, in denen aber seine Weltanschauung offen und ehrlich zum Ausdruck gekommen sei (ebd., S. 99ff.).

37 Die positive russisch-orthoduxe (hopie umfaßt nicht nur Konstantinopel, sondern auch Sibirien und Asien, somit handelt es sich um den zum ersten Mal explizit formulierten Dostoevskijschen Mythos des (Orients (vgl. POŻNIAK 1992).

38 Es handelt sich also um die von Paul Ricaur bemerkte ideologische Funktion der Integration und der Legitimation (der Autorităt) einer Gruppe.
} 


\section{3. ДЯДЮШКНН СОН (ИЗ МОРДАСОВСКИХ ЛЕТОПИСЕЙ) (1859) \\ [ONKEICHENS TRALM (AUIS IDEN CHRONIKEN IDER STADT MORIDASOV)] ${ }^{39}$}

Polnische Imageme treten in einem umfangreicheren literarischen Text Dostoevskijs zum ersten $\mathrm{Mal}$ in der Erzählung Djadjuškin son (1859) auf. Sie entstand - wie die Ode Na evropejskie sobytija $v 1854$ godu - in der Verbannung in Semipalatinsk. Die polnischen Imageme hăngen hauptsăchlich mit der Titelfigur der Erzählung, dem „Onkelchen“ Fürst K., zusammen. In einer der Geschichten des Fürsten taucht die Figur eines Polen auf, außerdem gibt es in dieser Erzăhlung noch zwei andere polnische Anspielungen: zum einen wird ein polnischer Arzt erwähnt und zum anderen eine spanische Insel, wahrscheinlich Mallorca auf der sich Chopin und George Sand aufgehalten haben, obwohl der Name Chopins nicht explizit genannt wird. ${ }^{10}$ Alle fremden lmageme werden dabei zur Charakterisierung der russischen Figuren eingesetzt, indem sie diese Figuren immanent, "von innen", als "Elemente“ ihres inneren, psychischen I.ebens bzw. "von außen“, in der Kontrastfunktion, charakterisieren. Alle handelnden Figuren sind darüber hinaus statisch bzw. stark typisiert und weisen groteske Züge auf, was sich auf die Entstehung dieser Geschichte aus einer von Dostoevskij geplanten Komödie zurückführen läßt. ${ }^{41}$

${ }^{39}$ Die deutschen Übersetzungen russischer Zitate aus Djadjuškın son werden nach der Ausgabe: DOSTOJEwSKI 1960, S. 9-188 (Onkelchens Truum. Aus den C'hroniken der Siludt Mtordássoff. lirzühlung), angeführt.

${ }^{10} \mathrm{Vgl}$. Bd. 2, S. 327 und die Anmerkung auf S. 517: Dostoevskij soll einen Artikel von

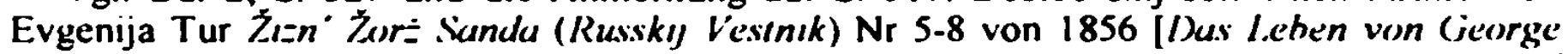
.iund; Russischer Botel gelesen haben, in dem der Aufenthalt Chopins und George Sands auf Mallorca beschrieben wird.

¿1 Vgl. Bd. 2, S. 296-398 und den Kommentar, ebd., S. 509-514: Djadjuškın son gehört

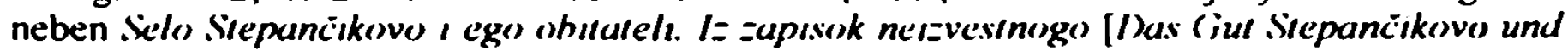
seine Bi'wohner. Aus den Aufzeichnunngen eines Inhekunnien| (1859) (vgl. Bd. 3, S. 5-168 und den Kommentar dazu, ebd., S. 496ff.) zu den ersten nach der Entlassung aus der Katorga und in der Verbannung in Semipalantinsk entstandenen literarischen Werken Dostoevskijs. 1)jadjuškın sonn ist aus den Plänen zu einer Komödie bzw. zu einem komischen Roman hervorgegangen, die Dostoevskij noch 1855 konzipiert haben will: vgl. Bd. 2, S. 510fr, auch zu den literarischen und authentischen Vorbildern des Fürsten $K$, der u.a. eine Autoparodie Dostoevskijs sein soll, bzw. zu den thematischen und gattungsspezifischen Bezügen u.a. zum russıschen Volkstheater - ..Petruska“ - zu Gogol , Griboedov, Puskin. Saltykov-Šcedrin, Fonvizm oder Turgenev (zum Theaterstuck I'rovincialka [I'rovinzlerın, (1850, veröffentlicht 1851) | bzw. zu Turgenevs Persönlichkeit selbst) (ehd., S. 512f.). Auch die komischen Namen der Figuren Dostoevskijs erinnern an die ,.sprechenden“ Namen der Figuren der oben erwähnten Autoren. $\mathrm{Vgl}$. auch die Anmerkung der Herausgeber der PSS zum intertextuellen Bezug der Cieschichte des ..Hauses Moskalevas“ zu einem Roman von Balzac: „Повесть моя заключает в себс по.лную " замечате.тьную историю возвышенія, славы " торжественного падения Мары А rekсандровны и всего се дома в Мордасове“" [..Meine firzählung umfaßt die ungekürne und bemerkenswerte Geschichte der Erhöhung. des höchsten Ruhmes und des feierlichen Sturzes unserer Marja Alexandrowna und ihres ganzen

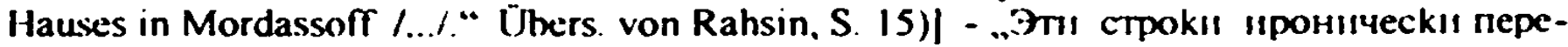

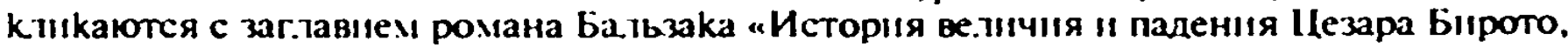
в тале.тьиа парфюмерной :аakı" [Diese Zeilen beziehen sich ironisch auf den Titel des 
Die Handlung dieser Erzăhlung, die in Form einer Chronik skandalöser Ereignisse von einem Ich-Erzăhler wiedergegeben wird, spielt in einem russischen Provinzstädtchen namens Mordasovo. ${ }^{42}$

Zu der Gruppe der russischen Bewohner des Städtchens, die die Langeweile mit Gerüchte-Frzählen und mit Intrigen vertreiben und ohne Ausnahme verwestlicht sind, gehören v.a. Mar ja Aleksandrovna Moskaleva, ${ }^{43}$ ihre Tochter Zinaida Afanas evna (Zina), ihr Mann Afanasij Matveic ${ }^{\text {‘4 }}$ sowie Petr Aleksandrovix Mozgljakov, ${ }^{45}$ außerdem der Lehrer Vasja, der Geliebte Zinas, der aber nicht zur adligen Gesellschaft von Mordasovo gehört. ${ }^{46}$ Daneben treten weitere russische Nebenfiguren auf, u.a. mehrere Damen der Mordasover Gesellschaft, z.B. Sof ja Petrovna Farpuchina, Nastas ja Petrovna Zjablova oder Natal'ja Dmitrievna Paskudina. ${ }^{47}$

Romans von Balzacs (jeschichle der (irößße und des Verfulls von ('ésur Birotteau. Parfümerichïndler, [Beigeordneter des zweilen Bezirks von Paris, Rilter der Ehrenlegıon usw.; = Histotre de la grandeur et de la décadence de ('ésar Birotteau, marchand parfumeur. adjoint au maire du deuxième arrondissement de l'aris, chevalier de la légion d'honneur. elc. (1838)], ebd., S. 516 zu S. 299.

2 Vgl. Bd. 2, S. 296 und die Anmerkung zu dem Namen Mordasovo, ebd., S. 515 Mordasovo soll ein Portrăt der Stadt Semipalatinsk sein, ebd., S. 511. Vgl. auch die Provinzstadt in der Roman-Chronik Besy oder das Städtchen Skotoprigonevsk, in der die Handlung des Romans Brat ja Kurumuzovy spielt.

${ }^{13}$ Sie hălt sich für die erste Dame von Mordasovo, von ihren Feinden wird sie .Napoleon“" genannt und wegen ihrer Intrigen und Klatschereien gehaßt und gefurchtet, vgl. ebd., S. 296f. Moskaleva zeichnet sich außerdem durch ihre ,jesuititische“ betrügerische Dialektik aus: vgl. S. 324ff., S. 331, S. 352ff, S. 360.

4 Der Mann Moskalevas hat viel mit der Figur des Gouverneurs fon Lembke aus dem Roman Besy gemeinsam, vgl. z.B. ebd., S. 298 und unten S. 324f.

${ }^{45} \mathrm{~V}_{\mathrm{gl}}$. ebd., S. 299, 303, 366ff., 397f. Laut Kommentar (ebd., S. 512) soll Mozgljakov eine Karikatur Evgenij Onegins sein. Sein Name geht auf das russische Wort mozgljuk [soszesk; Schwăchling. ..gewässerter Hering"| zurück, er ist eine Parallelfigur zu ..seinem Onkelchen“" Fürst K., ebenfalls ein Dandy und strebt nach .,neuen Ideen“ aus dem Westen (ebd.). Der satirische Bezug zu Onegin wird dagegen im Epilog der Erzählung besonders deutlich, vgl. S. $397 f$.

${ }^{46} \mathrm{Z}$ ina und Vasja sind die romantischen Liebhaber, die mit ihrem .Idealismus“ der ..verlogenen" Welt von Mordasovo gegenübergestellt werden. Beide Figuren werden mit Figuren Shakespeares (wohl mit Romeo und Julia) in Verbmdung gebracht, vgl. S. 324, S. 327, S. 334, S. 384, S. 39lf. Die Szene des Todes Vasjas scheint übrigens die Szene des Todes von Bazarov aus dem Roman Turgenevs (Nicy ‘ detı [Väter und Sühne; eigentl. Väter und Kınder] (1862) vorwegzunehmen, vgl. ebd., S. 390-394

"7 Alle diese Figuren haben komische, ,bedeutende“" Namen. Der Name Paskudına läßt sich beispielsweise auf das Wort paskudny/ |nackydный; ahscheulich. widerwärlıg, ekelhafi| zurückführen. Die grotesken Züge und Typisierung dieser Figuren werden z.B. in der folgenden Beschreibung einer der Damen sichtbar, in der diese boshafte Klatschbase mit einem Spatz bzw. mit einer Elster verglichen wird (vgl. Bd. 2, S. 303 oder 328f.): .По.лkоводница, Coфья Петровна Фариухина, то.лько нравственно походи.ла на copoky. Физичесkи она ckopie походіьіа на воробья. Это бы.та матенькая пятицесяпитетняя дама, с остреньkıмı r.лазkам!1, в веснушках и в же.тых пятнах по всему .лиу. На маленьком, иссохшем те.лье ее, помещенном на тоненьких kpenkих воробыных ножkах, бы.ло uाe.⿲oвое темное платье, всегда шумевшее, потому что полководница двух секунд не мог:ı иробыть в покое. Это была зловешая и мстттельная сплетница“. [S. 66: Ssofja 
$\mathrm{Zu}$ den russischen Figuren gehört auch der plözlich in Mordasovo aufgetauchte Fürst Gavrila K., der das monotone Leben des Städtchens, diese in sich geschlossene Welt, für eine Weile durcheinanderbringt. Seine Figur wird unten im Z.usammenhang mit den polnischen Imagemen besprochen.

$\mathrm{Zu}$ den wenigen fremden Figuren, die in der Erzăhlung als die „Anderen“ (als alter) vorkommen bzw. lediglich erwăhnt werden, gehören: ein Arzt, Kallist Stanislavix, dessen Vatersname auf polnische Herkunft hindeuten mag, ${ }^{48}$ ein jüdischer Pfandleiher, Bumštejn, ${ }^{49}$ eine deutsche Dame Luiza Karlovna ${ }^{50}$ und ein deutscher Gelehrter, der einmal absichtlich aus Karlsruhe nach Mordasovo gekommen war: „исследовать особенный род червячkа с рожками, kоторый водится в нашей губернии, и написавший об этом четыре тома in quarto“, $[, \ldots /$ um hier eine besondere Wurmart mit Hornchen, die in unserem Gouvernement vorkommt, zu erforschen, und der über dieses Würmchen vier Bände in Quart geschrieben hat $/ \ldots \%$, S. 10] und seitdem mit Frau Mar ja Aleksandrovna Moskaleva in einem Briefwechsel steht („ведет с ней почтительную и нравственную переписky из самого Карслруз“ [, , [tauscht mit ihr] aus Karlsruhe ehrerbietige und moralisch einwandfreie Briefe aus", ebd.]). ${ }^{51}$

Neben den fremden Figuren werden noch andere fremde Imageme in Djadjuškin son erwähnt, die sämtlich mit den verwestlichten russischen Figuren zusammenhängen und diese als solche charakterisieren. Aus der deutschen Literatur und Kultur werden Heine, Beethoven und Kant angeführt. ${ }^{52}$ Moskaleva spricht außerdem über Spanien bzw. über die Insel „Malaga“ (=Mallorca), die für sie ein utopischer idealer Gegenort zu Mordasovo und seiner Alltagsprosa

Petriwna Karpúchina [sic!|, die Frau eines Obersten, war nur moralisch mit einer Elster zu vergleichen. Körperlich erinnerte sie eher an einen Sperling. Sie war eine kleine, fünfzigjährige Dame mit scharfen, stechenden Äuglem in einem Gesicht, das ganz von Sommersprossen und anderen Flecken bedeckt erschien. Ihr kleiner, ausgetrockneter Körper, der auf zwei dünnen, festen Sperlingsbeinen stand, stak in emem dunklen Seidenkleid, das beständig rauschte, da die Dame sich nie, auch nicht zwei Sekunden lang, ruhig verhalten konnte. Sie war eine bosartige und rachsüchtıge Klatschbase.]

${ }^{40} \mathrm{Vgl}$. ebd., S. 327, 369, 395f. Nach Vrangel ${ }^{\prime}$ gab es in Semipalatinsk einen polnischen Arzt, Doktor Lamotte, der ein Vorbild für diese Figur gewesen sein könnte. Vgl. VRANGEL' 1912, S. 69-78.

$49 \mathrm{Vgl}$ Bd. 2, S. 323 und die Anmerkung auf S. 513, auch unten zu 7apıski $:$ Merlvogo) doma, in denen ein Jude dieses Namens vorkommt, S. 164, S. 193f. und S. 203.

so Ebd., S. 369f.

51 Ebd., S. 297

52 Beethoven und Kant kommen in den Geschichten des Fürsten K. vor, siehe dazu unten. Heine wird von Mozgljakov erwăhnt, vgl. ebd., S. 305f.: „Но nревозмог.ло че.ловеkо.лю6ие. koторое, kak выражается Гейне, везде суется с свомм носом“|..Doch die Năchstenliebe siegte, die hekanntlich, wie Heine sagt, ihre Nase überall hineinsteckt ${ }^{\prime \prime}, S$. 26]: siehe auch die Anmerkung zu dieser Stelle; S. 516: „В точности rakoro выражения у Г. Гейне нет, но в «Путевых картинах» («Итатия. ПI. Луксkие воды» - 1828) дтинный нос по.тукоми-

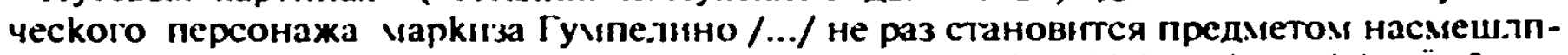
вых рассужлений автора." |Genau genommen gibt es bei H. Heine eine solche Äußerung nicht, aber in den .,Reisebildern" (.,Italien II. Die Bäder von Lukka“- 1828) wird die lange Nase der halbkomischen Figur des Marquis Gumpelino /.../ zum Gegenstand der spöttischen Betrachtungen des Autors."| Vgl. auch HEINE 1986, S. 88ff. (zu Markese Gumpelıno). 
ist. ${ }^{53}$ Mit den Figuren Moskalevas, Mozgljakovs, Zinas und Vasjas hăngt der bereits erwăhnte Name Shakespeares zusammen, der für Moskaleva das Symbol der lebensfernen unpraktischen „Romantik“ nicht nur ihrer Tochter und ihres Geliebten, sondern auch des jungen Mozgljakov ist, den sie dem alten Fürsten K., wohl seines Geldes wegen, vorzieht:

„/.../ ваш Шекспир давным - давно уже отжил свой век и если 6 воckpec, то, со всем своим умом, не разобрал бы в нашей жизни ни строчки! Если есть что-нибудь рыцарсkое и величественное в современном нам обществе, тak это именно в высшем сословии. Князь и в кульке князь, князь и в лачуге будет kak во дворие!“

[/.../ Ihr Shakespeare hat schon längst seine Zeit überlebt, und wenn er jetzt auferstünde, würde er bei all seinem Verstand doch keine Zeile von unserem gegenwärtigen Leben zu entziffern vermogen. Wenn es in unserer Gesellschaft überhaupt noch etwas Erhabenes und Ritterliches gibt, so finden wir das eben nur noch im hochstem Stande. Ein Fürst ist auch im Bauemkittel ein Fürst; ein Fürst wird sich auch in einer elenden Hütte wie in einem Schloß benehmen! ${ }^{54}$

Der Name Shakespeares bildet hier einen Teil der positiven romantischen Utopie, des positiven utopischen Imagothèmes des verwestlichten Rußlands, das durch die Figuren von Zina und Vasja vertreten wird. Thre Welt wird derjenigen der negativen verwestlichten Figuren, v.a. Moskalevas und ihresgleichen, gegenübergestellt, auch derjenigen Mozgljakovs, der sich eigentlich nur als ein "Romantiker" inszeniert bzw. tarnt und im ironischen Kontext als eine Parodie eines solchen Typs zu betrachten ist.

Alle anderen fremden Imageme, nicht nur die bereits erwăhnten Anspielungen auf Kant und Beethoven, sondern auch auf Byron, Casanova, Napoleon, auf den Papst und den Wiener Kongreß, auf Deutschland, auf das französische Mittelalter und seine Ritter und Damen sowie schließlich auf den falschen polnischen Grafen bzw. Koch hängen mit der Figur des Fürsten K. zusammen. Sie kommen in den phantastischen Geschichten dieser grotesken Figur vor, die von seiner Umgebung nicht emst genommen wird.

Der Fürst selbst wird in die Handlung zuerst vom Ich-Erzähler eingeführt und folgendermaßen vorgestellt:

/.../ смотря на него, невольно приходила мысль, что он сик) минуту развалится: до того он обветшал, или, лучше сказать, износился. /.../ говорили даже, что старичок помешался. Всем казалось особенно странным, что помешик четырех тысяч пуш /.../ живет в своем великолепном имении уединенно, совершенным затворником. /.../ Человеk он был k тому же добрейший, разумеется, не без некоторых особенных княжеских замашеk /.../. Рассkазывати, меж-

${ }^{53} \mathrm{Vgl}$. S. 324. S. 327, S. 354, S. 362. Dieses Spanien Moskalevas wird als eine stereotype idyllische Landschaft geschildert

54 $\mathrm{Vgl}$. S. 307f. [S. 30] und die Anmerkung, S. S16. 
ду прочим, что князь проводил болыше половины дня 32 своим туалетом и, казалось, был весь составлен из kakих-то kусочkов./.../ Он носиі nарик, усы, бакенбарды и dasce зспаньолkу - всё, do noследнего волоска, накіадное и великолепного черного ивета; белицся и рулянияя ехседневно /.../. Он хромал на левук ногу; утвержлали, что эта нога поддельная, а что настоящуо сломали ему, при kaком-то /.../ похождении, в Париже/.../. /../ Но верно было, одна -ko же, то, что правый глаз его был стеклянный, хотя и очень искусно подделанный. [kursiv d. Verf.]

[Gleichwohl kam einem bei seinem Anblick unwillkürlich der Gedanke, daß er sogleich auseinanderfallen müsse: so verlebt oder verbraucht war der Mann /... . Einmal hieß es sogar, der alte Herr sei richtig irrsinnig geworden. Am sonderbarsten fanden aber alle, daß ein so reicher Gutsbesitzer, der viertausend Leibeigene besaß /.../, auf seinem prachtvollen Gut von aller Welt vollig zurückgezogen lebte. /.../. Hinzu kommt, daß er ein gutmütiger Mensch war, freilich nicht ohne einige besondere fürstliche Angewohnheiten übler Art /.... Unter anderem wurde erzählt, daß der Fürst über die Hălfte des Iages zum Ankleiden brauche und der ganze Mensch aus zusammengesetzten Stücken bestănde. I.../ Er trug eine Perücke, falschen Schnurr- und Backenbart. und sogar die Fliege à la Mazarin unter der Unterlippe war unecht. Ihm war buchstäblich jedes Haar angeklebt und jedes glänzle im schönsten Schwarz. Er schminkte und puderte sich täglich /.../. Mit dem linken Bein hinkte er. Es wurde behauptet, daß dieses linke Bein unecht sei und er das echte in Paris gleichfalls bei Gelegenheit eines Liebesabenteuers gebrochen habe /.../. Tatsache war jedoch, daß sein rechtes Auge ein Glasauge war, natürlich ein sehr teures, sehr kunstvoll gearbeitetes. $]^{55}$

Das Äußere des Fürsten wird hier mit Hilfe einer Reihe von Motiven geschildert (u.a. die Perücke), die auch in den späteren literarischen Werken Dostoevskijs den dekadenten. verwestlichten russischen Figuren bzw. den westiichen stereutypen Figuren zugeschrieben werden. ${ }^{56}$ Doch nur in Djc:djuskin son

55 Ebd., S. 300f. [S. 16f.].

56 Die l'erücke, ein wichtiges ...Kleidungsstück“" des Fürsten Gavrila K., taucht als ein Symbol der Verwestlichung und der Dekadenz der durch sie charakterisierten Figuren in den Texten Dostoevskijs zum ersten Mal in Form der Koptbedeckung des Petersburger Beamten. Julian Mastakovic, auf (vgl. Bd. 18, S. 14: Pe'lerhurgskuja l.elopis' [ 'eler.shurger ('hronik] (1847). In Vel'tmans Roman . Sulomeju (1848) findet sich das Motiv bei dem falschen polnischen Grafen, Pan Želynskij. einem Betrüger und Falschspieler. Dor fungiert es cbenfalls als ein Attribut des literarischen russischen Stereotyps des Polen. des falschen Adligen bzw. des falschen Grafen und ist ein Element der kulturellen russischen Vorstellungskraft. Später ist es in den Text von Brut ja Kuramuzavy zur Charakteristik des polnischen Verführers integriert worden. Vgl.Vel timan 1957, z.B. S. 25. In Turgenevs Komödie P'rovincialku trägt der Fhemann. Aleksej Ivanovic Stupend ev, eine Perücke; sein Rivale Graf Ljubin färbt dagegen sein Haar, schminkt und puden sich, so daß diese zwei Figuren ebenfalls Bezüge zum Fürsten Gavrila K. aufweisen. Vgl. TuRCiENEV 1979, S. 410, S. 412 und S. 425.

Vgl. auch dic Geschichte über den künstlichen Bart für den Kutscher des Fürsten, den er darüber hinaus wegen dessen angeblıch kommunistischer (iesinnung fürchtet, S. 312 und S. 318 (..Ђopony cōpılти, дядюшkа! Но у него борода с немецkое государство? - Ну да, с не- 
treten diese Motive in einer derart einmaligen metonymisch-syntagmatischen Dichte auf, indem sie eine einzige groteske Figur charakterisieren, denn der Fürst besteht zur Gänze aus den aus dem „Westen“ entlehnten „Bestandteilen“, so daß er an eine sprechende leblose Puppe erinnert. Obwohl sich der Ich-Erzăhler von dieser Schilderung des Fürsten distanziert, indem er sie als die Wiedergabe der Nachrichten ausgibt, die der „offentlichen Meinung“, d.h. der Mordasover „Gerüchteküche“, entstammen, wird diese Charakteristik auch aus der Perspektive anderer Figuren bzw. durch seine eigenen Äußerungen und sein Benehmen bestătigt. Mozgljakov und Moskaleva nennen den Fürsten beispielsweise metaphorisch „полукомпозиция, a не человек“ [eine [Halb]Komposition, aber kein Mensch, S. 29; Erg. d. Verf.] bzw. ein „остаток“ [Überbleibsel], „обломок нашей аристократии“ [ein Bruchstück von unserer Aristokratie, S. 31]. ${ }^{57}$

Die Dekadenz und der „Verfall“, der Reliktcharakter, des Fürsten wird nicht nur durch sein Äußeres unterstrichen. Fürst K. wird als Karikatur eines russischen gealterten "Casanovas" geschildert. Wie jener schreibt er auch seine Memoiren. Zugleich wird er als edler "Ritter" geschildert bzw. auch "Idiot" genannt. Er will auch eine Einsiedelei besuchen bzw. lebt wie ein Einsiedler, worin sich seine moralische Ambivalenz außert. Diese groteske Figur enthalt somit mehrere, teilweise wiedersprüchliche fremde Imageme, die ihn zugleich positiv und negativ immanent charakterisieren. Er ist somit in der Welt der Erzăhlung eine Alius-Figur, ein ganz Fremder, der auf sie eine subversive Wirkung ausübt. In seiner Dekadenz ähnelt der Fürst den späteren polnischen stereotypen dekadenten bzw. (pseudo)adligen Figuren Dostoevskijs, die allerdings viel negativer, weil zusătzlich als betrügerisch bzw. dämonisch bőse geschildert werden. Die europäischen ,neuen Ideen“, nach denen er strebt bzw. die er verinnerlicht hat, seine aufgeklärt westeuropăische Haltung wird als nicht mehr lebensfahig dargestellt. Die Geschichte seines Besuches in Mordasovo endet folgerichtig auch mit seinem Tod. Der Fürst ist somit die Karikatur des russischen

мецкое государство. /.../ Но это ıскусственная. /.../ вдруг /.../ По.тучены вновь из -за гранишы превосходнейшите kучерсkле и rocподсkıе бороды, равномерно бакенбарды, зспаньолkи, усы и прочее /.././../ Вот и выписат я бороду кучерсkую, - действіте.тьно, борода заг.ляденіе! Но оказывается, что у Феофіцта своя собственная чуть не в два раза больше. Разумеется, возникто недоумение: сбріть ті свою ити пристанную назад отос.าать, а носіть натуратьную? Я думат-думат и решiL., что уж .тучше носіть искусственную." [S. 48: Der Bart abgenommen, Onkelchen? Aber er hat doch einen Bart von der Große des Konnigreichs Preußen!' 'Nun, ja, von der Große des Kónigreichs Preußen. /.../ Nur ist es ein künst-licher Bart. /.../ plotzlich schickt man mir einen Preis-Kurant zu. Man hat eine neue Sendung Bär-te aus dem Aus-lande erhalten, vor-züg-liche Kutscher- und Herren-băr-te, sowie Backenbărte, Schnurrbărte, Mouches usw. /... /.../ Und ich bestellte einen Kutscherbart, denn so ein Ban macht doch imposanter. Aber da zeigte es sich, daB Fe-o-fil einen natürlichen Bart hat, der fast zweimal so gro $B$ ist. Wie gesagt, was tun: soll man ihm den echten abnehmen oder den künstlichen zurücksenden und den natürlichen tragen lassen? Ich dachte und dachte, und beschloB, ihn doch den künstlichen tragen zu lassen.']. Diese Stelle ist eine groteske Wiederholung und zugleich paradoxe Zurücknahme der ..Bart-Reform“ Peters des Großen

57 Ebd., S. 307. 
verwestlichten adligen Aufklărer-Typs bzw. sogar das Symbol des Westens selbst, der sich überlebt hat. ${ }^{58}$

In einem der "leichten Theaterstücke“ des Fürsten ${ }^{59}$ bzw. in einer seiner Geschichten kommt ein Mann vor, der zuerst als Lord Byron, dann als ein polnischer Graf bezeichnet wird. Dieser polnische Graf stellt sich aber zum SchluB nicht als Graf, sondern als ein „Koch“ heraus. Er soll wăhrend des Wiener Kongresses den polnischen Tanz krakovjak [krakowiak; = polnischer Volkstanz aus der Krakauer Gegend] getanzt und sich dabei ein Bein gebrochen haben:

И вообще, когда я был за гра-ни-цей, я произволил нас-то-ящий fu-ro-re. Лорда Байрона помню. Мы были на друхеской но-ге. Восхитительно танцевал краковяк на Венском конгресе./... / Ну да, лорд Байрон. Впрочем, может быть, это был и не лорд Байрон, а kтонибудь другой. Именно не лорд Байрон, а один поляя! Я те-перь соверигено припоминаю. И пре-ори-ги-налыный был этот поляk: выдал себя за графа, а потом оказалось, что он был kакой-то kухлистер. Но только вос-хи-ти-тельно танцевал краковяк и наконеи сломал себе ногу. Я еще тогда на этот случай стихи сочинил:

Наш поляк

Танцевал kpakoвяk...

А там... а там, вот уж дальше и не припомню...

A kak ногу сломал,

Таниевать перестал.

/.../ Впрочем, может быть, и не mak, но только преудачные выши стишки... Вообще я теперь забыл некоторые происшествия. Это у меня от занятий. [kursiv die Verf.]

[Und überhaupt, als ich im Aus-lande war, machte ich tat-săch-lich Fu-rore. Entsinne mich lord Byrons. Wir standen auf freund-schaft-lichem Fuß. Auf dem Wiener KongreB tanzte er be-zau-bernd den Krakowjak. /.../ Nun ja, lord Byron. Übrigens. wie gesagt, vielleicht war es nicht Lord Byron. sondern irgend ein anderer Lord. Ganz. recht, es war nicht Lord Byron, sondern ein Po-le. Jetut besin-ne ich mich vollkommen! Das war ein aủßerst origi-neller Pole: er gab sich für einen Grafen aus, später aber stellte es sich heraus, daß er nur so etwas wie ein Koch war. Nur tanzte er ent-zück-end den

$58 \mathrm{Vgl}$. ebd., S. 306, S. 315f., S. 343ff., S. 368, S. 375fr., S. 378f,, S. 389. Vgl. auch die Figur des alten Fürsten Sokol'skij aus dem Roman I'sclrosıok, der ihm ähnlich ist und die Anmerkung, Bd. 2, S. 512 und unten S. 348.

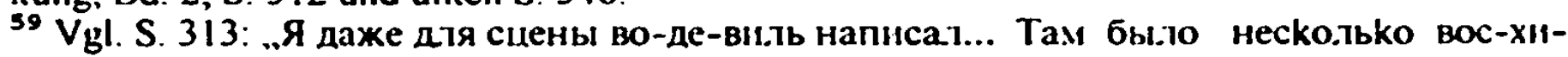
ти-те.ьных kуп:летов! Bпрочем, его никогда не итра.Il..." |.,Ich habe sogar für die Bühne ein Vau-de-ville geschrieben. Und es kamen darin auch einige ex-qui-site Couplets vor! Wie gesagt ... es ist aber nie gespielt worden“; S. 401 
Krakowjak und zu gu-ter Letzt brach er sich ein Bein. Ich machte da-mals noch ein Gedicht auf ihn:

Unser Po-le tanzte fürwahr

den Krakowjak ganz wunderbar...

Und dann... und dann... das habe ich nun lei-der vergessen...wie es weiter ging...

Doch als er sich brach das Bein,

Da stellte er das Tanzen ein...

I.../ vielleicht war es auch anders, jedenfalls war es ein sehr ge-lun-genes Gedicht... Überhaupt... ich habe jetzt einige Er-leb-nisse vergessen. Das kommt bei mir von den vielen Beschăftigungen... $]^{60}$

Die Erwähnung der „Freundschaft" des Fürsten K. mit Lord Byron wăhrend des Wiener Kongresses, wobei sich dieser aber als falscher polnischer Graf und schließlich als ein Koch herausstellt, deutet auf eine ironische Äquivalenz zwischen dem sich immerhin schriftstellerisch betätigenden Fürsten und dem romantischen englischen Dichter hin, der sich jedoch schlieBlich als eine fragwürdige ,maskierte" Figur entpuppt. Auch der falsche Lord Byron bzw. der polnische Koch bricht sich wie einst der Fürst das Bein, wodurch ebenfalls ihre "Verwandtschaft" betont wird. Diese Passage enthalt somit in der textimmanenten Perspektive eine zweifache ideologische Kritik, sowohl an den propolnischen Sympathien des englischen Dichters und an den Polen selbst als auch an dem (ebenfalls wie der Pole) "maskierten", verwestlichten russischen Fürsten, wobei die ironische antipolnische Anspielung nur aus dem textexternen historisehen Kontext herauszulesen ist, der aber wohl dem impliziten (russischen) Leser bekannt war. ${ }^{61}$ Der "tanzende" Wiener Kongreß hatte die endgültige Niederlage Napoleons (und Polens) besiegelt, denn dessen Niederlage bedeutete zugleich den Zusammenbruch des polnischen Strebens nach der Erlangung der nationalen Unabhăngigkeit, v.a. von Rußland. Der Figur Napoleons, des politischen Feindes Rußlands, fält daher in den Geschichten des Fürsten K. eine auBerordentlich wichtige Rolle zu. Die Figur des Fürsten selbst, des falschen „byronischen Helden“, erhält zum einen im Hinblick auf diesen historischen Hintergrund negativ utopische (subversive) Züge, zum anderen wird sie aber zugleich dem literarischen Stereotyp (einer Alter-Figur) des leichtsinnigen, den Krakowiak tanzenden Polen und eines falschen Grafen gegenübergestellt.

${ }^{60}$ Ebd., S. $313 f$. [S. 40f. ]. Vgl. auch die Anmerkung auf S. 517 über die Bezüge zu Gogol's Revizor [Revisor] und zu A. Dumas. Siehe auch die Erinnerungen der Tochter und der Frau Dostoevskijs sowie ŻAKIEWICZ 1968 (S. 83) und LEDNICKI 1953 (S. 280) zum ironischen Bezug auf Lord Byron und auf dessen Sympathie für Polen.

${ }^{61}$ Die Kritik an der Person und an Werken Byrons sowie am russischen Bvronismus wird seit I) Jadjuškin son in allen späteren literarischen und publizistischen Werken Dostoevskijs fortgeseta. 
Die oben erwăhnte „englisch-polnische“ ideologische Anspielung sowie alle anderen fremden Imageme aus den Geschichten des alten Fürsten weisen parallele Struktur und Funktion auf. ${ }^{62}$ Der Fürst wird als eine tragikomische bzw. als eine groteske Parodie eines russischen verwestlichten Aristokraten gezeigt, der als Narr auftritt und seine westlichen Ideen und seine Bildung lächerlich macht. Seine Vergeßlichkeit bzw. seine geistige Verwirrung, sein Leben an der Grenze zwischen "Traum" und "Wirklichkeit", heben zusätzlich den Unernst und die dekadente Künstlichkeit seiner Existenz hervor. „Der Westen in uns“, d.h. in den verwestlichten Russen, weist jedoch in der Figur des Fürsten keine dämonisch-bösen Züge auf, die den späteren verwestlichten Figuren aus den Romanen Dostoevskijs eigen sind: Er läßt sich als eine Ansammlung sowohl von positiven als auch von negativen exzentrisch-subversiven (utopischen) Eigenschaften bezeichnen, die in den späteren verwestlichten Figuren Dostoevskijs noch weiter ausdifferenziert und selektiv eingesetzt werden. Als eine Alius-Figur trägt er aber in sich bereits den Ansatz zu einem negativen utopischen Imagothème des verwestlichten Rußlands.

ZUSAMmENFASSUNG: Das polnische Imagem und die meisten fremden Imageme treten in Djadjuskin son im Zusammenhang mit der Figur des verwestlichten Onkelchens auf und charakterisieren diesen dekadenten Russen. Sie enthalten zugleich eine ideologische Anspielung auf die Niederlage Napoleons (Frankreichs) und somit Polens, auf die Niederlage der negativen westlichen "Ideen“, die sich gegen Rußland gerichtet haben. Diese "Ideen aus dem Westen“ werden aber bereits als von den russischen Adligen verinnerlicht bzw. angeeignet gezeigt und sind ein integraler Teil des nachpetrinischen Rußlands geworden: Der Fürst K. vergleicht sich sogar selbst mit Napoleon und mit dem Papst, somit ist er die Verkörperung bzw. ein Symbol der westlichen Ideen, deren Übernahme Rußland möglicherweise zugrunde richten wird. Diese Figur bildet als eine subversive Alius-Figur ansatzweise einen Teil des in den spăteren literarischen Werken Dostoevskijs noch differenzierter dargestellten negativen utopischen Imagothèmes des verwestlichten Rußlands. Die im Zusammenhang mit

62 In den anderen Geschichten des Fürsten wird z. B seın Diener Terent ev zuerst als der deutsche Philosoph Kant bezeichnet, dann aber mit einem fetten Truthahn verglichen (S. $312 \mathrm{f}$. Außerdem enwăhnt der Fürst einen deutschen Baron, seinen Rivalen, der $m$ eine Irrenanstalt eingeliefen worden scin soll - .. Я чуть- чуть не женицся на одной виконтессе, француженке. Я тогда бы.л чрезвычайно влюб.лен /.../. Но /.../ от.лучілся всего на лва часа, а другой " восторжествовал, один неменкий барон: он еше потом некоторое время в сумасшедием доме сиде.7“ (S. 315) /,.Ich hätte fast geheiratet, une Vicomtesse, eine Franzö-sin. Ich war damals sehr ver-liebt /.../. Aber /.../ ich war nur auf zwei Stunden fort-gegangen, und da siegte ein an-derer, ein deutscher Freiherr. Er saß später eine Zeitlang in einer Irrenanstalt“. S. 43| .. und eine bestimmte Gräfin Naunskaja (ein Graf Nainskij, ein Verwandter des Fürsten Valkovskij kommt auch im Roman Uinı̈̈ennye , oskorhlennve vor, vgl. Bd. 3, S. 238fr.), die ihren französischen Koch geheiratet habe (S. 342f.); der Fürst will auch in Deutschland Bekanntschaft mit Becthoven gemacht (S. 343) und dort Philosophie studiert haben (S. 315). Er bemitleidet Napesleon wegen seines grausamen Schicksals in der Verbannung (S. 365t7), meint außerlich ihm selbst sowie dem l'apst ähnlich zu sein (S. 365f.). Der Fürst soll auch ein Irreımuurer gewesen sein und war an aufklärerischen Ideen, 7.. B. an der Bauernbefreiung interessien (S. 378). 
dem Fürsten erwăhnten fremden Imageme sind aber zugleich ein Teil des negativen ideologischen Imagothèmes des Westens, denn die Figur Lord Byrcns bzw. des polnischen Kochs bildet den Kontrast (als alter) zum Fürsten K., der sich trotz seiner Okzidentalisierung doch als russischer Patriot herausstellt.

Die anderen fremden Imageme, v.a. die fremden stereotypen Figuren, erfüllen ebenfalls die Kontrastfunktion zu den russischen Figuren (als alter), v.a. der Jude oder der deutsche Professor. Das aus literarischen Stereotypen zusammengesetze Spanien Moskalevas spiegelt ihre verlogene banale Mentalitat wider, charakterisiert diese negativste verwestlichte Figur der Erzăhlung, die sich als eine "Romantikerin“ zeigen möchte. Die Erwähnung des möglicherweise polnischstămmigen Arztes betont dagegen das Lokalkolorit einer russischen Provinzstadt, die Dostoevskij aus eigenem Erleben bekannt war.

Der Name Shakespeares tritt in dieser Erzählung erstmalig in einem positiven (utopischen) Kontext auf, in dem er zur immanenten Charakteristik des romantisch-idealistischen russischen Paares dient (Vasja und Zina als russische Romeo und Julia). „Shakespeare“ läßt sich also (hier noch im Ansatz) als ein Teil des positiven utopischen Imagothèmes des verwestlichten Rußlands bezeichnen. Dieses fremde Imagem repräsentiert das von diesen Figuren angeeignete, positive utopische romantisch-idealistische, aber ebenfalls nicht mehr lebensfahige kulturelle „Erbe“ des „Westens“, der diesen Russen immanent ist. Es charakterisien jedoch diese Figuren positiv und setzt sie der verlogenen dekadenten Welt von Mordasovo entgegen. Die andere Anspielung auf Shakespeare und Heine, die im Zusammenhang mit Mozgljakov vorkommt, hat in dieser Figur eine parodistisch-negative Bedeutung, wodurch, wie die Erwăhnungen Casanovas, Lord Byrons, Kants oder Beethovens im Zusammenhang mit dem Fürsten K., die Ähnlichkeit dieser beiden Figuren hervorgehoben wird.

In Djadjuškin son werden alle handelnden russischen Figuren als verwestlicht dargestellt, es gibt in dieser Erzählung (mit Ausnahme des lediglich vom Fürsten erwahnten und ebenfalls verwestlichten, „kommunistisch gesinnten“ Kutschers sowie der Erwähnung eines seiner Bauern) noch keine handelnden "Vertreter" des russischen Volkes. Ähnlich wie in dem Roman v devjati pis 'mach gibt es in dieser Erzählung auch keine Elemente der positiven ,russisch- byzantinischorthodoxen" Utopie (die jedoch zum ersten $\mathrm{Mal}$ in den literarischen Texten Dostoevskijs in der oben besprochenen Ode aus dem Jahr 1854 explizit vorkommt). 


\section{4. ЗАПИСКИ ИЗ МЕРТВОГО ДОМА (1860-1862) \\ [AUFZEICHNINGEN AUS FINEM TOTENHAUS] ${ }^{63}$}

Zapiski iz Mertvogo doma (1860-62) nehmen innerhalb der literarischen Werke Dostoevskijs einen besonderen Platz ein. In diesen Aufzeichnungen sollen sich die Erfahrungen des Schriftstellers aus der Zeit in der Katorga niedergeschlagen haben. ${ }^{64}$ Chronologisch konnen die Zapiski iz Mertvogo doma als ein Werk an der Schwelle zwischen dem Frühwerk und den späteren großen Romanen bzw. der spăteren Publizistik bezeichnet werden. Denn in ihnen spiegelt sich die weltanschauliche Wende zu einer sich allmăhlich herausbildenden "russisch-orthodox-byzantinisch" geprägten Ideologie und Utopie wider, die zum ersten $\mathrm{Mal}$ in den literarischen Texten Dostoevskijs in der ebenfalls während der Verbannung geschriebenen Ode $\mathrm{Na}$ evropejskie sobytija v 1854 godu ihren Ausdruck gefunden hat. ${ }^{65}$ Zapiski iz Mertvogo doma gelten aber auch als das literarische Werk, mit dem Dostoevskij nach der mehrjährigen, durch die Verhaftung und Verbannung erzwungenen Abwesenheit seinen inzwischen verlorengegangenen Rang im literarischen Leben Rußlands wiedererlangen konnte.

Für die folgende Studie ist dieser Text von besonderem Interesse, denn in ihm treten mehrere individualisierte polnische Figuren auf. Lediglich im letzten Roman Dostoevskijs, Brat'ja Karamazovy, finden sich ähnlich selbständige, namentlich genannte polnische Figuren, die ebenfalls einen engen Bezug zu den Figuren der Polen in den Katorga-Aufzeichnungen aufweisen.

Als polnische Imageme sind hier die Figuren der Polen zu bezeichnen, die authentische Vorbilder haben, u.a. in den damaligen politischen Gefangenen in Omsk. Sie werden unten auf dem Hintergrund der russischen Figuren und im Kontext der anderen fremden Figuren sowie der übrigen fremden Imageme interpreticr.

Die in der Welt der Zapiski iz Mertvogo doma aus der Perspektive des Ich-Erzăhlers gezeigten russischen und fremden Figuren lassen sich in mehrere, dichotomische bzw. komplementäre, oft sich überlappende bzw. überschneidende Gruppen aufteilen. Zu solchen Gruppen gehören die Gefangenen und ihre Aufseher (die sich zugleich als "Opfer" und ", Henker" bzw. als "Herren" und „Diener" bezeichnen lassen); die Bewohner des Gefängnisses und die freie Welt

${ }^{63}$ Die deutschen Übersetzungen russischer Zitate aus Zapiski i= Merivogo desma werden nach der Ausgabe DostojEWSk 1957 angeführt.

64 Die bisherige Dostoevskij-Forschung bemühte sich, den direkten Bezug zwischen der Biographie Dostoevskijs und diesem Werk herauszufinden, ohne die Autonomie eines literarischen Textes zu beachten

$65 \mathrm{Vgl}$. zur Entstehung und Veröffentlichung der Zupıskı I Mertvogo doma sowie zu der literarischen (jattung dieser Aufzeichnungen, die an der Grenze zwischen "Fiktion“ und einem ..autobiographischen Dokument" schwanken. Bd. 4, S. 273ff. bzw. S. 289fr. Vgl. außerdem zu dem bereits in Zapiskı I Merivogo doma vorhandenen Sihirien-Atythos: POŻNIAK 1992, passim bzw. S. 37fr. (Syberıa w utopu historiozofic:=nej Dostojen:skiego

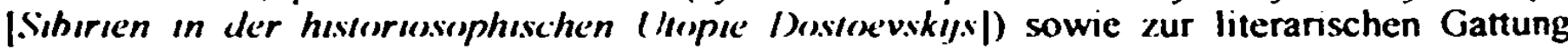
dieser Aufzeichnungen: MUCHA 1979. S. 82f. und zum biographischen Hintergrund in BUDANOVA / FRIDLENDER 1993-1995 (Bd. 1, S. 175-195) 
„draußen“ (zu der die Bewohner des Städtchens und die der freien Steppe gehören) oder aber die adligen und die nichtadligen Figuren (= das „Volk“), zu úiıcı sowohl die Gefangenen als auch ihre Aufseher und die Bewohner der freien Welt außerhalb des Gefängnisses zăhlen. Alle russischen und fremden Figuren können gleichzeitig mehreren dieser Gruppen angehören. Für die folgende Studie ist die Zweiteilung in adlige und nichtadlige Figuren besonders relevant. Dies gilt nicht nur im Hinblick auf die fremden Figuren, sondem v.a. auf die darin beschriebenen Polen. Denn bis auf wenige Ausnahmen gehören die Figuren der polnischen Gefangenen dem Adel an.

$\mathrm{Zu}$ den Figuren der russischen adligen Gefangenen gehören: der Ich-Erzăhler, Aleksandr Petrovic Gorjancikov ${ }^{66}$, der "Rahmenerzăhler", der Herausgeber sei-

${ }^{66} \mathrm{Vgl}$. die Charakterisierung Gorjančikovs durch den „.Rahmenerzähler". Gorjančikov wird als ein verwestlichter russischer Adliger dargestellt, der aber nach den in der Katorga verbrachten Jahren die Beziehungen zu seinen Verwandten abgebrochen und in einem sibirischen Städichen bis zu seinem frühen Tod (bzw. zu seinem angedeuteten moglichen Selbstmord) zurückgezogen gelebt hat: , $/ . . /$ Это быт чрезвычайно б.ледный и худой че.ловек, еще не старый, /.../ матенький и тшедушный. Одет бы.7 всегда весыма чисто, по -европейckи. /.../ По.лага.и, что у него до.џжна быть порядочная родня в Россіи, /.../ но знати, что он с самой ссы. .kи упорно пересек с ними всяkие сношения /.../. Знати, что он уби.т жену свою еще в первый год своего супружества, убит из ревности и сам донес на себя /... “ “(Bd. 4, S. 6ff.) [..Er war ein auffallend blasser und hagerer Mensch, noch nicht alt, /.../ klein und schwăchlich. Gekleidet war er stets sehr sauber und nach europäischer Art. I... Man war auch der Meinung. daß er in Rußland keine geringe Verwandtschaft habe I.../; doch gleichzeitig wußte man, daß er seit seiner Verbannung alle Beziehungen zu seinen Angehörigen abgebrochen hatte $/ \ldots /$, daB er seine Frau im ersten Jahr der Ehe aus Eifersucht ermordet und sich selbst dem Gericht angezeigt hatte $/ \ldots{ }^{\prime} ;$; . IIf.].

Diese Figur wird in der Forschung allzu direkt mit Dostoevskij selbst identifizien, so z.B. im Kommentar (ebd., S. 289), in dem darauf hingewiesen wird, daß schon vom zweiten Kapitel der Zupıskı iz Merivogo doma an: .Достоевскнй ведет pacckaз от себя, забыв о расckазчике: говорит о свицании в Сибири с декабристками, о по.тучении от них Еванге.ияя. /.../ о встрече с "давнишними шко.эьными товарищами» (стр. 229), о ттении книг" I.,Dostoevskij erzählt die Geschichte aus eigener Sicht, er vergißt den Erzähler: er spricht über die Begegnung in Sibirien mit den Dekabristenfrauen, über das von ihnen erhaltene Evangelium, /...i üher das Treffen mit den 'ehemaligen Schulkameraden' (S. 229), über das Bücherlesen"| Diese plötzlich eintretende Metamorphose bzw. ..Spaltung“ des Ich-Erzählers, der sich aus einem Kriminellen in einen politischen Gefangenen verwandelt (vgl. ebd., S. 28 , das (iespräch Gorjančikovs mit Akim Akimyč. .Да-с, дворян они не .ююбят, /.../ vivй нии политических, съесть рады; немудрено-с. (kursiv die Verf.]" [. Ja, das ist schon so, sie mögen die l:delleute nicht, /.../ hesonders die polııschen nichı: die würden sie am liebsten fressen. Das ist aber kein Wunder"; S. 52]), kann jedoch nicht als angebliche „Vergeßlichkeit" des Autors Dostoevskij, sondern als ein Verfahren zur Irreführung der Zensur betrachtet werden. Über die Probleme Dostoevskijs mit der Zensur wird im Kommentar berichtet (ebd., S. 276ff.). Siche dazu Mucha 1979, S. 82f., der über die im 18 Jahrhunder beliebte erzăhltechnische Konvention des ..gefundenen Manuskripts" der Aufzeichnungen Dostuevskijs schreibt. Die Einführung der Figur Gorjanciikovs hahe Dostoevskij von der Verantwortung für die Glaubwürdigkeit der Aufzeichnungen befrett, obwohl sic zugleich den Anspruch auf Authentizită als ein ..Dokument" erheben wurden Gorjančikov sei außerdem kein Pontăt Dostoevskijs aus der Zeit der Katorga. denn in dieser Figur spiegeln sich die Interessen für die Ansichten der russischen Konservatıven wider, die Dostoevskij erst nach dieser Zeit rezipient habe. In Zupıskı i= Merrvogo domu sind deswegen 
ner hinterlassenen Aufzeichnungen, und vier andere Mitgefangene und „Genossen" Gorjančikovs, von denen besonders drei, Akim Akimyc, A-v und ein angeblicher Vatermörder von Gorjančikov eingehend geschildert und analysiert werden. ${ }^{67} \mathrm{Zu}$ den anderen russischen Figuren aus der Gruppe der Aufseher, die moglicherweise adliger Herkunft sind, zählen der strenge und sadistisch-grausame Major, ${ }^{68}$ das árztliche Personal des Gefángnisses, ${ }^{69}$ die barmherzigen

die Fakten einer sorgfaltigen Auswahl unterzogen worden. MUCHA bezieht sich dabei auf PRZYBYLSKI 1964, S. 140 f.

${ }^{67}$ Fast alle namentlich genannten Figuren sollen, so die Dostoevskij-Forschung, authentische Vorbilder gehabt haben. Das Vorbild für Akim Akimyč soll bespielsweise ein gewisser Efim Belych sein, ein ehemaliger Fähnrich, der .,aus falsch verstandenem Patriotismus“ den kaukasischen Fürsten Murza bek Kubanov ermordet hatte. Im Kommentar wird auBerdem die Ansicht V. B. Šklovskijs über diese Figur angeführt, der Akim Akimyž mit dem Maksim Maksimyč Lermontovs, mit dem Belkin Puskkins bzw. mit dem Vergil Dantes verglichen hat, denn er führt den Ich-Erzăhler in die Welt des .,toten Hauses“ ein (ŠKLOVSKJ 1957, S. 104f.), m Bd. 4, S. 286f.: Akim Akimyč wird von Gorjančikov negativ als eine Art des, ,autoritären Charakters" (Adomo) geschildert (vgl. ebd., S. 26f., S. 50, S. 105, sowie S. 208f. über seine vollkommene Anpassung .,nо субордіннаuш!" |aus Subordination; S. 389| an das Leben in der Katorga), vgl. dazu unten, S. 192f; für die Figur von A-v soll dagegen ein Denunziant. Pavel Aristov, als Vorbild gedient haben, dessen Name auch in den Entwrirfen zur Figur Svidrigajlovs genannt wird, und für die Figur des Vatermörders der Fähnrich des Tobolsker Linienbataillons Dmitrij $\mathrm{N}$. Il'inskij. Il'inskij gilt darüber hinaus als eines der Vorbilder für die Figur Dmitrij Karamazovs. Vgl. ebd., S. 284ff. Das Vorbild für den vierten von dem IchErzähler erwähnten Adligen soll der Dichter und Petraševskij-Anhänger, S.F. Durov (18161869), sein, der zusammen mit Dostoevskij nach Omsk in die Katorga geschickt wurde. Durov soll seine revolutionären Ansichten trotz der Katorga beibehalten haben und sich bei den nichtadligen, einfachen Gefangenen großer Sympathie erfreut haben. Vgl. ebd., sowie bei MUCHA 1979, S. 81. Nach MUCHA paßte dieser vierte authentische adlige Gefangene wegen der Beliebtheit bei dem .Volk“ der Katorga und wegen seiner festen Ansichten nicht in das Konzept der 7upıskı $t=$ Merivogo doma hinein. Er wird darin lediglich nur in negativem Kontext und darüber hinaus nicht namentlich erwähnt, vgl. z. B. Bd. 4, S. 80. Siehe dazu unten im Zusammenhang mit den polnischen Figuren der Zupiskt $:$ M ferrvogo doma.

${ }_{68}$ Auch der sadistische Major, ein ..Henker-“ und em ..Lakaien-Typ“ zugleich, hat ein

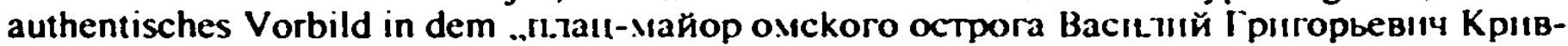
"10в“ |..Platzmajor des Omsker Gefangnisses Vasilij Grigor evic Krivcov"l, ebd., S. 288, siehe dazu auch unten, S. 182 und S. 184ff,, sowic im Zusammenhang mit SzYMON TOKARZEWSKI bei MUCHA 1979, S. 79. Vgl. auch TOKARZEWSKI 1907-9, Bd. I, S. 120-146 (das Kapitel l'rzyhuc're do) (Omska Waska |Ankunfı in (Imsk Waska|)

$69 \mathrm{Vgl}$. Bd. 4, S. 46: „Известно всем арестантам во всей РоссіII, что самехс сострада-

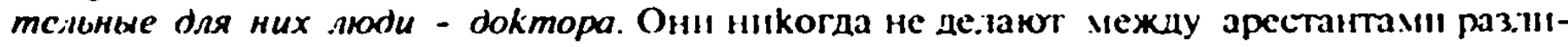
чня, kak нево.тьно де.лают почти все постороннне, kроме разве одного простого наро-

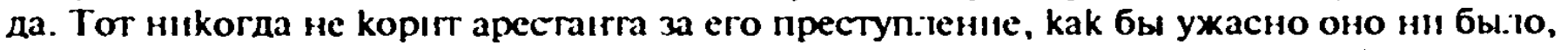
"I пронаст ему всё за понесенное им наказание " вообие за несчастье. Недаром же весь нарол во всей Россын называст преступление несчастьем, а преступников несчастнымII. Это г.лубоко знаменате.льное опреде.леніке. Оно тем бо.лее важно, что сде.лано бессознате.льно, инстінктівно. Локтора же - истинное прибежице арсстантов в

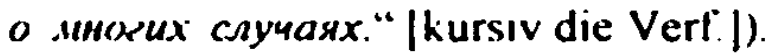

I..In ganz Rußland weiß jeder Arrestant. daß die miffühlends/en Menschen für thn die Ärzle sind. Niemals machen sie mit den Verbrechern einen Unterschied, wie sonst fast alle Menschen tun, ausgenommen das einfache Volk. Dieses wird niemals den Arrestanten wegen seines Verbrechens tadeln, wie entsetzlich das Begangene auch sein mag, und verzeiht ihm 
Dekabristenfrauen sowie eine zur grenzenlosen Nächstenliebe fahige Dame aus dem Stădtchen. ${ }^{70}$ Sowohl die Ärzte des Gefangniskrankenhauses, stellvertretend für alle russischen Ärzte, als auch die wohltătigen Bewohner des Städtchens werden positiv charakterisiert. Betont wird dabei ihr Mitleid, ihre grenzelose Năchstenliebe, die sie, wie das russische „Volk“, allen Verbrechern gegenüber zeigen. Dadurch weisen diese Figuren positiv utopische Eigenschaften, die sie mit dem russischen "Volk" teilen, auf, können als Vorlăufer der demütigen, barmherzigen russischen Alius-Figuren in den späteren Romanen betrachtet werden.

Die Gruppe der nichtadligen Russen in den Zapiski iz Mertvogo doma umfaßt ebenfalls mehrere Figuren, zu denen die Gefangenen der Katorga, ${ }^{11}$ außer ihnen

alles für die empfangene Strafe und überhaupt für sein Unglück. Nicht umsonst nennt das Volk in ganz Rußland das Verbrechen "Unglück" und den Verbrecher einen "Unglücklichen". Das ist eine tiefbedeutsame Bezeichnung für seine Auffassung des Verbrechens, und sie ist um so wichtiger, als sie ganz unbewußt, ganz instinktiv gebraucht wird. Die Arzle sind in vielen Fällen die einzıge Zuflucht der Arrestanten !... ${ }^{*}$ |kursiv die Verf.|; S. 87], sowie S. $141 \mathrm{ff}$.

${ }_{70} \mathrm{Vgl}$ ebd., S. 67f: „Есть в Сибири, /.../ несkо.ıько .ши, kоторые, kажется, назначением жизни своей поставтяют себе братский уход за «несчастными», состраданне и соболезнование о них, точно о родных детях, совершенно бескорыстное, святое. /.../ В городе, /.../ жІцта одна дама /.../, вдова. /.../ Казатось, назначением жизни своей она 11збрала помош ссыльным, но бо.лее всех заботитась о нас. /.../ мы, сидя в остроге, чувствовати, что там, за острогом, есть у нас преданнейший друг. /.../ Замечатась то.тько в ней, на kаждом шагу, одна бесконечная доброта“

[.,Es gibt dort in Sibirien /.../ einige solcher Menschen, die, wie es scheint, ihre ganze Lebensaufgabe darin sehen, den „Unglücklichen“ brüderliche Pflege angedeihen zu lassen und an ihrem Los Anteil zu nehmen, als wăren sie ihre eigenen Kinder - mit einem uneigennützigen, heiligen Mitleid. /../ In [der] Stadt /.../ lebte eine Witwe /.../. Sie hatte sich zu ihrer Lebensaufgabe gemacht, für die Verschickten zu sorgen, doch am meisten sorgte sie für uns. /.../Wir aber, die wir im Osstrogg saßen, wir fühlten und wußten, daß wir dort /.../ lienseits des GePangnisses; Erg. d. Verf.] einen treuen Freund hatten. /.../ Man sah in ihr nur, [auf jedem Schritt und Tritt, Erg. d. Verf.|, eine unendliche Güte“; S. 127f.].

Vgl. auch zum biographischen Kontext (über die Begegnung Dostoevskijs auf dem Weg in die Katorga mit den Dekabristenfrauen, mit N.D. Fonvizina, P.E. Annenkova und mit der Tochter Annenkovas. Fonvizina hatte Dostoevskij das später von ihm sorgfáltig das ganze Leben lang aufbewahrte Evangelium mit den darin versteckten zehn Rubel geschenkt) bei BUDANOVA / FRIDLENDER 1993-1995 (Bd. 1, S. 179f.).

${ }^{71} \mathrm{Zu}$ den wichtigsten Figuren der russischen nichtadligen Gefangenen, die von Gorjančikov mit besonderer Genauigkeit und Einfühlungsvermögen charakterisient werden, zählen sowohl schwere Verbrecher (und starke Persönlichkeiten zugleich) wie z.B. Petrov, Orlov, Kulikov ơłer Baklušin, als auch Menschen, die wie der sanfte Altglăubige und der Jurodivyj ,mit der Bibel" oder der ..Diener" Gorjancikovs, Sušilov, wegen anderer Delikte, oder sogar infolge einer Verwechslung bzw. einer "Namensvertauschung”, in die Katorga gekommen waren, vgl. ebd., S. 12ff., S. 29, S. 33f., S. 46f., S. 56ff., S. 82ff., $221 \mathrm{f}$. Siehe auch zu den angeblichen authentischen Vorbildern für diese Gefangenenfiguren ebd., S. 282ff. bzw. 290ff. (u.a. auch zu den „orkтонения pacckaз4иka“ I,Die Abweichungen des Erzăhlers”l, die Verbrechen der fiktiven Figuren noch schwerer sein zu lassen als diejenige ihrer authentischen Vorbilder, so z.B. wurde der Altglăubige in Zapiskı iz Mertvongo domu zu lebenslänglicher Katorga verurteilt, weil er eine orthodoxe Kirche in Brand gesteckt haben soll, sein Vorbild, Egor Voronov aus dem Cernigover Gouvernement, ivurde dagegen lediglich für .ненсполнение /.../ обенания присоединитьсяk единоверцам II небытие на свя- 
aber auch die Aufseher des Gefángnisses sowie die Bewohner des Städtchens gehören, von denen die meisten den Gefangenen, den „Unglücklichen“, gern Almosen „um Christi willen“ geben. ${ }^{72}$

$\mathrm{Zu}$ diesen beiden von Gorjancikov geschilderten adligen und nichtadligen russischen Gruppen gehören sowohl negative (böse) als auch positive (gute) Menschen, die von ihm als Individuen geschildert werden, deren psychisches Leben für ihn einen hochinteressanten Untersuchungsgegenstand bildet. ${ }^{73} \mathrm{Er}$

щеннодействии при бывшей закталkе /.../ новой церkви“" I.,die Nichterfüllung des Verprechens, sich den Glaubensgenossen I= Altgläubigen| anzuschließen und für die Abwesenheit bei der damaligen Grundsteinlegung für eine neue orthodoxe Kirche $/ . . .{ }^{\circ}$ l lebenslănglich eingespertr. Vgl. ebd., S. 33 und S. 282).

72 Vgl. z.B. ebd., S. $18 f$. (zur Sitte des prxdujunie [nodarmue, Almosen]). Vgl. auch BUDANOVAFrIDLENDER 1993-1995 (Bd. I, S. 182) über die Erinnerung Dostoevskijs an ein kleines Mädchen, das ihm im Winter 1850 ein Almosen mit den Worten .На, несчастный, возыми Христа рајн koneечky!" |Da, du Unglücklicher, nimm ein Kopekchen um Christi willen!] gegeben hattc. Diese Szene wird auch in Prestuplenie I nakuzanie angeführt, in: Bd. 6, S. 89.

${ }^{73}$ Siehe zur Typologie der guten und schlechten sowie der starken und schwachen Gefangenen, die verallgemeinernd die typischen Eigenschaften des ..russischen Charakters“" verkörpern, ebd., z.B. S. 196ff: „Тут все были .неттатели /..././../ Огромное большинство бы.10 мо.тчаливо ॥ злобно до ненависти, не .любито выставтять свонх надежд напоказ. Простодушие, откровенность бы.лі в презрениІ1. /.../ может быть, иной стыди.лся их про себя. $B$ русскон хараkmере сто.тько по.10жите.льности и трезвості взг.ляда, сто.1ько насмешkı над первым собою... /.../ Каждый был до того угрюм и само.юбив, что начннат презирать че.товека доброто и без само.юбия. Кроме этих нанвных и простоватых бо.тунов, все остальные, то есть молчаливые, резко разде.лялись на добрых и злых, на угрюмых и свет.лых. Угрюмых и зтых бы.то несравненно бо.тьше. /.../ Добрые - очень маленькая kучka - бы.ли тіхи, мо.тчаливо тан.ли про себя свон упования /.../. /.../ бы.7 ене отде.л впо.лне отчаявинхся. Таков бы.т, например, и старик из Стародубckıх с.1обод. /.../ Впрочем. у него бы.то свое спасение, свой выход: мо.итва и идея о мученлчестве. Сошедший с ума, зачлтавшийся в Биб.ин арестант, /.../ выдумал себе исход в добровольном, почти искусственном мученічестве. /.../ Потеряв ие.ть ॥ надежлу, че.ловек с тосkи обрашается нередко в чудовише... llе.ль у всех наших бы.7а свобода и выход из kаторпі" |kursiv die Verf.].

[... Hier waren alle l'hantusten /.../. /.../ Die meisten waren schweigsam und böse bis zu einem fast auf alles sich erstreckenden $\mathrm{Haß}$ und liebten es nicht, ihre Hoffnungen zur Schau zu tragen. Einfachheit und Offenherzigkeit wurden verachtet. $i . . /$ Wer weiß, vielleicht schämte sich so mancher innerlich seiner Träume. Im russsıschen ( harakter liegt so viel Sinn für die Wirklıchkeit und soviel Nüchtemheit des Blicks, soviel innerer Spott, in erster Lmie über sich selbst... /... Ein jeder war dermaßen verbittert und eigenliebig, daß er einen gutmütigen und nicht eigenliebigen Menschen einfach verachtete. Außer diesen naiven und ctwas einfältigen Schwätzern teilten sich dic anderen, das heißt die Schweigsamen, in Gute und Böse oder in Finstere und Heitere. Der Finsteren und Bosen gab es natürlich unvergleichlich mehr. /.../ Die Guten - nur eine kleine Schar - waren still, hegten ihre Hoffnungen stumm für sich $i . . /$. es |gab| /... noch eine Kategorie von völlig Hoffnungslosen /.../. Zu diesen gehörte auch der Alte aus dem Dorfe Starodúbowo $i$... . Aber er hatte schließlich doch eine Erlösung gefunden: das war das Gebet und der Glaube an sein Märtyrium. Ein anderer Strätling, der über dem Bibellesen wahsinnig geworden /.../ hatte sich als Rettung ein freiwilliges, fast künstliches Mărtyrium erdacht. /.../ Verlien der Mensch Ziel und Hoffnung, so verwandelt er sich nicht selten vor lauter Langeweile in ein Ungeheuer... Bei uns aber war das Ziel aller: die Freiheit und die Entlassung aus dem Zuchthaus“" [kursiv die Verf.]; S. 367ff.]. 
betont dabei die unüberwindbare Opposition, die Entfremdung zwischen den adligen und nichtadligen Gefangenen, wobei er alle Gefangenen als fremd und unglücklich bezeichnet. ${ }^{74}$ An mehreren Stellen der Zapiski iz Mertvogo doma wird der ProzeB seiner Anpassung an das Leben in der Katorga geschildert sowie seine voranschreitende "Einfühlung" in die Psyche der Gefangenen veranschaulicht, indem er seine mitfühlende, engagierte Haltung mit der unüberwindlichen Distanz vergleicht, die die Polen von dem „Volk“ trennt. ${ }^{75}$ Gorjanči-

Diese vom Ich-Erzăhler charakterisierten „Typen“ aus dem „Volk“, u.a. die .demütigen“ Mărtyrer des (orthodoxen) Glaubens, die für ihn, einen aufgeklărten Adligen, ..Sonderlinge“ sind, treten seit den Zapiski i= Merrvogo doma in allen spăteren Romanen Dostoevskijs als die positiven utopischen russischen Alius-Figuren auf.

44 Ebd., S. 13, vgl. auch mehrere Stellen, an denen das Gefăngnis als Mepmoux̃ doм [Merivy dom; Totenhuus] bezeichnet wird, z.B. S. 9, S. 195, S. 232 (Der Tag der Entlassung aus dem Gefangnis wird als die „Auferstehung von den Toten“ bezeichnet).

${ }^{73} \mathrm{Vgl}$. folgende Stellen in den Zupiski iz Mertvogo doma:

"/../ больщая часть [der Gefangenen] наконец меня полюбила и признала за ехорошего человеkа" (ebd., S. 26); "Я подумал, чmо здесь и всё mak же подло и низко. Но $я$ ошибался: я судит обо всех по А-ву“ (S. 64); „Я сан воруг сделался такин ме простонародьем, такнм же kаторжным, kak и они. Их привычки, понятия, мнения, обыкновения стали kak будто тоже моими, по крайней мере по форме, по закону, хотя я и не разде.тят их в сущности“ (S. 64$) ;,$ „../ первым вопросом монм при вступтении в острог бы.ло: kak вести себя, kak поставить себя перед этими .юдыми? /../ я решил, что наdо deрuсать себя kak нохно проще и независинее, /../ но и не отвсргать их. /..l мне и не хотелось замикаться перед нини в холодную и недоступную вемсливость, kak dелали поляки /... ${ }^{\prime}$ (S. 76f. ); ..Мало-помалу я стал распространять и круг моего знакомства. Впрочем, сам я не думат о знакомствах: /../ бы.т угрюм и недоверчив" (S. 82 ); ,.../ я не мог и даже не умел проникнуть во внутреннюю глубину зтой жсизи в начале мьего острога /... Я иногда просто начинат ненавидеть этіх таkих же страдатыцев, kak я. /.../ Я dаме завидьвал им в том. что они все-таки мемсу своини, в товариществе /.../. /../ Я первый готов свицете.ььтвовать, что в самой необразованной, в самой прідавтенной среде $i . . /$ встречал черты самого утонченного развіттия душевного.“ (S. 197); „.../ в последний год мосй kатореи /... между арестантам11 у меня было уже много друзсй и приятелей, окончательно решивших, что я хорошй че.іовек. Многие из них были мне преданны и искренно мобили меня [kursiv die Verf.]". (S. 229)

[S. 49: „Zuletzt aber hatte mich ein großer Tell derselben [der Gefangenen] gern und hielt mich für einen guten Menschen "‘. S. 122: „Jch glauble, daß hier im Ostrogg alle so schändlich und gemein wären. Aher ich läuschte mich: ich hatte nach A-ff auf alle geschlossen": $S$. 123: .Jch selh.st wurde plöt=lich zu ehensolchem einfachen Volk. zu einem sibirischen Sträfling wie sie. Ihre. Angewohnhelten. Begroffe. Meinungen. Silten wurden gleacham auch die meinen. wenigstens der Form, dem Gesetz. nach, wenn ich sie auch in Wirklichkeit gar nicht teilte": S. 143ff: , J.../ meine erste Frage mit dem Eintritt in den Ostrogg /.../ war: wie ich mich hier verhalten, wie ich mich zu diesen Menschen stellen sollte. $1 .$. i ich entschloß mich] l... daß man sich nach Möglichketl natürlich und freı benchmen müßte", [sie aher nicht ahzuweisen; Erg. d. Verf.| /... Andererselts wollte ich mich vor ihnen auch nicht hinier kaller und unnahhurer Höflchkeit verschanzen. wie es die Polen taten"; S. 154: "Mhl der Zeil vergrïßerte sich der Ḱreis meiner Bekannten. Ubrigens dachte ich selbst nicht daran, neue Bekanntschaften zu suchen; ich war immer noch unruhig, niedergeschlagen und mißtrauisch"; $S$. 367f.: ..In der ersten Zell meines Zuchthatuslehens war es mir gan: unmöglich, und ich hälte es auch gar nicht versianden, die ganze innere Ticfe dicises lehens zu erfassen /... /. Zuweilen begann ich, diese Menschen, die doch nicht weniger litten als ich, förmlich zu hassen. Ich 
kov macht somit einen von ihm selbst beobachteten und gewollten Proze $B$ der Angleichung an die nichtadligen Gefangenen durch, er bemüht sich, diese Menschen zu verstehen, trotz einer fast unüberwindbaren Kluft, die diesen gebildeten Adligen von den anderen Verbrechern băuerlicher Herkunft zu trennen scheint, so daß seine Aufzeichnungen eine Chronik des Reife- bzw. Entwicklungsprozesses sind, den der Ich-Erzăhlers im Kontakt und im Vergleich mit dem "Volk" und in der Konfrontation mit den anderen adligen Gefangenen durchgemacht hat.

Zu den fremden Figuren in Zapiski iz Mertvogo doma gehören außer den Polen der Jude Isaj Fomix Bumštejn, ${ }^{76}$ einige Kaukasier, u.a. zwei Lesgier und ein Tschetschene, ${ }^{7 \gamma}$ Kalmücken und Tataren. ${ }^{78}$ Einige Deutsche tauchen in der Er-

beneidete sie sogar, und wwar deshalh, well sie immerhin unter ihresgleichen waren, Iin einer Kumeradschaft lebten: Erg. d. Verf $\mid / . . /$. I.../ Ich bin als erster zu bezeugen bereit, daB ich in den allerungebildetsten und niedergedrücktesten Leuten /.../ Züge von zartester seelischer Entwicklung wahrgenommen habe“" S. 427: „.../fim letzten Jahr meiner Katorga; Erg. d. Verf. | besaB ich jetzt /.../ unter den Straflingen schon viele Freunde [und Kameraden; Erg. d. Verf.], die endgültig zu der Überzeugung gekommen waren, daß ich ein guter Mensch se1. Viele von innen waren mir aufrichtıg zugelan und liebten mich sogar". [kursiv die Verf. |]. ${ }^{76} \mathrm{Vgl}$. zu seinem Vorbild, Isaj Bumštel', ebd., S. 283f. Im Kommentar zum Bd. 4 wird angegeben, daß Isaj Bumštel' russisch-orthodoxen Glaubens gewesen sei (../../ в Статейных списkах сказано, что Исай Бумште.ль, мешанин из евреев, бы.л правос.тавного вероисповедания /.../; Достоевский же превращает его в еврея иудейсkого вероисповедания /.../.“|..In den Listen der Gefangenen wird gesagt, daß Isaj Bumštel’, ein Kleinbürger jüdischer Herkunft, russisch-orthodoxen Glaubens war /.../; Dostoevskij verwandelt ihn in einen Juden jüdischen Glaubens"), ebd.). In der dreibăndigen Chronik des Lebens Dostoevskijs (BUDANOVAFRIDLENDER 1993-1995, Bd. I, S. 184) wird jedoch bemerkt: ..В “Статейном списке об арестантах <...> за 1853 г." онибочно указано, что Исай Бумите.ль бы.7 правос.лавного вероисповедания /.../." |, In der 'Liste der Gefangenen /.../ für das Jahr 1853' hat man irrtümlicherweise angegeben. daß Isaj Bumštel russischorthodoxer Konfession war $/ \ldots / . \cdots /$ Vgl. auch zu seiner Charakteristik als ethnisches und literarisches Stereotyp des Juden, das Dostoevskij u.a. den jüdischen sterotypen Figuren Gogol's entlehnt hat, sowie zur jüdischen Frage bei Dostoevskij bei PożNiaK 1992, S. 108112 (das Kapitel: Desiojewski w kregu sprow jydowskich [Dostoevskly im (Imfeld der jïds.schen l'rage'), ebd., S. 100-137); INGOLD 1981, S. 16-43 und GOL.DSTEIN 1981, S. 14-31. Siche dazu oben, S. $103 \pi$.

77 Die Kaukusier gehōren zu den Mitbewohnem der Baracke Gorjančikovs: „С.лева от моего места на нарах помешалась kучka kaвkaзckux горисе, прис.ланных бо.льшею частію за грабежіl и на разные сроkи. Их бы.7о: два лезгина, один чсчснси II mpoc daгcстансkих mamap", |Links von meinem Pritschenplaty befand sich eine Gruppe Kaukasier, die den verschiedensten kaukasischen Bergvorlkern angehörten und großtenteils wegen Diebstahls zu mehr oder weniger Jahren Zwangsarbeit verurteilt worden waren. Es waren zwei Lésghier, ein Tschetschenze [sic!] und drei dághestanische Tataren; S. 96] Bd. 4, S. 50ff. Der Tsche'schene wird als ,.мрачнос и угрюмо cymectво“" |ein finsterer, mürrischer Mensch; ebd. ] beschrieben. Er spricht kaum mit den anderen Mitbewohnern der Baracke und schaut umher „, ненавистью, испод гобья и с отравленной, злобно-насмешливой у.лыбkой" (S. SO) |haßerfüllt, |unter der Stim hervor| und /.../ [mit einem] widerlich boshaften] und höhnisch|en lächeln|: ebd: Frg. d Verf. |: von den beiden l.esgiern „один /.../ бы.т уже старик, /.../ отъявтенный разбойник с виду. Зато другой, Нурра, произвел на меня с первого же дня самое отраднос, самое шицле впечат.тение. Это бы.т че.товек еце нестарый, росту невысокого, /.../ совершенный б.ондин с свет.то-го.тубыми глазами,

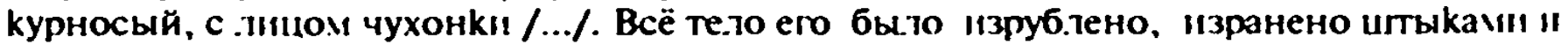


zahlung Baklusins auf. ${ }^{79}$ Neben diesen fremden Figuren, die bis auf wenige Ausnahmen innerhalb des Gefangnisses eingesperrt leben, werden noch die

пулямн. На Кавқазе он быт мирной, но постоянно уезжал потихоньку $k$ немнрным горцам и оттуда вместе с ними делат набепі на русckнх. B katopre eго все .1юбıни." (ebd.) [.,Der eine /.../ war schon ein alter Mann, /.../ dem Aussehen nach ein typischer Rauber. Dafur machte der andere, Núrra, schon am ersten Tage [den erfreulichsten, nettesten; Erg. d. Verf.] Eindruck auf mich. [Er war ] /.../ noch nicht alt, auch nicht groß, /.../ hochblond mit hellblauen Augen, [stumpfnasig; Erg. d. Verf. I, mit der Gesichtsform [einer Finnlănderin; Erg. d. Verf.] /.../. Sein ganzer Korper war zerhauen, mit Narben von Bajonettstichen und Kugeln bedeckt. Im Kaukasus hatte er zu den Botmåßigen gehört, die sich Rußland unterworfen hatten, war aber immer wieder heimlich zu den aufständischen Bergvőlkern geritten und hatte an ihren Angriffen auf die russischen Truppen teilgenommen. Im Ostrogg wurde er von allen geliebt"; S. 96].

Nurra wird von Gorjancikov als besonders ehrlich, offen, gutmütig und naiv wie ein Kind, darüber hinaus als ein frommer Muslim charakterisiert, der, obwohl er schlecht Russisch spricht, mit freundlichen Gesten Gorjancikov seine Sympathie und Mitgefühl kundgeben will (ebd.). Vgl. auch zu ihren Vorbildern, in: ebd., S. $281 \mathrm{ff}$, bes. S. 283 zum Vorbild Nurras: „Нура Шахсур.та Oг.лы, /.../ осужденный на шесть .лет, но просто за воровство, а не за участне в набегах на русckıx, kak сқазано у Достоевсkого“. "[Nurra Sachsurla Ogly, /.../ verurteilt zu sechs Jahren, aber einfach wegen Diebstahls und nicht für die Teilnahme an Überfallen auf Russen, wie bei Dostoevskij gesagt wird] Es bleibt offen, ob diese zusatzliche "Kriminalisierung“ der fremden Figuren im Bericht Gorjancikovs die Strenge der russichen Justiz gegenüber den Minderheiten innerhalb des russischen Imperiums, v.a. im Hinblick auf das Urteil der Zensur rechtfertigen sollte.

70 $\mathrm{Zu}$ den Talaren gehoren v.a. die drei Brüder, Mitbewohner der Baracke Gorjančikovs, unter ihnen der ideal schöne, sanfte und gute Alej, der als die positivste Figur unter den Gefangenen geschildert wird (vgl. zu dieser Figur unten, S. 167f.). Außer diesen drei treten in Zupıskı iz Mertvogo doma noch die Tataren Gazın und Mametka sowie der Kalmücke Aleksandra auf. (jazin wird als der grausamste. schrecklichste und düsterste aller Verbrecher, als die Verkorperung des Bosen, beschrieben („Этот Газин былт ужасное существо. /.../ Мне иногда представтятось, что я вінуу перед собой огромного, исполинсkого nayka, с че.ловека ве.личиною. /.../ Он бы. татарин: ужасно сицтен, /.../ с безобразной, /.../ огромной го.овой: /.../ Рассkазывати тоже про него, что он любит резать ма.тенькıх детей, единственно из удово.тьствия/.../. Всё это, может быть, и выдумали, /.../ но все эти выдумkи kak-то шит k нему, 6ы.7ı k .muу“, ebd., S. 40f.);

[..Dieser Gásin war eine grauenvolle Kreatur. /.../ es schien mir zuweilen, !.../ als hätte ich eine ungeheure Riesenspimne vor mir, ein Insekt von Menschengroße. /.../ Er war Tatar, war unheimlich stark $i . . /$, mit einem abscheulichen, [riesigen Kopf, Erg. d. Verf.] /.../; Iman erzăhite auch über ihn, daß er es liebte, kleine Kinder zu schlachten; Erg. d. Verf.], einzig zu seinem Vergnügen /.../. [Man hatte das alles vielleicht ausgedacht, /.../ aber alle diese Himgespinste paßten irgendwie zu ihm, standen ihm gut“" [Erg. d. Verf.]; S. 76f.].

Mametka wird dagegen als eine „чрезвычайно koмнчеckaя фигура“ I.,eine äußerst komische Erscheinung; S. 423“'] bezeichnet, und, weil er kein Russisch versteht, von den anderen Mitgefangenen wegen dieser ..Dummheit“ ausgelacht (ebd., S. 227).

${ }^{79} \mathrm{Vgl}$. ebd., S. 99ff. (die Erzăhlung Baklusins, eines ehemaligen Soldaten in R. [= Reval], des .nettesten Menschen“, der wegen seiner Liebe zu einer deutschen Wäscherin, Luise. und infolge der Intrige ihrer Tante aus Eifersucht seinen reichen deutschen Rivalen, einen Uhrmacher, erschossen hatte). Baklusin betont, daß der eingebildete deutsche Rivale ihn darüber hinaus beleidigt hătte: „Обıдно мне ста10, что уж с.7ишkом он таk меня низио ставıтт. А всего пуше, чro Луиза смотріrr" (ebd., S. 102) /,Es kränkte mich. daß er mich so niedrig stellte. Am meisten aber, daß Luisa alles sah; S. 193“] 
nichtrussischen Bewohner der freien sibirischen Steppe, die Kirgisen ${ }^{80}$ sowie mehrere Tiere auch als individualisierte "fremde" Figuren eingeführt. ${ }^{\theta 1}$ Der Jude, der als ein ethnisch-literarisches Stereotyp gestaltet wird, die Kaukasier,

๑o Vgl. ebd., S. 178: „На берегу же можно бы.о забыться: смотрішш, бывато, в этот необъятный, пустынный простор, точно зактюченный из окна своей тюрмы на свободу. Всё дтя меня бы.то тут дорого и мило: и ярkое горячее со.тне на бездонном синем небе, и цатекая песня киргиза /.../. /.../ Всё это бедно и дико, но свободно.“

l, Am Flußufer aber konnte man alles vergessen: da bleibt man denn zuweilen stehen und schaut in die unumfaßbare Weite /.../ wie /.../ ein Gefangener, der durch das $1 .$. / Fenster seiner Zelle in die Freiheit hinausschaut. Hier war mir alles teuer und lieb: die helle heiße Sonne am blauen bodenlosen Himmel, das ferne Lied eines Kirgisen /... Alles ist arm und primitiv [wild; Erg. d. Verf.], aber es ist frei!; S. 334"| Vgl. dazu unten, u.a. zu Prestuplenie , nakazunie, S. 275, und bei PożNIAK 1992, S. 37-51, bes. S. 45f:

„Syberia stawała siç sygnaturą Ziemi Obiccancj, toposu raju, którego wyznacznikami była zielen trawy i błękit nicba /.../. Desstojewski swiadomic kontrastuje obraz Syberii z katorgą.

Zrywa z tradycją utożsamiania, synonimizacji potocznej tych pojęć. Syberia przybiera postać krainy romantycznie mityczncj, otwartej, dzikicj i wolncj. /.../ Przestrzeń syberyjska staje siç przestrzenią sakralną. Gromadzą siç przesłanki dla konstrukcji zmienionego modelu Arkadii przyszłosici. /.../ Furicruwska utopia przybicra zabarwicnic chrzescijanisko-prawosławne w iresci oraz azjatyckıxyberyjską formę zewnętrzną".

[Sibirien wurde langsam zum Kennzeichen des Gelobten Landes, zum Topos des Paradieses, dessen Determinanten das Grün des Grases und das Blau des Himmels waren /.../. Dostoevskij stellt das Bild Sibiriens dem der Katorga (als Kontrast) gegenüber. Er bricht mit der Tradition der Identifizierung, der gewöhnlichen Gleichsetzung, dieser Begriffe. Sibirien nimmt die Gestalt eines romantisch muthischen, offenen, wilden und freien Landes an. /../ Der sibirische Raum wird zum sakralen Raum. Es sammeln sich Prämissen zur Konstruktion eines veränderten Modells Arkadiens der Zukunft an. /../ Die Utopie Fouriers nimmt dem Gehalt nach eine christlich-orthodoxe und der außeren Form nach eine asiatisch-sibirisische Färbung an.]

-1 Vgl. S. 185-194. Vgl. dazu auch die Erinnerung von SzYMON TOKARZEWSKl in: PODGórzeC 1984, S. 89f. (ein Fragment der Erinnerungen TokARzEwskis u.d.T. Suang(), über einen Hund dieses Namens, aus dem Band Katırinıcy [Kutorgusirüflınge] Warszawa 1912. Die russische Übersetzung dieses Kapitels von ARENDT 1936 (S. 495ff.) weicht von dem polnischen Original an mehreren Stellen ab, so wird z.B. bei TOKARZtwSKI über die be:sondere Zuneigung Suangos zu ihm selbst geschrieben (..Nieraz pies na ziemi usiadzie, ja przy nim przycupnę, obejmę go za szyję i, mocno wtuliwszy usta w jego kudły, w ten sposób tlumię łkania, aby nie wybuchnęły rozpaczliwie i głośno Jestem pewien, ze pies przyblęda wyróżniał mnie pośród towarzyszów, bo gdym skrył się umyślnie, biegał zaniepokojony szukajac mnie pomiędzy ivszystkimi“ I..Oft setzt sich der Hund auf den Boden, ich kauere mich neben ihm nieder, umarme seinen llals und, indem ich meinen Mund fest in sein Fell drücke. dämpfe ich auf diese Weise mein Schluchzen, damit es nicht verzweiflungsvoll und laut ausbricht. Ich bin sicher, daß der hergelaufene Hund mich unter meinen Genossen bevorzugt hat, denn er lief unrahig herum und suchte mich unter allen anderen, als ich mich absichtlich versteckt hatte. $"$, in: PODGORzF., 1981, S. 90), in der russischen Übersetzung wird dagegen über die liche Suangos zu Dostocvskij berichtet (vgl. z.B.: ARfNDT 1936, S. 500f. .Бывало, в часы отдыха, сядет соб̆ака на пол бараkа, Цостоевский обоймет ее 33 шею

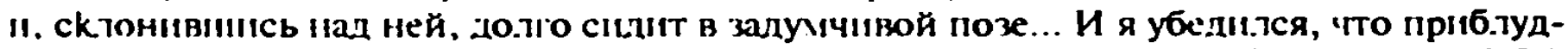
ный пес заметно выде.ля т его из среды всех наших товарнщей /.../." [Es kam vor, daß in den Mußestunden, der Hund sich auf den Boden der Baracke hinset $\pi$. Dostoevskij umarmt seinen Hals und, über ihn gebeugt, sitzt lange in einer nachdenklichen Körperhaltung.... Ich überzeugte mich, daß der hergelaufene Hund ihn sichtbar unter allen unseren Genossen bevorzugt hat $/ . . / . \mathrm{j})$. 
darunter die meisten Tataren und die Deutschen, erfullen dabei die Funktion der Anderen (als alter) und bilden den Kontrast zu den russischen Figuren.

Der Tatare Alej und die kirgisischen Bewohner der freien Steppe (ebenso die Tiere) weisen darüber hinaus neben dieser primären Kontrastfunktion zur russischen Gruppe (als die Anderen) die positive „sakral-utopische“ Dimension auf, sie sind die ganz Fremden (als alius). Besonders die „ideal schöne“ Figur des Tatars Alejs, trotz seiner ethnischen Fremdheit, die im Umgang mit dem Ich-Erzahler abgemildert und russifiziert wird, birgt in sich alle Tugenden des „(orthodox-)christlich-menschlichen Ideals", die in den spăteren Werken Dostoevskijs nur den russischen Figuren vorbehalten werden, so daß er als der erste Vorbote bzw. die symbolische und bereits in sich abgerundete, vollkommene Verkorperung der positiven christlich-russisch-orthodoxen Utopie, des positiven Imagothèmes des russisch-orthodoxen Rußlands betrachtet werden kann:

Трудно представить себе, kak этот мальчик во все время своей kaторги мог сохранить в себе таkую задушевность, симпатичность, не загрубеть, не развратиться. Это, впрочем, была сильная и стойкая натура, несмотря на всю видимую свою мягкость. /.../ Он был целомудрен, kak чистая девочka, и чей-нибудь ckверный, циничесkий, грязный или несправедливый, насильный поступok в остроге зажигал огонь негодования в его прекрасных глазах, /.../.../ он избегал ссор и брани, хотя был вообще не из таkих, которые бы дали себя обидеть безнаказанно, и умел за себя постоять. Но ссор он ни с кем не имел: его все любили и все ласкали. ${ }^{82}$

[Es ist schwer zu verstehen, wie dieser Junge es fertig brachte, sich wăhrend der ganzen Zeit seiner Kátorga seine Herzensweichheit zu erhalten, eine so strenge Ehrlichkeit in sich zu entwickeln, eine solche Herzlichkeit, so viel Sympathisches zu bewahren und nicht zu verrohen. nicht zu verderben. Übrigens war er eine starke und aufrechte Natur, trotz all seiner scheinbaren Weichheit. /.../ Er war keusch wie ein unberührtes Mädchen, und jede gemeine, zynische, schmutzige und jede ungerechte, gewalttătige Handlung im Ostrogg ließ seine schőnen Augen vor Unwillen erglühen /.../. /.../ er mischte sich nicht in das Geschimpfe ein und vermied jeden Streit, wenn er auch nicht zu jenen gehörte, die sich ungestraft beleidigen ließen.

22 Vgl. Bd. 4, S. 52 und auch zu seiner Beschreibung S. S1ff; zu seinem Vorbild vgl. ebd., S. 282ff:; Alej ist eine der ersten Figuren .,reinen Herzens“, zu denen Sonja Marmeladova, Myškin oder Aleša Karamazov gehören; er wird von Gorjančikov als ein "von Natur aus“ schöner und begabter Mensch bezeichnet: Er erlernt bei ihm mit großer Hingabe das Russische, als Lehrbuch wird dabei das Neue Testament benutzt. Obwohl Alej (wie seine Brüder) ein frommer Muslim ist, betont Gorjancikov den Eindruck, den das Neue Testament, v.a. die Bergpredigt und die Figur Christi, Isa, des ,heiligen Propheten“, auf Alej gemacht hat (ebd., S. 53f.). Dem Ideal-Schŏnen der Figur Alejs, in dem sich das Göttliche zu offenbaren scheint, eines Fremden, der sich aber von dem Russen Gorjancikov und von seiner Religion leicht .aneignen“ läßt, werden an der gleichen Stelle die düsteren, trotzigen, stolzen Figuren der Polen, des anderen Kaukasiers sowie die des komisch-grotesken Juden gegenübergestellt. wobei die christusähnliche Schönheit Alejs sich dadurch besser vor diesem negativen Hintergrund abzeichnen kann. Siehe dazu auch bei INGOLD 1981, S. 21 ff. 
Im Gegenteil, er verstand es sogar sehr gut, seinen Mann zu stehen. Aber es kam nie zu einem Streit zwischen ihm und irgendeinem Strafling: ihn hatten alle gern und von allen wurde er verhătschelt; S. 99]

In Zapiski iz Mertvogo doma, in denen mehrere oben erwähnte fremde Figuren auftreten, gibt es dagegen nur wenige andere fremde Imageme. Eins von diesen fremden Imagemen, das oben bereits erwähnt wurde, ist der Name Quasimodos, der außerlich håßlichen und innerlich guten und schönen Figur des Glockners aus Victor Hugos Roman Notre-Dame de Paris. $1482 \mathrm{mit}$ dem das menschliche Monstrum, der Denunziant A-v, als ein „нравственный Квазимодо“ ["ein sittlicher Quasimodo“ [vgl. bei Rahsin: „ein Monstrum, sittlich ein Ungeheuer"]l ironisch charakterisiert wird. ${ }^{83}$ Im "Zusammenhang mit den korperlichen Strafen in der Katorga und mit der psychologischen Analyse der Figuren der Henker werden einige "Gentlemen" erwăhnt, denen „возможность высечь свою жертву доставляіа нечто, напоминающцее .иаркиз де Сада и Бренвилье" [kursiv die Verf.]." ["die Möglichkeit, [ihre Opfer] peitschen zu können, Empfindungen hervorrief, die an den Marquis de Sade und die Marquise de Brinvilliers erinnern; Erg. d. Verf.“] ${ }^{84}$ In diesen „Henkern“

${ }^{83} \mathrm{Vgl}$. Bd. 4, S. 63 [S. 120] und 62f. [S.290] : Это 6ыл самый отвраптельный пример, до чего может опуститься и исподлиться че.товеk, /.../ без расскаяния. $/ . . /$ | я | никодга еще в жизни не встречал таkого по.лного нравственного падения, таkoro peuите.льного разврата "I таkой наг.лой низости, kak в А-ве. /.../ А-в ста.т и бы. kakıмм-то kyckoм мяса, с зубами и с же.тудком и с неуто.тмой жаждой найгрубейших, самых зверских те.зесных нас.лаждений, а за удовлетворение самого матейшего и прихотливейшего из этіх нас.лаждений он способен бы.7 хтаднокровнейшим образом убıть, зарезать, словом, на всё, .линь бы спрятаны бы.ли коншы в воду. /.../ И kak отврапттельно мне бы.то смотреть на епо вечную насмешливую у.тыбку. Это бы.то чудовище, нравственный Квазинодо. Прибавьте к тому, что он бы.т хіттер и умен, красив собой, несkо.лько даже образован, име.т способності |kursiv die Verf.].

[Er war das widerlichste Beispiel, bis zu welchem Grade der Mensch [ohne Reue] sich erniedrigen und sinken /.../ kann. /../ / ich habej eine so absolute sittliche Verkommenheit, eine so abscheuliche Verderbnis und so freche Gemeinheit wie bei A-ff niemals angetroffen. $/ . . /$ A-ff |wurde und war] ein Stück Fleisch mit Zähnen und einem Magen und mit unstillbarer Gier nach rohesten, tierischsten physischen Genüssen. Für die Befriedigung selbst der kleinsten und launischsten dieser Begierden wäre er fähig gewesen, in der kaltblütigsten Weise zu morden, zu erdrosseln, mit einem Wort, zu allem - vorausgesetzt nur, daB die Sache nicht herauskäme und er keine Strafe zu fürchten hătte. /.../ Und wie ekelhaft war es mir, sein ewig höhnisches Lächeln zu sehen. Es war ein Monstrum, sittlich ein Ungeheuer l= im Original ein sittlicher Quasimodo; Erg. d Verf. I. Dazu war er noch schlau und klug, hübsch, sogar gewissermaßen gebildet. nicht untegabt"; $S$. 118fr.]

${ }^{84}$ Bd. 4, S. 154. Vgl auch die Anmerkung zu dieser Stelle, ebd., S. 307f. Der Sadismus der Henker, die Prügelstrafen vollziehen, dient dem Ich-Erzähler als Vorwurf, um die korperlichen Strafen und die Gesellschaft aus den Positionen der christlichen Ethik zu kritisieren, die Menschen zu Tyrannen macht, ihnen die Macht gibt, „это безграничное тосподство нал те:10м, кровью и духом таkoro же, kak сам, че.ловеka, таk же созданного, брата по заkону Xpictoвy." I,.die unbegrenzte Herrschaft über einen menschlichen Körper, über das Fleisch und Geist eines Menschen. wie man selbst einer ist, der geschaffen wie wir und nach der Lehre Christi ein Bruder von uns ist“": S. 290|. Vgl. auch zu Dostoevskij und Marquis de Sade, unten, S. 221. 
deuten sich bereits die dämonisch-bösen verwestlichten russischen Alius-Figuren wie Valkovskij, Svidrigajlov oder Stavrogin an. Mit der Theateraufführung und mit der Figur des Gefangenen Petrov hăngen darüber hinaus andere Imageme wie z.B. die Namen Don Juan, ${ }^{85}$ Napoleon III., Alexandre Dumas oder Amerika zusammen. ${ }^{86}$ Alle diese Imageme haben jedoch in Zapiski i= Mertvogo doma noch keine Funktion als Elemente eines ausgepragten negativen utopischen Imagothèmes des verwestlichten Rußlands; lediglich die Figur des starken, rücksichtslosen und verhăltunismäßig gebildeteten Verbrechers Petrov, der, gierig nach dem Wissen aus dem Westen und über den Westen, Gorjancikov befragt, ăhnelt den verwestlichten nihilistischen Russen in den späteren Romanen Dostoevskijs. ${ }^{87}$

Neben diesen fremden Namen treten in Zapiski iz Mertvogo doma deutsche Imageme auf. Im Zusammenhang mit dem Gefängniskrankenhaus wird von Gorjancikov die deutsche Ordnung erwăhnt, ${ }^{88}$ die in den russischen Krankenhăusern herrsche und das russische Volk in Angst versetze; ein deutsches Imagem dient ihm darüber hinaus dazu, die von Emst geprägte Haltung der russischen den polnischen Gefangenen gegenüber hervorzuheben. Ihre düstere Achtung vor den Polen wird mit der scherzhaften bzw. leicht spöttischen Einstellung des russischen Volkes den Deutschen gegenüber verglichen:

Замечательно впрочем, что никто из каторжных в продолокение всего времени, /.../ не упрекнул их [der Polen] ни в происхождении, ни в вере их, ни в образе мыслей, что встречается в нашем простонародье относительно иностранцев, преимущественно немцев, хотя, впрочем, и очень редко. Впрочея, над немцами только разве слеются; немеи представцяет собою что-то глубоко комическое для русского простонародья. С нашими же каторжные обращались даже уважительно, гораздо более, чем с нами, русскими, и нисkолько не mpоzази их [kursiv die Verf., fett und kursiv Dostoevskij].

[Bemerkenswert ist dabei, daß kein einziger der russischen Sträflinge während dieser ganzen Zeit /.../ sich über ihre Nationalităt [der Polen], ihren Glauben oder ihre Denkweise absprechend geäußert hătte, wie es in unserem, einfachen Volke zuweilen bezüglich der Ausländer, namentlich der Deutschen, vorkommt, allerdings nur äußerst selten. Übrigens macht man sich auch über die Deutschen höchstens ein wenig lustig: der Deutsche hat für den einfachen Russen etwas überaus Komisches. Mit den polnischen Adligen [= im Original: Mit den unseren: Erg. d. Verf.] dagegen gingen die

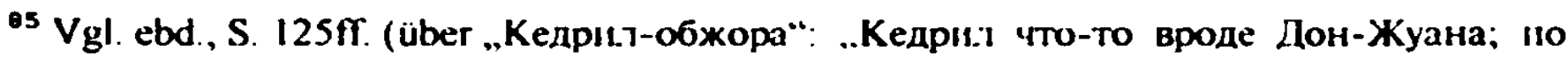
крайней мере il барина н с.лугу черті под конеu пьесы уносят в ад“ $\quad$ |..Kedrill der Vielfraß". ..Kedrill scheint eine Abart von Don Juan zu sein, wenigstens wird sowohl der Herr wic der Diener zum Schluß des Stücks von Teufeln in die Hölle geschleppt “: S 236| sowie über einen verliebten ..Brahmanen“) und die Anmerkungen dazu, ebd., S. 307. Fs handelt sich dabei um die bereits russisch-volkstümlich gewordenen fremden Figuren.

${ }^{96} \mathrm{Vgl}$. ebd., S. 83ff. (die Charakteristik Petrovs durch Gorjancikov) und auch die Anmerkungen dazu, ebd., S. 305

87 Ebd., vgl. z.B. S. 86 (u.a. die Episode des Bibcl-Diebstahls).

80 Ebd., S. 142.
} 
Străflinge viel besser um als mit uns russischen Adligen: sie rührten die Polen überhaupt nicht an [kursiv die Verf., fett und kursiv Dostoevskij]] ${ }^{89}$

Die polnischen Figuren gehören in ihrer Mehrheit zu den "Genossen“ bzw. „Kameraden“ [moвapumu, tovarišči; auch: Gefährten, Genossen. Freunde. Kollegen] Gorjancikovs, es sind vorwiegend politische Mitgefangene adliger Abstammung, obwohl es unter ihnen auch Nichtadlige gibt. Sie werden von Gorjancikov zum einen kollektiv, als eine geschlossene Gruppe eingeführt, zum anderen aber werden einzelne Figuren der Polen als Individuen namentlich genannt und ausführlich charakterisiert. Darüber hinaus werden aber auch andere, z.T. anonyme, gesichtslose Polen erwăhnt, die zur Masse der anderen Gefangenen gehören.

I. Als eine geschlossene Gruppe werden die polnischen politischen Gefangenen in den Kapiteln über die „ersten Eindrücke“ (Pervye vpeçatlenija) in der Katorga sowie über die Theateraufführung charakterisiert:

1. Fünf politische polnische Mitgefangene adliger Abstammung werden in dem zweiten Kapitel der Aufzeichnungen im Zusammenhang mit den russischen adligen Gefangenen erwähnt:

В kаторге было несколько чельвек из дворян. Во-первых, человек пять поляков. /.../ Каторхные страшно не любили поляков, даже болььие, чель ссььльных из русских дворян. Iloляки (я говорю об одних nолитических преступниках) были с ними kak-то утонченно, обидно вежсливы, крайне несообщительны и никак не могли скрыть перед арестантами своего $k$ ним отвращения, а те понимали это очень хорошо и платили той же монетою. [kursiv die Verf.]

[ Im Ostrogg gab es mehrere Edelleute. Zunächst fünf Polen. /.../ Alle Polen wurden von den Sträflingen äußerst wenig geliebt, sie waren ihnen noch viel verhaßter als die Sträflinge aus dem russischen Adelsstande. Die Polen (ich spreche hier nur von den politischen Verbrechern) waren zu ihnen ganz besonders, geradezu raffiniert. also beleidigend höflich. hielten sich möglichst fern von ihnen und konnten es auf keine Weise verbergen. daß die Sträflinge sie anekelten, was jene natürlich vorzüglich begriffen und wofür sie mit derselben Münze heimzahlten. [kursiv die Verf.] ${ }^{90}$

Es ist dic erste Erwähnung der polnischen politischen Gefangenen in Zapiski i= Mertvogo doma. Die Polen werden von Gorjancikov als die Fremden unter den russischen einfachen Gefangenen vorgestellt. Besonders die polnischen politischen Gefangenen sollen von den anderen (russischen) Katorga-Häftlingen gehaßt werden. Anhand der oben zitierten Passage wird aber nicht klar, ob der Haß der Häftlinge durch die ,beleidigende Höflichkeit“ und Reserviertheit der Polen verursacht wird oder ob die Reserviertheit der Polen eher als Antwort auf

${ }^{89}$ F.bd., S. 210 [S. 392]

${ }^{90}$ Bd. 4, S. 26 [S. 49]. 
die Ablehnung als "Fremde“ von seiten der Russen betrachtet werden kann. Die Polen isolieren sich aber zusätzlich selbst durch ihre negative Einstellung, durch ihre Verachtung, die an das Gefühl des Ekels gegenüber den Russen grenzt, und steigern auf diese Weise ihre Fremdheit ins Extreme. Auf diese Beschreibung der Polen folgen weitere Passagen, in denen Gorjancikov uber seine eigene anfangliche Fremdheit unter den anderen Mitgefangenen schreibt, die er aber mit der Zeit teilweise habe überwinden können, denn seine Mitgefangenen hătten ihn doch als einen ,guten Menschen" anerkannt. Anschließend an diese Passage werden die russischen adligen Gefangenen charakterisiert, die von ihm ebenfalls negativ beurteilt werden, so daß sich seine eigene Figur und sein Charakter sowohl von den polnischen als auch von den russischen adligen Verbrechern positiv abheben.

2. In der Fortsetzung des Kapitels über die ersten Eindrücke werden noch einmal sechs Polen, die zu den Mitbewohnem der Baracke Gorjancikovs gehören, kurz charakterisiert. Emeut wird ihr $\mathrm{HaB}$ auf die anderen (russischen) $\mathrm{Ge}$ fangenen betont, sie zeichnen sich aber auch durch das Gefühl der exklusiven (nationalen) Zugehorigkeit aus, so daß sie eine geschlossene Gruppe, wie eine "Familie“, bilden. Einige dieser Polen sind wie der Ich-Erzähler gebildet, aber, im Unterschied zu ihm selbst, nicht imstande, das „Volk“ der Katorga zu verstehen. Obwohl nichts genaueres über die Ursache ihrer Bestrafung mitgeteilt wird - denn sie werden, wie in dem obigen Zitat lediglich ,politische Gefangene“ genannt -, wird das Motiv der "leidenden Krankhaftigkeit", der "Mărtyrercharakter", dieser Figuren hervorgehoben, so daß angenommen werden kann, daß ihr Leid in ihrer Nationalităt und in ihren patriotischen Gefühlen seine Wurzeln hat:

Кроме черкесов, в казармах наших была еще целая кучка поляков, составиявшая совершенно отдельную сенью, почти не сообщавшуюся с прочими арестантами. Я сказал уже, что за свою искиючительность, за свою ненависть $k$ kаторжсныле русския они бьшіи в свою очередь всеми ненавидимы. Это были натуры изиученные, больные; их было человек шесть. Некоторые из них били люди образованные. /.../ От них же я иногда, в последние годы моей жизни в остроге, доставал кой-kаkие книги. [kursiv die Verf.]

[Außer den Tscherkessen und Tataren gab es in unserer Kaserne noch eine ganze Gesellschaft Polen. die eine Familie für sich bildeten und mit den übrigen Arrestanten fast überhaupt nicht sprachen. Ich sagte schon, dai3 sie für ihre Absonderung. für ihren $H a \beta$ auf die gefangenen Russen sich wiederum den $\mathrm{Ha \beta}$ aller anderen zuzogen. Es waren ihrer im ganzen sechs: kranke, ausgemergelte Geschöpfe. Einige von ihnen waren Gebildete; I...। Sie waren es auch, von denen ich in den letzen Jahren meines Ostrogglebens einige Bücher erhielt. [kursiv die Verf.] ${ }^{91}$

${ }^{91}$ Ebd., S. 54 [S. 103]. 
Nach einer sich anschließenden Reflexion Gorjancikovs über den Unterschied zwischen einem einfachen Gefangenen aus dem Volk (prostoljudin [nростицодин; ein Mann aus dem Volk]) und einem gebildeten Adligen wie ihm selbst, der seine ehemalige Umgebung und Gewohnheiten besonders schmerzhaft vermißt, werden die Polen noch einmal im Zusammenhang mit dem Juden Isaj Bumštejn erwăhnt:

/.../ nоляки составцяли особую цельную кучку. Их было шестеро, и они были вместе. Из всех каторжсных нащей казармы они любици тољько одного жида, и может быть единственно потому, что он их забавіки. Нашего жидка, впрочем, любияи дажсе и другие арестанmы, хотя решительно все без исключения смеялись нал ним. [kursiv die Verf.]

[/... die Polen bildeten eine besondere Clique für sich. Es waren ihrer sechs. und sie hielten alle zusammen. Von allen übrigen Sträflingen mochten sie nur einen Juden leiden, und vielleicht einzig aus dem Grunde, weil er sie belustigte. Dieses Jüdchen [= im Original: Unser Jüdchen; Erg. d. Verf.] wurde übrigens auch von den anderen Sträflingen gern gesehen, wenn sie auch alle ohne Ausnahme über ihn lachten] $]^{92}$

Die Betonung der exklusiven Zuneigung der Polen dem Juden gegenüber, der, wie sie selbst, als extrem fremd bzw. anders, aber aus der ,kollektiven“ Perspektive der russischen Gefangenen beschrieben wird, hebt emeut die Entfremdung der Polen von den anderen Gefangenen, ihre subversive Rolle (als Alius), hervor. ${ }^{93}$ Gorjančikov unterstreicht dagegen nochmals in dem Kapitel über seinen ersten Monat im Gefängnis, daß er selbst sich immer bemüht habe, sich nicht wie die Polen vor den einfachen Russen in ciner kühlen, distanzierten Höflichkeit zu verschließen. trotz der Verachtung, mit der ihm das Volk für diese Annäherungsbemühungen begegnet sei, so daB er lediglich in dem Hund Sarik einen Freund gefunden habe. ${ }^{94}$

3. Der kühle Abstand und die Entfremdung zwischen den Polen zu den anderen Gefangenen. die sich ihrer Gemeinschaft gegenüber fernhalten, werden auch in dem Kapitel über die Theateraufführung hervorgehoben:

Часу в сельмом пришел за мной Петров, и мы вместе отправились на прелставление. Нз нашей казарль отправицись почти все, кроле

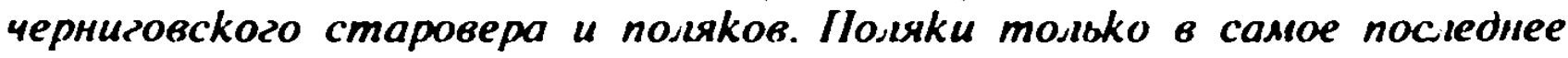
представ.іение, четвертого января, реиицись побывать в театре, и то после многих уверений, что там и хорошю, и весело, и безопасно. Брезеливоть поляков нимало не раздражала каторжных, а встре-

92 l:bd., S. 55 [S. 104]. Vgl. dazu INGOLD 1981, S. 16-43.

93 An einer früheren Stelle wird jedoch auch auf die gegenseitige vertrauensvolle Bezichung der Polen und des fromnien Altgläubigen angespielt, was den Behauptungen des Ich-Erzählers doch widerspricht, vgl. ebd., S. 34.

94 E.bd., S. 77. 
чены они были четвертого января очень вежливо. Их даже пропустили на лучшие места. Что же касается до черкесов и в особенности Исая Фомича, то для них наш театр был истинным наслаждением. [kursiv die Verf.]

[[Gegen sieben Uhr abends; Erg. d. Verf.] kam Petróff zu mir, /.../ und wir begaben uns ins 'Theater'. Aus unserer Kaserne gingen alle außer dem Altgläubigen und den Polen. Die Polen entschlossen sich erst kur= vor der letzten Aufführung, am vierten Januar, das Theater zu besuchen, und auch das erst nach langen Versicherungen, daß es dort sowohl gut wie lustig und ungefahrlich sei. Der Hochmut der Polen reizte die Sträflinge nicht im geringsten, und als sie endlich am vierten Januar erschienen, wurden sie sehr höflich empfangen, und man ließ sie sogar nach vorn zu den besseren Plätzen. Was nun die Tscherkessen und im besonderen Issai Fomitsch anbetriff, so war unser Theater für sie ein wahrer Hochgenuß. [kursiv die Verf. $11^{95}$

Die extreme Fremdheit der Polen wird hier erneut unterstrichen, denn sogar die anderen Fremden, der Jude und die Tscherkessen, überwinden ihre Andersartigkeit, indem sie sich mit dem russischen Katorga-Publikum in einem „asthetischen Erlebnis" für die Zeit der Theatervorstellung vereinigen konnen. Die Polen wollen aber der Auffuhrung nicht nur aus der Verachtung gegenüber dieser „unwürdigen“ Volksbelustigung, sondern auch aus Angst vor den Mitgefangenen fermbleiben. Gorjančikov betont die beinahe ehrfurchtsvolle, höfliche Haltung der "Theaterleute“ diesen mißtrauischen Menschen gegenüber, die sogar auf die besten Platze vorgelassen werden. Er fügt darüber hinaus hinzu, daß er selbst als ehemaliger Adliger und Theaterkenner sich ebenfalls der Achtung sowohl der Katorga-Schauspieler als auch des Publikums erfreute. Diese Einstellung der einfachen Gefangenen ihm gegenüber, ihre Wertschätzung seiner Kenntnisse der Theaterkunst sowie der von ihm vertretenen russischen Kultur überhaupt, ihre würdevolle und offene Haltung, wird metonymisch auf das ganze russische Volk übertragen, dessen Teil diese Gefangenen bilden. Man soll nur diese Menschen mit einem vorurteilsfreien Blick betrachten:

Нас, меня и Петрова, тотчас же пропустиии вперед, почти k самым скамейкам, /.../. Во мне отчасти видели иените.ия, знатока. бывшего и не в таких театрах, /.../ Они признавали, что в этол я могу судить лучше ux, что я видал и знаю больше их. Самые не расположенные из них kо мне (я знаю это) желали теперь моей похвалы их театру и безо всякого самоунихения пустили меня на лучшее место. /.../ Высшая и самая резкая хараkтеристическая черта нашего народа - это чувство справедливости и жажда ее. /.../ Стоит

${ }^{95}$ Ebd., S. 120 [S. 225f.]. Vgl. auch zu den Erinnerungen von SZYMON TOKARZEWSKI bei PODGORZEC 1984, S. 95-101, bes. S. 96ff. (über den Memoirenband Tokarzewskis Kutorinicy, in dem er schreibt, daß die Polen an den Vorbereitungen zur Theaterauffuhrung aktiv beteiligt gewesen seien. Sie hătten beispielsweise das „Bühnenbild“ gestaltet und den Vorhang bemalt). Vgl. dazu auch MuCHA 1979. 
только снять наружную, наносную кору и посмотреть на самое зерно повнимательнее, поближе, без предрассудков - и иной увидит в народе таkме веши, о которых и не предугадывал [kursiv die Verf.].

[Wir beide, Petróff und ich, wurden aber sofort durchgelassen, fast bis dicht an die Banke /.../. In mir sah man gewissermaßen einen Kenner und Kritikfähigen, der schon ganz andere Aufführungen gesehen hatte. /.../ Sie erkannten an, daß ich davon mehr verstand als sie, daß ich mehr gesehen hatte und besser zu urteilen vermochte. Selbst diejenigen, die mir am wenigsten gewogen waren, hätten jetzt gern von mir ein Lob ihres Theaters gehört und gaben mir ohne jede Selbsterniedrigung den guten Platz. I... Der großße und schärfste Charakter=ug unseres Volkes ist das Gefühl für Gerechtigkeit und das unbedingte Verlangen danach. I.../ Man braucht nur die äußere künstliche Schale zu entfernen und den Kern sich etwas aufmerksamer anzusehen, etwas năher und vorurteilsloser, und man wird in diesem Volk Dinge entdecken, von denen man sich nicht einmal hat trăumen lassen [kursiv die Verf.] ]

II. Außer dieser kollektiven Schilderung der Polen als einer isolierten Gruppe der Fremden unter den russischen und den anderen nichtrussischen Gefangenen werden diese vorwiegend adligen Mitgefangenen Gorjancikovs von ihm auch als einzelne Menschen, als Individuen, an mehreren Stellen der Aufzeichnungen charakterisiert:

1. Ein Gesprăch Gorjancikovs mit einem der Polen, M-ckij, wird in dem Kapitel über die ersten Eindrücke in der Katorga angeführt. M-ckij erklărt Gorjancikov, daß die Ursache für deren Unbeliebtheit bei den einfachen russischen Gefangenen in der adligen Herkunft liege. Diese Abneigung betreffe aber auch alle anderen adligen Gefangenen: "Они злятся на вас за то, что вы дворянин и на них не похожи. /../ Им бы очень хотелось вас оскорбить. јнизить. /../ Здесь ужасно тяжело для всех нас. Нам всех тяжелее во всех отношениях." [..Sie ärgern sich über Sie vielmchr deswegen, weil Sie Edelmann sind und ihnen nicht gleichen. Manche /.../ hätten gar zu große Lust. Sie zu beleidigen und z.u emiedrigen. /.../ es ist hier für uns alle entsetzlich schwer. Wir haben es in jeder Beziehung am schwersten von allen"] ${ }^{97}$

2. Ohne ihre nationale 7.ugehörigkeit zu nennen. die erst in den folgenden Kapiteln enwähnt wird, werden in dem Kapitel über den ersten Monat in der Katorga drei Polen vorgestellt: Der Pole B. als ein „Genosse“ Gorjančikovs aus dem Adel sowie zwei Freunde dieses Polen. ein junger und ein älterer und extrem frommer Mann:

96 [E.bd., S. 121f. [S. 228f.]

${ }^{97}$ Ebd., S. 32 [S. 61]. Der Haß der einfachen Gefangenen auf die Adligen kommt besonders deutlich in der Szene zum Vorschein, in der der betrunkene Tatar Gazin Gorjancikov umzubringen versucht, siehe ebd., S. 42. Siche auch zur Figur von M-ckij unten, S. 176f. und S. $194 f$. 
Другая работа, на которую я посылался, - в мастерской вергеть точильное колесо. /.../ обыкновенно посылаш двоих - меня и еще одного из дворян, Б./../ Б. бьль слабосильный, тщедуганый человек, еще молодой, страдавший грудью. Он прибыкі в острог с год передо мноко внесте с двумя другими из своих товарищей - одним стариком, всё время острожной жизни денно и ношно молившимся богу (за то очень уважали его арестанты) и умершим при мне, и с другим, еще очень молодым человеком, свежим, румяным, сильным, смелым, kоторый дорогою нес уставшего с пол-зтапа Б., что продолжалось семьсот верст сряду. Нужно было видеть их дружбу межлу собою. Б. бьл чельвек с прекрасньм образованием, благородный, с характером великодушныме, но испорченньме и раздражсенныме болезнью. [kursiv die Verf.]

[Eine andere Arbeit, die mir zugeteilt wurde, war: in der Werkstatt das $\mathrm{Rad}$ an der Drechslerbank zu drehen. /.../ man bestimmte gewöhnlich zwei dazu, mich und noch einen Adligen, B... /... B. war ein schwacher, kränklicher Mensch, noch jung, aber lungenleidend. Er war mit zwei Gefährten ein Jahr vor mir in den Ostrogg gekommen: der eine von ihnen, ein Greis, der während der ganzen Zeit seines Ostrogglebens Tag und Nacht betete, wofür ihn die Arrestanten ungemein achteten - starb bald nach meiner Ankunft; und der andere, ein noch sehr junger Mensch, der frisch, gesund, stark und mutig war, hatte unterwegs den schon nach der ersten Hălfte des Weges völlig erschöpften B. getragen, etwa siebenhundert Werst weit, ununterbrochen, bis zum Ostrogg. Diese Freundschaft hătte man sehen müssen! $B$. hatte eine vorzügliche Bildung genossen und hatte einen edlen. großzügigen Charakter, allein durch die Krankheit war er reizbar geworden und verbittert [kursiv die Verf.]; S. 152f.] ${ }^{98}$

Der erste ..kränkliche“ Pole wird als ein Beispiel eines dekadenten. lebensunfähigen Adligen vorgeführt. Positiv wird dagegen, sowohl vom Ich-Erzähler als auch von den (russischen) Gefangenen, die Freundschaft des zweiten, gesunden und jungen Polen zu seinem kranken „Kameraden"99 sowie der religiöse Eifer des dritten, älteren Polen bewertet. Diese Stelle steht insgesant im Zusammenhang mit den Reflexionen Gorjančikovs über die physische Arbeit und ihre heil-

${ }^{98}$ Ebd., S. 81 [S. 152f.]. Daß es sich dabei um polnische Gefangene handelt, wird erst aus den spateren Ausführungen Gorjančikovs erkennbar

${ }^{95}$ Ebd., S. 80ff. Der junge Pole wird auch an einer spateren Stelle positiv gezeichnet. Er wird sogar von den anderen Gefangenen wegen seiner physischen Starke und seines Charakters geschătzt: /../ Т-всkıй, 11з дворян, твердый и ве.пколушный мо:юдой че.ловск, без большого образования и јюбивший ужасно Б. Eго 11 всех другіх раз.ичали kаторжные и даже отчасти .тобити. Он был храбр, мужествен и сіцен, " это kаk-то высkазыва.10сь в kаждом жесте его (cbd., S. 203).

[/..J [T-skij] war ein junger Adliger, nicht sehr gebildet, doch ein fester und großzügiger Charakter - derselbe, der /.../B. /.../ rührend zugetan war. [der B. sehr liebte: Erg. d. Verf.| Er war der einzige von uns Adligen, mit dem die Străflinge eine Ausnahme machten: sic hatten ihn aufrichtig gern, ja zum teil liebten sie ihn sogar. Er war mutig und stark, und das außerte sich in jeder seiner Bewegungen; S. 380] 
same Wirkung für die Erhaltung der Gesundheit im Gefangnis, wobei er über die Schwierigkeiten der adligen Gefangenen berichtet, die Anerkennung der einfachen Gefangenen als ihnen gleichgestellte Arbeiter zu verdienen, denn die an eine solche Arbeit gewohnten Nichtadligen sehen auf die physisch schwăcheren Vertreter ihrer ehemaligen ,Herren" verächtlich herab. ${ }^{100}$

3. Die drei Polen M-ckij, T-vskij und B., d.h. die zwei oben dargestellten Freunde, treten auch in dem Kapitel über den "Aufstand" [Pretenzija; Die Beschwerde; Übers. v. Rahsin] auf, der sich wegen der schlechten Versorgung der Gefangenen zu erheben droht. Gorjancikov wird dabei erneut von einigen nichtadligen russischen Gefangenen verspottet und ausgelacht, weil er als Adliger sich in seiner Unwissenheit der Menge der protestierenden einfachen Gefangenen anschließen wollte. Er wird in die Küche zurückgedrängt, in der sich bereits u.a. polnische und russische adlige Gefangenen sowie der Jude Bumštejn und der Altgäubige versammelt haben. Die Polen, T-vskij, B. und M-ckij, erklären Gorjancikov ihre Lage und warnen ihn davor, sich an dem Aufstand auch nur passiv beteiligen zu wollen:

Их просто высеkут, а нас под суд. Майор нас всех ненавидит и рал погубить.

/.../ - Да и kаторжные выдадут нас головою, - прибавил М-цкий, когда мы вошли на кухнк.

/.../- Мы во сто раз больше рисковали бы, если 6 вышин; а для чего? Je haïs ces brigands. И неужели вы думаете хоть одну минуту, что их претензия состоится? Что за охота соваться в нелепость. [kursiv die Verf.]

[Die anderen würde man nur gelinde prügeln, wir aber kämen sofort vor Gericht. Der Major haßt uns. Es würde ihn freuen. uns etwas anhaben zu können. /.../ Und von den übrigen [Sträflingen] würde doch keiner für uns einstehen, sagte $\mathrm{M}$-zkij, als wir in die Küche eintratcn. /.../Wir würden hundertmal mehr riskieren als sie. wenn wir gingen, und wozu schließlich? Je haïs ces brigands. Und können Sie denn auch nur einen Augenblick glauben, daß eine Demonstration zustanden kommen wird? Ich habe keine Lust, auf solchen Blödsinn hereinzufallen. [kursiv die Verf.]1] ${ }^{101}$

In dieser Szene wird emeut die Entfremdung zwischen den adligen und den nichtadligen Gefangenen (und dem Aufsichtspersonal) sowie zwischen den Russen und den Fremden deutlich. Die Polen werden diesmal als die „Schicksalsgenossen" des Ich-Erzählers angeführt und als ihm gleichgestellte Gesprächspartner geschildert. Positiv wird emeut der Pole T-vskij, negativ M-ckij charakterisiert, dessen düsterer verbitterter Charakter, sein Haß und seine stolze Verachtung den russischen einfachen Gefangenen gegenüber, durch den französischen Satz. Je hais ces brigands symbolisien wird. Derselbe Satz kommt auch in der Szene der Entlassung M-kijs aus der Katorga vor, in der ebenfalls sein

$100 \mathrm{Vgl}$. ebd., S. 80fr.

101 F.bd., S. 203f. [S. 380ff.]. 
$\mathrm{Haß}$ auf die einfachen Gefangenen, sein Stolz, diesmal aber auch die Liebe zu seiner Mutter hervorgehoben werden:

Между тем М-kий с годами всё kak-то становился грустнее и мрачнее. Tocka odoлевала ezo. /.../ "Je hais ces brigandsw, повторял он мне часто, с ненавистью слотря на каторжных, которых я урие успел узнать блихе, и никакие доводы мои в их пользу на него не действоващи. /.../ Кстати: мы с ним часто говориіи по-франиузски /.../. М-kий воодушевцяцся, только вспоминая про свою мать. «Она стара, она больная, /.../ - она любит меня более всего на свете, а я здесь не знаю, жива она или нет? Довольно уљс дљя нее того, что она знала, как меня гоняли сkвозь строй...». [kursiv die Verf.]

[M-zkij wurde mit den Jahren immer finsterer und verschlossener. Der Schmer= [= im Original: Die Sehnsucht, die Schwermut; Erg. d. Verf.] verzehrte ihn. I.../ Je haïs ces brigands, sagte er of zu mir mit haßerfülltem Blick auf die Sträflinge, die ich bereits näher kennengelernt hatte, und alles, was ich zu deren Gunsten vorbrachte, war vollkommen in den Wind gesprochen. /.../ Mit ihm sprach ich ziemlich oft Französisch. /.../ Nur in einem Fall belebte sich M-kij: wenn er von seiner Mutter sprach. 'Sie ist alt.... sie ist krank /.../, sie liebte mich mehr als alles auf der Welt, ich aber weib nicht einmal, ob sie lebt oder tot ist. Wird es doch schon genug für sie gewesen sein, als sie erfahren mußte, daß ich Spießruten gelaufen bin ... [kursiv die Verf.]]

Der französische Satz aus dem Munde eines Polen hat in den Zapiski iz Mertvogo doma einen Leitmotivcharakter. Der Pole repräsentiert, als ein Vertreter der gebildeten Menschen aus dem Westen, die Unfähigkeit, in den russischen einfachen Gefangenen ihm gleichgestellte Individuen anerkennen zu können bzw. zu wollen. Gorjančikov dagegen hebt im Vergleich dazu seine eigene verständnisvolle Haltung diesen "Banditen" gegenüber hervor, unter denen Jahre später der Ich-Erzähler (= Dostoevskij) in dem Dnevnik pisatelja [Tagebuch des Schriftstellers] den gütigen Bauern Marej aus seiner Kindheitserinnerung widerzufinden glaubte. ${ }^{183}$ Alle polnischen Figuren der Zapiski i= Mertvogo doma werden dagegen wie der Pole M-ckij als statisch, als unfăhig zur Entwicklung, dargestellt, wobei sich schon in diesen Katorga-Aufzeichnungen ein Prozeß der immer weiter voranschreitenden Stereotypisierung solcher Figuren zu abzeichnen beginnt, die in den späteren literarischen Werken zu nationalen Stereotypen reduziert werden.

4. Der düstere polnische politische Gefangene, M-ckij, der als ein Nichtadliger einer Prügelstrafe unterzogen worden war, wird ebenfalls in der Fortsetzung des Kapitels über das Gefángniskrankenhaus dem russisch-orthodox getauften Kalmücken Aleksandr bzw. „Aleksandra“ gegenübergestellt:

${ }^{202}$ Ebd., S. 216 [S. 403].

${ }^{103}$ Vgl. Dnevnik pisatelja, Bd. 22, S. 46-50 sowie BUdANOVA Fridl.ENDER 1993-1995 (Bd. I, S. 186) 
Один наш арестантик, из особото отделения, крещеный kaциык Alekcaндр шіи Alekcaндра, kak звали его у нас, странный малый, плутоватый, бесстрашный и в то же время очень добродушный, pacckaзывал мне, kak он выходил свои четыре тысячи, расckазывал смеясь и шутя, но тут же клялся пресерьезно, что если 6 с детства, с самого нежного, /.../ он не вырос под пиетью, /.../ то он бы ни за что не вынес этих четырех тысяч. /.../

Прибавлю К этому одно: удивцдіся я всегда тому необшкновенному добродушию, тому беззюбию, с которым рассказывали все эти би-

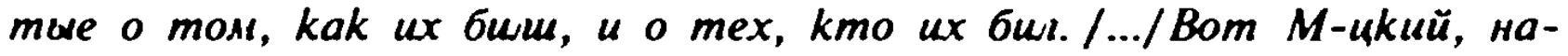
прияер, ряссказшвал мнне о своем наказании; он был не дворянин и проше: nятьсот. Я узнал об этом от других и сам спросил его: иравда ли это и kak это было? Он ответил kak-mo kopomko, kak буdmo c какою-то внутреннею болью, точно стараясь не глядеть на меня, и лищо его покраснело; через польинуты он посмотрел на меня, И в глазах его засверкал огонь ненависти, а губы затряслись от негодования. Я почувствоват, что он никогда не мог забыть этой странице uз cвoего nрошеduero. [kursiv die Verf.]

[So erzählte mir einer der Sträflinge [ein kleiner, lieber Arrestant; Erg. d. Verf.] aus der Besonderen Abteilung. ein getaufter Kalmücke. Alexander mit Namen - oder Alexcındra, wie er bei uns genannt wurde, ein eigenartiges, furchtloses Männlein, das gleichzeitig überaus gutherzig war -, wie er viertausend Schläge erhalten hatte, erzăhlte es lachend und scherzend. schwor aber gleich darauf, daß er, wenn er nicht von Kindheit an unter der Knute aufgewachsen wäre, /.../ diese viertausend Hiebe in keinem Fall überlebt hätte. /.../

Hier muB ich noch etwas hinzufügen: ich habe mich oft über die ungewöhnliche Gutmütigkeit und Arglosigkeit gewundert, mit der alle diese Gezüchtigten von der Züchtigung und von denen, die sie gezüchtigt hatten. sprachen. I... / Nur M-:kij war eine Ausnahme; er war nicht adlig und man hatle ihn zu fünfhundert verurteilt. Ich erfuhr es von anderen und fragte ihn einmal, ob es wahr sei, und wie er es ausgehalten habe. Er antwortete mir merkwürdig kurz - wie unter einem inneren Schmerz - und bemühte sich. mich nicht anzushehen, sein Gesicht aber wurde auffallend rot. Erst nach einer halhen Minute sah er mich wieder an und in seinen Augen glühte Haß. seine Lippen zitterten vor Unwillen I= im Original: vor Empörung; Erg. d. Verf.]. Da fühlte ich, daß er niemals diese Siunde in seiner lergangenheit werde vergessen können. [kursiv die Vert.]] ${ }^{104}$

Dem stolzen und haßerfüllten Polen, obwohl schließlich auch kein Adliger, wird der demütige, leiderfahrenc einfache Kalmücke gegenübergestellt, der zwar auch ein Fremder ist, aber als russisch-orthodox getaufter (hrist dem russischen Volk gleich wurde. Die familiär-positive Einstellung des Ich-Erzählers diesem Mann gegenüber wird zusätzlich durch das Diminutiv apecmarmuk laresıantik;

${ }^{104}$ Ebd., S. 145ff. [S. 273 und S. 276r.]. 
der kleine, liebe Arrestant] betont. Gorjancikov fügt diesen Passagen noch eine allgemeine Reflexion über die relativ gelassene Einstellung der russischen einfachen Gefangenen gegenüber körperlichen Strafen hinzu, die, ohne Gewissensbisse oder Schuldgefühle wegen ihrer Delikte zu haben, einen ,pragmatischen“ Gleichmut zeigen und zugleich passiven Widerstand gegen die Behörden leisten. ${ }^{105}$

5. Mehrere Polen, darunter die bereits in den früheren Kapiteln von Gorjancikov eingefuhrten B., T-vskij, M-kij und der alltere fromme Pole Ž-kij, werden erneut und besonders ausführlich in dem vorwiegend den polnischen und russischen adligen Gefangenen gewidmeten Kapitel Tovarišci $i$ [Die Gefährten; Übers. von Rahsin] beschrieben. ${ }^{106}$ Diese Polen werden aber von Gorjancikov zuerst nicht als Polen bezeichnet, sondern anschließend an die Passagen über die russischen adligen Mitgefangenen ${ }^{107}$ beschrieben. Ihre Zahl wird diesmal insgesamt auf acht Personen erhöht: „Кроме этих троих русских, оругшх в мое время перебывало у нас восемь человек. С некоторыми нз них я сходился довольно коротко, и даже с удовольствием, но не со всеми. Лучшие из них были какие-то болезненные, исключительные и нетерпимые в высшей степени" [kursiv die Verf.] [,Außer diesen drei Russen waren zu meiner Zeit noch [andere acht Männer; Erg. d. Verf.; bei Rahsin: ,mehrere polnische Adlige."] in unserem Ostrogg. Mit einigen von ihnen verkehrte ich ganz freundschaftlich und sogar gern, aber nicht mit allen. Die Besseren von ihnen waren gewissermaßen krankhafte, sonderbare und unduldsame Menschen"]. ${ }^{108}$

Gorjancikov entschuldigt sich anschließend selbst für seine reservierte Haltung diesen Menschen gegenüber, die er doch als ,.gute“ Menschen einzuschätzen weiß. Er entschuldigt auch die negative, haßerfüllte und abweisende Einstellung der Polen den russischen Mitgefangenen gegenüber, in denen sie keine Menschen zu erblicken vermochten, weil diese Einstellung hauptsächlich durch ihre krankhaften Charaktere sowie durch ihr schweres Schicksal und die Sehnsucht nach der fernen Heimat verursacht wurde:

/.../ впрочем, все они бьли больные нравственно, желинше, раздражсательные, недоверчивье. Это понятно: ил быль очень тяжелі, гораздо тяжелее, чем нам. Были они da.leko от своей родины. Hекоторые из них присланы на долгие сроки, на десять, на двенадшать лет, а главное, они с глубокия предубеждением слотрели на всех ок-

\footnotetext{
105 Ebd., S. $146 f$.

106 Im Kommentar zu Bd. 4 wird auf die Probleme mit der Zensur wegen dieses Kapitels üler die polnischen politischen Mitgefangenen Dostoevskijs hingewiesen: Erst nach langwierigen Verhandlungen honnte dieses Kapitel im Dezemberheft der Zeitschrift l're'm/ja son 1862 veroffentlicht werden, fehlte jedoch in der ersten Buchveröffentlichung aus dem gleichen Jahr sowie in der letzten zu Lebzeiten Dostoevskijs erschienenen Ausgabe von 1875, vgl. ebd., S. 278.

${ }^{107}$ Ebd., S. 208f.

${ }^{100}$ Ebd., S. 209 [S. 390].
} 
рузсающих, видели в каторжсных одно только зверство, и не могли, даже не хотели, разглядеть в них ни одной доброй черты, ничего человеческого, и что тоже очень бџло понятно: на эту несчастную точку зрения они были поставлены силою обстоятельств, судьбой. Ясное дело, что тосkа лушила их в остроге [kursiv die Verf.].

[Übrigens waren sie auch seelisch krank, verbittert, reizbar, mißtrauisch. Aber das ist ja auch begreiflich - sie hatten es dort sehr schwer, viel schwerer als wir Russen. Sie waren weit entfernt von ihrer Heimat und einige von ihnen waren zu zehn, zu zwanzig Jahren verurteilt. Der Hauptgrund ihres Unglücks war jedoch, daß sie unendlich voreingenommen auf ihre ganze Umgebung blickten, in den übrigen Sträflingen nichts als tierische Rohlinge sahen und an ihnen keinen einzigen guten Zug. überhaupt nichts Menschliches wahrnehmen konnten und nicht einmal wollten. Auf diesen unglücklichen Standpunkt waren sie durch die Macht der Verhältnisse [und des Schicksals: Erg. d Verf.] gebracht worden. Da ist es denn begreiflich, daß die Qual [= Sehnsucht, Schwermut: Erg. d. Verf.] sie zu ersticken drohte. [kursiv die Verf.]1]

Der Ich-Erzähler erwähnt jedoch anschließend die guten Beziehungen zwischen den Polen und den anderen Fremden. den Tscherkessen. Tataren. dem Juden sowie dem Altgläubigen. d.h. zwischen ihnen und den Vertretern der von Rußland ...angeigneten" Nichtrussen bzu. der wegen ihres Glaubens Verfolgten. ohne daß der (irund einer solchen Zuneigung und der krankhaften Verfassung der Polen genannt wird oder aus Zensurgründen genannt werden durfte. ${ }^{110}$

Erneut wird auch die Freundschaft zwischen T-vskij und dem kranken B. hervorgehoben, die. seitens des jungen T-vskij an kritiklose Verehrung grenzend. zu den Konflikten mit M-kij und dem Ich-Erzähler führt:

Б. был больной, /.../ раздражительный и нервный, но в сущности предобрый и даже великолушный. /.../ Я не вынес этото хараkтера и впоследєтвии разошелся с Б., но зато н!и когда не переставал лкбить его. /.../ Т-ский был хоть и необрапованный человек, но добрый, мужественный, славный мољодой человск, одним словом. Всё дело было в том, что он до того любил и уважал Б-го, /.../ что тех, которые чуть-чуть расхолились с Б-М, считат тотчас же почти своими врагами. Он и с М-kим. кажется, разошелся /.../ за Б-го /.../.

[Dieser [3. war ein kranker Mensch, /.../ reizbar und nervös, doch im (irunde von seltener (jüte und sogar groß $\%$ ügig. !... Zuletzt vertrug ich seinen ('harakter nicht mehr und brach meinen Verkehr mit ihm ab. hörte aber nie auf, ihn zu lieben. /.../ Dieser T. war freilich ein ungebildeter Mensch, dafür aber unglaublich gut. mutig chrlich - mit einem Wort: ein prächtiger junger Mann. Der (irund unseres Zerwürfnisses lag einfach darin, daß er

109 Ebd. S. 210 [S. 391t.].

110 Lbd. An diese Passage schließt sich eine andere an, in der Corjancikov über die relativ verstandnisvolle und als tolerant zu bezeichnende Finstellung der russischen Gefangenen diesen Polen gegenüber berichtet. 
seinen Freund B. dermaßen liebte und hochschătzte, daß er alle, die mit B. die Freundschaft brachen, sogleich für seine eigenen Feinde hielt. Auch mit M-zkij brach er spăter B.s wegen.] ${ }^{111}$

Gorjancikov erzăhlt darüber hinaus aber seine Diskussionen mit B. wăhrend der dreimonatigen Tatigkeit der beiden als Schreiber in der Kanzlei des Gefangnisses und bei der Arbeit in der Werkstatt:

Мы с ним болтали; говорили об наших надеждах, убеждениях. Славный был он человек; но убеждения его иногда были очень странные, исkлючительные. Часто у некоторого разряда людей, очень умных, устанавливаются иногда совершенно парадоксальные понятия. Но за них столько было в жизни выстрадано, rakoю дорогою ценою они достались, что оторваться от них уже слишком больно, почти невозможно. Б-кий с болью принимал каждое возражение и с едкостью отвечал мне. Впрочем, во многом, может быть, он был и правее меня, не знаю; но мы наконец расстались, и это было мне очень больно: мы уже много разделяли вместе.

[Bei der Arbeit unterhielten wir uns gewöhnlich; wir sprachen von unserem Hoffnungen, Überzeugungen ... B. war ein prăchtiger Mensch, nur waren seine Ansichten mitunter recht wunderlich und eigenartig. Es kommt oft vor, daß sich bei einer gewissen Art von Menschen, sogar sehr klugen Menschen, vollkommen paradoxe Begriffe entwickeln, von denen sie nicht abzubringen sind. Für diese Begriffe aber hat der Mensch so viel im Leben gelitten, er hat sie so teuer erkauft, daß es für ihn gar zu schmerzhaft wäre, wenn nicht unmöglich, sich von ihnen loszureißen. B. horte wie unter Schmerzen jeden meiner Widersprüche an und antwortete mir mit beißender Schärfe. Vielleicht war er auch mehr im Recht als ich - ich weiß es nicht. Zum Schluß aber gingen wir auseinander, was mir sehr leid tat und sehr naheging: wir hatten schon soviel miteinander geteilt.] $]^{12}$

Er teilt jedoch nicht mit, um welche Überzeugungen und Ansichten der beiden es sich gehandelt hatte und ob es sich dabei um politisch-ideologische Auseinandersetzungen wegen der ,polnischen Frage“ hätte handeln können. Hervorgehoben wird lediglich die Zuneigung des Ich-Erzählers zu B., die aber wegen objektiver Umstände, u.a. seines Charakters wegen. sich nicht zu emer festeren Bekanntschaft entwickeln konnte. ${ }^{113}$

Gorjančikov beschreibt auch ausführlich den Charakter des Polen M-kij und die Geschichte seiner Entlassung aus dem Gefangnis, der bereits an mehreren Stellen als ein schwieriger Mensch erwăhnt wurde, den er wegen des verschlossen, selbstbeherrschten, kühlen und mißtrauischen Charakters nicht ,lieb“ gewinnen konnte:

111 Ebd., S. 209 [S. 391].

212 Ebd., S. 214ff., bes. S. 216 [S. 403].

$113 \mathrm{Vgl}$. dazu unten, S. 196ff., u.a. zu den Erinnerungen von SZYMON TOKARzEWSKI, m denen er seine Diskussionen mit Dostoevskij in Omsk geschildert hat. 
С М-ким я хорошо сошелся с первого раза; никогда с ним не ссорился, уважсал его, но полюбить его, привязаться $k$ нелу я никогда не мюг. Это был гіубоко недоверчивый и озьбленный человек, но умевший удивительно хошоро вьадеть собой. Вот это-то слишком большое уменье и не нравилось в нем: kak-то чувствовалось, что он никогда и ни перед кем не развернет души своей. Впрочем, может быть, я и ошибаюсь. Это была натура силылая и в высшей степени благородная. Чрезвычайная, даже несколько иезуumckaя ловkость и осторожность его в обхождении с людияи выказывала его затаеннжй, гıубокий скептищизи. А между тем это была душа, страдающая иненно этой двойственностью: скептицизиа и циубокого, ничем непоколебимого верования в некоторые свои особые убежсдения и наdeжcdu. [kursiv die Verf.]

[Mit M. verstand ich mich stets [sofort: Erg. d. Verf.] sehr gut. Wir stritten uns niemals und ich achtete ihn, aber ihn zu lieben, an ihm =u hängen - das hätte ich nie vermocht. Er war ein unendlich mißtrauischer und verbitterter Mensch, der sich jedoch erstaunlich $=u$ beherrschen wußte. Diese gar zu große Selbstbeherrschung nun war es gerade, was mir nicht getiel: man fühlte unwillkürlich, daß er niemals und vor keinem einzigen Menschen seine Seele ganz aufdecken würde. Doch vielleicht irre ich mich auch. Sonst war er eine starke und durchaus edle Natur. Seine außergewöhnliche ein wenig jesuitische Gewandtheit und Vorsicht im Umgang mit Menschen verriet natürlich seinen großen geheimen Skeptizismus. Und dennoch litt seine Seele gerade unter ihrer Zweiheit: unter dem Skeptizismus und dem tiefen, durch nichts zu erschütternden Glauben an einige setner l'herzeugungen und Hoffnungen [kursiv die Verf.]] ${ }^{114}$

Der ..jesuitische“" Charakter von M-kij, trotz seiner einzelnen von Gorjančikov betonten edlen $\%$ üge des unbeugsamen. hoftinungsvollen Glaubens an die Richtigkeit der eigenen Öberıeugungen. erınnert an dic Schilderungen negativer verwestlichter Figuren aus den literarischen Werken Dostoevskijs wie z.B. Petr Aleksandrovic Valkovskij aus dem Roman Unizennve $i$ oskorhlennye, bei dem jedoch unter der Maske der äußeren Güte bzw. Freundlichkeit nur das Böse zu finden ist. 215

Die Reihe der ausführlichen Schilderungen der (jorjančikov am nächsten stehenden polnischen Mitgefangenen wird mit der Nacherzählung des Konflikts zwischen dem sadistischen Major ${ }^{126}$ und dem frommen Polen $\not{Z}-$-kij abgeschlossen, den dieser (Offizier mit einer willkürlich verhängten Prügelstrafe zu demütigen versucht:

Старика naka қаті. Ои лег под розии беспрекословно, закусил себе зубами руку и вытеріел наказание без малейшего kрика или стона, не иевелясь. /... Он должен был ирийти прямо из кордегардия, где

\footnotetext{
214 Bd. 4, S. 209 [S. 390t:]

$215 \mathrm{Vgl}$ dazu unten, $S$. $204 \mathrm{fr}$. bes $S .205 f$. und $S .217 \mathrm{ff}$

116 Vgl. zu ihm oben, S. 160.
} 
еro наkазывали. /.../ Ж-кий, не глядя ни на koro, с бледным лицом /.../, прошел между собравшихся на дворе каторжных, уже узнавших, что наказывают дворянина, вошел в казарму, прямо k своему месту, и, ни слова не говоря, стал на колени и начал молиться богу. Каторжные были поражены и даже растротаны. /.../ с этих пор и обходились с ним всегда почтительно. Им особенно понравилось, что он не кричал под розгами.

[Der Greis [= im Original: der Alte; Erg. d. Verf.] wurde gezüchtigt. Er streckte sich widerspruchslos hin, biß die Zähne in den Arm und ertrug die Strafe ohne einen Schrei oder ein Gestöhn, ohne sich zu rühren. /.../ Er mußte von der Wache, wo er bestraft wurde, sogleich in den Ostrogg kommen. /.../Sh. trat ein und ging, bleich, mit blutleeren, bebenden Lippen, /.../ durch die versammelte Schar der ihn enwartenden Sträflinge, die bereits erfahren hatten, daß ein Adliger gezüchtigt wurde - er ging geradeaus in die Kaserne, ging zu seinem Pritschenplatz, kniete, ohne ein Wort zu sagen, nieder und begann zu beten. Die Strätlinge waren verwundert und sogar erschüttert... /.../ Die Sträflinge achten ihn seit der Zeit sogar sehr und gehen stets ehrerbietig mit ihm um. Besonders gefiel ihnen, daß er während der Züchtigung nicht geschrien hatte. $]^{117}$

Gorjančikov betont nicht nur die unerschütterliche tiefe Frömmigkeit und den Glauben dieses Polen, sondern auch die Achtung der russischen Mitgefangenen vor seiner würdevollen Haltung. $\check{Z}$-kij wird jedoch insgesamt negativ dargestellt, als ein „честный, но несkолько странный“ [, ein durchaus ehrlicher, aber doch etwas eigentümlicher Mensch“; S. 393] Mensch. so daß ihn sogar B-kij und T-vskij: „очень не любили, даже не говорили, отзываясь о нем, что он угрям и вздорен"|,B. und T. liebten ihn gar nicht, ja, sie sprachen nicht einmal mit ihm, was sie damit begründeten. daß er eigensinnig und albern sei“]. ${ }^{118}$ Dieses kritische Urteil Gorjančikovs wird aber durch die besonders gespannten Beziehungen der Gefangenen untereinander relativiert und gemildert, die in einem Gefängnis typisch seien. obwohl er zugleich zugibt, daß:

Ж-кий был действительно человек довольно тупой и, может бөть, неприятньй. /.../ Я с ним хоть и никогда не ссорился, но особінно не сходился. Свой предмет, математику, он, кажется, знал. Помню, он всё мне силился растолковать на своем полурусском языke kakую-то особенную, им самим былуманную астрономическую систему. Мне говорили, что он это kогда-то напечатал, но над ним в учсном мире только посмеялись. Mile kажется, он был несколько поврежслен рассудком. По целым дням он молился на коленях богу, чем сиисkа: обпее уважение каторги и пользовался им до самой смерти своей. Он умер в нашем госпитале после тяжкой полезни, на моих глазах.

117 Bd. 4, S. 211 [S. 394].

118 libd., S. 210. 
[Freilich war Sh. in der Tat ein ziemlich stumpfer und vielleicht sogar unangenehmer Mensch. /.../Ich stritt mich zwar nie mit ihm, trat ihm aber auch nie năher. Sein Fach, die Mathematik, schien er allerdings zu beherrschen. Ich erinnere mich noch, wie er sich in seiner halbrussischen Sprechweise vergeblich bemühte, mir ein ganz besonderes, von ihm selbst erfundenes astronomisches System zu erklären. Die anderen Polen hatten mir aber schon gesagt, daß er es auch einmal veröffentlicht habe, von der wissenschaftlichen Welt jedoch nur ausgelacht worden sei. Eigentlich glaube ich. daß er geistig nicht ganz normal war. Er konnte tagelang ununterbrochen kniend beten, wodurch er sich bei den anderen Sträflingen allgemeine Achtung erworben hatte, die man ihm auch bis an sein Ende zollte. Er starb an einer schweren Krankheit in unserem Lazarett, starb vor meinen Augen. [kursiv die Verf.] ${ }^{119}$

Dieser Fall der Demütigung eines Adligen und wahnsinnigen Gelehrten wird jedoch lediglich durch den grausamen Charakter des sadistischen Majors erklärt, d.h. als eine Ausnahme hingestellt. ohne daß das russische System der Vollzugsanstalten kritisiert wurde. ${ }^{120}$ In diesen Passagen wird außerdem der Kontrast zwischen der Schilderung eines Fremden und darüber hinaus eines fanatischen Katholiken und den früher von Gorjancikov beschriebenen frommen Russen, des sanften, das Jesusgebet praktizierenden Altglăubigen brw. des die Heilige Schrift lesenden russisch-orthodoxen Gefangenen deutlich. ${ }^{121}$

Die Figur des Majors kommt darüber hinaus noch im Zusammenhang mit den Figuren anderer in dem Kapitel über die "Genossen“ beschriebenen Polen vor. Diese übrigen polnischen Gefangenen werden jedoch von Gorjančikov aus einem großeren Abstand als die oben erwähnten B., T-vskij, M-kij bzw. M-ckij und Ž-kij geschildert. Z.u ihnen gehøren rwei junge Menschen, ..присланные на kороткие сроки, малообразованные, но честные, простые, прямые“ [.,auf kurze Zeit verschickt, beide wenig gebildet, dafür aber ehrlich, einfach und offenherzig"; 405] und ein dritter Pole A-cukovskij, der als „уж слишком простоват" [,,schon ein wenig gar zu unbedeutend [einfältig; Erg. d. Verf.]“; S. 405] bezeichnet wird. ${ }^{122}$ Der vierte Pole wird dagegen in einigen Sätzen genauer und außerst negativ beschrieben:

Б-м, человек уже пожилой, производил на всех нас пресkверное впечатление. Не знаю, kak он попал в разряд таkих преступников, да и сам он отринат это. Это была грубая, мелкомешанская душа, с привычками и прави.ами лавочника, разбогатевые го на обсчитанные koneйkи. Он был безо всяkого образования и не интересовался ничем, кроме своего ремесла. Он бы.л маляр, но маляр из ряду вон, матяр великолепный.

119 Ebd., S. 210f. [S. 393].

$120 \mathrm{Vgl}$ ebd., S. $211 \mathrm{ff}$.

$121 \mathrm{Vgl}$ oben, S. 161ff. Siche auch unten zur Figur des wahnsinnig gewordenen frommen Polen. S. 188f.

122 Fbd., S. 217 
[/.../ ein gewisser B-m, ein schon bejahrter Mann, machte auf uns alle einen sehr schlechten Eindruck. Ich weiß nicht, wie er überhaupt unter die 'Politischen' [= solche Verbrecher; Erg. d. Verf.] geraten war; er selbst leugnete es, daß er zu ihnen gehore. $\mathrm{Er}$ war ein roher, kleinlicher Charakter [= eine kleinbürgerliche, spießbürgerliche Seele; Erg. d. Verf.], mit den Angewohnheiten und der Lebenssauffassung eines durch erfeilschte Kopeken reich gewordenen Kommis. Er war ganz ungebildet und interessierte sich für nichts, außer für sein Handwerk. Er war nămlich Maler, aber kein gewöhnlicher, sondem ein unvergleichlicher, unübertrefflicher!] ${ }^{123}$

Diese polnische Kleinbürger- und Handwerkerfigur hebt sich in den Augen Gorjancikovs scharf von den anderen einfachen russischen Gefangenen ab, die in ihrer Mehrheit als kriminell gewordene russische Bauern vorgestellt werden. Dank den handwerklichen Făhigkeiten dieses „polnischen Spießbürgers“, der mit Hilfe anderer Polen das schabige Haus des Majors wie einen Palast ausgemalt hat, kommt es zur Wandlung der Einstellung des Majors den Polen gegenüber:

Б-мом был он всё более и более доволен, а чрез него и другими, работавшими с ним вместе./.../ В этом месяце майор совершенно изменил свое мнение о всех наших и начал им покровительствовать. Дошло до того, что однажды вдруг он потребовал $k$ себе из острога Ж-ro.

- Ж-кий! - сkазал он, - я тебя осkорбил. Я тебя высеk напрасно, я знаю это. $Я$ расскаиваюсь. Понимаешь ты это? $Я, \Omega, \&$ - pacckaиваюсь! /.../ Кто ты передо мной? червяk! меньше червяkа: ты арестант! /.../

Ж-кий отвечал, что он понимает.

- Ну, таk теперь я мирюсь с тобой. [kursiv Dostoevskij]

[Mit B-m war er jetzt überaus zufrieden und durch B-m auch mit den beiden anderen Adligen, die mit diesem bei ihm arbeiteten. /.../ In dieser Zeit [= Monat] änderte der Major seine Meinung uber uns vollkommen und verhielt sich seitdem sehr gönnerhaft zu allen Adligen. Ja, eines Tages ging er sogar so weit, daß er plotzlich den alten Sh. zu sich rufen ließ. 'Sh-kij', sagte er, 'ich habe dich beleidigt. lch habe dich unnütz prügeln lassen, ich weiß es. Jetzt bereue ich es. Begreifst du, was das heißt? lch. ich. ich - bereue es!' /.../ 'Wer bist $d u$ vor mir? - Ein Wurm! Sogar weniger als ein Wurm: du bist ein Arrestant!' Sh. antwortete, daß er es begreife. /.../ Nun, dann will ich mich jetzt mit dir aussohnen ${ }^{\circ}$ [kursiv Dostoevskij]] ${ }^{124}$

Dieses Gesprăch und die versohnliche Geste des Majors dem von ihm emiedrigten Menschen gegenüber, worüber Gorjancikov von dem betroffenen Polen selbst gehört haben will, wird von ihm so kommentiert: „Стано быть, было же и в этом пьяном, вздорном и беспорядочном человеkе человечесkое чувство. /.../ Впрочем, пьяный вид, может быть, тому

123 Ebd. [S. 405].

${ }^{224}$ Ebd.. S. 217f. [S. 406]. 
много cпособствовал". I"So schlummerte denn vielleicht auch in diesem ewig betrunkenen, unsinnigen und unordentlichen Menschen noch ein menschliches Empfinden. /.../ Übrigens wird wohl auch sein betrunkener Zustand mit die Veranlassung dazu gewesen sein“]. ${ }^{125}$

Die oben angeführte „Versöhnungsszene“ mit dem Polen wird jedoch nicht als ein "kathartisches" Erlebnis des Majors geschildert, denn er handelt nicht aus christlicher Năchstenliebe und aus Demut gegenüber einem Mitmenschen, sondern wird als ein egozentrischer Mensch geschildert, wovon symbolisch die Wiederholung des Pronomens ,.Ich" in seiner An(Rede) zeugt. Auch ist der Pole für ihn kein „Mensch", kein .,Du“, sondern „weniger als ein Wurm", so daß die beiden kursiv gesetzten Pronomina keine Beziehung zwischen zwei gleichgestellten Subjekten bedeutet, sondern zwischen einem entmenschlichten "Ich", das lediglich aus einer "Uniform" besteht, und einem „Du“, das auf das Niveau einer ,nichtigen“ Kreatur, eines Gefangenen herabgesetzt wird.

Die positive Deutung dieser Szene seitens des Ich-Erzăhlers wird zusätzlich durch den Satz ..Впрочем, пьяный вид, может быть, тому много способствовал" relativiert, was auch durch die Beschreibung des weiteren Schicksals des Majors bestátigt wird. der schließlich wegen seiner Grausamkeit entlassen wird: „В мундире он был гроза, бог. В сюртуkе он өдруг стал совершенно ничел и смахивал на лакея. Удивительно, kak много составляет мундир у этих людей.“ [kursiv die Verf.] [,.in der Uniform war er ein Gewitter, ein Gott. Im Gehrock wurde er plöt-lich ein Nichts und ähnelte einem Lakaien. Erstaunlich, wie viel eine Uniform bei solchen Leuten ausmacht"; Übers. d. Verf.] ${ }^{126}$ Die Wendung сльахиваı на sаkея [ähnelte einem Lakaien], die an dieser Stelle zur Charakteristik eines heruntergekommenen autoritären russischen Offiziers dient, wird in den spăteren Werken Dostoevskijs ideologisch umfunktioniert und ausnahmslos zur Charakteristik polnischer stereotyper sowie anderer negativer verwestlichter Figuren eingesetzt.

6. Außer den in dem Kapitel Tovarišči vorkommenden Polen gibt es in Zapiski i= Mertrogo doma noch drei namentlich genannte polnische Figuren, zu denen neben einem jungen adligen Gefangenen zwei nichtadlige Aufseher gehören.

Im Schlußkapitel über die Entlassung Gorjančikovs aus dem Gefängnis wird ein Pole erwăhnt:

К-чинский, поляк из дворян, тихий и кроткий молодой человеk, тоже kak и я, любил много ходить в шабашное время по двору. Он думат чистым воздухом и моционом сохранить свое здоровье и наверстать весь вред душных казарменных ночей. “Я с нетерниением жиу вашего выхода, - сказал он мне с улыбкою, встретясь однажды со мной на прогулkе, - вы выйдете, и ужс я буду знать тогда, что мне ровно год остастся до выхода". [kursiv Dostoevskij]

${ }^{225}$ Ebd., S. 218 [S. 406].

${ }^{226}$ Ebd 
[K-tschinskij, ein adliger Pole, ein stiller, sanfter Jüngling, der gleich mir gem einsam hinter den Kasemen umherstrich und durch die Bewegung in der frischen Luft gleichsam seine Gesundheit vor dem schädlichen Einfluß der schwülen Nächte in der Kaserne bewahren wollte, sagte lăchelnd zu mir: 'Ich erwarte mit Ungeduld Ihre Entlassung... Wenn Sie gegangen sind, dann werde ich wissen, daß ich gerade noch ein Jahr auf die Freiheit zu warten habe'. [kursiv Dostoevskij]] ${ }^{127}$

Die Figur des sanften und stillen jungen Polen, die ebenfalls ein authentisches Vorbild haben soll, wird durch sonst nur russischen positiven Figuren vorbehaltenen Epitheta eine Ausnahme und hebt sich von den Schilderungen aller anderen polnischen Gefangenen in Zapiski iz Mertvogo doma ab.

Im Kapitel über die miBlungene Flucht der Gefangenen A-v und Kulikov (Pobeg [Eine Flucht; Übers. v. Rahsin]) tritt die Figur des polnischen Begleitsoldaten Koller auf, der von diesen russischen Gefangenen zur Hilfe überredet wurde:

В одном из батапьонов, стоявших в крепости, служсил один nоляk, энереический человек, и может быть, достойный лучией участи, человек уже пожиюий, молюдиеватый, серьезньй. Смолоду, только что придя на службу в Сибирь, он бежсал от глубокой mосkи по родине. Его поймали, наказали и года лва продержали в арестантсkих ротах. Кодга его поворотили опять в солдаты, он одумался и стал служсить ревностно, изо всех сил. За отличие его сделали ефрейтором. Это был человек с честолюбием, самонадеянный и знавший себе цену. Он так и смотрел, rak и говорил, kak знающий себе цену. Я несkолько раз в эти годы, встречал его между нашими конвойными. Мне koe-что roворили о нем и поляки. Мне показалось, что прежняя тосkа обратилась в нем в ненависть, скрытую, глухую, всегдашнюю. Этот человек мог решиться на всё, и Куликов не ошибся, выбрав его товарищем. Фамилия его была Коллер. [kursiv die Verf.]

[In einem der Bataillone, die in der Festung lagen, diente ein Pole, ein energischer Mensch, der eigentlich ein besseres Schicksal verdient hatte: er war nicht mehr jung. ernst und tapfer. In der Jugend war er sogleich nach seiner Ankunft in Sibirien aus Heimweh entflohen. Man hatte ihn aber eingefangen, bestraft und auf zwei Jahre in die Strafkompanie gesteckt. Als er dann wieder ins Bataillon zurückgekehn war, hatte er sich bedacht und seine Zeit gewissenhaft abzudienen begonnen. Dafür war or bald zum Gefreiten befördert worden. Er war ein ehrgeiziger, sebstbewußter Charakter: er blickte und sprach wie einer, der seinen eigenen Wert kennt. Ich sah ihn ziemlich oft unter unseren Eskortensoldaten; und die Polen hatten mir schon einiges von ihm erzählt. Es schien mir. daß sein früheres Heimweh sich in ihm mit der Zelt in verstecklen. dumpfen, ewigen Haß veruandelt hatte. Dieser Mensch konnte sich gleichfalls zu allem entschließen, und 
Kulikoff täuschte sich nicht, wenn er ihn zum Spießgesellen erwähite. Sein Familienname war Koller. [kursiv die Verf.]] ${ }^{12 \theta}$

Der Pole Koller wird von Gorjančikov positiv charakterisiert, sogar bewundert. Die Ursache fur den z.weifachen Verrat seiner Pflichten als Soldat der russischen Armee wird lediglich durch seine nationale Zugehörigkeit erklärt. Allein die Sehnsucht nach der Heimat hat aus Koller einen unberechenbaren und haßerfüllten Menschen gemacht. Auch in dieser Figur wird somit die unüberwindbare Fremdheit der Polen hervorgehoben, die sich wegen der allzustarken Liebe zu ihrem Heimatland nic als treue russische Untertanen erweisen können. Dieses konstante Motiv der Liebe zur Heimat macht auch aus den polnischen Figuren, die in den späteren literarischen Werken Dostoevskijs lediglich auf diese einzige Charaktereigenschaft reduzient werden, ,maskierte“ Lügner und Verräter, so daß die Figur Kollers als das Urbild eines solchen polnischen subversiven Verbrechers gelten kann. Koller hilft dabei den von Gorjancikov äußerst negativ beschricbenen Russen, dem Denunzianten $A-v$ und dem starken, rücksichtslosen und zynischen Verbrecher Kulikov, so daß Gorjancikov seiner Verwunderung und seinem Mitleid diesem sonst so ehrlich wirkenden Menschen gegenüber den Ausdruck gibt:

Стано быть, имеји же наши беглецы сильнейшее влияие на Коллера и поверил же он им, когда после долголетней и удачной в последние годы службы он, человек умный, солидный, расчетливый, решиился за ними следовать. /.../

Всех больше мне было жаль Коллера: он всё потерял, последние належды свои, прошел больше всех, кажется две тысячи, и отправлен был куда-то арестантом /.../.

[Unsere Flüchtlinge müssen auf Koller doch einen ungeheuren Einfluß gehabe haben, wenn er ihnen aufs Wor glauben und sich nach langjährigem und in der letzten Zeit erfolgreichem Dienst, als solider, kluger und berechnender Mensch. der er wvar, entschließen konnte, ihnen zu folgen. /.../ Am meisten tat mir Koller leid: er verlor alles, seine letzten lloffnungen, wurde am strengsten bestraft - mit zweitausend. wenn ich nicht irre - und kam als Sträfling irgendwohin in einen anderen Ostrogg. ${ }^{129}$

Der leute von Gorjančikov namentlich genannte Pole, der Unteroffizier Ostrožskij, wird als Beispiel eines psychisch kranken Menschen angeführt. wic es sie im (jefängniskrankenhaus gibt. (jorjancikov schildert zwei Begegnungen mit (Ostrožskij, den er durch M-ckij und $\mathrm{B}$. kennengelernt hat. Die erste Begegnung findet in einer Ziegelfabrik statt. wo dieser Pole als Oberaufseher tätig war. Er wird als älterer, „высокий, сухопавый“ [.groß von Wuchs, hager“; S. 299] Mensch von ..чрсзвычайно благобразной и даже вејичавой наружности“ [..von angenehmem und sogar imponierendem Äußeren“; ebd.] beschrieben. Erwähnt wird dabei auch, daß er aus dem Volk, ,нз простонародия" laus dem ein-

128 [3d. 4, S. 222 [S 414]

229 Fbd., S. 223 und 228 [S. 415 und S. 426] 
fachen Volk] stammt und nach Sibirien als „солдат бывшего в тридиатом году войска" ["Soldat der einstigen Armee aus den dreißiger Jahren"; Übers. d. Verf: dieser Satz fehlt in der Übers. Rahsins] gekommen ist, d.h. moglicherweise gegen die polnischen Aufständischen von 1830-31 in der nussischen Armee gekampft hat, aber trotzdem von $M-c k i j$ und von $B$. geliebt und geachtet wird. ${ }^{130}$ Gorjancikov fugt hinzu, daß Ostrožskij: „/.../ всё читал karоличесkую Библию. /.../ говорил тak ласkово, тak разумно, тak занимательно рассказывал, таk добродушно и честно смотрел“. [,Еr las bestăndig in der katholischen Bibel. /.../ er sprach so freundlich, verständig, wußte so interessant zu erzăhlen und blickte einen so gutmütig und ehrlich an“; ebd.] ${ }^{131}$ Die zweite Begegnung mit Ostrožskij findet viel später im Gefángniskrankenhaus statt:

С тех пор я не видал его года два, слышал только, что по kakoмy-то делу он находился под следствием, и вдруг его ввели $k$ нам в палату kak сумасшедшего. Он вошел с визгами, с хохотом и с самыми неприличными, с самыми камаринскими жестами пустился плясать по палате. Арестанты были в восторге, но мне стало таk грустно... Через три дня мы все уже не знали, куда с ним деваться. Он ссорился, дрался, визжал, пел песни, даже ночью, делал поминутно таkие отвратительные выходки, что всех начинало просто тошнить. Он никого не боялся.

[Seit der Zeit hatte ich ihn ganze zwei Jahre nicht gesehen, nur einmal hatte ich gehört, daß er sich in Untersuchungshaft befinde. Und nun plotzlich wurde er als Irrsinniger zu uns hereingeführt. Lachend, kreischend trat er ein und begann sofort mit den unanständigsten Gesten einen Tanz, ăhnlich der Kamárinskaja, zu tanzen. Die Straflinge waren entzückt, begeistert, mir aber zerriß es das Herz... Nach drei Tagen wußten wir nicht mehr, was wir mit ihm anfangen sollten. Er stritt. schimpfte sich mit allen und jedem herum, raufte, schrie, gröhlte, sang L,ieder, sogar in der Nacht, und machte in jedem Augenblick so ekelhafte Bewegungen, daß uns allen geradezu übel wurde. Er furchtete sich vor nichts und niemand. $]^{132}$

Auch in dieser polnischen Figur des glaubigen Katholiken aus dem Volk wird der Kontrast zu den oben erwăhnten russischen glaubigen Figuren deutlich. Trotz der anfänglichen Schilderung als edler, gutmütiger Menschen wird dieser Pole als ein echter psychisch Kranker zu einem "falschen Gottesnarren“ degradiert.

III. Neben den ausführlich besprochenen, als Individuen geschilderten Polen treten in Zapiski iz Mertvogo doma auch anonyme polnische Figuren auf, die sich nur als nationale Stereotypen bezeichnen lassen, die den Stereotypen (ebenfalls in der Funktion als alter) aus den spăteren literarischen Werken Dostoevskijs ăhnlich sind:

130 Ebd., S. 159.

131 Ebd.

132 Ebd. [S. 299]. 
1. Zu diesen anonymen Polen gehör ein Geiger, der für Geld den feiemden und trinkenden russischen Gefangenen vorspielt:

Был в остроге один полячок из бегльих солдат, очень гаденький, но игравший на ckpunke и имевший при себе инструмент - всё свое достояние. Ремесла он не имел никаkого и тем только и иромынлял, тто нанимался $k$ гулякщим играть веселые танцы. Должность его состояла в том, чтоб безотлучно следовать за своим пьяным хозяином из казармы в казарму и пилить на ckpипke изо всей мочи. Уасто на лице его явısıась ckyka, mocka. Но оkриk: «Играй, деньги взял!» - заставлял его снова пилить и пилить. [kursiv die Verf.]

[Es war da ein kleiner Pole, ein entlaufener Soldat, ein elendes Kerlchen, der auf der Geige zu spielen verstand und sein Instrument, das sein ganzes Kapital war, auch im Ostrogg bei sich hatte. Ein Handwerk verstand er nicht, und so war sein einziger Verdienst, daß er den 'Feiemden' für Geld muntere Tanzstücke aufspielte. Seine Aufgabe bestand in solchem Fall darin, daß er seinem betrunkenen Gönner aus einer Kaserne in die andere folgte und mit aller Ellbogenkraft auf seiner Fiedel tiedelte. Oft sah ich auf seinem Gesicht Langeweile und Kummer, doch der barsche Befehl: 'Spiel, bist bezahlt!' trieb ihn an, immer weiter zu fiedeln. [kursiv die Verf.]] ${ }^{133}$

Trotz seiner Anonymität teilt dieser Pole mit den anderen in Zapıski $\leftleftarrows$ Mertvogo doma auftretenden individuell geschilderten polnischen Figuren die Sehnsucht nach der Heimat, so daß dieses konstante Gefühl sich als eine stereotype Gruppeneigenschaft bezeichnen läßt, die allen Polen von Gorjančikov zugeschrieben wird und darüber hinaus als eine der Ursachen für ihre Isolation in der Katorga bzw. im Dienst in Sibirien gelten kann.

2. An einer anderen Stelle der Zapiskı iz Mertvogo doma, in dem oben erwähnten Kapitel über den ..Aufstand" der nichtadligen Gefangenen, wird erwähnt, daß sich an dieseın Aufstand die übrigen einfacher. Polen nicht beteiligen wollten: Были тут все острожные полячki из простых, примкнувииие тоже к дворянам [..Es waren hier auch alle Polackchen aus dem Volk. die sich im Gefängnis befanden. die sich den Adligen angeschlossen haben"; Übers. und kursiv die Verf. $]^{134}$

133 libd., S. 35. [S. 66]. Dieser schabige Pole wird außerdem im Zusammenhang mit den Exzessen des betrunkenen Tataren (jazin sowie im Kapitel uber die Weihnachtsfeier erwahnt.

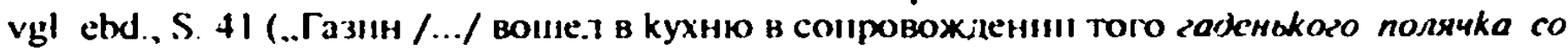

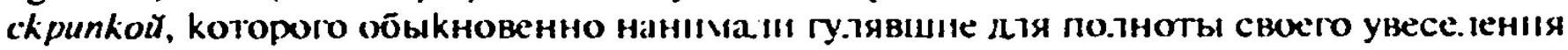
/... . I..Gazin /... kam in die Küche in der Begleitung dieses gunz und gur gurs/lgc'n l'oluckche'ns mul der (ie'spe. der gewöhnlich von den feiemden Gefangenen aur Vollendung ihrer Belustigung gemietet ivurde“) und S. 109 (.Пезячюк (о) ехрипкой уже ходил за какимто гулякой, нанятый на весь день, и пилил ему веселыс таныы. ") (...)er kleme l'oluck nus der (iegze folgte schon einem Zechenden, gemietet für den ganzen Tag, und fiedelte ihm irohlıche L.ieder" Übers und hursiv d. Verf. |

134 Ebd., S. 204. 
Dadurch wird immer wieder die Fremdheit und Isoliertheit auch der einfachen nichtadligen polnischen Gefangenen in der Katorga betont, ihre Unfahigkeit, sich von der Gruppe der russischen Gefangenen assimilieren zu lassen.

In allen oben angeführten Stellen, bei denen der Ich-Erzăhler über die adligen Polen spricht, sie aus seiner Perspektive einschătzt. fallt darüber hinaus seine schwankende, ambivalente Beurteilung dieser Figuren auf. Indem er die russischen Gefangenen bzw. das Aufsichtspersonal entweder nur negativ oder nur positiv zu beurteilen pflegt, relativiert Gorjancikov sein Urteil über die Polen auf die Weise, daß er immer eine kritische Äußerung zu mildern versucht bzw. eine positive durch eine negative in Frage stellt. Diese Ambivalenz wird meistens durch eine besondere, parallele, sich wiederholende Satzkonstruktionen geäußert, so z.B.: „Б. был человеk с прекрасным образованием, благородный, с характером великодушным, но испорченным и раздраженным болезнью" [..В. hatte eine vorzügliche Bildung genossen und hatte einen edlen, großzügigen Charakter, allein durch die Krankheit war er reizbar geworden und verbittert."]; „С некоторыми из них я сходился довольно kоротко и даже с удовольствием, но не со всеми“ [Mit einigen von ihnen verkehrte ich ganz freundschaftlich und sogar gern, aber nicht mit allen.]; „Б. был больной, /.../ раздражительный и нервный, но в сущности предобрый и даже великодуинный. /.../ Я не вынес этого хараkтера и впоследствии разошелся с Б., но зато никогда не переставал любить ero" [,Dieser B. war ein kranker Mensch. /.../ reizbar und nervös, doch im Grunde von seltener Güte und sogar großzügig. /.../Zuletzt vertrug ich seinen Charakter nicht mehr und brach meinen Verkehr mit ihm ab, höre aber nie auf, ihn zu lieben.“]; „С М-kим я хорошо сошелся с первого раза; никогда с ним не ссорился, уважал его, но полюбить его, привязаться k нему я ниkогда не мог. Это был глубоко недоверчивый и озлобленный человек, но умевшиий удивительно хошоро вјалеть собой“ [,Mit $M$. verstand ich mich stets [sofort; Erg. d. Verf.] sehr gut. Wir stritten uns niemals und ich achtete ihn, aber ihn zu lieben, an ihm zu hängen - das hätte ich nie vermocht. Er war ein unendlich mißtrauischer und verbitterter Mensch, der sich jedoch erstaunlich zu beherrschen wußte."], bzw. ./.../ впрочен, все они были больные нравственно, желчные, раздражительные, недоверчивые. Это понятно: им было очень тяжело, тораздо тяжелее, чем нам“ [„Übrigens waren sie auch seelisch krank, verbittert, reizbar, mißtrauisch. Aber das ist ja auch begreiflich - sie hatten es dort sehr schwer, viel schwerer als wir Russen."] und „Впрочел, во многом, может быть, он был и иравее меня, не знаю; но мы наконеш расстались, и это было мне очень больно: мы уже много разделяли вместе" [,V'ielleicht war er auch mehr im Recht als ich - ich weiß es nicht. Zum Schluß aber gingen wir auseinander, was mir sehr leid tat und sehr naheging: wir hatten schon soviel miteinander geteilt."]. ${ }^{135}$ Gegenüber den anderen nichtadligen Polen wird dagegen die kritische Haltung Gorjančihov's dadurch gemildert, daß er meistens von seinem Mitleid diesen Menschen gegenüber

${ }^{135}$ Vgl. Bd. 4, S. 81, S. 209, S. 219 und S. 216. 
spricht. Zwei Ausnahmen bilden die Urteile: ein nur positives Urteil über den jungen Polen K-cinskij und ein nur negatives über den Maler B-m.

Auffallend bei allen Stellen, an denen von den Polen die Rede ist, ist ferner, daß sie selbst fast nie selbst zu Wort kommen (eine Ausnahme bildet lediglich der Dialog mit dem Ich-Erzähler vor dem „Aufstand“ der Gefangenen), sondern immer von ihm selbst beschrieben und eingeschătzt werden. Seine wertende Position wird aber auf die oben erwăhnte Weise relativiert und als ambivalent gezeigt.

IV. In Zapiski iz Mertvogo doma gibt es außerdem nur wenige andere polnische Imageme:

1. Zweimal taucht darin die Wendung cmamb (б̈ыть) $c$ кем-нио̆удь запанибрата auf [stat' (byt') s kem-nibud' zapanibrata; jds. Duzbruder werden (sein); mit jd. in vertrautem Verkehr stehen $]^{136}$ - zum ersten Mal im Zusammenhang mit dem ordentlichen adligen russischen Mitgefangenen Gorjančikovs, Akim Akimyč. Akim Akimyč wird zum einen mit einem Deutschen verglichen - akkuraten, kak nетес [аккуратен, как немеи; genau, sorgfältig, sauber wie ein Deutscher 1-, zum anderen dient die Wendung cmamb (быть) $c$ кемнио̆удь за панибрата dazu, seine allzu familiăren Beziehungen zu den anderen Mitgefangenen zu charakterisieren:

/.../ редkо видал я таkoro чудаkа, kak этот Аkим Акимыч. /.../ Был он высоk, худощав, слабоумен, ужасно безграмотен, чрезвычайный резонер и акkуратен, каk немец. Каторжные смеялись над ним; но некоторые даже боялись с ним связываться за придирчивый, взыскательный и вздорный его характер. Он с первого шагу стал с нимеи запанибрата, ругался с ними, даже дрался. Уестен он бын феноменально. /.../ Наивен dо крайности. /.../ он kak будто ниkаk не мог понять своей вины настояшим образом /.../. Фонарики он делал мастерсkи, puботал sетодически, не отрываясь /.../. Благонрлвие и порядок он простирал /.../ до самого мелочного педантизиа. /.../ Не понравился он мне с первого же лня /.../. /.../ благонравие, казалось, поглотило в нем все остальные его человеческие дары и особенности, все страсти и желания, дурныс и хорошие. /.../ раз указанные ему правиіа он исполняl c священною аккуратностью. Если 6 завтра же приказали ему сделать совершено противное, он бы сделал и это с тою же самою покорностью и тшательностью/.../. [kursiv die Verf.]

[lch weiß nicht, ob ich sonst noch jemals einen so seltsamen Kauz wie Akim Akimytsch gesehen habe. /.../ Er war groß von Wuchs. hager, schwachgeistig, unglaublich ungebildet, ein großer Klugredner, und gewissenhaft wie ein Deutscher. Die Sträflinge lachten über ihn, viele aber

$136 \mathrm{Vgl}$. dazu VASMER 1953-1958 (Bd. 2, S. 309): ..[punibrul| nahuбpuim 'Busenfreund', |panibratsvol naнuбpimcmeo 'Busenfreundschaft, ukr. punibrát. Entlehnt aus poln. Voc. s.

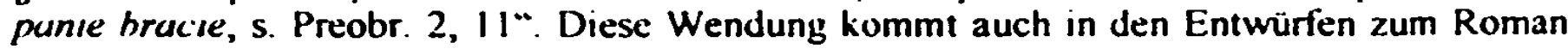
Pextrosiok vor. Vgl. dazu unten, S. 363f. 
furchteten sich sogar davor, mit ihm etwas zu tun zu haben, wegen seines streitsüchtigen, anmaßenden und unleidlichen Charakters. Er stellte sich von vomherein wie ein alter Dusbruder zu ihnen, schimpfte und raufte sich womöglich mit allen und jedem. Dabei war er phänomenal ehrlich. I.../ Naiv war er bis =ur Unglaublichkeit; /.../ [im Original: als ob er] seine Schuld doch nicht richtig [hätte] einsehen [verstehen können; Erg. d. Verf.]]. I.../ Solche Laternen [ $=$ Kleine Laternchen] verfertigte er meisterhaft, und er arbeitete [methodisch; Erg. d. Verf.] ohne Unterlaß. /.../ Wohlanständigkeit und Ordnung trieb er '...' bis zur kleinlichsten Pedanterie. /.../ Schon von diesem ersten Tage an gefiel er mir nicht /.../. /.../ sein Gehorsam, wie es schien. [hatte] /.../ alle übrigen menschlichen Gaben und Eigenheiten in ihm verschlungen. alle Leidenschaften und Wünsche, sowohl die guten wie die schlechten. /.../ [er erfüllte] die ihm einmal vorgeschriebenen Gesetze mit heiliger Gewissenhafiigkeit. Hätte man ihm am năchsten Tage befohlen, etwas dem, was er tags zuvor getan. genau Entgegengesetztes zu tun, so hätte er sicher auch dieses mit ganz demselben Gehorsam und derselben Sorgfalt verrichtet wie das andere [kursiv die Verf.]]

Akim Akimyč wird mit Hilfe der fremden Imageme (kak нелец; стал с ниsı запанибрата) als ein negativ „verwestlichter“ Russe gezeigt. Er bekommt dadurch einen „autoritären“, utopisch-subversiven Charakterzug (als ein Alius), läßt sich aber zugleich als ein psychologisch differenziertes Stereotyp des „tüchtigen Deutschen“ (als Alter) bezeichnen. Denn dieses Imagem (= Stereotyp eines Deutschen mit allen dazu gehörenden Attributen) bildet als ein Element des imaginaire social den weltanschaulichen Kern dieser Figur. Der Polonismus zeigt dagegen seine scheinbare Vertrautheit mit den anderen Gefangenen aus dem Volk, weil diese .,Vertrautheit" lediglich auf der Grundlage ihrer Furcht vor einem unberechenbaren und beschränkten, fanatischen Menschen beruht.

Ein zweites Mal wird dieselbe Wendung im Zusammenhang mit der Figur des (jefagenen Kulikov eingesetzt, um seine heruntergekommene soziale Position nach der mißlungenen Flucht zu bezeichnen: „/.../ арестанты в душе как-то перестали уважать его, как-то о́олее запаниоррата стапи с ним обходиться. Одним словом, с этого побега слава Куликова сильно померкла“ [,die Străflinge [schienen] innerlich aufgehör zu haben. ihn /.. / zu achten. Sie gingen mit ihm jet:t wie mit einem Gleichstehenden um. /.../ Ja. mit diesem mißglückten Fluchtversuch erlosch Kulikoffs Anschen".][kursiv die Verf. $]^{138}$

2. Der Jude Isaj Fomič Bumštejn spricht ein gebrochenes Russisch, das polnisch und weißrussisch gefärbt ist und seine Herkunft aus den südwestlichen Gebieten des russischen Imperiums verrät. Es handelt sich also um das weißrussische Masurieren: „хоцу зениться" [..mecht aheiraten”; S. 105]. Der Satz „Ну, нехай; был бы пан бог да гро́ши, тak везде хорошо будет“ [..Nu, is

${ }^{137} \mathrm{Vgl}$. Bd. 4, S. 26f., S. 50 und S. 105 [S. 49-51, S. 95f. und S. 198].

138 Ebd., S. 228f. [S. 426]. 
gutt. Hat man nur Gott den Herm und Kopekens, so wird sein überall gut ssu leben".] ${ }^{139}$ zeigt dagegen die tiefe Gläubigkeit Bumstejns, der sich nie von seinem Gott verlassen fühlt, von ihm überall „begleitet" wird, und zugleich seine „pragmatische“, ,kaufmännische“ Mentalităt, dank derer er sich überall zurechtfinden und glücklich sein kann. Er wird somit auf die zwei stereotypen „Eigenschaften“ seines „Volkes“ reduziert und bildet (auch durch das groteske bzw. „komische“ Äußere) den Kontrast (als ein Alter) zu den christlichen russischen Figuren in Zapiski iz Mertvogo doma, die "das Leid auf sich nehmen" und sich nicht um ihr ,irdisches" Hab und Gut kümmern.

Die Wendungen, die Isaj Fomic Bumstejn in den Mund gelegt werden, enstammen dem sogenannten Sibirischen Heft (Sibirskaja tetrad' [Das sibirische Heft]) Dostocvskijs. ${ }^{110}$ Darin kommen außerdem auch einige polnische Wendungen vor, die jedoch nicht in die Endfassung der Zapiski iz Merrvogo doma aufgenommen worden sind. ${ }^{111}$ Es ist darüber hinaus auffallend, daß diese polnischen Fremdworte und Wendungen nicht zur Charakterisierung der polnischen Figuren eingesetzt werden.

Aus diesem Überblick über die polnischen Imageme in Zapiski i= Mertvogo doma, zu denen sowohl polnische Figuren als auch einige wenige polnische Fremdworte bzw. Wendungen gehören. wird die besondere Wichtigkeit der als Personen eingeführten und ausführlich von Gorjančikov beschriebenen polnischen Figuren deutlich. Die meisten der namentlich in Zapiski i= Mertvogo doma geschilderten Polen sollen ihre authentischen Vorbilder in den Mitgefangenen Dostoevskijs in Omsk gehabt haben. Genannt werden dabei hauptsächlich vier polnische politische Gefangene SZYMON TOKARZEWSKI (T-vskij), JÖZEF Boguslawski (B.), Aleksander MIRECKI (M-ckij bzw. M-kij) und JózeF ZOCHOWSKI ( $\grave{Z}-k i j)$, deren biographische Daten in Zeitdokumenten überliefert sind, $^{112}$ sowie um einige andere Polen. JÓZEF ANCZYKOWSKI, KAROI. BEM,

${ }^{139}$ Ebd., S. 55 [S 177] und S. 94. Siehe dazu auch bei PożNiak 1992, S. 108-112, hes. S 109: ..Bumsztejn /.../ sepleni i mówi $z$ charakterystyczna intonacja oraz używa słów typowych dia mieszkaniców malych ukraninskich czy bialoruskich miasteczek. Język Isaja Fomicza tworzy mieszankę fonetyczno-leksykalno-składniowa zydowsko-polsko-ukrainsko-bialoruska [..Bumstejn / ... / spricht und lispelt mit der charakteristischen Betonung und benutzt Worte, die typisch für die Bewohner kleiner ukrainischer oder weiBrussischer Stådtchen sind. Die Sprache von Isaj Fomic ist eine phonetisch-lexikalisch-syntaktische, jüdisch-polnisch-ukrainischwe1Brussische Mischung"|. und bei INGOLD 1981, S. 16-43

${ }_{140} \mathrm{Vgl}$. Bd. 4, S. 238 (Satze 91. und 92.). Siehe auch die Anm. dazu, ebd., S. 315.

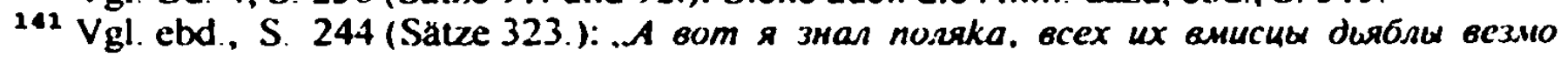

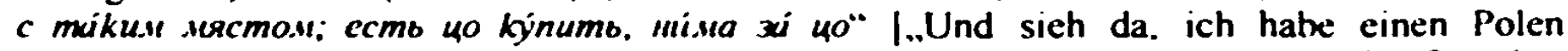
gekannt. Teufel sollen ste alle zusummen mit so einer Stadt holen; es gibt was zu kaufen, aber keın Geld dazu | = etwa ..nichts, wofür man was kaufen könnte|"|. Nur die Worte visech ich vmiscy [Bcex ux asucily wohl dic ukrainisch-weiBrussiche form von russ. vmesie (avecme, zusummen)] sind nicht polnisch (es müßte .ıch wssysikıch razem" heissen]. Siehe auch die Anm. dazu. ebd., S. 3196 .

${ }_{142}$ Siehe zu SzYMON TOKART.EWSKI und Jozef BOGUSLAWSKI unten, sowie zu ihnen und zu AL.EKSANDER MiRECKI und JOzEF ŻOCHOWSKi, bei MUCHA 1979, S 68fr., 7.BIGNIEW PODCOR7EC 1984, S. 85f., ARENDT 1936, S. 495f. bzw. den Kommentar im Bd. 4. S. 280f. und S. 288. $\mathrm{Vgl}$. auch die Angaben zu Dostoevskij, Durov, Aristov und zu den vier oben ge- 
LUDWIK KORCZYŃSKI und JAN MUSIALOWICZ, die lediglich ihrem Namen nach bekannt sind. ${ }^{143}$

nannten Polen in dem Statejnyj spisok o gosudarstvennych i polıtıceskıch prestupnikach. nachodjaščıchsja v Omskoj kreposı v katorínoj rabole 2 rasrjada. ljunja 19 -go dnja 1850 goda [Liste der zur Srafarbelt 2. Kategorie verurleilten staullichen und politischen Verbrecher, die sich in der Omsker Fesıung befinden. Den 19. Junı 18501, einer Gefangenenliste, unterzeichnet von dem Kommandanten des Gefangnisses in Omsk, Oberst de-Grave, angefün bei NiKOLAEVSKU 1898. ALEKSANDER MIRECK! (geb. 1820) wird darin folgendermaBen beschrieben: „/.../ 30 .лет, .шиом чнст, г.лаза же.ттокарые, во.лоса свет.лорусые, /.../ те.лосложения kрепkото, Цартсва По.льсkого Краkовсkий уроженец, /.../ в дурных постутках не замечен, но в нравственности сомните.ен, /.../ вероисповедания kaто.ничесkого, чернорабочий, грамоте: по.льской, французсkой, немецкой и российской знает, 2 aрш. 5 верш., хо.лост" $1, / \ldots / 30$ Jahre alt, reine Gesichtshaut, gelb-braune Augen, hellblonde Haare, /.../ starker Korperbau, Bürger des Konigreichs Polen, geborener Krakauer, /... schlechtes Benehmen ist nicht bemerkt worden, aber die sittliche Haltung zweifelhaft (aber von zweifelhafter Sittlichkeit), /.../ katholischer Konfession, ungelernter Arbeiter, liest und schreibt polnisch, französisch, deutsch und russisch, 2 Arschin [ein Arschin =0,71 m] 5 Werschok groß [ein Werschok = 4,4 cml, ledig."]. MIRECK! wurde für „участье в затоворе k пронзведению в Царстве По.тsckoм бунта“ |wegen der Teilnahme an einer Verschwörung zum Hervorrufen eines Aufstandes im Königreich Polen] zu zehn Jahren Katorga und zu einer Prügelstrafe („IInıирутенамı через 500 че.товеk один раз“ |zum einmaligen SpieBrutenlaufen durch 500 Leute]) verurteilt; nach PODGÓRZEC 1984 S. 85f.) wurde Mirecki ,za propagande patriotyczna Zwiazku Demokratycznego“ |wegen der patriotischen Propaganda für den Demokratischen Verein] nach Sibirien geschickt, ebd., S. 85. Vgl. auch die Angaben zu JozEF ZOCHOWSKI (1801-1851) bei NiKOLAFVSKJ 1898 : ./.../ по с.ловам его из штяхтічей, бывший профессор, /.../ приговорен к смертной казни, но ири самом испо.тнении приговора об̆яятенно дарование жизни, /.../ ведет себя хорошо, веронсповедания като.лического, чернорабочий, трамоте по-российсkı и поnо.іьсkı знает". [/.../ seinen Worten nach stammt er aus dem Kleinadel, ehemaliger Professor, /.../ zum Tode verurteilt, aber vor der Vollstreckung der Strafe wurde ihm das Leben geschenkt, /.../ gutes Benehmen, katholischer Konfession, ungelernter Arbeiter, liest und schreibt russisch und polnisch]. ZOCHOW'Sk war Mathematıkprofessor an der Universität Warschau (nach ZBIGNIEW PODGORZEC 1984, S. 85, ist Feliks Józef Żochowski Physikprofessor gewesen). Żochowski wurde ebenfalls zu zehn Jahren Katorga für eine patriotische Rede verurteilt, in der er um Hilfe für die Aufständischen von 1848 in Wielkopolska geworben hatte. Er starb in der Katorga. Vgl. MuCHA 1979, ebd. und Bd. 4, ebd.

${ }_{143} \mathrm{Vgl}$. dazu den Kommentar im Bd. 4, ebd. und BUDANOVAFridLENDER 1993-1995 (Bd. 1, S. 184ff.); darin wird darauf hingewiesen, daß JAN MuSIalowncz bzw. sein Name das Vorbild für Herrn Mussjalovic in dem Roman Brat ja Karamazovy geworden ist (S. 184: siehe dazu unten, S. $401 \mathrm{fr}$, bes. S. 405f.), daB KAROI. BEM (sein Name kónnte auch Bohm lauten, was von seiner deutschen Herkunft zeugen würde) in den Entwürfen zu diesem Roman erwähnt wird und daß das Gespräch zwischen Aleksander Mirecki und Dostoevskij nicht nur in Zapisk $:$ Merrvogo doma, sondern auch in Dncvnik pisatelja in der Erinnerung an den Bauem Marej vorkommt, siehe dazu oben. S. 177. MUCHA 1979 nennt außerdem noch zwei Polen, Mitgefangene Dostoevskijs aus Omsk, Karol Krzyżanowski und Jan Wozniakowski, über die es aber keine biographische Angaben gibt (S. 68ff.). Vgl. auch die Erinnerung von JUŽNYJ 1991 (S. 178-188), in denen noch ein Pole namens RoŽNOVSKu genannt wird, der wegen des Mordes an seiner Frau nach Omsk verbannt wurde und dor Dostoevskij begegnet sein soll. In den Erinnerungen JUŹNYJS weist dieser Pole, den er kurz vor dessen Tode 1880 in Staraja Russa kennengelemt hat, einige Gemeinsamkeiten mit dem Ich-Erzähler der Zupıskı I: Merrvogo domu. Aleksandr Petrovič Gorjančikov auf. 
Die polnischen Dostoevskij-Forscher widmen ihre besondere Aufmerksamkeit den zwei Mitgefangenen Dostoevskijs aus Omsk, SZYMON TOKARZEWSKI (T-vskij) und JÖzeF BOGUSLAWSKı (B.), weil diese polnischen politischen Hăftlinge ihre Erinnerungen an die Zeit in Sibirien und an die Bekanntschaft mit Dostoevskij hinterlassen haben. ${ }^{144}$ BOGL'SLAW MUCHA hat in seinem bereits angeführten Aufsatz. Fiodor Dostojewski c=asów katorgi (1850-1854) w opinii polskich wspótzestańców [Fedor Dostoevskij in der Zeit der Katorga (1850-54) im Urteil der polnischen Mitgefangenen ${ }^{245}$ die Erinnerungen der beiden Polen an Dostoevskij mit der Schilderung der Polen in Zapiski i= Mertwogo doma verglichen. MuCHA bemüht sich dabei, die gegenseitige Sicht sowohl der beiden Polen auf Dostoevskij als auch des Autors Dostoevskij auf die Polen miteinander zu konfrontieren, um anhand der Gemeinsamkeiten und der Unterschiede die Fiktion von der W'irklichkeit in Zapiski i Mertvogo doma besser trennen und die Schreibweise Dostoevskijs. der die Fakten einer bestimmten Auswahl unterzogen hat, objektiver beurteilen zu können.

In dem ersten Teil seines Aufsatzes analysiert Mucha die Schilderung Dostoevskijs in den Erinnerungen von SZYMON TOKARZEWSKI, die dieser nach seiner Rückkehr aus Sibirien nach 1883 niedergeschrieben hat. ${ }^{146}$ MUCHA be-

144 Vgl. TOKARZEWSKI 1907-9, 1918. DERS. 1922 und BOGUSLAWSKI 1896 (zit. nach MUCHA 1979, S. 69)

145 Ebd

246 Ebd., S. 69ff. In diesem Aufsatz kann man auch eine Kurzbiographic Szymon Tokarzewskis (1823-1900) linden Tokarzewski war Enkel eines Anhängers der Barer Konföderation und Sohn eines vermögenden Gutsbesitzers aus der Gegend um die Stadt l.ublin. Wegen der Zusammenarbeit mit Piotr Ściegienny (1800-1890), einem katholischen Priester, der die polnische Befreiungsbewegung in der Gegend um Kielce und Lublin organistert hatte, uurde Tokarzewski 1844 als dessen Emissär verhaftet, war zuerst in einem Gefangnis in L vov, von 1849 bis 1856 in den russischen Gefangnissen in Warszawa (c ylade/a ucurszun:ska |W'ur.schumer Zllade/le|), in Modlin. anschließend in Semipalatinsk und Omsk 1857 wurde Tokarzewski entlassen. Nach der Rückkehr nach Warszawa beteiligte er sich an dem Januar-Aufstand von 1863. 1864 wurde er emeut verhaftet und zu 19 Jahren Katorga verurteilt. Er kehrte erst $i 883$ nach Polen zurück (ebd., S. 68f.). In der Biographic Tokarzewskis bei POD(SORZEC 1984 (S. 85f.) wird außerdem geschricben. dals dieser nach semer ersten Verhaftung in dem Lublimer Gouvernement nach Galizien geflüchtet war und don ion den Osterreichem an die Russen ausgeliefen wurde. POOXiOR/FC fügt hinzu, daß3 Tokarzewski nach der Rückkchr aus Sibirien Im Jahre 1857 den Beruf eines Schusters erlernt hatte, um. wie der polnische Schuster Jan Kilinskı, der sich an dem Kościuszko-Aufstand gegen die Russen beteiligt hatte, die subversive Tätigkeit und patriotische Aufhlärungsarbeit hesser organisieren zu konnen und einen direkten Einfluß auf die Bevölkerung und auf die llandwerker von Wars/awa zu haben. Seme Erinnerungen hatte Tokarzewski nach der endgültigen Rückkehr nach Polen ab 1883 niedergeschricben, sie wurden aber erst posthum von seiner Witwe in mehreren Banden verolfentlicht. vgl ebd., $\mathrm{S} 85 \mathrm{f}$. In der von NIKOl.AEvSkIJ 1898 is. 220f.) angeführten liste wird Tokarzewskl folgendermaßen beschrieben:

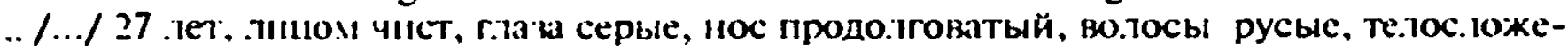

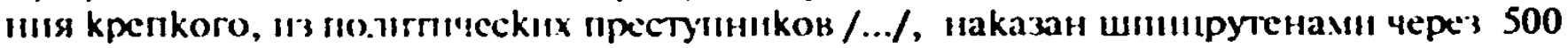

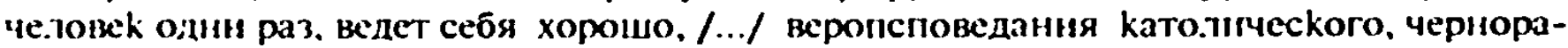

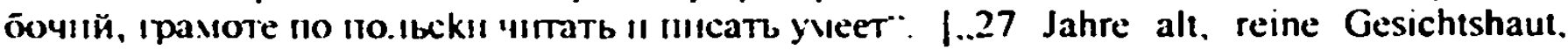
längliche Nase. blondes llaar, kraftiger Korperbau, aus den politischen Verbrechern /.../, veruneilt zu einmaligem Spießrutenlaufen durch 500 leute, gutes Benehmen. /... katholischer Konfession, ungelernter Arbeiter, liest und schresbt polnisch". 
merkt dabei, daß TOKARZEWSKI die ihm anvertrauten Aufzeichnungen seines Freundes JÓZEF BOGUSLAWSKI stellenweise abgeschrieben und somit vervollstăndigt habe. ${ }^{147}$ In den Aufzeichnungen der beiden Polen wird in der Auffassung MuCHAS die ideologische Wende in der Weltanschauung Dostoevskijs besonders sichtbar, die nach der Petraševcy-Zeit in der Katorga stattgefunden habe. Diese sich damals herausbildende konservativ-nationalistische und russisch-orthodoxe Ideologie Dostoevskijs wurde im folgenden zum ersten $\mathrm{Mal}$ in seinen sibirischen Gedichten explizit formuliert. ${ }^{188}$ Die Beurteilung Dostoevskijs in den Erinnerungen der beiden Polen fallt aus diesem Grund äußerst negativ aus. Sowohl TOKARZEWSKI als auch BOGUSLAWSKI schildern ihre heftigen politischen Diskussionen mit Dostoevskij und nennen ihn einen ,zwolennik knutowładztwa" [.,Anhänger der Knuten-Herrschaft"], einen großrussischen Nationalisten und Chauvinisten, der sich durch seine verächtliche Einstellung allen anderen Nationen und Kulturen gegenüber sowie durch eine russische messianistisch gefärbte Ideologie ausgezeichnet habe. ${ }^{149}$ MUCHA führt eine

147 MUCHA 1979 befreit jedoch Tokarzewski von dem Vorwurf des Plagiats, denn damals hatte er keine Aussicht darauf, die Aufzeichnungen seines früher verstorbenen Freundes veroffentlichen zu kơnnen (S. 69). Boguslawski, ein ehemaliger Student der Universităt in Dorpat, wurde wegen der Beteiligung an einer politischen Verschwörung zur mehrjährigen Katorga verurteilt, er starb 1857, (ebd.). Vgl. dazu auch BOBOw1CZ-POTOCKA 1975. Bei Nikolakvsku 1898 (S. 220f.) wird Boguslawski folgendermaßen geschildert: .31 года, .1ицо круг.лое, худошавое, г.лаза серые, во.лосы темнорусые /.../, 113 дворян ILарства Ilo.1bckoro, .ишен всех прав состояния с пере.омєением над го.овой через патача шпапи, ведет себя хорошо, /.../ вероисповедания kато.лнческого, чернорабочий, грамоте по по.тьсkı чıттать и писать умеет". $\mid .31$ Jahre alt, rundes, mageres Gesicht, dunkelblondes Haar /.../, aus dem Adel des Konigreichs Polen, jedes Recht auf Vermögen wurde ihm entzogen, indem ihm der Henker den Degen über dem Kopf gebrochen hat, gutes Benehmen, /...' katholischer Konfession, ungelernter Arbeiter, liest und schreibt polnisch.]

${ }_{148}$ MUCHA 1979, S. 70ff. Siche auch MuCHA 1977

$149 \mathrm{Vgl}$. MuCha 1979 (S. 70ff. bzw. S. 70f.): .Tokarzewski i Bogusławski z goryczą cytują nastçpującą wypowiedż 'tego skazarica za wolnosić i postçp': ' Wówczas bçdę szczęsliwy. jeśli zobaczç wszyst kic sąsiednie ludy pod panowaniem cara'. Wedtug ich relacji Dostojewski nigdy nic uważal Ukrainy, I itwy i Polski za zicmic wlączonc przemocą do imperium rosyjskicgo, lecz utrzymywał, iż stanowią onc odwicczną wlasnošć jego kraju. /...' Tokarzcuski /.../ domagal siç dla Rzeczpospolitcj przywriccnia granic sprzed pieruszego rozbioru, nictrudno

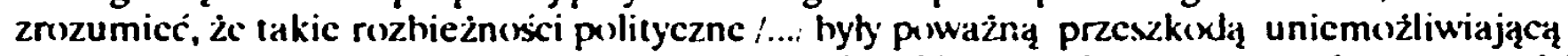
zajçcic kompromisowego stanowiska /.../. /.../ polcmiki, prowadzone w atmosferze wrogoxici i braku poszanowania dla interlokutorów prowadzity do zaostrzenia wzajemnych stosunkow i prayczyniały siç do prugłçhicnia antagonnizmu miçdzy Polakami a rosyjskim pisarzem”.

[Tokarzewski und Bogusławski zitieren mit Verbitterung die folgende Äußerung dieses wegen des Glaubens an die Freiheit und den Fortschritt Verurteilten: nur dann werde ich glücklich sein, wenn ich alle Nachbarvolker unter der Hertschafi des Zaren sehen werde. Ihrem Bericht nach hatte Dostoevskij nicmals Ukraine, Litauen und Polen für Länder gehalten, die mit Gewalt dem russischen Imperium einverleibt wurden. sondern behauptete, daß sie der ewige Besitz seines Landes sind. /.../ Tokarzewski $i . . /$ forderte für die [polnısche] Republik die Wiederherstellung der Grenzen aus der Zeit vor der ersten Teilung. und es ist nicht schwer zu verstehen, daß solche politische Meinungsunterschicde $/ \ldots$ l cin ernsthaftes Hindernis waren, um eine Kompromißhaltung einzunehmen /.../. Die Polemiken, die in einer Atmosphäre der Feindschaft und des Mangels an Achtung vor den Gesprächspartnern getührt wur- 
Stelle aus den Erinnerungen Tokarzewskis an, an der dieser über den extremen $\mathrm{HaB}$ Dostoevskijs auf die Polen berichtet, obwohl seiner Ansicht nach sowohl Dostoevskijs Name als seine Gesichtszüge die polnische Herkunft des Schriftstcllers hätten erkennen lassen:

Dostojewski nienawidził Polaków, o sobie mówił, (ponieważ z rysów twarzy i z nazwiska, niestety, znać było polskie jego pochodzenie), że gdyby wiedział, iż w żyłach jego jest choćby kropla krwi polskiej, kazałby ją natychmiast wypuścić. [Dostoevskij haßte die Polen, sagte er von sich selbst (weil aus seinen Gesichtszügen und seinem Namen nach, leider, die polnische Herkunft zu erkennen ist), daß, wenn er gewußt hätte, daß in seinen Adern auch nur ein Tropfen polnischen Bluts fließt, er ihn hätte entfernen lassen. $]^{150}$

den, verursachien die Verschärfung der gegenseitugen Bezichungen und vertiefien den Antagonismus zwischen den Polen und dem russischen Schriftsteller.]

150 Ebd., S. 71. MuCHA zitiert diese Stelle aus TOKARZEWSKi 1918, S. 168. nach der zweiten mchizensierten Auflage, sowie nach den Erinnerungen BOGLSLAwSKis 1896 (nr 286, S. 1) Vgl. zur vermeintlichen Venwandischaft (väterlicherseits) F.M. Dostoevskijs mit dem teılweise polonisierten Geschlecht der Dostoevskijs aus der Gegend um Pin sk bei VolockoJ 1933. S. 15f. :../.../ пре.аkов ЦостоевсkıIx (по чисто мужской .линІІІ) по всей вероятности с.іедует искать до 1.389 г. среді татарсkıєх мурз 3о.лотой Орды. Okо.ю 1389 r. происходит пересе.тение Ас.тана-Че.ео̆ı-ıурзы, родоначатьника ветви идушей k Достоевсkıм, на терріторию Мосkовсkого государства. .... В пос.ледуюших поко.лениях одна 113 ветвей потомства Ас.тана-Че.Іебı-мурзы по.тучает фамплию Иртищей ILII

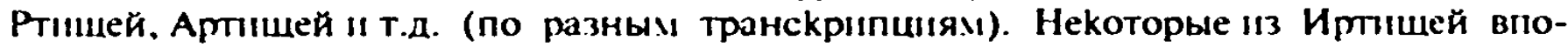
с.ле.лтсвиІІ эмıгрıруют в свıте князей Ярос.лавıчей в ЛІтву, в район IIıнсkого по-

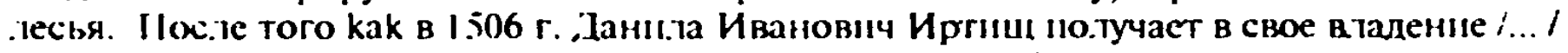

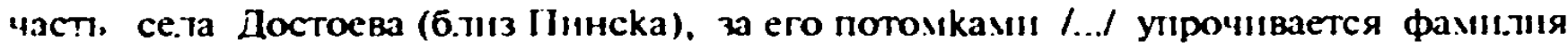

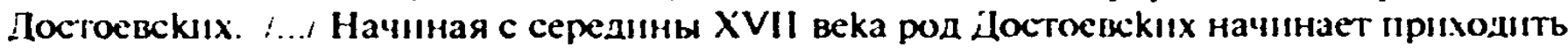
/... в угіадок. /.../ ІІх родос.ловная таб.ина /.../ обрывается на 1655 г. Дальше, до деда

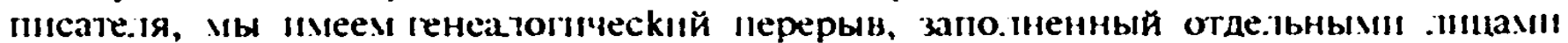

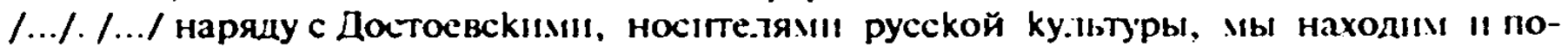
.онизированных представите.ей этого рода. Тақовым яв.яется, маіример, ('тефан

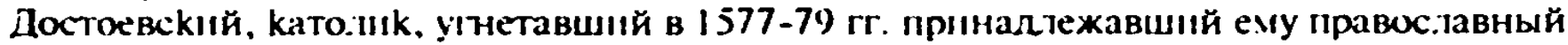

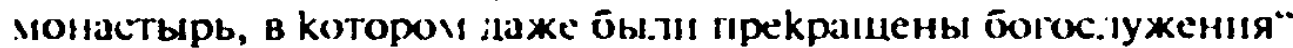

[/... die Vorfahren Dostoevskijs väterlicherseits soll man bis zum Jahre 1389 aller Wahrscheinlichkest nach unter den tatarischen Adligen | russ. murzumurz: $\cdot$ der Goldenen Hlorde suchen. Um 1389 erfolgt die Übersiedlung von Aslan-Celebi-murza, des Ahnherrn der Lınic, die bis zu den Dostoe' skijs fuhrt, aut das (iebiet des Moskauer Staates. /... Finige Generationen später bekommt cin Zweig der Nachkornmen von Aslan-Čelebi-murza den Namen Irtišč oder Rušč, Artišc usw (In verschiedenen Varıanien). Finige der Irtıščs wandern spater im Gefolge der Fürsten Jaroslavie nach I.ıtauen aus, in das Pinsker Waldgebiet |polex $e$ |. Nachdem Danıla Ivanovié Irtıše 1505 :... Besitzer cines Teils des Dorfes Dostoevo (in der Nahe von Pinsk) geworden war, erhielten /... seine Nachkommen den Namen Dostexevskij. i...' Von der Mitte des XVII. Jahrhunderts an beginnt der Niedergang der Familie Dostociskij. Ihre Stammtafel bricht im Jahre 1655 ab. Bis zum Großvater des Schriftstellers gibt es eine genealogische Unterbrechung. in der nur einzelne Personen dieses Namens genannt werden /.../.

zusammen mit den Dostoevskijs, die der russischen Kultur angehörten, finden wir auch die polonisierten Verteter dieser Familie fin solcher Vertreter war beispielsweise Stefan Dostoevskij, ein Katholık. der in den Jahren $1577-79$ ein auf seinem Gebiet befindliches orthodoxes Kloster unterdrückte. in dem es sogar keine (iottesdienste mehr geben durfte.] 
Der ideologische Konflikt zwischen den beiden Polen und Dostoevskij, der in ihren Erinnerungen beschrieben worden ist, habe sich mit der Zeit, besonders nach dem Ausbruch des Krimkriegs, extrem verschärft, so habe Dostoevskij den beiden polnischen Mitgefangenen eine patriotische Ode auf die von ihm erwartetete Eroberung Konstantinopels vorgetragen, die jene ironisch kommentiert hatten. ${ }^{151}$ Der ideologische Antagonismus zwischen den Polen und Dostoevskij führte schließlich zum Abbruch ihrer Kontakte, weil diese befürchteten, daß Dostoevskij sie bei den Behörden hätte denunzieren können. ${ }^{152}$

Die Ursache für den Konflikt zwischen den Polen und Dostoevskij erblickt Mucha einerseits in den kompromißlosen und intoleranten panslawistischen ideologischen Ansichten Dostoevskijs der „polnischen Frage“ gegenüber sowie andererseits in den ebenfalls intoleranten Ansichten der beiden Polen und in ihrer ablehnenden Einstellung dieser Ideologie gegenüber, wobei sie darüber hinaus Züge einer polnischen adligen Mentalităt aufweisen. ${ }^{153}$

Im zweiten Teil des Aufsatzes wendet sich MuCHA den Zapiski iz Mertvogo doma zu und bemerkt, daß die Schilderung der Polen darin positiver sei als diejenigen Dostoevskijs in den Erinnerungen seiner polnischen Mitgefangenen. In den Zapiski iz Mertvogo doma werde außerdem der Akzent nicht auf die ideologische Polemik mit den Polen, sondern auf die psychologische Analyse ihrer Charaktere gesetzt, wobei MuCHA jedoch Dostoevskijs Rücksicht auf die Zensur nicht erwähnt. ${ }^{154}$ Dostoevskij habe allerdings den adligen Polen ihre Verachtung und ihren $\mathrm{Haß}$ gegenüber den russischen einfachen Gefangenen nie verzeihen können. ${ }^{155}$ andererseits aber, laut der Erinnerungen anderer nichtpolnischer Zeitgenossen, habe er sich selbst diesen Mitgefangenen gegenüber ebenfalls zurückhaltend bzw. feindlich verhalten. ${ }^{156}$ In der Auffassung MUCHAS läßt sich in den Zapiski iz Mertvogo doma eine Tendenz beobachten, das Erlebnis der Begegnung mit den Polen in der Katorga einer bestimmten Auswahl zu unterziehen, so daß die Polen in dem Text Dostoevskijs fremder, einsamer, isolierter und exklusiver erscheinen, als sie sich in ihren Erinnerungen selbst dargestellt

PODGORZEC 1981 (S. 155ff.) behauptet, daß es wegen des Mangels an Dokumenten nicht möglich sei, die Herkunft F.M. Dostoevskijs von dem polonisierten adligen litauischen bzw. litauisch-polnischen Geschlecht zu beweisen, denn schon der Vater Dostoevskijs konnte seine adlige Herkunft nicht beweisen, als er sich 1828 bemühte, in das Gouvernement-Verzeichnis des russischen Adels aufgenommen zu werden: Es handle sich lediglich um einen von Dostoevskij und von seiner Familie geschaffenen und gepflegten Familienmythos (ebd.).

151 MuCIIA 1979, S. 7 Iff.

152 E:bd., S. 74

${ }^{153}$ Ebd., S. 73: Mucha bemerkt die Năhe der Ansichten Dostoevskijs zu Tjutčev. Siehe dazu oben, S. 147 und unten $S .218 f$.

154 Ebd., S. 76ff.

155 Ebd., S. 77ff: Mucha betont dabei, daß die Lektüre der Erinnerungen der heiden Polen ihre negative Einstellung den russischen Mitgefangenen gegenüber und ihre Haltung der .kulturellen Überheblichkeit" beweisen.

i56 Ebd., S. 77ff. Mucha führt als Beispiel die Erinnerungen von P.K Mar'janov (1895) an. eines degradierten Kadetten des Mannekorps aus Sankt-Petersburg. der Wachdienst in Omsk ausgeübt hatte. Vgl. MART'JANOV 1895, S. 448ff. 
haben. ${ }^{157}$ Zum Schluß seines Aufsatzes polemisient Mucha gegen die Ansicht von LEDNICKI, daß die relativ positive Darstellung der Polen in Zapiski iz Mertvogo doma im Vergleich mit den späteren Werken hauptsăchlich dem mildernden EinfluB des Baron Vrangel' zu verdanken sei. ${ }^{158}$ MuCHA stimmt der Ansicht von $Z$ BIGNIEW Z.AKIEWICZ ${ }^{159} \mathrm{zu}$, daß die relativ positive und objektive Darstellung der Polen durch die literarische Gattung der Zapiski iz Mertvogo doma zu erklären ist. Sie seien zugleich ,mehr als ein Dokument und weniger als eine Fiktion". MUCHA beruft sich wie ŻAKIEWICZ auf VIKTOR ŠKLOVSKIJS Ansicht, der Zapiski iz Mertvogo doma ein "Roman-Dokument“ bzw "Dokumentar-Roman" genannt hat. ${ }^{160}$ Ganz anders seien aber nach MUCHA die Polen in den anderen nur literarischen Werken Dostoevskijs geschildert, besonders in dem Roman Brat 'ja Karamazovy, in dem die früheren ideologischen Gegner Dostoevskijs aus Omsk, Tokarzewski und Bogusławski, karikiert worden seien. $^{161}$

Mucha hat jedoch in seinem Autsatz nicht die in Zapiski i= Mernogo doma erwähnten Figuren der nichtadligen Polen, 7.B. des melancholischen Geigers, berücksichtigt, die schon in diesem Werk als nationale Stereotypen den polnischen stereotypen Figuren aus den späteren literarischen Werken Dostoevskijs ähnlich und in gleicher Funktion eingesetzt worden sind. ŻAKIEWICZ hat dagegen über diese „schäbigen“ Figuren der einfachen „polacz-

${ }^{257}$ Ehd., S. 79ff.: Die Polen hatten z.B. bei der Theatervorstellung mitgewirkt, seien mıt den Vertretern der russischen adligen Gesellschaft von Omsk sowie mit der Frau des Kommandanten des Gefangnissses. Anna de Grave befreundet und hätten von ihr verbotene Zeitschriften und Bücher bekommen. Auch Dostoevskij selbst soll von den Behörden als Adliger nachsichtiger als die einfachen Gefangenen behandelt worden sein.

158 Ebd., S. 83. Vgl. dazu LeDNickI 1953, S. 267. .I have no doubt that this kindness, comprehension. sympathy and even admiration which Dostoevsky shows $i \ldots$, his unfortunate Polish comrades derives from his friend Baron A.E. Wrangel. In his humane book Reminiscences ahout T.M. Dessteevsky in Siheriu, Wrangel expressed his particular sympathy for the Poles in exile there. He quotes leners to his father in which he stresses the fact that he was particularly concerned with the unfortunate Polish poliucai prisoners, with all these educated youths. He also mentions the fact that Dostoevsky did not like them." Siehe auch VRANGEL."

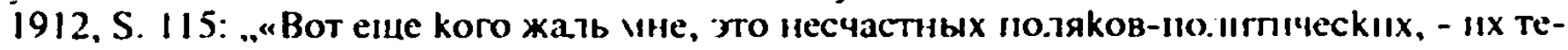
перь везут сюда много и все мо.юдежь образованная. Таk. например, вчера привезии 113 Варшавы графа Янычевского. Јворян везут до Тобо.іьcka, а отсю.а их оттравляют k месту назиачения вместе с убия̆и laми. Kakoro прогу:аттся, например. в Восточную Cибирь, несkо.лько тысячь верет, да еше зимою". | Wer mich sonst noch dauert. sind die unglücklichen politischen polnischen [Deportierten], man bringt jetat so viele hierher und alles ist gebildete Jugend. So hat man beispielsweise gestern den Grafen Janycevskij aus Warszawa gebracht. Adlige werden nach Tohol'sk gebracht, und von dort verschicht man sie zum Bestimmungsort zusammen mit den Mordern Dazu z.B. welch ein Spaziergang nach Ostsibirien. einige Tausend Werst, und im Winter / VRANGli: fügt in diesem von ihm zitterten Brief an seinen Vater an: .Ф.М. ЦІостоевский благодаря заступничеству Анненковых был доставлен на каторгу в Омск в кибитке“" Dostoevskij wurde dank der Fursprache der Annenkovs in die Katorga nach Omsk in einer Kibitka I= gedeckter Reiseschlitten| gebracht|, ethd. Siehe auch die neue Ausgabe: BFi.ov 1992.

${ }^{259}$ Ebd., S. 83. Vgl. Z.AKIEWTC7. 1968.

160 ZAKIEWICZ 1968, S. 67. Vgl. SKLOVISKIJ 1957, S. 123

${ }^{162}$ MUCHA 1979, S. 84rT. 
kowie“ „aus dem Volk“ bemerkt, daß die mit derjenigen dieser „polaczkowie“ kontrastierende leidenschaftlos objektive Schilderung Tokarzewskis und der anderen adligen Polen lediglich ihrer sozialen Position zu verdanken sei, denn diese adlige Polen „stanowili dla Dostojewskiego i dla czytelników Wspomnieñ [Erinnerungen; = Zapiski iz Mertvogo doma] obiekt szczególnie interesujący jako ludzie z tej samej klasy społecznej“. [„,bildeten für Dostoevskij und für die Leser der Erinnerungen als Menschen aus derselben sozialen Schicht ein besonders interessantes Objekt"]. ${ }^{162}$

ZUSAMMENFASSUNG: In der imagologischen Interpretation der Zapiski iz Mertvogo doma konnte ihr besonderer Charakter an der Schwelle zwischen dem Früh- und Spätwerk Dostoevskijs, auch im Hinblick auf die Darstellung der literarischen Fremdheit bestätigt werden, denn in ihnen wird der Prozeß der Herausbildung der ideologisch-utopischen, weltanschaulichen Grundlagen aller spăteren Romane und Erzählungen sichtbar, der hier als Prozeß der Konstituierung der kulturellen, russisch geprăgten Identităt des Ich-Erzăhlers gezeigt wird.

Aleksandr Petrovic Gorjančikov, ein verwestlichter russischer Adliger, macht diesen Reifeprozeß durch, indem er sich selbst mit den anderen Gefangenen, sowohl aus dem russischen "Volk" als auch mit den russischen Adligen und mit den Fremden vergleicht. Die wichtigste Funktion in diesem Bildungsproze $B$ erfüllt dabei die paradigmatische Opposition zwischen den adligen und nichtadligen Gefangenen, sowohl russischer als auch fremder Herkunft, die vom lch-Erzăhler ausführlich analysiert, aber als statisch. unverănderbar, gezeigt werden, worin sich die starke Stereotypisierungstendenz dieser Aufzeichnungen bemerkbar macht.

Zapiski iz Mertvogo doma bilden darüber hinaus eine Ansammlung von (sowohl als individuen als auch als Typen bzw. Stereotypen gezeigten, russischen und fremden) männlichen Figuren, die in allen späteren Werken vorkommen, entweder direkt übernommen oder weiter entwickelt und differenziert worden sind. In Zapiski iz Mertvogo doma gibt es somit Ansätze zu allen spăteren Figuren Dostoevskijs: für die positiven und negativen, russischen und fremden, die utopischen (als Alius) und die ideologisch geprägten (als Alter). Die statische Figurenkonstellation entspricht den geschlossen, mythischen Zeit- und Raumdimensionen dieser Geschichte, in der die authentischen Figuren und Erfahrungen aus Sibirien einer gezielten narrativen Selektion, als Fiktion und als weltanschauliches Dokument, unterzogen wurden. Die Geschichte, die in den Zapiski iz Mertvogo doma crıăhlt wird, hat somit eine metaphorische Funktion. es ist die Geschichte des symbolischen "Todes" und der "Auferstehung" Gorjancikovs. Sie laßßt sich als ein ..Heilsgeschehen“, als die Geschichte seiner „Erlösung“. dank dem Kontakt zu den russischen Gefangenen aus dem Volk und dank der Abgrenzung von den adligen ..Kameraden". bezeichnen. Zapiski $i=$ Mertvogo doma können somit ein "Bildungsroman“ genannt werden, in dem sich die Figur des Ich-Erzählers selbst seine ,neue“ Identität erschafft.

162 ŻAKJEWICZ 1968 , cbd., S. 80 
Die polnischen Imageme in den Zapiski iz Mertvogo doma, d.h. vorwiegend die darin auftretenden polnischen Figuren, werden aus der dreifachen Perspektive des Ich-Erzăhlers Aleksandr Petrovič Gorjancikov geschildert: als eine Gruppe, als Individuen und als anonyme nationale Stereotypen. In allen diesen drei Sichtweisen werden sie in der Kontrastfunktion als alter eingesetzt, sie werden sowohl dem Ich-Erzăhler selbst als den russischen Figuren bzw. den russifizierten Figuren der Tataren und gleichzeitig den adligen als auch den nichtadligen Mitgefangenen entgegengesetzt. Sie erfüllen eine „Katalysator'-Funktion, denn durch die Abgrenzung von ihnen, von ihrer adligen Mentalität, gelingt es Gorjancikov, die russischen Gefangenen aus dem Volk als ihm gleichgestellten Menschen (als die ..Bauern Marejs“) zu sehen und zu verstehen.

In der Schilderung der Polen als Gruppe bzw. als einzelne Personen wird jedoch die ideologische Funktion dieser Figuren durch die psychologische Analyse ihrer Charaktere durch Gorjancikov abgeschwächt, obwohl in der Gegenüberstellung der polnischen Katholiken und der russisch-orthodoxen bzw. sogar der muslimischen Gefangenen die Kritik am Katholizismus sichtbar wird, denn die Katholiken werden von Gorjancikov eindeutig negativ beurteilt.

Die individualisierte Schilderung der einzelnen polnischen Mitgefangenen weist jedoch eine Tendenz auf, diese Figuren ausschließlich als Vertreter ihrer Nation zu betrachten. die zur verstärkten Typisierung und zur ideologischen Vcrallgemeinerung führt und somit auch zur Stereotypisierung dieser Figuren. Diese Stereotypisierungstendenz, die später in dem letzten Roman Dostoevskijs Brat 'ja Karamazovy ihren Höhepunkt errreicht hat. äußert sich hauptsächlich in den ihnen exklusiv zugeschriebenen Eigenschaften, wie z.B. in der hypertrophen, ins Pathologische gesteigerten Sehnsucht nach und Liebe zu der fernen Heimat. in der extremen katholisch geprägten Frömmigkeit, im Hochmut und im Gefühl der Überlegenheit den Russen gegenüber. Die in der russischen Kultur, Literatur und Gesellschaft vorhandenen nationalen polnischen Stereotypen, die Dostoevskij bekannt gewesen sein dürften, konnten durch dic authentischen negativen persönlichen Erfahrungen bestätigt werden, die Dostoevskij in der Begegnung mit den adligen Polen gesammelt hatte, obwohl diese authentischen Erfahrungen darüber hinaus zusätzlich in den Zapiski iz Mertvogo doma einer ideologischen typisierenden Auswahl unterzogen wurden. Die polnischen Figuren werden darin als extrem Fremde unter den anderen Fremden dargestellt, wobei alle Gefangenen des Totenhauses als Fremde bezeichnet werden und das Tote Haus als das Symbol einer (jegenwelt bzw. der Hölle verstanden werden kann.

Solche stereotype Sichtweise auf die Polen dominiert auch in der Darstellung der einfachen nichtadligen Polen, ,aus dem Volk" und wird in die späteren literarischen Werke Dostoevskijs übernonmen, auf alle polnischen Figuren übertragen und zunehmend ideologisier, so da $B$ die $A$ nnahme plausibel erscheint, da $B$ dic Auslassung des Kapitels über dic polnischen Genossen in der Ausgabe der Zapiski i= Mertvogo doma von 1875 aus ideologischen Gründen vorgenommen worden ist. weil die differenziert individuelle und dokumentarisch-objektive Darstellung der Polen als Subjekte in diesem Kapitel in das spätere ideologische Konzept Dostocvskijs nicht mehr hineinpaßte. 
In der gleichen Funktion als alter wie die polnischen Figuren treten außerdem in Zapiski iz Mertvogo doma die Figuren des stereotyp dargestellten Juden Isaj Fomič Bumštejn sowie die Figuren der Deutschen (bzw. auch die Figur des Tschetschenen) auf.

Alle diese fremden Figuren werden aber nicht als Vertreter des „Westens“ insgesamt dargestell, sondern ihre Fremdheit, ihre Kontrastfunktion als alter wird durch ihre nationale bzw. ethnische, konfessionelle und soziale Zugehörigkeit betont.

Die Figuren der übrigen Fremden, vorwiegend der Tataren, werden dagegen teilweise nicht als Fremde unter Russen von Gorjancikov geschildert, denn sie bilden einen Teil des russischen Imperiums und haben sich dem russischen Volk assimiliert, sind russifiziert worden. Es handelt sich also um die von RuBland „angeeigneten“ Fremden wie z.B. Alej, dessen Figur auch in der Funktion als alius das „absolut Gute“ offenbart und somit die spăteren positiven utopischen russisch-orthodoxen Figuren vorwegnimmt. In dem russischen Adligen A-v offenbart sich dagegen das „absolut Bose“, er kann als eine der komplementăren Figuren zu Alej interpretiert werden und nimmt die negativen verwestlichten Figuren Dostoevskijs wie Svidrigajlov oder Valkovskij (als ein Alius) vorweg. Auch der Pole M-ckij tritt in der gleichen Funktion wie A-v auf.

Die anderen fremden Imageme dienen dagegen zur Charakterisierung der Figuren der russischen Gefangenen bzw. ihrer Henker, ihrer Aufseher, aber sie weisen noch in ihrer Funktion keine Anzeichen der Okzidentalisierung dieser Figuren auf, so daß sie noch nicht als Elemente eines ausgeprägten positiven bzw. negativen utopischen bzw. ideologischen Imagothèmes des verwestlichten Rußlands wie in den späteren literarischen Werken Dostoevskijs betrachtet werden konnen. Lediglich das polnisch-weißrussische Masurieren von Isaj Fomic betont seine Herkunft aus den "westlichen Gebieten“ des russischen Imperiums und seine Fremdheit unter den anderen Mitgefangenen.

In Zapiski iz Mertvogo doma läßt sich somit noch kein endgültig ausgeprägtes negatives bzw. auch kein positives (utopisches) Imagothème des verwestlichten Rußlands beobachten. Der Akzent wird auf die Trennung zwischen der adligen und nichtadligen Herkunft der Gefangenen bzw. zwischen ihrer konfessionellen und nationalen bzw. ethnischen Zugehorigkeit gelegt, so daß ihre Okzidentalisierung nicht hervorgehoben wird. In den Tapiski iz Mernogo doma ist aber ebenfalls noch kein (positives) russisch-orthodox-byzantinisches utopisches Imagothème ausgearbeitet worden, so daß fremde Figuren wie der Tatare Alej Träger des positiv Guten und Schönen sein kőnnen (bz.w. auch der junge Pole K-cinskij), obwohl zugleich eine Tendenz zu beobachten ist. nur die Vertreter des russischen Volkes positiv zu schildern. ${ }^{163}$ Dagegen läßt sich in Zapiski i= Mertvogo doma die Schilderung Sibiriens als ein Teil des in den späteren Werken entwickelten utopischen russisch-orthodox-byzantinischen Imagothèmes Rußlands bemerken. $163 \mathrm{Vgl}$ zur Ideologie des poćvenničestvo [Boxdensıändıgkeı] bei Dostocvskij z.B. bei L.AZAR]
1988 . 


\author{
5. УНИЖЕННЫЕ И ОСКОРБЛЕННЫЕ. \\ POMAH В ЧЕТЫРЕХ 'АССТЯХ ( ЭПНЛОГОМ (I86I) \\ [DIE ERNIEI)RI(TTEN (IND BELIKII)IGTEN] ${ }^{164}$
}

Uniz̈ennye $i$ oskorblennye ${ }^{165}$ ist der erste Roman, den Dostoevskij nach seiner Rückkehr aus der Verbannung in Sibirien geschrieben und veroffentlicht hat. Er ist also unmittelbar nach jener Zeit des Umbruchs entstanden, in der sich seine "neue“ religiös geprägte, russisch-byzantinisch-orthodoxe Weltanschauung herauszubilden begann. Unižennye i oskorblennye gehören darüber hinaus nicht nur zu der von Dostoevskij bevorzugten literarischen Gattung, sondern sind ebenfalls, wie die oben besprochenen früheren Werke, die Erzählung Djadjuškin son und die Zapiski i= Mertvogo doma, in der relativ hăufig in seinen literarischen Werken vorkommenden Ich-Form verfaßt.

In diesem ersten umfangreichen Roman Dostoevskijs treten jedoch im Vergleich zu den autobiographisch geprägten Zapiski iz Mertvogo doma, in denen adlige polnische Alter-Figuren eine wichtige Katalysator-Funktion bei der Konstituierung der kulturellen russischen Identităt des Ich-Erzählers erfüllen, keine polnischen Figuren auf, und es gibt darin nur wenige andere polnische Imageme: an einigen Stellen werden lediglich das Land Polen und die Namen der polnischen Städte Warszcowa und Ḱraków erwähnt, ohne daß sie mit Schilderungen dieser Städte oder polnischer Landschaft verbunden wären. Alle polnischen Imageme, die Erwăhnungen Polens und seiner ,alten“ sowie seiner „,neuen“ Hauptstadt, stehen ausschließlich im Zusammenhang mit dem Fürsten Petr Aleksandrovic Valkovskij, einer der wichtigsten Figuren des Romans. Nacheinander, jeweils von einer anderen figur des Romans, auch vom Ich-Erzähler selbst, wird über einige Reisen des Fürsten Valkovskij nach Polen berichtet: .nach Warszawa“, "nach Polen“ und zuletzt „,nach Kraków“. ${ }^{166}$

Die Figur des lch-Erzählers in Unizennye i oskorblennye weist einige Bezüge zum Leben Dostoevskijs auf, diesmal aber, anders als bei dem Ich-Erıahler Gorjancikov in Zapiski i= Mertvogo doma, sind es Bezüge auf die Zeit vot der Verbannung nach Sibirien, denn Ivan Petrovic ist ein junger Petersburger Schriftsteller, der gerade seinen ersten Roman veröffentlicht hat und dafür von der literarischen Kritik gepriesen wird. ${ }^{167} \mathrm{Er}$ schildert in seinen Aufzeichnungen, abgesehen von einem Rückblick auf seine Kindheit. ${ }^{168}$ Ereignisse, die er im letzten Jahr erlebt hat. ${ }^{169}$ Dieses verhängnisvolle Jahr wird aus der Perspektive

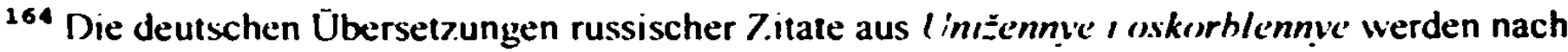
der Ausgabe DOSTOJEWSKI 1980a angeführt.

$165 \mathrm{Vgl}$. Bd. 3, S. 169ff. und die Anmerkungen der Herausgeber ebd., S. 517ff.

$166 \mathrm{Vgl}$. Bd. 3, S. 217, S. 226 und S. 336.

167 Die erste Fassung des Romans, die 1861 in der Zeitschrift Vremyes veröffentlicht wurde,

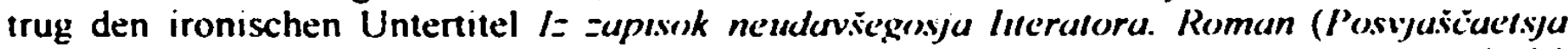
M.M. Dosileceskomu) IAus den Aufeechnungen cines mißratenen l.lleraten (M.M. Dosickevsky gewidmel)|. Vgl. Bd 3, S. 517ff

168 Siehe z.B. ebd., S. 177ff., S. 186 f. und S. 197 zur Vorgeschichte des Ich-Erzăhlers

169 Ebd., S. $177 f$. 
seines nahen Todes erzahlt, denn er leidet an Tuberkulose und befindet sich in einem Krankenhaus, das er seinen Worten nach nie wieder verlassen wird.

Die bereits im Titel des Romans angedeutete christliche Thematik låßt sich somit als die aus der Perspektive von Ivan Petrovic nacherzahlte Geschichte der „Beleidigung“ bzw. des „Betrugs“ der „guten“ Menschen und ihre daraus entstehende „Emiedrigung" festhalten, auf die entweder "Rache" oder "christliche Verzeihung" in Liebe und Demut folgen können. Die Beleidigung und aus ihr folgende Emiedrigung hat den positiven Figuren des Romans allein der Fürst Valkovskij zugefügt, eine der negativsten, "dämonischsten“ Figuren in allen Werken Dostoevskijs.

Die Handlung von Unižennye $i$ oskorblennye spielt, abgesehen von einigen Rückblenden, hauptsächlich in Petersburg. Zu den darin vorkommenden Figuren gehören sowohl Russen als auch Fremde. Die Gruppen russischer und fremder Figuren lassen sich aber noch weiter differenzieren, wobei in beiden Gruppen Abstufungen ihrer als russisch bzw. als fremd angegebenen Eigenschaften, d.h. ihrer kulturell-nationalen Identităt zu bemerken sind. Fremde Figuren werden als .russifiziert", russische Figuren dagegen mit Hilfe der sie charakterisierenden fremden Imageme als „verwestlicht" ${ }^{\text {170 }}$ geschildert. Ähnlich den Figuren aus den früheren literarischen Werken und im Unterschied zu den späteren Romanen Dostoevskijs sind in Unizennye $i$ oskorblenmye sowohl die russischen als auch die fremden Figuren als statisch zu bezeichnen, denn sie ändern sich im Laufe der Handlung nicht. sind bereits als feste unveränderliche Charaktere gestaltet worden.

Die Gruppe der russischen Figuren läßt sich hauptsächlich in zwei zentrale, aber konträre, zueinander in einer Konfliktsituation stehende Gruppen aufteilen. Die erste russische Gruppe bildet die verwestlichte, adlig-großbürgerliche Gruppe um den Fürsten Petr Aleksandrovič Valkovskij. $\mathrm{Zu}$ ihr gehören neben dem Fürsten selbst sein Sohn. Aleša Petrovic, die Geliebte des Fürsten, Gräfin Zinaida Fedorovna, deren Vornamen wohl eine Anspielung auf die zum Katholizismus konvertierte Fürstin Zinaida Aleksandrovna Volkonskaja sein kőnnte $^{171}$, sowie ihre reiche Stieftochter, Katerina Fedorovna Filimonova, die

170 Siehe zu der Aufteilung der Figuren in den literarischen Werken Dostoevskijs in die „russischen" und in die ..verwestlichten“, oben, S. 139

${ }^{i 71} \mathrm{Vgl}$. dazu ebd., S. $344 t^{\circ}$. und passim. Auffallend ist dabei die lautliche Äquivalenz zwischen den Namen Valkovsky - Volkonskaja. Siehe auch zu der zum Katholizismus konvertierten Fürstin Zinaida Volkonskaja, die u.a. eine Gonnerin und Freundin des polnischen natıonalen Dichters Adam Mickiewicz war, das einschlágige Kapitel bei MUCHA 1989 (Ḱrijlow'a muc I piękna ksıęina Zinuida Wolkoniska |Die Könıgin der Musen und der ¿.chönhell die liürsıın Zınada Volkonskaja I, S. 40fr) bzw. BAZYLOW 1984 (S. 118-122), dort auch über ihre Kontakte zu Adam Mickiewicz. Vgl. auch BROKGAuz/Efron (Bd.

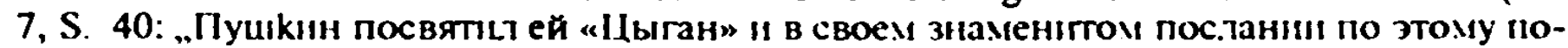
воду /.../ назвал ес «царншей муз н красоты»; /.../ В 1829 г. кн. В. I13 Мосkвы переехала прямо в Pıм, где ум. в 1862 г. строгой полвњжницей kaто.лıцизма“- [Puskin widmete ihr sein Gedicht Die Zıgeuner und in seiner berühmten poetischen Botschaft aus diesem AnlaB /.../ nannte er sie .Zarin der Musen und der Schönheit": /.../ 1829 übersiedelte die Fürstin V nach Rom, wo sie 1862 als strenge Katholikin gestorben ist.] Siehe auch BOL'SAA SOVETSKANA ENNCIKI.OPEDUA 1971, S. 309: „Bo.7kонckaя, Зинанда A тekcaimpовна (3 (14.) 12. 1792, Турин - 24.1 (5. 2). 1862, Рıм. /.../ Салон B.|о.лконской] в Мосkве в 1826-27 
aus der Perspektive des Ich-Erzăhlers jedoch als eine positive Figur geschildert wird, denn sie habe ein „reines Herz" und hohe Ideale. Sie liebt westeuropăische Musik: dem Ich-Erzăhler mőchte sie beispielsweise das dritte Klavierkonzert von Beethoven vorspielen. Sie weist also einige positive utopische Eigenschaften auf, die sie mit dem Ich-Erzăhler teilt. ${ }^{172}$

Die zweite russische Gruppe bildet die Familie von Nikolaj Sergeix Ichmenev, eines verarmten Adligen altrussischer Herkunft. Die Zugehorigkeit Ichmenevs zur vorpetrinischen bzw. zur Moskauer Rus' wird dadurch hervogehoben, daß sowohl die Familie Ichmenevs als auch die seiner Frau angeblich noch bei Karamzin erwăhnt werden, denn diese Geschlechter soll es bereits zur Zeit der Zaren Ivan Groznyj und Aleksej Michajlovix gegeben haben. Der alte Ichmenev wird als ein idealistischer, naiver, gutmütiger und romantisch-gefühlvoller, zur grenzenlosen Hingabe tähiger Mensch geschildert, wobei dessen psychologische Schilderung stark typologisiert erscheint und sein Charakter als ,typisch“ für die Russen aus der ,alten Rus“, d.h. aus der vorpetrinischen Zeit, bezeichnet wird. Somit weist Ichmenev einige positiv-utopische Züge aus, die ihn als eine positiv utopische russische Alius-Figur und zugleich als eine KontrastFigur gegenüber den negativ verwestlichten Russen auszeichnen. Die Schilderung Ichmenevs erinnert darüber hinaus an die Charakteristiken der Figuren (als .,soziale Typen ${ }^{\prime)}$ ) in den Romanen Balzacs: ${ }^{.73}$

Николай Сергеич был один из тех добрейших и наивно-романтичесkих люоей, komopыe mak хороши у нас на Руси, что бы ни говорили о них, и которые, если уж полюбят кого (иногда бог знает за

/../ посещапи А.С. Пуиики, А. Мицкевич, Е.А. Баратынский, Д.В. Веневитинов /.../. В 1819 уехата в Итатию. В рімской віLzте В[о.лконсkой] подо.лг жіLт Н.В. Гого.ть". |Volkonskaja, Zinaida Aleksandrovna /.../. Den Salon von V. in Moskau besuchten in den Jahren 1826-27 A.S Puskin, Adam Mickiewicz, E.A. Baratynskij, D.V. Venevitinov /.../. 1829 fuhr sie nach Italien. In dei röınischen Villa von V. lebte längere Zeit N. V. Gogo!'. J VI. auch das oben enwähnte Gedicht Puskins: Knjugınıe ZA. Volkonskoj. Pri posylke ej poèmy '('ygany' |Sredi rassejanno] Moskvy... | Der laürstin ZA. Volkonsko) gewidmet. Aus Anlaß der Absendung des Poems 'Dic Zigeuner': [Inmillen des zerstreuten Mioskutus]). In: PUSkiN 1949 b, Bd. 3, S. 12.

$172 \mathrm{Vgl}$ dazu Bd. 3, S. 225, S. 308-311, S. 344, S. $348 f$. und S. 352fr.

${ }^{173} \mathrm{Vgl}$. Z.B die Beschreibungen der Figuren aus dem Roman Illusions perdues (ersch. in drei Teilen, 1837, 1839 und 1844): „Les gens gènéreux font de mauvais commerçants. David était une de ces natures pudiques et tendres qui s'effraient d'une discussion, et qui cedent au moment ou l'adversaire leur pique un peu trop le coeur“ bzw. „Cette femme, une des plus charmantes et de plus délicieuses actrices de Paris. /.../ ètait le type de filles qui exercent à volonte la fascination sur les hommes. Coralie offrait le type sublime de la figure juive /..." (BALZAC 1966, S. 391 und 485f.). Nach LeERSEN 1991 b (S. 165-175) ist es das ..typische“ realistische Verfahren, in dem häufig die handelnden Figuren, ihr Äußeres und ihr Benehmen. enstprechend den narrativen Konventionen. die sie in der erzăhlten ..Geschichte" $(=$..plot", .Fabel“) zu erfüllen haben, als ".Typen“ charakterisiert werden. Darüber hinaus werden aber diese Figuren, gemäß den werkexternen, ,.ideologisch-sozialen“ Konventionen, auch als (nationale bzw. ethnische) Stereotypen dargestelit (S. 17 Iff.). In dem zweiten Balzac-Zitat handelt es sich tatsächlich um ein (positives) Stereotyp einer ..schönen Jüdin“ 
что), то отдаются ему всей душой, простирая иногда свою привязанность до комичесkoro.

[Nikolai Ssergejewitsch gehörte zu diesen herzensguten und naiv-romantischen Leuten. die bei uns in Rußland so liebenswert sind, was man auch sonst von ihnen sagen mag, und die, wenn sie einmal jemand gern haben (und mitunter Gott weiß wofür), sich ihm gleich mit ganzer Seele hingeben, so daß ihre Anhänglichkeit zuweilen geradezu komisch wird.] [kursiv die Verf.] $]^{174}$

Die zweite Gruppe um Ichmenev, die sich als (alt)russisch bzw. „vorpetrinisch" bezeichnen läßt, ist der ersten aristokratisch-großbürgerlichen und verwestlichten, „nachpetrinischen“"Gruppe der russischen Figuren um den Fürsten Petr Aleksandrovic Valkovskij sozial unterlegen. Sie setzt sich aus seiner Frau, Anna Andreevna, und seiner Tochter Natal'ja bzw. Nataša Nikolaevna ${ }^{175}$ zusammen.

Nikolaj Sergeic Ichmenev, seine Frau und Tochter sind die positiven russischen Figuren des Romans und Opfer des Fürsten Valkovskij, dessen Vorname. den er mit Peter dem Großen teilt, symbolisch für seine Okzidentalisierung steht. Sie werden als reine und liebende, der christlichen Verzeihung fahige Gestalten dargestellt, obwohl die russisch-orthodoxe Komponente ihres Glaubens noch nicht so stark hervorgehoben wird wie in den späteren Romanen. Wie alle anderen positiven Figuren des Romans, zu denen der Ich-Erzăhler sowie einige der fremden Figuren gehören. werden sie vom Fürsten Valkovskij entweder physisch, materiell oder psychisch zugrunde gerichtet, denn sie sterben wie der alte Smit, seine Tochter und Enkelin bzw. werden dazu gezwungen, ein neues unsicheres Leben anzufangen. wie die alten Ichmenevs und ihre Tochter Natasa.

Den positiven russischen Figuren des Romans wird die vorwiegend negativ dargestellte russische Gruppe um den Fürsten Valkovskij aus der gehobenen Petersburger Gesellschaft gegenübergestellt. Wie oben bemerkt, werden die Ereignisse des Romans aus der Perspektive des Erzăhlers Ivan Petrovic bzw. als die aus seiner Sicht wiedergegebene direkte Rede anderer handelnden Personen beschrieben: Es fehlen deshalb Kommentare eines auktorialen Erzählers. Aus den Äußerungen des Ich-Erzählers und anderer Figuren geht jedoch hervor, daß die Russen um Valkovskij keine besonders starke russische nationale Identität aufweisen. sondem ...verfremdet" bzw. verwestlicht sind. Die Gruppe um den Fürsten Valkovskij geht unbeschadet als ..Sieger“" über die anderen Russen bzw. teilweise russifizierten Fremden aus der Geschichte hervor, trotz ihrer moralischen Fragwürdigkeit, obwohl sie den idealistischen und moralisch aufrichtigen Menschen unterlegen ist, jedoch nur auf der ..utopischen“", .moralischen“ Ebene:

\footnotetext{
174 Vgl. ebd., S. 181, S. 179ff., S. 217 f. [S. 514].

175 Die Tochter Ichmenevs, Natal ja [Natasa], wird von dem sie liebenden Ich-Erzăhler als eine edle Frau, ,reinen Herzens" geschildert. Sie ist die Rivalin Katerinas um Aleśa Valkovskij und als eine Kontrastfigur zu Katerina anzusehen, siehe z.B. ebd.. S. 198fí.. S. 202. S. 270f., S. $317 f f$.
} 
И ты, и ты, девочка ты злая? И ты могла думать, что я проклял тебя, что я не приму тебя, если б ты пришла? /.../ A ckoльko раз зимой я поздно ночью на твою лестницу подымусь и в темных сенях стою, сквозь дверь прислушиваюсь: не услышу ли твоего толосkа? Не засмеешься ли ты? Проклял? Да ведь я в этот вечер к тебе приходил, простить тебя хотел и только от дверей воротился... О Наташа!

/.../ - Она здесь опять, у моего сердиа! /.../ о, благодарю тебя, Боже, за всё, за всё, и за гнев твой и за миюсть твою!...

/.../ О пусть мы униженые, пусть мы оскорбленные, но мы опять вместе, и пусть, пусть теперь торжествуют эти гордые и надменные, унизившие и оскорбившие нас! Пусть они бросят в нас камень! Не

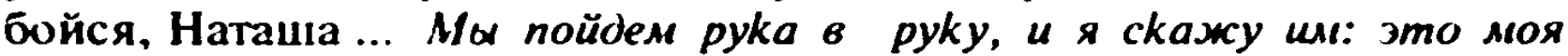
дорогая, это возиюбленная дочь моя, это безерешная дочь моя, которую вь оскорбили и унизиши, но которую я, я люблю и которую благос іов:ıю во веки веков!...

[Und du, und du, du böses Mädchen! - du hast glauben können, ich hätte dich verflucht, ich hätte dich nicht aufgenommen, wenn du gekommen wärest! /.../ Mehr als einmal bin ich im Winter spät abends deine Treppe hinaufgestiegen und habe auf dem dunklen Treppenabsatz gestanden und angestrengt gelauscht. um durch die Tür vielleicht doch deine liebe Stimme zu hören, oder vielleicht dein Lachen? Ich dich verfluchen? War ich doch an jenem Abend zu dir gegangen, um dir alles zu verzeihen - ja. das wollte ich! - und erst vor der Tür gab ich es auf... Oh, Natascha! /.../ Sie ist hier; wieder an meinem Herzen! /.../ Ich danke dir. Gott. für alles, für alles, auch für deinen Zorn. auch für deine Güte!... /.../ Mögen wir Erniedrigte. mögen wir Beleidigte sein. was tut das? - aber wir sind doch wieder beisammen! Und mögen sie doch, mögen sie doch triumphieren, die Stolzen und Hochmütigen. die uns erniedrigt und beleidigt haben! Mögen sie nur Steine auf uns werfen! Fürchte dich nicht, Natascha... Wir werden Hand in Hand gehen, und ich werde ihnen sagen: 'Dies ist meine teure, meine geliebte Tochter, mein sündloses. geliebtes Kind, das ihr belcidigt und erniedrigt habt. das ich aber über alles liebe, ich, und das ich für alle Ewigkeit segne'... '][kursiv dic Verf. $]^{276}$

In dieser Versöhnungsszene, die das ideelle Zentrum des Romans bildet, wird der alte Ichmenev mit Hilfe von Motiven aus dem Alten und Neuen Testament charakterisiert: Der Satz .J... о, благо:аарю тебя, Боже, за всё, за всё, и за гнев твой и за миіость твою! ..." I IIch danke dir. Gott. für alles, für alles, auch für deinen \%orn. auch für deine Güte!... /.../; Übers. von Rahsin| enthält wohl eine Anspielung aut das Buch Hiob. Folgende Passage - .Пусть они бросят в нас камень! /.../ Мы пойдем pyka в pyky, и я ckажу им: это моя дорогая. это возлюб.ленная почь моя, это безгрешная цочь моя, которую вы оскорби.ин и унизи:ни, но которую я, я люблю и которую благословляю во веки веkов!.." [..Mögen sie nur Steine auf uns werfen! /.../ Wir werden Hand in

${ }^{176}$ E.bu.. S 421f. [S 934I] 
Hand gehen, und ich werde ihnen sagen: 'Dies ist meine teure, meine geliebte Tochter, mein sündloses, geliebtes Kind, das ihr beleidigt und erniedrigt habt, das ich aber über alles liebe, ich, und das ich für alle Ewigkeit segne!...; Übers. v. Rahsin] - bezieht sich auf Joh. 8 (Jesus und die Sünderin) sowie auf das Gleichnis vom verlorenen Sohn (Luk 15, 11-32). Die verzeihende Liebe Ichmenevs bildet eine paradigmatische Opposition zu der unversöhnlichen Haltung des Engländers Smit seiner „verlorenen“ Tochter gegenüber und von dessen Tochter und Enkelin Nelli gegenüber dem Fürsten Valkovskij, ihrem "Verführer" und "Vater". ${ }^{177}$ Dem Fürsten Valkovskij wird aber nicht nur die Verzeihung seiner Tochter Nelli und seiner Frau, der Tochter Smits, verweigert, sondern auch die des alten Ichmenev selbst, denn lchmenev kann trotz seiner christlich geprägten Liebesfăhigkeit seinem Beleidigern ebenfalls nicht verzeihen. Obwohl Valkovskij und die Seinen als überlegene Egoisten weiter ihr Leben genießen kőnnen, „siegen“ sie doch nur auf der "innerweltlichen“ Ebene. auf der Ebene des „realen“ Lebens. Dadurch wird der Kontrast zwischen den positiven russischen Alius-Figuren und den negativen fremden bzw. den aus den "Westen" kommenden Figuren besonders deutlich.

Abgesehen von den beiden besprochenen zentralen russischen Gruppen treten in Unižennye i oskorblennye noch weitere russische Nebenfiguren auf: der „Privatdetektiv" des Fürsten Valkovskij, Masloboev, seine Freundin und Kumpane sowie eine gewisse Frau Bubnova, die Besitzerin eines offentlichen Hauses, die die Enkelin von Smit, Nelli, auf grausame Weise mißhandelt hatte. ${ }^{178}$ Alle diese Figuren sind auch als verwestlichte Petersburger Bürger zu bezeichnen. Masloboev wird vom Ich-Erzähler als ein guter, aber „verlorener" typischer Russe, als eine ambivalente Figur, die sowohl des Guten als auch des Bösen fahig ist, gezeichnet:

177 Ebd., S. 386f., S. 435ff, S. 441. Vgl. die letzten Worte Nellis an den Ich-Erzăhler: „поди k нежу и скажи, что я умер.та, а его не простьта. Сkажи ему тоже, что я Еванге.1ие недавно читата. Там сказано: прощайте всем врагам свонм. Ну, так я это чіттата, а

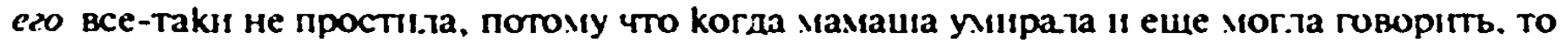
постеднее, что она сказала, было: "Проклинаю сгон, ну таk и я его проктінаю, не 39 себя, а за мамашу проkтіннаю...“ [kursiv Dostoevskij] (S. 441).

[S. 972: /../ geh zu $\mathrm{thm}$ und sage ihm, daß ich gestorben bin, ihm aber nicht verziehen habe. Sage ihm auch, daß ich die Bibel vor nicht langer Zeit gelesen habe. Dort ist gesagt: 'Vergebt allen euren Feinden!' Nun, ich habe das gelesen, ihm aber vergebe ich trotzdem nicht: denn als Mama im Sterben lag und noch sprechen konnte, war das letzte, was sie zu mir sagte: 'Ich verfluche ihn. Nun, und so verfluche auch ich ihn, verfluche ihn nicht um meinetwillen, sondern um Mamas willen... ] [kursiv Dostoevskij]

${ }^{170} \mathrm{Zu}$ Bubnova siehe ebd. S. 258f, 274; zu Masloboev und seinen „Freunden“" z. B S. 263f., S. 272ff., S. 330ff. Ihre Namen sind komisch und ..bedeutend" zugleich. Der Name .Bubnova“ kommt von hubnovyj |бубновый; Karo-bzw. Shellen-l. d.h. von einer Bezeichnung für die niedrigste Kartenfarbe, und enweckt moglicherweise eine Assoziation mit „Falschspielem". "Masloboev" laßßt sich dagegen auf das Wort mas/obojka |.nacroboüka; Buflermaschinc| zurückführen. Das Verfahren, den Figuren komisch-symbolische Namen zu geben, die auf ihre Charaktereigenschaften hinweisen, tritt in jedem literarischen Werk Dostocvskijs auf. 
Маслобоев был всегда славный матый, но всегда себе на уме и развит kak-то не по силам; хитрый, пронырливый, пролаз и kрючоk еще с самой школы, но в суиности человек не без сердща; погибший человек. Takux ıюdей межсу руссkими люdими мюного. Бывают они часто с болыними способностями; но всё это в них kak-то перепутывается, ца сверх того они в состоянии сознательно идти против своей совести из слабости на известных пунктах, и не только всегда погибают, но и сами заранее знают, что идут k погибели. Маслобоев, межлу прочим, потонул в вине. [kursiv die Verf.]

[Masslobojeff war immer ein prächtiger Bursche gewesen, aber er hatte von jeher seinen Kopf für sich gehabt und war gleichsam übermäßig begabt: schlau. gerissen. hintergründig. wissend, Jongleur mit Begriffen schon in der Schule, aber im Grunde ein Mensch nicht ohne Herz; ein verlorener Mensch. Solcher Menschen gibl es viele unter Russen. Oft sind sie sehr begabt. aber alle diese (jaben sind in ihnen irgendwie durcheinander geraten, in Unordnung. und außerdem sind sie aus Schwäche in gewissen Punkten imstande. bewußt gegen ihr Gewissen zu handeln. Darum pflegen sie denn nicht nur immer zu scheitern, sondern sie wissen es auch selbst schon im voraus, daß sie scheitern werden. Masslobojeff zum Beispiel ertrank im Alkohol. [im Wein: kursiv und Erg. d. Verf.]] ${ }^{179}$

Der "verlorene russische Mensch" und „Petersburger" Masloboev, der wohl wegen seiner Verwestlichung ...gegen sein Gewissen handeln" und "bewußt" scheitern kann, gehört einem anderen russischen $\Gamma_{y y}$ an als Ichmenev, der IchErzähler und der Fürst Valkovskij an. Diese Kontrast-Figur ist in ihrer Ambivalenz ..positiver“ als der ..dämonische“ Fürst Valkovskij und ..negativer” als Ichmenev und der positiv verwestlichte, ,idealistische“ Ich-Erzähler.

Dem in Nataša unglücklich verliebten Ivan Petrovič fällt dagegen eine besondere Rolle innerhalb der Welt dieses Romans zu. Fr tritt in der Funktion eines ..engelgleichen", ..cherubinischen“ Boten und zugleich eines ..Richters" über die anderen auf, vermittelt z:vischen allen (jestalten des Romans und zeigt sie aus seiner Sicht. Vom Fürsten Valkovskij wird er ironisch als ein ..Idealist”, als ein

279 I:bd., S 265 [S. 660]. Siche auch Masloboevs ..Beıchte“, die er gegenüber dem IchErzähler macht. in der er mit Hilfe fremder Imageme als ein verwestlichter Russe

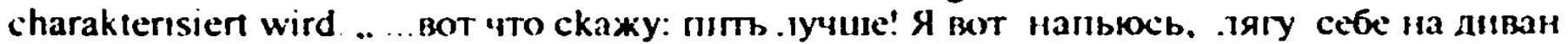

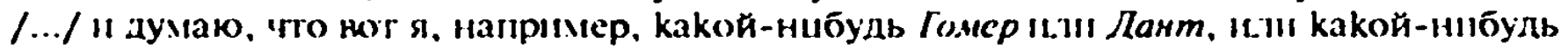

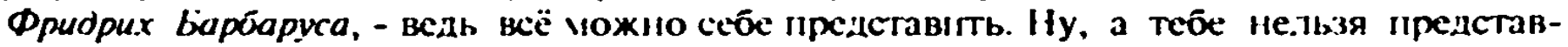

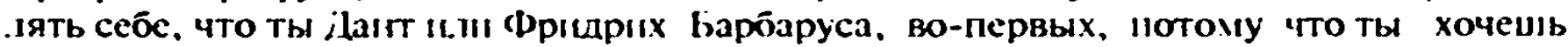

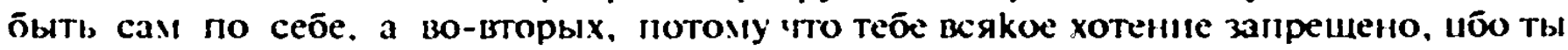
почтовая ктяча. У ченя вокоражение, а у тебя лействите.льность“ (cbd., S. 266). |kursıv die Verf.] [S. 66 I: Nun. darauf will ich dir erwidern, Bruder, es ist besser zu irinken! Sieh, ich betrinke mich. lege mich in meinem Zimmer auf den Diwan !... und denke mir, daß ich irgendein flomer oder / hame' sei, oder auch / rredrich Barhurosisa - denn vorstellen kann man sich ja alles. Du aber darfst dir nicht vorstellen, daß du Homer oder Dante bist; denn du willst du selbst sein, und alles 'Wollen' ist dir verboten; du bist eben ein bezahlter Postgaul. Ich lehe in der Finbildung. du in der Wirklichkeit |kursiv die Verf | | 
"Schiller" bezeichnet. ${ }^{180}$ Der Ich-Erzăhler wird auf diese Weise zu einer Parallelfigur zu dem Deutschen Genrich, der ebenfalls als ein „Schiller“, ein Trăumet und „Idealist" bezeichnet wird. Beide sind zu einer aufopferungsbereiten und demütigen Liebe fahig und gehen an ihr zugrunde. In Uniz̈ennye $i$ oskorblennye taucht somit zum ersten $\mathrm{Mal}$ in den literarischen Werken Dostoevskijs eine Figur des positiv verwestlichten russischen Idealisten, eines ,russischen Schillers", auf.

$\mathrm{Zu}$ den fremden Figuren des Romans gehøren leremija Smit, seine Tochter und die Enkelin Nelli bzw. Elena ${ }^{181}$ Der alte leremija Smit ist Englănder, ein in Rußland tătiger Unternehmer und russischer Untertan. Dieser in den Rückblenden als erfolgreicher Kapitalist dargestellte Mann, von seiner Tochter im Stich gelassen, geht in Armut und Elend zugnunde. Die Tochter von Smit erscheint nur in den Erinnerungen ihrer Tochter bzw. in dem Bericht des Detektivs Masloboev. Sie wird darin als eine „idealistische“ Frau gezeigt, obwohl sie aus Liebe zum Fürsten Valkovskij făhig war, ihren Vater zu „betrügen“. ${ }^{182}$ Die Enkelin Smits und die Tochter des Fürsten Valkovskij, Nelli bzw. Ellen, wird als krankhaftes Mädchen mit „unrussischen schwarzen Augen" beschrieben. Sie stirbt, ohne ihrem Vater verzeihen zu wollen. Den Erzähler schaut sie mißtrauisch mit "inquisitorischen Blicken" an. ${ }^{183}$ Der Kreis der Fremden um leremija Smit ist aber zugleich so stark russifiziert und vorwiegend positiv geschildert, so daß er ebenfalls im Kontrast (als alter) zu der Gruppe um Petr Aleksandrovic Valkovskij steht. Sowohl die Familie der Ichmenevs als auch der Smits sind eindeutig Valkovskijs Opfer. Eine Zwillingsfigur zum russischen Ich-Erzăhler ist der bereits erwăhnte ideal-gute Deutsche Heinrich (Genrich), der früh ver-

180 Ebd. z.B. S. 360 . Siehe auch den Kommentar zu den Bezügen zu Schiller und zu seinen Dramen Die Räuber und Kabale und liehe, ebd., S. 526. Vgl. auch zur Problematik Dostoevskij und Schiller bei SIMONS 1992-1993, S. 53-65.

${ }^{181}$ Im Kommentar zu (Inï̈ennye i oskorblennye, wird die ..protestantische Strenge“ von Smit hervorgehoben. Dem "grausamen protestantischen Gott“ wird im Roman Dostoevskijs „das Christentum als eine Religion der Liebe, Brüderlichkeit und Allverzeihung“ gegenübergestellt. Erwähnt werden auch intertextuelle Bezüge der Figuren von Nelli-Elena und von Smit u.a. zu den Romanen von Dickens The (Old ( uriosity. Shop (1840/41), und zu Goethes Wilhem Meısler, zu Mignon, vgl. den Kommentar zum Roman, ebd. S. 525. Zur Figur Smits vgl. auch ebd. S. 170-177, S. 335ff., S. 435ff: Smit hat den alttestamentarischen Prophetenvornamen Jeremia und ist unversohnlich auf Rache gesinnt. Vgl. auch LARY 1973, S. I50ff. (conc/usion: Dickens's ideal' types).

$122 \mathrm{Vgl}$. auch die Charakterisienung der Mutter durch Nelli, ebd. S. 299f., und Masloboev, S. 334-338, S. 435ff.

${ }^{103} \mathrm{Zu}$ Nelli-Elena siehe außerdem ebd. S. 208f., S. 253f., S. 260f., S. 294, S. 334fr., S. $370 \mathrm{ff}$, S. 385f., S. 410-420, S. 441 f. Im Kommentar zum Roman wird auf ihren Doppeinamen, NelliElena, hingewiesen, auf ihre Grenzsituation zwischen zwei Welten, zwischen Rußland und dem Westen. Diese Tochter Valkovskijs geht an einer unheilbaren Herzkrankheit zugrunde. Sie vereinigt das bose Prinzip des Vaters mit dem guten Prinzip der Mutter und leidet wie Dostoevskij und einige seiner literarischen Figuren, u.a. der Fürst Myškin, an Epilepsie, vgl. z.B. S. 526, S. 373 oder S. 441. 
storbene Freund und Geliebte der Tochter von Smit. ${ }^{184}$ Von allen diesen fremden Figuren ist auch nur dieser Deutsche als eine positiv-utopische Alius-Figur zu nennen, denn nur er weist eindeutig positive Eigenschaften auf.

In Unižennve $i$ oskorblennye treten außerdem noch mehrere deutsche Figuren auf, wie z.B. ein deutscher Arzt, ${ }^{185}$ eine sentimentale Cousine Heinrichs ${ }^{186}$, die deutschen Stammgäste der Müllerschen Konditorei in Petersburg ${ }^{187}$ und ein betrügerischer deutscher Gutsverwalter des Fürsten Valkovskij. Erwăhnt werden außerdem auch: ein „черномазенький жидок“ [ein dunkles, bräunliches Jüdchen], Besucher des Verlegers, von dem der Ich-Erzähler abhängig ist, und franzossische bzw. deutsche Prostituierte, z.B. Aleksandrina und Minna, die der Sohn Valkovskijs, Aleš, besucht. ${ }^{288}$ Es handelt sich bei allen um stereotype AlterFiguren, die von der voruicgend negativen Okzidentalisierung Petersburgs bzw. Rußlands zeugen.

Die fremden Imageme dienen also in Unižennye $i$ oskorblenmye sowohl zur Charakterisierung der russischen, aber verwestlichten und negativen Figuren.

184 Der Kaufmann Genrich wird im Bericht Masloboevs ebenfalls als Idealist, als „Schiller” bezeichnet und mit einem ..echten“ deutschen Namen .Feferkuchen“, "Frauenmil "ch" bzw ..Fejerbach" genannt. Es ist wohl eine ironische Anspielung auf den Philosnphen Feuerbach, ohne jedoch einen Bezug auf die Philosophie Feuerbachs aufzuweisen, siehe auch ebd. $\mathbf{S}$. 336ff. und S. 782: „У старıка была дочь, и дочь-то бы.7а kрасавıца, а у этой красавицы о̆ыл влюо̆.тенный в нее идеальней человек, братеи Шиллеру, поэт, в то же время купеи, нолодой мечтатель, одним с.товом - вполне немеи, Феферkухен kakoй-то“. I..Dieser Alte hatte nun, wie gesagt, eine Tochter, und diese seine einzige Tochter war eine Schönheit, und In diese Schönheit hatte sich ein junger Idealts/ verliebt - solch ein Seirensiück von . Schiller, [ein Bruder Schillers: Erg. d. Verf.] weißt du - ein Dichterling. der aber zugleich auch Kaufmann war, ein junger Trüume' und Schwärmer - mit einem Wort: ein echter Deutscher. Pfefferkuchen mit Namen“" / /kursiv die Verf.]. Die Zeit, die Nelli und ihre Mutter mit ihm in Italien bzw. in der Schweiz verbracht hatten. wird in ihren Erinnerungen als eine sentimental gefàrbte paradiesische Idylle geschildert. ebd., S. 337, S. 409.

${ }^{85} \mathrm{Vgl}$ zu seiner Freundschaft mit Nelli, ebd. S. 277f., S. 377ff. oder S. 381

$186 \mathrm{Vgl}$. auch Masloboevs Schilderung dieser deutschen Cousine Heinrichs. ebd., S. 436 und S. 96́3: „Он, конечно умер; но от одной 113 кузин его (теперь за одним бу.ооннико здесь в Петербурге), страстно ґіюб̆.ленной в него прежле и продо.іжавшей .юобить его .лет пятнадцать срялу, несмотря на то.тстото фатера-бу.ло'нияа, с которым невзначай прижит.ла восьмерых детей /.../, я и успе.7 /.../ узнать важную вещь: Генрих писат ей по нсмсикомуу обыкновению письма и дневники. /.../ Она, дура, важного-то в этіх письмax не поншма та, а понимацта в них только те места, где говоріття о лунс, о мейн либср Августин и о Buлаnde elle, кажется". [kursiv die Verf.]

[S. 963: Er ist natürlich schon langst tot. aber durch eme seiner Kusinen (jetzt ist sie hıer mit einem Bäker verheiratet), also durch diese Kusine, die einst glühend in ihn verliebt gewesen ist und ihn lünfund/wanzig Jahre lang |sic!| unveranden wcitergelieht hat, ungeachtet der Existenz ihres Mannes, des dicken Papa Bäckermeisters, mit dem sie ganz aus Versehen acht $K$ inder in die Welt gesetzt hat also durch diese Kusine habe ich $i$.../ einen ungemein wichtigen Umstand in Erfahrung gebracht. Dieser Heınrich hatte ihr nämlich nach deutscher (iewohnhe'll lange Briefe geschrieben, und vor dem Tode hatte er ihr dann noch verschiedene Papiere und so etwas wie ein Tagebuch zugesandt. Sie, die Gans [ :- die Dumme], hat natürlich von dem Geschreibsel nur die Siellen verstanden, wo er voin Mfonde, meincm liehe't Auglusim und. wenn ich nicht irre, von Wicland spricht |kursiv die Verf | ]

187 libd., S. 170-175.

${ }^{188}$ Fbd., S. 180, S. 423, S. 349, S. $400 f$ 
vorwiegend im Zusammenhang mit der nussischen Gruppe um den Füsten Valkovskij, als auch der fremden Figuren und der Figur des Ich-Erzahlers, die mit Hilfe dieser Imageme vorwiegend positiv charakterisiert werden. Die zentralen positiven fremden Figuren sind wie die episodischen stereotyp und weisen Bezüge zu literarischen Figuren aus der (west)europăischen Literatur auf. Dabei sind sie zum Teil als Symbole der als positiv bewerteten idealistischen kulturellen Tradition des „Westens" anzusehen. Die übrigen fremden Figuren, die ebenfalls entweder als literarische oder als nationale (ethnische) Stereotypen dargestellt werden, treten als alter, als die Anderen bzw. Kontrastfiguren zu den Russen auf.

In Unižennye $i$ oskorblennye lassen sich somit die Ansătze für zwei Imagothèmes des verwestlichten, „petrinischen“ Rußlands erkennen, die in den spăteren Romanen Dostoevskijs noch viel stărker ausgeprăgt sind: das negative utopisch-ideologische Imagothème, dessen Verkorperung hauptsăchlich der böse Fürst Valkovskij und teilweise die um ihn versammelten verwestlichten russischen Figuren sind, ${ }^{189}$ und das positive utopische Imagothème, dessen Verkorrperung die Gruppe der fremden, aber teilweise russifizierten Figuren um Ieremija Smit, der Deutsche Heinrich und der ideal gezeichnete russische IchErzăhler (die „Schillers“) bildet.

Auf dem Hintergrund der oben besprochenen Figurenkonstellation konnen im folgenden die bereits erwähnten polnischen Imageme interpretiert werden, die hauptsächlich mit den Figuren des Fürsten Valkovskijs und auch der Grăfm Zinaida verbunden sind.

1. Zum ersten Mal wird die ,neue“ polnische Hautpstadt, Warszaw $a$, in einem Gespräch zwischen der Frau des alten Ichmenev, Anna Andreevna und dem Erzăhler, Ivan Petrovič, über den Fürsten Valkovskij erwăhnt. Anna Andreevna erzăhlt Gerüchte über den Fürsten und seine Geliebte, Gräfin Zinaida Fedorovna. Valkovskij will seinen Sohn mit der reichen Stieftochter der Grafin. Katerina, verheiraten, um dadurch nicht nur an ihre Millionen heranzukommen, sondern auch die Ehe seines Sohnes mit Natasa Ichmeneva zu verhindern:

А графиня-то эта, когда еше муж ее был жив, зазорным повсдением отличалась. Умер муж-то - она за границу: все итальянцы да французы пошли, баронов kakих-то у себя завела; там и князя Петра Александровича подиепила. А падчерица ее, первого ее мужа, отkупшика, дочь меж тем росла да росла. /.../ да и два миллиона, что ей отец-отkупщик оставил, подросли. Теперь, говорят, у ней три милииона; князь-то и смекнул: вот бы Алешу женить! /.../ Князь сообщаст графине свое желание. Та и руками и ногами: без правил, говорят, женшина, буянка такая! Ее уже здесь не все, говорят, принимают; не то что за границей. /.../ ты, графиня, не беспоkoйся. /.../ A kak твоя падчерица выйдет за Алешу, таk и будет пара: и твоя невинная, и

189 Eine Ausnahme bildet die vom Ich-Erzähler positiv geschilderte Stieftochter der Gräfm Zinaida. die wie er selbst ein ,idealistischer Typ“ ist, siche dazu oben, S. 210 f. 
Aлеша мой дурачок; мы их и возьмем под начало и будем сообша опеkать; тогда и у тебя деньги будут. А то что, говорит, за меня замужк тебе идти? Хитрий человек! Масон! Тak полгода тому назад было, графиня не решалась, а теперь, говорят, в Варшаву ездили, талє и согласились. [kursiv die Verf.]

[Die Gräfin jedoch stand schon bei Lebzeiten ihres Gemahls in schlechtem Ruf. Als ihr Mann starb, reiste sie ins Ausland: hier lemte sie Italiener und Franzosen, Barone und Grafen kennen. und da hat sie sich denn den Fürsten Pjotr Alexandrowitsch gekrallt. Ihre Stieftochter aber, die Tochter ihres ersten Mannes, der ein Branntweinpächter war, wuchs allmählich heran. /.../ zugleich aber wuchsen auch die zwei Millionen heran, die ihr Vater für sie /.../ deponiert hatte. Jetzt, sagt man, habe sie drei Millionen. und da hat sich denn der Fürst gedacht, daß es sehr vorteilhaft wäre, Aljoscha mit ihr zu verheiraten. /.../ Der Fürst teilt also der Gräfin seinen W'unsch mit. Die aber ist dagegen, mit Hănden und Füßen. Ein tolles Weib soll sie sein, ohne jeden Anstand! Man sagt, hier werde sie schon nicht mehr von allen empfangen. wer weiß, wie es im Auslande gewesen ist! 'Du. Gräfin, beunruhige dich nicht.' /../ Wenn aber deine Stieftochter Aljoscha heiratet, so gibt das ein gutes Paar: sie ist unschuldig wie ein Engel und Aljoscha ein Dummkopf: wir werden sie beide zusammen bevormunden, dann wirst du Geld haben. Was nützt es dir, wenn ich dich heirate?' /.../ Ein schlauer Mensch! Ein Freimaurer! Vor einem halben Jahr hat die Gräfin sich nicht dazu entschließen können; jetzt, sagt man, seien sie nach Warschau gefahren, dort habe sie eingewilligt. [kursiv die Verf.]1 $]^{190}$

Sowohl der Fürst als auch die Gräfin werden in diesen an das Verfahres des skaz erinnernden Äußerungen von Anna Andreevna negativ als verwestlichte Vertreter des russischen Hochadels geschilder, die Rußland fast völlig entfremdet sind und ihre subversiven "Intrigen" in Polens Hauptstadt schmieden, wobei es sich aber nur um eine Wiedergabe der Stimme der "öffentlichen Meinung" handelt, die durch die Wiederholung von govorjat [roвopsm; man sagt, die Leute sagen] hörbar wird und das (iesagte relativiert.

Anschließend fügt die Frau Ichmenevs hinzu. daß ihre Familie sowie diejenige ihres Mannes dem altrussischen Adel angehörten und besser als die des Fürsten und der Stieftochter seien, so daß Natasa nur wegen ihrer Armut und nicht wegen ihrer l lerkunft eine ungleiche Partie für den Sohn des Fürsten sei:

А Натана ему ещце лучше была бы партия. Та откупиица, а Наташа -то из старинного лворянского дома, высокоблагородная девица. /.../ Ихменевы-то, ене ири Иване Васильевиче Грозном дворянами были, а что мой род, ШШумиловых, еше при Алekceе Михайловиче известен был, и цокументы есть у нас, и в истории Карамзина упомянуто. /.../ Богатством только и взя:Іи перед нами. Ну, да пусть тот, 
разбойник-то. Петр-то Александрович, о богатстве хлопочет; всем изестно: жестокосердая, жадная душа. В иезутить, говорят, тайно в Варшаве записался? Правда ли это? [kursiv die Verf.]

[Natascha wăre für ihn eine weit ebenbürtigere Partie. Jene ist bloß die Tochter eines Branntweinpăchters, Natascha aber stammt aus altem Adelsgeschlecht, ist ein hochwohlgeborenes Fräulein. /.../ Die Ichmenjeffs [gehörten] schon zu Zeiten Iwan Wassiljewitschs des Schrecklichen zum Adel /.../ und meine Familie, das Geschlecht der Schumilloffs, [war] schon unter Alexei Michailowitsch bekannt /.../ - wir haben die Dokumente darüber -, und auch in Karamsins Geschichte Rußlands sind wir erwăhnt. /.../ Nur an Reichtum sind sie uns über. Nun, moge sich dieser Rauber Pjotr Alexandrowitsch nur ums Geld mühen! das ist ja allen bekannt: er ist eine hartherzige, habgierige Seele. Er sei in Warschau, sagt man, heimlich =u den Jesuiten übergetreten! Ob das wohl wahr ist. was meinst du? [kursiv die Verf.]] ${ }^{191}$

Natasa und die Ichmenevs werden emeut dem Fürsten sowie der Grăfin und der Rivalin Katerina gegenübergestellt und als schlechte, nur auf das Materielle ausgerichtete, skrupellose Menschen geschildert. Betont wird auch das latente Motiv der geheimen Beziehungen zur katholischen Kirche, die durch die polnischen Jesuiten vertreten wird. Allerdings handelt es sich wieder lediglich um "Gerüchte". Der angebliche Eintritt des Fürsten in den Jesuitenorden in Warschau wird wie die früher erwähnte mögliche Zugehorigkeit zu einer Freimaurerloge, die er habe verheimlichen wollen, nicht direkt behauptet, sondern als eine Vermutung dargestellt.

Die fremden Imageme (,Jesuitenorden in Warschau" und "Freimaurer") machen aus den beiden Figuren ideologisch-politische Feinde RuBlands, die ein subversiv-destruktives Potential aufweisen. BOGUSŁAW MuCHA betont übrigens, $\mathrm{daB}$ unter den russischen katholischen Konvertiten sehr viele bekannte Personlichkeiten. Intellektuelle. Philosophen bzw. Schriftsteller waren. Ihr Beitritt zum römisch-katholischen Glauben mußte jedoch in Rußland verheimlicht werden. $^{192}$

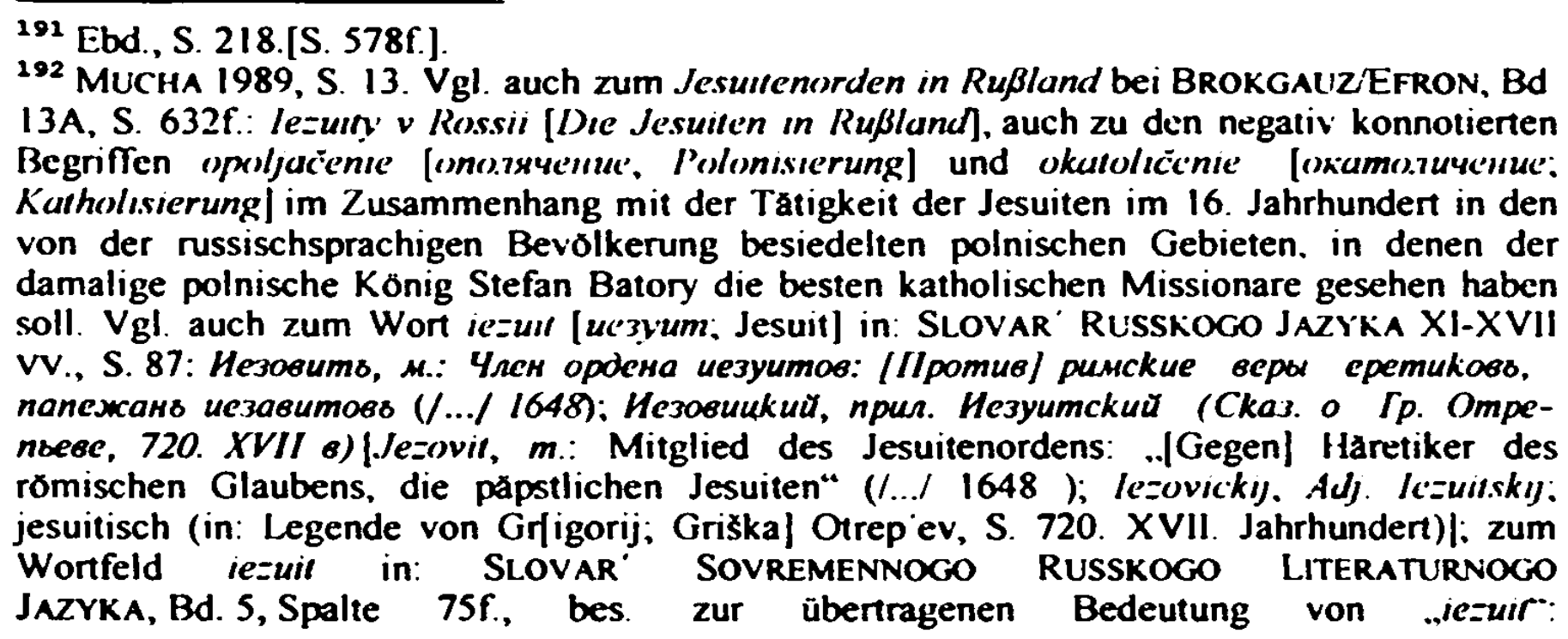


2. Zum zweiten Mal wird eine Reise des Fürsten Valkovskij nach Polen in der Erzăhlung von Ivan Petrovix über das geschickte Benehmen des Fürsten gegenüber seinem Sohn erwăhnt. Jener strebe konsequent danach, Aleša und Natała Ichmeneva zu trennen und ihn mit der reichen Stieftochter der Gräfin zu verbinden: als hilfreich erweist sich ihm dabei der unbeständig kindliche Charakter seines Sohnes:

Aлеша проговорился мне тайkоя, что отец kak будто немножко и рад был всей этой истории: ему нравиюсь во всем этом деле унижение Ихненева. Для формы же он продолжал изъявять свое неудовольствие сыну /..././.../ но всkоре уехал в Польщу, за графиней, у kоторой былыи тал dела, всё еще без устали преследуя свой проект св:ттовства. /.../ Князь добился наконец цели. До нас dошыи слухи, что дело о сватовстве пошло наконец на лад. В то время, которое я описываю, князь только что воротился в Петербург. /.../ Строго и настоятельно потребовал он разрыва; но сkоро догадался употребить гораздо лучшее средтсво и повез Areuly $\mathbf{k}$ графине.[kursiv die Verf.]

[Aljoscha dagegen deutete mir heimlich an, daß die ganze Geschichte seinem Vater in mancher Bezichung sogar angenehm wäre; ihm gefiele vor allem die Erniedrigung. die Ichmenjeff dadurch erfuhr. Der Form halber fuhr er jedoch fort. seine Unzufriedenheit seinem Sohn gegenüber aufrechtzuerhalten /.../. Doch bald darauf fuhr er nach Polen zu der Gräfin. die dort geschäflliche Angelegenheiten zu ordnen hatte, und verfolgte unablässig sein Heiratsprojekt. /.../ Der Fürst erreichte endlich sein Ziel. Zu uns drangen allerlei Gerüchte, daß die Sache für den Fürsten eine günstige Wendung genommen habe. Zu dieser Zeit war er dann wieder nach Petersburg zurückgekehrt. /.../ Schroff und nachdrücklich verlangte er die Trennung von Natascha. Doch bald besann er sich eines Besseren und führte Aljoscha zur Gräfin. [kursiv die Verf.] ] ${ }^{193}$

2. персн., о хитром, лицемернон чсловске. - .исзуитизяі: 2. тохсе. что исзуитетво = притворство, двуличис, лииснсрис, коварство|Jesuit: 2. übertragene Bed., üter einen schlauen, heuchlerischen Menschen .Jesuitismus": 2. dasselte wie Heucheler, Doppelzüngigkeit $=$ Verstellung, Falschheit $\mid=$ Zwei Gesichter haben], Heuchelei, Tücke, Arglist|. Angefühn werden Beispiele ua. aus Dostoevskijs Zupıskı is Mertvogon doma und 1)jadjuskin son, aus Pisemskij (das Stück (ior kaja sud'hına |/)as hıllere ichicksal|) sowic aus Cechov.

193 libd., S. 226 [S. 592]. Vgl. auch die ambivalente Beschrcibung der Grafin und dic Betonung ihrer Abhangigkeit von dem Fürsten, was aus der Sicht des Ich-Erzahlers als negativ beurtellt wird, ebd., S. 344: „.../ она мне kak-то нсхотя понравіцтась. /.../ взг.7ял бы.т чрезвычайно лобрый, но какой-то ветреный и шаловшво насмеш.ливый./.../ 13 этом взг.ляде выража оось тоже много ума, но бо.лее всего доброты и весе.лості. Мне

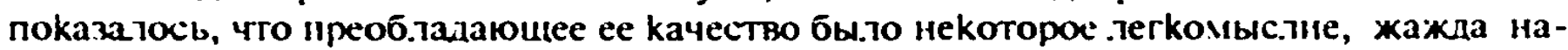
с.лаждений и каkой-то добродушный эгонзи, может о́ыть даже и бо.тышй. Она была под началои у киязя, киторей илел на нес чрезвычайное влияние". [kursiv die Verf.] [S. 799: Auf den ersten Eindruck muB ich sagen, daB sie mir gleichsam gegen meınen Willen gefiel. /.../ ihr Blick / war / überaus gutmütig, aber irgendwie flatterhaft und schelmisch-spottlustig. /.../ Ubrigens lag in ihrem Blick auch viel Klugheit, aber vor allem sprachen aus ihm doch Gutmütigkeit und ein heiteres Gemüt. Aber ihre vorherrschende Eigenschaft schien mir 
Der Fürst Petr Aleksandrovic Valkovskij wird auch hier in Form von „Geruchten" als ein Heuchler und Intrigant dargestellt. Das polnische Imagem erfült dabei die Funktion, inn und die Fürstin als „Feinde“ Rußlands (= als potentielle Katholiken) zu zeigen. Dadurch erhalt das Motiv der "Emiedrigung" Ichmenevs und seiner Tochter, die als Angehorige des alten russischen Adels die vorpetrinische orthodoxe Rus symbolisieren, eine zusatzliche ideologische Komponente. Die unmenschliche bzw. "nichtchristliche“ Haltung Valkovskijs wird durch seinen mutmaßlichen Kontakt zum katholischen Polen (zu den polnischen Jesuiten), d.h. durch seine Okzidentalisienung erklărt.

3. Zuletzt werden Kraków und Warszawa zweimal in den Erzahlungen Masloboevs über die tragische Geschichte der Tochter von Jeremija Smit und seiner Enkelin Nelli erwăhnt, die sich als die legitime Tochter des Fürsten Valkovskij erweist. Masloboev will jedoch gegenuber dem Ich-Erzăhler die direkte Nennung der Orte vermeiden, so daß in seiner Erzăhlung der Name der „alten“ polnischen Hautpstadt Kraków bzw. anderer europăischer Städte, u.a. Paris, symbolträchtig für Petersburg stehen dürte. ${ }^{194}$ Noch einmal erzăhit Masloboev über die Bemühungen des Fürsten, seine Frau und Tochter zu finden, nachdem er sich von ihnen vor dreizehn Jahren im Ausland getrennt hatte:

Еше зимой, еше прежде, чем Смит умер, только что князь вороmился из Варшавы, и начал он это дело./.../ Главное в том, что он нитkу потерял. Тринадцать лет, kak он расстался в Париже с Смитихой и бросил ее, но все эти тринадцать лет он неуклонно следил $3 а$ нею, знал, что она живет с Генрихом. /.../ знал, что у ней Нелли /.../, ну, одним словом, всё знал /.../. [kursiv die Verf.]

[Schon im Winter, noch bevor der alte Smith starb, begann der Fürst, sogleich nach seiner Rückkehr aus Warschau, mit den Nachforschungen. I.../ Die Hauptsache war nämlich die, daß er ihre Spur verloren hatte. Vor dreizehn Jahren hatte er die Smith in Paris sitzen lassen, aber trotzdem hatte er sie während dieser ganzen Zeit nicht aus dem Auge verloren, hatte gewußt, daß sie mit Heinrich zusammenlebte, /.../ wußte, daß sie eine Tochter, namens Nelly, hatte, /.../ mit einem Wort: er wußte alles /.../. [kursiv die Verf.]] ${ }^{195}$

Die oben erwăhnten polnischen Imageme, d.h. die Erwăhnungen der Namen der polnischen Stădte bzw. der Polenreisen des Fürsten Valkovskij dienen dazu.

doch ein gewisser Leichtsinn zu sein, neben Vergnügungssucht und einem gleichsam gutmūtigen Egoismus, der vielleicht sogar sehr groß war. Sie stand gan- unter dem Einfluß des l.ürsien. der eine ungehcure Machl ïher sie hesis $\beta$.] [kursiv die Verf.]

194 Ebd., S. 336 und S. 783: „Бы.70 ж это в городе Санта-фе-де-Ботота. a saксm, "I 8 Краkовс, но вернее всего, что в фюрстентум Нассау, вот что на зельтерской воде напIIсано, именно в Нассау; довольно с тебя?" [Geschehen aber ist es in Santa Fé de Bogota, vielleich aber auch in Krakau oder, was am wahrscheinlichsten ist, im Fürstentum Nassau, sieh mal, das hier auf der Seltersflasche steht. Also, wie gesagt: in Nassau. Bist du jetzt zufricden? | [kursiv die Verf. |

195 Ebd., S. 435 [S. 961]. 
den Fürsten bzw. die Grätin Zinaida negativ zu charakterisieren. Indem erwăhnt wird. daß Valkovskij in Polen dem Jesuitenorden beigetreten bzw. ein Freimaurer sei, bekommen die negativen Charaktereigenschaften dieser Figur eine zusätzliche Erklärung und eine symbolische Bedeutung. .Jesuit“ und „, böser Mensch" brw. "verwestlichter russischer Aristokrat" können somit als synomyme Bezeichnungen betrachtet werden. ${ }^{196}$ Valkovskij wird auf diese Weise außerst negativ als ein kalter, rationalistischer, zynischer verwestlichter Russe dargestellt und als der Vertreter des russischen nachpetrinischen Hochadels dem altrussischen Adligen Ichmenev und seiner Familie sowie dem lch-Erzăhler entgegengestellt. Der Fürst ist an dem Untergang aller drei Mitglieder der Familie Smit und an dem Unglück der Familie Ichmenevs sowie des Erzählers schuldig. Sein Vorname Petr mag wohl eine Anspielung auf Peter den Großen sein. Valkovskij ist ein der russischen počva [nouba], dem russischen Boden, entfremdeter Kosmopolit, ein Produkt der Petrinischen Retormen. Auch der Name l'alkovskij weckt Konnotationen mit der polnischen Sprache $[$ walka $=K a m p f]$ bzw. deutet auf seine ambivalente Destruktivität hin. ${ }^{197}$ Eine negative verwestlichte Figur, die ebenfalls Petr Aleksandrovič heißt und an Valkovskij erinnert. tritt auch im unvollendeten Roman Netocka lezvanova auf. Der Ich-Erzähler in den Zapiski iz Mertvogo doma heißt dagegen Aleksandr Petrovic. Der Name Petr bleibt jedoch in allen späteren literarischen Werken Dostoevskijs nur den negativen verwestlichten Figuren vorbehalten.

Valkovskij ist die negativste. und eigentlich böse Figur des Romans. Er eröffnet die Reihe der dämonischen llelden der Romane Dostoevskijs, der verwestlichten utopisch-bösen Alius-Figuren. zu denen Svidrigajlov oder Stavrogin gehören. ${ }^{198}$ Es fehlen ihm aber, z.B. im Unterschied zu Svidrigajlov, jegliche guten Gefühle und Eigenschaften. ${ }^{199}$ Valkovskij wird v.a. aus der Sicht anderer Gestalten des Romans gezeigt, z.B. des Ich-Erzählers, der Frau des alten Ichmenev, Anna Andreevna oder Masloboevs. Sie nennen ihn Judas ${ }^{200}$. Intrigant.

196 JA: ORlowshi hat dazi bemerkt, daß schon in diesem Roman, der noch vor dem Ausbruch des polnischen Aufstandes von 1863 verfaßt wurde, die offene Feindschaft Derstoes skijs gegenüber dem Westen. v.a gegenuber dem Katholizismus und dem Jesuitenorden. geäußer werde. Vgl. DE.RS. 1982, S. 89

$197 \mathrm{Vgl}$ dazu auch SI.OVAR SOVRINAENNOGO) RUSSKOCiO I.ITIRATLRNOCiO JAZYKA. Bd. 2.

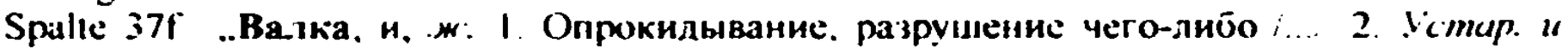

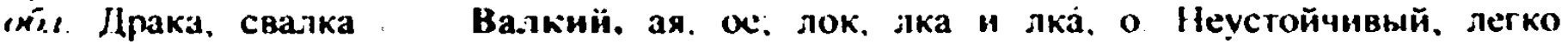

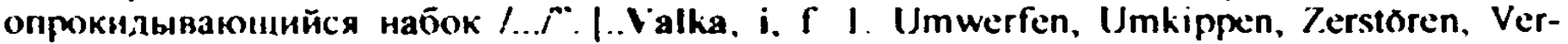

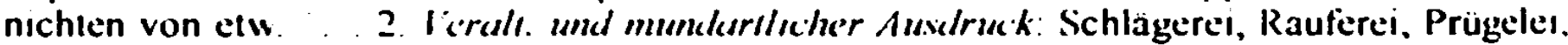
Handgemenge ... . Valkij. aja. oje. lok. Ika und Ika. o. Instabil, labil, schwankend. leicht umzuwertien. umzukippen, sich auf die Seite neigend $i . . r^{*}$.

$198 \mathrm{Vggl}$ auch den Kommentar der Herausgeber der PSS, u.a. zu den Bezügen zu Max Stirner. 13d. 3, S. $527 \mathrm{f}$ In seinem Igoismus und Individualismus erinnert Petr Aleksandrovic Valkov skij aber auch an die dämonischen (iestalien Byrons bzw lermontovs.

199 ()RioW'SKI 1982 nennt den Fürsten den abstoßendsten Charakter in diesem Roman (S. 90).

$200 \mathrm{~F}$ : is bezeichnend. daß $\mathrm{F}$ I Tjutčev in seinem 1867 anläßlich des Slavischen Kongresses m Moskau entstandenen (iedicht .i/av/anesm |An dic .S/ave'n] Polen .unseren Judas" nennt

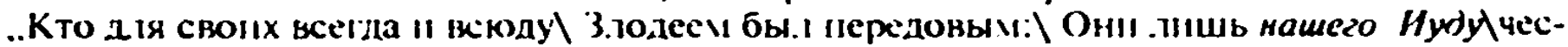

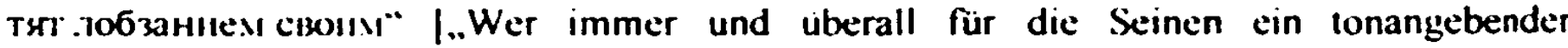


Betrüger bzw. Geschăftemacher. Der Fürst wird in seinem Äußeren und in seinem Inneren als ein unaufrichtiger, sich maskierender Mensch gezeichnet:

Он окинул нас быстрым, внимательным взглядом. По этому взгляду еще нельзя было угадать: явикся он врагом иш другам? /.../ Это был человек лет copoka пяти, не больше, с правильными и чрезвычайно красивыми чертами лица, которого выражение ищеняюсь судя по обстоятельствам; но изменялось резко, вполне, с необыкновенною быстротою, переходя от самого приятного dо самого угрномого или недовольного, kak будто внезапно была передернута kakaято пружинка. /.../ лицо его не производило приятного впечатиения. Это лицо именно отвращало от себя тем, что выражение его было kak будто не свое, а всегда напускное, обдунанное, заинствованное, и kakoe-то слепое убеждение зарождалось в вас, что вы никогда и не doбьетесь do настоящего его выражения. Взглядываясь пристальнее, вы начинали подозревать под всегдашней масkой что-то злое, хитрое и в высочайщей степени зооистическое. /.../ Он бы и хотел смотреть мягkо и ласkого, но лучи его взглядов kak будто раздваивались и между мягkими, ласковыми лучами мелькали жестkие, недоверчивые, пытливые, злые. /.../ Это была вполне породистая kрасота. [kursiv die Verf.]

[Er überflog uns alle mit einem schnellen, aufmerksamen Blick. Aus diesem Blick war noch nicht zu erkennen. ob er als Feind oder Freund kam. /.../ Er war ein Mann von fünfundvierzig Jahren, nicht älter, mit regelmäßigen und sehr schönen Gesichts=ügen, deren Ausdruck sich je nach den Umständen veränderte; aber diese Veränderung ging schroff, radikal und mit überraschender Plotzlichkeit vor sich, sprang vom angenehmsten Ausdruck in den verdrossensten oder unzufriedensten hinüber, als gehorchten sie einem mechanischen Druck auf eine Feder. I.../ sein Gesicht [machte] keinen angenehmen Eindruck. Es stieß einen eben dadurch $a b$, da $\beta$ sein Ausdruck gleichsam kein eigener, sondern immer nur ein vorgetäuschter, wohlüberlegter, übernommener sei, und so entstand in einem eine Art von blinder Überzeugung, daß man nie seinen wirklichen Ausdruck zu sehen bekommen werde. Schaute man noch schärfer $\mathrm{zu}$, so begann man hinter seiner gewohnten Maske etwas Böses, Schlaues und im höchsten Grade Egoistisches zu argwöhnen. /.../ Vielleicht hătte er auch weich und freundlich blicken wollen, aber die Strahlen seiner Blicke schienen sich gleichsam auf-uspalten, und zwischen den weichen, freundlichen Strahlen blitzten harte. mißtrauische, forschende, böse auf. /... Er war von einer vollkommenen rassigen Schönheit. [kursiv die Verf.] ${ }^{201}$

Bösewicht gewesen ist: $\backslash$ Nur der wird unseren. Judas \ mit Küssen ehren ${ }^{\mid}$| |kursiv und die deutsche Übersetzung die Verf.]. Vgl. TJuTCEV 1987 (S. 234, und die Anmerkung, S. 412). Siehe auch zum Verhāltnis Tjutčevs zu Polen bei Orlowski 1992, S. I15f. sowie DERS. 1993 und PRUS 1985.

202 Bd. 3, S. 244f. [S. 625f.]. Vgl. unten die Schilderung von Svidrigajlov (S. 277ff.) oder Stavrogin (S. $318 f$ f, bes. S. 340). 
Äußerlich ist der Fürst als ein schöner Mann mit aristokratischen weltmännischen Manieren geschildert, der in einem Augenblick den bösen eigenen Gesichtsausdruck mit einer Maske der Höflichkeit bedecken kann. ${ }^{202}$

Das Motiv des Entlehnten und Künstlichen wird hier mit dem der Maske (= eine Metapher für die Lüge und den Betrug) in eins gesetzt, so daß in dieser Figur metonymisch Elemente des russischen literarischen Stereotyps des Polen bzw. der polnischen Kultur und des Jesuiten vereinigt werden. Valkovskij läßt sich also als ein Symbol des verwestlichten, katholisch geprägten Russen verstehen.

Besonders in seiner „Beichte“ gegenüber dem Ich-Erzähler kommt das immanent Böse von Valkovskij zum Vorschein, indem er plötzlich seine „Maske“ abnimmt. sein ,Wahres“ Ich zeigt ${ }^{203}$. Valkovskij enwähnt u.a. seine chemalige Geliebte und ihre französische Zofe, die dem Marquis de Sade nacheifern wollten. wobei die Herrin nach außen die Maske einer tugendhaften abessa [abecca; $\ddot{A} b$ -

202 Siche ebd. S. 301 oder 340. Auch Nikol.A STrachov hat in seinem Aufsatz. zum polnischen Aufstand von 1863 Rokesvoj veopros [ Die falale. schicksulhafte Frage], der zuerst in der von Michail und Fedor Dostoevskij herausgegebenen Zeitschrift l're’mja die Künstlichkeit. das Entlehnte und Nichtlebensfähige der aus dem Westen übernommen polnischen Kultur

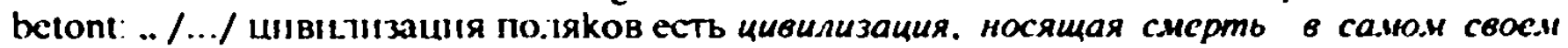
корне. /.../ в чем же мы мог.ли бы по.тагать сушественый недостаток по.тьской kу.льтуры? /.../ Не в том .71, что она бы.าа не народною, не с.лавянскою? Что в ней не бы.7о

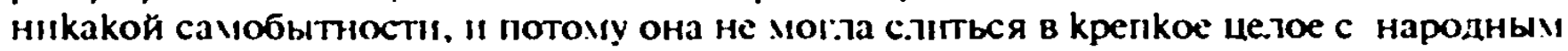

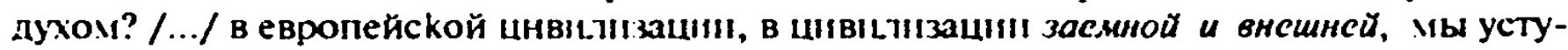

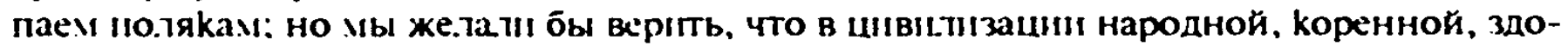
ровой мы превосходым их /... . $^{\circ}$ | kursiv N Strachov|

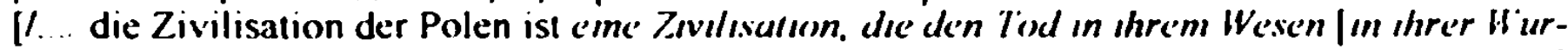
=el| Irügf. /... I worin können wir den wesentlichen Mangel der polnischen Kultur annehmen?

Wohl mcht darın, daß sie nicht volksnah, nicht slavisch war? Daß sie keine Eigenständigkeit besaß, und deshalb nicht imstande war, in ein festes Ganzes mit dem Volksgeist zu verschmelzen? ... : was die europäısche Zivilisatıon betriff, die entlehmt und äußerlich ist. sind wir den Polen unterlegen; aber wir wollen daran glauben, daß wir in der unseren volksnahen, ursprünglicheil urıd gesunden 7ivilisation ihr überlegen sind / ../. !kursıv N. Strachov |]

Vg! Strachov 1863. Siche auch den Abdruck dieses Artikels u.d.T. Rokovoly vopros

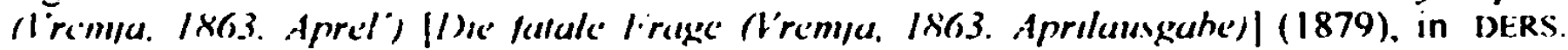
1969, Bd. 2, S 91-105. Das obige Zıtat stammt aus dieser späteren Ausgabe, S. 99 und S. $101 f$.

203 libd., S. 354ff, bes. S. 358: ..Он пронзводицт на меня виечат.ление kakoro-то гada, ka-

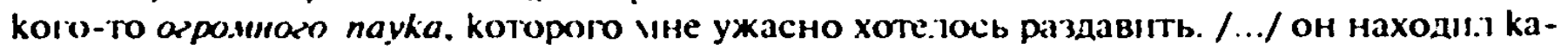

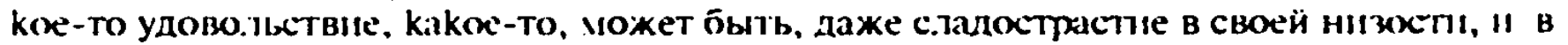

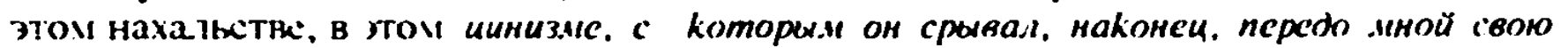

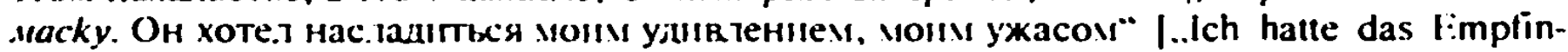

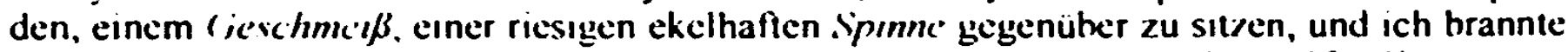
vor Verlangen, das scheußliche Tier platt zu schlagen, zu zertrampeln. /.../ er [fand| an seiner Schamlosigkeit ein gewisses Vergnügen, ja. vielleicht empfand er sogar gewisse Wollust bei

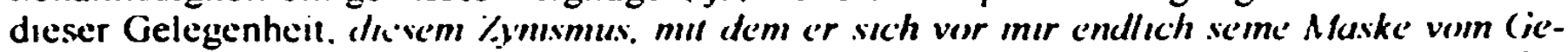

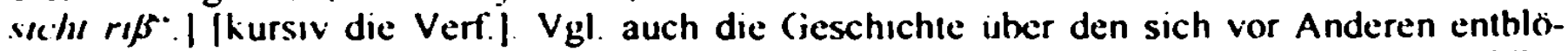
ssenden Pariser, die Valkovskij anschließend eriahlt Fr will durch seinen seelischen Exhibitionismus den ...Schiller" I van Petrovic schockieren, ebd., S $362 f$ Oft wird in dem Roman die Neigung des Fürsten zum Betrug betont, die als .jesurtisch“ bezeichnet wird, ebd., z.B. S 269.335 und passim 
tissin] trug, obwohl sie ein „Teufel in Person“ war. ${ }^{204}$ Er selbst bezeichnet sich in seiner "Beichte“ als außerst vital und lebenshungrig. Er will in seinem grenzenlosen Egoismus das Leben uneingeschränkt genießen, hat keine Ideale, empfindet keine Gewissensbisse und zeigt sich als ein Atheist. ${ }^{205}$ Paradoxerweise nennt sich Valkovskij eine „echte weite russische Natur". Diese Worte sind aber ironisch gemeint, denn es handelt sich um eine der "Masken“ des Fürsten, der ein verwestlichter Aristokrat ist und als "Jesuit", der Kontakte zum katholischen Polen hat, kein "Russe" und kein Patriot wie Ichmenev sein kann, sondern ein „verfalschter" Russe ist:

Я ведь русская натура, неподdельная русская натура, nатриот, люблю распахнуться, да и $\mathrm{k}$ тому же надо ловить минуту и насладиться жизнью. Умрем и - что там!

$[,] . . . /$ ich bin doch eine russische Natur, eine unverfälschte russische Natur, bin Patriot, - /.../ [ich mag es, mich ganz weit zu offnen; Erg. d. Verf.] Und man muß doch den Augenblick erhaschen und das Leben genießen. Sterben wir - was gibt's dann noch!"] [kursiv die Verf.] ${ }^{206}$

Valkovskij ist einer echten Liebe nicht fähig: Auch seinen Sohn Aleša betrachtet er mit Verachtung und nützt ihn aus. ${ }^{209}$ Alesa und Katerina Fedorovna bzw. die Gräfin Zinaida sind ihm gegenüber als relativ harmlose kindliche Egoisten zu bezeichnen, die sich für die neuen Ideen aus dem Westen interessieren, zugleich aber anmutig und anziehend sind, v.a. für Natasa oder den Ich-Erzăhler. ${ }^{208}$

204 Ebd., S. 363f. [S. 835]. In der „Beichte“ des Fürsten werden „таинственность и наглость обмана“ [.,die Heimlichkeit und die Unverschămtheit des Betruges“] der Gräfin, ..насмешка над всем, о чем графиня проповедовала в обществе как о высоком, недоступном и ненарушимом" [..Die Verhöhnung alles dessen. was die Gráfin in der Geselischaft als Hochstes und Heiligstes pries“| sowie „внутренний дьяволский хохот и сознательное попирание всего, чего нельзя попирать“|..dieses innerliche teuflische Gelăchter, mit dem sie es tat, dieses bewußte Unter-die-Füße-treten und Verleugnen alles dessen, was man doch nicht verleugnen kann“| betont: Да, это был сам дьявол во плоти, но он был непобедимо очарователен" I..Sie war der leibhaftige Teufel, ein Teufel von Fleisch und Blut, aber dieser Teufel war doch so bezaubernd, daß ihm niemand hătte widerstehen können "]. Siehe auch zu Dostoevskij und de Sade z.B. bei JACkSON: 1993a. S. 147 und S. 157f. (zu Valkovskij).

$205 \mathrm{Vgl}$. ebd., S. 365ff. Valkovskij spricht dabei von "wir”, d.h. von sich selbst als einem besonderen in Rußland vorhandenen sozıulen Typ: Я на все согласен, было бы мне хорошо, и у шжс тиких .е.иол, и нам действительно хорошо. Весь мир может кунанибудь провалиться, одни мы всплынем наверх" InIch bin mit allem einverstanden, wenn es nur mir gut geht. Und solcher Mtenschen wie ich giht es unter uns leguon, und uns geht es wirklich gut. Alles auf der Welt kann untergehen, nur wir allein werden nie untergehen. Sollte auch die ganze Erde irgendwohin versinken, wir würden selbst dann wieder hochkommen. immer wieder obenauf schwimmen". I [kursiv die Verf.] (S. 366 [S. 838f.]).

206 Ebd., S. 361. Damit wird auf die ..Breite der russischen Natur“ bzw. .Seele“, angespielt. die Widersprüche, auch verschiedene „Ideen“, darunter solche aus dem „Westen“ beherbergen kann. Siehe zum Ideologem die „russische Seele“ bei LAZARI 1995a. S. 86f. (Kusskaja duska, The Russian Soul) bzw. FrANz 1998.

207 Ebd. z.B., S. 308ff.

208 Ebd., z.B. S. $348 f f$. 
Die Figur des Fürsten Petr Aleksandrovic Valkovskij läßt sich somit als ein psychologisch differenziertes Stereotyp eines (polonisierten) russischen Jesuiten bezeichnen, indem er vorwiegend mit Hilfe der fremden, auch polnischen Imageme charakterisien wird: Valkovskij vereinigt in sich sämtliche negative Eigenschaften, die einem Jesuiten und einem Polen in der russischen kulturellen Tradition zugeschrieben werden. Die polnischen Imageme als Elemente des Porträts des Fürsten Valkovskij heben durch die Betonung seines aus Polen stammenden "Jesuitismus" und des aus dem Westen entlehnten Aristokratismus die immanent in dieser Figur vorhandene Negativität sowie die Entfremdung von der Welt, von der Kultur und der Religion der vorpetrinischen Russen hervor. Das „Böse“, der „Westen“ in den verwestlichten Russen bzw. in der russischen europäisierten Kultur ist als deren vermeintlicher destruktiver Katholizismus bzw. Atheismus immanent vorhanden. ${ }^{209}$ In der Typologie Mouras ist Valkovskij aber nicht nur der Andere - ein Alter, der den ,guten Russen“ gegenübergestellt wird -, sondern zugleich ein Alius, der ..ganz Fremde", in dem sich das Numinose als die destruktive Kraft des Bösen offenbart. Valkovskij ist zugleich auch als die Weiterentwicklung solcher Figuren wie der Russe A-v oder der Pole M-ckij aus den Zapiski i= Mertvogo doma zu betrachten. Er verkörpert als die erste literarische Figur Dostoevskijs vollkommen das negative utopische westliche Imagothème des aus dem Westen nach Rußland gekommenen Bösen. dem das Gute, das positive utopische russische Imagothème der christlichen Liebe und Verzeihung, die von den Ichmenevs und dem Ich-Erzähler symbolisiert wird, entgegengesetzt wird.

ZUSAMMENFASSUNG: Der erste umfangreiche Roman Dostoevskijs läßt sich aus imagologischer Sicht als die Weiterentwicklung der in den früheren literarischen Werken, besonders in den Zapiski iz Mertvogo doma, enthaltenen imagothematischen Ansätze betrachten. Die beiden großen Imagothèmes, das negativ-utopische des verwestlichten, „nachpetrinischen" Rußlands und das positiv-utopische der vorpetrinischen Rus", sind in ihm deutlicher als in den Zapisk! i= Mertvogo doma und zugleich schwăcher als in der ()de Na evropejskie sohvtija $v 1854$ godu ausgeprägt. weil sie keine starke ideologische Komponente wie diese Ode aufweisen. Zusätzlich tritt in Unižennye i oskorblennye neben den zwei oben erwähnten Imagothèmes das positive utopische Imagothème des verwestlichten Rußlands auf, das ebenfalls im Ansatz in dem Roman $v$ devjati pis'mach und in Djadjuskin son vorhanden war. In Unizennye i oskorblennye wird im Unterschied $7 . u$ den .Cervantes-“ und .,Shakespeare-“Anhängem aus den früheren Erzählungen dieses Imagotheme durch die Figuren der ..Schillerschen Idealisten" (den russischen Ich-Erzählers, den Deutschen Genrich und die Halb-Engländerin, die Tochter Smits) repräsentiert.

209 Valkovskij wäre somit nach der Bezeichnung von KĘpIviski 1990b die in der russisehen Kultur seit Jahrhunderten anwesende sterolype lighur eines ..hies n' postact lacha" lemes Teufels in der (ieslall eines I'olen |l.jachs||. Der l.jach, die pejorative Bezeichnung für den Polen, ist in dem Roman I/mizenny'c I eskerrhlenny'c in der Figur Valkovskijs, der ein Symbol des verwestlichten Rußland ist, in ein Stereotyp eines (polonisierten) Jesuiten umgewandzlt und wird somit als von Rußland verinnerlicht. assimiliert gezeigt. Siche dazu oben, S. 93ff. 
In allen erwăhnten Werken äußern sich aber die Imagothèmes in den paradigmatisch-antinomisch aufgebauten Figurenkonstellationen. Auch in Unižennye $i$ oskorblennye dienen die fremden Imageme, darunter die polnischen, dazu, alle Figuren dieses Romans, sowohl die positiven als auch die negativen, russischen und fremden, im Hinblick auf den Grad ihrer Okzidentalisierung zu charakterisieren, wobei alle Figuren, ăhnlich denen in den früheren Werken, statisch-unverănderlich und stereotyp (bzw. typisiert) sind. Die fremden Imageme, die zur Charakteristik sowohl der negativen russischen als auch der negativen fremden Figuren eingesetzt werden, darunter die polnischen, bilden das negative ideologisch-utopische Imagothème des verwestlichten Rußlands; die positiv konnotierten fremden Imageme, die zur Charakteristik der positiven russischen und fremden Figuren eingesetzt werden, bilden das positive utopische Imagothème des verwestlichten Rußlands.

Sowohl die russischen als auch die fremden, negativen und positiven Figuren des Romans werden mit Hilfe dieser Imageme als nationale, ethnische bzw. literarische Stereotypen gestaltet, u.a. anhand der Werke Goethes, E.T.A. Hoffmanns, Dickens', Victor Hugos und Schillers. Abgesehen von der eindeutig negativen Figur des Fürsten Valkovskij und den eindeutig positiven Figuren des Ich-Erzăhlers, des Deutschen Heinrich und der alten Ichmenevs, enthalten alle anderen Figuren, trotz ihrer stereotypen Abgeschlossenheit und Unveränderbarkeit je nach dem Grad ihrer Wichtigkeit bzw. "Zentralität" sowohl positive als auch negative Eigenschaften; zu diesen Figuren gehoren der .,protestantisch“ strenge und rachsüchtige Engländer Jeremija Smit und seine ebenfalls rachsüchtige Enkelin, die zudem Tochter Valkovskijs ist, sowie die Tochter Ichmenevs Natasa.

$\mathrm{Zu}$ den negativ verwestlichten russischen Figuren gehoren: Der Fürst Valkovskij, der als ein psychologisch differenziertes Stereotyp eines „Jesuiten“ und eines russischen ,polonisierten“ Aristokraten dargestellt und als ein Symbol bzw. eine Verkörperung des von der russischen nationalen und religiősen Tradition entfremdeten nachpetrinischen russischen Hochadels in der Funktion als alius, in dem sich das "Böse“ offenbart. zu verstehen ist. Die psychologisch äußerst differenzient dargestellte Figur Valkovskijs läßt sich als ein Produkt der schöpferischen, kreativen Vorstellungskraft bezeichnen, die dem Roman Unizennye $i$ oskorblennye und auch den späteren literarischen Werken Dostoevskijs eigen ist. Auch weitere negativ bzw. positiv verwestlichte russische Figuren werden je nach dem Grad ihrer Okzidentalisierung differenziert konstruiert. Die numinose Aura des „Bösen“ als absolute Negation oder des "Guten" als Ideal, die die zentralen Figuren auszeichnet, nimmt aber in den episodischen Figuren bis hin zur volligen Stereotypisierung ab. Sie werden überwiegend aus dem kulturell vermittelten imaginaire social geformt. das über das kreative Imaginäre dominiert.

$\mathrm{Zu}$ den positiven russischen Alius-Figuren gehören hautpsächlich der Ich-Erzahler und die Familie Ichmenevs. Die Figur des Ich-Erzăhlers weist dabei keine direkten Bindungen an die (alt)russische orthodox-byzantinische Tradition auf und wird als ein "Schiller" bezeichnet. Die anderen positiv dargestellten russischen Figuren in Unizenmye $i$ oskorblenmye zeichnen sich dagegen durch eine 
christlich geprågte Liebesfăhigkeit und Demut aus, die jedoch noch nicht explizit russisch-orthodox-byzantinisch, sondern lediglich "russisch-vorpetrinisch" genannt werden kann (die Zugehörigkeit der Ichmenevs zum alten russischen Adel). ${ }^{210}$

Die fremden Figuren lassen sich ebenfalls wie die verwestlichten russischen in negative und positive in verschiedenen Abstufungen aufteilen. Es handelt sich dabei um die in Rußland bzw. in Petersburg lebenden Fremden, die teilweise russifiziert sind. $\mathrm{Zu}$ den negativen fremden Figuren gehören vorwiegend als negative ethnische bzw. literarische Stereotypen (als alter) dargestellte Figuren des Juden, Deutschen sowie der Franzosen und Französinnen, die hier im Ansatz das negative ideologische Imagothème des verwestlichten Rußlands repräsentieren.

$\mathrm{Zu}$ den positiven fremden Figuren gehören sowohl episodische deutsche Figuren als auch die positiven Figuren des Deutschen Heinrich und der Familie des Engländers Smit, die insgesamt als literarische Stereotypen dargestellt sind. Heinrich und die Familie Smits bilden den Kontrast sowohl zu den negativ verwestlichten russischen Figuren um Valkovskij als auch komplementär zu der positiv verwestlichten Figur des Ich-Erzählers und zu den am wenigsten verwestlichten russischen Figuren der Ichmenevs.

210 Es erhebt sich dabeı die Frage, die anhand der folgenden Interpretationen bestätigt oder widerlegt werden kann, ob und inwieweit der ..Schillersche Idealismus“, der doch ein Bestandteil deutscher kultureller Tradition ist, also aus dem „Westen“ kommt, nicht nur in diesem Roman, sondem auch in den anderen literarischen Werken Dostoevskijs einen Teil des positiven utopıschen Imagothèmes des verwestlichten Rußlands bildet. Es müßte somit in den folgenden Interpretationen überprüft werden, ob man bei Dostoevskij von zwei utopischen Imagothèmes des verwestlichten Rußlands sprechen kann: von einem positiven und von einem negativen, bzw., ob die positiven ..westlichen“ Imageme (z.B. „Schiller“) in scinen Werken als angeeignet, "russifiziert“ betrachtet werden können. Vorläufig läßı sich aber festhalten. daß nicht nur bei Dostoevskij, sondern auch bei seinen Zeitgenossen, z. B. bei Turgenev, L.N. Tolstoj und bei den Slavophilen, sich beständig Zitate aus und Verweise auf Schiller finden (v.a. aus I een Rüuhern). Dieses intertextuelle Phänomen würde darauf hındeuten. daß Schiller in der zweiten Hälfte des neunzehnten Jahrhunderts einen integralen Teil der russischen Literatur und Kultur bildete, wie beispielsweise Shakespeare als ein Teil der deutschen Kultur empfunden wurde.

Die Annahme, daß ..Schiller“" von Dostoevskij nicht mehr als ganz. .firemd“" sondern als ein Tell der russischen Kultur betrachtet wurde, konnte die folgende imagothematisch relevante

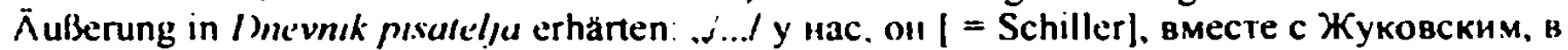
душу русскую всосался. клеймо в ней оставил, почти период в истории нашего развития обозначия" |/../ bei uns, hat er sich, zusammen mit /.ukovskij, in dic russische Seele eingesaugt, hat ihr ein Mal aufgedrückt, und fast eine ganze Periode in der Geschichte unserer Entwicklung bedeutet) (vgl. Bd. 23, S. 31 (1)nevnik pisatel/a za $1876 \mathrm{gerl}$. Jum". g/ava

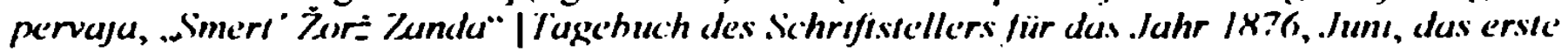

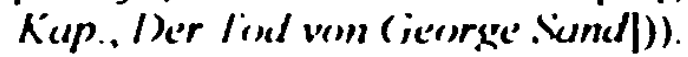

Es wird auch überpruft werden mussen. ob darüber hinaus in den Werken Dostoevskijs zwei Imagothemes des „.Westens“ zu finden sind, die neben den beiden des .verwestlichten Rußlands“" auftreten, oder, ob es sich eher um eine Opposition zwischen mehreren nationalen bzw. religiosen (westlichen) Imagothemes und Rußland handelt. z.B. das ..katholisch-jesuitischpolnische“, das ..idealistisch-deutsche“ oder das ..kapitalistisch-englische”. Vgl. die Literatur zu Schiller in Rußland und in der russischen L.iteratur: SimONS 1992-1993 (S. 64f.), sowic HARDER 1969 und ROGALSKI 1960. 
Stereotyp werden in Unižennye $i$ oskorblennye auch europäische Länder geschildert, so z.B. das konventionell klischeehafte Italien in der Erzăhlung Nellis. Das "Italien" Nellis erinnert somit an das "Spanien" Moskalevas. Neben den literarischen Stereotypen werden zur Charakterisierung des Raumes des Romans die "Realien“" Petersburgs, der am stărksten verwestlichten Stadt des petrinischen Rußlands im Stil der natürlichen Schule, hinzugefügt. 


\section{6. ЗНМНИЕ ЗАМЕТКН О ЛЕТННХ ВПЕЧАТЛЕННЯХ (1863) \\ [WINTERALIFZEI HNIINCIEN IIBER SOMMEREINDRIICKE] $]^{211}$}

Ein einziges polnisches Imagem, die Redewendung padam do nóg die schon in dem ersten in dieser Studie interpretierten literarischen Werk Dostoevskijs, in der Erzăhlung Roman $v$ devjati pis mach vorkommt, ${ }^{212}$ trifft man in den essayistischen Reiseskizzen Zimnie zametki o letnich vpečallenijach (1863) wieder. Diese wie die Zapiski iz Mertvogo doma in der Ich-Form verfaßten Aufzeichnungen über die "Eindrücke“ aus den großen Städten Westeuropas, Berlin, Koln, Dresden, London und Paris, sind nach der ersten Reise Dostoevskijs in den Westen in der Zeitschrift Vremja veröffentlicht worden. ${ }^{213}$ Sie weisen thematische Bezüge zu den publizistischen Aufsätzen auf, die er zu Beginn der sechziger Jahre verfaßt hat. Die Thematik der Zimnie zametki o letnich vpecatlenijach kreist um die Beziehungen zwischen „Rußland" und „Europa“ und erörtert die Folgen der „Europäisierung“ Rußlands aus der Sicht des damals in der Viremja entwickelten ideologisch-utopischen Programms der sogenannten "Bodenständigkeit" (počvenničestvo), das zwischen den Ansichten der westlich orientierten Autoren (beispielsweise A.1. Gercens oder I.S. Turgenevs) und der Slavophilen zu vermitteln versuchte. ${ }^{214}$

Die vier ersten der insgesamt acht Kapitel in Zimnie zametki o letnich vpecallenijach enthalten Reflexionen über das „russische Europa“, ${ }^{215}$ d.h. das nachpetrinische, „verwestlichte“ Rußland. In den vier letzten Kapiteln finden sich Reflexionen über ..Furopa" selbst.

Der Ich-Erzähler ${ }^{216}$ wird zu diesen im „ersten Teil“ (Kap. 1-4) enthaltenen grundlegenden, verallgemeinernden „winterlichen“ Reflexionen über die „Ver-

211 Die deutschen Übersetzungen russischer Zitate aus Zımmıe zumeıkı o leınıch vpeciulenyach werden nach der Ausgabe DOSTOJEWSKI 1958, S. 735-833/W'mlerulficichnungen über. Sommeremelrücke], angeführt.

212 Vgl oben, S. 140.

$213 \mathrm{Vgl}$ den Kommentar zu Entstehungsgeschichte und Gattungshezeichnung dieser ..Reiseaufzeichnungen“ in. Bd. 5, S. 357fr.: es wird darin u.a. auf die Bezüge zu den anderen publizistischen Aufsảzen Dostoevskijs aus der Zeitschrift Vremla sowie zu den Beschreibungen Westeuropas bei solchen russischen Autoren wie N.M. Karamzin. D.I Fonvizin. A.I. Gercen. A. Grigor ev bzw. zu den satirisch-politischen Aufzeichnungen H. Heines über Frankreich und Deutschland hingewiesen, v.a. zu dessen (iessündiussien (1853-1854). Betont wird auch die grundlegende Bedeutung der Zıminie zame'kı o lelnich vpeciullenyach für Dostoevskij selbst, der diese Skizzen für den zweiten Band der Ausgabe seiner Werke von 1865-1866 aus allen anderen in der V'remja veroffentlichten Aufsätzen ausgewählt hatte, ebd., S. $361 \mathrm{Vgl}$ auch IIFiNe 1982, S. 9-57.

214 Vgl dazu LAZARI 1988

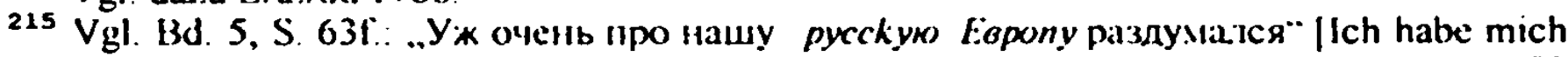
schon zu sehr vom Nachdenken über unser russisches liuropa umstricken lassen: S. 770 |kursiv die Verf. II.

216 Fs ist hier vom ..Ich-Erzahler“ und nicht von ..Dostoevskij”“ die Rede, weil die Form der Reiseaufzeichnungen, die in Rußland eine relativ lange Tradition aufweist, sich nicht eindeutig als ".Reisereponage“, als .Tatsachenliteratur”, bezeichnen läßt, obwohl der Erzähler von Zimnie zumetkı o letnich vpécullen!jach eindeutig autobiographische Züge aufweist. 
westlichung“ Rußlands durch die Erinnerungen an die „Sommerlichen“ Begegnungen mit Europäern im Zug und im Reisewagen und durch die Eindrücke aus den deutschen Stădten Berlin, Köln und Dresden angeregt. Anschließend widmet er sich im ,zweiten Teil“ (Kap. 4-8) den Betrachtungen über die westeuropăischen Hauptstădte London und Paris, in denen er Symbole des "Westens", seiner Kultur und Lebensweise, erblickt. In Zimnie zametki o letnich vpecatlenijach werden somit diejenigen negativen utopischen Imagothèmes des verwestlichten Rußlands und des Westens zum ersten Mal explizit formuliert, ${ }^{217}$ die in den Zapiski iz Mertvogo doma und in den anderen nach der Rückkehr aus der Verbannung veröffentlichten literarischen Werken in Ansätzen bereits implizit vorhanden waren. Dadurch bilden diese an der Grenze von Reiseskizze und publizistischen Text stehenden „subjektiven Aufzeichnungen“ zusammen mit den anderen publizistischen Schriften Dostoevskijs aus den sechziger Jahren eine programmatische Einheit.

Der "erste Teil" der Zimnie zametki o letnich vpecatlenijach, in dem das negative utopische Imagothème des verwestlichten Rußlands herausgearbeitet wird, beginnt mit dem Motiv der ursprünglichen Faszination des russischen IchErzăhlers für den „Westen" und seinet Sehnsucht "nach der Fremde“, d.h. nach "Europa", das aber zugleich mit dem parallelen Motiv seiner großen Enttăuschung mit dem metaphorisch genannten "Land der heiligen Wunder" bzw. mit dem „Gelobten Land" konfrontiert wird, ${ }^{218}$ die er während seiner ersten Reise nach Westeuropa erfahren hat.

217 Diese beıden utopischen Imagothèmes weisen auch eine ideologische Komponente auf, die hauptsächlich in den satirischen Beschreibungen der fremden stereotypen Figuren enthalten ist, wodurch der von Paul Riccur bemerkte komplementăre Charakter von „Utopien" und „Ideologien" bestătigt werden kann

21. $\mathrm{Vgl}$. ebd., S. 46f.: . .../ cko.1ьkо я ожицалт себе от этого путешеств!я! /.../ Вся 'страна святых чудес' представітся мне разом, с птичьего по.ета, kak земьяя обетованная с горы в перспеkтіве“ | /... / wieviel ich mir von dieser Reise versprach. /../ Das ganze "Land der heiligen Wunder" wird sich mir auf einmal darbieten, gleichsam aus der Vogelschau, wie das Gelobte Land von einem Berge aus in der Fernsicht; S. 738]. Zimnie zamelkı o letnich vpeciatlenyach werden dabei insgesamt aus einer zeitlichen, raumlichen und einer (selbst)ironischen Distanz („,aus der Vogelperspektive“) erzählt, denn der Ich-Erzähler betont, $\mathrm{da}$ er seine Reiseeindrücke erst nach der Rückkehr in die Heimat niedergeschrieben habe, er betont ebenfalls, daß seine Urteile wegen der Kürze seiner Reise und seiner angegriffenen Gesundheit möglicherweise allzu allgemein bzw. gar falsch seien. Sein Patriotismus und die Kritik des Westens werden immer wieder als „kein $\mathrm{Haß}$ gegenüber dem Ausland“ hingestellt. Der Ich- Erzahler hat darüber hinaus viel Gemeinsames mit dem veruestlichten .Paradoxalisten“ aus den Zapiskı iz podpol'ja [Aufjeichnungen aus dem (Intergrund] (1864), der ebenfalls vierzig Jahre alt ist und stăndig über seine schlechte Gesundheit klagt. u.a. über Leberbeschwerden, die ihn verbittert und bose gemacht hätten, vgl. ebd., S. 99ff. und S. 46f: .J../ разве можно хоть что-нибудь порядочно разг.ядеть, проехав сто.тько дорог в два с по.товиною месяца. /.../ в монх обстояте.тьствах невозможно не .тгать" |Kann man denn überhaupt etwas richtig erkennen, |wenn man so viele Wege in zweieinhalb Monaten bereist hat; Erg. d. Verf.]; S. 737; [ /../ in meiner Lage ist es unmoglich nicht zu lügen: Übers. d. Verf.], bzw. „O, ради Бога, не счнтайте, что любить родину - значит ругать иностраниев и что я так именно думаю“ |Doch - Gott behüte! - denken Sie nun nicht, daß sein Vaterland lieben die Auslănder schelten heiße, und daß ich es so verstehe: S. 745|. ebd., S. 51. Vgl. außerdem die Anmerkung im Bd. 5, zur Anpielung auf das Gedicht des 
Die erste enttăuschende Begegnung des Ich-Erzăhlers mit dem „Gelobten Land" fand auf der Hin- und Rückreise durch Deutschland statt. Seine Eindrücke von den deutschen Städten, ihren Sehenswürdigkeiten und Bewohnern, fallen negativ aus. Berlin erinnert inn sofort an Petersburg, so daß in der Beurteilung der deutschen Metropole sich nicht nur seine Abneigung gegenüber einer deutschen Stadt ăußert, die fast an eine Empfindung des physischen Ekels grenzt, sondern auch gegenüber Petersburg, der russischen "Nachahmung" einer westeuropaischen Stadt:

Берлин, например, произвел на меня самое кисьое впечатıение, и пробыл я в нем всего одни сутки. И я знаю теперь, что я виноват перед Берлином /.../. А отчего произошла пагубная ошибка моя? Решительно от того, что я, больной челювек, страдяющий печенью, двое сутok ckakaл по чугунке ckвозь дождь и туман до Берлина и, приехав в него, /.../ вдруг с первого взгляда заметиј, что Берлин до невероятности похож на Петербуре. /.../ K тому же сами берлинци, все do единого, смотрели такими немиали, что я,/.../ посkорее улизнул в Дрезден, питая гјубочайшее убеждение в том, что $k$ немцу надо особенно привыkать и что с непривычки его весьма трудно выносить в больших масcах [kursiv die Verf.].

[/.../ Berlin zum Beispiel, hat auf mich den sauersten Eindruck gemacht, und ich bin in dieser Stadt im ganzen vierundzwanzig Stunden geblieben. Heute weiß ich, daß ich Berlin unrecht tue /.../. Und woher kam mein unheilvoller Intum? Entschieden daher, daß ich, ein kranker. leberleidender Mensch, der zweimal vierundzwanzig Stunden lang mit der Eisenbahn durch Regen und Nebel nach Berlin gefahren war, /.../ plötzlich auf den ersten Blick nur dies wahmahm: daß Berlin bis zur Unglaublichkeit an

Slavophilen A. S. Chomjakovs Mecila |li:in Truum|(1835), in dem ebenfalls der Westen "страна святых чудес" |das Land der heiligen Wunder| genannt wird, obwohl er jedoch seine Giöße bereits eingebüßt habe und mit einem "мертвенный покров", einem leichentuch, bedcckt sei. Das Gedicht schließt mit der Zeile .Проснися, аремјющий Восток!" |Wach auf, du schlummernder Osten!|, ebd., S. 361. Dieses Zitat m Zimnie =umetkı o lènich vpeciullenıjach kündigt die skeptisch-ambivalente E:instellung des Ich-Erzählers dem Westen gegenüber an.

Vgl. Chomsakov 1969, S. 103: O, грустно, грустно мне! Ложiтtся тыма густая \ Па латьнем Запале, стране святых чудес: \Светьта прежние б.леднеют, догорая, \И звез-

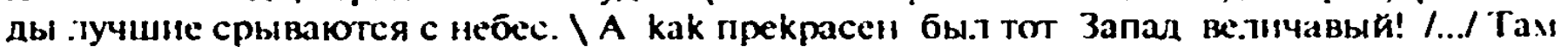
со.лние мудрости ветречати наши очи $\backslash / . . /$ Сия:та там .любовь в невинной красоте $/ . . /$ \И веры опиь живой потоки света .7ІLт!... /.../ Н Но rope! веk проше.1, и метрвенным покровом \залернут Запад весь. /.../ Ус.лышь же глас судьбы, /... Проснися, дрем.люциий Bocrok! [Traurig bin ich. so) traurig! Dichter Nebel / legt sich auf den fernen Westen. auf das Land der heiligen Wunder: , Die früheren hellen Himmelskorper erblassen. indem sie erloschen : Die hellsten Sterne fallen vom Himmel. / Und so wunderbar war dieser erhabene Westen! / Dort sind unsere Augen der Sonne der Weisheit begegnet. '...' Die Liebe erstrahlte dor in unschuldiger Schönheit. /.../ / Und das Feuer des lebendigen Glaubens ergoß sich in lichtströmen! /...' / Aber o weh! Ein Jahrhundert ist vergangen / Und der ganze Westen ist mit einem Leichentuch bedeckt. I... Höre die Stimme des Schicksals, $i . . . i$ Wach auf, du schlummemder Osten'] 
Petersburg erinnert. /.../ überdies sahen die Berliner alle so ungeheuer deutsch aus, daß ich, /.../ mich schleunigst nach Dresden davon machte, in meiner Brust die tiefste Überzeugung năhrend, daß man sich an den Deutschen erst besonders gewöhnen muß und er, wenn man sich noch nicht an ihn gewöhnt hat, in großen Massen schwer zu ertragen ist. $]^{219}$

Die Bewohner Berlins werden aus dieser „Vogelperspektive“ als nationale Stereotypen, als die Deutschen (als alter) gesehen, trotz der Relativienung dieser kritisch-verallgemeinernden Sicht, die durch die Müdigkeit und die kränkliche Verfassung des Ich-Erzăhlers immer wieder gerechtfertigt wird. Ähnlich fallen seine ersten flüchtigen Eindrücke über die Frauen aus Dresden, über den Kölner Dom, über „Kölnisch Wasser“ und die neue Kölner Brücke aus. ${ }^{220}$

Im zweiten und dritten Kapitel werden diese enttäuschenden Eindrücke mit Überlegungen über das „verhăngnisvolle“ Verhältnis Rußlands zum Westen verknüpft, von dem sich die Russen immer angezogen fühlten. Der Ich-Erzähler erortert dabei in einem Dialog mit seinen impliziten "verwestlichten" russischen Lesern die seit dem XVIII. Jahrhundert immer weiter voranschreitende und von ihm negativ beurteilte, weil unvollkommene und schädliche Okzidentalisierung der Russen bzw. des russischen Adels an Beispielen aus der russischen Literatur. ${ }^{221}$ Das RuBland des achtzehnten Jahrunderts wird dabei dem des neunzehn-

219 Ebd., S. 47 [S. 739].

220 Ebd., S. 47ff. Diese negativen Eindrücke werden mit dem Gefühl des verletzten Patriotismus und des Neides auf den zilisatorisch höher stehenden "Westen" vermischt, obwohl sic immer wieder durch die Betonung der kranklichen Verfassung abgemilden bzw. in Frage gestellt werden: Помню, мне тогда всё ито-то kазалось и слышалось. Второе об̈стояте.льство, разозлпвшее меня " сде.лавшее несправедпівым, бы.л новый kе.льнский мост. Мост, конечно, превосходный, и город справедтиво гордиття ІІм, но ине показалось, что уж с.лишком гордится. /.../ Я не आиаю, но нне показалось. что неменl kуражıтея. «Верно, догалатся, что я иностранеи и именно русский. - подумал яњ. По крайней мере его глаза чуть не проговаривали: “Ты вицишь наш мост, жа.кий руcсkıй, - ну таk ты червь перед нашим мостом и перед всяkı немеukı че.ловек, потому что у тебя нет таkoro мосташ. Сог.ласіттесь сами, что это обидно. Немеи. конечно, этого вовсе не говорил, даже. нохет, и на уне у него зтого не было, но ведь зто всё равно: я mak был уверсн тогда. /... / ито вскипел окончательно. [kursiv die Verfi.] [S. 74If:: Ich erinnere mich daran, ich glaubte damals daran, duß mir immer wieder irgend etwas auf diese H'eise erschien und daß ich so etwas hörte; Erg. d. Verf. l i... der aweite Umstand. der mich erboste und ungerecht machte, war die neue Kölner Brücke. Die Brücke ist natürlich wunderbar und die Stadt ist mit Recht stolz auf sie, aber mir schien doch. daB sie schon gar zu stolz auf ihre Brücke war. I..J/ch welß micht, ob ich mich läuschte. aher ich glaube dox'h, daß dieser Deutsche sich ganz besonders wichtig dünkte. ..Sicher hat er schon erraten, daß ich ein Ausländer bin, und zwar ein Russe", dachte ich. Wentgsienss schien mur sein Blick nahezu worlwïrllich =u sagen: ..Nun sieh du unsere Brücke. armseliger Russe! So wisse denn, daß du ein Wurm bist vor ihr und vor jedem einzelnen Deutschen, denn eine solche Brucke hast du nicht". Sie werden doch zugeben, daß so etwas kränkend ist. Nutürlich sagte der Deutsche das ja gar nicht. und vielleicht dachte er nicht einmal etwas ähnliches. aher das ist ja schlicßlich ne'hensüchlich: jedenfalls war ich damals so fest üherzeugt. ... daßß ich endgülıg wiütend wurde.]

${ }^{221} \mathrm{Vgl}$. Bd. S, S. 50- 64, z.B. folgende Uneile des Ich-Erzăhlers: „Господи, дa kakıle we мы руссkие? - /.../ Почему Европа iмкет на нас, /.../ таkuе сіцльное, во.льшебное, ири- 
ten gegenübergestellt. Indem die russischen „Oberschichten“ zur Zeit Fonvizins sich noch nicht endgültig dem „Volk“ entfremdet hătten und nur oberflächlich, durch die „europarischen“ Kleider, verwestlicht seien, ${ }^{222}$ ohne ihre nationale Identităt vollständig eingebüßt zu haben, sind die gebildeten adligen Russen des XIX. Jahrhunderts bereits auch in ihrem Denken dem, ,russischen Boden“ entfremdet und zu dem abstrakten Typ des „всемирный общечеловек“ [eines universalen Allgemein-Menschen] bzw. zu dem des "französischen Spießbürgers“ geworden. ${ }^{223}$ Dabei wird jenes Motiv der Verachtung des ,gebildeten“" russischen Adels gegenüber dem russischen "Volk" wiederholt eingesetzt, das in Zapiski iz Mertvogo doma zur Charakteristik der polnischen adligen Figuren diente. Es wird als ein Merkmal der negativen Okzidentalisierung auf die oberen russischen Schichtcn übertragen. ${ }^{24}$ Parallel zu dieser negativen Entwicklung

зывное впечат.тение? /.../ Kak еще не переродилысь мы окончате.лын в европейцев? Что мы не переродилиісь - с этім, я думаю, все сог.7асятся /... was sind wir denn für Russen? /.../ Warum macht denn Europa auf uns /../ einen so starken, so bezaubernden Eindruck, als rufe es uns herbei? /.../ Wie war es nur möglich, daß wir uns nicht endgültig in Europłer verwandelt haben? Denn: daß wir uns nicht verwandelt haben, das werden, denke ich, alle zugeben /.../: 746]

222 Vgl. ebd., S. 56f: .Напяливали шелковые чулкı, парикı, привешивали шпажонки вот и европеeщ“ (Man zog sich seidene Strümpte über die Beine bis zum Knie hinauf, man steckte den Kopf unter eine Perücke, man hängte sich links ein Deglein an und - war nun Europáer; 757|. Hier taucht somit u.a. emeut das Motiv der „Perücke“ auf, das bei dieser Stelle noch kein Merkmal der negativen dekadenten Okzidentalisierung eines Russen bzw. eines Fremden ist.

${ }^{223}$ Ebd., S. 59 und S. 57. Dem nach den ,aus dem Westen gekommenen Ideen“ gebildeten russischen „universalen Allgemcin-Menschen“ (всеяирный общсиеловсk), der in den Zimmic zame'kı " lelnich vpeciallenyach neben dem des .Homunculus“ vorkommt, wird in späteren publizistischen Schriften, bis hin zur ..Puskin-Rede“ (1880), der russische .Allmensch“ (всечеловеk) gegenübergestellt, der die Bindung an den ..Heımatboden“ (nочвa; počva), d.h. scine kulturell-nationale Identität, trotz der .,brüderlichen“ und ,.hingebungsvollen I.iebe" für alles Fremde nicht verloren hat. In der .Puskkm-Rede“" werden Puskins Aleko und Evgenij Oıegin sclch ...Petersburger Typen“, eine Verkörperung des ,.negativ verwestlichten Russen“ genannt. Puškin selbst sei dagegen der ..russische Nationaldichter", der in Tat jana Larina den Urtyp einer tief im russischen Boden veruurzelten Frau geschaffen hat, und er lasse sich als die vollkommene Verkörperung des russischen .Allmenschen“ bezeichnen. Vgl. Bd. 26

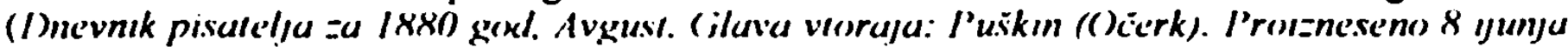

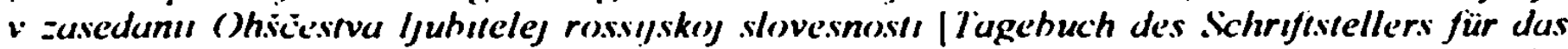

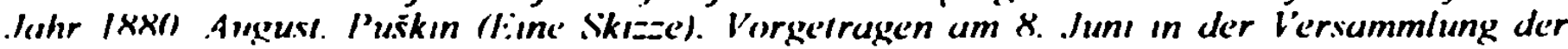
(iescllschufi der fireunde russischer l.tlerulur ), S. 136-149, passim

$224 \mathrm{Vgl}$. ebd Damals seien die russischen Adligen. Jlаже мужику /.../ понятнес /.../, меныне чужими ему, меньше немиами" (ebd., S. 57) ||Man war] dem Bauern doch verstăndlicher I..., war ihm weniger fremd, war weniger deutsch; S. 757). Jetzt dagegen: .. /.../ Гlетербург взя. свос. Теперь уж мы впо.те европейшы и дорос.и1./.../ народ нас совсем за иностранцев считтает, нй оцното с.юва нашего, /.../ ни одной мыс.ты нашей не понымает. /.../ kak свысоkа решаем вопросы, да kakıе вопросы-то: почвы нет, народа нет, национа.ььноть - это то.тько известная система податей, душа tabula rasa /.../. . (S. 57 und S. 59) //.../Petersburg hat gesiegt. Jetzt sind wir bereits ganze Furopäer. sind herangewachsen $/ . . /$ Jetzt hält uns das Volk bereits ganz und gar für Ausländer, versteht kein Wort von uns, $i . . /$ keinen Gedanken von uns $/ \ldots /, i . j$ mit welcher Herablassung lösen wir die Probleme, und noch dazu was für Probleme: es fehlt an Boden, es 
des nachpetrinischen Rußlands gebe es aber für den Ich-Erzăhler eine gegen die Verwestlichung gerichtete Bewegung, eine Kritik an der ,sklavischen Nachahmung des Westens", die er bereits in den Werken Fonvizins und bei anderen russischen Autoren, von Griboedov und Puskin bis Turgenev, bemerkt habe, ${ }^{225}$ denn:

Неужели ж и в самом деле есть kakoe-то химичеckoe соединение человечесkого духа с родной землей, что оторваться от нее ни за что нельзя, и хоть и оторвешься, таk все-таkи назад воротишься.

Ведь не с неба же /.../ свалилось k нам славянофильство /.../. [Sollte es doch tatsăchlich eine solche chemische Verbindung des Menschengeistes mit der Heimaterde geben, daß man sich um keinen Preis von ihr loszureißen vermag, und wenn man es dennoch versucht, dann doch immer wieder zu ihr zurückkehren muß? Der Slawophilismus ist bei uns doch gewiß nicht einfach vom Himmel herabgefallen /.../. $]^{226}$

Der nationale Charakter sei als der „Schopfer" der national geprăgten Kultur, als eine unauflosbare Vereinigung, als eine „organische Verbindung“ mit dem Heimatboden angeboren, so daß eine Rückkehr zu der verlorengegangenen kulturellen Identităt moglich sei. Diese angeborene Făhigkeit zur Ablehnung der fremden Kultur und zur Rückkehr zur počva, zum russischen „Volk“ und die Überwindung der Okzidentalisierung, wird somit zum eigentlichen Thema der ersten vier Kapitel der Zimnie zametki o letnich vpečatlenijach.

Das vierte Kapitel sowie das erste des „zweiten Teils“ (Kap. 4-8), in dem der "Westen" selbst negativ dargestellt und verurteilt wird, knüpft an eine im zweiten Kapitel angefuhrte stereotyp-kritische Äußerung Fonvizins über die Franzosen an („Рассудка француз не имеет, да и иметь его почел бы за великое для себя несчачтье" [Der Franzose kennt keine Besonnenheit (= eigentl. Verstand), ja, ihr Besitz würde ihm sogar als das großte persönliche Unglück erscheinen: $S$. 744] ) ${ }^{227}$ Diese Äußerung wird aber für den Ich-Erzähler zum Ausgangspunkt

fehlt an Volk; Nationalität - das ist nur ein bestimmtes Steuersystem; die Seele - tabula rasa /../; S. 758 und S. 761f.] . Es handle sich aber dabei um ..paбское преклонение /../ nеред европейскими формами цивнлизацин“ (S. 61) [sklavischer Kniefall vor den europaischen Formen der Zivillisation; S. 765 ]. Vgl. dazu auch S. 93 den Vergleich zwischen den Russen und Franzosen bzw. Auslăndern („Мы бо.тьше шиниkи, меньше дорожим свомм, даже не .тюбим свое /.../; . тезем в европейские, обшече.ловеческие интересы, не приталтежа ниkakой нации, а потому, естественно, относимя ко всему хо.тоднее, /.../ и во всяkом с.лучае отв.теченнее". [Wir sind mehr Zyniker, schătzen das Eigene weniger, ja, wir lieben es nicht einmal /.../.../ wir drăngen uns in europäische, universale Interessen, ohne überhaupt zu einer Nation zu gehoren, und so verhalten wir uns natürlich zu allem viel kühler /.../ und jedenfalls abstrakter; S. 824|).

$225 \mathrm{Vgl}$. ebd., S. 56ff. Besonders die Figur des scheinbaren ..Nihilisten“ Bazarov aus dem Roman Turgenevs (Mcy i dell zeichne sich durch eine Unruhe und Sehnsucht aus, die ihn als einen ..romantischen Idealisten" zeigen (..npıзнаk ве.rukoro сердиа" [Das Anzeichen eines großen Herzens; S. 7621), ebd., S. 59.

226 Ebd., S. 52 [S. 747].

227 Ebd., S. 50 [S. 744]. Siehe auch die Anmerkung dazu, ebd., S. 363: Es handelt sich um ein ungenaues Zitat aus einem Brief Fonvizins an P.I. Panin vom 18 (29) September 1778 aus Aachen, also aus Deutschland: „Рассудка француз не имеет и иметь его почел бы 
einer noch eindringlicheren, vertieften Kritik an den Franzosen eingesetzt, indem sie von ihm paradoxerweise durch seine eigenen Beobachtungen des franzósischen Bürgertums widerlegt wird, weil ihm die Franzosen (= die Pariser) im Frankreich des Napolen III. noch viel „rationaler“, „vernünftiger“, d.h. negativer erscheinen als ihre ,leichtsinnigen" Vorfahren vor einigen Jahrzehnten Fonvizin erschienen waren. ${ }^{228}$

In den vier auf diese Weise mit den Reflexionen über das verwestlichte Rußland verbundenen "westeuropäischen" Kapiteln werden die „Symbole“ des "Westens", die Hauptstädte London und Paris bzw. das Leben der Pariser Bürger eingehender geschildert. Den Eindrücken aus I.ondon sind aber im Vergleich mit Paris nur wenige Seiten bestimmt, die dem viel kürzeren Aufenthalt des Ich-Erzählers in dieser Stadt im Vergleich zu einem beinahe einmonatigen in Paris entsprechen.

Die englische Hauptstadt erscheint ihm dem äußeren Anschein nach belebter und bedrohlicher als das ...stille“, bürgerliche Paris, das mit einem stereotyp „ordentlichen" deutschen Universitätsstädtchen, mit Heidelberg, verglichen wird, so daß sie auf den ersten Blick einen Kontrast zu ihm bildet:

/.../ /Іариж удивительный город. И что за комфорт /.../ лля тех, kоторые имеют право на удобства, /.../ kakoe /.../ затишье порядkа. /.../ еще немного, и полуторамијлионный Париж обратится в какой-нибудь окаменельй в затишье и порядке профессорский немецкий гороdok. вроде, например, kakого-нибудь Гейдельберга. І../ Куды в зтом отношении, например, ЛІондон! /.../ Всё таk громладно и резко в своеобразности /.../ визе и вой мюашин, /.../ этот кажсущийся беспорядоk, kоторый в сунности есть буржуазный порядок в высочайшей степени, эта отравленная Темза, /../ эти великолепные скверы и парки, эти страшные углы города, kak Ваийтчапель, с его полуголым, ликим и голодным населением. Сити с своими миллионами и всемирной торговіей, кристатьный двореи, всемирная выставkа. [fett und kursiv Dostoevskij; kursiv die Verf.]

[ .../ Paris ist eine bewundernswerte Stadt. Und was für ein Komfort !... lür jene, die das Recht auf Bequemlichkeiten haben, /.../ welch eine /.../ Windstille in der Ordnung. /.../ noch ein Weilchen - und das eineinhalbmillionenköpfige Paris wird sich in irgend so ein in W'indstille und Ord-

несначтьем своей жнзни, нбо оный заставил бы его размыныять. когда может неселиться". |Der Franzose hat keinen Verstand und ihn zu haben würde er für das große Inglück seines lecbens halten. weil dieser ihn zum Denken gezuungen hätte, indem er sich doch amüsicren kann.|

${ }^{228}$ Ebd., S 64. Vgl. auch S. 85 über Paris in den Augen der Franzosen: .Dparuyza, To ects парнжаніна (потому что вель, в сунності, все франиузы нарижане), никогда не разуверіншь в том, что он не первый че.ловек на веем земном шаре. Bıрочем, о всем земHow uape, kpowe Ilapıжа, он весьма ма зо знает. Да и знать-то очень не хочет". [man wird] einen Pariser (denn im (irunde sind doch alle Franzosen Pariser) niemals davon üherzeugen :...i, daß er nicht der erste Mensch auf dem ganzen Erdball ist. Übrigens. von dem ganzen Erdball außer Paris weiß er nur äußerst wenig. Und er will auch nicht einmal viel davon wissen: S. 9101 
nung versteintes deutsches Professorenstädtchen verwandeln, von der Art zum Beispiel irgendeines Heidelberg. /.../ Wie anders ist dagegen in dieser Beziehung zum Beispiel London! /.../ Alles ist so riesenhaft und kraß in seiner Eigenart. I.../ dieses Gepfeif und Geheul der Maschinen, /.../ diese scheinbare Unordnung, die im Grunde die bourgoise Ordnung in höchster Entwicklung ist, diese vergiftete Themse, /.../ diese großartigen Squares und Parks, diese unheimlichen Stadtwinkel wie Whitechapel mit seiner halbnackten, wilden und hungrigen Bevölkerung, die City mit ihren Millionen und dem Welthandel, der Kristallpalast, die Weltausstellung... $]^{229}$

Trotz der äußeren Unterschiede werden aber beide Hauptstădte als das Kơnigreich des Gottes Baal, als ein Symbol des westlichen Materialismus, Individualismus und Egoismus bezeichnet. Denn die „bürgerliche Ordnung" von Paris und das Chaos, die "Unordnung" von London bilden nur scheinbare Gegensătze. In beiden Stădten dauert ein Kampf auf Leben und Tod an, „упорная, глухая и уже застарелая борьба, борьба на смерть всеобще западного личного начала с необходимостью хоть kak-нибудь ужиться вместе, хоть kak нибудь составить обшину и устроиться в одном муравейнике". [/../ [der] hartnăckige, dumpfe und schon veraltete Kampf /.../, der Kampf auf Tod und Leben, des allgemein westlichen persönlichen Prinzips mit der Notwendigkeit, sich doch irgendwie miteinander einzuleben; /.../ eine Gemeinschaft zu bilden und sich in einem einzigen Ameisenhaufen einzurichten /.../. $]^{230}$ Technische "Errungenschaften" der westlichen Zivilisation, durch die Londoner Weltausstellung und den Kristallpalast symbolisiert, werden in den darauffolgenden Schilderungen dem fast unbeschreiblichen Elend der Massen in den Arbeitervierteln gegenübergestellt. Im Zusammenhang mit dieser Beschreibung tauchen neben den Motiven, die zugleich fremde Imageme sind, wie des "Baals", „Babylons" und des „Kristallpalastes" das Motiv des ..Ameisenhaufens" [muravejnik; мууравейниk] auf. ${ }^{231}$ Nach TELESFOR POŹNIAK handelt es sich

${ }^{229}$ Ebd., S. 68f. [S. 778ff.]. Diese Schilderung Londons weist Bezūge zu dem Buch Friedrich Engels über Die lage der arheitenden Klasise in Iingland... auf, u.a. zu dem Kapitel über die großen englischen Stădte, dessen erste Auflage von 1845 Dostoevskij bekannt gewesen sein mag. Vgl. ENGEl.s 1845, S. 39-42 (die Beschreibung der Themse, der ..Massen der Arbeiter“ und der .,schlechten Viertel“, u.a. von Whitechapel, sowie das Motiv des ,Kneges Aller gegen Alle" und der Vereinsamung jedes einzelnen Menschen, ebd., bes. S. 36f. und S. 42).

230 Ebd., S. 69 [S. 779].

${ }^{231} \mathrm{Vgl}$. ebd, S. 70f: „. Это kакая-то библсйская картина, ито-то о вавильнс, какое-то пророчество из Anokanuncuса, в очню совершающееся. Вы чувствуете, что мното надо вековечного духовного отпора и отріпания, /.../ не поктоніться факту " не обоготворіть Ваaла, то есть не принять сушествующего за свой идеат |Das ist wie irgendein hiblisches Bild, irgend elwas von Babylon, ist wie eine Prophezeiung auss der Apokalypse, dic sich leibhaftig verwirklicht hat. Sie fühlen, daß es viel ewiger geistiger Gegenwehr und Verneinung bedarf, /.../ sich nicht vor der Tatsache zu beugen und Baal nicht für Gott zu haiten, das heißt, das Verwirklichte nicht anzuerkennen als unser Ideal; S. 780||kursiv die Verf.]. Die Motive des ..Kristallpalastes“ und des ..Ameisenhaufens" treten darüber hinaus in der gleichen Bedeutung in den Zupiski iz pxdpol lja auf. Neben den apokalyptischen Schilderungen des Elends einer Großstadt werden aber auch die Bemühungen der 
bei diesen düsteren Beschreibungen der westeuropäischen Großstadt um die biblische Variante des Mythos des Orients, der bereits in der Petrasevcy-Zeit als ein soziales Thema bei Dostoevskij entstanden und seit Zimnie zametki o letnich vpečatlenijach in den späteren literarischen und publizistischen Schriften Dostoevskijs als ein Symbol des Westens und des Petersburger verwestlichten Rußland anzutreffen sei. ${ }^{232}$

Trotz dieser endzeitlich-infernalen Beschreibungen Londons, des numinosen Symbols des Bosen, werden die Engländerinnen und Engländer vorwiegend po-

katholıschen Missionspropuganda, die Armen durch materielle Hilfe zu bekehren, sowie die anglikunische Kirche der Reichen kritisiert:

..Католический священник сау выс.ледт и вотрется в бедное семейство kakoго-нібудь работникkа. /.../ Он всех накормıт, оденет, обоореет, /.../ де.лается другом дома и пол конец обращает всех в като.личество. /.../ Анг.инансkıй же священник не пойлет k бедному. Бедных в иерковь не пускают /.../. Aнг.ликансkие священиkи "I еписkопы горды "I богаты /.../ и жиреют в совершенном спокойствин совесті. /.../ Это ре.липія богатых "I уж без масkи. По крайней мере рашюнатьно " без обмана. /.../ Но богатые анг.личане и вообще все тамоиныт золотте телыцы чрезвычайно религиозны, мрачно, утрюмо "I свогобразно. Английсkие поэты испокон веков .пюбят воспевать красоту пасторсkıх житиш в провиншин, /.../ их добродете.льных жен и идеатьно прекрасных бе.локурыъх дочерей с го.тубыми г.тазами", ebd., S. $73 f$.

[S. 786ff: Der katholische Geistliche spürt persönlich die arme Familie irgendeines Arbeiters auf, in die er sich dann unmerklich eindrängt. /... er gibt ihnen allen zu essen, gibt ihnen Kleider, sorgt für Heizung $/ . . . /$ wird zum Freund der ganzen Familie, und schließlich bekehr er sie alle zum Katholizismus. :...! Der anglikanische Geistliche dagegen wird doch nicht zu einem Armen gehen. Arme werden ja nicht einmal in die Kirche gelassen /... Die anglikanischen Pfarrer und Bischöfe sind stolz und reich i...' und werden dick in vollkommenster Gewissensruhe. /.../ Das ist die Religion der Reichen, und zwar ohne jede Maske. Nun. wenigstens ist's so - rationell, und es wird nichts vorgetäuscht. '.../ Doch die reichen Engländer und überhaupt alle dortigen goldnen Ochsen sind überaus religios, sind es auf eine finstere, mißmutige und eigentümliche Art. Die englıschen Dichter aber besingen von jeher mit Vorliebe die Schönheit der Pfarthäuser in der Provinz. /.../ ihre tugendhaften Frauen und idealschönen blonden, blauăugigen Töchter.]

232 V'gl. POZNI.AK 1992: ..Obraz ramowy Babilonu funkcjonuje w systemie ikonicznym Dostojewskiego jako znak ekwiwalent semantyczny materialistyczno-mechanistycznego swiatopogladu dezintegrującego zbiorowośc ludzka. I.../ Po pierwsze, ten makroznak stanowi parabole krysztalowegn palacu - mrowiska, po drugie - budowli, będącej ateistycznym wyzwaniem Boga. po triecie - miasta - wielkiej nierzadnicy, apokaliptycznego Babilonu. Osobnym wạtkıem jest mikrotemat Baala-Belzebuba, który pisarz wiaże z Babilonem pośrednio. nadalac owemu makroobrazowi infernalne zabarwienie", S. 77-99 (()ru'nl hıblınnv

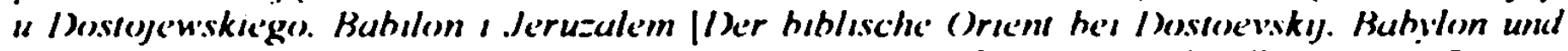
.lerusal'm]). bes S. 8017 [Das Rahmenbild Babylons funkttoniert im ikomschen System Dostoevskijs als eine semantische Äquivalenz für die matenalıstisch-mechanistische Weltanschauung, die eine menschliche Gemeinschaft desintegriert. I ...i Erstens bildet dieses Makro-Zeichen eine Parabel für den Kristallpalast und den Ameisenhaufens, zweitens für einen Bau, der die atheistische Herausforderung Gottes ist, und dnttens für eine Hure, das apokalypische Rom. Ein besonderes Motıv ist das Thema des Baal-Beelzebubs. das der Schriftsteller mit dem Babylons mittelbar verbindet, indem er diesem Makro-Zeichen eine infernale Färbung verleiht]. $V_{g l}$. auch ebd. zur Polemik mit und zu Bezügen zu Voltaire und Cernyševiskij (u.a. zum Motii des ..Ameisenhaufens"). Im Kommentar zum 5. Band wird darauf hingewiesen, daß N.G Cernyševskij dieses Motiv von Lessing übernommen hat. Bd. 5, S 371 Vgl. CERNYSF:VSKIJ 1948, S. 209ff. 
sitiv (als positive Stereotypen, d.h. als alter) geschildert, obwohl die englischen Arbeiter als ein "finsteres Volk“ bezeichnet werden. ${ }^{233}$ Die Englanderinnen sind für den Ich-Erzăhler die „schönsten Frauen der Welt“, die Englănder zeichnen sich dagegen, im Unterschied $\mathrm{zu}$ ihm selbst und $\mathrm{zu}$ anderen im Westen reisenden Russen, durch ihren Widerstand gegenüber den materiellen Versuchungen der Pariser Lảden sowie durch eine geregelte Lebensweise aus, die an ihnen auch beim Betrachten der Kunstwerke oder im Zug zu beobachten sei. ${ }^{234}$

${ }^{233} \mathrm{Vgl}$. Bd. 5, S. 70 (Beschreibung der sich am Wochenende, in der Nacht "vergnügenden“ Arbeiter: „Все пьяно, но без веселья, а мрачно, тяжело, и все́ как-то странно молчаливо“ [Alles ist betrunken, doch ohne Fróhlichkeit, ist vielmehr finster, schwer, und alles ist irgendwie eigentümlich stumm; S. 782 J).

234 Vgl. Bd. S, S. 71f. [784f.] (die Beschreibung einer jungen Frau im Prostituierten-Viertel: „Bо всем мире нет таkого красівого пाпа женшин, kak анг.тічанкі. /.../ Лıиа точно из kıпсеков. /.../ раз /.../ я увидел одну девушkу и остановится просто изудленныи: ничего подобного такой идеатьной красоте я еше не встречат никогда. /.../ Черты .тииа были нежны, тонки, что-то затаенное и грустное быто в ее преkpacном и немното гордом взгляде, что-то мыслящее и тоскующее. Мне кажется, у ней была чахотка. Она была, она не могла не быть выше всей этой то.ты несчастных женщин свомм развипiем: иначе, что же значіт .nицо че.ловечесkоe? /.../: [S. 783ff.: In der ganzen Welt gibt es keinen so schonen Frauentyp wie die Englanderin. /.../ Gesichter wie von einem Keepsake. /.../ [einmal; Erg. d.Verf.] /.../ erblickte ich /.../ ein Mădchen, vor dem ich einfach stehen blieb vor Verwunderung: eine so ideale Schonheit war mir noch nie begegnet. /.../ Ihre Züge waren zart und fein, etwas Verschwiegenes und Trauriges lag in ihrem schónen, ein wenig stolzen Blick, etwas Denkendes und Schwermütiges. Ich glaube, sie war schwindsüchtig. Sie stand in ihrer Entwicklung hoher, sie mußte einfach hoher stehen als alle diese unglücklichen Frauen denn was hătte sonst ein Menschenantlitz zu bedeuten?]). Das „idealschơne, vergeistigte “ Gesicht dieser Frau, das ein tiefes Leid ausdrückt und sie zu einem ..Subjekt" macht, erinnert an die Beschreibung des Gesichts von Nastas ja Filippovna in dem Roman /diot und kehrt somit als ein Motiv zur Charakterisierung einer idealschơnen verwestlichten Russin wieder. Auch das Motiv eines „,beleidigten Mådchens (Kindes) ${ }^{\star}$ kehrt in spăteren Romanen wieder: Помню раз, в то.тпе народа. /.../ я увидел одну девочку, лет шести не более, всю в .охмотях, грязную, босую /.../. Она шта /.../ с видом тakoro ropя, тakoro 6езвыходного отчаяния на .иие, что видеть это маленькое создание, /.../6ы.то даже kak-то неестественно и ужасно бо.льно“; [Einmal erblickte ich in dem Gewimmel der Straße ein Kind, ein Mädchen von hochstens sechs Jahren, bestimmt nicht alter, in Lumpen gekleidet, schmutzig, barfuB /.../. [Es] ging /.../ mit dem Ausdruck eines solchen Kummers, einer so hoffnungslosen Verzweiflung im Gesicht, daß der Anblick dieses kleinen Geschopfes $1 . . . /$ irgendwie geradezu widernatürlich war und entsetzlich schmerzte], ebd;

S 52f. (ein Englănder im Zug: „С.лева сицел чистый, кровный анг.тчанин, рыжый, с ангтийскщм пробором на го.ове и уситенно серьезный. Он во всю дорогу не сkазал ни

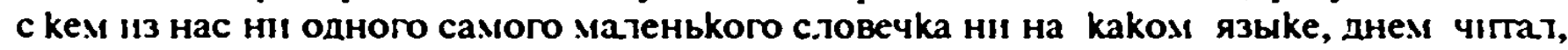
/.../ " kak то.тько стало десять часов вечера, немедленно снят свон сапопи и надел туф.ли. Вероятно, это так заведено у него бы.ло всю жизнь, и менять свонх привычек он не хотел и в ватоне “ [S. 749: Links saß ein echter, ein Vollblut-Englander, rotblond, mit einem englischen Scheitel und von betontem Emst. Wăhrend der ganzen Reise sagte er zu keinem einzigen von uns auch nur das kleinste Wort /.../; am Tage las er /.../, und abends zog er, sobald es zehn Uhr wurde, sogleich seine Stiefel aus und Pantoffeln an. Wahrscheinlich hatte er das in seinem Leben einmal so eingefuhrt, und seine Gewohnheiten wollte er offenbar auch auf der Reise nicht ăndern.]) und S. 77 (die Englănderinnen beim Einkăufen in Paris: „Pуссkим вообще ужасно хочется показать в магазинах, что у них необъятно много де- 
Diese englischen Figuren erinnern an diejenigen aus anderen literarischen Werken Dostoevskijs und verraten bereits seit dem Roman L'nizennye $i$ oskorblennye ihre literarische Herkunft (als literarische Stereotypen u.a. aus den Romanen Dickens). In allen literarischen Werken treten sie in Kontrastfunktion zu den russischen bzw. anderen fremden Figuren (als alter) auf und werden im Vergleich mit den meisten Fremden positiv geschildert. ${ }^{235}$

In Zimnie zametki o letnich vpecallenijach werden aber auch mehrere französische Figuren beschrieben: Polizisten im Reisewagen, ein älteres Ehepaar, das Besitzer eines Hotels ist, in dem der Ich-Erzăhler in Paris wohnt, sowie französische Bürger „an sich“, deren nationaler Charakter und Lebensweise. ${ }^{236}$ Auffallend ist der Kontrast zwischen der positiven Schilderung der gütigen und sich liebenden französischen Hotelbesitzer und der äußerst negativen der französischen Bürger, des französischen Bürgertums. Dieser Kontrast läßt sich wohl dadurch erklären, daß es sich im Fall der französischen (Spieß)bürger um das nationale Stereotyp handelt, das der in Rußland bekannten tranzösischen Trivialliteratur entstammt und in Zimnie zametki o letnich vpecatlenijach als Symbol des typischen französischen Bürgers eingesetzt worden ist, um das französische Bürgertum einer ideologischen Kritik unterziehen zu können. ${ }^{237}$

нег. Зато находится же на свете таkое бесстылство, kak например в анг.личанках, kоторые /.../ начінают - о ужас! - торговаться $113-3 а$ kakıx- нибудь десяти франков“.

[S. 794: Russen haben überhaupt die Sucht, bei Einkäufen in Läden so zu tun, als hătten sie unermeBlich viel Geld. Dafür aber gibt es auch eine Unverschämtheit in der Welt, wie zum Beispiel bei den Engländerinnen, die :...; |- wie entsetzlich! -; Erg. d. Verf.| wegen irgendwelcher zehn Franken zu handeln anfangen]) sowie S. 63 (Russen und Engländer in europäischen Museen: .. Bсе они ходят с пидами и жадно бросаются в kаждом городе c.ıотреть редкості, /.../ точно с.тужбу продо.тжают отечественную /.../: г.аззют на говядину Рубенса и верят, что это три грашиі /.../: бросаютя на Сикстинскую мадонну и стоят перед ней с тупым ожıданием /.../. И отходят удивาенные, что ничего не с.тучі1.тось. Это не самодово.льное и совериенно машинатьное .юбопытсво анг.лйских туристов и туристок, смотряних йо.лее в свой пил, чеи на редкости, ничего не ожидакumin /...

IS. $7680^{\circ}$. Alle haben sie den „Führer“ in der Hand, und in jeder Stadt stürzen sie sich gierig auf die Sehenswürdigkeiten $/ . . . ;$ als setzten sic einen vaterländischen Dienst for $/ . . /$ : sic yaften das Mastfleisch eines Rubens an und glauben $: \ldots i$, das seien die drei Grazien $i . . . ;$; sic stürzen sich zur Sixtinischen Madonna und stehen vor ihr in stumpfer Frrwartung /.../. Und sie gehen weg, verwunder, daß nichts geschehen ist. Das ist nicht das selbstzufriedene und vollkommen mechanische Interesse englischer Touristen und Touristmnen, die mehr in ihren ..Führer” sehen als auf die Sehenswürdigkeiten, die nichts enwarten i.../.1). Siehe besonders zu Sixtinischen Madonna unten. S. 266

${ }^{235} \mathrm{Vgl}$. dazu unten, beispielsweise im Zusammenhang mit dem Roman /grok, S. 248ก ${ }^{236} \mathrm{Vgl}$. Bd 5, S 64ff. (die Polizisten und das Ehepair), 74f. (die französischen Bürger bzw der Typ dex französischen Bürgers, seine Frau und ihr l,jebhaber als die .Franzosen an sich“) Positiv Wirl auch em Schweizer im 7.ug nach Paris beurteilt, ebd., S. 64 ..простой и скромный че.товек, средних .тет, чрезвычайно приятный собеседник, с kо-

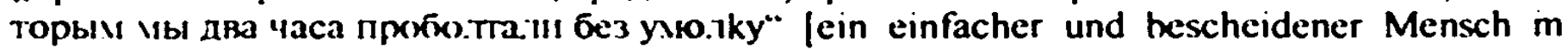
mittleren Jahren, mit dem wir zwei Stunden lang ununterbrochen geplaudert hatten]

${ }^{237}$ Die einschlägigen Kapitel tragen daher die Titel ()pyl o huriua. Brıhrı i mahıs |lim Versuch üher den Bourge'os. Brihri und Mkahisch| (durch diese .Kosenamen“ wird zusätzlich die typisıerende Beschreibung des französischen Bürgers (hourge'olis) unterstrichen), ebd., S. 74 und 90 . Vgl. auch ebd. S. 374 (die Anmerkung zur S. 95) über das französische Melodram 
Die Bürger von Paris, der Stadt des Baals, werden als selbstzufriedene, vertogene und betrügerische Egoisten und Materialisten charakterisiert, die auf $\mathrm{Be}$ achtung äußerlicher Formen aus sind. Trotz der scheinbar stabilen politisch-sozialen Lage des Bürgertums im Frankreich des Zweiten Kaiserreichs fürchten sie sich vor der Revolution. Der Charakter des franzosischen Bürgers, der franzósischen Frauen und Mănner, wird an mehreren Beispielen erlăuert. Thre negativen oben genannten Eigenschaften werden als durch den nationalen Charakter verursacht gedeutet:

Париханин, как птица страус, любит затыкать свою гольву в necok, чmoб mak умс и не видать настигающих его охотников. /.../ он /.../ чуть не говорит: «Вот, поторгую сегодня маленько в лавочке, да бог даст завтра опять поторгую /.../. Ну, а там, а там, только бы вот nockopee наkопить хоть kрошечky, и - «après moi le déluge». Omчeго он куда-то прибрал всех бедных и уверяет, что их совсем нет? /.../ Если посмотреть на большой двор в Палерояле вечером, /.../ то придется непременно пролить слезу умиления. Бесчисленные мужья прогуливаются с своими бесчисленными эпузами под руky, kpyгом резвятся их милые и благонравные детки, фонтанчик шумит и однообразным плеском струи напоминает ваме о чем-то покойном, /.../ геudestbбepeckos. /.../

Hakonить фортуну и иметь как можно больще вещей - это обратиіось в самый главный кодекс нравственности, в катехизис парижанина. /.../ Бедный Cokpam есть только глупый и вредный фразер и уважается только разве на театре. /.../ буржсуа /.../ ужасно љюбит поиграть и в высшее благородство. Все франиузы имеют удивительно благородный вид. У самого подлого франиузика, который за четвертак продаст вам родного отца, /.../ такая внушительная осанка, что на вас нападает недоумение. [kursiv die Verf.]

[Der Pariser liebt es, wie der Vogel Strauß, seinen Kopf in den Sand zu stecken, um die Jäger, die ihm schon auf den Fersen sind, einfach nicht =u sehen. /.../ als sage er fast wortwortlich: „Heute mache ich wieder ein paar Geschäftchen in meinem Laden und, so Gott will, morgen auch /.../. Nun und dann, dann aber ..., wenn man nur schneller ein Sümmchen in Sicherheit hătte, und /.../ «après moi le déluge»". Warum hat er alle Armen irgendwohin weggeschafft. und warum beteuert er. es gäbe sie /... überhaupt nicht? /... Betrachtet man abends [den Hof des Palais Royal; Erg. d. Verf.], so ist man unfehlbar versucht, eine Träne der Rührung zu vergießen. Um die Zeit ergehen sich nämlich dortselbst unzăhlige Ehemänner mit ihren unzăhligen Epousen am Arm /.../, indes ihre reizenden, wohlerzogenen Kinderchen ringsum spielen. Dazu plätschert das Springbrünnlein, und das eintonige Rauschen seines Wassers erinnert einen an etwas Ruhiges, /.../ Heidelbergisches. /.../

und die Komödie der Zeit Napoleons III., deren Handlung und Figuren in Zımnı zumetkı 0 lenich vpecullenyach parodistisch nacherzählt werden. 
Ein V'ermögen aufzuspeichern und möglichst viel Suchen zu besiten, das ist zum Hauptgesetz der Sittlichkeit, ja, zum Katechismus des Parisers geworden. /.../ Ein armer Sokrates ist nur ein dummer und schădlicher Phraseur und wird höchstens im Theater geachtet /.../. /.../ dieser Bourgois /.../ liebt /.../ es ungeheuer, sich als den edelsten der Menschen aufuspielen. I... Die Franzosen haben alle ein bewundernswertes edles Gehabe. Selbst der erbärmlichste Französchen, das für einen Viertelrubel seinen leiblichen Vater an Sie zu verkaufen bereit ist /.../, hat /.../ eine so sichere, selbstverständliche Haltung, daß Sie in Zweifeln befangen dastehen und sich bloß wundern können. ] $]^{338}$

238 Ebd., S. 74ff. [S. 788ff.], vgl auch die kritische Charakteristik des Ehe- und Familienlebens der Pariser Bürger und die negative Beschreibung der Französinnen, ebd., $\mathrm{S}$. 90ff. (Bribrı I nuabı:'):

..Восо̆ще парıжанин, чуть-чуть с деньжонкам!1, же.ая женитьсья, "1 выбирает невесту с деньжонками. /.../ бракы по .любви становятся всё бо.лее и бо.лее невозможными и счітаются почти непріцличнымıн. /.../ Мабıшь /.../ /е pопшет и не мечтает, kak в иных варварсkıх " смешных зем.ях, учиться, например в универсітетах и заседать в ктубах " депутатах. /.../ она, в суцностлі, таkая же kanırтатистkа " kопеечница, kak ॥ cупруг /.../ итра. интрига - в этом всё дтя мабиши. /.../ Мабıшь манерна, вы.ломана, вся нестественная, но это-то и пленяет, особенно б.лазированных и отчасти развращенных .юдей, потерявших вкус к свежей, непосредственной красоте./.../ Мабıшь /.../ лаже редко и хороша собой. Что-то даже злое в .лие. /.../ Дาя паріжанина бо.льшею частью всё равно, что настояшая .юбовь, что хорошая подде.лkа под любовь. Даже полде.лkа, может быть, бо.льше понравıтся":

[S. 820ff: Überhaupt wird ein Pariser, der heiraten will und selber Geld hat, sei es auch noch so wenig, unbedingt eine Braut mit Geld heiraten. /.../ Liebesheiraten werden immer unmoglicher und gelten fast schon für unanständig. /.../ Mabisch /.../ /murt einmal nicht und träumt nicht davon; Erg. d. Verf. I, wie es in manchen barbarischen und komischen I ändern geschieht. zum Beispiel irgend etwas zu lernen, an Hochschulen zu studieren und in Ausschüssen zu sitzen, oder gar Abgeordnete zu werden. /... im Grunde ist sie genau so eine /.../ [Kapitalistin. Erg. d. Verf.] und genau so geldgierig wie ihr Mann. /.../ Spiel aber, Intrige - das ist doch das Wichtigste fü Mabisch. !.../ Mabisch ist manierien, gezient, in allem unnatürlich, aber gerade das ist es ja, was bestrickt, besonders gewisse blasierte und mehr oder weniger verdorbene Männer. dic den Geschmack an frischer, unmittelbarer Schönheit verloren haben. $i . . f$ [Mabisch] /.../ ist sogar nur selten schön an sich. Sie hat sogar etwas Boses im Gesicht. /.../ Für den Pariser ist es meistentells vollkommen gleich, ob es echte Liete ist oder eine gute Nachahmung der liebe. Ja, vielleicht gefallt ihm die Nachahmung sogar von vornherein besser I

Ironisch dargestellt wird auch die ..Liebe” der franzosıschen Bürger ..zur Natur und zum Meer”. eine Anspielung auf Rousseau. .Буржуа $/ . . /$ имеет /.../ две законнейшее потребности. /... / зто - voir la mer, вндеть море. /.../ Ц Другая '... / это se rouler dans I'herbe

/.../ выехав за горол, чрезвычайно .юбит и даже за до.лг почіттет, пова.ятся в травс. iспо.лняет это даже с достоннством, чувствуя, что соединяется при зтом avec la nature , ॥ особенно .юбйт, ес.ли на него кто-нибудь в это время смотрітт. /.../ L homme de la nature et de la vérité!"”, chd. [S. 825t: Der Bourgeois hat /.../ zwei durchaus gesetzmaßige Bedürtnisse /.../. Das erste /.../ ist: voir la mer - das Meer zu sehen. $/ . . /$ das zweite /.../ ist - se rouler dans I'herbe...$/$ Der Panser, der aus Paris hinaus in die Umgebung fahrt. liebt es und halt es sogar für seine Pflicht, sich im Grase zu wälzen, durchdrungen von dem IBewußtscin, daß er sich nun avec la nature vereinigt; und besonders angenehm ist es ihm dann, wenn jemand dabei zusieht. $i . . / \mathrm{L}$ homme de la nature et de la vérité!] 
Emeut wird Paris mit Heidelberg verglichen, das im "Pariser" Kapitel der Zimnie zametki o letnich vpecatlenijach wiederkehrende Motiv des „leise und eintơnig plătschernden Springbrünnleins" dient als Metapher der (scheinbaren) Ordnung und Stille, der scheinbaren Tugendhaftigkeit der Pariser Bürger, die den Moralisten Sokrates nur als eine Theaterfigur, als einen harmlosen Schwătzer ertragen konnen. Ein anderes fremdes Imagem, die dem franzosischen Kơnig Ludwig XV. zugeschriebene Wendung Après moi le déluge dient ebenfalls zur Hervorhebung der kalten egoistischen Gleichgültigkeit der Franzosen gegenüber anderen "Menschen", die ihre Feinde und keine "Mitmenschen" sind. ${ }^{239}$

Das polnische Imagem - die Redewendung padam do nóg - wird in Zimnie zametki o letnich vpecatlenijach zur Charakterisienung der verlogenen lakaienhaften Liebedienerei, Kriecherei der Franzosen vor ihrem Kaiser Napoleon III., die aus ihrem nationalen Charakter hervorgehe, benutzt:

И почему мемсду бурмууа стоеько sаkеев, да еше при таkой благородной наружности? /.../ Лакейство въеdaется в натуру бурэсуа всё более и более и всё более и более считается dобродетелью. Tak и должно быть при теперешнем порядке вещей. /.../ $A$ главное, главное - натура помагает. /.../ Франиуз лобит умсасно забежсать вперед, kak-нибудь на глаза $k$ власти и слакейничать перед ней что-нибудь дажсе совериенно бескорыстно /.../. Взял я раз /.../ одну газету /.../. Смотрю: письма из Виши. В Виши гостил тогда император, ну и двор, разумеется; были кавалькады, гулянья. Корреспондент всё это описывает /.../:

«У нас много превосходных наездников. Разумеется, вы тотчас же угадали самого блестящего из всех. Его величество прогуливается каждый день в сопровождении своей свиты и т. д.»

/.../ тут /.../ расчет: пусть неправдоподобно, смешно, пусть сам владыkа посмотрит на это с отвращением и презрительным смехом, пусть, пусть, но зато увидит слепую покорность, увидит безкраничное mádan do мог, рабсkoе, глупое неправdоподобное, но зато mádaм do мог, а это главное. /.../ если 6 это было не в духе нации, если 6 таkая пошлая лесть не считалась /.../ совершенно в порядке вещей, и даже приличной - возможно ли было бы поместить в парижской газете такую корреспонденцию? [kursiv die Verf.; fett und kursiv Dostoevskij]

Das Bedürfnis des franzossischen Bürgers, sich .im Gras zu wälzen“, könnte möglicherweise eine Anspielung auf das Bild Manets Frühslück ım Freien (Déjeuner sur I'herbe) sein, das 1863 in Paris ausgestellt wurde und Dostoevskij bekannt gewesen sein dürfte. Siehe auch unten die stereotypen Schilderungen der Franzosen in den Romanen lgrok bzw. Poxirostok, die den französischen (SpieB)Bürgern aus Zimnıe zametkı o letnich vpeciutlenıjuch ähneln. S. $247 f$., S. 352ff. sowie S. $358 \mathrm{ff}$.

${ }^{239}$ In den Zapiski $t=$ podpol "ja wird sie in eine ,nihilistische" Äußerung des verwestlichten russischen Paradoxalisten, eines russischen .Teetrinkers" umgewandelt, vgl. Bd. 5, S. 369 (Anmerkung der Herausgeber zu ebd., S. 75) und ebd., S. 174 (7upiski $1=$ podpol 'ja): .. Я ckaжу, что свету проватиться, а чтоб мне чай всегда питть" [Ich sage: die ganze Welt mag von mir aus untergehen, denn ich will Tee trinken; Übers. v. Rahsin; Vgl. DosToJEWSkI $1980 \mathrm{~b}$ |A ufferchnungen aus dem (Intergrund). S. 566). 
[Und warum gibt es unter den Bourgeois so viele Lakaien, und das noch dazu bei so edlem Äußeren? /.../ Das Lakaientum frißt sich in die Natur des Bourgeois immer mehr hinein und wird immer mehr für eine Tugend gehalten. I.../ Doch die Hautpsache, die Hautpsache ist-daß die Natur selbst dazu hilfi. I.../ Der Francose liebt es ungeheuer, sich vor den Augen der Obrigkeil irgendwie auszuzeichnen, vor ihr irgendwie zu dienern. ihr womöglich ganz uneigenüt=ig einen Dienst zu erweisen. sogar ohne dafür eine sofortige Belohnung zu erwarten /.../. Einmal nahm ich im Café eine Zeitung in die Hand /.../. Mein Blick fiel auf eine Überschrift: „Briefe aus Vichy". In Vichy hielt sich damals gerade der Kaiser auf, nun und natürlich auch der ganze Hof: da gab es Spazierritte, Vergnügungen usw. Der Berichterstatter schildert alles /.../:

.,[Es gibt ] jetzt [bei uns; Erg. d. Verf.] viele vorzügliche Reiter /.../. Aber selbstverständlich erkennt man sofort den glänzendsten unter ihnen allen. Seine Majestät reitet jeden Tag in Begleitung seiner Suite usw. usw."

$/ . . /$ hier ist es $/ . . /$ eine $/ . . . /$ Berechnung $/ . . /$ : mag es auch unwahrscheinlich und womöglich lächerlich sein, mag der Herrscher [das] selbst mit Widerwillen [lesen] und /.../ [darüber verächtlich lachen; Erg. d. Verf.], mag er, mag er! - aber dafür wird er blinde Ergebenheit /.../ sehen, [das grenzenlose padam do nóg. das sklavische, dumme und unwahrscheinliche, das padam do nóg sehen; Erg. d. Vert. ] /.../, und das ist die Hauptsache. /.../ wenn so etwas nicht im Geiste der Nation läge, wenn eine so fade Schmeichelei nicht für durchaus /.../ in Ordnung und sogar für anständig gälte wäre es dann möglich, daß in einer Pariser Zeitung solche Berichte erschienen? [kursiv die Verf; fett und kursiv Dostocvskij]) ${ }^{240}$

Das zweimal in dieser Passage wiederholte und vom übrigen Text abgehobene. weil zusätzlich kursiv gesetzte polnische Imagem unterstreicht und verstärkt als stilistisches Mittel die ideologische Kritik des Ich-Erzählers an den Franzosen. Das (alt)polnische Idiom, das die „blinde, grenzenlose sklavische Ergebenheit", die .,lakaienhafte" Mentalität des polnischen verwestlichten Adels ausdrückt, wird hier doppelt verurteilt, weil es nicht nur "lakaienhaft", sondern auch eine "Maske“ ist, dem äußeren Schein dienen soll. Es unterstreicht somit die paradigmatische Äquivalenz zwischen dem polnischen Falschspieler aus der frühen Erzählung Roman $v$ devjati pis'mach und dem absichtlich verlogenen französischen Journalisten, denn es wird dadurch implizit angedeutet, da $B$ dic Polen den Franzosen ähnlich, daß ihre Nationalcharaktere verwandt seien, wobei die Lakaienhaftigkeit der Polen diejenige der Franzosen wohl noch übertrifft. ${ }^{241}$

240 Bd. 5, S. 82f. [S. 804ff] ].

${ }^{241}$ Neben diesem Beispiel für die Neıgung der Franzosen zur Kriecherei vor der Macht werden noch Beispiele über ihre Neigung zur .verlogenen falschen Beredsamkeit” angeführ. u a eine Rede des Rechtsanwalts und Abgeordneten Jules Favre und eine Führung im /'aniheon (zu den Gräbern großer Franzosen, Napoleons, Voltaires oder Rousseaus), die von einem .дряхтый п почтенный иныілид" |ein gebrechlicher und ehrwürdiger Invalıde| geleltet ivird: „Это уже был непосредственный, тak ckaзать народный пример .юбви k красноречігю" |Das war nun schon ein unmittelbares. ein sozusagen volkliches Beispiel der Liebe 
Alle besprochenen Reiseeindrücke bzw. Betrachtungen über Paris und London bzw. über den nationalen Charakter der Franzosen, der an Beispielen aus dem Leben des franzosischen Bürgers demonstriert wird, werden vom Ich-Erzăhler zu einem allgemeinen Urteil über den Westen zusammengefaßt. Er stellt fest, daß die Losung Liberté, égalité, fraternité wegen des rationalen Individualismus, des Strebens nach dem eigenen Nutzen und materiellen Wohlstand bei den Franzosen in ihrem Land bzw. im Westen überhaupt nicht zu verwirklichen sei:

Западный человек mолкует о братсве kak o великой dвихущей силе чельвечества и не догадывается, что негде взять братства, коли его нет в действительности. Но оказывается, что сделать братсва нельзя, потому что оно самю deлается, dается, в природе находится. A в природе франиузской, da и вообще западной, его не оказалось, а оказалось начало личное, начало особняkа, усиленного самосохра-

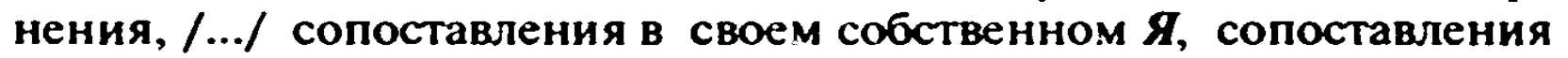
этого $\boldsymbol{Я}$ всей природе и всем остальным людям /.../. [fett und kursiv Dostoevskij ; kursiv die Verf.]

[Der Westeuropäer redet von Brüderlichkeit wie von einer großen, die Menschheit bewegenden Kraft und verfallt überhaupt nicht darauf, daß Brüderlichkeit sich von nirgendwoher nehmen läßt, wenn sie nicht als Wirklichkeit einfach vorhanden ist. I.../ Aber da zeigt es sich. daß Brüderlichkeit überhaupt nicht herzustellen ist. weil sie nämlich von selbst entsteht, weil sie gegeben sein, in der Natur liegen muß. In der französischen Natur aber. ja, in der westeuropäischen überhaupt, hat sich das wirkliche Vorhandensein der Brüderlichkeit nicht gezeigt, sondern statt ihrer das Vorhandensein des Prinzips der Einzelperson, der Personlichkeit, der betonten Selbsterhaltung, /.../ der Selbstbestimmung innerhalb des eigenen $/ c h, / . . /$ das Prinzip, dieses I ch der ganzen Natur und allen übrigen Menschen entgegenzustellen /.../. [fett und kursiv Dostoevskij; kursiv die Verf. []$^{242}$

Die Sozialisten hätten bereits diese Eigenart des westlichen Menschen erkannt und die Losung Liberté, égalité, fraternité um où la mort erweitert, nachdem sie eingesehen hătten, daß diese drei Werte nur durch Gewalt einzuführen seien. Es ist auch auffallend, daß der Ich-Erzähler nicht nur die westlichen bourgois, die besiuenden Gesellschaftsschichten verurteilt, sondern auch die Arbeiter, die für ihn eine ebensolche „Besitzer-Mentalităt" wie ihre „Arbeitgeber" aufweisen. ${ }^{243}$

I...' zur schönen Redekunst: S. 8181. dabeı wird die scheinbare Ehrlichkeit Rousseaus kritisiert. dessen Selbstbezeichnung / homme de la nature el de la vérilé von dem beredten Reiseführer vor seinem Grab angeführt wird, ebd., S. 89f. Vgl. auch unten die kritik der russischen verwestlichten Rechtsanwalte in l'odrosilok (S. 346 und S. 362f.), in Brul ju Kuramazovy sowie in der Publizistik Dostoevskijs (S. 410ff.).

242 Ebd. S. 79 [S. 797].

243 Ebd., S. 78 (.J...' работникı тоже все в душе собственникия: весь ıдеат ıхх в том, "тоб быть собственнıкамıl и наkопіть kak можно бо.тые вещей; такая уж натура“. 
Diesem in den Zimnie zametki o letnich vpecatlenijach herausgearbeiteten negativen utopischen Imagothèmes des Westens, das sich aus den oben besprochenen Imagemen, dem Stereotyp des französischen Bürgers und den ,apokalyptischen" Schilderungen von Paris und London, zusammensetzt, wird das positive utopische Imagothème einer "wahren Liebesgemeinschaft" der Menschen gegenübergestellt, die bereit seien, sich aus Liebe bedingungslos und restlos dem Wohl der Anderen bzw. füreinander aufzuopfem. Die Veranlagung, eine solche Gemeinschaft $\mathrm{zu}$ bilden, müsse jedoch angeboren $\operatorname{sein}^{244}$, und es ist anzunehmen, daß für den Ich-Erzähler das in den ersten vier Kapiteln erwähnte russische Volk eine solche zur selbstlosen Liebe fahige Natur habe, ohne daß jedoch in Zimnie zametki o letnich vpecatlenijach dies positive utopische russische Imagothème explizit „christlich-russisch-orthodox-(byzantinische)“ Prägung aufweist. ${ }^{245}$

Eine solche Utopie der „selbstlosen Gemeinschaft” wird aber als eine Möglichkeit angedeutet, obwohl im ersten Teil die eingeschobenen Reflexionen über das seit dem achtzehnten Jahrhundert verwestlichte Rußland. d.h. seine oberen Schichten, die sklavisch den Westen, v.a. Frankreich nachahmen, pessimistisch sind. ${ }^{246}$

ZLSAMMENFASSUNG: In den Zimnie zametki o letnich vpečatlenijach werden zum ersten $\mathrm{Mal}$ explizit die drei folgenden utopischen Imagothèmes herausgearbeitet: die negativen utopischen Imagothèmes des Westens und des verwestlichten nachpetrinischen Rußlands, die dem positiven utopischen Imagothème der „brüderlichen Liebesgemeinschaft” gegenübergestellt werden. Dieses dritte Imagothème wird als den vom Westen unberührten Russen $(=$ dem russischen Volk) angeboren dargestellt, ohne daß es jedoch bereits eine .,rus-

Idic Arbeiter sind doch alle in der Seele gleıchfalls Besitzer: das Ideal jedes einzelnen von ihnen besteht doch nur darin, Besitzer zu sein und sich moglichst viel Sachen anzuschaffen: so ist nun einmal ihre Natur; $S .796$ ) und $S .81$.

24 Vyl. ebd., S. 80. ...../ надо, чтоб оно сано собой сде.лалось, чтоб оно было в на-

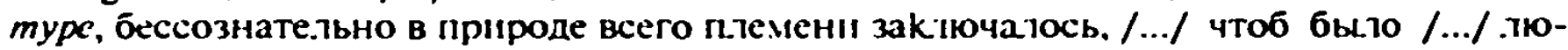
бящее начало - надо тюбить. Нало, чтоб самого инстинктівно тяну.ло на братсво, обшину, на сог.ласие, /.../ несмотря на все вековые страдания нашин, /.../ нес.мотря на вековое рабоство /.../” |kursiv Dostoevskij] |/.../ es ist nötıg, duß ess sich von selhst so muche. duß es in der Natur se'. daB es unbewußt in der Natur der ganzen Rasse liege /.../, damit es /.../ das Liebesprinzip |gebe|, muB man - lieben Es muB einen instinktiv zur Brüderlichkeit hınzıehen, zu Gemeinsamkeıt und Eintracht. /.../ trotz aller vielhundertjährigen Leiden des Volkes..... trotz jahrhundertelanger Knechtschaft /...; S. 799f. | [kursiv Dostoevskij|.

24 Ebd. Siehe zur russisch-orthodoxen und byzantinischen Anthropologie Dostoevskijs bei POZZNIAK 1992 sowie bei I.AZARI 1988

246 Die zwei Figuren aus den parallel zu den Zımnie zamerkı o letmich ypecullentjach enstandenen Zupiskı I polpul ja: der verwestlichte, egozentrische und einsame Ich-Erzahler, der Paradoxalist, der sich jedoch ,.in der Tiefe seines Herzens“" nach der Liebe schnt und gegen sich selbst retulliert, ohne aber die russische religiós-kulturelle Identität wieder erlangen

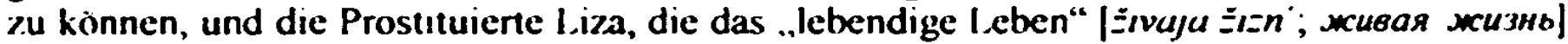
symbolisier, lassen sich als die ersten Verkörperungen der beiden utopischen Imagothèmes Rußlands bezeichnen, die in den später geschaffenen paradigmatisch oppositionellen russischen Figuren noch weiter ausdifferenzient werden 
sisch-orthodox-(byzantinische)" Komponente aufweist, die erst in den späteren literarischen Werken Dostoevskijs vorhanden ist.

Sowohl das polnische Imagem als auch die anderen fremden Imageme, z.B. die Namen solcher Franzosen wie Rousseau, Voltaire, Napoleon III., sind ein Teil des negativen utopischen Imagothèmes des Westens. Sie dienen hauptsăchlich zur Charakteristik des negativen Stereotyps des franzosischen (Spieß)bürgers (als alter), das seitdem in den Romanen Dostoevskijs vorkommt.

Die fremden Figuren (als alter) bilden in Zimnie zametki o letnich vpecatlenijach ebenfalls einen Teil des negativen utopischen Imagothèmes des Westens, obwohl ihre Charakteristik eine ideologische Komponente aufweist. Somit entsteht in Zimnie zametki o letnich vpecatlenijach auch das mit den fremden stereotypen Figuren verbundene negative ideologische Imagothème des Westens: Der franzosische Bürger wird als negatives nationales franzosisches Stereotyp vorgeführt und kritisiert. Das englische literarische nationale Stereotyp bzw. einzelne individualisierte Figuren der Fremden, englische Frauen und Mădchen bzw. das franzosische Ehepaar im Hotel, lassen sich dagegen als Teil des positiven ideologischen Imagothèmes des Westens bezeichnen, das aber zugleich positiv utopische Züge aufweist (die Beschreibung der ,ideal-schönen“ Englănderin, einer Alius-Figur).

In den Zimnie zametki o letnich vpečatlenijach gibt es dagegen kein positives utopisches Imagothèmc des verwestlichten Rußlands, das in den früheren literarischen Werken und in den späteren Romanen vorkommt, und durch solche positiven fremden Imageme wie z.B. Schiller oder Shakespeare symbolisiert wird. Indem aber diese positiven Imageme die positiv verwestlichten, ,idealistischen“ russischen Alius-Figuren charakterisieren, konnten sie in den polemisch-publizistischen „Reiseskizzen" nicht vorkommen. 
7. ИГРОК. РОМАН (ИЗ ЗАПИСОК МОЛОДОГО ЧЕЛОВЕКА) (1866)

[DER SPIELER (AUS DEN AUIFZEICHNINGGEN EINES תINGEN MENSCHEN)] ${ }^{247}$

Der Roman lgrok ist im Frühherbst des Jahres 1863 in Rom konzipiert worden, obwohl Dostoevskij die Arbeit daran bald abgebrochen hatte, um Prestuplenie $i$ nakazanie zu schreiben. Igrok konnte erst drei Jahre später veröffentlicht werden. ${ }^{248}$ Dieser in höchster Eile verfaßte Roman ist wie mehrere frühere literarische Werke ein Ich-Roman, in dem viele autobiographische Elemente thematisiert werden. Igrok gehört zusammen mit den gleichzeitig entworfenen Zimnie zametki o letnich vpecatlenijach und mit den Zapiski iz podpol'ja zu den ersten literarischen Werken Dostoevskijs, in denen die utopischen (und zugleich ideologischen) Imagothèmes des verwestlichten Rußlands und des Westens ihre endgültig herausgearbeitete Form anzunehmen beginnen. In Igrok finden sich besonders viele imagothematische Bezüge $\mathrm{zu}$ den Zimnie zametki o letnich vpečatlenijach. Dadurch läßt sich die Annahme erhärten, daß diesen Reiseaufzeichnungen eine grundlegende Bedeutung für die Evolution der utopisch-ideologischen Ansichten Dostoevskijs zufältt, die in den darauf folgenden literarischen Werken ästhetisch, d.h. sprachlich-stilistisch transformiert bzw. weiter entwickelt werden.

Die Handlung des Romans spielt in dem fiktiven deutschen Städtchen Ruletenburg ${ }^{249}$ und in Paris. Aleksej Ivanovič, der füfundzwanzigjährige Ich-Erzăh-

247 Die deutschen Übersetzungen russischer Zitate aus /grok werden nach der Ausgabe DOSTOJEWSKI $1980 \mathrm{~b}$ angeführt.

$248 \mathrm{Vgl}$. den Kommentar der Herausgeber Bd. 5, S. 398ff. zur Entstehungsgeschichte des Romans und zu autobiographischen und mtertextuellen Bezügen, u.a. zu Puškin, Lermontov, Balzac, George Sand und zu Thackeray.

249 Ebd: Es wird vermutet, daß Dostoevskij die russische Übersetzung der Reiseskizze Thackerays The Kicklehurys on the Rhine|Kikal'bjurl na Rejne: Die Kicklehurys am $R /$ e'm| (18.50) gekannt hat, die in derselben Nummer der 7eitschrift ()recessvennye zapıskı | Falerländısche: Annalen| unter dem Titel Anglyskıc |urıs/y |linglısche Tourıs/en| erschienen war, in der auch eine Komödie seines Bruders Michail veroffentlicht wurde Der Übersetzer A. Butakov hat dabei den Namen des deutschen Kurortes Rougetnonrehourg in Ruletenhurg. |Roulc/lenhurg| umgewandelt. Die Autoren des Kommentars finden auch Bezüge zwischen der Figur der betrügerischen Französın Blanche und der falschen I'rınzessin de Mlogador bei Thackerav, die eine französische Modistin ist. Siche auch bei BLAICHER 1992 zu Thackerays

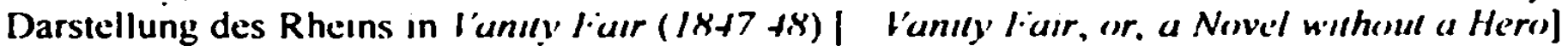
und $\mathrm{m}$ The Kicklehurys in the Rhıne, die nach dessen Ansicht hauptsächlich der Kritik der englischen Gesellschaft dienen (S. 128ff., vgl. bes. S. 131: The Kicklehury:s on the Rhine (1850) dient mehr der Satire englischer Reisender als der Darstellung Deutschlands“.). Vgl auch THACkFray 1902 (S. 169ff: The Kickleburys on tho Rhine). Es lassen sich jedoch noch weitere Bezüge zwischen der Erzählung Thackerays und dem Roman lgrok feststellen. Nicht nur die Figur der hetrügerischen Madame la Princesssc de Mtegrador (... little millıner in the street she mentioned is, and ....' dances at Mabille and Chàteau rouge"), sondern auch andere Figuren und die Schilderung des Roulettespiels sowie des Städtchens selbst erinnem an die Figuren und den Schauplatz von Igrok. Zu diesen Figuren gehören z.B. M/rs. I:anlaul, deren Äußeres ebenfalls an dasjenıge von Mkdemosselle Blanche erinnert; ludy Kicklehury, die wie die Tanıc aus Moskau sich im Roulletespiel beinahe ruinien hat, ein russsscher./unge, der im 
ler, schildert aus der Perspektive seiner unglücklichen Liebe und seiner Spielleidenschaft die Ereignisse, die er als Hauslehrer in der Familie eines russischen Generals in Westeuropa miterlebt hat. Der "Westen" bildet somit wie in den Zimnie zametki o letnich vpecatlenijach den Schauplatz, auf dem sich alle handelnden Figuren, sowohl Russen als auch Auslănder, abzeichnen. Das Stădtchen Ruletenburg, von dem nur das Hotel, der Park mit einem Springbrunnen, ${ }^{250}$, der Slangenberg [Schlangenberg], ein Ausflugsziel in der Umgebung des Stădtchens, ${ }^{251}$ sowie das Spielkasino erwăhnt werden und symbolische Bedeutung haben, erinnert in seiner Atmosphäre an einen "Zauberberg“. Die Besucher der Spielsăle wirken irreal, zumal es sich dabei v.a um kosmopolitische Vertreter der sogenannten höheren Schichten der europäischen Gesellschaft bzw. um getarnte Betrüger handelt, die dadurch zusătzlich das "exotisch-spielerische“ Element betonen. Aus den Briefen Dostoevskijs geht hervor, daß er beabsichtigt hatte, einen Typ des „auslăndischen“ Russen, der sich Rußland entfremdet hat,

Gegensatz zu der englischen Dame erfolgreich spielt; bzw. die Beschreibung der kosmopolitischen Besucher von Rougetnoirebourg und deren Spielleidenschafi, vgl. dazu THACKERAY 1902, S. 191ff, S. 197ff., S. 206ff., bes. S. 210. Die Schilderung des Wassertrinkens an der Quelle in Rougetnotrebourg erinnert dagegen an die Eindrücke aus Bad Ems, die Dostoevskij viel spăter in Dnevnik pisatelja als Beispiele für den „Sieg (der Deutschen) über die Arbeit“ [pobeda nad irudom] geschildert hat; vgl. z.B. die Schilderung eines hübschen Mădchen bei Thackeray, das Mineralwasserglăser unter die Kurgäste verteilt und eine ăhnliche Schilderung bei Dostoevskij. Vgl. ThaCKERAY 1902, S. 197ff. und Dnevnik pisatelja za 1876 god. Majoktjahr' [Das Tagebuch des. Schriftstellers für das .Jahr 1876. Maj-Okıober], Bd. 23, S. 73f. INemcy i trud. Nepostıżmye fokusy; Die Deutschen und die Arbett. Unfaßhare Kunststücke. [̈ber den Sicharfsinn].

${ }^{250}$ Das Motiv des Springbrunnens im Park von Ruletenburg, an dem sich der Ich-Erzähler mit Polina trifft (vgl. ebd., S. 212ff., S. 227ff.) ist eine Anspielung auf die „Heidelbergischen Springbrünnlein" des stillen bürgerlichen Paris in Zimnıe zumetkı o lelnıch vpečarlenijach (vgl. Bd. 5, S. 75f., S. 97 und passim). Zugleich handelt es sich aber auch um eine Anpielung auf die "Springbrunnen-Szene" in Puškms Drama Boris (iexhunov. Der "falsche Larensohn" Dmitrij Samozvanec |= der Falsche Demetrius, der Usurpator|, der ehemalige orthodoxe Mönch, der mit Hilfe des katholischen Polens den russischen Thron erobern will, triff sich an einem Springbrunnen mit der von ihm geliebten Polin Marina (Maryna Mniszek). Puskins Marina ist als eine gefühlskalte und machtbesessene Frau dargestellt und dem (alt)russischen negativen Stereotyp von Maryna Mniszek sowie dem einer „schónen Polin“ als eine „bose Verführerin" nachgebildet. Die Beziehungen zwischen Aleksej und Polina erinnern ebenfalls an diejenigen zwischen Dmitrij und Marina, so daß die "subversive" Okzidentalisierung der beiden russischen Figuren in lgrok durch diesen historisch-literarischen Subtext symbolisch vertieft wird. Vgl. PuSKN 1949b, Bd. 5. S. 278-286 (Neč. Sad. Fontan [Die Nacht. Der Garlen. Der Springhrunnen ().

${ }^{251}$ Der Ślangenberg, von dem sich Aleksej für Polina in den Abgrund stürzen will, hat ebenfalls eine symbolische Bedeutung. Er bezieht sich auf die ..zweifache“ Versuchung Aleksejs durch Polina und den „Westen“ (vgl. 1. Mo 3: „Der Sündenfall und dessen Folgen“ und Mt. 4, 1-11; Lk. 4, 1-13: „Die Versuchung Jesu“), für die er Roulette spielt, um Geld zu gewinnen. Aleksej erliegt also auch der „Versuchung durch den Baal“ (den .,bösen Geist"), von dem bereits der "Westen" wie in Zımnıe zamelkı o letnich vpečatlenijach beherrscht ist, vgl. Bd. S, S. 68ff. (Zimnie zumetki o letnich vpečatlenijach) und S. 214f., 223ff., 295ff. (Igrok)). Das Thema der drei Versuchungen Jesu kehrt erneut im Zusammenhang mit dem Großinquisitor in Ivan Karamazovs "Poem" wieder. Vgl. Bd. 14, S. 224ff., bes. S. 232ff. Siehe auch DOSTOJEWSKIJ 1985, S. 65ff. 
zu zeigen. In dem Roman lgrok taucht außerdem das Motiv der „zufalligen russischen Familie" auf, das wie dasjenige des "ausländischen Russen“, bereits in Zimnie zametki o letnich vpecallenijach erörtert und von Dostoevskij noch mehrmals aufgegriffen wurde, u.a. im Roman Podrostok (1875). ${ }^{252}$ Die "ausländischen Russen“, die im Westen leben und ihr Vermögen im Roulettespiel verlieren bzw. aus Armut das Glück im Spiel versuchen, werden als die Fremden im Ausland zum Thema des Romans. Zugleich werden vom lch-Erzähler die mit ihnen in irgendwelchen Beziehungen stehenden Fremden (Nichtrussen) geschildert: Franzosen, Deutsche, Engländer, Juden und Polen.

$\mathrm{Zu}$ der Gruppe der im Westen lebenden russischen Figuren, die in Ruletenburg durch ihre exotische Fremdheit bzw. Andersheit auffallen, gehören der IchErzăhler, Aleksej Ivanovic ${ }^{253}$ der russische General, seine Kinder und das ihn umgebende "Gefolge“ [svita, couma; Suite], ${ }^{254}$ darüber hinaus die Stieftochter des Generals. Polina Aleksandrovna. ${ }^{255}$

Alle Figuren der verwestlichen Russen, die nicht nur ,immanent verwestlicht“ sind, sondern auch in Westeuropa leben, sind in ihrer "Verfallenheit an den W'esten" und an die westliche materialistische Lebensweise vorwiegend negativ dargestellt. Sie sind ein Teil des schon im Roman Unižnnye i oskorblennye in Ansätzen vorhandenen und in Zimnie zametki o letnich vpečatlenijach herausgearbeiteten negativen utopischen Imagothèmes des venvestlichten Rußlands.

Eine besondere Rolle fallt dabei der plötzlich in Ruletenburg auftauchenden „Großmutter" [babuska; бaбyuka] bzw. der alten Großtante des Generals aus Moskau, Antonida Vasil evna Taraseviceva, zu, und ihren beiden russischen Dienern aus dem vom „Westen“ unberührten russischen Volk, die Kontrastfigu-

${ }^{252} \mathrm{Vgl}$ den Kommentar zu Bd. 5, S. $399 f$.

${ }^{253}$ Den Namen Aleksej teilt er nicht nur mit dem negativ verwestlichten Sohn des Fürsten Valkovskij, Aleša, aus dem Roman I'nižennye I oskorhlennye. sondern auch mit dem Slavophilen Aleksej S. Chomjakov, auf dessen Gedicht Mecilu über das zugrundegehende ..Land der heiligen Wunder" sich Zınime zumetkı oletnich vpecullenijuch beziehen. In der verwestlichten Figur Aleksejs deuten sich also bereits einige Züge der späteren positiv-utopıschen russischen Alius-Figuren an, v.a. von Aleša (Aleksej) Karamazov (dessen Name zugleich auf den russischen ..Gottesmenschen“" Aleksej hinweist), denn er leidet unter seiner .Verfallenheit" an den ..Westen".

254 Eine Ausfahrt (Kavalkade) des Generals und seines Gefolges zu „irgendwelchen Ruinen“ in der Umgebung von Ruletenburg hat moglicherweise einen Bezug zur Erwähnung (in den

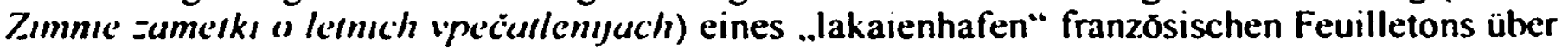
den Aufenthalt des Napolcons III in Vichy und über seine ..Kavalkaden" in Begleitung emes Gefolges, so daß der dem ..Westen“ verfallene russische General als eine Karikatur dieses llerrschers zu verstehen ist. Vgl. ebd., S. 82f. (7inmic zumetk o letmich vpécullemjach) und S. 209 (/grok).

255 Polina wird von der Moskauer Großmutter Praskov ja gennant (ebd., S. 256 und S. 278). Vgl dafu die Charakterisierung der ..verwestlıchten“" Mutter Tat janas in Puškins livgem! Onegin (Kap. 2, XIII), die sich zuerst. gerade andersherum, als die Tante des Generals,

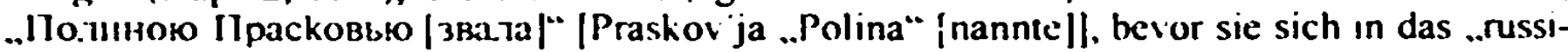
sche Leben auf dem Lande" so gut eingelebt hatte, daß sie..Акулькой прежнюю Селину [стата звать]" [|anfing.| die frühere Céline ..Akul 'ka" zu rufen]. Die Inversion dieses Motivs Puškins in /grok spielt auf die russische Urwüchsigkeit der "Großmutter" und zugleich auf die latent vorhandene Bindung Polinas an das ..vorpetrinische Rußland" an. Vgl. PLiSKIN 1949b, Bd. 5, S. 51 . 
ren zu den „ausländischen Russen“ sind. Die „Großmutter" verkörpert den Typus einer "vorpetrinischen Russin", was durch ihre Herkunft aus dem Moskauer Adel betont wird. Sprache, Benehmen, ihre Natürlichkeit und Ehrlichkeit charakterisieren diese Figur positiv, die trotz. ihrer Behinderung äußerst vital, lebensfroh, neugierig, aber auch herrschsüchtig ist. ${ }^{256}$ Doch auch sie verfallt sofort dem Roulettespiel, wobei diese Verfallenheit als eine Folge der fast kindlichen, durch ihr Alter verursachten Naivităt dieser Dame geschildert wird. Von den westeuropaischen Besuchern des Spielkasinos wird sie als sonderbare exotische Erscheinung betrachtet, die Polen und der Franzose De-Grie sind diejenigen, die die „dumme“ und reiche Russin als ihr Opfer ansehen, um ihr das Geld wegzunehmen (abgesehen davon, daß auch ihr Neffe, der russische General, die gleiche Absicht hat und auf ihren Tod wartet, um ihr Vermögen zu erben und die Franzosin zu heiraten). ${ }^{257}$

Zu der Gruppe der fremden, nichtrussischen Figuren, die als Bürger der westlichen Nationen im Westen „, bei sich und unter sich" sind, gehören u.a.: Franzosen - der falsche Graf, Monsieur le comte bzw. Marquis De-Grie ${ }^{258}$, in den

${ }^{256} \mathrm{Vgl}$. ebd., S. 250ff. Sie wird als eine "furchtgebietende“ Dame [грозная, groznaja; auch "drohend”, vgl. bei Rahsin: „angsteinfloßende“; S. 91] charakterisiert, womit zusatzlich ein Bezug zum Zaren Ivan Groznyj [ = Ivan dem Schrecklichen, eigentlich „dem Drohenden“] geschaffen wird. Die Figur der Tante aus Moskau ist die bildhafte, àsthetische Konkretisierung der imagothematischen Ausführungen in Zimnie zameiki o letnich vpecallenijach über den oberflăchlich, außerlich "verwestlichten" und volksnahen russischen Adel im Rußland Fonvizins. Vgl. Bd. 5, S. 56ff.

257 Der Vorname .Antonida“ konnte sich symbolisch sowohl auf den Heiligen Antonius den Großen (um 250 bis 356), der von "bösen Geistern" in der Wüste versucht wurde, als auch auf den Heiligen Antonius (982 bis 1073), Gründer des Kiever Hohlenklosters beziehen. Der Vatersname "Vasil'evna" schafft einen Bezug zu drei Moskauer Großfürsten dieses Namens und zu Vasilij IV. Ivanovic (1606-10) (=Vasilij Sujskij), der wăhrend der .Zeit der Wirren", nach der Ermordung des falschen Dmitrijs zum Zaren ausgerufen wurde. Der Name kann sich aber auch auf den Gottesnarren Vasilij Blažennyj [Basilius den Glückseeligen] beziehen, dessen Gebeine im Jahre 1588 in der von Ivan IV. (Groznyj) erbauten Moskauer Mariä-Schutzund-Fürbitte Kathedrale am Graben (..Basilius-Kathedrale ${ }^{\mu}$ ) beigesetzt wurden. Diese Kirche wurde 1611 wahhrend der polnischen Besatzung Moskaus geplündert. Der Nachname "Tarasevičeva" bezieht sich moglicherweise auf den ..polenfeindlichen" Taras Bul 'ba aus der gleichnamigen Erzählung Gogol's $(1835 ; 1842)$.

250 Der Name des falschen Grafen De-(irie bezieht sich ironisch auf die Gestalt des ('hevalier des (irıeux von François Prévost d'Exiles (Abbé Prévost) (1697-1763) in seiner Hıstoire du chevalter des (irieur el de Manon lescaul (1731),vgl dazu Bd. 5, S. 402. Auch diese Figur weist mehrere mtertextuelle Bezüge zu dem Stereotyp eines Pariser SpieBbürgers (und u.a. auch zu Rousseau) in Zımnie zametkı o letnich vpeciullenıjach auf, vgl. Z. B. die Imageme: ,se rouler dans l'herbe" sowie .I'homme de la nature et de la verite!"“ (ebd., S. 94) und ihre Transposition in lgrok in einem Gesprăch des Franzosen mit der ..Großmutter”. .Nous boirons du lait, sur l herbe fraiche, - прибавит Де-Грие с зверсkою злобой. Du lait, de l'herbe fraiche - это всё, что есть иде.татьно идицтичесkого у парижсkого буржуа: в этом, kak известно, взг.ляд его на nature et la vérité!"“ (ebd., S. 275) / /Wir werden Milch trinken, im frischem Gras], - fügte De-Grie mit tierischer Boshaftigkeit hinzu. [Milch, das frische Gras] - das ist alles, was ein franzosischer Bourgois an ideal Idyllischem besitzt -: darin, wie bekannt, erschöpt sich seine Sicht auf (die Natur und die Wahrheit!|). Der französische Verkăufer in Zımnie zumetkı o letnich vpeciallenıjach wird wie De-Grie ein 
Polina unglücklich verliebt ist, sowie eine gewisse Mademoiselle Blanche, ${ }^{259}$ ebenfalls eine Hochstaplerin, die, ăhnlich wie der Franzose De-Grie Polina, den in sie verliebten russischen General sowie, im Pariser Epilog des Romans, den Ich-Erzăhler materiell ausnutzt. ${ }^{260}$ Daneben treten noch andere Fremde auf: ein edelmútiger Englănder, Mister Astlej, ${ }^{261}$ der wie der Ich-Erzäler Polina aufrichtig liebt, sowie in episodischen Szenen der deutsche Baron Vurmergel ${ }^{\prime 262}$ mit

„Marquis" genannt, vgl. ebd., S. 77 (Zimnıe zametkı o letnich vpečallenıjach) und S. 213 (Igrok).

Mademoiselle Blanche lăßt sich als die „Verkorperung“ des „Mabiš-Typs“| |Ma bıche; meine Hirschkuh; = mein Liebling| aus den Zimnie zametki o letnich vpecatlenijach bezeichnen (neben dem oben erwăhnten Bezug zu Thackerays Madume la Princesse de Mogador). Vgl. z.B. ebd., S. 90ff. (Zimnie zametkı o letnich vpeciallenıjach) und S. 221 f. und $254 \mathrm{f}$. (lgrok).

${ }^{266}$ Der Ich-Erzăhler verfallt im Epilog des Romans dieser Betrügerin und fahr mit ihr nach Paris, nachdem Polina ihn und sein im Roulettespiel gewonnenes Geld in einem durch verletzten Stolz verursachten .,krankhaften Zustand" verstossen hat, statt mit ihm doch nach Rußland zurückzukehren. Die Reise Aleksejs nach Paris wird von Mister Astlej vorausgesagt: .Все руссkие, имея деньпи, едут в Париж, пояснит мистер Астлей голосом и тоном, kak будто прочел это no kнiskke" [Alle Russen reisen, wenn sie Geld haben, nach Paris, erklărte Mister Astley mit einer Stimme und in einem Ton, als lese er es irgendwo gedruckt: $S$ 185], ebd., S. 300. Das klingt wie eine Paraphrase der Ausführungen in Zimnie zametkı o letnich vpecallenijach über den "Cackij-Typ", der ins Ausland "flieh"“, statt in Rußland zu bleiben: ,Любят у нас Запад, .побят, и в крайнем случае, kak дойлет до точkи, все туда едут" (ebd., S. 62) [Man liebt bei uns $: . . . /$ den Westen, liebt ihn eben, und im außersten Fall /.../ fahren alle dorthin; S. 767]).

261 Dieser "Gentleman" soll dem russischen literarischen Stereotyp eines Engländers nachgebildet sowie sein Name dem Roman Ruth (1853) von Elizabeth Cleghom Gaskell entnommen worden sein, der 1863 in der Zeitschrift Vremja veroffentlicht wurde. Astley weist aber auch einige gemeinsame Züge mit dem ,.ideal schonen“ Sir Ralph aus dem Roman Incliana (1832) von George Sand [Amantine-Aurore-Lucile Dupin| (1804-1876) bzw. mit den Figuren von Dickens auf. Vgl. ebd., S. $401 \mathrm{f}$. Mister Astlej ist die positivste Figur des Romans, siehe ebd., S. 210 oder S. 222. Er ist schüchtern, aufrichtig, zurückhaltend, höflich und ein guter, liebender Mensch. Er erweckt sofort Sympathie bei der habuska (ebd., S. 251). Der lchErzähler selbst mag ihn ebenfalls, obwohl Astlej wie der Franzose De-Grie im Hinblick auf Polina sein Rivale ist. Polina zieht jedoch dem reichen (und edlen) Astlej den "formschönen“ Franzosen vor (vgl. ebd., z.B. S. 213). Die Beziehungen zwischen Polina, dem Ich-Erzähler, De-Grie und Mister Astlej erinnern an diejenigen zwischen Nastas ja Filippovna, Rogožin, Tockij und Myškin aus dem Roman ldhot (vgl. ebd., bes. S. 299f.). Astlej ist aber auch ein Kapitalist, ein "Zuckerfabrikant" (ebd., S. 316). Siehe zu den Stereotypen der Englănder in der russischen literatur bei KIPARSKY 1964

$262 \mathrm{Vgl}$. die Skandalszene im Park von Ruletenburg sowie die Beschreibung des deutschen Barons Vurmergel'm mit seiner Gattin (ebd., S. 231ff.). Polina fordert Aleksej dazu auf, statt sich vom Schlangenberg in den Abgrund zu stürzen, den Baron und seine Frau zu provozieren. Es handelt sich also um eine ironische Banalisierung des Motivs der „Versuchung“, denn Vurmergel' $m$ ist ebenfalls ein sprechender Name (dt. „Würmerhelm“, auch „Schlangenhelm“, von .Lindwurm“ für ..Drache“ oder „Schlange“). In Richard Wagners Ring des Nibelungen wird der Drache Fafner gelegentlich nur „Wurm“ genannt. Vgl. dazu WAGNER 1983, S. 204f. und S. 211. Siehe auch PAUL 1966, S. 401 (,Lindwurm“: .Drache“, ahd. Lindw'urm, mhd. lınıwurm. Der erste Bestandteil (an. lınnr) bedeutete früher für sich ..Schlange“" (urveru: mit lat. Ientus, ,biegsam“); der zweite (s. Wurm) dient zur Verdeutlichung") und S. 814 (Wurm: [...] In der ălteren Sprache fallt unter denselben [Begriff] alles, was kriecht, namentlich auch 
seiner Gattin - und mehrere andere fremde Figuren, darunter polnische, die als eine „Kulisse“ der Spielstadt und dem Spielkasino eine besondere Atmosphăre verleihen.

Auch alle Figuren der fremden Nichtrussen sind mit der einzigen Ausnahme, des „idealistischen" Englănders negativ geschildert, verkörpern den Materialismus des Westens, die Faszination des Geldes, das in Ruletenburg den Rang des höchsten Wertes besitzt. Das „Gold“, um welches diese Besucher des Spielcasinos mit extremer Leidenschaft und Selbstvergessenheit im Roulettespiel kămpfen, symbolisiert einen „Reigentanz des Westens um das Goldene Kalb“ (vgl. 2. Mo 32, 1-35).

Besonders negativ sind dabei die Figuren der Franzosen geschilder, die als falsche Aristokraten und raffinierte Hochstapler auftreten, die die ,auslăndischen Russen" als ihre Opfer betrachten und sie materiell ausnützen, nachdem sie sich sexuell hörig gemacht haben, ohne ihre Liebe erwidern zu können. Die ganze franzósische Gruppe wird in dem Roman lgrok als abstoßend für den Erzăhler, dafür anziehend für Polina und den General gezeigt. ${ }^{263}$ Polina wird der M-lle Blanche entgegengestellt. Alle drei Franzosen werden als Hochstapler und Betrüger großen Maßstabs aufgeführt. Mademoiselle Blanche und der falsche Marquis bzw. Graf De-Grie sind die negativsten Figuren in Igrok, sie verkorpern als alius den „bösen Westen“, dessen verheerenden Einfluß auf die Russen, ob-

die Schlangen, daher l.inctwurm); vgl. dazu: „Helm“. der, der nicht nur eine „zum Schutz im Kampf u. zugleich als Schmuck getragene, den ganzen Kopf bedeckende Haube aus getriebenem Metall als Teil der Rũstung eines Kriegers“ bedeutet, sondern auch „das kegel-, zelt- od. pyramidenförmige Dach eines Turmes; Turmhelm"), so daß cin symbolischer Bezug zur ZZinne des Tempels in Jerusalem" hergestellt wird (vgl. z.B. Mt 4, 5f.).

$263 \mathrm{Vgl}$. zur Charakteristik der Franzosen und Russen durch Aleksej: „ Большею частью мы, русckне, таk богато одарены, что дтя притичной формы нам нужна гения.тьноть. Ну, а гения.тьности-то всего чашче и не бывает, потому что она и вообще, редkо бывает. Это то.тыко у франиузов и, пожатуй у некоторых другіх европейцев таk хорошо определитась форма, что можно глядеть с чрезвычайным достоинством и быть самым недостойным человеkом. Oттого таk много форма у ніх значит. /.../ Oттого-то таk падkи наши барышни до французов, что форма у них хороша. По-моему, впрочем, ниkakoй формы и нет, а один тольkо петух, le coq gaulois. Bпрочем, этого я понимать не могу, я не женшина. Может быть, петухи хороши“, ebd., S. 230.

[S. 52f: Größtenteils sind wir aber, wir Russen, so reich begabt, daß wir zur Gestaltung einer uns angemessenen neuen Form des Anstands direkt Genialităt besitzen müßten. Nun, diese Genialităt aber fehlt uns gewöhnlich, zumal sie überhaupt ein seltenes Ding ist. Nur bei den Franzosen und, sagen wir, auch bei einigen anderen Europăem steht die Form bereits so fest, und man hat sich schon so lange in ihr geübt, daß man außerlich den größten Anstand markieren kann, selbst wenn man innerlich der niederträchtigste Mensch ist. Deshalb wird bei ihnen auch so viel Gewicht gelegt auf die Form. Deshalb hat diese so viel bei ihnen zu bedeuten. I...l Deshalb sind denn auch unsere Damen so eingenommen von den Franzosen, eben weil sie sich von den ăußeren Umgangsformen bestechen lassen. Ich verstehe das nicht. Meiner Ansicht nach ist da überhaupt keine Form vorhanden, ich sehe nur in ihnen den Hahn, le cog gaulois [den gallischen Hahn; Erg. d. Verf.]. Übrigens kann ich das wohl deshalb nicht verstehen, weil ich es nicht beurteilen kann: ich bin keine Dame. Vielleicht sind Hāhne gerade das Richtige]. 
wohl sie als psychologisch differenzierte Stereotypen der franzosischen Bürger zugleich eine ideologische Komponente aufweisen.

Die einzige positiv ideale fremde Alius-Figur ist der Engländer Mister Astlej, den man als eine Variante des schon in Unizennye $i$ oskorblennye vorkommenden Typs eines "Idealisten" bezeichnen kann. Er ist somit das psychologisch differenzierte (positive) Stereotyp eines Engländers.

Andere ebenfalls negative fremde Figuren der Deutschen, Juden oder Polen treten in Igrok als alter, als die "Anderen“ auf. Sie bilden ebenfalls den negativen Kontrast zu den verwestlichten russischen Figuren.

Die negativen fremden Figuren in Igrok verkörpern somit zwei Varianten des negativen Imagothème des „Westens“: die franzosischen betrügerischen Figuren in der Funktion als alius das utopische Imagothème; die episodischen fremden Figuren in der Funktion als alter das ideologische Imagothème des. Westens. Der positiv gezeichnete Englănder dagegen vertritt als einzige Ausnahme das positive utopische Imagothème des Westens.

Die negativen fremden Figuren der Franzosen sowie die positive Figur des Engländers sind die aus der westeuropäischen bzw. aus der russischen Literatur entlehnten und psychologisch erweiterten Stereotypen dieser Nationen. Die episodischen fremden Figuren sind dagegen negative nationale bzw. ethnische Stereotypen, wobei alle Figuren dem literarischen bzw. kulturellen imaginaire social entnommen sind.

Die polnischen Imageme, die in Igrok als episodische Figuren aufteten, werden insgesamt viermal im Zusammenhang mit dem Ich-Erzăhler, mit Mademoiselle Blanche und mit der „Großmutter" erwähnt:

1. Zum ersten Mal werden Polen zu Anfang des Romans in einem Gespräch des Ich-Erzählers mit dem Franzosen De-Grie und dem Engländer Astlej während eines gemeinsamen Mittagessens im Hotel erwăhnt. Der Franzose (DeGrie) wird dabei mit Hilfe der gleichen stereotypen Motive wic seine Landsleute in Zimnie zametki o letnich vpecatlenijach charakterisiert (das arrogante, großiuerische und herablassende Benehmen gegenüber den fremden Geprächpartnem und die "Liebe zur Beredsamkeit"), ${ }^{26 \%}$ so daB der in die Stieftochter des Generals Polina Aleksandrovna verliebte Aleksej Ivanovic den ihm verhaßten und unhöflichen Franzosen reizen will:

За столом французик тонировал необыкновенно; он со всеми небрежсен и важсен. /.../ Изредка я взглядыват на Полину Александровну; она совершенно не примечала меня. Кончилось тем, что я разозлился и решился грубить. [kursiv die Verf.] [Bei Tisch führte der Franzmann mehr als je das große Wort; er benahm sich allen gegenüber sehr nachlässig, wenn nicht gar geringschätzig [bzw.: geringschät=ig und hochmütig; Erg. d. Verf.]. /.../ Hin und wieder blickte ich zu Polina Alex-

264 Ebd., S. 210-212. Vgl. auch die parallele Stelle dazu in Zımnic zumeıkı o leınıch vpečallenıuch (S. 83ff.-S. 90), das Gespräch des Ich-Erzăhlers mit einigen Franzosen ,.an der luhle d'hile" eines llotels und seine Gedanken über die .,angeborene Beredsamkeit" der Franzosen bzw. des französischen Bourgois. 
androvna hinüber: sie übersah mich jedoch vollkommen. Es endete damit, daß ich wütend wurde und mich entschloß, einfach frech zu werden. ${ }^{265}$

Aleksej bemerkt, daß sich die Russen kaum an der table d'hôte im Ausland, in Paris, nicht einmal „am Rhein“ oder in der Schweiz zeigen könnten, weil sie von den poljaciški [nossquumku; von den kleinen Polackchen] und von den mit ihnen fühlenden Französchen beschimpft und schikaniert würden. Aleksej schildert darauf hin seinen Streit in einem Pariser Hotel mit einem Polen und einem franzosischen Offizier, der jenen Polen unterstützt hatte, um schließlich den Tischgenossen die Geschichte über den Skandal in der Vatikanischen Botschaft in Paris zu erzăhlen, den er hervorgerufen hat, weil er dort von dem Monsignore und dem Abbé als Russe schikaniert wurde. ${ }^{266} \mathrm{Er}$ mußte lange auf das römische Visum warten, weil der Prälat seinen Kaffee trank. Während der Wartezeit konnte er in einer französischen Zeitung einen antirussischen Artikel lesen: „Я хоть и спешил, но, конечно, сел ждать, вынул «Opinion nationale» и стал читать страшнейшее ругательство против России“. [Ich hatte zwar wenig Zeit, doch setzte ich mich hin. zog die „Opinion nationale“ hervor und begann zu lesen. Der Leitartikel war ein einziges großes Geschimpfe über Rußland. $]^{267}$

Diese Skandalgeschichte habe Aleksej jedoch mehr Achtung seitens der feindlichen Franzosen und anderer Gäste des Hotels verschafft, so daß:

Толстьй польский пан, самый враждебный ко мне челювек за табльдотом, стушевался на второй план. Французы даже перенесли, kогда я расckazar, что года два тому назад видел человеka, в которого французский егерь в двенадцатом году выстрелил - единственно только для того, чтоб разрядить ружье. Этот человек был тогда еще десятиелтним ребенком, и семсйство его не успело выехать из Mockвы. [kursiv dic Verf.]

[ Ein dicker polnischer Pan, der bis dahin die erste Rolle an der Table d'hôte gespielt hatte, mußte sich hinfort mit der zweiten Rolle begnügen $[/ \ldots /$, der mein großter Feind an der Table d'hôte gewesen war, zog sich in den Hintergrund, auf den zweiten Plan zurück; Erg. d. Verf.]. Ja, die Franzosen nahmen es nachher sogar hin, daß ich ihnen von einem Menschen erzählte, auf den ein französischer Chasseur im Jahre 1812 geschossen hat. einzig um sein Gewehr zu entladen. Dieser Mensch war damals ein zehnjähriger Knabe, und seine Familie hatte Moskau nicht rechtzeitig vor dem Einzug der Franzosen verlassen können. [kursiv die Verf.]] ${ }^{268}$

In dieser Passage wird explizit und implizit auf mehrere politische Ereignisse angespielt - auf den von Russen niedergeschlagenen polnischen Aufstand von 1863 und auf die öffentlichen französischen propolnischen Stimmungen, die für

265 Ebd., S. 210. [S. 12f.].

266 Fbd., S. $210 f$. Vgl dazu zur Biographie Dostoevskijs bei KJETSAA 1992, S. 204

267 Bd. 5, S. 211 und ebd., S. 14.

268 Ebd., S. 212 [S. 14f.]. 
alle Russen im Ausland, u.a. in Frankreich bzw. in der Vatikanischen Botschaft in Paris zu unangenehmen Begegnungen mit den dort anwesenden Polen sowie zu Konfliktsituationen und Schikanen führten. Darüber hinaus handelt es sich um eine Anspielung auf die Besetzung Moskaus durch Franzosen und Polen im Jahre 1812 sowie auf das angeblich barbarische Benehmen der französichen Soldaten gegenüber Russen. Die Figur des "dicken polnischen Herm" (als eine feindliche Alter-Figur) erweitert aber den Kontext dieser Szene um eine zusătzliche historische Dimension. Es handelt sich um ein negatives literarisches russisches Stereotyp des "dicken Polen", das möglicherweise aus dem Roman von Michail Nikolaevic Zagoskin Jurij Miloslavskij, ili Russkie v 1612 godu (1829) [Jurij Miloslavskij, oder Russen im Jahre 1612] stammt, d.h. bezieht sich auf die "Zeit der Wirren“, auf die polnisch-katholische Invasion der Moskauer Rus' am Anfang des siebzehnten Jahrhunderts. Der Streit zwischen Aleksej und De-Grie weist somit eine ideologische Funktion auf und bezieht sich auf die traditionelle, „ewige“ Feindschaft zwischen den Franzosen, Polen und Russen, zwischen der katholischen und der russisch-orthodoxen Kirche. In den Anspielungen auf die napoleonische (französische) Invasion im neunzehnten und auf die polnische im siebzehnten Jahrhundert ${ }^{269}$ wird aus der historischen (russisch-orthodoxen) Perspektive die rußlandfeindliche Politik Frankreichs nach dem polnischen Aufstand von 1863 verurteilt und zugleich der „Westen“ schlechthin, der mit Unterstützung der katholischen Kirche „schon immer" den Untergang Rußlands und dessen Glaubens herbeiführen will.

Aleksej wird darüber hinaus, trotz seiner Okzidentalisierung, nicht nur als ein russischer Patriot vorgestellt, sondern auch als eine positive Kontrastfigur zu dem eingebildeten Franzosen. Betont wird seine Eifersucht sowie seine emiedrigende, unsichere soziale und personliche Position bei der Familie des Generals, die ihn als einen mittellosen, „unbedeutenden" Russen im Ausland zeigt. Den positiven Kontrast zu De-Grie bildet aber auch der sympathisch dargestelite Mister Astlej, der bei dieser Szene in die Handlung eingeführt wird. ${ }^{270}$

269 Es handelt sich um die stereotype Figur des dicken Pun Kopyiinsku. Das Stereotyp des "dicken Polen“ kommt ebenfalls in den Romanen Podrosiok und Brai ja Karamazovy vor. Der patriotische, ,antiwestliche " Roman Zagoskins wurde nach den Erinnerungen des Bruders Dostoevskijs, Andrej Michajlovix, in ihrem Elternhaus als Familienlektüre vorgelesen. Vgl. dazu ZAGoSKIN 1987, S. 58ff., S. 67ff. bzw. S. I Isff. (Die Charakteristik des dicken und feigen Polen). Siche dazu die Anmerkung der Herausgeber im Bd. 15 (zu Brat ja Karamazeny ), S. 576 sowie unten, S. 354ff. (zu P'xdrostok) und S. 384f., S. 402ff. und S. 408 (zu Bral ja Karamazovy).

$270 \mathrm{Vgl}$. die Schilderung des Englănders durch Aleksej, Bd. 5, S. 210 :

„Этого странного ангтичанина я встретиц сначата в Пруссиі, в вагоне, где мы сиде.71 друг протлв друга, когда я догонят наних: /.../ Я никогда в жизни не втречат че.ловека бо.лее застенчивото; он застенчив до г.лупості и сам, конечно, знает об этом, позтому что он вовсе не г.туп. Впрочем, он очень ми.лый и тихй. /.../ Он объяви.7 мне, что бы.л нынешним .етом на Норі-Кане и что весьма хотелось ему быть на Нıжегородской ярмарkе. Не знаю, kak он познакомился с генералом; kажется, что он бесіреде.льно вюб.лен в По.ину. Когда она вош.ла он вспыхну.л kak зарево. Он бы. очень рал, что за сто.лом я сел с нім рядом, и, кажется, уже счіттает меня своім заkапычным другом“. 
2. Eine andere polnische stereotype Figur, ein falscher polnischer Graf, ist mit der Lebensgeschichte der Mademoiselle Blanche de Cominges bzw. Zel'má verbunden, die dem Ich-Erzähler von Mister Astlej erzählt wird:

Mademoiselle Blanche /.../ не называлась mademoiselle de Cominges, равномерно и мать еe madame veuve Cominges rorда не существовала. /.../ Де-Грие - Де-Грие тоже не было./.../ Марkизом Де-Грие стал тоже весьма недавно /.../. Даже можно предположить, что он и Де-Грие стал называться недавно. [kursiv die Verf.]

[Nur hieB sie /.../ nicht Mademoiselle de Cominges, und ebensowenig wußte man hier etwas von einer Madame veuve de Cominges. /.../ Des Grieux ... des Grieux ..., ja den gab es damals auch noch nicht. /../ Zum Marquis ist der Monsieur des Grieux wohl gleichfalls erst vor kurzer Zeit /.../ geworden. [Man kann sogar vermuten, daß er sich erst seit kurzer Zeit des Grieux nennt; Erg. d.Verf.] [kursiv die Verf.]] ${ }^{271}$

Mademoiselle Blanche war zuerst mit irgendeinem italienischen Fürsten „с историческим именем что-то вроде Барберини" [mit einem historischen Namen, so etwas wie Barberini] nach Ruletenburg gekommen, der aber eines Tages verschwand:

Долг в отеле ужасный. Mademoiselle Зельма (вместо Барберини она вдруг обратилась в mademoiselle Зельму́) была в последней степени отчаяния. Она выла и визжала на весь отель и разорвала в бешенстве свое платье. Тут же в отеле стоял один польский граф (все nутешествующие поляки - граф(x) /.../. Они переговорили, и к обеду она утешилась. Вгчером он появиіся с ней под руку в воксале. /.../ Она поступила прямо в тот разряд играющих на рулетке дам, которые, подхоля k столу, изо всей силы отталкивают плечом игроka, чтобы очистить себе место. [kursiv dic Verf.]

[Die Schulden im Hotel hatten eine erschreckende Höhe erreicht. Mademoiselle Selmá (denn anstatt Barberini hieß sie nun plötzlich Mademoiselle Selmá) blieb in der größten Verzweiflung zurück: sie schrie und weinte, daß man es im ganzen Hotel hören konnte, und zerriß [vor W'ut: Erg. d.Verf.] ihr Kleid. Zum Glück war in demselben Hotel ein polnischer Graf abgestiegen (alle reisenden Polen sind Grafen) /.../. Sie hatten

IS. 12: Diesen sonderbaren Engländer hatte ich bereits in Preußen kennengelernt. Wir saßen im Abteil einander gegenüber, als ich den Unsrigen nachreiste: /... Ich habe noch nie in meinem leben einen so schüchternen Menschen kennengelemt. Er ist bis zur Unglaublichkeit. geradezu bis zur Dummheit schüchtem, was er natürlich selbst ganz genau weiß; denn, daß er nicht dumm ist, sieht man ihm auf den ersten Blick an. Im übrigen ist er ein sympathischer, stiller Mensch. $i . . /$ er erzählte mir, daß er in diesem Sommer am Nordhap gewesen sei und sehr gern die Messe in Nishnij Nowgorod besucht hätte. Wie er mit dem General bekanntgeworden ist, weiß ich nicht. Jedenfalls scheint er mir in Polina grenzenlos verliebt zu sein. Als sie eintrat, wurde er feuerrot Offenbar war er sehr froh darüber, daß ich bei Tisch neben ihm zu sitzen kam, und anscheinend hält er mich für seinen besten Freund.] 271 Ebd., S. 247 [S. 85]. 
eine Unterredung und gegen Mittag beruhigte sie sich. Am Abend erschien er mit ihr im Kursaal /.... Sie trat sogleich in die Reihe jener Damen, die, wenn sie hier an den Spieltisch treten wollen, mit der Schulter ganz ungeniert einen Spieler fortstoßen, um sich Platz zu schaffen. [kursiv die Verf.] $]^{272}$

Der polnische Graf sei aber ebenfalls wie ihr früherer Verehrer eines Tages verschwunden. Die Französin versuchte daraufhin, den deutschen Baron Vurmergel'm für sich zu gewinnen und mußte Ruletenburg auf Wunsch der Polizei verlassen. Auf diese Weise wird zusătzlich der Gegensatz zwischen der franzosischen Betrügerin und Lebenskünstlerin und dem deutschen strengen Baron unterstrichen. Mister Astlej betont außerdem, daß die Franzosin die Ehe mit dem russischen General anstrebte, um nicht mehr solchen Unannehmlichkeiten ausgeset $\pi \mathrm{zu}$ werden. ${ }^{273}$ Der falsche polnische Graf wird dagegen als ein noch schlauerer Betrüger als die negative Figur der Französin gezeigt. Er ist ein (literarisches) negatives russisches Stereotyp des polnischen falschen Grafen und Falschspielers (als eine Alter-Figur), das emeut in dem Roman Brat ${ }^{\circ} \mathrm{ja}$ Karamazovy auftaucht und bereits wie in lgrok alle Polen vertritt, denn ,alle reisenden Polen sind Grafen". Sein Vorbild ist wohl, ebenfalls wie in Djadjuskin son und in Brat 'ja Karamazovy, der falsche polnische Graf, Pan Želynskij, ein Falschspieler aus Vel tmans Roman Salomeja (1848). ${ }^{274}$

3. Die polnischen Figuren tauchen in Igrok schließlich am Spieltisch des Kasinos auf, diesmal, um die "Großmutter“ Antonida Vasil "evna zu betrügen. Antonida Vasil'evna macht einen starken Eindruck auf das anwesende Publikum. Beim ersten Erscheinen der babuska am Spieltisch helfen ihr die Polen, einen freien Platz in der dichten Menge zu bekommen:

Она пожелата, наконен, разглядеть игру поближе. Не понимаю, kak это случилось, но лакеи и некоторые другие суетящиеся агенты (преимущественно проигравшиеся полячки, навязывающие свои услуги

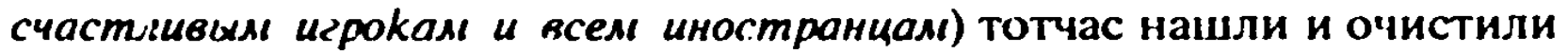
бабушке место, несмотря на всю эту тесноту, у самой середины стола, подле главного крупера, и подкатили туда ее кресло./.../Множество лорнетов обратилось в ее сторону. У круперов родились надежлы /.../. [kursiv die Verf.]

[Schließlich wünschte sie, das Spiel aus der Nähe anzusehen. Ich weiß selbst nicht, wie es zuging, aber den angestellten und den freipraktizierenden Dienern (letztere sind vornehmlich Polen [Polackchen; Erg. d. Verf.]. die ihr Geld verspielt haben und nun den glücklicheren Spielern oder Ausländern ihre Dienste aufdrängen) gelang es jedenfalls im Augenblick, trotz des Gedränges, neben dem Hauptcroupier, der an der Mitte des Tischcs sitzt, Platz zu schaffen, und ehe ich mich dessen versah, wurde auch schon

\footnotetext{
272 Ebd., S. 247t. [S. 86]

273 Fbd., S. 248

274 Vgl. VEL TMAN 1957 und unten, S. 386.
} 
ihr Rollstuhl dorthin gelenkt. /.../ Unzăhlige Lorgnons richteten sich auf sie. Die Croupiers schöpften Hoffnung /.../. [kursiv die Verf.] $]^{275}$

Die „lakaienhaften“ Polen und die ehemaligen „unglücklichen Spieler" - dies ist wohl eine ideologische Anspielung auf den 1863 verlorenen Aufstand und auf die "lakaienhafte" Haltung der Polen bzw. des polnischen Adels dem "Westen" gegenüber - treten noch in zwei weiteren "Spielszenen“ auf. Der Diener Potapyč erzählt Aleksej über das Spiel seiner Herrin:

К ней прикомандировался там тот самєий полячок, которому она дала давеча два фридрихсдора, и всё вреяєя руководил ее в игре./.../ Как нарочно, он понильл по-русски и даже больтал kоe-kak, слесью трех языков, таk что они koe-kak уразумели друг друга. Бабушка всё время нешадно ругала его, /.../ хоть тот беспрерывно «стелился под cmonku naньcku»./.../ - pacckазывал Потапыч. - С вами она мючно c барином обранцалась, а тот - таk, я сам видел своими глазами, убей бог на месте, - тут же у ней со стола воровал. Она его сама раза два на столе поймала, и уж костила она его, /.../ даже за волосенки раз omdергальа, право, не эгу, таk что кругом смех пошел. [kursiv und fett Dostoevskij ; kursiv die Verf.]

[Derselhe Polack, dem sie am Vormittag zwei Friedrichsdore geschenkt, hatte sich so geschickt ihr auf=udrängen gewußt, daß er bald ihr ganzes Spiel dirigierte. I.../ [Wie ausgerechnet verstand er Russisch und plauderte sogar ein wenig in einem Gemisch von drei Sprachen I.../; so daß sie einander ungefähr verstehen konnten; Großmütterchen hatte ihn die ganze Zeit schonungslos beschimpfi; Erg. d. Verf.] Und obschon dieser ihr ununterbrochen /.../ versichert hatte, daß er sich unter ihre ,stopki panjski" [breite: $=$ unter ihre herrschaftlichen Füßchen breite. ./../ - erzählte Potapyč; Erg. d. Verf.]. - „Mit ihnen, Alexei lwanowitsch, ging sie doch ganz wie mit einem Herrn um" /.../, ,jener aber - ich hab's doch mit meinen eigenen Augen gesehen, Gott straf mich! - jener hat ihr Geld unter ihren Augen vom Tisch gestohlen. Zweimal hat sic ihn sogar selbst dabei erwischt $/ . . . /$, und gescholten hat sie ilun, /.../ sogar an den Haaren hat sie ihn einmal gerissen /.../, ich lüge nicht -, so daß ringsum sogar gelacht wurde. [kursiv und fett Dostoevskij ; kursiv die Verf.]1 ${ }^{276}$

In dieser Passage kommt erneut und korrekt angeführt. obwohl in einer ironischen Diminutivform (als „cmesumucs nod cmonku naHscku" [sich unter die herrschafilichen Füßchen breiten]), das polnische Imagem padam do nóg vor, das bereits in Roman $v$ devjati pis mach als das „Fremdwort eines polnischen Falschspielers" einen verwestlichten Petersburger und in Zimnie zametki o letnich vpečatlenijach einen französischen .Jakaienhaften" Journalisten und somit

275 Bd. 5, S. 261 [S. 113].

276 Ebd., S. 280f. [S. 148f.] 
alle französischen Spießbürger als "Lakaien“ Napoleons III. charakterisiert. ${ }^{277}$ In Igrok handelt es sich wieder um das indirekt angeführte "fremde Wort" einer stereotypen Figur, des polnischen Falschspielers. Der Pole (= pejorativ das „Polackchen" genannt) wird aus zweifacher Perspektive dargestellt: der des Dieners der "Großmutter" aus dem russischen "Volk", in dessen naiver, volkstümlicher Sprechweise (als skaz) und aus der des Ich-Erzăhlers selbst, so daß er dadurch „entpersönlicht“ wird. Aus dieser Sicht entpuppt sich der scheinbare „Lakai" der "Großmutter" als „Teufel in der Gestalt eines Polen“, der die (Alt)Russin zum Spiel, d.h. zum „Götzendienst", verführt und sie dabei völlig „beherrscht“, obwohl sie sich dagegen heftig wehrt.

Zum zweiten Mal hat eine Gruppe von mehreren poljački die babuška am Spieltisch umringt. Sie kennen sich gut, gehören zusammen. Indem sie vorgeben, der im Spiel unerfahrenen Alten gute Ratschläge zu geben, schaffen sie ein Durcheinander und nutzen die Unordnung, um das Gold der Russin zu stehlen. ${ }^{278}$ Nachdem sie von der Polizei verjagt werden, taucht plötzlich der dritte Pole auf:

Взамен их тотчас же $k$ услугая ее явиіся третий поляк, уже совериенно чисто соворивший по-русски, одетый джентыьненом, хотя все-таки слахивавший на лакея, с огромными усамєи и с гонором. Он тоже целовал «стоnku nаньсkи» и «сmemuscя nod cmonku naньcku», но относительно окружаюІинх ве.л себя не слугою, а хозяином бабушки. Поминутно с каждым ходом обрашался он $\mathrm{k}$ ней и клялся ужаснейІиими КІятвами, что он сам нгоноровый» пан и что он не возмет ни единой kопейkи из денег бабушки. Он таk часто повторял эти клятвы, что та окончательно струсіияа. [kursiv die Verf.]

[An ihrer Stelle erschien sogleich [zu ihren Diensten: Erg. die Verf.] ein dritter Pole, der aber, im Gegensatz zu den anderen, fließend Russisch sprach und wie ein Gentleman gekleidet war - immerhin aber noch etwas Lakaienhaftes an sich hatte - und sich außerdem durch einen mächtigen Schnurrbart und durch ..Gónor" [honneur] auszeichnete. Er versicherte gleichfalls, daß er ihre ,s'opki panjski“ [herrschaftliche Füßchen; Erg. d. Verf.] küsse oder sich .,ihr $=u$ Füßen lege", doch verhielt er sich zur ganzen Umgebung anmaßend hochmütig und benahm sich wie ein Despot - kurz, er verstand es. sich von vornherein nicht als Diener, sondern als Gebieter der Bábuschka aufzuspielen. Alle Augenblicke, fast nach jedem Einsatz, wandte er sich an die Bábuschka und schwur mit den fürchterlichsten

${ }^{277} \mathrm{Vgl}$. Zimnle zumerkı " leınich vpeciutlenyuch, cbd., S. 82ff. und oben, S. 140f. und S. 239f In /grok gibt es einen direkten Bezug darauf im negativen ..Kommentar“ des leh-Erzählers zu den ..lakaienhaften" Beschreibungen der angeblichen Pracht der Spielkasinos in ausländischen und russischen Zeitungen. "Tepneть я не могу этой .таkиейщинын в фе.лье-

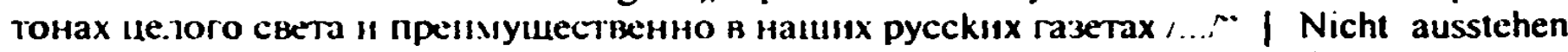
kann ich dieses Lakaientum der Feuilletonschreiber der ganzen Welt, namentlich aber unserer russischen fin unseren Leitungen: Erg. d. Verf.] /../; S. 221. ebd., Kap. 2, S. $215 \mathrm{fr}$. Im letzien Kapitel wird alxer Aleksej aus Not für fünf Monate zum lakaien eines Deutschen, der den stereotypen Namen Gince (= llinze) trägt, ebd., S. 311

278 Ebd., S. 282 
Schwüren, daß er selbst ein „,gonorovyj pan“ [ein ehrenhafter Herr; Erg. d. Verf.] sei und keine Kopeke von ihr annehmen werde. Und er wiederholte diese Schwüre so oft, daß die Bábuschka sich ganz eingeschüchtert fühlte. [kursiv die Verf.] $]^{279}$

Dieser "falsche polnische Gentleman" erinnert wieder an den "falschen polnischen Grafen“ „Pan Ž.elynskij“, dessen „Verwandter" in Igrok zuerst im Zusammenhang mit Mademoiselle Blanche vorkommt. Der "ritterliche“ Pole wird darüber hinaus wiederholt durch dasselbe (und nur leicht abgewandelte) polnische Idiom charakterisiert. Er ,maskiert sich" auch durch sein fehlerfreies Russisch, durch elegante Kleider und durch seine übergroßen, nach außen demonstrierten adligen Attribute: das "Ehrgefühl" und den „Schnurrbart", die letzteren die stereotypen Motive, die einen polnischen (Alt)Adligen ausmachen. Das Fhrgefühl des Polen in lgrok wird aber sofor relativiert, denn der Pole wird wie der heruntergekommene russische Platzmajor in Zapiski i= Mertvogo doma als "смеахивавший на лакея" [an einen Lakaien erinnernd / einem Lakaien ähnlich] bezeichnet. Der „falsche Graf" hilft der babuska mit seinen guten Ratschlägen zuerst gewinnen, indem er sich sich als ihr treuer Diener zeigt, obwohl er bereits zu ihrem "Herm" geworden ist. ${ }^{280}$ Nach einer Stunde ist er wieder in der Gesellschaft der gerade verjagten zwei schäbigen „Polackchen“ zu sehen. Gegen Ende dieses Spieltages kommen noch sechs weitere Polen hinzu. Die Russin wird am Abend sogar von jenen Polen zum Hotel begleiteh die schreiend neben ihrem Rollstuhl herlaufen:

уверяя ckoporoворkою, тто бабушка их в чем-то надула и должна им что-то отдать. Tak дошли до самого отеля, откуда их наконеи прогнали в толчки.

[und beteuerten in verwirrend schneller Sprechweise, daß die Bábuschka sie irgendwie betrogen habe und ihnen irgend etwas zurückerstatten müsse. So kamen sie bis zum Hotel, wo man sie endlich handgreiflich davonjagte. $]^{281}$

Aus diesen Zitaten wird der ideologisch begründete Kontrast und Konnikt zwischen diesen poljacki und der naiven alten Russin sowie ihrem Diener deutlich, die positiv als naive und gutmütige, aufrichtige Menschen geschildert werden. Die alte Moskauer Gutshesitzerin. die sich wie ein Kind für das Spiel ereifert. bildet den krassen Gegensatz. zu den versierten westlichen Falschspielern und Hochstaplern. Sie verkörpen symbolisch das bereits geschwächte (..gehbe-

279 Fbd., S. 283 [S. 153f.].

290 Die Russin läßt sich von dem Polen. einem ..lakaien“ aus dem ..Westen“ und des .Westens“, d h. symbolisch vom ..Westen“ selbst sklavisch beherrschen. Vgl. eine Äußerung von Mister Astlej gegenüber Polina, aus seiner ...westlichen“ Sicht. über die fehlende Selbstăndigkeit der Russen: „Он говорит, что мы русские, без европейцев ничего не знаем и ни к чему не способны ..." |Er sagt, die Russen wüßten ohne die Europäer nichts und wären ohne sie auch zu nichts fáhig... ; S. 1801. ebd., S. 297.

202 Ebd., S. 283f. und S. 155. 
hinderte“) „vorpetrinische Rußland“, die Moskauer Rus", die dem „Westen“ zum Opfer gefallen ist:

Довезли мы ее, матушkу, сюда - только водицы спросила испить, перекрестилась, и в постельку. Измучилась, что ли, она, тотчас заснула. Пошли бог сны ангельсkие! Ох, уж эта мне заграница! /.../ - говорил, что не $k$ добру. И уж посkорей бы в нашу Mockву! И чего-чего у нас дома нет, в Мосkве? Сад, цветы, kakих здесь и не бывает, дух, яблоньки наливаются, простор, - нет: надо было за границу! Ох-хоxo!..

[Wir brachten sie dann zurück, hierher, unser Mütterchen - nur ein Schlückchen Wasser wollte sie trinken, bekreuzigte sich und gleich ins Bett! Jedenfalls schlief sie sofort ein. Schick ihr nur gute Trăume, Allbarmherziger! Ach, ich sag wohl, dieses Ausland! /.../ Ich hab's ja vorausgesagh, daß dabei nichts Gutes herauskommen wird! Ja, wenn wir nur wieder in unserem Moskau wären! Und was haben wir nicht alles zu Hause? Es ist doch alles in Hülle und Fülle da! Haben einen Garten und Blumen, wie sie hier gar nicht zu sehen sind, und die Äppelchen [sic!] werden jetzt rot [Apfelbäumchen beginnen zu reifen; Erg. d.Verf.], und schöne Luft dazu und Platz überall genug [und die Weite; Erg. d. Verf.] - aber nein: es mußte ins Ausland gefahren werden! Óchhoho!] ${ }^{282}$

Die Moskauer Heimat, von dem russischen Diener aus dem „Volk" als ein schöner Garten und freier, offener Raum geschildert, denn ,prostor" [npocmop] kann auch „Freiheir ' bedeuten, wird zum utopischen, paradiesischen Ort „vor dem Sündenfall“. Die „Moskauer Rus““, das positive utopische Imagothène des vorpetrinischen Rußlands, wird mit Hilfe des Topos des „Garten Edens“ antithetisch dem „Reich des Baal“, dem „,bösen Westen“, der u.a. durch die betrügerischen Polen vertreten wird, gegenübergestellt.

Diese poljacki setzen sich in der Funktion als alter, als negativer Kontrast zu der Russin, aus den negativen nationalen stereotypen Eigenschaften zusammen, die den Polen in der russischen Kultur und Literatur traditionell zugeschrieben werden; diese werden hier ins Groteske gesteigert: ${ }^{283}$ Das ritterliche Fhrgefühl (honor), Beachtung äußerer Benehmensformen und Höflichkeit als Atributte eines Gentlemans werden bei ihnen als falsch und übertrieben gezeigt und mit lakaienhafter Dienstbereitschaft und Aufdringlichkeit verbunden. Sie verachten die alte Russin und sind nur an ihren kleinlichen Geschäften interessiert. Sie werden als "flache" stereotype Schattenfiguren ohne inneres, psychisches Leben gezeichnet. die dazu dienen. den naiven Charakter der Antonida Vasil'evna hervorzuheben, sic als ihr Opfer darzustellen, d.h. als das Opfer des westlichen Materialismus schlechthin. Die russischen Diener, Potapyč und Marfa werden im Verhăltnis zu den Polen als naive und fromme russische "Naturkinder" ge-

282 Ehd., S. 281 [S. 149]. Vgl. auch die naive Sprechweise im razgovornvy jazyk

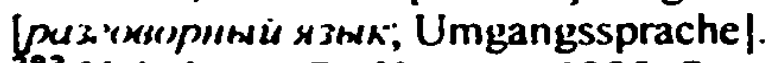

${ }^{203} \mathrm{Vgl}$. dazu Z.B.: IAANSLIK 1985, ORLOWSKI 1982. KęPINSKI I990a oder GoldGART 1986. 
zeigt, die ihre Herrin aufrichtig lieben, und den schäbigen polnischen Lakaien gegenübergestellt werden. ${ }^{284}$

4. Noch einmal tauchen diese Polen während des glücklichen Spiels des lchErzählers auf, ${ }^{285}$ als er, vom Erfolg und von der seelischen Spannung erschöpft, anfängt „грубые ошибки" [grobe Fehler] zu machen: „Подскакивали было и полячки с услугами, но я никого не слушал. Счастье не прерывалось!" [Neben mir tauchten natürlich wieder die bewußten Polen auf und boten mir ihre Dienste an, aber ich hörte auf niemanden. Das Glück verließ mich nicht. ${ }^{286}$ Überraschenderweise wird die Figur eines Juden aus Frankfurt positiver als die Polen erwähnt, so daß sie noch negativer geschildert werden: „- Уходите, уходите, - шептал мне чей-то голос справа. Эго был какой-то франкфуртский жид; он всё время стоял подле меня и. кажется, помагал мне иногда в игре“. ["Gehen Sie jetzt, gehen Sie fort! flüsterte mir von rechts jemand zu. Es war ein Frankfurter Jude; er hatte die ganze Zeit neben mir gestanden und mir beim Spiel, glaube ich, hin und wieder geholfen. $]^{287}$ In allen „polnischen" Passsagen werden diese Betrüger von den Russen durchschaut und verjagt, so daß dadurch angedeutet wird. daß "Rußland" imstande ist und war, die Agressionen des "Westens" (und u.a. des katholischen Polens) wie in jener in der Verbannung verfaßten Ode abzuwehren und den Feind zu besiegen.

Im lgrok gibt es also polnische Figuren, die in der Gestalt jener schäbigen poljacki aufureten, über die JERZY STEMPOWSKI, WACIAW L.EDNICKI und ZBIGNIEW ŻAKIEWICZ geschrieben haben, daß sie als Karikaturen die Rachegefühle Dostoevskijs befriedigen sollten bzw. ihn von seinem Schuldkomplex gegenüber Polen befreien, weil sie, in ihrer Nichtigkeit und Falschheit moralisch kompromittiert. den Untergang ihrer Heimat selbst verdient hätten. ${ }^{288} \mathrm{~J}_{\mathrm{AN}}$ OrLOWSKI dagegen erblickt in diesen häßlichen Polen die nationalistische ideologisch begründete Reaktion Dostoevskijs auf die Diskussion uni den polnischen Aufstand von 1863, der in Westeuropa Kritik an Rußland hervorrief und für Dostocvskij als Ausdruck des Kampfes der westlichen Zivilisation. des bürgerlichen politischen Systems und des Katholizismus gegen Rußland galt. ${ }^{289}$ Diese Annahmen können richtig sein, denn die polnischen Imageme treten im lgrok in Form negativer nationaler Stereotypen auf. Ihre Funktion ist eindeutig ideologisch, typologisch sind diese Figuren als die ..Anderen", als alter zu bezeichnen. ${ }^{290}$ Sie dienen primär der Hervorhebung der positiven Eigenschaften der Moskauer Gutsbesitzerin und ihrer aus dem russischen Volk stammenden Diener, außerdem betonen sie aber darüber hinaus die .,höllische" Atmosphäre des

284 Vgl. andere russische Figuren der ..Lakaien" und Diener in den literarischen Werken Dostoevskijs, z. B. die Titelfigur in der Erzahlung /'olzunkov (1848) (vgl. Bd. 2, S. 5-15) bzw Smerdjakov aus dem Roman Brat ja Kurumazovy, die jedoch immer als Subjekte, als .. wahre“ Menschen dargestellt werden und nicht so eindimensional wie die polnischen ..Lakaien“" sınd. 205 Bd. 5, S. 291 f.

286 Ebd. S. 293 und S. 173

207 Ebd., S. 294 und S. 173

${ }^{288}$ Vgl. HOSTOWIEC [STEMPOWSKI] 1961. LEDNICKI 1953. Z.AkIEWICZ 1968. Siche dazu oben. S. 111 iff.

$200^{\circ}$ ORLOWSKI 1982. S. 89

$290 \mathrm{Vgl}$. dazu auch dazu GeriGK 1992a. 
Spielkasinos, der Stadt Ruletenburg - einer Hochburg des Materialismus und der falschen Menschen. Ruletenburg und seine westlichen Bewohner sind somit das Symbol des Westens schlechthin. Den russischen Figuren der „Großmutter” und ihrer Diener als Vertretern des "vorpetrinischen RuBlands“ werden die verfremdeten, verwestlichten, in allen ihren Schwăchen gezeigten Russen sowie die Bewohner des Westens, v.a. Franzosen, kritisch entgegengestellt. Im Igrok gibt es dagegen keine polnischen Imageme, die zur immanenten Charakteristik russischer verwestlichter Figuren eingesetzt werden wie im oben besprochenen Roman Unizennye i oskorblennye. Im Igrok werden nicht nur die „Russen im Westen" sondern auch der "Westen" selbst kritisch "vorgeführt". 291

ZUSAMMENFASSUNG: Der Roman Igrok, der unmittelbar nach den Zimnie zametki o letnich vpecatlenijach entstanden ist, weist mehrere imagothematische Bezüge zu diesen „Reiseaufzeichnungen“ über „Rußland“ und „Europa“ auf. In ihm wurden die in Zimnie zametki o letnich vpecatlenijach ausgearbeiteten negativen Imagothèmes, das utopische des verwestlichten, „nachpetrinischen

291 Der Unterschied zwischen den Russen und Deutschen, die stellvetretend für den Westen genannt werden, wird ZB. in den Äußerungen des lch-Erzăhlers über die Opposition zwischen der russischen und deutschen Mentalität im Hinblick auf die Geld- und Kapitalanhäufung antithetisch zusammengefaßt, vgl. Bd. 5., S. 225f.: ,A я тучше захочу всю жизнь прокочевать в kıрпізсkой naтarke, - всkрıчал я, - чем поктонятся немецкому идо.ту. /.../ Heмeukoмy cпособу наkoIlтения богатств. /..../ есть здесь везде у них в kаждом доме свой фатер, ужасно добродетельный и необыкновенно честный. /.../ У kаждого эдакого фатера есть семья, I по вечерам все они вс.тух поучіrте.ьные kнипі читrают. /.../ Bce работают, kak во.лы, и все kолят деньгі, kak жıцы. /.../ Лет эдаk чрез пятьдесят ILлI! чрез семьдесят внуk первото фатера действіпе.льно уже осуществ.яет значіте.тьный

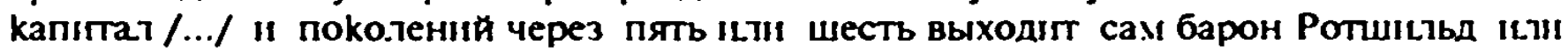
Гonne и Koмп. /.../ столетний ици двухсот.летпй иреемстьенный труд, терпение, ум, честность, характер, трердость, расчет, анст на крыше! /.../ я уж .тучше хочу дебоши-

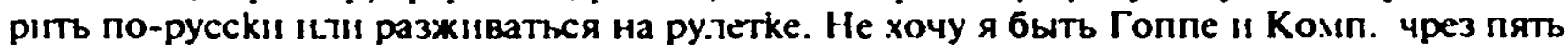
поколеншй. Мне деньпі нужны для меня самого, а я не счіттю всего себя чем-то необходимым и придаточным k kaпıтату“

[S. 43ff: 'Nun, was mich betrim', sagte ich lachend. 'so würde ich es vorzichen, mein ganzes Leben nomadisierend nach Kirgisenan zu verbringen als - den deutschen Götzen anzubcten

/.../ Die deutsche Art und Weise, Geld zusammen zu sparen. /.../ Jedes Familienoberhaupt ist hier ein entsetzlich tugendhafter und außerordentlich ehrbarer Vater. /../ Jeder dieser Váter hat natürlich eine Familie, und abends wird aus lehrreichen Büchern laut vorgelesen. /.../ Alle arbeiten sie wie die Jochochsen, und alle sparen sie Geld wie die Juden. /... So nach fünizig oder siebzig Jahren hat dann der Enkel jenes ersten Vaters schon ein ganz ansehnliches Vermögen, das er wieder seinem ältesten Sohne vermacht, dieser wieder seinem und so weiter, bis endlich ein Sproß nach fün oder sechs Generationen so etwas wie ein zweiter Baron Rothschild wird oder Hoppe und Kompagnie oder der Teufel weiß was sonst. /.../ Hundernoder zweihundertjăhriger Fleiß, Geduld, Verstand und Ehrlichkeit, praktische Berechnung. Charahter und Festigkett. und dazu ein Storchennest auf dem Dach! /.../ Nun, ich für meine Person wollte nur sagen, daß ich denn doch vorziehe, nach russischer An das Leben zu verschwelgen und durch das Roulette ein Vermögen zu erwerben. Ich danke dafür, nach fünf Generationen Hoppe und Co. zu sein! Ich will mein Geld für mich besizzen, und mir soll es gehören, nicht ich ihm. denn niemals könnte ich mich als Zugabe zum Kapital, als Nebensache betrachten ...] Diese Äußerungen Aleksejs über die deutsche Mentalität erinnern an diejenigen von MAX WEBER zur protestantischen Ethik, siehe DERS. 1993. 
Rußlands" und das utopisch-ideologische des "Westens“, asthetisch umgestaltet und in der Figurenkonstellation konkretisiert. Diesen beiden negativen Imagothèmes wird, ahnlich wie in Unizennye $i$ oskorblennye, das positive utopische Imagothème des "vorpetrinischen Rußlands" und des „zeitlos und ideal schönen russischen Volkes" gegenübergestellt, die aber noch keine ausgeprăgte russisch-orthodox-byzantinische Komponente aufweisen.

lgrok nimmt darüber hinaus wegen seiner thematischen Năhe zu Zimrie zametki o letnich vpečatlenijach eine Sonderstellung innerhalb aller anderen Romane Dostoevskijs ein, weil seine Handlung aussschließlich in Westeuropa, im Westen, spielt. Neben der Figurenkonstellation, sowohì den russischen als auch den fremden Figuren, hat also auch der Schauplatz der vom Ich-Erzähler geschilderten Ereignisse, der deutsche Kurort Ruletenburg und Paris, eine symbolische Funktion, symbolisiert den negativ dargestellten "Westen“, der wie in Zimnie zametki o letnich vpečatlenijach als das .Reich des Baal", als das "Babylon" aus der Offenbarung des Johannes, gezeigt wird.

Auf diesem negativen "dämonisch bösen Hintergnund" der westlichen „Roulette-Burg" treten alle Figuren des Romans auf, sowohl die russischen als auch die fremden.

Die vorwiegend negativ geschilderten Figuren der „ausländischen Russen“ repräsentieren das negative utopische Imagothème des verwestlichten Rußlands. Die vorwiegend positiv gezeichneten russischen Figuren der "Großmutter" aus Moskau und ihrer Diener aus dem „russischen Volk“ das positive utopische Imagothème des vorpetrinischen Rußlands, dabei werden sie aber von der Faszination des Westens wie ihre in Zimnıe zametki o letnich vpecallenijach geschilderten Vorfahren bedroht.

Die negativen französischen Alius-Figuren sind die ,.psychologisch differenzierten Stereotypen" der Pariser Spießbürger aus den Zimnie zametki o letnich vpecatlenijach und enthalten eine satirisch-ideologische Komponente. Sie verkörpern als alius den bösen, materialistischen und verlogenen Westen, das negative utopische Imagothème des Westens. Die positivste Figur des Romans, der "ideal schöne" Engländer Astlej entstammt westeuropäischen Romanen (Thackeray, Dickens bzw. George Sand) und ist ein positives psychologisch erweitertes Stereotyp. Eir verkörpen den Typ eines .Idealisten" und symbolisien das positive utopische Imagothème des Westens.

Die übrigen episodischen fremden Figuren, darunter die polnischen, treten in Igrok als alter auf und sind als negative nationale bzw. ethnische Stereotypen geschildert, die aus der russischen Kultur und l.iteratur entlehnt worden sind.

Somit repräsentieren sie das russische kulturell bzw. literarisch vermittelte imaginaire social. Diese Figuren symbolisieren in lgrok das negative ideologische Imagothème des Westens. Ihre .,dämonisch-böse Komponente“ tritt (als alius) wegen ihrer Stereotypisienung stark in den Hintergrund zurück. weil sie. v.a. die Polen, als politisch-ideologische Feinde Rußlands, als alter, vorkommen, hautpsăchlich in den Anspielungen des Ich-Erzählers auf den polnischen Aufstand von 1863. 
In Igrok treten insgesamt drei negative literarische polnische Stereotypen auf:

1. der Pole als "teuflischer Verfuhrer" (in der russischen Literatur seit der Figur des "Teufels in der Gestalt eines Ljachs" in der Povest "vremmenych let anwesend). In der Figur der verwestlichten „Polina“ läBt sich darüber hinaus eine intertextuelle Anspielung auf das Stereotyp der „Polin als Verfuhrerin“ finden, das auf Marina (Maryna Mniszek) aus Puškins Drama Boris Godunov zurückgeht, obwohl dieses Stereotyp zum ersten Mal im Kiever Paterik aufgetaucht ist,

2. der Pole als "falscher Graf" und als „Falschspieler", der auf den falschen Grafen Želynskij aus Vel'tmans Roman Salomeja zurückgeht,

3. und der „dicke Pole“, der aus Zagoskins Roman über die polnische Invasion der Moskauer Rus ${ }^{\circ}$ in der "Zeit der Wirren“ stammt.

Die polnischen Betrüger im Spielcasino und der polnische (falsche) Graf, die vorwiegend in der ideologischen Funktion als alter eingesetzt werden, enthalten also die utopisch negative Komponente des „Polen als teuflischer Verführer". In Igrok gibt es dagegen keine polnischen Imageme, die zur immanenten Charakteristik der verwestlichten Russen dienen, wie der Fürst Valkovskij in Unizennye $i$ oskorblennye, der als das psychologisch differenzierte Stereotyp des „(polonisierten) russischen Jesuiten" konzipiert wurde. 


\section{8. ПРЕСТУПЛЕНHЕ И НАКАЗАНHЕ. \\ РОМАН В ШЕСТИ 'ИСТЯХ ( ЭПИ:КОГОМ (I866) \\ [VERBREC 'HEN UND STRAFE] $]^{292}$}

Der Roman Prestuplenie $i$ nakazanie ist in den Jahren 1865-1866 entstanden, gleichzeitig mit Igrok, sowie unmittelbar nach den Zimnie zametki o letnich vpečatlenijach und Zapiski iz podpol'ja. Prestuplenie i nakazanie weist dabei besonders viele imagothematische Bezüge zu den Zapiski iz podpol'ja auf, ${ }^{293}$ obwohl darin auch einzelne Imageme und andere Motive aus früheren Werken zu finden sind, beispielsweise aus den Zapiski iz Mertvogo doma und aus Unižennye $i$ oskorblennye. Die beiden in Zimnie zametki o letnich vpecatlenijach herausgcarbeitenen utopischen Imagothèmes: das negative Imagothème des "verwestlichten (petrinischen, adligen) Rußlands" und das positive des „vorpetrinischen Rußlands“ bzw. des „,ussischen Volkes“ werden um einige zusätzliche Komponenten, hauptsächlich um die positiv "russisch-byzantinische" bzw. um die negativ ..russisch-orthodoxe" Komponente, bereichert und weiter ausdifferenziert. Die imagothematische Evolution betrifft auch die Verwendung polnischer Imageme, die in Prestuplenie i nakazanie sowohl als stereotype Alter-Figuren (wie im Roman lgrok) vorkommen, als auch zur immanenten Charakteristik der russischen Alius-Figuren (wie in Unizennye $i$ oskorblennye) eingesetzt werden. ${ }^{294}$

Die Gruppe der russischen Figuren ${ }^{295}$ dieses wie Zapiski iz podpol'ja in Sankt-Petersburg, in der verwestlichten Hauptstadt Rußlands spielenden Rumans, ist nicht wie in den früheren Werken einheitlich, sie zerfallt in weitere Gruppen von Figuren, die sich einerseits durch ihre Herkunft und ihren sozialen Status, andererseits durch ihre ,.Verfremdung“, durch ihre Okzidentalisierung mit westlichen Ideen und Lebensformen bzw. durch ihr Festhalten an der russischen Tradition voneinander unterscheiden.

$\mathrm{Zu}$ der Gruppe der relativ am stărksten verwestlichten russischen Figuren des Romans gehören die zentralen „Helden“: Rodion Romanovič Raskol' nikov und Arkadij Ivanovič Svidrigajlov, darüber hinaus weitere ..sekundäre“ und episodi-

292 Die deutschen Übersetuungen russischer Zitate aus /res/uplente I nukuzamie werden nach der Ausgabe DostojewSKIJ 1996a angeführt.

293 Auf den Bezug zuvischen dem ..Paradoxalisten“ und Liza aus Zapıskı I predpol ju sowie Raskol nikov und Sonja weisen auch die Herausgeber des Roman hin, vgl. I3d. 7, S 308f. Es lassen sich aber in P'restuplente I nakazanic und in Zupisks $:$ pextpol'ja mehrere parallele Motive (und fremde Imageme) finden, wie z.B. der ..nasse Schnee" (vgl. Bd. 5. S. 123ft. und Bd. 6, S. 121), der .. Kristallpalast“ (der auch in Zımmic zametkı o letmich vpeciallenijuch vorkommt) (Bd. 5, S. $119 \mathrm{ff}$ und Bd. 6, S. 123f: in Pres/uplente I nukuzume ein Gasthaus dieses Namens) oder des ..galligen“" Charakters des ..Paradoxalisten“ und Raskol nikovs (ebd., Bd. 5, S. 99זt und Bd. 6, S. 25 und passim).

$296 \mathrm{Vgl}$. zur Genese und zum Titel des Romans den Kommentar m Bd. 7. bes. S. 334.

295 In der folgenden Interpretation von Pres/uplenic , nokazanc wie auch in allen anderen Interpretationen können nur die wichtigen figuren exemplarisch erwähnt bzw. besprochen werden. ohne daß alle darin vorkommenden figuren dieser vielschichtigen literarischen Werke ausführlich in allen Aspekten erörtert werden. 
sche Figuren wie Katerina Ivanovna Marmeladova und deren Mann Semen Zacharovix Marmeladov, Petr Petrovix Lužin und Andrej Semenovic Lebezjatnikov, der ermittelnde Staatsanwalt Porfirij Petrovic bzw. der Freund Raskol nikovs, Dmitrij Prokof ic Razumichin. ${ }^{296} \mathrm{Zu}$ den russischen Figuren, die am christlichen Glauben, d.h. entweder am russisch-orthodoxen oder am ,alten“ russischen Glauben und somit an den russischen religiösen Tradition, auch als Sektierer, intensiv festhalten, wobei sich dieser Glaube zuweilen auch in fanatischer Form äußern kann, gehören: Sonja (Sof ja Semenovna Marmeladova), Lizaveta Ivanovna und Alena Ivanovna, die Opfer Raskol'nikovs, der Altglăubige Mikolka (Nikolaj Dement'ev), die Schwester und die Mutter Raskol nikovs, Avdot'ja Romanovna und Pul'cherija Aleksandrovna Raskol nikova.

Die russischen Figuren des Romans gehören dabei entweder dem Petersburger Bürgertum oder dem (verarmten) Adel an, das russische Volk tritt v.a. im Epilog des Romans als "kollektiver Held" auf. ${ }^{297}$ Im Vergleich zu den oben besprochenen Werken, besonders zu Unizennye $i$ oskorblennye, ist jedoch keine scharfe Trennung zwischen eindeutig negativen bzw. eindeutig positiven russischen Figuren möglich, weil alle wichtigen Figuren in Prestuplenie i nakazanie, abgesehen von den episodischen, stereotyp gezeichneten, psychologisch differenziert dargestellt werden und sowohl gute als auch schlechte Eigenschaften enthalten. Daher lăßt sich in Prestuplenie $i$ nakazanie keine ausschließlich negative zentrale Figur wie der Fürst Valkovskij in Unižennve $i$ oskorblennye finden, denn auch der "dämonisch-böse“ Svidrigajlov weist gute Eigenschaften auf und tritt in der Rolle des unerwartet erschienenen Wohltäters der Familie Marmeladovs, Sonjas und Raskol nikovs auf. Auch eine der weiteren negativen Figuren, Lužin, ist kein eindeutig „böser Dämon“, sondern ein kleinlicher Materialist, der lediglich als abstoßend geschilden wird. Eine Ausnahme bilden die

$296 \mathrm{Vgl}$. zu Raskol nikov, Svidrigajlov brw. Katerina Ivanovna unten im Zusammenhang mit den polnischen Imagemen. $V g l$. bes. zu Lužyn Bd. 6, S. 31-37, S. $111 \mathrm{ff} .119, \mathrm{~S} 116, \mathrm{~S}$. 156, S. $236 \mathrm{ff}^{\circ}$ bzw. 276ff., und zu Lebezjatnıkov ebd., S. 278ff., 280f., 284f. Beide sind Anhanger der ..neuen liberalen bzw. atheistisch-revolutionären Ideen“ aus dem Westen, u.a. des vulgären Utilitarismus und Materialismus, vgl. auch Bd. 7, S. 374f., S. 388fT; zu Portirij Petrovič ebd., z.B. S. $191 \mathrm{ff}$; zu Rasumichin, ebd.. z.B. S. 148ff. und passim. Vgl z.B. aber auch ebd.. S. 378: die Äußerung Svidrigajlovs über die ..seelische Brette der Russen“. Skhe auch auch zur Charakterıstık der einzelnen Figuren sowie zur Symbolik ihrer Namen z.B. bei WORN 1998, S. 5 Iff. Siche auch die Interpretation dieses Romans von GERIGK 1991 (S. 179 256: ,. Sichuld und Sïhnc").

297 Dic oben genannten wichtigen Figuren des Romans mit Ausnahme Svidrigajlovs (auch seine Frau Marta Petrovna ist eine reiche Grundbesitzerin) sind arm bzw. veramt Raskol nikov, seine Schwester Avdot ja (Dunja) Romanovna und Sonja (Sof ja Semenovna Marmeladova). Entsprechend arm sind auch ihre Verwandten. Der Vater Sonjas. Scmen Zacharye Marmeladov, seine Frau Katerina Ivanovna und ihre Kinder, die Mutter Raskol nikovs. Pul cherija Aleksandroina. der Student und Freund Raskol nikovs Drritrij Prokof ic Razumichin bzw. Vrazumıchin. Die übrigen Figuren wie der Sektierer Niholaj (Mikolka), die beiden Frauen und (Opfer Raskol nikovs, Lizaveta Ivanovna und ihre Sctwester Alena Ivanovna. der Schneider Kapernaumov, aber auch der Untersuchungsrichter, Porfinij Petrovič, Andrej Semenovič Lebezjatnikov und Petr Petrovič Lužin verdienen ihr Geld entweder durch ihre Arbeit bzw. dank ihren Geschäften oder als staatliche Beamten 
zwei positivsten Figuren des Romans, die sanftmütigen Sonja Marmeladova und Lizaveta, die von Raskol'nikov ermordete Schwester der geizigen Pfandleiherin Alena. die das positive utopische Imagothème des „byzantinischsektiererischen" (vorpetrinischen) Rußlands symbolisieren, aber, ohne daß, wie in den späteren Romanen Dostoevskijs, in deren christlichem Glauben die kirchliche "russisch-orthodoxe" Dimension anwesend wäre. Die grausame, egoistische Pfandleiherin vertritt die fanatische russisch-orthodoxe KirchenFrömmigkeit, die sich hauptsächlich in der Beachtung der Rituale äußert und mit der Unfăhigkeit zur Nächstenliebe verbunden ist: Alena repräsentien das negative utopische Imagothème des pervertierten orthodoxen, nachpetrinischen Rußlands. Der Beruf Alenas deutet auf ihre Okzidentalisierung hin und kann als Grund ihres "Egoismus" gelten. Ihre Schwester Lizaveta, die möglicherweise wie Mikolka einer russischen Sekte angehör, vertritt als eine Kontrastfigur zu Alena, als „Gottesnărrin“ [юродuвar; jurodivaja] den „vorpetrinischen“ (byzantinisch)-orthodox geprägten Glauben, der sich in einer grenzenlosen Demut und Liebesfăhigkeit außert, worin sie der Figur Sonjas komplementär ist. ${ }^{298}$ Alena und Lizaveta symbolisieren als Schwestern zwei „Gesichter" des russischen christlichen, des vor- und nachpetrinischen Rußlands und werden von Raskol'nikov, dem Vertueter des „verwestlichten“ rationalistischen (bzw. atheistischen) Rußlands, getötet.

Die verwestlichten russischen Figuren in Prestuplenie i nakazanie werden mit Hilfe mehrerer fremder Imageme, entsprechend dem Grad ihrer Okzidentalisierung, positiv als auch negativ charakterisiert. Positiv, wie in den früheren Romanen Dostoevskijs Unizennye i oskorblennye und Igrok, werden u.a. Namen und Werke der deutschen Autoren Heine und Schiller eingesetzt. ${ }^{299}$ Sie dienen

298 Vgl. dazu z.B. bei WORN 1998, S. 54; dort auch zur kritischen Darstellung der Figur des russisch-orthodoxen Geistlichen, der zu dem sterbenden Marmeladov kommt. Der Name Sionja ( $S\left(f^{j} j a\right)$, den alle positiv dargestellten glăubigen russischen Alıus-Frauenfiguren in den späteren literarischen Werken Dostoevskijs tragen, deutet auf die göttliche Weisheit hin und bildet den Bezug zur byzantinisch-orthodoxen Tradition. Der Name lizavela (russ. Elizavela; dt. $l: /$ subet $/ h)$, der im Hebräischen ...Mein Gott ist Vollkommenheit" bedeutet, spielt moglicherneise auf die Năhe dieser Figur zu Gott an bzw. auf die neutestamentliche Figur der Elisabeth. Frau Zacharias und Mutter Johannes' des Täufers (vgl. Luk. 1, 5ff.) Sonja sagt beispielsweise zu Raskol nikov, daß ..Lizaveta Gott schauen wird“" (.Она бога узріrт"), vgl. Bd. 6, S. 249. GERIGK 1991 weist auf den ironischen Bezug des Namens der håßlichen Wucherin (Alena $=$ Helena) zur ..schönen Helena“ hin (S. 182). Dieser Name könnte sich aber nicht nur auf diese ..europäische" mythologische Figur, sondern auch auf die Insel is. Hc/crna, auf der Napoleon Bonaparte (das Vorbild Raskol'nikovs) in der Verbannung gestorben ist, oder auch auf die Kaiserin Helena, Mutter Konstantins des Großen (geb. um 257 - gest. um 330). die nach einer legende das Kreuz Christi in Jerusalem aufgefunden haben soll, beziehen. Nachdem Raskol "nikov Alena ermordet hat, nimmt er „das Kreuz des Leides“ auf sich. Später bekommt er von Sonja ihr kupfernes Krewz, obwohl er sich lieber das silberne Kreuz umhängen würde, das er nach der Mordtat an Alena ., ihr auf die Brust geworfen hat"* (vgl. Bd. 6. S. 403).

$299^{\circ}$ In der Erzählung (..Beichte“) Marmeladovs kommt ein deutscher Petersburger namens ..Klopstock“ vor, der russische Näherinnen beschäftigt. Er hatte Sonja angestellt. sie aber bald "verjagt", weil sie angeblich durch ihre Ungeschicktheit ein .,holländisches Hemd" verdorben habe. Danach war sie gezwungen, auf die Straße zu gehen. Diese Anspielung auf den Verfas- 
wie in den früheren Werken Dostoevskijs zur Charakteristik der russischen verwestlichten Figuren, auch Raskol "nikovs, wodurch deren "Idealismus", das in diesen Figuren immanent vorhandene "Gute“, hervorgehoben wird, das sich wie in den früheren Romanen als ein Bestandteil des positiven utopischen Imagothème des verwestlichten RuBlands bezeichnen läBt. ${ }^{300}$ Neben den Erwähnungen deutscher Literatur gibt es in Prestuplenie $i$ nakazanie mehrere positiv konnotierte Anspielungen auf andere europaische Literaturen bzw. Kulturen, die an dieser Stelle nur exemplarisch genannt werden können, so z.B. auf die Sixtinische Madonna Raffaels und auf die Gestalt Ophelias, die beide in den Erzăhlungen und Trăumen Svidrigajlovs erwähnt werden. ${ }^{301}$ Eine wichtige Rolle spielt v.a. die Figur Napoleons I. die mit Raskol 'nikovs Theorie in engem Zusammenhang steht, und für ihn ein nachahmenswertes ideales Vorbild ist. das aber ihn negativ charakterisiert und somit das negative utopische Imagothème des Westens bzw. des verwestlichten RuBlands symbolisiert. Raskol'nikov wird aber auch mit Napoleon III. in Verbindung gebracht. ${ }^{302}$

ser des Epos Der Messias, Friedrich Gottlieb Klopstock (1724-1803), ist eine ideologische Kritik am deutschen Protestantismus und Pietismus und am "westlichen“ Glauben schlechthin, vgl. ebd., S. 17.

${ }^{300} \mathrm{Vgl}$. z.B. ebd., S. 333f: Katerina Ivanovna erinnert sich in der Szene ihres Todes an das Gedicht Hemes Du hast Diamanien und Perlen aus dem Buch der Lieder (1827) (daneben singt sie auch eine russische Romanze nach dem Gedicht Lermontovs Son [Der Traum] (1841)). Laut Anmerkung der Herausgeber (Bd. 7, S. 393) handelt es sich um ein Lied Schuberts, das sie vorsingen mochte. Im ('alulog of Works by $1 \%$. Schuberl based on the

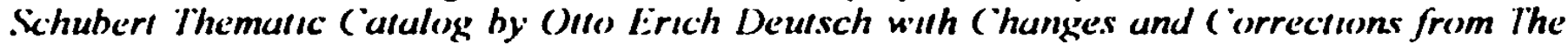
New (irove Dictionary of Miusic (im Internet unter www. richter.simplenet.com/Deutsch.html) wird jedoch eine solche Vertonung durch Schubert nicht angeführt. GozenPUn 1971 (S. 98) erwăhnt eine (russische) Romanze, die in Frage kommen könnte; Raskol nikov wird von Svidrigajlov als ein ..Schiller bezeichnet, Bd 6, S. 362, vgl auch S. 37 und die Anm. dazu, Bd. 7, S. 366: Raskol'nikov nennt seine Schwester und Mutter: „шиллеровские прекрасные души" I,.Schillersche Schöne Seelen": Bd. 6, S. 601: er zitiert auch eine Stelle über die Empfindungen eines zum Tode Verurteilten aus Victor Hugos / $\mathcal{e}$ dernier jour d'un condumné (1829) (vgl. Bd. 6, S. 123); Vgl. auch zur Rezeption Heines in der russischen Literatur: KilGE 1998b. An dieser Stelle kann jedoch die weitere, ảußerst umfangreıche Sekundärliteratur zur Rezeption einzelner westeuropaischer Schriftsteller, Künstler oder Philosophen nicht angeführt werden, zumal ihre Fragestellung die Problematik der folgenden Studie nicht unmittelbar berührt.

${ }^{301}$ Bd. 6, S. 369: Svidrigajlov erzăhlt über seine Verlobte, ein junges Mădchen, das er mit der ..Madonna Raffaels" und mit einer .Jurodivaja" vergleicht; darin außert sich seine Sehnsucht nach dem ..Ideal des Schönen“, und S. 390f. seine „verwestlichten Visionen“ bzw. sein halluzinatorischer Traum über die „Ophelıa” und ..Kamelıendame“. Siehe auch zum „Idealısmus” Svidrigajlovs, v.a. zu seinem Kult der Sirtınıschen Madonna, unten. Zur Rezeption des Dresdener Gemáldes in der russischen l.iteratur bei MuchA 1995, bes. S. 29 (zu Dostoevskij). Über die Elemente der orientalischen Kulturen, über den .Mythos des Orients ${ }^{*}$ in Presuplenie I nukuzanic' vgl. POŻNIAK 1992.

302 Vgl. z.B Bd. 6, S. 211 f., S. 263. Die Bezüge zwischen den beiden franzosischen Fiertschem und Raskol nikov deuten auf dic imagothematische Năhe zu Zımnic zumeıkı o leınıch vpeciullenıach und zu Zapıskı I podpol'ja hin. Siehe dazu GERIGK 1991, S. 204 (zu Napoeon 1.) und I.INDENAIEYR 1984 (über den Vergleich zwischen dem Plan des Umbaus von Paris, den Napoleon III. mit Hilfe des Architekten Georges Haussmann verwirklicht hat, und Jem ..Plan“ Raskol nikovs, der davon träumt, das Petersburger I Heumarkt-Viertel umzubauen und 
Die Gruppe der fremden Figuren in Prestuplenie $i$ nakazanie umfaßt neben den polnischen mehrere deutsche Nebenfiguren, v.a. deutsche Frauen, die negativ geschildert werden. ${ }^{303}$ Ausschließlich im negativen Kontext werden ebenfalls einige jüdische Figuren bzw. die Bezeichnung ,Jude" [z̈id; жud] als

somit „menschenfreundlicher" zu gestahen, wobei der Anblick des Elends dieser Gegend seinen Mordplan zu rechtfertigen scheint, ebd., S. 104ff.). LINDENMEYR schreibt außerdem über das Buch Napoleons III. Histoire de ('ésar (1865), in dem Napolcon Bonaparte und Julius (uesur erwăhnt werden und das auf die „Theorie“ Raskol nikov's eingewirkt haben soll (ebd.). In den „Plänen“" Raskol nikovs taucht auch das aus Zımnıe zumetkı o letnıch vpeciallentjach und lgrok bekannte Motiv des „Springbrunnens“ auf, vgl. Bd. 6, S. 60. Da er sich kurz davor zur Mordtat auf ..mechanische“" Weise hingezogen fühlt, als ob er in das „Rad einer Maschine“" hineingezogen würde (S. 58), entsteht der weitere Bezug zum industrialisierten London ( $=$ "Westen“), dem „Reich des Baals“, um so mehr, als Raskol nikov, dem gerade gelungen ist, das Beil zu stehlen, sagt: ..Не рассудок, так бес“ (wenn es kein Verstand war, so der Teufel bzw. der bōse Geist], der ihn dazu verführt habe (S. 60).

${ }^{303}$ Drei deutsche Frauen, die namentlich genannt werden und deren Âußeres beschrieben wird, treten in negativem Kontext auf: Amalija Fedorovna bzw. Ivanovna Lippevechsel', die Wirtin der Familie Marmeladovs, vgl. Bd. 6, S. 16f., 140f., 278ff, 291-309; eine bestimmte Luiza Ivanovna, Besitzerin eines offentlichen Hauses, ebd., S. $75 \mathrm{~m}$ und die Wirtin Svidrigajlovs, Gertruda Karlovna Resslich, ebd., S. 188, 228 und 253: „нностранка и сверx

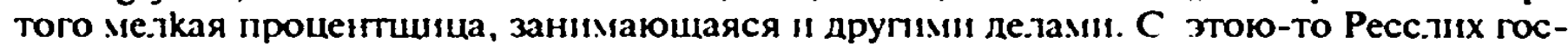
подин Свидригайлов находился в некоторых весьма 6.тизkıх и танинственных отношениях. У ней жи.ла датьняя родственница, /.../ г.тухонемая, девочка .лет пятнадиаті I даже четырнадиаті, которую эта Ресс.лих беспрерывно ненавице.ла и kаждым kусkом nonpekaта: даже бесче.овечно біцта. Раз она найдена была на чердаке удавившеюся. /.../ впос.ледствни яви.лся, однако, донос, что ребенок бы.т... жестоко оскорб.лен Свидригайловым. Правда, всё это бы.т донос от другой же немkı, отъявленной женшины и не пмевией доверія: /... / наконец /.../ всё органичицтось с.тухом“" (S. 228).

IS. 403f. Hier lebte und lebt wohl auch heute noch eine gewisse RöBlich, eine Auslanderin und Wucherin bescheidenen Formats, die allen moglichen Geschäften nachgeht. Zu dieser Frau Roßlich unterhielt Herr Swidrigajlov seit ewigen Zeiten gewisse höchlichst enge und undurchsichtige Bezichungen. Bei ihr wohnte eine entfernte Venwandte, $i . . /$ ein taubstummes Mädchen von fünfzehn oder sogar nur vierzehn Jahren, diese Roßlich haßte sic grenzenlos. rechnete ihr jeden Bissen vor und verprügelte sie sogar unmenschlich. Eines Tages hing sic auf dem Speicher in der Schlinge. !... nach einiger Zeit lief eine Anzeige ein, das Kind sei von Swidrigajlov ... grausam mißbraucht worden. Freilich, das Ganze blieb undurchsichtig, die Anzeige erfolgte durch eine andere Deutsche, ein übelbeleumundetes, unglaubliches Frauenzimmer; /.../ schließlich /.../ blieb nur ein Gerücht [zurück|]; das Motiv eines „beleidigten“ Mädchens kehrt in der Szene der Beichte Stavrogins bei Tichon vieder, vgl. Bd 11, S. $12 f f$. In Prestuplenie I nukazanie werden noch weitere deutsche Figuren erwähnt: Svidrigajlov erzählt über eine im Zug von einem Passagier geschlagene Deutsche im Zusammenhang mit seiner Frau, Marfa Petrovna, die er mehrmals ausgepeitscht haben soll, ebd., S. 215, vgl. dazu auch Bd. 7, S. 383. Erwăhnt werden u.a. noch. der Besitzer eines Mietshauses, ein reicher Deutscher Kozel', bei dem Sonja wohnt. Bd. 6, S. 23 und 138, ein deutscher geiziger Ilandwerker, bei dem Lužin eine Wohnung für sich und Dunja mieten wollte. ebd., S. 277. ein deutscher Arzt (..аккуратның старичок" |..ein gepflegter alter Herr, ein Deutscher”. S. 247\}), der den sterbenden Marmeladov behandelt, ebd., S. 142, und .какой-то пьяный мюнхенский немеи вроде паяца, с красным носом, но отчего-то чрезвычайно унылый” I..ein angeheiterter Deutscher aus München, eine Ar Clown mit roter Nase, Ider aus irgendeinem Grund außerordentlich verzagt aussah. war; Ergänzung des Zitats die Verf. $\left.\right|^{-*}$. S. 6751, der das Publikum in einem Lokal amüsiert, in dem auch Svidrigajlov zu verkehren pflegt, S. 383 
Schimpfwort erwähnt. ${ }^{304}$ Alle diese fremden Figuren treten als alter, als vorwiegend negative nationale bzw. ethnische Stereotypen, auf und bilden den Kontrast zu den russischen Figuren des Romans. Diese stereotypen Fremden betonen darüber hinaus den Schauplatz von Prestuplenie $i$ nakazanie, den das vetwestlichte Petersburg bildet, und lassen sich als Elemente des negativen ideologischen Imagothèmes des verwestlichten Rußlands bezeichnen, denn diese fremden Figuren sind Bewohner der petrinischen Hauptstadt mit ihrem besonderen „europaischen“ Kolorit.

In Prestuplenie i nakazanie gibt es nur drei Stellen, an denen explizit polnische Figuren vorkommen, implizit kann der Name des „Zwillingsbruders“ von Raskol nikov - Svidrigajlov - mit der polnisch-litauischen Geschichte, d.h. mit dem Namen des Bruders des polnischen Königs Jagiello, Svidrigajlo bzw. Świdrigiello in Verbindung gebracht werden. Alle polnischen Alter-Figuren spielen episodische Rollen. Sie werden insgesamt dreimal im Laufe der Handlung eingeführt: Zum ersten Mal wird ein „Pole“ im Gespräch zwischen dem Untersuchungsrichter Porfirij Petroviž und Raskol nikov erwăhnt: ${ }^{305}$ beim zweiten Mal werden drei poljački als Gäste von Katerina Ivanovna Marmeladova erwähnt, die bei dem Leichenschmaus Lpominki; nosıurku; eigentl. "Gedenkfeier"] für ihren verstorbenen Mann Marmeladov erschienen sind ${ }^{306}$; schließlich vergleicht sich Raskolnikov mit anderen Häftlingen, mit denen er in der Katorga eingespert ist. Unter diesen Mitgefangenen gibt es einige Polen. ${ }^{307}$

1. Die erste Erwăhnung eines Polen in Porfirij Petrovið̌s Gespräch mit Raskol'nikov bezieht sich auf die seelische Verfassung Raskol'nikovs, den Porfirij psychisch „brechen“ und zum Schuldbekenntnis bewegen will, ohne ihn dabei offen mit Gefängnis bedrohen zu können. Nur ein Pole würde gewissenlos ins Ausland fliehen, ein „entwickelter" Mensch wie Raskolnikov wäre dagegen zu solchem Schritt nicht fähig. Dieses Argument gehör zur psychologischen „Taktik“ Porfirijs, der sich als Kenner der „verbrecherischen russischen“ Seelen zu erkennen gibt. Diese Äußerung mag sich wohl auf den Typ des ..polnischen

304 Lužyn wird von Razumichin als „Jude“ bezeichnet, Bd. 6, S. 156, es ist aber nicht klar, ob Razumichın dies in übertragenem Sinne als Schimpfworı meint: .A мы все давеча поня.11, /.../ что этот че.товеk не нашего обшества. Не потому что он воше. завитой у парикмaхера, не потому что он свой ум спешіці выстав.ять, а потому что он сог.лядатай и

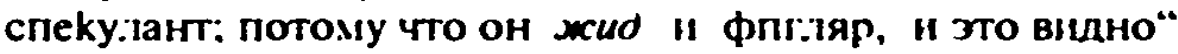

1..Wir haben nămlich alle gewußt, ...i daß dieser Mensch nicht zu uns gehört. Nicht, weil er stehenden Fußes vom Friseur kam, mit onduliertem Haar, und nicht, weil er es so eilig hatte, seine Ansichten zur Schau zu stellen, sondern weil er ein Voyeur und Spekulant ist, ein ./ud und ein Gaukler, und das sicht man"; S. 274] |kursiv die Verf. |. Auch die alte Pfandleiherin Alena wird als ..6orara kak wuס" |..reich wie ein ./zkle"; S. 88] [kursiv die Verf.] bezeichnet (S. 53). Eine jüdische Figur tritt außerdem in der Selbstmordszene Svidrigajlovs auf (S. 394f.); siehe dazu z.B. bei GERICK 1992a.

$305 \mathrm{Vgl}$. Bd. 6., S. 262.

306 Ehd., S. 290-309.

307 Ebd., S. 418 
Werschwörers" beziehen, der gegen Rußland mit unlauteren Mitteln kämpft und in mehreren russischen Romanen des neunzehnten Jahrhunderts aufuritt:

Да оставь я иного-то господина совсем одного /.../ и будь он у меня сознательно под вечным подозрением и страхом, таk ведь, ейбогу, закружится, право-с, сам придет /.../. Это и с муужиком сиволапым может произойти, а уж с нашим братом, современно умным чельвеком, да еще в известную сторону развитым, и подавно! /.../ я ведь /.../ знаю, что он мох жертвочка и никуда не убежит от меня! Да и куда ельу убежсать, хе-хе! За гранииу, что ли? За границу поляк убежит, а не он /..../. В глубину отечества убежит, что ли? Да ведь там мужики живут, настоящие, посконнье, русские; этак ведь современното развитый человек ckopeе острог предпочтет, чем с таkими иностранцами, kak муужики наши, жить, хе-хe! [kursiv die Verf.]

[Angenommen, ich überlasse manchen Herrn sich selbst: /.../ und wenn er in seinem Bewußtsein meinen ewigen Argwohn und seine ewige Angst mit sich henumträgt, dann wird es ihm schließlich, bei Gott, schwindlig werden, wirklich, er wird vielleicht von selbst herkommen /.../. Das kann auch einem einfältigen Russen [eigentl.: einem „rauhbeinigen“, gemeinem Bauern; Erg. d.Verf.] passieren, aber unsereinem, dem im Sinne der Zeit klugen Kopf, der sich darüber hinaus in einer bestimmten Richtung entwickelt, erst recht! /.../ ich weiß doch sowieso, daß er mein Opferlämmchen [eigentl.: mein süßes, liebes Opferchen; Erg. d. Verf.] ist und daß er mir nicht entkommt! Und wohin sollte er auch fliehen' Enva ins Ausland? Ein Pole würde ins Ausland fliehen, er aber nicht /.../ Vielleicht flieht er in den Schoß seiner Heimat, aber dort wohnen ja Bauern, echte, ungeschlachte russische Bauern; und ein im Sinne der Zeit gebildeter Mensch geht lieber ins Zuchthaus, als unter solchen Fremden [eigentl.: Ausländern; Erg. d. Verf.] zu leben, wie unsere Bäuerlein es für ihn sind, he-he-he! [kursiv die Verf.]]

Raskol nikov wird hier aus der Sicht Porfirijs sowohl einem „Polen“ als auch den „echten, ungeschlachten russischen Bauern" gegenübergestellt, denn er würde vor der Justiz weder ins "Ausland" (wie ein „Pole“), noch , in den Schoß der Heimat" Niehen. Er sei als ein in Petersburg lebender verwestlichter Russe und als ein ,im Sinne der Zeit kluger Kopf" sowohl den „fremden Ausländern“ (= den "Polen"), als auch dem ,russischen Volk" entfremdet, die für ihn ebenfalls „russische Ausländer" seien.

Andererseits bemerkt aber Porfirij, daß Raskol'nikov wie ein „rauhbeiniger, russischer Bauer" sich schließlich zu seiner Tat bekennen würde, so daß in dieser Äquivalenz auf das noch nicht gänzlich verlorengegangene ,russische Gewissen" Raskol'nikovs angespiclt wird.

Der von Porfirij erwähnte ins Ausland fliehende typische polnische Verbrecher wird Raskol nikov in der Funktion als alter gegenübergestellt und hebt des-

${ }^{308}$ Bd. 6., S. 261f. [S. 458f.]. 
sen positive russische Eigenschaft hervor, sich der Verantwortung für ein Verbrechen zu stellen und bereit zu sein, "Leid" als dessen Konsequenz auf sich zu nehmen. ${ }^{309}$ Neben der psychologischen Charakteristik Raskol'nikovs als "Russe" ist diese Äußerung Porfirijs als in einer zusatzlichen ideologischen Bedeutung zu betrachten, als Kritik bzw. Verurteilung politischer rußlandfeindlicher polnischer Verschworer, und bildet auch einen Teil des negativen ideologischen Imagothèmes des verwestlichten Rußlands. Das negative Stereotyp des „polnischen Verschwörers", das in Prestuplenie i nakazanie zum ersten Mal bei Dostoevskijs vorkommt, wird erneut in dem Roman Besy aufgegriffen und zur immanenten Charakteristik von Petr Stepanovic Verchovenskij eingesetzt. ${ }^{310}$

2. Beim zweiten Mal tauchen drei poljački bei der Begräbnisfeier für Marmeladov auf. ${ }^{311}$ Einer der Polen gehört zu den Untermietern im Hause der deutschen Wirtin Amalija Ivanovna Lippevechsel', die ebenfalls zu den eingeladenen Gästen zăhlt. ${ }^{312}$ Dieser жaıkuй nosssuok [Žalkij poljačok; armseliger, kleiner Pole, $=$ dieses elende Polackchen] hilft Katerina Ivanovna beim Einkaufen:

Заkупками распорядилась сама Катерина Ивановна, с помошию одного жильца, kakozo-то жалkого полячka, бог знает лля чего проживавшего у госпожи Липпевехзель, который тотчас же прикомандировался на посылки k Катерине Ивановне и бегал весь вчерашний день и всё это утро сломея голюву и высунув язык. кажется особенно стараясь, чтобы заметно било это последнее обстоятелиство. /.../ называл ее беспрестанно: «пани хорунжина», и надоел ей наконеи kak peдьka /.../. [kursiv die Verf.]

[Die Einkäufe hatte Katerina Iwanowna mit Unterstützung eines der Mieter besorgt, eines armseligen kleinen Polen, der aus weiß Gott welchem Grund bei Madame Lippewechsel logiente, sich sofort Katerina Iwanowna zur Verfügung gestellt hatte und den ganzen gestrigen Tag sowie den heutigen Vormittag herumgerannt war, mit hängender Zunge, offensichllich bemüht, letzeren Umsland aller Welt bemerkbar =u machen. [Er] /.../ sprach sie unentw'egt mit *pani chorri=na* [sic!] [eigentl. chorażyna; Erg. d. Verf.] an und wurde ihr schließlich so lästig wie eine Fliege [eigentl. idiom.: so unerträglich wie Rettich; Erg. d. Verf.] /.../. [kursiv d. Verf.]] ${ }^{313}$

Derselbe Pole erscheint auch bei dem Begräbnis von Marmeladov, um zwei uneingeladene Polen zum Essen mitzubringen. ${ }^{314}$ Alle Gäste Katerina Ivanovnas werden insgesamt „самые незначительные и бедные“ [„dic Unbe-

$309 \mathrm{Vgl}$. unten zur Stelle, bei der Porfirij Raskol nikov explizit mit dem Sektierer Miholka vergleicht und erneut den ..Lakaien westlicher Ideen“ gegenüberstellt, S. 280

$320 \mathrm{Vgl}$. dazu unten im Zusammenhang mit der Figur von Petr Stepanovic Verchovenskj, S. $331 \mathrm{ff}$, bes. S. 334 .

311 Ebd., S. 291-310.

312 Ebd., S. 287 und $291 \mathrm{ff}$.

${ }^{313}$ Ebd., S. 291 [S. 512]

314 Ebd., S. 293 
deutendsten und Ärmlichsten“] genannt ${ }^{315}$, die sich viel ,unzeremonieller" als jene poljački selbst benehmen, obwohl Katerina Ivanovna um die silbernen Loffel ihrer deutschen Wirtin fürchtet:

Сидят чинно рядышком. Пане, гей! - закричала она вдруг одному из них, - взяли бы блинов? /.../ Csотрите: вскочил, расkцанивается, смотрите, смотрите: должно бить, совсен голодние, беднше!/.../ Не шумят, по крайней мере, только... только, право, я боюсь за хозяйckuе серебряные ложски!... Амалия Ивановна /.../, если на случай покрадут ваши ложки, то я вам за них не отвечаю, предупреждаю заранее! /.../ не поняла, опять не поняла! Сидит разиня рот, смотрите: сова, сова настоящая, сычиха в новых лентах, хa-xa-xa! [kursiv d.Verf.]

[Und sitzen hier artig nebeneinander. Pan, he!« rief sie plötzlich einem von ihnen zu, shaben Sie auch von den Bliny bekommen? /.../ Sehen Sie: Er springt auf, macht einen Diener, sehen Sie, sehen Sie: Wahrscheinlich sind sie völlig ausgehungert, die Armen! /.../ Sie machen wenigstens keinen Krach, nur ... ich habe Angst um die silbernen Löffel der Wirtin!... Amalija Iwanowna!« /.../ »sollten Ihre Löffel gestohlen werden, bin ich dafür nicht verantwortlich, ich sage es im voraus!«/.../ »Sie hat es wieder nicht verstanden! Sie spert den Mund auf, sehen Sie: eine Eule, eine richtige Eule, ein Uhu mit neuen Bändern, ha-ha-ha!«] [kursiv die Verf.]] ${ }^{316}$

In diesen Passagen handelt es sich um das negative nationale Stereotyp des „elenden, armen Polackchens aus dem Volk“, das in Zapiski iz Mertvogo doma vorkommt und mit Hilfe gleicher Motive "konstruiert" wird. Dieses Stereotyp paßte besser in die dargestelite Welt von Prestuplenie i nakazanie als das Stereotyp des ,polnischen Falschspielers" in die des Igrok. Diese „Polen“ sind jedoch wie die "Helfer" bzw. Diener der „Großmutter" (potentielle) Diebe und "lakaienhaft" höflich, immer „,zu Diensten“ bereit, und halten „solidarisch“ zueinander. Darüber hinaus sprechen und laufen sie ebenso schnell wie die "Polen" in Igrok.

Die deutsche Wirtin. Amalija Ivanovna, ist aber auch als eine negative sterotype Alter-Figur beschrieben. Sie reizt mit ihrer Person (einer "Eule“ ăhnlich), ihrem Benehmen und mit ihrer "deutschen Ausprache" die kranke Katcrina I anovna, es kommt bald zum offenen Konflikt, der noch zusätzlich verschärft wird, v.a. wegen des von Petr Petrovič Lužin inszenierten Gelddiebstahls, dessen er Sonja beschuldigt. ${ }^{317}$ Dabei zeigen sich emeut alle drei Polen „solidarisch" empört über den Trick l.užins mit dem Hundertrubelschein: ,.Все три полячка́ ужасно горячились и кричали ему беспрестанно: «пане ла́йлак!", причем бормотани еше какие-то угрозы по-польски" ["Die drei kleinen Polen waren furchtbar aufgeregt und riefen immer wieder: "Panie lajdak!« I=

\footnotetext{
313 Ebd., S. 292 |S. 514).

311 Ebd., S. 294. [S. 517f.]

31. Ebd., S. 300ff.
} 
„lajdak“; „Sie sind ein Schuft!“; Erg. d. Verf.] und murmelten auf polnisch irgendwelche Drohungen".]"

Die polnischen Figuren werden wie einige andere Gåste Katerina Ivanovnas nicht näher beschrieben, sondem nur durch ihre nationale pejorative Bezeichnung, ihre allzu, ,hofliche" Haltung und die polnischen Fremd- bzw. Schimpfworter charakterisiert. Sie werden ahnlich wie die polnischen Betrüger und Falschspieler aus dem Igrok geschildert, obwohl sie in dieser Szene der Gedenkfeier fur Marmeladov nicht als Betrüger auftreten konnten, da ihre Funktion ist, das Elend und die Schăbigkeit des Lebens von Katerina Ivanovna und ihrer Familie zusătzlich hervorzuheben, denn das Haus, seine Mitbewohner und die deutsche Wirtin sind negativ geschildert. Sicherlich könnte diese Szene auch ohne jene Polen die gleiche Wirkung haben, obwohl bekannt ist, daß es damals in Petersburg viele Polen gab, die zu den armsten Schichten der Petersburger Bevölkerung zăhlten. ${ }^{319}$ JAN ORLOWSKI hat zu dieser Szene bemerkt, daß der Roman Prestuplenie $i$ nakazanie in der Zeit nach dem polnischen Aufstand von 1863 und als Reaktion Dostoevskijs auf die offentliche Diskussion darüber verfaßt worden sei. ${ }^{320}$ Die darin auftretenden polnischen Figuren seien „lebende Versatzstücke", die ohne einen direkten Zusammenhang mit der Handlung eingeführt würden. ${ }^{321}$ Alle Erwahnungen Polens stünden im Zusammenhang mit der „Hauptidee“ des Werkes Dostoevskijs über den „Kampf des Westens gegen RuBland". ${ }^{322}$ ZBIGNIEW ŻAKIEWICZ betont dagegen die nationale Solidarităt jener schăbigen Polen, die bei Katerina Ivanovna ohne Einladung erscheinen und sich trotz ihrer niedrigen sozialen Position korrekt und mit "Manieren" benehmen. ${ }^{323}$ Er bemerkt außerdem, daß Katerina Ivanovna von einem Polen mit „пани хорунжина“ Ipoln. ,pani Chorqyna“; Frau eines Fähnrichs] angesprochen wird, was sich auf ein polnisches Mădchen aus Semipalatinsk, Maryna O., beziehen konnte. ${ }^{324}$ Die erste Frau Dostoevskijs, Marija Isaeva. diente ebenfalls als Vorbild für diese Gestalt. Nach ŻAKIEWICZ könnte die Anrede an Katerina Ivanovna eine Anspielung auf ihre Eifersucht auf jene Maryna $O$. sein, für die sich Dostoevskij interessiert habe. Maryna $O$. wurde spăter, nachdem sie von einem jungen Russen verführt und verlassen sowie von einem Kirgisen mißbraucht worden war, mit einem Făhnrich verheiratet. $^{325}$

Katerina Ivanovna ${ }^{326}$ wird in der Szene der Gedenkfeier in ihrer elenden Umgebung, dem Milieu eines schăbigen Petersburger Mietshauses, in ihrer Wohnung, die einer Deutschen gehört, gezeigt. Sowohl die stereotyp gezeichneten polnischen Figuren als auch die deutsche Besitzerin des

\footnotetext{
319 Ebd., S. 309 |S. 545|.

$319 \mathrm{Vgl}$. dazu BELOV 1979 und BNZYLOW 1984

$320 \mathrm{Vgl}$. OrLOWSKI 1982, S. 94.

321 Ebd.

322 Ebd., S. 97.

323 Vgl. ŻAKIEWICZ, S. 84ff.

324 Ebd.

325 Ebd. Vgl. auch VRANGEL' 1992, S. 58 und S. 77f.

$326 \mathrm{Vgl}$. Bd. 6, S. 23, dic Schilderung Katerina Ivanovnas.
} 
Mietshauses, die ebenfalls als eine "flache“ Figur eingefühn wird, dienen als Kontrast zur tragischen Figur Katerina Ivanovnas und zu ihrer Familie. Die deutschen Figuren des Romans heben das "westliche", "Berlinische" Lokalkolorit des schlechten Petersburger Stadtviertels um den Heumarkt hervor, in dem die Handlung des Romans spielt. Sie haben also nicht nur wie die polnischen Figuren eine ideologische Funktion, sondern auch eine negativutopische. $^{327}$ Neben den biographischen Anspielungen handelt es sich also bei dieser ,polnischen“ Szene um die gezielt in ideologischer Funktion eingesetzten negativen nationalen polnischen Stereotypen, dic die Trostlosigkeit des Alltags armer Petersburger hervorheben und das negative ideologische Imagothème des verwestlichten Rußlands symbolisieren.

3. Polnische Figuren treten nochmals im Epilog von Prestuplenie i nakazanie im Zusammenhang mit Raskol'nikov auf. Er überlegt darin seine Rolle und seine Beziehung zu den anderen Gefangenen ${ }^{328}$ und bezeichnet sich selbst als einen ..Ausländer", einen Fremden unter den "Russen“ in der Katorga. Die polnischen politischen Häftlinge sind in dieser Umgebung ebenfalls wie Raskol'nikov isoliert, aber ihre verächtliche Einstellung gegenüber dem russischen Volk der Katorga kann selbst er, der auch bei den Anderen verhaßt und unbeliebt ist, nicht begreifen:

Вообше же и найболее стала удивлять его та страшная, та непрохоdusia nponacmь. kоторая лежала межлу ним и всем этим людом. Казалюсь, он и они быни разных наций. /.../Он знал и понимал общие причины таkoro разьединения; но никогда не допускал он прежде, чтоб эти иричины были на самом деле таk глубоки и сильны. $B$ ocmроге были тоже ссыльные поляки, политические преступники. Те просто считали весь этот люd за невежсы и хіопов и презирали их свысока; но Раскольников не мюг mak слотреть: он ясно видел, ито эти невежды во меногом гораздо умннее этих самышх по.ьяков. Бици mут и русские, тоже слишком презиравшие этот народ, - один бывший офицер и два семєинариста; Раскольников ясно замечал и их ошибky.

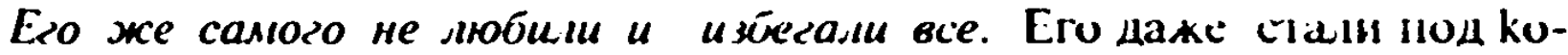
нец ненавидеть - почему? Он не знал того. Презирали его, смеялись над ним, смеялись над его преступлением те, которые были гораздо его преступнее. /.../ - Tw безбожник! Tw в бога не веруешь!- кричали ему. - Убить тебя нало. [kursiv die Verf.]

[7uallererst und am meisten wunderte er sich über jenen furchtbaren. jenen unüberschreitbaren Abgrund. der zwischen ihm und diesem ganzen Volk klaffte. Es war. als gehörten er und sie verschiedenen Nationen an. /.../ Er war sich über die allgemeinen Ursachen dieser Spaltung im klaren: aber er hatte es früher nie für möglich gehalten. daß diese Ursachen in

$327 \mathrm{Vgl}$. oben zur Beschreibung Berlins, dem Petersburg zum Verwechseln ähnlich ist, im Zinnie =amerkı o lernich vpeciallenijach. S. $228 \mathrm{f}$.

${ }^{328}$ Bd. 6, S. $417 f$. 
Wirklichkeit so tiefgreifend und bestimmend waren. Im Zuchthaus waren auch Polen. Politische. Sie hielten dieses Volk für ungebildetes Gesindel und Sklavenpack und sahen mit Geringschät=ung und Verachtung auf es herab: Raskolnikow konnte diese Anschauung aber nicht teilen: Er sah deutlich. daß dieses ungebildete Gesindel sich oftmals wesentlich intelligenter zeigte als eben diese Polen. Es waren auch Russen hier, die das Volk ebenfalls zutiefst verachteten - ein degradierter Offizier und zwei Seminaristen; Raskolnikow registrierte auch deren Irrtum.

Er selbst war bei allen unbeliebt, und alle mieden ihn. Schließlich wurde er sogar gehaßt - warum? Er wußte es nicht. Sie verachteten ihn, machten sich uber sein Verbrechen lustig, ausgerechnet Menschen, die weit schlimmere Verbrechen begangen hatten als er. /.../ Ein Gottloser bist du! Du glaubst nicht an Gott!* schrien sie. "Totschlagen muß man dich! $]$ [kursiv die Verf.]] ${ }^{329}$

Raskol'nikov wird innerhalb dieser Textstelle einerseits den Verbrechem aus dem "nussischen Volk" gegenübergestellt, von dem er sich durch seine Okzidentalisienung (und somit seinen Atheismus) entfremdet hat, „abgesondert“ ist, so $\mathrm{daB}$ sie füreinander $\mathrm{zu}$ "Ausländern" geworden sind, die ein "unüberschreitbarer Abgrund" trennt: zum anderen aber wird er auch den „polnischen politischen Verbrechern" (den „westlichen Feinden“ Rußlands) und zugleich den .gebildeten" Russen. einem ehemaligen Offizier, einem „verwestlichten Adligen“, und den „Seminaristen“ $(=$ Schülern eines Priesterseminars) gegenübergestellt, die genauso wie die Polen das „russische Volk“ verachten. ${ }^{330}$ Indem Raskol'nikov aber "seinen Imtum" erkennt. öffnet sich ihm eine Möglichkeit der Rückkehr zur „russischen Erde“, d.h. zur russischen "vorpetrinischen" Tradition, denn das "Volk" ist durch diese Reformen nicht "verwestlicht" worden. Die Polen "selbst, die einen engen motivischen Bezug zu den polnischen adligen Figuren aus Zapiski i= Mertvogo doma aufweisen, hălt Raskol 'nikov für „weniger intelligenter als die Verbrecher aus dem russischen Volk", so daß sie einen negativen Kontrast (als AlterFiguren) sowohl zu ihm als auch zum ,russischen Volk“ bilden.

In den Überlegungen Raskol'nikovs wird die Hauptproblematik von Prestuplenie i nakazanie zusammengefaßt: die Entfremdung (die „Abspaltung“) Raskol'nikovs von anderen Menschen bzw. vom russischen Volk und von Gott durch das Verbrechen, das durch die Übernahme "westlicher Ideen" zustande kam. und seine seelische Auferstehung durch ein öffentliches Bekenntnis, die aber erst dank der erlösenden liebe zu Sonja als möglich angedeutet wird. Raskolnikov vergleicht sich mit Svidrigajlov und entdeckt langsam. nach langen seelischen Qualen, daß er das „L eben“ doch mehr geliebt haben müsse als dieser scheinbar so vitale Selbstınörder:

329 Ebd., S. 418 [S. 737f.].

330 Hier handelt es sich um die Kritik an der offiziellen russisch-orthodoxen Kirche und an thren Intistutionen, die in den Brat ja Kuramazovy wieder vorkommt. 
Он страдал тоже от мысли: зачем он тогда себя не убил? /.../ Неужели таkая сила в этом желании жить и таk трудно одолеть еro? Одолел же Свидригайлов, боявшийся смерти?

Он с мучением задавал себе этот вопрос и не мог понять, что уж и тогда, когда стоял нал рекой, может быть, предчувствовал в себе и в убеждениях своих глубокую љожь. Он не понимал, что это предчувствие могло быть предвестником будущего перелома в жизни его, будущего воскресения его, будущего нового взгляда на жизнь. [kursiv die Verf.]

[Er litt ebensosehr unter dem anderen Gedanken: Warum hatte er sich damals nicht das Leben genommen? /.../ Ist es denn möglich, daß diesem Willen zu leben eine solche Macht innewohnt und daß es so schwer ist, ihn z.u überwinden? Hatte nicht Swidrigajlov, der sich vor dem Tode fürchtete, ihn schließlich überwunden?

Er quălte sich immer wieder mit dieser Frage und kam nicht darauf, daß er bereits damals, am Fluß, die tiefe Lüge in sich selbst und in seinen Über=eugungen geahnt hatte. Er kam nicht darauf, daß diese Ahnung der Vorbote einer künftigen Krisis seines Lebens gewesen war, seiner künftigen Auferstehung, seiner künftigen neuen Auffassung vom Leben. [kursiv die Verf.]]

Der Erzăhler kennt somit die tiefere Ursache dafür, daß Raskol'nikov keinen Selbstmord begangen hat, denn er habe damals ein ihm noch unbewußtes "Vorgefühl" dessen gehabt, daß seine ,Ideen" (wie diejenigen Svidrigajlovs) von der „Wahrheit" entfernt, eine „Lüge“, seien. Dadurch erfullt der Freitod der komplementären Figur Svidrigajlovs eine „Katalysator-Funktion“ im Prozeß der zuerst nur geahnten, „unbewußten“ Abkehr Raskol'nikovs von seiner "verwestlichten" Identităt. Diese "Ahnung" wird in der Katorga zu einem bewußten Katharsis-Frlebnis und zur Umkehr auf den Weg zur ,künftigen Auferstehung".

Neben dem Vergleich mit Svidrigajlov erfüllen auch die Reflexionen Raskol'nikovs über die Fremden der Katorga, über die polnischen Gefangenen sowie über die, wie er selbst, dem russischen Volk entfremdeten Russen eine wichtige Funktion, die Falschheit ihrer und seiner eigenen Überzeugungen und I laltungen erkennen zu können; erst diese Überlegungen führen ihn schließlich neben der plötzlichen "Offenbarung" seiner Liebe zu Sonja und dem apokalyptisch-prophetischen Traum, den er während seiner Krankheit in der Fastenzeit und zu Ostern erlebt. zu seiner „seelischen Auferstehung“" 332 Die

331 [Ebd. [S. 736].

332 Ebd., S. 419 กf. POŻNIAK 1992 interpretien den Traum Raskol nikovs als einen Bestandteıl des ..Mythos des Orients" bei Dostoevskij. Man muß jedoch gegen eine solche Deutung dieses Traums polemisieren, da cs sich in ihm um die falschen und destruktiven ldeen des Individualismus der westlichen Welt (Europas) handelt, von denen die Menschen wie von „Teufeln“, von .,bösen Dămonen“ besessen sind. Eine positive befreıende Rolle spielt dabeı aber auch die archaische Steppenlandschaft Sibiriens, die in dem Roman eine positiv -utopische Funktion hat, vgl. Bd. 6, S. 421 : „Рacko.тьников выше.л из сарая на самый берег, се.7 
polnischen Figuren haben hier als die extremen Fremden, als alter, ebenfalls wie Svidrigajlov eine „Katalysator-Funktion“, denn Raskol'nikov wird ihnen gegenübergestellt und erkennt dank ihnen seine eigene Entfremdung von der russischen kulturell-religiösen Tradition, den Verlust seiner wahren kulturellen Identităt, die er jedoch dank der Liebe zu Sonja wiedererlangen kann. ${ }^{333}$

Raskol'nikov wird also in Prestuplenie $i$ nakazanie zweimal den Polen gegenübergestellt. Porfirij Petrovic vergleicht ihn mit einem Polen, einem polnischen "Verschwörer", einer Figur aus russischen antinihilistischen Romanen, auch im Zusammenhang mit dem Altgläubigen Mikolka, wobei der Name Raskol'nikov auch in dieser Hinsicht symbolisch zu verstehen ist; im Epilog des Romans wird Raskol'nikov den polnischen politischen Gefangenen der Katorga gegenübergestellt, die als polnische Adlige nur durch ihre Verachtung den russischen verbrecherischen Bauem, dem "Volk“ der Katorga gegenüber charakterisient werden und als Raskol'nikovs „Schattenbilder" bzw. "Spiegelbilder" seine innere Wandlung provozieren. Raskol'nikov wird in Prestuplenie $i$ nakazanie als ein Mensch gezeigt, der ein „großer (verwestlichter) Sünder"geworden ist, der aber den Weg zur „seelischen Auferstehung“ erlangen kann, ${ }^{334}$ v.a. durch Sonja, in der sich das (,russische“)

на складенные у сарая бревна и стал г.яядеть на широкую и пустынную реку. С высоkoro бepera orkpывалась широкая оkрестность. С дальнего друтого берега чуть с.тышно доносіьтась песня. Там, в об.литой со.лнцем необозримой степи, чуть прнметнымн

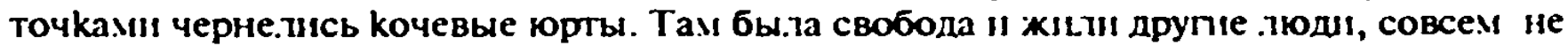
похожıле на здешніх, там kak бы самое время остановіцось, точно не прошии еще веka Aвpaana и стад его“

[S. 742: Raskolnikow trat aus dem Schuppen auf das Ufer hinaus, setzte sich auf die vor dem Schuppen aufgestapelten Baumstämme und sah auf den breiten, öden Fluß hinaus. Von dem hohen Ufer aus hatte man einen weiten Blick. Kaum hörbar klang vom anderen, fermen Ufer ein Lied herüber. Dort, in der Steppe lagen als kaum sichtbare schwarze Punkte die Jurten der Nomaden. Dort war Freiheit, dort lebten andere Menschen, den hiesigen völlig unăhnlich, dort schien die Zeit stehengeblieben, als wären die Tage Abrahams und seiner Herden noch nicht vergangen]. Diese Stelle bildet eine motıvisch-funktıonale Aquivalenz zur Beschreibung des "freien Raumes“ in Zupiskı I= Merivogo dome, siche oben, S. 166.

333 Siehe zur ähnlichen Funktion der polnischen Figuren in Zupıskı : Merivogo doma (S 202). 'Podrossosk (S. 358, S. 366) und in Brat ja Karamuzovy' (S. 382ff., S. 399f., S. 407, S 429f.).

$334 \mathrm{Vgl}$ zu Raskol nikovs Vorbildern, Bd. 7, S. 308ff., bes. S. 332ff., 342ff. Vgl. auch zu seiner Charakteristik: Bd. 6, S. 199f., 209ff., 222ff., 314fr., 319ff., 345ff., 352, 403ff., 416ff. Razumichin charaktensien ihn folgendermaßen als eine ..gedoppelte" Personlichkeit, in der zwei widersprüchliche Charaktere abwechselnd dominieren: „По.тора года я Родиона знаю: угрюм, мрачен, надиенен и ипохонарик. Ве.лкодушен и лобр. Чувств свонх не .любит высказывать и сkорей жестокость сде.лает, чем с.овами выскажет сердие. Иногда, вирочем, вовсе не ипохондрик, а просто хо.лоден и бесчувствен до бесчс.ловечия, право, точно в нем два протівопо.ожные характера поочередно сменяются“ ( $S$. 165). [S. 290: Ich kenne Rodion seit anderthalb Jahren: Er ist mürrisch, unfreundlich, verdrossen, hochmütig und stolz; in der letzen Zeit, vielleicht schon wesentlich länger, argwohnisch und hypochondrisch. Großmütig und gutherzig. Vermeidet es, seine Giefühle zu zeigen, und ist eher bereit, eine Grausamkeit zu begehen, als sein Herz auszuschütten. Manchmal ist er übrigens kein Hypochonder, sondern nur kalt und gefühllos bis zur Unmenschlichkeit. Wirklich, als ob in ihm zwei entgegengesetzte Charaktere stăndig wechselten.] 
sacrum offenbart. Sonja ist wie Lizaveta die religiöse Alius-Figur des Romans und die Verkörperung der demütigen (christlichen) Liebe, die aber ihren Ort außerhalb der russisch-orthodoxen Kirche hat und sich als eine „volksnahe“, unmittelbare ,russische“ Religiosität bezeichnen läßt. ${ }^{335}$

4. $\mathrm{Zu}$ den polnischen, mit der polnisch-litauischen Geschichte verbundenen Imagemen kann auch implizit der Name "Svidrigajlov“ gerechnet werden. Dieser Name könnte, wie oben erwähnt wurde, auf den zum Katholizismus konvertierten Bruder des polnisch-litauischen Königs Jagiello, Świdrigiello, bzw. Svidrigajlo (um 1370-1452) zurückgehen. ${ }^{330}$ In den russischen Zeitungen jener Zeit gab es jedoch auch einen sozialen Typ bzw. ein soziales negatives Stereotyp "Svidrigajlov", der die Rolle eines zu allen Diensten bereiten Menschen spielte und sich dabei auf Kosten anderer, z.B. dank Schmiergeldem, bereichern konnte. Wobei nicht auszuschließen ist, daß dieses Stereotyp ebenfalls auf die historische Figur Svidrigajlos zurückgeht. Es könnte sich also in Prestuplenie $i$ nakazanie um die Kontamination beider Namen, um eine Anspielung auf den Katholizismus des litauischen Aristokraten und auf das Stereotyp eines russischen Faktotums und Betrügers handeln. Raskol'nikov nennt einen Mann, der sich für ein betrunkenes junges Mädchen interessier, eben falls „Svidrigajlov“:

Vgl. auch seine gute Taten, S. 25 und 412 bzw. seine Träume, z. B. den Traum aus der Kindheit. ebd., S 45 und den „Kommentar“ des Erzăhlers dazu.

${ }^{335} \mathrm{Vgl}$ zu Sonja, z.B. ebd., S. 16ff., 143, $181 \mathrm{ff}, 241 \mathrm{ff}$ bzw. 247ff., 314ff., $419 \mathrm{ff}$. Sonja und l.izaveta werden von Raskol'nikov jurodivic [Gottesnärrinen] genannt, ebd., und S. 248 vọl auch S. 212. In ihrem Gesicht außert sich ..Kakoe-то нснасытиное сотраданіте“( S. 243) I "Ein unsılllbarces Mitleid"; S. 429 [kursiv Dostoevskij]l. sie ist so unfahig zu hassen, daB es. wenn sic aufgeregt wird, aussieht: „точь-в-точь как если бы рассердилась канарейка или другая маленькая птичка“ ( S. 244) [..ganz genau so, wie wenn ein Kanarienvogel oder ein anderes kleines Vogelchen zomig ivird"; S. 244]. Vgl. auch die plötzliche Wandlung Raskol nikovs, nachdem er Sonja aus dem Fenster des Gefängniskrankenhauses in der Katorga erblickt hat: . /.../ он нечаянно подоше. $k$ окну и вдруг увнде.7 вда.ли, у госпитатьных ворот, Соню. Она стояла и kak бы чего-то ждала. Что-то kak бы пронзило в ту минуту его сердие: он вздрогну.л и nockopee oтous.л от оkна“ (S. 420f.) |..zufallig |trat erl ans Fenster und sah plötzlich weit draußen, am Hoftor, Sonja. Sie stand da, als wartete sie auf etwas. Er glaubte, in diesem Augenblick einen Stich im Herzen zu spüren; er zuckte zusammen und trat rasch vom Fenster zurück“. S. 7411. Vgl. zu Sonja als ..evangelische“" Figur bei GUARDiNI 1951, S. 65ff. Siehe dazu darüber hinaus WORN 1998, S. 54 (u.a. auch über die sinnlich-körperliche Dimension der Liebe Sonjas zu Raskol nikov).

336 Siehe dazu Jfrnakorf, S. 47f. Siche dazu auch: WiElKa EnCYKLOPEdia PowSzECHNA 1968, S. 339 (zu Beles/un' Su'drigiello); BOL.'SAJA SOVETSKAJA FN(IK1.OPEDIJA 1976, S. 76 zu Svidrigajlo bzw. Švidrigajla; vgl. auch BRÜCKNER 1957, S. 535, zu Sin'ıdrygal, einer slereostypen pelnischen Volksbezeichnung: .Figlarz, trzpiot, ludowe. $z$ nazwy księcia Swidrygaila, brata Jagiellowego, o którym dziwy opowiadano, o zarloctwie, o smierci, w broszurach z. 17. wieku, wedle kronik“ ISchelm, Wildfang. volkstümlich, nach dem Namen des Fürsten Swidrygailo, Jagiellos Bruders, über den man wunderbare Geschichten erzählte, über seine Vollerei, über seinen Tod. in Flugschriften des 17. Jahrhunderts, nach den Chroniken]. 
И однаkо ж в стороне, шагах в пятнадщати, на краю бульвара, остановился один господин, которому, по всему видно было, очень бы хотелось тоже подойти $k$ девочke с kаkими-то целями. /.../ Раскольников ужасно разозлился; ему вдруг захотелось kak-нибудь оскорбить этото жирного франта. /.../ Эй вь, Свидригайцов! Вам чего mym нado? - крикныл он, сжимая кулаки и смеясь своими заленившимися от злобы губами. [kursiv die Verf.]

[Etwas abseits allerdings, etwa fünfzehn Schritte entfernt, am Rande des Boulevards, stand ein Herr, der allem Anschein nach nicht übel Lust hatte, sich ebenfalls mit irgendwelcher Absicht dem Madchen zu năhern. /.../ Zorn stieg in Raskolnikow hoch; plötzlich gelüstete es ihn, diesen feisten Gecken auf irgendeine Weise zu beleidigen. /.../ He, Sie Swidrigajlow! Was suchen Sie hier? rief er, ballte die Fauste und grinste mit vor Wut schăumenden Lippen. [kursiv die Verf.]] ${ }^{337}$

Bei dieser Stelle handelt es sich darüber hinaus um eine explizite Äquivalenz zwischen Arkadij Ivanovic Svidrigajlov und dem "feisten Gecken", der ein betrunkenes, hilfloses Madchen verführen will: Raskol'nkov hat kurz davor einen Brief von seiner Mutter erhalten, in dem sie ihm über die „Beleidigung“ seiner Schwester Dunja durch ihren ..Herren" Svidrigajlov berichtet. ${ }^{338}$

337 Bd. 6, S. 40 [S. 66]. Vgl. dazu Bd. 7, S. 367f. über einen solchen Typus, zit. nach der russischen Zeitschrift lskra [Der Funke] vom 14. Juli 1861, in deren Rubrik "Haw nuwyt" [..Man schreibt uns“| man über „фаты, бесчинствуюшие в провиниии“" |..Laffen, Fatzken, die in der Provinz ihr Unwesen treiben "I, besonders über zwei Typen: einen ,Ror(skavkın“" |von horcklavka: Gopodaska, Warze] («фат вроде пушkuнсkого графа Ну.инна)|,Ein Schnósel in der An des Puskininschen Grafen Nulm"] und dessen Handlanger Svidrigajlov berichtete: „«Свıцригай.7ов» - чиновник особых, ити, kak говорят особеннox, иті, kak еше выражаются, всяkих поручений... Это, еже.ли хотіте, фактор <...> че.товек темного происхождения, с трязиым прошедшим, .ичность отталkлваюшая, омерзите.льная для свежего честного взгляда, вкрадчивая, впо.тзающая в душу <...> Нужно .ти сочинить какую-нибудь каверзу, перенести куда следует сптетню, подгаліть... на это один готовый и татант.ливый че.товек - Свидригай.тов; /.../ И эта низкая, пскорб.ляюциая всякое че.ловеческое лостоинство. ползающая, вечно пресмыкающаяся .иччность 6.тагоденствует /.../. (/skra 1861, 14 ию.ля, № 26: c.N. таkже: Иckpa, 1861,13 января и 30 июня, КоN 2,24 )"

[Svidrigajlov ist ein Beamter für hesondere, oder wie man sagt für ungewühnliche, oder, wie man es auch auszudrücken pflegt, für allerlet Auftrăge... Er ist, wenn Sie wollen, ein Macher 1.../. ein Mensch dunkler Herkunft mit schmutziger Vergangenheit, der, vom unverdorbenen und ehrlichen Standpunkt aus beobachtet, als eine abstoßende und widerliche, ja ekelhafte, in die Seele eines Menschen hmeinkriechende, sich einschmeichelnde Persönlichkeit erscheint $i$...i. Soll man eine Intrige schmieden, ein Gerücht irgendwo verbereiten, jemandem ein Bein stellen...: dazu gibt es den immer bereiten und talentierten Menschen - Svidrigajlov; $i . . . /$ Und diese niederträchige, jede menschliche Würde beleidigende, kriechende, ewig herumscharwenzelnde, liebedienernde Person lebt in Wohlstand /... I. Iskra vom 14. Juli 1861, $\mathrm{Nr} 26$; siehe auch Iskra vom 13. Januar und 30. Juni, Nr. 2 und 24). Siehe auch JERNAKOFF 1981. ${ }_{338} \mathrm{Vgl}$ dazu Bd. 6, S. 35ff. und bei GeriGK 1991, S. 186f....Sowohl Lushin [der ..Verlobte“" der Schwester Raskol nikovs; Erg. d. Verf. | als auch Swidrigajlow werden ihm zu exemplarischen Ausbeutern finanzieller Not zum Zwecke der eigenen Lust und Herrschafi". 
Der Name des dämonischen Arkadij Ivanovic Svidrigajlov schafft einen Bezug sowohl zu dem polnisch-litauischen katholischen Fürsten als auch zu einem negativen sozialen russischen Stereotyp, so daß in diesem symbolischen Namen die ideologische (bzw. antikatholische) Anspielung mit einer „sozialkritischen“ Tendenz. verbunden wird. Der Mann auf dem Boulevard wird außerdem als ein жирный франт [= ein fetter, feister Geck] beschrieben, wodurch er an das Stereotyp des "dicken, fetten Polen“ erinnert, das in Igrok zum ersten Mal auftaucht. ${ }^{339}$

Der verwestlichte, ambivalente, auf russische Weise, ,seelisch breite“ Svidrigajlov wird übrigens wie der Fürst Valkovskij bzw. Stavrogin in dem um einige Jahre spăter entstandenen Roman Besy als ein schöner, aber zugleich abstoßender Mann beschrieben, der eine „Maske“ zu tragen scheint:

Это было kakoe-то странное лицо, похожее kаk бы на масkу : белое, румяное, с румяными, алыми губами, с светло-белокурою бородой и с довольно еше густыми белокурыми волосами. Гљаза бфли kak -то слишком голубые, а взгляд uх kak-то слишком тямел и неподвижен. Что-то было ужсасно неприятное в этоль красиволь и чрезвычайно моложавом, судя по летам, лице. Одежда Свидригайлова была щегольская /.../ На палье был огромный перстень с дорогим камнем". [kursiv die Verf.]

[Es war ein seltsames Gesicht, das einer Maske ähnelte: weiß, rotwangig. mit frischen, purpurroten Lippen. hellblondem Bart und noch ziemlich dichtem, blondem Haar. Die Augen waren irgenctwie auffallend blau und ihr Blick irgendwie auffallend schwer und siarr. Es lag etwas ausgesprochen Unangenehmes in diesem schönen und für sein Alter ungewöhnlich jugendlichen Gesicht. Swidrigajlov war elegant /.../ gekleidet. /.../ An einem Finger saß ein massiver Ring mit einem teuren Stein. [kursiv die Verf.]] ${ }^{340}$

Svidrigajlov wird mit Hilfe der gleichen Motive wie Valkovskij und Stavrogin beschrieben. ${ }^{341}$ Ungewöhnlich ist der Kontrast zwischen dem allzu "frischen, jugendlichen Gesicht" sowie den eleganten (westlich geschnittenen) Kleidern Svidrigajlovs und dem ,.auffallend“ maskenhaft ..schweren und starren Blick seiner Augen", der für den Erzähler (aus der Perspektive Raskol nikovs geschen) unangenehm erscheint. Die Starre des Blicks, die auch den dämonischen Stavrogin auszeichnet, erinnert an den Blick einer Schlange, die ein Symbol des ,hösen Geistes als Verführer" ist. Auf diese Weise wird Svidrigajlov als eine dämonische Alius-Figur, als ein „Teufel“, ein „Verführer zum Bösen" beschrieben. Sein Name verleiht ihm cine weitere symbolische Dimension, dic eines ,maskierten (polnisch-katholischen) Verführers“, so daß

339 Siehe oben, S. $251 \mathrm{f}$. und S. $277 \mathrm{ff}$.

340 Bd. 6, S. 357f. [S. 633]. Siche auch ebd., S. 188

341 Der Fürst Valkovskij zeigt in seinem Gesichtsausdruck ..hinter seiner gewohnten Maske etwas Böses, Schlaues und im höchsten Grade Egoistisches“", so daß er sich als ein latenter ..Jesuit" entpuppt. vgl dazu oben S. $217 f$. 
diese Figur auch auf das altrussische Stereotyp des ", Ljachs in der Gestalt eines Teufels" aus der Povest "vremmenych let zurückgehen könnte.

Im Unterschied zu Valkovskij ist er jedoch auch zu guten Gefühlen fahig und vollbringt Wohltaten: er versucht. Dunja finanziell z.u helfen, kümmert sich nach dem Tod Katerina Ivanovnas um ihre Kinder und hilft Sonja und Raskol'nikov. In der Nacht vor seinem Selbstmord geht er zu seiner jungen Verlobten und schenkt ihr fünfzehntausend Rubel. ${ }^{342}$ Bereits oben wurde seine Sehnsucht nach dem Ideal der (Sixtinischen) Madonna und einer Jurodivaja erwähnt, so daß auch diese Figur wie Raskol'nikov Elemente der positiven utopischen Imagothèmes, sowohl des verwestlichten Rußlands als auch des vorpetrinischen, „orthodox-byzantinischen" Rußlands enthălt, ohne daß diese positiven Imageme in ihm die Oberhand gewinnen und zur Wandlung Svidrigajlovs führen. Dieser "Doppelgänger" Raskol'nikovs bleibt in diesem Kontext die unerlöste Figur des Romans. Bei ihm überwiegen die dämonischen westlichen Eigenschaften. Er ist also durch seinen Namen als das "verkörperte" und psychologisch differenzierte Stereotyp eines "Svidrigajlovs" konzipiert. und in der Funktion als alius, als ein Symbol des aus dem „Westen nach Rußland gekommen Bösen", als ein Teil des negativen utopischen Imagothèmes des verwestlichten Rußlands zu verstehen.

Als ein anderer Doppelgänger Raskol'nikovs läßt sich außerdem der Sektierer - "raskol "nik" - Mikolka bezeichnen, der in der Tradition der russischen Volksfrömmigkeit lebt und ein Märtyrer des Glaubens werden, das „Leid auf sich nehmen" will.

$342 \mathrm{Vgl}$. zu den Wohltaten Svidrigajlovs ebd., S. 223, 334f., 384r. $\mathrm{Vgl}$. die Bedeutung des Imagems ..Amerika", das auch synomyn für den Selbstmord Svidrigajlovs eingesetzt wird: Svidrigajlov nennt seinen Selbstmord „eine Reise nach Amerika”; siehe auch unten zu diesem Imagem in den spateren literarischen Werken Dostoevskijs und zur positiv-utopischen Funktion der amerikanischen Motive bei Dostoevskij bei FALIkova 1994, S. 220ff. zu Svidrigajlov: Svidrigajlov kann aber gleichzeitig auch bosen Taten und Gedanken nachgehen. In den Entwürfen zu Presiuplenie I nakazanic wird er folgendermaßen charakterisiert: .С.вициигай.лов знает за собой таинственные ужасы, которых никому не рассkазывает, но в которых проговаривается фаkтами: это судорожных, звериных потребностей терзать и убивать. Хо.тодно-страстен. Зверь. Титр. /.../ Он очень холодно сказал раз (всkо.лзь совершенно) о том, что он убил челивека. Что ему с.луча тось убивать"

|Svidrigajlov kennt für sich, ihm eigene geheimnisvolle Schrecken, die er niemandem erzählt, sic jedoch als Fakten. Tatsachen verlauten lảßt: als krampfhafte Bedürfnisse zu qualen und zu töten. Kühl leidenschaftlich Bestie, Tiger. /.../ Einmal erzăhlte er sehr kühl (ganz beilauufig) darüber, duß er e'inen Menschen getiitet hat. Daß es ihm vorgekommen ist, zu töten); vgl. Bd. 7, S. 164. Siehe auch andere Entwürfe und den Kommentar zu Svidrigajlov, ebd., S. 156ff., 204, 315, 32 If. Außerdem Bd. 6, S. $215 f$., 223f, 354ft. (die ..Beichte“" Svidrigajlovs) sowie S. $376,383 f$., 394f.

${ }^{343} \mathrm{Vgl}$. ebd.. S. 347f. und S. 352 Portirij vergleicht Raskol'nikov mit dem ,ruskol'ntk" Mikolka und stellt beide einem ..verwestlichten Sektierer" (- einem ..lakaien westlicher Ideen“) und einem ..Bauem" gegenüber. Möglicherweise wird in dieser Szene erneut auf die .Polen" angespielt, die bei Dostoevskij ebenfalls als .L.akaien" bezeichnet werden: .Нет, не убежітте. Музии убежсит, модный ссктант убемсит - лакей иумсой мысли /.../. А вы ведь вашей теории уж больше не верітте, - І с чем вы убежітте? /.../ Я даже вот уверен, что вы асраданис надумаетесь принятьн: /.../ ПІотому страданье, Родінон

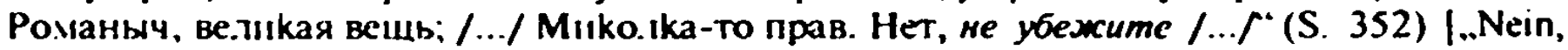
Sie werden nicht davonlaufen. Ein Buuer würde denonlaufen. ein moderner. Sektierer, der 
Die polnischen Imageme treten in dem Roman Prestuplenie $i$ nakazanie in den oben besprochenen Szenen in zwei Funktionen auf: sie sind zum einen als Kontrastfiguren zu den russischen Figuren Raskol 'nikovs und Katerina Ivanovnas eingesetzt; zum anderen wird die Figur Svidrigajlovs durch eine Anspielung auf Svidrigajlo immanent negativ, auch ideologisch charakterisiert. Im ersten Fall handelt es sich um die negativen nationalen Stereotypen bzw. Figuren, die als alter, als die Anderen, zur Hervorhebung der Personencharakteristik dienen; im zweiten Fall - wie in dem Roman Unizennye i oskorblennye der Fürst Valkovskij - wird die negative Figur Svidrigajlovs als die Verkörperung des „Bösen", hier durch seinen Namen als alius gezeichnet oder gar ,gebrandmarkt".

In den Manuskriptentwürfen und Textvarianten ${ }^{344}$ 2u Prestuplenie $i$ nakazanie gibt es dagegen keine Erwähnungen Polens, einen breiten Raum nehmen dafür die Erwägungen zum ,russischen Charakter" von Sonja ein, ${ }^{345}$ auch über die „Idee des Romans": „ИДЕЯ РОМАНА. Православное воззрение, в чем есть православие“ [„DIE IDEE DES ROMANS. Die orthodoxe Ansicht; worauf beruht die (russische) Orthodoxie."] [Übers. die Verf.], ${ }^{346}$ die sich darin äußere, daß: „Нет счастья в комфорте, покупается счастье страданием, /.../ есть таkая великая радость, за которую можно заплатить годами страдания. Человек не родится для счастья. Человек заслуживает свое счастье, и всегда страданием. [Es gibt kein Glück im Komfort, das Glück wird mit Leiden erkauft. /.../ es gibt eine solche große Freude, für die man mit Jahren des Leidens bezahlen kann. Der Mensch wird nicht fürs Glück geboren. Der Mensch verdient erst sein Glück, und immer durch Leiden; Übers. die Verf.]. In der Endfassung des Romans gibt es aber, trotz dieser und ahnlicher expliziter Formulierung in den Entwürfen, kein positives utopisches russischorthodoxes Imagothème, so daß sich die "orthodoxe Idee des freiwilligen Leides" hauptsächlich auf die dem ,russischen Volk" angeborene (christliche) Leidensfahigkeit bezieht. ${ }^{347}$

lakai eıner fremulen ldee der würde davon laufen !.../. Sie aber haben den Glauben an Ihre Theorie bcreits verloren. was können Sie auf die Flucht noch mitnehmen? /...' Ich für mein Teil bin sogar überzeugt, daß Sie eines Tages bereil sein werden. olas leid auf sich zu nehmen. /.../ Denn das Leiden, Rodion Romanowitsch, ist etwas Großes; /.../ Mikolka hat doch recht. Nem, Sie werden nicht davonlaufen /...\%; S. 624] [kursiv die Verf.]. Vgl. auch zur Äquivalenz zwischen den beiden Figuren bei GERIGK 1991, S. 207f. (über den Traum Raskol nikovs, in dem ein Pferd von einem Bauem namens Mikolka getotet wird: ,.../ der Sektierer [verweist ] auf jenen anderen Mikolka /.../, der in Rakolnikows Traum /.../ die Rolle des Tăters erfüllt /.../. So wird Rakolmkow von dem jungen Sektierer, der außerlich gesehen von ihm ablenkt, in Wahrheit auf sich selbst zugeführt"( $S .208$ )).

344 Vgl. Bd. 7.

${ }^{345}$ Vgl. ebd., z.B. S. 134f, 149, 152f.

346 Ebd., S. is 54 .

${ }^{347}$ E.bd., S. $154 \mathrm{ff}$, bes. S. 160ff, bes. S. 164. Darüber hinaus findet man in den Entwürfen Bemerkungen über den komplementáren Charakter von Svidrigajlov und Raskol nikov und über den verwestlichten Zaren Peter den Großen, der als ..Holländer“ bezeichnet uird. Vgl. ebd., S. 153, die Stelle, wo Raskol'nikov mit Peter dem Großen verglichen wird; alle negulıven verwesilichten männlichen Figuren Dostoevskijs haben den Vomamen Petr, vgl. z.B Petr Petroviz Lužin, Petr Aleksandrovic Valkovskij bzw. Petr Stepanovič Verchovenskij. 
ZUSAMmenfassung: In Prestuplenie $i$ nakacanie werden die beiden komplementären positiven und negativen utopischen Imagothèmes des verwestlichten Rußlands dem positiven utopischen „christlich-byzantinischen“ Imagothème des „vorpetrinisch-sektiererischen“ Rußlands gegenübergestellt. Alle drei Imagothèmes werden durch die russischen und fremden Figuren symbolisch "verkorpert", indem sie als positive oder negative russische Aliusoder negative fremde Alter-Figuren auftreten. Die Figurenkonstellation in Prestuplenie i nakazanie weist aus imagothematischer Sicht besonders enge Bezüge zu den Zapiski iz Mertvogo doma (zu den Alius-Figuren aus dem "russischen“ oder „russifizierten Volk“, zu den „Polen“ und zum Ich-Erzăhler selbst) sowie zu Zapiski iz podpol'ja (die Äquivalenzen zwischen dem „Paradoxalisten“ und Liza sowie Raskol nikov und Sonja) auf. Die in Zimnie zametki o letnich vpecatlenijach explizit formulierten Imagothèmes des .petrinischen, verwestlichten“ und des „vorpetrinischen, volksnahen Rußlands“ werden somit in Prestuplenie $i$ nakazanie auf metaphorisch-symbolischer Sinnebene konkretisiert und weiter ausdifferenziert. Alle negativen utopischen Imagothèmes weisen darüber hinaus eine ideologische Komponente auf.

Die negativen fremden Imageme, darunter die polnischen, treten in Prestuplenie $i$ nakazanie in zwei Funktionen auf: Zum einen als nationale bzw. ethnische (negative) stereotype Alter-Figuren dienen sie als Kontrast zu den russischen Figuren, hauptsächlich zu Raskol'nikov und Katerina Ivanovna, heben deren positive (russische) Eigenschaften und deren schäbige, verwestlichte Petersburger Umgebung hervor. In dieser Funktion als alter weisen diese vorwiegend negativen fremden Stereotypen, die dem russischen imaginare social und der russischen Literatur entstammen, auch eine ideologische Funktion auf und bilden die ideologische Komponente des negativen utopischen Imagothèmes des verwestlichten Rußlands: so erfüllen die negativen polnischen stereotypen Figuren eine primär ideologische Funktion, dasselbe gilt auch für die Erwähnungen der Juden. Die deutschen Figuren, v.a. Frauengestalten, die ebenfalls als alter zu bezeichnen sind, dienen zur Hervorhebung des "Berliner" Kolorits Petersburgs, auch als Kontrast zu russischen Gestalten, wobei ihre Auftritte zugleich als "komische Intermezzi“ eingesetzt werden.

Die Figur Svidrigajlovs dagegen, die sich psychologisch differenzien auf jenen „Svidrigajlov" als negatives russisches soziales Stereotyps bezieht, ${ }^{348}$ und als zentrale russische Figur die Leistung der kreativen Vorstellungskraft in den literarischen Werken Dostoevskijs ist, tritt in der Funktion als alius auf, als die Verkörperung bzw. als ein Symbol des „verwestlichten Rußlands“, des „Bösen aus dem Westen", obwohl auch in seinem stereotypen Namen eine versteckte ideologische Anspielung auf die rußlandfeindliche litauisch-polnische Geschichte enthalten ist. Svidrigajlov verkörpert wie der Fürst Valkovskij in Unizennye I oskorblennye das negative utopische Imagothème des verwestlichten Rußlands. Die negative Okzidentalisierung Raskol'nikovs, die aus ihm sogar einen Mörder gemacht hat, wird dagegen mit Hilfe anderer

340 $\mathrm{Vgl}$. dazu oben, S. $277 \mathrm{ff}$. 
negativer fremder, aber keiner polnischen Imageme, z.B. der Anspielung auf Napoleon I. und III. erreicht.

In Prestuplenie i nakazanie treten folgende polnische Imageme auf:

1. das negative Stereotyp des „polnischen Verschwörers“, das in diesem Roman zum ersten Mal im literarischen Werk Dostoevskijs vorkommt (vor dem Roman Besy);

2. das negative Stereotyp des „schäbigen Polackchens aus dem Volk“, das zum ersten Mal in Zapiski iz Mertvogo doma auftaucht;

3. die ,polnischen Adligen aus der Katorga“ (wie in Zapiski iz Mertvogo doma);

4. die Figur "Svidrigajlovs“ als ein psychologisch erweitertes Stereotyp eines "russischen Faktotums" mit den ideologisch-utopischen Komponenten (in der Anspielung auf den litauisch-polnisch-katholischen Fürsten und auf den "Ljachen in der Gestalt eines Teufels").

Die anderen positiven fremden Imageme wie beispielsweise die Erwăhnungen Heines oder Schillers bzw. der Sixlinischen Madonna oder der Figuren Shakespeares dienen zur positiven ,immanenten" Charakterisierung der verwestlichten russischen Figuren, darunter auch derjenigen Raskol'nikovs, Svidrigajlovs bzw. Katerina Ivanovnas oder Razumichins oder der Mutter und der Schwester Raskol nikovs, die das positive utopische Imagothème des verwestlichten Rußlands bilden. Besonders der Name Schiller (wie in Unizennye i oskorblennye) wird positiv zur Charakterisierung der verwestlichten, aber idealistischen russischen Gestalten eingesetzt (aber nicht der deutschen Alter-Figuren) und erfüllt die komplementäre Funktion zum „christlichen Idealismus“ und zur „vorpetrinischen", „altrussisch-byzantinisch" geprägten Aufopferungsbereitschaft von Sonja, L.izaveta oder Mikolka bzw. des, ,künftig seelisch auferstandenen“ Raskol'nikov.

Diesen drei westlichen Imagothèmes wird zum einen das positive utopische Imagothème des vorpetrinischen, „byzantinischen“ Rußlands gegenübergestellt, das durch die russischen Alius-Figuren wie z.B. die oben erwähnten Sonja, Lizaveta oder Mikolka vertreten wird. wobei deren .Einfluß“ auf die negativ verwestlichte russische Figur Raskol'nikov angedeutet wird, der zur inneren Wandlung, zur Rückkehr dieser Figur zur russischen religiös-kulturellen Identität führt: zum anderen verkörpert die Wucherin Alena das negative utopische Imagothème des rein formalkirchlichen russisch-orthodoxen (nachpetrinischen) Rußlands, wobei das positive utopische russisch-orthodoxe Imagotheme, das sich in den späteren Romanen herausgebildet hat. in Prestuplenie i nakazanie noch nicht anwesend ist. 


\section{9. ИДНОТ. РОМАН В ЧЕТЫРЕХ ЧАСТЯХ (1869) \\ $[D E R / D I O T]^{349}$}

Der zweite ..große“ Roman Dostoevskijs ist in imagothematischer Sicht nicht minder relevant als Prestuplenie i nakazanie. Bereits in seinem Titel deutet sich die Ambivalenz des Versuchs an, einen „ideal schönen Menschen“ [einen .,positiv schönen Menschen“; = „положительно прекрасный человек”] als literarische Figur zu gestalten. Dostoevskij beklagte sich übrigens selbst während der Arbeit an diesem Roman über die Schwierigkeiten, einen solchen „idealen Menschen" als einen "Russen" darzustellen, denn ein solches "Ideal" sei vor ihm weder in Rußland noch in Europa endgültig in einem Roman ausgearbeitet worden. ${ }^{350}$

Dic imagothematische Ambivalenz zeichnet daher nicht nur die Titelfigur, den "Idioten" Lev Nikolaevic Myškin aus, sondern auch alle zentralen Figuren des Romans. Sie repräsentieren die drei in den früheren Werken Dostoevskijs konstituierten utopischen Imagothèmes - die beiden komplementären Imagothèmes des negativ und positiv "verwestlichten (petrinischen)" Rußlands sowie das positive des "vorpetrinischen (volksnahen) Rußlands". Im Vergleich zu den früheren Werken jedoch, besonders zu Prestuplenie i nakazanie, ist im Idiot die relativ intensive immanente Okzidentalisierung aller wichtigen Figuren auffallend. Sie betriff auch diejenigen Figuren, die eine (alt)russische, „vorpetrinische" Identităt aufweisen, so daß keine von ihnen ein einziges Imagothème vertritt bzw. verkörpert. sondern eine verschwommene kulturclle Identität aufweist.

Obwohl der Roman Idiot während Dostocvskijs Aufenthalts in Westeuropa geschrieben worden ist, ${ }^{351}$ spielt die Handlung in RuBland. im „verwestlichten“" Petersburg und in Pavlovsk, einem in der Nähe der russischen Ilauptstadt gelegenen Erholungsort, in dem die Petersburger die Sommermonate zu verbringen płlegen. Das ,.Ausland” bzw. „Westeuropa“, das durch die Schweiz und die französische Stadt Lyon symbolisch vertreten wird, kommt vorwiegend in den Erzählungen der Titelfigur, des Fürsten Myškin, vor und dient zu dessen immanenter Charakterisierung. Im Fpilog des Romans wird Paris als diejenige „verhängnisvolle" westliche Stadt erwähnt. in der Aglaja Ivanovna Epančina, eine der zentralen Figuren des Romans, einen falschen polnischen Grafen heiratet und anschließend von einem polnischen Jesuiten zum katholischen Glauben "verführt" wird.

Wie in den bisher besprochenenen Werken kommen in Idiot mehrere fremde Imageme vor. $\mathrm{Zu}$ den polnischen Imagemen gehören nicht nur fiktive polnische

349 Die deutschen Übersetzungen russischer Zitate aus / $/ w$ I werden nach der Ausgabe DOSTOJEWSKu $1996 \mathrm{~b}$ angetührt. Der russische Text des Romans wird nach der Ausgabe von 1874 zitien, die im 8. und 9. Band der PSS edien ist, vgl. auch die Anmerkungen und den Kommentar zum Roman Idiot, Bd. 9, S. 334fr.

$350 \mathrm{Vgl}$. Bd. 9. S. 358 und den of zitierten Brief an die Nichte Dostoevskijs, S.A. Ivanova, vom I. (13.) I. 1868, in: Bd. 28, 2, S. 251 .

$351 \mathrm{Vgl}$. zur Entstehungsgeschichte des Romans. Bd. 9, S. 337ff. und 357ff. 
Figuren, sondern auch Anspielungen auf die polnische Kultur und Geschichte: erwăhnt wird eine Klavierballade des polnischen Komponisten Chopin, darüber hinaus die Beteiligung polnischer Soldaten an der Besatzung Moskaus im Jahre 1812 durch die Truppen Napoleon Bonapartes und ein Mörder, der möglicherweise von polnischer Herkunft ist. Zwei russische Figuren, Burdovskij und Radomskij, tragen Namen, die eine polnische Etymologie haben könnten. ${ }^{352}$ Alle polnischen lmageme hängen mit den russischen, aber relativ stark "verwestlichten" Figuren des Romans zusammen: mit Parfen Semenovix Rogožin, Aglaja Ivanovna Epančina, mit dem General Ivolgin, mit Evgenij Pavlovic Radomskij sowie mit zwei "Nihilisten", mit Burdovskij und dem Neffen Lebedevs, Doktorenko, indem sie diese Figuren entweder immanent (als alius) oder durch Kontrast (als alter) negativ charakterisieren.

Die aus mehreren Figuren bestehende russische Gruppe des Romans läßt sich einerseits nach dem Grad ihrer Entfremdung von den russischen kulturellen und religiösen Traditionen, d.h. ihrer Okzidentalisierung, bzw. andererseits nach dem Grad ihrer Bindung an die eigene russische Tradition noch weiter differenzieren. Hierbei sind jedoch keine klaren Trennungslinien zu ziehen zwischen den "vorpetrinisch russischen" und den "verwestlichten", sowie zwischen den ,.positiven" und den "negativen“ Figuren. Dies mag mit der Besonderheit der schriftstellerischen Technik, mit der für diesen Roman charakteristischen psychologischen Differenzierung bzw. Ambivalenz der russischen Figuren zusammenhängen, die hier in noch viel stärkerem Maße als in den früheren Werken Dostoevskijs zu beobachten ist. ${ }^{353}$

Im Mittelpunkt der Handlung stehen vier russische Figuren: Fürst Lev Nikolaevið̌ Myškin. Parfen Semenovič Rogožin, Nastas ja Filippovna Baraskova und Aglaja Ivanovna Epančina. Sie lassen sich ebenfalls nicht eindeutig hinsichtlich ihrer Okzidentalisicrung bzu. ihrer Zugehörigieii zur russischen religiös-kulturellen Traditionen cinordnen. ${ }^{354}$

$\mathrm{Zu}$ den russischen Figuren, die relativ intensiv an den russischen kulturellen Traditionen festhalten, u.a. an der russischen Volksfrömmigkeit bzw. am russisch-orthodoxen Glauben, und vorwiegend positiv dargestellt werden. gehören

352 Eine der sogenannten episodischen Figuren trägt darüber hinaus den ironischen Namen Biskup | = poln. Bischofl. es handelt sich aber dabei moglicherweise um einen jüdischen Geldspekulanten, einen Wucherer, obwohl seine ethnische Identität nicht erwähnt wird, vgl. dazu unten, S. $296 f$

${ }^{353} \mathrm{Vgl}$. dazu WOODWARD 1980. Nur sogenannte episodische, stereotyp gezeichnete Figuren, hauptsächlich der Fremden, Nichtrussen weisen feste nationale, ethnische bzw. soziale Identităt auf.

$354 \mathrm{Zu}$ anderen ..verwestlıchten“ Figuren gehören der General Ivan Fedorovic l:pančin, der Vater Aglajas und seine zwei anderen Töchter. Aleksandra und Adelaida. seine Fraù Lizaveta Prokof evna, der General Ardalion Aleksandrovic Ivolgin. seine Söhne Gavrila (Ganja) und Kolja (Nikolaj) sowie Ippolit Terent ev, Evgenij Pavlovic Radomskij, Luk jan Timofeevic lebedev und seine Kinder und der ..Nihilist“ Burdovskij. Vgl. auch zu den Interterenzen aller Figuren des Romans, nicht nur der vier zentralen oben erwähnten Figuren bei WOOUWARD. wobei er sich hauptsächlich auf die (tiefen)psychologisch motivierte Ähnlichkelt zwischen Myškin. Nastas ja Filippovna, Rogožin und Aglaja konzentrient hat. 
die Frau des Generals Epancin, Lizaveta Prokof evna, ${ }^{355}$ und Nastas ja Filippovna Baraskova; ${ }^{356}$ von den weiteren „Randfiguren“ Vera Luk'janovna Lebedeva ${ }^{357}$ obwohl sie auch mit Hilfe fremder Imageme als teilweise verwestlicht dargestellt werden. Von allen in Idiot auftretenden russischen Figuren weist nur die Mutter Rogožins, die als eine russische „Gottesnärrin“ (jurodivaja) geschildert wird, keine Spuren der Okzidentalisierung auf.

Eine besondere Rolle in der Welt des Romans nimmt dabei die Figur des Fürsten Lev Nikolaevic Myskin ein. Er wird oft als ein „russischer Christus“ verstanden und interpretiert. ${ }^{358}$ Diese Interpretation wird zusätzlich durch die

355 Lizaveta Prokof evna wird trotz ihrer Zugehörigkeit zur gehobenen adligen Petersburger Gesellschaft als der urwüchsige. kindliche Typ einer glaubigen Russin geschilden, denn sie ist wie Myškin mit der „vorpetrinischen, Moskauer Rus “ als seine Verwandte verbunden. Sie ist somit der Moskauer Großtante aus dem Roman /'sdrosiok ãhnlich. Lizaveta Prokof evna gehört das .,letzte“ Wort des Romans, denn ihr Kommentar zu den tragischen Ereignissen, den sie aus der Perspektive des Aufenthalts in ..Westeuropa“ und ihrer Sehnsucht nach .Rußland“ ăußert, verleiht den letzten Sătzen des Epilogs eine rührend-humorvolle Fărbung. Vgl. dazu Bd. 8, S. 7ff., 22f., S. 44 bzuv. S. 65 und S. 510.

356 Auch Nastas ja Filippovna weist einıge Bezüge zum „vorpetrinischen, sektiererischen Glauben" bzw. zu russischen kulturell-religiösen (Volks)Traditionen auf, trotz ihrer Okzidentalisierung, die auf die „Verführung" durch den vervestlichten Russen Tockij zurückgeht: Ihr Vatersname kann als eine Anspielung auf den Gründer der Sekte der Flagellanten [C $h / \mathrm{w}: \mathrm{y}]$ ], Filippow, gedeutet werden, was ihre ,seelische Selbstgeißelung" verdeutlichen würde, vgl. dazu auch ihre relativ bescheidene Lebensweise und ihren sonderbaren Bekanntenkreis in Petersburg, ebd., S. 39, S. 44, S. $114 \mathrm{f}$. Nastas ja Filıppovna ist zugleich eine ..verwestlichte russische femme falale" und eine ..büßende Sünderin“, denn sie weist wie Myškin Bezüge zum Neuen Testament und zur „idealen (christlichen) Schönhcit“ auf, ebd., Bd. 8, S. 205; auch Bd. 9, S. 401ff., 407f. Der Vorname Naslas ja - Anasiasicu deutet auf ihre seelische .Auferstehung“, bzw. auf eine christlich-byzantinısche Mărtyrerin aus dem 4. Jh hin; ihr Nachnahme - Baraškova (harašek, Tupaues:; /umm) auf ihre "Opferbereitschaft" und „Unschuld". Ihr Gesicht drückt „Leiden“ aus, ihre „Schonheit" ist "vergeistıgt”, zumındest für Myškin, vgl. ebd, S. 31f. bzw. S. 69. Eine Parallel- und Kontrastfigur zu ihr ist die ..Schweizerin“" Marie aus der Erzăhlung Myškins, vgl. Bd. 8, S. 62f. Siehe auch zu den Bezügen zu Filippow bei NeuHaUSER 1980, S 835ff.

${ }^{357} \mathrm{Vgl}$ zu Vera Lebedeva z.B. Bd. 8, S. 508 f.

358 Dostoevskij hat sich sein Leben lang mit der Gestalt Christi befaßt, so daß diese Problematik hier nur angedeutet werden kann. Vgl dazu den oben erwähnten Brief an S.A. Ivanova. S. 284, sowie den Brief an N.D. Fonvizina aus Omsk (etwa Ende Januar bis 20. Februar 1854), Bd. 28,1, S. 175ff., bes. S. 176. Siehe ferner den Essay der Verf: S Su'DERSKA 1998 Vgl. zur Problematik der ..Schönheit" bei Dostoevskij: LAZAR1 1988, S. 133ff.

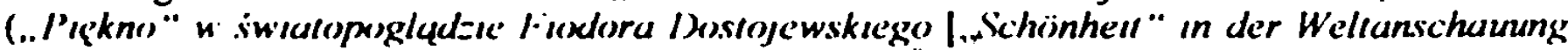
Iros/oxviky.y(). I.AZARI behauptet, daB Ethik und Ästhetik sich in der Weltanschauung Dostoevskijs nicht voneienander trennen lassen, so daß man lediglich über eine bestimmte Wertphilosophie Dostoevskijs sprechen kann. I.AZARI übersetzt die Stelle aus dem Brief an Ivanova als eine "wahrhaft schöne Figur”. ein ..wahrhaft schöner Mensch". Seiner Ansicht nach unterscheidet Dostoevskij, Apollon Grigor ev folgend, zwischen ..красота истинная и фальшивая“ |... Wahre und falsche Schönheit"]. Die „wahre Schönheit" beschränke sich nicht auf die Schönheit der Form. Sowohl Dostoevskij als auch Grigor ev bekämpften die Theorie der .,reinen Kunst“, die Schönheit ist für beide eine Idee. Diese Idee ist für Dostoevskij lediglich in Christus vollkommen verwirklichkt worden Myškin ist für LAZ.ARi der Versuch Dostoevskijs, diesc ."Idee der wahren Schönheit" darzustellen, die er aber nur in seıner Ästhetik des lächeriichen, in .,lăcherlicher” Form zu gestalten vermochte: Myškin ist 
expliziten Äußerungen Dostoevskijs in seinen Briefen und in den Entwürfen zum Roman Idiot unterstützt, in denen er schreibt, daß Christus für ihn das "Ideal menschlicher Schonheit" sei. ${ }^{359}$

Mit der rätselhaften Figur des „Idioten“ hängen aber neben den „vorpetrinisch-russischen" bzw. christlich-byzantinischen auch die meisten anderen fremden Imageme zusammen. Myškin wird „immanent" sowohl durch die Elemente des positiven utopischen Imagothèmes des „idealisierten Westens“ als auch gleichzeitig des "russisch-orthodox-byzantinischen Rußlands" charakterisiert. Er zeichnet sich daher durch eine verschwommene, ambivalente kulturelle Identität und eine utopische Unbestimmtheit (als alius) aus, die dieser Figur eine besondere "numinose Aura" verleihen. ${ }^{360}$

Myškin bildet das Zentrum der Ereignisse des Romans, seine Fremdheit löst die Geschehnisse und Konflikte des Romans aus. Er steht als der ,absolut Fremde", als alius, in dem sich das "Numinose" als das "Gute und Schöne", aber auch als das "Lächerliche", offenbart, immer in der Opposition, bildet immer den komplementären Kontrast zu anderen Figuren des Romans, wodurch zusătzlich der Bezug zu den (russisch-byzantinischen) heiligen Narren (jurodivye) betont wird. ${ }^{362}$ Myškin läßt sich somit als die ,religiöse Figur" des Romans

lächerlich wie der Christus auf einem unvollendeten Gemälde Kramskojs. Er ist sich als ein .Nart Gottes“ (uur(x)ivyj) jedoch seiner ..Lächerlichkeit" bewußt. LAZARI betont, daB die ästhetischen Ansichten Dostoevskijs Schelling und Hegel nahe stehen und sich in Opposition zur Kantschen Ästhetik befinden. Eine vermittelnde Rolle spielten dabei persönliche Kontakte Dostoevskijs zum Schellingianer Grigor'ev und zum Hegelianer Strachov, wobei für Dostoevskij die Schönheit nur in Christus vollendet erscheine, keine abstrakte Idee sei Christus sei für ihn das ,.absolut Schönc“ (S. 135ff. und S. 142fi.).

${ }^{359}$ In der Dostoevskij-Forschung gibt es jedoch Stimmen sowohl für als auch gegen eıne solche Annahme Vgl. z.B. GUARDINI 1951, S. 357ff Mül..eR 1996b vertritt dagegen die Ansicht, daß Myskin keine Darstellung Christi sei, obwohl er viele gemeinsame Züge mit Jesus aufweise (S. 816f.). Neben vielen anderen Werken ist auch Emest Renans $/ \mu$ vie de Jésus. (1863) bei der Schaffung der Figur Myškins relevant gewesen, was auf die „westlichen“ Quellen dieser Figur hindeuten würde. Vgl. dazu Bd. 9, S. 396ff. und z. B. Kisko 1980.

${ }^{360}$ Die Figur Myškin ăhnelt u.a auch dem ...idealschönen“ Engländer Mister Astlej in lgrok, vgl. oben, S. 248, S. 250ff. und S. 261. Siehe auch Bd. 9, S. 385-410 zu seinen "westlichen“ und "russischen” bzw. „orientalischen“ Vorbildern (der Jesus der Evangelisten und der .Jesus" Renans. L.N Tolstoj, mit dem er den gleichen Vornamen und Vatersnamen teilt, Rousseau, Don Quijote, Pickwick. Victor Hugos Jean Valjean und der russische Graf Kušelev-Bezborodko). Durch die Bezüge zum .Armen Rıtler Puskins und zum Don (uujore Cervantes" wird seine ...westlich-ritterliche Idee“, Nastas ja Filippovna zu ..retten“", mit der christlich-(byzantinischen) der $K^{\prime}$ 'messs und mit dem Hauptthema des Romans, der .Erlösung eines gefallenen Menschen", vereinigt. das von Victor Hugo, also aus dem ..Westen“, stammt. Siehe dazu auch Bd. 20, S. 28 (das Vorwort Dostocvskijs in Vremja (1862) zum Roman Hugos La Notre l lume de Puris). Siehe auch bei PoźNIAK 1992, S. 29ff., bes. S. 32: über die Figur Mohammeds bei Dostoevskij und über die Bezüge Myškins zum islamischen Propheten (u.a. zu seiner Krankheit). WOODWARD 1980, S. $118 \mathrm{ft}$, betont die Bezüge Myşkins zu den russischen Sekten, u.a. zu den Moskauer Altgläubigen und zu den $\left(h / y s / v\left(l \cdot l a g\left(/ l u n / \iota^{\prime} n\right)\right.\right.$ bzw. zu den Kussirulen, die er auch in den Figuren Rogožins und Nastas ja Filippovna findet. und die er die ..dunkle Seite“ der durch diese Figuren vertretenen (alt)russischen Religiosität nennt.

${ }^{361}$ In den Entwürfen zu dieser Figur finden sich folgende Sätze: „Князь ro.ıько прukосн.лся k их жизни. Но mо, чго бы он мог сде.ать и прелиринять, то всё умер.то с ним. Po- 
bezeichnen, auch in seinen mystischen Erlebnissen, die er seiner ,heihgen Krankheit", Epilepsie, verdankt. Diese Krankheit schwăcht jedoch zugleich seine Sexualităt und sein Ich, so daß die Erfüllung des Gebotes selbstloser christlicher Liebe ihm leichter als seinen "egoistischen Mitmenschen" fallt. ${ }^{362}$

In seinen kritischen Äußerungen über Westeuropa tritt Myskin, aus der werkimmanenten Erzählperspektive, als eine positive Kontrastfigur zu den negativ verwestlichten russischen und fremden Figuren auf, die das negative utopische Imagothème des verwestlichten Rußlands symbolisieren. Er macht aber in seiner "Rede" bei Epančins, in der er den "Westen", die "katholische Kirche" und den „Papst" kritisiert, und die durch das Gerücht ausgelöst wird, daß sein Wohltăter, Pavlišcev, Jesuit geworden sei, „seine Idee“ lăcherlich. Die "Lächerlichkeit" Myškins wäre vielleicht als die ästhetische "Entpragmatisierung" seiner russisch-orthodoxen, ,slavophil“ geprägten Ideologie zu verstehen, obwohl auch die anderen Gäste Epančins, die zur liberalen verwestlichten russischen Gesellschaft gehören, ironisch bzw. sogar grotesk geschildert werden. ${ }^{363}$

Als der letzte Vertreter eines alten, vorpetrinischen, seit der Zeit Peters des Großen jedoch heruntergekommenen russischen Adelsgeschlechts ist Myškin eng mit der altrussischen Geschichte und Tradition (wie der alte Ichmenev und seine Frau aus dem Roman Unizennye $i$ oskorblennye) verbunden. ${ }^{364}$ Myskin kommt aber paradoxerweise nach Petersburg aus den Schweizer Bergen. und zum SchluB des Romans wird er seelisch und physisch gebrochen in dieses westeuropaische Land zurückgebracht, das jedoch nur als eine utopische Landschaft ohne eine besonders ausgeprăgte nationale Charakterisierung auftritt. Die "Schweiz Myškins" wird lediglich aus seiner Perspektive geschildert und dient dazu, seine Okzidentalisierung und seine Fremdheit in der Welt des Romans zu betonen. Sie dient auch der ideologischen Kritik am „Protestantismus“ bzw. an der „protestantischen“ Mentalităt der von Myškin beschriebenen Bewohner eines Schweizer Bergdorfes. ${ }^{365}$

ссия dейстөовало на него постепенно. Прозрения его. Но где то.тько он ни прикоснулся - везде он остави.] ненсследимую черту“" [kursiv Dostoevskij] [Der Fürst hat lediglich (leicht) ihr Leben berühr!. Aber alles das, was er hătte bewirken und unternehmen können, ist zusammen mit ihm gestorben. Rußland hat auf ihn allmäh/ıch gewirkı. Seine linsichten. Aber überall dort, wo er etwas auch nur herührl hat, hat er em unauslöschliches Zeichen hinterlassen], vgl. Bd. 9, S. 242.

$362 \mathrm{Vgl}$. ebd., S. 220 bzw. S. 222. Siehe auch Bd. 8, S. 182ff: Die Urteile Myškins über .russische Atheisten“ und das ..religiöse Erlebnis“", das ..Atheisten“ nie verstehen könnten und das sich am intensivsten in ..russischem Volksglauben“ außere.

$363 \mathrm{Vgl}$. Bd. 8, S. 446ff., bes. S. 449i.

${ }^{364} \mathrm{Vgl}$. Bd. 8, S. 8. Dostoevskij hat u.a. seinen Namen der (ieschichte des russischen . Stautes Karamzins entnommen, in der von einem gewissen Myskin die Rede ist, der zusammen mit Ivaško Krivcov den Uspenskij Sobor im Kreml erbaut hatte, vgl. dazu Bd. 9, S. 385. Myškin hat außerdem eine besonders schöne Handschrift, er kann die altrussischen Handschrıften nachahmen, vgl dazu Bd. 8, S. 29 und Bd. 9, S. 431

$365 \mathrm{Vgl}$. Bd. 8, S. 35It; auch RAKUSA'lNGOLD 1981, die das Bild der Schwciz bei Dostoevskij ..keine objektive Auseinandersetzung mit der Schweiz" nennen (S. 31). Die Schilderungen der ..Schweizer idyllischen Berglandschaft“" erinnem jedoch teilweise an diejenigen Karamzins in dessen P'ıs'mu russkugo putešcstvenniku |Brıefe eines resuenden Russien]. Vgl. auch Karamzin 1984, z.B. S. I33ff. Siehe auch die deutsche Ausgabe 
Die weiteren wichtigen Figuren, Aglaja Ivanovna Epancina, Parfen Semenovic Rogožin, Evgenij Pavlovic Radomskij, Luk'jan Timofeevið Lebedev, Ganja (Gavrila) Ardalionovic Ivolgin, sein Vater, der General Ardalion Aleksandrovic Ivolgin, sowic Ippolit Terent ${ }^{\circ}{ }^{366}$ und die jungen „Nihilisten“, u.a. Antip Burdovskij und der Neffe Lebedevs, sind in Idiot die am meisten von den "westlichen fremden Ideen infizierten", verwestlichten Figuren, was sich u.a. durch den Verlust ihres Glaubens an Gott bzw. durch ihr Interesse am Katholizismus außert. Am Schluß des Romans bleibt es offen. ob manche von ihnen den Weg zur russischen kulturell-religiossen Tradition und zum russi-

KARAMSIN 1966, S. 189ff. In dem Lexikonbeitrag zum Thema /diolızm [/dıolıe: Idıotısmus] in: BROKGAUZ / EFRON 1894 (Bd. 12A, S. 802fr.) wird jedoch auch die negative Auswirkung des Schweizer Bergklimas erwähnt, das die Entwicklung dieser Krankheit (als deren besondere Form ..Kretinismus") bei den Bewohnern einiger Gegenden in der .ichwetz begünstigt, zu denen hauptsächlich die Kantone Urı und Wallis gehören (S. 803). Dieses Beispiel für den medizinisch-psychiatrischen Forschungsstand aus der zweiten Hălfte des neunzehnten Jahrhunderts deutet möglichenwetse auf einen weiteren negativen Aspekt der Okzidentalisierung Myškins hin, obwohl er bereits als ein kranker ..Idiot" in die Schweiz zur Kur geschickt worden ist. Vgl. auch unten im Zusammenhang mit der Figur Stavrogins, der eine Übersiedlung in den .,düsteren“ Kanton (Irı plant, S. 323, Fußnote 466.

${ }^{366}$ Die Figur lppolits, eines wegen seiner Schwindsucht zum „Tode verurteilten“ Jünglings, ist auch mit der Problematik des Glaubens an Gott bzw. dem Verlust desselben sowie der Sehnsucht nach der Unsterblichkeit angesichts des Todes verbunden, die sich in seinem Schwanken zwischen dem ,westlichen Atheismus" und der Sehnsucht nach dem .,(russischen) Glauben" äußert. In seiner Norwendıgen lirklürung wird die Kopie des Bildes Der leichnum ('hrısıı ım (irahe (1521) von Hans Holbein d.J., die im Hause Rogožins hăngt. beschrieben, vor dem Rogožin seinen Glauben verloren hat, vgl. Bd 8, S. 336fr. Auch dank einer guten Tat, die er vollbringt, hofft jedoch Ippolit, eine Art .Unsterblichkeit“" im Gedächtnis der aiis. ren Menschen zu erlangen, vgl. ebd., S. 334ff. Siehe auch MüLLER 1996c, S. 105f., der die Ansicht vertritt, da $B$ im Traum Ippolits, eines Vertreters der atheistischen russischen Generation der 60-er Jahre, sich nicht nur seine $Z$ weifel, sondern auch seine Sehnsucht nach dem Glauben an die Auferstehung und an die Unsterblichkeit äuBerten. $\mathrm{Vgl}$. auch eine Stelle aus den Notizbüchern Dostoevskijs aus den Jahren 1876-1877, in: Bd. 22, S. 202 und die Anm. dazu, ebd., S. 462, die sich auf die Osterpredigt des Johannes Chrysostomos bezıcht, in der wiederum ein Zitat aus Hosea 13,14 vorkommt: O lod. wo ist dem Siluchel? [Смерmь, de жало mво']. Diese Osterpredigt wird hier in ännlichem Kontext wie im Traum Ippolits enwăhnt: ..Христос - 1) kpacoтa, 2) нет .тучше, 3) ес.7и таk, то чудо, вот " вся вера, засим уже проповедь Ноанна Златоуста /.../. Обратно теперь математичесkие доказательства, чуть во:1осок и неверие (без поднятия духа и умицения). Это уже восторг, исступ.тение веры, всепроиение и всеобятाе. Крепко ойнимемтесь. поце.ууемтесь II начнем братьями. Гde, смерmь, твое жало, дde ade, noбeda? (S. 202)“

(kursiv d Verf. | [Christus, 1.) die Schönheit, 2.) es gibı nichts Besseres, 3.) wenn dem so ist, ist es das Wunder, das ist der ganze Glaube, folglich, schon die Predigt von locumn Zlaloust |Johannes Chrysostomos| $i .$. !. Umgekehrt aber, |gibt es| jetzt mathematische Beweise. |es reicht] nur ein Härchen und sofort [entsteht) der Unglaube (ohne eine Eihebung des Geistes und ohne eine Rührung). Aber das ist schon die Begeisterung, die Ekstase des Glaubens, die Allverzeihung und Allumarmung. laßt uns einander fest umarmen, küssen und fangen wir als Brüder [zu leben| an. Wo. o Tod, ist dem Silachel. wo ist. " Hölle. dem Siceg?| Vgl. die Anm. dazu, ebd., S. 462. Der gebrochene Stachel des schrecklichen Tiers in Ippolits Traum konnte den gebrochenen Stachel des Todes symbolisieren, auf den in der Osterpredigt des Johannes Chrysostomos angespielt wird. 
schen Glauben finden kơnnten, wie z.B. Evgenij Pavlovic Radomskij. ${ }^{367}$ Die anderen Figuren scheinen aber diesen Weg verfehlt zu haben: Aglaja geht nach Paris, heiratet einen Polen und konvertiert zum Katholizismus, Ippolit und der General Ivolgin sterben, Rogožin wird als Morder Nastas ja Filippovnas in die Katorga. in das "tote Haus" verbannt. wo er aber jedoch möglicherweise seelisch wie Raskol "nikov „auferstehen“ könnte. ${ }^{360}$

Wie oben bereits erwähnt, werden die fremden Imageme im Roman Idiot vorwiegend zur Charakterisierung der russischen Figuren eingesetzt, indem sie auf deren Okzidentalisierung hindeuten. Zu diesen fremden Imagemen gehören nicht nur fremde Figuren, darunter polnische, deutsche oder jüdische, sondern auch Erwăhnungen (west)europăischer Künstler oder Schriftsteller und ihrer Werke sowie mehrere Anspielungen nicht nur auf die westeuropaische Kultur, sondern auch auf die (west)europäische Geschichte und Lebensweise: auf historische Figuren, z.B. auf Napoleon Bonaparte, auf westeuropăische Städte, z.B. auf Basel. Lyon und Paris. Die meisten der fremden Imageme treten im Zusammenhang mit den zentralen Figuren Myskin bzw. Rogožin oder Nastas'ja Filippovna oder Aglaja auf, andere charakterisieren weitere Figuren: Lebedev, Tockij, den General Ivolgin und dessen Sohn (ianja, Radomskij oder Ippolit Terent'ev.

Den Fürsten Myskin charakterisieren solche Imageme wie die Figuren der "Schweizer" und die "Schweizer Landschaft", die Stadt Basel und einige Gemălde, darunter Der Leichnam Christi im Grabe Holbeins sowie die französische Stadt Lyon, die alle in seinen Erzählungen auftreten. $\mathrm{Zu}$ den fremden Figuren, die Myškin erwähnt, gehören der "gute Schweizer Doktor" bzw. „Professor" Schneider, die Hirtin Marie, die Schulkinder und andere Bewohner des Dorfes in den Schweizer Bergen, darunter ein strenger Pastor und ein Dorflehrer. Eine wichtige Rolle in diesen ,subjektiven“ Erinnerungen Myskins spielt sogar ein Escl aus Basel, dessen Schrei seinen Genesungsprozeß und die Überwindung eines Gefühls des Überwältigtseins durch die Fremdheit der westlichen Umgebung, d.h. seine immanente Okzidentalisierung, eingeleitet hat. ${ }^{369}$ Die

367 Vyl. Ed. 8, S. 508f: Im Epilog wird die Zuneigung Radomskijs nıcht nur zu Myškm und zu Kolja Ivolgin, sondem auch zu Vera lebedeva, einer sanften, gläubigen Russin erwăhnt. Dadurch wird aut seine mögliche Rückkehr zur russischen kulturellen Tradition angespielt, obwohl er sich selbst als einen ..in Rußland gänzlich überflüssigen Menschen“" (S. 887)|..совершенно .лишний че.товеk в Pоссин“| bezeichnet und sich für lăngere Zeit in ..Furopa“ niedergelassen hat. Es kann hier aber nicht auf das Motiv des ..überflüssigen Menschen" in der russisctien Literatur eingegangen werden, das auch in Zimnic zumetki o letnich vpecutlenyuch vorkommt. Siehe dazu KLUGE 1982.

368 $\mathrm{Vgl}$. zu den Vorbildern Rugožins, Nastas'ja Filippovnas und Aglajas Bd. 9, S. 385-410. $369 \mathrm{Vgl}$ [3d. 8, S. 48. .j... ужасно на меня подейтвова.10, что всё это чумслс, это я поня.7. Чужос меня убивато. Совершенно пробулисяя я от зтото мраkа, помню я, вече-

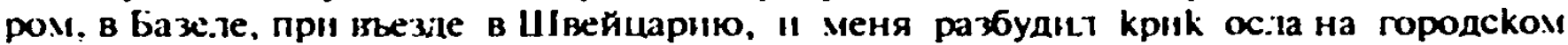
рынkе. Oсе.л ужасно поразцл меня и необыкновенно почему-то мне понравiцся. а с тем вместе вцруі в моей го.ове как бы всё проясне.ло |Am schlimmsten wirkte auf mich, daB alles etwas / remdes war; soviel hatte ich begriffen. Das Fremde totete mich. Ich tauchte aus dicsem Dunkel eines Ahends auf, in Basel, $i . . /$ gleich nach der Ankunft in der Schweiz. Mich weckte der Schrei eines Esels auf dem Marktplatz. Der Esel frappierte mich ungeheuer, er gefiel mir aus ırgendeinem Grunde ganz außerordentlich, und zugleich schien 
französische Stadt Lyon wird dagegen von Myškin lediglich im Kontext der Problematik der Todesstrafe als Ort einer Hinrichtung erwähnt. ${ }^{370}$ Die "Schweiz" und das "Frankreich" Myškins, aus seiner Perspektive gesehen, zeigen ihn als einen vorwiegend positiv "verwestlichten" Russen, der jedoch sowohl die negativ-utopischen als auch die positiv-utopischen Aspekte des "Westens" kennengelernt hat. Zugleich heben sie seine "Fremdheit" als "vorpetrinischer" Russe (als alius) dem "Westen" gegenüber, hervor. Die positiven fremden Figuren in den Erinnerungen Myškins: der gute Doktor Schneider, Marie und die Kinder vertreten darüber hinaus komplementär zu ihm das positive utopische Imagothème des Westens, dessen Teilaspekt die "idyllische Schweizer Landschaft“ bildet. ${ }^{371}$ Die Stadt Lyon als Ort einer Hinrichtung und der strenge Pastor und die grausamen, unbarmherzigen Bewohner des Schweizer Dorfes verkörpern dagegen das negative utopische Imagothème des Westens, wobei dieses Imagothème auch einen ideologischen Aspekt mitenthält, die Kritik an der ,katholischen“ bzw. „protestantischen“ (,westlichen“) Justiz und Moral.

Fremde Imageme sind darüber hinaus mit den Figuren Lebedevs und Tockijs verbunden: Mit der Problematik der Todesstrafe hängt die Geschichte der wăhrend der Französischen Revolution hingerichteten Gräfin Dubarry zusammen, einer der .,großen (westlichen) Sünderinnen“, für die Lebedev zu beten pflegt: ${ }^{372}$ der extrem verwestlichte Verführer von Nastas ja Filippovna, Afanasij Ivanovic Tockij, heiratet dagegen eine Französin, die einen Bezug zu den stereotypen Französinnen in Zimnie zametki o letnich vpečatlenijach und zu der Mademoiselle Blanche im Roman Igrok aufweist, und verläßt Rußland. Sein Name kann darüber hinaus auf seine destruktive todbringende Rolle im Leben Nastas'ja Filippovnas hindeuten. ${ }^{373}$ Diese negative Figur ist den anderen

sich in meinem Kopf alles zu klăren; S. 82f.] [kursiv Dostoevskij]. Siehe auch zu den Schweizer Eindrücken Myškins, ebd., bes. S. 48ff. bzw. 57ff. Die demütige Marie ist eine Parallelfigur zu Nastas ja Filippovna. Marie wird aber von Myskin im Unterschied zu Nastas ja Filippovna ,erlöst“. Sie findet Glück in der Liebe zu Myškin und zu den Kindern. Ihre Geschichte wird aber nur aus der Perspektive Myškins erzählt. vgl. ebd., S. 57ff., bes. S. $62 f$.

${ }^{370}$ Ehd., S. 19ff. und 54ff. Vgl. auch den Kommentar dazu, Bd. 9, S. $429 f$.

$371 \mathrm{Vgl}$. auch unten zu der anderen idealen (und authentischen) deutschen Figur des Doktor Gaas [eigentl. $\mathrm{Ha(a)s],} \mathrm{S.} 294$ und S. 376.

$372 \mathrm{Vgl}$. Bd. 8, S. 164f. Lebedev wird als ein Apokalypse-Ausleger und Erzähler von grotesken Geschichten geschilder, u.a. über Menschenfresser aus dem westeropäischen Mittelalter oder über den „Teufel“", wobei er sich auch für den Katholizismus interessiert. Er ist em moralisch ambivalenter ..Narr”, der die Welt des Romans in einer Endzeitperspektive erscheinen läßt. Mit ihm hängt also ebenfalls die „evangelische Schicht“ des Romans zusammen, die in dieser Studie nicht genauer betrachtet werden kann Vgl. 7.B. ebd., S. 7ff., S. 159ff. und S. 166ff. und S. 309-316; siehe auch Bd. 9. S. 371 und S. 393, über den Bezug zu A.I. Gercen und seinem Briefwechsel mit V.S. Pečerin (1853).

${ }^{373}$ Der Name Tixkyj ist moglichenveise von dem deutschen Wort ..Tor" abgeleitet worden. Vgl. auch ebd., S. 154: „/.../ генерат узнат, что Афанасий Иванович плснился одною засзмек франиумснкой высшего общества, маркизой и легитиянсткой, что брак состогтся ॥ что Афанасия Ивановича увезут в Парих, а потом куда-то в Бретань. «Ну.

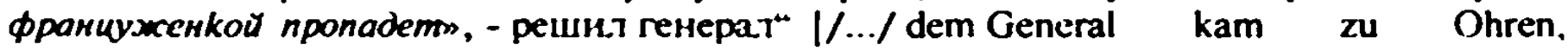


negativ-dämonischen Figuren, dem Fürsten Valkovskij oder Svidrigajlov sowie den anderen verwestlichten bzw. westlichen Verführem der russischen Frauenfiguren in anderen Werken Dostoevskijs verwandt, zu denen Stavrogin (im Roman Besy), der Franzose Lambert und Versilov in Podrostok, oder auch der Pole Mussjalovic in Brat 'ja Karamazovy gehören.

Im Roman Idiot spielen auch bestimmte westeuropåische Gemălde und literarische Werke eine wichtige Rolle, die mit den Figuren Myškins, Rogožins und Ippolits und im allgemeinen mit der christologisch-religiosen Problematik des Romans - des Glaubens an die Auferstehung Christi bzw. seines Verlustes, dem Schwanken zwischen dem "westlichen Atheismus" und "rationalem Skeptizismus" und dem „russisch-orthodoxen Glauben" mit dessen „byzantinischen Wurzeln" - zusammenhängen. Eine besonders wichtige symbolische Funktion hat das Bild von Hans Holbein d. J. Der Leichnam Christi im Grabe (1521). ${ }^{374}$ Auch der Kurzroman von Victor Hugo Le dernier jour d'un condamné (1829) ist für das Verständnis der Stellen aus dem Roman relevant, in denen die „zum Tode verurteilten" verwestlichten russischen Figuren geschildert werden. ${ }^{375}$ Nastas ja Filippovna liest außerdem kurz vor ihrem Tod Madame Bovary Flauberts und wird somit in Bezug zu der „emanzipierten“ Heldin dieses französischen Romans gebracht, die ebenfalls zugrundegegangen ist. ${ }^{376}$

daß Afanassij Iwanovitsch den Retzen einer reisenden Französin aus der höchsten (jesellschaft, Marquise und legitimistin, verfallen und die Heirat beschlossene Sache sei, daß Afanassij Iwanovitsch zunăchst nach Paris und dann irgendwohin in die Bretagne entfühn werden solle. 'Ja, diese Französın wird sein linde sein', entschied der General. ] [kursiv die Verf. I

374 Ebd., S. 181 ff., S. 338f. und Bd. 9, S. 399. Auch nach StoichrtA 1995, S. 429, hat Dostoevskij, bevor er das Gemälde Holbeins in Basel selbst sehen konnte, darüber in den Bricfen eines russischen Reisenden von N.M. KaRamzin gelesen. Vgl. dazu Karamzin 1984, S. 98: ..В Христе, снятом со kреста, не вилно ничего божественного; но kаk умерший че.ловек изображен он весьма естественно. Гlо преданию рассkазывают, что Гольб́.ин писат его с одного утопиеего Жида" [In dem vom Kreuz abgenommenen Christus kann man nichts Göttliches sehen; aber als ein toter Mensch ist er ganz natürlich dargestellt. Einer L.egende nach erzählt man, daß Holbein ihn nach eınen ertrunkenen Juden gemalt habel; vgl. auch Bd. 9, S. 399. Auch ein weiteres Gemălde aus Basel: Die linthuuptung des Johunnes von Hans Fries (1450-1520) ist für das Verständnis des Romans /dıot wichtig, Myškin erwăhnt es ebenfalls ım Zusammenhang mit seinen Geschichten über die Hinrichtungen, ebd., S 55, vgl. auch Bd. 9, S. 433. A.G. Dostojevskaja nennt in ihren Erinnerungen u.a. noch die Bilder der lirlüser (C'hrıstus) von Annibale Caracci, ('hrısıus mil der Münze von Tizian und die Madunna von Hans Holbein d.J. (d.h. Marıa mil der Fumilie dess Bürgermeisters Jakob Meyer zum Hasen (um 1528)), die ihrem Mann am besten gefallen hatten. Vgl. DostojevsKaJA 1971, S. 150. Moglicherweise ist das Gesicht Myskins dem Christus von Carracci nachgebıldet worden. Im November 1995 hat die Verf. in der Ausstellung über F.M. Dostojewski in Baden-Baden eine Postkante aus der Sammlung A.G. Dostojevskajas mit der Reproduktion des Bildes ( $/$ risius von Carracci gesehen. Vgl. den Katalog dieser Ausstellung: MnstOFWSKIJ STADT BADEN-BADEN. S 143: . Reproduktionen nach Werken Alter Meister aus der Sammlung A. Dostojewskajas: 137. Carracci. Christ. Photo 16,6 x 10,7"*. Myškin vergleicht übrigens das Gesicht der ältesten Tochter Epancins. Aleksandra, mit dem der Muedenna Holbeins. Bd. 8, S. 65.

$375 \mathrm{Vgl}$. 7.B. Bd. 9, S. $429 \mathrm{f}$.

376 Ebd., S. 499. 
Außerdem treten in Idiot weitere fremde Figuren auf, die zu den Bewohnem Petersburgs zahhlen: einige deutsche Frauen und Mănner, u.a. eine deutsche Bekannte von Nastas'ja Filippovna, die bei ihrem Geburtstag erscheint, ${ }^{377}$ ein „Baron bzw. Graf, mit einem deutschen Namen" und ein russischer Schriftsteller deutscher Herkunft, die Gaste Epancins. ${ }^{378}$ Es handelt sich bei diesen Figuren sämtlich um negative nationale Stereotypen, die als alter auftreten und der Kritik am "verwestlichten" Rußland dienen, obwohl sie zugleich eine ideologischkritische Komponente enthalten, die unmittelbar den "Westen" betrifft. Ippolit erwähnt außerdem einen wohltătigen deutscher. "General", es handelt sich dabei um F. P. Gaas (F. J. Haas), eine authentische Gestalt, den Oberarzt der Moskauer Gefangnisse, der allen Gefangenen geholfen hatte, die nach Sibirien ver-

${ }^{377}$ Ebd., S. 132: „Но молчаливая незнакомkа вряд .11 что и понять мог.ла: это была приезжая немка и руссkого языка ничего не знала; kроме того, kажется, была сто.тько же г.тупа, cko.тько и прекрасна. Она была внове, и уже принято бы.то приг.лашать ее на известные вечера, в пышнейшем костюме, причесанную kak на выставkу, и сажать kak претестную kapпıнку дтя того, чтобы ckpaciтr вечер, - точно тak, kak иные добывают дтя свонх вечеров у знакомых, на один раз, картину, вазу, статую ити экран“. [kursiv die Verf.]

[S. 227f: Aber die schweigsame Unbekannte war wohl kaum imstande, etwas zu verstehen: Sie war eine zugereiste Deutsche und konnte kein Wort Russisch; außerdem war sie anscheinend ebenso toricht wie schón. Sie war erst seit kurzem in Petersburg leigentl.: vor kurzem angekommen], aber es war bereits üblich, sie zu bestimmten Festen einzuladen und sie, in prachtvoller Toilette, wie fürs Schaufenster frisiert, als einen entzückenden Blickfang zu plazieren, um dem Abend eine besondere Note zu verleihen, genauso wie mancher Gastgeber für eine Soirée von Bekannten ein Gemălde, eine Vase, eine Plastik oder einen Kaminschirm für einen Abend ausborgt [kursiv die Verf.]]. Siehe auch ebd., S. 497f. Die Figur der schonen, aber stummen und somit "dummen" Deutschen, weil sie kein Russisch sprechen und verstehen kann, die deswegen nur als ein Requisit auftritt, geht auf das „gemeinslavische“ Stereotyp des „stummen Deutschen“ zurück. Vgl. dazu VASMER 1955 (Bd. 2, S. 211 f.): Heueu [nemec] Deut.scher, arus. Nêmbcb, /...' ursl. *nèmbcb ,Fremder”, gehơn zu nèmb .,stumm" (s. "ewoù (nemoj]).

370 Der Deutsche bei Epančins war „/../ один очень солидный военный генерат, барон ити траф, с немецkим именем, че.ловек чрезвычайной мо.талнвості, /.../ один из тех олимпийцев-адмннистраторов, которые знают всё, акроне разве самой Росиил /.../, //.../ ein hochst imposanter Militär, ein General, Baron oder Graf mit deutschem Namen ăußerst schwetgsam, l...' einer jener Olympier der Administrutıon. die alles kennen. "uußer Rußlund selhst I.../; S. 773f.] [kursiv die Verf.|, ebd., S. 443. Der General wird also nach dem .realistischen“ Verfahren als ein .subversiver”, ebenso stereotyp „schweigsamer" Deutscher dargestellt, der, obwohl er als ein „Fremder“ Rußland überhaupt nicht kennt, das Land doch "mitregient"; der Schriftsteller repräsentiert dagegen die ,bürgerliche“, „fremde“ und ebenso „subversive“ Intelligentsia:../../ из ненцев, но русский поэт, І, сверх того, совершенно притичный, таk что его можно было без опасения ввести в хорошее обшество. Он был счаст.ливой наружності, хотя почему-то несkо.лько отвратіттельной, /.../ принадлемсал k семейству немецкому, в высшей степени бурисуазнону, но и в высшей степени почтенному /..././.../ ein Dichter deutscher Abstammung, aber russischer Poet, noch dazu mit hochst anstandigen Manieren, so da $B$ er bedenkenlos in die gute Gesellschaft eingeführt werden konnte: Er erfreute sich eines glücklichen Äußeren, wenn es auch irgendwie ein bißchen abstoßend wirkte, /.../ |er] gehorte einer deutschen, zwar im hochsten Grade bürgerlichen, aber in ebendemselben Grade ehrbaren Familie an; S. 775f.! [kursiv die Verf.], ebd., S. 444f. 
schickt wurden. ${ }^{379}$ Rogožin und Myškin sind außerdem mit einem ,ritterlichen“ anglophilen Leutnant a. D. mit dem deutschen Namen Keller befreundet. ${ }^{380} \mathrm{Zu}$ den anderen fremden Figuren des Romans gehört u.a. ein jüdischer Pfandleiher Zejdler, für den sich Lebedev in einer Gerichtsverhandlung eingesetzt haben soll. $^{381}$

$379 \mathrm{Vgl}$. Bd. 9, S. 344 und Bd. 8, S. 335f.: .Единичное добро останется всегда, потому что оно есть потребность .личности, живая потребность прямого втияния одной тичності на другую. В Мосkве жиц. один старик, один 'генерат', /... с с немецким именем; он всю свою жизнь тасkатся по острогам и по преступникам; каждая пересы.тьная партія в Сибирь знала заранее, что на Воробьевых горах ее посетит 'старичок генерат. Он де.лат свое де.ло в высшей степени серьезно и набожно“:

[S. 585: Die Wohltätigkeit des einzelnen wird immer bleiben, weil sie ein Bedürfnis der Persönlichkeit ist, das lebendige Bedürfnis nach unmittelbarer Einwirkung einer Persönlichkeit auf eine andere. In Moskau lebte ein alter Mann, ein 'General', /.../ mit einem deutschen Namen; sein ganzes Leben lang suchte er Zuchthăuser und Verbrecher auf |eigentl.: schleppte er sich von einem Zuchthaus und Verbrecher zum anderen|: jeder Străflingstransport nach Sibirien wußte im voraus, daß er auf Worobjowy Gory von dem alten General verabschiedet wird. Er tat das mit tiefstem Emst und großer Frommigkeit]:

Gaas (= Haas) wird auch in den Entwürfen zu Prestuplenie । nakuzanıe erwähnt, Bd. 7, S. 80 Vgl. dazu: Kopflew 1984, S. 9f. (Vorwort von Heinrich Boll): „Das Leben des Dr. Friedrich Joseph Haas ist von ganz anderer Art als das des landlăufigen Helden. /.../Er war ein frommer Mensch, glăubig. auch kirchenglăubig, ein junger Katholik aus Münstereifel, den es über die Universitäten Koln, Jena, Wien nach Moskau verschlug, wo er Karriere zu machen begann, ein Modearzt, spăter Amtsarzt, der immer auch ein Amtsarzt war und blieb"; S. 126f. (über dessen Hilfe für die Polen, die nach dem Aufstand von 1830-31 nach Sibirien verschickt wurden; S. 188-191 (über Haas in den Werken Dostoevskijs), sowie S. 222: „Er [Haas] war ein Deutscher, der im Herzen Rußlands lebte, ein überzeugter Katholik inmitten überzeugter Russisch-Orthodoxen, in den ersten Jahren ein wohlhabender Beamter, zeitlehens ein anerkannter und hochangesehener Gelehrter, doch er wirkte unter den Allerărmsten, Verachteteten, Analphabeten, Rechtlosen..."

$380 \mathrm{Vgl}$. z.B. Bd. 8, S. 309f.: „З Знаете, я ужасно люб.лю в газетах читтать про анг.тй́сkие пар.аменты, /.../ kak они между собой объясняются, ведут себя, таk ckазать, kak ıо.лттиkи: «б.лагородный виконт, сицяший наңтротив», «благородный граф, разделяющий мыс.ль мою", “б.лагороднейший мой оппонент, удививиий Европу свонм пред.ложением», 10 есть все эті выражения, весь зтот парламентаризи свободного иароda - вот что для нашего брата заманчиво! Я пленяюсь, князь“. | kursiv d. Verf.|

[S. 541: Wissen sie, ich lese in den Zeitungen furchtbar gern von den englischen Parlamenten, I.../ wie sie miteinander umgehen, wie sie sich sozusagen wie Politiker benehmen: 'Der edle Viscount mir gegenüber', 'der edle Graf, der meine Ansicht teilt', 'mein edler Opponent, der ganz. Europa durch seinen Vorschlag in Erstaunen setzt, das heiBt, alle diese hübschen Ausdrücke, all dieser l'arlamintarısmus eines freten l'olkes - das ist es. was für unsereinen so verlockend ist. Ich bin entzückt $: .$. /! [kursiv die Verf ]]. Beı dieser Stelle handelt sich um eine positive ideologisch-gefarbte Beurteilung einer westlichen Staatsform und möglicherwerse um eine versteckte Kritik der russischen Vgl auch die ..Beichte" Kellers. ebd., S. 256

${ }^{301}$ Ebd., S. 161. Mit den Figuren (janja Ivolgins und Pticyns ist außerdem das Thema des .jüdischen Könıgs Rothschild" verbunden, vgl. dazu Bd. 8, S. 105 oder S. 387. Auch Ippolıt erwähnt Rothschild im Zusammenhang mit dem armen russischen Beamten. Surikov, dem er vorwirft, unfahıg zu sein, wie Rothschild reich zu werden, ebd., S. 326f. Rogożin bezeichnet Ganja darüber hinaus als .Judas“, ebd., S. 95. Siehe auch Bd. 9. S. 399f., wo auch auf den Bezug der ..Rothschild-Idee" Ganjas zu Heine hingewiesen wird. Eine Übersetzung von Zur

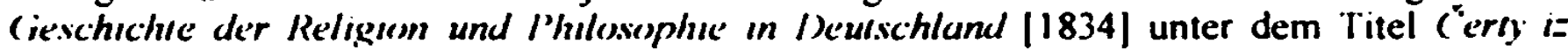

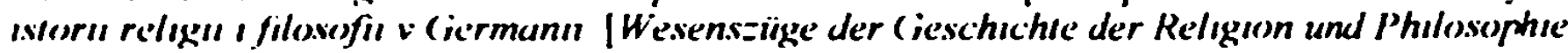


Abgesehen von der Figur des Doktor Haas, der als ein „idealer" Mensch (und ein Christ) das positive utopische Imagothème des verwestlichten Rußlands symbolisiert, bilden alle anderen fremden Figuren (als alter, als vorwiegend negative nationale bzw. ethnische Stereotypen) den Kontrast zu den russischen verwestlichten Figuren bzw. charakterisieren diese in negativer Weise, so z.B. die jüdischen Petersburger Figuren, die den „westlichen Materialismus“ verkörpern und somit als ein Teil des negativen ideologischen Imagothèmes des verwestlichten Rußlands zu betrachten sind. Der Vergleich Ganjas mit dem "Judenkönig" Rothschild, trotz seiner Ambivalenz und einiger positiver Eigenschaften, zeigt ihn als einen Vertreter des negativen utopischen Imagothèmes des verwestlichten Rußlands, für den die „Rothschildidee“ den höchsten Wert darstellt. ${ }^{382}$

Im folgenden werden auf dem Hintergrund der obigen Ausführungen zur Figurenkonstellation und zu den fremden Imagemen des Romans Idiot polnische lmageme ausführlicher interpretien, zu denen nicht nur einige polnische Figuren, sondem auch der Name des Komponisten Chopin und eine seiner Klavierballaden gehören, eine mögliche Anspielung auf die polnische Stadt Radom im Namen Radomskij, eine versteckte Anspielung auf einen sechsfachen Mörder, den Katholik und Polen Vitol'd Gorskij (Witold Górski), der im Zusammenhang mit den Figuren des „falschen Sohns“ Pavlišcevs, Burdovskij (dessen Name möglicherwcise auch eine polnische Etymologie hat) und des Neffen Lebedevs

in Deutschland) wurde in der Zeitschrift Dostoevskijs Epochu (1864; Heft. 13) veröffentlicht. Obwohl diese Übersetzung durch den Zensureingriff stark entstellt wurde. ist anzunehmen, daß der vollständige Text Heines Dostoevskij bekannt war, u.a. der Vergleich zwischen Rothschild und Christus. Vgl. dazu auch HEINE 1979, S. 72. Siehe auch zur .Rothschild-Idee“" bei Dostoevskij z.B. bei PozNIAK 1992, S. 100ff., bes. S. $116 \mathrm{ff}$.

....i obraz barona Rothschilda. wlaścicicla domu bankowego), personifikuje wolę ckonomieznego paxlbuju swiata przez kapitał zydowski. Na kompleks Rothschilda cicrpią wlaściwic wszyscy gliwni tohatcrowic Destojcwskiego, ch(xiaź nic u wszystkich ujawnia siç on expressis verbis. Tçsknota za nadczlowicczeństwem przcżera swiadomosic postaci marzących o zdobyciu dużcj iloși pieniçdzy. /.../ Kapitał rothschildowski [funkcjonuje w ldioxiel jako 'dodatek (xdpuxobniający obraz chrystoforycznego narodu. $i . .$. Rothschildyzm wiçc gencrujc nową religiç-religiç pieniądza. kult wartosici matcrialnych. ktorry uprawiają w Europic zarowno zwolennicy rewolucji burżuazyjncj, komunistycznej, jak i wrogi prawosłauiu katolicyzm"

[ ${ }^{\prime} . . /$ das Bild des Baron Rothschild, des Besitzers einer Bank, personifiziert den Willen des jüdischen Kapitals, die Welt ökonomisch zu erobern. An dem ..Rothschild-Komplex“ leiden eigentlich alle Hauptfiguren Dostoevskijs, obwohl er sich nicht bei allen expressis verhis offenbart. Die Sehnsuchi nach dem Ibermenschentum zerfrißt das Bewvißsein aller Figuren. die davon trăumen, an das große Geld zu kommen. /.../ Das Rothschildsche Kapital funktioniert in Idlost als eine. Zugabe“", die das Bild des christophorischen Volks verunstaltet. I... Rothschildismus generien somit eıne neue Religıon, die Religion des Geldes, den Kult der materiellen Werte, den sowohl Anhänger der bürgerlichen und kommunistischen Revolution als auch des der Orthodoxie feindlichen Katholizismus ausüben.]

382 Ganja weist aber auch einige positive Eigenschaften auf, vgl. Bd. 8, S. 144t., bes. S. 145 (er lehnt es ab, das brennende Geldpäckchen aus dem Feuer zu ziehen, nachdem Nastas'ja Filippovna ihn aufgefordert hat, das Geld, weswegen er sie heiraten wollte, für sich zu behalten) und ebd., S. 258ff. (er hilft Myškin, den Betrüger Burdovskij zu demaskieren). 
erwăhnt wird, und nicht zuletzt auch der Name des Wucherers Biskup, von dem Rogožin und Radomskij Geld geliehen haben.

1. Zum ersten Mal taucht ein kleiner Pole [poljačok, Polăckchen] in der Gruppe der um Rogožin versammelten Figuren auf:

Компания была чрезвычайно разнообразная и отличалась не тольkо разнообразием, но и безобразием. /.../ Кроме Лебедева, тут был и завитой Залёжев /.../ и подобные ему два-три посподина, очевидно из kупчиков. /.../ был один увивавшийся noлачоk.

[Die Gesellschaft war außerordentlich gemischt und zeichnete sich nicht nur durch ihre Buntheit, sondern auch durch ihr ungehöriges Benehmen aus. /.../ Außer Lebedjew befand sich unter ihnen auch der ondulierte Saljoschew /... nebst zwei, drei Herren von derselben Sorte, augenscheinlich Kaufleute [eigentl. Kaufleutchen; Erg. d. Verf.]. /.../ ein scharwenzelnder kleiner Pole [war da].] [kursiv die Verf.]] ${ }^{383}$

Neben dem „Polen“ betonen alle in dieser Szene auftretenden sonderbaren stereotypen Alter-Figuren, die den „Hof" des reichen und leidenschaftlichen Kaufmannssohn bilden, nicht nur die negative Okzidentalisierung Rogožins, sondern auch seinen groben und keineswegs „,salonfahigen“ Auftritt im Hause des Generals Ivolgin, wo sich gerade Nastas ja Filippovna aufhalt, die ihrerseits zu Ivolgins gekommen ist, um sich der Familie des Generals vorzustellen: Der Sohn von Ivolgin, Ganja, soll mit ihr verheiratet werden.

Die stereotype gesichtslose polnische Figur, die nur durch die nationale $\mathrm{Zu}$ gehörigkeit und durch die wie in den früheren literarischen Werken Dostoevskijs auftretende stereotype ,(alt)polnische“ Bereitschaft zu dienen (der „scharwenzelnde kleine Pole") charakterisiert wird, unterstreicht aber nicht nur die „Fremdheit" Rogožins in einem ,adligen" Petersburger Haus. Das nationale polnische Stereotyp hat daruber hinaus eine ideologische Funktion, sowohl als eine negative Kontrastfigur zu Rogožin selbst als auch als ein "Bestandteil" seiner "Welt", indem es seine "negativ verwestlichte Welt" in Opposition zu den anderen in dieser Szene auftretenden Figuren stellt. Obwohl die als polnisch .markierte" Figur durch ein anderes "westliches" Stereotyp ersetzt werden könnte, z.B. durch einen Franzosen oder Juden, verleiht das „Polackchen“ der Okzidentalisierung Rogožins (einer russischen Alius-Figur) eine besonders subversiv-negative, "teuflische", weil „rußlandfeindliche“ Komponente. Die „polnische" Szene fält aber zusătzlich auf, weil sie lediglich aus der Sicht des Erzăhlers dargestellt wird und nur er selbst "weiß", daß es sich um einen Polen handelt. Die anderen in der Szene auftretenden Figuren, Ganja und Kolja, die mit den Kumpanen von Rogožin konfrontiert werden. können dies kaum auf den ersten Blick erkennen. Der stereotype "Pole" ist also in einer gezielt ideologischen Funktion eingesetzt worden. Er hebt den subversiv-negativen Einfluß des „Westens" auf Rogožin hervor. Dieser besorgt übrigens das Geld für Nastas ja

${ }^{303}$ Bd. 8, S. 95 [S. 163f.]. 
Filippovna von einem bestimmten Herrn namens Biskup, möglicherweise einem Juden bzw. Polen, was zugleich eine ironische, ideologische Anspielung auf die ",irdische" Macht der katholischen Kirche ist. ${ }^{384}$

Die tragische Figur Rogožins, in der sich die Leidenschaft seines fanatischen und strengen Vaters, Geld zu sammeln, in die Leidenschaft für Nastas 'ja Filippovna umgewandelt hat, die aber zugleich ein Ausbruchsversuch aus der eigenen engen Welt ist, wird mit der Gruppe der zwielichtigen grotesken verwestlichten Figuren umgeben, die seine Entfremdung von den russischen Traditionen, sein „Verderben" betonen.

Obwohl sein Vater Beziehungen zu russischen Sektierern ${ }^{385}$ gehabt hatte und seine sanfte fromme Mutter eine echte Jurodivaja ist, ${ }^{386}$ wird er von religiosen Zweifeln gequält. Der Verlust seines (russischen) Glaubens wird durch das unablässige Betrachten der von seinem Vater geerbten Kopie des Bildes Holbeins Der Leichnam Christi im Grabe symbolisiert. ${ }^{387}$ Rogožin ist also die "dunkle“, negativ verwestlichte russische Alius-Figur des Romans, in der sich ahnlich wie in Raskol "nikov das „Böse“ zeigt, das nach RuBland aus dem „Westen“ gekommen ist. Er wird somit komplementär zu Myškin ebenfalls als der „ganz Fremde" geschildert, aber als ein Alius, der dem russischen Glauben entfremdet ist. Diese Figur bildet einen Teil des negativen utopischen Imagothèmes des verwestlichten Rußland sowie wegen einer gewissen Ähnlichkeit mit seinem Vater, der die Kopie des Holbeinschen Bildes einst erworben hat, einen Teil des negativen utopischen Imagothèmes des ,sektiererischen, aber pervertierten Rußlands“, das bereits dem negativen Einfluß des „Westens“ erlegen ist. ${ }^{388}$

2. Weitere polnische Imageme sind mit dem General Ivolgin verbunden, der neben seinem Sohn Ganja oder Lebedev ebenfalls zu den moralisch ambivalenten, verwestlichten Figuren des Romans gehört. Die polnischen Imageme kommen in seinen unwahrscheinlichen Geschichten vor, sie verleihen aber dieser Figur keine „dämonisch-bösen“, sondern eine grotesk-komische „westliche“ Färbung.

\footnotetext{
${ }^{384} \mathrm{~V}$ gl. ebd., S. 98, 251 und oben, S. 285.

325 Bd. 8, S. 170 ff, bes. S. 173 und 178. Vgl. dazu auch COMER 1996

$306 \mathrm{Vgl}$. zur Schilderung der Mutter Rogožins Bd. 8, S. $184 \mathrm{f}$.

$307 \mathrm{Vgl}$. Bd. 8, S. $181 \mathrm{f}$. Zu den Vorbildern und zum Namen Rogožins siehe z.B. Bd. 9 S 406f. Fir wird übrigens zum ..Bruder’" Myškins, indem er mit ihm Kreuze austauscht, Bd. 8, S $184 \mathrm{ff}^{\circ}$.

$380 \mathrm{Vgl}$. ebd., S. 172f. (über das Portrăt des Vaters von Rogožin, auf dem er .В скртюке покроя ненсикого, но длиннополом, с двумя меда.ямпи на шее, /.../ со снорщсннем и желтын лицом, с подозріттельным, скрытым II сkробным взг.лядом" [in еinem Gehrock nach deutschem Schnitt, aber länger, mit zwei Medaillen am Band, /...' [mit] runzligem, gelbem Gesicht, und jenem argwöhnischen, undurchdringlichen, grämlichen Blick: S. 300] [kursiv die Verf.] abgebildet worden ist, und auch zu dessen Beziehungen zu den Skopcy, zu der Sekte der Kastraten), sowie ebd., S. 181 (über die Kopie des Bildes von Holbein, die der Vater Rogožins gekauft hat). Diese Charakterisierung des düsteren Vaters Rogožins deutet auf dessen Beziehungen sowohl zum „Westen“, als auch zu den altrussischen religiösen Traditionen, die jedoch diese Figur negativ erscheinen lassen
} 
Chopin und eine seiner Balladen fur Klavier tauchen in einer Szene auf, in der General Ivolgin Myskin auf dem Weg zur Geburtstagsfeier von Nastas ja Filippovna uber seine angeblichen Bekanntschaften in der hoheren Petersburger Gesellschaft erzahit. Um diese zu beweisen, fuhrt er den Fürsten in ein Haus, in dem reiche, hochgestellte Persönlichkeiten wohnen. Nachdem er an eine Tür geklopft hat, wird er von einer Dame mit Mißtrauen betrachtet:

Покорнейшее прошу вас передать мой nоkлон, /.../ передайте им [Aлександра Михайловна] мое сердечное помелание того, чего они сами желали себе в чертверг, вечером, при звуках балцады ШІопена; они помнят... /.../.

- Знаете, мой милый, я несkолько поэт в душе, заметили вы это? [kursiv die Verf.]

[Bitte ergebenst, meine Empfehlungen zu übermitteln, /.../ ich wünschte ihr [Alexandra Michailowna] von Herzen alles, was sie sich selbst am Donnerstag, abends, bei den Klängen der Ballade von Chopin gewünscht hat: sie wird schon wissen... /.../

Wissen Sie, mein Lieber, ich bin in meiner Seele eigentlich ein Poet, haben Sie das noch nicht bemerkt?' [kursiv die Verf.]] ${ }^{389}$

Von der Dostoevskij-Forschung wird anhand von Briefen und anderen biographischen Dokumenten die Ansicht vertreten, daß Dostoevskij die Musik Chopins nicht mochte. ${ }^{390}$ Es ist ebenfalls bekannt, daß die vier Balladen Chopins mit den Werken von Adam Mickiewicz verglichen wurden: Die erste Ballade op. 23 (1836) wurde z.B. Konrad Wallenrod genannt. ${ }^{391}$ Die

${ }^{309}$ Bd. 8, S. 108f. [S. 188]

$390 \mathrm{Vgl}$. Z.B. KJETSAA 1992, S. 233.

${ }^{391} \mathrm{Vgl}$. dazu CORTOT O.J., S. 1. Cortot führ in seinem Kommentar zu den Balladen die Deutung von Laurent Ceillier (1924) an, in der dic vier Balladen ."Titel“ erhalten haben. die erste Bailade op.23 (1836) wurde dabei ('onrud Wallenrod gennant. Siehe zur Figur des Konrad Wallenroxl in der Publizistik Dostoevskijs in: Bd. 26, S. 58 (Innevnik pisulclja =a 1877 god. Okıjabr' 1877. (ilava 3. II. I.einjaja pespyika Sitaroj Pol'š mirı' sja [Tagehuch des Schrifistellers für das Jahr 1877. (Jktoher 1877. Kapıel 3. II. Der sommerliche Versuch des Alten Polens, sıch mul den Russen zu versöhnen (). Vgl. auch die Anm. ebd., S. 381. In diesem Aufsatz lehnt Dostoevskij kategorisch jegliche Versohnungsangebote polnischer Emigranten ab, die Rußland die Zusammenarbeit auf mehreren Gebieten, auch in der Wissenschaft und Kultur, vorgeschlagen haben. Dabei dient ihm die Figur Konrad Wallenrods als ein Beweis dafür, daß alle Polen Verrater wie Wallenrod seien und Rußland mit allen Mitteln Schaden zufügen wollten. Konrad Wallenrexd ist somit für Dostoevskij das Symbol eines heimtückischen polnischen Verräters: .J.../ всё это .лишь нам западня, /.../ наведут они $k$ нам Конралов Ватенродов, предате:лей: /../ по.ляk Старой По.льши инстінктівно, слепо ненавилитт Россию и рycckux“ $\mid / \ldots /$ das alles ist nur eine Falle für uns. /... sie führen bei uns Konrad Wallenrods ein, die Verrăter, /.../ ein Pole des Alten Polens haßt instinktiv, blind Rußland und die Russen|. Vgl. auch Bd. 27, S. 56: Zupisı literuturno-kriıčeskogo , puhlicističeskengo charaktiora $i=$ zapisno] tetradi 1880-1881 gg. [Notizen literarischen, literuturkritıschen und publizistıschen ('harakters aus dem Notızhefi aus den Jahren 1880-1881]): 
Erwăhnung einer der Balladen ist also nicht unmotiviert und deutet darauf hin, daß die von Ivolgin besuchte, aber von ihm „erfundene“ Familie möglicherweise ,propolnische" Sympathien hegt, "ruBlandfeindlich" ist. Der Name des „Bekannten“ Ivolgins, der Sokolovið heißen soll, könnte darüber hinaus auch polnisch sein, was die Tatsache erklaren würde, daß die „antirussische“, "subversive“ Ballade Chopins in diesem Hause gespielt wird. ${ }^{392}$ Der ,zu den Tơnen der Ballade Chopins“ geăußerte „Wunsch“ kőnnte somit der nach der „Befreiung“ Polens und nach dem „Untergang“" Rußlands sein.

Von einem Lügner ${ }^{393}$ erwăhnt, erscheint jedorh diese „polnische“ Anspielung zweideutig. Die ganze Szene dient hauptsächlich dazu, die soziale und menschliehe Degradation Ivolgins und seine "verwestlichte lügnerische Dichternatur" zu zeigen, die sich als seine negative immanente Okzidentalisierung äußert. Es handelt es sich somit um eine ideologische Anspielung auf den „,antirussischen“ Charakter der Musik Chopins, die laut Ivolgin in den Häusern einflußreicher Petersburger, also bereits in der russischen Hauptstadt, gehört würde.

Der General spricht noch einmal über die ..polnischen Ulanen“, die er in Moskau, während der französischen Besatzungszeit 1812 im Gefolge Napoleons gesehen habe: „- Н-нет, Констана тогда не было; /.../ но вместо него два ординариа, несkолько польских улан... ну вот, и вся свита, кроме генералов, разумеется, и маршалов, которых Наполеон брал с собой /.../“ [ N-nein, Constant war damals nicht zur Stelle; /.../ statt seiner zwei Ordonnanzen, einige polnische Ulanen... das war also das ganze Gefolge, außer den Generälen, versteht sich, und den Marschällen, die Napoleon mitnahm /.../: S. 724 [kursiv die Verf.]] 394 Seine Erzăhlung über den „Pagendienst“ bei Napoleon Bonaparte und seine gemeinsamen Ausritte mit dem Imperator, der ihn geliebt habe, dient diesmal dazu, seinen „Mut" und „Patriotismus“ zu zeigen, denn

\footnotetext{
„ИнквIıзітор уж тем однім безнравственен, что в сердце его, в совесті его мог.ла ужиться идея о необходимості сожитать .юдей. /.../ Конрад Валленрод тоже“ [kursiv die Verf.] [Der Inquisitor ist schon allein dadurch unmoralisch, weil in seinem Herzen, in seinem Gewissen die Idee entstehen konnte, daB es notwendig sei, Menschen auf dem Scheiterhaufen zu verbrennen. i... Konrud Wallenrod auch]. Diesen unmoralischen Menschen stellt Dostoevskij Christus als das moralische Vorbild und das menschliche Ideal gegenüber: „Нравственный образеи и идеат есть у меня, дан, Хрістос. Спрашнваю: сжег .ли бы он еретіков - нет. Ну таk значит сжиганне еретіков есть поступок безнравственый". [Das mir gegebene moralische Vorbild und Ideal ist Christus: Ich frage: würde er die Hăretiker verbrennen lassen - nein. Das heißt also, das Verbrennen der Hăretiker ist eine unmoralische Tat. I (ebd.). Es handelt sich dabei um die Polemik Dostoevskijs mit K. D. Kavelin, der in einem offenen Brief an Dostoevskij in Vestnık Livropy [Der Bote Europas] (Nr. II. 188()) ethischen Relativismus und Individualismus vertreten hat.

$392 \mathrm{Vgl}$. zu den Namen der polnischen literarischen Figuren in der russischen Literatur bei (jOL.DGART 1986

${ }^{393} \mathrm{Vgl}$. Bd. 9, S. 253 (aus den Entwūrfen zu den Figuren Ivolgins und Lebedevs) sowie den Kommentar der Herausgeber, ebd., S. 389f., S. 409f:: zum möglichen Vorbild Ivolgins, Fedor Lavrent evic Cholčinskij (gest. 1861), dem Großvater E.A. Stakenšnejder, der ein ..unvergleichlicher Geschichtenerzahler", "Staats-General“" und darüber hinaus ein glühender Verehrer Napoleon Bonapartes war (S. 389f.). Siehe auch MARTINSEN 1995 (über Ivolgin als einen Typ des ..russischen Lügners“).

${ }^{364}$ Bd. 8, S. 410 ff. bes. S. 415 und Bd. 9, S. $454 \mathrm{ff}$.
} 
der junge Page habe Napoleon unter vier Augen die ganze Aussichtslosigkeit seiner Bemuhungen, die Russen für sich zu gewinnen, auch wenn er ihren russisch-orthodoxen Glauben annehmen würde, klar gemacht. ${ }^{395}$

Eine tragische Episode aus der russischen Geschichte wird bei dieser Szene von einem echten Lügner, einem „Narren" asthetisch „verfremdet". Dadurch wird das Pathos der Geschehnisse sowie die "dämonische“"Figur Napoleons, das Symbol des "Bosen“, das aus dem „Westen“ Rußland und seinem Glauben droht, mit komisch-grotesken Zügen versehen. ${ }^{396}$ Es handelt sich aber dabei, ăhnlich wie in der Erwăhnung einer Ballade Chopins, um eine ideologische .antiwestliche“ und zugleich um eine antipolnische Anspielung.

Der General, der sich wegen eines Diebstahls von vierhundert Rubel gerade von seinem Freund Lebedev getrennt hat, erzählt aber diese Geschichte Myškin, um sich durch diese „patriotische“ Lüge zu "rehabilitieren": die Achtung vor sich selbst und in den Augen des Fürsten wieder zu gewinnen. Ivolgin wird im Idiot insgesamt als ein ambivalenter, schwacher, aber sympathischer und „gefallener" Mensch charakterisiert, der den anderen negativ verwestlichten, aber mit einigen „idealistischen" Zügen versehenen russischen Lügnerfiguren Dostoevskijs verwandt ist. ${ }^{397}$

3. Zwei polnische stereotype Figuren treten darüber hinaus im Epilog des Romans auf. Das Schicksal der schơnen und emanzipierten Aglaja Ivanovna Epancina wird mit einem „falschen“ polnischen Grafen sowie mit der katholischen Kirche verbunden. Nachdem Myskin in einen Zustand der endgültigen geistigen Umnachtung und "Idiotie“ versunken und in die Anstalt des Doktor Schneider in die Schweizer Berge gebracht worden ist, ${ }^{398}$ berichtet der Erzähler, daß Evgenij Pavlovic Radomskij in einigen Briefen an Vera Lebedeva das weitere Schicksal Aglajas beschrieben habe:

395 Bd. 8, ebd., S. 415: . ل.../ «Ребеноk! - говоріт он мне вдруг, - kak ты думаешь: ести я прнму правос.тавне и освобожу ваших рабов, пойдут 32 мной руссkıе ити нет?»«Hиkодra!» - всkричал я в негодовании. Напо.еон быт поражен. «В заб.тиставших па-

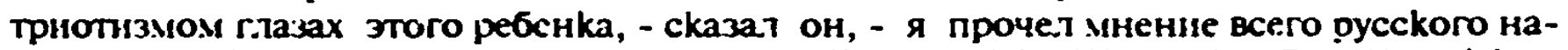
рода. /.../n" | Mein Kind'? wendet er sich plözlich an mich. 'Was meinst Du: Wenn ich zur Orthodoxie konvertiere und euren Sklaven die Freiheit gebe - werden dann die Russen mir folgen oder nicht? '- Nie und nimmer!' rief ich voller Entrüstung. Napoleon ist verblüft. 'In den vor Patriotismus aufleuchtenden Augen dieses Kindes', sagt er, 'lese ich die Meinung des ganzen russischen Volkes: S. 724f.). Ivolgin vertritt also hier, trotz seiner Faszination für Napoleon, die „Stimme“ des ganzen orthodoxen Rußlands.

${ }^{396}$ Moglicherweise handelt sich in dieser Szene auch um einen ..Dialog“ mit L.N. Tot.STOJS Krieg und Frieden |Vojna / mir|, dessen zwei erste Bande 1865-66 in dem Journal Russky ves/nik unter dem Titel , Das .Jahr $1805^{\circ}(1805$ g(x) veroffentlicht wurden (die erste vollstăndige Buchausgabe von V'ojna i mir ist in den Jahren 1868-69 erschienen), in dem die Figur Napoleon Bonapartes ebenfalls eine wichtige Rolle spielt. ..Napoleon" in den literarischen Werken Dostoevskijs ist (als Ideal der negativen verwestlichten russischen Figuren) das Symbol eines rücksichtslosen und gewissenlosen großen Verbrechers. Auch Myškin vergleicht sich an einer Stelle des Romans Idiol mit Napoleon (vgl. auch Bd. 8, S. 354 und Bd. 9, S. 141), so daB diese Anspielung auf seine negative Okzidentalisierung hindeuten könnte.

397 Bd. 8, S. 417ff.

$398 \mathrm{Vgl}$. Bd. 8, S. $508 f$. 
Про нее уведомлял Евгений Павлович в одном довольно нескладном письме из Парижа, что она, после короткой и необычайной привязанности $k$ одному змигранту, польскому графу, вышла вдруг за него замуж, против желания своих родителей, если и давших наkонец согласие, то потому, что дело угрожало kаким-то необыкновенным скандалом. /.../ Всё, чего трепетало семейство, уступая этому графу Аглаю, всё уже осуществилось в полгода, с прибавкой таких сюрпризов, о которых даже и не мыслили. Оkазалось, что этот граф и не граф, а если и змигрант действительно, то с kakoю-то темною и двусмысленною историей. Пленил он Аглаю необычайным благородством своей истерзавщейся страданияни по отчизне дущи, и до того пленил, что та, еще до выхода замуж, стала членом kakoгo-то заграничного колитета по восстановлению Польши и, сверх тото, попала в kатолическую исповедальнью kакого-то знаменитого патера, овладевшего ее умом до исступления. Колоссальное состояние графа /.../ оказалось совершенно небывалым. Мало того, в kakие-нибудь полгода после брака граф и друг его, знаменитый исповедник, успели совершенно поссорить Агльюю с семейством, таk что ее несколько месяцев уже и не видали... [kursiv die Verf.]

[Von ihr berichtete Jewgenij Pawlowitsch in einem ziemlich zusammenhanglosen Brief aus Paris, daß sie, augenblicklich und heftig für einen Emigranten entflammt. einen polnischen Grafen. diesen plötlich geheiratet habe. gegen den Willen ihrer Eltern. die zwar schließlich ihre Zustimmung gegeben hătten. aber nur deshalb, weil die Angelegenheit mit einem ungewöhnlichen Eklat zu enden drohte. /.../

Alles, was die Familie an Schlimmem befurchtet hatte, als sie Aglaja diesem Grafen anvertraute, war im Laufe eines halben Jahres bereits Wirklichkeit geworden. sogar mit solchen zusătzlichen Überraschungen, wie man sie sich nicht einmal hătte trăumen lassen. Es stellte sich unter anderem heraus, daß dieser Graf gar kein Graf war und wenn überhaupt Emigrant, so doch einer mit dunkler und zweideutiger V'orgeschichte. Er hatte Aglaja durch den ungemeinen Edelmut seiner vor Heimweh gemarterten Seele bezaubert, und zwar dermaßen bezaubert, daß sie noch vor ihrer Heirat Mitglied eines ausländischen Komitees, das sich die Wiederherstellung Polens zum Ziel gesetzt hatte. und darüber hinaus noch Beichtkind eines berühmten katholischen Paters wurde. der sie in vollige. an Fanatismus grenzende geistige Abhăngigkeit brachte. Das riesige Vermögen des Grafen /.../ erwies sich als nicht vorhanden. Damit nicht genug, ein halbes Jahr nach der Hochzeit war es dem Grafen und seinem Freund. dem berühmten Beichtiger, bereits gelungen. Aglaja mit der Familie völlig =u entweien, so daß ihre Angehorigen sie seit Monaten nicht mehr zu Gesicht bekommen hatten ... [kursiv die Verf.]] ${ }^{399}$

399 Ebd., S. 509 [S. 888f.]. 
Aglaja wird somit von zwei stereotypen "westlichen" Figuren in Paris, in der Stadt des „Baal" (Zimnie zametki o letnich vpecatlenijach), "verfuhrt". Es handelt sich hier einerseits um das negative Stereotyp des (falschen) polnischen Grafen, der bereits in zwei früheren Werken, in Djadjuskin son und in Igrok vorgekommen ist, sowie andererseits um das Stereotyp eines katholischen Paters, dessen nationale Zugehorigkeit jedoch nicht angegeben wird. Es ist jedoch anzunehmen, daß es sich entweder um einen Polen oder um einen Franzosen handelt, womoglich um einen Jesuiten, denn ein franzosischer Jesuit wird in Idiot als der „Verführer“ des Wohltăters Myškins, Pavlišcevs, zum Katholizismus genannt.

Der gesichtslose falsche polnische Graf ist, entsprechend dem Ort der „Verführung", ein Emigrant, denn die französische Hauptstadt war damals bekanntlich das Zentrum der polnischen Emigration in Westeuropa. Die einzige Charaktereigenschaft des Grafen ist folglich die "Liebe" zum "leidenden Vaterland". Das russische Wort otčizna [отчизна; Vaterland] ist in stilistischer Absicht, anstelle der Bezeichnung rodina [родинa; Heimat, Heimatland], eingesetzt worden, denn es erinnert an das polnische Wort ojc-y=na [Vaterland]. Die „edle, leidende Seele“ des Polen wird aber als moralisch fragwürdig gezeigt, denn er hat eine "dunkle" und "zwielichtige“ Vergangenheit hinter sich, ist daruber hinaus ein Betrüget, so daß das fanatische Engagement Aglajas in einem ausländischen Komitee zur Wiederherstellung Polens als "Besessenheit" und nicht als freie .moralische Tat" gezeigt wird. Der Pole enthăt somit ebenfalls die „dămonische“ Komponente des (altrussischen) Stereotyps des ,Ljachs in der Gestalt eines Teufels". Die stereotypen Figuren des falschen polnischen Grafen und des intrigierenden katholischen Paters gehören also dem (alt)russischen imaginaire social an. Sie weisen wic die negativen polnischen und franzosischen nationalen Stereotypen intertextuelle Bezüge zu den stereotypen Figuren aus der altrussischen Literatur, aus Vel'tmans Roman Salomeja bzw. aus den sogenannten .,antinihilistischen" russischen Romanen des neunzehnten Jahrhunderts auf.

Die „Verführung“ Aglajas schafft darüber hinaus eine doppelte Äquivalenz dieser Figur zu Nastas'ja Filippovna und zu Pavlišcev. Die Okzidentalisienung Aglajas übertrifft aber an Negativităt diejenige von Nastas ja Filippovna, denn sie verliert ihre kulturelle und religiőse russische Identităt vollständig, indem sie von ihrer Moskauer Mutter und ihrer Familie (= Rußland) für immer „abtrünnig" wird.

$100 \mathrm{Vgl}$. die .,antikatholischen“ Äußerungen Myškins als Reaktion auf den angeblichen Beitrit Pavlišcevs zum Jesuitenorden, der der katholischen Propaganda eines französischen Jesuiten zum Opfer gefallen sei, ebd., S. 449f:

.И вот бросает вдрут с.тужбу и всё, чтобы перейти в като.лиинзм и стать иезузтом, да еще чуть ие открытто, с восторгом kakим-то. /.../ Впрочем, вы таk ценіте покойного ... действительно, человек 6ыл добрейший, чему я и приписываю, в г.авных чертах успех этого проддохи Гуро! /.../ они даже претензии по завещанию хоте.іи выставить /... $\mu^{\prime}$. [Und plotzlich quittiert er den Dienst und gibt alles auf, um zu konvertieren und in den Jesuitenorden einzutreten. Und das beinahe öffentlich, wie verzückt! /../ Freilich. Sie schătzen den Verstorbenen sehr hoch... wirklich, den gütigsten Menschen, darauf führe ich ja auch im wesentlichen den Erfolg dieses alten Fuchses |eigentl. durchtriebener Kerl; Erg. d. Verf.] Gouraud zurück. /.../ die wollten sogar das Testament anfechten $/ . . / ;$ S. 784] 
Der „Untergang“ einer der Hauptheldinnen des Romans wird von WACLAW LEDNICKI auf folgende Weise kommentiert:

I have in mind the surprising finale of "The Idiot". How are we to explain the fate of Aglaya [Aglaja] Epancina? She is certainly the most attractive, the most independent and morally strong, the most deeply Russian of all Dostoevsky's feminine figures. How can we explain the fact that Dostoevsky predestined for her a future which, in his own mind, was the worst of all possible degradations? ${ }^{401}$

Für LEDNICKI ist der Epilog des Romans vor dem Hintergrund der antipolnischen Ressentiments Dostoevskijs interessant im Hinblick auf die wichtige Position, die Aglaja im Roman einnimmt: dieser Epilog stelle sich als ein bloßes "Klischee" dar, (wohl ist hier ein narratives Klischee gemeint), wenn man die Episode mit dem faschen Grafen von der Welt der Ideen und Fiktionen Dostoevskijs trennen würde. ${ }^{102}$ Auch in den Werken Turgenevs gebe es solche Episoden mit polnischen Grafen. Der Epilog des Romans könne deshalb, so LEDNICKI, als eine Variante des Turgenevschen Romans Nakanune [Am Vorabend] (1860) interpretiert werden, denn seine Hauptheldin heiratet einen Bulgaren, der für die Freiheit seiner Heimat kămpft. ${ }^{103}$ Nach LEDNICKI wăre es aber ehrlicher von Turgenev gewesen, wenn seine Heldin statt eines Bulgaren einen Polen gewăhlt hätte. N.A. DOBROLJuBOv ${ }^{104}$ habe diese Tatsache in einem Aufsatz über den Roman Turgenevs bemerkt, indem er sich fragt, warum Turgenev keinen Russen bzw. Polen eingeführt habe. ${ }^{405}$ Lednicki vermutet, daß Dostoevskij die Herausforderung Dobroljubovs angenommen und seine sarkastische Lösung des Problems amüsant gefunden habe. ${ }^{106}$ Eine andere Möglichkeit wăre, daß Dostoevskij in Aglaja die schöne Anna Korvin-Krukovskaja portrătierte, um deren Hand er sich beworben hatte. ${ }^{4 \theta 7}$ Korvin-Krukovskaja heiratete aber einen französischen Kommunarden. Victor Jacquelard, der nach der Niederschlagung des Aufstandes zum Tode verurteilt wurde. Für dessen Befreiung mußte ihr Vater den französischen Behörden an die 20000 Francs bezahlen. Die Familie der Korvin-Krukovskij war eine russifizierte polnische Familie aus Weißrußland. ${ }^{400}$

In den Entwürfen zum Idiot gibt es eine Bemerkung: „Arлar convertie“ [Aglaja konvertiert]. ${ }^{409}$ Diese Bemerkung und der Epilog des Romans deuten darauf hin, daß Dostoevskij ihre Abwendung von der russischen Orthodoxie und ihr Fall in den ..katholisch-jesuitischen Sumpf" in der ideologischen Funktion

\footnotetext{
101 Vgl. LEDNICN 1953, S. 286

${ }^{402}$ Ebd. S. 287

103 Ebd.

104 Vgl. DOBrounubov 1952, S. 50.

105 LEDNICKI 1953, S. 287f.

${ }^{106}$ Ebd

${ }^{407}$ Ebd. Vgl. zu Korvin-Krukovskaia Bd. 9, S. 386ff., und Bd. 12, S. 201.

${ }^{100}$ LF.DNICKJ 1953, S. 288.

${ }^{409}$ Bd. 9, S. 242.
} 
als Kritik am „falschen Christentum“ (= Katholizismus) eingefuhrt haben dürte. Der falsche polnische Graf erscheint als ein „Anti-Myskin“, bzw. als eine der Figuren des „westlichen Verführers“, dem sich Aglaja aus Verzweiflung und Protest hingibt, als ein Element des negativen ideologischen Imagothèmes des Westens, der RuBland bedroht.

Aglaja ist eine höhere verwestlichte Tochter aus einem reichen Petersburger Haus: Ihre Gesellschaft, ihre Umgebung setzt sich aus den hochadligen und von den Konventionen dieser Gesellschaft versklavten und größtenteils verlogenen verwestlichten Kosmopoliten zusammen. Sie wird als eine charakterstarke und nach der Befreiung aus der Enge ihrer Welt strebende Frau geschildert, denn sie trăumt von der Flucht ins Ausland. ${ }^{40}$ Die Erfullung ihrer Trăume wird ihr jcdoch zum "Verhängnis", denn sie wird zum "Opfer" eines fremden Verführers. Ihr Schicksal verlauft also parallel zu demjenigen von Nastas'ja Filippovna, die ihrerseits zum Opfer eines verfremdeten, "verwestlichten" Russen geworden ist.

4. Eine mögliche Anspielung auf den polnischen Hochadel ist der Name Radomskij. ${ }^{11}$ Evgenij Pavlovix Radomskij wird als ein russischer Aristokrat geschildert, der sich selbst einen in Rußland „überflüssigen Menschen" nennt und ins Ausland, in den Westen geht. obwohl er im Epilog eine Zuneigung zu der sanften Vera l.ebedeva zeigt und im Briefwechsel mit ihr und mit dem jüngeren Sohn Ivolgins, Kolja, steht, der ebenfalls als ein „vielversprechender“, „guter russischer" Junge geschildert wird. ${ }^{\mathbf{1 2}}$. Bereits der Vomame des Mădchens, Vera [Glaube], deutet auf ihren „(russischen) Glauben“ hin. In den Notizbüchern zum Idiot wird Radomskij Vel'monček genannt, er tritt dort als Verlobter Aglajas und Rivale des Fürsten auf. ${ }^{13}$ Auch dieser Name würde auf die mögliche polnische Abstammung Radomskijs (Vel'moncek) hinweisen. ${ }^{41}$ Radomskij ist jedoch keine dämonische Figur wie beispielsweise Svidrigajlov, denn in ihm wird die Möglichkeit der Rückkehr des russischen Adels zur počva, zur russischen kulturellen Identităt, angedeutet, wobei er auch durch einen gewissen ,liberalen Idealismus" gekennzeichnet ist, ohne daß diese Figur sich jedoch eindeutig als

$410 \mathrm{Vgl}$. Bd. 8, S. 356f.

$411 \mathrm{Vgl}$. dazu BEER 1978, S. 4 und 48.

12 Bd. 8, S. 508 Für BEER 1978 ist die Etymologie dieses Namens, seine Ableitung von der polnischen Stadt Rudom, allerdings nicht sicher.

${ }_{13}$ Vgl. Bd. 9, S. 270ff., bes. S. 274ff., S. 297f., S. 375f., und zum möglichen authentischen Vorbild dieser Figur und ebenfalls seines Onkels, Politkovskijs, der eine große Summe veruntreut und sich deswegen das Leben genommen hatte, ebd., S. 388. Nach der Ansicht KIRPOTINS 1980 ist Nikolaj Strachov als ein weiteres Vorbild dieser Figur zu nennen, so daß der Name Rudomski, der an den Namen der polnischen Stadt Radom erinnert, doch auf den für Dostoevskij verhängnisvollen Aufsatz Strachovs zur polnischen Frage in Vrempu ironisch anspielen könnte, obwohl KIRPOTTN in seinen Ausführungen auf die Bedeutung des Namens .Radomskij“" nicht eingeht.

is4 Vel'monciek klingt dem im Polnischen üblichen Wort wielmoذ̇a (= ein măchtiger, großer Hert) ahnlich, obwohl es eine gemeinslavische Etymologie hat. Das Wort vel moźa kommt in den Äußerungen des „verwestlichten“ Lebedevs vor, Bd. 8, S. 168: „Тут же, в толковании

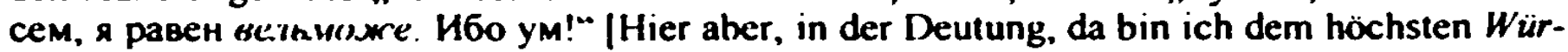
deniräger gleich. Denn ich habe Verstand!; S. 291] [kursiv die Verf.] 
der Typ eines "Idealisten", der den „russischen Schillers" aus den früheren Werken Dostoevskijs ăhnlich wăre, bezeichnen ließe, so daß er wie mehrere Figuren in Idiot ambivalent erscheint.

5. In dem Roman Idiot gibt es außerdem noch ein polnisches Imagem, eine Anspielung auf einen authentischen Polen, Vitol'd Gorskij (Witold Górski). ${ }^{15}$ Gorskij war Gymnasialschüler und Katholik polnischer Abstammung. Er hatte als Hauslehrer im Hause eines Moskauer Kaufmanns sechs Personen ermordet. Vor Gericht hatte er sich als Atheist bezeichnet. ${ }^{116}$ Mit ihm werden der "falsche“ Sohn Pavlišcevs, Antip Burdovskij bzw. auch andere Vertreter der neuen russischen nihilistischen Jugend, u.a. der Neffe Lebedevs verglichen. Burdovskij versucht übrigens, Myskin finanziell zu erpressen. ${ }^{127}$ Das Wort "burda" bedeutet im polnischen ein "Händelsucher", "Krakeeler" bzw. auch "Händel", "Krawall" oder „Krakeel". "18 Der im Roman angeführte Fall Gorskijs ist möglicherweise auch als Kontrast zu einer anderen von My§kin erwähnten Mordgeschichte konzipiert worden: Ein Bauer aus dem Gouvernement der Stadt Myškin hat seinen Freund wegen einer silbernen Uhr getotet, er stellt sich jedoch als ein glăubiger orthodoxer Christ heraus. Gorskij, ein Katholik und Pole, der sich als Atheist bezeichnet und daruber hinaus sein Verbrechen aus politischen Gründen vollbracht haben mochte, wăre eine Art Konrad Wallenrod, ein Verrăter RuBlands. ${ }^{49}$ Die Figuren Burdovskijs und des Neffen Lebedevs verkorpern das negative utopische Imagothème des verwestlichten Rußlands, ohne jedoch den Grad des extremen Dämonismus von Petr Stepanovic Verchovenskij in Besy aufzuweisen. Sie sind mogliche, potentielle Gorskijs bzw. Verchovenskijs.

6. In den Notizbüchem zu der ersten Fassung von Idiot, wird außerdem eine Begegnung des Vorlăufers Myškins und Min'onas (Mignon) ${ }^{\mathbf{4 2 0}}$ mit einem polnischen Soldaten erwăhnt, die ihrerseits als eine Urgestalt von Nastas'ja Filip-

$415 \mathrm{Vgl}$. dazu Bd. 8, S. 214 oder Bd. 9, S. 391-393. Im Roman Idiot werden noch weitere Verbrecher erwahnt, Bd. 9, ebd.

116 Ebd., S. 391.

427 Bd. 8, S. $159 f f$, bes. S. 161, S. $214 \mathrm{ff}$, S. 244

¿18 Vgl. dazu SLAwSKI 1952-1982 (Bd. 1, S. 50: ,burda 'awantura', od XVI. w., pierwotne znaczenie 'zapasy, turnieje" $/ \ldots /, / \ldots /$ archaiczne burda 'zwada, niepokój; niespokojny człowiek' (też słowac. burda 'drażliwy czlowiek"'; [burda 'Abenteuer', seit d. XVI. Jh., ursprüngliche Bedeutung Wettkămpfe, Toumiere" $/ . . . /$; archaisch burda Zank, Handel, Fehde, Unruhe; unruhiger Mensch (auch slowak. burda Teicht reizbarer, empfindlicher Mensch )]); LINDE 1951 (S. 198f, bes. S. 199: „3). Burda, y, m. czlowiek niespokojny, kłótnik, warchol, ein Händelmacher, unruhiger Kopf. /... $\left.{ }^{\circ}\right)$; IPPOLDT o.J. (S. 90: „burd/a, $\left.f[-\mathrm{y},-\mathrm{y}], 1\right)$ Händel, pl: 2) Krawall, $m$. Krakeel, $m$, Randal, $m$ /.../. - burda. $m[-y,-y]$, Hăndelsucher, Krakeeler, $m . "$ SLOVAR ' SOVREMENNOGO RUSSKOGO LITERATURNOGO JAZYKA (Bd. 1., Spalte 695f: „Бурда́, ы, ж. Смесь разных жидкостей; мутный напırтok. /.../ Переносно: путаница, вздор, чепуха“ [Burdá, у. f. Mischung verschiedener Flüssigkeiten; trübes Getrănk. /.../ Übertragen: Durcheinander, Wirrwar, dummes Zeug, Quatsch, Unsinn, Blodsinn].

${ }^{19} \mathrm{Vgl}$. dazu oben, S. 92, S. 118, S. 123ff., S. 298, sowie S. 393.

${ }^{420}$ Diese Figur bezieht sich wiederum auf Goethes Mignons. 
povna bzw. von Mar'ia Lebjadkina aus Besy angesehen wird"21: „Когда Идиот с Минњоной ходят по городу ночью, К ним привязывается отставной солдат-ородяга, полячищка, и не хочет отвязаться". [Während Idiot und Min ona nachts in der Stadt henumlaufen, lăuft ihnen ein pensionierter SoldatLandstreicher, ein Polackchen nach, und will nicht fortgehen. [kursiv die Verf.]] ${ }^{422}$ Es handelt sich also erneut um eine stereotype Figur, um das negative nationale Stereotyp des "Polackchens", das zum ersten Mal in Zapiski iz Mertvogo doma vorkommt, um eine Alter-Figur, die als eine ideologische, antipolnische Anspielung funktioniert: Der "Pole" wird auch hier den „Russen“, wohl in der ,ideologisch-politischen“ Weise, lăstig.

ZUSAMMENFASSUNG: Det Roman Idiot bildet in imagothematischer Hinsicht eine weitere Entwicklung und Differenzierung der in den früheren Werken vorkommenden Imagothèmes, aber in der Weise, daß jede der „zentralen“ russischen Figuren immanent zumindest zwei Imagothèmes repräsentiert. Abgesehen von den sekundaren bzw. "Randfiguren“, sowohl den russischen als auch fremden, weisen alle „Haupthelden“ eine verschwommene kulturell-religiose Identităt auf. Diese Ambivalenz deutet auf den „Übergangscharakter" dieses Romans im Vergleich mit den folgenden Werken hin. In Idiot spiegelt sich eine intensive Suche nach einem ,positiven russisch-orthodoxen Ideal" wider. Die relativ starke negative Okzidentalisienung der zentralen Figuren führt aber zu ihrem "Untergang", so daß im Unterschied zu Prestuplenie $i$ nakazanie der Roman Idiot als ein Werk über den „Tod" ohne eine mögliche oder auch nur eine angedeutete "Auferstehung" (auch im „russisch-orthodoxen Glauben“) zu verstehen ist. Das "westliche“ Bild Holbeins, Der Leichnam Christi im Grabe, weist somit eine zutiefst negative symbolische Bedeutung auf.

In Idiot werden alle fremden Imageme, auch die polnischen, zur Charakterisierung der nussischen Figuren eingesetzt, indem sie den Grad der Okzidentalisierung dieser Figuren, deren Enfremdung von den russischen kulturell-religiösen Traditionen bzw. die durch den westlichen Einfluß eingetretene Pervertierung dieser Traditionen bestimmen. Wegen der psychologischen Diffcrcnzicrung der zentralen russischen Figuren wird es jedoch schwierig, diese Figuren eindeutig als positiv bzw. negativ zu bezeichnen, denn sie weisen keine ausgeprägte kulturell-religiöse russische Identităt auf. Es läßt sich bei ihnen, je nach der Intensităt des Vorkommens der positiven oder negativen Eigenschaften, die teilweise mit dem Grad ihrer (positiven oder negativen) Verwestlichung zusammenhängen, eine Dominanz der „guten“ oder der „schlechten“ Charakterzüge beobachten. Aus dem Kontext der Handlung und aus der Erzählperspektive läßt sich aber schließen, daß als positiv einerseits die russisch-orthodoxe bzw. russisch-byzantinisch religiose Tradition der vorpetrinischen Herkunft suggeriert wird, auch nur als eine Sehnsucht nach dem (russisch-orthodoxen) Glauben, andererseits, jedoch mit Vorbehalt, ebenfalls der utopisch zu nennende westliche "Idealısmus" als positiv gilt, der in den früheren Romanen durch dic "verwestlichten Idealisten" (die "russischen Schillers") vertreten wird. Auch in dem

${ }^{421} \mathrm{Vgl}$. Bd. 9, S. 145 und S. $340 f$

122 Ebd., S. 145 
Roman Idioı låßt sich dabei eine weiterhin zunehmende positive bzw. negative Stereotypisienung der Figuren beobachten, die vom Grad ihrer Wichtigkeit für die Haupthandlung abhángig ist, was besonders in den fremden Figuren, die alle stereotyp sind, ausgeprägt ist.

Die fremden Imageme treten dabei wie in den oben besprochenen Werken in zwei Funktionen auf:

1. Als fremde Figuren (zu denen entweder Bewohner von Westeuropa oder in Rußland lebende Fremden gehören), als vorwiegend negativer Kontrast zu den russischen Figuren (als alter) und zugleich als deren Charakterisierung, wobei sie als ethnische bzw. nationale Stereotypen, auch literarischer Herkunft, d.h. als Elemente des imaginaire social zu bezeichnen sind. In dieser Kontrastfunktion sind sie vorwiegend ein Teil des negativen ideologischen Imagothèmes des „Westens“ bzw. des „verwestlichten Rußlands“. Zu den negativen nationalen bzw. ethnischen stereotypen Figuren gehören hauptsächlich die Figuren der Petersburger Deutschen, der Juden und der Polen.

Die ,guten Schweizer" aus den Erzählungen Myškins (Doktor Schneider, Marie und die Kinder), in ihm ,immanent" vorhanden, sind dagegen ein Teil des positiven utopischen Imagothèmes des "Westens" und werden den "bosen" (protestantischen) Schweizern gegenübergestellt, die einen Teil des negativen ideologischen Imagothèmes des „Westens“ bilden.

2. Die weiteren fremden Imageme, die u.a. mit Myškin, Rogožin oder mit Ippolit zusammenhängen, die Stadt Lyon sowie Frankreich mit seinem ,barbarisehen" Gerichtswesen und das Bild Holbeins, die „Jesuiten" und der „Papst", "Napoleon Bonaparte" und .,Rothschild" sind dagegen ausschlieBlich Elemente des negativen utopischen Imagothèmes des „verwestlichten Rußlands“, Symbole des „Bösen", das Rußland bereits teilweise überflutet hat. Sie dienen zur negativen utopischen Charakterisierung der verwestlichten russischen Figuren des Romans.

Im Roman Idiot überlappen sich wie in den bisher besprochenen Werken die ideologische und die utopische Funktion der fremden Imageme, darunter der fremden Figuren, u.a. der polnischen, die zugleich als alter und alius auftreten können, beispielsweise in den jüdischen Figuren bzw. in den antikatholischen Anspielungen auf die Jesuiten.

Die Figur Myškins weist sowohl die (utopische) Bindung an die (alt)russischbyzantinische, "vorpetrinische" Tradition als auch die positiven utopischen westlichen Charakterzüge auf. Seine verschwommene kulturell-religiöse Identität verleiht ihm den .,numinosen“ Charakter als eine Alius-Figur. Sein „Untergang“ im „Westen“ läßt sich womöglich als Ergebnis der gescheiterten Suche Dostoevskijs nach einem ,russischen Ideal" bezeichnen, das noch (relativ) ,zu“" viele "westliche Vorbilder" hat, d.h. mehrere intertextuelle Bezüge zu den "westlichen“ literarischen Figuren aufweist. Aber trotz der .,dunklen, westlichen" Seiten, die Myškin mit Rogožin und mit den anderen Figuren des Romans teilt, vereinigt er das positive utopische Imagothème des (orthodoxbyzantinischen) vorpetrinischen Rußlands mit dem positiven utopischen Imagothème des verwestlichten Rußlands. Er ist somit in imagothematischer Hinsicht eine .,hybride“, schwankende Figur. 
In det Figur Rogožins dominieren dagegen das negative utopische Imagothème des verwestlichten Rußlands und das negative Imagothème des pervertierten (alt)russischen, weil bereits teilweise verwestlichten Rußlands (als das Erbe des sektiererischen und negativ verwestlichten Vaters, eines russischen Kaufmanns). In ihm ist das kulturelle altrussisch-byzantinische Erbe der Mutter, einer "Gottesnärrin“, nur als eine Sehnsucht nach dem „Ideal“ bzw. nach dem "russischen Glauben" vorhanden, die er mit Nastas"ja Filippovna teilt. Auch in Nastas ja Filippovna und in Aglaja. den Opfern der "verwestlichten russischen“ brw. "westlichen" Verführer, überwiegen die negativen westlichen Einflüsse, das negative utopische Imagothème des verwestlichten Rußlands, die sich in dem Verlust ihrer religiösen und kulturellen russischen Identităt äußern und durch das Schwanken Nastas ja Filippovnas zwischen Myškin und Rogožin und durch Aglajas Heirat mit dem polnischen falschen Grafen symbolisiert werden. Ähnlich aufgebaut sind auch weitere verwestlichte Figuren wie beispielsweise Ippolit, Ganja Ivolgin, Lebedev, General Ivolgin und General Epančin bzw. die episodischen Figuren der Nihilisten, darunter Burdovskij, in denen die negative Verwestlichung Oberhand gewonnen hat. In den Figuren der Generalin Epancina sowie in den zwei anderen Schwestern Aglajas überwiegen dagegen positive Eigenschaften, sowohl russische als auch idealistisch westliche, die sich besonders bei der Generalin in deren Ähnlichkeit und Verwandtschaft mit Myškin àußert. In der Figur Radomskijs dominiert dagegen das positive utopische Imagothème des verwestlichten Rußlands, so daß er durch seine im Epilog angedeutete Zuneigung zu Vera Lebedeva bzw. durch die Freundschaft mit Kolja Ivolgin seine verlorengegangene russische Identität wiedererlangen könnte.

Die polnischen Imageme treten im Roman Idiot ebenfalls in den oben genannten zwei Funktionen aut. Die polnischen Figuren, die episodisch in einem Zusammenhang mit den Figuren Rogožins, des Generals Ivolgin und Aglajas vorkommen, charakterisieren diese Figuren einerseits als negativ ,.verwestlicht“, sind ein 7eichen ihrer moralischen Ambivalenz. bzw. Z.weideutigkeit, d.h., sie sind Elemente des negativen utopischen Imagothèmes des verwestlichten Rußlands, sie bilden aber zugleich (als alter) einen Kontrast zu diesen Figuren. In dieser Funkiiorı dienen sie darüber hinaus auch als antipolnische idenlogische Anspielungen.

Der "Pole“" in der Gruppe um Rogožin ist ein negatives nationales Stereotyp, der falsche polnische Graf und sein Beichtvater sind nicht nur nationale, sondern darüber hinaus literarische Stereotypen. Die polnischen (wie die französischen) Imageme in den Geschichten des Generals Ivolgin charakterisieren ihn ebenfalls als einen verwestlichten Russen. der das Böse aus dem Westen immanent ... in sich trägt", sie werden aber in seinen poetischen Fantasien bzw. Improvisationen durch seinen lügnerisch-komischen und patriotischen Kontext „verfremdet." Auf diese Weise wird die in diesen Szenen enthaltene Ideologie entschärft und gewinnt eine humoristische liärbung.

In den riguren Burdovskijs und anderer "Nihilisten”, dic als Atheisten und potentielle Mörder, als „Gorskijs“, geschildert werden, verbirgt sich ebenfalls das ,Böse aus dem Westen"., das jederzeit zum Ausbruch kommen könnte. Gorskij ist in diesem Zusammenhang ein verstecktes Symbol des ..Bösen“, des 
Verrăters Konrad Wallenrod bzw. einer der spateren sogenannten „Teufel" bzw. "Dămonen" [besy; бecu] ], die Rußland zugrunde richten wollen. Sie erfüllen wie Tockij, der Verfuhrer Nastas ja Filippovnas, eine ..todbringende“, destruktive Rolle. Diese polnischen Imageme bilden also einen Teil des negativen utopischen Imagothèmes des verwestlichten Rußlands. Lediglich die relativ positive Figur des liberalen russischen Adligen Radomskij bildet, trotz seines ,polnischen" Namens (dessen Etymologie sich übrigens nicht eindeutig auf die polnische Stadt Radom zurückführen läßt) eine Möglichkeit der Heilung bzw. seelischen Emeuerung Rußlands, denn die Figur Radomskijs weist einige „idealistische" Elemente des positiven utopischen Imagothèmes des verwestlichten Rußlands auf.

In Idiot treten somit folgende polnische Imageme auf:

1. das negative Stereotyp des "scharwenzelnden Polackchens“, eine Variante dieses Stereotyps aus den früheren Werken:

2. der Name "Chopin“ und eine seiner Balladen als ein Symbol der „negativsubversiven" Okzidentalisierung der"Petersburger Gesellschaft und Rußlands. Der polnische Komponist wird spăter noch einmal im Roman Besy im Zusammenhang mit dem „verwestlichten“ Schriftsteller Karmazinov genannt werden;

3. die ,polnischen Ulanen“ im Gefolge Napoleons erinnern an die Besetzung Moskaus im Jahre 1812, somit an die "lebensgefahrliche" Bedrohung Rußlands und seines Glaubens durch den „Westen“;

4. das negative Stereotyp des „polnischen faisclıcil Gïüen" äs "ncisuivilu Verführer" bildet eine Variante des "teuflischen Ljachs";

5. der Pariser Beichtvater dieses Grafen ist möglicherweise ein polnischer Jesuit in der gleichen Funktion als „Verführer" zum „falschen Christentum":

6. die Figur Burdovskijs als eine versteckte Anspielung auf den polnischen (atheistischen) Mörder Gorskij;

7. die Figur Radomskijs als eine Anspielung auf N.N. Strachov und als ein Symbol der Okzidentalisierung des russischen, sonst vorwiegend .,positiv“ geschilderten. liberalen Adels (als ,überflüssige Menschen“). 


\section{0. ВЕЧНЫЙ МУЖ. РАССКАЗ (1870) \\ [DER EWIGE GATTE. ERZÄHLLING] ${ }^{43}$}

Večnyj muz (1870) ist in Dresden, unmittelbar nach der Veroffentlichung des Romans Idiot und vor Beginn der Arbeit an Besy enstanden. Diese „Gelegenheitsarbeit" für die Zeitschrift N.N. Strachovs Zarja [Die Morgenröle] enthält besonders viele imagothematische Bezugge zu Zimnie zametki o letnich vpecatlenijach und zu Zapiski i $i$ podpol'ja, obwohl ihr "Sujet“ bzw. ihre „Geschichte" (Karlheinz Stierle) auch mehrere "russische" und "fremde" (,westliche") Vorbilder haben soll. ${ }^{24}$

Die Handlung der Erzăhlung spielt in Petersburg und teilweise in den umliegenden Erholungsorten, was an die Romane Idiot und Prestuplenie i nakazanie sowie Zapiski i podpol'ja erinnert. Die „Vorgeschichte" und der "Epilog" finden dagegen in der russischen Provinz statt.

In Večnyj muz treten nur wenige Figuren auf, wobei alle als „verwestlicht" zu bezeichnen sind. Alle Figuren weisen sowohl positive als auch negative Eigenschaften auf, sind nicht nur psychologisch äußerst differenziert gestaltet, sondern auch aus imagothematischer Sicht "labil“.

Durch eine besonders deutliche psychologische Ambivalenz ${ }^{425}$ zeichncn sich die beiden zentralen männlichen Figuren dieses „Eifersuchtsdramas“ aus: der „ewige Gatte" aus der Provinz, Pavel Pavlovic Trusockij ${ }^{426}$, und sein Petersbur-

${ }^{123}$ Die deutschen Übersetzungen russischer Zitate aus Večny mü werden nach der Ausgabe DOSTOJEWSkl 1959, S. 219-427 (I)er ewige (jatle), angefühn

${ }^{124} \mathrm{Vgl}$. Bd. 9, S. 469ff. zur Entstehungsgeschichte von V'ényj mü und zu den authentischen und fiktiven Vorbildern der Figuren Trusockijs und seiner Frau, Vel' Caninovs, der Familie Zachlebinins und des "Nihilisten" Lobovs, zu denen u.a. der Arzt Dostoevskijs, S.D. Janovskij und seine Frau A.I. Subert, die Geliebte A.E. Vrangel's, Ekaterina I. Gerngross, der Stiefsohn Dostoevskijs Pavel A. Isaev bzw. die Figuren Molières, Flauberts oder Turgenevs (bes. zu den Figuren in seiner Komödie l'rovincialka) gehören sollen; auch zu den Bezügen von Večnyj mú zu Paul de Kocks Roman la femme. le marı et l'amant (1830) bzw. zu den Werken anderer franzosischer Schriftsteller, u.a. zu A. Dumas (Fils). Dostoevskij hat wie in Zimnie zamelkı o letnich vpeciallenıach (1863) und in der fruhen Erzăhlung ( üuja ̇enu I mü pexl krovat ju (Proissestvie neohyknovennose) (Die fremde lirau und der I:hemann unter dem Bell (Eine ungewöhnliche Begehenhe't)] (1848) die franzosischen Autoren parodiert sowie die verlogene franzosische bürgerliche Moral kritisiert, ebd., S. 476ff.

25 KLUGE 1992 bemerkt zu den Figuren von V'ečnyj mü und der Komodie Turgenevs Provmcialka, deren Sujet Dostoevskij ubernommen hatte: ,.['rovincialka ist] eine psychologische Studie: eine ironisch dargebotene Dreiecksgeschichte unter oberflachlichen, an der Mode und an den geltenden Konventionen orientierten Zeitgenossen. /.../ Dostoevskij hat das Sujet /.../ zum Vorwurf genommen, daraus aber /.../ ein ungleich problematischeres Eifersuchtsdrama geschaffen. Aber dafür /.../ psychologisch anders veranlagte Romanhelden konzipiert, an denen Turgenevs bewußt eindimensionale Durchschnittstypen gar nicht gemessen werden konnen" (S. 34f.).

126 Der Name Trusockij läßt sich auf die russischen Worte trus bzw. trusost' [mpyc, mpycocmb; Feigling bzw. Feigheit. Kleinmut] zurückführen. Diese Figur ähnelt Aleksej

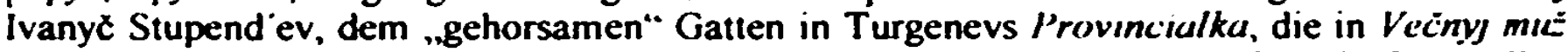
.aufgeführ" wird. Trusockij trăgt aber, trotz seiner Glatze, keine Perücke wie Stupend"ev 
ger Rivale, Aleksej Ivanovic Vel'caninov. ${ }^{47}$ Die Figur der verstorbenen Frau Trusockijs, Natal'ja Vasil 'evna, ${ }^{128}$ kommt nur in den Erinnerungen Vel 'Caninovs vor. Weil aber in Večmyj mü nur das ,innere Leben“ Vel' Caninovs genauer gezeigt wird, erscheint die "Psyche“ Trusockijs und seiner Frau, ihre Gedanken und Gefühle, aus seiner (voreingenommenen) Perspektive gesehen rătselhaft und widersprüchlich zugleich.

In diesen drei zentralen Figuren dominiert, wie in dem „leberkranken" Protagonisten in Zapiski iz podpol'ja, das negative utopische Imagothème des verwestlichten (,Petersburger") Rußlands. In Večnj'j mü fehlt dagegen, abgesehen von einigen "christlichen Anspielungen" in den moralischen Reflexionen Vel'Caninovs, das (positive) utopische Imagothème des orthodox-(byzantinischen) Rußlands, das bereits in Prestuplenie i nakazanie und in Idiot eine relevante Rolle gespielt hat. Obwohl Vel'caninov die Frau Trusockijs, Natal'ja

(vgl. dazu oben, S. 152, Fußnote 56). Er ..entbloßt sich" also, statt sich wie die .verwestlichte" Figur Turgenevs (und die vorwiegend ..negativ verwestlichten" russischen Figuren bzw. die Polen Dostoevskijs) zu „verkleiden“, zu .,maskieren“, was als eine „positivrussische" Eigenschaft zu bewerten ist. Seine hohe Fistelstimme kann danüber hinaus als eine versteckte Anspielung auf Turgenev selbst verstanden werden, der eine solche Stimme hatte und auch im nächsten Roman Besy als Karmazinov karikiert worden ist (vgl. unten, S. 337ff.). Vel'zaninov nennt Trusockij zunächst einen ,zahmen Typ“ des „ewigen Gatten“. Nach dem Tode seiner Frau verwandelt sich aber dieser in emen rachsüchtigen .,Raubtier-Typ“, so daß die beiden Figuren ihre Rollen tauschen. Das erklän auch, warum seine Frau ihm damals nicht erlaubt hatte, die Rolle Stupend'evs zu spielen. Vgl. dazu Bd. 9, S. 18ff., S. 22ff. bzw. S. 47 und S. 55 sowie den Kommentar zu den Bezügen zu Turgenevs Stück und zur Polemik Dostoevskijs in Vecinyj muz mit der von N.N. Strachov vorgeschlagenen Aufteilung literarischer Figuren (nach A.A. Grigor 'ev) in zwei Typen: den "Raubtier-Typ"

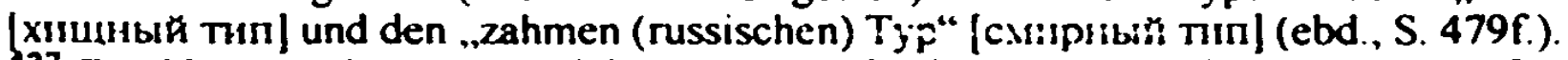

${ }_{27}$ Der Name Vel 'Caninov spielt dagegen auf scine ungewôhnliche .Korpergroße“, d.h. auf seinen hohen Wuchs, an (velıkı] [велukuü, groß] bzw. velıkan [велukaн, Rıese]). Turgenev war bekanntlich ein .großer" Mann, so daß diese Anspielung ebenfalls auf ihn hindeuten mag. Vel'zaninov hat die gleichen Vor- und Vatersnamen wie Stupend'ev (Aleksej Ivanovič), wodurch die Relativität der Aufteilung in "Typen" hervorgehoben wird. Äußerlich ist er den ..dämonischen" Alıus-Figuren, dem Fürsten Valkovskij und Svidrigajlov, ähnlich. ohne deren .dämonisch-böse" Charaktereigenschaften aufzuweisen. Er leidet darüber hinaus an Leberbeschwerden wie der ..Mensch aus dem Untergrund" und wie der Erzähler aus Zimnıe =ameıkı 0 leInich vpecallenyach. Vel caninov weist aber auch einige positive Eigenschaften auf, wird von Gewissensbissen gequălt, obwohl er sie eine ..Krankheit" nennt, und ist ..liebesfahig“". Er ist somit eine ambivalente, weil zugleich negativ und positiv verwestlichte Alius-Figur, vgl. dazu ebd. S. 5ff. (die Charakterisierung Vel čaninovs und die Erwăhnung seiner inneren "Spaltung“ (раздвогімость)), S. 12 und passim (über seinen „galligen“ Charakter), S. 39 (über die Freundschaft Vel 'caninovs mit der Familie Pogorel 'cev, in der seine Güte und Geradlinigkeit bzw. Ehrlichkeit zum Vorschein kommen) oder S. 72f. (sein weitmännisches Benehmen im Hause der Zachlebinins) bzw. S. 107 (seine Gleichgültigkeit dem Schicksal Rußlands gegenüber und seine plötzliche „Verjüngung”, nachdem er die materielle Sicherheit wiedergewonnen hat und sich wieder taglich ..ein feines und schmackhaftes Mittagessen" leisten kann). Vel'Caninov bezeichnet sich selbst und Trusockij als ..подпольные, гадкне люди“" [..lasterhafte, untergründige, garstige Menschen“; S. 380], (ebd., S. 87). Siehe zu Zimnie zumetki o leinich vpeciatlentjuch, oben S. 227 und S. 239.

${ }^{28}$ Diese Figur erinnert an die stereotypen Franzosinnen in Zimnic zamelkı o lelnich vpeciallenijach, vgl. oben S. 238f. und Bd. 9, S. 26. 
Vasil'evna, mit einer „хлыстовская богородица“ [einer „Gottesmutter der Chlysty", der Flagellanten] vergleicht, weist diese "verwestlichte Dame" aus der „besseren" Provinzgesellschaft keine Beziehung zum „russischen Volk“ auf. Diese Bezeichnung bezieht sich somit auf ihren besonderen, „russischen" Charakter:

„/.../ она была kak «хлыстовсkая богородица», kоторая в высшей степени верует в то, что она и в самом деле богородиша, - в высшей степени веровала и Наталья Васильевна в каждый из своих поступkов". [Sie war /.../ wie die Gottesmutter der Geisslersekte, die unerschütterlich daran glaubt, daß sie tatsăchlich die Gottesmutter sei; - so ahnlich glaubte auch Natalja Wassiljewna an die Richtigkeit all dessen, was sie tat.] $]^{429}$

Bei dieser Stelle handelt sich somit einerseits um eine kritische Anspielung auf das ..pervertierte falsche Christentum" dieser russischen Sekte; andererseits erscheint aber Frau Trusockaja im Vergleich mit ihren "westlichen Vorbildern“, besonders mit den in Zimnie zametki o letnich vpečatlenijach erwăhnten (stereotypen) Französinnen, viel „positiver", „edelmütiger“, denn sie glaubt an ihre "Unschuld“, wodurch sie den „bewußt verlogenen“ Französinnen überlegen, weil ehrlich und ,natürlich" ist. ${ }^{430}$

In Vecrnyj muz treten noch einige weitere, „sekundăre“ russische Figuren auf. $\mathrm{Zu}$ ihnen gehoren zwei Petersburger „Beamtenfamilien“. Eine von ihnen, die Zachlebinins, wird durch das „Vorkommen“ der Vertreter junger russischer "Nihilisten" und "Nihilistinnnen" bzw. durch ihre Kontakte zu ihnen als teilweise „negativ verwestlicht" charakterisiert. ${ }^{131}$ Erwähnt wird darüber hinaus ein Petersburger Beamter, der an „Nervenfieber" gestorbene Stepan Michajlovic Bagautov, ${ }^{432}$ der "letzte Nachfolger" Vel'caninovs in T., nachdem Vel'caninov „kak старый, негодный башмаk“ [„wie ein alter abgetragener Pantoffel“; S.

${ }^{29} \mathrm{Vgl}$. Bd. 9, S. 27 [S. 263]

${ }^{430} \mathrm{Vgl}$. oben, S. $238 \mathrm{f}$

431 Der Verlobte Nadjas, Aleksandr Lobov, bezeichnet sich selbst als einen enttåuschten ..Slavophilen“, der ein "Westler" geworden sei, weil es keine Russen gebe, die als moralische Autorităt gelten kónnten: „Быть гражданином - .уучше высшего обшества. /.../ в наш век в России не знаешь, kого уважать. Cor.ласітесь, что это ситьная бо.тезнь веka, korда не знаешь, кого уважать, - не правда .nı? /.../ прежде, давно уже, я бы.т чистый с.тавянофіц] по убеждениям, но теперь мы ждем зари с запада..." [Staatsbürger sein ist mehr wert als die ganze höhere Gesellschaft. $i . . /$ man [weiß] heutzutage in Rußland nicht, wen man achten soll. Sie müssen doch zugeben, daB das eine schlimme Zeitkrankhelt ist, wenn man nicht weiß, wen man achten soll, nicht wahr? /.../ früher, das ist schon lange her, da war ich ein |reiner; Erg. d. Verf.] Slawophile, in meinen Überzeugungen; doch jetzt, jetzt erwarten wir die Morgenröte aus dem Westen...: S. 413f.|. Nadja Zachlebinina teilt seine Ansichten, ist eine ..Nihilistin”, d.h. eine verwestlichte Figur. Sie wird auch demenstprechend als ein .Teufelchen"|hesenok: бесеноk| beschrieben Vgl. Bd. 9, S. 71.

${ }^{432}$ Der verwestlichte Petersburger Bagautov ist eine komplementäre bzw. aquivalente Figur zu Vel 'aninov. In dem in T. aufgeführten Stück Turgenevs spielt er die Rolle des Grafen Ljubin, des ".mißglückten Verführers“. Erwăhnt wird darüber hinaus nur seine .literarische Betătigung" sowie sein plötzlicher Tod und feierliches Begräbnis, an dem Trusockij teilnimmt, vgl. ebd S. 22ff., S. 29, S. 46f. und S. 51. 
$262]^{433}$ von Frau Trusockaja "fortgeworfen“ wurde. Eine wichtige, "kathartische" Rolle fur Vel'Caninov fallt in der Handlung der Figur der "Tochter" Trusockijs Liza zu. ${ }^{434}$

In Večnyj mü kommen, trotz der Okzidentalisierung aller Figuren, nur wenige fremde Imageme vor. Trusockij wird von $\mathrm{Vel}^{\prime}$ Caninov ironisch, aber auch aus einem gewissen Neidgefühl als "Schiller" bzw. "Quasimodo“ bezeichnet. Aus der Sicht des eitlen Petersburger Rivalen und „Ästheten“ wird der „provinzielle naive Idealismus“ Trusockijs durch die Hervorhebung seiner „ăußeren Haßlichkeit“ entwertet. Paradoxerweise wird dabei Trusockij wegen seiner „âsthetischen Empfindlichkeit" verurteilt. ${ }^{435}$

$433 \mathrm{Vgl}$. Bd. 9, S. 29.

434 Liza ist eine der positiven Figuren in Večnyj muz. Ihr Name schafft Bezüge zur Figur der Prostituierten Liza in Zapiskı I podpol'ja sowie zu der ,armen Liza“ Karamzins. Sie verkorpert den Typ des leidenden, .zu Tode gequătten Kindes“ [замученный ребеноk], denn sie wurde zuerst von Trusockij geliebt, dann aber, aus Eifersucht auf seine Frau, gequălt und "verstoßen", so daß er sie Vel '̌aninov, ihrem natürlichen Vater, „überlassen" hatte (vgl. ebd., S. 41, S. 49 und S. 62f.).

${ }^{435} \mathrm{Vgl}$. ebd., S. 102f, z.B. folgende Überlegungen Vel Caninovs: „Этот Квaзиsоdo uз $T$. слишком цостаточно был глуп и благороден дтя того, чтоб вшюбнться В .побовника своей жены /../. /.../ И нменно с таkим ШІиллером в образе Квазимодо II мог.то это пронзойти! /.../ Квазиноды .тюбят зстетіky, ух .любят! /.../ To.1bko у таkoro Квазинаdo и могла зародиться мыс.ть о «воскресении в новую жизнь» - посредством невинності мадемуазе.ль Захтебининой!/... Он меня из б.лагоговейного уважения ко мне повез и в б.лагородство чувств монх веруя, /.../ что мы / ... / обнимемся и заптачем, неподатеkу ot yeem!!!ocmi" [kursiv die Verf.] [S. 408ff: $/ . . /$ dieser Quasimodo aus T. war dumm genug und in seinen Voraussetzungen anständıg genug, um sich in den Liebhaber seiner Frau zu verlieben $/ . . . /$. . / und gerade bet solch einem Idealisten im Schillerschen Sinne. in der Gestalt eines (Duasimodo, [eigentl. mit einem Schiller in der Gestalt eines Quasimodo; Erg. d. Verf] war das móglich! /... Solche Quasimodi lieben Ästhetik, oh, und wie! /.../ nur in einem solchen Quasimodo konnte der Gedanke entstehen, durch die Unschuld einer Mademoiselle Sachlebinin zu einem "neuen Leben aufzuerstehen“! /../ er hat mich in ehrfurchtsvoller Hochachtung meiner Person und im festen Glauben an die Anständigkeit meiner Gefühle hingeführt, $i . .$, daß wir uns dort $/ . . /$ in der Nahe der Unschuld in die Arme sinken und miteinander weinen würden' [ kursiv die Verf.]]. Vel 'Caninov nennt auch nochmals Trusockij und den "nihilistischen" Verlobten von Nadja Zachlebinina "Llluлnept - nоэmo" [ihr SchillerianerDichter; Rahsin. S. 413; eigentl. ihr Schillers, ihr Dichter; Erg. d. Verf.]. ebd., S. 105. Trusockij zitient auch selbst die „Trojanische“ Ballade Schillers (IDas Siegesfest) in der Übersetzung Zukovskijs (vgl. ebd., $\not$ S. 44 und die Anmerkung S. 483). In Zuptskı $I$ Merrvogo doma wird allerdings das .menschliche Monstrum“, der Denunziant A-v, .,ein sittlicher Quasimodo" genannt (vgl. dazu oben. S. 168). Trusockij weist ebenfalls wie A-v einige "dämonische“ Züge (als potentieller Mơrder aus Eifersucht) auf, so daß er (wie der Verlobte Nadjas, Anhănger der ..neuen Ideen aus dem Westen“) kein ..purer Idealist", kein ..Schiller" und somit keine eindeutig ,positiv-verwestlichte Alius-Figur" ist. Vgl. auch die Anmerkung zur Hochschătzung von Victor Hugos Nolre-Dame de Parıs. $I \$ 82$ (1830) durch Dostoevskij, der darin die „Hauptidee der Kunst des neunzehnten Jahrhunderts“ - „восстановленне nогибшего человека“ [..Die Erlosung eines gefallenen Menschen"] gefunden zu haben glaubte, ebd., S. 482. Diese .Idee" verkorpert aber bei Hugo gerade der ...sittlich“ schóne und gute, aber ăußerlich „,hảßliche“ Glöckner Quasimodo. 
Außer „Schiller" werden daruber hinaus solche „positiv-utopische westliche“ Imageme wie „Dickens" und „Haydn“ erwăhnt. ${ }^{436}$ In Večnyj muz kommen mit Ausnahme einer einzigen fremden Figur, eines (deutschen) Arztes namens Koch, ${ }^{437}$ aberhaupt keine fremden Alter-Figuren vor.

Das einzige, obwohl latent vorhandene polnische Imagem tritt in Vecrnyj muz im Zusammenhang mit der Figur Vel'caninovs auf. Es handelt sich um eine Szene der Erzahlung, bei der er ein Lied Glinkas nach dem Gedicht Do D.D. (Moja pieszczotka...) [An D.D. (Mein Turteltäubchen...)] (Odessa 1825) von ADAM MICKIEWICZ vorsingt, wobei jedoch der Name des polnischen Dichters nicht genannt wird. ${ }^{438}$

Vel ' Caninov will durch dieses Lied Nadja beeindrucken, um sich an Trusockij zu răchen, der sich seinereits nach der Enttăuschung in der Fhe um dieses fünfzehnjăhrige „unschuldige“ Mădchen bewirbt:

Вельчанинов выбрал один, почти никому теперь не известный романс Глинки:

Когда в час веселый отkроешь ты губки

И мне заворkуешь нежнее толубки...

Он спел его, обрашаясь к одной только Наде /.../. /.../ Этот романс Вельчанинову удалось слышать в первый раз лет двадщать перед этим, когда он был еше студентом, от самого Глинки /.../.

Чтобы пропеть эту маленькую, но необыkновенную вешицу, нужна была непременно - правда, непременно настоящее, полное вдохновение, настоящая страсть или полное поэтическое ее усвоение. /.../ Вельчанинов /.../ почти усвош манеру пения Глинки; но теперь с первого же звука, с первого стиха и настоящее вдохновение зажглось в его душе и дрогнуло в голосе. /.../ и когда он допел, сверкаюшим взглядом обращаясь $\mathrm{k}$ Наде, последние слова романса:

Tеперь я смелее гляжу тебе в очи,

Уста приближаю и слушать нет мочи,

Хочу целовать, целовать, целовать!

Хочу целовать, целовать, целсвать! -

то Надя вздрогнула почти от испуга /.../ и в то же мгновение kak бы что-то отзвывчивое промелькнуло Вельчанинову в застыдившемся и почти оробевшем ее личике. [kursiv d. Verf.]

[Weltschaninoff wăhlte ein /.../ jetzt schon fast ganz vergessenes Lied von Glinka:

436 .Dickens“ wird im Hause Trusockijs in T. vorgelesen (vgl. ebd., S. 29), ein Klavierstück Haydns dagegen von der gutmütigen. sanften Katerina Zachlebninina für Vel 'caninov gespielt (ebd., S. 73f.).

437 Ebd.. S. 46 (Koch ist der Hausarat von Frau Trusockaja in T.).

${ }^{43}$ Nach der Niederschlagung des polnischen Aufstandes von 1830/31 durfte in Rußland aufgrund der Zensur der Name des polnischen, .rußlandfeindlichen“ Dichters nicht im Druck genannt werden. Er wird somit auch in den Werken Dostoevskijs nicht explizit erwăhnt. Vgl. ADAM MICKEVIC V RISSSKOJ PECAT, S. 4f, sowie den Aufsatz der Verf:: SWIDERSKA 1999b, S. 268f. Siehe ferner: MickIEwICZ 1955c, .S. 225f. Dieses Gedicht ist 1825 in Odessa entstanden 
„Wenn du vor mir stehst und zu mir sprichst..." [Wenn du in einer fröhlichen Stunde das Mündchen aufmachst / und anfangst, zu mir zartlicher als ein Täubchen zu gurren...; Erg. d. Verf.]

Wahrend des Vortrages wandte er sich ausschließlich an Nadja /.../. /.../ Dieses Lied [diese Romanze] hatte er als Student vor etwa zwanzig Jahren zum erstenmal gehört, und zwar vom Komponisten selbst vorgetragen [von Glinka selbst] /.../.

Um dieses kleine, doch ganz einzige Lied singen zu können, war unbedingt eines erforderlich: Echtheit, echte Begeisterung, wirkliche Leidenschaft oder - /.../ wenigstens die vollendete künstlerische Beherrschung des Ausdrucks dieser Gefuhle [/.../ war unbedingt Wahrheit, eine unbedingt echte, volle Inspiration, eine echte Leidenschaft oder ihre vollkommene poetische Aneignung notwendig; Erg. d. Verf. ]. /../ Weltschaninoff /.../ hatte sich /.../ die ganze Art seines Vortrags [von Glinka] unauslöschlich eingeprägt. Und auch diesmal erfaßte ihn, kaum daß er die ersten Worte gesungen hatte, wirkliche Begeisterung, und die Begeisterung wirkte auf seine Stimme zurück /.../ [/.../ hatte sich fast die Manier des Vortrags Glinkas angeeignet, jetzt aber, vom ersten Ton und Vers an, flammte eine echte Inspiration in seiner Seele auf und erzitterte in seiner Stimme; Erg. d. Verf.]. /.../ So kam es, daß Nadja, als er bei den Schlußworten [/.../ als er die letzten Worte der Romanze zu Ende gesungen hatte und sich dabei mit blitzenden Augen an Nadja wandte:]

„Nur küssen will ich Dich, küssen,

Nur küssen, küssen!“ [Jetzt schaue ich Dir offener in die Augen, / Nähere meine Lippen und habe keine Kraft mehr, zuzuhören, / Will ich küssen, küssen, küssen ...]

mit vor Leidenschaft blitzendem Blick ansah, erschrocken zusammenfuhr /.../ und im Moment war es /.../ als habe er in ihrem verschämten Gesichtchen und in ihren fast bangen Augen ein kurzes Frraten bemerkt [so erzitterte Nadja fast vor Schrecken /... / und in diesem Augenblick war es, als ob etwas Entgegenkommendes in ihrem verschämten und fast schüchtem gewordenen Gesichtchen aufblitzte]. [kursiv d. Verf.] ${ }^{439}$

${ }^{439}$ Bd. 9, S. 81f. [S. 369]. Vgl. den polnischen Originaltext und die deutsche Übersetzung von Karl Dedecius: „Moja pieszezotka, gdy w wcsiłej chwili/pocznic szczebiotać i kwilić i gruchać /.. / Ach! wtenczas śmielej w oczçta poglądam, / Usta pomykam i shuchać nic żądam, / Tylkocałować, całować, całowac” (Mickiewlcz 1955c, S. 225f.) [..Mein Turteltăubchen. wenn es guter Laune, / Beginnt zu gurren, zu zwitschern und raunen; /... Dann wird gleich dreister auch mein Wohlgefallen. / Ich schlieB die Lippen, will jetzt gar nichts wissen : Als nur noch küssen, immer wieder küssen (in: MickiEwICZ 1994, S. 115)]. Vgl. auch die Anmerkung zum Lied Glinkas (1843) (nach der Übersetzung des polnischen Textes von S. Golicyn (1834)) und zur Bekanntschaft Dostoevskijs mit M.1. Glinka, Bd. 9, S. 482. Vgl. auch zu den russischen Vertonungen der Gedichte von Adam Mickiewicz bei MuchA 1986, S. 95f. (zu M.I. Glinka und seinen Mickiewicz-Vertonungen) und S. 100f. (zu den Vertonungen desselben Gedichts von Mickiewicz sowie anderer seiner Gedichte, u.a. der Ballade Switezianku (Das Mädchen vom Swité̇-See], von Aljab ev, Kjui (= Cui), Dargomyžskij. RimskijKorsakov und $C$ ajkovskij). 
Das von Glinka vertonte erotische Gedicht Mickiewiczs charakterisiert Vel'Caninov als einen "verwestlichten Verfuhrer", obwohl er sich gegenüber Nadja als ein solcher "Verfuhrer" aus Routine (und Rache an Trusockij) benimmt. ${ }^{40}$ Aus der Perspektive des Erzahlers wird zudem das Lied Glinkas, dessen Auffuhrung und die Musikalităt Vel"Caninovs „positiv“ beurteilt: Das Lied erfordere vom Interpreten die "Wahrheit" bzw. ihre „vollkommene poetische (asthetische) Aneignung", die "wahre Inspiration" und "Leidenschaft", die Vel 'Caninov nicht nur nachzuahmen, sondem auch zu empfinden imstande sei. Trotzdem aber handelt es sich bei dieser Stelle, ungeachtet der Dominanz der psychologischen Motivation, um eine versteckte ideologische, antipolnische Anspielung, denn Vel'caninov wird durch dieses Gedicht als immanent ,negativ verwestlicht", als eine negativ-subversive Alius-Figur gezeigt. Eine zusätzliche Komik ensteht durch die Tatsache, daß Nadja, ein "nihilistisches Teufelchen“, sich durch eine viel "negativere Okzidentalisierung" auszeichnet als der „Verfuhrer" selbst." ${ }^{\text {"1 }}$ Im Epilog von Vecnyj muz reist Vel'Caninov wegen einer "Liebesaffäre" nach Odessa, an den Ort der einstigen Verbannung des polnischen Dichters, wo das von Glinka vertonte Gedicht geschrieben wurde. Es ist somit anzunehmen, daß das polnische Imagem nicht unmotiviert zur Charakterisienung Vel Caninovs eingesetzt worden ist. Es handelt sich um eine paradigmatische Äquivalenz zwischen ihm und Mickiewicz. ${ }^{112}$

ZUSAMMENFASSUNG: In Vecrnyj muz treten im Unterschied zu den Romanen Prestuplenie i nakazanie und Idiot lediglich zwei komplementäre utopische Imagothèmes des verwestlichten RuBlands, das negative und das positive, auf. Alle zentralen Figuren dieser Erzăhlung sind dabei sowohl positiv als auch negativ (immanent) "verwestlicht", so daß sie in imagothematischer Sicht wie im Roman Idiot ambivalent erscheinen. Ihre ,negativ-westlichen“ Eigenschaften dominieren jedoch über die .guten“, wodurch zugleich der Bezug zu Zımnie =ametki o letnich vpecatlenijach und zu Zapiski $i=$ podpol'ja bemerkbar wird. Die Okzidentalisierung äußert sich aber im Unterschied zu früheren Werken im Laufe der Handlung weniger durch die fremden Inageme als durch das Benchmen der zentraler, Figuren. Sie sind somit weniger statisch. weniger "stereotyp“ gestaltet, obwohl sie auf die aus der „westlichen“ bzw. aus der russischen literatur entlehnten ,.(Stereo)Typen“ zurückgehen. In der ausgeprägten psychologischen Differenziertheit kommt die Polemik Dostoevskijs gegen die "literarische Typenlehre" Strachovs zum Ausdruck. Es handelt sich aber auch um eine Parodie der "Typen“ im Theaterstück des „Westlers“ Turgenev, der in Večmyj muz.. unmittelbar vor seiner Karikierung in der Gestalt des Schriftstellers Karmazinov in Besy, angegriffen wird.

"40 Vor dem Besuch bei den Eltern Nadjas hat Vel'Caninov ..schwere, boshafte“ bzw. „häßliche Gedanken“ (vgl. Bd. 9. S. 68ff.), danach aber wird er „.schwermütig“. fühlt sich ..erniedrigt“ und nennt sein Benehmen „eine Lüge“ (ebd., S. 83f., S. 87).

¿A Vgl. dazu oben, S. 312.

$₫ 42$ Vgl. Bd. 9, S. 106f. und ŚWIDERSKA 1999b, S. 270f. (zur Verbannung Mickiewiczs in RuBland). 
In der Erzăhlung Večnyj mǚ wird das einzige polnische Imagem, das versteckte Zitat aus einem Gedicht MickIEWICZS, zur Charakterisierung der Figur Vel'Caninovs als "verwestlichten Verfürers" eingesetzt. Somit bildet dieses Imagem keine Ausnahme in den literarischen Werken Dostoevskijs, in denen Zitate aus den Werken von Mickiewicz im negativen Kontext vorkommen. Neben der immanenten Charakterisierung eines "verwestlichten Russen" als einem Teil des von Rußland "verinnerlichten Westens", des negativen utopischen Imagothèmes des verwestlichten Rußlands, dient aber das Lied Glinkas nach den Worten des polnischen Dichters als eine ideologische "antipolnische“ Anspielung.

Die Erwăhnungen „Schillers“ sowie „Quasimodos“ sind dagegen ein Teil des positiven utopischen Imagothèmes des verwestlichten Rußlands und charakterisieren Pavel Pavlovic Trusockij - einen „verwestlichten“, aber „idealistischen Russen" aus der Provinz.

Nicht nur die zentralen Figuren, sondern auch die „sekundären“ russischen verwestlichten Figuren sind in Večmyj muz nicht eindeutig als eine Verkörperung des „Dämonisch-Bösen aus dem Westen“ aufzufassen, trotz der Einführung der jungen russischen "Nihilisten", darunter des Verlobten von Nadja und Rivalen Trusockijs. Im Vergleich mit den fruheren literarischen Werken Dostoevskijs ist somit in Večnyj muz die Kritik am „Westen“ abgeschwächt worden. Diese Erzăhlung låßt sich aber mit ihrer psychologischen Problematik als eine Parodie auf westliche literarische Werke, v.a. auf französische Komödien bzw. Melodramen auffassen, auf die sich bereits Zimnie zametki o letnich vpecatlenijach kritisch beziehen. Vecnyj $m u \check{z}$ zeigt die negative Wirkung der „Okzidentalisierung" auf die ,bessere" russische Gesellschaf, nicht nur in Petersburg, sondern auch in der russischen Provinz. In Vecrnyj muz fehlen dagegen mit einer einzigen Ausnahme (des deutschen Arztes Koch) fremde stereotype Figuren (als alter), was durch den beschränkten Umfang dieser Erzăhlung verursacht worden sein könnte. 


\section{1. БЕСЫ. РОМАН В ТРЕХ ЧАСТЯX (1871-1872) \\ [BOSE GEISTER $]^{413}$}

Im Roman Besy, dem letzten in Westeuropa konzipierten und geschriebenen Werk Dostoevskijs, ${ }^{\text {"At }}$ dominiert (wie in Vecmyj muz) das negative utopische Imagothème des verwestlichten, „nachpetrinischen“ Rußlands. Das komolementäre positive utopische Imagothème des verwestlichten Rußlands, das besonders wichtig für das Verständnis des Romans ldiot ist, sowie das positive utopische des russisch-(orthodox-byzantinischen) Rußlands, das nicht nur in Idiot, sondem schon in Prestuplenie $i$ nakazanie eine relevante Rolle gespielt hat, treten in Besy in den Hintergrund zurück. Sie erfüllen jedoch auch in diesem Roman eine wichtige und notwendige Kontrastfunktion, dienen als eine „positive Folie", vor der sich die negative Okzidentalisienung der meisten „dämonisch-bösen" russischen Alius-Figuren besonders deutlich abhebt.

Besy läßt sich also mit Recht als ein „antinihilistischer Roman“ bezeichnen, als expliziter Beitrag zur Diskussion über die Auseinandersetzung zwischen "Rußland und Europa“ bzw. zwischen "Rußland und dem Westen“. Ein solcher "Kampf gegen den Westen" hat zwar auch in Dostoevskijs früheren literarischen Werken die Figurenkonstellation und dadurch den symbolischen Gehalt mitbestimmt. ${ }^{415}$ Bereits der Titel und die beiden Motti des Romans ${ }^{416}$ weisen auf diese „dämonische“ Problematik hin, die sich innerhalb eines umfangreichen Komplexes von philosophischen und ideologischen Fragen um das Verhältnis Rußlands zum Katholizismus, Sozialismus bzw. zu den atheistischen Anschauungen und Theorien bewegt. ${ }^{117}$ In Besy ist aber besonders vehement eine spezifische Problematik der früheren Werke sowie der Entwürfe zu diesem Roman, u.a. über den „großen Sünder“ bzw. den „Atheismus“, aufgegriffen und literarisch ausdifferenziert worden, die mit der des damals in RuBland

¿43 Die deutschen Übersetzungen russischer Zitate aus Besy werden nach der Ausgabe DOSTOJEWSKU 1998 angefürt

${ }^{444} \mathrm{Vgl}$. Bd. 10 und Bd. 12, S. 152. Zur Entstehungsgeschichte des Romans, siehe z.B. Bd. 12, S. $161 \mathrm{ff}$.

¿4s Vgl. Bd. 12, ebd. und S. 167 u.a. zu Danilevskij, Strachov, Gercen oder Turgenev, deren Bücher und Aufsätze zur Problematik der. Auseinandersetzung zwischen Rußland und dem Westen“ Dostoevskij bekannt waren. Vgl. z.B. DANILEvSKu 1991. Das Buch Danilevskijs (1871), in dem versucht wird, eine Kulturtypologie zu schaffen, um das ..slavisch-orthodoxe Rußland" gegen den ..katholisch-protestantischen Westen" besser abheben zu können, wurde von Dostoevskij gelesen und positiv beurteilt. Dieses Buch läßt sich in gewisser Hinsicht mit dem Buch HUNTINGTONS 1996 vergleichen, obwohl Danilevskijs Unteile über die künftigen Schicksale der Welt bzw Europas und die Wege der Weltpolitik, bereits vor mehr als einem Jahrhunder aufgeschrieben, aus dieser zeitlichen Entfernung viel spekulativer, apodiktischer und gefahrlicher als diejenigen Huntingtons erscheinen.

\$46 Es handelt sich um Zitate aus der Ballade Besy [I) Puškins sowie um eine Stelle aus dem Lukasevangelium, Kap. 8, V. 32-35; vgl. dazu auch Bd. 10, S. 6 und Bd. 12, S. $252 \mathrm{f}$.

17 Vgl. dazu Bd. 12, S. 253f. Siehe dazu auch z.B. WAlicki 1975 sowie DERS. 1980, oder WARD 1986. 
vieldiskutierten "Nihilismus der 60-er Jahre“ verbunden wurde. Wie Dostoevskij in einem seiner Briefe geschrieben hatte, wollte er sich in Besy dazu „restlos" ausprechen:

„То, что пишу, - вещь тенденциозная, хочется высkазаться по-горячее. (Вот завопят-то про меня нигилисты и западники, что реmpozpad !) Да черт с ними, а я до последнего слова высkажусь“. [Das, was ich schreibe, ist eine tendenziöse Sache, man will sich doch darüber ganz leidenschaftlich ausprechen. (Da fangen die Nihilisten und Westler über mich zu schreien an, daß ich ein Reaktionär bin) Der Teufel soll sie holen, aber ich werde mich bis zum letzten Wort ausprechen. [kursiv Dostoevskij]l ${ }^{40}$

Der politisch motivierte Mord an einem Studenten der Moskauer Landwirtschaftlichen Akademie, I.I. Ivanov, der im Januar 1869 von der revolutionären Gruppe um den Terroristen S.G. Nečaev (1847-1882) ausgeführt wurde, ${ }^{119}$ hat Dostoevskij zusătzlich dazu bewogen, einen aktuellen politisch-ideologischen Roman zu schreiben. ${ }^{450}$ Der Roman Besy wurde deshalb nach seinem Erscheinen von der damaligen russischen Literaturkritik einerseits mit den ,antinihilistischen" Romanen von V.V. Krestovskij, V.P. Kljušnikov, V. P. Avenarius, N. D. Achsarumov oder auch von A. F. Pisemskij und N. S. I.eskov verglichen, ${ }^{451}$ andererseits aber auch als eine Auseinandersetzung mit N.G. Cernysevskij sowie mit anderen sogenannten liberal-demokratischen Autoren, u.a. mit N.G. Pomjalovskij, V.A.Slepcov bzw. mit Turgenev oder Gončarov angesehen. ${ }^{452}$

Die Haupthandlung von Besy spielt in einer russischen Provinzstadt und ihrer Umgebung, „Westeuropa“ sowie Petersburg und Moskau werden nur in Rück-

${ }^{48} \mathrm{Vgl}$. Bd. 12, S. 164: ein Zitat aus dem Brief an N.N. Strachov vom 25. Mărz (6. April) 1870. Vgl. außerdem ebd., S. 176 über den Brief Dostoevskijs an den Thronfolger A.A. Romanov vom Februar 1873

$449 \mathrm{Vgl}$. dazu ebd., S. $192 \mathrm{ff}$.

450 Dostoevskij hatte darüber hinaus den antinihilistischen Roman Na nozach [Bus aufs Messer] (1870-71) N.S. Leskovs gelesen und sich positiv zu einigen seiner Figuren geäußert, u.a. einer .Nihilistin“. Vgl. Bd. 12, S. 166 (der Brief Dostoevskijs an A. N. Majkov vom 18./30. Januar 1871).

${ }^{451} \mathrm{Vgl}$. dazu ebd., S. 165 und S. 257-272. Vgl. den Aufsatz zum ..antinihilistischen Roman“ im Rußland des 19. Jahrhunderts von BiAlokOzOWICZ 1994. Der Vergleich zwischen diesen Romanen und dem Roman Besy' im Hinblick auf die Darstellung der polnischen bzw. fremden Problematik, der polnischen und fremdem Imageme und Imagothèmes wäre sicherlich ergiebig. Diese Problematik, die einer gesonderten Studie wert ware, kann an dieser Stelle nur angedeutet werden. Es handelt sich u.a. um folgende Romane: N.S. Leskovs Nekudu [Nirgendwohin (1863), (Obojdennye [Die Benacherligien](1863) bzw. Na no:ach (1870-71). A.F. Pisemskijs $V$ 'salamučennoe more |loas aufgewiühlte Meer| (1863) und $V$ vodovorote [Im Wassenwirbel bzw. Im Sirwelel] (1871), V.V. Krestovskijs l'unurgovo sicado ['anurgs Herde] (1865) und um den spateren Roman IVe sily' [Zn'el Mlächic| (1874) (vgl Jazu auch KRESTOVSKIJ 1899 oder KLUSSNIKOV 1865).

$452 \mathrm{Vgl}$. dazu ebd., S. $165 \mathrm{ff}$. 
blenden erwăhnt. ${ }^{453}$ Im Mittelpunkt der Handlung stehen sich die Vertreter zweier nussischer Generationen gegenüber: die Generation der „Văter“ bzw. der „Eltem" aus der russischen Intelligenz bzw. aus dem Adel der 40er Jahre und ihre „Kinder," zu denen u.a. die "nihilistische" jüngere Generation der 60er Jahre gehört.

Zur Generation der „verwestlichten Văter" bzw. „Mütter" gehören Stepan Trofimovic Verchovenskij und sein Bekanntenkreis, seine Gönnerin, die Generalswitwe Varvara Petrovna Stavrogina, der „große Schriftsteller“ Karmazinov, der Gouverneur der Stadt, ein „russischer" Deutscher namens (fon) Lembke sowie seine russische Frau Julija Michajlovna. Zur Generation der Kinder gehören die Sohne von Stepan Trofimovic Verchovenskij und von Varvara Petrovna Stavrogina - Petr Stepanovic Verchovenskij und Nikolaj Vsevolodovic Stavrogin, darüber hinaus Ivan Pavlovic Satov und seine Schwester Dar'ja Pavlovna - Kinder eines Lakaien im Hause Stavrogin. Außerdem zählen noch hierzu folgende Figuren: die Frau Şatovs, Marie, der Ingenieur Aleksej Nilyč Kirillov, Anton Lavrent 'evix G-v, der Erzähler bzw. der Chronist des Romans selbst sowie Liza Tušina, die Tochter einer gewissen Dame aus der Provinzstadt, Praskov'ja Ivanovna Drozdova. Dieser Generation zuzuordnen ist auch die Gruppe der „Verschwörer“ (der „Linsrigen“) um Petr Stepanovic Verchovenskij, der nicht nur die Bekannten Stepan Trofimovic Verchovenskijs angehoren, sondern auch der von Petr Stepanovic Verchovenskijs hochgeschatzte Theoretiker Sigalev.

Neben diesen beiden russischen Gruppen gibt es in Besy noch zwei weitere russische Figuren. ${ }^{454}$ die sich nicht ohne Vorbehalt als .,russisch-orthodox-

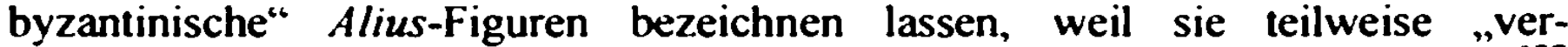
westlicht" und ambivalent sind. Es sind der .Jurodivyj“ Semen Jakovlevic ${ }^{455}$ und der Mönch bzw. russisch-orthodoxe Bischof Tichon. ${ }^{456}$ Auch Kapitän Lebjadkin, der Bruder von Mar ja Timofeevna Lebjadkina, laßt sich in seiner Ambivalenz nicht eindeutig charakterisieren, obwohl bei ihm die "westlichen" Eigenschaften überwiegen. Diese Figur repräsentiert den Typus eines „verwestlichten russischen Narren" bzw. „Lügners" und ist solchen Figuren wie dem

$453 \mathrm{Vgl}$. Bd. 12, S. 223f: Es wird dabei auf die Stadt Tver als Vorbild der Provinzstadt hingewiesen. Siehe dort auch zur Erzählform des Romans als (hronik, zum Wechsel vom Ich-Erzähler zum ..allwissenden“ Erzähler (vgl. auch S. I73ff.). Vgl. auch TUNIMANOV 1984 und KARUAKIN 1983.

434 Als ein ..kollektiver Held" treten die streikenden Arbeiter auf Diese Arbeiter sind aber das ..russische Volk", sie benehmen sich während des Streiks bel ihrem Auftritt vor dem Gouverneur wie die ..russischen Bauern", die mit ihrem . Herrn" in Demut und Achtung sprechen wollen, d.h. sie sind von den Ideen der .,Nihilisten“ nur oberflächlich berührt worden, vgl. z.B. Bd. 10, S. 366.

${ }^{455}$ Bd. 10, S. 254ff., vgl auch Bd. 12. S. 234f. und S. 302 zu seinen möglichen authentıschen Vorbildem

${ }^{456} \mathrm{Vgl}$. Bd. II, z.B. S. 6ff: Tichon ist möglicherweise als ein „verwandelter Stavrogin“, ein zum russisch-orthodoxen Glauben bekchrter oder zurückgekehrter ..großer Sünder" zu verstehen. Vgl. auch Bd. 12, S. 185, S. 222, S. 224 und S. 238, und ebd. S. 298, die Anm. zu Bd. 10, S. 203, zu seinem Vorbild Tichon 7.adonskij (= Timofej Savel evic Kirillov (1724-1783)). Nach A.S DOLININ ist Tichon auch eines der Vorbilder Kirillovs, der auch seinen „weltlichen“" Namen hat, vgl. Bd. 12, S. 222 (zit. nach DERS. 1928-1959, Bd. 2., 1930, S 474-475). 
General Ivolgin (in Idiot) sowie Maksimov und Fedor Karamazov (in Brat'ja Karamazovy) verwandt. ${ }^{457}$ Der Verbrecher Fed'ka Katoržnyj ${ }^{458}$ vertritt dagegen das "negativ verwestlichte russische Volk". Daneben erscheinen in Besy drei „verwestlichte" bzw. "russisch-orthodox-byzantinisch" geprăgte ,positiv-utopische" russische Alius-Figuren: der unglückliche Rivale Stavrogins um Liza Tusina, der Offizier Mavrikij Nikolaevic, ${ }^{459}$ Mar'ja Timofeenna Lebjadkina $^{\$ 60}$ und die „Bibelverkăuferin“ Sof ja Matveevna Ulitina. ${ }^{462}$

Die meisten der oben genannten Vertreter der "Eltern" und der "Kinder" zeichnen sich durch ihre bereits angedeutete Ambivalenz aus, sie schwanken zwischen "Rußland" und dem "Westen" (und zugleich zwischen dem "Guten" und „Bösen“) bzw. entscheiden sich nach einer Zeit des Schwankens entweder für oder gegen Rußland, d.h. für oder gegen den "westlichen Atheismus“ bzw. "Liberalismus" und für oder gegen das "russisch-orthodoxe Christentum", wobei die "russischen" oder die "westlichen" Eigenschaften jeweils in unterschiedlichen Proportionen in ihnen vorhanden sind. Am negativsten und am meisten "verwestlicht" erscheinen dabei Petr Stepanovic Verchovenskij und sein Kreis, der ,große Schriftsteller" Karmazinov und die Frau des Deutschen fon Lembke, Julija Michajlovna. Diese Alius-Figuren vertreten das negativ verwestlichte, „petrinische“ Rußland, sind als ein Teil des negativen utopischen Imagothèmes des verwestlichten Rußlands anzusehen, wobei sich in ihnen die negativ ideologischen mit den negativ utopischen, "westlichen" Elementen überlagern. Stavrogin, Satov und Kirillov, die Schwester Satovs Dar ja, Liza, die Mutter Stavrogins und Stepan Trofimovic Verchovenskij weisen dagegen sowohl "westliche" (negative und positive) als auch „russisch-orthodoxe" (posi-

${ }^{457} \mathrm{Vgl}$. dazu S. 425f. (zu lvolgin) und S. 529f. (zu Maksimov).

4se Vgl. Bd. 10, S. 204 und Bd. 12, S. 235. Fed'ka Katoržnyj wurde von Stepan Trofimovic Verchovenskij im Kartenspiel verspielt. Der „Vater" Verchovenskij trăgt somit die Schuld am verbrecherischen Lebenswandel seines ehemaligen Leibeigenen, der nach seiner Flucht aus der Verbannung Kontakte zu dessen „nihilistischen“ Sohn Petr Stepanovic Verchovenskij aufgenommen hat und ihm als bezahlter Mörder, als ..Killer” dient: „Tы беr.лый c karopru? Переменіл участь. /.../ Петр Степановіч паспортом по всей Расее, /.../ об.лагонадеживают, /... говорят. папаша тебя в клубе аглииком в карте тогда проиграл; так я. говорят, несправединвым сие бесчеловечие нахожу“. [kursiv die Verf.] I 'Du bist aus dem Zuchthaus entlaufen?' 'Hab mein Los gewechselt. /.../ Pjotr Stepanowitsch [macht mir] vie!erlei Hoffnungen auf einen $\mathrm{Paß}$, der fürs ganze Mütterchen Rußland gilt $/ . . . ;$, sagen sıe. der Herr l'apa dich im engelländischen ('luh he'im Karlenklopfen verspielt hat; und ich, sagen sie, halte derlei Unmenschliches für ungerecht : S. 340f.]

${ }^{459} \mathrm{Vgl}$. z.B. Bd. 10, S 222f, S. 259f. (Die positive Charakterisierung Mavrikijs durch den Erzähler in der Szene bei dem „Jurodivyj“: „ - Maвpıkıй Hıko.ıаевич! - обратıцась k нему вдруг Лиза, - тот господин на ко.єенх уше., станьте на его место на ко.лени. /.../ Он /.../ без приг.лашения /.../ ста. среди комнаты на ко.тени,, на вицу у всех. Думаю, что он с.лишком был потрясен в де.ликатпій и простой душе своей грубою, г.тумите.тьою выходkоһ̆ Лизы“.) ( Mawrikij Nikolaewitsch;, wandte sich plotzlich Lisa an ihn. dieser kniende Herr ist $/ . . . /$ fortgegangen, knien Sie doch an seiner Stelle nieder. $\ldots . . / \mathrm{Er}$... kniete $i . . /$ mitten im Raum nieder, vor aller Augen. Ich denke, daß er in der Tiefe seiner rücksichtsvollen und schlichten Seele von dem groben, hohnischen Einfall Lisas /.../ unendlich erschüttert war; S. 439f. I, S. 295f. (Die Szene bei Stavrogin) oder S. 409ff (Der Tod Lizas).

${ }^{460} \mathrm{Vgl}$. z.B. Bd. 10, S. 206ff. und Bd. 12, S. 235.

${ }^{461}$ Vgl. z.B. Bd. 10, S. 486ff. 
tive) Elemente auf. Besonders positiv erscheinen dabei Stepan Trofimovic Verchovenskij und Satov, in denen positive verwestlichte Eigenschaften uberwiegen, so daß bei diesen „verwestlichten Idealisten“ eine Wiedergewinnung der Bindung an die russisch-orthodoxe, religioss-kulturelle Tradition, der russischen religios-kulturellen Identităt, angedeutet wird. Stavrogin, Kirillov oder Liza bleiben in dieser Hinsicht ambivalent, weisen aber wie die ambivalenten verwestlichten Figuren in den früheren Romanen Dostoevskijs (Svidrigajlov und Raskol'nikov bzw. Nastas'ja Filippovna, Rogožin oder Ippolit, wie auch spăter Ivan Karamazov) eine "Sehnsucht" nach dem (russisch-orthodoxen) Glauben auf. Nur im Untergang, in Krankheit bzw. im Tod (auch als Freitod) können diese Figuren ihre negative Okzidentalisierung überwinden und „erlöst“ werden. Mavrikij Nikolaevic ist dagegen als ein positiver „verwestlichter Idealist" anzusehen, der keine negativen destruktiven Komponenten der Okzidentalisierung aufzuweisen hat, wie sie bei Stavrogin oder Kirillov vorhanden sind. ${ }^{462} \mathrm{Er}$ ahnelt Dmitrij Karamazov und verkorpert somit das positive utopische Imagothème des verwestlichten Rußlands. Dasselbe läßt sich auch über die Schwester Satovs, Dar'ja, und über Varvara Petrovna Stavrogina, die ebenfalls als ,positiv verwestlicht" geschildert werden, sagen.

Die russischen Figuren des „Jurodivyjs“ Semen Jakovlevix und des Mönchs Tichon weisen ebenfalls Elemente der Okzidentalisierung auf, wobei besonders der "Gottesnarr" Semen Jakovlevic das sektiererische „nachpetrinische" Rußland vertritt und dem düsteren, "verwestlichten" Vater Rogožins, der auch Scmen heißt, ähnlich ist. Eine „dämonisch-böse“, komplementäre Figur zu den adligen russischen "Nihilisten" ist der aus der Katorga entlaufene Fed'ka Katoržnyj, der das negative utopische Imagothème des „verwestlichten russischen Volkes" reprăsentiert, welches in Brat "ja Karamazovy der "Lakai" Smerdjakov vertritt. ${ }^{63}$ Das positive utopische Imagothème des ...ussisch-orthodox-byzantinischen" Rußlands, sowohl des „Volkes“ als auch des russischen „Bürgertums“ vertreten dagegen einerseits die Gottesnärrin Mar ja Timofeevna Lebjadkina und die "Bibelverkäuferin" Sof ja Matveevna Ulitina. ${ }^{46}$

Im Vergleich zum Roman Idiot treten in Besy mehrere sowohl positive als auch negative verwestlichte und russische Figuren auf. trotz der psychologischen Differenzierung und dem „Schwanken zwischen dem Westen und RuBland" bei den zentralen Figuren dieses Romans. Diese relative "Vereinfachung" der Figuren läßt sich möglicherweise auf den ideologisch-polemischen Charakter des Romans zurückführen.

\footnotetext{
\$62 Wobei die negatıve Okzidentalisierung in diesem Roman hauptsächlich mit der .revolutionăren Bewegung", mit der ..(atheistischen) Revolution" (= ..ohne Gott ist alles erlaubt“), gleichzusetzen ist. Vgl. dazu den Aufsatz von KLUGE 1998a

${ }^{463} \mathrm{Vgl}$. dazu unten, S. 370ff.

"s4 Auch ihre Namen Mar ja bzw. Sof ja deuten auf sakrale Bezüge dieser Figuren hin und verbinden sie mit den anderen ..sanftmütigen" russischen Alıus-Figuren in den Romanen Dostoevskijs.
} 
In Besy lassen sich wie in früheren Werken Dostoevskijs auch mehrere fremde Imageme, auch polnische, beobachten, ${ }^{465}$ die zum einen als stereotype Alter-Figuren, als Kontrast zu den russischen Figuren auftreten, wăhrend andere Imageme die „verwestlichten" russischen Alius- Figuren immanent charakterisieren.

Zu den fremden Imagemen gehören u.a. die Erwăhnungen Deutschlands, der Schweiz und „Amerikas“. ${ }^{466}$ Auch Palästina, Jerusalem und Athos ${ }^{467}$ werden in den Rückblenden als Reiseziele bzw. als Fluchtorte der verwestlichten Figuren erwăhnt, v.a. im Zusammenhang mit Nikolaj Vsevolodovič Stavrogin und Petr Stepanovic Verchovenskijs. Mit den positiven utopischen Visionen von der "geistigen Schönheit" des Vaters Verchovenskij bzw. vom "Goldenen Zeitalter" Stavrogins werden die Gemälde aus der Dresdener Galerie, also aus dem „Westen", Die Sixtinische Madonna Raffaels ${ }^{\mathbf{1 8 0}}$ und Acis und Galatea von Claude

465 Bei der folgenden Interpretation werden auch handschriftliche Materialien und Textvarianten zu Besy sowie das von der Zensur verbotene Kapitel U Tichona [Bei Tichon] mitberücksichtig. Vgl. dazu Bd. 11.

666 In Deutschland (Berlin) hat Stepan Trofimovic Verchovenskij seine „Studien“ betrieben, vgl. Bd. 10, S. 24ff; während der Sitzung der Revolutionăre bei Virginskij wird Dresden von Petr Stepanovic Verchovenskij als ein moglicher Ort des Exils empfohlen (ebd., S. 315); Nikolaj Vsevolodovič Stavrogin hat seinen utopischen Traum vom Goldenen Zeitalter in einem deutschen Stådtchen getrăumt (vgl. Bd. 11, S. 21f.); der große (und eitle) Schriftsteller Semen Egorovic Karmazinov lebt in Karlsruhe und mochte dort auch begraben werden: .Да, я распрощаюсь; скажу свое «Мегсі» и уеду, и там... в Кар.тьсруэ... закрою глаза мои, - начат мато-помату расkисать Кармазинов. /.../ Нам, великим людям, остается, сде.тав свое дело, поскорее закрывать г.лаза, не иша награды. /.../ Дайте адрес, и я приеду k вам в Кар.льсруэ на вашу мопиту, - безмерно расхохотался немец", S. 349ff. ["O, ja, ich nehme Abdschied; ich sage Merci und breche auf .... um dort ... in Karlsruhe ... meine Augen für ewig zu schließen'. Nach und nach zerfloß Karmasinow vor Rührung [eigentl.: ... fing Karmazinov an, sich langsam wie ein Sauerteig aufzuweichen]. /.../Wir, die Großen. müssen, wenn unsere Aufgabe erfüllt ist, baldigst die Augen schließen, ohne auf Lohn zu warten. /.../ Geben Sie mir Ihre Adresse, und ich werde Sie in Karlsruhe an Ihrem Grab besuchen'. Der Deutsche lachte wieder unmåBig; S. 640]; Petr Stepanovic Verchovenskij kommt aus Genf, aus dem .,Herzen“ des nihilistisch-anarchistischen Westens, und flieht zum Schluß des Romans möglicherweise dorthin, Bd. 10, S.52ff., S. 63 und 464f. und 477ff; Stavrogin (und auch andere Figuren des Romans, vgl. z.B. ebd., S. 45ff.) reist nach Westeuropa, u.a. in die Schweiz, er plant aber auch, sich in die Schweiz, in den Kanton Uri, ,zurückzuziehen“: S. 217f., 401f., 513f:: Kirillov und Satov reisten gemeinsam nach Amerika, um an sich selbst das Leben eines Menschen „в самом тяжелом его общественном положении“ lauf der untersten sozialen Stufe; S. 181 | zu erleben: S. 112, 192ff, bes. S. $196 \mathrm{f}$.

${ }^{467}$ Bd. 10, S. 45; Bd. 11, S. $20 f$.

${ }^{168} \mathrm{Vgl}$. z.B. Bd. 10, S. 25, 265f., 372f., siehe auch ebd., S. 505f.: die profession de fot Stepan Trofimovič Verchovenskijs und den Kommentar im Bd. 12, S. 249 über die Textänderungen vor der Verôffentlichung der letzten Fassung des Romans: .В речи Степана Трофимовича "Христос" был заменен на "Рафаеля»" |In der Rede Stepan Trofimovičs war „Christus“ an die Stelle .Raffaels" getreten], was ebenfalls darauf schließen läßt, daß mit dem Gemälde Raffaels die geistige wahre Schönheit Christi, des .,menschlichen Ideals“, gemeint ist und nicht nur die ..schöne Form an sich", was auch als ein Vorzeichen der geistigen Ermeuerung Stepan Trofimovic Verchovenskijs im Epilog des Romans interpretiert werden könnte; vgl. dazu die konträren Ansichten der Atheisten bzw. Liberalen Karmazinov und Julija Michajlovna über die Madonna Raffaels, die einen engen Bezug zur kritischen Āußenung des 
Lorrain $^{469}$ in Verbindung gebracht. Eine ăhnlich positive Rolle wie „Schiller" in den fruheren Werken spielt in Besy "Shakespeare“, $\$ 70$ der ebenfalls in den kritischen Äußerungen Stepan Trofimovic Verchovenskijs zu den asthetischen Ansichten der Utilitaristen vorkommt.

In Besy treten dagegen im Vergleich zu den früheren Romanen relativ wenig fremde Figuren auf: neben den beiden deutschen Figuren - dem oben erwăhnten Gouverneur fon Lembke ${ }^{67}$ und seinem Mitarbeiter und zugleich entfernten Ver-

Erzahlers in Zımnie zametkı o letnich vpecatlenyach über die russischen und englischen Touristen aufweisen (vgl. dazu oben, S. 235f., Fn 234): . $/ . . . /$ я просидета два часа пред

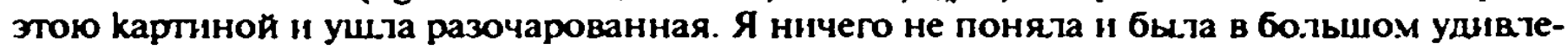
нии. Кармазинов тоже говорит, что трудно понять. Теперь все ничего не находя, и pycckuе и анг.пччане. Всю эту с.лаву старики прокричати“, ebd., S. 235 |/.../ ich habe zwei Stunden lang vor diesem Bild gesessen und bin enttăuscht weggegangen. Ich habe überhaupt nichts verstanden und mich sehr gewundert. Karmasinow sagt auch, es wäre schwer zu verstehen. Jetzt findet keiner mehr etwas Besonderes daran, die Russen nicht, die Engläder auch nicht. Ihr ganzer Ruhm rührt vor dem Gefasel der Alten her', S. 396].

${ }^{169} \mathrm{Bzw}$. Küstenlandschaff mit Acts und (jalatea (1657), vgl. Bd. 11, S. 21f. Siehe auch unten zum Traum Versilovs im Roman Podrostok (S. 349f., S. 350 und S. 364) sowie Bd. 12, 320f., die Anm. zum Bd. 11, S. 21 f.

$470 \mathrm{Vgl}$. z.B. Bd. 10, S. 372f., auch Nikolaj Vsevolodovic Stavrogin wird von Stepan Trofimovic Verchovenskij mit Shakespeares „Prinz Garri“ in Verbindung gebracht (ebd., $S$. 36). Der Erzahler vergleicht das jugendliche ,atheistische Poem“ Verchovenskijs, in dem wie in Zimnie zametki o leinich vpečalenijach der ,babylonische Turm“, das Symbol des „Westens", vorkommt, mit dem zweiten Teil von Goethes „Faust“. ebd., S. 9f. Verchovenskij vergleicht sich auch selbst mit Goethe bzw. mit einem ,alten Griechen“. Er erwăhnt darüber hinaus George Sand, so daß dadurch seine .sozialkritische“, aus der heutigen Sicht „femini-

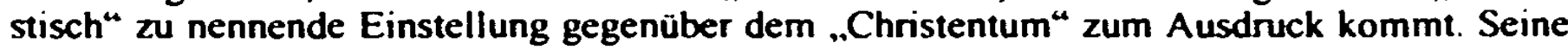
..heidnische“ Gleichgültigkeit den russisch-orthodoxen Ritualen und die „.Distanzierung“ gegenüber den (stereotypen) ,Jesuiten" heben zusătzlich seine Kritik an der russischen Orthodoxie und am Katholizismus hervor: , Я ckopee древний язычник, kak ве.ш!kıй Гете ити kak древний греk. И одно уже то, что христианство не понято жениину, - что таk ветиkо.тепно развита Жорж Занд в одном из свонх гениатьных романов. Насчет же покіонснй, потов и всет прочего, то не понимаю, kомy kakoе до меня де.ло? Как бы ни хлопотали здесь наши доносчиkи, а иезугтом я быть не же.таю", [Ich bin eher ein alter Heide wie der große Goethe oder ein antiker Grieche. Schon allein deshalb, weil das Christentum kein Verstăndnis für die Frau hat, wie es George Sand in einem ihrer genialen Romane so glänzend zeigt. Und was nun den Kultus, das Fasten und dergleichen angeht, so kann ich nicht verstehen, warum überhaupt jemand an mir Anstoß nimmt. Mögen sich unsere Schnüffler auf den Kopf stellen - aber ich bin kein Jesuit: S. 50], ebd., S. 32. Verchovenskij zitient auch das Gedicht Puskins über den Armen Rutter, das schon in I lwot Myškin als einen "Idealisten" charakterisien und in Besy im Zusammenhang mit Verchovenskijs „Kult“ der. Sixıınıschen Madonna und mit seiner Kritik an den materialistischpragmatischen Ansichten russischer „Nihilisten“ sowie mit seiner „platonischen“ Bezichung zu Varvara Petrovna Stavrogina steht, ebd., S. 266. In Bcsy gibt cs dagegen keinen cxplızı so genannten idealistischen ..Schiller", trotz des Idealismus einiger positiver Figuren, darunter auch Stepan Trofimovic Verchovenskij selbst.

${ }^{41} \mathrm{Vgl}$. zur Figur fon Lembkes, Bd. 10, S. 48f. bzw. S. $241 \mathrm{ff}$. Der Name .,fon Lembke“ (= $(\mathrm{amm})$ deutet weniger auf seine ..Unschuld“ als ironisch auf seine .Făhigkeiten“" hin; vgl. auch ebd., S. 338ff. sowie Bd. 12, S. $216 \mathrm{f}$. und 224 (über die möglichen Vorbilder für Lembke und Bljums, den Gouverneur von Tver' P.T. Baranov |von russ. haran, Gapan, = 
wandten Bljum ${ }^{42}$ - werden noch deutsche Ärzte erwähnt, u.a. ein gewisser Doktor Zal'cfis, der den todkranken Stepan Trofimovic Verchovenskij pflegt ${ }^{43}$, sowie der Jude Ljamšn aus dem Kreis um den Vater und Sohn Verchovenskijs. ${ }^{44}$ Die Figuren Lembkes, Bljums und Ljamsins lassen sich nach der Typologie Mouras als alter, als die Anderen, bezeichnen, die als der negative Kontrast den Russen gegenübergestellt werden. Sie sind als negative nationale bzw. ethnische Stereotypen dargestellt und zugleich als grotesk-komische bzw. nur lăcherliche Figuren konzipiert. Sie sind aber auch Symbole des „Bösen“, die "Dämonen“ bzw. „bösen Geister", von denen RuBland besessen ist. Besonders der Jude und Nihilist aus der Gruppe Petr Stepanovic Verchovenskijs, Ljamšin, ist als ein solches Symbol aufzufassen: Mit Nachdruck werden vom Ich-Erzăhler seine blasphemischen Handlungen hervorgehoben. ${ }^{476}$

Alle polnischen Imageme in Besy sind mit Stepan Trofimovic Verchovenskij, seinem Sohn Petr Stepanovic Verchovenskij und mit dessen Kreis, auch mit dem Kreis Julija Michajlovnas sowie mit Nikolaj Vsevolodovic Stavrogin und

Hammel, Schafbock, Widder| und seinen Mitarbeiter N. G. Levental') sowie die Entwürfe zu Besy, Bd. 11, S. 137: die Worte Satovs:

„Немеи - естественный враг России, /.../ Чем они хва.яятяя, что они дтя нас сделати? Они во всем ниже нас. Их коатиция в России, один друтого подсаживает. Заговор 150 -летний. /.../ Все бездарності с.тужицти в высших чинах с бараньия презрением $k$ pycckus". II)er Deutsche ist der natürliche Feind Rußlands. /... Womit geben sie so an, was haben sie fur uns getan? Sie sind in allem niedriger als wir. Ihre Koalition in Rußland, einer hilft dem anderen hinauf. Eine 150-jührige Verschwörung. /.../ Alle Stümper dienten in höheren Diensträngen mit ciner „Hammcl-l'eruchıung " für dic' Russen.] [kursiv die Verf.]

${ }^{472} \mathrm{Vgl}$. auch zur stereotypen Charakteristik Bljums, ebd. 10, S. 281: „“Несчастные» немиы не миф, а действігтельно существуют, даже в России, и имеют свой собственый тип. /../ был он аkkуратен, но kak-то с.лишком, без нужды и во вред себе, мрачен: рыжий, высокий, сгрорб.ленный, унылый, даже чувствительный и, при всей своей приниюкенності, упрямый и настойчивый, kak во., хотя всегда невпопад". I Die glücklosen Deutschen sind keine Legende [kein Mythos], sondem sie existieren wirklich, sogar in Rußland, und stellen einen eigenen Typus dar. $i . . /$ Er war pünktlich und genau, aber irgendwie viel zu sehr, übertrieben, zu seinem eigenen Schaden, und immer finster; rothaarig, lang. gebeugt. niedergeschlagen, sogar gefühlvoll und bei aller Bescheidenheit hartnäckig und stur wie ein Ochse, aber immer am falschen Ort; S. 478]. Siehe auch Bd. 12, S. $216 \mathrm{f}$.

${ }^{43} \mathrm{Vgl}$. Bd. 10, S. 504: „[Доктор Зальифиі1] был весьма почтенный старичок " довольно опытный практик /..." [ [Doktor Salzfisch] war ein durchaus wärdiger alter Herr und ein ziemlich erfahrener Praktiker /...; S. 911]. Sein Name - Zal "cfiš [..Salzfisch"] - macht aber aus ihm eine ,komische“ Figur. Ein anderer deutscher Doktor zăhlt zu den Bekannten von Julija Michajlovna, ebd., S. 348.

67. Vgl. z.B. Bd. 10, S. 30ff., 250ff. Siehe dazu auch INGOLD 1981, S. 70ff;; GoldSTEIN 1981, S. 68ff., bes. S. 72ff. und PożNiAK 1992, S. 100ff. und S. 113ff.

"7s Stavrogin erzăhlt aber lediglich von .,seinem" verschnupften kleinen „Teufelchen”, vgl. Bd. 10, S. 231: „O kakoй мой демон! Это просто ма тенькıй, гаденькıй, зо:отушный бесенок с насморkом, из неудавшихся". [ Ach, was ist das schon für ein Damon! Das ist einfach ein kleines, ekelhaftes, skrofuloses, böses Geistchen. das den Schnupfen hat, eines von den nicht arrivierten'; S. 3871

${ }^{476}$ Ebd., S. 250ff. 
Karmazinov verbunden, d.h. ausschließlich mit den verwestlichten Figuren des Romans.

1. Die meisten polnischen Imageme hăngen mit der Figur des „Westlers“ Stepan Trofimovix Verchovenskijs zusammen. Zu seinen Vorbildern werden mehrere authentische Gestalten der "Westler", der russischen liberalen Intelligenz der 40-er Jahre, gezăhlt, z.B. Gercen, Belinskij, Caadaev, Turgenev oder Kukolnik. ${ }^{77}$ Sowohl im Text des Romans als auch in den zugehörigen Entwürfen wird aber besonders haufig der Name des russischen Historikers Timofej Nikolaevic Granovskij (1813-1855) erwăhnt. Verchovenskij wird in den Entwirfen sogar zuerst als "Granovskij“ bezeichnet: ${ }^{478}$ Das Leben Granovskijs und seine Schriften, die sich hauptsächlich auf die Geschichte Westeuropas beziehen, werden in Besy in satirischer Absicht ausgenutzt.

In den Entwirfen wird in der Diskussion zwischen Granovskij und Satov über die "ausländischen“, darunter auch über die polnischen katholischen Frauen, den von dem "russischen Boden“ entfremdeten Vertretern der russischen Intelligenz bzw. der Schicht der Staatsbeamten gesprochen und das Thema der nationalen russischen Identităt erortert, die durch diese ,gefăhrlichen Beziehungen“ geschwăcht werde. Es wird auch eine „zweite polnische Frau“ von "Granovskij“ erwăhnt:

Ш<атов> Говорит, что это признак оторванности от почвы и от корня, если человек становится наклонен любить женшин других наций, т.е. если иностранки становятся мигее свошх./../ Вицяние nолек-kатоличек на наших чиновников и генералов. /.../ Признак сильной национальности, если граждане больше всего любят и уважают своих родных женшин. /.../

NB. Первая жена Гр<ановсkого> была немkа, 2-я - noльka. [kursiv die Verf.].

[ $\$<$ atov > sagt, daß es ein Anzeichen der Trennung vom Boden und von der Wurzel ist, wenn ein Mann anfangt, dazu zu neigen, Frauen anderer Nationen zu lieben, d.h. wenn ihm die Ausländerinnen lieber als die eigenen Frauen werden. /.../ Der Einfluß der katholischen Polinnen auf unsere Beamte und Generäle. /.../ Ein Anzeichen starker Nationalităt, wenn die Bürger mehr als alle anderen ihre eigenen heimischen Frauen lieben und achten. /.../ NB. Die erste Frau Gr<anovskijs > war eine Deutsche, die 2-te eine Polin.][Übers. und kursiv die Verf.] ${ }^{480}$

$47 \mathrm{Vgl}$. Bd. 12, S. 167ff.

170 Ebd., S. 169fr. und Bd. I1, S. 65f., und passim.

47 Vgl. Bd. 10, S. 7ff. und auch z.B. DMITRIEV 1969. In einer polnischen Enzyklopadie aus dem Jahr 1862 wird außerdem davon berichtet, daB Granovskij der in Moskau studierenden polnischen Jugend sehr gut bekannt gewesen sei und sich durch seine .objektiven Ansichten“ (besstronne poglacty) in der, ,polnischen Frage" ausgezeichnet habe. Vgl ENCYKL.OPEDIA PowszeCHNA, S. 576f. ((iranoniskı. Tymoleusz). Siehe auch Brokgauz / EFRON (Bd. 9, 1898, S. $561 \mathrm{ff}$.) oder LEVANDOVSKu 1989 bzw. ASINOVSKNA 1955.

${ }^{100} \mathrm{Bd}$. 11 , S. 120. 
In diesem Zitat kommt das (alt)russische Stereotyp der „Polin“ als „Verführerin" vor. Diese stereotypen Alter-Figuren haben aber eine zusätzliche "subversive" Funktion. Als katholische Polinnen, also als fremde Ehefrauen fremden Glaubens, dazu aus einem feindlichen Land, „berauben“ sie ihre russischen Mănner der nationalen Identităt und ihres russisch-orthodoxen Glaubens. Es handelt sich somit nicht nur um eine ideologisch-antipolnische, sondern auch um eine antikatholische Anspielung. In der Endfassung von Besy wird jedoch lediglich auf eine "Beziehung" der ersten russischen Frau von Stepan Trofimovic Verchovenskij zu einem „Polackchen“ angespielt, so daß er durch kein polnisches Imagem (durch keine ,polnische Frau“) immanent „, negativ verwestlicht" ist. ${ }^{481}$

Im Zusammenhang mit diesem „liberalen Theisten“ kommt darüber hinaus sowohl in den Entwürfen als auch im Roman ein nach Rußland verbannter polnischer katholischer Priester vor, eine Alter-Figur, die zu den ,zufalligen“ Gästen Stepan Trofimovič Verchovenskijs zählt:

.Являлись k нам в kружок и случайные гости; /.../ Привел было Липутин ссыльного ксендза Слоньщевского, и некоторое время его принимали по принципу, но потом и принимать не стали“. [Manchmal erschienen in unserm Kreis Gäste, die uns der Zufall zuführte; /.../ Liputin brachte einmal den verbannten polnischen Geistlichen Slonzewiski mit, und eine Zeitlang ließen wir ihn aus Prinzip an unseren Abenden teilnehmen, aber dann verkehrten wir nicht mehr mit ihm.] [kursiv die Verf.] $]^{482}$

Daß dieser Pole bei Verchovenskij ,aus Prinzip“ empfangen wird, soll auf die subversiven (propolnischen) Ansichten seines „Kreises“ hindeuten. Der „plötzliche" Abbruch der Beziehungen zu diesem Priester läßt sich aber als ein positives Anzeichen, als eine „patriotische Tat" deuten und kündigt die Rückkehr Stepan Trofimovičs zur russisch-orthodoxen kulturellen Identität im Epilog des Romans an.

In den Entwürfen zum Roman organisiert „Granovskij“ sogar eine Lesung zugunsten eines verbannten polnischen katholischen Priesters, die mit Skandal und Verhaftung endet; es wird u.a. auch der "Vaterlandsverrat" (,измена отечеству“) erwähnt, so daß in der Endfassung des Romans die ",negative“ Okzidentalisierung Verchovenskijs abgeschwächt wurde.

Während des Petersburger Aufenthalts Verchovenskijs und Varvara Petrovna Stavroginas, als der ehemalige "Professor" seine Kontakte zu der westlich

181 Die zweite Frau Stepan Trofimovic Verchovenskijs ist dagegen eine Deutsche aus Berlin. Sie zeichnet sich wie die deutschen Figuren in /diot durch eine stereotyp deutsche ..Schweigsamkeit" aus, die übrigens als ihre einzige „Charaktereigenschaft” enwähnt wird. Vgl. dazu Bd. 10, S. 11 .

${ }^{482}$ Bd. 10, S. 30 [S. 44].

${ }^{483}$ Bd. 11, S. 139, vgl. auch ebd., S. 142, S. 189, S. 198, und passim, was darauf schließen läß $\mathrm{haB}$ diesem polnischen Priester ursprünglich eine wichtigere Rolle als in der Endfassung des Romans zugedacht worden war. 
orientierten Intelligencija in der Hauptstadt emeuern mochte, taucht u.a. das Thema der Wiederherstellung Polens „bis zum Dnepr" auf:

Говорили об уничтожении цензуры и буkвы 8, о заменении руссkих буkв латынсkими, /.../ о полезности раздробления России по народностям с вольною федеративною связью, об уничтожении армии и флота, о восстановлении Польии по Днепр, о крестьянской реформе и прокламациях, об уничтожении наследства, семейства, детей и священников, о правах женшины /.../. Ясно было, что в этом сброде новых людей много мошеннников, но несомненно было, что много и честных, весьма даже привлекательных лиц /.../. [kursiv die Verf.]

[Man unterhielt sich über die Abschaffung der Zensur und des harten Zeichens, über das Ersetzen des russischen Alphabets durch das lateinische, /.../ über die Zweckmäßigkeit einer Aufteilung Rußlands in nationale Einheiten in freier foderativer Verbindung, über den Abbau von Armee und Flotte, über die Wiederherstellung Polens bis zum Dnjepr, über die Landreform und die Proklamationen, über die Abschaffung von Erbrecht, Familie, Kindern und Geistlichen, über die Rechte der Frau /.../. Es war klar, daß in diesem Kunterbunt von neuen Menschen mancher Schwindler zu finden war, aber zweifellos auch viele ehrliche, sogar außerordentlich anziehende Personlichkeiten /.../. [kursiv die Verf.]] ${ }^{\text {(84 }}$

Der „Diskurs“ dieser Petersburger Intellektuellen wird vom Ich-Erzăhler, der selber "verwestlicht" ist, teilweise „positiv" beurteilt, weil es sich dabei nicht nur um die Wiederherstellung Polens in den Grenzen vor der ersten Teilung und die "Latinisierung" des russischen Alphabets handelt, sondern auch um die Aufhebung der Leibeigenschaft oder um die Gleichberechtigung der Frauen.

In der Fortsetzung dieser Episode werden aber diese ,.neuen Russen“ und "Atheisten“ als freche, egoistische „Betrüger" gezeigt, so daß alle von ihnen verlangten .Reformen“, die eine „Verwestlichung" Rußlands zum Ziel haben. im negativen Kontext erscheinen. Besonders die „Wiederherstellung" Polens steht neben der .,Schriftreform" symbolisch für die "Auflösung" Rußlands und für den Verlust der kulturellen russischen Identităt. Weil aber Stepan Trofimovic Verchovenskij und seine Gönnerin von diesen „Nihilisten“ schließlich „verstossen“ werden, zeigen sie sich als „Patrioten“. Ihr "Idealismus" bildet den positiven Kontrast zu den ,gottlosen Utilistaristen“.

$\mathrm{Zu}$ den Freunden von Stepan Trofimovic Verchovenskij in der Provinz gehört außerdem der oben enwăhnte Jude Ljamšin, der eine musikalische Parodie des Französisch-Preussischen Krieges anbietet. ${ }^{486}$ Nach LEDNICKI $^{487}$ ist diese

484 Bd. 10.S 22 [S. 31]. vgl. dazu Bd. 12, S. $283 f$.

"es Es handelt sich bei dieser Passage auch um eine Anspielung auf den „ăsthetischen“ und .Ideologischen" Gegner Dostoevskijs, Cemysevskij, dessen Ansichten schon in Zimnie zametkı o leinich vpeciallenijach und in Zapiskı Is pridpol'ja angegriffen werden. Vgl. z.B. oben, S. 234, Fußnote 232.

${ }^{486}$ Bd. 10, S. 25If. Vgl dazu auch INGOLD 1981, bzw. GOLDSTEIN 1981 
Parodie ein Motiv, das Dostoevskij von ADAM MICKIEWICZ entlehnt und ironisch umgedeutet hat, ein „Echo“ der musikalischen Künste des zimbelspielenden patriotischen Juden Jankiel im polnischen Nationalepos Pan Tadeusz. ${ }^{\$ 8}$

Obwohl Stepan Trofimovic Verchovenskij als der "Vater" bzw. der "Erzieher" der "Nihilistengeneration" an der "Besessenheit" Rußlands durch "westliche Ideen" mitschuldig ist, wird diese Figur des liberalen Westlers der 40-er Jahre, trotz der "ideologischen" sowie auch „persönlichen“ Schwăchen, relativ sympathisch, positiv dargestellt. ${ }^{489} \mathrm{Er}$ ist zur geistigen, zur religiosen Emeue-

$487 \mathrm{Vgl}$. LEDNICKI 1953, S. 303-308: „/.../ Dostoevsky took the idea of the disturbance of a national hymn by a noisy 'insolent' melody from $/ . . /$ Mickiewicz $/ . . /$, but he made a parody of it. Dostoevsky could have openly parodied, but that would have been in bad taste. There were so many reasons to 'parody' Jankiel's performance by a transposition into a Marsetllaise and Meın lıeber Augusıı" (S. 303f. und 307). Vgl. auch dazu PoŻNIAK 1992, S. 100ff,, bes. S. 114. Poźniak erwähnt dagegen die Figur Jankiels nicht, ebd. Vgl. auch INGOLD 1981, S. 74f. Ingold nennt als das Vorbild Ljamšins den deutsch-jüdischen Pianisten Karl (Charles) lewy [Levi] (ebd.). Vgl. auch ALT'MAN 1971, S. 212f. (Ljamšin I muikant Karl Levi [Ljamsin und der Musikant Karl Levi]). Alt'man beruft sich seinerseits auf die Erinnerungen V. A. Sollogubs (Moskva-Leningrad 1931, S. 419f.) an einen Auftritt Levis im Hause eines der glühendsten polnischen Patrioten, bei dem er auf dem Klavier mit der linken Hand die polnische Nationalhymne Jeszcze Polska nıe zginęla [Noch ist Polen nicht verloren] und zugleich mit der rechten eins von den beliebtesten gemütvollen russischen Lieder gespielt hatte). ses Vgl. auch MICKIEWICZ 1955a (Pan Tadeusz czyli ostalni zajazd na litwie. Historia szlachecka = roku 1811 , 1812 we dwunasiu ksiegach wierszem. [Herr Tadeusz oder der letzle Einrıtl in L.tlauen. Eine adlıge (ieschichte uus dem Jahre 1811 und 1812 in wölf Büchern in Versen]: S. 106-109 (Księga czwarta. Dyplomatyka i lowy: Karczma [Das vierte Buch. Diplomatie und Jagd: Die alte Schenke] ) und S. 349-353 (Księga dw'unasla. Kochajmy się: Koncert nad koncerlamı [Das zwölfie Buch. Liehen wir uns: Das Konzert der Konzerie]), sowie MiCKIEWICZ 1962, S. 201 (Die Anmerkung des Herausgebers zur Figur des Juden Jankiel: Mickiewicz habe in Petersburg Jankiel Liberman, einen hervorragenden Zimbelspieler (Beckenschlăger) kennengelemt und in l'an Tadeus: geschildert). LeDNICKI 1953 (S. 302) unterstellt noch eine weitere Anspielung auf das Gedicht von MICKIEWICZ Pomnik Piotra Wielkiego [Das Denkmal Peters des (jroßen] in den Entwürfen zu Besy: Bei Mickiewicz wird dieses Denkmal mit einem zu „Eis erstarten Wasserfall der Tyrannei“" verglichen, den aber der „warme Wind der Freiheit aus dem Westen“ zum Sturz bringen wird. Lednicki vergleicht diese Metapher mit einer Äußerung Satovs über den ..festen“ deutschen Nationalismus, den er dem seit der Zeit Peter des Großen ,schwankenden“ russischen nationalen Gefühl gegenüberstellt. Vgl. dazu Entwürfe zu Besy, Bd. 11, S. 156: ._ немец]/.../ верует в себя и в сінту свою - /.../ что и есть самая суиность национатьності. /.../ У нас не верят себе i.../. Шатость во всем двухсотлетняя. Вся реформа наша, с Петра начнная, состояла лишь в

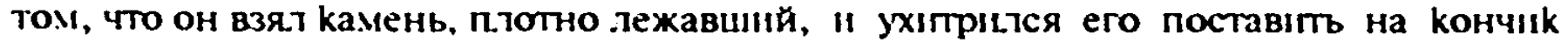
угла. Мы на этой тоике стоия и балансируем. Ветер дунет и полетия" ||Der Deutsche $/ . . . /$ glaubt an sich und an seine $\mathrm{Kraft} / \ldots /$, was das eigentliche Wesen der Nationalitát ist. /.../ Bei uns glaubt man sich selbst nicht. /.../ In allem gibt es eine zweihundertjährige Ambivalenz. Unsere ganze Reform, mit Peter angefangen, bestand nur darin, daß er einen Stein nahm, der fest auf der Erde lag und ihn geschickt auf das kleine spitze Eck stellte. Wir stehen also auf diesem P'unkt und balancieren. Wenn der Wind auf einmal weht. kippen wir um] [kursiv die Verf.]. Auch in dem symbolischen Namen Satov wird auf das russische Verb uamambcr (= schwanken) angespielt. Siehe auch MICKIEWICZ 1955b (S. 283-285: (Istep: Pomnik Piotra Wielkiego [Anhang: Das Denkmal Peters des (jroßen]).

${ }^{489} \mathrm{Vgl}$. die Charakterisierung Verchovenskijs in den Entwürfen zu Besy, in der das Motiv des ..ästhetischen Idealismus" und des ..heidnischen Glaubens" an das Goldene Zeitalter vor- 
rung fahig und findet moglicherweise vor seinem Tode den Weg zum (russischorthodoxen) Glauben an das "menschliche Ideal", der vom "Christusbild" Renans zum (nussisch-orthodoxen) „Christusbild der Evangelien“ fuhrt. Die entscheidende Rolle bei seiner Wandlung fallt der Evangelienverkäuferin Sof ja Matveevna zu, einer russischen Alius-Figur, obwohl der Chronist die ,religiose Bekehrung" Verchovenskijs lediglich als ein "Gerücht" nacherzăhlt. ${ }^{400}$ Zusammen mit Sof ja Matveevna will er aber sogar das Evangelium" unter das ,russische Volk" bringen. Von ihr betreut, stirbt er auf dem Weg in das Dorf Spasov, dessen Name eine Anspielung auf den Spas [Cnac], auf Christus den Erloser, ist. Verchovenskij deutet auch die Stelle aus dem Lukasevangelium, die dem Roman als Motto vorangestellt ist, indem er die russischen "Nihilisten“, zu denen

kommen, die auch den "Traum" Stavrogins sowie die utopischen Visionen Versilovs (im năchsten Roman Podrosiok) prăgen, ..Портрет чистого и ицеатьного западника со всеми kрасотами. /.../ Большой поэт, не без фразы. Просмотрел совсем русскую жизнь. Чурается нипцтизма и не понімает его. /.../ "Оставьте мне бога il iсkусство. Уступаю

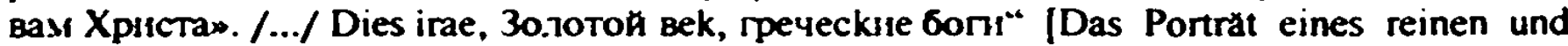
idealen Westlers mit allen Schonheiten. /.../ großer Dichter, nicht ohne Phrase. Hatte das russische Leben ganz übersehen. Ängstigt sich vor dem Nihilismus und versteht ihn nicht. I.../ Laßt mir Gott und die Kunst. Ich trete euch Christus ab. \%.../ Dies irae [Der Tag des Zoms], das Goldene Zeiltalter, griechische Gotter] (Bd. 11, S. 65f.).

$90 \mathrm{Vgl}$. Bd. 10, S. 486ff: „Vous êtes ce qu' on appelle kніггоноша; /.../ Je n'ai rien contre l'Evangile, et... Я давно уже хоте.1 перечитать... У него мелkну.ло в ту минуту, что он не чıттал Евангетия по крайней мере лет тридиать и только разве лет семь назад припомніLт из него kane.тьку по Ренановой kниге «Vie de Jésus». /.../ Народ ре.иигозен, /.../ но он еще не знает Еванге.ия. Я емуу изложу его.../.../. /../ Она прочитата нагорную проповедь. /.../ прочтите мне еще что-нибудь /.../. /.../ одно место... о свиньях, /.../ я помню, бесы вошти в свиней и все потону.ר"“, bzw. S. 505f.: „B самом .ли де.ле он увероват, ити ветичественна церемония совершенного таинстьа потряс.та его и возбуди.а художественную восприінгчивость его натуры, но он твердо и, говорят, с бо.льшим чувством произнес неско.лько с.тов прямо вразрез многому 113 его прежніх убеждений". /.../ Мое бессмертие уже потому необходимо, что бог не захочет сде.лать неправды и погасить совсем огонь раз розгоревшейся $\mathrm{k}$ нему любви в моем сердие. И что дороже .любви? / ... / kогда я понял... эту подставтенную .ланіту, я ... я тут же и еще кой-что поня]...J' ai menti toute ma vie, всю, всю жизнь!" [kursiv die Verf.]

[S. 883ff: 'Vous êtes ce qu on appelle Bibelverkäuferin; /.../ Je n'ai rien contre I'Evangile, et... Ich wollte es schon immer wieder lesen.. .' In diesem Augenblick ging es ihm durch den Sinn, daß er das Evangelium seit wenigstens dreißig Jahren nicht gelesen und sich nur vor etwa sieben Jahren an einiges daraus erinnert hatte, während der Lektüre von Renans neuem Buch \&Vie de Jésus». /.../ Das Volk ist religios. /.../ aber es kennt das Evangelium noch nicht Ich werde es ihm auslegen.../.../. /../ Sie las ihm die Bergpredigt vor. /.../ lesen Sie mir noch etwas vor /.../. /../ eine Stelle /.../ ... von den Schweinen /.../. Ich erinnere mich, daß die bosen Geister in die Schweine fahren und alle ertrinken $1 . . . /$ : S. 913: Ob er nun wirklich zum Glauben gefunden oder ob die erhabene Zeremonie der Heiligen Sakramente ihn erschüttert hat er soll jedenfalls mit Festigkeit und, wie mun sugt, mit tiefem Gefühl einige Worte gesagt habèn, die manchen seiner früheren Überzeugungen geradezu widersprachen. Meine Unsterblichkeit ist schon allein deshalb unentbehrlich, weil Gott kein Unrecht wird begehen und das Feuer der Liebe, die in meinem Herzen für Ihn entbrannt ist, endgültig wird auslöschen wollen. Und was gibt es Kostbareres denn die Liebe! $i . . ;$ als ich diese ... diese dargebotene Backe verstand, habe ich ... auch einiges mehr verstanden... J ai menti toute ma vie ... mein ganzes, ganzes Leben lang! [kursiv die Verf.] 
er sich selbst zăhlt, die „bösen Geister" nennt, von denen Rußland „besessen“ ist. Die polnischen Imageme, die im Zusammenhang mit dieser Figur genannt worden sind, betreffen somit das „Wesen" Verchovenskijs nicht, sie treten in seinem Umkreis auf. Seine Okzidentalisienung ist aber nur vorübergehend, ist ihm nicht "immanent" eigen, worin er sich vom Fürsten Valkovskij oder von seinem Sohn Petr Stepanovic Verchovenskij unterscheidet.

In der Figur Stepan Trofimovic Verchovenskijs kommt es im Epilog des Romans zur Auseinandersetzung zwischen dem positiven „westlichen utopischen Idealismus", die u.a. durch seinen Kult der Sixtinischen Madonna bzw. "Shakespeares", "Goethes“ bzw. auch „George Sands“ symbolisiert wird, d.h. durch sein Ideal der "Schónheit“, die in der Kunst und Literatur ausgedrückt wird, und dem russisch-orthodoxen Glauben, der kurz vor seinem Tode in ihm die Oberhand gewinnen mag, obschon diese Erlossung Verchovenskijs durch die indirekte Wiedergabe der Ereignisse durch den „verwestlichten“ Erzăhler relativiert wird. Die polnischen Imageme treten lediglich als Kontrast zu dieser Figur auf, und dienen somit nicht zur immanenten Charakteristik dieser grundsătzlich positiven Figur, wie ganz im Gegenteil bei seinem Sohn Petr Stepanovix Verchovenskij, der zu den negativsten Figuren in Besy gehört.

2. Mit Petr Stepanovix Verchovenskij, der, wie oben bereits bemerkt, neben Sigalev $^{491}$ wohl eine der negativsten dämonisch-bösen Figuren des Romans ist, sind weitere polnische Imageme verbunden.

Stepan Trofimovic Verchovenskij soll nach den Worten des Ich-Erzählers in erster Ehe mit einer Russin verheiratet gewesen sein, die ihn jedoch verlassen hatte und in Paris gestorben war. ${ }^{42}$ Der dieser Ehe entstammende Sohn, Petr Stepanovic Verchovenskij, wurde von seinem Vater zu Verwandten geschickt und kann daher nicht als sein „Schüler" im wortwortlichen Sinne betrachtet werden. Der junge Verchovenskij betrachtet seinen Vater mit arroganter Verachtung und rechnet unbarmherzig mit dessen "Erziehung“ ab, nachdem er aus dem Ausland in die Provinzstadt gekommen ist. ${ }^{493}$ Dabei kommen Tatsachen zum Vorschein, die darauf hinweisen, daß Petr Stepanovic Verchovenskij der Sohn eines Polen ist, mit dem jene erste Frau von Stepan Trofimovic Verchovenskij von Berlin aus nach Paris geflohen war:

- Но скажи же мне наконец, изверг, сын ли ты мой или нет?

- Об этом тебе лучше знать.

/.../ - я документ-то /.../ отысkал. /.../ Правда, ничего нет точного, можешь утешиться. Это только записка мюей матери $k$ этольу пољя4ky. Но, судя по ее хараkтеру...

491 Sigalev lăßt sich als alter ego Verchovenskijs bezeichnen. Er ist aber, im Unterschied zum .Praktiker" Verchovenskij, der "Theoretiker" der terroristisch-revolutionären Bewegung, Verfasser des von Verchovenskij geschatzten utopisch-sozialistischen Traktats (vgl. dazu Bd. 10, S. 310ff. und S. 322f.).

492 Vgl. Bd. 10, S. 11.

${ }^{493}$ Ebd, S. 24 und S. $237 f$ f. 
/.../ В Петербурге, когда я был еще гимназистом, не он ли будил меня по два раза в ночь, /.../ и kak вы думаете, что расckазывал мне по ночам-то? /.../ Or нето я от первого и услыхал.

/.../ С моей точkи зрения, не беспокойся: я мать не виню; ты mak ты, nольк mak nоляk, мне всё равно. [kursiv die Verf.]

['Sag mir endlich, du Ungeheuer, bist du mein Sohn oder nicht?'

'Das solltest du besser wissen. /.../ ich habe das Dokument doch gefunden. /.../ Freilich, etwas Genaueres gibt es nicht, damit kannst du dich trösten. Nur ein Briefchen von meiner Mutter an diesen Polacken. Aber wenn man ihren Charakter in Betracht zieht...\%.../ War er es nicht selbst, der in Petersburg mich, einen kleinen Gymnasiasten, in der Nacht zweimal weckte, /.../ und was glauben Sie, was er mir dann nächtelang erzählte? /.../ Er war der erste, von dem ich sie horte.' /.../ Von meinem Standpunkt aus brauchst du keine Bedenken zu haben; ich gebe meiner Mutter keine Schuld; ob du es warst, ob es der Pole war, mir ist es schnuppe!' [kursiv die Verf.] $]^{494}$

Auf die "rhetorische“ Frage des „Vaters", ob Petr, den er ein „Ungeheuer" nennt, „sein“ Sohn sei, erzăhlt Petr Stepanovic Verchovenskij über eine aufgefundene Notiz seiner Mutter an ein bestimmtes „Polackchen“, was er für einen Beweis hălt, daß er der Sohn dieses Polen sei. Als eine zusätzliche Bestätigung dienen ihm die năchtlichen „Bekenntnisse“ von Stepan Trofumovic, die dieser ihm vor Jahren in Petersburg gemacht hatte. Die Gleichgültigkeit des jungen Verchovenskij dem „Vater" und seiner Herkunft und Familie gegenüber hebt seinen .zynischen Pragmatismus“, d.h. seine Ablehnung aller traditionellen Werte, hervor: Der junge Verchovenskij tritt in dieser Szene als sterotyper „Nihilist“" auf.

Das „Polackchen“ (als eine Alter-Figur) ist dagegen das von Dostoevskij „beliebte“ negative Stereotyp des "polnischen Verführers", das bereits in früheren Werken die gleiche Funktion, auch als ideologische Anspielung, erfüllt hat. In Besy „vererbt" aber dieses ..Polackchen" seine "teuflischen" Eigenschaften einem Russen, seinem Sohn, wodurch seine „subversive, rußlandfeindliche polnische Natur" der jungen russischen Generation immanent geworden ist. Der russische "Nihilist“" Petr Stepanovið Verchovenskij ist auf diese Weise zum „bösen Geist" nicht nur wegen seiner "westlichen Erziehung" geworden, sondern ist bereits .genetisch" durch seine vermeintliche halbpolnische Abstammung vorbelastet, was ihn noch gefährlicher erscheinen läßt. Seine negative Okzidentalisierung ist dadurch als für inmer "unheilbar" anzusehen.

Petr Stepanovic Verchovenskijs wird auch als eine beinahe ,numinos“ abstoBende Figur beschrieben. Sein Äußeres, seine Redensweise und sein Benehmen entsprechen seiner "Herkunft“, indem er dem Stereotyp des „Polackchens“, des "Ljachs in der Gestalt eines Teufels", ähnlich ist:

${ }^{494}$ Ebd., S. 240 [S. 404f.] 
Никто не скажет, что он дурен собой, но лицо ето никому не понравится. Голова его удлинена $k$ затылkу и kak бы сплюснута с боков, таk что лицо его кажется вострым, /.../ носик маленький и востреньkий, губы длинные и тонкие. Выражение лица словно болезненное, но это только кажется. /.../ Он ходит и движется очень торопливо, но никуда не торопится. /.../ В нем большое самодовольство, но он сам его в себе не примечает нисколько.

Говорит он ckopo, торопливо, но в то же время самоуверенно /.../. /.../ Выговор у него удивительно ясен; слова его сыплются, kak ровные, kрупные зернушки, всегда подобранные и всегда готовые $\mathrm{k}$ вашим услугам. /.../ Вам kak-то начинает представляться, что языk у него во рту, должно быть, kаkой-нибудь особенной формы, kakoйнибудь необыкновенно длинный и тонкий, ужасно красный и с чрезвычайно восртым, беспрерывно и невольно вертяшимся кончиkом.

[Niemand kann behaupten, er sei unansehnlich, aber sein Gesicht gefallt niemand. Sein Hinterkopf ist lang, wie auf beiden Seiten zusammengedrückt, so daß sein Gesicht schmal und spitz erscheint. /.../ das Näschen klein und spitz, die Lippen sind dünn und lang. Der Gesichtsausdruck scheint leidend, aber das scheint nur so. /.../ Er geht und bewegt sich sehr hastig, aber er ist niemals eilig. /.../ Er ist mit sich höchst zufrieden, aber ohne es je selbst zu merken. /.../ Er artikuliert erstaunlich deutlich; seine Worte perlen wie ebenmäßige, große Körner [Körnchen], stets passend und stets jedem zu Diensten. /.../ Und auf einmal drăngt sich die Vorstellung auf, die Zunge in seinem Mund müsse eine ganz besondere Form haben, irgendwie ungewöhnlich lang und schmal sein, ganz furchtbar rot, mit einer außerordentlich scharfen, unentwegt und wie von selbst kreisenden Spitze.] $]^{495}$

Verchovenskij wird mit Hilfe der gleichen Motive wie die polnischen stereotypen Figuren, die ...scharwenzelnden Polackchen“" in den früheren Werken Dostoevskijs charakterisiert, obwohl er zugleich als Individuum beschrieben wird. Er läuft und spricht genauso schnell und ist immer „zu Diensten“ bereit wie jene "Polackchen" in Igrok oder in Prestuplenie i nakazanie. Er wird aber im Unterschied zu diesen polnischen Figuren - weit ausführlicher charakterisiert. Die Aufmerksamkeit des Lesers wird zuerst auf seinen langen und seitlich flach zusammengedrückten, schmalen Kopf, auf das kleine, spitze Näschen sowie auf seine langen und dünnen Lippen gerichtet. Seine Selbstsicherheit, die er ebenfalls mit den stereotypen Polen teilt, äußert sich besonders in seiner Redeweise. In seiner klaren, ,perlenden“ Ausprache, in den „ebenmäßig wie Körnchen" artikulierten Worten, äußert sich seine stetige "Dienstbereitschaft". was den Eindruck erweckt, als ob er eine besonders bewegliche, rote, lange und spitze Zunge hätte. Die Aussprache Verchovenskij hat zum einen etwas „Künstliches“. "Statisches“, „Vorgeformtes“, also etwas Stereotypes an sich, zum an-

${ }^{495} \mathrm{Vgl}$. ebd., hier S. 143f. und S. 295 [S. 235f.], S. 464ff. und S. 476ff. sowie zu Ljamšin ebd. S. $248 f$ f. 
deren verleiht ihm die Beschreibung seiner Zunge etwas „Reptilhaftes“, so daß er, auch wegen des langen, flachen Kopfes, an eine Schlange erinnert. Dadurch wird in dieser Figur eine zweifache Äquivalenz geschaffen, nicht nur zum stereotypen "Ljach in der Gestalt eines Teufels“, sondern auch zum „biblischen bösen Geist“`96, obwohl beide Symbole sich auf den „Verführer zum Bösen“ beziehen.

Obwohl Verchovenskij psychologisch differenziert dargestellt wird und ungeachtet seiner russischer Vorbilder, Nečaev bzw. Bazarov, ${ }^{497}$ teilt er doch mehrere gemeinsame Motive mit den polnischen stereotypen Figuren. Er läßt sich somit wie die russischen Alius-Figuren, Petr Aleksandrovic Valkovskij oder Svidrigajlov, als „psychologisch differenziertes Stereotyp eines Polen“, als eine von ,petrinischen“ Russen angeeignete fremde Identitătsstruktur, bezeichnen. Im Fall Verchovenskij wird diese „subversive“ Personlichkeitsstruktur durch seine halbpolnische Herkunft zusătzlich hervorgehoben.

Der ,junge“ Verchovenskij, der den Vornamen Petr trägt, den Namen aller negativ verwestlichten, „petrinischen" russischen Figuren, weist zusătzlich im Laufe der Handlung noch weitere Bezüge zu einem stereotypen „Polackchen“ auf. Er nennt sich selbst der selbsternannte „Lakai“ Stavrogins und einen „Betrüger". Im Epilog des Romans flieht er in den "Westen" wie ein in Prestuplenie $i$ nakazanie erwăhnter ,polnischer Verschworrer" und wie ein "Lakai des Westens". Aus Stavrogin mochte Verchovenskij einen Ivan Carevič bzw. einen Usurpator (wie Dmitrij Samozvanec) machen, sich mit dem Papst verbünden und im Geiste von Šigalevs Theorie über die versklavten, durch Mord und Terror gleich gemachten Menschen herrschen. ${ }^{498}$ Sein ideales politisches System möchte er wie eine Smuta, eine "Zeit der Wirren“, verwirklichen, was genug Assoziationen mit der polnisch(-katholischen) Invasion der Moskauer Rus`im 17. Jahrhundert schafft. ${ }^{499}$ Petr Stepanovic Verchovenskij spielt somit in Besy die Funktion des „Teufels“, des ..Antichristen“, was zusätzlich durch die An-

496 In einer ăhnlich stereotypen Weise wird auch der Jude Ljamšin, eine Alter-Figur, charakterisient. Vgl ebd., und auch S. 298ff., 325f. Vgl. auch zum biblischen Symbol der „Schlange“, z.B. bei LURKER 1987, S. 318-320, bes. S. 318: "Die erste biblische Aussage uber die Schlange nennt als deren Hauptmerkmal die List, ja, sie "war listiger als alle anderen Tiere des Feldes (Gen 3,1). Die gespaltene Zunge der Schlange wird in Übereinstimmung mit ihrer 'Doppelzungigkeit erkannt: durch ihre trügerischen Versprechungen - 'Ihr werdet sein wie Gott' (Gen 3,5) - verführt sie die ersten Menschen zum Essen der verbotenen Frucht Das Auftreten der Schlange bezeichnet den entscheidenden Wendepunkt des Paradiesdramas: Sic verspricht Leben 'O nein, auf keinen Fall werdet ihr sterben' (Gen 3,4) -, bringt aber in Wahrheit den Tod". Siehe auch SPIrZING 1989, S.285f.

${ }^{497}$ Vgl. dazu Bd. 12, S. 172 ff., bzw. S. 175 (u.a. zu Petr Stepanovic Verchovenskij als eınem herslosen Buzarov - опоиленныд Базаров), S. 200ff. Erwăhnt wird auch, daß der polnischstämmige Petersburger Rechtsanwalt Wlodzimierz Spasowicz. der Verteidiger im Prozeß Necaevs war und ihn darüber hinaus als einen ..Praktiker" des Nihilismus bezeichnct haben soll (S. 210f.).

498 Bd. 10, S. 297ff., S. 319fr., bes. S. 323ff.

999 Ebd. Stavrogin wird aber auch von der Jurodivaja Mar ja Lebjadkina als der Sumozanec, (irıske (Mrep ev, als der .falsche Carevic“", erkannt (S. 214ff.). Stavrogin enttăuscht aber schließlich Petr Stepanovid Verchovenskij selbst, der ihn ein "Herrensöhnihen“ (барчонок) nennt (S. 326 bzw. S. 408). 
spielung auf den „Papst“ im Kontext seiner ganzen Person und den im Roman dargelegten Anschauungen hervorgehoben wird. Er ist somit eine idealtypische „immanent bose, verwestlichte“ Alius-Figuren und in der extremen Negativität und in der extremen Okzidentalisierung besonders dem Fürsten Petr Aleksandrovic Valkovskij ăhnlich. Verchovenskij hat zugleich eine ideologische, extrem antipolnische und antikatholische Funktion, indem er als die verbrecherische Verkörperung des "Bösen", der negativen atheististischen "Ideen" aus dem „Westen" auftritt, die Rußland zugrunde richten wollen. Er symbolisiert eindeutig das negativ utopische, ,petrinische“ Imagothème des verwestlichten Rußlands, ist sowohl negativ-utopisch als das Symbol des Bösen, als auch negativ-ideologisch mit antipolnischen bzw. antikatholischen Akzenten besetzt.

3. Im Zusammenhang mit der Figur Julija Michajlovna und dem Kreis um sie und um Petr Stepanovix Verchovenskij tritt noch ein weiteres polnisches Imagem, eine weitere polnische Figur auf:

/.../ в толпе молодых дам и полураспущенных молодых людей, составлявших обычную свиту Юлии Михайловны и между которыми эта распушенность принималась за веселость, а грошовый иинизм за ум, я заметил два-три новых лица: kakozo-то заезжего, очень юлившего nолька, kakoro-то немца-доктора, здорового старика, тромко и с наслаждением смеявшегося поминутно собственным своим вицам, и наконец, kakoro-то очень молодого kнязька из Петербурга, автоматичесkой фигуры, с осанкой государственного человека и в ужасно длинных воротничkах. [kursiv die Verf.]

$[/ \ldots /$ in dem Schwarm junger Damen und halbliederlicher junger Herren, dem üblichen Gefolge Julija Michajlownas, die Liederlichkeit für Lebensfreude und billigen Zynismus für Geist hielt. [bemerkte ich] zwei oder drei neue Gesichter: einen durchreisenden, um sie scharwenzelnden Polen, einen deutschen Arzt, einen kräftigen alten Herm, der laut und genüßlich alle Augenblicke über seine eigenen "Fitze" lachte, und schließlich irgendein junges Fürstchen aus Petersburg, ein mechanisches Spielzeug mit der Haltung eines bedeutenden Staatsmannes und schrecklich hohem Stehksagen [kursiv die Verf.]] ${ }^{500}$

In dieser Gruppenszene, die ansonsten Hintergrund des „Wortduells“ zwischen Karmazinov und Stepan Trofimovic Verchovenskij abgibt, spielt sich eine Auseinandersetzung zwischen zwei Imagothèmes ab: dem „negativen utopischen Imagothème des verwestlichten Rußlands", das der völlig Rußland entfremdete, in Deutschland lebende Schriftsteller Karmazinov vertritt. und dem „positiven“, das von Verchovenskij „verkörpert" wird. Die fremden. stereotypen Alter-Figuren dienen dabei zur negativen Charakterisierung der verwestlichten Frau des „deutschen“ Gouverneurs, die Karmazinov als einen „willkommenen“ Gast betrachtet und für eine Autorität hält. Das Julija Michajlovna üblicherweise

${ }^{500}$ Bd. 10, S. 348 [S. 637]. 
begleitende „Gefolge“ zeichnet sich aus der kritischen Sicht des Erzăhlers durch "Liederlichkeit" und „billigen Zynismus" aus, die aber fur "Lebensfreude" und für "Geist" bzw. für "Verstand" gehalten werden. Der Erzăhler bemerkt dabei hauptsächlich drei Figuren: ein "durchreisendes und sehr scharwenzeldes Polackchen", einen robusten, selbstzufriedenen deutschen Arzt sowie ein junges „Fürstchen“ aus den Petersburger Regienungskreisen, das an eine „Puppe“ erinnert.

Diese Szene ist drei Gruppenszenen aus früheren Werken Dostoevskijs ăhnlieh: sie erinnert an die Beschreibung des "Gefolges" von Napoleons III. in Zimnie zametki o letnich vpecatlenijach und an dessen Parodie, an das Gefolge des russischen Generals in Igrok, sowie besonders an die Rogožin umgebende Gruppe stereotyper Figuren im Roman Idiot, in der ein ,scharwenzelndes Polackchen" vorkommt.

In Besy werden sowohl die Figur des lediglich auf einen Charakterzug reduzierten Polen als auch die des im folgenden Gesprăch mit Karmazinov etwas genauer charakterisierten Deutschen als "latente Feinde“ Rußlands und seines Glaubens eingeführt. Die polnische Figur bildet neben den anderen fremden Figuren den Kontrast (als alter) zu den russischen Figuren und deutet auf die negative Okzidentalisierung Julija Michajlovnas hin, deren "Liebling" gerade Petr Stepanovic Verchovenskij geworden ist. Dadurch wird zusătzlich der paradigmatische "subversive“ Bezug zwischen dem „Polackchen" in ihrem "Gefolge“ und dem russischen "Nihilisten" geschaffen. Alle drei Alter-Figuren vertreten somit drei im Hintergrund der Handlung präsente Elemente, die RuBland latent gefăhrden und die negative Okzidentalisierung russischer „höherer Schichten“ symbolisieren.

4. In dem "letzten“ literarischen Werk Karmazinovs, Merci, wird noch ein anderes polnisches Imagem eingesetrt: Es wird darin u.a. der Name Chopins erwăhnt:

Тема... /.../ Kak ни хмурились наши губернские лбы целую половину чтения, ничего не могли одолет: /.../. Правда, много говорилось о лкбви, о любви гения k kакой-то особе, но признаюсь это вышло несkолько неловkо. /.../ Тут непременно kругом растет дрок (непременно дрок или kаkая-нибудь таkая трава, о которой надобно справлятся в ботанике). /.../ Сидят они где-то в Германии. /.../ Kakar-mo pycaska запumasa в kустах. Глюk заиграл в тростнике на ckpиrke. «/.../ и расстались навеки" /.../ он /.../ три года criyckaется в Мосkвс под Сухаревою башней, и вдруг /.../ находит /.../ схимника. /.../ Тут опять заклубился туман, явился Гофман, просвисталь uз Iloneна русалkа /..././.../ Одним словом, я, может быть, и не таk передаю /.../, но смысл болтовни был именно в этом роде. /.../ Великий европейсkий философ, великий ученый, изобретатель, труженик, мученик - все эти труждаюшиеся и обременные для нанего русckого великого гения решительно вроде поваров у него на kухне. Он барин, а они являются $k$ нему с kолnakaми в pykax и 
ждут приказаний. Правда, он надменно усмехается и над Россией во всех отношениях пред великими умами Европы /.../ Он берет чужую идею, приплетает $k$ ней ее антитез, и каламбур готов. Есть преступление, нет преступления; правды нет, праведников нет; атеизм, дарвинизм. /.../ Тут казенный припадок байроновсkой тосkи, гримаса из Гейне, что-нибудь из Печорина, - и пошла, и пошла, засвистала машина... [kursiv die Verf.]

[Das Thema... /.../ Wie sehr auch unsere Gouvernementsköpfe während der ganzen ersten Hälfte der Lesung ihre Stirne runzelten, sie konnten nicht dahinterkommen /.../. Freilich, es war viel von Liebe die Rede, von der Liebe eines Genies zu irgendeiner Person, aber (ich muß es gestehen) gerade das war ein wenig peinlich. /.../ Dabei durfte der Ginster ringsum (es mußte unbedingt Ginster oder ein anderes Kraut wachsen, das man erst in einem botanischen Atlas suchen muß) nicht fehlen. /.../ Sie sitzen /.../ irgendwo in Deutschland. /.../Eine Nixe piepste im Gebüsch. Der Ritter von Gluck spielte im Schilf die Geige. /.../ und wir trennten uns auf ewig. /.../ nun steigt er [drei Jahre lang: Erg. d. Verf.] hinab, /.../ in Moskau unter dem Sucharjew-Turm, und plötzlich, /.../ sieht er /.../ einen Einsiedler. /.../ Und wieder ballten sich Nebelschwaden, erschien E.T.A. Hoffmann, wieder flötete eine Nixe eine Melodie von Chopin /.../. Kurz. vielleicht gebe ich es nicht wortgetreu wieder /.../, aber der Sinn dieses Geschwätzes war ganz genau von dieser Art. /.../ Der große europäische Philosoph, der große Gelehrte, Erfinder, ewige Arbeiter, Märtyrer - alle diese Mühseligen und $\mathrm{Be}$ ladenen sind für unser russisches Genie nichts anderes als Köche in seiner Küche. Er ist der gnädige Herr, und sie treten vor ihn hin, ihre Kochmützen in der Hand, um seine Befehle entgegenzunehmen. Freilich, er belächelt herablassend [vor diesen großen Geistern Europas] auch Rußland /.../. /../ Er greift eine fremde Idee auf, strickt ihr eine Antithese an, und der Calembour ist fertig. Fs gibt Verbrechen, es gibt kein Verbrechen, es gibt keine Wahrheit, keine Gerechten; Atheismus, Darwinismus. /.../ Ein obligater Anfall von Weltschmerz à la Byron, eine Grimasse à la Heine, eine Prise Petschorin - und die Lokomotive fähn pfeifend an... [kursiv die Verf.]] $]^{501}$

Die Figur Karmazinovs hat bekanntlich ein authentisches Vorbild, den vorwiegend in Deutschland und in Frankreich lebenden. liberal gesinnten russischen Schriftsteller und russischen „Westler" Ivan Turgenev. Bei der zitierten Szene in Besv handelt es sich um die von der Forschung diskutierte Parodie von Turgenevs Erzăhlungen Turgenevs Prizraki (Fanta-ija) [Gespenster (Eine Phantasie)] (zuerst 1864 in Dostoevskijs Zeitschrift Epocha erschien) und Dovol'no (Otruvok iz zapisok umersego chudo:nika) [Genug (Ein Fragment aus den Aufeeichnungen eines verstorbenen Künstlers)] (1865). ${ }^{502}$ Der Angriff des

${ }_{501}^{501}$ Bd. 10, S. 366f. [S 670ff.].

$502 \mathrm{Vgl}$. dazu ebd. S. 365 und passim und oben (zu leciny muz), S. 152, Fußnote 56. Karmazinov hat wie Turgenev (und wie Trusockij in V'einy mü) eine hohe Stımme (..у него бы.т с.лишком kрикливый го.лос. несkо.лько даже женственный, и притом с 
Chronisten in Besy, gilt aber nicht nur Turgenev selbst, sondern hauptsăchlich seinen „asthetischen Ansichten", seinen "relativistisch-atheistischen Weltanschauung" und seiner "Kritik" an Rußland in seinem kurz vor Besy veröffentlichten Roman Dym [Rauch] (1867). Die "verwestlichte" Schreibweise Karmazinovs ( $=$ Turgenevs) wird aus der kritischen Erzăhlperspektive verfremdet und karikiert, die teilweise mit der Sicht des russischen durchschnittlichen, aber schon "verwestlichten" und sogar „nihilistischen" Provinzpublikums gleichgesetzt wird. Das "Thema" des "letzten Werks" Karmazinovs kann für dieses Publikum nur unverstăndlich sein, obwohl zugleich angedeutet wird, daß es nicht nur die Russen aus der Provinz nicht verstehen könnten, denn Karmazinovs Werk setzt sich vollständig aus den aus dem „Westen“ entlehnten und für die Russen fremden "Ideen“" zusammen. ${ }^{503}$ Er habe keine eigenen Gedanken, er kopiere lediglich die "Ideen aus dem Westen“. Die „westlichen“ Schriftsteller, Denker und Künstler, deren originale Leistungen positiv beurteilt werden, warten gehorsam wie die „Köche“ auf die Befehle ihres Herm, Karmazinov, der darüber hinaus Rußland von oben herab betrachtet. Er wird somit an dieser Stelle noch negativer als alle ihm dienenden „westlichen Märtyrer der Arbeit" beurteilt, weil er nicht nur ihre "Ideen" übernimmt, sondem sie relativiert, indem er zu einer fremden "These" (wohl nach Hegelscher Manier) eine Anthithese stellt, und sie in ein Paradox verwandelt. Alles erscheint ihm als ein "Calembour", es gibt für ihn „kein „Verbrechen" und „keine Wahrheit" mehr, sondern nur den "Atheismus" und "Darwinismus".

Die "relativistisch-formalistische Ästhetik" in Karmazinovs Merci, dessen Titel schon ein "Fremdwort", eine "Höflichkeitsfloskel" ist und auf "Inhaltsleere" schließen läßt, setzt sich aus mehreren fremden Imagemen und anderen Motiven zusammen, die somit insgesamt "selbstreferenziell“" sind, denn der Erzähler und das Publikum können keinen "Sinn“ und „Bezug zur russischen Wirklichkeit" in diesem Werk finden. Neben einer "Grimasse aus Heine" und der ,Byronschen Schwermut" bzw., noch schlimmer, ihrer "Kopie" nach Lermontov, sowie neben mehreren anderen Anspielungen auf die europäische Geschichte, hauptsachlich auf die "antike, römische Welt", kommt darin auch eme "Fee Chopins" vor. Obwohl es sich hier um eine Anspielung auf die von Turgenev geliebte Săngerin und Komponistin Pauline Viardot handeln soll, die einige Mazurkas Chopins für Singstimme arrangient hatte, ist mit Chopins "Fee“ [русалка; rusalka] eine der „subversiven“ Klavierballaden Chopins gemeint, die mit den Gedichten von Mickiewicz, u.a. mit der Ballade Switezianka, in Verbindung gebracht wurde und die schon in Idiot als ideologische Anspielung fungiert

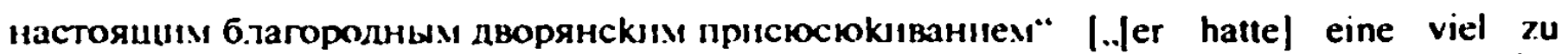
schrille, fast weibische Stımme /.../, noch dazu mit dem echten, vomehmen Lispeln des Mannes von Adel"“: S. 6691, ebd., S 365) und weist noch viele andere Gemeinsamkeiten mit Turgenev auf. An dieser Stelle kann aber nicht ausführlicher auf diese besondere Problematik in Bexy und auf die umfangreiche Sekundárliteratur dazu eingegangen werden. Vgl auch den Exkurs über die lebenslänglich ambivalenten Beziehungen zwischen Dostoevskij und Turgenev bei KLUGE 1992, S. 107-112. Siehe femer TURGenev 1981 (S. 191-219: Prisrakı (1:untazıja): S. 210-231: Drvol'no (Otryvok is zaptsok umeršego chudo:̈nika)).

503 Die Kritik des Chronisten nimmt also die ..postmoderne“ Texttheorie, u.a. die der ..Intertextualităt" , vorweg. 
und auch in Besy die negative, rußlandfeindliche Okzidentalisierung Karmazinovs bedeutet. ${ }^{504}$ Die "entlehnte“, "verwestlichte" Ästhetik Karmazinovs in Merci kann aber auch insgesamt als eine Äquivalenz zur ,polnischen", ebenfalls aus dem "Westen" entlehnten Kultur betrachtet werden. ${ }^{505}$

Das vom Ich-Erzahler kommentierte „letzte“ Werk Karmazinovs ist somit nicht nur als boshafte Parodie der literarischen "Produkte“ Turgenevs aufzufassen; ausgelacht und karikiert wird seine Ästhetik „westeuropäischen" Charakters: der Ästhetizismus und Atheismus der Ansichten Karmazinovs, die nichts Gemeinsames mit einer Auffasssung der Ästhetik als einem "Wertsystem" haben. Diese Ästhetik, obwohl noch „westlicher" Prägung, vertritt der später vom lch-Erzăhler geschilderte Auftritt des ideellen Gegners Karmazinovs - Stepan Trofimovic Verchovenskij.

Diese Szene, die von dem russischen Chronisten aus seiner Perspektive nacherzählt wird, deutet aber auch auf seine provinzielle „Einfachheit" (wie auch auf die des russischen Publikums) hin und unterstreicht die Fremdheit Karmazinovs in diesem russischen, obwohl auch „verwestlichten“, teilweise "nihilistischen" Milieu. Von Karmazinov selbst wird aber diese Einfachheit des Provinzpublikums als „Primitivität" gedeutet. ${ }^{507}$

Auch der Name Karmazinov könnte zusätzlich auf die Okzidentalisierung dieser Figur, auf die "Infizierung" mit "westlichen", rußlandfeindlichen und revolutionären bzw. nihilistischen Ideen verweisen, denn in der polnischen Sprache bedeutet das Wort karmazyn zum einen „Karmin“, „Karmesin“ bzw. die rote Farbe eines Stoffs, zum anderen aber auch einen altpolnischen Adligen. ${ }^{500}$

$504 \mathrm{Vgl}$. auch Bd. 12, S. 311 , die Anmerkung zur Seite 366f. (nach GozENPUD 1971, S. 116). Vgl. dazu auch oben, S. 298f. (zu ldiot).

${ }^{505} \mathrm{Vgl}$ dazu oben im Zusammenhang mit Petr Aleksandrovič Valkovskij in (Inižennye , oskorhlennye sowie mit dem Aufsatz Strachovs zur ,polnischen Frage“, S. 220f.

${ }_{506} \mathrm{Vgl}$. Bd. 10, S. 37Iff. An anderen Stellen des Romans werden aber die moralische Fragwürdigkeit Verchovenskijs ( vgl. das Schicksal seines ehemaligen Leibeigenen Fed'ka) sowie die Gleichgültigkeit Karmazinovs gegenüber der Sixtinischen Mtadonna angedeutet, was emen Schatten auf die ästhetischen Äußerungen der beiden wirft. Vgl. dazu oben, S. 323f., Fußnote 486, und ebd., S. 235.

507 Bd. 10, S. 368: ,| Кармазинов| хоть и у.тыбатся ироничесkи, но сіцтьно быт поражен. /... « А всдь не таkой, kak вы думаете, я ведь за вас, то.лько хваште меня, хватите болыше, /.../ я это ужасно люб.лю...»/.../ Господа, прокрічал он наконец, /.../ я вІьжу, чrо моя бедная поэмkа не туда попата. Да и сам, кажется, не туда попа.". I [Karmazinow] lächelte ironisch, war aber sehr verblüff. /.../'Ich bin ja gar nicht so, wie Sie glauben. Ich bin doch auf Ihrer Seite! Sie müssen mich nur loben, /...' mehr loben, /.../ ich mag das doch so furchtbar gern... \%... Meine Herrschaften!' schrie er endlich, $/ . . /$ 'Ich sehe, daß mein armes kleines Poem nicht an die richtige Adresse gelangt ist. Und ich selbst bin, wie es scheint, nicht an die richtige Adresse gelangt ; S. 674f.]

${ }^{508} \mathrm{Vgl}$. auch IPPOLDT o.J., S. 372: ,karmazyn, m (-u), 1) Karmesin, n; 2) polnischer Edelmann (aus altem (ieschlecht). - -owy, adj, kermesrot: -owa s=lachic |Karmesinadel... |. alter Adel“. Der Name „Karmazınov“" wăre also zugleich eine ıdeologische Anspielung auf das Alıe l'olen. Vgl auch StAWSKI 1952-1982 (Bd. 2., Heft I (6)), S. 78f: ,karmazyn, szkarłat, barwa ciemno-czerwona: tkanina ciemno-czenwona od XVI w., w dawnej Polsce też 'szlachcic starożytnego rodu' (nazwany od żupanow tej barwy, będacych przywilejem starych rodow $/ . . . /)^{*}$. [... Scharlachfarbe, dunkelrote Farbe; dunkelroter Stoff vom XVI. Jh. bekannt., im alten Polen auch 'Adliger aus einem altertümlichen Geschlecht' (nach dem żupun I = alt- 
Karmazinov gehort wie Stepan Trofimovix Verchovenskij zu der Generation der "Văter" der Nihilisten, im Unterschied zu Stepan Trofimovic Verchovenskij ist er aber zu einer „geistigen Emeuerung“ nicht fahig, er wird als ein durch und durch verwestlichter, Rußland vollig entfremdeter adliger und eitler Kosmopolit geschildert. Er vertritt somit als eine eindeutig negativ verwestlichte russische Figur das negative ideologische Imagothème des verwestlichten RuBlands, obwohl ohne „Beimischung" der „dămonisch-bösen" Eigenschaften.

5. Ein polnisches Imagem kommt darüber hinaus im Zusammenhang mit dem vieldeutigen, „dămonischen" und „lauwarmen“ Nikolaj Vsevolodovic Stavrogin vor. Das Land Polen spielt eine gewisse Rolle in seiner Biographie, in Form einer Anspielung auf seine Teilnahme an der Niederschlagung des polnischen Aufstandes gegen RuBland von 1863:

„B шестьdесяm третьеле году ему kak-то удалось отличиться; ему дали kрестик и произвели в унтер-офицеры, а затем kak-то уж ckopo и в офицеры“. [Im Jahr dreiundsechzig gelang es ihm einmal, sich auszuzeichnen; er erhielt das Tapferkeitskreuz [eigentl.: ein Kreuzchen], wurde zum Unteroffizier befordert und irgendwie allzu schnell [eigentl.: ... und dann irgendwie schon rasch...] auch zum Offizier.] [kursiv die Verf.]

Es handelt sich hier nicht um eine immanente, direkte Charakteristik Stavrogins durch das polnische Imagem, wie es beispielsweise im Fall der Reisen des Fürsten Valkovskij nach Polen gewesen ist, denn Stavrogin wird durch die ăußeren Umstände, nach seiner Degradierung wegen seines skandalösen Benehmens dazu gezwungen, sich an diesem Krieg zu beteiligen, um eine Beforderung in der Armee und Rehabilitienung zu erlangen. ${ }^{510}$ Es ist ihm auch nur „gelungen“, sich auszuzeichnen und ein "Kreuzchen“ zu bekommen, wodurch aber seine Tapferkeit im Kampf gegen die rußlandfeindlichen Polen hervorgehoben wird, d.h. eine positive russische Eigenschaft.

Einige negative polnische stereotype Figuren kommen außerdem im Zusammeniang mit Stavrogin in den erhaltenen Textvarianten zu dem von Katkov ab-

polnische Kleidung des Adels] dieser Farbe genannt, den zu tragen ein Privileg alter Geschlechter war /.../.)] Vgl. auch nussische Worterbücher: SLOVAR' SOVRFMFN:NOGO RUSSKOGO LTERATURNOGO JAZYKA, (Bd. 5, S. 822: „kapmazim, a, м. старіннно тонkоe cykно kрасного цвета /.../ |altertümliches feines Tuch roter Farbe /... $\left.\right|^{*}$; DAL' 1956, S. 92: .kармазшит, м. южн. тонкое, ярkо-а тое сукно | ... südl. feines, hellrotes, scharlachfarbenes Tuch...|", bzw. VASMER 1953-1958 (Bd. 1, S. 533f: „kapmazan himbeerroter Stoff, | ... l ukr. karmayn. Über poln. karmazyn bzw. nhd. karmesin aus ital. curmesino, das auf arab. germazi, girmizi scharlachfarbig' von aind krmıs 'Wurm' |.. | zurückgeht". Laut diesen Worterbüchem bezieht sich in der russischen Sprache die Bedeutung dieses Wortes lediglich auf die (rote) Farbe eines Stoffs. Es bleibt also offen, inwiewett die polnische Bedeutung Dostoevskij bekannt war.

509 Bd. 10, S. 36, vgl. auch Bd. 12, S. 289: „По-видимому, намек на участие Ставрогнна в подав:єени польского восстания“. |Offenbar eine Anspielung auf die Teilnahme Stavrogins an der Niederschlagung des polnischen Aufstandes.]

$520 \mathrm{Vgl}$. ebd. 
gelehnten Kapitel U Tichona [Bei Tichon] vor. Es handelt sich hier ebenfalls um eine ideologische Anspielung und nicht um ein Mittel zur direkten Charakterisierung Stavrogins: In der schriftlichen „Beichte“ Stavrogins werden einige Polen erwăhnt, die zu den Bewohnern des Petersburges Mietshauses gehören, in dem Stavrogin damals wohnte:

В этих многочисленных номерах, обладавших самым дурным запахом пиши, гнездилось много людей, всё чиновников без места или на маленьком месте, докторов с отьезлом, разньх поляков, всегда около меня юливиих. (In diesen zahlreichen Zimmern, vom übelsten Essensgeruch beherrscht, nisteten viele Menschen, alles waren Beamte ohne Stelle oder mit unbedeutender Stelle, Ärzte auf Reisen, verschiedene ständig um mich scharwenzelnde Polen.] [kursiv die Verf.] ${ }^{511}$

Diese Stelle ist den anderen polnischen stereotyp-ideologischen Szenen äquivalent, nicht nur der Szene bei Julija Michajlovna in Besy, sondern auch einer im Roman Prestuplenie i nakazanie, obwohl die negativen Polenstereotypen (als alter) dort im Zusammenhang mit der Charakteristik Katerina Ivanovnas, der Frau Marmeladovs, in einer etwas „erweiterten" Fassung, auch in "Dialogen", vorkommen. ${ }^{512}$ Betont wird hier hauptsächlich das Elend der Mietshäuser, in denen arme Petersburger "nisten", das auch durch die Hervorhebung des Motivs des "schlechten Geruchs des Essens" besonders ekelhaft erscheint und an die "Schlechten Berliner Gerüche" erinnert, die in Zimnie zametki o letnich vpecatlenijach enwähnt werden. Zugleich aber wird der subversive "Untergrundcharakter" des l-ebens Stavrogins betont, so daß seine „Welt" der des "Menschen aus dem Untergrund" ähnlich ist. Seine negative Okzidentalisierung wird zusäztlich durch die stereotypen ,scharwenzelnden Polen“ betont.

An einer anderen Stelle der "Beichte" Stavrogins handelt es sich um das von Lednicki bemerkte „obsessing theme“ des mißhandelten Mädchens, das auf ein polnisches Mädchen. Maryna O. aus Semipalatinsk, zurückgehe - an das hier in der Figur Matrełas erinnert werde. ${ }^{523}$

Stavrogin wird jedoch insgesamt, trotz seines „Dämonismus“ und seiner Entfremdung vom russisch-orthodoxen Glauben bzw. trotz des Verlustes der russischen religiös-kulturellen Identität, hauptsächlich nicht immanent durch polnische Imageme wie Petr Stepanovic Verchovenskij charakterisiert, was auf seinen ,lauwarmen“ unentschiedenen ambivalenten Dualismus, seine unentschiedene ideelle Lage zwischen dem „Westen" und „Rußland", auf seinen Charakter eines noch nicht bekehrten ,großen Sünders“ hindeuten würde. ${ }^{514}$

521 Bd. 12, S. 109.

$512 \mathrm{Vgl}$. oben, S. 270ff. In einem anderen Romanentwurf Smert poela [Der Tou eines Iichler.s], der vor Besy entstanden ist, kommt ein gewisser pan P.sepjardovskı vor, vgl. Bd. 9, S. 121 .

$513 \mathrm{Vgl}$. LEDNICKI 1953, S. $150 \mathrm{ff}$.

514 Vgl. auch zu den Vorbildern Stavrogins Bd. 12, S. 181-192, 227ff., 237-246. Der Name Sicovrogin deutet auf seine Sehnsucht nach dem ,Kreuz" hin, seine Heirat mit Mar ja Timofeevna Lebjadkina auf die Sehnsucht nach dem „russischen Volk“, dem er sich entfrem- 
ZUSAMMENFASSUNG: In Besy spielt das negative utopische Imagothème des verwestlichten, "nachpetrinischen" Rußlands, athnlich wie in Zimnie zametki o letnich vpecatlenijach bzw. in Zapiski iz podpol'ja sowie im Roman Prestuplenie i nakazanie, die dominante Rolle. Daneben tritt das $\mathrm{zu}$ ihm komplementăre positive utopische Imagothème des verwestlichten RuBlands auf, das ebenfalls in der Figurenkonstellation symbolisch konstituiert wird. Wegen der psychologischen und imagothematischen Ambivalenz der zentralen Figuren kommen aber beide Imagothèmes in ihnen zugleich vor. In Besy gibt es auch die beiden Imagothèmes des „orthodox-byzantinischen Rußlands“ sowie des „verwestlichten nachpetrinischen russischen Volkes", die jedoch im Hintergund stehen.

Wie in den oben besprochenen Romanen treten fremde Imageme in Besy in zwei imagothematisch bildenden Funktionen auf, indem sie zur „außeren“ (als Alter-Figuren) sowie zur „immanenten“ Charakterisierung der verwestlichten russischen Figuren, der Alius-Figuren, sowohl der positiven als auch der negativen, dienen:

1. Als Elemente der immanenten Charakterisierung verursachen fremde Imageme die negative Verfremdung der russischen Figuren, „dämonisieren“ sie zum einen (wie beispielsweise Stavrogin oder Kirillov), oder sie symbolisieren die positive Okzidentalisierung, die „Idealisierung" einiger Figuren (der „positive Teil" der Personlichkeiten Stavrogins und Kirillovs; der "Idealismus“ Stepan Trofimovix Verchovenskijs oder Mavrikij Nikolaeviðs);

2. Als fremde stereotype Alter-Figuren in der Kontrast-Funktion zu den russischen Figuren haben fremde Imageme eine vorwiegend negative ideologische Bedeutung (fon Lembke, Bljum, Ljamšin bzw. die polnischen Figuren).

Die fremden Imageme charakterisieren somit zum einen (als Teil des negativen utopischen Imagothème des verwestlichten Rußlands) die negativ verwestlichten russischen Alius-Figuren, beispielsweise Karmazinov oder Petr Stepanovic Verchovenskij; zum anderen dienen sie (als Teil des positiven utopischen Imagothèmes des verwestlichten Rußlands) zur Charakterisierung der Figuren der „positiv verwestlichten Idealisten“ wie Stepan Trofimovic Verchovenskij, Mavrikij Nikolacvic oder Satov. Die „positiven“ Imageme bilden die „bessere“ Seite des Charakters Stavrogins (sein utopischer Traum vom "Goldenen Zeitalter"). Die fremden Imageme verleihen auch den russischen verwestlichen Figuren aus dem „Volk" eine negative Färbung (z.B. Jurodivyj Semen Jakovleviž oder Fed'ka Katoržnyj).

Die polnischen Imageme, die auch in den zwei oben genannten Funktionen eingesetzt werden, dienen dabei ausschlieBlich zur Charakterisierung der negativ verwestlichten russischen Figuren. Diese russischen Figuren werden ausnahmslos als moralisch fragwürdig bz.w. ambivalent, auf der Suche nach dem Sinn des

det hat. Seine Utopie des vergangenen Goldenen Zeitalters ist dagegen noch rein mythologisch, ohne daß darin der christliche Gott erwahnt wird. Eine ähnliche Utopie wird jedoch spater im Zukunftstraum Versilovs durch das Erscheinen Christi „erganzt“" (vgl. unten, $S$. 349f., Fußnote 531). Sonst ist die Figur Stavrogins sowohl äußerlich als auch seinem Charakter nach den „numinos-bösen Dämonen“- Valkovskij oder Svidrigajlov - ăhnlich, vgl. 2.B. Bd. 10, S. 35ff., S. 145, S. 164ff., S. 182. 
Lebens bzw. nach der religiơs-kulturellen Identităt geschildert. Keine polnischen Imageme sind dagegen mit den vorwiegend "positiv verwestlicht" geschilderten Figuren Satovs und Kirillovs ${ }^{515}$ sowie mit allen weiblichen Figuren, Mar"ja Timofeevna Lebjadkina, Liza, Dar'ja, Marie Satova und Varvara Petrovna, verbunden, mit Ausnahme der negativ verwestlichten Julija Michajlovna.

Im Zusammenhang mit Stepan Trofimovix Verchovenskij (sowie mit Stavrogin) dienen polnische Imageme nicht zu ihrer immanenten Charakterisierung. Besonders bei Stepan Trofimovi Verchovenskij deuten sie auf seine „positive" Fähigkeit hin, dank seinem "Idealismus" die Okzidentalisierung zu überwinden und zum russischen Glauben zurückzufinden. Polnische Figuren als negative nationale Stereotypen treten lediglich als Kontrast (als alter) zu diesen Figuren auf, zugleich handelt sich um eine ideologische antipolnische bzw. antikatholische Anspielung, auch im Falle der Erwăhnung politischer Diskussionen in Petersburg über die „Wiederherstellung Polens", bei denen Stepan Trofimovic Verchovenskij aber nicht als engagierter Teilnehmer auftritt.

In ähnlicher Funktion wird auch Stavrogin durch eine polnische Figur (als alter) in dem Kapitel $U$ Tichona charakterisiert; die Erwähnung der Niederschlagung des polnischen Aufstandes von 1863, an der Stavrogin teilgenommen hat, dient ebenfalls als eine ideologische Anspielung, zeigt aber auch einen gewissen „russischen Patriotismus" Stavrogins. Eine negative stereotype polnische Figur (als alter) kommt auch im Zusammenhang mit der durch ihren deutschen Mann negativ verwestlichten Julja Michajlovna vor.

Petr Stepanovix Verchovenskij hingegen läßt sich als ein „psychologisch differenziertes Stereotyp des ,polnischen Verschwörers“ bzw. des "Ljachs in der Gestalt des bösen Geistes (Teufels)“ bezeichnen, denn ein solches Stereotyp dient als strukturelle Folie dieser Figur. Er wird aber durch die psychologisch weitgehend differenzierte Darstellung zum Alius, zu einer „dämonischen“ russischen Figur, die das „Böse aus dem Westen“ symbolisiert, und gehört wie Petr Aleksandrovix Valkovskij oder Svidrigajlov zu der Reihe der Figuren, die Schöpfungen der kreativen Imagination Dostoevskijs sind.

Der Schriftsteller Karmazinov wird ebenfalls immanent durch fremde Imageme, darunter durch "Chopin“ und durch den eigenen Namen charakterisiert. Er ist eine negative, „bơse“, aber hauptsächlich eine lächerlich-komische Figur, ohne das „dämonisch-tragische“ Pathos des „großen Sünders“ Stavrogin bzw. ohne den kalt-rationalen Nihilismus Petr Stepanovic Verchovenskijs aufzuweisen. Die Motive für die „Verharmlosung" dieser Figur sind möglicherweise in ihrer Funktion als Karikatur Turgenevs zu suchen.

Polen spielt also in Besy als der immanente Teil des negativen ideologischen Imagothèmes des verwestlichten, ,.petrinischen“ Rußlands (in den russischen

515 Satov, der als ein Opfer der Nihilisten endet, findet in der Liebe zu seiner Frau und in der Suche nach dem nationalen russischen Gott, in seinem ..slavophilen" Glauben an das russische Volk die .Erlosung“" Vgl. zu seinen Vorbildem, u.a. K.E. Golubov bzw. V.1. Kel'siev, Bd. 12, S 178ff,, 209ff., 23 Iff,, sowie zu Kirillov, der den gleichen Vomamen wie der Held der altrussichen Heiligenlegenden Aleksej hat: sein Vatersname erweckt Assoziationen mit Nil Sorskij, ebd., S. $221 \mathrm{ff}$. und S. $231 \mathrm{ff}$. Vgl auch zu Kirillov und Tichon Zadonskij oben, S. 320, Fußnote 456. 
Alius-Figuren) und zugleich als der ideologische Feind Rußlands (in den AlterFiguren) eine für das Verstăndnis dieses Romans relevante Rolle.

In Besy treten folgende polnische Imageme auf:

1. ein polnischer katholischer Priester (eine Alter-Figur), der den „Kreis“ um Stepan Trofimovic Verchovenskij als "negativ verwestlicht" charakterisiert (es handelt sich moglicherweise um das Stereotyp des ,polnischen Jesuiten“);

2. das negative Stereotyp des „scharwenzelnden Polackchens“ (eine Alter-Figur), das: erstens Petr Stepanovic Verchovenskij (eine Alius-Figur) immanent und zweitens den Kreis um Julija Michajlovna (wie in einer ăhnlichen Szene in Prestuplenie i nakazanie Rogožin) negativ charakterisiert;

3. „Chopins Fee“ (= eine seiner Balladen), die den "verwestlichten" Schriftsteller Karmazinov negativ immanent (als ein Alius) charakterisiert;

4. der Name „Karmazinov" selbst, der unter anderem einen Bezug zur altpolnischen Kultur hat und auf den ".entlehnten“ (= ,polnischen“) Charakter der Ästhetik Karamzinovs hindeuten soll;

5. der polnische Aufstand gegen Rußland von 1863, an dem Stavrogin teilgenommen haben soll, wodurch er, trotz der negativen Okzidentalisierung, als „Patriot" gezeigt wird. 


\section{2. ПОДРОСТОК. РОМАН В ТРЕХ ЧАСТЯХ (1875) \\ $[D E R \text { JIINGLING }]^{516}$}

Im vorletzten Roman Dostoevskijs dominiert im Unterschied zum düsteren, „apokalyptischen" Roman Besy das positive utopische Imagothème des verwestlichten Rußlands. Zum ersten Mal kommt jedoch in diesem Roman dem positiven utopischen Imagothème des russisch-(orthodox-byzantinischen) Rußlands eine gleichwertig relevante Rolle zu. Das negative utopische Imagothème des verwestlichten, ,petrinischen" RuBlands (mit einer negativen ideologischen Komponente) ist in Podrostok diesen beiden positiven Imagothèmes untergeordnet. Dieses negative Imagothème wird vorwiegend durch fremde Alter- und Alius-Figuren repräsentiert.

Podrostok läßt sich, ähnlich wie Besy, als eine Auseinandersetzung mit der Generationsproblematik bezeichnen. Beide Romane beziehen sich thematisch auf Turgenevs Roman Otcy $i$ deti. ${ }^{517}$ Podrostok wird darüber hinaus wie mehrere frühere Werke Dostoevskijs aus der subjektiven Ich-Perspektive erzăhlt. Der jugendliche Ich-Erzähler erinnert besonders an den frühen Kurzroman Netočka Nezvanova (1849), dessen erzählendes Subjekt jedoch ein Mådchen war.

Der einundzwanzigjăhrige Arkadij Makarovic Dolgorukij ${ }^{518}$ schildert in seinen Aufzeichnungen Freignisse und Erlebnisse des zurückliegenden Jahres, in dem er einen geistigen Reifeprozeß durchgemacht hat, sowohl als Mensch als auch als Mann erwachsen geworden ist. ${ }^{519}$

Die Handlung des Romans spielt wie in den meisten Werken Dostoevskijs hauptsächlich in Petersburg. in der ..verwestlichten“ Hauptstadt Rußlands. In Rückblenden werden Moskau und das Gut Versilovs im Gouvernement Tula sowie Westeuropa. v.a. Deutschland (Bad Ems) erwähnt.

526 Die deutschen Übersetzungen russischer Zitate aus P'sdrussiok werden nach der Ausgabe DOSTOJEWSKI 1957 angeführ

527 Vgl. zur Entstehungsgeschichte des Romans: Bd. 17, S. 252ff. Der Roman l'odrosiok, an dem Dostoevskij seit 1874 gearbeitet hatte, ist 1875 in Nekrasovs Zeitschrift (Otečes/vennve zupiskı erschienen. $\mathrm{Vgl}$. auch die Gesamtinterpretation des Romans P'odrusiok von GeRiGk 1965

${ }^{518} \mathrm{Vgl}$. Bd. 17, S. 274ff. zum Alter Arkadijs: In den Entwürfen ist vom zwanzigjăhrigen ..Jüngling“" die Rede, der über sich selbst im Alter von neunzehn schreibt; mit dem Abschluß der Aufzeichnungen beginnt somit das einundzwanzige Lebensjahr Arkadijs, vgl. Bd. 13, S 6: ..Я - кончившии курс пाмназист, а теперь мне уже двадцать первый год" |lch habe das Gymnasium absolviert und stehe heute schon im einundzwanzigsten Lebensjahr; S. 9].

$519 \mathrm{Im}$ Kommentar der PSS wird auf die Liberalisierung der Ideologie Dostoevskijs in l'odroxvok hingewiesen, die teilweise mit der Veroffentlichung dieses Romans $m$ der Zeitschrift Nekrasovs zusammenhängen könnte. Dostoevskij habe außerdem als Redakteur der konservativen Z.eitschrift (ircżdunin [Jer Bürger] das russische l.eben besser kennengelemt. u.a. auch gewisse Anzeichen der moralischen Zersetzung und ... Unordnung" nicht nur in den höheren Schichten der russischen Gesellschaft, sondern auch im russischen .. Volk“ selbst bemerkt. vgl. ebd. S. 257fr. bzw. S. 259ff 
In Podrostok treten (wie in Besy) erneut einige extrem „verwestlichte“ und extrem „russische“ Figuren auf, die zwei konträre bzw. komplementäre Pole bilden. Daneben findet man aber auch ,ambivalente" Figuren, die in unterschiedlichem Grade positiv bzw. negativ „verwestlicht" sind.

Die Gruppe der zentralen russischen Figuren bilden: der Ich-Erähler Arkadij Makarovic Dolgorukij und seine Eltern: der adlige verwestlichte Vater Andrej Petrovic Versilov und die aus dem Volk stammende Mutter Sofja Andreevna. ${ }^{520}$ Eine wichtige Rolle spielt der episodisch auftretende Pilger Makar Ivanovic Dolgorukij, der .,gesetzliche Vater" Arkadijs. ${ }^{521}$ Makar ist wie Sof ja ein Bauer auf dem Gut Versilovs gewesen und hat dort als Gärtner gearbeitet, bevor Sof ja Andreevna ihn aus Liebe zu Versilov verlassen hat. Makar und Sof ja, zwei gläubige und sanftmütige Alius-Figuren aus dem „Volk“, vertreten in Podrostok das positive utopische Imagothème des russisch-(orthodoxbyzantinischen) Rußlands. Arkadijs "Reifeprozeß" spielt sich zwischen den beiden unterschiedlichen "Vätern", Versilov auf der einen sowie der Mutter und

$520^{\circ} \mathrm{Vgl}$. zu ihrer „weisen“ Demut und zu ihrem „reinen Herzen“ z. B. Bd. 13, S. IIff., bzw zu ihrem Glauben an Christus, ebd., z.B. S. 215: .Христос, Apkaila, всё простाт: " ху:лу твою простіт, " хуже твоего простит. Хрілтос - отец, Христос не нужлается и сиять будет даже в самой r.тубокой тьме..." | Christus verzeiht alles, Arkáscha. er verzeiht auch deme lästcrung, und verzeiht auch noch Schlimmeres. Christus ist aller Vater, Christus bedarf selbst nichts und wird noch in der tiefsten Finsternis leuchten ... . S. 409| Vgl auch FRIERSON 1993.

$521 \mathrm{Vgl}$. ebd., S. 13f., S. 283fr., S. 308ff. oder S. 363ff bzw. Bd. 17, S. 308f und S. 372 die Anm. zu Bd. 13, S. 109, zu seiner „Verwandischaft” u.a. mit dem $1 \%$ as Nekrasovs, mit lolstojs Platon Kuratuev oder mit dem Pilger Parfeny (vgl. auch die Entwürfe zu l'ix/ros/ok Bd. 16, S. 150; und in Brat ja Kuramazovy Bd. 14, S 27 und Bd 15, S. 201; siche auch. Skat.anie O STRANStril. Seine Geschichte mit dem .Wolf (Bd. 13, S. 330) deutet darauf hin. daß diese Figur viel Gemeinsames mit dem Bauern Marej hat (vgl. Inncvnık pısulc/ju, Bc. 22. S. 46-50, vgl. dazu oben, S. 122 und S. 177 (Fußnote 103). Makar ist ein ,russischer Pilser". er symbolisien die nussisch-orthodoxe Volksfrommigkeit, die positive ..russisch-orthrdoxbyzantinische Utopie“", die der ..positiven westlichen Utopie“ Versilovs sowie der .,negariven westlichen Rothschildidec" Arkadijs entgegengesetzt ist (so aufzufassen ist z. B. seme Ge-

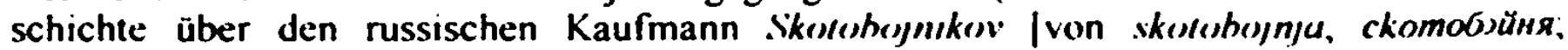
Schlachthof 7, der zuerst ein grausamer und herzloser ..Kapitalist”, ..Rothschild" aus der .ussischen Provinz gewesen ist, sich aber schließlich in einen ..demütigen Pilger" verwandelt. ebd.. S. 313fr.). Makar praktizien das ..Jesusgebet“, ist aber im Unterschied zu Sof ja Andreevna auch für das ${ }_{n}$ Wissen aus dem Westen“ offen, vgl z B. 287fr., 312ff. Vgl. auch PÖNIAK 1992, S. 52-76, sowic AUFRICHTIGE ERZAHI.UNGFN: der erste Teil der Aufrichligen lirzihlungen e'ines russischen /'ilyers soll 1870 erschienen sein und könnte Dostoevskij bekannt gewesen sein (S. 7). Siche auch die russische Ausgabe: OTKROVENNYE RASSKA2Y STRANVIKA, bzw. ZAMFIRESCO 1990. Die Äußerung Makars: .A aдвокат известно ч то «нанятая совесть"“ | Man weiß doch, was so $n$ Advokat ist ein Advokat ist ein geme'le'te's (iensiven"; kursiv Rahsm, S. 589) (Bd. 13. S. 310) deutet auf die Selbständigkeit seiner Urte le im Hinblick auf diese vom ...Westen“ übernommene ..Profession“ hzw. auf die Kritik des ..westlich“ gepragten russischen Gerichtswesens hm. Dieser kritische Gedanke wird im trat ja

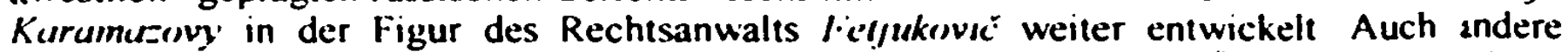
Äußerungen Makars. z.B. über die Selbstmörder, werden in den Äußerungen Zosimas uiederholt. 
Makar auf der anderen Seite ab, die jeweils zwei komplementăre Seiten Rußlands reprăsentieren. ${ }^{522}$

$\mathrm{Zu}$ den weiteren verwestlichten russischen Figuren des Romans, die sowohl positive als auch negative Eingenschaften aufweisen und in unterschiedlichem Grade "verwestlicht" sind, gehören die Schwester Arkadijs, Liza Makarovna, und ihr Geliebter, der junge Fürst Sergej Petrovič Sokol'skij, ${ }^{523}$ die Kinder

522 Schon der Name Dolgorukij weist auf die doppelte Herkunft Arkadijs hin: auf seine Bindung an die altrussische Tradition (vgl. den Großfürsten von Moskau Jurij Vladimirovic Dolgorukij) bzw. auf seinen ,geistigen Adel“ und an das „russische Volk“, denn er hat diesen altrussischen aristokratischen Namen von seinem gesetzlichen Vater, Makar Dolgorukij, einem einfachen Bauer, ererbt. Arkadij vereinigt somit in sich zwei positive Komponenten des „vorpetrinischen Rußlands, der alten Rus'". Er wird aber in der Suche nach der durch seine „zufállige“" Geburt verlorengegangenen Identităt auch den ,negativen westlichen Ideen“ ausgesetza. Diese Suche wird in seinem .Schwanken", seiner Ambivalenz zwischen der "Rothschildidee" und der Sehnsucht nach "блаzообразис" | „würdiges Aussehen"; ,schöne Form"| deutlich. Die ..Schónheit" findet er in der "Rückkehr" zu seinem gesetzlichen „Vater", dem rusischen Pilger Makar Dolgorukij, Bd. 13, S. 308f. Die „Rothschildidee“ Arkadijs war jedoch schon vor der Begegnung mit Makar asketisch (und ,antisemitisch") geprägt und mit der .großen Idee" der Wohltătigkeit verbunden, vgl. Bd. 13, S. 65ff,, bes. S. 76 (.Чем безнравственно и чем низко то, что из мномества мсидовских, вредных и грязных рук миляионы стекутся в руки трезвого и твердого схимника. /../я уже не раз схватыва1 тот момент в будущем, когда /.../ я отдам все мон миzлионы людям“; [kursiv die Verf.]) (Was soll denn dabei unsittlich und niedrig sein, wenn aus vielen jüdischen, schădlichen und schmutzigen Händen diese Millionen in die Hand eines nüchternen und standhaften Asketen /.../ zusammenfließen? /.../ lich habe/ in meinen Traumen schon mehr als einmal jenen Augenblick vorausbedacht, I...i [wenn; Erg. d. Verf.] ich alle meinen Millionen den Menschen hingeben (werdel: S. 145f. I und S. 307 (das ambivalente Urteil über die .,weite. breite Seele eines russischen Menschen“): „/...i я тысячу раз дивится на эту способность че.ловеkа (II, kажется руссkого че.ловека по преимушеству) ле.леять в душе своей высочайший идеат с величайшею подтостью /.../. Широкость .mi это особенная в русском че.ловеке, которая его датеко поведет, ити просто подтость - вот Bonpoc!" $\mid / \ldots$. ich habe mich wohl schon tausendmal über diese Fähigkeit des Menschen (und wie mir scheint, besonders des russischen Menschen) gewundert, das höchste Ideal neben der niedrigsten Gemeinheit in seiner Seele hegen zu konnen /.../. lst das nun bloß eine besondere Weitherzigkeit der Natur gerade des russischen Menschen, die ihn zu Großem prădestiniert. oder ist das nur ganz gewöhnliche Gemeinheit? - das ist die Frage!; S. 583f.]; S. 373 bzw. S. $451 \mathrm{ff}$. In den Entwürfen wird diese Ambivalenz explizit geäußert, vgl. Bd. 16, S. 148: , Jlyx [lодростка Колебание“ [Der (jeisl des Jünglings. Schwanken]. Siehe außerderm zur „Rothschildidee": GOLDSTEIN 1981, S. 61-67, und INGOLD 1981, S. 80-88. Arkadij liebt auch seine Mutter, Sof ja Andreevna, obwohl er unter dem negativen, westlichen Einfluß Lamberts und Tusars, bei denen er die Rolle eines ..Lakaien“ spielte, sich ihrer zuerst geschămt hat, vgl. Bd. 13 . S. $97 f f$ und S. $270 f$.

${ }^{523}$ Liza wird als ein .stolzes, verwestlichtes“ Mädchen geschilder, das jedoch in der Liebe zum Fürsten Sokol'skij ihre ..Sehnsucht nach I.eiden" ertüllt. Sie ähnelt somit Mikolka aus dem Roman Presiuplenie I nakazanie und weist einen Charakterzug auf. der den Figuren Dostoevskijs aus dem ..russischen Volk“ eigen ist, vgl. Bd. 13, S. 84, S. 245, S. $291 \mathrm{f}$., S. 450f. Der Geliebte von Liza, der junge Fürst Sokol'skij, geht wegen knmineller Machenschaften zugrunde, repräsentiert aber den ,altrussischen" Adel; er gehört wie Myskin einem alten Fürstengeschlecht an. Sein Gegenspieler, der gleichnamige (komplementäre) Fürst Nikolaj Ivanovic Sokol'skij, gehorrt dagegen dem jüngeren Zweig dieses Geschlechts an, das 
Versilovs aus der ersten Ehe, die Tochter Anna Andreevna und ihr Bruder, ${ }^{524}$ außerdem der alte Fürst Sokol'skij ${ }^{525}$ und seine Tochter, Katerina Nikolaevna Achmakova, eine reiche Generalswitwe, die sowohl von Versilov als auch von seinem Sohn Arkadij geliebt wird, aber beinahe einen deutschen Baron, einen „westlichen Verführer", heiratet. ${ }^{526}$ Erwăhnt wird außerdem eine Reihe anderer russsicher Figuren, so z.B. eine politische Verschwörergruppe um Vasin und Dergacov und um den Spekulanten, Fälscher und Intriganten Stebel'kov, ${ }^{527}$ zwei junge Russen, Andreev und Trišatov, eine junge Selbstmörderin Olja und deren Mutter, ${ }^{528}$ eine Bekannte Versilovs und die Erzicherin Arkadijs, Tat jana Pavlovna. ${ }^{529}$ Ausschließlich im Epilog des Romans begegnet die Figur des Lehrers, Nikolaj Semenovic, dessen Äußerungen zu den Aufzeichnungen Arkadijs die Problematik des Romans abschließend kommentieren. ${ }^{530}$

Alle in unterschiedlichem Grade ,verwestlichten“ russischen Figuren werden wie in den oben erörterten Romanen mit Hilfe fremder Imageme, darunter auch polnischer, charakterisiert. Es lassen sich unter ihnen zum einen einige verwestlichte Figuren unterscheiden, in denen positive, ,idealistische-westliche“

erst nach den Reformen Peters des Großen, also nach der ..Okzidentalisierung“ Rußlands, sich bereichert hat. Vgl. ebd., S. 157ff., S. I75ff. und S. $245 \mathrm{ff}$.

524 Die Halbschwester Arkadijs, Anna Andreevna, gehört zu den „verwestlichten“, aber nicht eindeutig negativen Figuren: Sie intrigiert mit Lambert, lehnt aber zugleich das Geld des alten Fürsten Sokol'skij ab. Arkadij erinnert sie an eine „Nonne“" den älteren Fürsten Sokol'skij, der sie heiraten will, an eine ..Engländerin aus einem Bilderbuch“", wodurch sie den stereotypen Englånderinnen in Zımnie zameıkı ") leınıch vpečatlenıach ähnlich ist, vgl. ebd., S. $33, \mathrm{~S}$. $192 \mathrm{fr}$, S. 255 (.J .../ это - строгое и прелестное лицо, лицо из английского кипсека“. $\mid / \ldots i$ sie hat das strenge und schöne Gesicht eines englischen Keepsake; S. 4831), S. 325ff., S. 339ff., S. 403ff.. S. 450. Der gesetzliche Sohn Versilovs aus erster Ehe ist dagegen eine extrem negative Figur, die das ..Volk“ verachtet, vgl. die Szene der „Emiedrigung und Beleidigung" Arkadijs, ebd., S. 398ff.

325 Seine Figur ist dem Fürsten Gavrila K. in 1)jadjuškın son ähnlich, ohne aber durch die polnischen Imageme ,.verwestlicht“ zu sein, vgl. z.B. Bd. 13, S. 23f. und passim sowie oben, S. 148ff. und $S$. 154, Fußnote 58.

526 Vgl. ebd., S. 23, S. $203 \mathrm{fr}$ : Die Figur Achmakovas verkörpert für Arkadij, trotz ihrer Okzidentalisierung, das ..Ideal einer russischen Frau“. Sie habc das runde Gesicht eines russischen Bauernmädchens. Er nennt sie das ..lebendige Leben“" und zugleich ..Student”, wodurch auf die Figur Lizas in Zapiskı iz poxpol ja und auf Achmakovas Streben nach der "westlichen Bildung" angespielt wird. Achmakova nennt sich selbst eine .Rußland liebende Russin“" sie interessient sich für Politik (ebd., S. 207 und S. 219f.), obwohl sie als Tochter des alten Fürsten Sokol skij zugleich zu den „verwestlichten“ Figuren aus der höheren adligen Gesellschaft gehört. Sie verlobt sich für kurze Zeit mit dem deutschen Baron B oring. Für Versilov ist sie dagegen die Verkorperung ...aller laster" (ebd., S. 219).

527 Vgl. z.B. ebd., S. 39ff., S. I18ff., S. $245 f$ f, S.332 sowie Bd. 17, S. 298ff. Die Gruppe der sozialistisch gestimmten Verschwörer um Vasin wird jedoch viel weniger ..darmonisch“ als diejenige von Petr Stepanovic Verchovenskij in Besy geschildert.

528 Vgl. Bd. 13, S. 141 ff. Die Problematik des Selbstmords kann hier nicht năher erörten werden, obwohl sie ebenfalls mit der negativen Okzidentalisierung, mit der ..Infizierung“ der russischen Selbstmörder mit atheistischen bzw. .nihilistischen“ Anschauungen aus dem

Westen" zusammenhăngt.

$529 \mathrm{Vgl}$. z. B. ebd., S. 19f.

${ }^{530}$ Fbd., S. $451 \pi$. 
Züge überwiegen. Zu diesen Figuren gehoren Versilov, ${ }^{531}$ der sich als "letzter" bzw, als "russischer Europăer" bezeichnet und als ein Vertreter des russischen verwestlichten Adels das „ideelle positive Erbe Europas“ aufgenommen bzw. aufbewahrt hat, ${ }^{532}$ der Sohn Versilovs und der Ich-Erzähler Arkadij sowie die „sekundăren“ bzw. „episodischen“, ambivalenten Figuren, Trisatov und

531 Der Name Versılov könnte auf den „Kampf um den Glauben“ hindeuten (Bepcusos= „верь ситой“ [glaube mit Anstrengung]), obwohl in Staraja Russa eine Familie dieses Namens gelebt hat, u.a. ein Gutsbesitzer Andrej Pavlovic Versilov, vgl. dazu Bd. 17, S. 262, Anm 1 (nach REJNUS 1971, S. 28). Zu seinen „westlich“ geprăgten Vorbildern sollen Caadaev, Gercen oder auch Turgenevs Rudin gehören (Bd. 17, S. 264ff., 283ff., bes. S. 288ff.). Sein mógliches Vorbild könnte auch Apollon A. Grigor'ev sein (vgl. zu Grigor ev und Dostoevskij bei LAZARI 1996, S. 37ff.). Die ambivalente, „breite russische Natur" Versilovs umfaßt sowohl "liberal-(a)theistisch-sozialistische Ideen" als auch die "Liebe zu Rußland und zu Christus", einer .großen Idee", die für ihn Sof ja und Makar verkörpern. Er ist positiver als Valkovskij, Svidrigajlov bzw. Stavrogin dargestellt, wird ein "Schiller" genannt bzw. mit den Figuren "Shakespeares“ verglichen (vgl. z.B. Bd. 13, S. 224, S. 363, S. 382.). Seine Beziehung zum „Katholizismus“ wird nur angedeutet (Bd. 13, S. 30ff., S. 51 f., S. 56ff. S. 378ff. und die Entwürfe in Bd. 16, z.B. S. 112, S. 163f., S. 199, in denen sie stărker betont wird); seine Kritik am „atheistischen Westen“ läßt sich an der Erwăhnung des „zweiten Prozesses Jesu" im England des 18. Jahrhunderts ablesen (Bd. 13, S. 222; siehe dazu GERIGK 1992a, S. 91ff., der darin lediglich eine ideologische antisemitische Anspielung sieht); Versilov ist aber gleichgültig der Ikonenverehrung gegenüber, in seiner Wohnung hangt eine Kopie der Sixtmischen Madonna und der Florentıner Bronzetür (Bd. 13, S. 82); das Zerschlagen der .Altglăubigen-lkone“, des „Vermächtnisses Makars“, auf der zwei Gestalten dargestellt sind, in zwei gleiche Teile, kann zum einen eine blasphemische Handlung, zum anderen aber die endgültige Spaltung Versilovs, als ein endgültiger Bruch zwischen seinen beiden Identităten, der „westeuropäischen“ und der „(alt)russischen“ bedeuten (ebd., S. 13, S. 408ff. und z.B. Bd. 16, S. 226). Die Sehnsucht Versilovs nach dem „Glauben“ wird aber davor in seiner zweiten utopischen Vision deutlich, die mit dem Erscheinen Christi endet. Die beiden positiven Utopien Versilovs: des vergangenen und des künftigen Goldenen Zeitalters sind aber „westlicher Herkunft": die ersıe Vision ist dem „Traum" Stavrogins gleich (das .,belebte“" mythologische Gemalde ( $l a u d e$ lorrains), die zweite stammt von Heinrich Heine (Vgl. Die Nordsee (1825-1826), Erster (yklus, XIl. Frieden. in: Heine 1975, S. 391f. und Bd. 16, S. $374 \mathrm{ff}$. und Bd. 17, S. 389f.). Versilov ist somit der ,heimatlose russische Wanderer" im Unterschied zum ,russischen Pilger" Makar, der in der byzantinisch-orthodoxen religiosen Volkstradition "verwurzelt“" ist.

532 Versilov verurteilt den ..blutigen“, „militanten“ Atheismus, vgl. Bd. 13, S. 172f. (zu

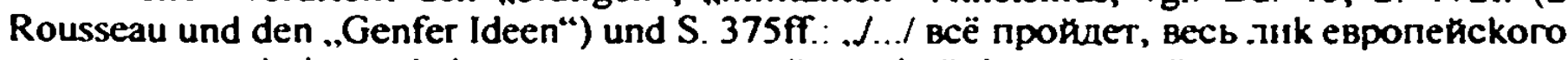
старого мпра /.../; но, kak носіте.ль высшей руссkой kу.льтурной мыс.ли, я не мог до-

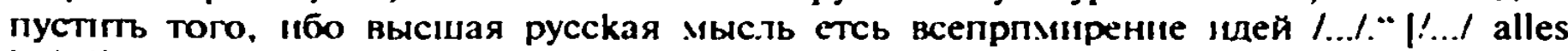
[wird] vergehen, das ganze Antlitz der europäischen Alten Welt $; . \ldots /$ /...; aber als Träger des höheren russischen Kulturgedankens konnte ich das nicht gelten lassen, denn der hohere russische Gedanke ist eben die Versöhnung aller Ideen miteinander; S. 712f.] ( S. 3.75f., vgl auch Bd. 16, S. 428ff.) Versilov begreift sich als "Vertreter" der russischen Kultur, die sich das „Erbe“ der im „Westen“ durch die ,,atheistische“ und ..kommunistische“ Revolution bereits untergangenen kulturellen Tradition ..angeeignet" und ..aufbewahr" " hat. Diese Stellen erinnem einerseits an die Anspielung auf Chomjakovs Gedicht Mećla in Zımnıc zameıki o leınıch vpeciullenyach, andererseits aber an die ..Puskkin-Rede“ (1880), in der Dostoevskij über die Fähigkeit des ,.russischen Allmenschen" spricht, sich alle fremden Kulturen ...in Liebe anzueignen", vgl. dazu oben S. 230, zu Zimnie zametkı o letnich vpeciallenjjach und Bd. 26 (I) nevnik pisalelja za 1880 ged. Puikin (Oc̈erk)). 
Andreev, ${ }^{533}$ die an ihrer (teilweise) negativen Okzidentalisierung zugrunde gehen. Diese "idealistischen" Russen vertreten trotz einiger negativer Züge als "russische Schillers" das positive utopische Imagothème des verwestlichten Rußlands. Im Zusammenhang mit ihnen werden solche positiven fremden Imageme wie Claude Lorrains Gemalde Acis und Galatea, ${ }^{34}$ die Sixtinische Madonna Raffaels, die Florentiner Bronzetür, 535 "Schiller",536 "Goethe" und dessen Faust, ${ }^{537}$ "Shakespeare", 530 "Dickens"539" und "Victor Hugo" erwăhnt. ${ }^{510} \mathrm{Zu}$ den fremden Imagemen, die vorwiegend die negative Okzidentalisiêrung der oben erwăhnten sowie einiger anderer Figuren hervorheben, wie z.B. Achmakova, die politisch-revolutionäre Verschwörergruppe um Vasin und Dergacov, der Spekulant Stebel'kov, der altere Fürst Sokol'skij oder Tat"jana Pavlovna, gehören u.a. "Napoleon" und "Bismarck", 541 "das aufklarrerische England" als On des "inszenierten "neuen Prozesses" Jesu,

$533 \mathrm{Vgl}$ zu diesen Figuren unten, S. 355ff.

534 Vgl. Bd. 13, S. 375f., Bd. 17, S. 389, Bd. 16, S. 428f.: In den Entwürfen wird die ,positive Utopie" Lorrains als ein Symbol des daraus hervorgegangenen und „blutig“ gewordenen „westlichen Atheismus“ bezeichnet.

$\dddot{3}_{35}$ Ebd., S. 82. Vgl. oben zu Stepan Trofimovic Verchovenskij, S. 326ff.

536 Ebd., S. 363: Arkadij vergleicht den "Realisten“ Lambert, der die Frauen für „niedriger“ als die Mănner hălt, mit den „Idealisten“ (.,Schillers“) wie er selbst und sein Vater. Da er aber plant, Achmakova zu „erpressen“, will er diese „niedrige“ Tat vor sich selbst „rechtfertigen“ und gibt Lambert recht, denn ..Schillers in reiner Form gebe es nicht“. Vgl. auch zu dem in den literarischen Werken Dostoevskijs vorkommenden Ausdruck „,npekpacное и высоkое“ [das "Schöne und Erhabene"], der auch in P'odrostok (z.B. in der Erinnerung Versilovs an sein „Reuebekenntnis“" vor Makar) auf Schiller (bzw. auf seine Kant-Interpretion) zurückgeht, ebd., S. 106 und Bd. 17, S. 371 f.

$537 \mathrm{Vgl}$. Bd. 13, S. 352f. und unten zu Trisatov, S. 355ff., bes. S. 359f. Siehe auch SERMAN 1997.

530 Vgl. Bd. 13, S. 76f. (Arkadij will durch die Verwirklichung seiner „Idee" noch ..größer” als alle ..Shakespeares“ und andere .große Mănner" werden), S. 209 (der „Idealist“ Versilov wird mit „Othello" verglichen, der Desdemona und sich selbst nicht aus "Eifersucht", sondem „wegen des Verlusts seines Ideals“ ermordet habe), bzw. S. 224 oder S. 382 (Versilov spricht über ..schmerzhafie Szenen“ [Болиныс cuенb; kursiv Dostoevskij] in den Werken der "groBen Künstler", die für immer im Gedächtnis blieben „wie eine Wunde“, dazu gehören „последнй моно.лог Oте.цо у Шекспира, Евгений у ног Татьяны, ици встреча бет.лого каторжника с ребенком, с девочкой в хо.лодную ночь, у ко.лодша, в Misérubles Buktopa Гюro /... / Ider letzte Monolog Othellos bei Shakespeare, /.../ [Evgenij zu Füßen Tatjanas; Erg. d. Verf.], oder in den .Afisérahles" von Victor Hugo die Begegnung des entsprungenen Zuchthauslers mit dem kleinen Madchen in der kalten Nacht am Brunnen; $S$. 7271

539 Ebd., S. 353

540 Ebd., S. 383

s41 Ebd., S. 76, S. 182, S. 370 (..Napoleon“" v.a. im Zusammenhang mit der ..Rothschildidee“ Arkadijs und in den Âußerungen Stebel kovs zur ..Französischen Revolution“) und S 77 , 207, 277, 370 (..Bismarck“" - v.a. im Gesprăch zwischen Arkadij und Achmakova über seine .Idee ${ }^{\omega}$, die ,reiner" als diejenige Bismarcks sei, und in den Äußerungen Versilovs zum Portrăt Sof jas sowie der Französin Alphonsine zur „Frauenfrage“, vgl. auch Bd. 17, S. 383f.). Es handelt sich also um eine indirekte ideologische Kritik der Figuren dieser westlichen Stsatsmänner

542 Ebd., S. 222. 
Amerika, d.h. die „Vereinigten Staaten“543, und „Deutschland“. Im Zusammenhang mit Versilov kommt darüber hinaus nicht nur der Koran, sondern auch die Anspielung auf die "katholische Kirche“ bzw. die "Jesuiten“ vor. ${ }^{544}$ Die negativ eingesetzten fremden Imageme bilden das negative utopische Imagothème des verwestlichten RuBlands, obwohl fast alle verwestlichten Figuren einige positive Eigenschaften, entweder eine „Sehnsucht nach dem (russisch-orthodoxen) Glauben" oder nach einem "westlichen Ideal" aufweisen. Nur Stebel'kov bzw. der einmal erwăhnte gesetzliche Sohn Versilovs sind eindeutig negativ verwestlichte Figuren.

In Podrostok treten auch einige fremde Figuren auf: ein junger Deutscher, Kraft, $^{545}$ ein Bekannter Vasins, der sich wegen seiner Idee von der ,Zweitrangigkeit" der Russen umgebracht hat; zwei deutsche Barone, der bereits erwähnte Baron B oring, mit dem Achmakova für kurze Zeit verlobt war, sowie sein Freund, der Baron R.; ${ }^{546}$ erwăhnt wird auch ein deutscher Arzt, Edmund Karly飞 Lichten, der den kranken Makar in Moskau behandelt hatte. ${ }^{547}$

543 Ebd., S. 42, S. 168, S. 174, S. 268, erwähnt wird „Amerika“ (bzw. die „Vereinigten Staaten“) im Zusammenhang mit der „Idee“ Arkadijs und ihrem „Zusammenbruch" sowie mit der Gruppe Dergacovs: als ein „utopischer“ Fluchtort und im Zusammenhang mit den "LügenGeschichten" von Petr Ippolitoviz und der von Versilov bemerkten .,russischen Leidenschaft", andere durch Lügen beglücken zu wollen (S. 168). Petr Ippolitovic gehơrt zu den "verwestlichten Lügnem“ Dostoevskijs, vgl. dazu oben, S. 297ff,, bes. S. 299.

54 Vgl. die Worte Versilovs über die ..physisch begründete Unfahigkeit des Menschen“, den ..Năchsten zu lieben“ (die an die Ansichten Ivan Karamazovs erinnern), der eine Stelle aus dem Koran zitiert (ebd., S. 175), Vgl. unten zu Brat ja Karamazovy, S. 372, Fußnote 595. Arkadij wundert sich wegen dieser Äußerung Versilovs darüber, daß man diesen einen "Christen“. einen „,kettentragenden katholischen Mönch“ bzw. einen „Prediger“ genannt habe. Versilov geht jedoch auf die Frage nach den „Ketten“ nicht ein, was als eine Bestatigung seiner Neigung zum ...atheistisch gewordenen Katholizismus" interpretiert werden konne. Siehe auch zum Korun bzw. Islam bei Dostoevskij PożNIAK 1992, S. 11-36.

$545 \mathrm{Vgl}$. Bd. 13, S. 39ff., 53ff., 133ff. vgl. dazu auch Bd. 17, S. 366 und 374ff. zu den authentischen Vorbildem Krafts (u.a. zu P.Ja. Caadaev, zu einem Selbstmorder namens Kramer, dem Studienkollegen von A. F. Koni, über die die damalige Presse berichtet hatte). Der Deutsche Kraft kommt nach Petersburg aus Wilna, d.h. aus dem polnisch-litauisch-katholischen und "rußlandfeindlichen" Gebiet, was die Entstehung seiner "Idee" erklăren könnte. Sein Gesicht macht auf Arkadij, trotz seiner Würde und Sensibilităt, einen unangenehmen Eindruck (S. 43f.); Kraft betont, daß er die ..Idee“ der .Zweitrangigkeit“" des russischen Volkes nicht aus ..Patriotismus" erfunden habe. Obwohl er für einen ..Deutschen“" gehalten wird, bezeichnet er sich selbst als einen ..Russen“ (S. 45), was seinen Selbstmord verstăndlich machen würde: Ein „russifizierter Deutscher“, d.h. ein Angehoriger einer den Russen „überlegenen Rasse“, kann seine emiedrigende Lage nicht ertragen. Sein „sprechender“ Name ist móglicherweise Hinweis auf das damals populäre ,positivistisch-materialistische“ Werk Ludwig Büchners Krafı und Sioff (1855). Vgl. zur paradoxen Figur Krafts bei GERIGK 1992b.

${ }^{546} \mathrm{Vgl}$. Bd. 13, S. 184, 257f., 436ff., S. 448: „/.../ по.дkовник, лет тріцицати пяти, шеголеватый тпп офицера, сухощавый, с немного слишком продо.лговатым .ищом, с рыжеватыми усами и даже ресницами. Лицо его хоть и совсем некрасиво, но с резкой и вызывающей физиономией“. [/.../ Oberst, etwa fünfunddreißig Jahre alt. der Typ eines eleganten Offiziers: sehnig. mit einem um eine Idee zu langen Gesicht, einem rơtlichblonden Schnurrbart und ebensolchen Wimpern. Sein Gesicht war zwar gar nicht hübsch, aber es war von scharfem Schnitt und herausforderndem Ausdruck; S. 486f.| Sein Äußeres ăhnelt dem 
Eine wichtige Rolle im Leben Arkadijs spielt die „dămonisch bose Figur" des Franzosen Lambert sowie seiner Gebliebten, Alphonsine. In den Kindheitserinnenungen Arkadijs taucht auch ein weiterer Franzose, Tusar, der Besitzer des Moskauer Internats, auf. ${ }^{548}$ Erwăhnt wird daruber hinaus ein Roulette spielender, ,betrügerischer" Jude ${ }^{549}$. Alle fremden Figuren treten in Podrostok in der

negativen nationalen Stereotyp eines .,strengen " preußischen Offiziers, das auch in der englischen Literatur verbreitet war, vgl. BLAICHER 1992, S. 36-39. B'oring gelingt es aber nicht, Achmakova, die trotz ihrer Okzidentalisierung eine "Russin" geblieben ist, zu "verführen". Seine Figur erfüllt die gleiche Funktion wie die fon Lembkes in Besy, deutet auf dic negative Okzidentalisienung der höheren Schichten der russischen Gesellschaft. Vgl. dazu auch die ..Skandalszene“ mit Anna Andreevna und Arkadij, in der er sich als ein stereotyper ,deutscher Soldat“ herausstellt, ebd. S. 436: „/.../ он ей rрозит /.../ "1 /.../ топат ногммs - одним стовом, сказался грубый солдат-немец, несмотря на свой весь «высший свет». /../ он натете. еше в том состоянии вбесившеюося господина, в котором даже I остроумнейшие .поди этой нашюоатьности готовы иногда драться, kak сапожниki.*. | /.../ er drohte ihr, und /.../ stampfte $;. . . /$ sogar mit dem FuB - kurz, der brutak deutsche Soldat kam in ihm zum Vorschein, ungeachtet seiner ganzen Zugehorigkeit zur hochsten Gesellschaft'. I.../ er war sofort, und zwar in der Gemütsverfassung des wildgewordenen Herm, losgefahren, also in einem Zustand, in dem selbst die geistreichsten Leute dieser Rasse [ejgentl.: Nationalităt] wie die Schuster zu einer Keilerei bereit sind; S. 826]

5.7 Ebd., S. 286. Der deutsche Arzt aus Moskau wird nicht genauer geschildert, sondem nur erwăhnt. Er gehön zur Reihe der positiv geschilderten deutschen Ärzte, die in fast allen literarischen Werken Dostoevskijs aufteten.

540 Der aus Paris stammenden Tusar ist wie Lambert als ein ..psychologisch differenziertes Stereotyp eines franzósischen Spießbürgers“ (Zımnıe zumerkı o leınich vpečatlenıach) zu bezeichnen., und so "klein" und .fett" wie das Stereotyp des in Igrok und in einer anderen Szene in "'odrostok vorkommenenden .Polackchens", so daß diese Alter-figur eine "Synthese“ zweier „westlicher" Stereotypen ist: Das Symbol des „Westens“, dem sich ..Rußland" untergeordnet hat. Diese Figur ist auch dem ..kleinen und dicken Polen“, Hertn Mussjalovic in Brat ja Karamuzovy ahnlich, der aber kein ungebildeter ..Schuster, sondern ein „Tierara”“ ist (Vgl. Bd. 13, S. 96ff: „Это быт очень матеньkıй и очень птотненьkıй французик, .лет сорока пяті и действıттельно парижского пронсхождения, разумеется I1 3 canожников /.../, /.../ - че.ловеk r.тубоkо необразованный“ [Er war ein sehr kleiner und dicker Franzose, ungefăhr fünfundvierzig Jahre alt und tatsăchlich geborener Pariser natürlich ehemaliger Schusteı oder so was /.../. /... ein vollstăndig ungebildeter Mensch; S. 185]). Tusar verachtet das ,russische Volk“. Arkadij wurde von ihm wegen seines niedrigen sozialen Standes als .Lakai" behandelt (S. 96f.) und hatte sich vor ihm seiner Mutter geschămt. Ihr Besuch, an den er sich später im „Traum“ erinnert, hatte nach der .Osterwche“ stattgefunden. Der ...angenehme, schwingende Klang der Glocke" einer alten russisch-orthodoxen Kirche, die noch in der Zeit des Zaren Aleksej Michajlovic erbaut wurde und gegenüber der Pension liegt, die ,jungen, grünen Birkenblătter“ und der ..Sonnenuntergang“, die den Besuch der Mutter Sof ja begleiten, symbolisieren die .. vorpetrinische, orthodoxe Rus"“, bilden den positiv-utopischen Kontrast zur „westlichen“ Pension Tusars, dem Ort der .Erniedrigung und Beleidigung“ Arkadijs und seiner Mutter durch den „Westen“" bzw. durch das .aus dem Westen gekommene Bose“" (ebd. S. 270ff.).

$349 \mathrm{Vgl}$. Bd. 13, S. 230: ../.../ а подле меня, с.лева, помещался всё время один гнитенький франтик, я думаю, нз жиаков; /../ и вдруг, /.../ этот жиценок протяпивает руку и преспокойно тащит одну мою кредітку“. / /../ neben mir saß die ganze Zeit ein schıbiger kleiner Stutzer [eigentl.. ein kleıner verfaulter...], wenn ich nicht irre, ein Jüdchen [eigentl.: eins von den Jüdchen]; /.../ und plötzlich [streckt] dieses Jüdchen die Hand |aus] und [n:mmt] absolut gelassen den cinen der beiden Scheine an sich; S. 436] Die Szene mit dem ..Jüdhen“" erinnert an diejenige mit den „diebischen Polackchen“ in /grok, vgl. oben, S. 250ff. 
Kontrast-Funktion als alter zu den Russen auf, werden dabei als negative nationale bzw. ethnische Stereotypen eingesetzt. Sie bilden somit das negative ideologische Imagothème des verwestlichten Rußlands. Nur die Figur des Franzosen Lambert, die unten genauer besprochen wird, enthăt als alius extrem ,dămonische", negative Charakterzüge, so daß er sich in seiner extremen Negativităt nur mit dem "dămonisch-bősen" Petr Aleksandrovið Valkovskij in Unižennye $i$ oskorblennye vergleichen laßit.

In Podrostok treten im Verhaltnis zu den früheren literarischen Werken Dostoevskijs nur wenige polnische Imageme auf, ${ }^{\mathbf{5 0}}$ die jeweils in einem Zusammenhang mit dem Ich-Erzăhler Arkadij stehen, ohne ihn jedoch immanent zu charakterisieren. Zu diesen Imagemen gehören polnische Figuren: die Erwăhnung ,polnischer Frauen“ in einem Gespräch mit seinem Vater und zwei „polnische Herren“, die in einer Skandalszene auftreten. LEDNICKI hat darüber hinaus Arkadijs Beschreibung eines Petersburger Morgens als eine versteckte Anspielung auf die Schilderungen Petersburgs in den Gedichten von Adam Mickiewicz verstanden, obwohl es sich dabei auch um Bezūge auf Puskin bzw. auf Dostoevskijs frühere Texte, z.B. auf seine Novelle Belye noči [Weiße Nächte] (1848), handeln könnte.

1. Das erste polnische Imagem, die Erwăhnung „polnischer Frauen“, die den russischen Frauen zusammen mit anderen fremden bzw. westeuropăischen Frauen gegenübergestellt werden, taucht im Gesprăch Arkadijs mit seinem Vater auf. Versilov erzăhlt seinem Sohn über seine Liebe zu Sof ja Andreevna. Arkadij stellt ihm die Frage, ob und warum er sie, eine Bauerin, geliebt habe:

Русская женшина - женшиной никогда не бывает.

- Полька, франиуженка бываст? Или итальянка, /.../, вот что способно пленить цивилизованного русckorо высшей среды, вроде Версилова?

- Ну, мог ли я ожидать, что встречу славянофила? - рассмеялся Версилов. [kursiv die Verf.]

['Die russische Frau - ist niemals Weib.' Ach, und die Polin, die Franzosin, die ist es etwa? Oder die Italienerin, /.../ die so einen zivilisierten Russen der hoheren Stănde, von der Art eines Werssiloff, zu bezaubern vermag?' 'Nun sag einer', rief er lachend aus, 'hătte ich ahnen können, daß ich hier auf einen Slawophilen stoßen würde!' [ kursiv die Verf.] ] ${ }^{551}$

$550 \mathrm{Vgl}$. Orıowski 1982, S. 94, der die Ursache für das geringere Interesse Dostoevskijs an der polnischen Problematik darin erblickt, daß die ..polnische Frage“ weniger Beachtung in der russischen Offentlichkeit der 1870-er Jahre als in der Zeit unmittelbar nach dem polnischen Aufstand von 1863 fand, was sich in den letzten Romanen Dostoevskijs Podrostok und Brat 'ja Karamazony' widerspiegle, denn Dostoevskij habe ăußerst sensibel auf jegliche Änderungen der russischen offentlichen Meinung reagiert.

551 Vgl. ebd., S. 104 [S. 200]. 
Indem Versilov behauptet, daß eine „russische Frau“ niemals eine „Frau sei“, wird dadurch auf seine hautpsăchlich "intellektuell" brw. „idealistisch" motivierte Beziehung zu Sof ja verwiesen, in der ex keine gleichberechtigte Partnerin, sondern eine "Vertreterin des russischen Volkes", des "vorpetrinischen Rußlands", suchte. Arkadijs Frage spielt aber zugleich auf die Liebe Versilovs zu Achmakova an, die, ăhnlich wie Versilov, das adlige, "verwestlichte“ ("nachpetrinische") Rußland reprasentiert. Die fremden stereotypen Frauen, die angeblich die „zivilisierten“ russischen Mănner faszinieren (u.a. das an erster Stelle erwăhnte altrussische Stereotyp der „verführerischen Polin“), symbolisieren die Okzidentalisierung der russischen Adligen und den Verlust ihrer national-religiösen Identităt. Diese Passage ăhnelt deshalb einer Äußerung Satovs in den Entwürfen zu Besy und bildet eine Äquivalenz zwischen Versilov und Stepan Trofimovic Verchovenskij (und dessen Vorbild Granovskij), die der gleichen Generation des liberalen russischen Adels angehoren. ${ }^{552}$

In der Frage Arkadijs wird die „breite russische Natur" Versilovs angesprochen, der Widersprüche in sich vereinigt und zugleich ein "Russe" und ein "verwestlichter nussischer Adliger" ist, d.h. ein Typ des in Zimnie zametki o letnich vpečatlenijach erwähnten "russischen Europäers", der sich dem .,Katholizismus" nähert, aber paradoxerweise „Ketten“ trăgt, um durch die „katholisch" gepragte asketische Disziplin den „europaischen“"Teil seiner „Seele“ zu bezăhmen, den seine leidenschaftliche Liebe zu Achmakova bildet. ${ }^{553}$ Die Mutter Arkadijs, die den fremden Frauen gegenübergestellt wird, symbolisiert dagegen das ,positive Ideal einer russischen Frau aus dem Volk“.554 Versilov liebt in ihr das "russische Volk", das er verstehen möchte. ${ }^{555}$ Sof ja werden somit einerseits die sterotypen Alter-Figuren der „Frauen aus dem Westen“ gegenübergestellt, andererseits aber die „verwestlichte Russin“, Katerina Achmakova, die das .petrinische Rußland" repräsentiert, die Versilov zuerst in "Westeuropa", in Deutschland, am Rhein, kennengelernt hat.

2. Außer den oben erwähnten Polinnen treten in Podrostok zwei andere polnische månnliche Alter-Figuren auf, die in eine Skandalszene verwickelt werden.

$352 \mathrm{Vgl}$ dazu oben. S. 326ff Eine Zwischenstellung zwischen Sof ja und Achmakova nimmt im Leben Versilovs die ..Idiotin“ Lidija Achmakova ein, die kranke Stieftochter Katerinas. vgl. ebd., S. 370 f.

533 KOTEL NIKOV. 1996, S. 198f., findet in der Figur des ..Deisten“ Versilov nach seinem .Z.usammenbruch“, in seiner .Idiotie“ die mögliche Rückkehr zum ..kenotischen Ideal des russischen Volkes“", zur ..christlichen geistigen Schönheit”, das auch das Ideal Sof jas ist. d.h. zum Christus. Nach dieser Interpretation würde der Intellektuelle Versilov seine Okzidentalisierung überwinden und zur christlich-asketischen, ..russisch-orthodox-byzantinischen “ kulturellen Identität als „.Gottesnarr” zurückkehren können. Vgl auch oben, S. 100.

${ }^{554}$ Sie ist der Figur von Sonja (.Sifju) Semenovna Marmeladova aus Pres/uplenie i nukuzunie venvandt. Vgl. dazu oben, S. 264f. (Fußnote 298) und S. 277 (Fußnote 335) und bei V. KOTEL NIKOV 1996, S. 199

s5s Vgl. Bd. 13, 370f. („Он 6.7аженно у.лыбну.лся, хотя в у.лыбke ero " отразц.лось kak бы что-то страдатьческое, лучше сkазать, что- то гунаннос, высшсе..." |Er lächelte glücklich, wenn auch in seinem Lacheln gleichsam ein Leid lag, oder richtiger, etwas schmerzlich Nachsıchtiges |eigentl : etwas gequălt Duldsames], menschlich Höheres [eigentl.: etwas Humanes, Hŏheres]; S. 702] [kursiv die Verf.]), 380ff., $384 f f$. 
An diesem Skandal, der sich in einem eleganten Petersburger Restaurant in der Morskaja-Straße abspielt, nehmen neben diesen beiden Polen Arkadij, der Franzose Lambert sowie drei andere Russen, Bekannte Lamberts, teil: der "große“ Andreev, der sich dadais nennt (= franz. Tolpel), der ",hübsche“ Trišatov und ein als pockennarbig bezeichneter namenloser russischer Herr. Einer der Bekannten Lamberts, der "große", sich nie waschende Andreev, versucht durch sein herausforderndes Benehmen, Geld von Lambert zu erpressen. Er benutzt die zwei Polen am Nebentisch als eine günstige Gelegenheit, einen Skandal zu provozieren:

От нас через стол, шагах в пяти, обедали два господина и оживленно разговаривали. Оба были чрезвычайно щекотливого вида средных лет господа. Один высокий и очень толстьй, другой - тохе очень толстый, но маленький. Говорили они по-польски о теперешних nарихских событиях. Dadais уже давно на них любопытно поглядывал и прислушивался. Маленький nоляк, очевидно, показался ему фигурой комическою, и он тотчас возненавидел его по примеру всех желчных и печеночных людей, у которых это всегда вдрут происходит безо всякого даже повода. Вдруг маленький польк произнес икя dепуmama Madbe de Монжо, но по привычке очень многих поляков, выговорил его по-польски, то есть с ударением на предпоследнием слоге, и вышло не Мадье́ де Монжо́ а Ма́дье де Мо́нжо. Того только и надо было dadais. Он повернулся $\mathrm{k}$ полякам и, важно выпрямившись, раздельно и громkо, вдруг произнес, kak бы обращаясь с вопросом:

- Ма́дье де Мо́нжо?

Поляки свирепо обернулись k нему.

- Что вам надо? - грозно крикнул большой толстый поляя поруссku. Dadais выждал.

- Ма́дье де Мо́нжо? - повторил он вдруг опять на всю залу, не давая более никаkих объяснений, точно таk же kak давеча глупо повторяl яєне у двери, надвигаясь на меня: Dolgorowki? Поляки вскочили с места, Ламберт выскочил из-за стола, бросился было к Андрееву, но оставив его, подскочил $k$ nолякам и принялся унихенно извинятся перед ними.

- Это - щуты, пане, это - шуты! - презрительно повторял маленький nоляk, весь красньй, kak морkовь, от негодования. - Ckоро нельзя будет приходить! - $B$ зале тоже зашевелились, тоже раздавался ропот, но больше смех. [kursiv d. Verf.]

[Nicht weit von uns, vielleicht fünf Schritte von unserem Tisch, speisten zwei Herren, die sich lebhaft unterhielten. Beide waren in mittleren Jahren, und man sah ihnen sofort eine gewisse übertriebene Empfindlichkeit [eigentl.: beide waren von heiklem Aussehen] an. Der eine war groß und sehr dick, der andere gleichfalls sehr dick, aber klein. Sie unterhielten sich auf polnisch über die neuesten Pariser Ereignisse. Der dadais hatte sie schon lange aufmerksam betrachtet und zu ihnen hinübergehorcht. Der kleinere Pole erschien ihm offenbar als komische Figur, und er haßte ihn sofort, wie 
das bei Leuten, die an der Galle oder Leber leiden, sehr hăufig ohne jeglichen Grund geschieht. Plotzlich sprach der kleine Pole den Namen des Deputierten Madier de Montjeau aus, aber nach Gewohnheit sehr vieler Polen sprach er ihn polnisch aus, das heiBt, er betonte statt der letzten die vorletzte Silbe: also nicht Madiér de Monjeáu, sondern Mádier de Mónjeau. Das genügte dem dadais. Er wandte sich auf seinem Platz zu den Polen um, reckte sich stolz und sagte plotzlich laut und deutlich, als richte er eine Frage an sie:

'Madièr de Monjeáu?' [eigentl.: Mádier de Mónjeau?]

Die Polen drehten sich wütend nach ihm um.

'Was wïnschen Sie?' schrie der große [dicke] Pole ihn laut auf russisch an.

Der dadais wartete einen Augenblick.

'Madiér de Monjeáu?' [eigentl.: Mádier de Mónjeau?], wiederholte er plotzlich noch einmal laut, daß es über den ganzen Saal hin zu hören war, doch ohne weiter irgendeine Erklärung abzugeben, genau so dumm, wie er vor der Tür bei Lambert drohend auf mich zugetrelen und mehrmals [albern] den Namen 'Dolgorowky' ausgesprochen hatte.

Die Polen sprangen auf, Lambert schnellte hinter dem Tisch in die Hohe und wollte, wie es schien, sich auf Andrejeff stürzen, besann sich aber und eilte zu den Polen, um sie untertänigst [eigentl.: demütig] um Entschuldigung zu bitten.

'Das sind ja Narren, Pane, das sind ja Narren', rief der kleine Pole mit Verachtung, vor Zorn dabei rot wie eine Mohrrübe. Man kann ja bald nicht mehr herkommen!' Auch sonst entstand Unruhe im Saal, man hörte murren [Murren], hauptsăchlich freilich lachen [Lachen]. [kursiv die Verf. $]^{556}$

Obwohl die beiden polnischen Figuren nicht als "Polackchen“, sondern als "Polen" bezeichnet werden, handelt es sich erneut um das negative nationale Stereotyp des "dicken, kleinen Polen“, das aus Zagoskins Roman über die polnische Invasion in der "Zeit der Wirren“ stammt, und in Igrok in einer ähnlichen ideologischen, antipolischen Anspielung vorkommt, in dem früheren Roman aber in einer vom Ich-Erzähler selbst ,provozierten“ Skandalszene.

Die beiden Polen in Podrostok zeichnen sich auch durch ein stereotyp "heikles“, „polnisches“ Benehmen aus. Sie reagieren „überempfindlich“ und gereizt auf die Provokation Andreevs, worin sich ihr „Haß" auf die „Russen“ und ihr "übertriebenes Ehrgefühl" außert. Eine zusătzliche „Komik" in ihrem Auftritt entsteht dadurch, daß es zwei komplementăre Figuren sind, von denen die eine "dick“ und „sehr klein“, die andere dagegen „dick" und „sehr groß" ist. Die beiden Polen im letzten Roman Brat 'ja Karamazovy fallen durch einen ähnlichen Kontrast der Korpergröße auf, so daß die Szene in Podrostok dem "Aufurit" der Polen in Mokroe äquivalent ist. ${ }^{557}$ Auch in Podrostok fallt dem ,kleinen, dicken

556 Bd. 13, S. 349fr. [S. 666f.].

557 Vgl oben zur Figur des Franzosen Tušar, der auch einem solchen stereotypen Polacichen ahnlich ist, S. 352 (Fußnote 548). 
Polen“ die „negative Hauptrolle“ zu, denn er ist es, der den „grundlosen“ Haß Andreevs erweckt.

Ähnlich "heikel“" und „subversiv" wie im letzten Roman Dostoevskijs ist auch das Gesprăchsthema der Polen, denn sie reden über die aktuelle franzosische Politik, wobei der „,kleine Pole“ durch seine „polnische Betonung“"des Namens eines linksorientierten franzosischen Abgeordneten Andreev reizt. ${ }^{558}$. Es handelt sich somit um eine übliche „Dostoevskijsche antipolnische und antifranzösische“, d.h. um eine ,antiwestliche“ Anspielung, in der ein negatives literarisches Stereotyp eingesetzt wird.

Die Polen fallen insgesamt durch drei als "negativ“ beschriebene Eigenschaften auf: durch ihr Aussehen, durch die polnische, d.h. „falsche" Aussprache sowie durch ihr übertrieben verächtliches und gereiztes Benehmen. Unter ihrem „komischen“ Äußeren verbirgt sich aber eine potentielle Gefahr für Rußland. Die beiden Alter-Figuren verkorpern das negative ideologische Imagothème des "Westens" und dienen wie die Figur Lamberts als eine negative Folie, von der sich „positiv“ die jungen Russen abheben. Die ganze, aus der kritischen, ,.voreingenommenen" Perspektive Arkadijs geschilderte Szene, der das modische Restaurant und seine Găste „widerlich“ findet, charakterisiert aber nicht nur den Franzosen Lambert und die zwei anderen jungen Russen, sondern auch ihn selbst.

Lambert verhăt sich aus der Sicht des Ich-Erzăhlers und im Unterschied zu Andreev und Trišatov wie ein „Lakai der Polen“, er erniedrigt sich vor den polnischen „Herren“, denn er bittet sie „demütig“ um Verzeihung. Seine „demütige Hoflichkeit" erinnert an die übertriebene "Dienstbereitschaft" des stereotypen französischen Spießbürgers, die in Zimnie zametki o letnich vpečatlenijach sogar mit Hilfe des polnischen Idioms padam do nóg parodiert wird: ${ }^{\mathbf{5 9}}$

Да, у меня есть хараkтер, побольше, чем у тебя, потому что ты $в$ рабстве у первого встречного. Ты нас осралєи, ты у поляков, kak лакей, прощения просші. /.../ Я тебе не друг, а ты мошенник. /.../ мне.

558 Vgl. Bd. 17. S. 387, die Anm. zur S. 351: „Mадье де Монжо /.../ (1814-1892) - французский государственый деяте.ть, участник рево.люции $1848 \mathrm{r}$,, протпвник Нало.леона III, во время правления которого находится в эмІІташи1: пос.ле 1871 г. член НацІ1онатьного собрания, в kотором примыkат k оппозишионным .евым группировкам“ |Madićr de Montjeáu /.../ (1814-1892), franzosischer Staatsmann, Teilnehmer der Revolution von 1848, Gegner Napoleons III, während dessen Regierungszeit im Exil, nach 1871 Mitglied der Nationalversammlung, in der er mit den oppositionellen linksorientierten Gruppierungen sympathisierte|. Siehe auch Bd. 16, S. 421, zum Entwurf dieser Szene, in der u.a. der Name dieses franzosischen Abgeordneten sowie ein polnischer Satz ( эоньце пане?; [Slonce. punie?; .Die Sonne, mein Herr?'] vorkommt. Andreev wird als ein ..гражданин местечка Butte aux Cailles“ [Bürger des Städtchens... |franz. des „Wachtelhügel-Städtchens“...]| (= Synonym für ein „französisches westliches Krähwinkel“), als ein ..gebildeter Zyniker”, charakterisiert. Laut Kommentar (Bd. 17, S. 326f. und S. 425) richtet sich Andreev gegen die russischen „Westler“, u.a. gegen Gercen, die sich .,russische Fdelmănner und Weltbürger” ( jentılhomme russe et curoyen du monde) genannt haben. Die Figur des bürgerliche Normen mißachtenden Andreev soll sich auch auf den freiheitsliebenden Wilhelm Tell Schillers beziehen (ebd.).

559 Vgl. dazu oben, S. 226, S. 239f. Siehe auch S. 140, S. 255 und S. $423 f$. 
главное обидно, что ты думаешь, что можешь мне и теперь повелевать kak у Тушара, тогда kak ты у всех здешних сам в рабстве.

['Ja, ich habe mehr Charakter als du, denn du bist Sklave jedes ersten besten. Du hast uns blamiert, wie ein Lakai hast du die Polen um Entschuldigung gebeten.' /.../ 'Ich bin nicht dein Freund, /.../ [und] du [bist] ein Schuft. /.../ vor allen Dingen ărgert es mich, daß du dir einbildest, mich auch jetzt noch so kommandieren zu kōnnen wie bei Touchard, wăhrend du doch hier selbst der Sklave aller anderen bist ${ }^{\circ}$. [kursiv die Verf.]] ${ }^{560}$

Lambert wird von Arkadij endgültig als der „Sklave aller anderen“, und hauptsăchlich der „Polen“, entlarvt. Es handelt sich also um die „Selbstbefreiung" des jungen Russen, der sich von Lambert losgelost hat, dem Symbol des "Rußland unterdrückenden Westen". Lambert verlient dadurch nicht nur seine "Macht" über den jungen Russen, sondern auch dessen „Achtung“, d.h. seine frühere, durch Gewalt erlangte "Autorităt". Die beiden Polen haben in dem "Befreiungsproze B" Arkadijs eine "Katalysator-Funktion“.

Dank dem "Polen-Skandal" hat sich Lambert, der frühere "sadistische Herr" Arkadijs, der ihn bei Tušar als seinen Lakai behandelt hat, selbst als "Lakai der Polen" erwiesen und sich .endgültig als ein "Schuf" gezeigt. ${ }^{561}$ "Die Figur Lamberts, die im Leben Arkadijs die verhängnisvolle Rolle des „Verfuhrers zum Bösen" spielt, übernimmt im Roman Podrostok die Funktion, die in anderen Romanen den "dämonisch-bosen" verwestlichten russischen Figuren zugefallen ist, zu denen Petr Aleksandrovic Valkovskij, Svidrigajlov oder Petr Stepanovic Verchovenskij gehoren. Lambert ist wie diese als eine "Verkorperung des Bösen aus dem Westen" (als ein Alius) aufzufassen. Er låßt sich, auch wegen seines Namens ${ }^{562}$, zugleich als ein psychologisch differenziertes Stereotyp eines franzosischen Spießbürgers aus Zimnie zametki o letnich vpečatlenijach bezeichnen. ${ }^{563} \mathrm{Er}$ ist die Verkorperung des negativen utopischen Imagothèmes des verwestlichten RuBlands.

$560 \mathrm{Vgl}$. Bd. 13, S. 355 [S. 674f.].

$561 \mathrm{Vgl}$. ebd., S. 429, wo Lambert als ein um Anna Andreevna „ю.7ившй“ [scharwenzelnder] Lakai bezeichnet wird, d.h. er benimmt sich wie ein ..Polackchen"“.

562 Der Name lambert ist móglicherweise eine Anspielung auf den Sizz der Pariser polnischen konservativen aristokratischen Emigration um den Fürsten ADAM JERZY CZARTORYSKı (1770-1861), auf das Hötel lamhert. Vgl. dazu WIELKA ENCYKLOPEDIA POWSZECHNA (1963, S. 700f. (zu Czartoryski), bzw. 1964, S. 752 (zu Hoitel l ambert)).

${ }_{563} \mathrm{Vgl}$. ebd., S. 27f., S. 73, S. 270ff., S. 275ff., S. 306, S. 322ff., S. 348ff., S. 363, S. $404 \mathrm{ff}$. und S. 418ff. In der Moskauer Pension Tušar war der Franzose Lambert nicht nur der ..sadistische Herr" Arkadijs, er führte ihn auch in seine "lasterhaften Affaren" ein. Lambert wird außerdem als ein ,ungláubig gewordener Katholik“ bzw. als .Atheist“ geschildert:

../... у Тушара /.../ Когда он ездит на конфирмацию, то k нему приехал аббат Pиго поздравıть с первым причастіем, и оба кину.лись в слезах друг другу на шею /.../.

Когда у нето умер отец, он выне., /.../ через два года [я| встретиці / его] на у.лице./.../ [он] показал мне пятьсот руб.лей и ве.ел. с собой ехать. /.../ Он сказат, что деньги уташил сегодня у матери /.../, а что вчера к нему приходи.7 аббат Рито увешевать /.../, «а я выну.л нож и сказал, что я его зарежу" /.../, что его мать в сношениях с аббатом Рито /.../, и что всё, что они говорят иро иричастие, - вздор/.../. 
Die Episode in einem modischen Petersburger Restaurant zeigt außerdem nicht nur den moralischen Verfall des Franzosen Lambert, eines "Atheisten", "Lügners", "Intriganten“ und „Erpressers“, d.h. des „Westens an sich" bzw. des "Westens in Rußland", von dessen zerstorerischem „Einfluß", von dem Rußland beherrscht $\mathrm{zu}$ werden droht, sondern darüber hinaus charakterisiert sie positiv Arkadij und die beiden jungen russischen Bekannten Lamberts. Wie zeitweise Arkadij, der sich jedoch von seiner "Knechtschaft" befreien konnte, sind Andreev und Trisatov Lamberts Opfer, Vertreter der auf die „schiefe Bahn“ geratenen verwestlichten russischen Jugend, denn Andreev und Trißatov werden als "Idealisten“ und nicht ausschließlich negativ geschildert. Andreev erscheint als ein „galliger Untergrundmensch", d.h. als ein wegen seiner Okzidentalisie-

[S. 51f:: /.../ bei Touchard /.../ [kam zu] seiner Erstkommunion der Abbé Rigaud zu ihm gefahren, um ihm von Herzen zu gratulieren [eigentl.: ... als er zur Konfirmalion fuhr, kam zu ihm der Abbé Rigaud gefahren, um ihm zum ersten Abendmahl zu gratulieren], und beide fielen unter Tränen einander um den Hals. /.../ Als sein Vater starb, trat er aus, /.../, nach zwei Jahren aber begegnete ich ihm einmal auf der Straße. /.../ Er /.../ zeigte mir fünfhundert Rubel und sagte, ich solle mitkommen. /.../ Von dem Gelde sagte er, er habe es an demselben Morgen [eigentl.: heute] /.../ seiner Mutter entwendet /../, gestern aber sei der Abbe Rigaud zu ihm gekommen, um ihm Vorhaltungen zu machen. /.../ ' ich aber zog das Messer und sagte, ich würde ihn erstechen', erzăhlte er. /.../ [er sagte], daß seine Mutter mit diesem Abbé Rigaud ein Verhältnis habe, /... daß alles, wa sie da von der Kommunion redeten, Unsinn sei. [kursiv die Verf.]. Indem der "Katholik“ Lambert zu einer Konfirmatıon fahrt (also einer protestantischen Initiation), wobei es sich hier nur um eine (katholische) Kommunion handeln kann, wird die „Ignoranz" des Erzăhlers Arkadij bezüglich der beiden "westlichen“ Konfessionen sichtbar (S. 27), dt. S. 51f. Der darauf folgende gemeinsame „Besuch“ bei einer Prostituierten und die Tötung eines Kanarienvogels, auf den Lambert schießt, erinner hier ironisch umgewandelt an die ..blasphemische Tat" eines Bauern, der auf eine Hostie geschossen hat (vgl. auch Bd. 17, S. 372, zum Bezug Makars zu Vlas Nekrasovs und zum Feuilleton Dostoevskijs Vlas aus Inevnik pisatelja (1873). Das Gesicht Lamberts wird als „Maske“ beschrieben. Trotz der .französischen Nase" ist er den "dămonisch-bösen" russischen Figuren Valkovskij und Stavrogin, ähnlich: „Волосы у него были черные ужасно, .пио белое и румяное, kak на мacke, нос дтинный, с горбом, kak у французов, зубы бе.лые, г.лаза черные“ (S. 27) / Sein Haar war pechschwarz, sein Gesicht weiß und rosig, wie eine Maske, die Nase lang und gebogen, wie sie Franzosen gewöhnlich haben; dazu weiße Zähne, schwarze Augen; S. 52], siehe auch Bd. 17, S. 309, S. 326f., S. 364f. Auch die französische Geliebte Lamberts, Alphonsine, ähnelt einer „spießbürgerlichen Französin“ in Zimnic zamelkı o lelnich vpećallenijach bzw. der Französin Blanche in /grok (vgl. Bd. 13, S. 275ff: „странное kakoe-то сушество, высокого роста и сухощавая, kak щепka, девица, брюнетка, с длинной татией, с дтнным лицом, с прыгаюшми глазами и с вватившимися щеками, - страшно износившееся сущетсво!" |ein sonderbares Gechöpf, lang und mager wie ein Holzspan, brünett, mit einer langen Taille, einem langen Gesicht, unruhigen Augen und eingefallenen Wangen - ein furchtbar verlebtes [eigentl.: verbrauchtes Wesen. Geschöp 7 Frauenzimmer!: S. 521] ), sie beschwcrt sich übrigens vor Arkadij und nennt Lambert einen .Bismarck“, ebd., S. 276f., und Bd. 17, S. 383f. Sie ist aber eine ..Lügnerin“ und ..Intrigantin" wie Lambert (vgl. z.B. S. 440ff.). Beide ahneln auch in ihrer Ordnungsliebe den Pariser Spießbürgern aus Zımnie zametki o letnich vpecarlenijach, vgl. Bd. 13, S. 418. Zu dem Vornamen Alphonsme vgl. Bd. 17, S. 383. Zur Herkunft des Namens lambert vgl. ebd., S. 387: Es handelt sich um den französischen, ..klischeehaften“' Satz (hé. lambirl' où esı lambert. as-1u vu lambert?, mit dem ihn Andreev reizt (vgl. z. B. Bd. 13, S. 347ff., S. 354, S. 673). 
rung (als „Lakai“ Lamberts, des „Westens") verbitterter und selbstironisch gewordener ",russicher Idealist“. Er parodient nicht nur die „schlechte“ Aussprache der Polen, sondern auch die "falsche" Aussprache russischer Namen durch die "Franzosen“ („Dolgorowky“). Aus Verzweiflung über seine aussichtslose Lage und die finanzielle Abhängigkeit von Lambert begeht er schließlich Selbstmord; in den Entwürfen wird er mit Schillers "Wilhelm Tell" verglichen. ${ }^{564}$ Trišatov zeigt sich im folgenden als begabter Musiker und sensibler Mensch, der wegen materieller Schwierigkeiten in die Gesellschaft Lamberts geraten ist. In seinen utopischen positiven Visionen wird neben der Tragödie Gretchens aus Goethes Faust eine Szene aus Dickens' Roman The Old Curiosity Shop (1840/41) erwähnt, zu dem es schon im Roman Unï̌ennye $i$ oskorblennye, v.a. in den Figuren Nellis und Smits, einen Bezug gegeben hat. ${ }^{565}$ Andreev und Trisatov sind also wie Arkadij und sein Vater "russische Idealisten“, sie verkörpern das positive utopische Imagothème des verwestlichten Rußlands.

3. WACLAW LEDNICKI und die russische Forscherin A.V. ARCHIPOVA haben in Podrostok anhand des Vergleichs von Textstellen eine versteckte Anspielung auf den dritten Teil des Dramas D-iady [Ahnenfeier] von ADAM MICKIEWICZ finden wollen. Es handelt sich um den Vergleich zwischen der Beschreibung Petersburgs (und des Denkmals Peters des Großen) als eines Stadt-Phantoms, eines „Trugbilds“ im Roman Dostoevskijs mit einer ähnlichen Schilderung Petersburgs in dem Gedicht Oleszkiewicz aus dem Exkurs des Dramas des polnischen Autors. Archipova vertritt sogar die Ansicht, daß es bei Dostoevskij einen Bezug auf Mickiewicz nicht nur in Podrostok, sondern auch in seiner frühen Erzahlung Slaboe serdce [Das schwache Herz] (1848) sowie in zwei späteren Feuilletons: Peterburgskie snovidenija v stichach i proze [Petersburger Trüume in Versen und in Prosa] (1861) und im Dnevnik pisatelja von 1873 Mecty $i$ grezy [Träume und Trugbilder] gebe. ${ }^{566}$

Obwohl diese Annahme plausibel erscheint, muß doch zugleich darauf hingewiesen werden, daß die Spezifik der Darstellung Petersburgs in Podrostok nicht so eindeutig und ausschließlich Mickiewicz angehen mag, sondern daß es sich bei der einschlägigen Stelle primär um einen Bezug auf Puškins bzw. auch auf Gogol's Beschreibungen Petersburgs handelt, wenn auch das Drama von Mickiewicz Dostoevskij bekannt gewesen sein dürfte, was durch ein Zitat in den Entwürfen zum Roman Brat 'ja Karamazovy belegt werden kann. ${ }^{567}$

$564 \mathrm{Vgl}$. ebd., S. 449.

$565 \mathrm{Vgl}$. Bd. 13, S. $351 \mathrm{ff}$. In diesen ..utopischen Visionen“ bzw. Trăumereien außert sich die Sehnsucht Triłatovs nach dem ..Ideal“" und nach dem „Glauben“, die er allerdings nicht im russisch-orthodoxen Glauben. sondern in der „westlichen Kultur“" sucht, d.h., darin zeigt sich sein Verlust der russischen national-religiosen Identität, seine positive westliche Utopie ist dem .Traum“ Versilovs äquivalent.

$566 \mathrm{Vgl}$. LEDNICKI 1953, S. 295ff.): ..Mickiewicz also notes the mirage-like effect suggested by the ephemeral and iantastic aspects of Petersburg" (S. 297); Lednicki bemerkt darüber hinaus die Polemik zwischen Puškin, Mickiewicz und Gogol' (S. 301ff.) und ARCHaPOVA 1994. S. I5ff.

$567 \mathrm{Vgl}$. auch zu den polemischen Beziehungen zwischen Mickiewicz und Puškin den Aufsatz der Verf. ŚWIDERSKA 1999a, S. 19ff.: Das Poem Puškins Mednyj vscalnık ist als eine .polemi- 
Falls aber beide Forscher den Bezug auf das Drama des polnischen Dichters in Podrostok richtig erkannt haben sollten, wirde die "Trugbild-Vision eines Petersburgers Morgens“ zu den wenigen polnischen Imagemen in diesem Roman gehoren: ${ }^{568}$

В тakoe nетербурrсkoе утро, гнилое, сырое и туманное, дикая мечта kakoro-нибудь пушkинсkого Германна из «Пиковой дамы» (kоллоссальное лицо, необычайный, совершенно петербургский тип - тип из петербургского периода!), мне кажется, долкна еще более уkрепиться. Мне сто раз, среди этого тумана, задавалась странная, но навязчивая греза: «A что, kak разлетится этот туман и уйдет kверху, не уйдет ли с ним вместе и весь этот гнилой, склизный город, подымется с туманом и исчезнет kak дым, и останется прежнее финсkоe бoлото, а посреди его, пожалуй, для красы, бронзовый всадник на жарkо дышащем, загнанном коне?». /.../ «Вот они все кидаются и мечутся, а почем знать, может бьть, всё это чей-нибудь сон, и ни одногото человека здесь нет настоящего, истинного, ни одного постуnka действительного? Кто-нибудь вдруг проснется, кому это всё грезится, - и всё вдруг исчезнет».

[An einem solchen modrigen, feuchten und nebligen Petersburger Morgen muß sich, wie mir scheint, der tolle Einfall eines Puschkinschen Hermann aus der „Pique-Dame“ (eine kolossale Gestalt, ein ungewohnlicher, durchaus Petersburger Typus - ein Typus aus der Petersburger Periode unserer Geschichte!) - noch mehr festigen und erstarken. In diesem Nebel ist mir hundertmal die sonderbare, zudringliche, durch nichts zu verscheuchende Vorstellung gekommen: 'Wie aber, wenn dieser Nebel verfloge und in die Hohe stiege? - wurde dann nicht mit ihm zusammen auch diese ganze modrige, sumpfige Stadt emporsteigen und wie Rauch verfliegen? - und was zurückbliebe, wäre dann nur der frühere finnische Sumpf, und mitten in ihm, meinetwegen als Schmuck, der Eherne Reiter auf dem

sche Antwort“ auf den dritten Teil des Dramas Dziady von Mickiewicz verfaßt worden. Es ist entstanden, nachdem Puškin 1833 von einem Freund ein Exemplar der Pariser Ausgabe der „Dichtungen“ (ersch. 1832) von Mickiewicz, u.a. mit diesem Drama, geschenkt bekommen, sich damit intensiv beschaftigt und daraus sogar die Gedichte Oleszkiewicz und Pomnik Pioıra Wielkıego [Das Denkmal Peters des Großen] in polnischer Sprache abgeschrieben hatte (ebd., S. 19f.). In der Buchfassung dieses Aufsatzes (SWIDERSKA 1999b, S. 281ff.) wurde das Jahr, in dem Puskin die Ausgabe von ( ) ziacty erhalten hatte, wohl aus Versehen mit 1837 angegeben (ebd., S. 281). Siehe ferner zu den Entwürfen zu Brat ja Karamazovy unten, S. $423 \mathrm{f}$. ${ }^{6} \mathrm{Vgl}$. die einschlăgige Textstelle bei Mickiewicz: „Gdy siç najtçższym mrozcm nich) ¿arzy, / Nagle zsiniało, plamami czcmicje, /... / Wiatr zawiał ciepły. Owe shupy dymów, / Ów gmach powictrzny, jak miasto olbrzymı́w, / Niknł̨c poxd nicbem, jak carów widziadło, / Runçto w gruzy i na ziemię spadło: / I tym rzckami po ulicach płynął (... ".. ( Oleszkiewic:z. Dzieñ przed powodzia peter.sburskg $182+\mathrm{r}$. [Der Tag vor der Petersburger (̈ber.schwemmung 1824]) [Wenn im strengsten Frost der Himmel gleißt im Licht, / Plotzlich grau geworden dunkle Flecken trăgt, [...] Warmer Wind kam auf. - Des Rauches lange Fahnen, / Jenes Luftgebild, Behausung von Titanen, / Schwand dahin wie eines Zaren Zauberwelt, / Die in Trümmem auf die Erde niederfallt: / Rauch, in Stromen auf die Strassen ausgegossen [... ].], zit. nach MickIEWICZ 1991, S. 474f. Siehe auch Bd. 17, S. 372, die Anm. zur S. $113 f$. 
heißschnaubenden überjagten Pferde'.$/ . . /$ 'Da hasten und eilen sie nun alle hin und her und mühen sich $a b$, aber wer weiB, vielleicht ist das alles nur ein Traum von irgend jemand, und es gibt hier nicht einen einzigen leibhaftigen, wirklichen Menschen, nicht eine einzige wirkliche Handlung? Irgend jemand, dessen Traum dies alles ist, wird plötzlich aufwachen - und alles wird dann jăh verschwunden sein ... $]^{569}$

In der „Vision“ Arkadijs wird jedoch zum einen explizit die Figur des Deutschen Germann [Hermann] aus Puškins Erzăhlung Pikovaja Dama [Pique Dame] (veröffent. 1834) erwähnt, der für Arkadij ein „Petersburger kolossaler Typ“, d.h. eine „reale“ Gestalt ist, sowie zum anderen das Denkmal Peters des Großen, so daß es sich bei dieser Stelle zugleich um einen Bezug auf Puskins Poem Mednyj vsadnik [Der eherne Reiter] (1833/34) handelt.

Petersburg ist furr Arkadij die "irreale Stadt", ein "Traum" (Peters des Großen) und vertritt metonymisch das "irreale" und "faule, petrinische Rußland", von diesem Zaren „erfunden" und auf einem "finnischen (= fremden) Sumpfgebiet" errichtet. Die beschaftigten Petersburger erscheinen nicht als "wahre, wirkliche Menschen", keine von ihren „Handlungen“ ist als "wirklich" zu bezeichnen, wodurch symbolisch auf den "moralisch fragwürdigen", "irrealen" Charakter des .verwestlichten, petrinischen“ Rußlands hingewiesen wird. Der „phantastische Traum" des Puskinschen Germann, der davon trăumt, durch Kartenspiel reich zu werden, hătte somit einen entsprechenden stimulierenden Hintergrund gefunden.

Die Reflexion Arkadijs deutet kritisch auf die „Entfremdung“ der russischen Hauptstadt vom früheren ,alten Rußland" hin und charakterisiert Arkadij positiv als einen Russen, der sich der Gefahr der Okzidentalisierung Rußlands beuußt ist. Puskins Germann, der darüber hinaus ein Deutscher, also ein Fremder ist, vertritt außerdem wie Arkadij eine „Rothschildidee“, denn er erblickt im .Reichtum" den Weg, um weltliche Macht zu erlangen, von der sich aber die Figur Dostoevskijs bereits zu befreien versucht. Die Trugbild-Vision in Podrostok bildet somit einen Teil des negativen utopischen Imagothèmes des verwestlichten Rußlands. Sie ăhnelt aber doch der Kritik Rußlands bei Mickiewicz, für den Petersburg ebenfalls eine „numinos-böse“ Stadt („carów widziadło"; des, eines bzw. der "Zaren Zauberwelt") ist. Auf das Gedicht von Mickiewicz könnte sich auch die „Rauch-Metapher” beziehen. Das „phantastisehe" und ..neblige" Petersburg wird sich wie der "Traum irgendeines Mensehen", wie "Rauch" bei dessen Aufwachen zu nichts auflosen. - Die russische ,petrinische“ Hauptstadt wird als vollig losgelost vom „russischen Boden" geschildert.

4. In den Entwürfen zum Podrostok wird außerdem ein gewisser Rechtsanwalt erwähnt. der auf einen Dostoevskij bekannten Moskauer Juristen zurückgehen soll:: 570

$569 \mathrm{Vgl}$ Bd. 13, S. 113 [S. 216].

$570 \mathrm{Vgl}$ die Anm. dazu in Bd. 17, S. 396 
Bepmumcя nодлячuшka Жеромский, adвokamumka. Портрет. (Передоверил противному адвокату.)

Треснули основы под революцией реформ. Замутилось море. Исчезли и смераись определения и границы добра и зла. Н.В. Д-ko * Xерамсkші. Ньнче честно не прохсивешь. [Der kleine gemeine, niedertrăchtige Schuft, Žeromskij, das schăbige Rechtsanwăltchen, dreht sich flink herum. Das Portrăt. (Habe dem widerlichen Rechtsanwalt Vollmacht erteilt). Unter der Last der revolutionären Reformen sind die Grundlagen zusammengebrochen. Das Meer ist auf einmal trube geworden. Verschwunden und nivelliert sind die Begriffsbestimmungen und die Grenzen zwischen Gut und Bose. N.V. D-ko und Żeromskij. Heutzutage läßt sich ehrlich nicht leben.] [kursiv die Verf.; fett und kursiv Dostoevskij] ${ }^{511}$

Der Rechtsanwalt Žeromskij wird nicht explizit als Pole bezeichnet, aber die beiden abwertenden Diminutiva nodısчumka [podljačiška; der kleine gemeine, niedertrăchtige Schuft] und adookamumka [advokatiška; das schăbige Rechtsanwältchen] wecken Assoziationen mit den "schăbigen Polackchen" [poljački, poljačiski]. Auch das Verb oepmumcs [ vertitsja, dreht sich (flink), von вepmemocs, vertet 'sja, sich drehen] weist auf seine „flinken", schnellen Bewegungen und auf seine "Geschicklichkeit" hin, die ebenfalls die stereotypen „Polackchen“ negativ auszeichnet. Im Zusammenhang mit diesem ,niedertrăchtigen" Vertreter der russischen Justiz wird auf den Verfall der "sozialen Werte“ und der Sittlichkeit in Rußland hingewiesen und auf den metaphorischen Titel des "antinihilistischen" Romans von A.F. Pisemskij, Vzbalamučennoe more (1863), angespielt, in dem RuBland mit einem durch "Nihilisten", u.a. durch Polen, ,aufgewühlten Meer" verglichen wird. ${ }^{572}$

$\mathrm{Da}$ es außerdem im Rußland des neunzehnten Jahrhunderts mehrere Juristen polnischer Herkunft gab, zu denen beispielsweise der Vater von WACLAW LEDNICKI gehörte, ${ }^{573}$ und der Name Zeromski in Polen aufuritt (vgl. den polnischen Schriftsteller Stefan Żeromski), ist die polnische Herkunft dieses Dostoevskij bekannten Rechtsanwalts anzunehmen.

Makar Dolgorukij, die russische Alius-Figur, nennt die Rechtsanwälte nach „băuerlicher Art" das .gemietete Gewissen“. ${ }^{374}$ In dem Roman Brat"ja Karamazovy, in dem der Petersburger Anwalt polnischer Herkunft Spasowicz als Fetjukovic karikiert wurde, klingt das Echo dieses Urteils nach. Der Kontext. in dem der Name in den Entwürfen zu Podrostok genannt wird, macht eine solche Kritik am „verwestlichten“ russischen Gerichtswesens umso einleuchtender. $^{575}$

$571 \mathrm{Vgl}$. Bd. 16, S. 7

$572 \mathrm{Vgl} \mathrm{dazu}$ oben im Zusammenhang mit Besv. S. 319.

573 Vgl. dazu z.B. DzWONKOWSKI 1991, S. 111 ff. über ALEKSANDER LEDNICKI, den Vater des Slavisten WaClaw Lednicki, bzW. Zu Wlodzimerz SPasowicz vgl. KulCzycKa-Saloni 1975

574 Vgl. oben. S. 346, FuBnote 521 und Bd. 13, S. 310.

$575 \mathrm{Vgl}$. Bd. 17, S. 396. In den Entwürfen zum Poxdrostok gibt es in der Charakteristik des

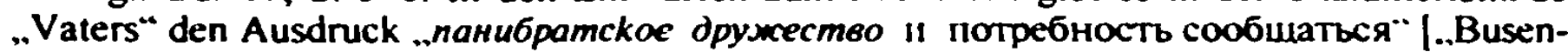


ZUSAMMENFASSUNG: Im vorletzten Roman Dostoevskijs spielt das positive utopische Imagothème des verwestlichten, ,petrinischen“ Rußlands die dominante Rolle. Zum ersten Mal kommt aber komplementar dazu das positive utopische Imagothème des russisch-(orthodox-byzantinischen), "vorpetrinischen" RuBlands (= des "russischen Volkes) vor, so daß das negative utopische Imagothème des verwestlichten Rußlands, das die "Welt" von Besy beherrscht hat, eine untergeordnete Rolle spielt. Dieses negative lmagothème wird in Podrostok fast ausschlieBlich durch fremde Figuren reprasentiert, was als seine zunehmende „Marginalisierung" bzw. „Verdrängung“ verstanden werden kann. Alle fremden Figuren in Podrostok weisen darüber hinaus einen engen Bezug zu den stereotypen Figuren in Zimnie zametki o letnich vpecatlenijach sowie in lgrok auf.

Die drei oben genannten Imagothèmes treten dagegen in Podrostok wie in allen früheren Werken Dostoevskijs in der Figurenkonstellation auf, wobei alle Figuren in unterschiedlichem Grad als "verwestlicht", „petrinisch" bzw. als "russisch-(orthodox-byzantinisch)" charakterisient werden. In Podrostok lăßt sich auch keine wesentliche Änderung im Hinblick auf die zweifache Funktion der fremden Imageme beobachten:

Zum einen dienen sie zur immanenten positiven bzw. negativen Charakterisienung der verwestlichten russischen Alius-Figuren, zum anderen als fremde Alter-Figuren in der Kontrastfunktion zu den russischen Figuren. Besonders die fremden Alter-Figuren weisen dabei eine vorwiegend „ideologische" Bedeutung auf. die sich jedoch meistens mit der "utopischen“ überschneidet.

$\mathrm{Zu}$ den vorwiegend ,positiv verwestlichten“ Figuren gehören in Podrosık der Ich-Erzăhler Arkadij, dessen Vater Versilov sowie Andreev und Trišatov. Es sind die bereits in den früheren Werken vorkommenden "Idealisten" (,.Schillers“), ungeachtet dessen, daß sic zugleich einige negative westliche Züge aufweisen. Diese Figuren verkörpern den vom „petrinischen, europarischen RuBland" angeeigneten und im "Westen" bereits untergangenen "Idealismus", der durch solche fremde Imageme wie „Goethe“, "Shakespeare“, „Dickens“" oder ..Lorrain" symbolisiert wird und in diesen „europasisierten“ Russen lebendig geblieben ist, d.h. das positive utopische Imago:hème des verwestlichten RuBlands.

Zu den vorwiegend „negativ verwestlichten“ Figuren gehören die gesezlichen Kinder Versilovs. die beiden Fürsten Sokol'skij, Katerina Achmakova, der Kreis um Vasin und Dergacov sowie der Spekulant Stebel kov, obwohl auch die meisten dieser Figuren psychologisch differenziert und ambivalent sind. Diese Figuren verkörpern das negative utopische Imagothème des verwestlichten Rußlands. denn sie können dem ..Bösen aus dem Westen“ nicht widerstehen.

Zu den negativen westlichen Imagemen, als ein Teil des negativen utopischen Imagothèmes des „Westens“, gehört auch die Anspielung auf die politischen Ereignisse in Frankreich (z.B. auf die Pariser Komune) in den Äußerungen Versilovs, der darin den "Tod der europaischen positiven Utopie“ erblickt.

freundschaff" und das Bedürfnis, sich mitzuteılen] [kursiv die Verf.], vgl. Bd. 16, S. 50. Vgl. dazu oben, S. 192. 
Dabei läßt sich beobachten, daß, wie in den früheren Romanen Dostoevskijs, am positivsten bzw. am negativsten verwestlicht die weniger wichtigen „Rand“Figuren bzw. die sogenannten "Nebenfiguren" sowie die episodisch auftretenden stereotypen Figuren erscheinen, wăhrend die sogenannten Hauptfiguren bzw. die zentralen Figuren des Romans differenzierter gestaltet sind.

In der Funktion des Kontrastes (als alter) zu den russischen Figuren treten in Podrostok der stereotype und negativ geschilderte deutsche Baron B oring und sein Freund, der Baron R. auf. B'oring fallt außerdem auch die Rolle des mißlungenen „westlichen Verführers" Achmakovas zu, ohne daB er jedoch „dämonische" Züge offenbaren würde. Negative "Ideen aus dem Westen" symbolisiert auch die Figur des Roulette spielenden Juden, eines "Schattens" Rothschilds, bzw. der Franzose Tušar, der åußerlich dem Stereotyp des „dicken Polackchen“ ăhnelt und der Jesuit abbat Rigo (Abbé Rigaud). Diese Figuren vertreten das "Böse aus dem Westen“ als Teil des negativen utopischen Imagothèmes des verwestlichten Rußlands.

Eine besonders negative Funktion fallt dabei der Figur des Franzosen Lambert $z u$, denn er läßt sich als das psychologisch differenzierte Stereotyp eines „französischen Spießbürgers" aus Zimnie zametki o letnich vpečatlenijach bezeichnen. Dieser Franzose ist aber wegen seiner destruktiven „dämonischen" Negativităt nicht nur eine Alter-Figur, sondern zugleich als ein Symbol des "Bösen" aus dem Westen, als ein Alius, aufzufassen, er ist den dämonischen Figuren wie Stavrogin oder Svidrigajlov bzw. Petr Stepanovic Verchovenskij ăhnlich und erscheint als eine Verkörperung des "Teufels in der Gestalt eines Franzosen“. Er ähnelt somit als "Verführer zum Bösen" dem altrussischen Stereotyp des "Ljachs in der Gestalt eines Teufels", um so mehr, als sein Name möglicherweise auch auf die polnische rußlandfeindliche Pariser Emigration hindeuten mag. In der Szene mit dem französischen katholischen Pater und der darauffolgenden Tötung eines Kanarienvogels wird Lambert als ein „westlicher atheistischer Vlas" geschildert. L ambert ist außerdem die einzige Figur des Romans, die keine „Sehnsucht nach positiven Idealen" aufweist: auch darin ähnelt er dem Stereotyp des nur an Geld denkenden französischen Spießbürgers. Seine "Gemeinheit" und seine "Lakaienhaftigkeit" wird in der Szene mit den beiden Polen besonders deutlich und bildet eine Äquivalenz zu der ,angeborenen Lakaienhaftigkeit" des stereotypen Franzosen in Zimnie zametki o letnich vpečatlenijach. Zugleich ahnelt er aber auch dem komplementären Stereotyp des ,scharwenzelndem Polackchens".

Die polnischen Imageme treten in Podrostok ebenfalls in diesen zwei Funktionen auf. Sie dienen als negativer Kontrast zu den russischen Figuren und charakterisieren positiv den weltanschaulich noch nicht ganz gefestigten, aber idealistischen Ich-Erzăhler Arkadij, der zwischen zwei "Welten“ schwankt, zwischen dem positiv-utopischen „vorpetrinischen. orthodox-byzantinischen Rußland" und dem .,petrinischen, verwestlichten Rußland" in seinen zwei Aspekten.

576 In den Romanen Dostoevskijs treten mehrere Figuren bzw. Gruppen von Figuren auf, die sich nur schwer in den traditionellen Bezeichnungen wie ..Haupt-“ oder ...Nebenfiguren“ beschreiben lassen. Die genaue typologische Beschreibung der Figurenkonstellationen in diesen Romanen würde eine getrennte Studie erforden. 
dem positiven und negativen, die einerseits von seiner Mutter Sof ja und seinem gesetzlichen Vater Makar, sowie andererseits von seinem naturlichen Vater Versilov und von dem Franzosen Lambert symbolisiert werden. Arkadij wird jedoch als ein Russe gezeigt, der den negativen „westlichen“ Einfluß überwinden kann.

In der negativen Kontrast- und „Katalysator"-Funktion zur Figur Arkadijs (und daneben zu den Vertretern der gleichen Generation, Andreev und Trisatov) treten die beiden polnischen Alter-Figuren auf. Lambert wird in der Skandalszene als ein "Lakai des Westens", d.h. ironisch sogar als ein "Lakai der Polen", gezeigh, was die "Befreiung" Arkadijs von dem "Einfluß" des "Westens" symbolisieren konnte. Außer dieser Doppel-Funktion dienen aber diese negativen nationalen Stereotypen als ideologische Anspielung.

Auch die Erwăhnung des Stereotyps der "Polin als Verführerin“ im Gespräch Arkadijs mit Versilov ist eine (ideologische) Anspielung. Sie deutet aber auch auf Achmakova, eine „verwestlichte Russin“ hin, die Versilov liebt und charakterisiert (als alter) sowohl Achmakova und Versilov als auch Arkadij, der hier "slavophile“, positive Züge (wie Satov in den Entwürfen zu Besy) aufweist.

Die polnischen Alter-Figuren bilden einen Teil des negativen utopischen Imagothèmes des verwestlichten Rußlands (mit einer ideologischen Komponente) als Bedrohung für die politische und kulturell-religiőse Identităt RuBlands.

Wenn die Annahme von Lednicki und Archipova richtig sein sollte, würde die von ihnen in der "Petersburg-Vision" Arkadijs gefundene, aber versteckte Anspielung auf die negative Schilderung Petersburgs von Mickiewicz, die in dieser Szene neben dem expliziten Bezug auf die "Petersburger" Figur des Deutschen Germann und auf Peter den Großen Puskins vorkommt, auf die Distanz Arkadijs zu dieser verwestlichten neuen Hauptstadt Rußlands hindeuten, trotz seiner vorübergehenden Begeisterung für die westliche Idee, reich zu werden (wie James Rothschild), für eine Idee, deren „Anhänger“ auch Puškins Germann ist. Es handelt sich also bei dieser Szene um eine indirekte Kritik der Okzidentalisierung Rußlands. Petersburg erscheint darin durch die Vermittlung Puškins und ggf. auch Mickiewiczs als der wesentliche Teil des negativen utopischen Imagothèmes des verwestlichten (petrinischen) Rußlands.

Makar und Sof ja, teilweise Liza, Tat jana Pavlovna und der junge Fürst Sokol'skij, vertreten dagegen das positive russisch-(orthodox-byzantinische) utopische Imagothème des vorpetrinischen Rußlands. Elemente dieses positiven russischen Imagothèmes, abgesehen von den beiden Alius-Figuren Sof jas und Makars, überschneiden sich aber in allen anderen wichtigen Figuren mit den positiven bzw. negativen utopischen Imagothèmes, wobei je nach dem Grad der Okzidentalisierung einer Figur das eine oder andere Imagothème die Oberhand gewinnt bzw. das komplementăre andere Imagothème ablost. 
In Podrostok treten folgende polnische Imageme auf:

1. Zwei explizit genannte Imageme:

- das bereits in Igrok auftretende altrussische Stereotyp der „Polin als Verführerin“

- und das ebenfalls aus Igrok bekannte Stereotyp des „dicken (kleinen) Polen“, das auf Zagoskins Roman zurückgeht.

2. Darüber hinaus setzen sich andere fremde Figuren aus einigen ,polnischen Teil-Imagemen" zusammen:

- der Franzose Tušar ist ăußerlich dem „dicken Polen“ ăhnlich;

- das "diebische Jüdchen" benimmt sich wie die „betrügerischen, schăbigen Polackchen" in Igrok;

- die Figur Lamberts weist drei „polnische Teil-Imageme“ auf: erstens deutet sein Name symbolisch auf das Hôtel Lambert hin, den Sitz der Pariser polnischen Emigration; zweitens benimmt er sich wie ein „,scharwenzelndes, zu FüBen liegendes Polackchen", und drittens läßt er sich als die "französische Variante" des Stereotyps des "Ljachs in der Gestalt eines Teufels“, des „Verführers zum Bösen“ bezeichnen.

3. Ein "latentes“ polnisches Imagem ist die mögliche Anspielung in der "Trugbild-Vision" Arkadijs auf das Gedicht Oleszkiewicz von Adam Mickiewicz.

Abgesehen von der möglichen Anspielung auf Mickiewiczs Petersburg-Kritik treten somit in Podrostok keine polnischen Imageme zur immanenten Charakteristik russischer Alius-Figuren auf. 


\section{3. БРАТЬЯ КАРАМАЗОВЫ. \\ РОМАН В ЧЕТЫРЕХ ЧАСТЯХ(' ЭПИII) (OM (1879-1880) \\ [DIE BRÜDER KARAMAZOV] ${ }^{577}$}

Der letzte Roman Dostoevskijs nimmt aus imagothematischer Sicht eine besondere Stellung unter den bisher besprochenen literarischen Werken Dostoevskijs ein, denn er läßt sich als die imagothematische Bilanz seines literarischen Werks bezeichnen: ${ }^{578}$ In Brat ja Karamazovy kommen alle aus den früheren Werken bekannten Imagothèmes vor. Jedes dieser Imagothèmes wird fast ,idealtypisch“ von einer der zentralen Figuren des Romans repräsentiert. Die dominante Rolle fallt - ungeachtet der äußerst differenzierten und subtilen psychologisch-imagothematischen Darstellungsweise - dem positiv utopischen Imagothème des .russisch-orthodox-byzantinischen“ Rußlands zu.

Dieser besondere ..russisch-imagothematische" Charakter des Romans erklărt auch die Tatsache, daß in Brat ja Karamazovy nur wenige fremde Alter-Figuren auftreten, obwohl mehrere fremde Imageme zur Charakterisierung der „verwestlichten" russischen Figuren eingesetzt werden.

Brat ja Karamazovy nehmen aber auch im Hinblick auf das Vorkommen polnischer Imageme eine Sonderstellung unter allen Romanen Dostoevskijs ein. denn nur in ihnen treten individualisierte, namentlich genannte polnische Figuren auf, die einen besonders engen Bezug zu den Polen in den Katorga-Aufzeichnungen Zapiski iz Mertvogo doma aufweisen. ${ }^{579}$

Die Handlung der Brat'ja Karamazovy spielt ausschließlich in Rußland und wie diejenige des Romans Besy in der Provinz. Den Schauplatz bilden zum einen das Städtchen Skotoprigon 'evsk, dessen Name der Ich-Erzähler erst im 7.usammenhang mit dem Prozeß Dmitrij Karamazovs zum ersten Mal erwähnt. ${ }^{580}$ und zum anderen das diesem Städtchen benachbarte Kloster und die dazu gehörende Einsiedelei [skit: ckum] des starec Zosima [cmapeu; „ein alter Mann. Greis“" $=$.geistiger Lehrer“]. ${ }^{581}$ Als episodische Schauplätze kommen einige um

577 Dic deutschen Übersetzungen russischer Zitate aus Brai ja Kuramazovy werden nach der Ausgabe DOSTOJEWSKI 1986b zitien.

$378 \mathrm{Vgl}$. den ausfürlichen Kommentar zu Entstehung. Veröffentlichung. Rezeption und zur Thematik. Bd 15, S. 397ff.

$579 \mathrm{Vgl}$ dazu oben. S. 170-191

580 Der Name des Städtchens ist als ..bedeutend“, wenn nicht als .,symbolträchtig“ aufzufassen (Skotoprigon 'evsk; = etwa das...Städchen, wohin das Vieh zusammengetrieben ivird") und bezieht sich möglicherweise auf die darin versammelten .verwestlichten Russen“, wodurch zugleich ein Bezug auf die ,bösen Geister“ und die .,Schweineherde“ in Besy gesetzt wird. Vgl. Bd. 15, S. 15: „увы, так называстся иаш ropoдок, я до.tro сkрыва.7 сго имя“|о weh! so heiBt unser Stadchen, lange genug habe ich seinen Namen verheimlicht: $S$. 980] Siehe z.B. auch den Kommentar, ebd., S. $453 \mathrm{ff}$ (zu Staraja Russa) und S $479 f$. (zum Erahler In Brul ja Kuramuzovy) sowie ReJNUS 1971, bei dem ebenfalls auf Staraja Russa als das Vorbild dieses Städtchens hingewiesen wird.

sa1 Als Vorbild des Klosters und der Einsiedelei Zosimas soll das Kloster und die Einsiedelei Optina Pustyn bei Kosel sk im Gouvernement Tula gedient haben, die Dostoevskij und VI.S. 
Skotoprigon'evsk liegende Ortschaften vor, wie das Dorf Mokroe, mit dem der polnische Teil der Handlung verbunden ist. Darüber hinaus werden als Wohnbzw. Fluchtorte der handelnden russischen Figuren Moskau und Petersburg, d.h. die ,alte" und die „neue" russische Hauptstadt, genannt.

In Brat'ja Karamazovy treten mehrere russische Figuren auf, die nicht nur psychologisch, sondern, wie oben bereits bemerkt, auch im Hinblick auf ihre "nationale" (,russische“) und „kulturelle“ Identităt differenziert dargestellt werden. Sie lassen sich sowohl hinsichtlich des Grades ihrer Verwurzelung in der russischen religios-kulturellen Tradition als auch ihrer Okzidentalisierung aufteilen und noch weiter differenzieren. Dabei ist auffallend, daß unter den "russisch-orthodox-byzantinischen" und "verwestlichten" russischen Alius-Figuren sowohl positive als auch negative Figuren auftreten. Alle zentralen Figuren weisen zugleich „westliche" als auch „russische“" (positive und/oder negative) Züge auf. Sie schwanken zwischen dem verwestlichten, petrinischen und dem orthodox-byzantinischen, vorpetrinischen Rußland, obwohl bei jeder von ihnen jeweils positive oder negative "russische" bzw. "westliche" Eigenschaften dominieren. Dagegen lassen sich die sekundären Figuren, die sogenannten Nebenund Randfiguren, entweder als nur "russisch" (positiv oder negativ) bzw. als "russisch verwestlicht“ (ebenfalls positiv oder negativ) bezeichnen, und zeigen eine starke Tendenz zur Stereotypisierung. Im Kontext der fiktionalen Welt des Romans wird aber die positive Bindung an die, russisch-orthodox-byzantinische“ Tradition ${ }^{582}$ als das erstrebenswerte Ideal aller Figuren angedeutet, so daß sich darin eine bestimmte Werthierarchie äußert.

In Brat 'ja Karamazovy lassen sich im Hinblick auf die imagothematische Differenzierung einige Figurengruppen unterscheiden. $\mathrm{Zu}$ den am stărksten verwestlichten russischen Figuren des Romans, in denen die negative bzw. positive Okzidentalisierung dominiert, gehoren: Fedor Pavlovic Karamazov ${ }^{583}$ und seine

Solov'ev im Juni 1878 besucht hatten, siehe dazu z.B. KorEL'NIKov 1994, S. 168-179, oder BUDANOVAFRIDLENDER 1993-1995 (Bd. 3, S. 278f.). Vgl. auch Bd. 15, S. 412.

502 Die „russisch-orthodox-byzantinische“ Tradition wird hier in dem der fiktionalen Welt der Romane Dostoevskijs eigentümlichen immanenten Sinne verstanden. Es wird dabei nicht der Anspruch erhoben, sein "Bild" der russischen Orthodoxie mit dem seiner Zeitgenossen oder dem „Eigenbild” der russisch-orthodoxen Kirche seiner Zeit zu vergleichen.

${ }^{503}$ Der Ich-Erzähler betont die „национатьная бесто.товость“ [den nationalen Unverstand] dieses Karamazov, nennt ihn „mun человеka не то.тько дрянного и развратного, но вместе с тем н бесто.лkового, - но из таkіх, однаkо бесто.лковых, kоторые умеют от.лично обде.тывать свои имушественные де.тиики“| |.der Typ eines nicht nur schlechten und den Lüsten ergebenen, vielmehr zudem auch noch eines unverständigen Menschen, die imstande sind, vortrefflich ihre Geldgeschăftchen zu führen /... ${ }^{*} ;$ S. 11] [kursiv die Verf.]. Er wird als geldgieriger, egoistischer, sexuell hemmungsloser und ..sentimental boshafter" Mann bezeichnet, der geschätsbedingte Kontakte mit mehreren Juden hat (.."со мнопіми жідамиı,

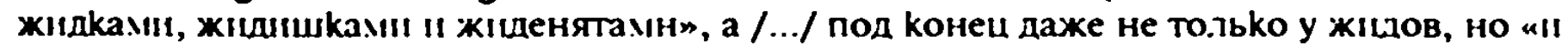
у евреев быт принят"“. |.. mit vielen Juden und Jüdchen, Jüdinnen und Jüdınnenchen , und ist $/ . . . /$ schließlich sogar nicht nur bei den Juden, vielmehr auch bei den 'Hebräern' empfangen worden “"; S. 37|)) und ist einem "altromischen dekadenten Patrizier” ahnelt ( „Особенно он указыват на свой нос, /.../ а Настоящий рияиский. - говори.7 он, - вместе с kадыком настоящая физиономия древнего патрииия времен упадкам. Этім он, кажелся, гордицтся" |kursiv die Verf.] [.,Im besonderen pflegte er hinzuweisen auf seine Nase, 
erste Frau, Adelaida Ivanovna Miusova ${ }^{584}$ sowie ihr Cousin Petr Aleksandrovic Miusov, ${ }^{585}$ seine beiden Srhne Ivan und Dmitrij, ${ }^{586}$ die Verlobte Dmitrijs, Katerina Ivanovna Verchovceva ${ }^{587}$ darüber hinaus der uneheliche Sohn Fedor Pavlovic Karamazovs, Pavel Fedorovic Smerdjakov, ${ }^{588}$ der Seminarist und

1.... 'Dıe rıchtige Römernase'. pflegte er zu sagen, 'mit dem Adamsapfel zusammen die echte Physıognomie eines altrömischen Putrizıers zur Zell des Verfulls'.": S. 39)). Dieser verwestlichte Adlige spielt ironisch auf die ..entzauberte", "lutheranische Holle“ der deutschen Aufklărung an: „Ведь невозможно же, думаю, чтобы черти меня крючьями по3абыты сташить k себе, когда я помру. Ну вот и думаю: крючья? А откуда они у них? /.../ я вот готов поверітьь в ад то.тько чтобы без пото.лkа: выходіт оно kak будто де.лиkaтнее, просвешеннее, по-.лютерансkи то есть“ $\mid / \ldots /$ es ist unmöglich, so denke ich, daß die Teufel vergessen werden, mich mit ihren Haken zu sich zu schleifen, wenn ich sterbe. Nun /.../ [denke ich] dann: Haken? Aber woher nehmen sie sie denn? /../ Ich /.../ habe nichts dagegen, an die Hoblle zu glauben, nur muß sie ohne Decke sein, sieht weniger aberglāubisch aus, mehr in der Art der Lutheraner, sozusagen; S. 41). Fedor Pavlovic Karamazov nennt sich auch den .,regierenden Graf von Moor". Seine ...autoironischen“ Äußerungen werden aber durch seine „bosen Taten“ und den negativen Kommentar des Erzahlers relativiert. Vgl. dazu Bd. 14. S. 7ff.: S. 2Iff. bzw. S. 66 und passim.

so4 Die erste Frau Fedor Pavlovic Karamazovs ist wegen ihres „romantisch-shakespearischen Idealismus“ zugrundegegangen. Sie wird mit einer verwestlichten „romantischen" russischen Selbsmorderin der vorletzten Generation verglichen, welche die ihr „fremde .Ophelias“ bis hin zum Selbstmord nachgespielt hat: , $f . . / 6$ босіцтась с выcokoro 6epera, /.../ в /.../peky /.../. единственно 113-за тото, чтобы nоходить на шеkспировсkую Офе.тию. /.../ и поступок Аде.танды Ивановны Миусовой бы.7 без сомнения отто.лосkом чужих веяни /.../ | /../ [sie warf] sich /../ von einem hohen /.../ Ufer in cmen /.../Fluß $/ . . /$ : einzig und allem deshalb, um der Shakespearschen Ophelia zu gleichen. $/ . . /$ Ähnlich dem war auch das Vorgehen der Adelaida Iwanowna Miussow i.../ zweifellos das Echo fremder Einflüsse /..."; S. 121, ebd., S. 7ff

585 Der Vormund Dmitrijs und Aleksejs, em ,.liberaler russischer Europaer“, lebt in Paris, hat sich dort an der Revolution des Jahres 1848 beteiligt und soll mit Proudhon und Bakunin bekannt gewesen sem, vgl. ebd., S. 10ff. Sein Vorname und Vatersname, die er mit den negativ verwestlichten russischen Figuren (vgl. Petr Aleksandrovic Valkovskij) teilt, deuten auf seine ..negative petrinische“ Okzidentalısierung hin. Er erinnert an Versilov, ohne dessen ..Sehnsucht nach dem (russisch-orthodoxen) Glauben" aufzuweisen.

506 Dmilrif und Ivan weisen u.a. Bezüge zu Karl und Franz. Moor auf und beide sind als ..russische Schillers” zu bezeichnen, obwohl sie auch andere ...westliche“ und ., russische“ Komponenten aufweisen. $\mathrm{Vgl}$. den Kommentar zu den Vorbildern dieser Figuren, u.a. zu Schiller: Bd. 15, S $415 \mathrm{ff}$, S. 456fr., S. 460ff. und passim.

507 Mit ihrem Stolz und Pflicht- sowie EhrbewuBtsein erinnent sie an Katerina Ivanovna Marmeladova in Prestuplente' i nukazunie. Ivan vergleicht sie mit der Dame aus Schillers Ballade Der Hundschuh; Eine Kontrastfigur zu der in Petersburg aufgewachsenen Katerina Ivanovna ist deren volksnahe Halbschwester Agaf ja. Vgl. ebd., S. $100 f f .$, S. $169 f$., bes. S. I75f

508 Der vierte Sohn Fedor Pavlovic Karamazovs und der Lizaveta Smerdjašcaja, einer .Jurodivaja“, erinnert an die Figuren der "lakalenhaften Polackchen“. Aus Rache für seine soziale Benachteiligung quält er Katzen und Hunde, haßt ..Rußland", kleidet sich „westlich" und lernt Französisch. Sein Gesicht ist aber dem eines ..russischen Kastraten“ (ckoneu) ähnlich Seine ,jesuitisch-atheistische“ Denkweise kommt in einem (iespräch über einen ..Märtyrer des russisch-orthodoxen Glaubens“ zum Ausdruck, denn er hat die Ansichten Ivans (..ohne Gott ist alles erlaubt“) übernommen. Nach dem Mord an seinem Vater, fühn ihn aber das Schuldbewußtsein in den Selbstmord. Smerdjakov liest kurz davor Isaak den Syrer, was auf den Zusammenbruch seiner ,"westlich" und ,,atheistisch“" geprägten Identitát hindeuten mag (vgl dazu Bd. 14, S. 48 und S. 89, sowie Bd 15, S. 533 und S. 541, die Anspielungen 
„heimliche“ Cousin Grusen'kas Michail Ivanovic Rakitin ${ }^{509}$ die reiche, liberalverwestlichte Witwe Katerina Osipovna Chochlakova ${ }^{590}$ und deren kranke Tochter Liza, ${ }^{591}$ der Schüler Kolja Krasotkin, ${ }^{592}$ der Rechtsanwalt Fetjukovic ${ }^{593}$ und nicht zuletzt die Figur des Teufels, der Ivan als ein verarmter russischer Adliger erscheint. ${ }^{594}$ Am negativsten sind dabei Fedor Pavlovic Karamazov,

Zosimas auf diesen Kirchenvater (.,Нет греха непростительного - кроме греха нераскаянного") [es gibt keine unverzeihliche Sünde, außer einer ungebüßten Sünde]) und auf dieselbe „Lektüre" des Dieners Grigorij; in der Bibliothek Dostoevskijs gab es eine russische Übersetzung von dessen Slova poctviżničeskie. Moskva 1858 [Bußfertige Worte], aus der dieser Satz stammt (ebd., S. 12)). Der Erzăhler vergleicht Smerdjakov mit einem ,trăumenden Bauer" auf Kramskojs Bild Sozercutel |Der Betrachtende], der aber nach dem plotzlichen Enwachen sowohl nach .Jerusalem pilgern" als auch .,ein Haus in Brand" stecken konnte. In dieser Metapher wird er zum Symbol des „verwestlichten, verimen russischen Volkes“. Vgl. Bd. 14, S. 85ff;; S. 90ff; S. 113ff. (bes. S. 116f. über das Bild Kramskojs); S. 203ff. (über seine Sympathie für die Invasion Napoleons im Jahre 1812 und über seinen „auslandischen Charakter", ebd., S. 205), $241 \mathrm{ff}$. und Bd. 15, S. $41 \mathrm{ff}$., bes. S. 59ff; S. 135ff. Vgl. auch Dnevnik pisatelja, Bd. 25 (janvar' 1877) (Januar 1877), S. 12-17, das Kapitel über den wegen seiner Treue zum russisch-orthodoxen Glauben zu Tode gequälten Soldaten Foma Danilov.

${ }_{589}$ Er vertritt eine vulgärmaterialistisch-sozialistische Weltanschauung und weist wie Miusov keine Bindung an die russische kulturelle Tradition auf, obwohl er sich als Theologe bzw. als Geistlicher (,.Seminarist“) ausbilden låßt. In den Entwürfen spricht er einen Satz, den anschließend die Polen wiederholen: . $f . . . /$ Русский народ не добр, потому что не цивилизован" [Das russische Volk ist nicht gut, weil es nicht zivilisiert ist ] (S. 256) und: .Поляки: «Русский народ не может быть добр, потому что не цивилизован»" [Die Polen: Das russische Volk kann nicht gut sein, weil es nicht zivilisient ist ] (S. 285). Siehe auch unten und Bd. 14, S. 36ff.; S. $72 \mathrm{ff}$, bes. S. 76f; Bd. 15, S. 26ff., S. 99ff. und S. $114 \mathrm{f}$.

590 Sie sucht bei Zosima Hilfe wegen ihrer religiösen Zweifel. Sie glaubt nicht mehr an die Unsterblichkeit der Seele und an das Postulat der Năchstenliebe; dabei zitiert sie Turgenevs Olcy $i$ deti (.,Ну что, думаю, я всю жизнь верица - умру, и вдруг ничего нет, и то.тько «вырастет . ворзвратіт веру?"“ INun, was denn? denke ich. Ich habe das ganze Leben geglaubt - ich werde sterben, und plötzlich ist da gar nichts. Und es wird nur die Klette wachsen auf dem Grab', wie ich bei einem Schriftsteller gelesen habe. Das ist furchtbar! Wodurch, wodurch kann ich nur den Glauben wiedererlangen?"; S. 96 J). Vgl. Bd. 14, S. 43 und S. 49ff, bes. S. $52 \mathrm{ff}$. sowie Bd. 15, die Anmerkung zu Bd. 14, S. 52 auf S. $533 \mathrm{f}$.

${ }^{591}$ Sie vertritt die ambivalente, junge Generation, schwankt zwischen „Glauben und Unglauben", was sich in ihrem Schwanken zwischen Aleša und Ivan äußert. Sie und Aleša haben aber gemeinsame Trăume über die "Teufel", worin sie Ivan ähnlich sind. Vgl. Bd. 14. S. 164ff., S. 201f. (das Gesprăch Lizas mit Alesa: „Bы kak-то ckазаты /.../, что я монах? /.../ -А я в бога-то вот, может быть, н не верую". ISie haben doch eben /.../ irgendwie betont, daß ich ein Mönch bin? /... I Ich aber glaube vielleicht gar nicht einmal an Gott!; $\mathrm{S}$. 378| ) und Bd. 15, S. 20ff., bes. S. 23fr. zu dem von der Forschung als stark antisemitisch verurteilten Gespräch Lizas mit Aleša.

592 Kolja nennt sich einen Sozialisten und beruft sich auf Rakitin. Er unterhält sich mit Aleša über Voltaires ( cundide, über Napoleons .,konservative Meinung zur Frauenfrage" bzw. über die .russischen Auswanderer nach Amerika", indem er Ansichten Gercens bzw. Belinskijs wiederholt. Er ist wie Liza ein ambivalent verwestlichter junger Russe. Vgl. dazu Bd. 14, S 473ff., 483ff; Bd. 15, S. 499ff. und die Anmerkungen zu den Seiten 499ff. und S. 583ff

593 Siehe zu Fetjukovic unten, S. 379, S. 403 und S. 414ff.

$594 \mathrm{Vgl}$. dazu Bd. 15, S. 69ff. Ivan ist wie Rakitin und sein Vater die am meisten schimpfende und den Teufel beschworrende Figur, so daß seine Teufelsvision der konsequente Ausdruck 
Smerdjakov, Rakitin und Fetjukovic und der Teufel (als der Doppelganger Ivans) dargestellt, die das negative utopische Imagothème des verwestlichten RuBlands reprăsentieren. Adelaida Ivanovna Miusova und Petr Aleksandroviz Miusov, Katerina Ivanovna Verchovceva, Frau Chochlakova und Liza sowie Kolja Krasotkin weisen neben negativen auch einige positive Züge der ,idealistischen" Okzidentalisierung auf, die im ,russischen Schiller“ Dmitrij die vollkommenste Verkorperung des positiven utopischen Imagothèmes des verwestlichten Rußlands (ähnlich Versilov) gefunden hat. Dmitrij kann dank seiner Liebe zu Grušen ka und seinem, ,Idealismus“ den Weg zur russischen religiösen Tradition und die verlorengegangene „russische“ Identităt am schnellsten von allen „verwestlichten“ Figuren wiederfinden. Ivan weist dagegen als eine ambivalent-verwestlichte .Alius-Figur neben einigen positiven ,idealistischen westlichen“ Zügen auch negative, ,dämonische“" auf, die sich sogar in seiner Teufelsvision materialisieren, so daß er am heftigsten um die Rückkehr zur russischen Identităt und zum russisch-orthodoxen Glauben ringen muß.

$\mathrm{Zu}$ den am wenigsten von der westlichen Kultur berührten russischen Figuren bzw. zu denen, die den westlichen Einfluß bereits überwunden haben oder dagegen kämpfen, zăhlen: Aleksej Fedorovič (Aleša) Karamazov, ${ }^{596}$ der geistige Vater Aleksejs, starec Zosima (Zinovij) ${ }^{597}$ und sein älterer Bruder Markel', ${ }^{598}$

dieser Negativităt ist, obwohl sie die .Entäußerung“ nur einer seiner weltanschaulichen Hälften darstellt.

395 Mit Ivan hăngen die meisten fremden Imageme zusammen. Als ..Atheist“" interessien er sich für die ..Naturwissenschaften“ und die ..westlichen“ Philosophen (Kant, Descartes und Voltaire) sowie für den ..Katholizismus und Sozialismus“. Er liebt .abstrakt“ die ...Menschheit", träumt vom „Goldenen Z.eitalter”, glaubt aber nicht (wie Versilov) an eine ,.angeborene Făhigkeit zur Năchstenliebe“" (vgl. oben, S. 351) und wird an der Ermordung seines Vaters mitschuldig. Er ist wie Dmitrij ein ..großer Sünder“, der möglicherweise den .,(russisch-orthodoxen) Glauben“ wiederfinden kann. Er lehnt nicht die Existenz Gottes ab, sondern dessen .unschuldig leidende Welt“. läßt sich von Zosima ..segnen“"; liebt seine Brüder und Katerina Ivanovna und rettet einen betrunkenen Bauem, obwohl er ihn zuerst erfrieren lassen wollte. Seine Ambivalenz zwischen dem ,westlichen Unglauben und russischen Glauben“ äußert sich sowohl im "Poem" als auch in der Teufelsvision. Die durch Schuldbewußtsein verursachte Krankheit kann den Prozeß der Ent-Okzidentalisierung Ivans einleiten. Die Mutter Ivans (und zugleıch Alesas) Sof ja lvanovna ist eine (..russisch-orthodox-byzantinische") Alıus-Figur. Vgl. dazu Bd. 14, S. I $5 \mathrm{ff}$., S. 55ff., S. 65ff., S. $117 \mathrm{ff}$. S. 175ff., 208ff. und Bd. 15, S. 36ff., S. $49 \mathrm{ff}$. S. $69 \mathrm{ff}$. und den Kommentar, ebd., S. 402ff., $416 \mathrm{f}$.

596 Aleša (Aleksej), vom Erzähler als die ..Hautpfigur” des Romans und dessen angekündigten zweiten Teils bezeichnet, weist sowohl ,.(alt)russische“ als auch ..tvestlıche“ Bezüge zum „Gottesmenschen Aleksej” [Alckccă ucsosck 6omcuü] aus der altrussischen lleılıgenlegende auf, so daß der ganze Roman sich auf die hagiographische altrussische Literatur bezieht, zu Alej in Zupiskı is Merivosgo demu. zu Myskıın und Sonja Marmeladova sowie zu Alesa Valkovskıj). Vgl. zu den ,.altrussisch-byzantinischen“ Bezügen bei POŻNıAK 1992, passım.

597 Seine Vorbilder sind u.a. slurec Amvrosij aus Optma Pustyn. Tichon Zadonskij. Paisij Velickovskij bzw. der Pilger Parfenij. Zosima hat sich von einem „verwestlichten“ Adligen und ..potentiellen großen Sunder" zu einem .,russischen Monch“ entwickelt: Er ist tolerant. auch den ..Atheisten“" gegenüber, betont, daß es ..unter Atheisten gute Menschen" gebe und daB man .,für sie beten“ solle (Bd 14, S. 149), licbt Christus, alle Menschen und Lebewesen sowie dic ..Mutter Iirde“, was seine „Verwurzelung“ in der slavischen vorchristlichen hulturellen Tradition hervorhebt. In seiner Z.elle hăngen eine lkone (aus der Zeit vor dem Raskol), 
die Mutter Alesas und Ivans, Sof ja Ivanovna, ${ }^{599}$ und die Mutter Smerdjakovs, Lizaveta Smerdjascaja, ${ }^{600}$ Agrafena Aleksandrovna (Grusen'ka) Svetlova ${ }^{601}$ die Klosterbrüder Ferapont und Paisij ${ }^{602}$ und der Diener Fedor Pavlovic Karamazovs, Grigorij Vasil'evic Kutuzov. ${ }^{603}$ Zosima vertritt dabei die „sakrale Gegenwelt" zu der "profanen Welt" von Skotoprigon"evsk. Er, Aleša und sein früh verstorbener Bruder Markel', Sof ja, die Mutter Ivans und Alesas, sowie die Mutter Smerdjakovs reprăsentieren das positive utopische Imagothème des "russisch-orthodox-byzantinischen" Rußlands.

Zosima, Markel", Sof ja und Lizaveta sind dabei als diejenigen Figuren zu bezeichnen, die endgültig dem ,nussisch-orthodoxen Glauben“ und der kulturellreligiösen russischen Tradition zugehörig sind, obwohl Zosima und Markel', bevor sie zum russisch-orthodoxen Glauben zurückgekehrt sind, als "verwestlichte“ Russen sogar dem „Atheismus“ bzw. "Liberalismus“ verfallen waren. In diesen beiden Figuren erweitert sich somit das positive utopische Imagothème des verwestlichten Rußlands (als die „Utopie des irdischen Paradieses“) um die „christlich-russisch-orthodoxe“ Dimension. Nur Sof ja und Lizaveta symbolisieren ohne Vorbehalte (als Jurodivye, „Gottesnärrinnen") die "(alt)russische, vorpetrinisch-byzantinisch" geprägte Tradition, obwohl sie als

ein katholisches Kreuz (.,Mater dolorosa“) sowie Kopien „westeuropäischer“ Bilder. Der nach seinem Tode einsetzende Leichengeruch widerlegt die Erwartung eines „Wunders“ und erfordert von Aleša das Gegenteil eines von ..außßeren Wundern" abhăngigen Glaubens, den aber der .,atheistische“ Großinquisitor Ivans verlangt. Vgl. Bd. 14, S. 26ff. (das Kapitel über die slurcy), 36ff. (die Beschreibung Zosimas und seiner Zelle aus der "verwestlichten" Perspektive Miusovs), 257ff. (das Buch über den ..russischen Mornch“), 295ff. (der Tod Zosimas); siehe auch den Kommentar, Bd. 15, S. 419, S. 426ff., S. 475ff., S. 482ff.

598 Dieser "verwestlichte“ Gymnasiast wird wegen einer tödlichen Krankheit von einem .Atheisten“" zu einem „Glăubigen“. Er ist Ivan und Versilov ăhnlich sowie eine Kontrastfigur zu Ippolit Terent 'ev in Idıot, bei dem diese Dimension sich nur latent in Tràumen offenban hat. Die Erinnerung an Markel" veruandelt Zinovij in einen „russischen Mönch" und „Pilger", anstatt einen Menschen im Duell zu tơten. Vgl. Bd. 14, S. 260ff, bes. S. 261: Die „Osterliche“ Verwandlung Markel's: , J.../ сидит тихий, kроткий, у.лыбается, сам 6о.тьной, а .лик веселый, ралостный. Изменицся он весь душевно - такая дивная нача тась в нем вдруг перемена!" [.,Er sitzt still, sanft, er lăchelt, ganz krank, sein Gesicht aber ist heiter, freudig. Er wurde dabei seelisch ein ganz anderer - eine so wunderbare Verănderung begann plotzlich mit ihm vorzugehen!'; S. 494].

${ }^{598}$ Sof ja Ivanovna axhnelt den anderen Sof ja-Figuren: Sonja Marmeladova oder der Mutter Arkadijs. Dank einer Erinnerung an sie kehrt Aleša nach Skotoprigon evsk zurück, um ihr Grab aufzusuchen Vgl. ebd.. S. 12ff.: S. 17f

${ }^{600} \mathrm{Vgl}$. ebd., S. 90ff. Die Mutter Smerdjakovs stammt jedoch aus einer ..Bürgerfamılie“, d.h. nicht aus dem "russischen Volk“.

${ }^{601}$ Diese Figur wird im Zusammenhang mit der polnischen Thematik besprochen.

${ }^{602} \mathrm{Vgl}$. dazu z.B. Bd. 14, S. 148ff., S. 295ff

${ }^{603}$ Der Diener Grigorij, ein Russe aus dem „Volk“, trägt den Namen des berühmten russischen Staatsmanns und Generals Michail Illarionovic Golenišcev-Kutuzov (1745-1819), wodurch er dem Napoleon Bonaparte verehrenden Lakaien Smerdjakov gegenübergestellt wird. Trotz seiner Treue zu Fedor Pavlovic Karamazov und seinen Sorgen um dessen Söhne wird Grigorij als ein eigensinniger, zuweilen grausamer Mensch dargestellt: So kann ihm Smerdjakov die Verachtung wegen seiner unehelichen Herkunft nicht verzeihen. Vgl. dazu z.B. Bd. 14, S. 85ff, S. 204f. 
Opfer des negativ verwestlichten Russen Fedor Pavlovic Karamazov zugnundegehen.

Alesa weist dagegen neben den positiven „altrussischen, vorpetrinischen" Eigenschaften auch eine gewisse Anfalligkeit "westlichen Ideen" gegenüber auf, so daß er möglicherweise auch den Typus des ,großen Sünders“ verkorpert, der über den Weg der Okzidentalisierung, des Verlustes des russisch-orthodoxen Glaubens, zurück zu seinem Ausgangspunkt gelangen kann. ${ }^{604}$ Der stereotyp rigoros-asketische und intolerante Mönch Ferapont vertritt dagegen neben anderen Klosterbrüdern den ritual-fanatischen Aspekt des russisch-orthodoxen Glaubens. In seiner extrem asketischen Lebensweise und in seinen Teufelsvisionen zeigt er sich als ein neidischer, kleinlicher Egoist, der, nur um sein eigenes Heil besorgt, die anderen haßt und nicht bereit ist, den leidenden Menschen zu helfen. Ferapont ist somit eine negative Kontrastfigur zu Zosima. Der gebildete und tolerante Vater Paisij läßt sich dagegen als eine ăquivalente Figur zu Zosima bezeichnen, obwohl in ihm die rationale Komponente noch stărker als in Zosima hervortritt.

Feraponts Glaube wird dem toleranten Glauben Zosimas, Paisijs und dem der russischen starcy gegenübergestellt. $\mathrm{Er}$ symbolisient das negative utopische Imagothème des pervertiert-fanatischen orthodoxen Rußlands, das teilweise auch von dem gleichzeitig negativ verwestlichten Smerdjakov als einem moglichen Anhänger der Sekte der Kastraten vertreten wird. Der Diener Grigorij ist dagegen ein Vertreter des noch nicht durch den „westlichen“ Einfluß berührten "russischen Volkes".

Alle zentralen und mehrere weitere Figuren des Romans weisen somit sowohl Elemente „(alt)russischer", "vorpetrinischer" als auch „petrinischer", "verwestlicher" russischer Kultur in unterschiedlichem Grade auf. In den Figuren Alešas, Zosimas und dessen Bruder Markel's bzw. in der Figur Grusen'kas überwiegen Elemente der „altrussisch-vorpetrinischen“ bzw. der „russischorthodox-byzantinischen" religiösen Tradition, in den Figuren Ivans und Dmitrijs Elemente der „westlichen“ bzw. „russisch-petrinischen“ Kultur. Im Laufe der Handlung werden jedoch die meisten im Zentrum der Handlung stehenden Figuren, darunter alle Brïder Karamazov, dem jeweils entgegengesetuten. komplementären ..russischen" bzw. "Westlichen“ Einfluß

604 Alesa wird schon am Anfang des Romans als den ,sozialistischen“ Einflüssen gegenüber ..anfallig“ bezeıchnet und ist eine ..Parallelfigur” zu Markel”. Seine „Anfälligkeit dem Westen gegenüber“ ăußert sich nach dem Tode Zosimas in den Begegnungen mit Rakitin. Ivan. Liza und Kolja. Er unterläBt es auch, Dmitrij zu sehen, wodurch er dessen Unglück hătte abwenden können. Seine Traumvision über die ..Hochzeit zu Kanaa“, Zosima und Christus, bildet eine paradigmatısche Opposıtion zum Teufelsgespräch und zum Poem Ivans, sowie eine Äquivalenz zum .Kindchen-Traum“" Dmitrijs. Sie hebt seine ..allumfassende Liebesfahigkeit" und ..Standhaftigkeit" hervor, die sich dann in der Begegnung mit den Freunden Iljusas am ..Stein“ außert. der möglicherweise symbolisch auch auf Christus hindeutet. Siehe dazu Llerki: 1987, S. 358-360 (Symbolik des Steins). Vgl. zu Aleša: Bd. 14, S. 17ff., S. 24ff., S. 201, S. 209fr., S. $221 \mathrm{ff}$, S. 309ff., S. 325ff., S. 500; Bd. 15, S. 194ff., S. 404ff., S. 413ff. oder S. 474fr. Vgl dazu aber auch JACKSON 1999, der den ,.westlich-Schillerschen“ Charakter der "Rede am Stein" betont. Iir vergleicht sie mit Schillers Ode An die lireude und mit deren Vertonung im Finale von Beethovens Neunter Symphonie, ebd., S. 12. 
ausgesetzt. Es wird darüber hinaus angedeutet, daß die verwestlichten Figuren die verlorengegangene bzw. bis dahin nicht vorhandene Bindung an die "(alt)russische" Tradition und an den "russisch-orthodoxen Glauben" (wieder)erlangen könnten: So gewinnt beispielsweise in den Figuren Dmitrijs und Grusen'kas die „russische“" religiös-kulturelle Identität die Oberhand. In der am stărksten verwestlichten Figur Ivans wird ebenfalls die Ambivalenz zwischen "Rußland" bzw. "Rus"“ und dem "Westen", zwischen der Sehnsucht nach dem ,altrussischen“ Glauben und dem „westlichen“, „rationalen“ und „atheistischen Skeptizismus“ sichtbar. Diese Ambivalenz entladt sich schließlich in seinem „Wahnsinn“, der als eine Identitătskrise zu verstehen ist. Sie kann ihn aber zu einer angedeuteten inneren Heilung führen, die mit der Wiedererlangung der ,russisch“" geprägten religiös-kulturellen Identităt gleichzusetzen ist.

In Brat ja Karamazovy werden wie in allen bisherigen Romanen Dostoevskijs mehrere fremde Imageme, darunter die polnischen, zur positiven bzw. negativen Charakterisierung der russischen Figuren eingesetzt. Es handelt sich dabei unter anderem um die Erwăhnungen mehrerer authentischer fremder Figuren: um Namen westeuropäischer Künstler, Schriftsteller, Philosophen oder Politiker wie z.B. Schiller, ${ }^{605}$ Goethe, ${ }^{606}$ Shakespeare, ${ }^{607}$ V. Hugo, ${ }^{608}$ Voltaire, ${ }^{609}$ Diderot, $^{610}$ Napoleon Bonaparte, ${ }^{611}$ Proudhon ${ }^{612}$ und sogar Luther, ${ }^{613}$ sowie um die Erwähnungen „westlicher" bzw. „westeuropäischer" Kunst- bzw. Literaturwerke. Erwăhnt werden darüber hinaus einige westeuropăische Lănder und Stădte wie z.B. Frankreich, Paris ${ }^{614}$ und Rom, ${ }^{615}$ oder auch Westeuropa ${ }^{626}$ und Amerika ${ }^{617}$, die in Brat ja Karamazovy in ähnlicher Funktion wie in den früheren literarischen Werken Dostoevskijs vorkommen. ${ }^{618}$

Alle diese Erwăhnungen fremder Imageme hängen mit den "verwestlichten“ russischen Figuren zusammen: mit Fedor Pavlovič Karamazov, seinen Söhnen Dmitrij, Ivan und Smerdjakov, mit Miusov bzw. mit Rakitin und Kolja. Im Zu-

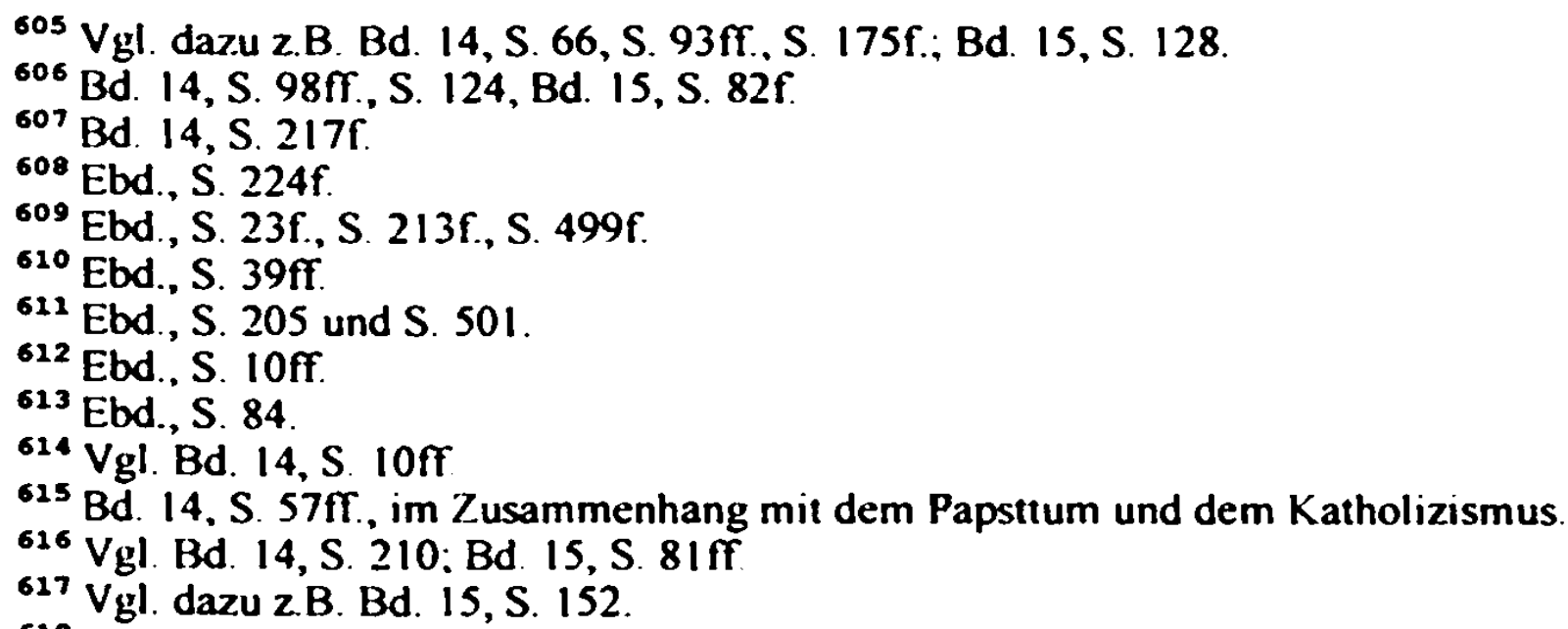

$618 \mathrm{Vgl}$ dazu oben. Neben diesen oben genannten (west)europäischen fremden Imagemen werden noch andere erwànnt, wie z.B. die authentische Figur des in einem Petersburger Bordell ermordeten russischen Deutschen fon Zon, einer komplementären ..Lüstling-Figur" zu F.P. Karamazov, dessen Name er im Zusammenhang mit Maksimov nennt, siehe dazu Bd. 14, S. 34, S. $81 \mathrm{ff}$. und Bd. 15 den Kommentar auf S. 539f., sowie bei RejNus 1971, S. 45f., zu einem fon Zon, dessen Verwandien aus Staraja Russa: ..Генерал-майор K.К. фон Зон, бывший управляющий Старорусского курорта“" [General-Major K.K. fon Zon [von Sonn]. ehemaliger Verwalter des Kurorts Staraja Russa] 
sammenhang mit Ivan treten beispielsweise sowohl positive als auch negative fremde Imageme auf. Der ,.Schillersche Idealismus" und der „utopische Traum vom goldenenen Zeitalter", den er mit Versilov bzw. mit Stavrogin teilt, bilden einen Teil des positiven utopischen Imagothèmes des verwestlichten Rußlands. Das Interesse Ivans für den "Katholizismus" und den "Atheismus“, die sein „Poem" vom Großinquisitor bzw. seine Teufelsvisionen symbolisieren, bildet einen Teil des negativen utopischen Imagothèmes des verwestlichten Rußlands, welches in dieser Figur gegen die "russisch-orthodoxe Welt", gegen den „(alt)russischen“ Glauben ankämpft. Auch die anderen oben erwăhnten russischen verwestlichten Figuren werden durch die fremden Imageme jeweils in ihrer positiven oder negativen Okzidentalisierung charakterisiert und zugleich dadurch differenzient dargestellt.

In Brat ja Karamazovy treten im Vergleich mit den die Handlung dominierenden russischen Figuren nur wenige fremde handelnde Figuren auf: Die beiden Polen ${ }^{619}$ und ein deutscher Arzt Doktor Gercenštube. ${ }^{620}$ Lediglich erwähnt werden außerdem einige andere fremde Figuren: die Polinnen, die Deutschen, Doktor Ejsenšmit, der den todkranken Bruder Zinovijs (Zosimas) Markel' behandelt hat ${ }^{621}$, sowie ein im Gespräch zwischen Kolja und Aleša namentlich nicht genannter deutscher Gelehrter, der sich kritisch über die jungen Russen geåußert haben soll, ${ }^{622}$ ein französischer Geheimpolizist, ${ }^{623}$ die Spanier des

619 Siehe dazu unten, S. 383ff.

${ }^{620}$ Er weist Bezüge zu dem deutschen Arat Friedrich Joseph Haas auf, der in Iduot explizit erwahnt wird. Vgl. dazu oben, S. 293 und S. 294f. Siehe auch Bd. 14., S. 50, S. 165f., S. 191. S. 472, S. 487 sowie Bd. 15 (das Kapitel über die Aussage Gercenštube vor Gericht, dem er die „Geschichte über das Pfund Nüsse“ erzählt, das er vor dreiundzwanzig Jahren Dmitrij geschenkt und ihm dabei die deutschen Bezeichnungen für dic Dreieinigkeit beigebracht hat,

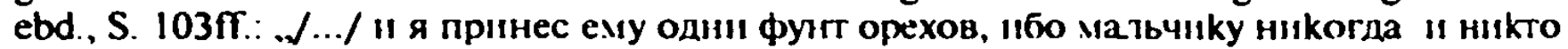
еще не прнносит фунт орехов, 11 я подня. мой палец и ckaзат ему: "Maıьчиk! Gott der Vater», - он засмея.7ся " rowopirt: «Gott der Vater», - «Gott der Sohn». Oн cue зacмeяtcst

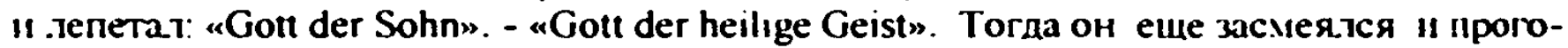
Bopili cko.tbko wor: "Gott der heilige Geist"/... " l., und so brachte ich ihm ein Pfund Nüsse, denn dem Knaben hatte doch niemand jemals ein Pfund Nüsse gebracht, und ich erhob meinen Finger und sagte ihm: 'Knabe! Gott der Vater' er lachte und spricht: 'Gott der Vater' 'Gott der Sohn'. Er lachte noch einmal und lispelte: 'Gott der Sohn'. Gott der heilige Geist Da lachte er noch einmal und murmelte so gut er konnte: 'Gott der heilige Geist“; S. 11521. Gercenštube wird dabei positiv den verwestlichten russischen Ärzten gegenübergestelt, die als Experten im Prozeß Dmitrijs vorgesprochen haben. Die Geschichte mit dem ..Pfund Nusse“ zeıgt nicht nur seine tätige Năchstenliebe. sondern auch den dem „westlichen“ (protestantischen) Glauben gegenüber offenen (harakter Dmitrijs, der sich schon in dessen früher Kindheit zeigt, so daß der deutsche ,.idealistische“ Arzt die Rolle seines ,geistigen Vaters“ ertüllt. ${ }_{621} \mathrm{Vgl}$. Bd. 14, S. 262. Auch der Teufel Ivans erwähnt u.a. einen deutschen Arat, von dem er sich gegen seine rheumatischen Beschwerden habe behandeln lassen, vgl. Bd. 15, S. 76. ${ }^{622} \mathrm{Vgl}$. Bd. 14, S 502, das Gespräch zwischen Aleふa und Koljas: .Hıkakıx знаний ॥ беззаветное самомненік - вот что хоте. сkазать немец npo pycckoro wko.тьніка. - Ax. да ведь это совершенно верно! - захохотал вдруг Ко.я /.../. Браво, немец! /.../ Хотя всеrakı немцев надо дуинтт. Пусть они там сицьны в науkах, а их всех нацо душіть.. За что же душіть-то? - у.лыбну.лся Алеuіа. - Ну я соврат, может быть, сог.ланаюс"“. I..Keinlerlei Kenntnisse und eine zügellose Selbstüberzeugtheit - das ist es, was der Deutsche von dem russischen Schüler sagen wollte . Ach, das ist ja durchaus richtig!' lachte pliczlich 
sechszehnten Jahrhunderts, darunter der Großinquisitor aus dem "Poem“ Ivans; die Schweizer und die Türken in dessen Gesprăch mit Alesa, ${ }^{624}$ wobei die letzteren auch im Zusammenhang mit dem Tod Zosimas und dem Kloster Athos vorkommen. $^{625}$ Vorwiegend im Zusammenhang mit Fedor Pavlovic Karamazov, Rakitin, Grusen'ka und Liza werden die Juden aus der Sicht des Erzăhlers ebenfalls im negativen Kontext erwähnt, denn diese russischen Figuren werden als den „Juden ăhnlich gewordene Geschäftemacher" bezeichnet. ${ }^{6}$

Am positivsten von den oben erwähnten fremden Figuren ist der deutsche Arzt Gercenstube dargestellt, obwohl er wie alle anderen deutschen Ärzte in den literarischen Werken Dostoevskijs stereotyp charakterisiert wird. ${ }^{627}$ Gercenštube tritt wie alle fremden Figuren in der Funktion als alter auf, aber als positiver Kontrast zu den russischen verwestlichten Figuren, v.a. im Zusammenhang mit Dmitrij als Gegensatz zu dessen Vater, Fedor Pavlovið Karamazov. Durch seine tătige Năchstenliebe kann er als eine, obwohl fremde, so doch teilweise „russifizierte“, komplementäre Figur zu Zosima, als ,geistiger Vater“ Dmitrijs, be-

Kolja. /... 'Bravo Deutscher /.../ Wenn man auch gleichwohl die Deutschen erdrosseln muß. Mogen sie auch stark in den Wissenschaften sein, man muß sie aber gleichwohl erdrossein...' 'Warum denn erdrosseln?' lachte Aljoscha. 'Nun, ich habe vielleicht gelogen, ich gestehe es ein "c.; S. 949f.]

${ }^{623} \mathrm{Vgl}$. Bd. 14, S. 62: Miusov erzahlt im Zusammenhang mit der Diskussion bei Zosima von dem Aufsatz Ivans über die besondere „Angst der franzosischen Polizisten vor den an Gott glaubenden Sozialisten“, die sie viel mehr als die „unglăubigen“ fürchten

624 Bd. 14, S. 224ff. (zum Großinquisitor) und ebd., S. 217 (Ivan fuhrt Beispiele der Greueltaten an, die die Türken während des Balkankrieges verübt haben) sowie S. 218f. (die Erzählung Ivans über die Hinrichtung eines Schweizer Verbrechers in Genf, der kurz zuvor von einem Schweizer Pastor zum christlichen Glauben bekehrt worden war. Diese Geschichte hat Ivan in einer der religiosen Erbauung dienenenden ..protestantischen Broschüre“ gelesen, die in RuBland verbreitet wurde).

$625 \mathrm{Vgl}$. ebd., S. 300.

626 Vgl. dazu ebd., S. 12, S, 21 f. (zu F.P. Karamazov), S. 74 (zu Rakitin), S. 311 (zu Grušen ka, die von dem Ich-Erzahler als eine „жıдовka“ [.,eine richtige Jüdin“; S. 596] bezeichnet wird) , S. 374 („жиды“ [Juden],, die in der Szene in Mokroe erwähnt werden, die .на uнмбатах“ [..,auf dem Zimbal“" S. 717] und .,на ckpunkax“ [..auf der Geige“; S. 717] spielen): vgl. auch Bd. 15, S. 22ff. (zum Gespräch Lizas mit Aleša über den Ritualmord an einem christlichen Kind. den ein Jude verübt haben soll). Siehe dazu auch INGO1.D 1981, S. 89f. und GolosteIN 1981, S. 155f.

${ }^{627}$ Gercenštube I= ..Stube des Herzens: Stube, in der das Herz (= das Gute) wohnt"I wird vom Erzähler als ein deutscher protestantischer Pietist (..Hermhuter” bzw. ..Bohmischer Bruder" (= „Hussit") bezeichnet, obwohl seine .,konfessionelle“ Zugehorigkeit nur vermutet wird „./.../ врач добросовестиый, че.ловек прекрасный и б.лагочестівый, kakой-то гернгутер и.ли “моравсkий брат" - уж не знаю наверно“ l. $^{\prime} \ldots i^{\prime}$ ein gewissenhafter Arzt, em guter und gottesfürchtiger Mensch, irgendein Hermhuter oder 'Măhrischer Bruder'- ich weiß es nicht mehr genau“; S. 1146]. Trotz der Hervorhebung seiner selbstlosen Güte wird er ein ..selbstsicherer" Deutscher genannt (..упрям kak ..y.7“) (..eigensinnig wie ein Maultier”: S. 1146| ) und seine Fremdheit durch das Motiv der .,fremden“ Ausprache und Syntax seiner russischen Sätze hervorgehoben: .. .../ Надо прибавітт, что он говоріц по-руссkи много "I охотно, но kak-то у него каждая фраза выходица на немецkıй манер, что, вирочем,

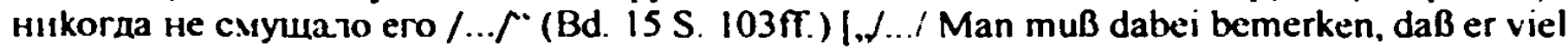
und gern Russisch sprach, aber gleichwohl kam jeder Satz bei ihm irgendwie aut deutsche Art heraus, was ihn ubrigens niemals verwirte $/ . . . \%$ S. 11471. 
zeichnet werden. Er vertritt wie Dmitrij das positive utopische Imagothème des verwestlichten Rußlands, und ist zugleich als eine den anderen „idealistischen“ Figuren der Deutschen und den positiv verwestlichten Russen, den „Schillers" Dostoevskijs, ăquivalente Alius-Figur zu bezeichnen. ${ }^{628}$

62* Gercenštube weist auch thematische Bezüge zu dem wohltătigen deutschen Protestanten Doktor Gindenburg auf, auf dessen Trauerfeier im Inevnik pisatelja Dostoevskij beschrieben hat, nachdem er über den Tod dieses Arztes aus einem Brief von Sof ja Lur e, einer Jüdin aus Minsk, erfahren hatte (Bd. 25, S. 88-94 ( Dnevnik pisatelja za 1877: Mart. (jlava Iret ja. I. Pochorony obšcečeloveka und II: Eidiničny] sluçaj. [Drıltes Kapılel. I. IDas Begräbnıs eines Allgemein-Menschen und II. Ein Einzelfall |) und ebd., S. 392 (die Anm. der Herausgeber der PSS)): „Провожает его весь город, звучат kо.локо.ла всех церkвей, поютея мо.литвы на всех языkах. Пастор со с.лезами товоріт свою речь над расkрытой мопьой. Раввин /.../ сменяет его и говорит свою речь и .льет те же с.лезы. /.../ Что в том, что, разойдясь, каждый прімется за старые предрассудки. Капля точіт камень, а вот эті-то "общине че.товеки» побеждают мир, соединяя его; предрассудkи будут бледнеть с kаждым единичным с.тучаем и наконец вовсе исчезнут“ [kursiv Dostoevskij] (ebd., S. 90ff.). [Die ganze Stadt nimmt von ihm Abschied. die Glocken aller [orthodoxen] Kirchen lăuten, es werden Gebete in allen Sprachen gesungen. Der Pastor hălt unter Trănen seine Rede am offenen Grab. Der Rabbiner $;. . . /$ wechselt ihn ab und hält seine Rede und vergießt die gleichen Tränen. /.../ Was soll es, daß, nachdem alle auseinander gegangen sind, sie sich an ihre alten Vorurteile heranmachen werden. Der Tropfen glăttet den Stein, und so werden diese „Allgcmein-Menschen" die Welt besiegen, indem sie sie vereinigen; die Vorurteile werden mit jedem solchen Einzelfall immer schwächer und verschwinden schließlich ganz.]

Dostoevskij erblickte in Gindenburg einen schon in Zimnıe zametkı o leınıch vpecullenijach vorkommenden ,europäischen Allgemein-Menschen“ (im Gegensatz zum „russischen Allmenschen"), den positiv-utopischen .Einzelfall“" der Năchstenliebe und eine mögliche Lösung der ,jüdischen Frage“ durch die Übenvindung der ..Vorurteile“, jedoch eingeschränkt, weil nur seitens der „Christen“. An dieser Stelle ist es nicht möglich, diesen, trotz des ganzen humanităren Pathos, antisemitisch geprägten Text zu interpretieren, in dem der Erzähler sich anschließend ein .,realistisches Genrebild" mit Doktor Gindenburg in der Hütte der armen Jüdin „vorstellt“, das er mit dem Bild Svetočı chrısııans/v'a bzw. Svelıč̀ Nerına (1877) (1)ıe fackeln des (Mristentums bzw. Die liackeln Neros] des polnischen, also "westlichen“" und ..katholischen“ Historienmalers G.l. Semiradskij (Henryk Sicmiradzki) kritisch vergleicht, weil Semiradskijs Gemălde wie die meisten Bilder von dessen Zeitgenossen .,kein moralisches Zentrum“ hätten (ebd., S. 74-88: „Ес.ли б я бы.л живопıсеи, я именно бы написал этот «жанр», эту ночь у еврейки-родитьницы. /.../ Бедный новорожденный еврей-

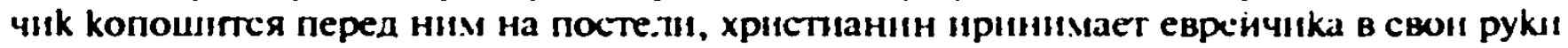
и обвивает его рубашкой с птеч свогт. Разрешение еврейсkого вопроса, господа! /.../ Всё это вицитт сверху Христос, и доктор знает это: жЭто бедный жіцок вырастет и, может, снимет и сам с плеча рубашку и отдаст хрістианину, вспомнная рассkаз о рожденин своем" /.../ Cбудется ли зто? всроятнсе всего, 4то нет, но ведь сботься .uuxem /... " I Wenn ich ein Maler wäre, würde ich eben dieses .Genrebild“ malen, diese Nacht bei der gebărenden Hebräerin. /... Das arme, gerade zur Welt gekommene kleine Hebraerchen krabbelt vor ihm auf dem Bett. und der Christ nimmt den kleinen [Hebräer] auf seinen Arm und wickelt ihn in das von seinen Schultern abgenommene Hemd. Die Losung der jüdischen Frage, meine Herrschaften! I...' Alles das sieht von oben Christus, und der Doktor weiß das: 'Dieses arme Jüdchen wird groß und wird vielleicht selbst sein Hemd von seiner Schulter nehmen und einem Christen geben, wenn es sich an die Erzählung von seiner Geburt erinnert' . '.../Wird das eintreffen? Wahrscheinlicher als alles andere ist es, daß es sich nicht verwirklıcht, aber es konnte sich doch verwirklichen].

Vgl auch zur ,jüdischen Frage“ in I. nevnık pısatelja bei INGOLD 1981, S. 99ff. 
Die im Zusammenhang mit den verwestlichten Russen Miusov und Ivan vorkommenden fremden Figuren dienen dagegen zu deren immanenten Charakterisierung, denn sie weisen auf die Okzidentalisierung dieser nussischen Alius-Figuren hin. Sie sind somit als Teil des negativen utopischen Imagothèmes des verwestlichten Rußlands zu betrachten. Die in diesen fremden Figuren enthaltenen kritischen Bezüge zum „Katholizismus“ bzw. zum „Protestantismus“ können jedoch auch als eine Anspielung auf die ideologischen Feinde Rußlands und seiner Religion verstanden werden. Ebenfalls negativ sind alle Erwăhnungen der jüdischen Figuren, die als negative literarisch-ethnische Stereotypen der „Geschäftemacher" bzw. "ländlichen Geigen-" oder "Zimbelspieler" vorkommen und einerseits als alter, als Kontrast zu den Russen, andererseits als alius, als das Symbol des Rußland beherrschenden „westlichen Materialismus“ bzw. des dadurch symbolisierten „Bósen“ betrachtet werden konnen.

Auf dem Hintergrund der oben besprochenen russischen Welt des Romans sowie der darin auftretenden fremden Imageme werden im folgenden polnische Imageme in Brat 'ja Karamazovy interpretiert. Zu diesen Imagemen gehören:

die beiden oben erwăhnte polnische Figuren, die im Zusammenhang mit der Lebensgeschichte Grušen kas eingeführt werden;

zwei Anspielungen auf den Petersburger Rechtsanwalt polnischer Herkunft WlodzIMIERZ SPASOWICZ: die erste in einer der Äußerungen Ivans über das Leid der Kinder und die zweite im Zusammenhang mit der Figur des Rechstanwalts Dmitrijs, Fetjukovic;

die Anspielung auf den polnischen Dichter ADAM MICKIEWICZ aus einem Gedicht Puskins, das an Mickiewicz gerichtet ist.

Ergänzend können polnische Sătze bzw. idiomatische Ausdrücke aus den erhaltenen Entwürfen zu den polnischen Szenen in Mokroe gennant werden.

1. Zwei namentlich genannte polnische Figuren, Hert Mussjalovic (= Musiałowicz) und Herr Vrublevskij (= Wróblewski), treten im Zusammenhang mit der Lebensgeschichte Grušn'kas auf. Der erste Pole, ein ehemaliger Offizier, hat sie als ein junges Mädchen verführt und verlassen, kehrt aber nach fünf Jahren verwitwet und völlig verarmt in der Gesellschaft eines anderen Polen, pan Vrublevskij, zurück: Er will Grusen'ka wegen ihres inzwischen angesammelten Vermógens heiraten. ${ }^{629}$

629 Grušen ka ist nach Ansicht von ŻAKIEWICZ 1968 (S. 88) einem polnischen Mädchen. Maryna O., aus Semipalatinsk nachgebildet worden, das mit der ersten Frau Dostoevskijs bekannt war und mit 17 Jahren zuerst von einem jungen Russen verführt und anschließend von einem Kirgisen mißbraucht wurde. Siehe dazu auch oben sowie bei LEDNICKI 1953, S. 150tr., wonach das häufig in den Werken Dostoevskijs vorkommende Motiv des ..vergewaltigten jungen Mädchens" auf diese junge Polin zurückgehen würde. REJNUS I971 (S. 46ff., bes. S.48) schreibt dagegen, daB eine Bewohnerin von Staraja Russa und Bekannte Dostoevskijs und dessen Frau, Gruß̌en ka Men '̌ova, die für das wichtigste Vorbild Grušen kas in Brat ja Karamazovy gehalten wird, einen russischen Oberieutnant I. Korovajkin geliebt hatte und von ihm verlassen wurde. Obwohl Dostoevskij also einen "Russen“ in der Rolle des Verführers von Grušen ka hătte darstellen kōnnen, habe er sich dennoch für einen ..Polen“" entschieden. 
Zum ersten Mal wird die Geschichte der Verführung Grusen'kas aus der Sicht ihrer Rivalin, Katerina Ivanovna, im Gesprach mi: Aleša in dor Srene der scheinbaren Versohnung zwischen ihr und Grusen'ka erwăhnt, ohne daß dabei die nationale Zugehörigkeit des Verführers genannt wird:

Был один, один тоже офицер, мы его полюбили, мы ему всё принесли, давно это было, пять лет тому назад, а он нас забыл, он женился. Теперь он овдовел, писал, он едет сюда, - и знайте, что мы одного его, одного его только любим до сих пор и любили всю жизнь! Он приедет, и Грушенька опять будет счастлива /.../.

[Es war da einer, gleichfalls ein Offizier, den haben wir liebgewonnen. Wir haben ihm alles dargebracht. Das war schon längst, vor fünf Jahren; er aber hat uns vergessen, er hat geheiratet. Jetzt ist er Witwer geworden, hat geschrieben, daß er hierherkommen werde - und wissen Sie, daß wir ihn, ihn allein lieben, bis jetzt, bis jetzt noch, und das ganze Leben nur ihn geliebt haben? Er wird kommen, und Grušen ka wird wiederum glücklich $\operatorname{sein} / . . . /.]^{630}$

Der „ehemalige Verfürer" Grušen kas wird lediglich als ein Offizier vorgestellt. der sie "vergessen" und eine ,andere Frau geheirater" habe. Hervorgehoben wird dabei das Motiv der "treuen, unglücklichen und verzeihenden Liebe" Grušen 'kas zu ihm, die auch jetzt „glücklich“ sein könnte, nachdem er ihr seine Rückkehr brieflich angekündigt hat. Grusen'ka, die kurz zuvor als eine ,gefallene Frau" und als die „böse Verführerin“ Dmitrijs erwähnt wurde, erscheint plötzlich als das „unschuldige Opfer eines (fremden) Verführers“. Sie „venvandelt sich" dadurch aus einer "Verführerin" in ein "Opfer", vertauscht ihre Rollen.

In dieser Passage wird aber auch Katerina selbst als Opfer charakterisiert. Sie will ihre Rivalin rechtfertigen, indem sie sich mit ihr vergleicht. Wie Grušen'ka wurde sie von einem "Offizier" verfün und vergessen, soll ihn aber immer noch lieben und wartet auf seine Rückkchı. Sie ist die treue Verlobte Dmitrijs geblieben. eines ehemaligen Offiziers, der sie aber Grusen'kas wegen vergessen hat. Obwohl Katerina Dmitrij nicht liebt. sondem seinen Bruder Ivan, will sie trotzdem aus stolzem Pfichtbewußtsein seine Verlobte bleiben. Beide weibliche Figuren, Girušen ka, eine „Russin aus der Provinz“" und die „verwestlichte“, adlige Katerina Ivanovna lassen sich somit als aquivalent bzw. komplementär bezeichnen. Auch Dmitrij wird zum ersten Mal dem noch unbekannten Verführer Grušen 'kas gegenübergestellt und erscheint als eine positive Kontrast-Figur, denn er hat Katerina nicht wie jener verführt, sondern sich ihr gegenüber immer edelmütig verhalten.

In demselben Kapitel wird ergänzend zu dieser Passage nicht nur der Pole als ein „Verführer aus dem Westen“ erwähnt, sondern auch Grušen kas Leben vorgestellt. Sie stammt aus einer bürgerlichen Familie eines niedrigen russisch-orthodoxen Geistlichen und wird aus der Sicht Alešas als eine "(ideal)typisch

${ }^{630}$ Bd. 14, S. 138 [S. 258f.]. 
schơne“, aber „gewơnnliche Russin“ beschrieben ${ }^{631}$, die sich nach der „Verführung" durch den Polen von einem kindlich-naiven, sanftmütigen Mädchen in eine teilweise negativ "verwestlichte“ Geschäftsfrau verwandelt hat ${ }^{632}$ Wie sich spăter zeigt, ist sie aber trotz ihrer Okzidentalisierung eine liebende und zur "Nachstenliebe" fahige Russin, eine positive russische Alius-Figur, geblieben. So hilft sie beispielsweise Aleša seine Glaubenskrise nach dem Tode Zosimas zu überwinden: Auf den Besuch bei Grušen ka folgt seine „seelische Auferstehung" in dem Kapitel Kana Galilejskaja [Die Hochzeit zu Kana].

Der "Verführer" Grušen'kas und seine nationale Zugehörigkeit wird zum zweiten Mal von ihrem Cousin Rakitin ebenfalls in einem Gesprăch mit Aleša erwăhnt:

„- Поляк он, ее офицер этот, /.../ да и не офицер он вовсе теперь, он /.../ чиновником в Сибири служил /.../, kakoй nолячоночеk мозглявенький. Место, говорят, потерял. Прослышал теперь, что у Грушеньки капитал завелся, вот и вернулся - в том и все чудеса“. ['Er ist ein Pole, dieser Offizier' /.../ 'ja, und er ist jetzt auch überhaupt nicht mehr Offizier, er dient als Beamter [eigentl.: diente als Beamter in Sibirien] /.../, es muß wohl irgendein jämmerliches Polenkerlchen sein.

${ }^{631} \mathrm{Vgl}$. Bd. 14, S. 311 und S. 136ff. (Beschreibung des „positiven“ und „faszinierenden“ Eindrucks, den sie auf Alesa gemacht hat: „B A.ewe kak будто что передерну.ось. Он приковатся k ней взг.лядом, г.таз отвесті не мог. Вот она, эта ужасная женщина «зверь» /.../. /.../ пред нім стоя.7о, казатось бы, самое обыkновенное и простое сушество на взгляд, - добрая, митая женшина, по.ооим красивая, но так похожая на всех другтх краснвых, но “обыкновенных» женшин! Правда, хороша она быта очень, очень даже, - русская красота, так мнопмм до страсти .тобнмая. /.../ Атешу поразнто всего 6о.лее в этом .иие его детское, простодушное выраженне. Она глядела как дітя, радоватась чему-то kak дıгя/.../. Взгляд ее весе.лит душу - Алеша это почувствоват“, bes. S. 136f.). [S. 255f:: Aljoscha war es, als ob sich etwas in ihm umdrehe. Er heftete sich an sie mit seinem Blick und konnte die Augen nicht von ihr wenden. Da ist sie denn auch, dieses schrecklichc Weib - die Bestie $/ . . /$. |vor ihm) $i . . j$ stand, so schien es auf den ersten Blick. das allergewöhnlichste und einfachste Geschopf, ein gutes, liebes Weib, geben wir zu, ein hübsches Weib, aber so ähnlich allen anderen, allergewöhnlichsten Frauen! Freilich, schön war sie, sehr sogar - eine russische Schönheit, wie sie von vielen bis zur Leidenschaft geliebt wird. /... / Was den Aljoscha am allermeisten erstaunte in diesem Gesicht, war ein kindlichaufrichtiger Ausdruck! Ihr Blick war der eines Kindes, das sich über irgend etwas freut $/ . .$. lhr Blick stimmte die Seele heiter - Aljoscha fühlte das.]

Grušen kas Köper wird mit dem der Venus von Milo verglichen und ihre .,süßlich-künstliche" Aussprache als eine .,schlechte Gewohnheit" betont, die sie wegen ihrer geringen Bildung für besonders „elegant“" hält, wodurch der Widerspruch zwischen ihrer .kindlichen Natvitat" und der angelemten, ,aus dem Westen übernommenen Künstlichkeit” hervorgehoben wird.

${ }^{632}$ Sie wurde von einem russischen .Kapitalisten“ Samsonov .gerettet“, wodurch sie sich in eine materialistisch gesinnte, „wie eine Jüdin“ an das Geldmachen denkende Frau verwandelt hat (vgl. ebd., S. 311 f.). Der Name Samsonov deutet möglicherweise auf den alttestamentarischen Samson (vgl. z.B. Richter 14-16) und im Kontext der Handlung des Romans auf das ,jüdische Wesen" dieses russischen Kaufmanns hin, obwohl es einen Kaufmann dieses Namens in Staraja Russa gegeben hat, vgl. ReJNUS 1971, S. 50f.

${ }^{633} \mathrm{Vgl}$. Bd. 14, S. 325ff. 
Man sagt, er habe seine Stelle verloren. Er hat jetzt erfahren, daß bei Grušen kas sich Kapital angehauft hat, und da ist er denn auch zurückgekehrt - das ist die Erklărung des ganzen Wunders!' $]^{634}$

Der Pole erscheint hier zum ersten Mal als das bereits aus Zapiski iz Mertvogo doma bekannte Stereotyp des .,schăbigen Polackchen“, das entsprechend der intertextuellen Logik nach Skotoprigon'evsk aus „Sibirien“ zurückkehrt. Die „sibirische Herkunft" des Polackchens laß̉ sich zugleich als eine für den russischen Leser eindeutige Anspielung auf eine antirussische Vergangenheit des Polen verstehen, denn Sibirien war der Ort der Verbannung polnischer ,politischer Verbrecher" bzw. "Verschwörer". Das „schăbige Polackchen" wird hier seiner Würde und Autorität als Offizier beraubt und durch die pejorativen Dimunutivformen herabsetzend charakterisiert „полячоночек мозглявенький“ [ein ganz schăbiges, kränkliches Polackchen]). Er ist cin unbedeutender Beamter, der zu Grušen ka nur wegen ihres Geldes zurückkehren will, weil er arm und ,arbeitslos" geworden ist. Die moralisch fragwürdige und niedrige soziale Position sowie die Geldgier des Polen werden aber von einer moralisch fragwürdigen verwestlichten Figur, dem ..Atheisten“ Rakitin hervorgehoben, der bereits im gleichen Kapitel als „Materialist” und „Verräter“ dargestellt wird und für fünfundzwanzig Rubel Grušen'ka versprochen hat, mit Aleša zu kommen. Rakitin will ähnlich dem Polen eine Frau wegen ihres Geldes heiraten (die reiche Frau Chochlakova), um als „Kapitalist“" in Petersburg leben zu konnen. Als Zeuge im Prozeß Dmitrijs äußert er sich aber dann verächtlich über Grusen $k a$, scine Cousine. wird aber sofort von Fetjukovic als falscher Zeuge .kompromittiert". Rakitin tritt somit in Brat'ja Karamazovy als eine parallele negative Figur zu dem ..Polackchen" auf. ${ }^{635}$

Bevor der „polnische Verführer" und sein Begleiter endlich selbst in dem Wirtshaus in Mokroe auftreten, ${ }^{636}$ wird in zwei früheren Kapiteln der polnische ehemalige „Offizier" und sein Brief an Grušen ka nochmals erwăhnt:

Да и в самом этом первом письме «офицера", /.../ говорилось о приезде этого нового соперника весьма неопределенно: письмо было очень туманное, очень высоkопарное и наполнено лишь чувствительностью /.../. /.../ Митенька /.../ в ту минуту уловил kak бы неkоторое невольное и тордос презрение $k$ этому посланию из Сибири в лице самой Групеньки.

[ Ja, und es war auch in diesem ersten Brief des 'Offiziers $/ . . . /$ nur in sehr unbestimmten Ausdrücken die Rede gewesen von der Ankunft dieses neuen Nebenbuhlers: der Brief war sehr nebelhaft, sehr schwülstig und nur mit Empfindsamkeiten angefüllt. /.../ Mitenka /.../ [habe] in diesem Augenblick im Gesicht der Gruschenka selber etwas wie ein unwillkürliches und stolzes Verachten wahrgenommen.] ${ }^{637}$

\footnotetext{
634 Ebd., S. 324 [S. 62 lf.].

$635 \mathrm{Vgl}$ ebd. S. $318 \mathrm{ff}$.

636 I:bd., S. 376-401.

${ }^{637}$ Ebd., S. 329f. [S. 623].
} 
In dieser Passage, die zum Kommentar des Erzählers gehört, wird zum einen der "hochmütige" und "konventionell-gehoben zărtliche" Stil des Briefs des Polen hervogehoben, der gănzlich aus Höflichkeitsfloskeln besteht und vollkommen dem Charakter dieses ,scharwenzelnden Polackchen“ entspricht. Zugleich aber wird die „unwillkürlich" negative, „verăchtliche“ Einstellung Grusen kas diesem Brief gegenüber angedeutet, die Dmitrij in ihrem "Gesichtsausdruck" lesen kann. Im „konventionellen" Charakter des Briefes kommt außerdem zum ersten Mal die „verachtende Distanz" des Polen, Vertreters der "höheren, westlichen“, bzw. vom „Westen üternommenen, adligen polnischen Kultur" einer „nichtadligen Russin" gegenüber zum Ausdruck. Die Brief-Szene wird dabei lediglich aus der Sicht Dmitrijs, bedingt durch seine besondere psychische Verfassung, geschildert. Sein Bangen um Grusen kas Gunst und die Eifersucht auf den Vater Fedor Karamasov als Ausdruck seiner aufrichtigen Liebe zu ihr zeichnet sich emeut als positiver Kontrast zum „konventionell-höflichen“ Brief des Polen ab.

Die nächtliche Fahrt Dmitrijs nach Mokroe wie auch die darauf folgenden „polnischen“ Kapitel des Romans werden ebenfalls vorwiegend aus seiner Perspektive erzăhlt, dienen der positiven Charakterisienung Dmitrijs und zeigen seine innere Wandlung, seine ,seelische Auferstehung", nachdem er sich von der Liebe Grusen kas zu ihm überzeugt hat.

Schon im Gespräch mit dem Kutscher Andrej, einem Bauern, wird die demütige Bereitschaft Dmitrijs gezeigt, Grußen ka wegen der selbstlos gewordenen Liebe zu ihr dem Rivalen zu überlassen, wobei er anschließend Selbstmord begehen will. ${ }^{638}$

In Mokroe werden die beiden Polen, der Beamte und sein Begleiter, zuerst vom Besitzer des Wirtshauses Trifon Borisyc, negativ charakterisiert. Er stuft sie ihrem Aussehen und dem vermuteten niedrigen sozialen Rang nach als „unbedeutende Größen" ein. Dmitrij betrachtet er dagegen als einen willkommenen, weil einen verschwenderischen Gast. ${ }^{639}$ Trifon Borisyc wird dabei selbst als reicher, „verwestlichter" Bauer vorgestellt, der sich wegen seiner Besitzgier dem "Glauben des russischen Volkes" entfremdet hat. ein "Kapitalist" geworden ist. Die negative Einschätzung der Polen durch Trifon Borisyc ähnelt derjenigen Rakitins, der die Menschen lediglich nach ihrem Besitz einzuschätzen pflegt. Trifon Borisyč repräsentiert somit das verwestlichte russische Bauerntum, indem Rakitin das verwestlichte russische Bürgertum vertritt.

Der Auftritt des .,polnischen Verführers" wird bis zu den Mokroe-Kapiteln, in denen der polnische, imagothematische Strang der Handlung seinen Kulminationspunkt erreicht, aus mehrfacher Perspektive und durch eine Reihe von negativen Motiven angekündigt. Der Pole erscheint dadurch in zunehmender Weise

630 $\mathrm{Vgl}$. ebd., S. 367ff. Dmitrij bittet den Kutscher stellvertretend für alle Menschen um Vergebung, nachdem dieser ihm die .,Volkslegende“ über den Abstieg Christi in die Hölle und die Befreiung der Sünder erzahlt hat. Dmitrij vergleicht sich jedoch dabei selbst mit Hamlet bzw. mit Yorick, so daß dadurch zum einen sowohl seine „Verwurzelung“" in der altrussischen religiösen Tradition als auch seine positive Okzidentalisierung hervorgehoben wird. Siehe dazu auch die Anmerkungen in Bd. 15, S. 575f.

${ }^{639} \mathrm{Vgl}$. Bd. 14, S. 373f. 
als eine negative Kontrastfigur zu Dmitrij, indem Dmitrij selbst immer positiver charakterisiert wird.

In den Mokroe-Kapiteln werden die beiden Polen weiterhin aus seiner Sicht geschildert, so daß der Gegensatz zwischen ihm und den „Fremden“ noch stärker hervortritt. Er erblickt sie dort zum ersten Mal auch aus einer „eingeschränkten“ Perspektive - aus einem „Versteck“ - bevor er in das Zimmer eindringt, in dem sich Grusen 'ka mit ihnen sowie mit den zwei Russen Maksimov und Kalganov, aufhalt. Hervorgehoben wird dabei die „demütige“ und „selbstlose“ Haltung Dmitrijs Grušen ka und dem Polen gegenüber, die durch die leidenschaftliche Liebe zu ihr und den in derselben Nacht gefaßten Entschluß, Selbstmord zu begehen, psychologisch motiviert ist, so daß der Eindruck von den beiden Polen "wertfrei-positiv" zu sein scheint, obwohl die Beobachtungen Mitjas (Dmitrijs) mit einem latent kritischen bzw. negativen Kommentar des Erzählers begleitet werden:

/.../ На диване сидел он, а подле дивана, /.../ kakoй-то другой незнаkомец. Тот, который сидел на диване развалясь, kурил трубky, и у Мити лишь промелkнуло, что это kakoй-то толстоватый и широkолицый человечеk, ростом, должно быть, невысокий и kak будто на что-то сердитый. Товарищ же его, другой незнакомец, показался Мите что-то уж чрезвычайно высоkого роста; но более он ничего не мог разглядеть. [kursiv Dostoevskij]

[Auf dem Sofa saß er, neben dem Sofa, /.../ ein anderer Unbekannter. Der, welcher auf dem Sofa hingestreckt saß, rauchte eine Pfeife, und Mitja schien es, daB dies ein untersetzter und breitgesichtiger Mann sei von wohl nicht zu hohem Wuchs und dem Gesichtsausdruck, als ob er auf irgend etwas erzürnt sei. Sein Kamerad aber, der andere Unbekannte, schien Mitja schon von außerordentlich hohem Wuchs zu sein; weiter vermochte er aber nichts zu erkennen. [kursiv Dostoevskij]] ${ }^{640}$

Der „polnische Rivale“ Dmitrijs, der zunăchst als ein durch Kursivschrift hervogehobenes Personalpronomen „er" auftritt, wird von einem anderen "unbekannten Kameraden" [mosapum; tovarišč; auch: Gefährte, Genosse] begleitet. Beide fallen aber auch durch einige andere Merkmale auf. Der „Verführer" sitzt ..ausgestreckt" auf einem Sofa und raucht Pfeife, wodurch seine der Situation unangemessene entspannte und unhofliche Haltung hervorgehoben wird. $\mathrm{Zu}$ sătzlich wird er vom Erzăhler als ..gereizt" bzw. „verărgert“ und durch pejorative Diminutiva als ein „kleines, dickes Mănnlein mit einem breiten Gesicht“ beschrieben, sein Begleiter lediglich ungewöhnlich „groß" genannt. Durch diesen komischen Kontrast ihrer Körpergroße entsteht eine Äquivalenz zu dem polnischen "Kontrastpaar" in Podrostok, das sich ebenfalls aus zwei negativen stereotypen polnischen Figuren zusammensetzt. Der geheimnisvolle "Verführer" Grusen kas „entpuppt sich" in dieser Passage endgültig als das in mehreren bisherigen Werken Dostoevskijs vorkommende Stereotyp des „dicken Polen“, das

${ }^{610}$ Bd. 14, S. 375 [S. 719f.]. 
auf Zagoskin zurückgcht und auch in Brat 'ja Karamazovy in ahnnlicher Funktion auftritt. Die Bezeichnung des anderen Polen als mosapum schaff aber zugleich einen weiteren intertextuellen Bezug zu Zapiski iz Mertvogo doma, in denen die polnischen politischen Gefangenen als moвapumu bezeichnet worden sind.

Nachdem Dmitrij trotz. des Protestes des Polen von Kalganov und Maksimov begrüßt und aufgefordert worden ist, in ihrer Gesellschaft zu bleiben, ist er imstande, die beiden Polen genauer anzuschauen:

Пан на диване поражат его своею осанкой, польским акцентом, а главное - трубкой. /.../ Несkолько обрюзглое, почти уже сорокалетнее лицо пана с очень маленьким носиком, под которым виднелись два претоненькие востренькие усика, нафарбленные и нахальные, не возбудило в Мите тоже ни малейших пока вопросов. Даже очень дрянненький паричоk пана, сделанный в Сибири, с преглупо зачесанными вперед височками, не поразил Митю: «Значит, тak и надо, коли парик» - блаженно продолжал он созерцать. Другой же пан, сидевший у стены, более молодой, чем пан на диване, смотревший на всю компанию дерзко и задорно и с молчаливым презрением слушавший обший разговор, опять-таkи поразил Митю только очень высоким своим ростом, ужасно непропорциональным с паном, сидевшим на диване. /.../ Мелькнуло у него тоже, что этот высокий пан, вероятно, друг и приспешник пану на диване, kak бы «телохранитель его", и что маленький пан с трубкой, конечно командует паном высоким. Но и это всё казалось Мите ужасно kak хорошо и бесспорно.

[Bei dem Herrn auf dem Diwan fiel ihm die würdevolle Haltung auf, die polnische Aussprache und vor allem - die Pfeife. /.../ Das etwas aufgedunsene, fast schon vierzigjährige Gesicht des Polen, mit einem sehr kleinen Näschen, unter dem der dünne und spitze Schnurrbart hervorsah, geschwärzt und frech, rief gleichfalls vorderhand noch nicht die geringsten Fragen in Mitja hervor. Sogar das sehr jămmerliche Perückchen dieses Herrn (es war in Sibirien gefertigt und hatte einfaltig vorgebürstete Schläfenhaare) machte keinen besonderen Eindruck auf Mitja: 'das heißt also, so muß es auch sein, wenn er schon eine Perücke trăgt', fuhr er in seliger Stimmung fort, sich selber zu erklären. An dem andern Herrn aber, der an der Wand saß (er war jünger als der auf dem Diwan), auf die ganze Gesellschaft frech und herausfordernd blickte und mit schweigender Verachtung dem allgemeinen Gespråch gelauscht hatte, fiel Mitja gleichfalls nur sein außerordentlich hoher Wuchs auf, der in seltsamem Gegensatz stand zu der Figur des auf dem Diwan sitzenden Polen. /.../ Er ahnte gleichfalls, daß dieser hochgewachsene Herr wahrscheinlich der Freund und Helfershelfer des Herm auf dem Diwan sei, sozusagen seine 'Leibwache', und daß der kleine Herr mit der Pfeife natürlich den hochgewachsenen Herm kommandiere. 
Aber es kam Mitja so vor, daß auch dies alles furchtbar gut und durchaus einwandfrei sei.] $]^{6 / 1}$

In dieser Textstelle werden die beiden Polen zum ersten Mal genauer „von außen" geschildert und jeweils als pan [= Herr] bezeichnet, wodurch die Distanz Dmitrijs (und des Erzăhlers) zu ihnen, ihre "komische Fremdheit", hervogehoben wird. Besonders genau wird dabei aus der voreingenommenen, aber verzückten Sicht Dmitrijs der „Verführer" geschildert. Er schockiert ihn durch die überhebliche Haltung, durch den polnischen Akzent sowie erneut durch seine Pfeife. Das Gesicht dieses „reifen, fast vierzigjährigen Mannes“ ist „ein wenig aufgedunsen“, er hat „ein kleines Näschen“, „zwei ganz dünne, spitze Schnurrbărtchen“, die zudem .,gefärbt und frech“ sind, und trägt ein „ganz schäbiges Perückchen", das in Sibirien gemacht wurde. Die häßliche Perückc und das gefärbte Schnurrbärtchen deuten auf die „dekadente Künstlichkeit“ des Polen und auf seine Neigung hin, sich zu verkleiden hin, d.h. sich zu verfälschen bzw. zu maskieren. Das Motiv der Perücke schafft aber einen zusătzlichen Bezug des Polen zur stereotypen Figur des polnischen falschen Grafen und Falschspielers in Vel'tmans Roman Salomeja, worauf sich schon die früheren perücketragenden Figuren Dostoevskijs, Julian Mastakovic aus einem frühen Feuilleton und der Fürst Gavrila, das „Onkelchen“ aus Djadjuškin son, beziehen. Der polnische „Verführer" stellt sich auch bald, seinem literarischen, stereotypen Vorbild konsequent entsprechend, als Falschspieler heraus. ${ }^{642}$ Auch seine

${ }^{642}$ Ebd., S. 378 [S. 724f.].

$6 \star 2 \mathrm{Zu}$ den typischen Merkmalen des nationalen Stereotyps eines Polen in der russischen Literatur vgl. z.B. GOLDGART 1986, S. $118 \mathrm{f}$. Siehe auch die Anmerkung der Herausgeber in Bd. 15, S. 576, über mögliche Bezüge der polnischen Figuren in Brat 'ja Karamazovy' zu den Polen in den Romanen N.S. Leskovs Nekuda (1864), V.P. Kljušnikovs Murevo (1864), und Vs.V. Krestovskijs Punurgogo stado (1869) sowie zur Figur des Pun Kopyčınskij aus

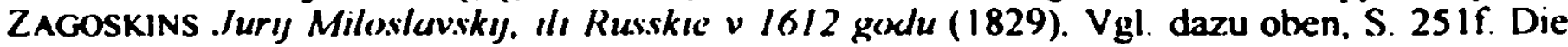
Autoren des Kommentars zu Bd. 15 berufen sich dabei auf GroSSMAN 1934, S. 108-1 10, sowie auf das Kapitel Posledny romun Dosfereviskijskoggo [Der letzle Roman Ioss/oevskjss ] in: DERS. 1935, S. 29f., und auf den Essay von M.A. ANTONOVIC: Misilı()-askeliciesky romun [Atysthisch-usketıscher Romun], in: DERS. 1961, S. 412. Vgl auch die Charakterisierung des falschen polnischen Grafen. Pan Ž.elynskij in ALEKSANDR FOMIC VEL'TMANS Sulomeja (VEL'TMAN 1957, S. 25: „Пан Же.лынсkий бы.7 знатный итрок, старый пес в рыжем па-

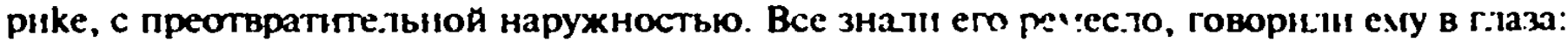
«Ты, пан шу.лер! с тобой не.тьзя итрать!» Он на это издават звук: «х3, Х3, Х3, Х3?», са-

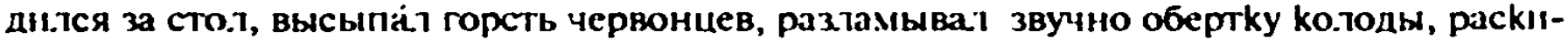
дыват ее, kak веер, и, пропустнв с тресkом kарту в kарту, kла.л ттхо на сто.л и пронзноснт: жНе угодно .ли?» на это маническос с.лово ничего не.тзя бы.7о отвечать, kроме "Угодно!»".

[Herr Żelynskij uar ein berühmter Spieler, ein alter Rüde mit roter Perückc, mit einem ganz widerlichen Äußeren. Alle wußten von seinem Handwerk und sagten ihm ins Gesicht: 'Du pan, bist ein Falschspieler! Mit dir darf man nicht spielen. Er gab darauf ein Geräusch von sich: 'he, he, he, he?', setzte sich an den Tisch, schüttete eine Handvoll Tscherwonez (goldene Zehnrubelmünzen| aus, erbrach klangvoll den Umschlag eines (neuen) Kartenspiels, streute die Karten wie in einem Fächer aus, und nachdem er die Karten mit Krachen duchgemischt halte, legte er sie leise auf den Tisch und sprach feierlich aus: 'Wäre es Ihnen recht?'. Auf dieses magische Wort konnte man nichts anderes antworten als 'Es ist recht!'] 
Pfeife scheint etwas Exotisches an sich zu haben und zeichnet den polnischen Herren als einen dem ,russischen, ländlichen" Milieu in Mokroe Fremden aus.

In der Beschreibung dieses Polen treten somit alle bisher getrennt vorkommenden Motive zur Charakterisierung der "dekadent-westlichen" russischen und polnischen Figuren auf, nicht nur des dekadenten Fürsten Gavrila in Djadjuškin son, sondern beispielsweise auch Petr Stepanovic Verchovenskijs in Besy. Sie bilden in einer metonymisch auffallenden Dichte ein synthetisch-symbolisches Portrắt des „Polen als Verführer". Der Pole in Brat "ja Karamazovy läßt sich daher als eine „synthetisch-stereotype“ Figur bezeichnen, die mehrere negative außere "westliche" und ,polnische" Merkmale vereinigt, die durch eine "verăchtliche" und "frech-überhebliche" Haltung eines (adligen) Polen gegenüber den Russen begleitet werden.

Der zweite, große Pole und „gehorsame Leibwächter" des „Verfürers“ erinnert dagegen als sein "Genosse" bzw. .Kamerad" an den "tapferen" Polen Tvskij in Zapiski iz Mertvogo doma, den Freund und "Beschützer" des kranken adligen B. Das Motiv der in "Sibirien" gemachten Perücke des "dicken Polen“ kann deswegen zusătzlich als eine ironische Anspielung auf diese Aufzeichnungen verstanden werden. und kündigt die politisch-ideologisch geprägte, antirussische Haltung der beiden Polen an, die sich in der Fortsetzung dieses Kapitels offenbart.

Die beiden Polen bilden als zwei komplementäre Alter-Figuren den negativen Kontrast bzw. den negativen Hintergrund, auf dem sich die Figur des Russen Dmitrijs positiv abzeichnet: seine kindliche Naivität, die er seinem "Idealismus" und der ,großen I iebe“ zu GruŠen'ka verdankt. Die ,naiv-unkritischen“ Beobachtungen Dmitrijs werden aber dabei durch den Erzăhler relativiert bzw. korrigiert, indem sie als vorübergehend und durch dessen ekstatischen, extremen seelischen Zustand hervorgerufen bezeichnet werden.

Im weiteren Verlauf des Gesprăchs zwischen den Polen und den Russen. Kalganov und Maksimov sowie Dmitrij und Grusen'ka, wird zusătzlich die kulturelle Überheblichkeit des polnischen „Verführers" und seines „Leibwächters" den Russen gegenüber betont, die sich in ihrer Arroganz sowie in der absichtlichen Entstellung, „Polonisierung“" russischer Worte außert, obwohl sie "ordentlich" Russisch sprechen können. ${ }^{643}$

Der Kommentar des Erzählers entblößt dabei die Haltung der Polen den Russen gegenüber als ungerecht und unbegründet. darüber hinaus macht er sie lächerlich. Ihr Benehmen provoziert Grusen ka. so daß ihre Aufregung und ihr Unbehagen bzw. gerechter Zorn ihrem "früheren Geliebten“ gegenüber wachsen. Sie ermahnt ihn ungeduldig, russisch wie damals vor funf Jahren zu sprechen. Die einst .,enttăuschte“ und „,beleidigte“ Liebe Grušen kas zu dem Polen schlăgt auf diese Weise in eine verăchtliche Abneigung um:

${ }^{643} \mathrm{Vgl}$. Bd. 14, S. 379: „Пан с трубкой говорицт по-руссkı порядочно, по крайней мере гораздо лучше, чем представ тялся. Русские с.лова, ес.ли и употреб.лял их, kоверкал на польскıй лад“" |..Der polnische Herr mit der Pfeife konnte ganz ordentlich Russisch sprechen, wenigstens viel besser, als er sich den Anschein gab. Wenn er sich aber russischer Worte bediente, so pflegte er sie zu entstellen, indem er sie dem Polnischen anpaßte“: S. 727] 
- Да что крулева, это королева, что ли? - перебила вдруг Грушенька. /.../ По-руссkи, говори по-руссkи, чтобы ни одного слова польсkого не было! - закричала она на него. - Говорил он прежде порусски, неужели забыл в пять лет! - Она вся покраснела от пнева.

- Пани Агриппина..

- Я Аграфена, я Грушенька, говори по-руссkи, или слушать не хочу! - Пан запыхтел от гонора и, ломая руссkую речь, быстро и напыщенно произнес:

- Пани Аграфена, я пшиехал забыть старое и простить его, забыть, что было допрежь сегодня...

[Was ist das denn 'kruleva', ist das etwa 'koreleva' [Königin] unterbrach ihn plotzlich Grušen'ka; Erg. d. Verf.] /.../ 'Russisch, sprich Russisch, keine einziges polnisches Wort will ich mehr hören!' schrie sie ihn an. 'Du hast doch früher Russisch gesprochen, hast du das wirklich vergessen in fünf Jahren!' Sie war ganz rot geworden vor Wut. 'Pani Agrippina...' 'Ich bin - Agrafena, ich bin Gruschenka, sprich Russisch, oder ich will es gar nicht hören!' Der polnische Herr keuchte vor gekranktem Ehrgeiz, und Russisch radebrechend, sprach er rasch und hochtrabend:

Pani Agrafena, ich bin gekommen, um das Alte zu vergessen und es zu verzeihen, $\mathrm{zu}$ vergessen, was bis heute war... $]^{644}$

In diesem Dialog zwischen Grusen'ka und dem Polen fallt auf, daß ihr Zorn nicht dem „Verführer" als einem „Mann", der sie verlassen hat, sondern als einem „Polen" gilt. Er ärgert sie, weil er ein „Pole“ ist und sie „kruleva“ (poln. królowa; Konnigin) und „Agrippina“ nennt, obwohl er "früher" mit ihr Russisch gesprochen, d.h. vor ihr seine polnische Identităt „versteckt“ bzw. sich ..maskiert" hatte. Der Pole reagient auf die Vorwürfe Grušen'kas ebenfalls nicht wie ein ,Mann“, sondern wie ein „Pole“. Sein „adliges polnisches Ehrgefühl“ (honor) ist verletzt worden und er spricht „schnell und aufgeblasen" in (absichtlich) gebrochenem Russisch, daß er ,gekommen sei“ (er sagt: „nшиехал“, statt russ. „приехал“" bzw. statt m!n. ,przyjechałem“), um das ..Alte zu vergessen und zu verzeihen", obwohl er es ist, der Grusen ka um Verzeihung bitten sollte.

Im imagothematischen Kontext des Dialogs müssen die Worte „kruleva“ und "Agrippina“ für Grušen ka besonders „beleidigend" sein. Zum einen wird sie. das „Opfer des Polen“, von dem „falschen, verräterischen Geliebten“, der sich ihr gegenüber nicht "ritterlich" benommen hat, auf polnisch "Königin" genannt: zum anderen schafft die polnische Form ihres Namens den Bezug zu der im römischen Köln geborenen römischen Kaiserin Julia Agrippina. Mutter des Kaisers Nero, der bekanntlich Christen verfolgt hatte, so daß dadurch symbolisch der ..antichristliche“ Charakter des „westlichen (römisch-katholischen) Verführers" betont wird. Der Pole erscheint besonders deutlich als „Verführer zum Bosen“, als das Stereotyp des „teuflischen Ljachs“, der gekommen ist, um sich mit der „Russin“ scheinbar zu versöhnen.

${ }^{644} \mathrm{Vgl}$. ebd. [S. 741$]$ und z.B. S. 377, S. $387 f$. 
Die Thematik des ganzen Gesprăchs zwischen den Polen und Russen in Mokroe weist einen betont ideologischen Charakter auf. Die Polen werden dabei als die „Polen an sich“, d.h. als nationalistische, intolerant-streitsüchtige und unversöhnlich gestimmte politische Feinde der Russen gezeigt.

Nachdem Dmitrij das Gespräch zwischen den Polen, Grušen'ka, Maksimov und Kalganov durch sein plötzliches Erscheinen unterbrochen hat, wird der Streit aus Anlaß der von Maksimov erzăhlten Geschichte über die "fragwürdige Tugend der Polinnen" fortgeführt, von denen die "russischen Kavalleristen" (= "Offiziere") in den „Zwanziger Jahren des neunzehnten Jahrhunderts“ verführt und mit Zustimmung der Eltern zur Heirat gezwungen worden seien. In der Geschichte Maksimovs handelt es sich erneut um das (alt)russische literarische Stereotyp der „Polin als Verführerin“, das hier zur Rechtfertigung Grusen'kas und zur Demaskierung der „Polinnen“ dient. Es sind die „Polen“ und die „Polinnen“, die die „Russinnen“ und "Russen“ verführen, so daß diese als „Opfer der westlichen Verführer" erscheinen. ${ }^{645}$ Obwohl Maksimov selbst als ein verwestlichter, schäbiger und heruntergekommener, aber doch gutmütiger „Lügner”, als ein dem General Ivolgin ăhnlicher Typ geschildert wird, der besonders von dem jungen und ebenfalls verwestlichten Russen Kalganov immer wieder gerechtfertigt wird. ${ }^{646}$ reagieren die Polen überreizt und betrachten diese Geschichte als

645 Siehe dazu z.B. GoldGaRT 1986, S. 124, bzw. KEPIŃSKI 1990a, S. 154f: .Zadziwiająco wcześnie pojawia siç tak powszechny pxiźnicj w literaturze rusyjskiej, szezególnie w XIX wieku, motyw powabnej i kuszącej Polki, bo oto wśród heroicznych zaiste zmagan mnichoiw z pokusami życia, jakie opisujc Pateryk kijowsko-pieczerski, znajdujemy intercsujjącą historiç o Mojżeszu zwanym Węgrzynem (Ügrin) /.../. Motyw grzesznej Polki powtarzać siç bçdzie piżniej w innych utworach piśmiennictwa staroruskiego i przejęty przez literaturę rosyjską stanie siç jednym ze stereotypơw polskosci“".

[Erstaunlich früh erscheint das so häufig in der russischen Literatur vorkommende, besonders im XIX. Jahrhundert allgemein vorhandene Motiv der anziehenden und verführerischen Polin. weil wir nămlich unter den wahrhaftig heroischen Kămpfen der Mơnche gegen die Verlockungen des Lebens, die im Palerık des Kiewer Hohlenklosters beschrieben werden, eine interessante Geschichte über den Mose Ungar (Ugrin) genannt, finden. /.../ Das Motiv der sündigen Polin wiederholt sich auch später in anderen Texten des altrussischen Schrifitums, und, von der russischen Literatur übernommen, wird es zu einem der Stereotypen des Polentums.]

${ }^{616} \mathrm{Vgl}$. Bd. 14, S. 379ff. Maksimov erzăhlt nicht nur die Geschichte über die verführerischen Polinnen, sondern auch über seine Ehe mit einer behinderten Polin, und fügt mehrere Anspielungen auf die Werke russischer Dichter und Schriftsteller wie Karamzin, Batjuškov, Puškin oder Gogol' bzw. Gonçarov hinzu, in denen er nicht nur seine gute Kenntnis dieser Autoren, sonderm auch das Interesse u.a. für die französische Literatur, d.h. für den „Westen“ zum Ausdruck bringt, denn die von ihm zitierten russischen literarischen Werke haben die "westeuropäische“ bzw. .,antike“ Kultur zum Thema. Dieser „verwestlichte russische Narr“ und ..Lügner" wird aber schließlich bei Grušen 'ka Obdach finden und sich bei ihr in einen russischen demütigen ..Jurodivyj" verwandeln, siehe dazu die Anmerkung, Bd. I5, S. 576t. auch zu Maksimov selbst, der von Fedor Pavlovið Karamazov mit dem Lüstling fon Zon verglichen wird. Die Geschichte über die Polin, die sich ein Bein gebrochen hat, erinnert zudem an die Geschichte des Onkelchens Gavrila über den falschen polnischen Grafen bzw.Koch. der sich beim krukovjuk-Tanzen das Bein bricht. Vgl. dazu oben, S. 154ff. sowie Bd. 14, S. 34, S. $81 \mathrm{ff}$. und Bd. 15, den Kommentar auf S. 539f., und auch Bd. 15, S. 6fT. Petr Fomic Kalganov, der Verwandte des verwestlichten Miusov, erkennt jedoch das „wahre Wesen” 
eine Beleidigung sowohl ihrer selbst als auch der Ehre der polnischen adligen Damen, obwohl doch der Pole selber Grusen'ka einst verfuhrt, betrogen, verlassen und auf diese Weise ihre Würde bzw. Ehre zutiefst beleidigt hat. Das verlogene und einseitig auf sich selbst bezogene Ehrgefühl des polnischen „Beleidigers" und seines Begleiters wird zusătzlich durch ihr auffallendes Äußeres veranschaulicht, das einen Gegensatz zu ihren hochtrabenden Äußerungen bildet, denn sowohl er als auch sein Begleiter werden als schmutzige und schäbige arme Kerle beschrieben, obwohl sie ihre den Russen überlegene höhere „zivilisierte“ bzw. „kultivierte" Herkunft immer wieder betonen.

Nach diesem Streit versucht der immer noch „demütig“ gestimmte Dmitrij, die Polen und Russen miteinander $\mathrm{zu}$ versöhnen, indem er vorschlägt, einen "Toast auf Polens Wohl" gemeinsam mit den beiden Polen zu trinken. Die versohnliche Geste Dmitrijs wird jedoch zunichte gemacht, indem die Polen bereit sind, auf Rußlands Wohl zu trinken, aber in den Grenzen vor dem Jahre 1772, d.h. vor der ersten Teilung Polens:

- За Польшу, панове, пью за вашу Польшу, за польский край? воскликнул Митя.

- Бардзо ми то мило, пане, выпием (это мне очень приятно, пане, выпьем), важно и благосkлонно проговорил пан на диване и взял свой стакан.

- И другой пан, kak его, эй, ясневельмохсный, бери стаkан! - хлопотал Митя.

- Пан Врубцевсkий, подсказал пан на диване.

Maksimovs und verteidigt ihn als einen ..edlen Lügner”, der mit .,seinen Lügen-Geschichten Menschen erfreuen und unterhalten" will, siehe dazu Bd. 14, S. 32 und S. 381, sowie zu den ..Lügner-Typen“" in den Werken Dostoevskijs oben im Zusammenhang mit General Ivolgin, S. 297ff. Kalganov, der selbst noch ein .Jüngling" ist, erinnert sowohl an die Figur Arkadij Dolgorukijs als auch an andere verwestlichte russische Figuren Dostoevskijs und konnte als ein noch nicht ganz geformter, potentieller ..Stavrogin-Typ“ bezeichnet werden, der sich noch nicht fur oder gegen ..Rußland" entscheiden konnte. Siehe unten zu der versohnlichen Haltung Kalganovs den Polen gegenüber, vgl. auch die Beschreibung scines Äußeren (Bd. 14, S. 32 und S. 379ff.). Sein Name (Petr) deutet aber auf seinen negativ „verwestlichten-petrinischen“ Charakter hin

${ }_{647} \mathrm{Vgl}$. z.B. ebd. S. 380ff. (vgl. die „Beobachtungen“ Dmıtruss, durch den Frzahler wiedergegeben, die die Reaktion der Polen auf die Geschichten Maksimovs im negativen Kontexı erschemen lassen: „Miте то.тbko броси.ся в г.лаза огромный смазной сапог ето с то.лстою и грязною подошвой. Да и вобо̆е оба пана были одеты дово.тьно засатен110 “ (..Mitja fiel nur sein gewaltiger Stiefel auf, der eine dicke und schmutzige Sohle hatte. Ja, und überhaupt waren beide Polen ziemlich schmierig gekleidet“; S. 727f.|). Der „schmutzige Schuh" des Polen, die Tatsache, daß die beiden Polen keine Uhr bei sich tragen, obwohl sic sich gegenseitig nach der genauen Zeit erkundigen, macht ihre ehrenvolle und sich betont ..kultiviert" bzw. .zivilisiert“ gebende Haltung den Russen gegenüber fraguürdig, wenn nicht lächerlich, ohne daß die Ursachen ihres schăbigen Auftretens, das einen negativen Kontrast zu ihrer stolzen Haltung bildet, psychologisch motiviert bzw. hinterfragt würden, wie es beispielsweise bei dem heruntergekommenen Adligen Maksimov der Fall ist. Hervorgehoben wird außerdem die Verachtung der Polen nicht nur den Russen, sondern auch dem polnischen Volk gegenüber, denn sie stellen polnische ..adlige Damen“ den „polnischen Băuerinnen“ gegenüber. 
/.../ Bce трое выпили.

- Тепгерь за Россию, панове, и побратаемся!

- Налей и нам, сkазала Грушенька, - за Россию и я хочу пить.

/.../ Все, кроме панов, выпили /.../. Панове же и не дотронулись до своих [стаkанов].

- Kak же вы, панове? - воскликнул Митя. /.../ Пан Врублевский взял стакан, поднял его и зычным голосом проговорил:

- За Россию в пределах до семьсот семьдесят второго года!

- Oто бардзо пенкне! (Bоm mak хорошо!) - крикнул другой пан, и оба разом осушили свои стаkаны.

- Дурачье же вы, панове! - сорвалось вдруг у Мити.

- Па-не!! - прокричали оба пана с угрозою, наставившись на Митю, kak петухи. Особенно вскипел пан Врублевский.

- Ale не можно не мець слабосыщи до своего краю? - возгласил он. (Разве можно не любить своей стороны?). [kursiv die Verf.]

['Auf Polen, ihr Herren, ich trinke auf euer Polen, auf das polnische Reich' [eigentl. auf das polnische Land. Provinz]!'rief Mitja aus. 'Das ist mir sehr angenehm, mein Herr, trinken wir', sprach gewichtig und herablassend der polnische Herr auf dem Diwan und nahm sein Glas.

'Auch der andere Herr, wie heißt er, heda. Huldvoller, nimm dein Glas rief Mitja. 'Herr Wrublewski!' soufflierte der Herr auf dem Diwan. /.../ Alle drei tranken aus. /.../ Jetzt auf Rußland, ihr Herren, und laßt uns Brüderschaft schließen!' 'Gieß auch uns ein', sprach Grušen'ka: 'auf Rußland will auch ich trinken!' /.../ Alle außer den polnischen Herren tranken. /.../ Die polnischen Herren hatte die ihrigen [Gläser] nicht einmal berührt. 'Wie denn, ihr Herren?' rief Mitja aus. /.../

Herr Wrublewski nahm das Glas, erhob es und sprach mit lautschallender Stimme: 'Auf Rußland innerhalb der Grenzen, die es bis zum Jahre 1772 innehatte!

'So ist es richtig!' rief der andere polnische Herr, und beide leerten auf einmal ihre Gläser. 'Schafsköpfe seid ihr, ihr Herren! entrang sich plötzlich Mitja. 'Herr!' schrien drohend beide polnische Herren, indem sie sich wie Hăhne gegenüberstellten. Besonders Herr Wrublewski war in Wut geraten. 'Kann man denn sein Vaterland nicht lieben?' rief er aus. '] ${ }^{64 \theta}$

Die Toast-Szene zeigt drei unterschiedliche Haltungen der auftretenden Figuren der „polnischen Frage“ gegenüber. Dmitrij will sich mit den Polen ,aussöhnen", will aber mit ihnen einen Toast auf das "polnische L.and" [noлlckuй kpaü; pol'skij kraj] trinken, d.h. auf die „polnische (westliche) Provinz" innerhalb des "russischen Imperiums"; Grusen"ka will nur auf das Wohl „Rußlands" trinken. sie ignoriert somit die „polnische Frage“ völlig. Die beiden Polen vertreten schließlich die unversöhnliche, antirussische Haltung der polnischen Patrioten, denn sie wollen überhaupt nicht auf das Wohl ..Rußlands“, sondern nur auf das des „Alten Polen“ vor den drei Teilungen anstoßen. Sie werden

${ }^{648} \mathrm{Bd} .14, \mathrm{~S} .383$ [S. 733f.] 
dafür von Dmitrij als „Narren“ bzw. „Dummkopfe“ beschimpft und vom Erzăhler mit zwei gereizten Hăhnen verglichen. Besonders "unversohnlich“ den Russen gegenüber zeigt sich der ,große Pole“ Vrublevskij [von poln. wróbel; vrubel"; Spatz], dessen „komischer" Name hier zum ersten Mal genannt wird. Er äußert zuerst auf Russisch mit „schallender Stimme“ die Aufforderung, auf „Polen in den Grenzen vor 1772“ zu trinken und er ist es wieder, der „vor Wut kocht" und mit „voller Stimme“ auf das Recht pocht. das eigene Land lieben zu dürfen. In diesem polnischen Fragesatz „- Але не можно не мець слабосьци до своеro краю?" [poln.: "- Ale nie można nie mieć słabości do swojego kraju?"; ,- Aber kann man keine Schwäche für das eigene Land haben?"] fehlt die polnische Fragepartikel „czy“ bzw. „czyz" bzw. das Wort „przeciež: [„,doch“: "- Ale [czy'] nic można [przecież] nie mieć słabosici do swojego kraju?"; „- Aber kann man [denn doch] keine Schwäche für das eigene Land haben?"]. obwohl er korrekt ist. Dieser rhetorische Fragesatz ist als Protest des Polen zu verstehen, der gegen Dmitrijs Äußerungen gerichtet ist. Die zwei anderen polnischen Sätze, die der „dicke Pole“ ausspricht [„Бардзо мо то мило ране, выпием“; poln. ..Bardzo mi [to] milo, panie, wypijem"; "Es ist mir sehr angenehm, Herr, laßt uns trinken [trinken wir]" und „- Oто бардзо пенкне!“; "Oto [eigentl.: To] bardzo pięknie"; „Das ist sehr schon"] sind nicht ganz korrekt. weil die beiden Demonstrativpronomen nicht richtig eingesetzt sind. Im ersten Satz ist das Wörtchen „to" überflüssig (obwohl es auch „dialektal" bedingt sein könnte), im zweiten müßte "to" statt "oto" stehen. Diese Inkorrektheiten konnen aber auch als die "Absicht" des ..Polen" interpretiert werden, sein Polnisch zu „russifizieren" und anstatt Russisch zu sprechen, den polnischen Sätzen eine „russische Färbung“ zu verleihen. Dmitrij redet dagegen die beiden Polen mit panowie bzw. mit jasnevel "mo:nyj [ „ясневельможный”; zu poln. jaśniewielmozmy; hochwohlgeboren] an, was darauf hindeuten soll, daß er über einige Kenntnisse der polnischen Sprache verfügt. Die in Klammem hinzugefügten russischen Übersetrungen erleichtem nicht nur dem russischen Leser die Lektüre dieser Sătze, sondern heben textimmanent die Fremdheit und die Unverständlichkeit dieser Sätze für die russischen Figuren hervor.

Als Ursache für die verfehlte Verbrüderung zwischen Dmitrij und seinem polnischem Rivalen wird die unversöhnliche und feindliche Haltung der Polen den Russen gegenüber angegeben, die sich sogar in einem scheinbar unpolitischen Kontext als Vertreter der Interessen ihres $I$ andes verstehen wollen. In der Anspielung auf die erste Teilung Polens, d.h. auf ein verhängnisvolles Ereignis in der russisch-polnischen Geschichte. handelt es sich um die ,polnische Frage", die für die russische Politik und offentliche Meinung. auch in der Zeit, in der die Handlung des Romans spielt, ideologisch relevant und zugleich heikel gewesen ist. Die beiden polnischen stereotypen Figuren sind in dieser Streitszene als Stellvertreter ,adliger polnischer Patrioten“ zu verstehen, d.h. der politischen Feinde Rußlands, die die Wiederherstellung des .Alten Polens“ aus der Zeit vor den Teilungen anstrebten und gegen Rußland mit allen Mitteln kämpften. ${ }^{649}$ Das

${ }^{649} \mathrm{Vgl}$. dazu die publizistischen Aufsătze Dostoevskijs zu rußlandfeidlichen Vertretern des .Alten P'olen" in Bd. 26, S. 54-59 (I)nevnik pisatelja =a 1877 god. ()ktjabr 1877. (jlava 3: I. Rınskıe klerikaly u nus v Rossı. II. I.e'njaja propylka Siaroj Pol'š miril sja |Tagehuch des 
rußlandfeindliche Benehmen der Polen wird hier jedoch zur Charakterisierung Dmitrijs und anderer Russen eingesetzt, die sich im Vergleich mit den "unwürdigen" Gesprăchspartnern als "Rußland liebende Patrioten" benehmen. Von allen in dieser Szene auftretenden russischen Figuren ist nur Dmitrij bereit, sich bei den Polen zu entschuldigen bzw. sich mit ihnen zu versöhnen, was weniger seinen politischen Ansichten als seiner Befürchtung zu verdanken ist, Grusen kas ehemaligen Geliebten und dadurch sie selbst zu reizen und ihre $\mathrm{Zu}$ neigung zu verlieren. Die Polen werden dagegen zusătzlich lăcherlich gemacht, indem sie in ihrem patriotisch bedingten Zorn mit zwei "Hăhnen" verglichen werden. Auch der bereits genannte komische Name des arroganten und besonders patriotisch bzw. nationalistisch gesinnten "Leibwächters" des polnischen Herren mit Pfeife, Herr Vrublevskij, macht ihn besonders durch den Kontrast zu seinem hohen Wuchs lăcherlich. ${ }^{650}$

Der „edle Zor" und die "würdevolle“ patriotische Haltung des polnischen Rivalen Dmitrijs und dessen Begleiters werden in der auf den mißglückten Toast folgenden Szene des Kartenspiels als moralisch fragwürdig gezeigt. Die beiden Polen werden bald vom Wirt als professionelle Falschspieler entlarvt, die mit gefalschten Karten Geld gewonnen haben, indem er die von ihnen versteckten

Schriftstellers für das Jahr 1877. Oktoher 1877. Kapitel 3.: I. Römische Klerikale bei uns in Rußlund. II. Der sommerliche Versuch des Alten Polens. sich mit den Russen zu versöhnen]) und zur "römisch-katholisch-polnischen Verschwörung" gegen Rußland, ebd., passim. Vgl. dazu oben, S. 298, im Zusammenhang mit Konrad Wallenrod. Die Argumentationsweise in der Publizistik Dostoevskijs erinnen an diejenige M.N. Katkovs, in dessen Aufsătzen zur ..polnischen Frage“. Vgl. z. B. KATKOV 1887, S. 225 und S. 228: „По.льckoе возстание вовсе не народное возстаніе: восстать не народъ, а шляхта и духовенство. Это не борьба за свободу, а борьба за втасть, - же.ланіе с.лабаго покорить себе си.тьнаго. /.../ По.льсkоіезуисткая интрига замыш.ляеть конечную пагубу дтя Руссkаго посударства, д.я pycckaro народа и вместе дтя руссkой правос.лавной церkвии. Ловкость интриги успь.та на время отвести намґ г.лаза“ (Передовая статья в № 130 «Московсkих Ведомостей» (15 июня [1863])). [Der polnische Aufstand ist gar kein nationaler Aufstand: das Volk hat sich nicht erhoben, sondern der Adel und die Geistlichen. Es ist kein Kampf für die Freiheit, sondern ein Kampf um die Macht, - der Wunsch des Schwachen, den Starken zu erobern. /.../ Die polnisch-jesuitische Intrige hat natürlich den Untergang des Russisschen Staates im Sinn, des russischen Volkes und zugleich der russischen orthodoxen Kirche. Die Raffimiertheit der Intrige hat zeitweise unsere Blicke davon abzulenken vermocht (leitartikel in der $\mathrm{Nr} .130 \mathrm{der}$ Moskauer Nachrichten (15. Juni 1863)).]

${ }^{650}$ Siehe zu den Namen der beiden Polen sowie zu den Bezügen zu den Zupıskı i= Mertvogo doma, oben, S. 194ff. Die beiden Polen werden außerdem von Grusen ka mit nemyxu umbeuckue [indischer Hahn, = Truthahn], ihr Geliebter mit einem ce.reзens [Enterich], von Dmitrij mit каnzyuы [Kapaune] verglichen, vgl. Bd. 14, S. 386 und S. 387f. Die Toast-Szene erinnert darüber hinaus an eine ähnliche Toast-Szene zwischen Russen und Polen im Roman Zagoskins, in der jedoch der positive ..Held“ Jurij Miloslavskij sich weigert, auf die Gesundheit des polnischen Konigs (und zugleich des künftigen russischen Zaren) zu trinken und auf diese Weise seinen Patriotismus gegenüber dem negativ dargestellten polonophilen russischen Bojaren Krucina-Šalonskij sowie gegenüber dessen polnischen Gästen, den polnischen ..Besatzungssoldaten“, zeigt. Der Kommandant des polnischen Regiments, Pan Tyškevix, wird dabei wie der Russe Jurij positiv geschildert und bildet den Kontrast zu anderen Polen, darunter zu Pan Kopy夭̇inskij, die sich durch „огромные усы” [, riesigen Schnurrbart"] sowie sowie „надменный вид“" [.hochmütige Haltung"] auszeichnen. Vgl. ZAGOSKIN 1987, S. $121 \mathrm{ff}$. bzw. S. $112 \mathrm{ff}$. 
Karten findet. ${ }^{651}$ Der polnische „Verführer“ ist darüber hinaus bereit, Grušen ka für dreitausend Rubel an Dmitrij abzugeben. Det Bestechungsversuch scheitert lediglich deswegen, weil Dmitrijs dem Polen und dessen „Leibwachter" nur einen Teil dieser Summe sofort auszahlen kann, wodurch er deren Mißtrauen weckt und ihnen zugleich die Gelegenheit gibt, sich moralisch empört und beleidigt zu fühlen. ${ }^{652}$ Der von Dmitrij beleidigte Pole wird von Grusen ka endgültig verstoßen, nachdem sie erkannt hat, daß er nicht ihretwegen, sondern lediglich wegen ihres Geldes zurückgekehrt ist. ${ }^{653}$

Trotz der Demaskierung als Falschspieler verlieren aber die beiden Polen bis zuletzt ihre von "Würde" und "Ehre" (honor) strotzende ,ritterliche" Haltung nicht. Beide zeigen sich im Gegenteil empört über den Vorschlag Dmitrijs. Der „große Pole“ nennt Grušen ka eine „offentliche Dirne“ und droht ihr sogar völlig „unritterlich“ mit der Faust. Dmitrij trägt ihn aber sofort auf seinen Armen hinaus, so daß er als ein beinahe übermenschlich starker, mythologischer „Athlet" erscheint und den ideologischen Feind durch seine Entschlossenheit und physische Stărke besiegt:

/.../ пан Врублевкий, сkонфуженый и взбешенный, обратясь kо Грушеньке и грозя ей kулаком, закричал: - Публична шельма! - Но не успел он и воскликнуть, kak Митя бросился на него, /.../ поднял на воздух и в один миг вынес из залы /.../. [/.../ Herт Wrublewski, verstort und in rasender Wut /.../ [wandte sich] an Grusen'ka /.../ [drohte ihr mit der Faust und schrie sie an:] 'Öffentliche Dirne du!' Er hatte das aber noch nicht ausgerufen, als Mitja sich auf ihn stürzte, /.../ in die Luft hob und in einem Augenblick aus dem Saal /.../ trug. ${ }^{654}$

$651 \mathrm{Vgl}$. dazu in Bd. 14, S.384ff. die Kartenspielszene, in der die Polen, besonders der "Verführer" Grušen kas, das Spiel wie ein Ritual zelebrieren: „Паны уже усе:иісь "I pacпечатати итру. Смотре.7II же гораздо привет.ливее, Iочті .аскаво. ПІан на диване заkуріLт новую трубку и приготовіцтся метать; в .тице его изобразицась даже некая торжественность" |Die polnischen Herren hatten schon Platz genommen und das Kartenspiel entsiegelt. Sie blickten aber bei weitem hoflicher, fast freundlich drein. Der Herr auf dem Diwan hatte eine neue Pfeife angesteckt und war eben daran, die Karten aufzudecken; in seinem Gesıcht malte sich sogar eine gewisse Feierlichkeit: S. 736]. Die von dem Polen erzahlte Anekdote über den ehrenvollen Kartenspieler Podvysockij, der seine E.hre (honor) .aufs Spiel" gesetza und von dem ebenso ehrenvollen Warschauer "бáнкep“ [..Bankier", der Bankhalter] eine Milllion als Gewinn bekommen hat, dient zusatzlich als komischer und pejorativer Kontrast zu seiner fragwürdigen, von den Russen entlarvten Spielmoral, ebd., S. 385. Siehe auch dazu Bd. 15, S. 577 und S. 449: die Anmerkungen der Herausgeber zum Brief Dostoevskijs an N.A. Ljubimov vom 16. November 1879, in dem Dostocvskij ihm über diese von polnischen Kartenspielem gehörte Anekdote schreibt, sowic Bd. 30, 1 (S 130f.). Auch in der Szene des Kartenspiels ist Mitja zur Versohnung mit den Polen bereit. nachdem Kalganov die Anekdote über den Herm Podvysockij als univahr bezeichnet hat (Bd. 14, S. 385); in dieser Passage wird außerdem emeut die ..typisch“" polnische adlige Mentalität als verlogen karikiert und die „versöhnliche“ Haltung Dmıtrijs dem Polen gegenüber betont.

$652 \mathrm{Vgl}$. Bd. 14. S. 387.

${ }^{653} \mathrm{Ebd}$., S. 388

${ }^{654}$ Ebd., S. 389 [S. 743] 
Der „dicke Pole“ wird noch intensiver, weil "flammend-“ bzw. "purpurrot" vor "Wut" als die in Podrostok vorkommende "dicke" stereotype polnische Figur, die sich lediglich "wie eine Mohrrübe" verfärbt. Er behält zugleich wie ein "Mensch mit Charakter" seine "wichtigtuerische, ernsthafte Würde" und seinen "Ehrgeiz":

/.../ Маленький пан, багровый от ярости, но нисколько не потерявший своей сановитости, /.../ остановился и вдруг проговорил, обрашаясь k Грушеньке:

- Пани, ежсели хцешь исць за мною, идзыми, если не - бывай здрова! (Пани, если хочешь идти за мной - пойдем, а если нет - то прощай!)

И важно, пыхтя от негодования и амбиции, прошел в дверь. Чељовеk был с хараkтером: он еше после всего происшедшего, не терял надежды, что пани пойdет за ния, - до того ценил себя. [kursiv die Verf.]

[Der kleine Herr, rotbraun vor Wut, aber ohne im geringsten seine Würde zu verlieren, /.../ blieb /.../ stehen und sprach plotzlich, indem er sich an Gruschenka wandte: 'Pani. wenn Du mir folgen willst - komm, wenn aber nicht - so leb wohl!' Und mit gewichtiger Miene, keuchend vor Unwillen und gekränktem Ehrgeiz, ging er zur Tür. Er war ein Mann von Charakter: er hatte nicht einmal nach alledem, was vorausgegangen war, die Hoffnung verloren, daß Gruschenka [eigentl. pani] ihm folgen werde - eine so hohe Meinung hatte er von sich. $]^{655}$

Der stereotype Pole wird bei dieser Szene mit einigen zusätzlichen Motiven ausgestattet. Er spricht weiterhin polnisch, wodurch er als ein Individuum, aber den Russen fremd und unverständlich erscheint. Er ist kein gleichwertiges Subjekt, sondern ein "ganz kleiner, Herr", eine auf ihre nationale Zugehorrigkeit reduzierte stereotype Figur. Der polnische Satz "Пани, ежели хцешь исць за мною, идзьми, если не - бывай здрова!“ [poln.: „Pani, jeżeli chcesz iść za mnoju [eigentl.: za mna; „... mir folgen“ bzw. ze mną: mit mir ], idżmy [eigentl.: chodżmy; ,gehen wir" ], jeśli nie - bywaj zdrowa": = .,Herrin, wenn Du mir folgen willst, gehen wir, wenn nicht, lebe wohl!“]) ist korrekt, obwohl ein wenig „russifiziert“ (,за мною“). Die teilweise Russifizierung dieses Satzes läßt sich als eine vom Erzăhler eingesetzte Inkorrektheit bezeichnen, damit dadurch die Verachtung des Polen der russischen Sprache gegenüber hervorgehoben wird. Die Aufforderung an Grušen'ka, „ihm zu folgen“", läßt sich zusätzlich als eine verachtende Einstellung gegenüber Grušen'ka verstehen, die ihm widerspruchslos ,gehorchen“" soll.

Nachdem sich die Polen in einem anderen Zimmer des Wirtshauses selbst eingeschlossen haben, werden sie in dem auf die Skandalszene folgenden Kapitel Bred [Fieberwahn] nochmals erwähnt, indem sie von Grušen'ka eingeladen werden, ihrem Tanz zuzuschauen:

${ }^{655}$ Ebd. [S. 744]. 
- Эй вы... Подвысоикие! Выходите, она плясать хочет, вас зовет.

- Лaйdak! - прокричал в ответ kоторый-то из панов.

- А ты пódлайdak! Мелkий ты подлечоночеk; вот ты kто.

- Перестали бы вы над Польшей-то насмехаться, - сентенциозно заметил Калганов, тоже не под силу себе охмелевший.

- Молчи, мальчиk! Если я ему сkазал подлеца, не значит, что я всей Польше сказал подлеца. Не составцяет один лайдак Польши. Молчи, хорошенький мальчик, kонфетky kушай.

- Ax kakиe! Точно они не љюdи. Чего они не хотят sлирumься? - ckaзала Грушенька и вышла плясать. [kursiv die Verf.]

['Ei, ihr da ... Podwisozkis! Kommt herein, sie will tanzen, sie ruft euch!' 'Strolch!' schrie zur Antwort einer von den polnischen Herren. 'Du bist aber ein Strolchchen! [eigentl.: ein Unterschuft] Du bist ein ganz kleines Gaunerchen. Das bist du!' 'Hören Sie auf, über Polen zu spotten', bemerkte belehrend Kalganow, der gleichfalls über seine Krafte getrunken hatte. 'Schweig still, Knabe! Wenn ich ihn einen Schuft genannt habe, so heißt das doch nicht. daß ich ganz Polen so schimpfe. Ein Strolch macht nicht ganz Polen aus. Schweig, du hübscher Knabe - iB ein Konfekt!' 'Ach, was seid ihr für welche! Gleich als ob sie nicht Menschen wären! Weshalb wollen sie sich denn nicht versöhnen?' sprach Gruschenka und trat heraus, um zu tanzen. [kursiv die Verf.] ] ${ }^{656}$

Dmitrij nennt die Polen „Podvysockie“, was eine ironische Anspielung auf die von dem "dicken Polen" kurz zuvor erzahlte Anekdote über den chrenhaften Kartenspieler Podvysockij ist. Einer der Polen beschimpft ihn darauf hin als lajdak [lajdak; Schuft]. Dmitrij erwidert seinerseits dieses "typische polnische Schimpfwort", das bereits von den "schabigen Polackchen" in Prestuplenie $i$ nakazanie benutzt wurde, indem er den Polen „nо́длайдак“" [ein „Unterschuft"] und „мелкий подіечоночек” [ein ganz geringer schäbiger gemeiner Kerl] nennt, was eine besondere pejorative Diminutivform ist, die an das Wort ,poljacok" erinnert. Der Name des polnischen Kartenspielers wird von Dmitrij als kollektive Bezeichnung der beiden stellvertretend für alle Polen eingesetzt und kann als ein Stereotypisierungsverfahren des Erzählers aufgefaßt werden. Beide Herren werden ironisch auf das negative nationale Stereotyp des Polen als "Falschspieler" bzw. .Betrüger" reduziert. obwohl Dmitrij dem Einwand Kalganovs, daß er sich über Polen lustig mache bzw. sie verhöhne, widerspricht. ${ }^{657}$ Kalganov selbst wird auch von Dmitrij nicht ernst genommen, son-

${ }^{656}$ Ebd., S. 397f. [S. 759].

657 LEDNICKI 1953, S. 285f, bemerkt zu dieser Szene: „One may casily understand the fact that practically all these disgusting details of the character and behaviour of the two Poles were gathered in order to kill the year 1772. Dostoevsky is merciless and terribly adroit. Here the ideological gambler appears again. /.../ when Mitya had become drunk, he suddenly /.../ shouted: 'Be quiet, my pretty boy, eat a sweetmeat'. How dishonest Dostoevsky is here! He establishes an escape for himself by giving public opinion a sweetmeat. There is no doubt that the whole Polish episode in The Brothers Karamazov, whose central point is the discussion about the Polish historical frontiers and partitions, is an echo of Dostoevsky's arguments with Tokarzewski in Siberia". 
dern wie ein „Kind“ bzw. ein „Junge“ betrachtet, das lieber „Bonbons“ essen soll - zumal er noch betrunken ist - statt sich in die „Politik“ einzumischen.

Obwohl die Russen, Dmitrij und Kalganov, in dieser Tanz-Szene den Polen erneut vorschlagen, sich mit ihnen zu versöhnen, lehnen diese beleidigt das friedliche Angebot ab und verharren in ihrem ,nationalen Stol" und in der Verachtung den Russen gegenüber. Der verallgemeinemde Einwand Kalganovs gegen Dmitrij, der diesem eine verächtliche Einstellung nicht nur gegenüber den beiden Polen, sondern auch gegenüber ihrem Land, das sie vertreten, vorgeworfen hat, kann als ein Hinweis gedeutet werden. daß diese Szene ebenfalls ideologisch gelesen werden soll. Die beiden Polen, die den russischen Versöhnungsversuch ablehnen, könnten erneut als Vertreter des rußlandfeindlichen (alt)adligen Polen gemeint sein. Das von Grušen'ka benutzte Wort „мириться" [, sich versöhnen“] tritt auch in den vor der Entstehung der Brat'ja Karamazovy veröffentlichten publizistischen Aufsătzen Dostoevskij zur "polnischen Frage“ auf, in denen er über die unversöhnlich "feindliche“ und „verrăterische" Haltung der „klerikal-adligen" und dem "Papst" nahestehenden „Vertreter des Alten Polens" berichtet, die bereit sind, mit allen Mitteln, auch durch Betrug und Verrat, für die Wiederherstellung ihres Landes in den Grenzen vor der ersten Teilung gegen Rußland zu kämpfen, und sich nie mit Rußland versöhnen wollen. ${ }^{658}$ Auch der Ausruf Grušen kas, daß die Polen „точно не люди“ [, als ob sie keine Menschen wären“; „wie keine Menschen“] seien, betont die verallgemeinernde und stereotypisierende Sicht auf die beiden polnischen Herren, die hier als Repräsentanten ihrer Nation zu verstehen sind.

Die ,polenfreundliche“ Haltung Kalganovs, die er bereits in der vorhergehenden Skandalszene im Gespräch mit Maksimov über die „Polinnen“ gezeigt hat, wird sofort abgeschwächt, weil dieser junge Russe als ein "verwestlichter, petrinischer" Verwandter des verwestlichten und liberalen Petr Aleksandrovic Miusov vorgestellt wird (beide tragen auch den symbolträchtigen Vornamen Petr). Kalganov langweilt sich in Mokroe, er findet russische Volkslieder „vulgär" und .grob“, wobei er seinen an „westlich-dekadenten“ Mustern ausgerichteten Geschmack offenbart.

Charakteristisch ist hier die zweideutige Reaktion des zwischen dem "Westen" und "Rußland" stehenden jungen Russen, der wie ein "Westler" "Volkslieder" und die russische „народность“ [Volkstümlichkeit] nicht genug kultiviert findet, sich davor "ekelt", sich nicht damit "schmutzig" machen will und es eine ..Schweinerei“" nennt: „Калганов же смотрел тak, kak будто чем запачкался. "Свинство это всё, эта вся народность /.../»". 660

[Kalganow

$650 \mathrm{Vgl}$. Bd. 26, S. 54-59.

659 So interpretiert diese Szene KalJNowSKA 1994, S. 62 : „Jednak polskość pana Musiałowicza i pana Wróblewskicgo określa ich obu do tego stopnia, ż mimo zapcwnicń Dymitra, iż obelga dotyczy tylko pewnego łajdaka, który - tak siç akurat złożyło - jest Polakicm, wnioskowac można, żc słowa Dostojewskiego /.../ dotyczą Polaków i polskosíci w ingólc“” [Doch das Polentum der Herren Musialowicz und Wróblewski prăgt sie in solchem Grade, daß trotz der Versicherung Dmitrijs, daß die Beleidigung nur einem bestimmten Schuft gilt, der gerade ein Pole ist, den Schluß ziehen läßt, daß Dostoevskijs Worte den Polen und dem Polentum im allgemeinen gelten.]

${ }^{660}$ Bd. 14, S. $392 f$. 
machte aber ein Gesicht, als ob er sich mit irgend etwas beschmutat habe: 'Schweinerei ist das alles, diese ganze 'Volkstümlichkeit /.../“"; S. 749] Andererseits zeigt er sich aber als ein russischer konservativer "Slavophiler“, der ein zeitgenðssisches russisches, "verwestlichtes“ Volkslied paradoxerweise als „gestrig“, überholt verurteilt, weil in ihm Menschen lediglich wegen ihres Besitzes geschatzt werden. Stellvertretend für diese Reichen, für die Geld den höchsten Wert darstellt, werden dabei u.a. "Kaufleute“ (und die "Juden“) genannt. ${ }^{661}$

Wie in dem vorhergehenden Kapitel dienen in dieser "folkloristisch" gefarbten Szene die beiden Polen und ihr Verteidiger Kalganov als Kontrast (als alter) zu dem russischen Paar, zu Dmitrij und Grusen ka, die dank dem Skandal ihre Liebe erkennen und endlich zueinander finden. Hervorgehoben wird dabei die Ehrlichkeit, die "russisch-orthodox-byzantinische Demut" und die Bereitschaft, „alle um Verzeihung zu bitten“ und „allen verzeihen zu können“, die sowohl Grušen ka als auch Dmitrij zeigen. ${ }^{662}$ Grušen'ka bekennt dabei Dmitrij ihre Liebe erst, nachdem sie eingesehen hat, daß der Pole, den sie ,immer zu lieben wăhnte", sie enttäuscht und ihren Erwartungen nicht entsprochen hat. Sie stellt dem früheren, idealisierten und als "Russe“ aufgetretenen Verführer, den jetzigen "Polen" gegenüber, der sich in einen „ganz Anderen“ verwandelt hat ( „/...) он тогда был таkой со мной ласkовый, таkой развеселый, мне песни пел... Или уж показался таким дуре мне, девчонке...") ${ }^{.663}[, / \ldots /$ er war damals mit mir so freundlich, so heiter, er sang mir Lieder... Oder schien er mir damals nur so, ich war ja eine Dumme, ein kleines Mădchen... “; S. 754]

Die „naiven" Erwartungen Grušen kas und ihre immer noch zur "Verzeihung" bereite Liebe wird durch die überhebliche Haltung des Polen zerstört, ihre „Seele“ wird wie mit "Spülwasser übergossen“, ernüchtert. Der Pole benimmt sich ihr gegenüber wie ein ,L ehrer", so daß es ihr unmöglich ist, als eine gleich-

662 ,.Но особенно не понравцтась е.гу одна «новая» песенка с бойим п.лясовым напевом /.../. « - Это совсем вчерашняя песня, - заметіл он вс.тух, - " kто это им сочиняет! Недостает, чтобы же.лезнодорожник аль жид проехаіи и девушек пытали: эті всех бы nобедиц.7иц", ebd. |.,Das ist durchaus ein Lied von gestern', bemerkte er laut. 'Und wer verfaßt ihnen nur dies? Es fehlt nur noch, daß der Eisenbahner oder ein Jude vorbeifahrt und die Mädchen auf die Probe stellt: die hătten gewiß alle besiegt!‘: S. 750].

${ }_{662} \mathrm{Vgl}$. Bd. 14. S. 394fr. Grušen'ka betont dabei den Einfluß Alešas, dem sie eine gute Tat erwiesen und geholfen hat, seine Glaubenskrise nach dem Tode Zosimas zu überwinden (ebd., S. 397). Die ..bußfertige Verwandlung“ Dmıtrijs wird dagegen durch den symbolıschen Traum über das ,.Kindchen“ angedeutet, nach dem er bereit ist, das ..Leid auf sich zu nehmen“ und seine Schuld zu bekennen, obwohl er doch seinen Vater nicht ermordet hat, was auf die Rückkehr Dmitrijs zum russischen Glauben hindeutet, in den Überlegungen Dmitrijs in Mokroe gibt es außerdem eine Anspielung auf den inneren Kampf Jesu in Gethsemane vor seiner Gefangennahme und Hinrichtung: ..Meine Seele ist sehr betrübt, bis zum Tod. /...i Mein Vater, wenn es möglich ist, so gehe dieser Kelch an mir vorüber, doch nicht wie ich will. sondern wie du willst, geschehe“. wodurch Dmitrijs kenotische Opferbereitschaft angedeutet wird: ..Боже, оживи поверженното у забора! Пронеси эту страшную чашу мимо меня!" I..Meın Gott, gib dem, den ich am Gartenzaun niederschlug. das Leben zurück! i aB diesen furchtbaren Kelch an mir vorübergehen"; S. 7531. Siehe dazu z. B. Mt 26, 38-40, Lk 22, 44. Vgl. Bd. 14, S 394 und S. 456ff. Auch im Roman /dict gibt es eine ăhnliche Beschreibung des mneren Kampfes Myškins, vgl. Bd. 8, S. 256 (die Szene im Park in Pavlousk). 663 Bd 14, S. 395. 
berechtigte Partnerin mit ihm zu sprechen, ,ihr Wort hinzuzufügen“, weil er sie "belehren" will. Sie kann sein "Gesicht" nicht mehr erkennen: „A теперь, господи, да это не тот, совсем не он, не он вовсе. Я и с лица его не узнала. /.../ Вся душа замирала, и вот он меня тут точно из шайки помоями окатил. Точно учитель говорит: всё таkое ученое, важное, встретил таk важно /.../. Слова некуда ввернуть". ${ }^{664}$ [Jetzt aber, mein Goth, ja, das ist gar nicht jener /.../. /.../ Ich habe ihn auch gar nicht nach dem Gesicht erkannt. /.../ Meine ganze Seele erstarb mir, und da hat er mich gleich wie aus dem Kübel mit Spülicht übergossen, so ganz wie ein Lehrer spricht er: alles so gelehrt, gewichtig, er empfing mich so ernsthatt /.../. Ich konnte kein Wort hervorbringen [eigentl: Kein Wort läßt sich da einflechten]; S. 754f.]

In dieser Äußerung Grušen kas wird auf die verăchtliche Haltung des ,zivilisierten Polen“ den „Russen“ gegenüber angespielt. Sie ist als eine symbolischbildhafte, exemplarische Erweiterung des in den Entwürfen von den Polen und von Rakitin ausgesprochenen Satzes zu verstehen, obwohl die „polnische aus dem Westen übernommene Zivilisation“ lediglich das "Spülwasser der westlichen Zivilisation" ist. Dmitrij nennt darüber hinaus zuerst den für gefährlich gehaltenen polnischen Rivalen "фатальный человеk" [der fatale Mensch], der sich jedoch schließlich als komisch und gar nicht emst zu nehmen erweist. Die Worte "fatal" (verhängnisvoll, schicksalhaft) und „Lehrer", mit denen der Pole charakterisiert wird, erinnern an ähnliche Ausdrücke aus dem Aufsatz Nikolaj Strachovs Rokovoj vopros [Die fatale, schicksalhafte Frage], in dem er nach dem Ausbruch des Polnischen Aufstandes von 1863 gegen RuBland die polnische Kultur beschrieben hat. ${ }^{665}$ In Brat ja Karamazovy wird aber diese von Strachov in der V'remja erörterte, für RuBland „fatale Frage“ als "unbedeutend" herabgesetzt und gar nicht als ...gefährlich" betrachtet. ${ }^{666}$

Der negativ eingeschätzte Pole übernimmt dabei die „Katalysator"-Funktion, denn sein Auftritt hilft sowohl Grušen'ka als auch Dmitrij, sich zu verwandeln, sich seelisch zu reinigen und von der Last der Vergangenheit zu befreien, indem er von den beiden in seiner Nichtigkeit erkannt wird. Der "fatale" und stereotyp

664 Ebd.

$665 \mathrm{Vgl}$. zum Aufsatz Strachovs, oben, S. 220. Die Schilderung der beiden stereotypen poinischen Figuren erinnert ebenfalls an die Polenfiguren aus dem ..historischen Poem " Pokınuty zumok [loas verlassene Sichloß) (1878) von LIODOR (ILIODOR) PAL'MIN (1841-1891). Vgl. PAL MIN 1878, S. 188-204. Pal'min hat als Mickiewicz-Übersetzer in diesem Gedicht das "sarmatische Alte Polen" Augusts II. und des letzten polnischen Konigs Stanisław August Poniatowski in Anlehnung an Pan Tadeus: thematisier, wobei er jedoch dieses bereits vergangene Polen nicht verherrlicht, sondern als dekadent und nicht mehr lebensfahig zeigt. Das Gedicht PAL' MINS Skvoz' nagar c'veča ugrjumo hlešcet ... [I)urch das aufgetuule Wachs. (etgentl.: Verhrennungsrückstände) leuchtet düster die Kerze (die Flamme der Kerze)... | ist in der Zeitschrift Vremja (4, April 1863, S. 296) erschienen, so daB angenommen werden kann, daB Dostoevskij diesen Dichter kannte. Vgl. zu Vremja: NeCAEva 1972 sowie DIES. 1975. S. 254 (die Inhaltsangabe der Zeitschrift Vremja). Siehe zum Thema PAL'MIN und Polen bei ORLOWSKI 1992, S. $164 f$.

666 Bd. 14, S. 394: „Страшное привидение обратитось вдруг во что-то такое ма.าенькое. rakoe koмичесkое; его снес.ти руками в спатьню и запер.mи на kточ" |..Dieses furchtbare Gespenst hatte sich plotzlich in etwas so Kleines, so Komisches verwandelt: man hatte ihn auf Händen ins Schlafzimmer getragen und eingeschlossen“; S. 752f. I. 
dargestellte Pole trăgt somit dazu bei, daß Grušn ka und Dmitrij erst dann zueinander finden, nachdem sie den Polen als den „betrügerischen Vertreter polnischer adliger" Mentalităt und somit ,polnischer Kultur" entlarvt haben, der RuBland und die Russen verachtet und zudem als dessen politischer Feind auftritt. So steht es auch um die Beschreibung des Äußeren des polnischen Verführers Grušen'kas, dessen „dekadent-künstliche“ Aufmachung den Urteilen Strachovs über Polen entspricht, daß die polnische Kultur "dekadent" und „eklektisch" und "nicht lebensfahig" ist, sondern lediglich immer den „Westen" nachgeahmt hat. Eine wichtige Rolle spielt dabei die besondere Redeweise der beiden Herren, die wegen der vielen von ihnen benutzten polnischen Worte und Ausdrücke stark verfremdet und verfremdend wirkt und die Verständigung dieser Figuren mit den russischen Gesprăchspartnern verhindert, obwohl, wie der Erzăhler bemerkt, diese beiden Polen gut russisch sprechen können. ${ }^{667}$ Die polnischen Sătze, die sie aussprechen, sind darüber hinaus von stereotypem Charakter, mit Wörtem und Idiomen gespickt, die auf die adlige polnische Mentalitat dieser Herren hinweisen. ${ }^{668}$

Die beiden Polen werden noch dreimal im Zusammenhang mit der Dmitrijund Grusen 'ka-Handlung erwăhnt:

Sie werden zuerst als Zeugen nach der Verhaftung Dmitrijs in Mokroe eingeführt, danach schreiben sie Briefe an Grusen'ka, in denen sie diese um Geld bitten, um schließlich von dem Rechtsanwalt Fetjukovic bei Dmitrijs Gerichtsverhandlung verhort zu werden.

Bei dem Verhör in Mokroe werden zum ersten Mal der Name des „Verführers" Grušen'kas und sein Beruf sowie der Beruf des ihn begleitenden "Leibwăchters", Herm Vrublevskij, genannt:

Допросили и поляков. /.../ Явились они с достоинством, хотя и не без некоторого страху. Главный, то есть маленький пан, оказался чиновником двенадцатото kласса в отставkе, служил в Сибири ветеринаром, по фамилии же был пан Муссялович. Пан же Врублевский оказался вольнопрактикующим дантистом, nо-руссkи зубным врачом.

[Man verhorte auch die Polen. /.../ Sie erschienen mit Würde, wenn auch nicht ganz ohne Furcht. Die Hauptperson, das heißt der kleine 'Pan', erwies sich als ein Beamter der zwolltien Klasse außer Dienst: er hatte in Sibirien als Tierarzt gedient und trug den Namen Musjalowitsch. Der Herr Wrublewski aber stellte sich vor als 'freipraktizierender Dentist', auf russisch Zahnarzt. ${ }^{669}$

667 Siehe dazu auch KALINOWSKA 1994, S. 62ff.

${ }^{660}$ Siehe außerdem unten zu den polnischen Worten und Sätzen in den Entwürfen zu Brat ja Karamazovy; zu denen auch auch ein ironisiertes Zitat aus Mickiewiczs I)zıacty gehort (vgl. Bd. 15, S. 279). Vgl. dazu Z.AKIEWICZ 1968, S. 86f; I.EDNICKI 1953, S. 311 und KALINOWSKA 1994, S. 63ff.

${ }^{669}$ Bd. 14, S. 451 [S. 860]. ŻAKIEWICZ, S. 88 bemerkt, daß der Beruf des Herm Vrublevskij als eine Erinnerung Dostoevskijs an die Zeit in Sibirien betrachtet werden könne, weil es un- 
Die Würde der Polen wird durch ihre Angst herabgesetzt. Der ,,dicke Verführer", „der winzige Herr Mussjalovic“, ein ehemaliger Beamter niedrigsten Ranges, der als ein "Tierarzt" in Sibirien tătig war, zeigt sich endgültig als eine bedeutungslose Figur. Der „große“ Pole wird als komplementär zu ihm gezeigt, indem er sich als "Zahnarzt" heraustellt, wobei diese Berufsbezeichnung auf polnisch [poln. dentysta; "Dentist“, Zahnarzt] wiedergegeben wird, aber vom Erzähler als daнmucm, d.h. in ihrer der französischen Aussprache entsprechenenden ,phonetischen" Form, als ein französisches, "westliches" Lehnwort im Polnischen ["dantist"; franz. dentiste], aufgeschrieben wird, wodurch er ironisch die "westliche" Verbundenheit des Polen hervorhebt.

Trotz dieser unbedeutenden sozialen Position und trotz seiner Unsicherheit, wird erneut das arrogante Auftreten des kleinen polnischen Herren betont, welches mit dem von ihm soeben verursachten Skandal und mit der beschämenden, entwürdigenden Demaskierung des Betrugs beim Kartespiel zusammenhängt. ${ }^{6}$

Es stellt sich bei dem Verhör zusătzlich heraus, daß die beiden Polen, „по русски /.../ умели даже весьма и весьма правильно говорить, кроме разве выговора иных слов“ [Es erwies sich, daß sie das Russische sogar sehr gut zu sprechen verstanden, abgesehen höchstens von der Aussprache einiger Wörter], so daß ihr gebrochenes bzw. „russifiziertes Polnisch“ eine absichtliche Verstellung war. ${ }^{671}$

Die Aussagen der Polen belasten Dmitrij schwer, weil sie dem Untersuchungsrichter von dessen Bestechungsversuch erzăhlen, zumal dieser das betrügerische Benehmen der Polen beim Kartenspiel außer acht laßt. ${ }^{672}$

Auch die Briefe, in denen die Polen anschließend Grušen ka um Geld bitten, zeugen zum einen von ihrer entsetzlichen Armut und aussichtslosen Lage, zum anderen aber von ihrem .,nationalen Stolz", den sie sogar in einer solchen entuürdigenden Lage behalten haben und der ihren adligen Begriff der ritterlichen Ehre (..honor") karikiert, obwohl sie wie Bettler Grušen'ka schließlich um Almosen bitten:

Первое письмо, полученное Грушенькой, было длинное, на почтовом листе большого формата, запечатанное большою фамильною печатью и страшно темное и витиеватое, тak что Грушенька прочла только половину и бросила, ровно ничего не поняв. /.../ За этим первым письмом последовало на другой день второе, в котором пан Муссялович просил ссудить его двумя тысячами рублей на самый kоротkий сроk. Груненька это письмо оставила без ответа. 3атем последовал уже целый ряд писем. по письму в день, всё таk же важных и витиеватых, но в которых сумма, просимая взаймы, постепенно спускаясь, дошла до ста рублей, до двадиати пяти, до десяти рублей, и наконец вдруг Грушенька получила письмо, в котором оба

te: den Polen, die nach Sibirien verbannt wurden, viele Ärzte gegeben habe, wie z.B. Doktor Lamotte in Semipalatinsk, der Dostoevskij bekannt war.

671 Vgl. Bd. 14, S. 452.

67: Ebd. [S. 861].

672 Ebd., S. 453. 
пана просили у ней один только рубль и проложили расписky, на kоторой оба и подписались. Тогда Грушеньке стало вдруг жаль, и она, в сумерки, сбегала сама k пану. Нашла она обоих поляков в страшной бедности, почти в нищете, без кушанья, без дров, без папирос, задолжавших хозяйkе. Двести рублей, выигранные в Моkром у Мити, куда-то быстро исчезли. Удивило, однако же, Грушеньку, что встретили ее оба пана с заносчивою важностью и независимостью, с величайшим этикетом, с раздутыми речами. Грушенька только рассмеялась и дала своему «прежнему» десять рублей. /.../ Но с тех пор паны ухватились за Грушеньку и каждый день ее бомбардовали письмами с просьбой о деньгах, а та каждый день посылала понемножky.

[Der erste Brief, den Gruschenka emplangen hatte, war lang, auf einem Briefbogen von großem Format geschrieben, mit einem großen Familienwappen gesiegelt und furchtbar dunkel und schwülstig /... . Diesem ersten Brief war am andern Tag ein anderer gefolgt. worin Pan Musjalowitsch bat, ihm zweitausend Rubel zu leihen, auf dic allerkürzeste Frist. Auch diesen Brief ließ Gruschenka unbeantwortet. Darauf folgten schon eine ganze Reihe Briefe, jeden Tag einer, alle ebenso gewichtig und schwülstig, nur $\mathrm{daB}$ die erbetene Summe allmählich abnahm /../, und endlich /.../ [baten] beide polnische Herren nur um einen Rubel /... Da begann denn Gruschenka plötzlich Mitleid zu empfinden /.../. /../ Sie fand beide Polen in furchtbarer Armut. fast als Bettler /../. /... Es erstaunte indes Gruschenka. daß die beiden polnischen Herren sie mit hochnäsiger Gewichtigkeit und Unabhängigkeit empfingen, nach der strengsten Etikette und mit aufgeblasenen Redensarten. (iruschenka brach nur in Lachen aus und gab ihrem 'Früheren' zehn Rubel. /.../ von da an hatter. sich aber die polnisclien llerren an Gruschenka angeklammert und bombardierten sie täglich mit Bricfen und der Bitte um (jeld, und jene sandte innen jedesmal ein wenig. ${ }^{673}$

Die Komik dieser Passage besteht im Kontrast zwischen einer ganzen „Reihe“ von großformatigen Briefen der Polen, die mit einem ,Familiensiegel“ verschlossen und "dunkel, wichtigtuerisch und schwülstig" sind. in denen sie aber Cirušen ka bitten. ihnen immer kleinere (jeldsummen, bis hin zu „einem Rubel“, zu borgen. Das ,große Familiensiegel“ zeugt von adliger llerkunft des „Verführers", der „dunkle. schwülstige" Stil dagegen von seiner ,jesuitisch-barocken Rhetorik“, so daß hier der Bezug dieser Figur zum „dicken Polen“ \%agoskins aus der Zeit der polnischen Rußland-Invasion am Anfang des siebzehnten Jahrunderts sichtbar wird.

Trotz. ihrer Armut verhalten sich aber die Polen gegenüber der ,barmherıigen Russin" aufgeblasen und überheblich. beachten peinlichst die .Etikette“. d.h. die konventionellen Umgangsformen des polnischen Adels, und halten ihr belehrende Reden. Fs liegt nahe, diese stereotypen Figuren symbolisch als Vertreter des von Rußland besiegten (alt)adligen, sarmatischen Polens zu verstehen, das

${ }^{673}$ Bd. 15. S. 8f. [S 967f.] 
sich aber dennoch stolz und uberheblich zeigt, obwohl es, arm wie ein Bettler, Rußland um Almosen bitten muß.

Das von Mitleid bestimmte Verhalten Grusen'kas den beiden Polen gegenüber, die ihnen mit kleinen Geldgaben und pirozki [pirozok; kleine gefullte $\mathrm{Pa}$ steten, Piroggen] hilft, bildet hier den Kontrast zu diesen sie „verachtenden“ Menschen und zeigt Grusen 'ka als "russische Christin“, umso mehr, als sie nicht nur die beiden Polen, sondern auch den armen Maksimov unterstützt. Durch die finanzielle Hilfe für die Polen und die Besuche Grusen kas bei dem „Ehemaligen", der sich nach ihrem gesundheitlichen Zustand während ihrer schweren Krankheit erkundigt und sie dadurch gerührt hat, wird aber nicht nur die Barmherzigkeit Grušen'kas, die sein Opfer gewesen ist, hervogehoben, sondern auch ihre eifersüchtige Liebe zu Dmitrij, den sie dadurch provozieren will, weil sie noch an dessen Liebe zu Katerina Ivanovna glaubt. Der erkrankte Pole versucht dagegen GruSen ka wiederholt zu „verführen“, indem er sich vor ihr als der frühere fröhliche und russische Lieder singende Offizier "maskiert". Er hofft also noch immer, sie erneut erobern zu können. ${ }^{674}$

Der „aufgeblasene patriotisch-nationalistische Stolz" der Polen wird nochmals und endgültig in der Szene des Verhörs durch den Verteidiger Dmitrijs, Fetjukovič, verlacht. Fetjukovic entlarvt sie als Falschspieler, so daß ihr Hochmut und ihre arrogant zur Schau gestellte nationale Zugehörigkeit als moralisch fragwürdig erscheinen, ungeachtet dessen, daß der Rechtsanwalt alle gefahrlichen Zeugen moralisch zu kompromittieren versucht, um dadurch ihre Aussagen als unseriös darzustellen, was der Erzähler als ein für ihn charakteristisches Verfahren bezeichnet:

То же приключилось и с поляками: те явились гордо и независимо. Громко засвидетельствовали, что, во-первых, оба «служили короне» и что «пан Митя» предлагал им три тысячи, чтобы купить их честь, и что они сами видели болышие деньги в pykax его. Пан Муссянович вставцил страшно много польских слов в свои фразы, и видя, что это mолько возвышает его в глазах преdсеdателя и прокурора, возвысил наконеи свой дух окончательно и стал уже совсен говорить no-nольсkи. Но Фетюкович поймал и их в свои тенета: kak ни вилял позванный опять Трифон Борисович, а все-таkи до.лжен был сознаться, что его колода карт была подменена паном Врублевским своею, а что пан Муссялович, меча банк, передернул карты. Это уже и подтвердил Калтанов, давая в свою очергдь показание, и оба пана удалишсь с некоторым срамом, дажсе при смехе публики.

Затем точно таk произошло почти со всеми наиболее опаснейшими свидетелями. Каждого-то из них сумел Фетюкович нравственно размарать и отпустить с некоторым носом. [kursiv die Verf.]

[Das gleiche widerfuhr den Polen. Die traten stolz und unabhängig auf. Laut bezeugten sie, daß sie erstens 'beide der Krone dienten', daß 'Pan Mitja' ihnen dreitausend angeboten habe, um ihre Ehre zu erkaufen, und

${ }^{674}$ Ebd., S. 9. 
daß sie selber große Summen in seinen Hănden gesehen hătten. Pan Musjalowitsch fügte furchtbar viel polnische Worte seinen Phrasen ein, und da er sah. daß dies ihn nur in den Augen des Präsidenten und des Staatsamwalts erhöhe, faßte er endlich endgültig Mut und begann schon völlig polnisch zu sprechen. Aber Fetjukowitsch fing auch sie in seine Netze. Welche Ausflüchte auch der wiederum aufgerufene Trifon Borisowitsch machte, er mußte gleichwohl bekennen, daß sein Spiel Karten von Pan Wrublewski durch das seinige ersetzt worden war, und daß Pan Musjalowitsch, als er die Bank hielt, eine falsche Karte aufgeschlagen hatte. Dies bezeugte auch Kalganow, als er seinerseits verhörn wurde, und beide Pane entfernten sich mit ein wenig Schmach bedeckt und sogar unter dem Gelächter des Publikums. Darauf ging es fast genauso mit allen gefăhrlichsten Zeugen. Jeden von ihnen verstand Fetjukowitsch moralisch zu beschmutzen, so daß sie mit langer Nase abziehen mußten. [kursiv die Verf.] $]^{675}$

Diese Szene läßt sich in drei Abschnitte aufteilen. Zuerst treten die Polen "stolz und unabhängig“ auf. Die Wendung «служили kороне», „dienten der Krone", kann als eine Anspielung darauf verstanden werden, daß sie mit "Krone“ den (alt)polnischen, souveränen Staat [R=eczpospolita; die adlige polnische Republik] vor den Teilungen meinen. Sie haben somit eigentlich nicht „Rußland" gedient, sondern sich „subversiv“ gegen die russischen nationalen Interessen gerichtet. Dabei betonen sie zusätzlich, daß der "Russe“ Dmitrij ihre „Ehre“ „kaufen“ wollte. Um diese „Ehre“ völlig wiederherstellen zu können, fangt aber der „dicke Pole" langsam an, immer mehr polnische Worte in seine Satze einzuflechten, um anschließend nur polnisch zu sprechen, d.h. er wird dem russischen Publikum völlig unverständlich. Einen komischen Effekt bildet aber die unerwartete Reaktion des Gerichstvorsitzenden und des Staatsanwalts. Diese beiden "verwestlichten" Russen schätzen Mussjalovič gerade wegen seiner polnischen Worte und Säze, welche ihn gerade in ihren Augen „erhöhen“. Ungeachtet des „patriotischen Geistes“ des Polen, werden aber die beiden polnischen Figuren bald als Falschspieler entlarvt und verlacht, so daß die „stolze Erhöhung“ ihres „.Geistes“ mit einer Emiedrigung endet. Diese Erniedrigung bereitet aber den Polen ausgerechnet der „verwestlichte“ Rechtsanwalt Fetjukovič. dessen Vorbild bekanntlich der polnischstämmige Jurist Spasowicz ist, so daß sie dadurch besonders paradox erscheint.

Auch in dieser Szene wird der stereotype ('harakter der beiden Polen sichthar Sie benehmen sich wie die polnischen stereotypen Figuren im Roman Zagoskins. dessen Handlung im Jahre 1612, kurz vor dem Ende der für Rußland so fatalen Zeit der Wirren spielt, ${ }^{676}$ wodurch jene Fremdheit und rußlandfeindliche Haltung der beiden Herren zum wiederholten Mal hervorgehoben werden, welche sie bereits zuvor in den Mokroe-Kapiteln ausgezeichnet haben. Sowohl pan Vrublevskij als auch pan Mussjalovic sind als die "Dostoevskijsche" Variante des literarischen Stereotyps des polnischen Adligen des siebzehnten Jahr-

675 Ebd., S. 102 [S. $1144 f$ ].

676 Siehe oben S. 252. 
hunderts, des Vertreters des "altpolnischen, sarmatischen Adels“ auzufassen, das durch ihn um eine neuere Komponente, das Stereotyp des "Polen als Falschspieler", ergänzt worden ist. ${ }^{677}$

In der Dostoevskij-Forschung, die sich mit der polnischen Problematik in seinen literarischen Werken auseinandergesetzt hat, ${ }^{6 / 8}$ wird üblicherweise die Vermutung geäußert, daß die Figuren der beiden polnischen Herren den polnischen Mitgefangenen Dostoevskijs in der Omsker Katorga nachgebildet seien. So gab es beispielsweise unter diesen Mitgefangenen einen Polen JaN MUSIALOWICZ, von dem jedoch lediglich der Name bekannt ist. ${ }^{679}$ In den enthaltenen Entwürfen zu Brat'ja Karamazovy wird dagegen der Verführer Grušen'kas BEM genannt, und es ist zugleich bekannt. daß zu den Mitgefangenen Dostoevskijs ein gewisser Pole KAROL BEM gehörte. Er wird in den Zapiski iz Mertvogo doma als vor ohne jegliche Bildung bzw. ohne jegliche politische Interessen, der nur an Geld denkt, charakterisiert, wobei sein Name nur mit dem ersten Buchstaben angegeben wird, d.h. in der Weise wie die authentischen Namen anderer polnischer Mitgefangener Dostoevskijs abgekürzt werden. ${ }^{680}$ Polnische Dostoevskij-Forscher vermuten außerdem, daß der "kleine dicke Pole" sein Vorbild einem anderen polnischen Mitgefangenen Dostoevskijs, dem politischen Häftling JózEF BOGUSLAWSKI, zu verdanken habe, obwohl doch der gebildete und kranke polnische Adlige BogUSLAWSKI nur wegen dessen Freundschaft mit dem jungen, hochgewachsenen und mutigen SZYMON TOKARZEWSKı als Vorbild für den Verführer Grušen kas in Frage kommen könnte.

„Pan Mussjalovič läßt sich somit als synthetische Figur bezeichnen, die sich zugleich aus den Eigenschaften der russischen literarischen Stereotypen des

${ }^{677}$ Siehe dazu oben, S. 386, auch zum Bezug zu Vel tmans Roman Salomeja. Vgl. auch oben, S. 394 zu der Anekdote über pan Podvysockij, die Dostoevskij von dem polnischen Kartenspieler erzählt wurde, so daß man annehmen kann, daß er sich gut in diesem Milieu ausgekannt haben mag. Siehe auch LAkIEWICZ 1968, S. 87f.

$678 \mathrm{Vgl}$. oben zu Zupiskı I Merlvogo doma, S. 194ff.

$679 \mathrm{Vgl}$. dazu auch MuCHA 1979 (S. 68ff.); Bd. 4, S. 217 und ebd, den Kommentar der Herausgeber zu Zupiski i= Merivogo doma, S.280, sowie BUDANOVA i FRIDLENDER 19931995 (Bd. I, S. I 84ff: die Autoren weisen darauf hin, daß JAN MLSIALOWIC $Z$ das Vorbild für Herrn Mus:yulovic in Brat ja Karumazovy' ist (S. 184)).

${ }^{680} \mathrm{Vgl}$. dazu oben, S. 194f. und Bd. 4, S. 217. Vgl. auch die Entwürfe, Bd. 15, S. 287, S. 296 und S. 305 sowie S. 344 (hier wird der Verführer Grušen kas zuerst Bem, dann MHus.s/ulevic

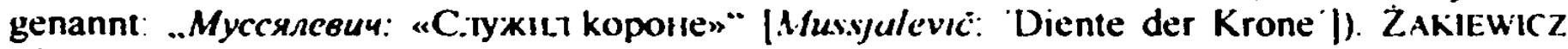
1968 behauptet jedoch, daß der Name Bem sich auf den polnischen General Jozef Bem beziehe: .W wypadku Bema w intencji Dostojewskiego lezala chęć dyskredytacji nazıviska polskiego generala Józefa Bema. W okresie przebywania Dostojewskiego na Syberii nazwisko Bema bylo glośne $w$ całej Rosji, a tym bardziej znane i bliskie polskim uczestnikom Powstania Wegierskiego - podkomendnym Bema i znajomym Dostojewskiego z Semipalatynska" (S. 87) [Im Fall Bems war dic Absicht Dostoevskijs, den Namen dieses pulnischen Generals zu diskreditieren. In der Zeit des Aufenthalts Dostoevskijs in Sibirien war der Name Bems in ganz Rußland bekannt: umso mehr war er also den polnischen Teilnehmem des Ungarischen Aufstandes, den Unterbefehlshabern Bems und Bekannten Dostoevskijs aus Semipalatinsk. bekannt und nah.- l. Wie oben bereits bemerkt, gab es in Omsk tatsächlich einen Polen namens Bem, so daß der Bezug zu dem General Bem nicht zwingend sein muß. 
..Polen“ als „des bösen Verführers“, als eines „(schäbigen) Falschspielers“ sowie der beiden polnischen Figuren in Zapiski iz Mertvogo doma, der beiden B.s, des kranken Adligen und des geldgierigen spießbürgerlichen Malers, zusammensetzt.

Der riesige "Leibwăchter“ des kleinen Polen Vrublevskij, der sich neben seinem hohen Wuchs noch durch seine überhebliche, hochnäsige Haltung den Russen gegenüber auszeichnet, sei dagegen viel wahrscheinlicher dem politischen Gefagenen adliger Herkunft, SZYMON TOKARZEWSKI, nachgebildet worden (T-vskij in Zapiski iz Mernogo doma). ${ }^{681}$ Nach ZBIGNIEW ZAKIEWICZ und WACLAW LEDNICKI ist die in den polnischen Mokroe-Kapiteln enthaltene Anspielung auf die erste polnische Teilung von 1772 als Rache Dostoevskijs für die Beleidigungen aus der Katorgazeit und als Abreagieren seines Schuldkomplexes gegenüber Polen bzw. als seine nationalistisch-konformistische Haltung in der Lösung der polnischen Frage aufzufassen, wenn man darüber hinaus auch seine Publizistik heranzieht. ${ }^{682}$ Nach JAN ORLOWSKI ist aber in dieser Mokroe-Episode die antipolnische Stimmung, die in den früheren literarischen Werken Dostoevskijs vorhertschend ist. gemildert worden, obwohl beide polnischen $\mathrm{Fi}$ guren, als negative Stereotypen geschildert werden und somit gerade die Steigerung der ideologischen Kritik Polens beweisen. ${ }^{683}$

Abgesehen von den authentischen Vorbildern der polnischen Figuren in den Zapiski iz Mertvogo doma sowie ungeachtet ihrer möglichen Bezüge zu den beiden Polen in Brat 'ja Karamazovy, die bereits ausführlich im Zusammenhang mit den sibirischen Aufzeichnungen besprochen wurden, läßt sich im Zusammenhang mit den Figuren der beiden Polen in Brat ja Karamacovy feststellen, daß sie im Vergleich mit den Polen in Zapiski iz Mertvogo doma lediglich auf deren negative Figenschaften reduziert worden sind. Darüber hinaus wurden sic noch um weitere negative Züge ergänzt und somit karikien, wobei die nationale und soziale Zugehörigkeit dieser Figuren (als polnische patriotische rußlandfemdiiche Adlige) besonders hervorgehoben wird. Wie bereits gezeigt wurde. sind die Figuren der Polen in Brat ja Karamazoni aber nicht nur als psychologisch reduzierte und karikierte Porträts der polnischen politischen Mitgefangen Dostoevskijs aus Omsk aufzufassen, sondern auch als aus der russischen Literatur entlehnte negative nationale Stereotypen der (altadligen) Polen, wodurch ihre Komik und ihre Funktion als alter, als Kontrast zu den russischen Figuren. auch als ihre ,ideologischen“ Feinde verstärkt wird. Zu ähnlichen Schlußfolgerungen ist auch IZ.ABEL.A F. KAI.INOWSKA in ihrem oben bereits erwähnten Aufsatz. über die Schilderungen der Polen in den Brat'ja Karamazovy gekom-

681 Siehe u.a. genauer zU SZYMON TOKARJFWSKI, JOZFF BOKiUSLAWSKI und 7.u den anderen Mitgefangen Dostoevshijs in der Katorga oben. S. 194ff Vgl. auch MuchA 1979, S. 68ff., PODGORJEC 1984, S. 85f.. den Kommentar der russischen Herausgeber in Bd. 4, S. 280 und S. 288: ZAKIEWICZ. 1968, S. 85f.

602 ZAKIEWICZ 1968, S. 85ff. und L.FIDNICKI 1953, S. 284ff

603 Gemeint sind dabei wohl die ĀuBerungen Dmitrijs und Kalganovs, die jedoch ihrem Kontext nach die Figuren dieser Russen eher noch ..christlicher" erscheinen lassen. Vgl. auch ORI.OWSKI 1982, S. 94 
men, ${ }^{684}$ die die Ansichten von STEMPOWSKI und LEDNICKI ${ }^{685}$ über die polnischen Figuren aufs neue hat überprüfen wollen, obwohl sie nicht genauer auf die den stereotypen Ursprung dieser Figuren eingegangen ist. Das Hauptthema der „polnischen Szenen“ ist nach KALINOWSKA die Überlegenheit der Russen gegenüber den Polen, indem diese als Stereotypen entmenschlicht und vom Erzăhler ihrer inneren Stimmen beraubt werden. Die russischen Figuren können sich dagegen dank diesen polnischen Fremden innerlich vom sogenanten opolaczenie ["Polonisierung"] befreien, wobei diese Bezeichnung N.N. Strachovs, die KALINOWSKA hier anwendet, den Mechanismus der „Katharsis“ der Russen genau wiedergeben könne, weil auch die russischen Figuren, die mit den Polen in Mokroe konfrontiert werden, zuerst als moralisch fragwürdig beschrieben würden. ${ }^{686}$

Zusammenfassend kann im Zusammenhang mit den polnischen Mokroe-Kapiteln festgehalten werden, daß die beiden polnischen Figuren darin in der Funktion als alter, als „ideologischer Feind“ auftreten. Die beiden Polen dienen als Kontrast zu den Figuren Grušen kas und Dmitrijs, stărken deren nationale und religiös-kulturelle Identităt, indem sie wie ein "Katalysator" die "innere Wandlung" und "Läuterung" dieser russischen Figuren herbeiführen. Der Pole Mussjalovic tritt darüber hinaus in der Rolle des „Verführers“ Grušen'kas auf, die als eine „schöne Russin“ beschrieben wird, und somit schließt er die Reihe der Verführer der "schönen und unschuldigen Russinnen“ in den Romanen Dostoevskijs ab, die entweder aus dem „Westen“ kommen und keine Russen oder aber verwestlichte adlige Russen sind. Zu den fremden Verführern gehören neben Herm Mussjalovix der Franzose und falsche Aristokrat De Grie, der namenlose falsche polnische Graf, den Aglaja geheiratet hat, oder der deutsche Baron B'oring. den Achmakova heiraten will; zu den verwestlichten adligen russischen Verführem Aleša Valkovskij, Svidrigajlov, Tockij und Stavrogin. Die Funktion des "westlichen" bzw. „verwestlichten russischen Verführers", der eine „(schöne) Russin“ „beleidigt“ und sie ihrer russischen religiösen bzw. kulturellen Identităt (vorübergehend) beraubt, eine Funktion, die auch der Pole in der Handlung der Brat'ja Karamazovy erfüllt, erklärt. warum der Verführer

\footnotetext{
$684 \mathrm{Vgl}$. KaLINOWSKA 1994.

665 Siehe dazu oben. $S$. $111 \mathrm{ff}$.

686 KALINOWSKA 1994 (S. 66f.) bezieht sich ebenfalls auf den oben envähnten Aufsatz. Strachovs Rokovoy vopros und auf dessen Beurteilung der russischen und polnischen Kulturen in V'remja: ..Sposób przedstawienia Polaków w Braciach Karamazow jest odpowiedzia Dostojewskiego na obraz̨, o której mówi Strachow. Polacy w jego powiesci upadaja na dno ponizenia moralnego po to, by Rosja mogła zwyciężyć. Pisarz udowadnia w ten sposób sobie i swoim rodakom, że prawdziwie rosyjska kultura może się zmierzyć ze z.latynizowana. zapatrzona na Zachód Polska - i odniesć moralne zwycięstwo“. [Die An der Darstellung der Polen in den Brüdem Karamazov ist die Antwort Dostoevskijs auf die Beleidigung. über die Strachov spricht. Die Polen in seinem Roman fallen in den Abgrund der moralischen Emiedrigung, damit Rußland siegen kann. Der Schriftsteller beweist auf diese Weise sich selbst und seinen Landsleuten, daß die wahthatige russische Kultur dem latinisierten, in den Westen vernarten Polen die Stim bieten kann - und den moralischen Sieg davon trägt. I
} 
Grusen kas kein "Russe“ sein konnte. ${ }^{687}$ Wie in den oben besprochenen Romanen Dostoevskijs sind die Figuren der beiden Polen stereotyp gestaltet, sie sind zum einen psychologisch reduzierte, entmenschlichte, karikierte Figuren der authentischen politischen polnischen Mitgefangenen Dostoevskijs aus Omsk, die in den Zapiski iz Mertvogo doma noch als Individuen psychologisch differenzien dargestellt worden sind, ${ }^{\mathbf{6 8 9}}$ zum anderen sind sie aus den Elementen des negativen nationalen bzw. ethnischen Stereotyps des polnischen Adligen zusammengesetzt. das in mehreren Werken russischer Literatur des neunzehnten Jahrhunderts vorkommt, bei ZAGOSKIN oder VEL'TMAN bZw. in den publizistischen Aufsătzen STRACHOvs zur ,polnischen Frage“. Das Stereotyp des polnischen Adligen, auch als „Verführer" und als „Falschspieler“, tritt komplementär in der Kontrast- und Ergänzungsfunktion zu dem ebenfalls negativen Stereotyp des polnischen politischen "Verschwörers" auf, der vorwiegend in den antinihilistischen literarischen Werken KLJUŚNIKOVS, KRESTOVSKIJS bzW. PISEMSKIJS vorkommt. Dieses polnische Stereotyp ist auch ein Kontrast zu Raskol 'nikov in Prestuplenie i nakazanie und dient in Besy als "stereotype Tiefenstruktur" zur Schaffung der russischen .,dämonischen“ Alius-Figur von Petr Stepanovic Verchovenskij, eines psychologisch differenzierten Stereotyps des ,politischen Verschwörers“, der Dostoevskijschen Variante des "subversiven politischen Verschwörers".

In Brat'ja Karamazovy verkörpern somit die stereotypen polnischen Figuren einen Teil des negativen utopischen Imagothèmes des verwestlichten Rußlands, indem sie seine ideologische Komponente bilden, das dem positiv-utopischen des verwestlichten Rußlands (in der Figur Dmitrijs) und zugleich dem positivutopischen des russisch-orthodox-byzantinischen Rußlands (in dem verwandelten Paar Dmitrij und Grušen ka) gegenübergestellt wird. Dabei sind diese Figuren ..Jächerlich" und ..gemein“, aber nicht ,dämonisch böse“, darüber hinaus weisen sie keine „römisch-katholische“ Komponente auf. ${ }^{689}$

Der russische Rivale des Polen, Dmitrij, ist dagegen zuerst ein .,positiv verwestlichter Idealist“, ein „russischer Schiller”, in dessen „breiter russischer Na-

ee7 Auch in dem oben erwähnten Roman 7agoskins .Jury Mileslusvsky. Il Russkie v 1612 eıx/u (1829) spielt die authentische Figur des Pan Gonsevskij, der in der Zeit der Wirten Kommandant der polnischen (jarnıson in Moskau war, die Rolle des „Verführers“ der ..schönen Russin“ Anastas ja Timofecvna Salonskaja sowie die des Rivalen Jurij Miloslavskij Gonsevskijs um Anastas ja, denn sie ist auf Wunsch ihres polonophilen und verträterischbosen Vaters mit ihm bereits verlobt. Vgl. ZAcioskin 1987, S. 37. S. $81 \mathrm{ff}$. und passim. Siehe auch die Anm. zu Korvin-Gonsevskij, ebd S 695

$68 \mathrm{~V}$ gl. dazu oben im Kapitel über Zupıskı I: Merivogo domu, S. 179 (Fußnote 106), über das Weglassen des polnischen Kapitels in den späteren, zu Lebzeıten Dostoevskijs veröffentlichten Ausgaben, das wohl u.a. dadurch verursacht wurde, daß die Figuren der Polen in Zupiskı is Merlvogo doma einen zu großen Widerspruch zu den bereits stark stereotypisierten und ideologisierten weiterentwickelten polnischen Figuren in den späten literarischen Werken Dostocvskijs gebildet hätten.

${ }^{69}$ Die wohl im polnischen Wortschatz aus den Entwürfen enthalten ist, siche dazu unten $S$. 423ff. Auch STEMPOWSKl 1961 venveist auf die Künstlichkeit, Konstruiertheit der Polenfiguren in den Romanen Dostoevskijs: wenn sie auch wie in Brat ja Karamazovy individualisien dargestellt, äußerlich als ..Menschen" beschneben und mit Namen versehen werden, bleiben sie eindimensional (S. 235f.). $V_{g l}$. dazu oben, $S$. IIIf. 
tur" noch vor seinen kathartischen Erlebnissen in Mokroe die positiven „westlichen" Imageme uber die russischen dominieren. ${ }^{600}$ Die Figur Dmitrijs vertritt daher zuerst das positive utopische Imagothème des verwestlichten Rußlands. Dank den oben besprochenen Erlebnissen in Mokroe, den "Schuldgefühlen“, der „bußfertigen Demut" und der "Liebe zu Grušen'ka“, verwandelt er sich aber nach seiner Verhaftung in eine russische Alius-Figur und bildet dann einen Teil des positiven utopischen Imagothèmes des „orthodox-byzantinischen“ Rußlands. Eine ahnliche Metamorphose erlebt auch Grušen'ka. In Mokroe überwindet sie endgültig ihre "Liebe“ zu dem polnischen Herm, den „westlichen", „verderblichen" Einfluß, nachdem sie den Polen als einen Fremden und Feind Rußlands erkannt hat, der sie und alles Russische haßt und verachtet. Grušen 'ka verwandelt sich aufgrund ihres Hasses auf den Polen und der Liebe zu Dmitrij ebenfalls in eine russische Alius-Figur, findet zu ihren russischen „Wurzeln“, zu ihrer beinahe verlorengegangenen religiösen und kulturellen Identităt zurück. Das „Schwanken“ Dmitrijs und Grusen kas zwischen dem „Westen“ und „Rußland" wird somit in der Konfrontation mit den beiden Polen beendet. ${ }^{691}$

Außer den beiden polnischen Figuren, die in der Grušen ka- und DmitrijHandlung eine wichtige Rolle spielen, gibt es in Brat'ja Karamazovy noch weitere polnische Imageme: Zwei Anspielungen auf den Petersburger Rechtsanwalt. Juristen, Literaten und Publizisten polnisch-russischer Herkunft, WLODZIMIERZ SpaSOwicz, der in der Figur des Rechtsanwalts Dmitrijs, Fetjukovic, porträtien bzw. karikiert worden ist, sowie eine Anspielung auf den polnischen Dichter ADAM MICKIEWICZ in der Rede des Staatsanwalts, der eine Stelle aus einem an Mickiewicz gerichteten Gedicht Puškins anführt.

690 An mehreren Stellen des Romans wird die .,breite Seele* Dmitrijs erwähnt, die Widersprüche in sich beherbergen kann. zu denen u.a. .zwei“ Ideale der Schönheit, der „vergcistigt-gutcn“ (..Madonna“) und der .,.irdisch-bðsen“ („Sodom“), sowie sein "Schillerscher Idealismus" gehören. Vgl. dazu z.B. Bd. 14, S. 93ff., bes. S. 100, und Bd. 15 die Entwürfe, ebd., S. 366: „Спасıбо немеu: Golt... Я ведь чту, чту... Я ведь пректоняюсь. О, не знаете дуиш моей. Я UІи.тер. Любіте.ль"“|Deutscher. Ich danke dir: Gott Ich verehre, verehre doch... Ich verneige mich. Oh, Sie kennen meine Seele nicht. Ich bin Schiller - Liebhaterl. In der Liebe zu Grusen ka spiegelt sich auch die Verwandlung und Vergeistigung Dmitrijs wider, siehe Bd. 15, S. 33: ..И томит она меня, .тюбовью томит. "то прежде! Прежде меня то:иkо изпиоы инферналыне томици, а теперь я всю ее душу в свою душу принят и через нее сам человеkом стал!"* |Und sie quălt mich, durch ihre Liebe quält sie mich. Was bedeutet dagegen das, was vordem war? Vordem quälten mich nur die höllischen Linien ihres Körpers, jetzt aber habe ich ihre ganze Seele in meine Seele aufgenommen und bin durch sie selber zu einem Menschen geworden!; S. 1015/ (Gespräch mit Aleša). Auch ein von der Forschung erwähntes authentisches Vorbild Dmitrijs. Apollon Grigor'ev, soll stăndig zwischen..Rußland und Europa“ (= dem ..Westen”) geschwankt haben. Vgl. dazu Bd. IS (Kommentar der Herausgeber), S. 456. Siehe auch dazu LAZARI 1996. ${ }^{691}$ Die Verwandlung Grušen 'kas hat jedoch schon in dem Kapitel l.ukovku unter dem Einfluß Alešas begonnen, der für sie weiterhin geistige Autorität besitzt, siehe oben. S 381 . Nach der Episode in Mokroe und nach der Verhaftung Dmitrijs verwandelt sich Grušen ka nicht nur seelisch, sondern auch åußerlich, vgl. Bd. 15, S. 5. 
2. Das erste polnische Imagem, die Anspielung auf den Rechtsanwalt WlodzIMIERZ SPASOWICZ, kommt zuerst in einet der Äußerungen Ivans übet das Leid der Kinder in dem Kapitel Bunt [Die Auflehnung] des Fünften Buchs Pro u Contra [Für und Wider] vor ${ }^{692}$ :

\section{/.../ интеллигентный образованный господин и его дама cekут} собственную дочkу, младенца семи лет, розгами /.../. /.../ Дело каkим -то чертовым неприличным случаем доходит до суда. Нанимается адвокат. Русский народ давно уже назвал у нас адвоката - «аблакат нанятая совесть». Адвоkат кричит в защиту своего клиента. «Дело, десkaть, таkое простое, семейное и обыkновенное, отец nocek дочky,

692 Die Anspielungen auf WiOdzIMIERZ SPASOWICZ. hat zum ersten Mal LEDNICKI 1953 (S. 291-295) bemekt. Siehe dazu auch ŻAKIEWICZ 1968, S. 88. Vgl. außerdem zur ausführlichen Biographie und zum Werk bei KULCZYCKA-SALON1 1975: „Historię rodziny Spasowiczów, zapisana na kartkach kultury polskiej i rosyjskiej, zacząc możemy od Daniela, syna Józefa, a ojca Wlodzimierza. /.../ Prawie wszystkie [przekazy] traktuja go jak Rosjanina zonatego z Polka (stad też /../ Wlodzimierz uważany jest za syna małżenstwa mieszanego narodowo i wyznaniowo), ale jedni $z$ jego znajomych $z$ aprobata drudzy $z$ wyrażna dezaprobata informację te uzupelniaja uwaga. że chociaż prawoslawny, to jednak w domu mówil wylącznie po polsku I cala rodzina prowadzila tryb życia polski“" (S. 11) [Die Geschichte der Familie der Spasowiczs, gleichsam Blätter der polnischen und russischen Kultur, kann man mit Daniel, dem Sohn Josephs und Wlodzimierzs Vater beginnen. /.../ Fast alle [Überlieferungen] betrachten ihn als einen mit einer Polin verheirateten Russen (daher wird $i$... Wlodzimierz als der Sohn eines national und konfessionell gemischten Ehepaars gesehen), obwohl einige von seinen Bekannten zustimmend oder ablehnend diese Mitteilung mit der Bemerkung ergänzen, daß er, obwohl orthodox, zu Hause auschließlıch Polnisch sprach, sowie daß die ganze Familie eine polnische Lebensweise hatte]:

siehe auch: DIES. 1972, S. 40ff. Vgl. auch Bd. 22 (I)nevnik pisalelja fïr dus Jahr 1876. Kap. 2. liehruar 1876 (über den l:all Kronchergs), S. 50-73) und die Anmerkungen der Herausge-

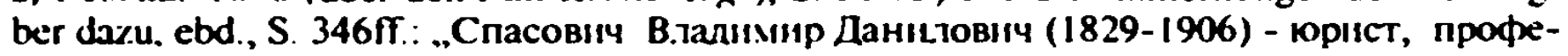
ссор Петербургckoro універсітета (1857-1861), .іттературовед " пиб.лиинст, постоянный сотрудінк журната «Вестнік Европы». На процессе Кроненберга он выступат зашитником. /.../ Спасовича назначіцт зашитником Кроененберга суд. /.../ Спасович по.тьзовался репутацией че.ловека передовых убеждений, особенно после тоro kak в 1861 r. он в чнс.іе лругіх прорессоров ПІтербургского универсітета подат в отставkу в знак протеста против репрессий в отношении студентов. /.../ Достоев-

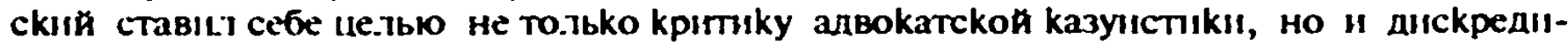

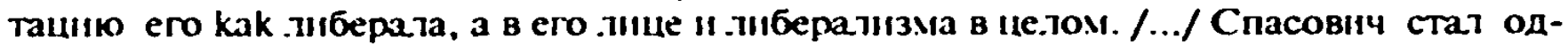

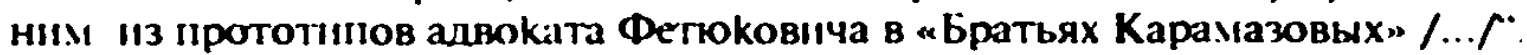

[Spasovič. Vladimir Danilovic (1829-1906), Jurist, Professor der Petersburger Universităt (1857-1861), Literaturwissenschaftler und Publizist, stăndiger Mitarbeiter der Zeitschrift ,.Der Bote Europas". Im ProzeB Kronenbergs trat er als Verteidiger auf. /../ Spasovic wurde vom Gericht als Vertcidiger bestellt. /.../ Spasovic erfreute sich eines /guten] Rufs als Mann von fortschrittlichen Überzeugungen. besonders. seit er im Jahre 186I, zusammen mit anderen Professoren der Petersburger Universităt, ein Gesuch mit der Bitte um die Suspendierung vom Dienst als Zeichen des Protestes gegen die Repressalien gegenüber den Studenten einreichte /... D Dostoevskij hat sich zum Ziel gesetzt, nicht nur die Advokaten-Kasuistik zu kritisieren, sondem ihn auch als eınen L.iberalen in Mißkredit zu bringen, und an seinem Beispiel den ganzen Liberalismus. /.../ Spasovic wurde eines der Vorbilder des Rechtsanwalts Fetjukovic in den Brüdern Karamazov. I 
и вот, k стыду наших дней, дошло до суда!» Убежденные присяжные удаляются и выносят оправдательный приговор. Публика ревет от счастья, что они оправдали мучителя. Э-эх, меня не было там, я бы рявкнул предложение учредить стипендию в честь имени истязателя! ... Картинки прелестные.

[/.../ der aufgeklärte, gebildete Herr und seine Dame [peitschen] ihr eigenes siebenjähriges Töchterchen mit der Rute /.../. - /.../ Die Sache kommt, wenn der Fall gar zu teuflisch und unanständig ist, vor Gericht. Es wird ein Anwalt genommen. Das russische Volk nennt langst schon den Advokaten 'ein gemietetes Gewissen'. Der Advokat ruft denn auch zur Verteidigung seines Klienten aus: 'Die Sache ist doch so einfach, eine ganz gewöhnliche Familienangelegenheit: der Vater schlug sein Töchterchen, und das ist jetzt, zur Schmach unserer Tage, vor das Gericht gekommen!' Die von ihm überzeugten Geschworenen ziehen sich zurück und fallen dann ein freisprechendes Urteil. Das Publikum brüllt vor Freude darüber, daß man den Peiniger seines Töchterchens freisprach! - Schade nur, daß ich nicht dort war: ich hătte ausgerufen, man sollte ein Stipendium errichten zu Ehren und auf den Namen dieses Folterknechtes..! das sind kostliche Bildchen. $]^{693}$

Nachdem Ivan kurz zuvor Aleša über die der .,russischen Geschichte“ eigentümliche „Vorliebe“ erzählt, nicht nur Menschen, sondern auch Tiere auf bestialische Weise zu schlagen, deren kritische Schilderung er in "Nekrasovs Versen“ über einen Bauern fand, der „sein Pferd mit der Peitsche auf die sanften Augen schlägt", führt er ein anderes von ihm ,notiertes“ Beispiel an. Ein ,intelligenter und gebildeter Herr" hatte zusammen mit seiner "Dame" ihr siebenjähriges Töchterchen mit Ruten ausgepeitscht. Der Vater des Mădchens wird aber vor Gericht von den Geschworenen freigesprochen, nachdem sein Rechtsanwalt ihnen in überzeugender Weise den „Fall“ als eine „einfache, gewöhnliche Familiengeschichte" darstellt. Das Publikum reagien begeistert und ..schreit" dabei "vor Glück". Ivan schlägt seinerseits ironisch vor, diesem ,.Folterknecht" zu Ehren ein "Stipendium" zu stiften und bezeichnet seine "Geschichten" als "entzückende Bildchen".

Es handelt sich hier um die Anspielung auf den Fall Stanislav Leopol'dovic Kronebergs (bzw. Kronenbergs), der wegen der Mißhandlung seiner siebenjahrigen unehelichen Tochter angeklagt wurde. WLODZIMIERZ SPASOWICZ, der Kronebergs Rechtsanwalt war, ist es gelungen, diesen vor der Katorga zu bewahren. Über den „Fall Kroneberg" im Zusammenhang mit dessen berühmt-berüchtigten Petersburger Prozeß hat Dostoevskij ausführlich im Dnevnik pisatelja

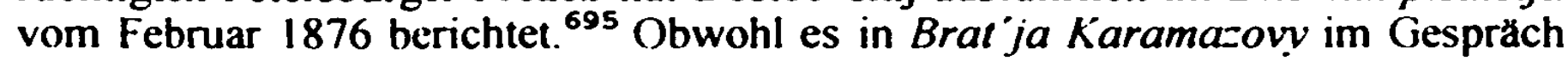

${ }_{693}^{693}$ Bd. 14, S. 219f. [S. 413f.].

694 JACKSON 1999 (S. 2ff.) stellt die ..Bildchen“ Ivans dem ,ganzen Bild“ der ..Rede Alešas am Stein“, als deren Widerlegung, entgegen, wobei er den ,Protest“ Ivans als .,abstrakt" und .theatralisch“, als eine ,.unaufrichtige Selbstinszenierung eines Egoisten““ interpretiert.

${ }^{695} \mathrm{Vgl}$. zur Person Kronenhergs (bzw. Kronebergs), Inevnik pisutelja, Bd. 22, S. 58ft. (kritisch-ironischer Kommentar Dostoevskijs zur Rede von Spusowicz). Siehe auch ebd., S. 
Ivans mit Aleša primăr um die Anklage Ivans gegen „Gott” geht, der das „Leid“ nicht nur der „unschuldigen Kinder", sondern auch der "ganzen Schöpfung“, der Menschen und Tiere, zuläßt, dient der Fall des grausamen Vaters und dessen Rechtsanwalts jedoch nicht nur als Beispiel für das von Gott erlaubte „Böse“, sondern auch zur Kritik des russischen Gerichtswesens und des Berufs des Rechtsanwalts, die als Produkte der "westlichen rationalistisch-liberalen Ethik“ in Rußland aus dem "Westen" übernommen wurden. Die ganze Passage zeigt die ambivalente Einstellung Ivans Rußland und dem „russischen Volk“ gegenüber. Er kritisient zuerst, dem liberalen und sozialkritischen, „verwestlichten“ Dichter Nekrasov folgend. die ,Barbarei des russischen Bauern“. ${ }^{696}$ Dann aber identifizient er sich mit der „Stimme des russischen Volkes“ und wie der russische Bauer und Pilger Makar in Podrostok nennt er einen Rechtsanwalt ein .gemietetes Gewissen“, wobei er die volkstümlich „entstellte“ Form des für das "Volk" unverständlichen Fremdwortes ,aдвokar" [advokat; Rechstanwalt] als ..аблакат“" [,ablakat"] wiedergibt. Ivan verurteilt auch den Prozeß und die enthusiastische Reaktion des „verwestlichten“ Publikums auf den Freispruch für den bestialischen Vater. Ein Rechtsanwalt wird dabei als Vertreter der „westlichen“, „rationalistischen Ethik“ und der ..Justiz" verstanden, die in der Opposition zu der bis dahin in Rußland geltenden "Gewissensethik“ steht, die auf "christlich-orthodoxen“ Grundlagen ruht. ${ }^{697}$ In dieser Passage wird also die

346: die Anmerkung zur Seite 50: .Дело Станистава Леопольдовича Кроненберга (род. 1845), обвинявшегося в истязании своей семитетней дочери Марии (род. 1868), с.тушалось 23-24 января 1876 г. в первом отде.лении С.-Петербургсkого окружного суда. Процесс вызват бо.тылой резонанс" |Der Fall von Stanislav Leopol dovic Kronenberg (geb. 1845), der der Mißhandlung seiner siebenjăhrigen Tochter Marija (geb. 1868) beschuldigt wurde, wurde am 23 und 24 Januar 1876 im Ersten Senat des S. Petersburger Kreisgerichts verthandelt. Der ProzeB hatte eine große Resonanzl. Vgl. auch Bd. 15. S. 553f., dip Anmerkungen zu Bd. 14, S. 219f:. ..Неkоторые дета.ли процесса, с.оова и выряжения, воспронзведенные и ckазанные Достоевсkим в “Дневнике писате.я», повторены здесь Иваном“" [Einige Details des Prozesses, einzelne Worte und Āußerungen, die Dostoevskij in seinem .. Tagebuch des Schriftstellers“" wiedergegeben und geäußer hat, werden hier von Ivan wiederholt| und weiter: ..В де.ле Кронеберга адвокатом бы.л В.Д. Спасович (1829 - 1906). Достосвскıй дает развернутый анашіз его речіл в том же февря.ъском выпуске «ДневHuka пuсате.ляп 391876 r. (r.). 2)“ (ebd.). IIm Fall Kronenbergs war V.L. Spasovic (1829. 1906)| der Verteıdiger. Dostoevskij gibt eine ausführliche Analyse seiner Rede in demselben Februarheft des .. Tagebuch des Schriftstellers“ fur das Jahr 1876 (das zweite Kapitel)]. Obwohl anhand der Sekundärliteratur und der oben angeführten Quellen und Kommentare nicht eindeutig festzulegen ist, ob Kronenberg Pole war, so ist jedoch andererseits eindeutig klar, daß er in Polen und in Westeuropa gelebt hatte und somit als ein „Vertreter des verwestlichten RuBlands“ sowohl fur die damalige russische Öffentlichkeit als auch für Dostoevskij galt

696 Dicse Stelle bıldet auch eıne Äquivalenz zum .. Traum Raskol nikovs“" über das zu Tode geprügelte Pferd, wodurch Raskol nikov und Ivan ebenfalls äquivalent erscheinen. Vgl. dazu oben, S. 276 und S. $281 f$. (Fußnoten 334 und 343 ).

$697 \mathrm{Vgl}$. dazu Bd. 22, S. 53tf. und passim, z.B. .J.../ адвокат и никогда не может действовать по совесті, не может ирать снкею совестьк, если 6 лаже и хоте. не играть /.../ |..... / Der Verteidiger kann auch niemals nach seinem Gewissen handeln, er kann nicht umhin. nicht mit seinem Gewissen zu spielen, auch wenn er sogar nicht damit spielen mochte I... $\Gamma^{-} \mid$(S. 53f.) und weiter zum ProzeB Kronebergs: ,/.../ г-н Спасович тоже замечате.тьно та ант.ливый адвоkат. Речь сло /.../. рерx Іісkусства: тем не менее она оставица в душе 
mögliche Wandlung Ivans, seine Rückkehr zu den „orthodoxen Idealen“ des russischen Volks angedeutet. Seine kritischen Ansichten beziehen sich darüber hinaus sehr eng auf die kritische Schilderung des "Falls Kronenbergs" und dessen Verteidigers SPASOWICZ in Dnevnik pisatelja, so daß angenommen werden muß, daß Ivan hier die Stimme des Publizisten Dostoevskijs repräsentient. SPASOWICZ und KRONENBERG, auf die Ivan anspielt, werden also als Vertreter des "verwestlichten" Rußlands, von dessen "Liberalismus" und "Rationalismus" angesehen und verurteilt. ${ }^{698}$ Zugleich symbolisieren die Beiden das aus dem "Westen" nach „Rußland" gekommene „Böse“, bilden als alius einen Teil des negativen utopischen Imagothèmes des verwestlichten Rußlands. Ivan selbst hat trotz seines "westlich“ gefärbten rationalen „euklidischen Verstandes“ dieses „Böse“ erkannt und verurteilt. Dies deutet auf seine Fähigkeit hin, sich moralisch wie Dmitrij verwandeln zu können, der nach dem visionären Traum vom „Kindchen“ seine Verantwortung für die ,Leiden“" der Schøpfung erkannt und die „eigene Schuld" dafür auf sich genommen hat. ${ }^{699}$

моей почти отвратительное впечатление. /.../ Он отверг даже ребенка, мцаденчество его, он уничтожит и вырват с корнем из сердец свонх с.тушателей даже самую жатость k нему. /.../ «Всяkне средтсва хороши, ес.ии ведут k прекрасной цели»./.../ Эта жа.ость - дратоценность наша, и искоренять ее из общества страшно. Когда общество перестанет жатеть с.лабых и угнетенных, тогда /.../ оно очерствеет о засохнет, станет развратно и бесп.одно“ (ebd., S. 56f. und S. 71) [/.../ Herr Spasovic ist auch ein auffallend talentienter Advokat, seine Rede /.../ der Gipfel der Kunst; ungeachtet dessen hat sie in meiner Seele fast einen widerlichen Eindruck hinterlassen. /../ Er verstieß sogar das Kind, sein kindliches Alter, er vernichtete und zog aus den Herzen seiner Zuhörer sogar die Wurzel des Mitleids mit ihm. /.../ Alle Mittel sind gut, wenn sie einem wunderschönen Zweck dienen'/.../ Dieses Mitleid ist unser Schatz, und es ist furchtbar, es aus der Gesellschaft mit der Wurzel auszureißen. Wenn die Gesellschaft aufhört. mit den Schwachen und Beladenen Mitleid zu haben, dann /... / wird sie hartherzig und trocknet aus, wird ausschweifend und unfruchtbar]. $698 \mathrm{Vgl}$. dazu KULCZYCKA-SALONI 1975, S. 143ff. KULCZYCKA-SAlONI schreibt auch über den Angriff Dostoevskijs auf Spasowicz [Spasovic] im Zusammenhang mit dem Prozeß Kroneberg sowie über dessen Tätigkeit als Verteidiger bei kriminellen und politischen Prozessen der 70-er Jahre in Rußland, so war er z.B. Rechtsanwalt im politischen Prozeß Nexaevs und semer Gruppe (1871) bzw. im Strafprozeß wegen des Mordes an fon Zon (ebd., S. 144f.). Die Autorin berichtet auch über die Angriffe Katkovs gegen Spasovič, der ihn aus Anlaß des Prozesses Nečaevs als einen „Fremden" bezeichnet, der sich in die inneren russischen Angelegenheiten eingemischt habe, ohne ein Recht dazu zu haben (S. 147). In den Anmerkungen zum Fall Kronenherg in Inevnik pisatelja werden weitere russische Pressestimmen angeführt, u.a. die P.D. Boborykins, die die Fremdheit der westeuropåischen bzw. franzosischen Erziehungsmoral und Behandlung der Kinder im Vergleich zu der russischen betonen, die Kroneberg, dessen franzosische Geliebte und ein Genfer Pastorenehepaar verkorpert hätten, Bd. 22, S. 348. Diesen aus dem Westen gekommenen grausamen Menschen werden auch in Inevnik pisatelja „russische Frauen aus dem Volk“ gegenübergestellt, die aus Liebe zu dem mißhandelten Kind den Vater angeklagt hatten. Diese Zeugen aus dem Volk wurden aber von Spasovič entwürdigend behandelt und moralisch kompromittiert, siehe ebd., S. 6iff. Die Opposition zwischen einem demütigen und barmherzigen russischen Bauern und dem Polen $M$ ckij, dem Vetreter der westlich geprăgten kaltherzigen Intelligenz, wird auch im Kapitel über den Bauern Marej abgehandelt, das in Innevnık pisalelja für das Jahr 1876 direkı vor den Kapiteln zum $/$ all Kronehergs steht, vgl. ebd., S. 46ff.

899 Siehe dazu oben, S. 398 (Fußnote 662) und Bd. 15, S. 26ff. 
Wlodzimierz Spasowicz wird in Brat ja Karamazovy zum zweiten Mal als der Rechtsanwalt Dmitrijs, Fetjukovič, eingefürt und karikiert, denn auch in den Kapiteln über die Gerichtsverhandlung Dmitrijs wird die Kritik am verwestlichten russischen Gerichtswesen fortgesetzt. das in Fetjukovic die perfekte "Verkörperung“" gefunden hat.

Bevor Fetjukovic in den Kapiteln über die Gerichtsverhandlung auftritt, wird er zunăchst in zwei Gesprächen Alešas mit Grušen ka und Dmitrij erwăhnt. Im ersten Gesprăch Alešas mit Grušen ka werden dreitausend Rubel genannt, das Honorar, für welches Fetjukovic bereit ist, Dmitrij zu verteidigen. Außerdem wird aber auch erwăhnt, daß Fetjukovic hauptsächlich wegen des „Ruhms“ zugesagt habe, der ihn nach dem gewonnenen ProzeB erwarten würde. ${ }^{700}$ Im zweiten Gespräch Alešas mit Dmitrij nennt dieser Fetjukovic ,мягкая столичная шельма" [„ein weicher hauptstädtischer Schurke, Schelm“] sowie einen ..Бернар" (Bernard $)^{701}$, indem er auf die rationalistisch-positivistischen ethischen Ansichten Fetjukovič's anspielt, weil dieser Dmitrij keinen Glauben und kein Vertrauen schenkt und an dessen Schuld glaubt.

Fetjukovic wird anschließend vor seinem Auftritt im Gerichtssaal beschrieben, wobei der Eindruck des Erzählers negativ ausfällt:

Талант его был известен повсеместно, и это уже не в первый раз, что он являлся в провиниии защищать громкие уголовные дела. /.../ Тут /.../ же яви.ся /.../ и зашиттни, знаменитый Фетюkович, и kak бы kakoй-то полавленный гул пронесся в зале. Это был длинный, сухой человек, с дтинными, тонкими ногами, с чрезвычайно длинным и б.тедными, тонкими пальцами, с обритым лицом, со сkромно причесанными, довольно короткими волосами, с тонкими, изредка кривившимися, не то насмешкой, не то улыбкой губами. На вид ему было лет copok. Лицо его было бы и приятным, если бы не глаза его, сами по себе неболышие и невыразительные, но до редкости близkо один от другого поставленные, таk что их разделяла всего только одна тонкая косточkа его продолговагого тонkого носа. Словом, физиономия эта имела в себе что-то резkо птичье, что поражало. Он был во фраkе и в белом ralbctyke.

${ }^{700} \mathrm{Vgl}$. dazu Bd. $15, \mathrm{~S} .10$

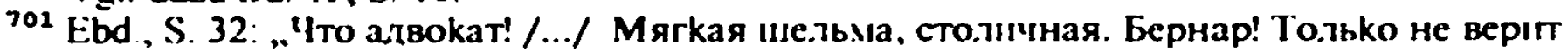
ченя ни на с.ломанный грош. Верıт, что я уби.т, вообрази себе, - уж я вижу. «Зачем

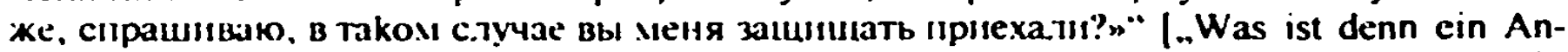
walt! ....' Ein sanftuender Schelm, ein Großstadtmensch, ein Bernard! Er glaubt mir nicht einmal für emen zerbrochenen Groschen: er glaubt. ich habe den Mord begangen, stelle dir nur vor das sehe ich schon. Weshalb sind Sie denn nur', frage ich ihn, wenn dem so ist, hierhergehommen, mich zu verteidigen?' $\cdots$. S. 10131.

Dmitrij vergleıcht Fetjukovic (und auch Rakitin) mit dem französischen Physiologen und Pathologen Claude Bernard (1813-1878). der ein Anhänger des philosophıschen Positivismus war. Bernard hatte in Frankireich die Theorie des naturalistischen experimentellen Romans Zolas trecinfluBt, in RuBland wurde er u a von Cernvševskij geschätzt und von N.N. Strachov übersetzt, vgl dazu ebd., S. 588, die Anmerkung zur S. 32. 
[Sein Talent war überall bekannt, und es war nicht zum erstenmal, daß er in der Provinz auftrat, um bei berühmt gewordenen Kriminalfallen zu verteidigen. /... Dort erschien auch /.../ der Verteidiger, der berühmte Fetjukowitsch, und es war als ob eine unterdrückte Bewegung durch den Saal gehe. Das war ein langer, hagerer Mensch, mit langen, dünnen Beinen, mit außerordentlich langen, blassen und schmalen Fingern, mit rasiertem Gesicht, mit bescheiden gekämmten, ziemlich kurzen Haaren und mit schmalen Lippen, die sich nur selten kräuselten, sei es zum Hohn, sei es zu einem Lächeln. Er war anscheinend vierzig Jahre alt. Sein Gesicht wäre sogar angenehm gewesen, wenn nicht seine Augen, an und für sich nicht groß und nicht ausdrucksvoll, in ganz auffallender Weise nahe beieinander gestanden hätten, so daß sie einzig und allein das feine Knöchelchen seiner länglichen feinen Nase voneinander trennte. Er war im Frack und weißer Halsbinde.] ${ }^{702}$

Hervorgehoben wird das „dumpfe Getöse“ der Stimmen des „verwestlichten“ provinziellen Publikums, auf welchen sein Auftritt einen positiv überwaltigenden Eindruck gemacht hat. Fetjukovic wird als ein "Intellektueller westlichen Typs“, wenn nicht als „Eierkopf“, so doch als ein „Vogelkopf" dargestellt. Er wird als "langer, trockener Mensch" beschrieben. Seine Beine sind lang, seine Finger ebenfalls "ungewöhlich lang und blaß". Sein Gesicht ist glatt rasiert (d.h. ohne den „vorpetrinisch-russischen Bart"), seine Haare kurz geschnitten. Besonders auffallend sind seine ,kleinen und ausdruckslosen Augen“, die lediglich durch ein „zartes Knöchelchen der länglichen dünnen Nase“ voneinander getrennt sind, so daß er etwas "Vogelhaftes" an sich hat und als eine komischgroteske Figur, bzw. metaphorisch wie ein .,lebendiges Paragraphenzeichen aus einem Gesetzbuch" erscheint. Er trägt ebenfalls einen „westlichen Anzug“, einen „Frack“. Die "dünne, lange“ und "trockene Blăsse“, die „dünnen. ironisch lächelnden Lippen" dieses Menschen heben somit sein ..abstrakt-kritisches", aus den „westlichen Büchern" entnommenes „Wissen“ hervor. Der Name Fetjukovic geht dabei auf das Wort фетюк [fetjuk] zurück, das Tölpel, träger Mensch bedeutet, auf ein Schimpfwort, das auch in den Toten Seelen Gogol's vorkommt, ${ }^{703}$ und nicht nur ironisch den talentierten, wortgewandten Juristen als einen ungeschickten und trăgen Menschen bezeichnet, sondern auch auf dessen Unfähigkeit hinweisen mag. Dmitrijs wahres Wesen zu erkennen und ihn geschickt von dem Mordverdacht zu befreien. Der Name Fetjukovic bildet auch den ironischen Kontrast zum Namen von dessen Vorbild. Spasowicz, der auf das russische Wort „cnac“ zurückgeht und Assoziationen mit dem Erlöser, Hei-

\footnotetext{
702 Bd. 15., S. 93f. [S. 1123 und 1128 ].

$703 \mathrm{Vgl}$. dazu LEDNICKI 1953, S. $291 \mathrm{ff}$, bes. S. 292) sowie VASMER 1953-1958, Bd. 3, S. 211 und Slovar SOVREMENNOGO RUSSKOGO LITERATURNOGO JATYKA, Bd. 16, Spalte 1328f: „Фетюk, -á, М.: У'cmap. простореч. Нерасторопный, бездеяте.ьный йін г.тупый, несообразыте.льный че.ловеk“ [Fetjuk, -a, m: veralt., Umganssprache. Ungewandt. langsam, untätig. müßiggängerisch oder dumm, schwer von Begriff, begriffsstutzig... |. Das Wor fet)uk kommt in Gogol's Toten Seelen vor (als ein Schimpfwort. das von Nozdrev gebraucht wird).
} 
land, d.h. mit Christus, sowie mit dem Wort „спасти“ bzw. „cnacarb“ (= ,erlosen", "retten") erweckt. ${ }^{704}$ SPASOWICZ hat jedoch den "Fall Kronenbergs", über den Ivan spricht, gewonnen, d.h. einen "Henker" befreit, "erlost", indem FETJUKOVIC den unschuldigen Dmitrij nicht überzeugend genug vor Augen der provinziellen, noch nicht ganz "verwestlichten“ Geschworenen verteidigen konnte.

Die Verteidigunsstrategie Fetjukovičs, sein Vorgehen beim Verhör der Zeugen sowie seine Rede sind den Beschreibungen des Verhaltens von Spasowicz im Kronenberg-Prozeß im Dnevnik pisatelja ahnlich. Wie Spasowicz kompromittien Fetjukovic moralisch die gefăhrlichen Zeugen, v.a. diejenigen aus dem "Volk“, er laßt sich von seinem „Talent" hinreißen, er will mit allen "Mitteln zum Zweck" gelangen, und dabei seinen "Ruhm" als Rechtsanwalt genießen und stărken. ${ }^{705}$ Fetjukovic verrăt seine Ansichten über den Fall Dmitrijs aber erst in der abschließenden Rede, in der er ebenfalls seine "ловkие приемы“ [geschickten Tricks] einsetzt, die sogar an seinem sich „leicht biegendem" bzw. „krümmem Rücken" sichtbar werden. Durch seine Gewandtheit ist er den schnell und gewandt laufenden und sprechenden Polen bzw. dem „dämonischen" Petr Stepanovic Verchovenskij ăhnlich:

Всё затихто, когда раздались первые слова знаменитого оратора. Вся зала впилась в него глазами. /.../ Ни малейшей попьтки на kрасноречие, на патетичесkие нотки, на звеняшие чувством словечkи. Это был человеk, заговоривший в интимном kругу сочувствуюших людей. Голос у него был прекрасный, громкий и симпатичный, и даже в самом голосе этом kak будто заслышалось уже нечто исkреннее и простодушное. Но всем стало понятно, что оратор может вдруг подняться до истинного патетического - и «ударить по сердиам с неведомою силой». /.../ Одно не понравилось было дамам: он всё kak-то изіибался спиной, особенно в начале речи, не то что kианяясь, a kak бы стремясь и летя $\mathbf{k}$ своим слушателям, причем нагибался именно kak бы половиной своей длинной спины, kak будто в середине этой длинной и тонkой спины его был устроен таkой шалнер, тak что она могла сгибаться чуть не под прямым углом. /.../ Речь его можно было бы разделить на две половины: первая половина - это kритиkа, это опровержение обвинения, иногда злое и сарkастичесkoe. Но во второй половине речи kak бы вдруг изменил и тон и даже прием свой и разом возвысился до патетичеckoro, a зала kak будто ждала того и вся затрепетала от восторга.

[Alles verstummte, als die ersten Worte des beruhmten Redners erklangen. /.../ Er ließ durchaus keine pathetischen Phrasen erklingen. er machte nicht den geringsten Versuch. schönredend zu sein und von Gefühl durchzitterte Wörtchen anzubringen. Das war vielmehr ein Mensch, der im inti-

${ }^{704}$ In der Zeitschriftenfassung der Brat ja Karamazovy hieß Fetjukovic: Egozovic, was noch dem Namen . Spasowic: [Spusiovic] ähnlicher klang und darüber hinaus auf das Wort ego, auf seinen „westlichen Egozentrismus“ hinweist (KULCZYCKA-SALONI 1975, S. 149)

$705 \mathrm{Vgl}$. dazu Bd. 15, S. 96. Siehe dazu auch Bd. 22, S. 50ff. 
men Kreis Gleichgesinnter sprach. Seine Stimme war schön, laut sympathisch, und es war sogar, als ob gerade bereits in dieser Stimme etwas Aufrichtiges und Naives zum Ausdruck komme. Indes wurde es allen auf der Stelle klar, daß der Redner sich auch plötzlich zum wirklichen Pathetischen erheben könne - und an die Herzen zu schlagen vermöge mit nie gehörter Kraft $^{\circ}$ /.../ Eines nur wollte den Damen nicht gefallen: er krümmte immer so seltsam seinen Rücken, besonders zu Beginn der Rede, nicht gerade so, als ob er grüte, vielmehr, als ob er zu seinen Hörem hinstrebe und hinfliege, wobei es genauso aussah, als ob er sich gerade in der Mitte seines langen und dünnen Rückens beugte, und es befinde sich gerade dort ein Schamier, so da $B$ er sich fast in einem rechten Winkel zu beugen imstande sei. /.../ Man konnte seine Rede in zwei Hälften teilen: die erste Hälfte war die Kritik, die Widerlegung der Anklage; sie war bisweilen boshaft und sarkastisch. In der zweiten Hälfte seiner Rede war es aber so, als habe er plötzlich sowohl seinen Ton wie auch seine ganze Methode geändert und sich mit einem Mal zum Pathetischen erhoben; der Saal schien dies aber erwartet zu haben und erbebte völlig vor Entzücken.] ${ }^{706}$

Fetjukovix wird hier nicht nur äußerlich, sondern auch als Redner beschrieben. Das Publikum zeigt sich von ihm fasziniert, bleibt "still" und "verschlingt" ihn mit den Augen [eigentl.: „saugt sich“ ihn mit den Augen „ein“]. Er hat eine wunderschöne, kräftige und sympathische Stimme. in der sich etwas Aufrichtiges und Vertrauensseliges vernehmen läßt. Er redet vor dem Publikum wie in einem „intimen Kreis mitfühlender Menschen“, ohne Anstrengung, seine Beredsamkeit zu zeigen, ohne „pathetische Noten" und ohne "gefühlvoll klingende Wörtchen“, obwohl er auch des „wahrhaftigen Pathos" făhig sei. Der Erzähler relativiert jedoch den positiven Eindruck, den Fetjukovic auf das Publikum macht, indem er hinzufügt, daß das alles nur so erscheine, „als ob" [kak будто] sei. Einen schlechten Eindruck, besonders auf die Damen, macht auch sein langer und dünner Rücken, der sich auf eine Weise zu „krümmen“ scheint, „als ob sich in seiner Mitte ein Scharnier" befinde, „so daß er sich fast in einem rechten Winkel zu beugen imstande ist". An diesem zweigeteilten Rücken Fetjukovičs wird seine ambivalente Haltung bzw. das nur Scheinbare seiner Aufrichtigkeit sichtbar. Er fliegt und strebt aus Höflichkeit wie ein Vogel dem Publikum entgegen, so daß er darin an die ,zu Füßen fallenden“ Polen erinnert.

Diese moralische Spaltung bzw. Zweiteilung des Rechtsanwalts entspricht den zwei Teilen bzw. Hälften seiner Verteidigungsrede, die im Kontrast zueienander stehen. Obwohl Fetjukovix im ersten, kritischen Teil seiner Rede den Mordverdacht als unbegrümdet und Dmitrijs Unschuld beinahe bewiesen hat, ,ändert er „plötzlich Ton und Verfahrensweise“, wird .,pathetisch“, wodurch er das Publikum (wie Spasowicz im Kronenberg-Prozeß) begeistert. Fetjukovič opfert aber dadurch Dmitrijs Schicksal seiner "modernen liheralen Idee“. daß der Mord am eigenen Vater erlaubt ist, und der Morder freigesprochen werden solle, wenn der Vater seine Rolle nicht erfült und diesen Namen nicht verdient habe.

${ }^{706}$ Bd. 15, S. 152f. [S. 1239f.]. Vgl. dazu Bd. 22, S. 57ff.: „Речь r-на Спасовича. Јовкие приемы“|Die Rede des Herm Spasowicz. Geschickte, flinke Verfahrensweise] 
Dadurch wird Fetjukovic als eine Ivan ăquivalente Figur vorgestellt; seine "Idee“ ist auch mit det ..Idee“ Ivans identisch, daß „ohne Gott alles erlaubt" ist, so daß beide komplementären Figuren das negative utopische Imagothème des verwestlichten RuBlands symbolisieren, obwohl Ivan sich von dieser Vorstellung befreien kann. ${ }^{707}$

Die Gegenüberstellung von Staatsanwalt und Verteidiger und ihrer Reden dient zusătzlich dazu, Fetjukovic als einen Vertreter des "Rationalismus“, der "westlichen" Auffassung von Recht und Gerechtigkeit zu kritisieren und ihn selbst dabei moralisch zu entlarven. LEDNICKı hat in seiner Rede einen ,anti-orthodoxen" Satz gefunden, der im folgenden von dem Staatsanwalt in seinem Angriff auf Fetjukovic aufgenommen wird:

Исправляются Евангелие и религия: это, дескать, всё мистика, а вот у нас лишь настоящее христианство, уже проверенное анализом рассудkа и здравых понятий. И вот воздвигают пред нами лжеподобие Христа! В ню ме меру мерите, воммеритсл и сам. восклицает зашитник /.../. /.../ Мы заглядываем в Евангелие лишь накануне речей наших для того, чтобы блеснуть знакомством все-таkи с довольно оригинальным сочинением, которое может пригодиться и послужить для некоторого зффекта, по мере надобности, всё по размеру надобности! А Христос именно велит не таk делать, беречься таk делать, потому что злобный мир таk делает, мы же дольжны прощать и .таниту свою подствавтять /.../. Вот чему учил нас бог наш, а не тому, что запреццать детям убив:ть отцов есть предрассудок. $И$ не станель мь поправлять с кафедры истины и здравых понятий Евангелие бога намего. Которого защитник удостоивает назвать лишь жраспятым человеколюбцелєу, в противополомность всей православной России, взывающей $k$ неяв: .. Ти бо еси Бог наш!..." [fett und kursiv Dostoevskij; kursiv die Verf.]

[Man verbessert das Evangelium und dic Religion, das ist sozusagen alles Mystik. nur hier bei uns ist wirkliches Christentum, schon nachgeprüft an der Analyse der Vernunft und der gesunden Begriffe! Und da gibt man uns dann auch noch ein Falschbild von Christus! 'Mit welchem Maß man mißt, mit dem wird einem auch gemessen werden: ruft der Verteidiger aus /../. /... Wir blicken eben nur am Vorabend unserer Reden ins Evangelium hinein, einzig zu dem Zweck, durch seine Kenntnis zu glănzen. [eigentl.: eines immerhin originalen Werks] wenn wir dabei auch in einer recht originellen Weise hinzudichten. falls uns das zu einem gewissen Effekt taugen und dienen kann, je nach Bedarf? Aber Christus gebietet gerade. nicht so zu verfahren. sich davor zu hüten, weil die böse Welt so verfähr, wir aber verzeihen. unsere Wange hinhalten /.../. Das ist es, was uns unser (iott lehrte, aber nicht, daß es ein Vorurteil sei, den Kindern zu verbieten. ihre Väter zu morden. Wir werden auch nicht von dem Katheder der

${ }^{707} \mathrm{Vgl}$ Bd 15. S. $161 \mathrm{ff}$ und hes. S. 169ff. zur Rede des Rechtsanwalts, in der er zuerst richlig Smerdjakov als den Mörder Fedor Pavlovic Karamazovs entlarvt. um dann seine Erkenntnis der ..ldec” zu opfern 
Wahrheit und der gesunden Begriffe dies Evangelium unseres Gottes verbessern, den der Verteidiger nur einen 'gekreuzigten Menschenfreund' zu nennen würdigt, im Gegensatz zum ganzen rechtgläubigen Rußland, das zu ihm aufruft: 'Denn Du bist unser Gott!' [kursiv die Verf.]] ${ }^{708}$

Der Staatsanwalt wirft Fetjukovic vor, daß er das „Evangelium“ und die .Religion" auf die "westlich-rationalistische" Weise als "Mystik" entlarven und ein „wahres Christentum" aufrichten wolle, das mit Hilfe der „analytischen Vernunft" und der "gesunden Begriffe" des "menschlichen Verstandes", "verbessert" worden sei. Es handle sich aber um einen "Schein-Christus" (,Antichrist"; „Teufel"), dessen „Bild" von Fetjukovic ,aufgerichtet" wird. Fetjukovix schaue in das Evangelium, um mit der Kenntnis dieses originalen Werks in seinen Reden zu glänzen, lediglich wegen eines publikumswirksamen Effekts. Fetjukovic usurpiere im "Namen der Wahrheit", das „verbesserte Christentum" zu propagieren, er verfälsche aber die christlichen Gebote, indem er vom Recht auf Vergeltung und sogar vom Recht auf den „Vatermord aus Rache“ spreche, indem er das Gebot der Verzeihung und der aus Nächstenliebe „hingehaltenen anderen Wange" ignoriere. Fetjukovic nenne Christus einen .лишь "распятым человеколюбцем»" [,nur "einen gekreuzigten Philanthropen"] und richte sich dadurch gegen das ..ganze orthodoxe Rußland“.

Die Figur Fetjukovičs erscheint somit in der Rede des Staatsanwalts als „Verführer" zum „Bösen“, der das „Bild des Antichrists“, des durch die „westliche“ Wissenschaft, durch ihren Anspruch auf Wahrheit verfâlschten, entstellten "russisch-orthodoxen Christus" verbreiten will. Er zeige sich hier besonders deutlich als ein „böser Geist“, als eine subversive, gegen das „orthodoxe Rußland“ gerichtetete Alius-Figur, so daß die Tiefenstruktur dieser Figur die stereotype Komponente des "westlichen teuflischen Verfuhrers" (u.a. des "Ljachs") mitenthält.

Die „liberal-atheistischen“, „rationalistischen“ Ansichten Fetjukovic's werden nicht nur von dem Staatsanwalt, einem weniger erfolgreichen, aber ehrlichen und ernsthaften, ambivalent „verwestlichten“ Gegner Fetjukovičs, sondern auch von den Geschworenen aus dem "Volk" "richtig“ erkannt, die sich aus russischen Bauern und Kaufleuten zusammensetzen. Fetjukovic wird dabei als Atheist gezeigt, der in Christus lediglich einen Menschen sieht. Der Vatermord ist für ihn moralisch gerechtfertigt, wenn der Vater wie jener ermordete Fedor Pavlovic Karamazov den Namen eines Vaters nicht verdiene, denn Fetjukovic begreift den „religiösen Mystizismus“ nicht, er möchte alles mit dem rationalen menschlichen "irdischen Maß" messen. Darin ist er in dieser Textstelle als cin Vertreter des "euklidischen Verstandes“ erneut Ivan Karamazov verwandt. ${ }^{709}$ Sowohl der Staatsanwalt als auch die Geschworenen lassen sich aber von Fetjukovič nicht tăuschen und sprechen Dmitrij die Schuld zu. denn Dmitrij ist im symbolisch-,,imagothematischen“, im werkimmanenten Kontext des Romans, als eine "verwestlichte" Figur wie der "Atheist" Ivan. nicht nur

\footnotetext{
708 Vgl. ebd., S. 175 [S. 1282f.] zur oben zitierten Stelle aus der Rede des Staatsanwalts, die sich auf eine Stelle aus der Rede des Rechstanwalts Fetjukovic bezieht (S. 169).

${ }^{709} \mathrm{Vgl}$. Bd. 14, S. 214.
} 
aufgrund der Indizienlage, sondern auch "metaphysisch“, „intentional" des Vatermords schuldig, wenn auch Smerdjakov den Mord für beide Brüder ausgeführt hat und Dmitrij selbst sich bis zu Beginn der Gerichtsverhandlung dank den Erlebnissen in Mokroe innerlich gewandelt hat. ${ }^{710}$

Die Figur Fetjukovic's, in der WLODzIMIERZ SPASOwICZ karikient wird, tritt somit in den Kapiteln über die Gerichtsverhandlung sowie in der Anspielung Ivans auf den "Fall Kronenbergs" als ein Alius, als Teil des negativen utopischen Imagothèmes des verwestlichten RuBlands auf und symbolisiert den negativen "westlichen" Einfluß auf das religios-moralische und soziale Leben Rußlands. 711

3. Das zweite polnische Imagem, eine Anspielung auf den polnischen Dichter ADAM MiCKIEWIC7, tritt in der Rede des Staatsanwalts auf, in der dieser eine Stelle aus einem an Mickiewicz gerichteten Gedicht Puskins auf Fedor Pavlovic Karamazov bezieht. Sie wurde zum ersten Mal von WACLAW LEDNICKI bemerkt $^{712}$ :

$310 \mathrm{Vgl}$. Bd. 15, S. 91, S. 123ff. zur Charakteristik des Staatsanwalts als eines einst gedemütigten. kränklichen, aber ernsthaften. Menschen. der Rußland liebt und darüber hinaus als glaubiger orthodoxer Russe ist. Die Ansichten des Staatsanwalts lassen sich als die mit den Augen eines skeptischen Erzăhlers wiedergegebenen Ansichten Dostoevskijs in Dnevnnı pisarelja bezeichnen. Vgl. auch ebd., S. 173ff. das Kapitel Mužički za scebja posiojalı [Die Büuerlein trusen für sich selber ein|), in dem die Geschworenen aus dem Volk Dmitrij für schuldig befinden. trotz der spizzfindigen thetorischen Făhigkeiten Fetjukovies. Das kritische und sich großtenteils für Fetjukovic einsetzende Publikum (vorwiegend die Damen), dessen Stimmen vom Erzähler mit Humor und Ironie wiedergegeben werden, ist dagegen wic Fetjukovic selbst teilweise venvestlicht. Siehe ebd., S. 89ff., S. I5If. bzw. S. 173ff., bes. $176 \mathrm{fr}$.

${ }^{711}$ KULCZYCKA-SALON1 1975. S. 149f.) schreibt dayu: „W Spasuwiczu /.../ skoncentrowaty siç cerhy ludzkic, ktrirych Desttocwski nic lubit: Polak, inteligent z grupy ..profesorskich liberakiw" '...l, kaliher profesjonalny i spotcezny tej poxitaci jest najlepszym micrnikicm zainteresowania pisarza Polakami i napiçcia negatywnych w stosunku do nich uczuć. Charakterystycznc jest, że właśnic w Polaku, chec nic nazwanym tak, upersenifikowat inteligencję i kazal jcj siç micrzyć z pokorą̧ i intuicją moralną ludu i przcgrać w tym starciu“" [In Spasowicz l...t versammelten sich soziale Eigenschaften, die Dostoevskij nicht mochte: Ein Pole, ein Intellektueller aus der Reihe der ..Professorenliberalen“ $i .$. /. Der berufliche und soziale Rang dieser (iestalt ist der beste Beweis des Interesses fur die Polen und der gespannten, negativen Gefuhle ihnen gegenüber. Charakteristisch ist. daB er eben in diesem Polen, obwohl er nicht als ein Pole bezeichnet wird, die Intelligentsia personifizierte und ihr befiehl, sich mit der Demut und der moralischen Intuition des Volkes zu messen und diese Auseinandersetzung zu verlieren. I

KIIICZYCKA-SAL.ON herichtet ehenfalls über die persönlichen Unannehmlichkeiten für Spasowicz, nachdem Krut ju Kurumuzovy ersehienen waren, obwohl die heimlichen Anspielungen auf seine Person den meisten damaligen lesem des Romans unkenntlich bleiben mußten. so daß er sich seitdem nicht mehr fur die Verbreitung der Werke Dostoevskijs im Polen eingesetn habe. ebd vgl. auch Difs. 1972, S 42

712 Vgl. Lf.DNicki 1953, S. 291: „To apply to Fedor Pavlovich Karamazov what Pushkin said to Mickiewicz. The msinuation is clear enough". Siehe ferner PUSKIN 1949b, Bd. 3, S. 280 ..Он межау нами жил / Срель п.лемени ему чужого; злобы / В душе своей $k$ нам не пи-

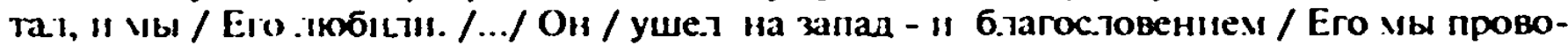
ans:m. Ho теперь / Наш мпрный гость нам стал врагом - "1 ядом / Стихи свон, в угоду 
„Посмотрите, наконец, на наш разврат, на наших сладострастников. Федор Павлович, несчастная жертва теkушего процесса, есть пред иными из них почти невинный младенец. А ведь мы все его знати, он межсду нами жић..." [kursiv die Verf.] [Schauen Sie endlich auf unsere Unzucht, auf unsere Wollüstlinge. Fjodor Pawlowitsch, das unglückliche Opfer des vorliegenden Prozesses, ist im Vergleich mit ihnen fast ein unschuldiger Săugling. Aber wir kannten ihn ja, er lebte unter uns. [kursiv die Verf.]]

Fedor Pavlovic Karamazov kommt in dieser Passage als ein Beispiel des zeitgenössischen typischen „russischen Lüstlings“" vor, er vertritt exemplarisch die "russische Tendenz zur Unzucht". Im Vergleich mit einigen ,noch schlimmeren Fällen der verbrecherischen Ausschweifung“ erscheint er als "unglückliches Opfer", als ein „почти невинный младенеи“ [ein „fast unschuldiges Säugling“]. Das kirchenslavische Wort „младенец“ schafft dabei eine ironische Anspielung auf das mit diesem Wort bezeichnete Jesuskind. Indem der Staatsanwalt darüber hinaus den ermordeten Karamazov „einen von uns“, einen, der „unter uns gelebt" hat, nennt, betont er die alltăgliche Vertrautheit des Publikums mit ihm (und mit seinem "Laster") und schafft eine Analogie zwischen diesem "dekadenten“ Russen und seinen ,durchschnittlichen Zeitgenossen“. Durch den Bezug auf ein Gedicht Puskins, das an Mickiewicz gerichtet ist, einen „rußlandfeindlichen" polnischen Dichter, einen „Verrăter der russischen Freunde", werden aber zugleich die „westlichen“" Wurzeln Karamazovs und seiner ,Laster" hervorgehoben, die eine negative, „subversiv-verrăterische“ Komponente, mitenthalten.

Der patriotisch gesinnte Staatsanwalt, dessen Ansichten über die soziale Lage Rußlands denjenigen Dostoevskijs aus dem Dnevnik pisatelja ăhnlich sind, gibt mehrere Beispiele für die verzweifelten, depressiven Stimmungen und für die Demoralisierung der russischen Gesellschaft an, für die er stellvertretend den ermordeten Fedor Karamazov nennt. Das Zitat aus dem Gedicht Puskins, in dem dieser MICKIEWICZ zuerst als seinen „Freund“ bezeichnet, der jedoch, nachdem er in den "Westen" gegangen ist, seine "russischen Freunde" verraten habe, betont die moralische Fragwürdigkeit Fedor Karamazovs, der in Brat "ja Karamazovy als die Verkörperung der Laster des verwestlichten russischen Adels geschildert wird. Die versteckte Anspielung auf die Person MiCKIEWICZ dient somit im Kontext der Rede des Staatsanwalts und durch die Vermittlung Puskins der Kritik des ,verwestlichten“ Rußlands, dessen Vertreter Fedor Pavlovic Karamazov ist, und bildet wie die Figur Fetjukovič's einen Teil des negativen utopischen Imagothèmes des verwestlichten Rußlands. Es ist

черни буйной, / Он напояет. /... (1834) [Er lebte unter uns, / Unter dem fremden Geschlecht; keine Bosheit / Năhrte er in seiner Seele, und wir / Liebten ihn. /... $\mathrm{Er} /$ ist in den Westen gegangen - und mit einem Segen / Haben wir ihn verabschicdet. Aber jetzt .' Unser friedlicher Gast ist unser Feind geworden - und mit Gift / Füllt er, dem zügellosen Pobbel zuliebe / Seine Verse. I. Siehe auch die Anmerkung zu diesem unvollendet gebliebenen Gedicht. ebd., S. 739. sowie zu seiner Erstveroffentlichung durch Vasilij A. Zukovskij in PuSkIN 1949 a. S. 1251 .

${ }^{723} \mathrm{Vgl}$. Bd. 15, S. 124 [S. 1185 ]. 
außerdem die einzige und zudem die einzige negative Anspielung auf die Person des polnischen Dichters in den literarischen Werken Dostoevskijs, wăhrend in einigen anderen literarischen Werken ausschließlich intertextuelle Anspielungen auf literarische Werke Mickiewicz's zu finden sind. ${ }^{714}$

4. Ergänzend werden weitere polnische Imageme besprochen, die in den erhalten gebliebenen Entwürfen zur Grušen ka- und Dmitrij-Handlung vorkommen, von dem Kapitel Lukovka [Die Zwiebel; eigentl.: Das Zwiebelchen] und den darauffolgenden polnischen Kapiteln in Mokroe bis hin zu den Verhören der Zeugen und dem Prozeß Dmitrijs. ${ }^{715}$ Die Entwürfe zu Brat $j a$ Karamazovy unterscheiden sich thematisch nur geringfügig von der Endfassung des Romans, so daß unten nur die wenigen nicht in die veröffentlichte Fassung eingegangenen polnischen Imageme erörten werden. Es handelt sich dabei um die negative Charakteristik der polnischen Figuren und der „Polen und Polinnen", die zum einen vom Erzähler, zum anderen von den handelnden russischen Figuren bzw. von den Polen selbst geăußert werden. Zu den Äußenungen der Polen gehören darüber hinaus mehrere polnische Worte und Sătze, die einerseits alltäglichen Wortschatz aus der Umgangssprache enthalten, andererscits aber idiomatischen Charakter aufweisen und nur teilweise in der Endfassung zu finden sind. ${ }^{726}$

In der Charakteristik der polnischen Figuren, sowohl durch den Erzähler als auch durch die russischen Figuren. wird wie in der Endfassung die kulturelle und ideologische Opposition zwischen den Polen und den Russen und die feindliche und arrogante Einstellung der Polen den Russen gegenüber hervorgehoben, beispielsweise in den folgenden Passagen:

По:яки ободряются, а жених произносит тяжелую и важную речь, что, тak kak он хочет удостоить Грушеньку руkи, то сkоль неприятно ему появ:ение прежних лиц. Выходки против этой ре'іи Грушеньkи. Грушенька в оппозицию. принимает Митю с радостью, и Митя в друг ободряется. /.../

- Я космополит, пью первый. Поляк не пьет: «За Россию в гранипах 72-го тла»- Дypak же вы, пане. О Польше и России (бред Ивана [!]). /...।

Груше: «Богиня!» Он тогда говорил: «Богиня!» - Kak челювсkа любить можешь, a kak pycckoro нет. - Нет, и kak pycckoro. - Kakoй же бы ты был поляk после этого?

IDie Polen schöpfen Mut und der Verlobte hält eine schwerfallige und gewichtige Rede, daß ihm, weil er ihr durch die Heirat eine Ehre erweisen will, das Frscheinen der früheren Personen um so mehr unangenehm ist.

\footnotetext{
714 Wenn man zwei mogliche Anspielungen auf den Aufenthaltson Mickiewiczs in Rußland, in Odessa, hinzufügt In l'cinyl muz (vgl oten S. 314) sowie in Brat ja Karamazovy. Fedor Pavlovic Karamazov hält sich ebenfalls einige Jahre lang in Südrußland und in Odessa auf, vil Bd. 14, S. 21

7 ' $\mathrm{Vgl}$ dazu Bd. 15, \$ $254 \mathrm{f}$

$716 \mathrm{~V}$ gl. ebd. bes. S. $271 \mathrm{fr}$.
} 
Ausfalle Grušen kas gegen diese Rede. Grušen ka geht in die Opposition, begrüßt Mitja mit Freude, und Mitja schöpft plotzlich Mut. /.../ Ich bin Kosmopolit, ich trinke als erster. Der Pole trinkt nicht: 'Auf Rußland in den Grenzen vor $1772^{\circ}$. Herr, Sie sind ein Dummkopf. Über Polen und Rußland (Fieberwahn Ivans [!]). /.../ Zu Grušen'ka: 'Göttin!' Er sagte damals: 'GórtiN' Als einen Mann kannst du mich lieben, aber als einen Russen nicht. - Nein, auch als einen Russen. - Welcher? Was für ein Pole wărest du dann?] ${ }^{717}$

Im ersten Abschnitt hält der Pole, der hier als „Verlobter" Grušen kas bezeichnet wird, ihr eine "schwerfallige und wichtigtuerische Rede“. Er will Grusen 'ka durch die Heirat eine Ehre erweisen. Grušen'ka stellt sich aber in die Opposition zu ihm und begrüßt Mitja [Dmitrij] mit Freude. In dieser Textstelle wird explizit der Gegensatz zwischen dem Polen und den beiden Russen betont. Im zweiten Abschnitt, der in der Endfassung zur Toast-Szene geworden ist, nennt Dmitrij sich einen „Kosmopolit“. Es handelt sich dabei aber nur um eine Hervorhebung seiner versöhnlichen Haltung dem Rivalen gegenüber.

Im dritten Abschnitt kommt dagegen besonders deutlich der national-ideologische Gegensatz zwischen dem ,polnischen Verführer" und der „Russin“" (Grušen'ka) zum Vorschein. „Damals“, d.h. zu der Zeit als er sie verführt hatte, nannte er sie auf russisch eine "Göttin", hatte sich als ein "Russe" vor ihr maskiert. "Jetzt“" wirft er ihr vor, daß sie ihn „als einen Menschen [als einen Mann]“, aber nicht als „einen Russen lieben könne“. Grušen'ka antwortet, daß sie ihn auch als einen "Russen" lieben könnte, er sei aber "kein Pole“ mehr, d.h., sie entlarvt seinen Betrug, seine scheinbare "russische" Identităt. Er habe sich damals lediglich vor ihr für einen "Russen" ausgeben wollen, obwohl er niemals ein solcher sein könne. Hervorgehoben wird hier das stereotype Motiv des Mißtrauens der Russen den als "Russen maskierten (verräterischen) Polen“ gegenüber.

In den weiteren Äußerungen der Polen über sie selbst werden sie als Vertreter des „Westens", der "westlichen" Kultur charakterisiert, darunter auch in den von ihnen geăußerten polnischen Sătzen, in denen die vom .Katholizismus" und vom ritterlichen Ehrbegriff (,honor") geprägte patriotische adlige polnische Mentalităt karikient wird:

- Падам до ног. - Свёнтка матkа Ченстохова. - /.../ Схизматики. Схизма. /.../ - Свободна. Вольна. Крыж. - Цихо вшендзе, бендзе. Цо то. Дьябли. - Вшисии. Нехай, пане. Посполита жечь. - Ржонд. Камора. /.../ Польсkа дама. /.../ - Я дал мое сердце, но панна... /.../; Поляки: «Русский народ не может быть цобр, потому что не цивилизован".

[Ich falle [Ihnen] zu Füßen. Die heilige Mutter [von] Censtochova [poln. Częstochowa] [bzw. das Heiligenbild der [Gottes]Mutter von...]. /.../ Schismatiker. Schisma. /.../Frei, Unabhängig. Kreuz. Still ist es überall, es

${ }^{717} \mathrm{Vgl}$. Bd. 15, S. 275f. und S. 287f. 
wird etwas. Was ist das. Die Teufel. Alle. Es soll ..., Herr. Die Republik. Regierung. Kamorra. /.../ Polnische Dame. /.../ Ich habe mein Herz gegeben, aber das Frăulein... /.../; Die Polen: 'Das russische Volk kann nicht gut sein, weil es nicht zivilisient ist $\left.{ }^{\prime}\right]^{718}$

Hier handelt es sich um eine „Sammlung“ idiomatischer, stereotyper Äußerungen, Zitate und symbolischer Begriffe, d.h. polnischer Imageme, die sich auf die polnische adlige Mentalităt, Literatur, Religion (den katholischen Glauben der Polen), auf die Geschichte bzw. auf die polnische Kultur im allgemeinen sowie auf die "Liebe der Polen zu ihrem L.and" beziehen. Neben der in symbolischer Bedeutung in mehreren Werken Dostoevskijs vorkommenden Wendung pactam do nóg, die dic "altpolnisch-adlige (lakaienhafte) Höflichkeit" der Polen, auch als "Lakaien des Westens", symbolisiert, ${ }^{719}$ kommt das symbolträchtige "Heiligenbild der Gottesmutter von Ченстохона" [Częstochowa], der Schutzpatronin Polens, vor, die nicht ganz korrekt bezeichnet wird, denn es müßte hier statt „Свёнтkа матkа Ченстохова“ [sventka, „swiątka“], wohl „Swięta Matka Boska Częstochowska" ["die Heilige Gottesmutter aus Częstochowa"] stehen. Das Wort "Свёнтka“ [sventka; ,swiątka"] ist dabei entweder eine inkorrekte Form für „swięta“ [.,Heilige“] oder eine .Neuschőpfung“ Dostoevskijs, eine feminine unübliche Form von .swiątek" [poln. "Heiligenbild"] ${ }^{720}$ Die katholischen Polen werden im folgenden als "Schismatiker" bezeichnet. Auf das "(alte), freie" und auf das durch die drei Teilungen "gekreuzigte Polen" beziehen sich die Begriffe "Свободна. Вольна. Крыж“" [„свободна“: russ. „frei“, unabhängig: = „вольна“: poln. „wolna“; „Крыж“ ist eine ukrainisch (= von ukr. križ) gefárbte (dialektale) Variante von poln. „krzyż: „Kreuz"]. „Щихо виендзе, бендзе. Цо то. Дьябли“ [= „Überall ist still, es wird [geschieht etwas]. Was ist das? Böse Geister [Teufel]] ist ein ironisch entstelltes und ergänztes Zitat aus dem exemplarisch patriotischen (und antirusssichen, messianistischen) Draina voin Adam Mickicwicz. $D=i a d y .{ }^{721}$ Durch das hinzugefügte, im Original nicht vorhandene Wort .льябли“" werden die Polen zu „Teufeln“, zum Symbol des ,bösen Feindes“ Rußlands, und der ,polnische Messianismus“ Mickiewicz.s wird als eine Schöpfung des „Antichristen“ bezeichnet. Die frühe ..Rzeczpospolita" [,.Посполита жечь"; die polnische .,adlige Republik"] und die polnische (Exil)regierung (.,ржонл“ [poln. ..rzad“]), die als ..Kamora“" [vgl. „Kamorra" bzw. Camorra: der neapolitanische, die Bourbonen unterstützende (verbrecherische) Geheimbund] bezeichnet wird, schließen diese Reihe ab, die

718 Libd., S. 279 und S. 285.

719 Auch in der Endfassung des Romans sind die polnischen Sătze, die die beiden Herren aussprechen, von stereotypem Charakter, obwohl darin die Wendung pudam dos nizg nicht vorkommt und es keıne Anspielung auf den katholischen Glauben gibt. Vgl. dazu oben, S. 140f.

720 Der Verfasserin war unmöglich festzustellen, ob diese Form dialektal oder archaisch, bzw. ein ..Neologismus“" Dostoevskijs ist.

$721 \mathrm{Vgl}$ dazu MICKIEWICZ 1991, S. 46f. (I)-ıach. Teil II: „Chór: Ciemno wszedzie, glucho wszędzıe: Co to bedzie, co to bedzie?". |IJe Ahnenfeıcer, Teil II: Chor: Dunkel, dumpf ist es aut Erden [eigentl.: überall]. Was soll werden. was soll werden?: Übers. v Walter SCHAMSCHIT.A]). Vgl. auch ZAKIEWI(Z 1968, S. 86f. und LeDNICKI 1953, S. 311). 
in zutreffender Weise grundlegende Züge der polnischen, katholisch geprägten Kultur(geschichte) beschreibt.

Anschließend wird noch eine polnische Dame erwăhnt und ein unvollständiger Satz angeführ, die zur "fremden Rede“ des „,betrügerischen polnischen Verführers" gehören. Grušen'ka bildet dabei einen negativen Kontrast zu dieser „polnischen Dame“. Obwohl der Pole Grušn'ka „sein Herz geschenkt“ habe, hat sie es wohl im Unterschied zu einer „polnischen Dame“ nicht entsprechend "geschătat". Es wird auch der Grund für eine solche Reaktion Grušn'kas angegeben: Die "Russen“ sind für die "Polen" „kein zivilisiertes Volk“, deswegen „können“ sie nicht „gut" sein. Es ist derselbe Satz, den in den Entwürfen Rakitin ausspricht, so daß dieser "russische Atheist" und „Materialist" den Polen äquivalent erscheint. ${ }^{722}$

Die polnischen Worte und teilweise idiomatischen Wendungen in den Entwürfen beweisen, daß Dostoevskij über gute Kenntnisse der polnischen Sprache, Literatur und Kultur verfügte, was ihm erlaubt habe, diese Kenntisse gezielt zur „,ideologischen" Kritik Polens in seinen literarischen Werken einzusetzen. Einem Brief von Dostoevskijs Bruder Michail Michajlovič, der an den Vater gerichtet war, kann man entnehmen, daß die beiden Brüder wăhrend ihrer Studienzeit in Petersburg Polnisch gelernt und polnische Literatur in der Originalfassung gelesen haben. Von den guten Polnischkenntnissen Dostoevskijs kann aber auch der bereits oben angeführte Brief an Ljubimov vom 16. November 1879 zcugen, in dem Dostoevskij diesen um besonders sorgfältige Korrekturen, der. wie er meint, richtigen polnischen Sätze in der Druckfassung bittet. ${ }^{723}$ Es ist darüber hinaus bekannt, daß Dostoevskij noch als Student an der Petersburger Ingenieur-Schule mit einem Polen befreundet war. ${ }^{724}$ Diese noch vor der Verhaftung und Verbannung nach Sibirien erworbenen Kenntnisse der polnischen Sprache und Kultur sowie seine Kontakte mit Polen waren sicherlich in der Omsker Katorga nicht ohne Bedeutung, obwohl fast alle polnischen politischen Mitgefangenen Dostoevskijs Russisch bzw. Französisch sprechen konnten. ${ }^{725}$

Die Meinungen der polnischen Dostoevskij-Forscher über die Polnischkenntnisse Dostoevskijs und über die Funktion des polnischen Wortschatzes sowohl in der Endfassung der Brat ja Karamazovy als auch in den Entwürfen gehen jedoch auseinander. Während WACLAW LEDNICKI behauptet, daß Dostoevskij über gute Polnischkenntnisse verfügt habe, ${ }^{726}$ vertritt ZBIGNIEW ZAKIEWICZ die Ansicht, daß die polnischen Wendungen in den Entwürfen außerst inkorrekt seien und somit lediglich von geringen Kenntnissen zeugt. ZAKIEWICZ bemerkt aber,

722 Vgl. oben, S. 371 (Fußnote 589).

723 Vgl. dazu oben S. 394 (Fußnote 651) und KUMPAN / KONECNYJ 1981 (S. 73: Brief M.M. Lostoevskijs an den Vater aus Petersburg vom 17. Februar 1838). Vgl. auch Bd. 28,1, S. 402 (die Anmerkung der Herausgeber zum Brief F.M. Dostoevskijs an den Vater vom 5 . Juli 1838), sowie den Brief an N.A. Ljubimov Bd. 30, 1, cbd. S. 131

${ }^{724} \mathrm{Vgl}$. bei RIZENKAMPF 1973 (S. 330f.) über die Freundschaft Dostoevskijs mit dem Polen Stanislav Osipovic Stalevskij, der Dostoevskij mit den Werken von Mickievvicz bekannt gemacht haben soll.

${ }^{725} \mathrm{Vgl}$. dazu oben S. $194 \mathrm{fr}$.

${ }^{726} \mathrm{Vgl}$. LEDNICKI 1953, S. 284. 
daß die Zusammenstellung dieser Wendungen, von denen nur ein kleiner Teil in der Endfassung benutzt worden ist, gute Kenntnisse der Mentalitát des polnischen Adels und der Angehörigen der polnischen Intelligenz verrate. Der polnische Dostoevskij-Forscher vermutet auch, daß der polnische Wortschatz teilweise eine Erinnerung Dostoevskijs an die Zeit in der Katorga sei und aus dem Gedăchtnis aufgeschrieben bzw. von einer anderen Person diktiert oder den sogenannten "antinihilistischen“" Romanen entnommen sei. Diese polnischen Idiome und Sătze, die sowohl im Roman als auch in den Entwürfen angeführt werden, sollen danüber hinaus auf die Pläne Dostoevskijs zur Fortsetzung des Romans hindeuten, in der ebenfalls polnische Figuren auftreten sollten, obwohl diese spekulativen Annahmen doch schwer nachzuvollziehen sind, denn die enthaltenen Entwürfe beziehen sich auschließlich auf den Roman Brat 'ja Karamazovy. ${ }^{727}$ IZABELA F. KALINOWSKA schenkt dagegen den in polnischer Sprache verfaßten Äußerungen der beiden polnischen Herren besondere Aufmerksamkeit. ${ }^{728}$ Besonders auffallend sei dabei, daß die beiden stereotypen Figuren vom Erzăhler hauptsächlich mit Hilfe ihrer Sprechweise, die aus einer Mischung von Russisch und Polnisch besteht, als "fremd" und „entmenschlicht" dargestellt werden. Dostoevskij zeige dabei ein großes „Einfühlungsvermögen in die stilistischen Möglichkeiten des Polnischen“, indem er den Grad der Entstellung des Russischen durch die Interferenz mit dem Polnischen áußerst prăzise modulieren konne. ${ }^{729}$ KALINOWSKA meint, daß die polnischen Figuren in der begrenzten Lahl der konventionellen Wendungen „eingeschlossen“" worden sind, damit ihre Stimmen der Subjektivität entbehren und als eine Ergänzung des Autorenwortes (Bachtin) über sie betrachtet werden kơnnten. ${ }^{730}$

Im Gegensatz. zu einer positiven Beurteilung des besonderen stilistischen „Einfühlungsvermögens“ Dostoevskijs in die polnische Sprache in der Endfassung des Romans, behauptet sie zugleich, daß die Entwürfe zu Brat 'ja Karamazovy von keinen guten Polnischkentnissen Dostoevskijs zeugten. Sie enthielten .russische Übersetzungen" und seien darüber hinaus „fchlerhaft“. Nach Ansicht

727 Vgl. ZAKIF.WICZ 1968, S. 86f.

$728 \mathrm{Vgl}$. KalinOWSKA 1994, S. 62ff.

729 Ebd. S. 63: .j.../ polscy bxhaterowic, pozbawicni własnego glosu, przemawiają w powicsci Dasiojewskicgo w swoim wlasnym jçzyku. /.../ Dasiojewski wykazuje duże wyczucic jধzzyka polskicgo. W zalcźnonici od okulicznosici, modulujc - poprzez interferencje z polskim - stor pien znickształcenia jধzyka r(xyjskiego. W'śrixd niewiclu uwag narratora dotyczących 'życia wewnçtrzncgo' Polakow jest jedna sugerująca, żc ich język /.../ $/$ jeszeze jedna forma (sszustwa. /.../ j̧̧zyk /.../ staje siç zewnętrznym przejawem oxdmiennosici Polakơw, ich draźniącej olxcosici /.../. Ich slowa /.../ są obxc - i dlatego narrator z łatwosicią je omija, nic zagłçbia siç w myśli Polakow, nic objaśnia ich motywiw zachowania“ [/.../ polnische Gestalten, eigener Stinıme beraubt, reden in Dustoevskijs Roman in ihrer eigenen Sprache. /.../ Dostoevskij zeigt ein großkes Eintühlungsvermögen in die polnische Sprache. Abhängig von dem jeweiligen Kontext, modulient er durch die Interferenz mit dem Polnischen den Grad der Entstellung der russischen Sprache. Unter den wenigen Bemerkungen des Erzählers, die das 'innere Leben' der Polen betreffen, ist eine, die suggeriert, daB ihre Sprache /.../ eine Form des Betrugs ist /.../ Die Sprache /.../ wird zum äußeren Merkmal der Andersartigkeit der Polen, ihrer ärgerlichen Fremdheit /.../. Thre Worte $i . . /$ sind fremd. und der Erzahler kann sie deswegen außer acht lassen, er vertieft sich nicht in ihre Gedanken. erklärt Motive ihres Verhaltens nicht] ${ }^{730}$ Ehd. S. $63 f$ 
KALINOWSKAS, die teilweise mit derjenigen von ŻAKIEWICZ übereinstimmt, enthălte der erste Teil der polnischen Vokabeln, der mit russischen Übersetzungen versehen ist und sich vorwiegend auf den Alltag bezieht, das sprachliche Material, das teilweise in der Endfassung benutzt worden ist. Der zweite Teil (ohne russische Ubersetzungen), dessen Thematik sich auf die polnische Lebensweise und Kultur bis hin zu dem Zitat aus Dziady erstreckt, sei dagegen aus dem Gedächtnis aufgeschrieben und als eine Erinnerung an die Jahre in der Katorga zu betrachten. ${ }^{931}$ Die Behauptungen Kalinowskas sind wegen eines Mangels an einschlägigen (auto)biographischen Materialien aus der Zeit der Katorga und der Arbeit an den Brat 'ja Karamazovy lediglich spekulativ und nicht überzeugend. Es ließe sich nur anhand einer sprachwissenschaftlichen und sprachgeschichtlichen Analyse des polnischen Wortschatzes Dostoevskijs feststellen, inwieweit es sich um sprachliche Fehler oder aber um dialektal und historisch bzw. um werkimmanent bedingte stilistische sprachliche Abweichungen handelt. Eine solche Analyse würde aber den imagothematischen Rahmen dieser Studie überschreiten und müßte in einer anderen Untersuchung genau erortert werden.

Trotz der ambivalenten und oft spekulativen Beurteilung des ,polnischen“ Wortschatzes und dessen Funktion in der Endfassung und in den Entwürfen des Romans Brat ja Karamazovy durch die Forschung, läßt sich aber nicht bestreiten, daß dieser Wortschatz äußerst gezielt und mit subtiler stilistischer Differenziertheit zur Charakterisierung der polnischen Alter-Figuren eingesetzt wurde. Er erfüllt eine ideologische Funktion und dient als stilistisches Mittel, die polnischen Figuren als "fremd", als "ideologische Feinde Rußlands“, erscheinen zu lassen. Sie werden als negative nationale und literarische Stereotypen und als Vertreter der "rußlandfeindlichen verwestlichten" polnischen Kultur den russischen Figuren als negativer Kontrast gegenübergestellt. Dadurch dienen sie als .Katalysator" zur .,Verwandlung“ des Paares Grušen ka-Dmitrij, in .,russischorthodoxe" Alius-Figuren und bilden den "negativ-subversiven" Hintergrund, auf dem das russische Paar besonders positiv erscheint.

Zusammenfassung: Der letzte Roman Dostoevskijs bildet in imagothematischer Hinsicht die Bilanz seines Schaffens. In ihm treten alle aus den früheren literarischen Werken bekannten Imagothèmes auf. Die drei zentralen Figuren der „Brüder Karamazov", Aleša, Ivan und Dmitrij, repräsentieren dabei die drei Haupt-Imagothèmes in den literarischen Werken Dostoevskijs: Aleša das positiv-utopische Imagothème des "russisch-orthodox-byzantinischen", vorpetrinischen Rußlands, Ivan das negativ utopische und Dmitrij (vor seiner Wandlung) das positiv-utopische Imagothème des verwestlichten, petrinischen Rußlands. Die anderen Figuren lassen sich als komplementăr bzw. äquivalent zu diesen drei ,zentralen“"Figuren bezeichnen. Sie vertreten die zusätzlichen Komponenten dieser drei Imagothèmes. Die dominante Rolle spielt in Brat ja Karamazovy aber das positiv-utopische Imagothème des „orthodox-byzantinischen“, vorpetrinischen Rußlands, weil alle zentralen, psychologisch differenzierten ver-

${ }^{732}$ Ebd., S. $64 f$. 
westlichten Figuren im Laufe der Handlung sich in die positiven russischen Alius-Figuren verwandeln, die ,russisch-orthodox-byzantinische" Identităt wiedererlangen wollen bzw. können. Brat "ja Karamazovy ist somit das „russischste" der literarischen Werke Dostoevskijs. In diesem Werk treten auch die wenigsten fremden Figuren auf. Aufallend dabei ist, daß Brat'ja Karamazovy als eine endgültige „Abrechnung“ mit den Polen zu verstehen ist, die als stereotype Alter-Figuren die negative, ideologische, rußlandfeindliche Komponente des negativ-utopischen Imagothèmes des verwestlichten Rußlands reprăsentieren.

Alle fremden Imageme kommen auch im letzten Roman Dostoevskijs in zwei Funktionen vor: Zum einen dienen sie zur positiven bzw. negativen ,immanenten" Charakterisierung der russischen verwestlichten Figuren; zum anderen treten sie als fremde Figuren (als alter) in der Kontrastfunktion zu den russischen Figuren auf. Diese beiden Funktionen überschneiden sich aber teilweise, so daß einige fremde Imageme, besonders fremde Figuren, die in den Äußerungen der russischen Figuren auftreten, sowohl als (ideologische) Kontrastfiguren als auch als ein Mittel zur Charakterisierung der „inneren“ (utopischen) Welt der jeweiligen russischen Figur eingesetzt werden.

Die fremden Imageme, als Mittel zur immanenten Charakteristik der verwestlichten russischen Figuren, bilden dabei das positive und das negative utopische Imagothème des verwestlichten, petrinischen Rußlands. Das positive utopische Imagothème des verwestlichten Rußlands bilden „idealistische", "Schillersche" Eigenschaften, die hauptsächlich in solchen zentralen Figuren wie Ivan und Dmitrij zu beobachten sind; der wohltătige deutsche Art Gercenštube verkörpen dagegen (als "Idealist") das positive utopische Imagothème des verwestlichten Rußlands. Das negative utopische Imagothème des verwestlichten, ..petrinischen" Rußlands repräsentieren dagegen Fedor Pavlovic Karamazov, Smerdjakov, Fetjukovič, Rakitin oder teilweise Liza Chochlakova, auch der negative, "dämonisch-böse“ (bzw. atheistisch-liberale) Teil der fiktiven „Seelen“ bzw. „Persönlichkeiten“ Ivans, Katerina Ivanovnas, Koljas, Grušen kas oder andeutungsweise Alešas.

Die fremden Imageme, die als handelnde Figuren auftreten, bilden einen Teil des negativ bzw. positiv utopischen Imagothèmes des verwestlichten Rußlands. Die negativen fremden Figuren repräsentieren dabei die ideologische Komponente dieses Imagothèmes. Dazu gehören hauptsächlich die polnischen und jüdischen Figuren, wobei die letzteren zur immanenten Charakteristik Fedor Pavlovič Karamazovs und Grušen kas eingesetzt werden und somit auch das negativ-utopische, subversive „Böse aus dem Westen“ symbolisieren. ${ }^{732}$

Komplementär zu den „westlichen“ Imagothèmes vertreten Zosima, Markel”, Aleš, Paisij, Sof ja, Lizaveta und Grigorij das positive utopische Imagothème des „russisch-orthodox-byzantinischen“, vorpetrinischen Rußlands. Smerdjakov und der Mönch Ferapont vertreten dagegen das negativ-utopische Imagothème des pervertierten fanatischen sektiererischen bzw. petrinisch-orthodoxen Rußlands. Dabei läßt sich eine Tendenz zur Stereotypisierung der Figuren beobachten, die entweder bereits endgültig ,verwestlicht“ oder ,russisch-orthodox-(by-

732 Die jüdischen Fıguren, wie auch die Türken, sind auch als Elemente des orientalischislamıschen Imagothèmes aufzufassen, vgl dazu hautpsächlich bei PoźNIAK 1992, passim. 
zantinisch)“ geprägt gewesen oder erst dazu geworden sind. Die „stereotype Festigkeit" dieser Figuren läßt sich darüber hinaus auch als das Endergebnis eines „Schwankens“, einer Ambivalenz, zwischen dem „Westen“ und „RuBland“ verstehen, eines Prozesses, dem alle zentralen russischen Figuren bzw. alle wichtigen russischen Figuren unterliegen. Alle zentralen Figuren sind in Brat ' ja Karamazovy jedoch psychologisch und kulturell differenziert und ambivalent dargestellt; als deren Ideal wird aber durch den Verlauf der Handlung und durch andere Erzăhlmittel zur Schaffung der fiktionalen Welt des Romans der utopische Zustand der „Geborgenheit" im „russisch-orthodox-byzantinischen" Glauben, wie ihn Zosima, Markel", Sof ja und teilweise Aleša verstehen und praktizieren, suggeriert.

Auf diesem Hintergrund anderer fremder Imageme treten die polnischen Imageme ebenfalls in den zwei oben genannten Funktionen auf:

Die polnischen Figuren sind in der ideologischen Kontrastfunktion (als alter) zu den russischen, hauptsächlich zu Grušen ka und Dmitrij, als negative nationale und literarische Stereotypen eingesetzt. Sie verkörpern die in Bral'ja Karamazovy betont ausgeprägte ideologische Komponente des negativ-utopischen Imagothèmes des verwestlichten Rußlands. Zusätzlich tritt der erste Pole auch als „Typ des westlichen Verführers“ einer „Russin“ auf, d.h. als Bedrohung für die russische religiös-kulturelle Identităt. Beide polnische Herren gehören dabei dem imaginaire social bzw. imaginaire littéraire, dem kulturell vermittelten russischen Imaginären an; sie sind negative literarische russische Stereotypen eines polnischen (falschen) Adligen des „Alten Polen“ aus dem 17. Jahrhundert und zusätzlich mit den Komponenten des negativen Stereotyps eines polnischen Falschspielers und zugleich des polnischen (falschen) Adligen sowie des "schäbigen, scharwenzelnden Polackchen" versetzt, aber nicht "dämonisch" böse, also nicht als Alius aufzufassen; sie lassen sich auch als stereotypisierte, entmenschlichte Figuren der Polen aus Zapiski iz Mertvogo doma bezeichnen. was eine Besonderheit der kreativen Imagination in den literarischen Werken Dostoevskijs ist. Die Polen in Brat ja Karamazovy bilden ebenfalls den Kulminationspunkt der imagothematischen kreativen Vorstellungskraft in den literarischen Werken Dostoevskijs. Sie sind als das synthetisch-stereotype Porträt eines "Polen als ideologischen und politisch-religiösen Feindes Rußlands" kreiert worden, das sich aus beinahe sämtlichen literarischen russischen Polen-Stereotypen zusammengesetzt.

Die Anspielung auf die authentische Figur des Rechtsanwalts Spasowicz, die zur Charakteristik des verwestlichten Rechtsanwalts Fetjukovix dient, bildet dagegen einen Teil des negativen utopischen Imagothèmes verwestlichten, petrinischen Rußlands. Fetjukovix tritt darüber hinaus als Kontrast zu dem patriotischen Staatsanwalt, zu Dmitrij und zu den anderen russischen Alius-Figuren auf.

Die Anspielung auf Mick'IEWICZ durch die Zitierung Puškin in der Rede des Staatsanwalts charakterisient immanent Fedor Pavlovic Karamazov, diese eindeutig negative und abscheulich „dämonische“ Figur des verwestlichten russischen nachpetrinischen Adligen, und bildet somit ebenfalls einen Teil des negativen utopischen Imagothème des verwestlichten Rußlands. 
In Brat'ja Karamazovy kommen folgende polnische Imageme vor:

1. Die Figur des namentlich genannten Polen, des „Verfürers“ Grušen kas, enthălt fast sämtliche negative Eigenschaften der negativen literarischen und nationalen (alt)russischen Stereotypen: den „dicken Polen“ Zagoskins; den ,polnischen Falschspielers" und den (,falschen“) Adligen Vel "tmans bzw. das Stereotyp des "Podvysockijs“; das „schăbige“ und das „,scharwenzelnde Polackchen“", die mit der zum Stereotyp reduzierten Figur der beiden Polen („B's": „Bem“ und „Bogusławski“) aus Zapiski iz Mertvogo doma ergănzt und zugleich überhőht wurde. Als "Verführer" Grušen'kas enthălt er zugleich die Komponente des altrussischen Stereotyps des „Polen als teuflischen Verführers“.

2. Der „große Pole“ und "Leibwăchter" des „dicken Polen“ ist dagegen die auf ein Stereotyp reduzierte Figur von Szymon Tokarzewski, des Mitgefangenen Dostoevskijs und des "Leibwăchters 'Bogusławskis" (T-vskij in Zapiski iz Mertvogo doma).

Die beiden Figuren enthalten aber zugleich wegen des Bezug zu den sibirischen Bekannten Dostoevskijs die Komponente des „Polen als politischen Verschwörers".

3. Komplementär zur polnischen Figur des „Verführers“ Grusen 'kas tritt in Brat ja Karamazovy das altrussische Stereotyp der „Polin als Verführerin“ auf.

4. Die Anspielung auf den Rechtsanwalt Spasowicz dient zum einen zur immanenten positiven Charakterisienung Ivans und zugleich zur immanenten Charakterisierung Fetjukovičs, der beiden russischen negativen Alius-Figuren. "Spasowicz“" symbolisien dabei das „verwestlichte, gemietete, atheistische Gewissen“ des petrinischen Rußlands, das „Böse“ als „Verführung des Antichrists".

5. Das Zitat aus einem Gedicht über Mickiewicz charakterisien immanent Fedor Pavlovic Karamazov als Alius-Figur des "Verräters“ und schafft den negativen Bezug zwischen diesem ,verwestlichten Lüstling“ und dem „polnischen Dichter". 


\section{ZUSAMMENFASSUNG DER EINZELINTERPRETATIONEN}

Es läßt sich zusammenfassend im Hinblick auf die Funktion der polnischen und der anderen fremden Imageme in den literarischen Werken Dostoevskijs festhalten, daß sie sowohl in den Romanen als auch in den weiteren literarischen Werken zur Charakterisierung der russischen Figuren in zweierlei Weise eingesetzt werden:

1. Polnische und fremde Imageme werden zur sogenannten immanenten Charakterisierung der russischen Figuren eingesetzt, so daß diese russischen Figuren auf diese Weise verfremdet, d.h. hauptsächlich „verwestlicht" werden.

2. Polnische und fremde Imageme (ausschließlich als fremde Figuren) charakterisieren russische Figuren, indem sie zu ihnen als Kontrast auftreten.

In der ersten Funktion lassen sich die von den fremden (auch von den polnischen) Imagemen immanent charakterisierten russischen Figuren als Alius, als die ,ganz Fremden", bezeichnen, denn diese russischen Alius-Figuren weisen meistens eine „numinose“, „sakrale“ Funktion auf: als die ,absolut bösen“" bzu: als die .,absolut guten“" Figuren. ${ }^{733}$ Sie haben somit eine negative bzw. eine positive utopische Dimension, d.h. sie erfullen in ihrer extremen „Fremdheit" eine subversive Funktion, stellen die Integrität der russischen, eigenen Welt dieser Werke in Frage.

Polnische Imageme dienen dabei fast ausschlieBlich zur immanenten Charakteristik der extrem negativen russischen Figuren. indem sie diese Figuren als negativ verwestlicht, als eine „Verkörperung des Bösen aus dem Westen“ erscheinen lassen, wobei diese Figuren im Kontext des jeweiligen literarischen Werkes hauptsächlich wegen ihrer Beziehungen zum (polnischen) Katholizismus (Jesuitismus) oder wegen ihres Atheismus bzw. ihrer sozialistischen Über-

${ }^{733}$ Diese Figuren werden aber hier beispielsweise nicht als ..Ideale ${ }^{-*}$ im Sinne Kants (oder Schillers) bezeichnet, denn erstens hält sich diese Arbeit an die Ansătze aus der Hermeneutik Rıcoeurs, die ein anderes Koordinatensystem bildet. und zweitens müßten die Bezüge zwischen Kant und Ricour auf der einen Seite sowie Dostoevskij und Kant andererseits in getrennten Untersuchungen erörtert werden, die den Rahmen dieser Arbeit überschreiten würden. Vgl. dazu auch RICCEUR 1986a, S. 228: „le lien analogique qui fait de tout homme mon semblable ne nous est accessible qu à travers $/ . . /$ de pratıques imagınatıves, telles que l'uléologic et l'uropıe". Obwohl Ricoeur die Fähigkeit, in allen Menschen uns analoge Wesen zu sehen, .ein Ideal der Kommunikation“, .. une Idee au sens Kantien“ nennt, wird sie aber immer durch Ideologie oder Utopie beeinflußt bzw. entstellt (ebd.). Bei dieser Passage wird nochmals der historisch und kulturell bedingte Charakter des imaginarire social deutlich. Siehe ferner zu Ricour und Kant: DECLEve 1966 und zu Dostoevskij und Kant: GOLOSOWKER 1963, wobei für Golosowker Kant in diesem Roman europäische theoretische Philosophie vertritt (ebd., S. 96), so daB seine These den Ergebnissen der vorliegenden Arbeit nicht widerspricht. 
zeugungen als das „Bóse aus dem Westen“ bezeichnet werden können, was sich besonders deutlich in den Romanen Dostoevskijs beobachten laßt.

$\mathrm{Zu}$ den russischen Figuren, die durch polnische Imageme negativ verwestlicht werden, gehoren v.a. zentrale Romanfiguren, die als sogenannte Haupt- bzw. als wichtige Nebenfiguren auftreten. Petr Aleksandrovic Valkovskij, Svidrigajlov, Burdovskij, Petr Stepanovic Verchovenskij, Karmazinov, Fedor Pavlovic Karamazov bzw. Fetjukovic können hier als Beispiele genannt werden. Fast alle diese Figuren werden als negative verwestlichte Russen durch polnische Imageme charakterisiert, wodurch sie besonders subversiv-utopisch, als das "Böse aus dem Westen“ erscheinen. Die „Tiefenstruktur" ihrer Persönlichkeiten geht teilweise auf die negativen polnischen Stereotypen zurück. Sie lassen sich daher als negative ,psychologisch differenzierte literarische negativ polonisierte Stereotypen" bezeichnen. Petr Aleksandrovic Valkovskij ist ein "maskierter" Jesuit, Svidrigajlov ein ,zwielichtiger Handlanger", Petr Stepanovic Verchovenskij ein ,politischer Verschworer“ bzw. Karmazinov ein „dekadenter Adliger".

Diese Figuren sind statisch, verändern sich im Laufe der Handlung kaum bzw. werden durch den (Frei-)Tod daran gehindert, sich zu ändern, d.h. sich dem "russisch-orthodox-byzantinischen Glauben" und den russischen (vorpetrinischen) Traditionen zuzuwenden.

Obwohl diese Figuren auf der Grundlage der nationalen bzw. literarischen negativen polnischen Stereotypen konstruiert sind, die zugleich im kulturell-literarischen (russischen) Imaginären vorkommen, lassen sie sich als Schöpfungen der produktiven Imagination in den W'erken Dostoevskijs bezeichnen, die als psychologisch differenzierte Subjekte, als verwestlichte Figuren der Russen kreiert worden sind.

In ihrer negativ sakralen utopisch-subversiven Funktion bilden diese Figuren das negative utopische Imagothème des verwestlichten, petrinischen RuBlands, wobei sie immer eine ideologische Komponente enthalten (dazu gehöri v.a. die Kritik an „Polen“ und am ..Katholizismus“), die wohl ihrer Herkunft als Stereotypen zuzuschreiben ist.

Auch andere fremde Imageme, u.a. deutsche, französische und englische, tragen zur positiven bzw. zur negativen immanenten Charakteristik der russischen Figuren bei, indem sie diese Figuren positiv bzw. negativ verfremden, „verwestlichen". ihnen die utopische (negative oder positive) Dimension verleihen.

In einer ähnlichen, den polnischen Imagemen äquivalenten bzw. komplementären Funktion, treten v.a. Elemente der französischen Kultur auf. Sie „dămonisieren" auf negative Weise russische Figuren, so daß diese ebenfalls in der Funktion als calius auftreten.

Einige Imageme aus der deutschen Kultur (v.a. aus der deutschen Literatur) dienen dagegen zur positiven (Okzidentalisierung einer bestimmten nussischen Figur, indem sie diese Figur als "Idealisten“ (z.B. als den ,russischen Schiller") erscheinen lassen.

Die negativ verwestlichten russischen Figuren, die ausschließlich durch negative Imageme, darunter polnische, konstruiert werden und als Nebenfiguren auftreten, sind meistens statisch, neigen dazu, zu Stereotypen zu werden. Indem 
sie sich nicht ändern, können sie auch keinen Weg zum „russischen Glauben“ und zur russischen kulturellen („byzantinisch-russisch-orthodoxen“) Tradition, wie z.B. Fedor Pavlovic Karamazov, Rakitin oder Miusov in den Brat 'ja Karamazovy, finden, sie weisen auch keine „Sehnsucht" danach auf.

Dagegen gehören die positiv verwestlichten russischen Figuren, in denen die positive (utopisch-ideale) Okzidentalisienung über die negative dominiert. zu den dynamischen (Haupt)figuren, die den Weg zu "Rußland“ möglicherweise wiederfinden können bzw. eine "Sehnsucht" danach verspüren, obwohl sie beispielsweise auch durch den Tod oder durch eine Krankheit diesem „Oszillieren zwischen dem Westen und Rußland" nicht entkommen können oder an der endgültigen Rückkehr zur russischen kulturell-religiösen Identität gehindert werden. $\mathrm{Zu}$ diesen Figuren gehören, abgesehen von denen der früheren Romane Unizennye $i$ oskorblennye und Igrok, in denen alle Figuren statisch sind, Raskol'nikov, teilweise Svidrigajlov, Radomskij, Rogožin, Stepan Trofimoviz Verchovenskij, Stavrogin, Arkadij, Versilov, Dmitrij, Grušen'ka und Ivan Karamazov.

Diese Figuren verkörpern teilweise das positive utopische Imagothème des verwestlichten Rußlands, wobei sie auch eine utopische negative Komponente in verschiedenem Grad aufweisen können (bzw. sogar müssen), um sich ändern zu können.

In der zweiten Funktion als Kontrast zu den russischen Figuren treten polnische und andere fremde Imageme als Figuren auf. Dabei weisen sie die Funktion als alter auf. Diese Alter-Figuren sind dabei ausschließlich als negative oder als positive nationale, ethnische und literarische Stereotypen aufgebaut bzw. konstruiert. Sie sind dem sozialen (kulturellen) Imaginären entnommen, verändem sich nicht, sind statisch und erfüllen primär eine ideologische Funktion, obwohl sie auch eine utopische Komponente mitenthalten.

Polnische Figuren treten dabei als negative nationale bzw. literarische Stereotypen auf: als Stereotyp des .,Ljachs in der Gestalt eines Teufels“, des „Kartenspielers und Betrügers" bzw. des "falschen Adligen“, des ..politischen Verschwörers", des "katholischen Priesters" (Jesuiten bzw. eines Geistlichen), des "dicken dekadenten (alt)polnischen Adligen“" (aus dem XVII. Jahrhundert), des "schäbigen, schwarwenzelnden Polackchen" oder auch einer „Polin als Verführerin“. Die meisten dieser Stereotypen entstammen der russischen Literatur, z.B. den Romanen 7.agoskins und Vel tmans bzw. Pisemskijs und anderer ,antinihilistischer" russischer Autoren, oder auch der altrussischen Literatur. Polnische Alter-Figuren können auch in einer ,.Katalysator"-Funktion auftreten, indem sie den ihnen gegenübergestellten Russen in einem durch sie, durch ihre Negativität ausgelösten „Bekehrungserlebnis“ die Rückkehr zur russischen Identität ermöglichen. Eine solche Funktion haben beispielsweise polnische Figuren in Prestuplenie i nakazanie, in Podrostok oder in Brat 'ja Karamazovy.

Auch andere fremde Figuren in den literarischen Werken Dostoevskijs sind als negative oder positive nationale, ethnische bzw. literarische Stereotypen „aufgebaut". Zu den positiven literarischen und zugleich nationalen Stereotypen 
gehören die deutschen „Schillertypen“ und die „deutschen Ärztefiguren“, oder auch die ,ideal schönen und guten“ Engländer und Engländerinnen.

$\mathrm{Zu}$ den negativen nationalen bzw. ethnischen (und zugleich literarischen) Stereotypen gehören neben den Polen die Figuren der „Franzosen und Französinnen“" sowie der „Juden" bzw. der „deutschen Frauen“.

Diese Stereotypen gehören mit Ausnahme des Franzosen Lambert, der ein psychologisch differenziertes Stereotyp eines "französischen Spießbürgers“" ist und als eine relativ wichtige Figur auftrit,, zu den episodischen Figuren, die keine eigene Stimme und Gesicht haben, somit nicht als Subjekte bezeichnet werden können.

Alle negativen fremden Alter-Figuren bilden dabei die ideologische Komponente des negativ utopischen Imagothèmes des verwestlichten Rußlands (als ,politische oder ideologische Feinde“ Rußlands und des „russisch-orthodoxen Glaubens"), denn sie weisen als die "bösen" Figuren (z.B. die „Juden" und „Franzosen") auch eine „dämonische", utopisch-negative Komponente auf. Die positiven deutschen und englischen Alter-Figuren bilden dagegen das positive utopische Imagothème des Westens bzw. des verwestlichten Rußlands, wobei die ideologische Funktion der utopischen untergeordnet bleibt.

Komplementär zu den fremden Figuren treten in den literarischen Werken Dostoevskijs positive russische Alius-Figuren auf, in denen die russische kulturell-religiöse (,orthodoxe-byzantinische") Komponente dominiert. Dazu gehören Sonja Marmeladova, die Mutter Arkadijs, Sof ja oder ihr Mann Makar bzw. der starec Zosima. Sie sind ebenfalls statisch und stark stereotypisiert bzw. typisiert dargestellt. Sie stellen den von den anderen (noch) verwestlichten russischen Figuren erwüuschten ,utopischen Endzustand“ der Entwicklung einer russischen Figur dar.

Die psychologisch differenzierten russischen Alius-Figuren wie z.B. Aleša Karamazov weisen dagegen immer eine negative (latente) Okzidentalisierung aut, so daß sie sich als dynamisch und „schwankend“, ainbivalent bezeichnen lassen. Dazu gehören v.a. Figuren der jungen Russen und Russinnen wie Arkadij Dolgonkij, Liza Chochlakova oder Kolja Krasotkin.

Alle russischen Alius-Figuren verkörpern (teilweise) das positive Imagothème des vorpetrinischen, ..russisch-orthodox-byzantinischen" Rußlands, das dem negativen des petrinischen, verwestlichten Rußlands komplementär gegenübergestellt wird. Dieses positive utopische Imagothème weist ebenfalls eine ideologische Komponente auf, die sich ihrer Stereotypisierung zuschreiben lăß auch diese Figuren sind auf der Grundlage der russischen (Auto)Stereotypen konstruiert.

Dabei låßt sich bemerken. daß in allen positiv "orthodox-byzantinischen“, vorpetrinischen bzw. negativ utopischen verwestlichten russischen Alius-Figuren sich die dominierende utopische und die zusätzliche ideologische Komponente überschneiden bzw. vervollständigen.

Neben den vorwiegend positiven russischen Figuren gibt es in den Romanen Dostoevskijs das negative utopische Imagothème des pervertierten sektiererischen baw. des pervertierten russisch-orthodoxen, petrinischen Rußlands. Als Beispiele lassen sich die Wucherin Alena bzw. der Vater Rogožins oder der fal- 
sche Jurodivyj in Besy nennen, indem alle diese Figuren auch teilweise negativ verwestlicht sind.

In den literarischen Werken Dostoevskijs treten somit zwei Imagothèmes des verwestlichten Rußlands auf:

das negative utopische Imagothème,

das positive utopische Imagothème,

wobei die komplementåre negative bzw. positive ideologische Komponente in jedem dieser Imagothèmes mitenthalten ist. Die utopische Komponente (negativ oder positiv) dominiert in den russischen verwestlichten Alius-Figuren, die ideologische in den Alter-Figuren.

Komplementăr dazu kommen darin zwei Imagothèmes des "russisch-orthodox-(byzantinischen)“ Rußlands vor: das „vorpetrinisch“ geprảgte positive utopische Imagothème und das negative Imagothème des „petrinischen", sektiererischen bzw. pervertierten orthodoxen Rußlands.

Alle fremden Figuren sind statisch und können nie als Hauptfigur auftreten: Die Fremden treten immer als Neben- bzw. als episodische Figuren auf.

Als dynamische Hauptfiguren, die (als Subjekte) psychologisch differenziert sind, können nur russische Figuren auftreten, die zugleich positiv und negativ verwestlicht sind und dabei eine "Sehnsucht" nach dem "russisch-orthodox-byzantinischen Glauben" aufweisen, d.h. in denen die positiv utopischen russischen und westlichen Imageme dominieren. ${ }^{734}$

${ }^{734}$ Diese Ergebnisse lassen sich als eine Widerlegung der These Bachtins von der Gleichberechtigung aller Figuren Dostoevskijs auffassen, denn zum einen verfügen die stereotypisierten sowohl russischen als auch fremden Figuren nicht über individualisierte „eigene Stimmen" (vgl. dazu auch KALINOWSKA 1994 und oben, S. 121f.), zum anderen sind die zentralen, vorwiegend positiv verwestlichten russischen Figuren ambivalent, denn sie repräsentieren zugleich das „Eigene“ und das „Fremde“, darüber hinaus sind sie wandlungsfähig und können die russische kulturelle Identităt wieder erlangen. Bachtin hat diese Eigenschaften der zentralen Figuren bemerkt. sie aber als die ..Stimme“ des Publizisten Dostoevskij und als ..oberflächliche Momente“ (.поверхностные моменты“) ignorier beispielsweise den ..monologischen Epilog“ des Romans Prestuplenic I nakazanie; darüber hinaus hat er die episodischen Figuren nicht miteinbezogen, deren Unfreiheit seiner Polyphonie-These widersprechen konnten (vgl. dazu BACHTIN 1972, S, 154f.). Siehe ferner die Kritik an Bachtin bei ALLAIN 1996, der die dominante, ,diktatorische Stimme des Autors“ im Inneren der Stimmen der Hauptfiguren zu finden glaubt, so daß aus ihrer Unfreiheit eine .,höhere Form künstlerischer Freiheit des Autors" entstehe, die eine Unterordnung unter ein .,monarchisches“ erzählerisches Konzept ermoglicht, wobei er wohl mit ..Autor" den Erzähler meint. Nur die episodischen Figuren konnen in ihrem zuweilen unberechenbaren Benehmen ihrer Unfreiheit eine ..Prise Anarchie“ verleihen (ebd., S. 18f.). Der bereits oben erwăhnte JONES (1990 und 1998) spitzt dagegen die These Bachtins zu und spricht über die „Dekonstruktion des Sinns“ bei Dostoevskij, die eine Krise des Bewußtseins am Rande des Abgrunds widerspiegle. Sie außere sich in der antimimetischen Poetik des .,fantastischen Realismus“als ein „.Chaos der Stimmen“, obwohl er doch zugibt, daß es möglich sei, Dostoevskij weiter im Rahmen eines „logozentrischen Diskurses“. z.B. als einen „Christen“ oder ..Humanisten“ zu lesen (JONES 1998, S. 9ff. und S. 19). 
Es låßt sich dabei bemerken, daß die oben aufgezählten Imagothèmes in allen literarischen Werken Dostoevskijs vorkommen, obwohl die russisch-orthodoxe Komponente zuerst in Prestuplenie $i$ nakazanie sich andeutet und bis zu den Brat'ja Karamazovy immer deutlicher hervortritt, so daß sie schließlich dominant wird.

Diese Entwicklung betrifft v.a. die Romane Dostoevskijs, obwohl auch in seinen anderen literarischen Texten fremde (polnische) und russische Imageme und Imagothèmes in ähnlichen Funktionen vorkommen, die aber wegen der Kürze dieser Texte nicht so stark ausgeprägt sind.

In dieser Studie konnte somit festgestellt werden, daB die in ihr angewandte modifizierte imagologische Methode der französischen Forscher, die sich auf Paul Ricœurs Hermeutik und auf dessen Theorie der Imagination stützt, in der die Imagination nicht nur als individuelle, sondern auch als soziale produktive bzw. reproduktive (das soziale Imaginäre) in zwei komplementär-oppositionellen Varianten als Ideologie und Utopie auftreten kann, auch bei der Interpretation der nationalen, ethnischen bzw. im allgemeinen der kulturellen Fremdheit in den literarischen Werken Dostoevskijs am Beispiel der Darstellung Polens äuBerst ergiebig sein kann.

Die fremden Imageme, die mehrere Varianten von Imagothèmes bilden, werden dabei immer der eigenen, russischen Welt der literarischen Werke Dostoevskijs dialektisch bzw. komplementär gegenübergestellt. Wegen des personalistisch-dialektischen Charakters der Erzählweise Dostoevskijs spiegelt sich die Darstellung der Fremdheit hauptsächlich in der Figurenkonstellation dieser Werke wider.

In allen Werken Dostoevskijs läßt sich darüber hinaus eine Tendenz zur Typologisierung bzw. zur Stereotypisienung aller Figuren beobachten, was im Zusammenhang mit den oben im theoretisch-methodologischen Teil erwähnten Forschungsbeiträgen bereits angedeutet wurde.

In der vorhegenden Arbeit wurde somit nicht nur die Funktion der polnischen Fremdelemente im Kontext anderer Fremdelemente innerhalb der fiktionalen Welt der literarischen Werke Dostoevskijs ermittelt, sondern es wurde auch der direkte Zusammenhang zwischen der nationalen, ethnischen bzw. kulturellen Zugehörigkeit der einzelnen Figuren und deren Rang und Funktion innerhalb dieser Werke. d.h. ein Zusammenhang zwischen der thematischen, inhaltichen und der formalen. kompositionellen Ebene dieser Werke festgestellt. Es ergab sich somit, daß im Hinblick auf die Darstellung der kulturellen Fremdheit ein dialektischer Zusammenhang zwischen der formalen, kompositionellen und der ideellen, philosophisch-weltanschaulichen Ebene der literarischen Werke Dostoevskijs besteht. Es wurde dabei die hervorragende Rolle des sozialen Imaginären bestätigt, das zum einen als "Material" bei der Schaffung der psychologisch differenzierten Figuren, der Schöpfungen der produktiven kreativen Imagination Dostoevskijs, eingesetut und andererseits direkt als nationale, ethnische oder literarische Stereotypen übemommen wurde und somit immer unentbehrlich war. 


\section{LITERATURVERZEICHNIS}

\section{A. Ausgaben der Texte Dostoevskius}

Dostoevskij, Fedor Michajlovic

1928-1959 Pis'ma. Bd. 1-4. Dolınin. A.S. (Hg.). Moskva-Leningrad.

1972-1990 Polnoe sobranie sočinenij $v$ tridcati tomach. Leningrad.

Dostojewski, F.M. [Dostoevskij, Fedor Michajlovic]

1957 Sämtliche Werke in zehn Bänden. Bd. 5 (Der Jüngling. Roman). Übers. v. E.K. Rahsin. München: Piper.

1958 Sämtliche Werke in zehn Bänden. Bd. 6 (Auf=eichnungen aus einem Totenhaus und drei Erä̈hlungen). Übers. v. E.K. Rahsin. München: Piper.

1959 Sämtliche Werke in zehn Bänden. Bd. 9 (Der Spieler. Späle Romane und Novellen). Übers. v. E.K. Rahsin. München: Piper.

1960 Sämtliche Werke in zehn Bänden. Bd. 10 (Onkelchens Traum und zwei Romane). Übers. v. E.K. Rahsin. München: Piper.

1980a Sämtliche Werke in zehn Bänden. Bd. 2 (Onkelchens Traum und zwei Romane). Übers. v. E.K. Rahsin. München: Piper.

1980b Sämtliche Werke in zehn Bänden. Bd. 4 (Der Spieler. Späte Romane und Novellen). Übers. v. E.K. Rahsin. München: Piper.

1985 Großinquisitor. Übersetzt von Marliese Ackermann. $\mathrm{Hg}$. und erläutert von Ludolf Müller. München: Wewel (Quellen und Studien zur russischen Geistesgeschichte; 4).

1986a Der Doppelgänger. Frühe Prosa I. In: Gesammelte Werke in zwanzig Bänden. Bd 1. Hg. v. Gerhard Dudek und Michael Wegner. Übers. v. Wilhelm Plackmeyer. Berlin und Weimar: Aufbau-Verlag.

1986b Die Brüder Karamasow. Roman in zwei Teilbänden. Aus dem Russischen von Karl Nötzel. In: Sämtliche Romane und Erzählungen in sechzehn Bänden. Bd. 14. Frankfurt a.M.: Insel (it 974).

Dostojewskij, Fjodor [Dostoevskij, Fedor Michajlovic]]

1996a Verbrechen und Strafe. Aus dem Russischen von Swctlana Geier. Zürich: Ammann. 
1996b Der Idiot. Roman. Aus dem Russischen von Swetlana Geier. Zürich: Ammann.

1998 Böse Geister. Roman. Aus dem Russischen von Swetlana Geier. Zürich: Ammann.

\section{B. FORSCHUNGSLITERATUR}

Adam Mickevic v russkoj pečati

1957 Adam Mickevic $v$ russkoj pećati 1825-1955. Bibliograficeskie materialy. Moskva-Leningrad (Akademija nauk SSSR. Institut Russkoj Literatury (PuSkinskij Dom)).

Allain, Louis

1984 Dostöevski et l'Autre. Lille: Presse Universitaires de Lille. Paris: Institut d'Etudes Slaves (Bibliothèque russe de l'Institut d'Etudes Slaves ; 70).

$1996 K$ voprosu o 'nezavisimych golosach' geroev $v$ romanach Dostoevskogo (iezisy protiv Bachtina). In: Slavia Orientalis, Tom XVL, Nr 1. S. 13-19.

Allport Gordon W.

1971

Die Natur des Vorurteils. Köln.

Al'tman. Moisej Semenovic

1971

I arsenala imen i prototipov literaturmych geroev Dostoevskogo. In: V.G. Bazanov und G.M. Fridlender (Hgg.): Dostoevskij i ego vremja. Leningrad, S. 196216.

Antonovic. M.A.

Literaturno-kritičeskie stat 'i. Moskva-Leningrad.

Anderson, Roger B.

1986 Dostoevsky. Myths of Duality. Gainesville: University

Archinova, A.V. of Florida Press.

1994 Dostoevskij i Mickevic. In: Dostoevskij. Materialy i issledovanija. Bd. 11. Sankt-Peterburg, S. 13-27.

Arendt. V.B.

[Tokarževskij, Šimon]: F.M. Dostoevskij v Omskoj katorge (l'ospominanija katorz̈anina). Perevod s pol'skogo V.B. Arendta. In: Zven ja 6. Moskva, S. 495-512.

Asinovskaja, G.A.

E istorii peredovych idej $v$ russkoj medievistike (Timofej N. Granovskij). Moskva 1955. 
Aufrichtige Eraahlungen

1995

Austin, John-Langshaw

1962

Aylesworth, Gary E.

1991

Azodo, Ada Uzoamaka

1993

Bachtin, Michail M

1963

1972

Bader, Rudolf

1988

Balzac, [Honoré de]

1966

Baranski, Zbigniew

1969

1994

Barres, Egon

1978

Barthes, Roland

1981

Bartoszyñski, Kazimierz.

1971
Jungclausen, Emmanuel (Hg.): Aufrichtige Erzählungen eines russischen Pilgers. Die vollständige Ausgabe. Freiburg, Basel, Wien: Herder ('1974) (HerderSpektrum; 4156).

How to Do Things with Words. Harvard.

Dialogue, Text, Narrative: Confronting Gadamer and Ricoeur. In: Silverman 1991, S. 63-81.

L'Imaginaire dans les Romans de Camara Laye. New York, San Francisco, Bem (u.a.): Lang (Studies in African and African-American Culture; 4).

Problemy poètiki Dostoevskogo. Moskva (2. Auflage) ['1929].

Problemy poètiki Dostoevskogo. Moskva (3. Auflage).

Eiconics and Comparative Literature Imagology. A Discussion of the Interdisciplinary and Transdisciplinary Aspects of an Imagological Approach in the Australian Contex. In: Commonwealth. Essays and Studies. Reciprocal Images of Britain and the Commonwealth. Bd. 11, Nr. 1, Autumn. S. 22-31.

Illusions perdues. In: La Comédie Humaine. Bd. 3. Paris.

Iwan Turgieniew w kregu spraw polskich. In: Slavia Orientalis, 3, S. 259-265.

Literatura polska $w$ Rosji w latach siedemdziesiatych XIX wieku. In: Preeglad Humanistyc=ny 3, S. 59-77.

Vorurteile: Theorie, Forschungsergebnisse, Praxisrelevanz. Opladen: Leske (UTB 704: Pädagogik).

Mythologies. Paris.

Le grain de la voix. Entretiens 1962-1980. Paris.

Zagadnienie komunikacji literackiej w utworach narracyjmych. In: Sławinski, Janusz (Hg.): Problemy socjologii literatury. Wroclaw [u.a.], S. 127-148. 
Bar-Tal, Daniel et al. (Hgg.)

1989

Bassewitz, Susanne von

1990

Bassnett, Susan

1993

Bazyłow, Ludwik

1973

1984

Beer, Hans-Peter

1978

Belknap, R[obert]

1996

Beller, Manfred

1992

Belov, S[ergej] V.

Benveniste, Émile

Benz. Wolfgang 1966 1996

Berghan, Marion

1977

Bernard-Donals, Michael F.

1994
Stereotyping and Prejudice. New York, Berlin, Heidelberg (u.a.): Springer.

Stereotypen und Massenmedien: Zum Deutschlandbild in französischen Tageszeitungen. Wiesbaden: Deutscher Uni-Verlag (DUV: Sozialwissenschaften). Zugl.: Diss. Univ. Münster 1987.

Comparative Literature. A Critical Introduction. Oxford (UK) / Cambridge (USA).

Spoleczeñstwo rosyjskie $w$ pierwszej polowie XIX wieku. Wroclaw [u.a.]: Zakład Narodowy im. Ossolińskich Wydawnictwo.

Polacy w Petersburgu. Wrocław [u.a.].

Die Gestalt des Evgenij Pavlovic Radomskij in Dostoevskijs Roman „Der Idiot“. Tübingen (Skripten des Slavischen Seminars der Universität Tübingen 15).

O tradicii épistoljarnogo romana $v$ 'Romane $v$ devjati pis 'mach' Dostoevskogo. In: Dostoevskij. Materialy $i$ issledovanija. Bd. 13. Sankt-Peterburg. S. 23-28.

Stoff, Motiv, Thema. In: BrackertStückrath (Hgg.) 1992, S. 30-39.

Roman Dostoevskogo „Prestuplenie i nakazanie“. Kommentarij. Leningrad.

Problèmes de linguistique générale. Paris.

Feindhild und V'orurteil: Beiträge über Ausgrenzung und V'erfolgung. München: Dt. Taschenbuch-Verl. (dtv 4(094).

Images of Africa in Black American Literature. London: Macmillan.

Mikhail Bakhtin: Between Phenomenology and Marxism. Cambridge: Cambridge University Press (Literature, Culture, Theory 11 ). 
Bertram Anne/Richard A. Spears

1993

NTC's Dictionary of Proverbs and Clichés. Lincolnwood (Chicago): National Textbook Company, NTC Publishing Group.

Bhabha, Homi K.

1991

1995

Białokozowicz, Bazyli

1962

1966

1971

1994

Blaicher, Günther

1987

1992

Bleicher, Thomas

1980

1986

1993

Bobowicz-Potocka. Zofia 1975

Bobrownicka. Maria

1992

1995
Nation and Narration. London: Routledge.

The location of culture. London: Routledge.

Powstanie stuczniowe w poezji rosyjskiej lat sześćdtiesiatych XIX wieku. In: Jezyk rosyjski. Jg. 15, November-Dezember, 5, S. 1-10.

Lwa Tolstoja zwiqzki = Polska. Warszawa.

$Z$ dziejów wzajemnych polsko-rosyjskich zwiqzków literackich $w X I X$ wieku. Warszawa. in hisk

Antynihilistyc=na powieść (Antinigilistic=eskij roman). In: Nieuważny (Hg.) 1994, S. 27.

(Hg.): Erstarrtes Denken. Studien zu Klischee, Stereotyp und Vorurteil in englischsprachiger Literatur. Tübingen: Narr.

Das Deutschlandbild in der englischen Literatur. Darmstadt.

Elemente einer komparatistischen Imagologie. In: Riesz (Hg.) 1980a, S. 12-24.

Auf der Suche nach der modernen Maghrebinität. Amrouches literarische Initiation und Mediation. In: Riesz/Boemer/Scholz (Hg.) 1986, S. 378-398.

Interkulturelle Mediation: Zur Kooperation wischen Komparatistik und interkultureller Germanistik bei der Entwicklung eıner interdis=iplinären Fremdheitsforschung. In: Wierlacher (Hg.) 1993, S. 333-354.

Kto byl wlaściwym autorem rozdzialu posiwięconego Dostojewskiemu w ksiq̇ice Szymona Tokarzewskiego .Siedem lat katorgi'? In: Preeglad Humanistuc=ny 8, S. 91-94.

(Hg.): Mity narodowe w literaturach slowianiskich. Studia poswięcone XI Międzynarodowemu Kongresowi Slawistów w Bratuslawie. Kraków (Zeszyty Naukow'e Uniwersytetu Jagielloniskiego 1060; Prace historyc=noliterackie z. 81).

Narkotyk mitu: S=kice o swiadomości narodowej $i$ kulturowej slowian zachodnich $i$ poludniowych. Krakow. 
Boden, Dieter

1982 Die Deutschen in der russischen und der sowjetischen Literatur. Traum und Alptraum. München und Wien: Olzog (Analysen und Perspektiven Bd. 15/16).

Boerner, Peter

1975a Das Bild vom anderen Land als Gegenstand literarischer Forschung. In: Sprache im technischen Zeitalter 56, S. 313-321.

1975b National Images and Their Place in Literary Research: Germany as Seen by Eighteenth-Century French and English Reading Audiences. In: Monatshefte für deutschen Unterricht, deutsche Sprache und Literatur 67, S. 358-370.

Bogdal, Klaus-Michael (Hg.)

1990

1993

Bogusławski, Józef

1896

Bohun, Michat

1996

Neue Literaturtheorien. Eine Einführung. Opladen: Westdeutscher Verlag (WV studium 156).

Neue Literaturtheorien in der Praxis. Textanalysen von Kafkas ,.Vor dem Geset “". Opladen: Westdeutscher Verlag (WV studium 169).

Wspomnienia Sybiraka. In: Nowa Reforma 249-299.

Bol Šaja Sovetskaja Énciklopedija

Fiodor Dostojewski i idea upadku cywilizacji europejskiej. Katowice.
1971
Bd. 5.Moskva.
1976
Bd. 23. Moskva.

Borgotta. Edgar L./Marie L. Borgotta (Hgg.)

1992 Encyclopedia of Sociologv. Bd. I. New York [u.a.].

Boyer, Bernard-Marc

1973

Wechselseitige Stereotvpen in Deutschland und Frankreich. In: Zeitschrift für Kulturaustausch 23,3, S. $65 \mathrm{ff}$.

Brachfeld. Oliver

1962 Note sur l'imagologie ethnique. In: Revue de Psychologie des Peuples 17, S. 341-349.

Brackert, Helmut/Jöm Stückrath (Hgg.)

1992

Literaturwissenschaft. Ein Grundkurs. Reinbek bei Hamburg: Rowohlt Taschenbuch Verlag (Rowohlts Enzyklopädie).

Brang. Peter

.Images ${ }^{\circ}$ und ,Mirages ${ }^{\circ}$ in Turgenevs Darstellung der Nationalcharaktere. Klischeezertrümmerung oder Trendverstärkung? In: Thiergen. Peter (Hg.): Ivan S. Turgenev: Leben, Werk und Wirkung: Beiträge der Internationalen Fachkonferenz aus Anlaß des 175. (jeburtstages. Bamberg. 15.-18. September 1993. Mün- 
Brokgauz, F.A./.A. Efron (Hgg.)

chen: Sagner (Vorträge und Abhandlungen zur Slavistik 27), S. 1-25.

1892-1898 Encyklopedičeskij Slovar', Bd. 7, 9, 12A, 13A. S.-

Brunel, Pierre (Hg.)

Peterburg.

1981 Mythes, images, représentations. Actes du XIV congrès de la société française de littérature générale et comparée. Limoges 1977. Limoges: Trames (79).

1994a Dictionnaire des mythes littéraires. [Monaco]: Éd. du Rocher (Nouvelle édition augmentée).

1994b Mythes et Littérature. Paris: Presse de l'Université de Paris-Sorbonne.

Brunel, P./Cl. Pichois/A.-M. Rousseau

$1983 Q$ Qu'est-ce que la littérature comparée? Paris.

Brunel, Pierre/Yves Chevrel (Hgg.)

1989 Précis de littérature comparée. Paris.

Brückner, Aleksander

1957

Brunnbauer, Barbara U.

1995

Brunner, Emil

1947 Unser Glaube. Eine christliche Unterweisung. Zürich: Theologischer Verlag Zürich.

Brzoza, Halina

1984 Dostojewski. Mysl a forma. Lódż.

1995 Dostojewski. Międy mitem. tragediq i apokalipsq. Toruń.

Budanova, N.F.

1992 Dostoevskij o Christe $i$ istine. In: Dostoevskij. Materialy $i$ isseldovanija. Bd. 10. Sankt-Peterburg. S. 21-29.

Budanova, N.F./G.M. Fridlender (Hgg.)

1993-1995 Letopis' 'zi=ni i tvorčestva F.M. Dostoevskogo v trex tomach. 1821-1881. Bd. 1-3, Sankt-Peterburg.

Bulgakov, Sergij

Die Orthodoxie. Die Lehre der orthodoxen Kirche. Übersetzt und eingeleitet von Thomas Bremer. Trier: Paulinus Verlag (Sophia: Quellen ostlicher Theologie 29). 
Cadot, Michel

1967 La Russie dans la vie intellectuelle française (18391856). Paris: Fayard.

Carr, David

1997 White und Ricœur: Die narrative Erä̈hlform und das Allıägliche. In: Stückrath/Zbinden (Hgg.) 1997, S. 169179.

Carré, Jean-Marie

1920

Gothe en Angleterre. Étude de littérature comparée. Paris: Plon (Deuxième édition).

1927 Images d'Amerique. Lyon: Lardanchet.

1947 Les écrivains français et le mirage allemand. (18001940). Paris.

Chardin. Philippe

1989

Thématique comparatiste. In: Brunel/Chevrel (Hgg.) 1989, S. 163-176.

Chevrel, Yves

1989

La littérature comparée. Paris.

Chodera, Jan

1974 Das Bild Polens in der deutschen Literatur. In: Kommunität. Berlin, 69/70, S. 28-47.

Chomjakov, Aleksej S.

1969

Stichotvorenija i dramy. Leningrad (Biblioteka poeta. Bol'Saja serija; vtoroe izd.)

Comer, William J.

1996 Rogozhin and the ,Castrates': Russian Religious Traditions in Dostoevsky's. The Idiot'. In: Slavic and European Journal, 40, I (Spring), S. 85-99.

Corbey, Raymond/Joep Leerssen (Hgg.)

1991

Alterity. Identity. Image. Selves and Others in Society and Scholarship. Amsterdam-Atlanta (Amsterdam Studies on Cultural Identity; 1 ).

Cortot, Alfred

o.J. Éditions de Travail des Civres de Chopin. Ballades Op. 23-38-47-52. Paris.

Cross, Anthony Glenn/Smith, Gerald Stanton

1984 Eighteenth Century Russian Literature, Culture and Thought: A Bibliography of English-Language Scholarship and Translations. Newtonville.

Cross, Anthony Glenn

1985

Černyševskii, N.G.

1918
The Russian Theme in English Literature from the Sixteenth Century to 1980. Introductory Survey and a Bibliography. Oxford: Willem A. Meeuws.

Lessing. ego vremja, ego ¿izn' $i$ dejatel'nost'. In: Polnoe sobranie sočinenij [N.G. Cermvševskago]. Bd. 3. 
(Sovremennik 1857. Kritika i bibliografija. Zametki o zurnale v $1857 \mathrm{~g}$. Stat'i po krest'janskomu voprosu. Lessing). Petrograd, S. 585ff.

1948 Lessing, ego vremja, ego ¿̇in' $i$ dejatel'nost'. In: Polnoe sobranie soćinenij v 15 tomach. Bd. 4. (Stat'i $i$ recen-ii (856-1857). Moskva, S. 202ff.

Dal', Vladimir

1956 Tolkovyj slovar’ „̇ivogo velikorusskogo jazyka. Bd. 2, Moskva.

Dąbek-Wirgowa, Teresa/Andrzej Z. Makowiecki (Hgg.)

1992 Kategoria Europy w kulturach slowiańskich. Warszawa.

Danilevskij, Nikolaj Ja.

1991

Dcclève, Henri

1966

Derrida, Jacques

1967a De la grammatologie.

$1967 \mathrm{~b} \quad L$ écriture et la différence. Paris.

1974 Grammatologie. Frankfurt a.M.: Suhrkamp.

Descombes, Vincent

Rossija i Evropa. Moskva (Nachdruck der Ausgabe: Rossija i Evropa. V'zgljad na kul'turnyja i političeskija otnošenija Slavjanskago mira $k$ Germano-Romanskomu. Sanktpeterburg 1871, izdanie ispravlennoe i dopolnennoe).

1979

Diels, Paul

Le Kantisme selon quelques philosophes contemporains: P. Ricour, E. W'eil, M. Scheler, M. Heidegger. Phil. Diss. Katholische Univ. Louvain.

Le Mème et l'Autre. Quarante-cinq ans de philosophie française (1933-1978). Paris.

1963 Die slavischen V'ölker. Wiesbaden: Harrassowitz.

Dihle, Albrecht

1994

Dinzelbacher, Peter (Hg.)

1993

Dmitriev, S.S. (Hg.)

1969

Die Griechen und die Fremden. München: Beck.

Europäische Mentalitätsgeschichte: Hauptthemen in Einzeldarstellungen. Stuttgart: Kröner (Kröners Taschenausgabe; 469). in Litk

Granovskıj, Timofej Nikolaevič. Bibliografija (18281967). Moskva.

Dobroljubov, N.A.

1952

Sobranie sočinenij $v$ trex tomach. Bd. 3: Stat $i$ recenzii. Moskva. 
Dostojewski [Dostoevskij], Aimée

1920 Dostojewski geschildert von seiner Tochter. München: Ernst Reinhardt.

Dostoevskaja, A.G.

1971 Vospominanija. Moskva.

Dostojewskij. Stadt Baden-Baden

1995 Fjodor M. Dostojewskij. Stadt Baden-Baden 1995 (Katalog der Ausstellung des Staatlichen Literaturmuseums Moskau vom 15. Oktober bis 19. November im Jesuitensaal des Rathauses Baden-Baden).

Dubnow, Simon [Dubnov, Semen Markovic]

1920 Die neueste Geschichte des jüdischen Volkes. 17891914. 2 Bde. Berlin: Jüdischer Verlag.

1925-1929 Weltgeschichte des jüdischen Volkes. 10 Bände. Berlin: Jüdischer Verlag.

Durand, Gilbert

1978 Les Structures anthropologiques de l'imaginaire: Introduction à l'archétypologie générale. Paris.

Dutu. Alexandru

1980

1985 Histoire littéraire et histoire des mentalités. Une récapitulation. In: Synthesis 12, S. 86-89.

Dworski, Andrzej

1983

Dyserinck, Hugo

1964

Littérature et histoire de mentalités. Les modèles d'humanité. In: Actes du VIlle Congres de I'AICL. Köpeczi, Béla/György M. Vajda (Hgg.). Bd. 2, Stuttgart, S. 517-522.

Puszkin w kregu kultury polskiej. Wroclaw (Acta Universitatis Wratislaviensis 720 ; Slavica Wratislavensia 30).

Zur Sonderstellung der französisch schreibenden flämischen Autoren der Generation von 1880. In: Die neueren Sprachen, Jg. 13, H. 10, S. 468-480.

1966 Tum Problem der ...images" und .. mirages" und ihrer Untersuchung im Rahmen der lergleichenden Literaturwissenschaft. In: Arcadia I, S. 107-120.

1977

Komparatistik. Eine Einführung. Bonn.

1978

Über Möglichkeiten und Grenzen der Komparatistik. In: Konzepte der Komparatistik l. Mainzer Komparatistische Hefte, 2. S. $15 \mathrm{ff}$.

1980a Der Beitrag der Komparatistik zur Rezeptionsforschung und die Möglichkeit einer fachspezifischen Rezeptionsforschung innerhalb der Komparatistik. In: Konstantinovic, Zoran/Manfred Naumann (Hg.): Proceedings of the IXth Congress of the ICL.A. Bd. 2. Innsbruck, S. 135-140. 
1980b Die Quellen der Negritude-Theorie als Gegenstand der komparatistischen Imagologie. In: Komparatistische Hefie, 1 (1980), 1, S. 31-40.

1982 Komparatistische Imagologie jenseits von „Werkimmanen=" und „Werktranszenden=". In: Synthesis 9, S. 27. 40.

1988a Komparatistische Imagologie. Zur politischen Tragweite einer europäischen Wissenschafi von der Literatur. In: Dyserinck/Syndram (Hgg.) 1988, S. 13- 37.

1988b Zur Entwicklung der komparatistischen Imagologie. In: Colloquium Helveticum, 7, S. 19-42.

1989 Die Problematik der Nationalität aus der Sicht der Vergleichenden Literaturwissenschaft. In: Entstehung und Bewahrung einer Nation - Ein Thema der Gesellschaftsgeschichte? Tagung des Landesverbandes nordrhein-westfälischer Geschichtslehrer in Zusammenarbeit mit der Landeszentrale für politische Bildung Nordrhein-Westfalen vom 27. bis 29. Juni 1988 im Gustav-Streseman-Institut. In: Geschichte Politik und ihre Didaktik, Sonderheft, 6, Paderborn, S.61-72.

1991 Komparatistik. Eine Einführung. 3. durchges. und erw. Auflage ( $\left.{ }^{1} 1977\right)$. Bonn: Bouvier (Aachener Beiträge zur Komparatistik; 1).

1992a Komparatistik als Europaforschung. In: Dyserinck/Syndram (Hgg.) 1992, S. 31-62.

1992b Graf Hermann Keyserlings Südamerikanische Meditationen aus der Sicht der komparatistischen Imagologie. In: Siebenmann/König (Hgg.) 1992, S. 147162.

1997 Uber neue und erneuerte Perspektiven der komparatistischen Imagologie angesichts der Reaktivierung der Beziehungen zum osteuropäischen Raum. In: Mehnert (Hg.) 1997, S. 12-28.

Dyserinck, Hugo/Manfred S. Fischer (Hgg.)

1985

Internationale Bibliographie $=u$ Geschichte und Theorie der Komparatistik. Stuttgart (Hiersemanns Bibliographische Handbücher; 5).

Dyserinck, Hugo/Karl Ulrich Syndram (Hgg.)

1988 Europa und das nationale Selbstverständnis. Imagologische Probleme in Literatur. Kunst und Kultur des 19. und 20. Jahrhunderts. Bonn.

Dyserinck, Hugo/Karl Ulrich Syndram (Hgg.)

1992

Komparatistik und Europaforschung. Perspektiven vergleichender Literatur- und Kulturwissenschaft. Bom: Bouvier (Aachener Beiträge zur Komparatistik: 9). 
Dzikowska, Elżbieta

1993

Dzwonkowski, Włodzimierz

Das Gedicht „Bajonelt aufgesett" von W. Broniewski und dessen deutsche Übersetung. Zum Problem des Vorkommens von Stereotypen im polnisch-deutschen Dialog. In: Germanistentreffen Bundesrepublik Deutschland-Polen: Regensburg, 6.9.-30.9. 1993. Dokumentation der Tagungsbeiträge. Hg. v. DAAD Bonn. Bonn (Reihe Germanistik), S.43-.51.

\section{1}

Dżouns, Malkol'm V

1998

Eicher, Elisabeth [u.a.] (Hgg.)
Rosja a Polska. Warszawa.

1995

Eliade, Mircea

1963

Encyklopedia Powszechna

Engels, Friedrich

1862

1845

Elistratov, V.S.

1994

Erfen, Irenc/Karl-Heinz Spiess (Hgg.)

Dostoevskij posle Bachtina (Issledovanie fantastičeskogo realizma Dostoevskogo). Sankt-Peterburg.

Spiegelbilder. Was Ost- und Westdeutsche übereinander erzählen. Tübingen: Tübinger Vereinigung für Volkskunde e.V.

Aspects du mythe. Paris 1963.

Bd. 10., Warszawa.

Die Lage der arbeitenden Klasse in England: nach eigner Anschauung und authentischen Quellen. Leipzig: Wigand.

Rossija kak mif (k voprosu o strukturno-mifilogičeskich tipach vosprijatija Rossii Zapadom). In: Rossija i Zapad 1994, S. 6-18.

1997

Fremdheit und Reisen im Mittelalter. Stuttgart: Steiner.

Esaulov, I.A.

1994

Fitiemble. Rene

1963

Comparaison n'est pas raison. La crise de la littérature comparée. Paris.

1988-1989 L'Europe chinoise. Bd. I: De l'Empire romain à Leibniz. Paris: Gallimard 1988; Bd. 2.: De la sinophilie à la sinophobie. Paris: Gallimard 1989 (Bibliothèque des Idées).

1954-1961 Le mythe de Rimbaud. Bd. I: Genèse du mythe 18691949. Bibliographie analvtique et critique survie d'un 
Falck, Colin

1994

Falck, Lennart

1992

Falikova, N.E.

1994

Farley, John E.

1995

Fauskevăg, Svein Eirik

1993

Fedotov, George P.

1966

Felmy, Karl Christian

1990

Feuer Miller, Robin

1981

Firchow, Peter

1990

Fischer, Manfred S.

1977

$1979 a$ supplément aux iconographies. Paris 1954 (3. Aufl.). Bd. 2: Structure du mythe. Paris 1961 (nouvelle édition, revue, corrigée, augmentée de nombreux passages censurés en 1952).

Myth. Truth and Literature: Towards a True Post-modernism. Cambridge: Cambridge Univ. Press.

Sprachliche „Klischees“ und Rezeption: empirische Untersuchung zum Trivialitätsbegriff. Bern, Frankfurt a. M. (u.a.): Lang (Zürcher germanistische Studien; 33). Zugl. Diss. Univ. Zürich 1991.

Amerikanskie motivy $v$ pozdnich romanach F.M. Dostoevskogo. In: Zacharov, V.N. (Hg.): Novye aspekty v izučenii Dostoevskogo. Sbornik naučnych trudov. Petrozavodsk 1994, S. 199-241.

Majority-Minority Relations. Englewood Cliffs, New Jersey, Prentice Hall (3. Auflage).

Allégorie et tradition. Etude sur la technique allégorique et la structure mythique dans .. Le Roi des Aulnes" de Michel Tournier. Oslo: Solum Forlag: Paris: Didier Erudition.

The Russian Religious Mind. Bd. 1: Kievan Christianity. Cambridge, Mass.: Harvard University Press (1946).

Die orthodoxe Theologie der Gegenwart. Eine Einführung. Darmstadt: Wissenschaftliche Buchgesellschaft.

Dostoevsky and „The Idiot". Author, Narrator, and Reader. Cambridge. Mass. and London: Harvard University Press.

The Nature and Uses of Imagologv. In: Valdès (Hg.) 1990, S. 135-142.

Probleme internationaler Literaturrezeption. Michel Tourniers ,..Le Roi des Aulnes" im deutsch-französischem Kontext. Mit Geleitwort von Michel Iournier. Bonn (Aachener Beitrăge zur Komparatistik: 2).

Komparatistik: Das Aachener Programm. In: Deutsche Universitätszeitung 35, 24, S. 778-81. 
1979b Komparatistische Imagologie. Für eine interdisziplinäre Erforschung national-imagotyper Systeme. In: Zeitschrifi für Sozialpsychologie 10, S. 30-44.

$1981 \quad$ Nationale Images als Gegenstand Vergleichender Literaturgeschichte. Untersuchungen zur Entstehung der komparatistischen Imagologie. Bonn: Bouvier (Aachener Beitrăge zur Komparatistik; 6).

1987 Literarische Imagologie am Scheideweg. Die Erforschung des ..Bildes vom anderen Land" in der Literatur-Komparatistik. In: Blaicher (Hg.) 1987, S. 55-71.

1992 Europäisches und nationales Selbstverständnis bei Ernst Robert Curtius. In: Dyserinck/Syndram (Hgg.) 1992, S. 321- 365.

Foucault. Michel

Frank, Peter R.

L'Archéologie du Scrvoir. Paris.

Spiegelungen Polens in der deutschen Literatur von Opit bis zu Grass. Skiz=en zum Image/Mirage eines lolkes und zum historischen Hintergrund. In: Erkennen und Deuten. Essons =ur Literatur und Literaturtheorie. Edgar Lohner in memoriam. Unter Mitarbeit zahlreicher Fachgelehrter hg. v. Martha Woodmansee/Walther F. W. Lohnes. Berlin: Erich Schmidt 1983, S. 172-195.

Franz, Norbert

1998

Die Russische Seele: Wie sie ist, wer sie kennt, und wozu man sie braucht. (Vorträge am Slavischen Seminar der L'niversität Tühingen; 14). Tübingen.

Frege, Gottlob

1967

Über Sinn und Bedeutung. In: Kleine Schriften. Hg. von Ignacio Angelelli. Darmstadt: Wissenschaftliche Buchgesellschaft. S. 143-162.

Friedberg, Maurice

1970

Frierson, Cathy A.

1993

Fues. Wolfram Malte

The Jew in Tsarist Russia. In: The Jew in Post-Stalin Soviet Literature. Washington. S. 10-19.

Peasant Icons. Representations of Rural People in l.ate Nineteenth-Century Russia. New York. Oxford: Oxford University Press.

1995

Text als Intertext: Zur Moderne in der deutschen Literatur des 20. Jahrhunderts. Heidelberg: Winter (Probleme der Dichtung, Studien zur deutschen Literaturgeschichte; 23 ). 
Gadamer, Hans-Georg

1967

1975 Wahrheit und Methode. Grundzüge einer philosophischen Hermeneutik. Tübingen: J.C.B. Mohr (Paul Siebeck) ${ }^{4} 1975$ (unverănderter Nachdruck der 3., erweiterten Auflage).

Galster, Bohdan

\section{1}

Gerigk, Horst-Jürgen

Dostojewski w Polsce. In: Znak 1/2, S. 186-195.

1965

Versuch über Dostoevskijs .,Jüngling “. Ein Beitrag zur Theorie des Romans. München: Fink (Forum Slavicum; Hg. v. Dmitrij Tschiževskij; 4).

1981 Die Gründe für die Wirkung Dostoevskijs. In: Dostoevsky Studies. Journal of the International Dostoevsky Society, 2, S. 3-26.

1991 Die Sache der Dichtung, dargestellt an Shakespeares "Hamlet", Hölderlins „Abendphantasie" und Dostojewskijs „Schuld und Sühne “. Hürtgenwald: Pressler.

1992a Dostojewskij - der Ideologe und Dichter. In: Jahrbuch der Dostojewskij-Gesellschaft, 1, Flensburg, S. 90-103.

1992b Dostojewskijs "Paradoxalist“. Anmerkungen =u den ..Aufeeichnungen aus einem Kellerloch". In: Geyer/Hagenbüchle (Hgg.), S. 481-497.

1995 Die Russen in Amerika. Dostojewskij. Tolstoj, Turgenjew und Tschechow in ihrer Bedeutung für die Literatur der USA. Hürtgenwald: Pressler.

1997a Gerigk, Horst-Jürgen (Hg.): .Die Brüder Karamasow". Dostojewskijs letter Roman in heutiger Sicht. Elf Vorträge des IX. Symposiums der internationalen Dostojewskij-Gesellschafi Gaming. Niederösterreich 30. Juli -6. August 1995. Dresden: Dresden Univ. Press (Artes liberales; 1 ).

1997b Die Architektonik der ..Brüder Karamasow". In: Gerigk (Hg.) 1997a: „.Die Brüder Karamasow“, S. 4774.

Gerrits, André/Nanci Adler (Hgg.)

1995

Vampires Unstaked. National Images, Stereotypes and Myths in East Central Europe. Proceedings of the Colloquium. Amsterdam. 18-20 Mav 1994. Amsterdam [u.a.].

Geyer, Paul/Roland Hagenbüchle (Hgg.)

1992

Das Paradox: Eine Herausforderung des abendländischen Denkens. Tübingen: Stauffenburg (Stauffenburg Colloquium; 21). 
Geyer, Carl-Friedrich

1996

Giesen. Bernhard (Hg.)

1991

Gilman, Sander L.

1985 Difference and Pathology. Stereotypes of Sexuality. Race and Madness. Ithaca. London: Cornell University' Press.

Girard, René

1963 Dostoïevski, du double à l'unité. Paris: Plon.

1972 La Violence et le Sacré. Paris: Grasset.

Gockel, Heinz

1979 Mythologie als Ontologie. Zum Mythosbegriff im 19.

Götz, Nikolaus

1989 Das Deutschlandbild Voltaires in seinen historiographischen Werken. Trier. Zugl. Diss. Univ. Trier 1987.

Golczewski, Frank

1974 Das Deutschlandbild der Polen 1918-1939. Eine Untersuchung der Historiographie und der Publizistik. Düsseldorf.

Goldstein, David 1.

1981 Dostoevsky and the Jews. Foreword by Joseph Frank.

(jolosowker, Ja. E. Austin and London.

1963 Dostoevskij i Kant. Razmyšlenie citatelja nad romanom 'Brat 'ja Karamazovy' i traktatom Kanta 'Kritika cistogo razuma'. Moskva.

Gollwitzer, Heinz

1962

Goldgart. Stella

Die gelbe Gefahr. Geschichte eines Schlagworts. Studien =um imperialistischen Denken. Göttingen.

1986 Stereotyp Polaka w literatur=e rosyjskiej XIX wieku.

Gorev, B. [Goldman. Boris Isaakovič] In: K.uzny (Hg.) 1986, S. 117-125. In i.

1922

Russkaja literatura i evrei. In: L'vov-Rogačevskij, V. [Rogačev'skij, Vasilij L'vovič] 1922, S. 5-92.

(jozenpud, Abram A.[kimovic]]

1971

Dostoevskij i muzyka. L.eningrad.

Graevenitz, Gerhart von

1987

Mythos: Zur Geschichte einer Denkgewohnheit. Stuttgart: Metzler. 
Grauby, Françoise

1994

Greverus, Ina-Maria

1995

Grillparzer, Franz

1987

Grišin, D.V.

1971

Grossman, Leonid P.

1924

1934

1935

Gross, Stefan

1980

Grzybek. P.

1990

Guardini, Romano

1951

Gurvitch, Georges [Gurvic, Georgij Davidovic]

Dostoevskij i iudaizm. Ispoved' odnogo evreja. Moskva.

Die Jüdin von Toledo. Trauerspiel in fünf Aufzügen. In: Werke in sechs Bänden. $\mathrm{Hg}$. v. Helmut Bachmaier. Bd. 3 (Dramen 1828-1851). Frankfurt a.M.: Deutscher Klassiker Verlag, S. 483-555.

Dostoevskij-človek, pisatel’ i mify. Melbourne.

Dostoevskij i pravitel'stvennye krugi 1870-ch godov. In: Literaturnoe nasledstvo, Bd. 15. Moskva, S. 83162.

F.M. Dostoevskij. Brat'ja Karamazovy. Bd. 1. Moskva.

Ernst Robert Curtius und die deutsche Romanistik der zwanziger Jahre. Zum Problem nationaler Images in der Literaturwissenschafi. Bonn: Bouvier (Aachener Beiträge zur Komparatistik; 5).

Kulturelle Stereotype und stereotype Texte. In: Koch, W. (Hg.): Natürlichkeit der Sprache und der Kultur. Bochum: Brockmeyer (Bochumer Beitrăge zur Semiotik; 18), S. 300-327.

Religiöse Gestalten in Dostojewskijs Werk. Studien über den Glauben München: Kơsel ${ }^{4} 1951$. iu hi $i^{2}$ 1969

Guyard, Marius-François

1951

Günther, Hans

1993
Symbolisme social et sociologie dynamique. Présentation. choix de textes. biographie. bibliograpie par Jean [Auger] Duvignaud. Paris.

La littérature comparée. Avant-propos de Jean-Marie Carré. Paris.

Der sozialistische Übermensch. M. Gor 'kij und der sowjetische Heldenmythos. Stuttgart, Weimar: Metzler. 
1994 Der Helden- und Feindmythos in der totalitären Kultur. Tübingen (Vorträge am Slavischen Seminar der Universität Tübingen; 3).

Hahn, Hans Henning ( $\mathrm{Hg}$.

1995

Historische Stereotypenforschung: methodische Überlegungen und empirische Befunde. Oldenburg: Bibliotheks- und Informationssystem der Universität

Handbuch zur Nestorchronik Oldenburg.

1977

Die Nestorchronik. Der altrussische Text der Nestorchronik in der Redaktion des Abtes Silvestr aus dem Jahre 1116 und ihrer Fortsetzung bis zum Jahre 1305 in der Handschrift des Mönches Lavrentij aus dem Jahre 1377 sowie die Fortsetzung der Suzdaler Chronik bis zum Jahre 1419 nach der Akademiehandschrift. Nachdruck der zweiten Auflage des ersten Bandes der „Vollständigen Sammlung russischer Chroniken" ("Polnoe sobranie russkich letopisej"). Leningrad 1926-1928. München: Fink (Handbuch zur Nestorchronik: Hg. von Ludolf Müller; Bd 1; Forum Slavicum; Bd. 48.).

Hanslik, Inge

1985

Das Bild Rußlands und Polens im Frankreich des 18. Jahrhunderts. Frankfurt a. M. (u.a.): Lang (Europäische Hochschulschriften, R. 13; 102).

I larder, Hans-Bernd

1969

H larris. W.V.

1992 Dictionary of Concepts in Literary Criticism and Theory. New York.

Harreß, Birgit

1993

Hastedt. Claudia

Mensch und Welt in Dostoevskijs Werk. Ein Beitrag zur poetuschen Anthropologie. Köln. Weimar, Wien: Böhlau (Bausteine zur Slavischen Philologie und Kulturgeschichte; Reihe A: Slavistische Forschungen; N.F $8(68))$.

Schiller in Rußland: Materialien =u einer Wirkungsgeschichte, 1789-1814. Bad Homburg (u.a.): Gehlen (Frankfurter Beiträge zur Gennanistik: 4). Zugl. Habil.-Schrift. Univ. Frankfun a.M.

1998

Heidegger, Martin

Selhstkomplexität. Individualität und so:iale Kategorisierung. Münster, New York, München, Berlin: Waxmann (Texte zur Sozialpsychologie 2). Zugl.: Diss. Univ. Münster 1997.

Sein und Zeit. Tübingen: Niemeyer "' 1986. 
Heinıe, Heinrich

1973

1975

1979

1982

1986

Heinurich, Klaus

1982

Heitrmann, Klaus

1996

Henmig, Thomas

1996

Henttschel, Gerd

1995

Herrmann. Dagmar ( $\mathrm{Hg}$.)

1988a

1988b

1992
Historisch-kritische Gesamtausgabe der Werke. Bd. 6: Briefe aus Berlin. Über Polen. Reisebilder I/II. Hamburg: Hoffmann und Campe.

Historisch-kritische Gesamtausgabe der Werke. Bd. 1/: Buch der Lieder. Text. Hamburg: Hoffmann und Campe.

Historisch-kritische Gesamtausgabe der Werke. Bd. 8/1: Die romantische Schule. Text. Hamburg: Hoffmann und Campe.

Historisch-kritische Gesamtausgabe der Werke. Bd. 15: Geständnisse. Memoiren und kleinere autobiographische Schriften. Hamburg: Hoffmann und Campe.

Historisch-kritische Gesamtausgabe der Werke, Bd. 7/I.: Reisebilder III/IV. Text. Hamburg: Hoffmann und Campe.

Parmenides und Jona. Vier Studien über das Verhältnis von Philosophie und Mythologie. Frankfurt a.M.: Stroemfeld.

Spiegelungen. Romanistische Beiträge zur Imagologie. Hg. v. Gert Pinkernell und Oskar Roth. Heidelberg: Winter.

Intertextualität als ethische Dimension. Peter Handkes Ästhetik ,nach Auschwit=“. Würzburg: Königshausen \& Neumann (Epistemata: Reihe Literaturwissenschaft: 180). Zugl.: Diss. Univ. Tübingen 1994.

Stereotyp und Prototyp: Überlegungen zur begrifflichen Abgrenzung vom linguistischen Standpunkt. In: Hahn (Hg.) 1995, S. 14-40.

Deutsche und Deutschland aus russischer Sicht. 11.17. Jahrhundert. München: Fink (West-Östliche Spiegelungen. Wuppertaler Projekt zur Erforschung der Geschichte Deutsch-Russischer Fremdenbilder unter d. Leitung von Lew Kopelew, R. B. 1).

Deutsche und Deutschland in der russischen Lyrik des frühen 20. Jahrhunderts. München: Fink (West-Östliche Spiegelungen: R. B. Sonderband).

Deutsche und Deutschland aus russischer Sicht. 18. Jahrhundert: Aufklärung. München: Fink (West-Östliche Spiegelungen. R. B. 2). 
Hettema, Theo Leonardus

1996

Hielscher, Karla

1999

Hillmann, Karl-Heinz

1994

Hinderer, Walter

1985

1993

Hingley, Ronald

1967a

$1967 b$

1972

1981

Hoffmann, Johannes

1986

Hogrebe. Wolfram

1993

Horn, Peter

1987

Horstmanu, Axel

1993
Reading for Good. Narrative Theology and Ethics in the Joseph Story from the Perspective of Riccur's Hermeneutics. Kampen. (Studies in Philosophical Theology, 18). Zugl. Diss. Univ. Leiden 1966.

Dostojewski in Deutschland. Frankfurt a.M., Leipzig: Insel (Insel Taschenbuch 2576).

Wörterbuch der Soziologie. Stuttgart: Kröner (KTA 410; 4. uberarb. und erg. Auflage).

Produzierte und erfahrene Fremde. Zu den Funktionen des Amerika-Themas bei Bertolt Brecht. In: Wierlacher (Hg.) 1985, S. 47-64.

Das Phantom des Herrn Kannitverstan. Methodische Überlegungen $=u$ einer interkulturellen Literaturwissenschaft als Fremdheitswissenschaft. In: Wierlacher (Hg.) 1993, S. 199-217.

Russian Writers and Society 1825-1904. New York, Toronto: McGraw-Hill Book Company (World University Library).

Von Puschkin bis Tolstoj. Eine Literatursoziologie. München: Kindler (Kindlers Universitäts Bibliothek: World University Library).

Die russische Geheimpolizei 1565-1970. Bayreuth: Hestia.

Russian Writers and Society 1917-1978. London: Methuen ${ }^{2} 1981$ ( $\left.{ }^{1} 1979\right)$ (University paperbacks: 727).

Stereotypen. Vorurteile. Völkerbilder in Ost und West in Wissenschaft und Unterricht: eine Bibliographie. Wiesbaden: Harrassowitz.

Die epistemische Bedeutung des Fremden. In: Wierlacher (Hg.) 1993, S. 355-369.

Fremdheitskonstruktionen weißer Kolonisten. In: Wierlacher (Hg.) 1987, S. 405-418.

Das Fremde und das Eigene - ..Assimilation" als hermeneutischer Begriff. In: Wierlacher (Hg.) 1993, S. $371-409$. 
Hostowiec, Paweł [Stempowski, Jerzy]

1961 Polacy w powiesciach Dostojewskiego. In: Eseje dla Kassandry. Paryż, S. 228-246.

Hsia, Adrian

1997 Chinesia. The European Construction of China in the Literature of the $17 \mathrm{th}$ and $18 \mathrm{th}$ Centuries. Tübingen: Niemeyer (Communicatio; 10).

Hugo, Victor

o.J. Der Glöckner von Notre-Dame. Mit Bildern von Gustav Brion in Gravüre von Yon und Perrichon. Übersetzt v. Arthur von Riha. Berlin.

$1993 \quad$ Notre-Dame de Paris. 1482. Paris.

Huntington, Samuel $\mathbf{P}$

1996

Der Kampf der Kulturen (The Clash of Civilizations). Die Neugestaltung der Weltpolitik im 21. Jahhundert. München-Wien.

Hubbs, Joanna

1988

Mother Russia. The Feminine Myth in Russian Culture. Bloomington and Indianapolis: Indiana University Press.

Hübner, Kurt

Ingold, Felix Phillip

1985

Die Wahrheit des Mythos. München: Beck.

Ippoldt, Juliusz

1981

o.J.

Dostojewskij und das Judentum. Frankfurt a.M.: Insel.

Slownik niemiecko-polski i polsko-niemiecki. C=ęść druga polsko-niemiecka (Handwörterbuch der deutschen und polnischen Sprache. Zweiter Teil: polnischdeutsch). Warszawa o.J.: Trzaska, Evert, MichalskiVerlag.

Iwanow, Wjatscheslaw [Ivanov, Vjačeslav]

1932

Jackson, Robert Louis

Dostojewskij. Tragödie - Mythos - Mystik. Tübingen.

1984

Jackson, Robert Louis (Hg.): Dostoevskv: New Perspectives. Prentice-Hall: Englewood.

1993a Dostoevsky and the Marquis de Sade. The Final Encounter. In: Jackson 1993b, S. 144-161.

1993b Dialogues with Dostoevsky. The Overwhelming Questions. Stanford: Stanford University Press.

1999 Alešas Rede am Stein. Das ganze Bild. Tübingen (Vorträge am Slavischen Seminar der Universität Tübingen: 29).

Jamme, Christoph

"Gott an hat ein Gewand": Grenzen und Perspektiven philosophischer Mythos-Theorien der Gegenwart. Frankfurt a.M.: Suhrkamp. 
Janaszek-Ivaničková, Halina

1980 Ospólczesnej komparatystyce literackiej. Warszawa.

1990 La relation entre le sien et l'étrange dans 'L'Etrangere' de Maria Kuncewiczowa et 'La Terre $d^{\prime}$ Urlo' de Milos:. In: Proceedings of the XIIth Congress of the ICLA. München 1988. Bauer, Roger [u.a.] (Hg.). Bd. 2. München, S. 113-117.

Jauss, Hans Robert

1977

Ästhetische Erfahrung und literarische Hermeneutik. Bd. I: Versuche im Feld der ästhetischen Erfahrung. München: Fink (UTB 692).

Jazukiewicz-Osełkowska, L,udwika

1981 Fiodor Dostojewski a literatura polska. In: Jezyk Rosyjski, 4, Jg. 34, S. 195-200.

Jeismann, Michael

1992 Das Vaterland der Feinde. Studien zum nationalen Feindbegriff und Selbstverständnis in Deutschland und Frankreich 1792-1918. Stuttgart: Klett-Cotta (Sprache und Geschichte 19).

Jernakoff. Nadja

1981

"Crime and Punishment ".: Svidrigajlov - A Character in His Own Right. In: Transactions of the Association of Russian-American Scholars in the USA, 14, S. 44 59.

Jersch-Wenzel, Steffi (Hg.)

1987

Jervolino, Domenico

1984

Deutsche - Polen - Juden. Ihre Beziehungen von den Anfängen bis ins 20. Jahrhundert. Beiträge =u einer Tagung. Berlin: Spiess (Finzelveröffentlichungen der Historischen Kommission zu Berlin; 58).

1990 The Cogito and Hermeneutics: The Question of the Subject in Ricceur. Dordrecht [u.a.]. [Englische Übersetzung von Jervolino 1984].

Johnston, Otto W.

1990

Jolles, André

1958 Einfache Formen: Legende, Sage, Mythe, Rätsel. Spruch. Kasus, Memorabile, Märchen. Wit. Darmstadt: Wiss. Buchgesellschaft ${ }^{2} 1958$.

Jones, Malcolm V.

Der deutsche Nationalmvthos. Ursprung eines politischen Programms. Stuttgart: Metzler.

1990 Dostoevsky after Bakhtin. Readings in Dostoevsky's Fantastic Realism, New York, Cambridge [u.a.]: Cambridge University Press. 
Joseph Jurt

Južnyj, A.

1978-1979 Rencontres. L'image de l'Afrique et des africains dans la littérature française. Un état présent des recherches. In: Cuvres \& Crtitique III, 2-IV, I, S. 219-137.

1991 Iz vospominanij o F.M. Dostoevskom. In: Vajnerman, Viktor: Dostoevskij i Omsk. Omsk, S. 112-118 [zuerst in: Literaturnaja Gruzija 2 (1983), S. 178-188].

Kabbani, Rana

1986

1991

Kaiser, Gerhard R.

Europe's myths of Orient: Devise and Rule. Basingstoke: Macmillan.

1980

Kalinowska, Izabela F.

1994

Kappeler, Andreas

Offener Brief an die Christenheit. Düsseldorf: Econ.

1987

1990 Kappeler, Andreas (Hg.): Die Russen. Ihr Nationalbewußtse in in Gechichte und Gegenwart. Köln: Markus (Nationalităten- und Regionalprobleme in Osteuropa; 5).

Einführung in die Vergleichende Literaturwissenschaft. Forschungsstand - Kritik - Aufgaben. Darmstadt: Wissenschaftliche Buchgesellschaft.

Dostojewski i Polacy. In: Teksty Drugie 1, S. 59-67.

Kappeler, Andreas [u.a.] (Hgg.): Die Deutschen im Russischen Reich und im Sowjetstaat. Köln: Markus (Nationalitäten- und Regionalprobleme in Osteuropa: 1).

Karamsin. Nikolaj Michailowitsch [Karamzin, Nikolaj Michajlovic]

1966 Briefe eines reisenden Russen. Übers. v. Johann Richter. München: Winkler.

Karamzin, Nikolaj Michajlovic

1984 Pis 'ma russkogo putešestvennika. Lotman, Ju. M. (u.a.)

Karjakin, Ju. F. (Hg.). Leningrad.

1983 Začem Chroniker v „Besach“. In: Dostoevskij. Materialy $i$ issledovanija. Bd. 5. Leningrad, S. 113-131.

Karpf, Ernst [u.a.] (Hgg.)

1995

..Getürkte Bilder". Zur Inszenierung von Fremden im Film. Marburg: Schüren Presseverlag (Arnoldshainer Filmgespräche 12).

Kataev, Vladimir B.

1994

Cechov und Deutschland (Zur Problemstellung). Tübingen ${ }^{2} 1994$ (Vorträge am Slavischen Seminar der Universităt Tübingen 2). 
1997 Richard Vagner $i$ russkie pisateli XIX veka. Tübingen (Vortrăge am Slavischen Seminar der Universităt Tũbingen $\mathrm{Nr} .11 \mathrm{c}$ ).

Kataev, V.B./R.-D. Kluge (Hgg.)

Katkov, M.N.

1996 Cechovi Germanija. Moskva 1996.

1887

Sobranie statej po pol'skomu voprosu pomeščavíichsja $v$ Moskovskich Vedomostjach. Russkom Vestnike i Sovremennoj Letopisi. Vypusk pervyj. Moskva.

Keller, Mechthild

1985

1987

1992

Kępinski, Andrzej

1986

$1990 \mathrm{a}$

1990b

Kijko, E.I.

Keller, Mechthild [u.a.] (Hgg.): Russen und Rußland aus deutscher Sicht. 9.-17. Jahrhundert. München 1985 (West-östliche Spiegelungen, R. A. 1).

Keller, Mechthild ( $\mathrm{Hg}$.): Russen und Rußland aus deutscher Sicht. 18. Jahrhundert: Aufklärung. München (West-östliche Spiegelungen, R.A. 2).

Keller, Mechthild (Hg.): Russen und Rußland aus deutscher Sicht. 19. Jahrhundert: Von der Jahrhundertwende bis zur Reichsgründung (1800-1871). München (West-ostliche Spiegelungen, R.A. 3).

Typologia relacji kulturowych polsko-rosyjskich w pierwszych d-iesięcioleciach XIX wieku. In: Lużny (Hg.) 1986, S. 105-116.

Lach $i$ Moskal. Z dziejów stereotypu. Warszawa-Kraków.

Bies w postaci Lacha. çyli u źródel stereotypu. In: Lużny (Hg.) 1990, S. 191-i98.

1980

Kiparsky, Valentin

1964

Kirpotin, Valerij. Ja.

1980

Kjetsaa, (jeir

Klin, Eugeniuš

Dostoevskij i Renan. In. Dostoevskij. Materialy i issledovanija. Bd. 4. Leningrad. S. 106-122.

English and American Characters in Russian Fiction. Berlin (Veröffentlichungen der Abteilung für slavische Sprachen und Literaturen des Osteuropa-Instituts an der Freien Universität Berlin; Bd. 31).

Dostoevskij. Strachov i Evgenij Pavlovič Radomskij. In: Mir Dostoevskogo. Etjucty $i$ issledovanija. Moskva, S. 135-152.

Dostojewskij. Sträfling - Spieler - Dichterfürst. Wiesbaden: VMA.

1981 Methoden und Probleme der vergleichenden Literaturwissenschaft. Arbeitstagung der bilateralen Germani- 
Kljušnikov, V. [P.]

1865

Kloocke, Kurt

1985

Kloepfer, Rolf

1994

Kloos, Ulrike

1992

Kluge, Rolf-Dieter

1964

1967

1969

1982

1984

1987
1986 Die deutsch-polnischen Literaturbeziehungen als Prüfstein der Germanistik und Komparatistik. In: Akten des 7. Internationalen Germanisten-Kongresses. Bd. 9: Deutsche Literatur in der Weltliteratur. Kulturnation statt politischer Nation? Hg. von Fr. N. Mennemeier und Conrad Wiedemann. Tübingen: Niemeyer, S. 9194.

sten-Komission DDR-VR Polen v. 15.-16. Oktober 1980 in Markkleeberg. In: Zeitschrift für Germanistik (Berlin) 2, 4, S. 464-466.

Marevo. Roman v četyrech castjach. Moskva.

Formtraditionen - Roman und Geschichte: Dargestellt am Beispiel des Briefromans. In: Ludwig (Hg.) 1985, S. 189-207.

Imagologie et transferts culturels. L'Image du tiers monde ..noir" dans le roman français actuel. In: Studi Italiani di Linguistica Teoretica e Applicata, Jg. 23, 3, S. 523-536.

Niederlandbild und deutsche Germanistik 1800-1933. Ein Beitrag zur komparatistischen Imagologie. Amsterdam-Atlanta (Studia Imagologica; 4).

Die Rolle Polens in Aleksandr Bloks Versepos .V'ozmezdie". In: Die Welt der Slawen. Jg. 9, H. 4, S. 426-435.

Westeuropa und Rußland im Weltbild Aleksandr Bloks. München (Slavistische Beiträge: 27).

Darstellung und Bewertung des Deutschen Ordens in der deutschen und polnischen Literatur. In: Zeitschrift für Osiforschung, Jg. 18, 1, S. 15-53.

Zum Wandel des Menschenbildes in der russischen Literatur des 19. und 20. Jahrhunderts. In: Festschrift für Wilhelm Lettenbauer. Mèstan, A. und E. Weiher (Hgg.). Freiburg, S. 81-94.

Versuch über russische Kinderliteratur. Linguistische und poetologische V'orüberlegungen für eine Gegenstandsbestimmung. In: Zeitschrift für Slavische Philologie, Jg. 44, H. I, S. 36-75.

Belinskij und Dostoevskij im Streit um Puskkins Tat 'jana. Zur Deutungsgeschichte des Romans .. Evgenij Onegin". In: Zeitschrift für Slawistik 32. 2, S. 238250. 
1992 Ivan S. Turgenev. Dichtung wischen Hoffnung und Entsagung. München: Wewel (Quellen und Studien zur russischen Geistesgeschichte; Band 11).

1996 Richard Vagner v Rossii. Postanovka problemy. Tübingen (Vortrăge am Slavischen Seminar der Universităt Tübingen, Nr. 11A).

1998a Die Dämonen der Revolution. In: Setzer/Müller/Kluge (Hgg.) 1998, S. 89-110.

1998b Heinrich Heine in Rußland. Tübingen (Vorträge am Slavischen Seminar der Universität Tübingen 15).

1999 Kluge, R.-D. (Hg.): Von Polen. Poesie und Politik ... Adam Mickiewic= 1798-1998. Mit einem Essay von Karl Dedecius und Beiträgen von Tilman Berger, Gerardo Cunico, Wojciech Ductik (u.a.). Tübingen: Attempto.

2000 Deutsche und Polen: eine neuralgische Nachbarschaft im Spiegel der Literatur. In: Jekutsch, Ulrike/Walter Kroll (Hgg.): Slavische Literaturen im Dialog. Festschrift für Reinhard Lauer. Wiesbaden: Harrassowitz, S. 439-457.

2002 Polen im Leben und Werk von Nikolaus Lenau vor dem Hintergrund der schwäbischen Polenbegeisterung 1830 (Aufsatz im Druck in der Festschrift für Gerhard Giesemann, hrsg. von Ulrike Jekutsch).

Kluge. R.-D./H. Willich-Lederbogen/V.B. Kataev (Hgg.)

2001

Knapp, Liza

1996

Kohn. Hans

1948

Komorowski, Manfred

1976

Konstantinovic, Zoran

1988

1991
Richard Vagner $v$ Rossii. IEbrannye trudy učastnikov russko-nemeckoj konferencii $v$ marte 1997 goda $v$ Moskve $v$ dvuch tomach. 2 Bde. Tübingen (Skripten des Slavischen Seminars der Universität Tübingen 34).

The Annihilation of Inertia. Dostoevsky and Metaphysics. Evanston, Illinois: Northwestern University Press (Studies in Russian Literatur and Theory).

Propheten ihrer Völker (Studien zum Nationalismus des 19. Jahrhunder(s). Bern.

Das Spanienbild Voltaires. Frankfurt a.M.: Lang (Europäische Hochschulschriften. R. 13;41).

Vergleichende Literaturwissenschaft: Bestandsaufnahme und Ausblicke. Bern, Frankfurt a. M. [u.a.]: Lang (Germanistische Lehrbücher; 81).

"Interkulturelle Germanistik" oder Komparatistik. In: Akten des VIII. Internationalen Germanisten-Kongresses Tokyo 1990. Bd. 2. München: ludicium, S. 45-49. 
1992a Monokultureller Wissenschaftlichkeitsanspruch versus kulturelle Multinationalität. Zum Verhältnis zwischen "Interkultureller Germanistik" und Komparatistik. In: Dyserinck/Syndram (Hgg.) 1992, S. 281-288.

1992b Das Anderswerden der Konkretisation. Zum Problem der Alterität in der Vergleichenden Literaturwissenschaft. In: Leerssen/Syndram (Hg.) 1992, S. 273-280.

Koopmann, Helmut

1979

$1979 a$

Kopelcw, Lew

1984

(Hg.): Mythos und Mythologie in der Literatur des 19. Jahrhunderts. Frankfurt a. M.: Klostermann (Studien zur Philosophie und Literatur des neunzehnten Jahrhunderts 36).

Heinrich Heine und die Politisierung des Mythos. In: Koopmann (Hg.) 1979, S. $141-158$.

Der heilige Doktor Fjodor Petrowitsch: Die Geschichte des Friedrich Joseph Haas, er=ählt von..., Bad Münstereifel 1780 - Moskau 1853. Hamburg: Hoffmann und Campe.

Koppen, Enwin/Rüdiger von Tiedemann (Hgg.)

1983

Kortüm, Hans-Hennig 1996

Koschnik, Wolfgang $\mathbf{J}$. 1993

Kościołek Anna

1994

Kotel'nikov, V.A.

1996

1994

Koziełek, Gerard

1989
Wege =ur Komparatıstik. Sonderheft für Horst Rüdiger zum fünfundsiebzigsten Geburtstag. In: Arcadia. Sonderheft.

Menschen und Mentalitäten: Einführung in Vorstellungswelten des Mittelalters. Berlin: AkademieVerlag.

Standardwörterbuch für die Sozialwissenschaften Standard Dictionary of the Social Sciences. Bd. 2. München, London, New York, Paris: Saur.

C=lowiek Ewangelii "' .. Dzienniku pisarza" Fiodora Dostojewskiego. Torun.

Kenozis kak tvorčeskıj motiv u Dostoevskogo. In: Dostoevskij. Materialy $i$ issledovanija. Bd. 13, Sankt-Peterburg. S. 194-200.

Pravoslavnaja asketika i russkaja literatura (Na puti $k$ Optinoj). Sankt-Peterburg.

Das Polenbild der Deutschen 1772-1848. Anthologie. Heidelberg: Carl Winter (Reihe Siegen. Beituăge zur Literatur- und Sprach- und Medienwissenschaft: 83). 
Krestovskij, Vsevolod Vladimirovic

1899 Krovavyj puf. Romany. 1. Panurgovo stado. 2. Dve sily. In: Sobranie sočinenij. Bd. 4. Sankt Peterburg.

Kristeva, Julia

1990 Fremde sind wir uns selbst. Frankfurt a.M. (Ed.S. 1604 ; N.F. 604).

Kumpan, K.A./A.M. Koneěnyj (Hgg.)

1981 Pis'ma Michaila Dostoevskogo $k$ otcu. In: Pamjatniki Kul'tury. Novye otkrytija 1980. Moskva, S. 69-86.

Krusche, Dietrich/Alois Wierlacher (Hgg.)

1990

Kulczycka-Saloni, Janina

1972

1975

1991

Kunow, Rüdiger

1981

Kurz Gerhard

1982

Kusakov, A.V.

1990

Kuźma, Erazm

1980

1992

L abarrière, Pierre-Jean

1982

Lary, N.M.

1973

Lazari, Andrzej [de]

1988
Hermeneutik der Fremde. München: Iudicium.

Dostojewski w Polsce. In: Miesięcznik Literacki, 3, S. 36-48.

Wlodzimier= Spasowicz. Zarys Monograficzny. Wroclaw (u.a.) (Biblioteka Towarzystwa im. Adama Miekiewicza; Bd.9).

Die Figur des Fremden im polnischen Roman aus der Zeit nach den nationalen Aufständen. In: Zeitschrift für Slawistik 36, S. 81-89.

Das Klischee als kognitive Strategie im literarischen Text. Diss. Univ. Würzburg.

Metapher. Allegorie. Symbol. Göttingen: Vandenhoeck und Ruprecht (Kleine Vandenhoeck-Reihe; 1486).

Puškin i Pol'ša. Tula.

Mit Orientu i kultury Zachodu w literaturze XIX i XX wieku. Szczecin (Wyższa Szkoła Pedagogiczna w Szczecinie. Rozprawy i Studia: 41).

Mit w' literaturze. Mitotwórstwo. In: Brodzka, Alina [u.a.] (I lgg.): Slownik literatury polskiej XX wieku. Wroclaw [u.a.], S. 636-647.

Le discours de l'altérité. Paris: P.U.F.

Dostoevsky and Dickens. A Study of Literary Influence. London and Boston.

„Pocswiennictwo": Z badań nad historiq idei w Rosji. Lódż (Acta Universitatis Lodziensis, Rozprawy habilitacyjne; 69). 
1995a Lazari (Hg.): The Russian Mentality. Lexicon. Katowice 1995 (Interdisciplinary Team of Soviet Studies at the University of Lodz, Ideas in Russia).

1995b Dostoevskij kak ideologičeskij avtoritet $v$ političeskoj bor be našich dnej lo kategorii vsecelovecnosti. Gaming 1995 (= Vortrag, gehalten während des IX. Internationalen Dostoevskij Symposiums in Gaming).

1996 "Ostatni romantyk“. Apollon Grigorjew (Zarys monografii siwiatopogladu). Katowice (Idee w Rosji; Interdyscyplinarny Zespół Badan Sowietologicznych Uniwersytetu Lódzkiego).

Lednicki, Waclaw

1926

1935

1953

Leiner, Wolfgang

1991

Leerssen, Joep

1991 Echoes and Images: Reflections upon Foreign Space. In: Corbey/Leerssen 1991, S. 123-138.

1991b Mimesis and Stereotype. In: Yearbook of European Studies, 4, S. 165-175.

Leerssen, Joep/Karl Ulrich Syndram (Hgg.)

Aleksander Puszkin. Studja. Kraków.

Prayjaciele Moskale. Krakow.

Russia. Poland and the West. Essays in Literary and Cultural History. New York.

Das Deutschlandbild in der französischen Literatur. Darmstadt: Wiss. Buchgesellschaft (2., erw. Aufl.; Studienausgabe).

1992

Europa Provincia Mundi. Essavs in Comparative Literatur and European Studies offered to Hugo Dyserinck on the Occasion of His Sixty-Fifih Birthday. Amsterdam, Atlanta.

L.ewitter, L. R.

1984 Conrad, Dostoevsky, and the Russo-Polish Antagonism. In: The Modern Language Review. 79, S. 653663.

Levandovskij, A.A.

1989

Lévinas, Emmanuel

1965

1974

$1987 a$

$1987 b$

1989

T. N. Granovskij v russkom obščestvennom dviženii. Moskva.

Totalité et Infini. Essai sur l'extériorité. La Haye: Nijhoff ${ }^{2} 1965$ (Phaenomenologica: 8).

Autrement qu'être ou au-delà de l'essence. La Haye: Nijhoff (Phaenomenologica: 54).

Humanisme de l'autre homme. Paris: Fata Morgana.

Hors sujet: Paris: Fata Morgana.

Humanismus des anderen Menschen. Hamburg: Meiner. 
1992 Jenseits des Seins oder anders als Sein geschieht. Freiburg: Alber.

1995 Zwischen uns. Versuche über das Denken an den Anderen. Müchen: Hanser.

Leyens, Jacques-Philippe / Vincent Yzerbit, George Schadron

1994 Stereotypes and Social Cognition. London, Thousand Oaks, New Dehli: Sage.

Linde, Samuel Bogumił $M$.

1951

Slownik jezyka polskiego (Nachdruck der zweiten, verb. Auflage Lwów 1854), Bd. 1. Warszawa ${ }^{3} 1951$.

Lindenmeyr, Adele

1984

Raskol 'nikov's City and the Napoleonic Plan. In: Jackson (Hg.) 1984, S. 99-110.

Link, Jürgen/Wulf Wülfing (Hgg.)

1991 Nationale Mythen und Symbole in der zweiten Hälfte des 19. Jahrhunderts. Strukturen und Funktionen von Konzepten nationaler Identität. Stuttgart: Klett-Cotta (Sprache und Geschichte: 16).

Lipiansky, Marc E[dmond]

1979a L'àme française ou le National-Libéralisme. Analyse d'une représentation sociale. Paris.

1979b L'imagerie de l'identité: le couple France-Allemagne. In: Ethnopsychologie. Revue de Psychologie des Peuples, 34, S. 273-282.

Lipiansky, Marc E[dmond]'Jean-René Ladmiral

1989 La communication interculturelle. Paris (Bibliothèque européenne des sciences de l'éducation).

l.ippmann, Walter

1922 Public Opinion. New York.

L.obsien, Eckhard

1964 Die öffentliche Meinung. München.

1987 .Ulysses " und die Klischees der anglo-irischen Tradition. In: Blaicher (Hg.) 1987, S. 284-294.

L.ortholary, Albert

1951

Lotman, Jurij M./A. Piatigorskij

Le mirage russe en France au XVIII' siècle. Paris.

1969 Le Text et la fonction. In: Semiotica 2, S. 205-217.

L.otman Jurij M[ichajlovič]

1970

O semiotike ponjatij ..styd" i ,.strach" w mechani=me kul'tury. In. Tezisy dokladov IV letnej skolv po vtoričnym modelirujuściom sistemam. Tartu.

1971 Struktura khudo=hestvennogo teksta. Providence: Brown University Press (The Brown University Slavic Reprint Series).

1972 Die Struktur literarischer Texte. München: Fink. 
1974 O pojeciu prestr=eni geografic=nej w średniowieczmych tekstach staroruskich. In: Teksty 3, S. 93-103.

1976 Problem przestrzeni artustycznej. In: Pamiętnik literacki I, S. 213-226.

Lawlor, Leonard

1991 The Dialectical Unity of Hermeneutics: On Riccur and Gadamer. In: Silverman (Hg.) 1991, S. 82-89.

I.uchsinger, Martin

1996

l.udwig, Hans-Werncr (Hg.)

Mythos Italien: Denkbilder des Fremden in der deutschsprachigen Gegenwartsliteratur. Köln, Weimar, Wien: Böhlau (Literatur-Kultur-Geschlecht: Große Reihe 6). Zugl.: Diss. Univ. Zürich 1994.

1985

Arbeitsbuch

Romananalyse.

Wissenschaftiche Buchgesellschaft.

Lück, Kurt

1938 Der Mythos vom Deutschen in der polnischen Volksüberlieferung und Literatur. Forschungen zur deutschpolnischen Nachbarschaft im ostmitteleuropäischen Raum. o.O. (Ostdeutsche Forschungen; 7).

Luhmann, Niklas/Jürgen Habermas (Hgg.)

1971

Luhmann. Niklas

1977

Lukàcs, Georg

1962

L.urker, Manfred

1987

L'vov-Rogačevskij, V.

1922

1979
Theorie der Gesellschaft oder Sozialtechnologie. Was leistet die Systemforschung? Frankfurt a.M.: Suhrkamp.

Zweckbegriff und Systemrationalität. Frankfurt a.M.: Suhrkamp (stw 12).

Die Theorie des Romans. Ein geschichtsphilosophischer V'ersuch über die Formen der großen Epik. Darmstadt.

Wörterbuch biblischer Bilder und Sumbole. München: Kösel (3., erweiterte Aufl.).

gačevskij, Vasilij L'vovič]

Russko-evrejskaja literatura. S vvodnoj stat'ej B. Goreva [Boris Isaakovič Goldman]: „Russkaja literatura $i$ evrei". Moskva.

A History of Russian-Jewish Literature. $\mathrm{Hg}$. und übers. von Arthur Levin. Mit B. Gorev's [Boris Isaakovic Goldman] Essay ..Russian Literature and the Jew's". Ann Arbor: Ardis. [Engl. Übers. von L'vovRogačevskij 1922] 
Luzny, Ryszard (Hg.)

1986

1990

Magnuszewski, Józef

1990

Malinowski, Bronisław

1958

1990

Mannoni, Octave

1984

Maren-Grisebach, Manon

1970

Marten, Eckhard

1989

Martinsen, Deborah

1995

Marulic. Marko

1970

Mart'janov, Petr, K. 1895

Marx, Christa

1990

Matich, Olga

1986
Polacy w jyciu kulturalnym Rosji. Wroclaw [u.a.] 1986.

Literatura rosyjska i jej kulturowe konteksty. Wrocław [u.a.].

Pogranicza kultur jako jeden = çynników ks=taltujacych literatury slowiańskie lod polowy XIV do polowy XVIII wieku). In: Preeglad Humanistyc=ny 5/6, S. 9-15.

Mit w psychice ludów pierwotnych. In: Szkice = teorii kulturv. Warszawa, S. 467-522.

Dziela. Andrzej K. Paluch (Hg.). Bd. 7 (Mit, magia, religia). Warszawa.

Prospero et Caliban. Paris.

Methoden der Literaturwissenschaft. Tübingen: Francke (UTB 121).

Das Deutschlandbild in der amerikanischen Auslandsberichterstattung: ein kommunikationswissenschaftlicher Beitrag zur Nationenbildforschung. Wiesbaden: Dt. Univ.- Verl.

The Cover-Up: General Ivolgin and Private Kolpakov. In: Slovic and East European Journal. Jg. 39, 2 (Summer), S. 184-199.

Judita, Suzana, Pjesme. Zagreb (Pet stoljeća hrvatské književnosti: 4), S. 35-125.

$V$ perelome veka (II. Morjacki). In: Istoričeskij vestnik 11 (1895), S. 434-463.

Das Bild der Sowjetunion im westdeutschen Fernsehen. Eine medienkritische Studie =um Reflex des politischen Wandels 1986/1987 in der Sowjetunion aus literaturso=iologischer Sicht. Frankfurt a.M. [u.a.]: Lang (Europäische Hochschulschriften, R. 40; 24). Zugl.: Diss. Univ. Tübingen 1989.

The Idiot: A Feminist Reading. In: Dostoevski and the human condition after a century. $\mathrm{Hg}$. v. Ugrinsky, Alexej, Frank S. Lambasa und Valija K. Ozolins. Hof- 
Mattern. Jens

Mauron, Charles

1996

1950

1962

Meyendorff, John ( $\mathrm{Hg}$.

1966

Mecklenburg, Norben

1987

Meyer, Ursula 1.

1991

Mehnert, Elke ( $\mathrm{Hg}$.)

1997

Metzeltin. Michael

1997

Meuter, Norbert

1995

Micewski. Andrzej

1976

Mickiewicz. Adam

1955a

$1955 b$ stra University: Greenwood Press (Contributions to the study of world literature 16), S. 53-60.

Paul Ricœur =ur Einführung. Hamburg: Junius.

Introduction à la psychanalyse de Mallarmé. Paris.

Des Métaphores obsédantes au Mythe personnel. Introduction à la Psychocritique. Paris.

Fedotov, George P.: The Russian Religious Mind. Bd. 2: The Middle Ages. The Thirteenth to The Fifieenth Centuries. Cambridge, Mass.: Harvard University Press.

Über kulturelle und poetische Alterität: Kultur- und literaturtheoretische Grundprobleme einer interkulturellen Germanistik. In: Wierlacher (Hg.) 1987, S. 563584.

Paul Ricour. Die Grundzüge seiner Philosophie. Aachen: ein-Fach-Verlag (Einfuhrung in französische Denker; 1).

Imagologica Slavica. Bilder vom eigenen und dem anderen Land. Frankfurt a.M., Berlin, Bern (u.a.): Lang (Studien zur Reiseliteratur- und Imagologieforschung 1).

Der Andere und der Fremde. Eine linguistisch-kognitive Untersuchung. Wien (Cinderella: 1).

Narrative Identität. Das Problem der persönlichen Identität im Anschluß an Ernst Tugendhat. Niklas Luhman und Paul Ricœur. Stuttgart 1995. Zugl. Düsseldorf, Univ. Diss. 1993.

Das Deutschlandbild in der katholischen Publizistik Polens 1969-1974. München: Kaiser (Reihe Entwicklung und Frieden, Materialien: 5).

Pan Tadeusz csyli ostatni zajazd na Litwie. Historia s=lachecka $=$ roku 1811 i 1812 we dwinustu ksiegach wierszem. In: Dzieła. Bd. 4. Warszawa.

Dziad, Częśc trzecia. Ustęp: Droga do Rosji; Prsedmieścia stolicy; Petersburg; Pomnik Piotra Wielkiego; Oleszkiewicz. Dzień przed powodziq petersbur- 
$1955 \mathrm{c}$

1962

1991

1994

Mielke, Andreas

1992

Mitosek. Zofia

1974

1983

1997

1998

Mongin, Olivier

1994

Morson. Gary Saul

1981

1983

1994

Moura, Jean-Marc

1992a ska 1824. In: Dziela. Utwory dramatyczne. Bd. 3. Warszawa.

Dziela. Bd. 1. Wiersze. Warszawa.

Pan Tadeusz czyli ostatni zajazd na Litwie. Historia szlachecka = roku 1811 i 1812 we dwunastu ksiegach wierszem. Stanisław Pigon (Hg.). Wrocław, Warszawa, Kraków (Biblioteka Narodowa, seria 1; 83).

Die Ahnenfeier. Ein Poem. Zweisprachige Ausgabe. Übersetzt, herausgegeben und mit einem Nachwort versehen von Walter Schamschula. Mit einem Vorwort von Hans Rothe. Koln-Weimar-Wien: Bohlau (Schriften der Bundesrepublik Deutschland zur Förderung der Slawischen Studien; Bd. 14).

Dichtung und Prosa. Ein Lesebuch von Karl Dedecius. Frankfurt a.M.: Suhrkamp (Polnische Bibliothek).

Nigra sum et formosa: Afrikanerinnen in der deutschen Literatur des Mittelalters. Texte und Kontexte =um Bild des Afrikaners in der literarischen Imagologie. Stuttgart: Helfant (Helfant-Texte; 11).

Literatura i stereotypy. Wrocław [u.a.] (Polska Akademia Nauk. Komitet Nauk o Literaturze Polskiej. Rozprawy literackie; 5).

Teorie badań literackich. Praegląd historyczm. Warszawa.

Mimesis. Zjawisko i problem. Warszawa.

Teorie badań literackich. Warszawa.

Paul Rıcaur. Paris (Les contemporains).

The Boundaries of Genre. Dostoevsky's ..Diary of a W'riter" and the Traditions of Literary Utopia. Austin (University of Texas Press Slavic Series; 4).

Dostoevsky's Anti-Semitism and the Critics: A Revien Artıcle. In: Slavic and East Europe Journal 27, 3, S. 302-317.

Narrative and Freedom. The Shadow's of Time. New Haven and London: Yale University Press.

l.'imagologie littéraire, essai de mise au point historique et critique. In: Revue de Littérature Comparée, 263, Jg. 66, Juillet-Septembre, 3 (1992), S. 271-287. 
1992b L'image du tiers monde dans le roman français contemporain. Paris: Presses Universitaires de France 1992 (Ecriture. Collection dirigée par Béatrice Didier).

1994 Imagologie littéraire et mythocritique: rencontres et divergences de deux recherches comparatistes. In: Brunel, Pierre (Hg.): Mythes et Littérature. Paris: Presse de l'Université de Paris-Sorbonne 1994, S. 129141.

Mucha, Bogusław

1977

1979

1986

1989

1995

Musio', Karol

1980

Müller, Ludolf

Syberyjskie wiersze Dostojewskiego. In: Zeszyty $\mathrm{Na}$ ukowe Uniwersytetu Jagiellońskiego 465, Prace Historyczno-Literackie 36, S. 93-104.

Fiodor Dostojewski czasów katorgi (1850-1854) w opinii polskich wspóteslańców. In: Zeszyty Naukowe Uniwersytetu Jagiellońskiego DXXVI, Prace Historyczno-Literackie 37. Kraków, S. 67-86.

Polacy a rosyjska kultura mucyc=na XIX wieku. In: Lużny (Hg.) 1986, S. 91-103.

Rosjanie wobec katolicy=mu. Lódź.

Madonna Sykstuńska Rafaela w opinii pisaryy rosyjskich (koniec XVIII-XIX w.). In: Slavia Orientalis, Jg. 44,1, S. $15-30$.

Wagner und Polen. Wagner a Polska. Bayreuth (Reihe Edition Musica Bayreuth).

Das Bild vom Deutschen in der russischen Literatur. In: Der Remter 3, 4, S. 39-47.

1981 Die Gestalt Christi im Leben und Werk Dostojewskijs. In: Quatember. V'ierteljahreshefte für Erneuerung und Einheit der Kirche 45, H. 1, S. 68-76.

1984 Helden und Heilige aus russischer Frühzeit. Dreißig Er=ählungen aus der altrussischen Nestorchronik. München: Erich Wewel Verlag (Quellen und Studien zur russischen Geistesgeschichte hg. von Ludolf Müller; 3).

1996a Dostojewskij und Deutschland. In: Jahrbuch der Deutschen Dostojewskij-Gesellschaft 3, Flensburg, S. 9-26.

1996b Nachwort. In: Dostojewskij, Fjodor M. Dostojewskij [Dostoevskij, Fedor Michajloviz]]: Der Idiot. München: Deutscher Taschenbuch Verlag, S. 809-832.

1996c Christus: Der Natur unterworfen oder auferstanden? Die Gestalt Christi in Leben und Werk Dostojewskijs (III). In: Zeitwende. Die Neue Furche 67 (April), H. 2, S. 98-108. 
1998 Der Kampf Dostojewskijs gegen den Westen. In: Jahrbuch der Deutschen Dostojewskij-Gesellschafi 5, Flensburg, S. 29-41.

Namowicz, Tadeusz

1980

1992

Nečaeva, V.S.

1972

1975

Neuhăuser, Rudolf

1980

1993

1998

Neumann. Friedrich Wilhelm

Zur komparatistischen Erforschung genetischer und typologischer Kontaktbeziehungen zwischen der polnischen und deutschen Literatur. In: Acta Universitatis Lodziensis. Zeszyty Naukowe Uniwersytetu Lód-kiego. Nauki humanistyc=no-spoleczne I. H. 54, S. 5-20.

Le "thème polonais" dans la littérature de la République Démocratique Allemande. In: Dyserinck/Syndram (Hgg.) 1992, S. 189- 212.

Žurnal M.M. i F.M. Dostoevskichs 'Vremja'. I86I1863. Moskva.

Žurnal M.M. i F.M. Dostoevskichs 'Epocha'. 18641865. Moskva.

Nachwort. In: Dostojewskij, Fjodor M. [Dostoevskij, F.M.]: Der Idiot. München: Winkler-Verlag, S. 807840.

F.M. Dostoevskij: Die großen Romane und Erä̈hlungen. Interpretationen und Analysen. Wien, Köln. Weimar: Böhlau.

Neuhăuser, Rudolf (Hg.): Polyfunktion und Metaparodie. Aufsätze zum 175. Geburtstag Fedor Michajlovic Dostoevskijs. Dresden: Dresden Univ. Press (Dostoevsky Studies: Supplements; 1 ).

1960

Deutschland im russischen Schrifttum. Ein Beitrag =ur Charakterologie des russischen Volkes. In: Die Welt der Slaven. Jg. 5, S. 113-130.

Nichols, Francis W. (Hg.)

1995

Nieuważny, Florian (Hg.) 1994

Nikolaevskij, K.

1898
Christianity and the Stranger. Historical Essays. Atlanta, Georgia: Scholars Press (South Florida-Rochester-Saint Louis Studies on Religion and the Social Order; 12).

Slownik pisarzy rosyjskich. Warszawa ( $Z$ prac Zakładu Literatur Wschodniosłowianskich Instytutu Slawistyki PAN).

Tovarišči F.M. Dostoevskogo po katorge. In: Istoričeskij vestnik. 1, S. 219-222. 
Noelle-Neumann, Elisabeth

1990

Das Stereotyp als Verkehrsmittel der öffentlichen Meinung. In: Lippmann, Walter: Die öffentliche Meinung. Reprint des Publizistik-Klassikers. Bochum: Brockmeyer (Bochumer Studien zur Publizistik und Kom-

Nuiten, Henk/Maurice Geelen munikationswissenschaft; 63), S. 286-299.

1989

Baudelaire et le cliché. Le cliché entre les mains de l'auteur des "Fleurs du Mal". Stuttgart (Zeitschrift für französische Sprache und Literatur, Beihefte, N.F. 17).

Oakes, Penelope J./S. Alexander Haslam/John C. Tumer

Oergel, Maike

1994 Stereotyping and Social Reality. Oxford: Blackwell.

1996 Literature as the Modern Sacred Text. The Development of the Mythopoetic Concept of Literature 17701830. In: Neil, Thomas/Françoise Le Saux (Hgg.): Myth and its Legacy in European Literature. Durham: University of Durham (Durham modern language series: German 6), S. 115-132;

Olschowsky, Heinrich

1999

Wie lassen sich nationale Stereotype abrüsten? Tadeus: Ró̇ewic:' Umgang mit dem Bild des Deutschen. In: Kissel. Wolfgang Stephan [u.a.] (Hgg.): Kultur als Übersetzung. Festschrıfi für Klaus Städtke zum 65. Geburtstag. Würzburg, S. 239-256.

Onasch, Konrad

1960 Dostojewski-Biographie. Materialsammlung zur Beschäftigung mit religiösen und theologischen Fragen in der Dichtung F. M. Dostojewskis. Zürich.

1962 Einführung in die Konfessionskunde der orthodoxen Kirchen. Berlin: de Gruyter (Sammlung Göschen: 1197/1197a).

1978 Dostoevskijs „Kinderglaube“. In: Canadian-American Slavic Studies, 12, 3 (Fall), S. 377-381.

1983 Persönlichkeit und Leiden im Werk Dostoevskijs. In: Zeitschrift für Slawistik. Bd. 28, H. 5, S. . 712-719.

Opalski, Magdalena/Bartal Israel

1992

Orłowski, Hubert

1996
Poles and Jews. A Failed Brotherhood. Hanover und London.

„Polnische Wirtschaft“. Zum deutschen Polendiskurs der Neuzeit. Wiesbaden: Harrassowitz. (Studien der Forschungsstelle Ostmitteleuropa an der Universität Dortmund; 21). 
Orłowski, Jan

1982 Reakcje Dostojewskiego na sprawy polskie. In: Przeglad Humanistyczny, 5-6, S. 85-97.

1984 Polska w zwierciadle poezji rosyjskiej okresu I wojmy światowej. Lublin.

1986 Postacie Polaków w prozie rosyjskiej okresu I wojmy światowej. In: Łużny (Hg.) 1986, S. 127-143.

1990 o polskich inspiracjach $w$ literaturze rosyjskiej. Zarys problemu. In: Lużny (Hg.) 1990, S. 131-167.

$1992 \quad Z$ dziejów antypolskich obsesji w literaturze rosyjskiej. Od wieku XVIII do roku 1917. Warszawa.

1993 Neizvestnoe stichotvorenie Tjutčera an Mickevič In: Slavia Orientalis, Jg. 42, 1 (), S. 71-73.

$1995 \quad$ Miecze i galazki oliwne. Antologia poezji rosyjskiej o Polsce (wiek XVIII-XX). Warszawa.

O'Sullivan, Emer

1989

Otkrovennye rasskazy strannika

Das ästhetische Potential nationaler Stereotypen in literarischen Texten. Auf der Grundlage einer Untersuchung des Englandbildes in der deutschsprachigen Kinder- und Jugendliteratur nach 1960. Tübingen: Stauffenburg (Stauffenburg Colloquium 8).

1990 Friend and foe. The image of Germany and the Germans in. British children's fiction from 1870 to the present. Tübingen: Narr (Studies in English and Comparative Literature 6).

1948

Otto, Rudolf

1926

1932

Pageaux, Daniel-Henri

1971

1982

1984
Otkrovenmye rasskazy strannika duchovnomu svoemu otcu. Pariž.

West-östliche Mystik. Vergleich und Unterscheidung zur Wesensdeutung. Gotha: Klotz (Bücherei der christlichen Welt).

Das Heilige. Über das Irrationale in der Idee des Göttlichen und sein Verhältnis zum Rationalen. München: Beck.

Images du Portugal dans les Lettres Françaises (17001755). Paris: Fundação Calouste Gulbenkian Centro Cultural Português (Memórias e Documentos para a História Luso-Francesa: 7).

Une perspective d'études en littérature comparée: l'imagerie culturelle. In: Synthesis 8, S. 169-185.

Pageaux, Daniel-Henri ( $\mathrm{Hg}$.): Images et mvthes d'Haïti. Paris. 
1986

1988

1989

1992

Pal'min, Liodor [Iliodor]

1878

Pamjatniki I
Parvi, Jerzy

teratury drevnej

1980

1977

Pascal, Pierre

1966

1995

Passmann, Uwe

1989

Paul, Hermann

1966

Pavlovskaja, A.V.

1994

Peabody, Dean

Petersen, Peter

1985

1994

Pfahl-Traughber, Armin

1993
Littérature comparée et sciences humaines. Pour un renouveau des études comparatistes. In: Riesz/ Boerner/Scholz (Hgg.) 1986, S. 65-75.

De l'image à l'imaginaire. In: Colloquium Helveticum 7, S. 9-17.

De l'imagerie culturelle à l'imaginaire. In: Brunel/Chevrel (Hgg.) 1989, S. 133-161.

De l'imagologie à la theorie en littérature comparée. Eléments de réflexion. In: Leerssen/Syndram (Hgg.) 1992, S. 297-307.

Pokinutyj zamok. In: Smy na-javu. Sobranie stichotvorenij. Moskva, S. 188-204.

j Rusi

Pamjatniki literatury drevnej Rusi. XII. vek. Moskva.

Polska w twórczości i dzialalności Wiktora Hugo. Warszawa .

Die russische Volksfrömmigkeit. Marburg (Sonderdruck aus „Kyrios", Vierteljahresschrift für Kirchenund Geistesgeschichte Osteuropas).

Dostoïevski et Dieu. Précédé de „Le malentendu“ par Frédéric Boyer. Paris: Desclée de Brouwer.

Orte fern. das Leben. Die Fremde als Fluchtpunkt des Denkens. Deutsch-europäische Literatur bis 1820. Würzburg: Königshausen u. Neumann. Zugl.: Diss. Univ. Freiburg (Breisgau) 1987.

Deutsches Wörterbuch. Fünfte Auflage, bearb.von Werner Betz. Tübingen.

Stereotipy vosprijatija Rossii i russkich na Zapade. In: Rossija i Zapad 1994, S. 19-30.

National Characteristics. Cambridge [u.a.].

Klischee als Sujet. Hans Werner Henzes ,. The English Cat" und sein ...Arbeitstagebuch". In: Kolleritsch, Otto (Hg.): Klischee und Wirklichkeit in der musikalischen Moderne. Wien, Graz 1994 (Studien zur Wertungsforschung: 28), S. 62-91.

Der antisemitisch-antifreimaurerische Verschwörungsmythos in der Weimarer Republik und im NS-Staa!. 
Pichois, Claude

1957 L'image de la Belgique dans les lettres françaises de 1830 à 1870. Paris.

Pichois, Claude/Andrè-M. Rousseau

Wien: Braumüller (Vergleichende Gesellschaftsgeschichte und politische Ideengeschichte der Neuzeit 9).

1967

La littérature comparée. Paris.

1971 Vergleichende Literaturwissenschaft. Eine Einführung in die Geschichte, die Methoden und Probleme der Komparatistik. Deutsch von Peter André Bloch. Düsseldorf.

Pincus, Fred L./Ehrlich, Howard J. (Hgg.)

1994 Race and Ethnic Conflict. Contending Views on Prejudice. Discrimination, and Ethnoviolence. Boulder, San Francisco, Oxford.

Pisemskij, A.F.

$1959 \sqrt{ }$ vodovorote. In: Sobranie sočinenij $v$ devjati tomach. Bd. 6. Moskva.

Pletnev, R.

1976 Zametki $k$ stat'e D.V. Grišina „Byl-li Dostoevskij antisemitom?" In: Vestnik Russkogo Christianskogo Dviženija. 107, Paris, S. 118-120.

Podgórzec, Zbigniew

1981

W kregu rod-iny Dostojewskiego (Legendy i rzeczywistośc). In: Znak 1/2, S. 153-177.

1984 Podgórzec, Zbigniew (Hg.): Okrutny talent. Dostojewski we wspomnieniach, krytyce $i$ dokumentach. Kraków, Wrocław.

Polnoe sobranie russkich letopisej

1926 Polnoe sobranie russkich letopisej i=davaemoe postojanno Istoriko-Archeografičeskoj Komissieju Akademii Nauk SSSR. T. 1. Lavrent'ev'skaja letopis', vyp. 1: Povest'vremenmych let. Leningrad.

Polti, Adolf

1997 Zur Rezeption und Kritik von ..Zeit und Erzählung“. In: Stückrath/Zbinden (Hgg.) 1997, S. 230-253.

Popper, Karl R.

1972 Objective Knowledge. An Evolutionan Approach. Oxford.

1973 Objektive Erkenntnis. Ein evolutionärer Entwurf. Aus dem Englischen übersetzt von Hermann Vetter. Hamburg: Hoffmann und Campe (Hoffmann und Campe: Kritische Wissenschaft).

1979 Ausgangspunkte: Meine intellektuelle Entwicklung. Hamburg: Hoffmann und Campe. 
Poźniak, Telesfor

$1980 \quad$ Aleksander Blok w kregu spraw polskich. In: Literatura Radziecka, 11, S. 154-160.

1992 Dostojewski $i$ Wschód. Szkic = pogranicza kultur. Wrocław (Slavica Wratislaviensia; 75).

Prammer, Franz

1988

Preobraženskij, A.G.

1959

Prus, Kazimierz

Die philosophische Hermeneutik Paul Ricaurs in ihrer Bedeutung für eine theologische Sprachtheorie. Innsbruck, Wien: Tyrolia (Innsbrucker theologische Studien; 22).

1985 Fiodor Tiutczew o Polsce $i$ Polakach. In: Prace Humanistyc=ne, 25, S. 193-200.

Przybylski, Ryszard

1964

Puskin, Aleksandr Sergeevic

Étimologičeskij slovar' russkogo jazyka. Bd. 1, Moskva.

1949a Polnoe sobranie socinenij, Bd. 3,2 (Stichotvorenija 1826-1836. Skazki). 0.O.: Izdatel'stvo Akademii Nauk SSSR.

1949b Polnoe sobranie sočinenij v desjati tomach. Bd. 3 (Stichotvorenija 1827-1836) und Bd. 5 (Evgenij Onegin. Dramatičeskie proizvedenija). Moskva.

Pypin, $\mathrm{M}$.

1881

"Kwestya polska w literaturze rosyjskiej". Przekład z rosyjskiego. Dodatek bezpłatny do „Prawdy.“ Warszawa.

Quasthoff, Uta

1973 Soziales Vorurteil und Kommunikation - Eine sprachwissenschafiliche Analyse des Stereotyps. Ein interdis=iplinärer Versuch im Bereich von Linguistik, Sozialwissenschaft und Psychologie. Frankfurt a.M.

Radłowski, Zygmunt/Jerzy Wojtczak

1994 Jak narody widza siebie nawzajem. O Polakach w

Rakusa, IIma/Felix Philipp Ingold Europie. Warszawa.

1981

Raulet, Gérard

Dostojewskij in der Schweiz. Ein Reader. Frankfurt a.M.: Insel.

1986

Gehemmte Zukunft. Zur gegemwärtigen Krise der Emanzipation. Darmstadt, Neuwied: Luchterhand (Sammlung Luchterhand: 649).

1988 L'enfer des bonnes intentions ou: Peut-on échapper aux stéréotypes? In: Allemagnes d'aujourdhui. Revue 
Reagan, Ch.E. (Hg.)

1979

Reents, Christine

1984

Rejnus L.M.

Richards. David

1971

1994

Ricour, Paul

1975 La métaphore vive. Paris.

1976

1980

1983

1984

1985

$1986 a$

$1986 b$

$1989 a$

$1989 b$

Le conflit des interpretations. Essais d'herméneutique. Paris.

1971a Die Fehlbarkeit des Menschen. Phänomenologie der Schuld I. Übersetzt v. Maria Otto. Freiburg/München: Alber.

1971b Symbolik des Bösen. Phänomenologie der Schuld IL Übersetzt v. Maria Otto. Freiburg/München: Alber.

française d'information sur les deux Allemagnes, Nouvelle Série, 105, juillet-septembre, S. 3-23.

Studies in the Philosophy of Paul Ricaur. Athens (Ohio).

Die Bibel als Schul- und Hausbuch für Kinder: Werkanalvse und Wirkungsgeschichte einer frühen Schulund Kinderbibel im evangelischen Raum. Johann Hübner: Zweymal zwey und funff-ig auserlesene biblische Historien, der Jugend zum Besten abgefasset..., Leipzig I7It bis Leipzig 1874 und Schwelm 1902. Göttingen: Vandenhoeck und Ruprecht (Arbeiten zur Religionspädagogik: 2).

Dostoevskij v Staroj Russe. Leningrad ${ }^{2} 1971$.

Masks of difference. Cultural representations in literature, anthropology and art. Cambridge Univ. Press (Cultural Margins; 2).

Interpretation Theory: Discourse and the Surplus of Meaning. Fort Worth, Texas.

Essanis on Biblical Interpretation. Edited with an Introduction by I.ewis S. Mudge. Philadelphia: Fortress Press.

Temps et récit I. Paris.

Temps et récit II. La configuration dans le récit de fiction. Paris.

Temps et récit III. Le Temps raconté. Paris.

Du texte à l'action. Essais d'herméneutique II. Paris.

Lectures on Ideology and Utopia. George H. Taylor (Hg.). New York: Columbia University Press.

Jezyk, tekst. interpretacja. Wybór pism. Wybrała i wstępem poprzedziła Katarzyna Rosner. Przełożyli Piotr Graff i Katarzyna Rosner. Warszawa.

Ricocur, Paul/Stéphane Mosès/Catherine Chalier/Guy Petitdemange/Marc Faessler: Répondre d'Autrui, Em- 
manuel Lévinas: Autour d'un entretien avec Emmanuel Lévinas. Textes réunis par Jean-Christophe Aeschlimann. Neuchâtel: À la Baconnière.

1990a Soi-Même comme un Autre. Paris.

1990b Liebe und Gerechtigkeit (Amour et justice). Mit einer deutschen Parallelübersetzung von Matthias Raden. Tübingen: Mohr.

1992 Paul Ricour ou la confrontation des héritages. Entretien. In: France Catholique, 17 janvier, 2338, S. 14-21.

1996 Le mal [dans la lecture de Dostoïevski, de S. Freud. de la Bible et comment le mal est à traiter par la justice]. Entretien avec Bernard Sichère. In: La règle du jeu 7, 19, mai, S. 88-105.

Riesz, János

1979 Beat Ludwig von Muralts ,Lettres sur les Anglais et les Français et sur les Voyages" und ihre Rezeption. Eine literarische "Querelle" der französischen Frühaufklärung. München: Fink.

1980a Riesz, János (Hg.): Literarische Imagologie - Formen und Funktionen nationaler Stereotype in der Literatur. Komparatistische Hefie 2.

1980b Zur Omnipräsenz nationaler und ethnischer Stereotype. In: Riesz (Hg.) 1980a, S. 3-11.

Riesz, János/Peter Boemer/Bernhard Scholz (Hgg.)

1986 Sensus Communis. Contemporary Trends in Comparative Literature. Festschrifi für Henry Remak. Tubingen: Narr.

Riffaterre, $M$.

1971 Essais de stylistique structurale. Paris.

Riemann, Wolfgang

1983

Das Deutschlandbild in der modernen türkischen Literatur. Wiesbaden: Harrassowitz.

Rinner, Fridrun/Klaus Zerinschek (Hgg.)

1981

Komparatistik. Theoretische Überlegungen und südeuropäische Wechselseitigkeit. Festschrift für Zoran Konstantinovic. Heidelberg.

Ritter, J./Gründer, K. (Hgg.)

1992

Rizenkampf, $\mathrm{A}$.

1973 Vospominanija o Fedore Michajloviče Dostoevskom. Kogan, G.F. (Hg.) In: Literaturnoe nasledstoo. F.M1. Dostoevskij. Novye materialy $i$ issledovanija. Bd. 86. Moskva, S. 330-331. 
Rogalski, Aleksander

1960

Ronen, Ruth

1994

Rosner, Katarzyna

Rossija i Zapad

1989

1994

Rothe, Hans

1988

Rüdiger, Horst (Hg.)

1971

1973

Sadji. Amadou Booker

1985

Said, Edward W.

1980

1993

1994

1995

Saraskina, L.

1989

Schaff, Adam

1967

Schäffter, Ottfricd (Hg.)

1991
Rosja - Europa. Wzajemne zwiqzki, wpływy $i$ zależności kulturalno-literackie. Warszawa.

Possible worlds in literary theory. Cambridge: Cambridge University Press.

Wstep. In: Ricœur 1989a, S. 5-60.

Rossija i Zapad Dialog Kul'tur. Moskva. (Moskovskij Gosudarstvennyj Univeritet, Fakul'tet Inostrannych Jazykov, Centr po Izučeniju Vzaimodejstvija Kul'tur).

Fremd- und Eigenbilder von und über Slaven. vornehmlich bei Polen und Russen. In: Dyserinck/Syndram (Hgg.) 1988, S.295-319.

Zur Theorie der Vergleichenden Literaturwissenschaft. Mit Beiträgen von Gerhard Bauer, Erwin Koppen, Manfred Gsteiger. Berlin, New York: Gruyter (Komparatistische Studien. Beihefte zu „Arcadia“ 1).

Komparatistik. Aufgaben und Methoden. Stuttgart, Berlin, Köln, Mainz: Kohlhammer.

Das Bild des Negro-Afrikaners in der deutschen Kolonialliteratur (1884-1945). Ein Beitrag zur literarischen Imagologie Schwarzafrikas. Berlin: Reimer (Beiträge zur Kulturanthropologie).

L'Orientalisme: l'Orient creé par l'Occident. Mit einem Vorwort von Tzvetan Todorov. Paris.

Culture and Imperialism. New York: Knopf.

Kultur und Imperialismus: Einbildungskraft und Politik im Zeitalter der Macht. Frankfurt am Main: Fischer.

Orientalism. Western conceptions of the Orient. With a new afterword. London: Penguin Books ('1978).

$V$ koordinatach ponimanija. In: Voprosy literatury $7, \mathrm{~S}$. 60-67.

Szkice = filozofii jezzkka. Warszawa.

Das Fremde: Erfahrungsmöglichkeiten zwischen Faszination und Bedrohung. Opladen: Westdt. Verl. 
Schmeling, Manfred ( $\mathrm{Hg}$.)

1995

Weltliteratur heute. Konzepte und Perspektiven. Würzburg (Saarbrücker Beiträge zur vergleichenden Literatur und Kulturgeschichte; 1).

Schmidt, Karin

1992

Untersuchungen zum Südamerikabild in den "Südamerikanischen Meditationen" von Graf Hermann Keyserling. Ein Beitrag zur komparatistischen Imagologie. Diss. Univ. Aachen.

Schmitt, Carl

1963

Der Begriff des Politischen. Berlin 1963 (Neuauflage).

Schmitt, Reinhold/Gerhard Stickel (Hgg.)

1997 Polen und Deutsche im Gespräch. Tübingen: Nart

Schneider, Gerhard (Studien zur deutschen Sprache; 8).

1995 Affirmation und Anderssein. Eine dialektische Konzeption personaler Identität. Opladen: Westdeutscher Verlag (Beitrăge zur psychologsichen Forschung; 31).

Schrover, Els

1991

Altérité dans .. Vendredi ou les limbes du Pacifique de Michel Tournier: Une analyse déconstructive. In: Corbey/Leerssen (Hgg.) 1991, S.205-217.

Schroter, Susanne

1982

Komparatistik und Ideengeschichte. „History of ideas “" und Geistesgeschichte in ihrem Einfluß auf die internationale Komparatistik. Frankfurt a. M.: Lang (Europăische Hochschulschriften. Reihe XVIII. Vergleichende Literaturwissenschaften; 27).

Schultz, Irmgard

1994 Der erregende Mythos vom Geld. Die neue Verbindung von Zeit, Geld und Geschlecht im Okologiezeitalter. Frankfurt a.M., New York: Campus.

Schultze, Brigitte

(u ha He 1974

Schulz, Robert Kenneth

1969

Searle, John.-R.

1978
Der Dialog in F.M. Dostoevskijs ..Idiot". München: Sagner (Slavistische Beiträge; 76).

The Portraval of the German in Russian Novels Goncarov, Turgenev, Dostoevskij, Tolstoj. München (Slavistische Beiträge; 42).

Schwarz, Dorothee/Thomas Heckert/Rudolf Pollach

Studien und Materialien zu Dostoevskijs Roman ,. Der Idiot '. Tübingen (Skripten und Materialien des Slavischen Seminars der Universităt Tübingen; 17).

The Philosophy of Language. Oxford 's 1977. 
Secretan, Philibert

1995

Segal, Robert A. (Hg.)

1996a

$1996 b$

$1996 c$

1996d Psychology and Myth. New York: London: Garland 1996.

Semczuk, Antoni

1987

Serman. 1.Z.

1997 Dostoevskij i Gete. In: Dostoevskij. Materialy i issledovanija. Bd. 14. Sankt-Peterburg, S. 46-57.

Setzer, Heinz/Ludolf Müller/Rolf-Dieter Kluge (Hgg.)

1998

Shakespeare. William

1999

Shaw, Harry

1972

Siebenmann, Gustav

1988

1992

Siebenmann. Gustav/Hans-Joachim König (Hgg.)

F.M. Dostoevskij.
Tübingen: Attempto.

Romeo and Juliet. Romeo und Julia. Englisch-deutsche Studienausgabe. Deutsche Prosafassung. Anmerkungen, Einleitung und Kommentar von Ulrike Frit:. Tübingen: Stauffenburg.

Dictionary of Literany Terms. New York [u.a.].

Das Lateinamerikabild der Deutschen. Quellen, Raster. Wandlungen. In: Colloquium Helveticum, 7, S. 57-83.

Methodisches zur Bildforschung. In: Siebenmann/König (Hgg.) 1992, S. 1-17.

1992

Das Bild Lateinamerikas im deutschen Sprachraum. Ein Arbeitsgespräch an der Hersog August Bibliothek W'olfenbüttel, 15.-17. Mär= 1989. Tübingen: Nicmeyer.

Sigrist, Christian

1990 Das Rußlandbild des Marquis de Custine: Von der Civilisationskritik zur Rußlandfeindlichkeit. Frankfurt a.M.: Lang (Soziologie und Anthropologie; 6).

Silbermann. Alphons 1994
Alle Kreter lügen. Die Kunst. mit Vorurteilen zu leben. Bergisch Gladbach: Lübbe ${ }^{2} 1994$. 
Sills, David L. (Hg.)

1968

Silverman, Hugh J. (Hg.)

1991

Simons, John-D.

International Encyclopedia of the Social Sciences. Bd. 15. New York: The Macmillan Company \& The Free Press.

Gadamer and Hermeneutics. Science Culture, Literature. Plato, Heidegger. Barthes, Ricour. Habermas, Derrida. New York and London (Continental Philosophy; IV).

1992-1993 The Sublime in Schiller and Dostoevsky. In: GermanoSlavica 7-8:2-1, S. 53-65.

Six, Bernd

1987 Stereotype und Vorurteile im Kontext sozialpsychologischer Forschung. In: Blaicher (Hg.) 1987, S. $41-54$.

Skazanie o stranstvii

1856

Skorupka, Stanisław

1967

Sokoljanskij, M.G.

1983 F.M. Dostoevskij i Džosef Konrad. In: Zeitschrift für Slawistik, Jg. 28, 5, S. 738-751.

Slovar' russkogo jazyka XI-XVII vv.

Skazanie o stranstvii i putešestvii po Rossii. Moldavii. Turcii $i$ Svjatoj zemle postrizennika Svjatoj gory Afonskija inoka Parfenija. č. I-IV. Izd. 2-e, ispr. Moskva.

1979 Slovar' russkogo jazyka XI-XVII vv. Vypusk 6. Moskva.

Slovar' sovremennogo russkogo literaturnogo jazyka

1948-1964 Slovar' sovremennogo russkogo literaturnogo jazyka Bd. 1, 2, 5, 6, 16. Moskva-Leningrad.

Slattery, Dennis Patrick

1983

The Idiot. Dostoevsky's fantastic prince: a phenomenological approach. New York (u.a.): Lang (American University Studies: Ser. 12, Slavic lanSłownik współczesnych pisarzy polskich guages and literature 1 ).

1964 Słownik terminów literackich

Slownik wspótczesnych pisaryy polskich. Warszawa.

1998

Sławiński, Janusz [u.a.] (Hg.): Slownik terminów literackich. Wrocław, Warszawa [u.a.] ${ }^{3} 1998$.

Slawski, Franciszek

1952-1982 Slownik etymologiczmy jezyka polskiego. Bd. 1-5. Kraków. 
Smaga, Józef

1987 Wstep. In: F.M. Dostojewski [F.M. Dostoevskij]:: Zbrodnia i kara. Smaga, Józef (Hg.). Wroclaw [u.a.], S. XCVIII-CI.

1995 Wstep. In: F.M. Dostojewski [F.M. Dostoevskij]: Bracia Karamazow. Smaga, Józef (Hg.). Wroclaw [u.a.]:, S. III-CXXIII.

Sorge, Veit

1995 Die literarischen Länderbilder in den Liedtexten Wolf Biermanns und Wladimir Wysozkis von 1960 bis 1980: Ein imagologischer Vergleich. Dresden. Zugl.: Diss. Technische Univ. Chemnitz-Zwickau 1995.

Spitzing, Günter

1989

Spörk, Ingrid

1993

1996

Stanzel, Franz. K.

1974

1987

Steins, Martin

1972

Stempczyńska, Barbara

1980

Lexikon by=antinisch-christlicher Symbole. Die Bilderwelt Griechenlands und Kleinasiens. München.

Sexuelle und kulturelle Differen am Beispiel der "belle juive" in der Literatur. In: Nahe Fremde fremde Nähe. Frauen forschen zu Ethnos, Kultur. Geschlecht. 5. Tagung zur Frauenforschung vom 15.-18. Oktober 1992 in Rethof/Leibnit=. Wien: Frauenverlag (Reihe Frauenforschung: 24), S. 217-235.

Das Phantasma vom .. Anderen “. Überlegungen zu Genese und Aktualität des Fremdbildes am Beispiel der ...Juden “. In: Hodl, Klaus (Hg.): Der Umgang mit dem ..Anderen": Juden, Frauen, Fremde. ... Wien [u.a.]: Bohlau 1996 (Böhlaus Zeitgeschichtliche Bibliothek: 32) S. 23-30.

Der literarische Aspekt unserer l'orstellungen vom Charakter fremder l'ölker. In: Anzeiger der österreichischen Akademie der Wissenschaften. PhilosophischHistorische Klasse 111, 4, S.63-82.

Das Nationalitätenschema in der Literatur und seine Entstehung =u Beginn der Neuzeit. In: Blaicher (Hg.) 1987, S. 84-96.

Das Bild des Schwarzen in der europäischen Kolonialliteratur 1870-1918. Frankfurt a.M.: Thesen Verlag Vowinckel (Vergleichende Literaturwissenschaft: 1), zugl.: Aachen, Univ.-Diss. 1971.

Dostojewski a malarstwo. Katowice. 
Steempowski, Jerzy

1988

1995

Stosichita, Victor I.

1995

Strachov, Nikolaj

1863

1969

Strcelka, Joseph

1978

Strcoebe, Wolfgang/Chester A. Insko

1989

Stülben, Jens

1995

Sestov, Lev

1903

Šklcovskij, Viktor B.

1957

1997 burg.
Szkice literackie. Jerzy Timoszewicz (Hg.). Bd. 1: Chimera jako zwierze pociagowe (1929-1941); Bd. 2.: Klimat zycia i klimat literatury (1948-68). Warszawa.

Die Polen in den Romanen Dostoewskijs. Aus dem Polnischen von Renate Schmidgall. In: Klecel, Marek (Hg.): Polen zwischen Ost und West. Polnische Essays des 20. Jahrhunderts. Eine Anthologie. Frankfurt a.M.: Suhrkamp (Polnische Bibliothek), S. 97-120.

Ein Idiot in der Schweiz. Bildbeschreibung bei Dostojewski. In: Boehm, Gottfried/Helmut Pfotenhauer. (Hgg.): Beschreibungskunst - Kunstbeschreibung. Ekphrasis von der Antike bis zur Gegenwart. München: Fink, S. 425-439.

Rokovoj vopros. Zametka [Russkago] po povodu pol 'skago voprosa. In: Vremja 4, S.152-163.

Bor'ba $s$ Zapadom v našej literature. Istoričeskie $i$ kriticeskie očerki. Bd. 1-2. (Nachdruck der dritten russischen Ausgabe Kiev 1897). The Hague, Paris: Mouton 1969 (Slavistic Printings and Reprintings; 176/1/2).

Methodologie der Literaturwissenschafi. Tübingen: Niemeyer.

Stereotype, Prejudice, and Discrimination: Changing Conceptions in Theory and Research. In: Bar-Tal Daniel et al. (Hgg.) 1989, S. 3-34.

Deutsche Polen-Bilder. Aspekte ethnischer Imagotype und Stereotype in der Literatur. In: Hahn (Hg.) 1995, S. 41-74.

Stüıckrath, Jörg/Zbinden, Jürg (Hgg.)

Metageschichte. Hayden White und Paul Ricaur. Dargestellte Wirklichkeit in der europäischen Kultur im Kontext von Husserl. Weber, Auerbach und Gombrich. Baden-Baden: Nomos (ZIF / Interdisziplinăre Studien; 2).

Dostoevskij i Ničse. Filosofija tragedii. Sankt-Peter-

Za i protiv. Zametki o Dostoevskom. Moskva 1957. 
Świderska, Małgorzata

1993-1994 Die Darstellung Polens in den Romanen F. M. Do-stoevskijs. Eine imagologische Untersuchung. Schriftliche Hausarbeit zur Erlangung des Grades „Magister Artium“. Tübingen, WS 1993/94.

1998 Der .Idiot" - ein moderner Christus?. In: Setzer/Müller/Kluge (Hgg.) 1998, S. 111-135.

1999a Mickiewicz und die russische Literatur: Puschkin. Karolina Pawlowa. Dostojewski, Tübingen 1999 (Vortrăge am Slavischen Seminar der Universităt Tübingen; 26).

1999b Mickiewicz und die russische Literatur: Puschkin. Karolina Pawlowa, Dostojewski. In: Kluge (Hg.), 1999, S. 267-296.

2000 Studien zur literaturwissenschafilichen Imagologie. Das literarische Werk F.M. Dostoevskijs aus imagologischer Sicht mit besonderer Berücksichtigung der Darstellung Polens. Diss. Univ. Tübingen.

Syndram, Karl Ulrich

1989

1990

1991

1992a

1992b

Szyrocki. Marian

Kulturpublizistik und nationales Verständnis. Untersuchungen zur Kunst- und Kulturpolitik in den Rundschaueeitschrifien des Deutschen Kaiserreiches (197I19/4). Berlin 1989 (Kunst, Kultur und Politik im Deutschen Kaiserreich: 9).

Das Problem der nationalen Literaturgeschichtsschreibung als Gegenstand der komparatistischen Imagologie: In: Proceedings of the XIIth Congress of the ICLA. Bd. 4. München, S. 36-42.

The Aesthetics of Alterity: Literature and the imagological Approach. In: Yearbook of European Studies, 4, S. 177-191.

Kulturwissenschaftliche Europaforschung - Prämissen und Perspektiven: Ein komparatistisches Konzept. In: Dyserinck/Syndram (Hgg.) 1992, S. 31-62.

.. Laboratorium Europa“. Zur kulturwissenschaftlichen Begründung der Komparatistik. In: Leersen/Syndram (Hgg.) 1992, S. 83-96.

[1975] Das Bild des Polen in der deutschen Literatur und das Bild des Deutschen in der Literatur der Volksrepublik Polen. Düsseldorf o.J. (Fraternitas Reihe; 8).

Śliwowski, René

Sprawa polska w powieści rosyjskiej lat sześćdziesiqtych XIX wieku. In: Język rosyjski. Jg. 12, Mărz-April, 2, S. 1-8. 
$1963 Z$ perspektywy stulecia. Sprawa polska w rosyjskiej publicystyce $i$ literaturze pięknej lat sześćdziesiatych XIX wieku. In: Slavia Orientalis, 1, S. 3-30.

Tanty, Mieczysław

1970

Tatarkiewicz, Wladyslaw

1976

1980

Tazbir, Janusz (Hg.)

Thackeray, William Makepeace

Panslawizm, carat. Polacy. Zjazd slowianiski w Moskwie 1867 roku. Warszawa.

Thackeray, William Makepeace

Dzieje sześciu pojęć. Sztuka, piękno, forma, twórczość. odtwórczość, przė̇ycie estetyczne. Warszawa.

1902

A History of Six Ideas: An Essay in Aesthetics. The Hague: Nijhoff.

Mity i stereotypy w dziejach Polski. Warszawa 1991.

The Christmas Books of Mr. M.A. Titmarsh etc. In: The Works of William Makepeace Thackeray in Thirteen Volumes. Bd. 9. London.

Thiess, Frank

1971 Dostojewski. Realismus am Rande der Transzendenz. Stuttgart: Seewald.

Thomasset, Alain

1996 Paul Ricour. Une poétique de la morale. Aux fondements d'une éthique herméneutique et narrative dans une perspective chrétienne. Leuven 1996 (Bibliotheca Ephemeridum Theologicarum Lovaniensium; CXXIV).

Tietz, Manfred

1980 Das französische Spanienbild zwischen Aufklärung und Romantik. Inhalte, Funktion und Repliken. In: Riesz (Hg.) 1980a, S. 25-41.

Tjutcev, Fedor Ivanovic 1987

Todorov, Tzvetan

1982

Polnoe sobranie stichotvorenij. Leningrad (Biblioteka poeta, Bol'šaja serija; 3).

La conquête de l'Amérique. La question de l'Autre. Paris.

1985 Die Eroberung Amerikas: Das Problem des Anderen. Frankfurt a.M.: Suhrkamp (es 1213).

1989 Nous et les Autres. La refléxion française sur la diversité humaine. Paris.

1993 Angesichts des Äußersten. München: Fink.

1995 La vie commune. Essais d'anthropologie générale. Paris.

Tokarzewski, Szymon

1907-1909 Pamiętniki 1846-1857. Bd. 1: Siedem lat katorgi; Bd. 2: Ciernistym szlakiem. Warszawa. 
1918 Siedem lat katorgi. Warszawa (2. erw. Ausgabe).

1922 Katorinicy. Warszawa.

Tomczak, Frauke

1992

Torke, Hans-Joachim $(\mathrm{Hg}$.)

1985

Mtythos und Alltäglichkeit am Beispiel von Joycess .Ulysses" und Döblins „Berlin Alexanderplat"“. Eiin Versuch zur Rekontruktion moderner Poetiken. Frankfurt a.M., Berlin, Bern (u.a.): Lang (Europäische Hochschulschriften; Reihe XVIII: Vergleichende Literaturwissenschaft 66).

Lexikon der Geschichte Rußlands. Von den Anfänge:n bis zur Oktober-Revolution. München.

Törnquist-Plewa, Barbara

1992

The wheel of Polish fortune: myths in Polish collectiwe consciousness during the first years of Solidarity. Lumd (Lund Slavonic Monographs: 2).

Trautmann, $\mathbf{R}$.

1931 Die altrussische Nestorchronik. Übersetzt umd kommentient von $\mathbf{R}$. Trautmann. Leipzig.

Trochimiak, Jan

1980

Iwan Turgıeniew a Polska. In: Studia Polono-SlaviciaOrientalia. Acta litteraria, 6. Wrocław [u.a.], S.12.5143.

1985 Turgieniew. Warszawa.

Tschiževskij, D. [Dmitrij Čiževskij]

1969 Die Nestor-Chronik. Eingeleitet und kommentiert von D. Tschiževskij [Dmitrij Čiževskij]. Wiesbaden.

Tunimanov Vladimir A.

1984

The Narrator in .. The Devils" In' Jackson (Hg.) 1984, S. 145-175.

Turgenev, Ivan Sergeevic

$1978 \mathrm{ff}$.

Polnoe sobranie sočinenij $i$ pisem v tridcati tomach. Moskva.

1979 Polnoe sobranie sočinenij i pisem v tridcati tomach. Sočinenija v duenadcati tomach. Bd. 2: Scenv i komedii 1843-1852. Moskva.

1981 Polnoe sobranie socinenij i pisem $v$ tridcati tomach. Socinenija $v$ dvenadcati tomach. Bd. 7: Otcy $i$ deti. Povesti i rasskazy. Dim. Moskva.

Turk, Horst

1990 Alienität und Alterität als Schlüsselbegriffe einer Kultursemantik. In: Jahrbuch für Internationale Germanistik, 22, 11.1, S. 8-31.

1993 Selbst- und Fremdbilder in den deutschsprachigen Literaturen. Zur Übersetung der Kulturen. In: Frank, Armin Paul. Kurt-Jürgen Maass [u.a.] (Hg.): Überset- 
Tüschau 16 [= Forschungsgruppe aus 16 Personen]

zen, verstehen. Brücken bauen. Geisteswissenschafiliches und literarisches Uberseten im internationalen Kulturaustausch. Teil 1. Berlin (Göttinger Beitrăge zur internationalen Übersetzungsforschung; 8,1), S. 58-84.

1998

Tynjanov, Jurij

1969

Die Darstellung anderer Kulturen. Ermittlung von Stereotypen in deutschen Polen-Reiseführern (der Jahre 1990-1996). Oberhausen: Athena (Beitrăge zur Kulturwissenschaft; 1 ).

Wagner, Richard

1983

Über literarische Evolution [O literaturnoj évoljucii]. In: Striedter, Jurij (Hg.): Texte der russischen Formalisten. Bd. 1: Texte zur allgemeinen Literaturtheorie und zur Theorie der Prosa. München: Fink (Theorie und Geschichte der Literatur und der schönen Künste. Texte und Abhandlungen; 6, 1), S. 431-461.

Wajda, Kazimierz $(\mathrm{Hg}$.)

1991

Waldenfels, Bernhard

1983

1987

Der Ring des Nibelungen. Frankfurt a.M.: Insel (Dichtungen und Schrifien. Jubiläumsausgabe in zehn Bänden. Hg. von Dieter Borchmeyer. Bd. 3).

Polacy $i$ Niemcy. $Z$ badań nad kszlaltowaniem hetero-stereotypów etnicznych. Zbiór studiów. Torun.

Phänomenologie in Frankreich. Frankfurt a.M.: Suhrkamp.

kamp (Neuausgabe) (stw 644).

1997-1999 Studien zur Phänomenologie des Fremden. Bd. 1-4.

Frankfurt a.M.: Suhrkamp (stw 1320; 1351; 1397: 1442).

Waldenfels, Bernhard/Därmann, Iris (Hgg.)

1998

Der Anspruch des Anderen: Perspektiven phänomenologischer Ethık. München: Fink (Übergänge; 32).

Vester, Heinz-Günter 1996

Kollektive Identitäten und Mentalitäten: von der Völkerpsychologie zur kulturvergleichenden Soziologie und interkulturellen Kommunikation. Frankfurt a.M.: IKO-Verlag für Interkulturelle Kommunikation (Beiträge zur sozialwissenschaftlichen Analyse interkultureller Beziehungen; 1) 
Walicki, Andrzej

1975

1980

1991

Walter, Klaus-Peter

1985

Ward. Bruce K.

1986

Watzlawick. Paul

1987

Weber, Max

1968

1978

1993

Weimann, Robert (Hg.)

1997

Weisstein, Ulrich

1968

1981

Wekking. Joop

1990
The Slavophile Controversy. History of a Conservative Utopia in Nineteenth Century Russian Thought. Orxford.

A History of Russian Thought from the Enlightenmesnt to Marxism. Oxford.

Aleksander Hercen. Kwestia polska i geneza pewnycch stereotypów. Warszawa.

Das Bild der Juden im russischen Roman des 20. Jahurhunderts. In: Strauss, Herbert A./Christian Hoffmamn (Hgg.): Juden und Judentum in der Literatur. Müınchen: Deutscher Taschenbuch Verlag, S. 338-366.

Dostoyevsky's Critique of the West. The Quest for the Earthly Paradise. Waterloo, Ontario.

Wie wirklich ist die Wirklichkeit? Wahn Täuschungen - Verstehen. München, Zürich: Piper.

Gesammelte Aufsätze zur Wissenschafislehre. Tübiingen. Mohr (3., erw. u. verb. Aufl.).

Gesammelte Aufsätze zur Religionssoziologie. I: Die protestantische Ethik und der Geist des Kapitalismaus. II: Hinduismus und Buddhismus. Tübingen: Mohr.

Die protestantische Ethik und der ..Geist" des Kapitalismus. Hg. von Klaus Lichtblau und Johanmes Weiß. Bodenheim: Athenäum Hain Hanstein.

Ränder der Moderne. Repräsentation und Alterität im (post)kolonialen Diskurs. Frankfurt a.M.: Suhrkamp (stw 1311).

Einführung in die Vergleichende Literaturwissenschaft. Stuttgart (u.a.).

Vergleichende Literaturwissenschaft. Erster Bericht 1968-1977. Frankfurt a.M. (Jahrbuch für Internationale Germanistik, R. C., Forschungsberichte; 2).

Untersuchungen zur Rezeption der nationalsozialistischen Weltanschaurung in den konfessionellen Periodika der Niederlande 1933-1940. Ein Beitrag zur komparatistischen Imagologie. Amsterdam-Atlanta (Amsterdamer Publikationen zur Sprache und Literatur; 85). 
Wellek, René

1953 The Concept of Comparative Literature. In: Yearbook of Comparative and General Literature, 2, S. $1 \mathrm{ff}$.

1959 The Crisis of Comparative Literature. In: Proceedings of the Second Congress of the ICLA. Chapel Hill, N.C., S. 149-159.

1973 Die Krise der Vergleichenden Literaturwissenschaft. In: Rüdiger (Hg) 1973, S. 93-103.

Wellek, René/Warren Austin

1985 Theorie der Literatur. Königstein/Ts.: Athenäum (Athenäum-Taschenbücher 2005).

Welsen, $P$.

1991 Paul Ricœur. In: Nida-Rümelin, Julian (Hg.): Philosophie der Gegenwart in Einzeldarstellungen. Von Adorno bis v. Wright. Stuttgart: Kröner (Kröners Taschenausgabe 423), S. 499-503.

Wertheimer, Jürgen

1994

Wertheimer, Jürgen (Hg.): Von Poesie und Politik. Zur Geschichte einer dubiosen Beziehung. Tübingen.

1993 Literatur als Medium der Wahrnehmung und Verarbeitung von Fremdheit (indische, japanische und europäische Literatur im Dialog). In: Erfahrungen des Fremden: Vortrăge im Sommersemester 1992. Sammelband der Vorträge des Studium Generale der RuprechtKarls-Universităt Heidelberg. Heidelberg, S. 81-96.

Wielka Encyklopedia Powszechna PWN

1963

1964

1968

Wierlacher, Alois $(\mathrm{Hg}$.

1985

1987

1993

Wietnege, Katrin

1992
Bd. 2. Warszawa.

Bd. 4. Warszawa.

Bd. 11. Warszawa.

Das Fremde und das Eigene: Prolegomena zu einer interkulturellen Germanistik. München: ludicium (Publikationen der Gesellschaft für Interkulturelle Germanistik; 1).

Perspektiven und Verfahren interkultureller Germanistik. Akten des l. Kongresses der Gesellschaft für Interkulturelle Germanistik. München: ludicium (Publikationen der Gesellschaft für Interkulturelle Germanistik: 3).

Kulturthema Fremdheit. Leitbegriffe und Problemfelder kulturwissenschafilicher Fremdheitsforschung. München: Judicium (Kulturthenen; 1).

Jede Metapher ein kleiner Mythos. Studien =um Verhältnis von Mythos und moderner Metaphorik in 
Willers, Ulrich

1988

Winkgens, Meinhard

1987

Winkler, Markus

1995

Winterling, Peter

1985

Wodenegg, Andrea

1987

Wojcicka, Urszula

1983

Wood, D. (Hg.)

1991

Woodward, James B.

1980

Wörn, Dietrich

1998 frühexpressionistischer Lyrik. Münster; New York: Waxmann. Zugl.: Diss. Univ. Münster 1991.

Friedrich Nietsches antichristliche Christologie. Eine theologische Rekonstruktion. Innsbruck, Wien: Tyrolia (Innsbrucker theologische Studien; 23).

Das Italienbild bei D.H. Lawrence unter besonderer Berücksichtigung von .. The Lost Girl". Zur ästhetischen Produktivität nationaler Stereotypen. In: Blaicher (Hg.) 1987, S. 295-310.

Mythisches Denken zwischen Romantik und Realismus. Zur Erfahrung kultureller Fremdheit im Werk Heinrich Heines. Tübingen: Niemeyer (Studien zur deutschen Literatur; 138).

Rückzug aus der Revolution: Eine Untersuchung zum Deutschlandbild und zur Literaturtheorie bei Madame de Staël und Charles de Villiers. Rheinfelden: Schăuble (Reihe Romanistik; 63). Zugl. Diss. Univ. Freiburg i. Br. 1985.

Das Bild der Juden Osteuropas. Ein Beitrag zur komparatistischen Imagologie an Textbeispielen von Karl Emil Franzos und Leopold von Sacher-Masoch. Frankfurt a.M. (u.a.): l ang (Europäische Hochschulschriften. R. 1, 927).

Hagiografia staroruska $w$ kregu pisarzy rosyiskich wieku XIX: = badañ nad traducjami piśmiennictwa staroruskiego w nowożtnej literaturze rosyjskiej. Bydgoszcz 1983.

On Paul Riccur. Narrative and Interpretation. London-New York: Routledge.

Overlapping Portraits in Dostoevskij's ,. The Idiot “. In: Scando-Slavica 26, S. 115-127.

F. M. Dostoevskijs Roman ,..Schuld und Sühne" oder .. V'erbrechen und Sirafe - eine Einführung. In: Setzer/Müller/Kluge (Hgg.) 1998, S. 45-62. 
Wrzesiński, Wojciech

1991

1992

1993

Wülfing, Wolf

1979

Valdés, Mario J. (Hg.)

1990

VanderMey, Randall J.

1993

Vansina. F.D.

Vasmer, Max

2000

1953-1958

Vel'tman, Aleksandr Fomic

1957

Veselovskij, A.N.

1989

Vespermann, Susanne

1995

Volkmann, Hans-Erich (Hg.)

Paul Ricaur. Bibliographie primaire et secondaire/Primary and Secondary Bibliography 1935-2000. Leuven (Bibliotheca Ephemeridum Theologicarum Lovaniensium: CXLVIII).

Zum Napoleon-Mythos in der deutschen Literatur des 19. Jahrhunderts. In: Koopmann (Hg.) 1979, S. 81108.

Toward a Theory of Comparative Literature: Selected papers presented in the Division of Literature at the XIth International Comparative Literature Congress. ln: Actes Du XIème congrès de l'AILC (Paris, 20-24 août 1985), Bd. 3. New York, Bern (u.a.): Lang.

God Talk. The Triteness \& Truth in Christian Clichés. Downers Grove, Ill..

Wrzesinski, Wojciech (Hg.): Wokót stereotypów PolaWratislaviensis; 1136. Historia; 79).

Sasiad czy wróg? Ze studiów nad kszlallowaniem obrazu Niemca w Polsce w latach 1795-1939. Wrocław. ców i Polaków. Wroclaw (Acta Universitatis Wratislaviensis; 1554. Historia 114).

Russisches Etymologisches Wörterbuch. Bd. 1-3. Heidelberg.

Priključenija, počerpnutve is morja こitejskogo. Salomeja. Moskva (1. Aufl. 1848).

Istoričeskaja poètika. Moskva.

Margaret Atwood. Eine mythokritische Analyse ihrer Werke. Augsburg: Wißner (Beitrăge zur Kanadistik: 5).

Volockoj, M.V.

1994

1933

Das Rußlandbild im Dritten Reich. Köln [u.a.]: Böhlau.

Chronika roda Dostoevskogo. 1506-1933. Predislovie P.M. Zinov`eva. Moskva.

Vrangel', A.E. [Aleksandr Egorovic]

1912

Vospominanija o F.M. Dostoevskom v Sibiri 185+-56 gg. S.-Peterburg. 
1992 Vospominanija o F.M. Dostoevskom v Sibiri 18541856. In: Belov, S.V. (Hg.): Dve ljubvi F.M. Dostoev'skogo. Sankt-Peterburg 1992, S. 33-109.

Zabrovskij, A.P.

$1994 K$ probleme tipologii obraca inostranca $v$ russkoyj literature. In: Rossija i Zapad 1994, S. 87-105.

Zach, Wolfgang

1987

Das Stereotyp als literarische Norm. Zum dominanten Denkmodell des Klassizismus. In: Blaicher (Hg.) 1987, S. 97-113.

Zacharasiewicz, Waldemar

1977 Die Klimatheorie in der englischen Literatur und Literaturkritik von der Mitte des 16. bis zum frühen 18. Jahrhundert. Wien, Stuttgart.

Zagoskin, Michail Nikolaevic

1987

Jurij Miloslavskij, ili Russkie v 1612 godu. In: Socinenija $v$ duruch tomach. Bd. 1. Istoričeskaja prosa. Moskva.

Zamfiresco, Dan (Hg.)

1990

Dobrotoljubie. La Philocalie Slavonne de Païssy Velichkovsky. Reproduction anastatique intégrale de l'édition princeps, Moscou, I793. Bucarest (Monuments de la culture mondiale).

Zawodzinski, Karol Wiktor 1931

Uwagi w sprawie artykulu p. Jerzego Stempowskiego "Polacy w powieściach Dostojewskiego." In: Preeglad Wspólczesny 111, S. 469-472.

Zbinden, Jürg

1997

Krise und Mimesis. Zur Rekonstruktion und Kritik von Paul Ricours Begrifflichkeit in .. Zeit und Ersählung". In: Stückrath/Zbinden (Hg.) 1997, S. 180-198.

Zepp, Klaus Peter

1990

Ziejka, Franciszek

1977

Zijderveld. Anton C.

1979

Privatmythos und Wahn. Das mythopoetische Konzept im Werk Elias Canettis. Frankfurt a.M.: L ang (Europaische Hochschulschriften: Reihe 1, Deutsche Sprache und Literatur; 1165). Zugl.: Diss. Freie Unıv. Berlin 1988.

Wręgu mitów polskich. Kraków.

On Cliches: The Supersedure of Meaning by Function in Modernity. London.

1987 On the Nature and Functions of Clichés. In: Blaicter (Hg.) 1987, S. 26-40. 
Zima. Peter V.

1986 Roman und Ideologie. Zur Sozialgeschichte des modernen Romans. München: Fink.

1991 Literarische Ästhetik: Methoden und Modelle der Literaturwissenschafi. Tübingen: Francke (UTB 1590).

1992 Komparatistik. Einführung in die Vergleichende Literaturwissenschaft. Tübingen: Francke (UTB 1705).

1994 Die Dekonstruktion: Einführung und Kritik. Tübingen, Basel: Francke (UTB 1805).

Zitzewitz, Hasso von

1991

Zybura, Marek

1985

Zakiewicz Zbigniew

1962

1968

Żmegax, Viktor

1996
Das deutsche Polenbild in der Geschichte. Entstehung - Einflüsse - Auswirkungen. Koln, Weimar, Wien: Böhlau.

Zur Justinus-Kerner-Rezeption in Polen und RuBland. In: Beiträge zur schwäbischen Literatur- und Geistesgeschichte 3, S. 54-74.

$Z$ problematyki polskiej w twórczości $F$. Dostojewskiego. In: Zeszyty Naukowe Wysszej Szkoty Pedagogicznej w Opolu. Filologia rosyjska I. Opole, S. 61-85. Polacy u Dostojewskiego. In: Twórczość, 6, S. 75-89.

Der historische und typologische Jude: Studien =u jüdischen Gestalten in der Literatur der Jahrhundertwende. Tübingen: Niemeyer (Untersuchungen zur deutschen Literaturgeschichte: 89 ). 


\section{Die Welt der Slaven}

Sammelbände - Сборники

Hcrausgegeben von

Peter Rehder und Igor Smimov

Bd. $2+4+8+12$ : Beiträge der Europäischen Slavistischen Linguistik (Polyslav). Herausgegeben von K. Böttger, S. Dönninghaus, M. Giger, R. Marzari, B. Wiemer.

Bd. 1: 1998. Hardcover. X, 212 S. 86.- DM. (ISBN 3-87690-705-5)

Bd. 2: 1999. Hardcover. VIII, 320 S. I12.- DM. (ISBN 3-87690-738-1)

Bd. 3: 2000. Hardcover. X. 232 S. 94.- DM. (ISBN 3-87690-773-X)

Bd. 4: 2001. Hardcover. VIII. 292 S. 98.- DM. (ISBN 3-87690-803-5)

Bd. 3:Lebenskunst - Kunstleben. Жизнетворчество в русской культуре XVIII - XX вB. Herausgegeben von Schamma Schahadat.

1998. Hardcover. 229 S. 86.- DM. (ISBN 3-87690-706-3)

Bd. 5: Festschrlft für Klaus Trost zum 65. Geburtstag. Herausgegeben von E. Hansack, W. Koschmal, N. Nübler, R. Vecerka.

1999. Hardcover. 355 S. 120.- DM. (ISBN 3-87690-739-X)

Bd. 6: Poetik der Metadiskursivität. Zum postmodernen Prosa-, Film- und Dramenwerk von Vladimir Sorokin. Herausgegeben von Dagmar Burkhart.

1999. Hardcover. 244 S. 96.- DM. (ISBN 3-87690-745.4)

Bd. 7: Kapitel zur Poetik Karel Hynek Máchas. Die tschechische Romantik im europäischen Kontext. Beiträge zum Internationalen Bohemistischen MáchaSymposium an der Universität Potsdam 21.-22.1.1995. Herausgegeben von Herta Schmid in Zusammenarbeit mit dem Ústav pro Zeskou literaturu Akademie Věd České Republiky und unter Mitwirkung von Holt Meyer und Irina Wutsdorff.

2000. Hardcover. 307 S. 120.- DM. (ISBN 3-87690-756-X)

Bd. 9: Hypertext Omчаянuе / Cверxтекст Despair. Studien zu Vladimir Nabokovs Roman-Rätsel. Herausgezeben yon Iger Smirnov. Internetredaktion: Harry Raiser, Natalja Sander, Lora Schlothauer.

2000. Hardcover. 279 S. 98.- DM. (ISBN 3-87690-777-2)

Bd. 10: Entgrenzte Repräsentationen // Gebrochene Realitäten. Danilo Kiš im Spannungsfeld von Ethik, Literatur und Politik. Herausgegeben von Angela Richter unter Mitwirkung von Tatjana Petzer.

2001. Hardcover. 226 S. 76.- DM. (ISBN 3-87690-783-7

Bd. 11: Количественность н градуальность в естественном языке. Quantität und Graduierung in der natürlichen Sprache. Herausgegeben von Alexander Kiklevix.

2001. Hardcover. VIII, 212 S. 68.- DM. (ISBN 3-87690-782-9)

\section{Verlag OtTO SAgneR • D-80328 MÜNChEN}

e-mail: postmaster@kubon-sagner.de 